DIMITRIS DRAGATAKIS (1914-2001):

ADVANCING HIS LEGACY \& CONCERTO FOR VIOLA

USING TWENTY-FIRST-CENTURY DIGITAL TOOLS

BY

ELYSE N. DALABAKIS

\begin{abstract}
A dissertation
submitted to Victoria University of Wellington

in fulfilment of the requirements for the degree of

Doctor of Philosophy in Music
\end{abstract}

Victoria University of Wellington - Te Herenga Waka

New Zealand School of Music - Te Kōkī 
To the Dragatakis family and all lovers of modern Greek music 


\section{Table of Contents}

Table of Figures ..............................................................................................................

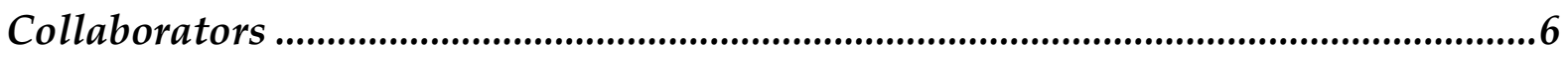

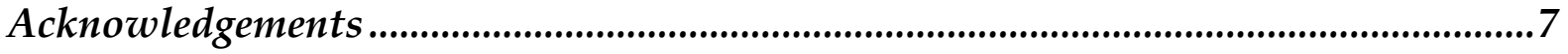

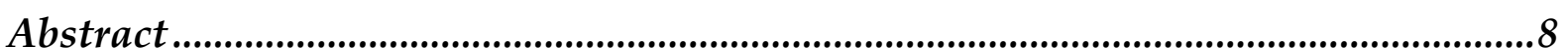

Note to the reader ..........................................................................................................................9

Chapter 1: Introduction...................................................................................................10

1.1 Methodology ……………………………................................................................................17

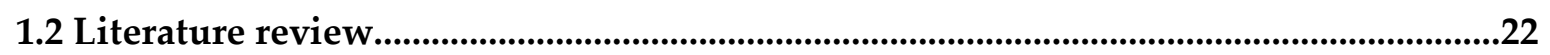

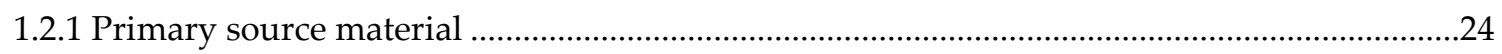

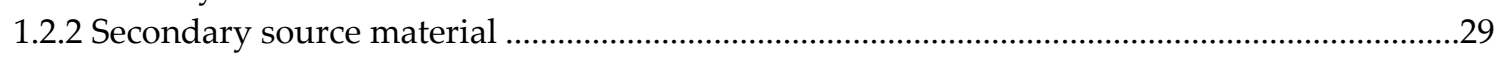

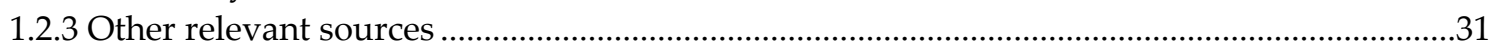

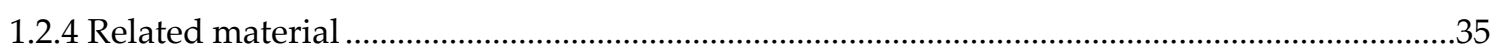

Chapter 2: Impressions of Dragatakis ..............................................................................39

2.1 Impression of Dragatakis through interviews........................................................................40

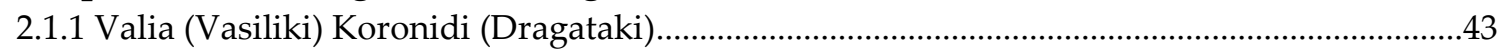

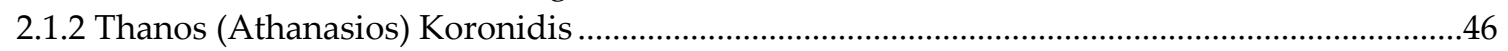

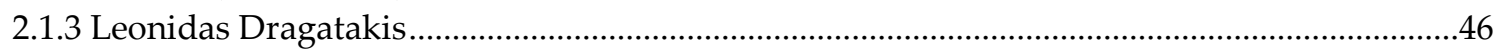

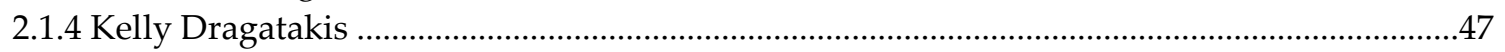

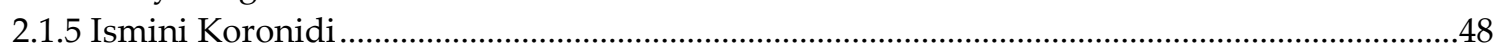

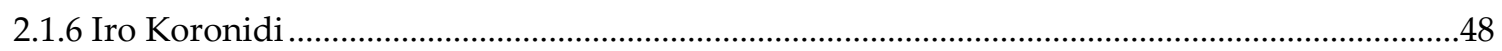

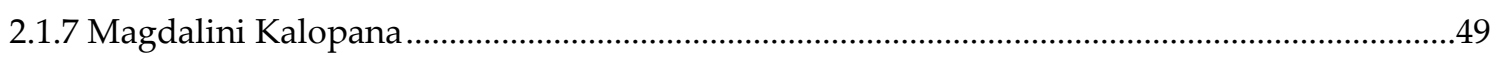

Chapter 3: Digital tools for Dragatakis...........................................................................51

3.1 Dimitris Dragatakis Archive digital database website.........................................................52

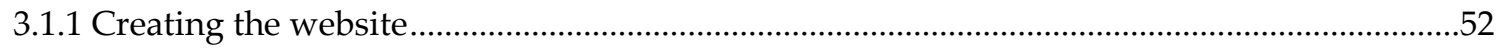

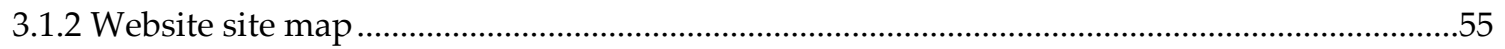

3.2 Catalogue of works for Dragatakis archive...................................................................57

3.3 Catalogue of works including viola.......................................................................................84

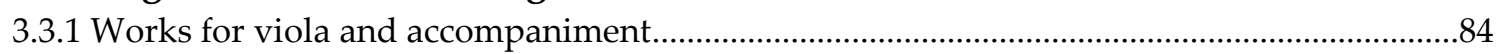

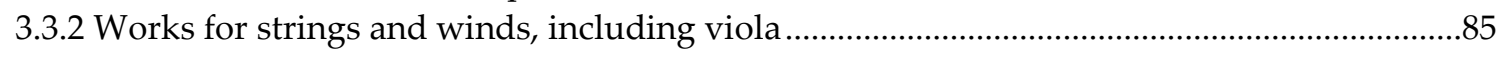

3.4 Video and audio databases................................................................................................87

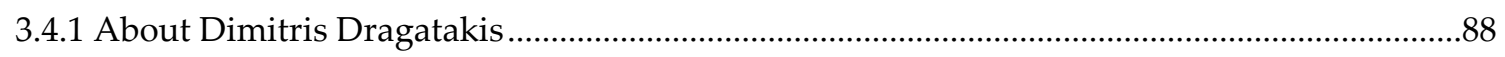

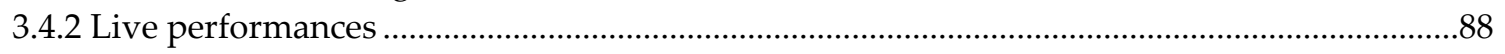

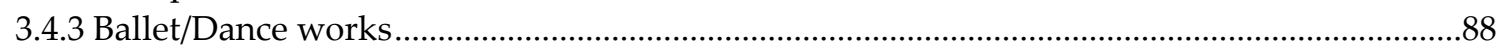

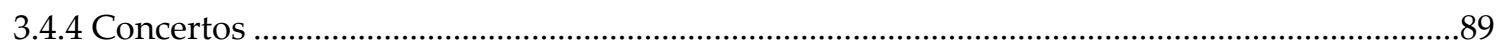

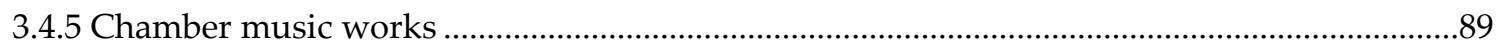

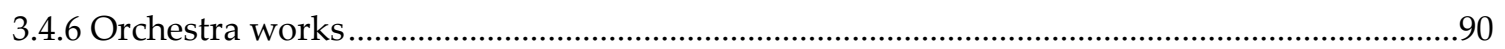

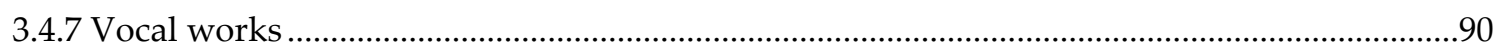

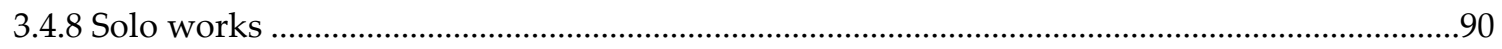

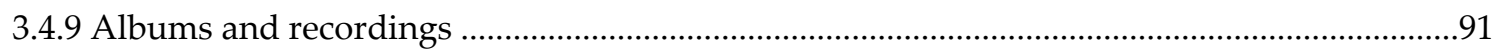

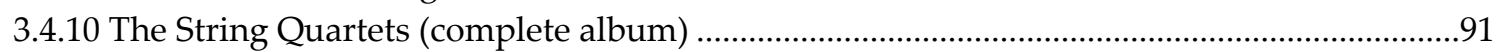




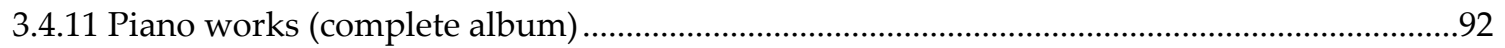

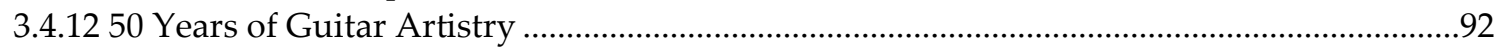

3.4.13 Dimitris Dragatakis - Chamber Music I (complete album) ...............................................92

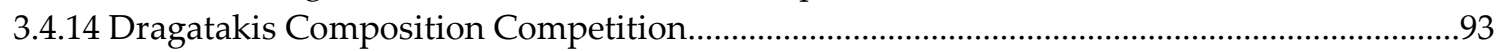

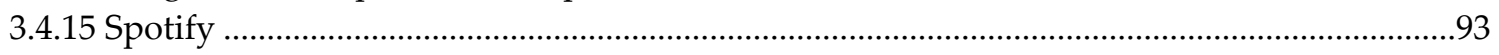

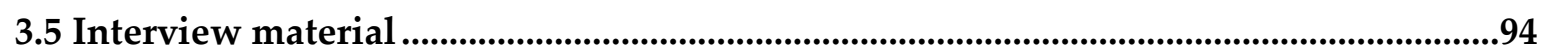

Chapter 4: Concerto for Viola - a digital case study ..................................................95

4.1 Interview with Artur Paciorkiewicz ...........................................................................................97

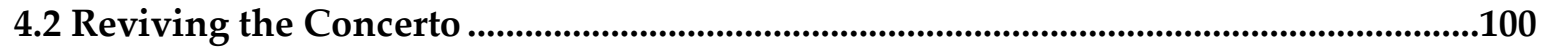

4.2.1 Recording of the premiere performance from 1993 ............................................................100

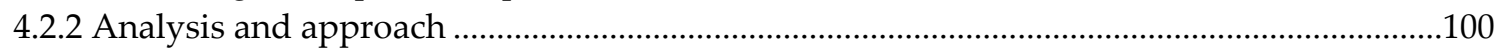

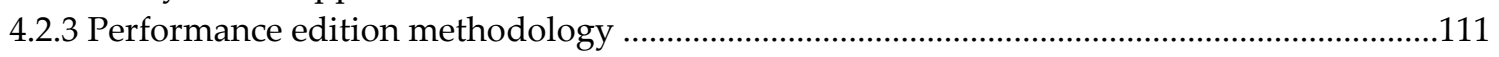

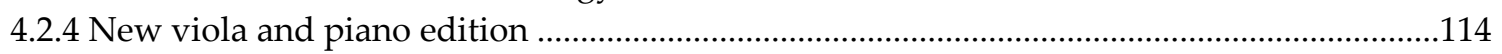

4.2.5 New viola, piano, percussion quintet chamber music edition ...........................................160

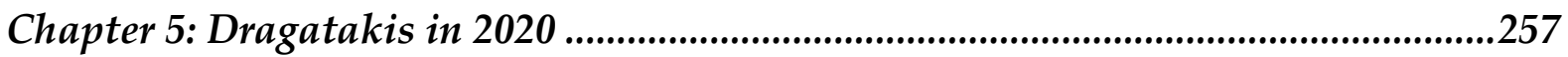

5.1 Dragatakis' reception in Greece and abroad............................................................257

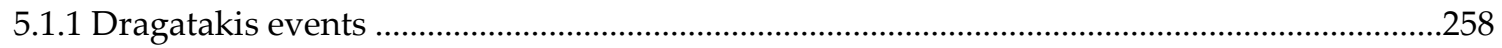

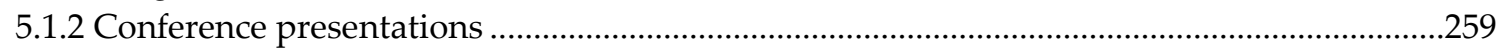

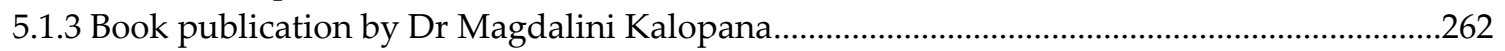

5.1.4 Dragatakis digital database and website statistics .............................................................262

5.2 Advancing twentieth-century composers' legacies through digital tools...................263

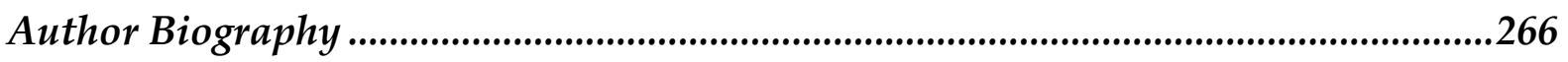

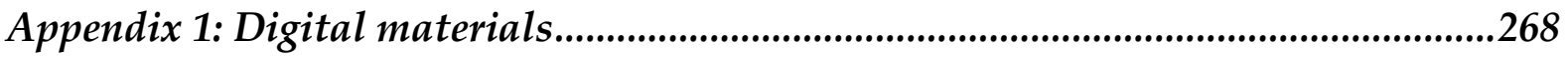

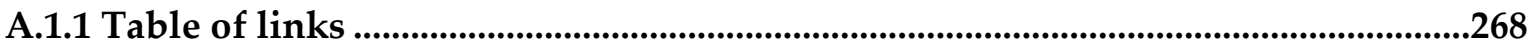

A.1.2 PDF of digital database website .....................................................................................270

Appendix 2: Concerto for Viola manuscripts...............................................................504

Appendix 3: Concerto for Viola 1993 performance part and score ..............................593

Appendix 4: Correspondence and interview materials.................................................682

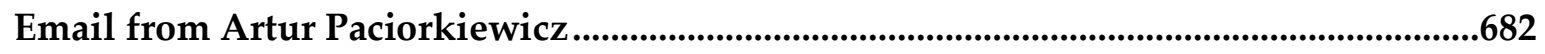

Questionnaires ..............................................................................................................................684

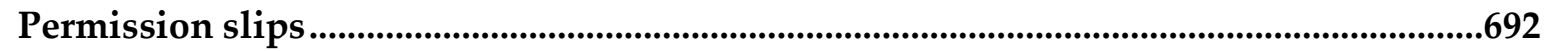

Appendix 5: Research residency and IVC presentation .................................................702

Appendix 6: New orchestra score and complete orchestra parts ................................717

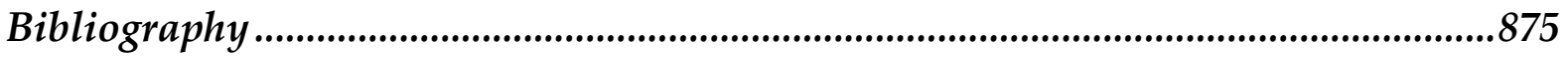




\section{Table of Figures}

Figure 1. Dimitris Dragatakis - 1980. Photo from Dimitris Dragatakis Archive digital database website.

Figure 2. From left to right: Elyse Dalabakis, Dr Magdalini Kalopana, Valia Koronidi.

November 2018. Photo by author.

Figure 3. The Dimitris Dragatakis Archive, meticulously organised by the Directors and Curator of the Archive. Photo by author.

Figure 4. The Dimitris Dragatakis Archive currently houses all the Dimitris Dragatakis materials, including one of two busts made for the composer. The other bust is a bronze bust, which is permanently fixed in Dragatakis' village of Epirus. Photo by author. 25

Figure 5. The Dimitris Dragatakis Archive has also preserved his final cigarette. To hear more about the item, see Valia Koronidi's interview in Chapter 2. Photo by author.

Figure 6. Photo of the Dragatakis and Koronidis family and Dr Magdalini Kalopana, taken in 2014 at the 100 Years Since Birth exhibition at Megaron. From left to right: Thanos Koronidis, Kelly Dragatakis, Leonidas Dragatakis, Ismini Koronidi, Magdalini Kalopana, Valia Koronidi, and Iro Koronidi. Photo from the Dimitris Dragatakis Archive digital database website.

Figure 7. Map of Greece for interview material.

Figure 8. Photo of Valia Koronidi with her father's bronze bust in his hometown of Platanousa, Epirus. Photo from the Dimitris Dragatakis Archive digital database website. 45 Figure 9. Dimitris Dragatakis' desk, now located in the Dimitris Dragatakis Archive. His desk has been mostly left as it was the day he died in December 2001. Photo by author. 53

Figure 10. Dimitris Dragatakis' office, now part of the Dimitris Dragatakis Archive. 54

Figure 11. Rhythmic theme analysis key table. 103

Figure 12. Melodic theme analysis key table. 104

Figure 13. Concerto for Viola, Moderato - Analysis Table. 108

Figure 14. Author. Photo by Hannah Neman. 266 


\section{Collaborators}

Below is a list of collaborators who are mentioned throughout this project. This list is in alphabetical order according to their last names.

- Brendan Agnew: engraver or typesetter for the new viola and piano edition and viola, piano, percussion edition for the Concerto for Viola

- Kelly Dragatakis: Dragatakis' daughter-in-law

- Leonidas Dragatakis: Dragatakis' son, Co-Director of the Dimitris Dragatakis Archive, Board Secretary for the Friends of Dragatakis Society

- Gabriela Glapska: collaborative pianist

- Magdalini Kalopana: Curator of Dragatakis Archive and leading Dragatakis scholar

- Thanos (Athanasios) Koronidis: Dragatakis' son-in-law

- Ismini Koronidi: Dragatakis' granddaughter

- Iro Koronidi: Dragatakis' granddaughter

- Valia (Vasiliki) Koronidi (Dragataki): Dragatakis' daughter, Co-Director of the Dimitris Dragatakis Archive, Board Treasurer for the Friends of Dragatakis Society

- Hannah Neman: collaborative percussionist

- Artur Paciorkiewicz: premiered Dimitris Dragatakis' Concerto for Viola in 1993; viola soloist and orchestral musician 


\section{Acknowledgements}

This project was made possible through the financial support of the New Zealand School of Music's Barbara Finlayson Scholarship and Victoria University of Wellington Faculty grants. I would like to thank my primary supervisor Professor Donald Maurice and secondary supervisor Dr Dave Wilson who guided me through this project and supported my academic goals.

I am especially grateful to the Koronidis and Dragatakis families with whom I had the great pleasure to work and connect during this project in Athens, specifically: Valia and Thanos Koronidi, Leonidas and Kelly Dragatakis, and Ismini and Iro Koronidi, as well as the active performers, performance scholars, and musicologists in the Athens community who also greatly assisted in informing this project: Magdalini Kalopana, Christos Kolovos, Lorenda Ramou, and Thomas Tamvakos.

A warm thank you to my friends and colleagues who assisted in breathing life back into this music, namely: Brendan Agnew (engraver), Gabriela Glapska (collaborative pianist), and Hannah Neman (collaborative percussionist). Our collaborations and your thoughtful feedback ensured this piece is accessible to future performers and scholars. A special thank you to Madeleine Collinge, my editor, for her thorough work and keen eye for detail.

Mostly importantly, thank you to my family for their never-ending support and encouragement especially: my partner Hannah for cheering me on across the finish line, my parents for their countless words of wisdom and encouragement, and my grandparents for being a constant source of inspiration. 


\section{Abstract}

This project focuses on Dimitris Dragatakis (1914-2001), his legacy, and Concerto for Viola in the twenty-first century. The research examines the following overarching questions within interlaced scholarly and creative components of the dissertation:

How can we use twenty-first-century digital tools to promote Dimitris Dragatakis, one of Greece's most important modern composers, to advance his legacy including, importantly, his Concerto for Viola, and to assist future scholars and performers in accessing information about his life and music?

This dissertation discusses the digital tools and processes used to advance the legacy of Dimitris Dragatakis and to promote his Concerto for Viola. These tools and processes include creating and publishing the Dragatakis Archive Digital Database website, recording interviews with the Dragatakis family and leading Dragatakis scholar, and using his Concerto for Viola (1992) as a digital case study. The digital case study demonstrates how twenty-first-century performers, scholars, and archivists might approach advancing the works of lesser-known composers through digital media. In this case study, a new viola and piano performance edition and percussion chamber music performance edition are offered, a new digital orchestra score along with complete orchestral parts is made available, interview material with the violist who premiered the work has been recorded, and the recently unearthed premiere performance recording of the work from the Dragatakis archive has been included in an interactive video created by the researcher. This project also aims to provide a model for future performers and scholars to use to assist future projects beyond this topic. 


\section{Note to the reader}

Due to the digital nature of this research, this dissertation is best viewed in digital format. Throughout the dissertation there are interactive hyperlinks that link to further materials in order to enhance the reader's experience. These materials include video and audio recordings, links to manuscripts, and a newly created viola and piano part, among others. A complete table of links can be found in Appendix 1. The dissertation was designed this way to ensure information about Dragatakis and his archive remain accessible in electronic form to future performers and scholars.

For the purposes of examination and submission, a PDF version of the Dragatakis Archive Digital database website has been included in Chapter 3: Digital Tools for Dragatakis. This is to show the magnitude of the database website created during the artist residency in Greece in collaboration with the archive; however, the website is best viewed via an internet browser.

It is recommended to view this dissertation in Adobe and utilise the 'Bookmarks' function. To find the 'Bookmarks' function, open this PDF in Adobe and look on the left-hand side and click on the 'bookmark' icon. After clicking on the 'bookmark' icon, a window on the left will appear with an interactive table of contents. The reader can use this list to toggle to different sections throughout the dissertation. The reader is encouraged to use this function as the main purpose of the dissertation is to engage with twenty-first-century digital tools. 


\section{Chapter 1: Introduction}

This research focuses on digital humanities and how to advance the legacy and works of lesser-known composers using twenty-first-century digital tools, focusing specifically on Greek composer Dimitris Dragatakis and his Concerto for Viola. The Concerto for Viola is used as a digital case study to demonstrate how twenty-firstcentury performers, scholars, and archivists might approach advancing the works of lesser-known composers through digital media.

This study aims to ensure Dragatakis's legacy and musical works remain accessible to future performers and scholars. The need for this type of study has been brought into the light in our currently 'contactless' and 'socially-distanced' world which because of COVID-19 has become the new normal more quickly than I had anticipated at the outset of this research project.

Stemming from my passion for Greek traditional music, Greek art music, and twentieth-century Greek history, this project was inspired by a previous 'note-to-self' which read 'Dragatakis $\rightarrow$ find out more'. Upon 'finding out more', I discovered that he was a violist - like myself - and had written a concerto for viola, and his works were considered widely accepted according to an article on New Grove; ${ }^{1}$ yet he was relatively unknown outside Greece, and little was available in terms of finding more information about him or accessing his music. Other than short biographic information and miscellaneous mentions here and there across the internet, I could not find more information about Dragatakis or his Concerto for Viola. ${ }^{2}$

\footnotetext{
${ }^{1}$ Magdalini Kalopana, "Dragatakis, Dimitris." Grove Music Online. 3 September 2014. https://doi.org/10.1093/gmo/9781561592630.article.08120.

2 IEMA, “Dimitris Dragatakis - Biography."

http://composers.musicportal.gr/?lang=el\&c=dragatakis\&a=1.
} 


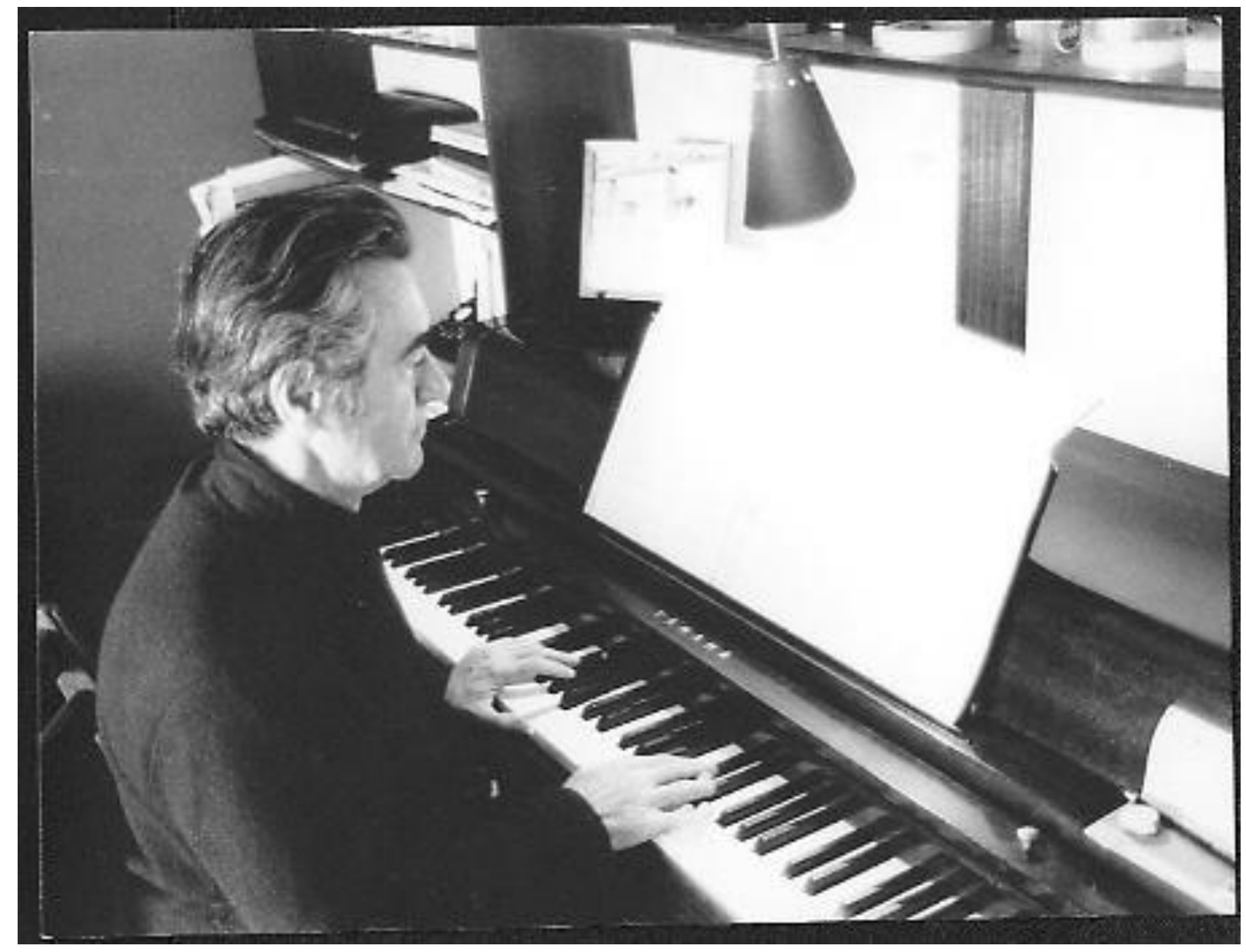

Figure 1. Dimitris Dragatakis - 1980. Photo from Dimitris Dragatakis Archive digital database website.

I found the Institute for Research on Music and Acoustics (IEMA) [Institoúto Érevnas Mousikís E Akoustikís - Kéntro Mousikís Tekmiríosis] website, which lists nearly 900 different entries in its database; however, there is little other information except for the listings. All the catalogued listings have similar formats: a photo or picture of the cover - such as a manuscript or cassette case - or, in the case of recordings, 30-second soundbites. The Concerto for Viola has two 30-second soundbite recordings from the premiere performance. In these two soundbite recordings, however, listeners unfortunately can only hear applause, white noise, and ten seconds of the beginning of the performance. ${ }^{3}$

\footnotetext{
${ }^{3}$ IEMA, "Viola Concerto and Krakow Orchestra: iem.CMC.DDR.rmc.61.1." http://digitize.iema.gr/is_ent_en.php?phys_item_id=305\&entity_id=315; IEMA, “Concerto for
} 
This lack of digitally available information motivated me to consider the possibility of developing my research project in a way that might address this deficiency. I started by trying to contact IEMA to see if I might be able to access the digital sources catalogued on their website. After many attempts between 2016 and 2018 I was eventually put in touch with the Director of the Dragatakis Archive, Valia Koronidi, and Curator of the Dragatakis Archive and leading Dragatakis scholar, Magdalini Kalopana.

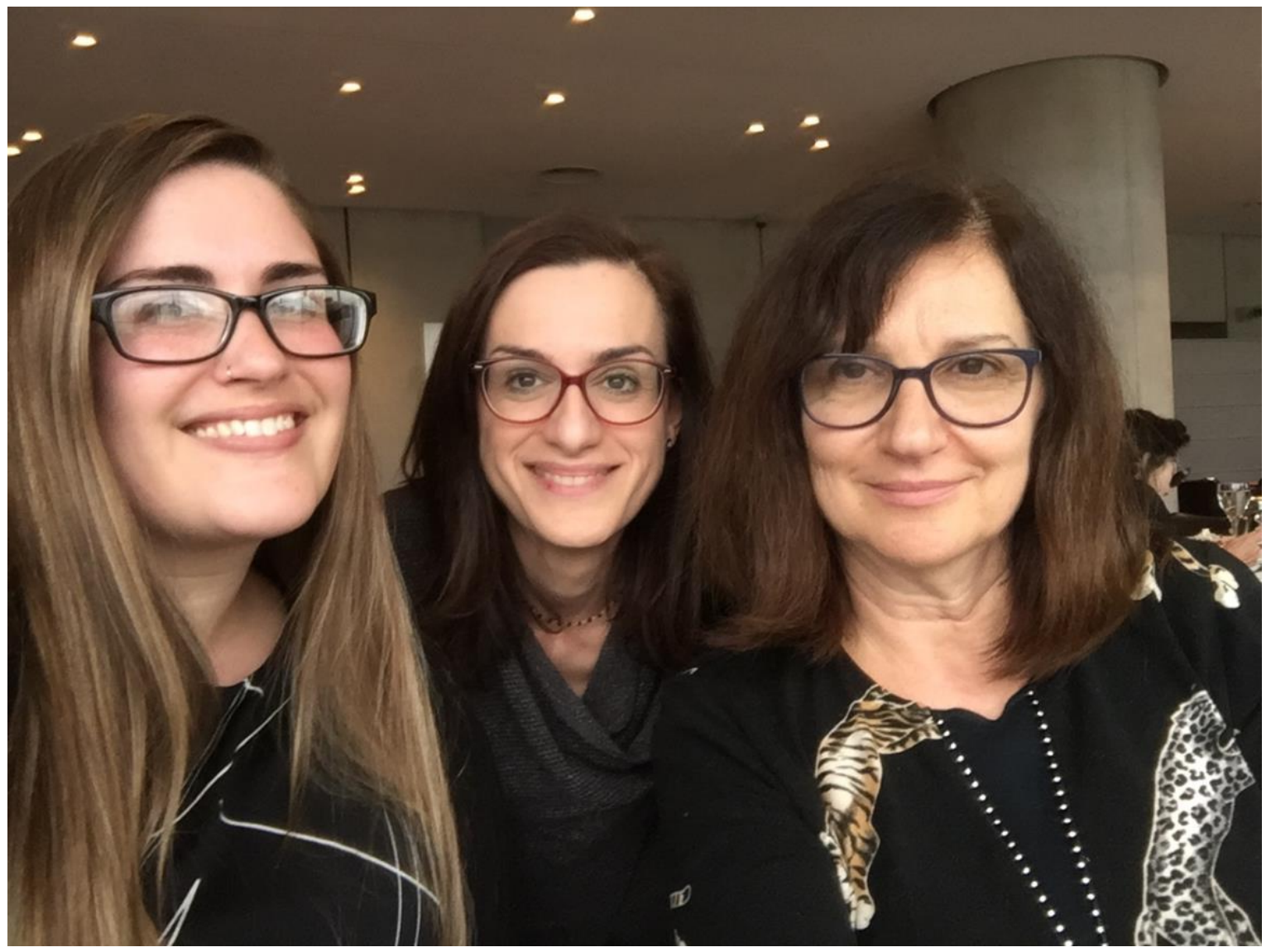

Figure 2. From left to right: Elyse Dalabakis, Dr Magdalini Kalopana, Valia Koronidi.

November 2018. Photo by author.

Viola and Orchestra of Krakow: iem.CMC.DDR.rmc.85.1."

http://digitize.iema.gr/is_ent_en.php?phys_item_id=354\&entity_id=377. 
Through this contact with Koronidi and Kalopana, we decided it would be best for me to meet with them in Athens, Greece, to discuss my project and how we might work together. From there, the project took flight and the aim became clear: how can we advance Dimitris Dragatakis' legacy and Concerto for Viola using twenty-firstcentury digital tools?

After our meeting in November 2018, I was formally invited to undertake a research residency at the Dragatakis Archive in Athens, Greece, during October 2019. ${ }^{4}$ During this time, I created the Dragatakis Archive digital database website. Also during this time I conducted live, audio-recorded interviews with Valia Koronidi, Leonidas Dragatakis, Thanos Koronidi, Kelly Dragatakis, Ismini Koronidi, Iro Koronidi, and Magdalini Kalopana. ${ }^{5}$

As already outlined above, the overall aim of this research is to promote Dimitris Dragatakis and advance his legacy in the twenty-first century. In asking the question 'how can we advance his legacy and Concerto for Viola?', I have chosen to use twentyfirst-century digital tools to put this aim into practice. These tools are described within the 'Digital Tools for Dragatakis' section of the dissertation. By making information about his life and legacy accessible, this project aims to assist future performers and scholars while also preserving and promoting the legacy of Dragatakis, and it also provides a model for future scholars to use in terms of methodology for similar projects.

At the outset of this project, resources about Dimitris Dragatakis were limited. With the exception of a New Grove subscription or visiting Greek libraries in person, the

\footnotetext{
${ }^{4}$ See also Appendix 5: Artist Residency and IVC Presentation.

${ }^{5}$ YouTube, “Dimitris Dragatakis Interviews." Playlist. Last modified 30 June 2020.

https://www.youtube.com/playlist?list=PLEsL50b4ObArVmfV1JL2QbYuV75kpKf73.
} 
information contained within this dissertation has been largely inaccessible until now. This dissertation greatly increases the extant knowledge of Dragatakis and his works, using digital tools to assist in making information about Dragatakis accessible to a wide international audience. Furthermore, a less common approach to this dissertation has been taken by making the research digitally interactive, including digital components. This approach complements both the work and the thorough research that precedes this project, namely, research by Dr Magdalini Kalopana and other Dragatakis scholars and Greek art music archivists and aficionados. While there is biographical information available pertaining to Dragatakis, the information remains difficult to access - this research provides a solution.

Other original aspects of this dissertation include the typeset orchestra score and parts and a newly created performance edition for viola and piano, including an optional percussion chamber music version, for Dragatakis' unpublished Concerto for Viola. Before this project the existing piano reduction in the Dragatakis Archive was very skeletal, making it suitable for rehearsal but not for performance in a viola and piano version. This made it difficult to perform the Concerto without an orchestra. The only accessible recording of the work is the recording of the premiere performance and it is included in this dissertation. Until the publication of this research, copies of the manuscript and premiere performance recordings were kept only in the Dragatakis Archive in Athens, Greece and a copy of the 1993 solo viola part remained in Artur Paciorkiewicz's personal library. The newly typeset orchestra score and solo part, new viola and piano performance edition, new percussion chamber music performance edition, and original manuscripts are also included in this dissertation.

In order to create the performance editions, the researcher sought the permission of the Dimitris Dragatakis Archive and collaborated with Brendan Agnew (engraver), Gabriela Glapska (collaborative pianist), and Hannah Neman (collaborative 
percussionist). ${ }^{6}$ The manuscript and 1993 orchestra score and viola solo part were used to inform the new stand-alone viola and piano edition in collaboration with Glapska. For the new percussion chamber music edition, the 1993 orchestra score's percussion parts were reduced to three staves in collaboration with Neman. Agnew typeset the 1993 viola solo part, orchestra score, and parts to create the newly typeset versions included in this dissertation. He also typeset the piano reduction from the Dragatakis Archive and updated the viola and piano edition and percussion edition according to the collaborative process between the researcher, Glapska, and Neman.

This dissertation also includes an interactive tool for future performers; this is referred to as the 'interactive 1993 performance part'. This part includes a PDF of the premiere performance solo viola part along with the recording of the premiere performance and can be found in 4.2.2.1.1 Music from Epirus and interactive PDF. This will enable musicians to listen to the recording and observe the soloist's original notations. The idea behind the interactive 1993 performance part germinated during the COVID-19 global pandemic. During lockdown, I was scheduled to record the new viola and piano version and optional percussion chamber music version for the Concerto for Viola, but this was cancelled. While New Zealand went back to almost normal life after two months in lockdown, a few weeks before this dissertation was submitted, the uncertainty of the pandemic made the recording part of this project unviable. The work submitted with this dissertation is thorough, but I felt strongly about providing future performers and scholars with digital tools to utilise in their own research or performance; thus, I felt the need to provide the performance part with attached audio in order to partially substitute the recording aspect of the work. The interactive 1993 performance part is another digital tool that can be used in future.

\footnotetext{
${ }^{6}$ See also Collaborators and 4.2.3 Performance edition methodology.
} 
Since the start of this project and as a result of the residency in Greece this research has resulted in the following tangible results:

- $\quad$ Over four hours of recorded interviews with the Dragatakis family and the leading Dragatakis scholar.

- $\quad$ Creation of the 233-page Dimitris Dragatakis Archive Digital Database Website.

- $\quad$ Full catalogue of works for the Dragatakis Archive.

- $\quad$ A stand-alone catalogue of the works including viola.

- Video and audio databases for the composer's works hosted through YouTube and Spotify.

Specifically for the Concerto for Viola, this has included:

- $\quad$ access to the premiere performance recording

- 1993 premiere performance part from Artur Paciorkiewicz

- $\quad$ newly produced video, which includes the 1993 premiere recording and interactive solo viola performance part, now hosted on the Dimitris Dragatakis - Composer YouTube page

- $\quad$ analysis and approach section

- $\quad$ performing edition for viola and piano

- $\quad$ performing edition for optional percussion quintet chamber music version

- $\quad$ interactive 1993 performance part

- $\quad$ newly typeset solo viola part

- $\quad$ newly typeset orchestra score with parts

- $\quad$ conference presentation at the 45th International Viola Congress in Poland.

Going forward, this project not only offers these tangible results, which in turn assist in advancing and promoting Dragatakis' legacy and Concerto for Viola, but also offers a framework for future performers and scholars interested in advancing and promoting the life and works of lesser-known composers. 
In our currently socially distanced, contactless world where international travel is not an option at this time, this research brings the information and resources to researchers and performers, and makes this information accessible in a digital format. At the start of this project, the importance and need for this research was known; however, the current COVID-19 pandemic has accelerated the need for research such as this and the tangible results it has provided.

\subsection{Methodology}

The methodology used in this project pertains to digital humanities such as online databases, music notation software, premiere recording, digital database website creation, YouTube, interview material, critical and performance edition methodologies, and archival processes.

Digital humanities in this case simply means the application of digital tools or media to traditional humanities topics, such as music scholarship. The field of digital humanities is characterised by a distinct focus on collaborative work, research, and dissemination, including building tools and platforms that are transferable and conducive to collaborative scholarship. Digital humanities incorporates and builds upon traditional research methodologies and approaches to the study, preservation, classification, and dissemination of information as applied in the humanities. As such, digital humanities is a rapidly evolving field that naturally encompasses various methods and disciplines. ${ }^{7}$ The inherently collaborative and cross-disciplinary nature of digital humanities gives rise to varying examples of the form of digital archives, online publishing, online databases, and can even be seen to include formats such as social media and video games. One example of this is where network maps of social media interactions are created by researchers and algorithms which are then able to

\footnotetext{
${ }^{7}$ Susan Schreibman et al., A New Companion to Digital Humanities.
} 
be disseminated to organisations and companies, which will utilise the information to enable more efficient advertising. In the context of this project, researchers and contributors from multiple fields provided perspective and input, such as an archivist, historian, collaborative performer, music librarian, music theorist, musicologist, and the researcher who provided input from the perspective of music scholarship, use of digital tools, and website creation.

The term digital humanities, as applied within this dissertation, refers to the digital tools and methods utilised in this research that have aided in making the legacy of and Concerto for Viola by Dimitris Dragatakis accessible to future performers and scholars, as outlined in Chapter 3: Digital Tools for Dragatakis.

The literature review following this section outlines the sources referred to in this section, other relevant sources, and other related material. This part of the dissertation may also serve future performers and scholars who are interested in Dragatakis, as the sources discussed - while perhaps not referred to directly in the dissertation - are important in order to fully understand and appreciate the context of Dragatakis' life, works, and legacy.

The dissertation opens with the introduction, this methodology section, and literature review and then proceeds to Chapter 2: Impressions of Dragatakis, which provides original interview material from the researcher's fieldwork and artist residency at the Dragatakis Archives and Greek Music Archives in Athens, Greece, during October 2019. These interviews were conducted with Dimitris Dragatakis' family members and a leading Dragatakis scholar. ${ }^{8}$ The aim of these interview questions, chosen by the researcher in consultation with the supervisors, was to feature impressions of Dimitris Dragatakis from individuals who were closest to him during his life. These

\footnotetext{
${ }^{8}$ See also Collaborators.
} 
questions were chosen to discover more information about the individual interviewee's biographical information and also their own personal memories and impressions of, and relationship with Dragatakis. Specific ethical considerations pertaining to respecting the physical and intellectual property of the Dragatakis Archive, English as a second language, and different cultural backgrounds were taken into account when designing the interview questions and conducting the interviews. It should be recognised that an interviewer's approach potentially affects interviewees response to questions, as well as the information and personal opinions the interviewee is prepared to divulge. In order to mitigate these ethical considerations, the interviewees were sent the questions before the interviews and it was communicated in the consent form and verbally that the interviewees could decline to answer any question at any time. A copy of the recorded interviews and interview questions were sent to the interviewees before the publication of this dissertation at which time it was made clear to the interview participants that they may clarify their answers if desired.

While the biographical information pertaining to Dragatakis has been thoroughly researched by leading Dragatakis scholar, Dr Magdalini Kalopana, the second chapter offers a different perspective: it provides biographic information about the individuals who have diligently worked to ensure Dragatakis and his legacy remain relevant after his death as well as their impressions of Dragatakis during his life. These interviews were audio recorded and edited, uploaded to YouTube, and provided to each interviewee and the Dragatakis Archive.

Chapter 3: Digital Tools for Dragatakis discusses the digital tools used and digital creations made for this project. The first digital tool outlined is the Dimitris Dragatakis Archive digital database website. This was created in October 2019 during the researcher's artist residency at the Dragatakis Archive in Athens, Greece, in consultation with Valia Koronidi and Leonidas Dragatakis. In accordance with their 
vision, the researcher created the digital database website and took the first steps in making the Dragatakis Archive digital and accessible.

Accompanying the digital database website is a YouTube channel and Dimitris Dragatakis' Spotify Artist Page. ${ }^{9}$ While creating the digital database website, the researcher collated over 300 videos previously uploaded to YouTube, created an artist profile for Dimitris Dragatakis, and connected all the previously recorded videos to this new profile through the YouTube playlist function. The researcher also claimed the Dimitris Dragatakis Spotify Artist page, a page previously inaccessible to the Dimitris Dragatakis Archive. In the 'Digital Tools' section these processes are discussed in detail and links to the created material are provided.

Also, during the artist residency and outlined in this chapter, the researcher created a digital catalogue of works for the Dragatakis Archive, collated from secondary source material by Dr Magdalini Kalopana and primary source material in the Dragatakis Archive. This was done in consultation with the Dragatakis Archive directors and was uploaded to the website. A copy of this list is also included in this dissertation, in addition to a separate catalogue of Dragatakis works for viola only.

Throughout this type of research work, numerous decisions are required, for example, to determine how to present the items found through the research process, which items to choose for presentation, and how to structure the chosen platforms, such as the digital database website used for the dissemination of the research. These decisions have a direct effect on the form and content of the output, which is an inevitable feature of this type of research. In undertaking the research work for this

\footnotetext{
${ }^{9}$ YouTube, "Dimitris Dragatakis - Composer." https://www.youtube.com/channel/UCkQmGQkud3iSzKse3StF_ug?view_as=subscriber. Spotify, “Dimitris Dragatakis." https://open.spotify.com/artist/7mx3q8GQBomkCxdO0zVoE4.
} 
project, accessibility was the primary goal and directly influenced the resulting outputs. For example, archive materials were digitised in order to feature these resources on the digital database website, and further for world-wide dissemination outside Greece. The researcher tried wherever possible to include all of the currently available or accessible items pertaining to the life and works of Dragatakis and related resources.

Chapter 4: Concerto for Viola - a digital case study uses Dragatakis' Concerto for Viola as a digital case study to model how twenty-first-century performers and scholars might utilise digital tools to advance the works and legacy of lesser-known composers. The chapter also includes information about the Concerto and an interview with Artur Paciorkiewicz, the viola soloist who premiered the Concerto for Viola in 1993; an analysis and approach section for the first movement, Moderato; the new viola and piano performance edition; the new viola, piano, and percussion performance edition; links to new digital/typeset orchestra score and complete orchestra parts; orchestra manuscript; piano reduction manuscript; interactive 1993 performance part from the premiere accompanied by the premiere recording; and video created by the researcher with interactive solo part, as outlined in this case study. As discussed in the Introduction and later outlined in 4.2.3 Performance edition methodology, the approach to creating the new performance editions was a collaboration between the researcher, Dimitris Dragatakis Archive, and the engraver, collaborative pianist, and collaborative percussionist. ${ }^{10}$ The Concerto for Viola manuscript and 1993 viola solo performance part and orchestra score were used to inform the new stand-alone piano edition and new percussion chamber music edition.

The final chapter, Chapter 5: Dragatakis in 2020, examines the events, organisations, and research dedicated to Dragatakis that have included his works since his death,

\footnotetext{
${ }^{10}$ See also Collaborators and 4.2.3 Performance edition methodology.
} 
including a lecture presentation by the researcher, Dragatakis' reception in Greece and abroad, the biennial Dragatakis Composition Competition, the Friends of Dragatakis Society, a new book and scholarly publications concerning Dragatakis, digital statistics since creating the Dimitris Dragatakis Archive digital database website in late 2019, and what work remains to be done for the Dragatakis Archive and digital database.

The appendices in this dissertation include information that was previously inaccessible to the general public:

- A table of links included throughout the dissertation for reference.

- Concerto for Viola manuscripts, including piano reduction, orchestra score, 1993 orchestra score and performance part.

- Interview material, including interview permission slips, questionnaires, and interview transcripts.

- Artist residency and International Viola Congress presentation information, including artist residency invitation, media appearances and releases pertaining to research and lecture presentation.

- New orchestra score and complete orchestral parts for Concerto for Viola.

The overall aim of this project is not only to assist in making information about Dragatakis, his life, legacy, and works accessible but also to use this dissertation as a model for future performers and scholars to further advance the legacy and works of lesser-known composers.

\subsection{Literature review}

The sources and research materials discussed in this literature review pertain to Dimitris Dragatakis. These sources are either primary biographical or musical sources in archive and digital form or secondary source materials. Other literature discussed 
here includes reference resources related to creating performance editions, digital humanities, twentieth-century music trends, Greek traditional music, Greek history and politics, and nationalism and music.

There are many books, articles, interviews, and other resources detailing the historical, political, social, and musical factors within the scope of this dissertation. However, the existing literature - and more importantly access to existing literature - relating specifically to Dimitris Dragatakis, though growing steadily, was inadequate at the outset of this research considering the composer's importance in the history of Greek music and composition. Prior to the publication of this research, it was difficult to locate one source that hosted accessible bibliographic material and musical information pertaining to Dimitris Dragatakis, or Greek composers more generally. Thus, the need for this research was born. The following literature review will aid future performers and scholars who are interested in Dimitris Dragatakis and contains sources which have been identified to pertain to Dimitris Dragatakis and his legacy as well as other sources that address the themes previously mentioned. The materials assist in examining the overall question of the research project: How can we use twenty-first-century digital tools to promote Dimitris Dragatakis, one of Greece's most important modern Greek composers; to advance his legacy and his Concerto for Viola; and to assist future scholars and performers in accessing information about his life and music? 


\subsubsection{Primary source material}

The sources discussed in this section are primary source materials located in the Dimitris Dragatakis Archive or were created through the researcher's fieldwork.

The Dimitris Dragatakis Archive houses all manuscripts and known typeset music as well as other primary source materials. The Archive is located in Dimitris Dragatakis' former home in Athens, Greece.

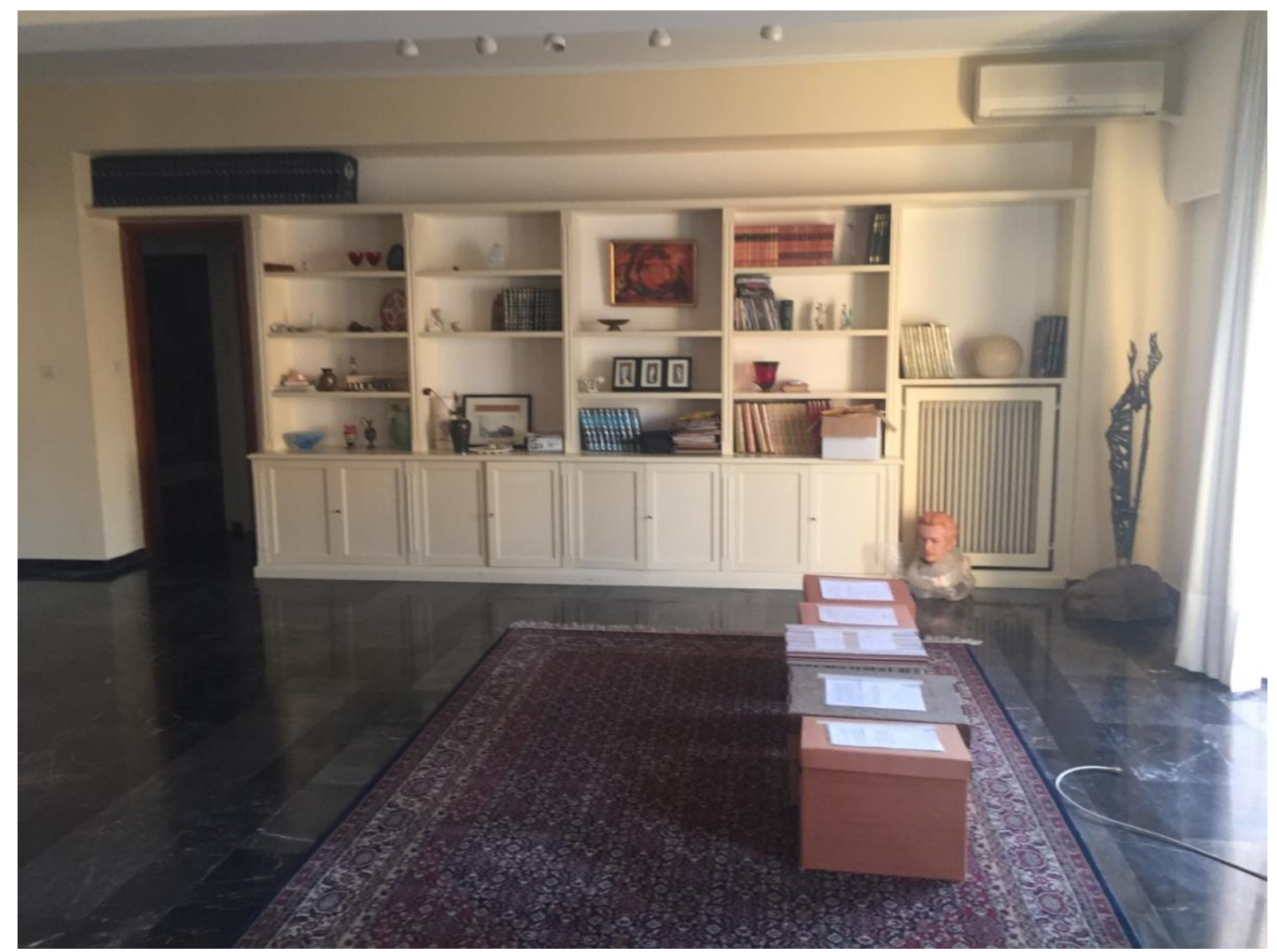

Figure 3. The Dimitris Dragatakis Archive, meticulously organised by the Directors and Curator of the Archive. Photo by author. 


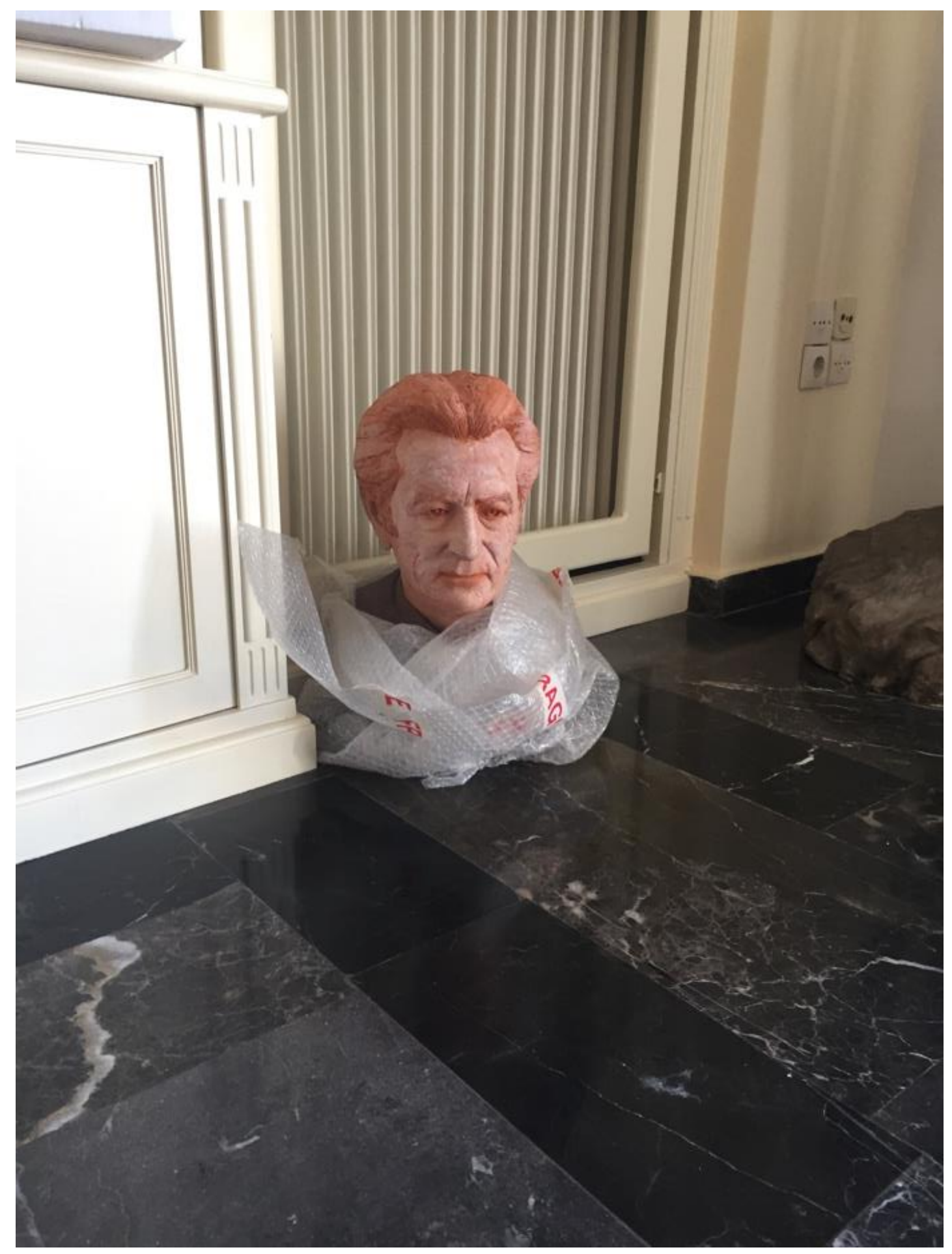

Figure 4. The Dimitris Dragatakis Archive currently houses all the Dimitris Dragatakis materials, including one of two busts made for the composer. The other bust is a bronze bust, which is permanently fixed in Dragatakis' village of Epirus. Photo by author. 


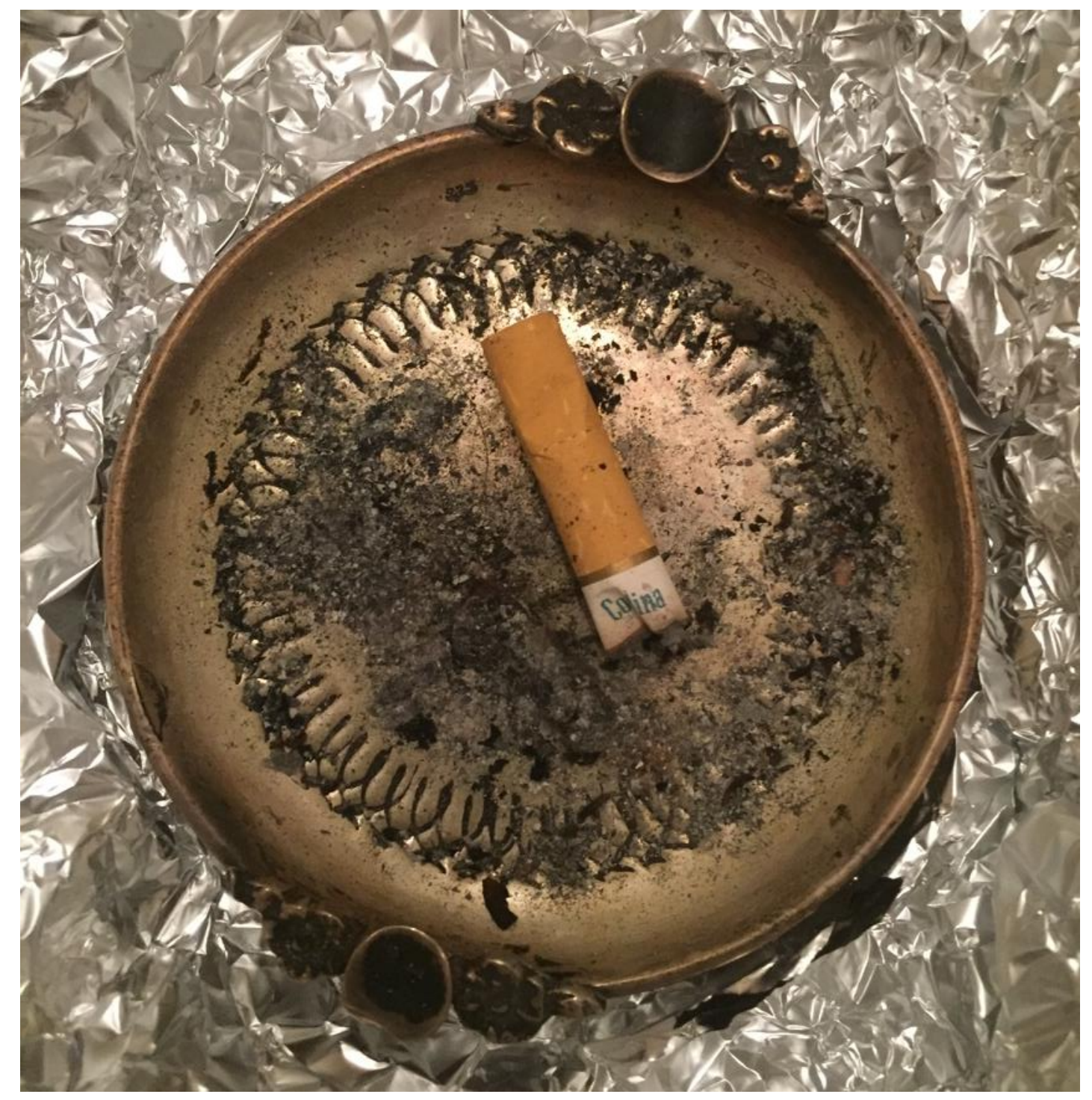

Figure 5. The Dimitris Dragatakis Archive has also preserved his final cigarette. To hear more about the item, see Valia Koronidi's interview in Chapter 2. Photo by author.

\subsubsection{Archive sources}

The Dimitris Dragatakis Archive currently houses all of Dimitris Dragatakis' manuscripts. Two manuscripts were provided to and used by the researcher for this project: the manuscript for the Concerto for Viola orchestra score and the piano reduction. ${ }^{11}$

${ }^{11}$ Dimitris Dragatakis, “Concerto for Viola," Collection of Manuscripts, Dimitris Dragatakis Archive. 
During the researcher's artist residency, digital scans of the front pages of manuscripts and typeset versions of over 150 works were taken and uploaded to the digital database website for works that had not been published by Nakas Music House or typeset by Dragatakis himself. ${ }^{12}$

Also recently released from the archive and included in the dissertation is the recording from the premiere performance of Concerto for Viola in 1993, which assists in advancing the work and making it more accessible to future performers and scholars. ${ }^{13}$

During the researcher's artist residency, further archival resources were viewed and handled, such as concert programmes, orchestral parts with markings, cassette tapes, recordings, personal items, photographs, and manuscripts. Many of these primary source materials are not included or referenced, but serve as potential post-doctoral projects outlined in the final chapter of this dissertation.

\subsubsection{Digital sources}

At the start of this project the digital material pertaining to Dragatakis was limited to a Wikipedia page, which included outdated information, the occasional scholarly article or doctoral dissertation dedicated or referring to him, and a short biography in Greek on the Institute for Research on Music and Acoustics (IEMA) [Institoúto Érevnas

\footnotetext{
${ }^{12}$ Nakas Music Publishing House is a publishing house in Greece. During Dimitris Dragatakis' life, he had a contract with them to publish his works. For a list of Nakas publications, see the Catalogue of Works in Chapter 3: Digital Tools.

${ }^{13}$ Artur Paciorkiewicz, “Concerto for Viola," by Dimitris Dragatakis, 1993 premiere performance recording.
} 
Mousikís \& Akoustikís - Kéntro Mousikís Tekmiríosis] website. ${ }^{14}$ Even more limited was information on his Concerto for Viola. ${ }^{15}$

Now at the culmination of this research, information about Dragatakis can be found easily through Google and other digital platforms. The materials referenced in this section either existed prior to this research or were created by the researcher during the course of this project and are referenced later in this dissertation.

\section{Institute for Research on Music and Acoustics (IEMA) [Institoúto Érevnas Mousikís}

\section{E Akoustikís - Kéntro Mousikís Tekmiríosis]}

While there are over 890 different entries on the Institute for Research on Music and Acoustics (IEMA) website relating to Dragatakis and his works, these scans and digital materials are difficult to access. ${ }^{16}$ IEMA offers a catalogue of digitised items, but the files are essentially inaccessible unless they are sent directly to the researcher or a researcher is given access to the materials in person to view physical copies. Physical copies are naturally preferred and have a different type of excitement to them, but the only way to access the physical copies is to travel to the Archives in Athens, Greece, and in a COVID-19 world there is currently no way to access these resources.

After investigating the listings in IEMA, the researcher found that some of these entries are duplicates, ${ }^{17}$ nonetheless, this is important in that it is indicative of

\footnotetext{
${ }^{14}$ Kalopana, “Dragatakis, Dimitris"; IEMA, “Dimitris Dragatakis.”

${ }^{15}$ IEMA, “Viola and Krakow Orchestra: iem.CMC.DDR.rmc.61." Physical item listing, Dragatakis collection. http://digitize.iema.gr/is pi en.php?phys item id=305; IEMA, “Concerto for Viola and Orchestra of Krakow: iem.CMC.DDR.rmc.85.1."

${ }^{16}$ IEMA, “Home Page.” https://www.iema.gr/home/?lang=en.

${ }^{17}$ IEMA, “Home Page.” https://www.iema.gr/home/?lang=en.
} 
Dragatakis' reception. This alone shows Dragatakis' favourable reception within Greece and on a small international scale. There are no listings of Nakas Music House published scores in the IEMA database, only the physical hand-written manuscripts and recordings of works among other primary sources. The website database includes photographs or scans of the catalogued items. Unfortunately, as mentioned previously, at this time the search function of the database does not function properly and therefore the information in the database is practically inaccessible.

\section{Digital Tools}

The new digital tools created during this project are outlined later and include a Dimitris Dragatakis Archive digital database website, a catalogue of works and catalogue of works for viola, a YouTube page with a collection of over 300 videos, a Dimitris Dragatakis Spotify Page, interview material, the Concerto for Viola premiere recording, and a new stand-alone piano part and optional percussion chamber music edition for Dragatakis's Concerto for Viola.

These sources are referenced throughout the dissertation and are a valuable contribution to their respective area of research and scholarship.

\subsubsection{Secondary source material}

The sources discussed in this section are secondary sources relating directly to Dragatakis, his life, work, and legacy. The literature available in this category is limited to two works by Dr Magdalini Kalopana.

At the end of 2019, Kalopana published Dimitris Dragatakis: Systematic and Biobibliographical works catalogue [Systēmatikos kai Bio-bibliographikos Katalogos Ergōn] 
through Nakas Publishing House. ${ }^{18}$ This book is written in Greek and details the life and works of Dimitris Dragatakis. Each work by Dragatakis is described in extreme detail and programme note material is provided. Since this book was published towards the end of this project, it is not referred to directly; however, Dr Kalopana's PhD dissertation - which inspired her recently published book - was used often as a reference throughout this project and during the creation of the Dimitris Dragatakis Archive digital database website. ${ }^{19}$

Preceding her book, Dr Kalopana thoroughly researched and presented information about Dragatakis. Her articles include a New Grove article titled "Dragatakis, Dimitris", which includes a full list of works and biographic information. ${ }^{20}$ She has also presented numerous papers on the topic at domestic and international conferences. ${ }^{21}$ Dr Kalopana is considered the leading Dragatakis scholar and has a wealth of knowledge concerning Dragatakis' life and works.

\footnotetext{
${ }^{18}$ Magdalini Kalopana, Dimitris Dragatakis: Katalogos ergon [Dimitris Dragatakis: catalogue of works, Dimitris Dragatakis: Systematic and Bio-bibliographical Works Catalogue. Athens: Nakas Publishing House, 2019.

${ }^{19}$ Magdalini Kalopana, “Dimitris Dragatakis: Katalogos ergon [Dimitris Dragatakis: catalogue of works]." PhD dissertation, National and Kapodistrian University of Athens, 2009.

${ }^{20}$ Magdalini Kalopana, "Dragatakis, Dimitris," Grove Music Online. 3 September 2014. https://doi.org/10.1093/gmo/9781561592630.article.08120.
}

${ }^{21}$ Magdalini Kalopana, “The influence of musical avant-garde in the works of Dimitris Dragatakis of the late '50s and the "60s." Conference presentation, International Conference Beyond the Centres: Musical Avant-Gardes Since 1950, Aristotle University of Thessaloniki, Greece, July 1-3, 2010. http://btc.web.auth.gr/; "Dragatakis, Dimitris"; “Dimitris Dragatakis: Katalogos ergon” (2009). 


\subsubsection{Other relevant sources}

The sources discussed in this section are also secondary sources and relate to the themes of digital humanities, creating performance editions, twentieth-century music trends, and Greek traditional music as discussed in the dissertation.

\section{Performance editions}

The research includes the newly created stand-alone piano performance edition and the percussion chamber music edition of Dragatakis' Concerto for Viola. The creation of these performance editions was aided by considering Grier's The Critical Editing of Music: History, Method, and Practice, Lorenda Ramou's Dimitris Dragatakis - Complete Piano Works critical edition, and Gabriela Glapska's PhD dissertation The life and music of André Tchaikowsky, one of the most recent $\mathrm{PhD}$ in Music dissertations to pass through completion at the New Zealand School of Music before this project.

\section{Digital humanities}

Sources pertaining to digital humanities considered for this project were $A$ New Companion to Digital Humanities and Companion to Digital Humanities. ${ }^{22}$ The latter, published in 2004, collates thirty-seven original articles written by leading scholars in the field of digital humanities positioned within an historical perspective, relating the emerging field of digital humanities to traditional fields of humanities such as archaeology, art history, linguistics and lexicography, literary studies, and music, philosophy, religion, among others. This resource was useful in understanding the development and progression of the field of digital humanities, the perceptions of the work in this field, and the potential for the field going forward.

\footnotetext{
${ }^{22}$ Schreibman et al., A New Companion to Digital Humanities; Schreibman et al., A Companion to Digital Humanities.
} 
The former source, A New Companion to Digital Humanities, was published in 2016 and reflects in its contents over a decade of development in both the language and the technology within the field of digital humanities. In comparison to its 2004 counterpart, this volume was particularly useful in demonstrating how technological and institutional changes in recent history have impacted the viability of the field of digital humanities, and its value to continuing scholarship across a wide range of disciplines. In particular, Chapter 4 of A New Companion to Digital Humanities examines the issues faced when incorporating digital humanities projects into traditional academic environments, including the inherent challenges of the collaborative nature of digital humanities in a cross-disciplinary environment, and the infrastructure and resources required to support these projects. Chapter 5 follows on to discuss methods of "Becoming Interdisciplinary", offering methods and advice on the nature of digital humanities projects to expand beyond the scope of the original discipline. Chapter 11 comments on the development of what is known as the 'methodological commons' or the underlying framework that has evolved in relation to the conceptualisation and understanding of the field and nature of digital humanities.

\section{Twentieth-century music trends}

Dragatakis was a twentieth-century Greek composer, and research preceding this project confirms he was influenced by twentieth-century music trends; therefore, in order to fully understand Dragatakis and his music it is important for performers and scholars to grasp concepts of twentieth-century music trends. Which musical trends are not entirely clear, however, as Dragatakis was known on many occasions to state definitively that he was not influenced by any particular musical trends or movements. In this way, it may be said that no single influence was shown or made dominant in his works. Whilst Dragatakis' compositions show influence from many veins, any claims to be made regarding influence on Dragatakis and his compositions 
are conjecture based on his (assumed) immediate influences including those associated with the time when he lived and people and places where he resided.

The importance of twentieth-century music and musical trends, especially western trends, cannot be understated, as this was a large influence on Greek composers of the twentieth century. In the article "Music Education in Nineteenth-Century Greece: Its Institutions and their Contribution to Urban Musical Life," Romanou and Barbaki examine the stage of the twentieth-century compositional landscape in Greece that was set by the nineteenth-century Greek National School composers, growing close ties to western compositional tactics while preserving traditional Greek songs and instruments, and aiming to develop a 'national' style for the Greek nation. This article by Romanou and Barbaki, which is highly relevant to research topics concerning Dragatakis, utilises a framework of context and historical narrative in order to examine themes relating to music and culture including religion, politics, language, aesthetics, tradition and folk music, social class, education, and more. By examining the history and politics of three representative centres of Greece including Athens, the capital of the Greek state since 1834, as well as Constantinople and Corfu, two of the most dissimilar musical cultures but which both influenced music education in Athens, a clearer understanding of music education in nineteenth-century Greece can be defined.

Another source considered that discusses twentieth-century music trends is Music of the Twentieth Century: A Study of Its Elements and Structure. This source goes into detail and explains factors that contributed to the evolution of music, including scientific and industrial revolutions and discoveries, as well as adaptations and changes in musical styles and composition techniques in the twentieth century. ${ }^{23}$ At the centre of

\footnotetext{
${ }^{23}$ Ton De Leeuw et al., Music of the Twentieth Century: A Study of Its Elements and Structure. Amsterdam: Amsterdam University Press, 2005.
} 
the text is an exploration of a dichotomy in which modern music is highly individualised, both in creation and perception, and yet this practice of individualism is normalised so that it produces works that sound abnormal to so many listeners. Whereas Romantic composers sought to escape the tight bonds of musical elements and forms of the Classical era in a search for tools for greater musical expression, the focus of writing music in the twentieth century seemed to shift from expressing oneself to demonstration of technical abilities. In relation to Dragatakis' Concerto for Viola, for instance, we see definitive elements of rhythm, melody, timbre, and even influences of Greek traditional and folk music as well as atonality, all elements discussed in this source.

\section{Greek traditional music}

Greek traditional and traditional world music, and music and nationalism, are topics intertwined within the musical history of Greece, and opinions are varied on the treatment of folk songs and traditional music throughout history and in the twentieth century. It is known and confirmed through previous research and the researcher's own fieldwork that Dragatakis was influenced by Greek traditional music from Epirus in the northern part of Greece and traditional musicians. ${ }^{24}$ While Dragatakis' writing embodies a western style in terms of form and structure, his melodic and rhythmic writings are entirely his own but also very much of Greece.

Given that Greek traditional music is generally an aural tradition passed down through rote learning, there is little written about it or how it was approached. Authors who touch upon the subject of traditional music within and outside Greece include Bohlman, Silverman, Mantzos and Nitsiakos, Dougherty and Kurke, Kalopana, and also Taylor, who embed the discussion of traditional music within a historical survey of music in Greece and the larger discussion of 'nation' and 'music

${ }^{24}$ Dalabakis, “Dimitris Dragatakis Interviews". 
and nationalism'. ${ }^{25}$ Silverman explores the reception through history relating to Balkan music and Romani musicians, including their reception in Greece and the nature of their influence in major areas and musical styles of Greece. Dougherty and Kurke collate writings from various authors who examine aspects of Ancient Greek culture including its composition, which included a number of disparate sub-cultures that confronted one another and contested their own values and meanings, subsequently negotiating and renegotiating their identity continuously. Furthermore, through the collection of writings this source examines definitions of 'culture' as well as associated terms and concepts such as ideology, ethnicity, cultural contact, and cultural exchange. The primary significance of the Taylor article is found within his focus upon the notion that the fullest understanding of composers and their works comes not just from the analysis of musical and technical properties of the music itself, but also through understanding the life, influences, and experiences of composers including their culture and history.

\subsubsection{Related material}

The material discussed in this section is related to the research; however, it is not directly discussed or used within the dissertation. The materials are nevertheless important for future scholars and performs to digest in order to understand the full context of Dragatakis, his life, works, and legacy.

\footnotetext{
${ }^{25}$ Philip Bohlman, Focus: Music, Nationalism, and the Making of New Europe. New York: Routledge, 2011; Carol Silverman, Romani Routes: Cultural Politics and Balkan Music in Diaspora. Cary: Oxford University Press, 2015; Constantinos Mantzos and and Vassilis Nitsiakos, Negotiating Culture: Political Uses of Polyphonic Folk Songs in Greece and Albania. England: Ashgate, 2003; Carol Dougherty and Leslie Kurke, The Cultures within Ancient Greek Culture: Contact, Conflict, Collaboration. Cambridge: Cambridge University Press, 2003; Magdalini Kalopana, “Dimitris Dragatakis: Katalogos ergon," 2009; Timothy Taylor, Beyond Exoticism: Western Music and the World. Durham: Duke University Press, 2007.
} 
For the purposes of this project, these sources are not discussed directly but were used to gain the wider perspective needed for this project. The themes covered in this section pertain to Greek history, Greek politics, and nationalism and music. Any scholar or performer looking to find more information about Dragatakis or to fully understand the context of his music is encouraged to delve deeper into the sources outlined.

\section{Greek history and politics, nationalism and music}

The link between tradition and modernity is a strong theme in Greek music, and many scholars argue that politics, nationalism, and music are inextricably linked throughout Greek history. Gail Holst-Warhaft argues that music and politics in Greek culture are inseparably linked, and have been from as early as the sixth century BC. ${ }^{26}$ The article focuses on a case study of the music of composer Mikis Theodorakis, a twentiethcentury left-wing composer who was well-known in the western world for a previous film score, and whose music was banned in Greece by the military dictatorship in 1967 because of the symbolic nature of Theodorakis' music to Greece and against the regime. The author situates this case study within politically and culturally significant history, discussing the birth of the modern Greek nation and the part music and politics have played in the development of the nation and national culture, and the role they maintain today.

Similarly, well-known scholar Philip Bohlman states that any attempt to discuss or understand European music cannot be separated from discourse surrounding nationalism and its fundamental contribution to "the ontology of Europe's music, that is, to music's 'way of being' in Europe." 27 Bohlman's statement contradicts much of

\footnotetext{
${ }^{26}$ Gail Holst-Warhaft, "Politics and Popular Music in Modern Greece," Journal of Political and Military Sociology 30, no. 2 (2002): 297-323.

${ }^{27}$ Bohlman, Focus, xxii.
} 
the discourse on the topic, which considered nationalism to be an element of certain types of music, such as traditional music and folk songs, and as a movement associated with times of war and national, social, and political issues. However, Bohlman stresses the ever-changing nature of the concepts associated with nationalism, including 'national' and 'nationalistic', and the fact that these (separate) concepts are defined by different people and different places, and their personal experiences and resulting perspectives. In doing so he highlights the relationship between history and culture, and thus the nature of European music and nationalism to be intrinsically interconnected. Bohlman explores and defines various concepts including folk music, nationalism, nationalism in music, the State, the Nation, transnational, the Nation-State, and others.

Risto Pekka Pennanen's essay titled “The Nationalization of Ottoman Popular Music in Greece" is focused through the lens of a musical case study - the reception of Ottoman-Greek cafe music in post-Ottoman Greece - addressing themes of culture, nationalism, boundaries, identity, multiculturalism, and reception in the popular music of post-Ottoman Greece. ${ }^{28}$ Similarly, Mantzos and Nitsiakos examine the same themes in an article titled "Negotiating Culture: Political Uses of Polyphonic Folk Songs in Greece and Albania". ${ }^{29}$

Between these sources lies a resource which stems from a background of political science, examining the meaning and effects of 'cultural hybridity' titled Critique of Exotica: Music, Politics, and the Culture Industry. ${ }^{30}$ In this case, John Hutnyk uses the

\footnotetext{
${ }^{28}$ Risto Pekka Pennanen, “The Nationalization of Ottoman Popular Music in Greece," Ethnomusicology: Journal of the Society for Ethnomusicology, 48, no. 1 (2004): 1-25.

${ }^{29}$ Mantzos and Nitsiakos, "Negotiating Culture."

${ }^{30}$ John Hutnyk, Critique of Exotica: Music, Politics and the Culture Industry. London: Pluto Press, 2000.
} 
growing popularity of Asian culture in the West as a case study through which to examine cultural appropriation and appropriation of 'exotica' across the globe. Hutnyk incorporates an examination of political and cultural history alongside several artists' music, and the intersection of that music with race, culture, and politics, effectively utilising a combined version of the previous methodologies employed by the aforementioned sources by collating timelines of multiple sources within a case study in which various themes are explored. These three sources, among others, are starting points for an examination of acknowledged historical, national, social, and political factors in Greek history. Within cultural hybridity comes musical hybridity, especially with the delicately intertwined history of Greek politics, nationalism, and music. Musical hybridity is explored within cultural hybridity and nationalism by relevant scholars and authors. ${ }^{31}$

${ }^{31}$ Rebecca Draisey-Callishaw, “'Fusions and Confusions': Reflections on Intercultural Collaboration, Musical Hybridity, and the Intersubjective Nature of Reality," Journal of Canadian Society for Traditional Music 39, no. 2 (2012): 61-81; Mark Fitzgerald and John O'Flynn, Music and Identity in Ireland and Beyond. Farnham: Taylor and Francis, 2014; Bliss Sheryl Little, "Folk Song and the Construction of Greek National Music: Writings and Compositions of Georgios Lambelet, Manolis Kalomiris, and Yannis Constantinidis." PhD dissertation, University of Maryland, College Park, 2001; Mantzos and Nitsiakos, "Negotiating Culture"; Pennanen, "The Nationalization of Ottoman Popular Music in Greece"; Tina K. Ramnarine, Musical Performance in the Diaspora. London: Taylor and Francis, 2008; Silverman, Romani Routes; Taylor, Beyond Exoticism; Stanković, Peter, “Appropriating 'Balkan': Rock and Nationalism in Slovenia," Critical Sociology 27, no. 3 (2001): 98-115. 


\section{Chapter 2: Impressions of Dragatakis}

Born in a small mountain village in Epirus, Dimitris Dragatakis lived a fulfilled life according to his family, enjoyed a career as a violist, and is known as one of Greece's most important modern composers. His legacy lives on today in those who diligently work to preserve and promote his archive and music.

The biographic material pertaining to Dragatakis has been thoroughly researched and was addressed in the literature review. This section includes impressions of Dragatakis from his family and a leading Dragatakis scholar. ${ }^{32}$ This collection of interviews offers future performers and scholars an insight into Dragatakis and those who have persistently worked to preserve his music and legacy and offers a different perspective to this area of scholarship.

As explained by his family, Dragatakis took an interest in those around him and was a mentor to others. ${ }^{33}$ Adjectives used to describe him have been 'thoughtful', 'humble' and 'laconic', among other many other positive attributes. ${ }^{34}$ It has been said, and confirmed through documented research, that he was inspired by the sounds of nature and his compositions heavily influenced by traditional Greek music. ${ }^{35}$

\footnotetext{
${ }^{32}$ See Collaborators.

${ }^{33}$ Ismini Koronidi, Interview with the author, interview by Elyse Dalabakis, Dimitris Dragatakis Interview Collection, October 24, 2019, audio [14:51].

${ }^{34}$ Ismini Koronidi, Interview; Kelly Dragatakis, Interview with the author, interview by Elyse Dalabakis, Dimitris Dragatakis Interview Collection, October 26, 2019, audio [09:38].

${ }^{35}$ Kelly Dragatakis, Interview; Leonidas Dragatakis, Interview with the author, interview by Elyse Dalabakis, Dimitris Dragatakis Interview Collection, October 26, 2019, audio [30:09]; Valia Koronidi, Interview with the author, interview by Elyse Dalabakis, Dimitris Dragatakis Interview Collection, October 11, 2019, audio [53:48]; Kalopana, “Dragatakis, Dimitris.”
} 
He enjoyed a peaceful home and work space, and like many composers needed his own space at times for his creativity. ${ }^{36}$ He encouraged his children and grandchildren to learn music theory in order to appreciate all music has to offer and, in the case of his granddaughters, Iro and Ismini Koronidi, taught them music theory for a brief period. Other than music theory knowledge, Dragatakis instilled in them all the 'freedom of choice' and encouraged them to live a life doing what made them happiest. ${ }^{37}$

Dragatakis, while a man of few words, thoroughly expressed himself through his musical compositions. It is mentioned in conversations with family and friends that he spoke few words due to his upbringing in a small village. Although he may have spoken few words, this was more than made up for in his complex musical works. His compositions are a direct insight into his thoughts and reflections. ${ }^{38}$

These interviews offer a previously unrecorded perspective on Dimitris Dragatakis, his life, his works, and his legacy, and add an invaluable contribution to this topic and area of scholarship.

\subsection{Impression of Dragatakis through interviews}

This section contains over four hours of audio-recorded interview material and is most effectively experienced by reading the interview and interviewee summary, opening the recorded interview link, and reviewing the interview questionnaire provided while listening. The questionnaires for each individual can also be found in Appendix

\footnotetext{
${ }^{36}$ Valia Koronidi, Interview; Magdalini Kalopana, Interview with the author, interview by Elyse Dalabakis, Dimitris Dragatakis Interview Collection, October 11, 2019, audio [39:53].

${ }^{37}$ Iro Koronidi, Interview with the author, interview by Elyse Dalabakis, Dimitris Dragatakis Interview Collection, October 24, 2019, audio [21:06]; Leonidas Dragatakis, Interview. 38 Valia Koronidi, interview.
} 
4. The reader is encouraged to view this in Adobe and use the 'Bookmarker' tab on the left-hand side to navigate through the dissertation if needed.

The material in this section was collected during the researcher's artist residency at the Dimitris Dragatakis Archive in Athens, Greece, in October 2019. While other sources offer a factual and chronological biography, this project attempts to offer impressions of Dimitris Dragatakis taken from interviews with his family members and a leading Dragatakis scholar. Through this medium, we learn about a different side of Dragatakis - as a father, grandfather, and friend, and how the people closest to him understood his life and works. This section highlights Dragatakis through the perspective of the individuals who have worked the hardest to preserve and promote Dragatakis' legacy after his death in 2001.

The interviews were conducted either at the home of Thanos and Valia Koronidis or the home of Leonidas and Kelly Dragatakis. The interviewees were asked a series of questions in line with the Victoria University of Wellington - Te Herenga Waka Human Ethics requirements and all have given written consent to be included in this dissertation. For a list of interviewees, please see Collaborators at the beginning of this dissertation. 


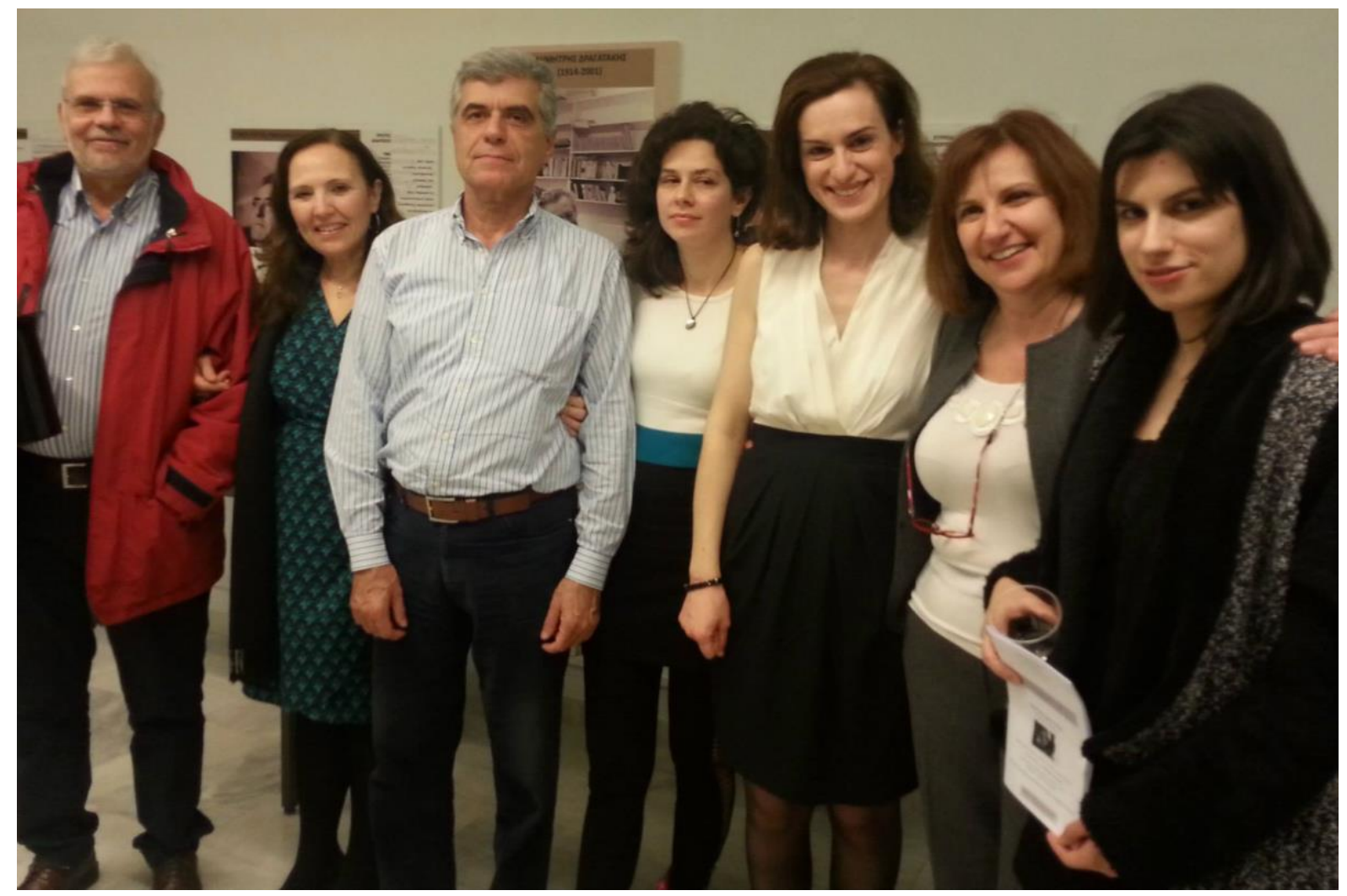

Figure 6. Photo of the Dragatakis and Koronidis family and Dr Magdalini Kalopana, taken in 2014 at the 100 Years Since Birth exhibition at Megaron. From left to right: Thanos Koronidis, Kelly Dragatakis, Leonidas Dragatakis, Ismini Koronidi, Magdalini Kalopana, Valia Koronidi, and Iro Koronidi. Photo from the Dimitris Dragatakis Archive digital database website.

On the following page, there is an interactive map of Greece that shows the distance between Epirus, where Dragatakis was born, and Athens, where Dragatakis later lived, studied, and worked. Please click on the link to view in an internet browser. Through using Google Maps, the reader can zoom in or use street-view on the locations mentioned in the interviews as desired, among other things within the capabilities of Google Maps.

Many of these places are referenced in the interviews in the following section. It is of special importance to highlight the distance from Epirus to Athens - this would have been a similar journey Dimitris Dragatakis took with his brothers when their father took them to see Manolis Kalomiris at the Greek National Conservatoire, the founder of the school and considered to be one of the most important Greek composers, in the 
hope Kalomiris would take his sons in as students - which he did, thus starting Dragatakis' musical career. ${ }^{39}$

To reiterate, this map is interactive - the reader is encouraged to click on the image, which opens in Google Maps. A link is also available below the image.

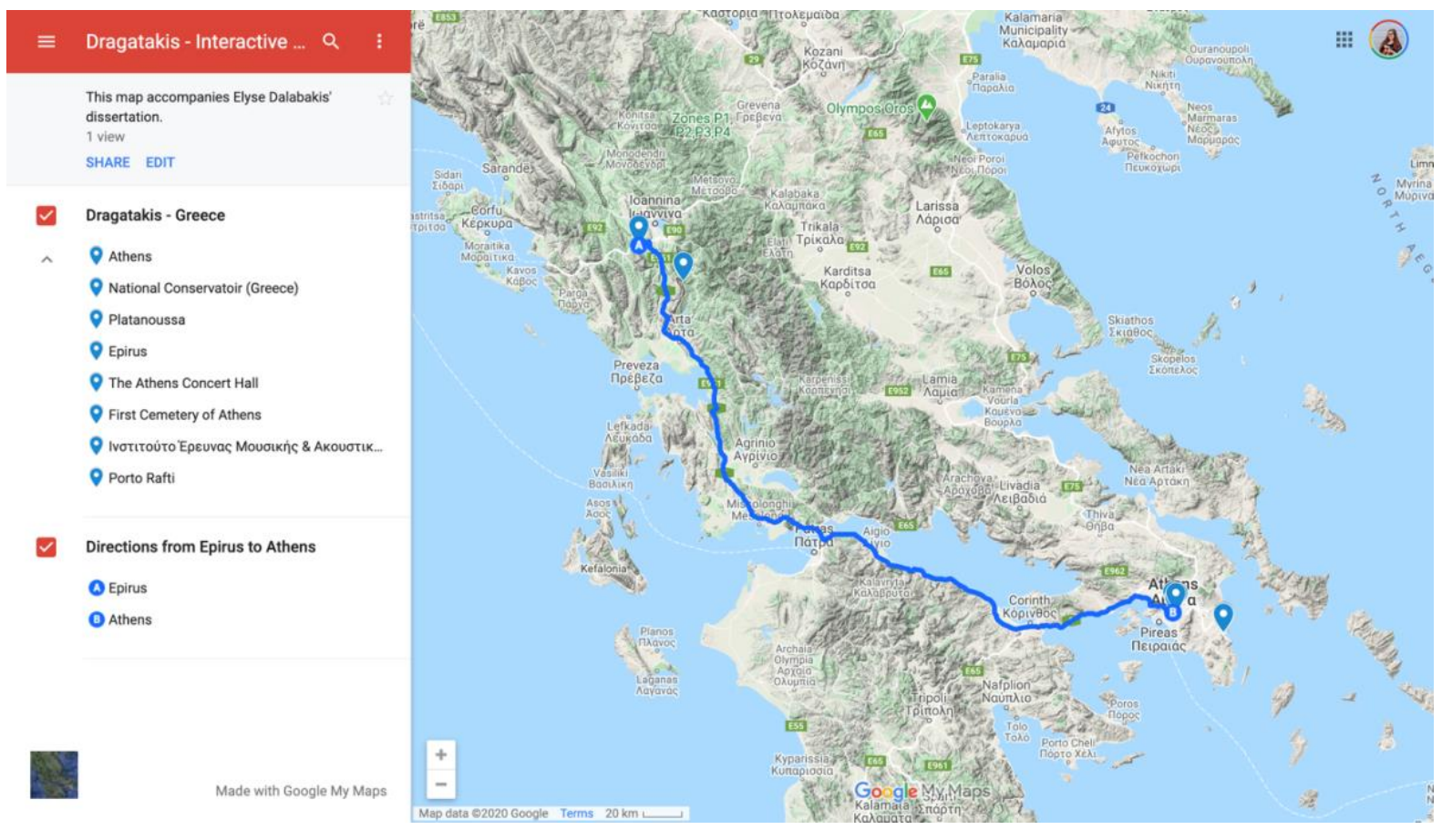

Figure 7. Map of Greece for interview material.

https://www.google.com/maps/d/drive?state=\%7B $\% 22$ ids $\% 22 \% 3 \mathrm{~A} \% 5 \mathrm{~B} \% 2210 \mathrm{ANySE}$ IDWew7R9fRdgNBqQ2H JQV0LfB $\% 22 \% 5 \mathrm{D} \% 2 \mathrm{C} \% 22$ action $\% 22 \% 3 \mathrm{~A} \% 22$ open $\% 22 \% 2$ C\%22userId \%22\%3A\%22108563963853381467598\%22\%7D\&usp=sharing

\subsubsection{Valia (Vasiliki) Koronidi (Dragataki)}

This interview took place on 11 October 2019 at Thanos and Valia Koronidi's house. A link to the audio recording can be found here. The audio recording includes only the voice of the interviewee. To assist with listening to the audio interview recording,

${ }^{39}$ Valia Koronidi, interview; Magdalini Kalopana, interview. 
please refer to the questionnaire here. The full links can be found after the interview and interviewee summary.

Valia Koronidi is the daughter of Dimitris Dragatakis and the Director of the Dimitris Dragatakis Archive. She also serves on the Board of the Friends of Dragatakis Society as Treasurer. Valia actively works to preserve and promote her father's legacy. She is a generous and kind woman who is eager to share material and information about her father, his music, and his legacy. She works hard to plan the biennial Dragatakis Composition Competition in association with the Greek Composers Union and runs the day-to-day tasks of the archive with Magdalini Kalopana, the archive's curator. Koronidi also acts on behalf of the estate in relation to any music or CD recording publication of her father's work.

In her moving interview, she recalls memories of Dragatakis as a man, a composer, and as a father. She also speaks about her grandparents, how her parents met, the important role her mother played in her life and within her family, and her father's last day. Her interview provides a personal, human perspective on Dragatakis and his legacy.

Audio recording: https://youtu.be/8 hvDigjrzs

Interview Questionnaire: https://drive.google.com/file/d/13wqnInYzpa-

5RhtF0hdK5qxv1TKPe9te/view?usp=sharing 


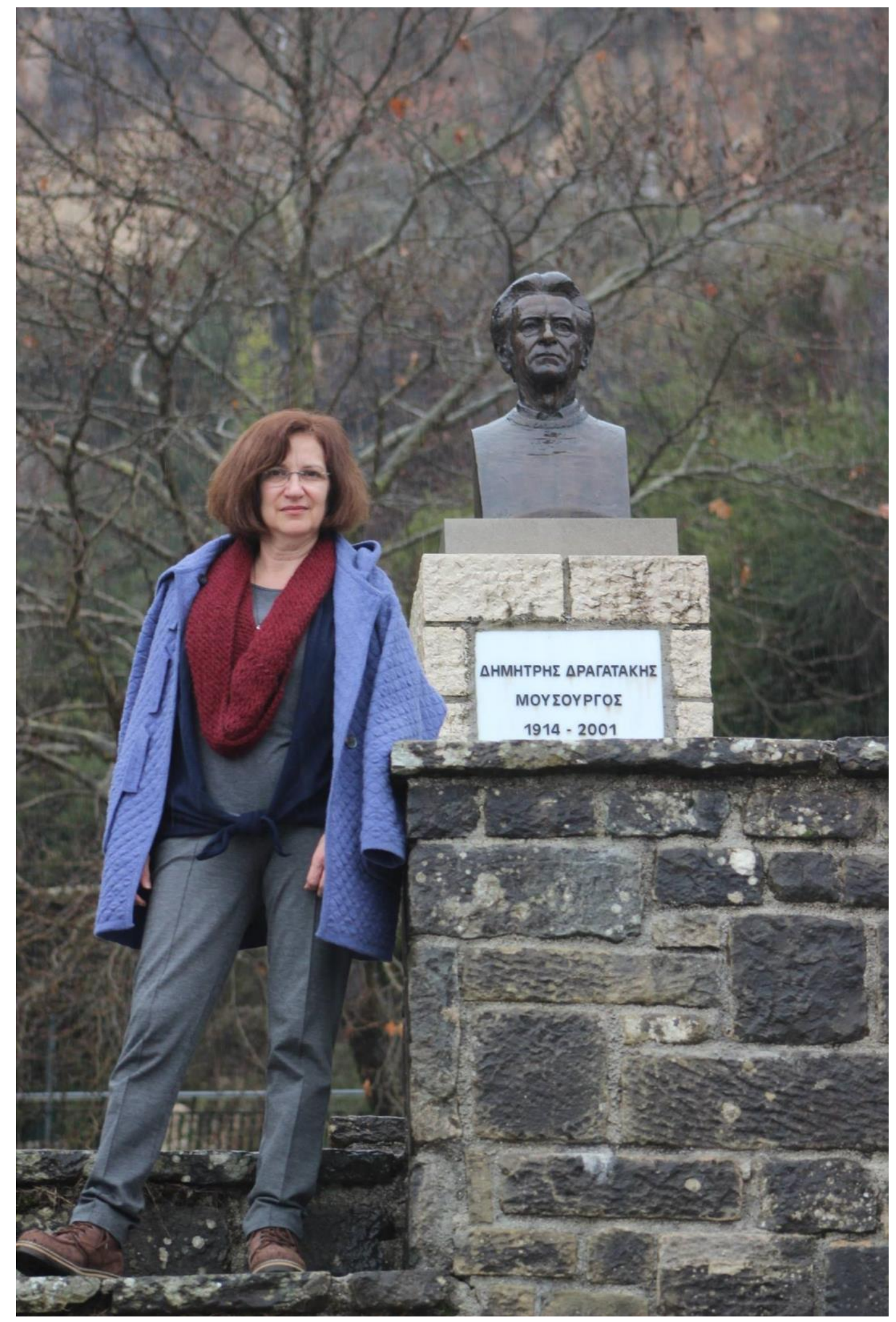

Figure 8. Photo of Valia Koronidi with her father's bronze bust in his hometown of Platanousa, Epirus. Photo from the Dimitris Dragatakis Archive digital database website. 


\subsubsection{Thanos (Athanasios) Koronidis}

This interview took place on 11 October 2019 at the house of Thanos and Valia Koronidis. A link to the audio recording can be found here. A full link can be found after the interview and interviewee summary. The interview questions for this interview were impromptu.

Thanos Koronidi is married to Valia Koronidi, and is subsequently son-in-law to Dimitris Dragatakis. Thanos is an honest and generous man who works diligently to assist the Dimitris Dragatakis Archive. He ensured all technology requirements were met during the researcher's artist residency in Athens, Greece, and was pivotal in the success of the project.

In his interview, Thanos recalls memories of when he was young living in Athens, his impressions of Dragatakis as person and composer, and tells an anecdotal story about Dragatakis, which sums him up as a humble, witty man with purpose and depth.

\section{Audio recording: https://youtu.be/734Xz4xpXFM}

\subsubsection{Leonidas Dragatakis}

This interview took place on 26 October 2019 at Leonidas and Kelly Dragatakis' house. A link to the audio recording can be found here. The audio recording includes only the voice of the interviewee. To assist with listening to the audio interview recording, please refer to the questionnaire here. The full links can be found after the interview and interviewee summary.

Leonidas Dragatakis is the eldest son of Dimitris Dragatakis, the brother of Valia Koronidi, and is married to Kelly Dragatakis. He also serves on the Board as the Secretary of the Friends of Dragatakis Society. Leonidas, or 'Leo' to those closest to 
him, is a welcoming and generous man who firmly works towards preserving, enhancing, and advancing his father's legacy.

In his interview he recalls his childhood, what it was like growing up in Greece, what Dragatakis was like as a father, his time studying overseas and meeting his wife Kelly, and why he took on the role of Director of the Dragatakis Archive, among other things.

Audio recording: https://youtu.be/61H0aX8A1v4

Interview questionnaire:

https://drive.google.com/file/d/1p3kW49pcuKgVQiX6UlDsfhbis]8kNkLV/view?usp= sharing

\subsubsection{Kelly Dragatakis}

This interview took place on 26 October 2019 at Leonidas and Kelly Dragatakis' house. A link to the audio recording can be found here. The audio recording includes only the voice of the interviewee. A full link can be found after the interview and interviewee summary. The interview questions for this interview were impromptu.

Kelly Dragatakis married Leonidas Dragatakis and subsequently became Dimitris Dragatakis' daughter-in-law. Kelly and Leonidas met while they were both studying in the United States. Kelly is a caring individual who truly finds the best in every situation.

In her interview, she recalls her impressions of her father-in-law and recounts a few specific memories from their time together. In general, she recalls Dragatakis and the influence nature had on him and his musical compositions.

Audio recording: https://youtu.be/4 QdvnkpAco 


\subsubsection{Ismini Koronidi}

This interview took place on 24 October 2019 at the house of Thanos and Valia Koronidis. A link to the audio recording can be found here. The audio recording includes only the voice of the interviewee. To assist with listening to the audio interview recording, please refer to the questionnaire here. The full links can be found after the interview and interviewee summary.

Ismini Koronidi is the eldest daughter of Thanos and Valia Koronidis, and granddaughter to Dimitris Dragatakis. An accomplished and talented architect, she is also a hardworking and loving mother to her children. With a keen eye for design, she was pivotal in the digital database website creation process and helped the researcher with providing the Dragatakis Archive logo, as well as many photos found on the website. In general, Ismini's feedback on the website design played an important role in the website's overall look.

In her interview, Ismini speaks about her papou, ${ }^{40}$ her time with him, and recalls a specific conversation they had together about the connection between music and architecture.

Audio recording: https://youtu.be/b0zO FISOwI

Interview questionnaire:

https://drive.google.com/file/d/1hatmqJqligLyRtZ4EI0oyMrimd7NJ768/view?usp=sh aring

\subsubsection{Iro Koronidi}

This interview took place on 24 October 2019 at the house of Thanos and Valia Koronidis. A link to the audio recording can be found here. The audio recording

\footnotetext{
${ }^{40}$ Papou in Greek translates to 'grandfather'.
} 
includes only the voice of the interviewee. To assist with listening to the audio interview recording, please refer to the questionnaire here. The full links can be found after the interview and interviewee summary.

Iro Koronidi is the youngest daughter of Thanos and Valia Koronidi, and granddaughter to Dimitris Dragatakis. A hard worker and talented architect, she is passionate about life in general.

In her interview, she recalls memories from her childhood about her papou and speaks about her life thus far and going forward. Perhaps most importantly, Iro's (and Ismini's) comments capture a side of Dragatakis not many musicians or composercolleagues may have known during his lifetime.

Audio recording: https://youtu.be/V51kdk9z6K0

Interview Questionnaire:

https://drive.google.com/file/d/1LquXVOO61o3yzpqdrcLrTF uu3jSoD9e/view?usp= sharing

\subsubsection{Magdalini Kalopana}

This interview took place on 11 October 2019 at the house of Thanos and Valia Koronidis. A link to the audio recording can be found here. The audio recording includes only the voice of the interviewee. To assist with listening to the audio interview recording, please refer to the questionnaire here. The full links can be found after the interview and interviewee summary.

In 1998, Dr Kalopana started her research in the Dimitris Dragatakis Archive and worked with Dimitris Dragatakis from then until his death in 2001. She is the leading Dragatakis scholar and curator for the Dragatakis Archive. Dr Kalopana continues to be an active performer and musicologist in Greece. 
She remembers her time with Dragatakis fondly and says he holds a warm place in her heart still today. Since his death, she takes the greatest of care in preserving his archive material. As the curator of the archive and leading Dragatakis scholar, she is often called upon to provide programme information, $C D$ liner notes, or publications of this nature.

Her interview outlines Dragatakis' life and works. She also recalls part of her life as a musician and student, what it was like to work with Dragatakis, and Dragatakis' reputation in Greece today. Dr Kalopana's interview offers an invaluable perspective - as the leading Dragatakis scholar this interview resource is a valuable contribution to this area of scholarship.

Audio recording: https://youtu.be/8rMxausS2EU

Interview Questionnaire:

https://drive.google.com/file/d/1SgVTbIuaxoJA0oaEds2jE2OI1n-

ypXli/view? usp=sharing 


\section{Chapter 3: Digital tools for Dragatakis}

The following sections discuss the digital tools used for this dissertation, which were created during the researcher's artist residency at the Dimitris Dragatakis Archive, including the Dimitris Dragatakis Archive digital database website, the video and audio databases, the digital catalogue of works, and how the dissertation itself serves as a further digital tool to advance and promote Dragatakis' life, works, and legacy. ${ }^{41}$

The published digital database website was created to be used as an online database of digital tools for performers and scholars and includes information about Dragatakis' life and compositions, upcoming event information and important past event information, media resources including videos and photos, links to news articles and scholarly material, and information about the Dragatakis Composition Competition and Friends of Dragatakis Society.

The YouTube channel was designed for use by performers and scholars as a video database. Currently, the Friends of Dragatakis Society is unaware of any further videos existing on the internet than those now included on the Dragatakis YouTube channel.

Further online research revealed there was a Dimitris Dragatakis Spotify Artist page, which had some of his discography already added. The researcher was able to claim and gain access to the Dimitris Dragatakis Spotify Artist Page. ${ }^{42}$ The researcher was also able to provide login access to the Dragatakis Archive - this page was not previously accessible by the Dimitris Dragatakis Archive or the Archive Directors. How the researcher gained accessed and claimed the Spotify Artist Page is outlined in section 3.4 Video and audio database.

\footnotetext{
${ }^{41}$ Susan Schreibman et al., A New Companion to Digital Humanities.

42 “Dimitris Dragatakis," Spotify, https://open.spotify.com/artist/7mx3q8GQBomkCxdO0zVoE4.
} 
Currently, the Spotify page hosts ten different albums that include works by Dimitris Dragatakis. ${ }^{43}$ While not a full audio database, the Spotify page is a start in the right direction - there is future work to be done to release recorded material from the Dimitris Dragatakis Archive.

Also discussed within this section is the release of the Concerto for Viola premiere recording and the use of the Concerto for Viola as a digital case study in the following chapter.

\subsection{Dimitris Dragatakis Archive digital database website}

The Dimitris Dragatakis Archive digital database website was created in correspondence with the Directors of the Dimitris Dragatakis Archive during the researcher's artist residency in October 2019. The following section discusses the process of creating the website.

A PDF of the 233-page digital database website is included as Appendix 1.2.

\subsubsection{Creating the website}

The Dimitris Dragatakis Archive website was created through collating scholarly articles, past and upcoming events information, relevant photos, Dragatakis Composition Competition history, Friends of Dragatakis Society information, and Dragatakis' biographical material (taken from the Irida CD Dimitris Dragatakis - The String Quartets), among other information.

The largest task was creating materials for the digital database and website as there are over 150 pieces to list on the website and each listing required a digital preview of

\footnotetext{
${ }^{43}$ See more at the Spotify FAQs page. https://artists.spotify.com/faq/access.
} 
the work to be made. This required time in the archive taking a 'preview' scan of each work. The scanning was done at Dimitris Dragatakis' own desk in his office - his desk has been left in almost the same state as he left it when he passed in 2001. Remaining on the desk are 'notes to self', a calendar, and miscellaneous pencils and small bits of eraser, among other things.

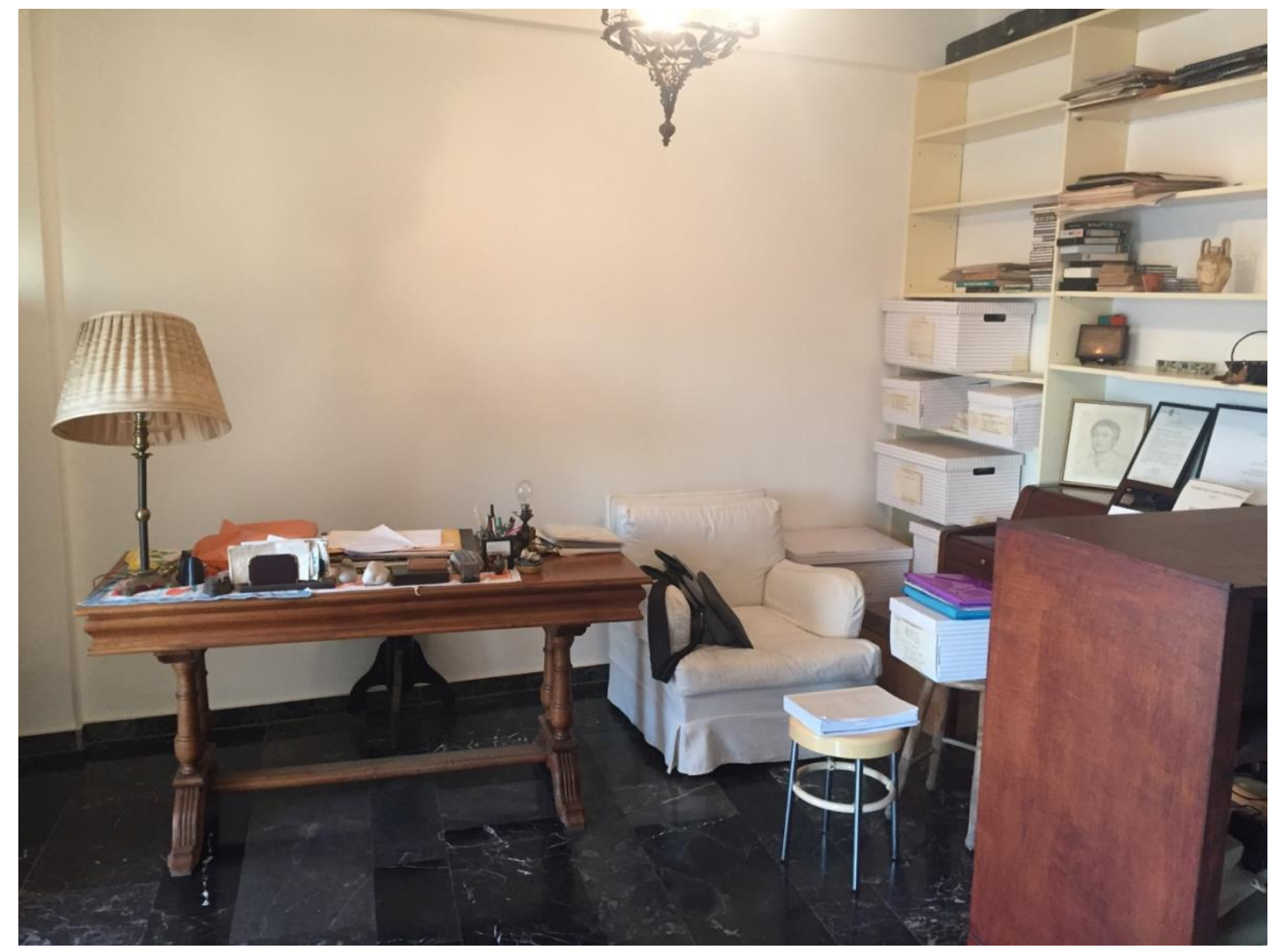

Figure 9. Dimitris Dragatakis' desk, now located in the Dimitris Dragatakis Archive. His desk has been mostly left as it was the day he died in December 2001. Photo by author.

On the digital database website there is now an official Dragatakis Archive list of works with links that connect to the designated page on the website and to Nakas Music House, if applicable. This list is also included later in the dissertation.

After collating and creating all of this information, it was time to create the website. The website is hosted through Wix. The researcher has also set-up full Search Engine 
Optimisation (SEO) capabilities. Website statistics are outlined in the final section of this dissertation. The website now functions as a digital database of the archive, and will be added to over time.

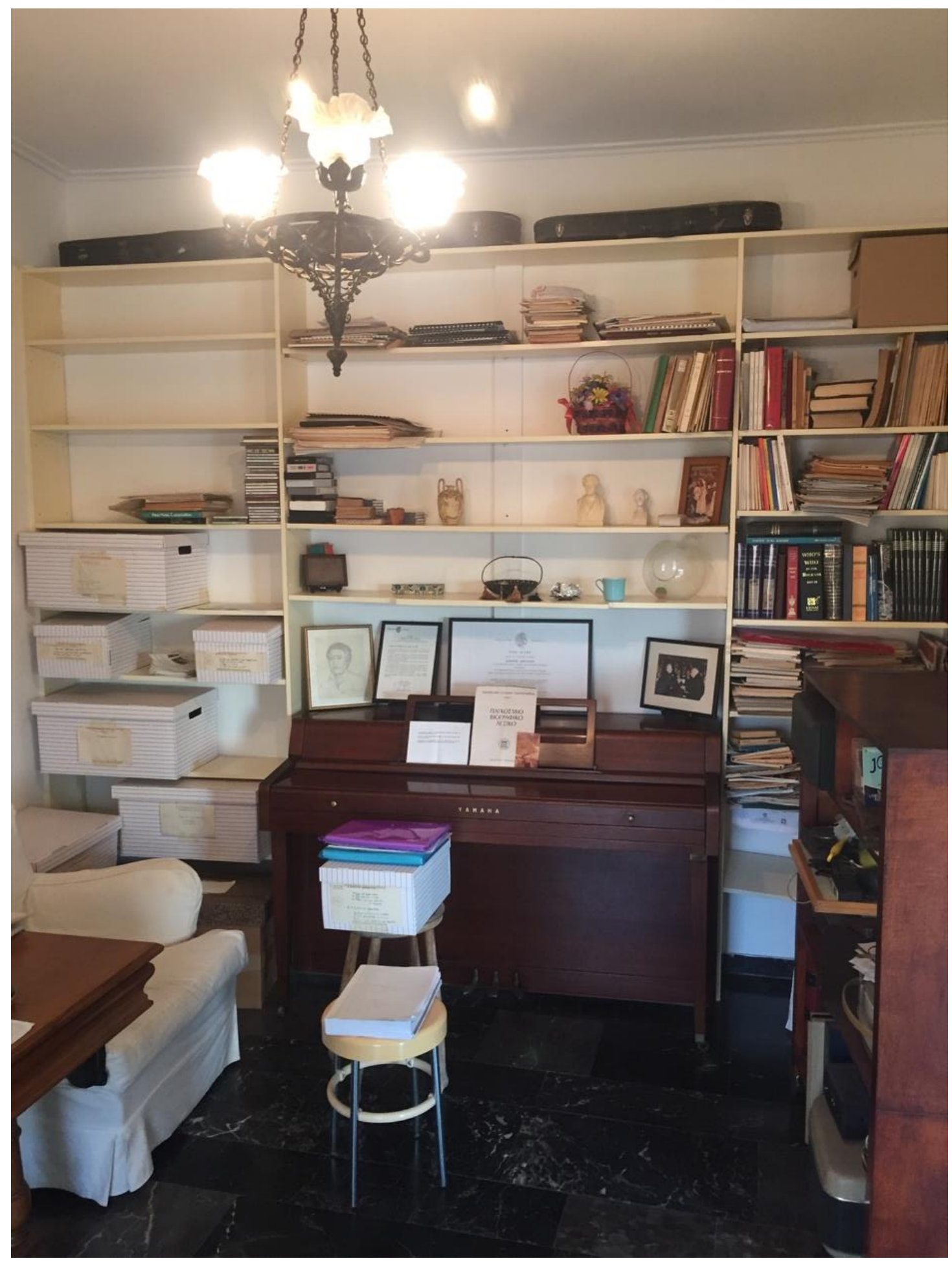

Figure 10. Dimitris Dragatakis' office, now part of the Dimitris Dragatakis Archive. 


\subsubsection{Website site map}

Below is a site map for the Dimitris Dragatakis digital database and website. The overall concept and design of the website are the original work of the researcher. The website can be visited from here.

https://www.dimitrisdragatakis.com/

$\underline{\text { Home }}$

$\underline{\text { About }}$

Dimitris Dragatakis (1914-2001)

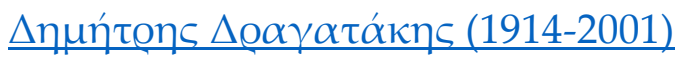

The Society

Dragatakis Composition Competition

Greek Composers' Union

Compositions

Chamber Music for Mixed Ensembles

Chamber Music for Strings

Chamber Music for Winds \& Brass

Choral Works

Concertos

Orchestral Works

$\underline{\text { Solo Works }}$

$\underline{\text { Vocal Works }}$

$\underline{\text { Media }}$

Photo Gallery

Video Library

Discography 
Spotify

Events Calendar

Upcoming Events

$\underline{\text { Past Events }}$

News

News \& Reviews

$\underline{\text { Scholarly Publications }}$

Support Us

Contact 


\subsection{Catalogue of works for Dragatakis archive}

The following is a list created during the researcher's artist residency and can also be found on the Dimitris Dragatakis Archive database website. The list includes categories listed alphabetically, and within each category the works are then listed chronologically. Specific citations can be found at the end of this list or in the Appendix.

\section{Dimitris Dragatakis Archive}

\section{List of Works}

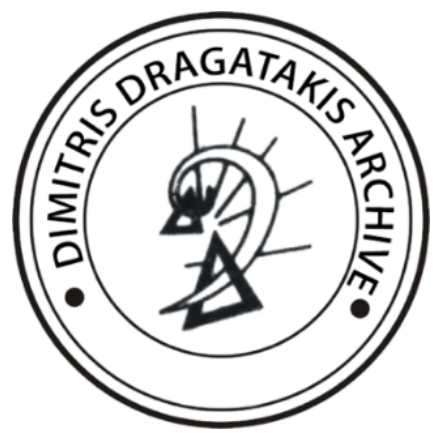

The following list of works is the property of the Dimitris Dragatakis Archive. The list includes categories of works in alphabetical order and within each category the works are listed chronologically. This document was created from primary sources in the Dragatakis Archive and secondary sources from Dr Magdalini Kalopana's Grove Music Online article “Dimitris Dragatakis" (September 2014) and PhD dissertation ("Dimitris Dragatakis: Katalogos ergon [Dimitris Dragatakis: catalogue of works]") from the National and Kapodistrian University of Athens (2009), and Philippos Nakas Music House publications. The full citations can be found at the end of this list.

For more detailed information about each work, please also see Dr Magdalini Kalopana's book Dimitris Dragatakis: Systematic and Bio-Bibliographical Works Catalogue [Systēmatikos kai Bio-bibliographikos Katalogos Ergōn] (Athens, Greece: Philippos Nakas Music House, 2019). 
The Dragatakis Archive and Friends of Dragatakis Society would like to thank Dr Magdalini Kalopana for her thorough and excellent research and assistance with organising the Dragatakis Archive, Elyse Dalabakis for adding links to the Philippos Nakas Music House and Dragatakis website below, Ismini Koronidi for providing the background images included in this document, and Valia Koronidi for assisting with access to materials in the Dragatakis Archive.

\section{LIST OF WORKS TABLE OF CONTENTS}

\begin{tabular}{|l|l|}
\hline Chamber Music for Mixed Ensembles & 286 \\
\hline Chamber Music for Strings & 287 \\
\hline$\underline{\text { Chamber Music for Winds \& Brass }}$ & 290 \\
\hline$\underline{\text { Choral Works }}$ & 291 \\
\hline Concertos & 293 \\
\hline Dance & 296 \\
\hline Electronic & 296 \\
\hline Orchestral Works & 297 \\
\hline Solo Works & 300 \\
\hline Soundtrack recording and music for special occasions & 302 \\
\hline Theatre & 302 \\
\hline Vocal Works & 304 \\
\hline Miscellaneous & 307 \\
\hline Incomplete & 309 \\
\hline Bibliography & 310 \\
\hline
\end{tabular}


CHAMBER MUSIC FOR MIXED ENSEMBLES (10 works)

\begin{tabular}{|c|c|c|c|c|}
\hline Title & Year & Instrumentation & $\begin{array}{l}\text { Edition } \\
\text { type }\end{array}$ & Notes \\
\hline $\begin{array}{l}\text { Afieroma (Dedication), } \\
\text { variation on a theme } \\
\text { by Manolis Kalomiris }\end{array}$ & 1963 & $\begin{array}{l}\text { Flute, Oboe, } \\
\text { Clarinet in } \mathrm{Bb}, \\
\text { Trumpet in C, } \\
\text { two Violins, } \\
\text { Cello, Piano }\end{array}$ & $\begin{array}{l}\text { Dragatakis } \\
\text { edition }\end{array}$ & $\begin{array}{l}\text { Dedicated to } \\
\text { Manolis Kalomiris; } \\
\text { copyright by } \\
\text { Manolis Kalomiris } \\
\text { Society }\end{array}$ \\
\hline Diaphores (Differences) & 1965 & $\begin{array}{l}\text { Flute, Oboe, } \\
\text { Clarinet in Bb, } \\
\text { Horn in F, } \\
\text { Timpani, Snare } \\
\text { Drum, Violin, } \\
\text { Cello }\end{array}$ & $\begin{array}{l}\text { Manuscript } \\
\text { only }\end{array}$ & \\
\hline $\begin{array}{l}\text { Mousiki gia treis (Music } \\
\text { for three) }\end{array}$ & 1969 & $\begin{array}{l}\text { Violin, Horn in F, } \\
\text { Piano }\end{array}$ & $\begin{array}{l}\text { Dragatakis } \\
\text { edition }\end{array}$ & \\
\hline $\begin{array}{l}\text { Anadromes } \\
\text { I(Retrospections I) }\end{array}$ & 1976 & $\begin{array}{l}\text { Flute, Guitar, } \\
\text { Tuba, Cello, } \\
\text { Double Bass, } \\
\text { Piano }\end{array}$ & $\begin{array}{l}\text { Philippos } \\
\text { Nakas } \\
\underline{\text { Music }} \\
\underline{\text { House }}\end{array}$ & \\
\hline $\begin{array}{l}\text { Anadromes } \\
\text { III (Retrospections III) }\end{array}$ & 1978 & $\begin{array}{l}\text { Violin, Cello, } \\
\text { Piano }\end{array}$ & $\begin{array}{l}\text { Dragatakis } \\
\text { edition }\end{array}$ & For Byron Fidetzis \\
\hline $\begin{array}{l}\text { Praktiko } 19 \text { (Practical } \\
\underline{\text { 19) }}\end{array}$ & 1979 & $\begin{array}{l}\text { Violin, Clarinet in } \\
\mathrm{Bb} \text {, Horn in F, } \\
\text { Trumpet in C } \\
\text { (con sordino), } \\
\text { Piano }\end{array}$ & $\begin{array}{l}\text { Dragatakis } \\
\text { edition }\end{array}$ & \\
\hline Trio & 1986 & $\begin{array}{l}\text { Clarinet in } \mathrm{C} \text {, } \\
\text { Percussion, Piano }\end{array}$ & $\begin{array}{l}\text { Dragatakis } \\
\text { edition }\end{array}$ & $\begin{array}{l}\text { For Vicky Stylianou; } \\
\text { detailed } \\
\text { information about } \\
\text { the percussion }\end{array}$ \\
\hline
\end{tabular}




\begin{tabular}{|c|c|c|c|c|}
\hline & & & & $\begin{array}{l}\text { instrumentation can } \\
\text { be found on the } \\
\text { website listing for } \\
\text { this piece. }\end{array}$ \\
\hline $\begin{array}{l}\text { Chorikou } \\
\text { Scholion (Chorics } \\
\text { commentary) }\end{array}$ & 1993 & $\begin{array}{l}\text { Flute, Clarinet in } \\
\text { Bb, Horn in F, } \\
\text { Trumpet in C, } \\
\text { Violin, Cello, } \\
\text { Timpani, } \\
\text { Percussion, Piano }\end{array}$ & $\begin{array}{l}\text { Dragatakis } \\
\text { edition }\end{array}$ & $\begin{array}{l}\text { Detailed } \\
\text { information about } \\
\text { the percussion } \\
\text { instrumentation can } \\
\text { be found on the } \\
\text { website listing for } \\
\text { this piece. }\end{array}$ \\
\hline Ar-Tho-Ta $(A r-T h o-T a)$ & 1996 & $\begin{array}{l}\text { Violin, Alto } \\
\text { Saxophone, Piano }\end{array}$ & $\begin{array}{l}\text { Dragatakis } \\
\text { edition }\end{array}$ & \\
\hline Quartet No.6 & 1999 & $\begin{array}{l}\text { Violin, Oboe, } \\
\text { Viola, Cello }\end{array}$ & $\begin{array}{l}\text { Dragatakis } \\
\text { edition }\end{array}$ & \\
\hline
\end{tabular}

CHAMBER MUSIC FOR STRINGS (20 works)

\begin{tabular}{|c|c|c|c|c|}
\hline Title & Year & Instrumentation & $\begin{array}{l}\text { Edition } \\
\text { type }\end{array}$ & Notes \\
\hline \multirow[t]{3}{*}{ Nanourisma (Berceuse) } & \multirow[t]{3}{*}{$\begin{array}{l}\text { Indeterminate, } \\
\text { estimated } \\
1942-49\end{array}$} & Violin and Piano & $\begin{array}{l}\text { Philippos } \\
\text { Nakas } \\
\text { Music } \\
\text { House }\end{array}$ & \multirow{3}{*}{$\begin{array}{l}\text { There are } \\
\text { four different } \\
\text { arrangements } \\
\text { of this work } \\
\text { for strings: } \\
\text { Violin, Piano; } \\
\text { Cello, Piano; } \\
\text { Viola, Piano; } \\
\text { String } \\
\text { Quartet. }\end{array}$} \\
\hline & & Viola and Piano & $\begin{array}{l}\text { Transcribed } \\
\text { by V. } \\
\text { Giapalakis }\end{array}$ & \\
\hline & & Cello and Piano & $\begin{array}{l}\text { Philippos } \\
\text { Nakas } \\
\text { Music } \\
\text { House (out } \\
\text { of print) }\end{array}$ & \\
\hline
\end{tabular}




\begin{tabular}{|c|c|c|c|}
\hline & & String Quartet & $\begin{array}{l}\text { Transcribed } \\
\text { by V. } \\
\text { Giapalakis }\end{array}$ \\
\hline Choros (Dance) & $\begin{array}{l}\text { Indeterminate, } \\
\text { estimated } \\
1949-57\end{array}$ & Violin and Piano & $\begin{array}{l}\text { Philippos } \\
\underline{\text { Nakas }} \\
\underline{\text { Music }} \\
\underline{\text { House }}\end{array}$ \\
\hline$\underline{\text { Anamnisi (Remembrance) }}$ & 1942 & Violin and Piano & $\begin{array}{l}\text { Dragatakis } \\
\text { edition }\end{array}$ \\
\hline String Quartet No. 1 & 1957 & String Quartet & $\begin{array}{l}\text { Dragatakis } \\
\text { edition }\end{array}$ \\
\hline Sonata No. 1 & 1958 & Violin and Piano & $\begin{array}{l}\text { Philippos } \\
\underline{\text { Nakas }} \\
\underline{\text { Music }} \\
\underline{\text { House }}\end{array}$ \\
\hline String Quartet No. 2 & 1958 & String Quartet & $\begin{array}{l}\text { Dragatakis } \\
\text { edition }\end{array}$ \\
\hline$\underline{\text { Trio }}$ & 1960 & $\begin{array}{l}\text { Two violins and } \\
\text { viola }\end{array}$ & $\begin{array}{l}\text { Dragatakis } \\
\text { edition }\end{array}$ \\
\hline String Quartet No. 3 & 1960 & String Quartet & Manuscript \\
\hline Sonata No. 2 & 1961 & Violin and Piano & $\begin{array}{l}\text { Dragatakis } \\
\text { edition }\end{array}$ \\
\hline $\begin{array}{l}\text { Suite for double string } \\
\text { quartet }\end{array}$ & 1961 & $\begin{array}{l}\text { Double string } \\
\text { quartet (four } \\
\text { violins, two } \\
\text { violas, two } \\
\text { cellos) }\end{array}$ & $\begin{array}{l}\text { Philippos } \\
\underline{\text { Nakas }} \\
\underline{\text { Music }} \\
\underline{\text { House }}\end{array}$ \\
\hline$\underline{\text { Trio }}$ & 1965 & $\begin{array}{l}\text { Violin, Viola, } \\
\text { Cello }\end{array}$ & $\begin{array}{l}\text { Dragatakis } \\
\text { edition }\end{array}$ \\
\hline Diafores (Differences) & 1965 & Violin and Piano & $\begin{array}{l}\text { Philippos } \\
\text { Nakas }\end{array}$ \\
\hline
\end{tabular}




\begin{tabular}{|c|c|c|c|}
\hline & & & $\begin{array}{l}\text { Music } \\
\text { House }\end{array}$ \\
\hline String Quartet No. 4 & 1967 & String Quartet & $\begin{array}{l}\text { Dragatakis } \\
\text { edition }\end{array}$ \\
\hline$\underline{\mathrm{Liz}-\mathrm{Va}(\mathrm{Liz}-\mathrm{Va})}$ & 1969 & Two guitars & $\begin{array}{l}\text { Philippos } \\
\text { Nakas } \\
\underline{\text { Music }} \\
\text { House }\end{array}$ \\
\hline$\underline{D u o}$ & 1971 & Violin and Piano & $\begin{array}{l}\text { Philippos } \\
\underline{\text { Nakas }} \\
\underline{\text { Music }} \\
\underline{\text { House }}\end{array}$ \\
\hline String Quartet No. 5 & 1974 & String Quartet & $\begin{array}{l}\text { Dragatakis } \\
\text { edition }\end{array}$ \\
\hline$\underline{D u o}$ & 1982 & Viola and Piano & $\begin{array}{l}\text { Philippos } \\
\underline{\text { Nakas }} \\
\underline{\text { Music }} \\
\underline{\text { House }}\end{array}$ \\
\hline$\underline{D u o}$ & 1984 & $\begin{array}{l}\text { Violin and } \\
\text { Guitar }\end{array}$ & $\begin{array}{l}\text { Dragatakis } \\
\text { edition }\end{array}$ \\
\hline Sonata & 1985 & Cello and Piano & $\begin{array}{l}\text { Philippos } \\
\underline{\text { Nakas }} \\
\underline{\text { Music }} \\
\underline{\text { House }}\end{array}$ \\
\hline String Quartet No. 7 & 2001 & String Quartet & $\begin{array}{l}\text { Dragatakis } \\
\text { edition }\end{array}$ \\
\hline
\end{tabular}


CHAMBER MUSIC FOR WINDS \& BRASS (10 works)

\begin{tabular}{|c|c|c|c|c|}
\hline Title & Year & Instrumentation & Edition type & Notes \\
\hline$\underline{\text { Trio }}$ & 1962 & $\begin{array}{l}\text { Oboe, Clarinet in } \mathrm{Bb} \text {, } \\
\text { Bassoon }\end{array}$ & $\begin{array}{l}\text { Manuscript } \\
\text { only }\end{array}$ & \\
\hline$\underline{\text { Trio }}$ & 1962 & $\begin{array}{l}\text { Trumpet, Horn, } \\
\text { Trombone }\end{array}$ & $\begin{array}{l}\text { Philippos } \\
\text { Nakas Music } \\
\text { House }\end{array}$ & \\
\hline Woodwind Quintet & 1964 & $\begin{array}{l}\text { Flute, Oboe, Clarinet in } \\
\mathrm{Bb} \text {, Bassoon, Horn in F }\end{array}$ & $\begin{array}{l}\text { Dragatakis } \\
\text { edition }\end{array}$ & \\
\hline Epilogos (Epilogue) & 1970 & $\begin{array}{l}\text { Two trumpets, Horn, } \\
\text { Trombone, Tuba }\end{array}$ & $\begin{array}{l}\text { Manuscript } \\
\text { only }\end{array}$ & \\
\hline $\begin{array}{l}\text { Mousiki gia } \\
\text { chalkina (Music for } \\
\text { brass) }\end{array}$ & 1971 & $\begin{array}{l}\text { Trumpet, Horn, } \\
\text { Trombone, Tuba }\end{array}$ & $\begin{array}{l}\text { Manuscript } \\
\text { only }\end{array}$ & \\
\hline Dialogoi (Dialogues) & 1974 & $\begin{array}{l}\text { Two wind quartets: two } \\
\text { Oboes, two Clarinets in } \\
\text { Bb, two Bassoons, two } \\
\text { Horns in F }\end{array}$ & $\begin{array}{l}\text { Dragatakis } \\
\text { edition }\end{array}$ & \\
\hline$\underline{D u o}$ & 1977 & Tuba and Clarinet in $\mathrm{Bb}$ & $\begin{array}{l}\text { Dragatakis } \\
\text { edition }\end{array}$ & \\
\hline$\underline{D \text { Duo }}$ & 1981 & $\begin{array}{l}\text { Clarinet in } \mathrm{Bb} \text { and } \\
\text { Piano }\end{array}$ & $\begin{array}{l}\underline{\text { Philippos }} \\
\text { Nakas Music } \\
\underline{\text { House }}\end{array}$ & \\
\hline En Samo (In Samos) & 1998 & Flute and Piano & $\begin{array}{l}\text { Dragatakis } \\
\text { edition }\end{array}$ & \\
\hline Nanourisma (Berceuse) & 2001 & $\begin{array}{l}\text { Alto Saxophone and } \\
\text { Piano }\end{array}$ & $\begin{array}{l}\text { Dragatakis } \\
\text { edition }\end{array}$ & \\
\hline
\end{tabular}


CHORAL WORKS (13 works)

\begin{tabular}{|c|c|c|c|c|}
\hline Title & Year & Instrumentation & $\begin{array}{l}\text { Edition } \\
\text { type }\end{array}$ & Notes \\
\hline $\begin{array}{l}\text { Erot' anikite (Love } \\
\text { invincible), } \\
\text { Sophocles, Antigone, third } \\
\text { stasimon }\end{array}$ & $\begin{array}{l}\text { Indeterminate, } \\
\text { estimated } 1969\end{array}$ & Male chorus & $\begin{array}{l}\text { Manuscript } \\
\text { only }\end{array}$ & \\
\hline $\begin{array}{l}\text { O choros (The chorus), } \\
\text { Euripides, The } \\
\text { Heracleidae, fourth } \\
\text { stasimon }\end{array}$ & $\begin{array}{l}\text { Indeterminate, } \\
\text { estimated } 1970\end{array}$ & Male chorus & $\begin{array}{l}\text { Manuscript } \\
\text { only }\end{array}$ & \\
\hline $\begin{array}{l}\text { Taxidi (Journey) } \\
\text { G. Kotzioulas }\end{array}$ & 1980 & Chorus & $\begin{array}{l}\text { Published } \\
\text { in a book } \\
\text { titled } \\
\text { 'Works of } \\
\text { Greek } \\
\text { composers } \\
\text { for choir } \\
\text { and } \\
\text { acapella'; } \\
\text { Manuscript }\end{array}$ & $\begin{array}{l}\text { Published by the } \\
\text { Ministry of } \\
\text { Civilization and } \\
\text { Sciences, } \\
\text { Musical } \\
\text { Publications }\end{array}$ \\
\hline $\begin{array}{l}\text { Thalassino (Marine), D. } \\
\text { Dragatakēs }\end{array}$ & 1980 & Chorus & $\begin{array}{l}\text { Manuscript } \\
\text { only }\end{array}$ & \\
\hline $\begin{array}{l}\text { I treli rodia (The crazy } \\
\text { pomegranate tree), Od. } \\
\text { Elytis }\end{array}$ & 1981 & Chorus & $\begin{array}{l}\text { Manuscript } \\
\text { only }\end{array}$ & $\begin{array}{l}\text { I treli rodia and } \\
\text { Mana are } \\
\text { included in the } \\
\text { same } \\
\text { manuscript }\end{array}$ \\
\hline
\end{tabular}




\begin{tabular}{|c|c|c|c|c|}
\hline $\begin{array}{l}\text { Mana (Mother), V. } \\
\text { Theodorou }\end{array}$ & 1982 & Women's choir & $\begin{array}{l}\text { Manuscript } \\
\text { only }\end{array}$ & $\begin{array}{l}\text { Note from } \\
\text { Dragatakis says } \\
\text { "may need to be } \\
\text { transposed up } \\
\text { one tone"; I treli } \\
\text { rodia and Mana } \\
\text { are included in } \\
\text { the same } \\
\text { manuscript }\end{array}$ \\
\hline $\begin{array}{l}\text { I lismonia (Forgetfulness), } \\
\text { I. Dragataki }\end{array}$ & 1986 & Chorus & $\begin{array}{l}\text { Manuscript } \\
\text { only }\end{array}$ & \\
\hline $\begin{array}{l}\text { T' oneiro (The dream), } \\
\text { Chr. Apostolatou }\end{array}$ & 1986 & $\begin{array}{l}\text { For three solo } \\
\text { voices and } \\
\text { children's choir }\end{array}$ & $\begin{array}{l}\text { Manuscript } \\
\text { only }\end{array}$ & \\
\hline $\begin{array}{l}\text { Efchi tis manas (The } \\
\text { mother's wish), } \\
\text { Iro Dragataki }\end{array}$ & 1986 & Chorus & $\begin{array}{l}\text { Manuscript } \\
\text { only }\end{array}$ & \\
\hline $\begin{array}{l}\text { T'oneiro tis manas (The } \\
\text { mother's dream), D. } \\
\text { Dragatakis }\end{array}$ & 1994 & Chorus & $\begin{array}{l}\text { Manuscript } \\
\text { only }\end{array}$ & \\
\hline $\begin{array}{l}\text { Ton vrachon touton (This } \\
\text { rock), } \\
\text { D. Kourouklis }\end{array}$ & 1997 & Chorus & $\begin{array}{l}\text { Dragatakis } \\
\text { edition }\end{array}$ & \\
\hline $\begin{array}{l}\text { Agnoristi } \\
\text { (Unrecognisable), } \\
\text { D. Solomos }\end{array}$ & 1997 & Chorus & $\begin{array}{l}\text { Dragatakis } \\
\text { edition }\end{array}$ & \\
\hline $\begin{array}{l}\text { To aeri (The breeze), } \\
\text { M. Avlichos }\end{array}$ & 1997 & Chorus & $\begin{array}{l}\text { Dragatakis } \\
\text { edition }\end{array}$ & \\
\hline
\end{tabular}


CONCERTOS (14 works)

\begin{tabular}{|c|c|c|c|c|}
\hline Title & Year & Instrumentation & $\begin{array}{l}\text { Edition } \\
\text { type }\end{array}$ & Notes \\
\hline Concerto for Viola & $\begin{array}{l}\text { Indeterminate, } \\
\text { estimated } \\
1949-57\end{array}$ & Viola and Piano & $\begin{array}{l}\text { Manuscript } \\
\text { only }\end{array}$ & $\begin{array}{l}\text { This work } \\
\text { exists in piano } \\
\text { reduction } \\
\text { manuscript } \\
\text { only. }\end{array}$ \\
\hline Concertino for Clarinet & 1962 & $\begin{array}{l}\text { Clarinet and } \\
\text { string orchestra }\end{array}$ & $\begin{array}{l}\text { Philippos } \\
\underline{\text { Nakas }} \\
\underline{\text { Music }} \\
\underline{\text { House }}\end{array}$ & \\
\hline Concertino for Horn & 1965 & $\begin{array}{l}\text { Horn in F and } \\
\text { instrumental } \\
\text { ensemble (Flute, } \\
\text { Oboe, Piccolo } \\
\text { Trumpet/Clarino, } \\
\text { Timpani, Violin } \\
\text { 1, Violin 2, Viola, } \\
\text { cello, Double } \\
\text { Bass) }\end{array}$ & $\begin{array}{l}\text { Philippos } \\
\text { Nakas } \\
\underline{\text { Music }} \\
\underline{\text { House }}\end{array}$ & \\
\hline Concerto for Violin & 1969 & $\begin{array}{l}\text { Violin and } \\
\text { orchestra }\end{array}$ & $\begin{array}{l}\text { Philippos } \\
\text { Nakas } \\
\underline{\text { Music }} \\
\underline{\text { House }}\end{array}$ & $\begin{array}{l}\text { Full orchestra } \\
\text { instrumentation } \\
\text { can be found on } \\
\text { the website } \\
\text { listing for this } \\
\text { piece. }\end{array}$ \\
\hline Adagio for Viola & 1969 & $\begin{array}{l}\text { Viola, Piano, } \\
\text { string orchestra }\end{array}$ & $\begin{array}{l}\text { Dragatakis } \\
\text { edition }\end{array}$ & \\
\hline
\end{tabular}




\begin{tabular}{|c|c|c|c|c|}
\hline Concerto for Cello & 1972 & $\begin{array}{l}\text { Cello and } \\
\text { orchestra }\end{array}$ & $\begin{array}{l}\text { Dragatakis } \\
\text { edition }\end{array}$ & $\begin{array}{l}\text { Full orchestra } \\
\text { instrumentation } \\
\text { can be found on } \\
\text { the website } \\
\text { listing for this } \\
\text { piece. }\end{array}$ \\
\hline Concerto for Oboe & 1973 & $\begin{array}{l}\text { Oboe and string } \\
\text { orchestra }\end{array}$ & $\begin{array}{l}\text { Dragatakis } \\
\text { edition }\end{array}$ & $\begin{array}{l}\text { Full orchestra } \\
\text { instrumentation } \\
\text { can be found on } \\
\text { the website } \\
\text { listing for this } \\
\text { piece. }\end{array}$ \\
\hline Concerto for Piano & $1975-77$ & $\begin{array}{l}\text { Piano and } \\
\text { orchestra }\end{array}$ & $\begin{array}{l}\text { Dragatakis } \\
\text { edition }\end{array}$ & $\begin{array}{l}\text { Full orchestra } \\
\text { instrumentation } \\
\text { can be found on } \\
\text { the website } \\
\text { listing for this } \\
\text { piece. }\end{array}$ \\
\hline $\begin{array}{l}\text { Concerto for Two } \\
\text { Guitars }\end{array}$ & 1978 & $\begin{array}{l}\text { Two guitars and } \\
\text { orchestra }\end{array}$ & $\begin{array}{l}\text { Dragatakis } \\
\text { edition }\end{array}$ & $\begin{array}{l}\text { Full orchestra } \\
\text { instrumentation } \\
\text { can be found on } \\
\text { the website } \\
\text { listing for this } \\
\text { piece. }\end{array}$ \\
\hline Concerto for Tuba & 1983 & $\begin{array}{l}\text { Tuba and } \\
\text { orchestra }\end{array}$ & $\begin{array}{l}\text { Dragatakis } \\
\text { edition }\end{array}$ & $\begin{array}{l}\text { Full orchestra } \\
\text { instrumentation } \\
\text { can be found on } \\
\text { the website } \\
\text { listing for this } \\
\text { piece. }\end{array}$ \\
\hline
\end{tabular}




\begin{tabular}{|c|c|c|c|c|}
\hline Concertino for Sandouri & 1988 & $\begin{array}{l}\text { Santouri } \\
\text { (hammered } \\
\text { dulcimer) and } \\
\text { orchestra }\end{array}$ & $\begin{array}{l}\text { Dragatakis } \\
\text { edition }\end{array}$ & $\begin{array}{l}\text { Full orchestra } \\
\text { instrumentation } \\
\text { can be found on } \\
\text { the website } \\
\text { listing for this } \\
\text { piece. }\end{array}$ \\
\hline Concerto for Viola & 1992 & $\begin{array}{l}\text { Viola and } \\
\text { orchestra }\end{array}$ & $\begin{array}{l}\text { Dragatakis } \\
\text { edition; } \\
\text { piano } \\
\text { reduction } \\
\text { typeset by } \\
\text { Elyse } \\
\text { Dalabakis } \\
\text { from the } \\
\text { manuscript }\end{array}$ & \\
\hline $\begin{array}{l}\text { Concerto for Alto } \\
\text { Saxophone }\end{array}$ & 1997 & $\begin{array}{l}\text { Alto Saxophone } \\
\text { and orchestra }\end{array}$ & $\begin{array}{l}\text { Dragatakis } \\
\text { edition }\end{array}$ & $\begin{array}{l}\text { Full orchestra } \\
\text { instrumentation } \\
\text { can be found on } \\
\text { the website } \\
\text { listing for this } \\
\text { piece. }\end{array}$ \\
\hline $\begin{array}{l}\text { Nanourisma (Berceuse) } \\
\underline{\text { for Alto Saxophone }}\end{array}$ & 2001 & $\begin{array}{l}\text { Alto Saxophone } \\
\text { and string } \\
\text { orchestra }\end{array}$ & $\begin{array}{l}\text { Dragatakis } \\
\text { edition }\end{array}$ & \\
\hline
\end{tabular}




\section{DANCE (5 works)}

The music works for dance or ballet were written for mixed ensembles, at times pairing obscure instruments with traditional western instruments. This was done to achieve the soundscape, or mood, of the theatrical work or dance choreography. For information about the instrumentation of the pieces, please get in touch with us.

\begin{tabular}{|c|c|c|c|c|}
\hline Title & Year & Instrumentation & $\begin{array}{l}\text { Edition } \\
\text { type }\end{array}$ & Notes \\
\hline Ballet Suite No. 1 & 1963 & $\begin{array}{l}\text { Orchestra or } \\
\text { solo piano }\end{array}$ & Manuscript & $\begin{array}{l}\text { For full } \\
\text { instrumentation, } \\
\text { please contact us. }\end{array}$ \\
\hline $\begin{array}{l}\text { Ballet Suite No. 2, Odysseas } \\
\text { kai Nafsika (Ulysses and } \\
\text { Nausicaa) }\end{array}$ & 1964 & $\begin{array}{l}\text { Instrumental } \\
\text { ensemble }\end{array}$ & Manuscript & $\begin{array}{l}\text { For full } \\
\text { instrumentation, } \\
\text { please contact us. }\end{array}$ \\
\hline $\begin{array}{l}\text { Ballet Suite No. 3, Tou } \\
\text { Koutrouli o gamos (The } \\
\text { marriage of Koutroulis) }\end{array}$ & 1964 & $\begin{array}{l}\text { Instrumental } \\
\text { ensemble }\end{array}$ & Manuscript & $\begin{array}{l}\text { For full } \\
\text { instrumentation, } \\
\text { please contact us. }\end{array}$ \\
\hline $\begin{array}{l}\text { Ballet Suite No. 4, Pinelopi } i \\
\text { Anamoni (Penelope or } \\
\text { awaiting) }\end{array}$ & 1969 & $\begin{array}{l}\text { Instrumental } \\
\text { ensemble, } \\
\text { voices, tape; or } \\
\text { solo piano }\end{array}$ & Manuscript & $\begin{array}{l}\text { For full } \\
\text { instrumentation, } \\
\text { please contact us. }\end{array}$ \\
\hline $\begin{array}{l}\text { Ballet Suite No. 5, O choros tis } \\
\text { Nafsikas (Nausicaa's dance) }\end{array}$ & 1970 & $\begin{array}{l}\text { Instrumental } \\
\text { ensemble, two } \\
\text { narrators, tape }\end{array}$ & Manuscript & $\begin{array}{l}\text { For full } \\
\text { instrumentation, } \\
\text { please contact us. }\end{array}$ \\
\hline
\end{tabular}


ELECTRONIC (3 works)

\begin{tabular}{|c|c|c|c|c|}
\hline Title & Year & Instrumentation & $\begin{array}{l}\text { Edition } \\
\text { type }\end{array}$ & Notes \\
\hline Mythologias I (Mythology I) & 1970 & Tape & No score & \\
\hline $\begin{array}{l}\text { Mythologias II (Mythology } \\
\text { II) }\end{array}$ & 1970 & Tape & No score & \\
\hline $\begin{array}{l}\text { Zalouch (Zalouch), } \\
\text { T. Tolia }\end{array}$ & 1971 & $\begin{array}{l}\text { Instrumental } \\
\text { ensemble, two } \\
\text { tapes, four } \\
\text { narrators }\end{array}$ & Manuscript & $\begin{array}{l}\text { For full } \\
\text { instrumentation, } \\
\text { please contact us. }\end{array}$ \\
\hline
\end{tabular}

ORCHESTRAL WORKS (15 works)

\begin{tabular}{|c|c|c|c|c|}
\hline Title & Year & $\begin{array}{l}\text { Instrumen } \\
\text { tation }\end{array}$ & $\begin{array}{l}\text { Edition } \\
\text { type }\end{array}$ & Notes \\
\hline $\begin{array}{l}\text { Treis Melodies (Three } \\
\text { melodies) }\end{array}$ & $\begin{array}{l}\text { Indeterminate, } \\
\text { estimated } \\
1949-57\end{array}$ & $\begin{array}{l}\text { String } \\
\text { orchestra }\end{array}$ & $\begin{array}{l}\text { Manuscript } \\
\text { only }\end{array}$ & \\
\hline $\begin{array}{l}\text { Lyrika Skitsa (Lyric } \\
\text { sketches) }\end{array}$ & 1958 & $\begin{array}{l}\text { String } \\
\text { orchestra }\end{array}$ & $\begin{array}{l}\text { Dragatakis } \\
\text { edition }\end{array}$ & \\
\hline Dokimio (Essay) & 1958 & Orchestra & $\begin{array}{l}\text { Philippos } \\
\underline{\text { Nakas }} \\
\underline{\text { Music }} \\
\underline{\text { House }}\end{array}$ & $\begin{array}{l}\text { Full orchestra } \\
\text { instrumentation } \\
\text { can be found on } \\
\text { the website listing } \\
\text { for this piece. }\end{array}$ \\
\hline Symphony No. 1 & 1959 & Orchestra & $\begin{array}{l}\text { Philippos } \\
\underline{\text { Nakas }} \\
\underline{\text { Music }} \\
\underline{\text { House }}\end{array}$ & $\begin{array}{l}\text { Full orchestra } \\
\text { instrumentation } \\
\text { can be found on } \\
\text { the website listing } \\
\text { for this piece. }\end{array}$ \\
\hline Symphony No. 2 & 1960 & Orchestra & $\begin{array}{l}\text { Dragatakis } \\
\text { edition }\end{array}$ & $\begin{array}{l}\text { Full orchestra } \\
\text { instrumentation }\end{array}$ \\
\hline
\end{tabular}




\begin{tabular}{|c|c|c|c|c|}
\hline & & & & $\begin{array}{l}\text { can be found on } \\
\text { the website listing } \\
\text { for this piece. }\end{array}$ \\
\hline $\begin{array}{l}\text { Symphony No. } \\
\underline{\text { 3, Mikri (Little) }}\end{array}$ & 1964 & Orchestra & $\begin{array}{l}\text { Philippos } \\
\underline{\text { Nakas }} \\
\underline{\text { Music }} \\
\underline{\text { House }}\end{array}$ & $\begin{array}{l}\text { Full orchestra } \\
\text { instrumentation } \\
\text { can be found on } \\
\text { the website listing } \\
\text { for this piece. }\end{array}$ \\
\hline Symphony No. 4 & 1966 & Orchestra & $\begin{array}{l}\text { Dragatakis } \\
\text { edition }\end{array}$ & $\begin{array}{l}\text { Full orchestra } \\
\text { instrumentation } \\
\text { can be found on } \\
\text { the website listing } \\
\text { for this piece. }\end{array}$ \\
\hline $\begin{array}{l}\text { Tessera Skitsa (Four } \\
\underline{\text { sketches) }}\end{array}$ & $1966-68$ & $\begin{array}{l}\text { String } \\
\text { orchestra, } \\
\text { divided } \\
\text { into three } \\
\text { parts }\end{array}$ & $\begin{array}{l}\text { Dragatakis } \\
\text { edition }\end{array}$ & \\
\hline Strophes (Turns) & $1970-72$ & Orchestra & $\begin{array}{l}\text { Philippos } \\
\underline{\text { Nakas }} \\
\underline{\text { Music }} \\
\underline{\text { House }}\end{array}$ & $\begin{array}{l}\text { Dedicated to his } \\
\text { wife, Iro } \\
\text { Dragataki; Full } \\
\text { orchestra } \\
\text { instrumentation } \\
\text { can be found on } \\
\text { the website listing } \\
\text { for this piece. }\end{array}$ \\
\hline Dromena (Actions) & 1974 & Orchestra & $\begin{array}{l}\text { Dragatakis } \\
\text { edition }\end{array}$ & $\begin{array}{l}\text { Full orchestra } \\
\text { instrumentation } \\
\text { can be found on } \\
\text { the website listing } \\
\text { for this piece. }\end{array}$ \\
\hline
\end{tabular}




\begin{tabular}{|c|c|c|c|c|}
\hline $\begin{array}{l}\text { Symphony No. } 5 \\
\text { O peri ton Acheronta } \\
\text { mythos (The myth about } \\
\text { Acheron) }\end{array}$ & 1979-80 & Orchestra & $\begin{array}{l}\text { Philippos } \\
\underline{\text { Nakas }} \\
\underline{\text { Music }} \\
\underline{\text { House }}\end{array}$ & $\begin{array}{l}\text { Dedicated to his } \\
\text { daughter, Valia } \\
\text { Dragataki- } \\
\text { Koronidi; Full } \\
\text { orchestra } \\
\text { instrumentation } \\
\text { can be found on } \\
\text { the website listing } \\
\text { for this piece. }\end{array}$ \\
\hline Mnimes (Memories) & 1981-82 & Orchestra & $\begin{array}{l}\text { Dragatakis } \\
\text { edition }\end{array}$ & $\begin{array}{l}\text { Full orchestra } \\
\text { instrumentation } \\
\text { can be found on } \\
\text { the website listing } \\
\text { for this piece. }\end{array}$ \\
\hline $\begin{array}{l}\text { Symphony No. } 6 \\
\text { To chreos (The duty) }\end{array}$ & 1989 & Orchestra & $\begin{array}{l}\text { Dragatakis } \\
\text { edition }\end{array}$ & $\begin{array}{l}\text { Full orchestra } \\
\text { instrumentation } \\
\text { can be found on } \\
\text { the website listing } \\
\text { for this piece. }\end{array}$ \\
\hline $\begin{array}{l}\text { Spondes ston } 210 \text { aiona } \\
\text { (Libations to the } 21 \text { st } \\
\text { century) }\end{array}$ & 1998 & Orchestra & $\begin{array}{l}\text { Dragatakis } \\
\text { edition }\end{array}$ & $\begin{array}{l}\text { Full orchestra } \\
\text { instrumentation } \\
\text { can be found on } \\
\text { the website listing } \\
\text { for this piece. }\end{array}$ \\
\hline $\begin{array}{l}\text { Antirropa (Counterbalances) } \\
\text { Three Preludes for Orchestra }\end{array}$ & 1998 & Orchestra & $\begin{array}{l}\text { Dragatakis } \\
\text { edition }\end{array}$ & $\begin{array}{l}\text { Full orchestra } \\
\text { instrumentation } \\
\text { can be found on } \\
\text { the website listing } \\
\text { for this piece. }\end{array}$ \\
\hline
\end{tabular}


SOLO WORKS (18 works)

\begin{tabular}{|c|c|c|c|c|}
\hline Title & Year & $\begin{array}{l}\text { Instrumentat } \\
\text { ion }\end{array}$ & Edition type & Notes \\
\hline Petalouda (Papillon) & $\begin{array}{l}\text { Indeterminate, } \\
\text { estimated } \\
\text { before } 1940\end{array}$ & Piano & $\begin{array}{l}\text { Philippos } \\
\text { Nakas Music } \\
\underline{\text { House }}\end{array}$ & \\
\hline Nostalgia (Nostalgia) & $\begin{array}{l}\text { Indeterminate, } \\
\text { estimated } c \text {. } \\
1940\end{array}$ & Piano & $\begin{array}{l}\text { Philippos } \\
\text { Nakas Music } \\
\underline{\text { House }}\end{array}$ & \\
\hline $\begin{array}{l}\text { Mikri Balanta (Petite } \\
\text { Ballade) }\end{array}$ & 1949 & Piano & $\begin{array}{l}\text { Philippos } \\
\text { Nakas Music } \\
\text { House }\end{array}$ & \\
\hline Sonatina No. 1 & 1961 & Piano & $\begin{array}{l}\text { Philippos } \\
\text { Nakas Music } \\
\underline{\text { House }}\end{array}$ & \\
\hline Sonatina No. 2 & 1963 & Piano & $\begin{array}{l}\text { Philippos } \\
\text { Nakas Music } \\
\underline{\text { House }}\end{array}$ & \\
\hline Antikes (Antiques) & 1972 & Piano & $\begin{array}{l}\text { Philippos } \\
\text { Nakas Music } \\
\underline{\text { House }}\end{array}$ & $\begin{array}{l}\text { Dedicated to } \\
\text { pianist Nelly } \\
\text { Semitecolo }\end{array}$ \\
\hline $\begin{array}{l}\text { Treis Omilies (Three } \\
\underline{\text { speeches) }}\end{array}$ & 1973 & Flute & $\begin{array}{l}\text { Dragatakis } \\
\text { edition }\end{array}$ & \\
\hline Elegeio (Elegy) & 1974 & Tuba & $\begin{array}{l}\text { Manuscript; } \\
\text { typeset by } \\
\text { Panos } \\
\text { Iliopoulos } \\
(2009)\end{array}$ & \\
\hline $\begin{array}{l}\text { Anadromes } \\
\text { II (Retrospections II) }\end{array}$ & 1977 & Piano & $\begin{array}{l}\text { Philippos } \\
\text { Nakas Music } \\
\underline{\text { House }}\end{array}$ & \\
\hline
\end{tabular}




\begin{tabular}{|c|c|c|c|c|}
\hline$\underline{\text { Spoudi I (Etude I) }}$ & 1981 & Piano & $\begin{array}{l}\text { Philippos } \\
\text { Nakas Music } \\
\underline{\text { House }}\end{array}$ & \\
\hline Spoudi II (Etude II) & 1981 & Piano & $\begin{array}{l}\text { Philippos } \\
\text { Nakas Music } \\
\underline{\text { House }}\end{array}$ & \\
\hline $\begin{array}{l}\text { Anadromes } \\
\text { IV (Retrospections IV) }\end{array}$ & 1983 & $\begin{array}{l}\text { Two pianos } \\
\text { (two players, } \\
\text { four hands) }\end{array}$ & $\begin{array}{l}\text { Philippos } \\
\text { Nakas Music } \\
\text { House (out of } \\
\text { print) }\end{array}$ & \\
\hline$\underline{\text { Antilogoi (Refute) }}$ & 1988 & $\begin{array}{l}\text { Two pianos } \\
\text { (four players, } \\
\text { eight hands) }\end{array}$ & $\begin{array}{l}\text { Dragatakis } \\
\text { edition }\end{array}$ & \\
\hline Inelia (Inelia) & 1997 & Piano & $\begin{array}{l}\text { Philippos } \\
\text { Nakas Music } \\
\underline{\text { House }}\end{array}$ & \\
\hline $\begin{array}{l}\text { Monologos ar. } 2 \\
\text { (Monologue no .2) }\end{array}$ & 2000 & Cello & $\begin{array}{l}\text { Dragatakis } \\
\text { edition }\end{array}$ & \\
\hline $\begin{array}{l}\text { Monologos ar. } 4 \\
\text { (Monologue no. 4) }\end{array}$ & 2001 & Piano & $\begin{array}{l}\underline{\text { Philippos }} \\
\underline{\text { Nakas Music }} \\
\underline{\text { House }}\end{array}$ & \\
\hline $\begin{array}{l}\text { Monologos ar. } 3 \\
\text { (Monologue no. 3) }\end{array}$ & 2001 & Violin & $\begin{array}{l}\text { Dragatakis } \\
\text { edition }\end{array}$ & \\
\hline Kithara (Guitar) & 2001 & Guitar & $\begin{array}{l}\text { Dragatakis } \\
\text { edition }\end{array}$ & $\begin{array}{l}\text { Revised and } \\
\text { fingered by } \\
\text { Evangelos } \\
\text { Assimakopoulos }\end{array}$ \\
\hline
\end{tabular}


SOUNDTRACK RECORDING AND MUSIC FOR SPECIAL OCCASIONS (4 works)

\begin{tabular}{|c|c|c|c|c|}
\hline Title & Year & Instrumentation & $\begin{array}{l}\text { Edition } \\
\text { type }\end{array}$ & Notes \\
\hline $\begin{array}{l}\text { Salpisma gia tin eisodo tou } \\
\text { Olympiakou Fotos sto Stadio } \\
\text { (Fanfare for the entry of the } \\
\text { Olympic light into the } \\
\text { stadium) }\end{array}$ & 1969 & $\begin{array}{l}\text { Four trumpets } \\
\text { and three } \\
\text { trombones }\end{array}$ & Manuscript & \\
\hline $\begin{array}{l}\text { Ymnos gia to Olympiako Fos } \\
\text { (Anthem for the Olympic }\end{array}$ & 1969 & $\begin{array}{l}\text { Choir (acapella); } \\
\text { or choir and piano }\end{array}$ & Manuscript & \\
\hline $\begin{array}{l}\text { light) } \\
\text { S. Sperantzas }\end{array}$ & & $\begin{array}{l}\text { Choir (acapella), } \\
\text { band (transcribed } \\
\text { by M. Kastellis) }\end{array}$ & Manuscript & $\begin{array}{l}\text { For full } \\
\text { instrumentation, } \\
\text { please contact us. }\end{array}$ \\
\hline $\begin{array}{l}\text { Ichos kai Fos (Sound and } \\
\text { light) } \\
\text { Jean Baelen }\end{array}$ & 1972 & $\begin{array}{l}\text { Instrumental } \\
\text { ensemble }\end{array}$ & Manuscript & $\begin{array}{l}\text { For full } \\
\text { instrumentation, } \\
\text { please contact us. }\end{array}$ \\
\hline Koutouki (Koutouki) & 1972 & $\begin{array}{l}\text { Instrumental } \\
\text { ensemble, tape }\end{array}$ & Manuscript & $\begin{array}{l}\text { For full } \\
\text { instrumentation, } \\
\text { please contact us. }\end{array}$ \\
\hline
\end{tabular}

\section{THEATRE (9 works)}

The music for the theatre works were written for mixed ensembles, at times pairing obscure instruments with traditional western instruments. This was done to achieve the soundscape, or mood, of the theatrical work. For information about the instrumentation of the pieces, please get in touch with us.

\begin{tabular}{|l|l|l|l|l|}
\hline Title & Year & Instrumentation & $\begin{array}{l}\text { Edition } \\
\text { type }\end{array}$ & Notes \\
\hline Mideia (Medea), Euripides & 1968 & $\begin{array}{l}\text { Instrumental } \\
\text { ensemble }\end{array}$ & Manuscript & $\begin{array}{l}\text { For full } \\
\text { instrumentation, } \\
\text { please contact us. }\end{array}$ \\
\hline
\end{tabular}




\begin{tabular}{|c|c|c|c|c|}
\hline $\begin{array}{l}\text { I epistrofi tou Odyssea (The } \\
\text { Return of Ulysses), D. } \\
\text { Siatopoulos }\end{array}$ & 1968 & $\begin{array}{l}\text { Flute and } \\
\text { Santouri }\end{array}$ & Manuscript & $\begin{array}{l}\text { For more } \\
\text { information about } \\
\text { this piece, please } \\
\text { contact us. }\end{array}$ \\
\hline $\begin{array}{l}\text { Antigoni (Antigone), } \\
\text { Sophocles }\end{array}$ & 1969 & $\begin{array}{l}\text { Instrumental } \\
\text { ensemble }\end{array}$ & Manuscript & $\begin{array}{l}\text { For full } \\
\text { instrumentation, } \\
\text { please contact us. }\end{array}$ \\
\hline $\begin{array}{l}\text { Agamemnon (Agamemnon), } \\
\text { T.Roussos }\end{array}$ & 1969 & $\begin{array}{l}\text { Instrumental } \\
\text { ensemble }\end{array}$ & Manuscript & $\begin{array}{l}\text { For full } \\
\text { instrumentation, } \\
\text { please contact us. }\end{array}$ \\
\hline $\begin{array}{l}\text { Irakleidai (The Heracleidae), } \\
\text { Euripides }\end{array}$ & 1970 & $\begin{array}{l}\text { Instrumental } \\
\text { ensemble }\end{array}$ & Manuscript & $\begin{array}{l}\text { For full } \\
\text { instrumentation, } \\
\text { please contact us. }\end{array}$ \\
\hline $\begin{array}{l}\text { Ifigeneia en Tavrois (Iphigenia } \\
\text { in Tauris), Euripides }\end{array}$ & 1971 & $\begin{array}{l}\text { Instrumental } \\
\text { ensemble }\end{array}$ & Manuscript & $\begin{array}{l}\text { For full } \\
\text { instrumentation, } \\
\text { please contact us. }\end{array}$ \\
\hline $\begin{array}{l}\text { Mavrolykoi (Black-wolves), M. } \\
\text { Skouloudis }\end{array}$ & 1971 & $\begin{array}{l}\text { Instrumental } \\
\text { ensemble }\end{array}$ & Manuscript & $\begin{array}{l}\text { For full } \\
\text { instrumentation, } \\
\text { please contact us. }\end{array}$ \\
\hline Ilektra (Electra), Sophocles & 1973 & $\begin{array}{l}\text { Instrumental } \\
\text { ensemble }\end{array}$ & Manuscript & $\begin{array}{l}\text { For full } \\
\text { instrumentation, } \\
\text { please contact us. }\end{array}$ \\
\hline Electra, G. Arkas & 1973 & $\begin{array}{l}\text { Instrumental } \\
\text { ensemble }\end{array}$ & Manuscript & $\begin{array}{l}\text { For full } \\
\text { instrumentation, } \\
\text { please contact us. }\end{array}$ \\
\hline
\end{tabular}


VOCAL WORKS (28 works)

\begin{tabular}{|c|c|c|c|c|}
\hline Title & Year & Instrumentation & $\begin{array}{l}\text { Edition } \\
\text { type }\end{array}$ & Notes \\
\hline $\begin{array}{l}\text { O tseligkas (The chief } \\
\text { shepherd), K. } \\
\text { Krystallis }\end{array}$ & $\begin{array}{l}\text { Indeterminate, } \\
\text { estimated } \\
1942-49\end{array}$ & Voice and piano & $\begin{array}{l}\text { Manuscript } \\
\text { only }\end{array}$ & \\
\hline $\begin{array}{l}\frac{\text { Tachtarisma }}{\text { (Dandling song) } \text { [on }} \\
\text { traditional verses] }\end{array}$ & $\begin{array}{l}\text { Indeterminate, } \\
\text { estimated } \\
1942-49\end{array}$ & Voice and piano & $\begin{array}{l}\text { Manuscript } \\
\text { only }\end{array}$ & \\
\hline $\begin{array}{l}\text { Tragoudi (Song), M. } \\
\text { Veloudis }\end{array}$ & $\begin{array}{l}\text { Indeterminate, } \\
\text { estimated } \\
1957-58\end{array}$ & Voice and piano & $\begin{array}{l}\text { Manuscript } \\
\text { only }\end{array}$ & \\
\hline $\begin{array}{l}\text { Ta prot'asteria (The } \\
\text { first stars), F. } \\
\text { Angoules }\end{array}$ & 1961 & Voice and piano & $\begin{array}{l}\text { Dragatakis } \\
\text { edition }\end{array}$ & $\begin{array}{l}\text { Included in the } \\
\text { Collections of Songs, } \\
\text { op. } 1\end{array}$ \\
\hline $\begin{array}{l}\text { Tsakizo tis lianes elies } \\
\text { (Cracking the thin } \\
\text { olives), V. } \\
\text { Theodorou }\end{array}$ & 1961 & Voice and piano & $\begin{array}{l}\text { Dragatakis } \\
\text { edition }\end{array}$ & $\begin{array}{l}\text { Included in the } \\
\text { Collections of Songs, } \\
\text { op. } 1\end{array}$ \\
\hline $\begin{array}{l}\text { Poulia ein' ta chronia } \\
\text { (Years are like birds), } \\
\text { F. Angoules }\end{array}$ & 1961 & Voice and piano & $\begin{array}{l}\text { Dragatakis } \\
\text { edition }\end{array}$ & $\begin{array}{l}\text { Included in the } \\
\text { Collections of Songs, } \\
\text { op. } 1\end{array}$ \\
\hline $\begin{array}{l}\frac{\text { Ibalanta tis }}{\text { Gkouentolin }} \\
\text { (Gwendolin's ballad) } \\
\text { J. Anouilh, Becket }\end{array}$ & 1968 & Voice and piano & $\begin{array}{l}\text { Dragatakis } \\
\text { edition }\end{array}$ & $\begin{array}{l}\text { Included in the } \\
\text { Collections of Songs, } \\
\text { op. } 1\end{array}$ \\
\hline $\begin{array}{l}\text { Anafora stin } \\
\text { Ilektra (Reference to } \\
\text { Electra), T. Roussos }\end{array}$ & 1968 & $\begin{array}{l}\text { Soprano or } \\
\text { Mezzo, Viola, } \\
\text { Horn, Piano }\end{array}$ & $\begin{array}{l}\text { Manuscript } \\
\text { only }\end{array}$ & \\
\hline
\end{tabular}




\begin{tabular}{|c|c|c|c|c|}
\hline $\begin{array}{l}\text { Ochi ta roda (Not the } \\
\text { roses), G. Drosinis }\end{array}$ & 1971 & Voice and piano & $\begin{array}{l}\text { Dragatakis } \\
\text { edition }\end{array}$ & $\begin{array}{l}\text { Included in the } \\
\text { Collections of Songs, } \\
\text { op. } 1\end{array}$ \\
\hline $\begin{array}{l}\text { De thelo tou kissou (I } \\
\text { don't want the ivy's } \\
\text { [deceiving height]), G. } \\
\text { Drosinis }\end{array}$ & 1971 & Voice and piano & $\begin{array}{l}\text { Dragatakis } \\
\text { edition }\end{array}$ & $\begin{array}{l}\text { Included in the } \\
\text { Collections of Songs, } \\
\text { op. } 1\end{array}$ \\
\hline $\begin{array}{l}\text { Me poia lachtara } \\
\text { (With which longing), } \\
\text { G. Drosinis }\end{array}$ & 1971 & Voice and piano & $\begin{array}{l}\text { Dragatakis } \\
\text { edition }\end{array}$ & $\begin{array}{l}\text { Included in the } \\
\text { Collections of Songs, } \\
\text { op. } 1\end{array}$ \\
\hline $\begin{array}{l}\text { Na se prosmeno (To } \\
\text { await for you), G. } \\
\text { Drosinis }\end{array}$ & 1971 & Voice and piano & $\begin{array}{l}\text { Dragatakis } \\
\text { edition }\end{array}$ & $\begin{array}{l}\text { Included in the } \\
\text { Collections of Songs, } \\
\text { op. } 1\end{array}$ \\
\hline $\begin{array}{l}\text { Echei apops' ena } \\
\text { fengari (There's a } \\
\text { moon tonight), K. } \\
\text { Kontoulēs }\end{array}$ & 1979 & Voice and piano & $\begin{array}{l}\text { Dragatakis } \\
\text { edition }\end{array}$ & $\begin{array}{l}\text { Included in the } \\
\text { Collections of Songs, } \\
\text { op. } 1\end{array}$ \\
\hline $\begin{array}{l}\text { Monologos ar. } \\
1 \text { (Monologue no.1), } \\
\text { D. Dragatakis }\end{array}$ & 1979 & Acapella voice & $\begin{array}{l}\text { Dragatakis } \\
\text { edition }\end{array}$ & $\begin{array}{l}\text { Included in the } \\
\text { Collections of Songs, } \\
\text { op. } 1\end{array}$ \\
\hline $\begin{array}{l}\frac{\text { Nanourisma }}{\text { (Lullaby), D. }} \\
\text { Dragatakis }\end{array}$ & 1980 & Voice and piano & $\begin{array}{l}\text { Dragatakis } \\
\text { edition }\end{array}$ & $\begin{array}{l}\text { Included in the } \\
\text { Collections of Songs, } \\
\text { op. } 1\end{array}$ \\
\hline $\begin{array}{l}\text { Dyo peristeria perasan } \\
\text { (Two doves passed } \\
\text { by), D. Dragatakis }\end{array}$ & 1980 & Voice and piano & $\begin{array}{l}\text { Dragatakis } \\
\text { edition }\end{array}$ & $\begin{array}{l}\text { Included in the } \\
\text { Collections of Songs, } \\
\text { op. } 1\end{array}$ \\
\hline \multirow[t]{2}{*}{$\begin{array}{l}\text { Vithleem (Bethlehem), } \\
\text { D. Dragatakis }\end{array}$} & \multirow[t]{2}{*}{1980} & Bass and Piano & $\begin{array}{l}\text { Dragatakis } \\
\text { edition }\end{array}$ & \multirow{2}{*}{$\begin{array}{l}\text { Both versions are } \\
\text { included in the } \\
\text { Collections of Songs, } \\
\text { op. } 1\end{array}$} \\
\hline & & $\begin{array}{l}\text { Baritone and } \\
\text { Piano }\end{array}$ & $\begin{array}{l}\text { Dragatakis } \\
\text { edition }\end{array}$ & \\
\hline
\end{tabular}




\begin{tabular}{|c|c|c|c|c|}
\hline $\begin{array}{l}\text { I treli rodia (The crazy } \\
\text { pomegranate tree), } \\
\text { Od. Elytis }\end{array}$ & 1981 & Voice and piano & $\begin{array}{l}\text { Dragatakis } \\
\text { edition }\end{array}$ & $\begin{array}{l}\text { There are two } \\
\text { versions in } \\
\text { different keys; } \\
\text { included in the } \\
\text { Collections of Songs, } \\
\text { op. } 1\end{array}$ \\
\hline $\begin{array}{l}\text { Mana (Mother), V. } \\
\text { Theodorou }\end{array}$ & 1981 & Voice and piano & $\begin{array}{l}\text { Dragatakis } \\
\text { edition }\end{array}$ & $\begin{array}{l}\text { Included in the } \\
\text { Collections of Songs, } \\
\text { op. } 1\end{array}$ \\
\hline $\begin{array}{l}\text { Isoun mikri (You were } \\
\text { [a] young [girl]), V. } \\
\text { Theodorou }\end{array}$ & 1982 & Voice and piano & $\begin{array}{l}\text { Dragatakis } \\
\text { edition }\end{array}$ & $\begin{array}{l}\text { Included in the } \\
\text { Collections of Songs, } \\
\text { op. } 1\end{array}$ \\
\hline $\begin{array}{l}\text { Piano nero (Holding } \\
\text { water), V. } \\
\text { Theodorou }\end{array}$ & 1982 & Voice and piano & $\begin{array}{l}\text { Dragatakis } \\
\text { edition }\end{array}$ & $\begin{array}{l}\text { Included in the } \\
\text { Collections of Songs, } \\
\text { op. } 1\end{array}$ \\
\hline $\begin{array}{l}\text { T'Aprili to fengari } \\
\text { (April's moon) } \mathrm{V} \text {. } \\
\text { Theodorou }\end{array}$ & 1982 & Voice and piano & $\begin{array}{l}\text { Dragatakis } \\
\text { edition }\end{array}$ & $\begin{array}{l}\text { Included in the } \\
\text { Collections of Songs, } \\
\text { op. } 1\end{array}$ \\
\hline $\begin{array}{l}\text { Mythologias } \\
\text { III (Mythology III), } \\
\text { Euripides }\end{array}$ & 1985 & $\begin{array}{l}\text { Soprano and } \\
\text { orchestra }\end{array}$ & $\begin{array}{l}\text { Philippos } \\
\underline{\text { Nakas }} \\
\underline{\text { Music }} \\
\underline{\text { House }}\end{array}$ & $\begin{array}{l}\text { Full } \\
\text { instrumentation } \\
\text { can be found on } \\
\text { the website listing } \\
\text { for this piece. }\end{array}$ \\
\hline $\begin{array}{l}\text { Odi XIII: Ta } \\
\text { ifaisteia (Ode XIII: the } \\
\text { volcanoes), A. Kalvos }\end{array}$ & 1992 & $\begin{array}{l}\text { Soprano, Flute, } \\
\text { Violin, Cello, } \\
\text { Timpani, } \\
\text { Percussion, } \\
\text { Piano }\end{array}$ & $\begin{array}{l}\text { Manuscript } \\
\text { only }\end{array}$ & $\begin{array}{l}\text { Full percussion } \\
\text { instrumentation } \\
\text { can be found on } \\
\text { the website listing } \\
\text { for this piece. }\end{array}$ \\
\hline $\begin{array}{l}\text { Antitheseis: } \\
\text { Katerina (Contrasts: }\end{array}$ & 1995 & $\begin{array}{l}\text { Soprano, Alto, } \\
\text { Baritone, Bass, }\end{array}$ & $\begin{array}{l}\text { Dragatakis } \\
\text { edition }\end{array}$ & $\begin{array}{l}\text { Full orchestra } \\
\text { instrumentation } \\
\text { can be found on }\end{array}$ \\
\hline
\end{tabular}




\begin{tabular}{|c|c|c|c|c|}
\hline $\begin{array}{l}\text { Katherine), } \\
\text { D.Dragatakis }\end{array}$ & & $\begin{array}{l}\text { orchestra } \\
\text { ensemble }\end{array}$ & & $\begin{array}{l}\text { the website listing } \\
\text { for this piece. }\end{array}$ \\
\hline $\begin{array}{l}\text { Mideias } \\
\text { apoichoi (Medea's } \\
\text { reverberations), } \\
\text { Euripides }\end{array}$ & 1995 & $\begin{array}{l}\text { Four Sopranos, } \\
\text { four Altos, } \\
\text { orchestral } \\
\text { ensemble }\end{array}$ & $\begin{array}{l}\text { Manuscript } \\
\text { only }\end{array}$ & $\begin{array}{l}\text { Full orchestra } \\
\text { instrumentation } \\
\text { can be found on } \\
\text { the website listing } \\
\text { for this piece. }\end{array}$ \\
\hline $\begin{array}{l}\text { Enypnio (While } \\
\text { Asleep), } \\
\text { D.Dragatakis }\end{array}$ & 2000 & Voice and piano & $\begin{array}{l}\text { Dragatakis } \\
\text { edition }\end{array}$ & $\begin{array}{l}\text { Written for Olga } \\
\text { Athanasiaidou }\end{array}$ \\
\hline $\begin{array}{l}\text { Collection of Songs, } \\
o p, 1\end{array}$ & 2020 & $\begin{array}{l}\text { See } \\
\text { instrumentation } \\
\text { in the listed } \\
\text { works above or } \\
\text { website listing } \\
\text { for details }\end{array}$ & $\begin{array}{l}\text { Dragatakis } \\
\text { edition }\end{array}$ & $\begin{array}{l}\text { To be published in } \\
2020\end{array}$ \\
\hline
\end{tabular}

MISCELLANEOUS (8 works)

\begin{tabular}{|c|c|c|c|c|}
\hline Title & Year & Instrumentation & $\begin{array}{l}\text { Edition } \\
\text { type }\end{array}$ & Notes \\
\hline $\begin{array}{l}\text { Preloudio kai } \\
\text { Fougka (Prelude and } \\
\text { fugue) }\end{array}$ & $\begin{array}{l}\text { Indeterminate, } \\
\text { estimated } \\
\text { 1952-55 }\end{array}$ & $\mathrm{S}, \mathrm{A}, \mathrm{T}, \mathrm{B}$ & Manuscript & $\begin{array}{l}\text { A music theory } \\
\text { assignment } \\
\text { during his } \\
\text { studies }\end{array}$ \\
\hline $\begin{array}{l}\text { Fougka } \\
\text { Exetaseon (Examination } \\
\text { fugue), variation on a } \\
\text { theme by Manolis } \\
\text { Kalomiris }\end{array}$ & 1955 & $\mathrm{~S}, \mathrm{~A}, \mathrm{~T}, \mathrm{~B}$ & Manuscript & $\begin{array}{l}\text { A music theory } \\
\text { assignment } \\
\text { during his } \\
\text { studies }\end{array}$ \\
\hline $\begin{array}{l}\text { Ymnos gia to } \\
\text { Panepistimio }\end{array}$ & $\begin{array}{l}\text { Indeterminate, } \\
\text { estimated } 1955\end{array}$ & $\begin{array}{l}\text { Voice and Piano } \\
\text { Chorus }\end{array}$ & $\begin{array}{l}\text { Manuscript } \\
\text { Manuscript }\end{array}$ & Undated work \\
\hline
\end{tabular}




\begin{tabular}{|c|c|c|c|c|}
\hline $\begin{array}{l}\text { Thessalonikis (Anthem } \\
\text { for Thessaloniki's } \\
\text { University) }\end{array}$ & & & & \\
\hline $\begin{array}{l}\text { Anthem for the Olympic } \\
\text { Light }\end{array}$ & 1969 & Band & Manuscript & $\begin{array}{l}\text { Transcription } \\
\text { for band by M. } \\
\text { Kastellis }\end{array}$ \\
\hline $\begin{array}{l}\text { Ifigeneia en } \\
\text { Avlidi (Iphigenia in } \\
\text { Avlidi), Euripides }\end{array}$ & $\begin{array}{l}\text { Indeterminate, } \\
\text { estimated } 1975\end{array}$ & Indeterminate & $\begin{array}{l}\text { No } \\
\text { manuscript } \\
\text { or } \\
\text { recording }\end{array}$ & $\begin{array}{l}\text { Lost work; only } \\
\text { information of } \\
\text { existence is } \\
\text { programme of } \\
\text { the first } \\
\text { performance } \\
(1975)\end{array}$ \\
\hline $\begin{array}{l}\text { Anadromes } \\
V \text { (Retrospections V) }\end{array}$ & 1979-1999 & Not applicable & $\begin{array}{l}\text { Philippos } \\
\underline{\text { Nakas }} \\
\underline{\text { Music }} \\
\underline{\text { House }}\end{array}$ & $\begin{array}{l}\text { Exam papers } \\
\text { (from } 1979 \text { to } \\
\text { 1999) for } \\
\text { Harmony, } \\
\text { Counterpoint, } \\
\text { Fugue and } \\
\text { Composition }\end{array}$ \\
\hline $\begin{array}{l}\text { Ornis Alkyon (Bird } \\
\text { Alcyon), } \\
\text { Euripides, Iphigenia in } \\
\text { Tauris, second stasimon }\end{array}$ & $\begin{array}{l}\text { Indeterminate, } \\
\text { estimated } \\
\text { 1998-2001 }\end{array}$ & Chorus & Manuscript & $\begin{array}{l}\text { Harmonisation } \\
\text { by Sp. Klapsis }\end{array}$ \\
\hline En Samo (In Samos) & 2005 & $\begin{array}{l}\text { Flute, Cello, } \\
\text { Piano }\end{array}$ & Manuscript & $\begin{array}{l}\text { Transcribed by } \\
\text { Sp. Papikinos }\end{array}$ \\
\hline
\end{tabular}


INCOMPLETE ( 2 works)

\begin{tabular}{|c|c|c|c|c|}
\hline Title & Year & Instrumentation & Edition type & Notes \\
\hline Symphony No. 7 & $\begin{array}{l}\text { Indeterminate, } \\
\text { estimated } \\
\text { 1992-2001 }\end{array}$ & $\begin{array}{l}\text { Orchestra, } \\
\text { chorus, children's } \\
\text { chorus, two solo } \\
\text { voices }\end{array}$ & Manuscript & $\begin{array}{l}\text { For full } \\
\text { instrumentation, } \\
\text { please contact us. }\end{array}$ \\
\hline $\begin{array}{l}\text { Itan mia fora } \\
\text { (There was once), } \\
\text { V. Goula }\end{array}$ & $\begin{array}{l}\text { Indeterminate, } \\
\text { estimated } \\
\text { 2000-2001 }\end{array}$ & Choir & Manuscript & \\
\hline
\end{tabular}


List of works bibliography used for Dimitris Dragatakis Archive - List of works

Dragatakis, Dimitris. Collection of Works. Dragatakis Archives.

Dragatakis, Dimitris. Dragatakis Edition Collection. Dragatakis Archives.

Dragatakis, Dimitris. Dragatakis Manuscript Collection. Dragatakis Archives.

Dragatakis, Dimitris. Collection of works by Dragatakis. Athens, Greece: Philippos Nakas Music House. Accessed October 2019.

https://www.nakas.gr/ser?st=dragatakis

Kalopana, Magdalini. "Dimitris Dragatakis.” Grove Music Online. 3 September 2014; Accessed October 2019.

https://www.oxfordmusiconline.com/grovemusic/view/10.1093/gmo/97815615926 30.001.0001/omo-9781561592630-e-0000008120.

Kalopana, Magdalini. “Dimitris Dragatakis: Katalogos ergon [Dimitris Dragatakis: catalogue of works]." PhD Dissertation, National and Kapodistrian University of Athens, 2009. 


\subsection{Catalogue of works including viola}

Below are two lists of works, 'works for viola and accompaniment' and 'works for strings and winds, including viola', by Dragatakis. These lists function as tools for future violists, scholars, or concert presenters. The information in the list includes title, year, instrumentation, edition type, and notes about the work if applicable.

\subsubsection{Works for viola and accompaniment}

\begin{tabular}{|l|l|l|l|l|}
\hline Title & Year & Instrumentation & Edition type & Notes \\
\hline $\begin{array}{l}\text { Concerto for } \\
\text { viola }\end{array}$ & $\begin{array}{l}\text { Indeterminate, } \\
\text { estimated } \\
1949-57\end{array}$ & Viola and piano & $\begin{array}{l}\text { Manuscript } \\
\text { form }\end{array}$ & $\begin{array}{l}\text { This work } \\
\text { exists in piano } \\
\text { reduction } \\
\text { manuscript } \\
\text { only. }\end{array}$ \\
\hline Adagio & 1969 & $\begin{array}{l}\text { String orchestra, } \\
\text { piano, and viola }\end{array}$ & $\begin{array}{l}\text { Has never } \\
\text { been } \\
\text { performed. }\end{array}$ \\
\hline Duo & 1982 & $\begin{array}{l}\text { Viola and piano } \\
\text { Recorded on } \\
\text { 'Dimitris } \\
\text { Dragatakis - } \\
\text { Chamber }\end{array}$ \\
\hline $\begin{array}{l}\text { Concerto for } \\
\text { viola and }\end{array}$ & 1992 & $\begin{array}{l}\text { Viola and } \\
\text { orchestra; viola } \\
\text { and piano; viola } \\
\text { and percussion }\end{array}$ & $\begin{array}{l}\text { Dragatakis } \\
\text { edition; } \\
\text { Dalabakis } \\
\text { arrangement }\end{array}$ & $\begin{array}{l}\text { Premiered in } \\
\text { 1993 (Athens) } \\
\text { recording } \\
\text { available on } \\
\text { YouTube }\end{array}$ \\
\hline
\end{tabular}


3.3.2 Works for strings and winds, including viola

\begin{tabular}{|c|c|c|c|c|}
\hline Title & Year & Instrumentation & Edition type & Notes \\
\hline Trio & 1965 & $\begin{array}{l}\text { Two violins and } \\
\text { viola }\end{array}$ & $\begin{array}{l}\text { Dragatakis } \\
\text { edition }\end{array}$ & \\
\hline $\begin{array}{l}\text { Suite for } \\
\text { double string } \\
\text { quartet }\end{array}$ & 1961 & String Octet & $\begin{array}{l}\text { Philippos Nakas } \\
\text { Music House }\end{array}$ & \\
\hline $\begin{array}{l}\text { String Quartet } \\
\text { No. } 1\end{array}$ & 1957 & $\begin{array}{l}\text { String Quartet } \\
\text { (two violins, } \\
\text { viola, cello) }\end{array}$ & $\begin{array}{l}\text { Dragatakis } \\
\text { edition }\end{array}$ & $\begin{array}{l}\text { Recorded on } \\
\text { 'Dimitris } \\
\text { Dragatakis - } \\
\text { Complete } \\
\text { String } \\
\text { Quartets' }\end{array}$ \\
\hline $\begin{array}{l}\text { String Quartet } \\
\text { No. } 2\end{array}$ & 1958 & $\begin{array}{l}\text { String Quartet } \\
\text { (two violins, } \\
\text { viola, cello) }\end{array}$ & $\begin{array}{l}\text { Dragatakis } \\
\text { edition }\end{array}$ & $\begin{array}{l}\text { Recorded on } \\
\text { 'Dimitris } \\
\text { Dragatakis - } \\
\text { Complete } \\
\text { String } \\
\text { Quartets' }\end{array}$ \\
\hline $\begin{array}{l}\text { String Quartet } \\
\text { No. } 3\end{array}$ & 1960 & $\begin{array}{l}\text { String Quartet } \\
\text { (two violins, } \\
\text { viola, cello) }\end{array}$ & Manuscript & $\begin{array}{l}\text { Recorded on } \\
\text { 'Dimitris } \\
\text { Dragatakis - } \\
\text { Complete } \\
\text { String } \\
\text { Quartets' }\end{array}$ \\
\hline
\end{tabular}




\begin{tabular}{|c|c|c|c|c|}
\hline $\begin{array}{l}\text { String Quartet } \\
\text { No. } 4\end{array}$ & 1967 & $\begin{array}{l}\text { String Quartet } \\
\text { (two violins, } \\
\text { viola, cello) }\end{array}$ & $\begin{array}{l}\text { Dragatakis } \\
\text { edition }\end{array}$ & $\begin{array}{l}\text { Recorded on } \\
\text { 'Dimitris } \\
\text { Dragatakis - } \\
\text { Complete } \\
\text { String } \\
\text { Quartets' }\end{array}$ \\
\hline $\begin{array}{l}\text { String Quartet } \\
\text { No. } 5\end{array}$ & 1974 & $\begin{array}{l}\text { String Quartet } \\
\text { (two violins, } \\
\text { viola, cello) }\end{array}$ & $\begin{array}{l}\text { Dragatakis } \\
\text { edition }\end{array}$ & $\begin{array}{l}\text { Recorded on } \\
\text { 'Dimitris } \\
\text { Dragatakis - } \\
\text { Complete } \\
\text { String } \\
\text { Quartets' }\end{array}$ \\
\hline $\begin{array}{l}\text { String Quartet } \\
\text { No. } 6\end{array}$ & 1999 & $\begin{array}{l}\text { Quartet (violin, } \\
\text { Oboe, Viola, } \\
\text { Cello) }\end{array}$ & $\begin{array}{l}\text { Dragatakis } \\
\text { edition }\end{array}$ & $\begin{array}{l}\text { Recorded on } \\
\text { 'Dimitris } \\
\text { Dragatakis - } \\
\text { Chamber } \\
\text { Music I' }\end{array}$ \\
\hline $\begin{array}{l}\text { String Quartet } \\
\text { No. } 7\end{array}$ & 2001 & $\begin{array}{l}\text { String Quartet } \\
\text { (two violins, } \\
\text { viola, cello) }\end{array}$ & & $\begin{array}{l}\text { Recorded on } \\
\text { 'Dimitris } \\
\text { Dragatakis - } \\
\text { Complete } \\
\text { String } \\
\text { Quartets' }\end{array}$ \\
\hline Trio & 1965 & $\begin{array}{l}\text { Violin, viola, } \\
\text { cello }\end{array}$ & $\begin{array}{l}\text { Dragatakis } \\
\text { edition }\end{array}$ & \\
\hline
\end{tabular}




\subsection{Video and audio databases}

During the researcher's artist residency at the Greek Music Archives - Dragatakis Archive (Athens, Greece) in October 2019, other digital platforms were created for Dimitris Dragatakis including a YouTube page and to gain access to the Dimitris Dragatakis Spotify Artist Page.

YouTube was used to collate all the existing videos of Dragatakis and his music onto one page, making recordings, documentary, and other video materials easily accessible to future performers, and scholars. ${ }^{44}$ On YouTube, playlists can be created that then appear on the channel so in this case the researcher was able to add videos posted by other channels to a playlist that then appears on the Dimitris Dragatakis Composer YouTube video database.

It was important to claim the Dimitris Dragatakis Spotify page for a few reasons. To claim a Spotify Artist page, a Spotify page is normally created automatically and music uploaded by a third-party distributor. After this page is created, the artist can then claim the page. This was the case for Dimitris Dragatakis - he had a Spotify Page that included previous recordings and the researcher was able to claim this page during the artist residency. It was important to claim the page as the page can now be updated with current biographical information and can be linked to the digital database website and Facebook page. This provides consistency and accessibility for all the digital platforms, which in turn will assist future listeners in finding other resources about Dimitris Dragatakis and his archive.

This section includes links and descriptions of all fourteen different playlists on the Dimitris Dragatakis - Composer YouTube page and a final link to the Dimitris Dragatakis Spotify page. In total the YouTube channel hosts 328 videos between the

44 "Dimitris Dragatakis - Composer," YouTube. 
fourteen playlists. Viewers can hear recordings of his concertos, chamber music, orchestra works, vocal works, solo works, select complete albums, live performances, and documentaries and presentations or talks about Dimitris Dragatakis.

\subsubsection{About Dimitris Dragatakis}

This playlist includes documentary material from the Greek Ministry of Culture's film about Dragatakis and his life and works and talks/lectures and presentations about Dragatakis by Dr Magdalini Kalopana. ${ }^{45}$

\section{$\underline{\text { About Dimitris Dragatakis playlist }}$}

https://www.youtube.com/playlist?list=PL6JUXwumA0GQGgNzQR2vXLRpPeIDXs $\underline{\operatorname{RcZ}}$

\subsubsection{Live performances}

Within this seventeen-video playlist, viewers can watch live performances of works by Dragatakis including concertos, chamber music, and symphonies. ${ }^{46}$

\section{Live performance playlist}

\section{https://www.youtube.com/playlist?list=PL6JUXwumA0GQs-Giw6cKE-13nVqYCi hS}

\subsubsection{Ballet/Dance works}

This playlist includes a short clip of a ballet performance by the Greek National Opera's Ballet Studio. The video contains the music Ballet Suite No. 4, Pinelopi $i$

\footnotetext{
45 “Dimitris Dragatakis - Composer," YouTube.

46 Ibid.
} 
Anamoni (Penelope or awaiting) (1969) for instrumental ensemble, voices, tape, or solo piano by Dragatakis. ${ }^{47}$ The work currently exists only in manuscript form.

Ballet/Dance works playlist

https://www.youtube.com/playlist?list=PL6JUXwumA0GQAcJ2KKFiExI3Z97x-bjae

\subsubsection{Concertos}

In this playlist viewers can hear the violin, viola, oboe, and guitar concertos and saxophone with orchestra edition of Berceuse. Interestingly, viewers can watch the more recent performance of Concerto for Violin from the 2014 'Dimitris Dragatakis: 100 years since birth' concert as well as the live premiere recording. ${ }^{48}$

Concertos playlist

https://www.youtube.com/playlist?list=PL6JUXwumA0GQIimp XPb26rKYmEKJEg $\underline{X F}$

\subsubsection{Chamber music works}

Featuring Dragatakis' chamber works only, this playlist has over fifty-five videos and includes live performances and studio recordings. ${ }^{49}$

\section{Chamber music works playlist}

\footnotetext{
47 "Dimitris Dragatakis - Composer," YouTube.

${ }^{48}$ Ibid.

${ }^{49}$ Ibid.
} 


\subsubsection{Orchestra works}

Dragatakis' orchestral works are considered by some to be his greatest compositions. ${ }^{50}$ In this playlist the viewer can watch live performances and listen to live recordings as well as world premiere performances from the 2014 Dimitris Dragatakis: 100 years since birth concert. ${ }^{51}$

Orchestra works playlist

https://www.youtube.com/playlist?list=PL6JUXwumA0GSOMsRICpx1BThNCoOrV $\underline{\mathrm{huR}}$

\subsubsection{Vocal works}

This playlist includes recordings and live performances of some of Dragatakis' vocal works. ${ }^{52}$

\section{Vocal works playlist}

https://www.youtube.com/playlist?list=PL6JUXwumA0GRNOz4K1TNry5JE8pjG6Q $\underline{4 \mathrm{z}}$

\subsubsection{Solo works}

Works for flute and piano can be found on this playlist, including Lorenda Ramou's Naxos CD Dimitris Dragatakis: Complete Solo Piano Music. ${ }^{53}$

\footnotetext{
${ }^{50}$ Kalopana, "Dimitris, Dragatakis."

51 "Dimitris Dragatakis - Composer," YouTube.

${ }^{52}$ Ibid.

${ }^{53}$ Ibid.
} 
$\underline{\text { Solo works playlist }}$

https://www.youtube.com/playlist?list=PL6JUXwumA0GTkAIHtasVB4xp4TqLS4wY $\underline{7}$

\subsubsection{Albums and recordings}

Featuring sixty-eight videos, this playlist hosts all the studio album recordings uploaded to YouTube, which include Irida's Dimitris Dragatakis: Chamber Music I; Naxos' Dimitris Dragatakis: Complete Solo Piano Music; sound archive recordings from the radio programme Third Programme - ERT; Metamorphosis works for oboe and piano; Evangelos \& Liza: 50 years of guitar artistry; Works by Greek Composers; Naxos' Ballades for Saxophone and Orchestra; and Irida's Dimitris Dragatakis: The String Quartets. ${ }^{54}$

\section{$\underline{\text { Albums and recordings playlists }}$}

https://www.youtube.com/playlist?list=PL6JUXwumA0GQzBO3cU9dMPNqH3Vph anAq

\subsubsection{The String Quartets (complete album)}

This playlist features the complete 2019 Irida album Dimitris Dragatakis: The String Quartets.55

The String Quartets (complete album) playlist

\footnotetext{
54 "Dimitris Dragatakis - Composer," YouTube.

${ }^{55}$ Ibid.
} 


\subsubsection{Piano works (complete album)}

In this playlist, viewers can listen to the complete Naxos recording Dimitris Dragatakis:

Complete Solo Piano Music by Lorenda Ramou. ${ }^{56}$

\section{$\underline{\text { Piano works (complete album) playlist }}$}

https://www.youtube.com/playlist?list=PL6JUXwumA0GRkVst QhcBfxEsryPmlnvd

\subsubsection{Years of Guitar Artistry}

This playlist features a recording from album Evangelos $\mathcal{E}$ Liza: 50 years of guitar artistry, which includes a live performance of Dragatakis' Concerto for Two Guitars. ${ }^{57}$

\section{Years of Guitar Artistry playlist}

https://www.youtube.com/playlist?list=PL6JUXwumA0GRAtunbze2UrB2W-

$\underline{\text { FDg6LTY }}$

\subsubsection{Dimitris Dragatakis - Chamber Music I (complete album)}

Featuring a complete playlist of Irida's Dimitris Dragatakis: Chamber Music I, the viewer can listen to chamber music work written for various instrument combinations including violin, oboe, viola, and cello; clarinet and piano; viola and piano; wind octet; flute, oboe, clarinet, horn, and bassoon; clarinet and bassoon; and violin and piano. ${ }^{58}$

Dimitris Dragatakis - Chamber Music I (complete album) playlist

\footnotetext{
56 "Dimitris Dragatakis - Composer," YouTube.

${ }^{57}$ Ibid.

${ }^{58}$ Ibid.
} 
https://www.youtube.com/playlist?list=PL6JUXwumA0GR4Dq_P2ktI zVYS6FacEX

$\underline{C}$

\subsubsection{Dragatakis Composition Competition}

This playlist has videos pertaining to the biennial Dragatakis Composition Competition. One video features a performance of the first prize-winning work from 2007/2008, a work written for flute and sounds. Other videos included feature talks before the competition or other important events relating to the competition. ${ }^{59}$

\section{Dragatakis Composition Competition playlist}

https://www.youtube.com/playlist?list=PL6IUXwumA0GTYmeFu-

tlzbhyimb583AFO

\subsubsection{Spotify}

This is a link to the Dimitris Dragatakis Spotify Page. The music uploaded to this page automatically appears and would have been submitted by the music record label or a third-party distributor. The researcher has added biography information, a link to the Dimitris Dragatakis Archive digital database and website, and updated the Spotify cover image. This was done in consultation with the Dimitris Dragatakis Archive Directors. ${ }^{60}$

\section{Dimitris Dragatakis Spotify Page}

https://open.spotify.com/artist/7mx3q8GQBomkCxdO0zVoE4

\footnotetext{
59 “Dimitris Dragatakis - Composer," YouTube.

${ }^{60}$ Spotify, “Dimitris Dragatakis." https://open.spotify.com/artist/7mx3q8GQBomkCxdO0zVoE4.
} 


\subsection{Interview material}

The interview material outlined in the previous section is an important digital tool going forward. These resources will aid future performers and scholars in their understanding of Dragatakis and his life and works.

All of the interview material has been uploaded to the Dimitris Dragatakis Archive Google Drive, which is shared with the Directors of the Archive and the researcher. The intention going forward is to release these videos either through the digital database website, YouTube, or both. 


\section{Chapter 4: Concerto for Viola - a digital case study}

The Concerto for Viola is used as a digital case study to demonstrate how twenty-firstcentury performers, scholars, and archivists might approach advancing the legacy and works of lesser-known composers using twenty-first-century digital tools. This section starts with background information about the Concerto for Viola, which was generously provided by Artur Paciorkiewicz, the violist who premiered the work in Athens in 1993. The methodology for creating the new viola and piano performance edition and optional viola, piano, and percussion chamber music performance edition is then discussed and links to the orchestra and piano reduction manuscript are provided. The manuscripts have been provided by the Dragatakis archive and are not for reproduction. These can also be found in Appendix 2: Concerto for Viola manuscripts.

An analysis of the first movement of the work, Moderato, and a suggested approach is offered in this section, which includes a table analysis and written portion. Within the approach section, resources to traditional music of Epirus are provided as well as the interactive 1993 performance part, which also includes the premiere recording so the reader can follow along.

A new digital orchestra score along with complete orchestral parts have also been created by the researcher and included for future performers and scholars.

When starting this project, the researcher met with the primary supervisor to discuss the digital case study focus, the Concerto for Viola. According to an entry on the IEMA database website, the concerto was premiered in 1993 by Polish violist Artur Paciorkiewicz, who just so happened to also be a colleague of the researcher's primary 
supervisor Professor Donald Maurice. ${ }^{61}$ After a few email exchanges, the performance part and score were obtained from Mr Paciorkiewicz and the project was able to take flight. ${ }^{62}$

Shortly thereafter, IEMA returned the researcher's correspondence and put her in touch with Valia Koronidi, the Dragatakis Archive Director, and Magdalini Kalopana, the Dragatakis Archive Curator. It was decided between the three of them that the researcher would fly to Athens, Greece - en route to Rotterdam, Netherlands, to participate and perform at the 45th International Viola Congress - to discuss her research project with them.

Upon securing the recording of the 1993 premiere performance from the Greek Archives in Athens, Greece, Mr Paciorkiewicz mentioned via email correspondence that he had never heard his own recording until it was released from the archive in early 2018, twenty-five years later. ${ }^{63}$ Around this time, the 'call for proposals' opened for the 46th International Viola Congress (IVC) which was to be held in Poznan, Poland, near to where Mr Paciorkiewicz resides. It was then that the researcher invited Mr Paciorkiewicz to be part of the 46th IVC lecture Dimitris Dragatakis (1914-2001): Concerto for Viola pertaining to the research project. A summary of this lecture presentation can be found in Chapter 5: Dragatakis in $2020 .{ }^{64}$

International Viola Congresses aim "to promote and encourage the development of new viola repertoire, new insights into existing repertoire, and viola-related research,

\footnotetext{
${ }^{61}$ IEMA, “Home page.” https://www.iema.gr/home/?lang=en.

${ }^{62}$ See also Appendix 4, Artur Paciorkiewicz email message to author November 16, 2017.

${ }^{63}$ See also Appendix 4, Artur Paciorkiewicz email message to author November 16, 2017.

64 "International Viola Society," International Viola Society website, accessed June 2020.

http://www.internationalviolasociety.org/.
} 
by bringing together international and national artists, organisations, and institutions through public recitals, lectures, and masterclasses. International Viola Congresses have been held annually since 1973, mostly in Europe and North America, and have assisted in promoting the ever-increasing standards of excellence in viola performance and scholarship" ${ }^{65}$

For the purposes of the dissertation and this section, the interview transcript has been inserted below. A link to a video recording of the interview during the lecture presentation in Poznan, Poland, can be found in the Chapter 5: Dragatakis in 2020.

\subsection{Interview with Artur Paciorkiewicz}

Below is an interview transcript taken from the researcher's presentation at the 46th International Viola Congress in Poznan, Poland. During this presentation, the researcher had the great pleasure of interviewing Artur Paciorkiewicz - the Polish violist who premiered the Dragatakis Concerto for Viola in 1993 in Athens, Greece. Before the presentation, the researcher and Mr Paciorkiewicz discussed what was to be said during the presentation and Mr Paciorkiewicz spoke in Polish while the researcher translated into English. A link to the presentation in Poznan, Poland, can be found in Chapter 5: Dragatakis in 2020.

Interview transcript with Artur Paciorkiewicz:

1. What was it like working with Dragatakis? How long did you work on learning this piece and how much was Dragatakis involved in the practice and rehearsal process?

Proposal of a concerto for viola by Dimitris Dragatakis I received a month before my performance in Athens.

\footnotetext{
65 "About the 44th IVC", 44th International Viola Congress website, accessed June 2020. https://ivcwgtn2017.wixsite.com/44th-ivcwgtn2017/44th-international-viola-congress.
} 
I met composer only during rehearsal in Athens, the day before the concert. He didn't have any comments about me to my surprise, but he had a few suggestions for the orchestra, mainly for the dynamic proportions.

2. Were you sent a full score or just the viola part?

Fortunately, apart from the solo viola, I also received a full score of the concert[o].

3. Did you work with a rehearsal pianist? How much rehearsal time with the orchestra was devoted to the concerto?

I learned the concert[o] while studying the score. Unfortunately, I didn't have a piano score. I had one rehearsal with the Cracow Philharmonic Orchestra (CPO) in Cracow, and the other one in Athens the day before the concert and the general rehearsal on the day of the concert.

4. How did you find learning his work? Was there anything you found particularly challenging? What did you enjoy the most?

Working on mastering the concert[o] was not particularly difficult for me, perhaps because it was stylistically similar to the concert[o]s I had in my repertoire - Tadeusz Paciorkiewicz and Grażyna Bacewicz. The only difficulty for me was the limited amount of time I had at my disposal at that time, because in the same time I had also contracted other performances with different programmes.

In general, I liked the concert[o]. Well written and well instrumented. The viola has a field to show off and is not covered by the orchestra.

5. How did the Krakow Philharmonic come about performing this work, do you know? Were you contracted by the orchestra or Dragatakis? Were you a member of the $\mathrm{KPO}$ at that time? 
The CPO [KPO] participated with great commitment not only in mastering Dragatakis concert[o] but also other works such as Krzysztof Penderecki's "Polish Requiem", which was also performed in Athens the day before my performance.

The trip of the CPO and all the soloist to Athens was handled by the Impressariat (Artistic Agency) of the Polish Radio and TV. I received an invitation from this Agency. The Agency organised concerts for several ensembles and soloist[s], including the Varsovia String Quartet, which I founded.

I had no information as to why the premiere of Dragatakis Concerto was not undertaken by the Greek soloist.

I suppose the organisers of the Music Festival in Athens were looking for a known name, that's why they invited Yuri Bashmet to perform the first performance. Unfortunately, a month before the concert, he cancelled his performance.

I was never a member of the CPO. At that time, I was a member of the Orchestra Sinfonia Varsovia as a leader of the viola section.

6. Any memories from your time learning the Concerto, rehearsing and performing it, and/or working with Dragatakis that stand out in your mind?

Dimitris Dragatakis was pleased with my performance. From what I remember, he was an older man, very distinguished and serious. He didn't show his feelings and did not look for any personal contacts.

7. Is there anything else you'd like to share with us about this piece?

The concert[o] was very warmly received by the audience. Krzysztof Penderecki and his wife were also present at the first performance of the Concerto. They liked the concert[o] very much and said it was worth including it in my repertoire. 


\subsection{Reviving the Concerto}

After emailing with Mr Paciorkiewicz, the researcher sought to obtain the premiere recording of the work from the Dimitris Dragatakis Archive. The researcher felt, with the permission of the Dimitris Dragatakis Archive, the recording should be shared with a wider audience. Thus, permission was given to play the premiere recording (link below) during the researcher's conference presentation, share it with $\mathrm{Mr}$ Paciorkiewicz, and upload the recording to YouTube with interactive solo part.

Another part of reviving the Concerto, also outlined in the following section, is the creation of the new viola part and edition and the viola, piano, and percussion chamber music edition. Both parts are equally important in securing the future of this work in that they will provide greater accessibility and thus more opportunities for the work to be performed again.

\subsubsection{Recording of the premiere performance from 1993}

This recording was released from the archive specifically for this project. The link takes you to a video created by the researcher, which includes an interactive solo part. Many thanks to the Dimitris Dragatakis Archive, Friends of Dragatakis Society, and specifically Valia Koronidi and Magdalini Kalopana for their assistance in accessing this recording and gaining permission to make it available. This resource can be utilised by future performers who are interested in learning this piece.

\section{https://youtu.be/ZUkwPZ7Fg4g}

\subsubsection{Analysis and approach}

The following section offers an analysis of Moderato, the first movement of Dimitris Dragatakis' Concerto for Viola. Also included is an analysis chart that can be applied to 
the entire movement. The first movement was chosen for this analysis as it is the most complicated movement musically in terms of form and thematic material.

\subsubsection{Approach}

When approaching this work as a performer, the researcher recommends utilising all the digital tools offered within this dissertation: the Dimitris Dragatakis Archive digital database website, the interactive 1993 performance part, the video database and Spotify to listen to recordings of other works, and manuscripts.

Dr Magdalini Kalopana also emphasised the importance of the 1993 premiere recording of this work. Dimitris Dragatakis was present for the rehearsal process for the Concerto for Viola and told Mr Paciorkiewicz he enjoyed his interpretation; therefore, Dragatakis would have had input in how the orchestra and $\mathrm{Mr}$ Paciorkiewicz performed the work. ${ }^{66}$ It is important for future performers, educators, and scholars to consider this going forward.

\subsection{Music from Epirus and interactive PDF}

Another tool that can be utilised by performers is the following playlist featuring music from Epirus. The influence of traditional Greek music from Epirus in Dragatakis' music was stressed during the interviews with family and the leading Dragatakis scholar. This playlist is a valuable resource for performers interested in learning and hearing more about traditional Greek music from Epirus.

\section{$\underline{\text { YouTube playlist - Music of Epirus }}$}

\section{https://www.youtube.com/playlist?list=PLEsL50b4ObArrUjYzP0jR2ZnWjwo1GftY}

\footnotetext{
${ }^{66}$ See also Appendix 4, Artur Paciorkiewicz email message to author November 16, 2017.
} 
Below is a link to the interactive 1993 performance part. This PDF includes the 1993 solo viola performance part with the premiere recording. Please follow the link below and download the PDF. To play the recording, click the 'play arrow' in the upper lefthand corner and a window will appear that plays the recording. This PDF will be a useful tool for future performers to aid them in their learning of and approach to the work.

Interactive PDF - 1993 solo viola performance part and premiere recording

https://drive.google.com/drive/folders/1xCaTwoCkCpVkP fpwlaBl45t9SG94NPx?us $\mathrm{p}=$ sharing

\subsubsection{Analysis of Movement I: Moderato}

Below is an analysis key that breaks down the rhythmic and thematic material. This key can be used throughout the first movement and other two movements. The reader is encouraged to refer to this key while reading the analysis table and description.

This key will assist future performers and scholars in their understanding of Dimitris Dragatakis' Concerto for Viola and can be applied to the stand-alone piano part and orchestral score. 


\begin{tabular}{|l|l|l|}
\hline \multicolumn{2}{|c|}{ Rhythmic themes } & \\
Rhythmic & Short- & Musical Notation \\
Theme 1 & short-long & (RT1)
\end{tabular}

Figure 11. Rhythmic theme analysis key table. 


\begin{tabular}{|c|c|c|}
\hline \multicolumn{2}{|c|}{ Melodic themes } & \multirow[t]{2}{*}{ Musical Notation } \\
\hline $\begin{array}{l}\text { Melodic } \\
\text { theme } 1 \\
\text { (MT1) }\end{array}$ & $\begin{array}{l}\text { Upper } \\
\text { neighbour } \\
\text { tone } \\
\text { motion }\end{array}$ & \\
\hline $\begin{array}{l}\text { Melodic } \\
\text { theme } 2 \\
\text { (MT2) }\end{array}$ & $\begin{array}{l}\text { Falling/ } \\
\text { rising } \\
\text { thirds }\end{array}$ & 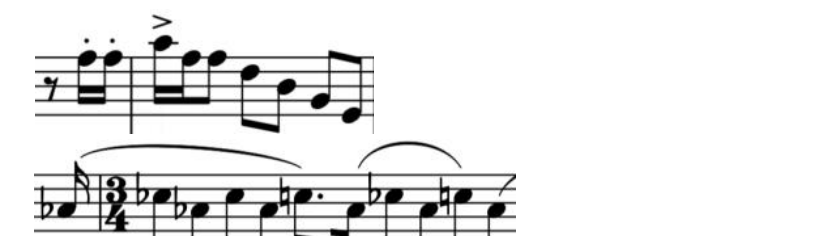 \\
\hline $\begin{array}{l}\text { Melodic } \\
\text { theme } 3 \\
\text { (MT3) }\end{array}$ & $\begin{array}{l}\text { Linear } \\
\text { leap/step }\end{array}$ & - \\
\hline $\begin{array}{l}\text { Melodic } \\
\text { theme } 4 \\
\text { (MT4) }\end{array}$ & $\begin{array}{l}\text { Two } \\
\text { leading } \\
\text { grace notes } \\
\text { (RT1) }\end{array}$ & +2 \\
\hline $\begin{array}{l}\text { Rising } \\
\text { fifth }\end{array}$ & $\begin{array}{l}\text { Leap of } 5 \text { th } \\
\text { (e.g. first } \\
\text { two notes) }\end{array}$ & 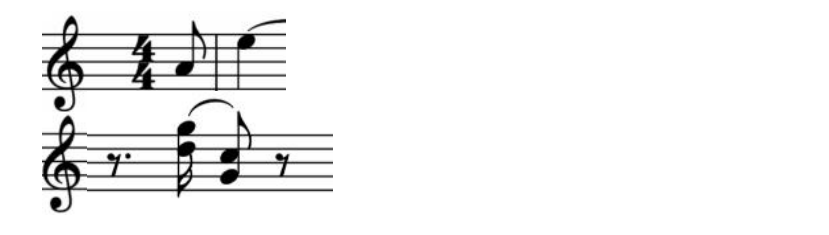 \\
\hline Tri-tone & $\begin{array}{l}\text { Linear or } \\
\text { vertical } \\
\text { Tri-tone }\end{array}$ & $\frac{1}{6}+60000$ \\
\hline
\end{tabular}

Figure 12. Melodic theme analysis key table. 


\section{CONCERTO FOR VIOLA AND ORCHESTRA I Dimitris Dragatakis \\ Analysis: First Movement - Moderato}

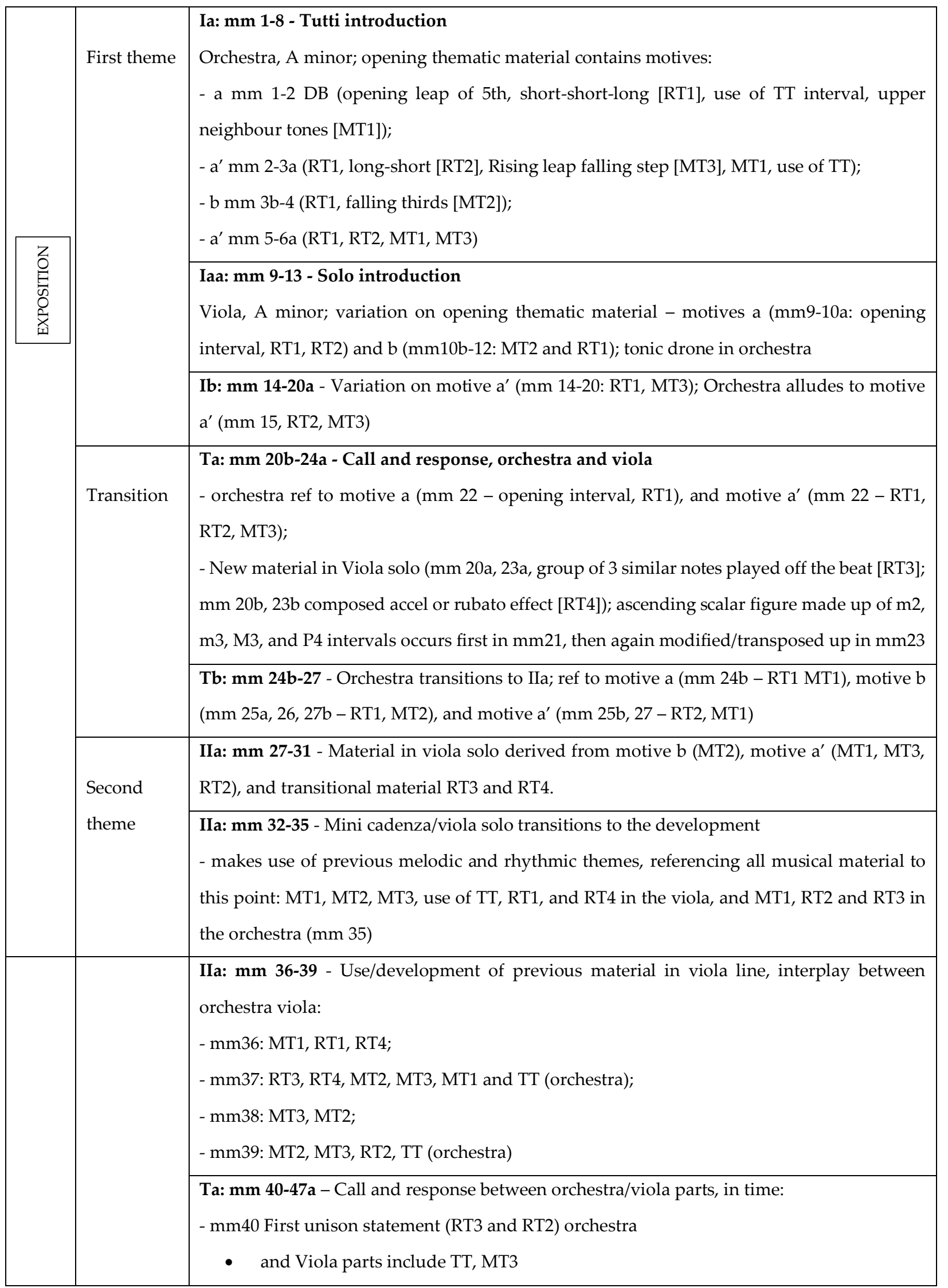




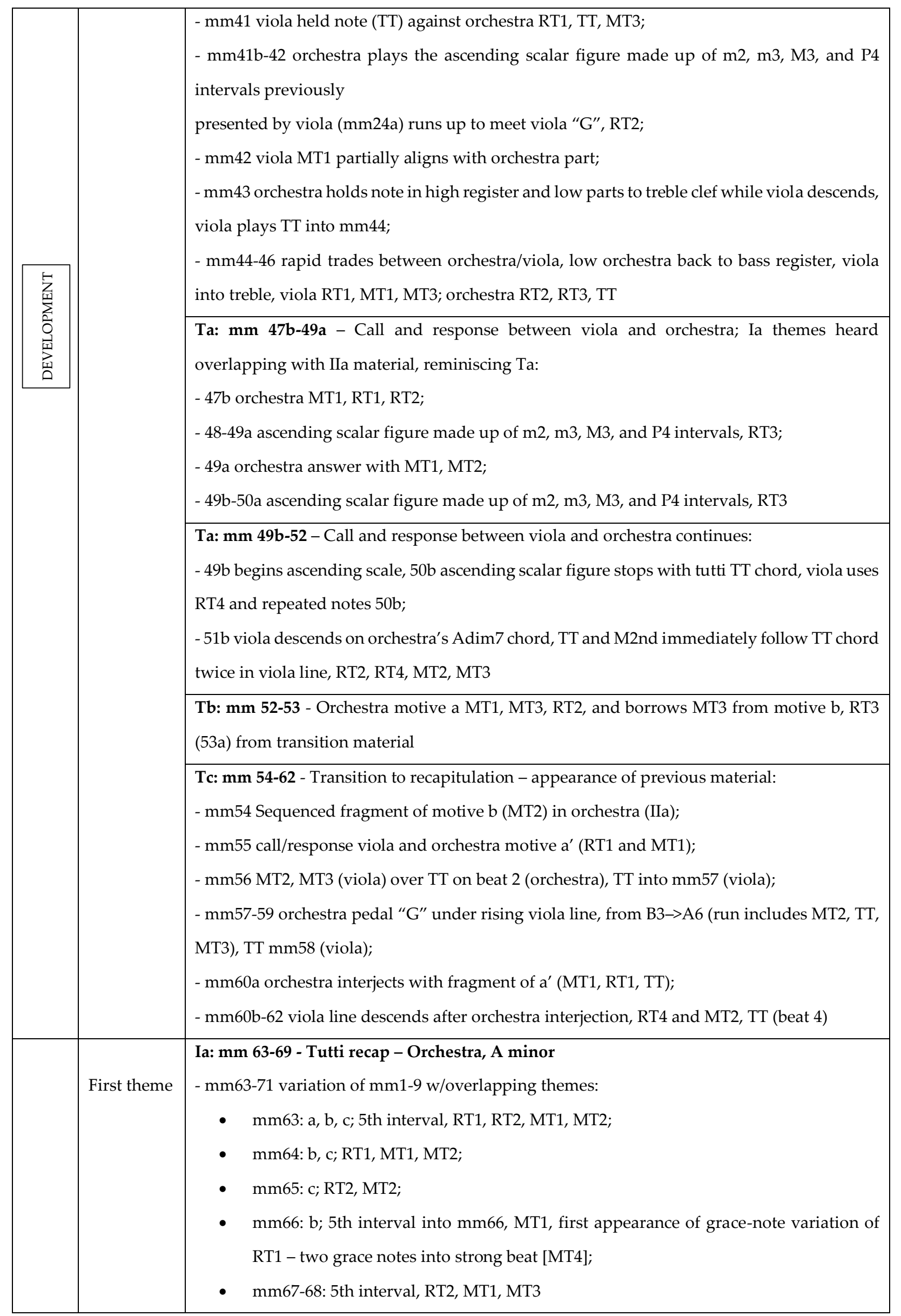




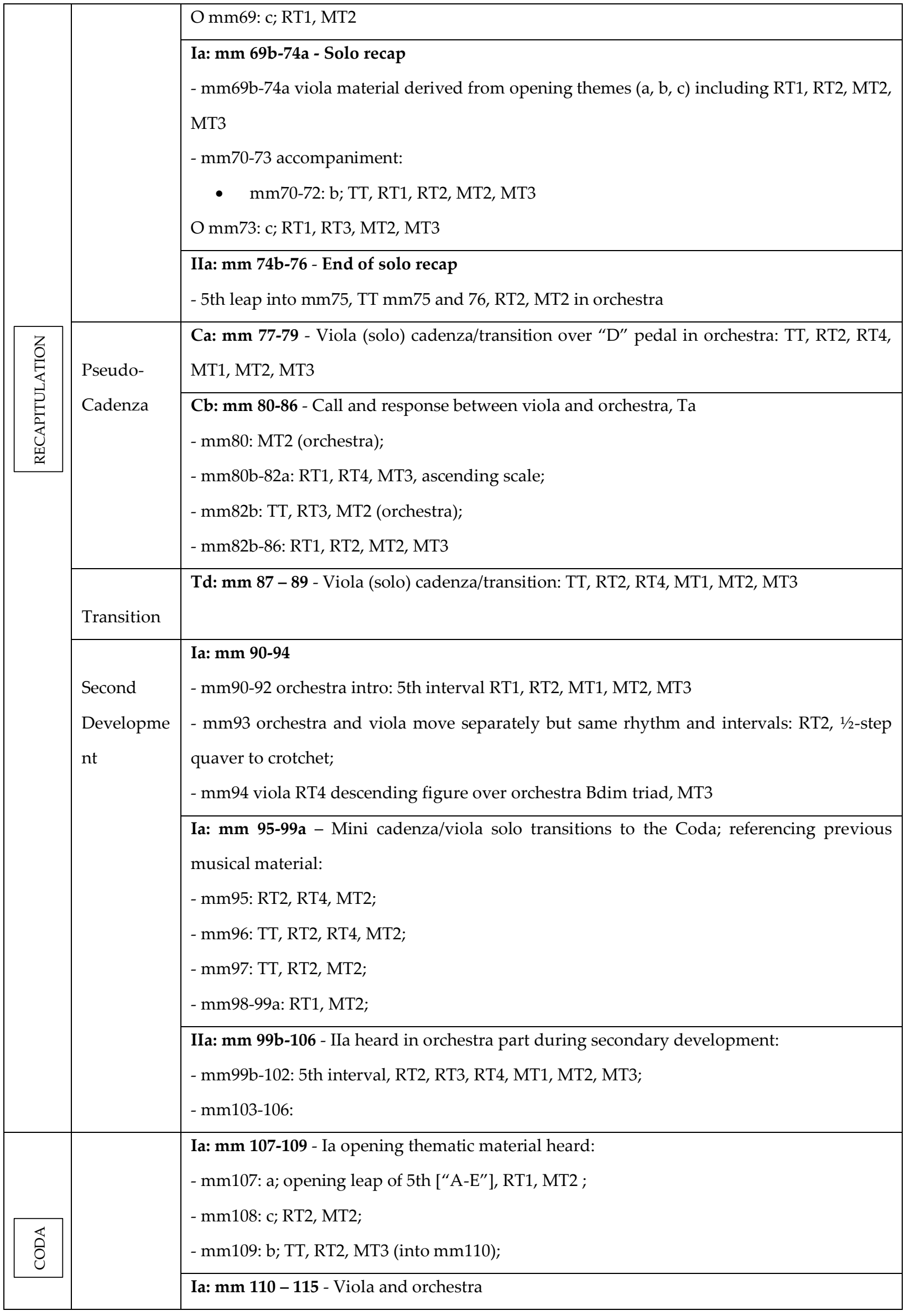




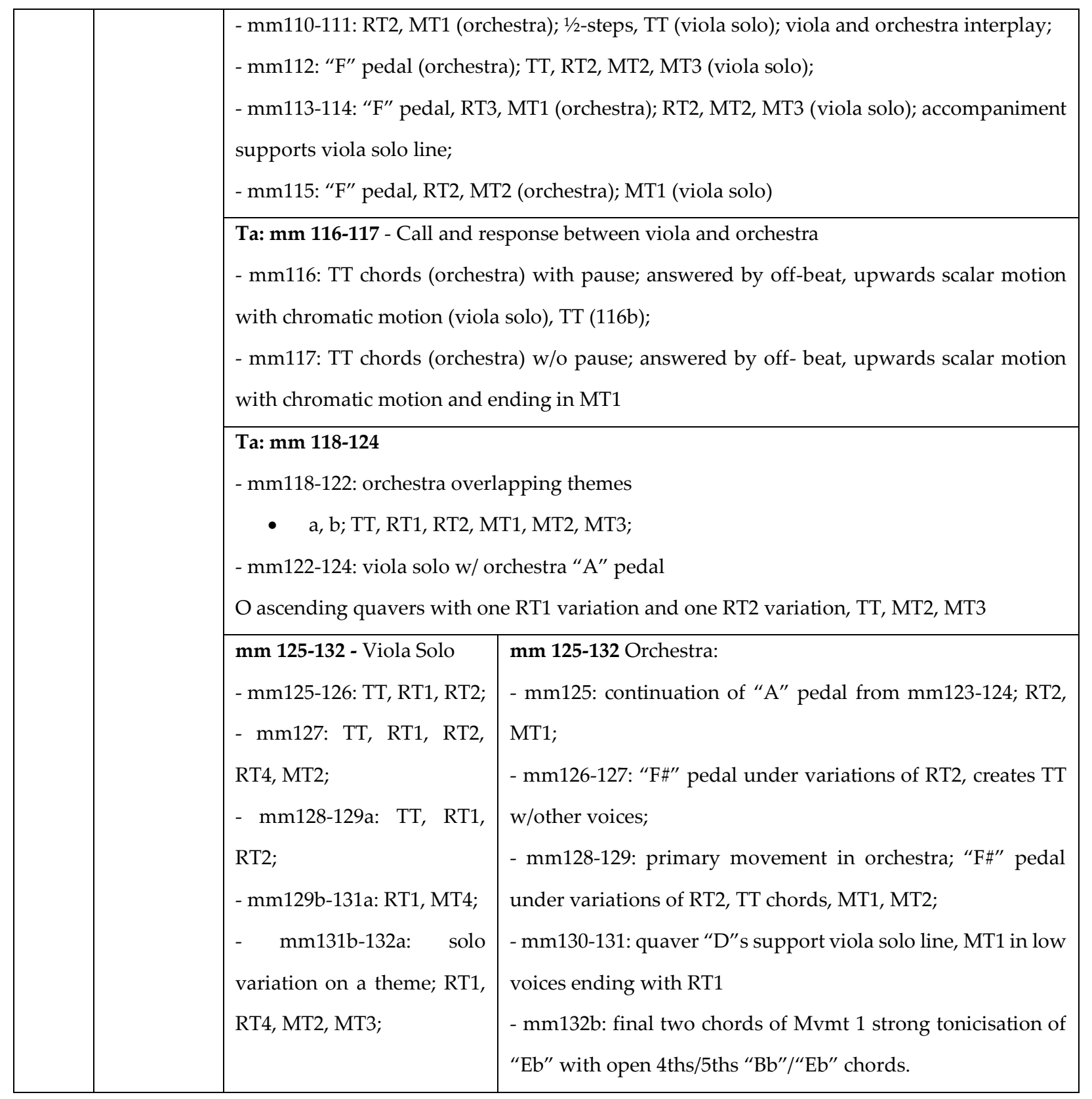

Figure 13. Concerto for Viola, Moderato - Analysis Table. 


\subsection{Summary of Features}

\section{Tonality and harmonic progression}

Dragatakis' style of writing lends itself to tonal ambiguity for a few reasons. There are strong tonicisations; however, often they only occur in portions or sections of the orchestra while other voices move in neighbour-tone motion between chords that seemingly do not belong to the key of the tonicisation. The writing is generally very linear in nature, moving either in chromatic motion or arpeggiations, in either case moving through (implied) harmonies rapidly. Some of the harmonic implications are simply the result of the vertical alignment of what is primarily a linear compositional technique.

Some of the harmonic implications are simply the result of the vertical alignment of what is primarily a linear compositional technique. An example of this can be found in bar 122 to 125 . The solo viola line is written in this linear manner and features a combination of half-steps and thirds which imply a rapid succession of harmonies through bar 122-123a and leads the ear to hear various notes as the "tonic"; however the addition of the " $\mathrm{A}$ " pedal in the orchestra parts in bar 123 on beat two provides the implication of a stable tonicization of " $\mathrm{A}$ ". This specific example is also outlined in the table analysis under "Ta: mm 118-125a" of the Coda section.

\section{Melody}

Dragatakis' melodies favour intervals including minor 2nds (m2), minor 3rds (m3), major 3rds (M3), perfect 4ths (P4), tri-tones (TT), perfect 5ths (P5), with some large leaps that span over an octave in the solo viola part, as well as chromatic motion. Melodic themes that have been identified are:

- MT1: neighbour tones

- MT2: falling/rising 3rds

- MT3: leap/step OR step/leap combination

- MT4: two leading grace notes, melodic variation on RT1 
- TT: Tri-tones.

\section{Rhythm}

Concerto for Viola has a few notable rhythmic elements including frequent change of metre, the juxtaposition of short-long note values, groupings of three notes, off-beat phrases, and composed rhythmic rubato. Rhythmic themes that have been identified are:

- RT1: short-short long

- RT2: dotted quaver/semi-quaver and 3:1 variations (e.g. dotted crotchet/quaver)

- RT3: three-note, off-beat grouping, variation on RT1

- RT4:written rhythmic rubato.

\section{Innovative orchestration techniques}

The innovation in Dragatakis' writing appears in the details of the aforementioned writing style. This includes a few distinct orchestration techniques that help to form Dragatakis' 'compositional fingerprint'.

In the first instance, Dragatakis orchestrates the Concerto so as to ensure that the solo viola line will be heard. To compensate for this, Dragatakis often writes call-andresponse style interactions between the solo viola part and the orchestra parts, writing in only a pedal tone or (often) cutting the orchestra off completely when the solo viola line plays (e.g. Mvmt I mm10-13; mm21-23; m28; mm32-34). With regards to the pitch as previously stated, when the viola solo and the orchestra do play simultaneously, Dragatakis carefully orchestrates the parts so that the sonic/aural space occupied by the pitches written in the viola solo part and the orchestra parts are not overlapping. In other words, the viola part has notes that are not doubled in the orchestra, and very rarely do the ranges of the viola solo part and the orchestral parts cross. 
For example, mm14-16 the viola stays below range of $\mathrm{RH} /$ upper instruments, then ascends through and above range of $\mathrm{RH}$ before those instruments re-enter, and then movement in the orchestra and the viola is interlocking, the viola stops before tutti chords into 21. As well, Dragatakis' use of percussion instruments for their additional timbre is such a distinct feature of his compositional style within this work that the concerto seems almost incomplete without the percussion parts included. This is why I have created a viola, piano, and percussion performance edition.

\section{Link to new orchestra score and complete orchestral parts}

Below is a link to a newly typeset orchestra score and orchestra parts. Before this project, an orchestra score and parts did not exist outside the archive. This material adds a valuable contribution to topics surrounding Dragatakis, but also to viola scholarship and digital humanities, and assists in making this work accessible to future performers and scholars.

\section{Link to orchestra score and complete parts}

https://drive.google.com/drive/folders/1Wt5YQVMBB3lIqckpm5LTRxcA1VhNiP8E? $\underline{\text { usp }=\text { sharing }}$

\subsubsection{Performance edition methodology}

To create the new performing edition based on the existing piano reduction, the researcher set up a plan involving a few parts:

1. Seek permission from the Dimitris Dragatakis Archive to typeset the piano reduction.

2. Hire an engraver to typeset piano reduction.

3. Work with a collaborative pianist to read through and rehearse piano reduction. 
4. Use the manuscript, orchestra score, and performance part from 1993 to inform the new stand-alone piano edition.

5. Work with collaborative percussionist to create stand-alone percussion part.

6. Use orchestra score from 1993 to flesh out percussion chamber music version for viola solo, piano, and three percussionists.

It was apparent the researcher would need to seek the advice and guidance of other professionals to ensure these new editions could be created; therefore, she engaged Brendan Agnew as the engraver, Gabriela Glapska as the collaborative pianist, and Hannah Neman as the collaborative percussionist. Short biographic material about each of them has been included below.

\subsubsection{Gabriela Glapska}

Gabriela Glapska is a Polish-born pianist currently living and working in Wellington, New Zealand. She received her Master's Degree with Distinction in Poland studying under the tutelage of prof. Ewa Poblocka and has recently completed her PhD degree in music (piano class of Dr Jian Liu) with the major performance component from Victoria University of Wellington (Wellington, New Zealand).

Gabriela works at Te Kōkī New Zealand School of Music as an accompanist for the brass department and is also an active soloist and chamber musician with a strong interest in contemporary music. Gabriela has been the resident pianist for the annual Nelson Composers Workshops since 2017 and a pianist for the 44th International Viola Congress in 2017 held in Wellington, New Zealand.

Gabriela collaborates with many award-winning composers on solo and ensemble projects, Wellington-based contemporary music ensemble STROMA, and soprano Barbara Paterson. In January and February 2020, Paterson and Glapska performed six shows of the opera production La Voix Humaine by Poulenc as part of New Zealand's 
international biennial arts celebration, the New Zealand Festival of the Arts. Gabriela is currently a member of TrioNique - the only professional flute-sax-piano chamber group in New Zealand, and a founding member of Ghost Piano Trio. ${ }^{67}$

\subsubsection{Hannah Neman}

Hannah Neman is a multifarious freelance musician, music educator, and arts administrator and advocate based in Wellington, New Zealand, who has garnered a high level of respect within the New Zealand and international arts sector. Miss Neman performs regularly with ensembles throughout New Zealand and has presented multiple solo and chamber music recitals since moving to New Zealand in 2014. She records on many occasions as a studio and pit musician, is commissioned often to present education workshops reaching upwards of 10,000 New Zealand students every year, and in November 2019 won a percussion position with the Drum Line of the Central Band of the Royal New Zealand Air Force. She has been guest artist-in-residence and education clinician-in-residence for institutions around the world, most recently as guest education clinician for North Shore Brass and Howick Brass Bands and guest percussionist-in-residence for the highly successful inaugural New Zealand edition of RimuFest $2020 .{ }^{68}$

\subsubsection{Brendan Agnew}

Brendan has been involved with music since starting piano lessons at the age of five, later beginning trumpet lessons at the age of eleven. He has been awarded scholarships for trumpet performance with the New Zealand Symphony Orchestra National Youth Orchestra, the Auckland Philharmonia Orchestra, and the Manukau Symphony Orchestra. Brendan has also performed as Principal Trumpet of the

\footnotetext{
${ }^{67}$ Biographical information and wording provided by Gabriela Glapska.

${ }^{68}$ Biographical material and wording provided by Hannah Neman.
} 
Hawkes Bay Orchestra and Festival Opera, and in a variety of groups across New Zealand.

Now employed in the music library of the New Zealand Symphony Orchestra, he is an experienced arranger, copyist, and typesetter, with materials prepared for and performed by the National Brass Band of New Zealand, the New Zealand Youth Brass Ensemble, the New Zealand School of Music Orchestra and Saxophone Ensemble, the Off Broadway Big Band, St Andrew's Big Band, and a number of schools and theatre companies throughout New Zealand.

Brendan has a wide range of experience in many different genres with a range of ensembles, and has studied performance and musicology at the University of Auckland and the New Zealand School of Music. ${ }^{69}$

\subsubsection{New viola and piano edition}

After receiving the manuscript of the piano reduction from the Dragatakis Archive, the part was immediately typeset by the engraver. Upon completion, the researcher and collaborative pianist rehearsed the work and it became apparent the piano reduction manuscript was a sketch of the orchestral score to come. This meant, for example, the opening chord was thin, needing the bottom octave to emulate the intended soundscape or orchestral accompaniment.

Together, the researcher, collaborative pianist, and engraver created a stand-alone piano part for the Concerto for Viola. Using the piano reduction and 1993 orchestra score from the premiere performance, the researcher was able to create the part, which was further edited by Gabriela Glapska and Brendan Agnew.

\footnotetext{
${ }^{69}$ Biographical material and wording provided by Brendan Agnew.
} 
Overall, the piano reduction harmonies have been fleshed out to sound fuller and truer to the intended soundscape and orchestral score. Through this process and rehearsing the work, it was apparent that the intended soundscape for the work was still lacking. After listening to the premiere recording, it was obvious the percussive timbres in the orchestra part play a vital role, so it was decided to also create a viola, piano, and percussion chamber music version from the orchestra score. This part and its creation are outlined in the next section.

The part for the Concerto for Viola piano edition appears on the following page. To view the PDF please click on the link below.

\section{Concerto for Viola - viola and piano version}

https://drive.google.com/drive/folders/1cP6MTkZA9TguDMWeWTigTaMiSJcsy21S? $\underline{\text { usp }=\text { sharing }}$ 


\title{
Dimitris Dragatakis
}

\section{Concerto for Viola and Orchestra}

\author{
$\underline{\text { Piano }}$
}

Created by Elyse Dalabakis

Piano part edited by Gabriela Glapska

Reduction and engraving by Brendan Agnew 



\section{Concerto for Viola and Orchestra I}

Dimitris Dragatakis
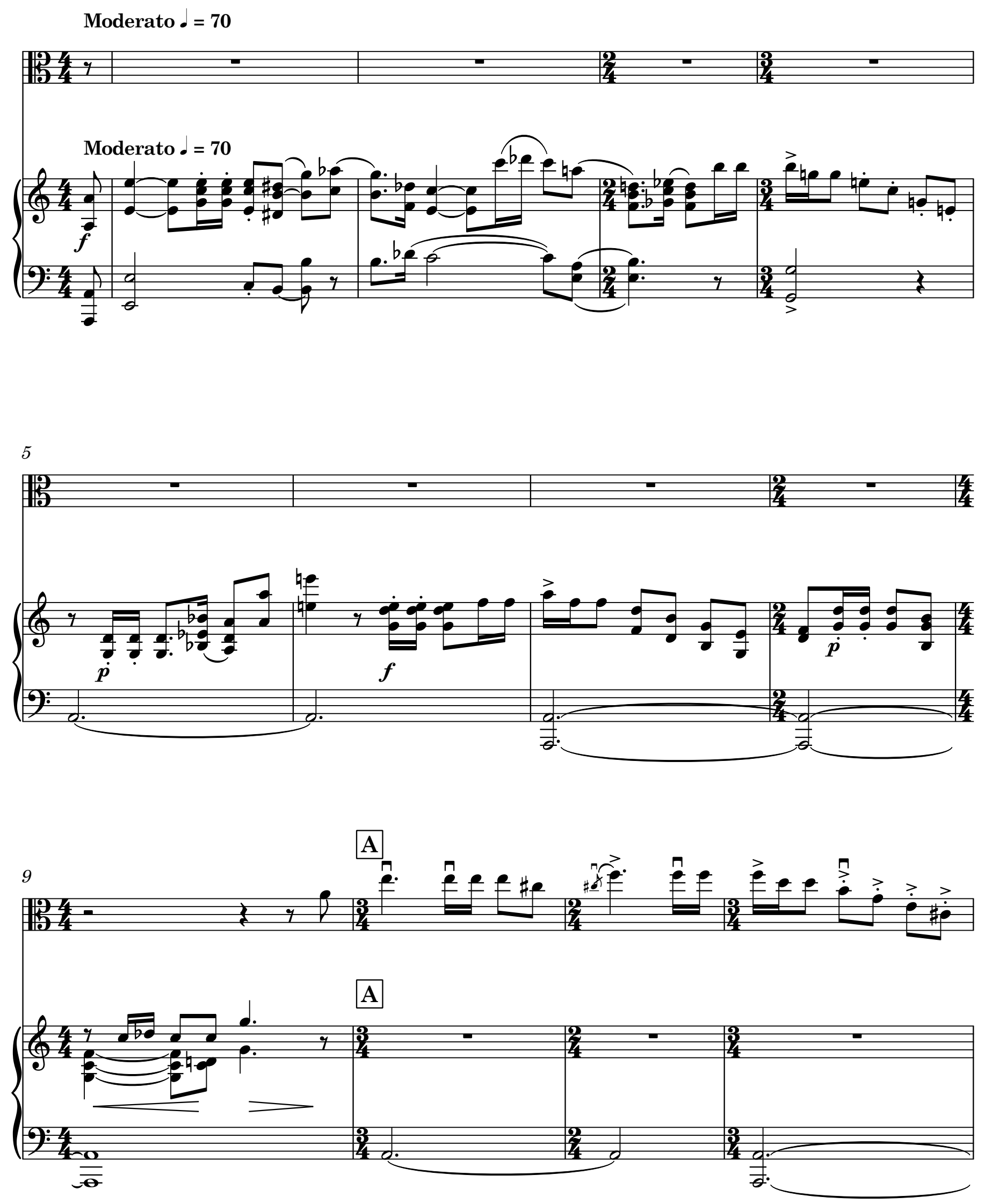

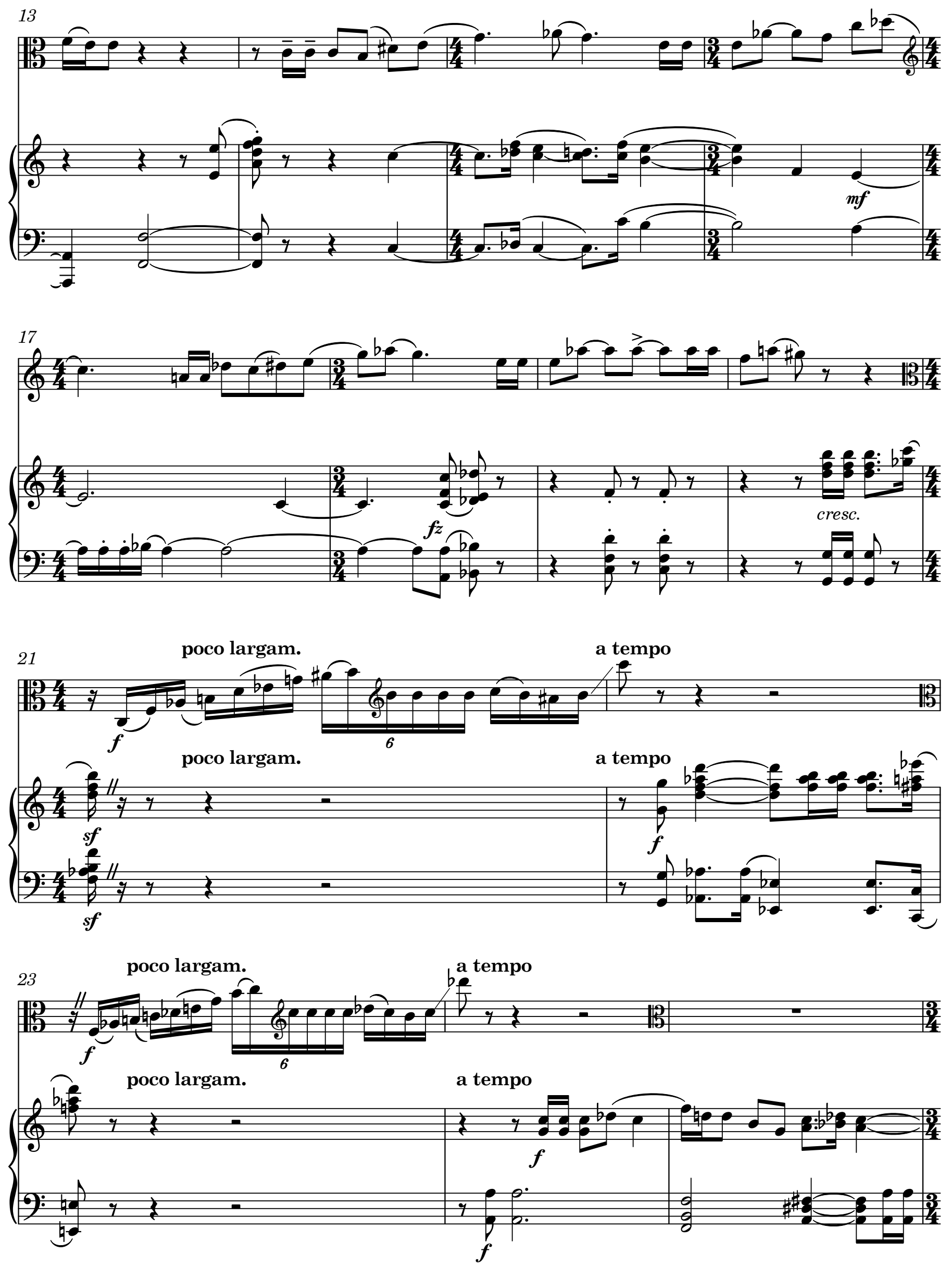
26 molto rall. $\quad$ B a tempo
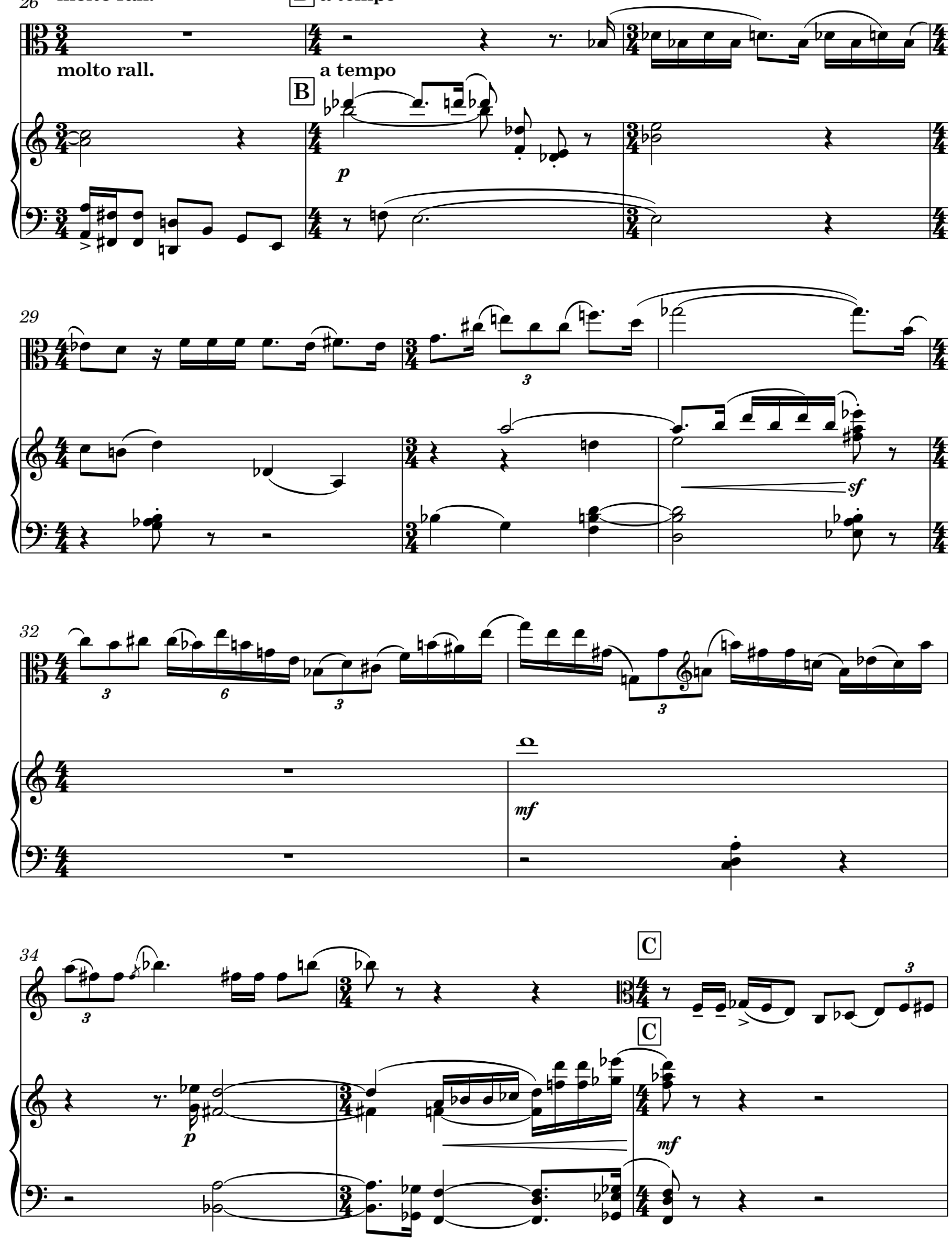

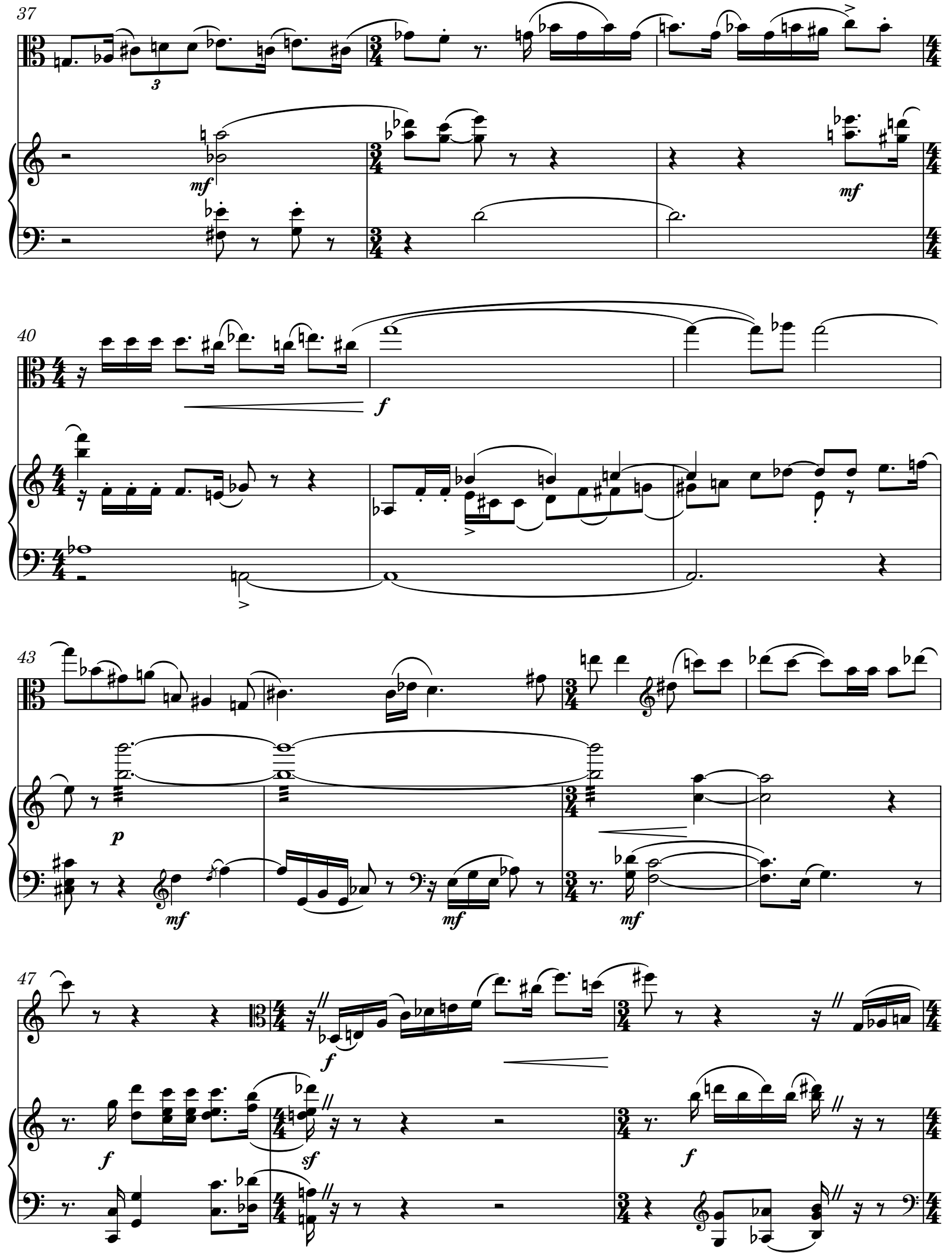

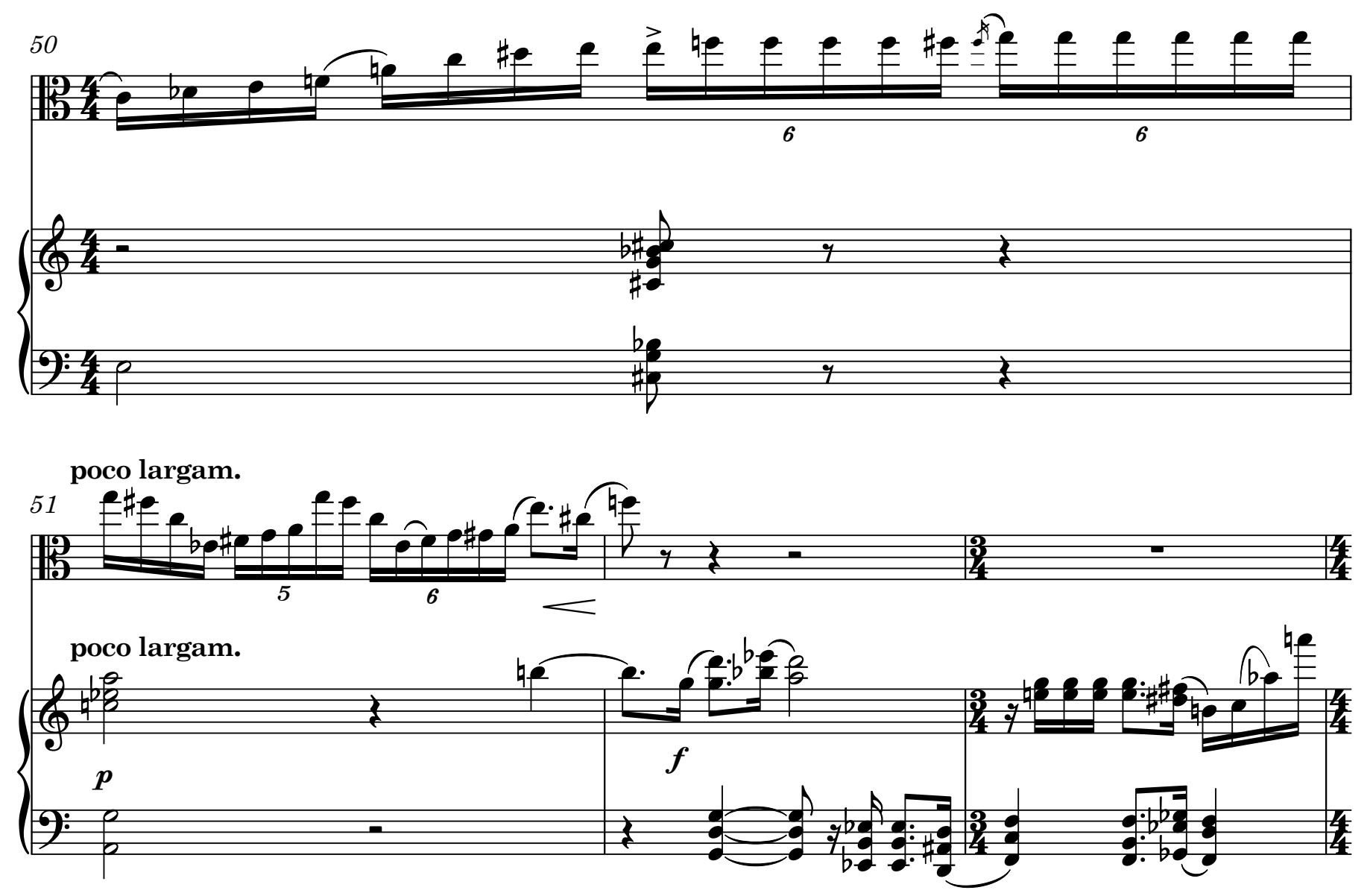

poco sostenuto
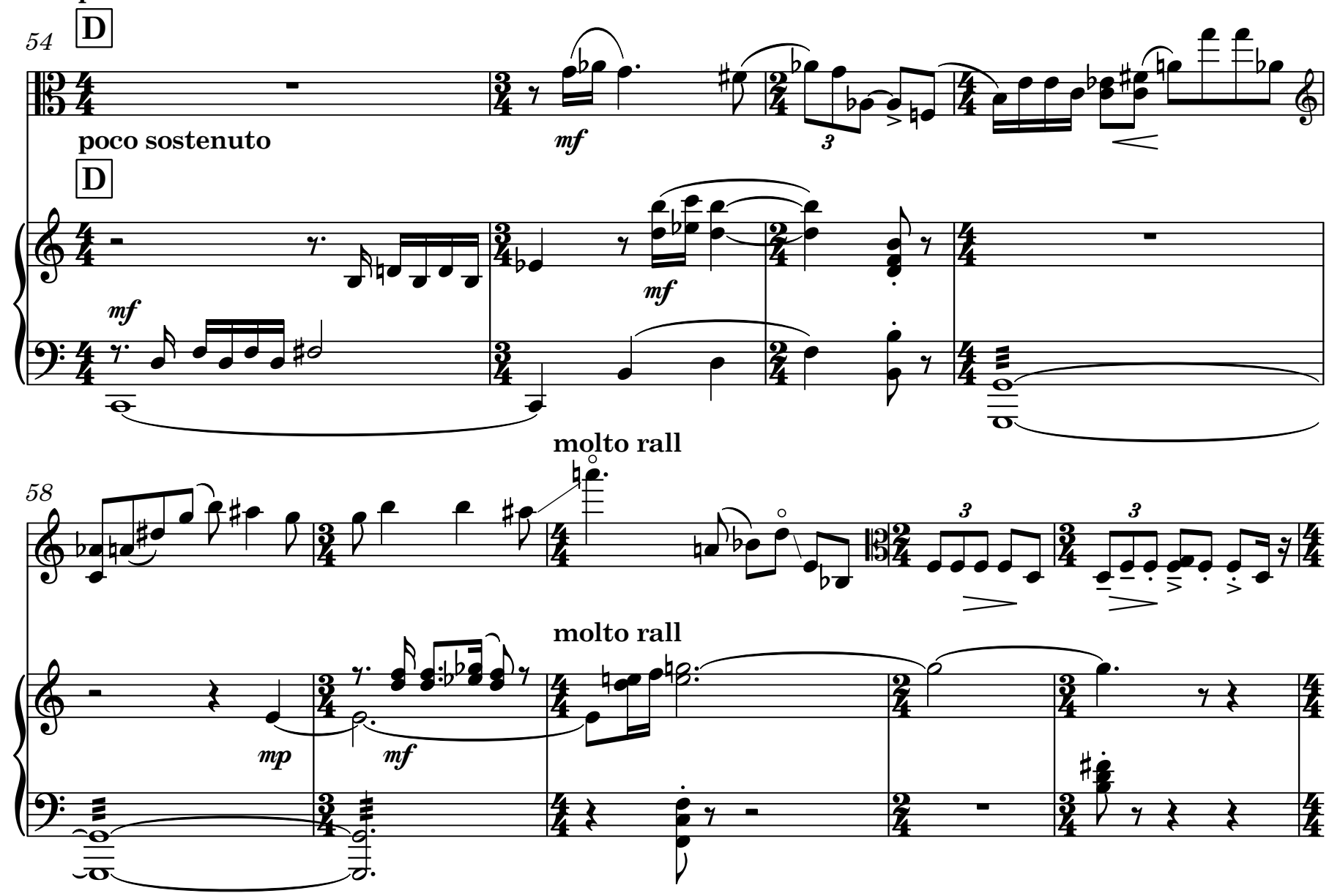
a tempo

$63 \mathbf{E}$

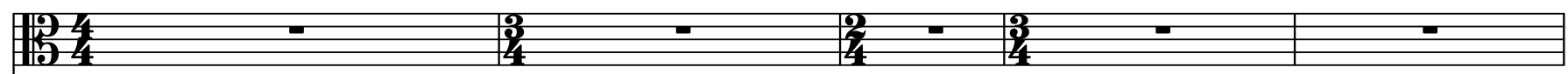
a tempo
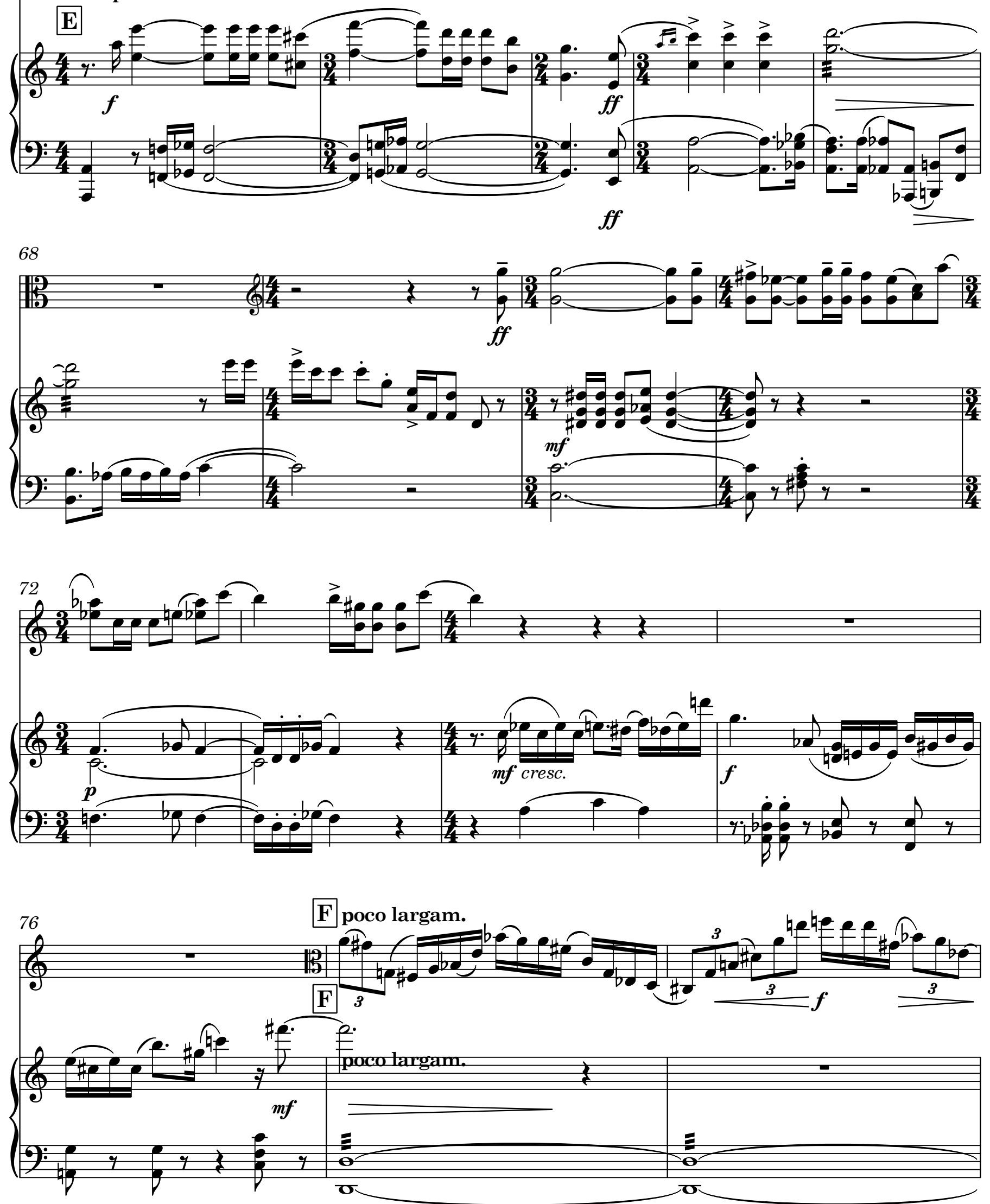

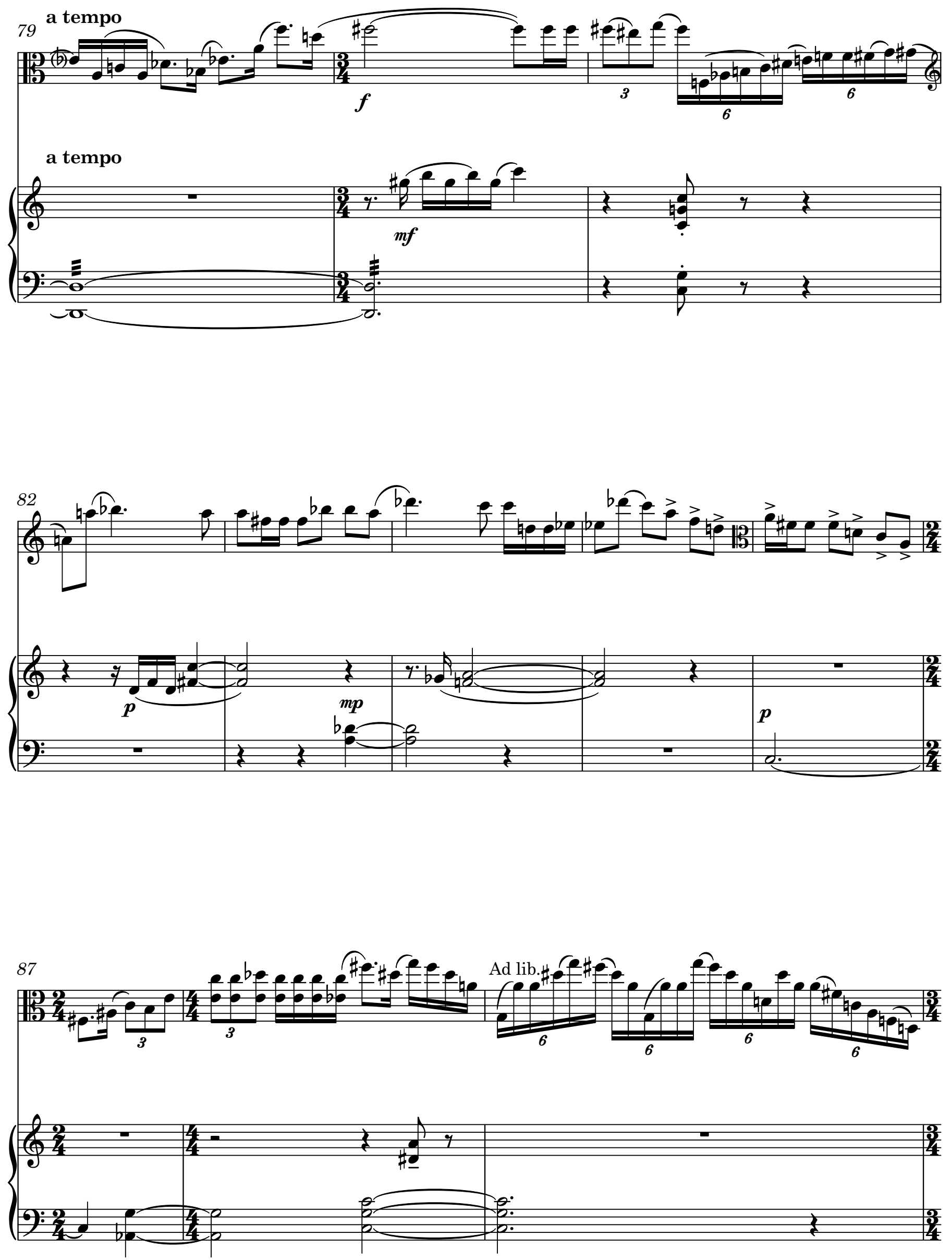
$90 \quad \mathbf{G}$
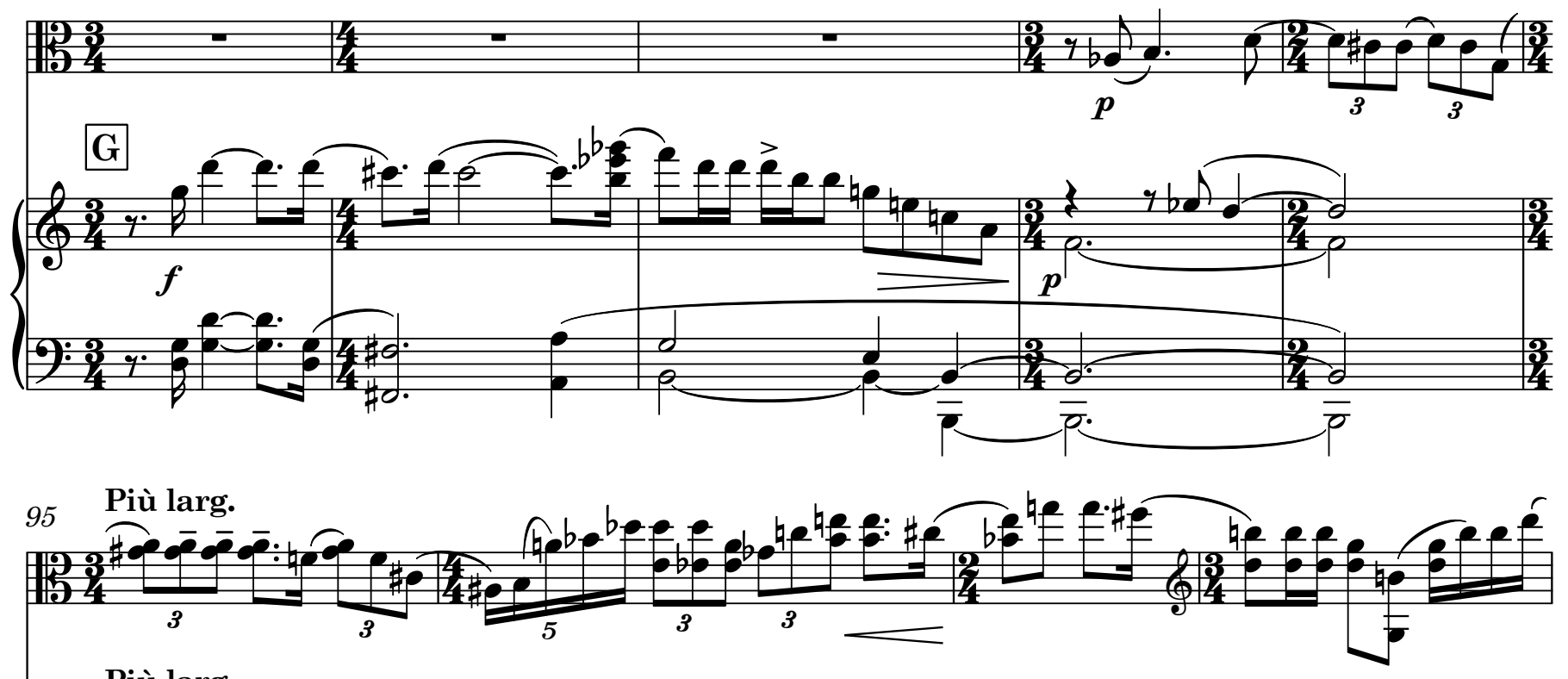
Più larg.
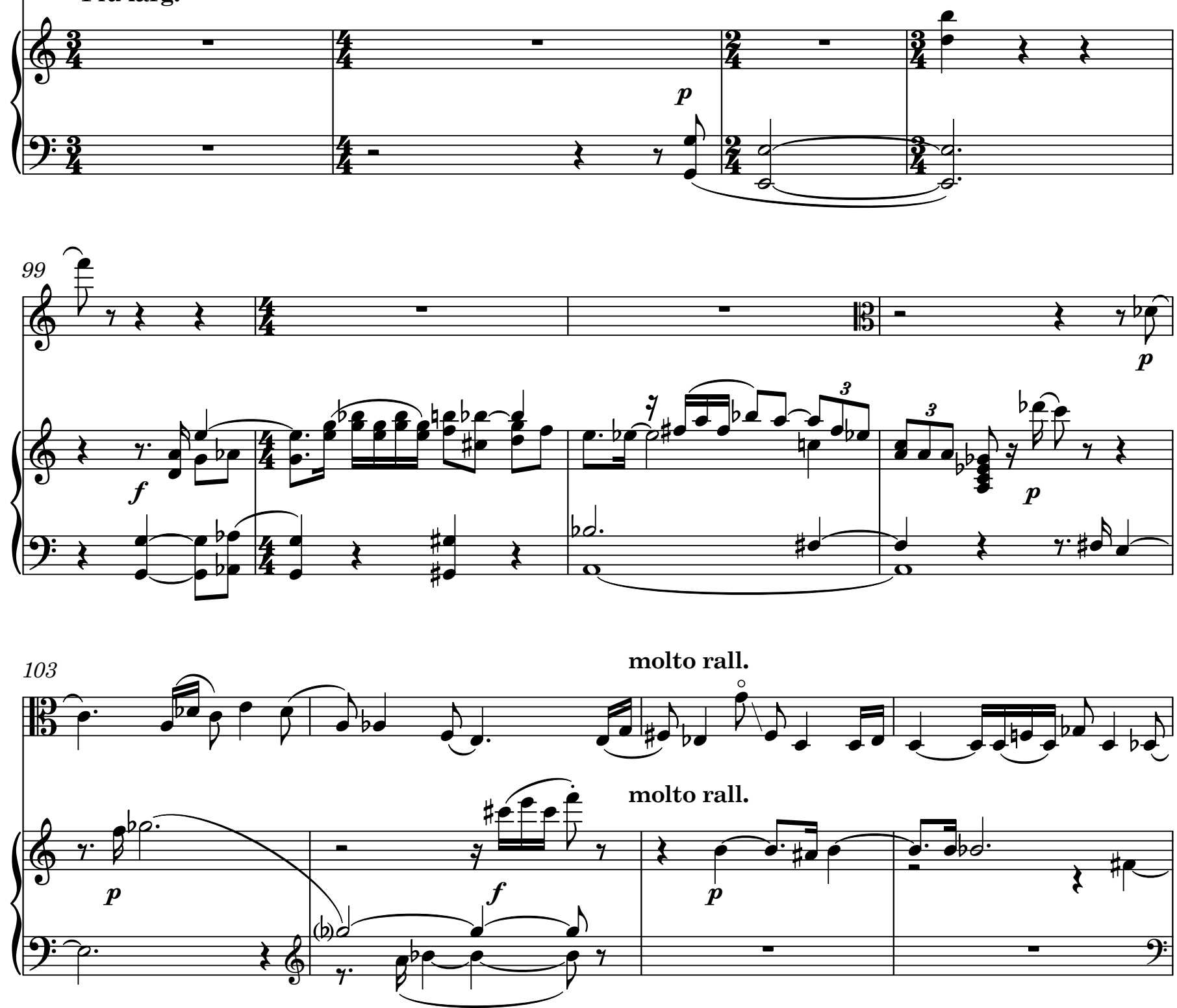
$\mathbf{H}$

107 a tempo
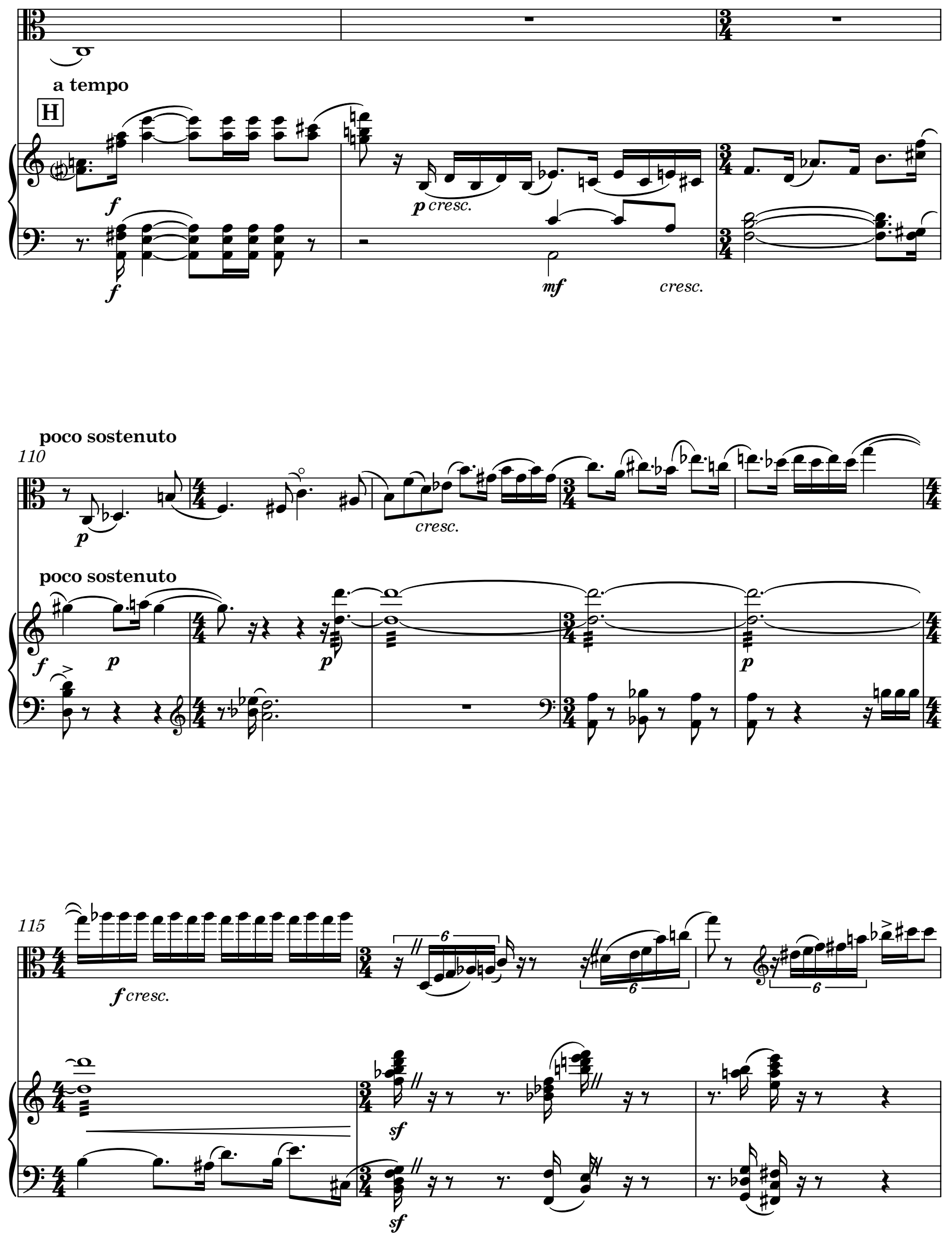


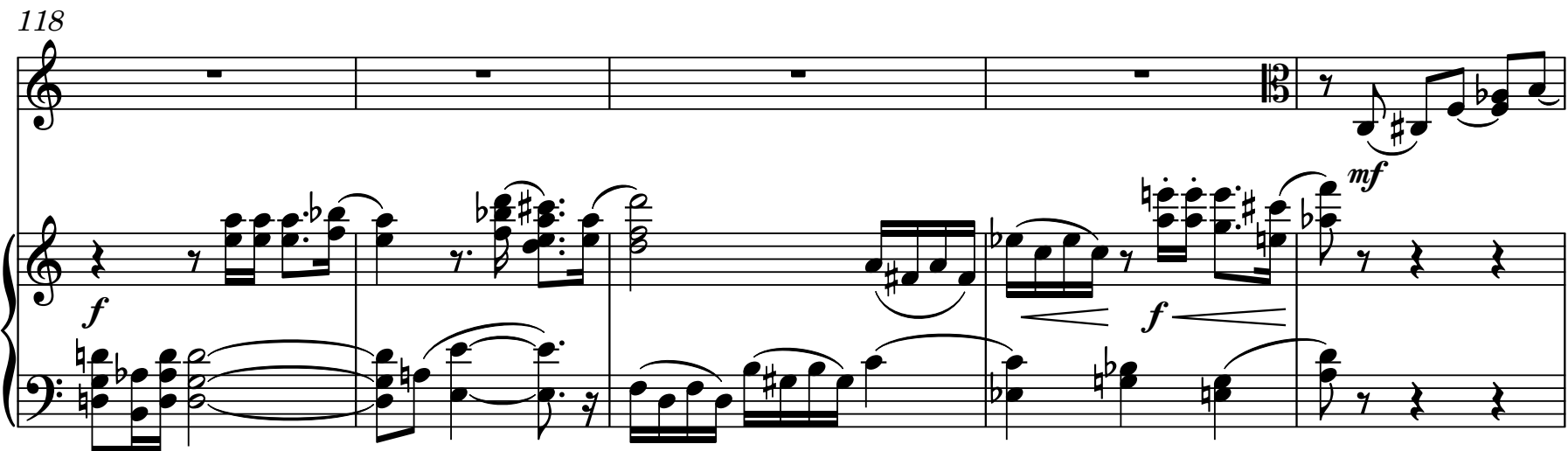

I

cresc.
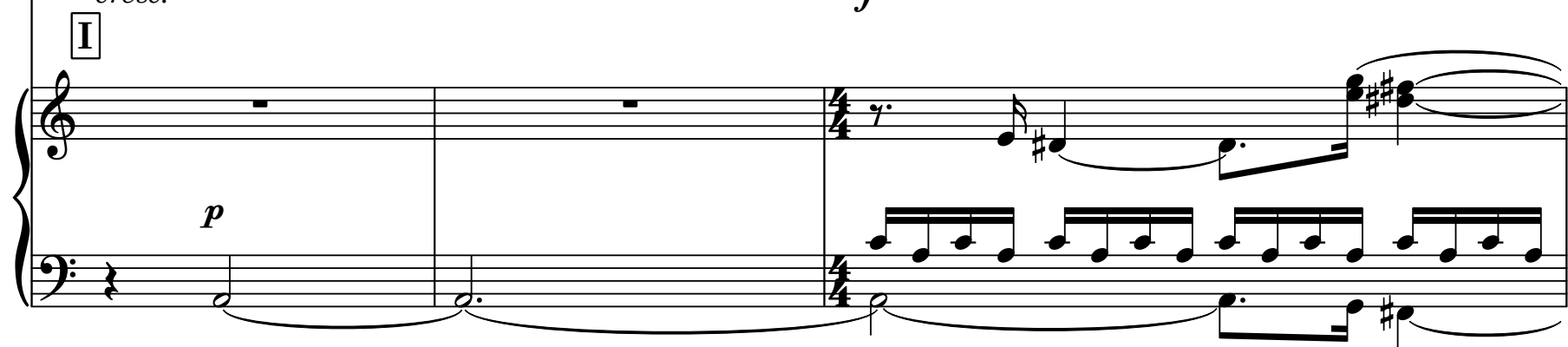

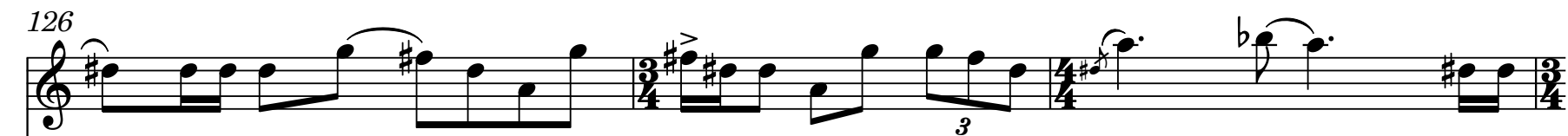

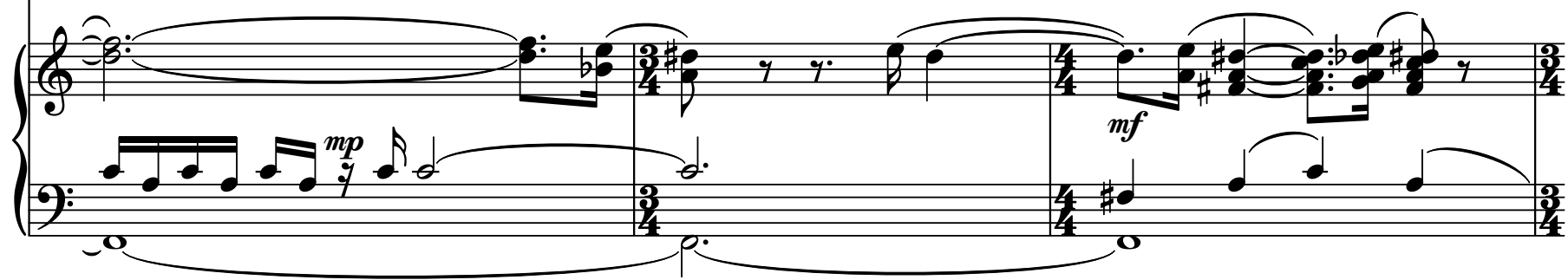

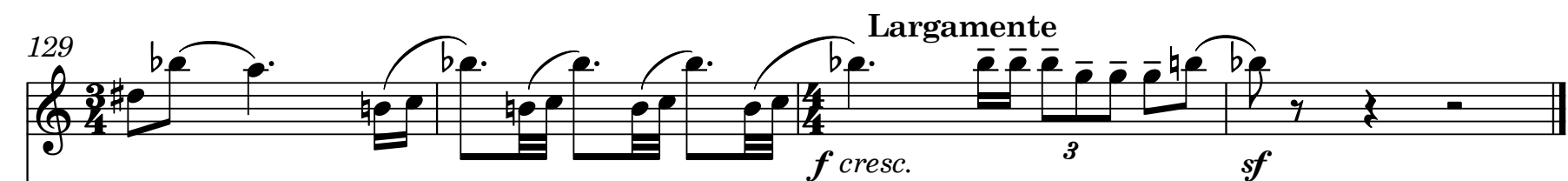

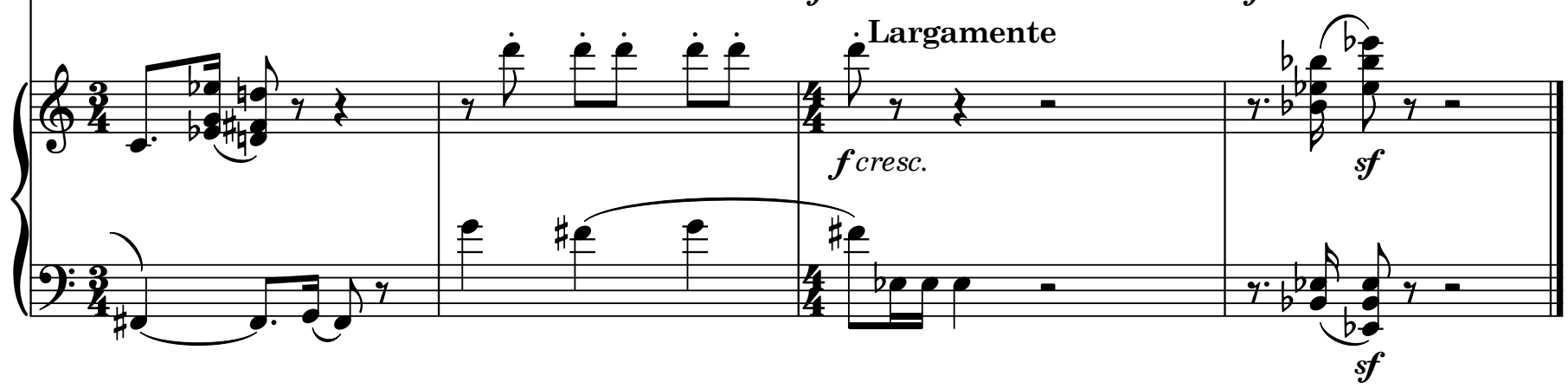




\section{II.}

Andantino $\delta=75$
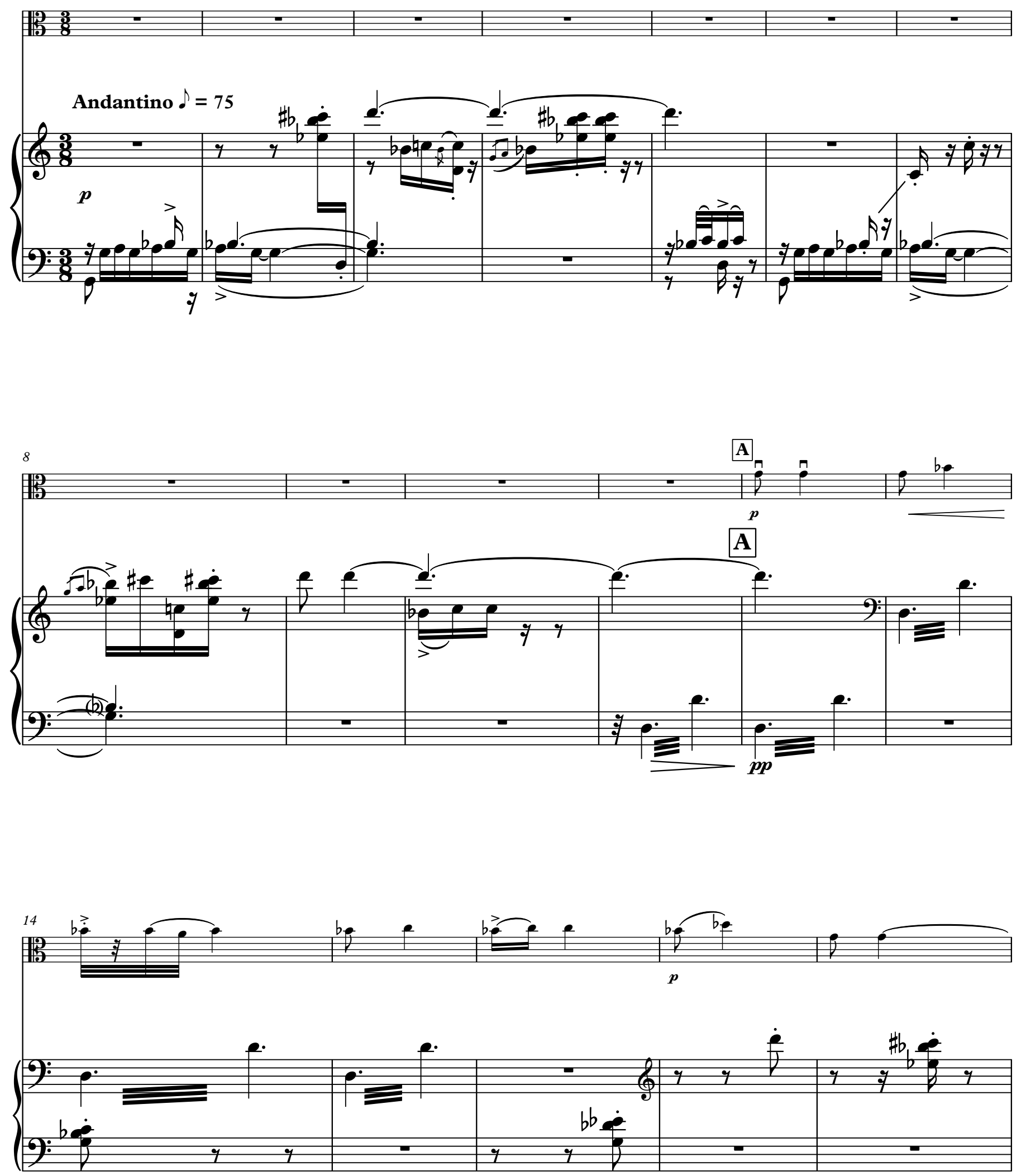

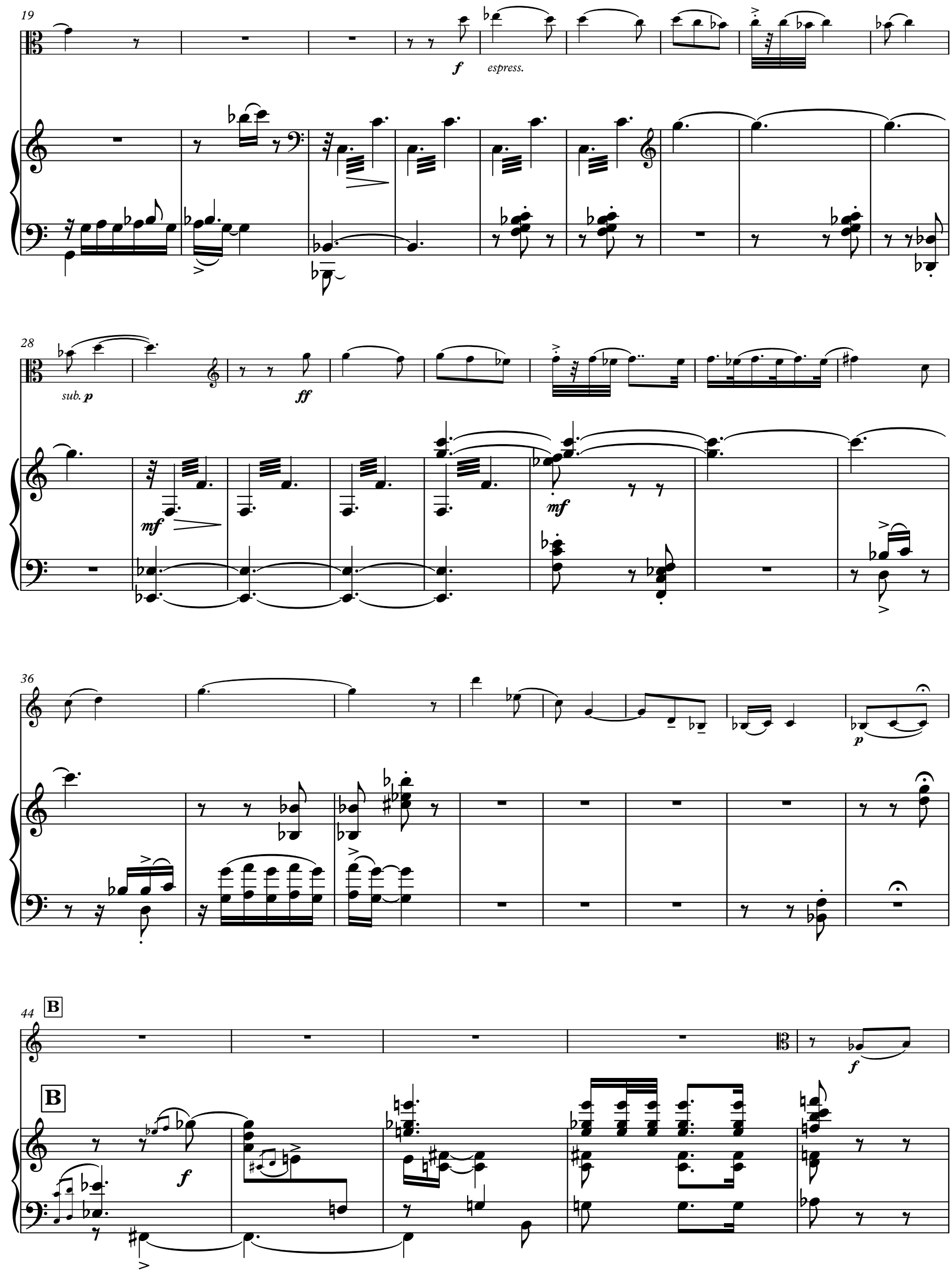


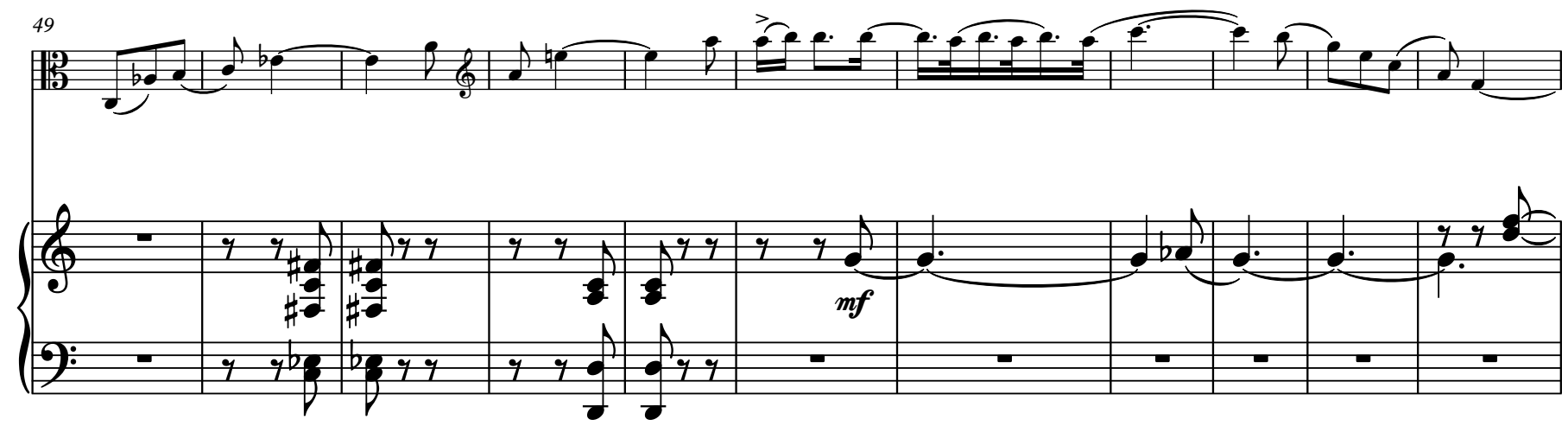

C
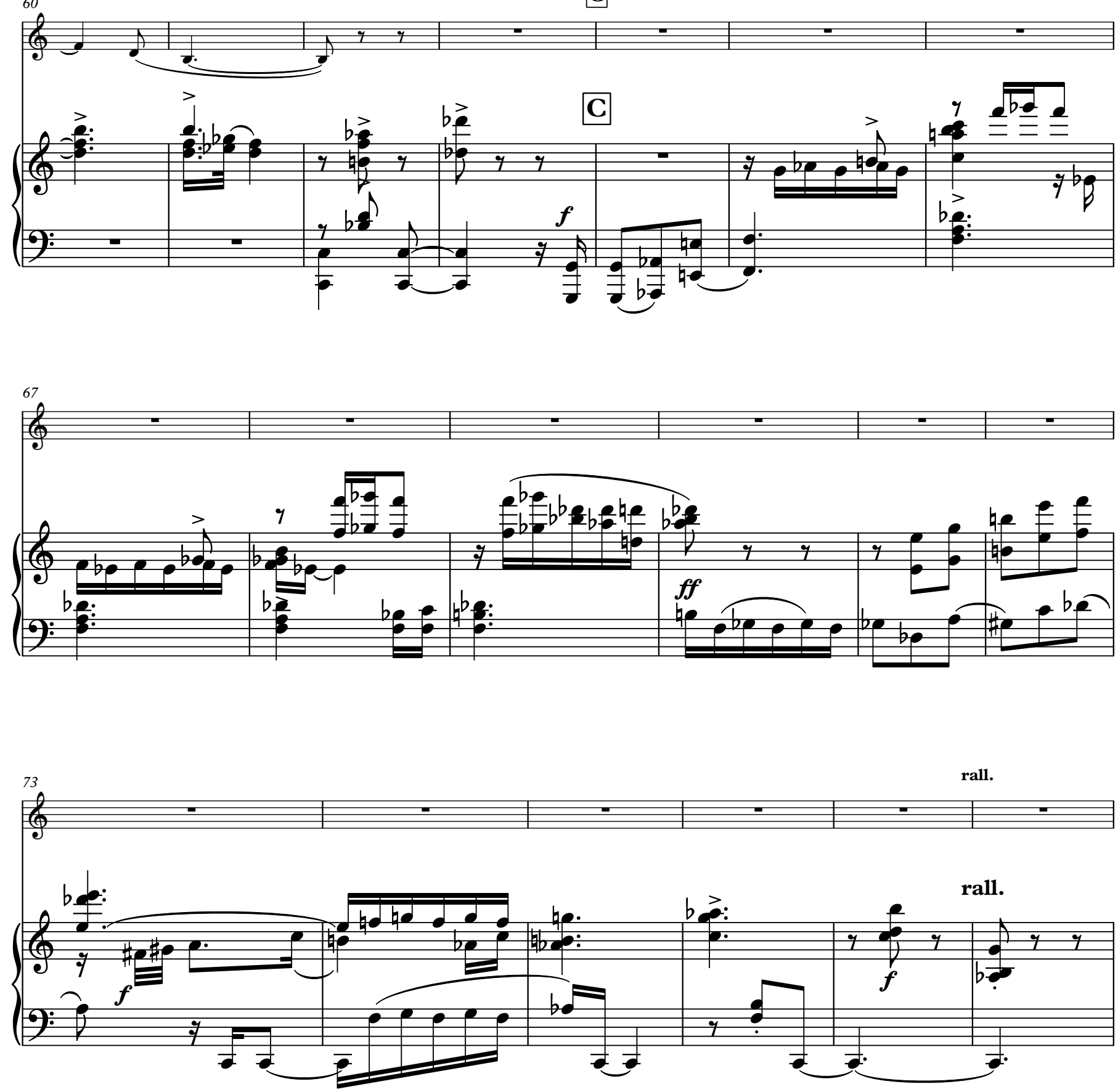
$\oint^{\mathrm{D} \text { larghetto }}$

D larghetto

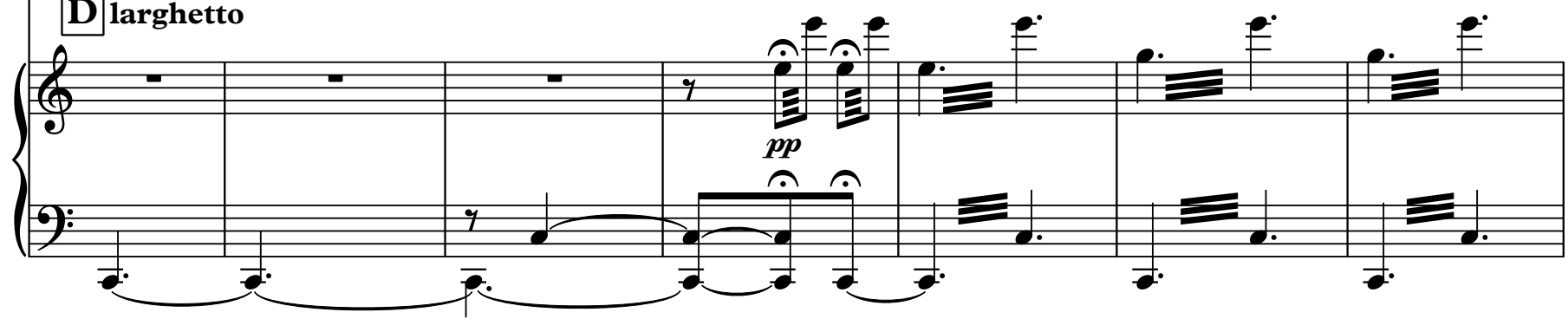

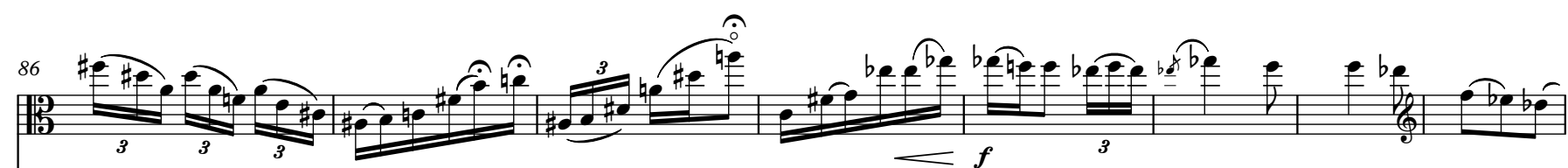
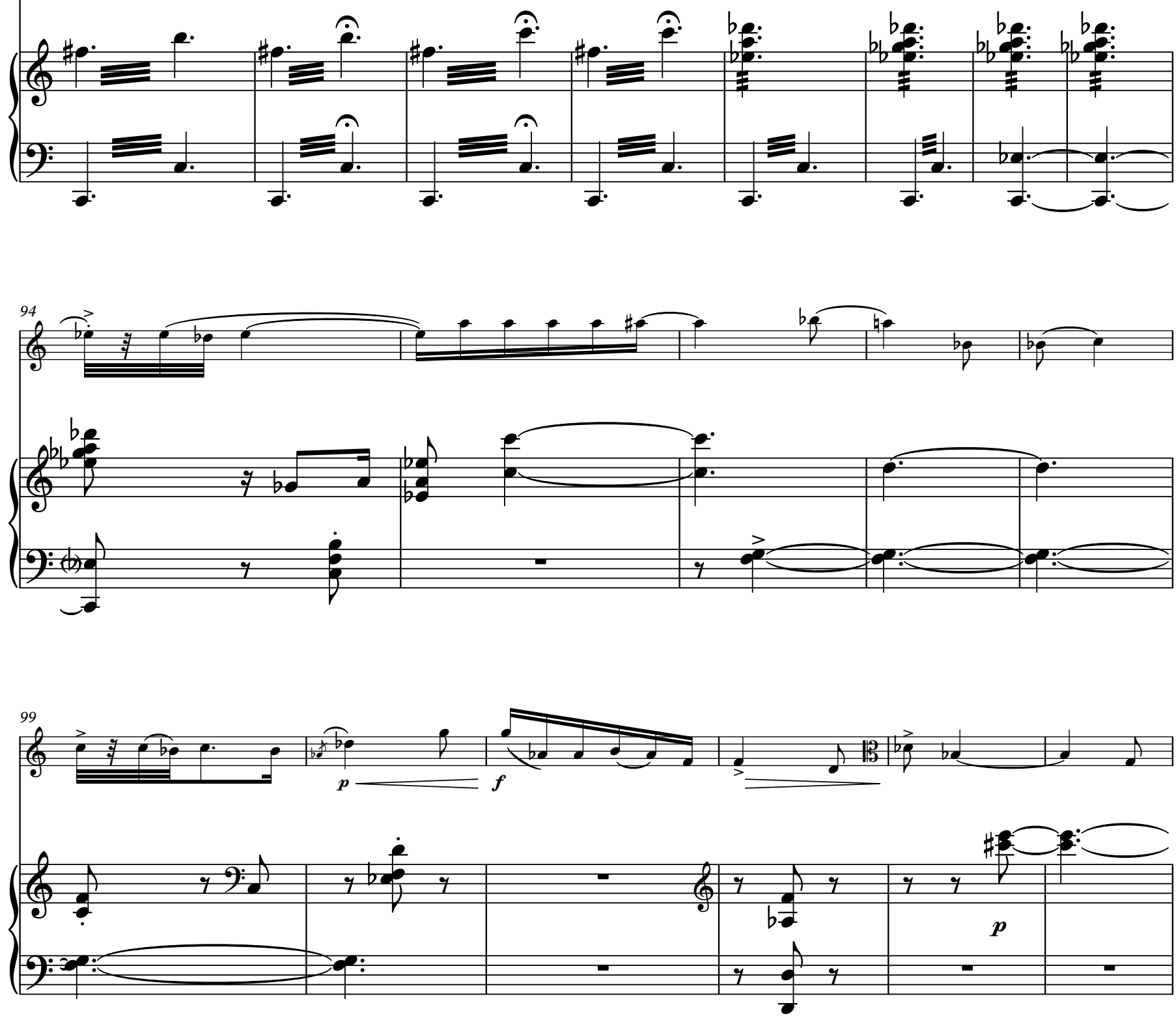

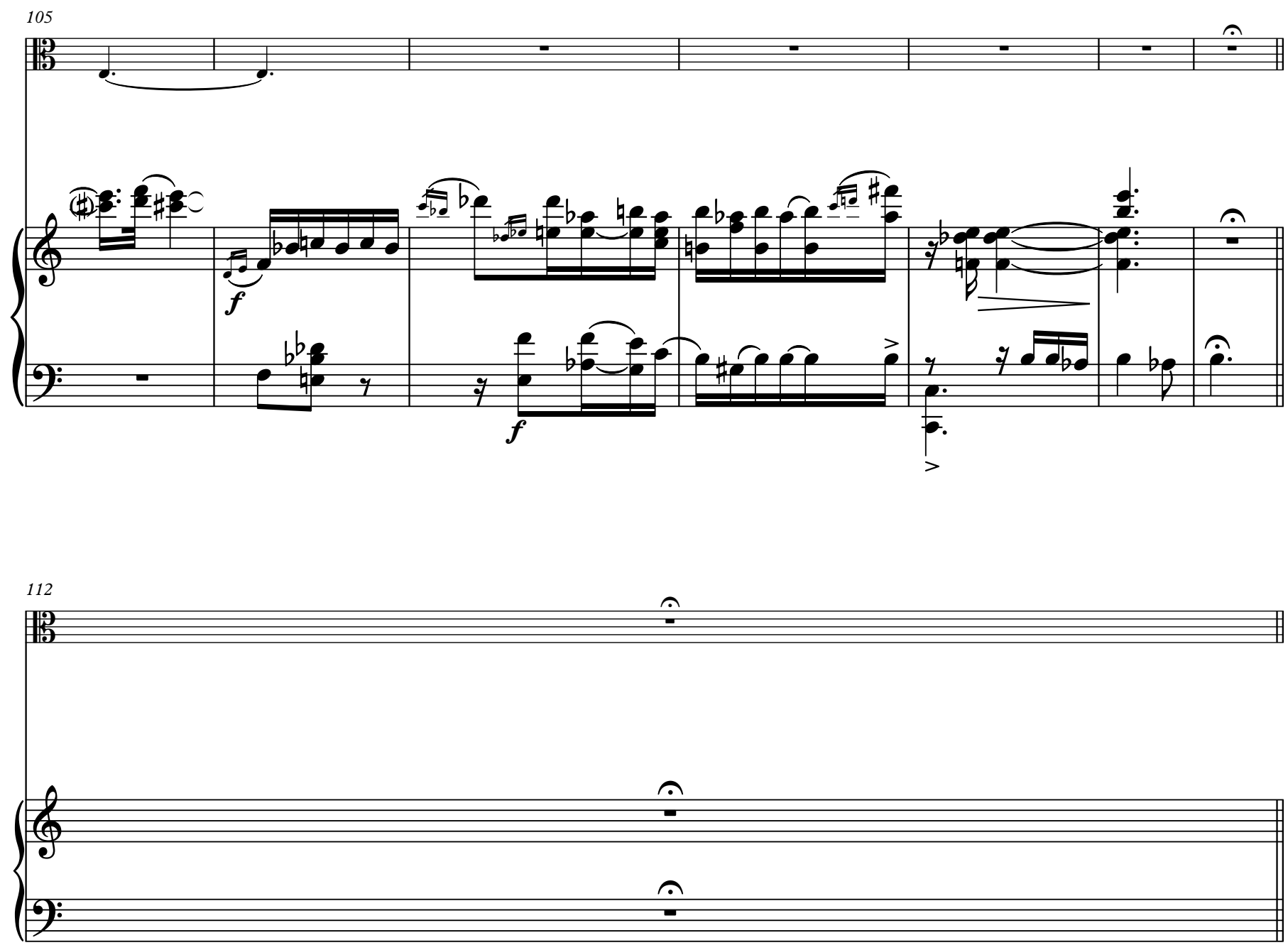

E Kadenz

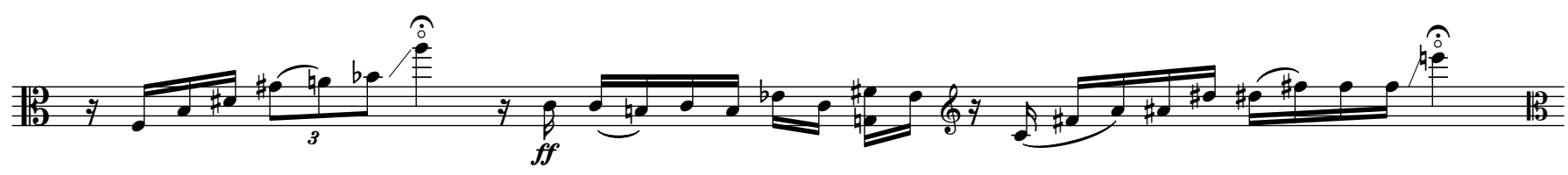

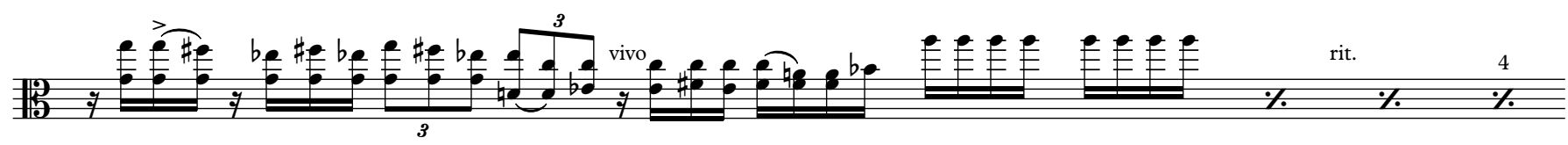




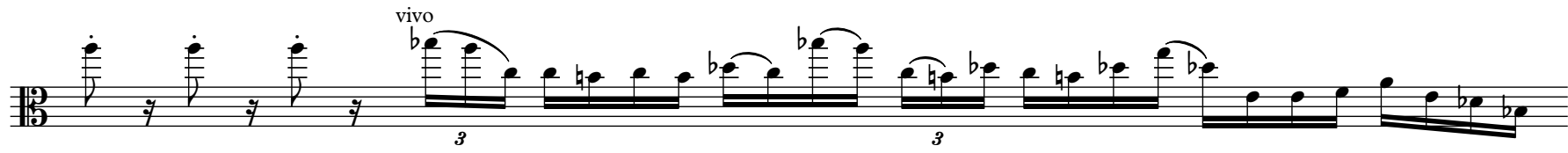

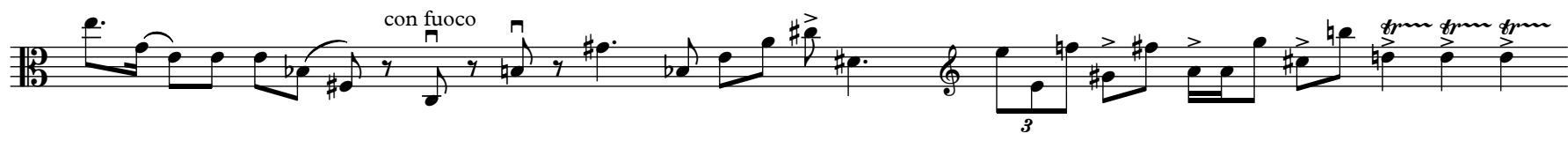

(a)

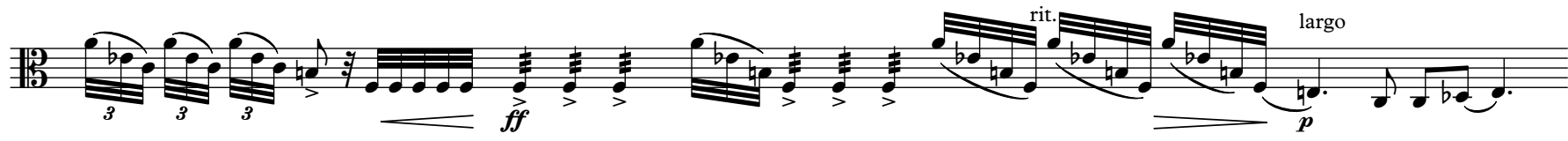

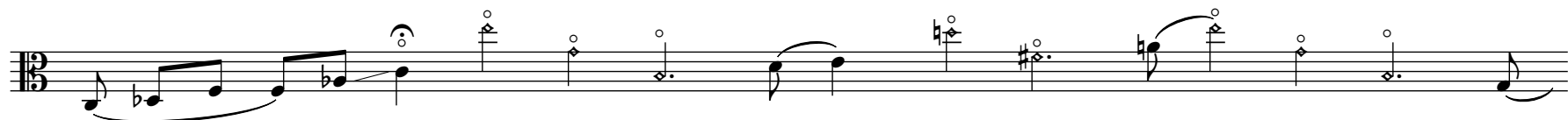

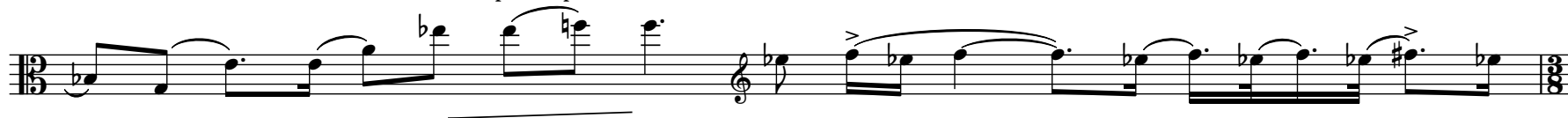

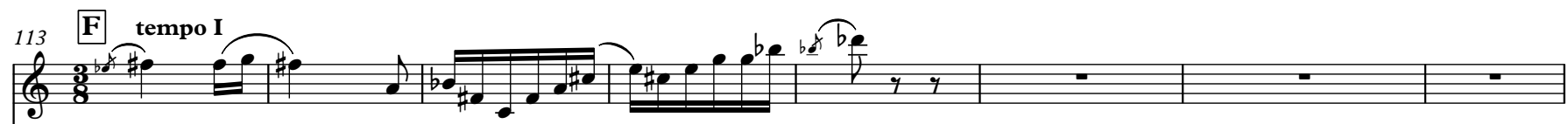

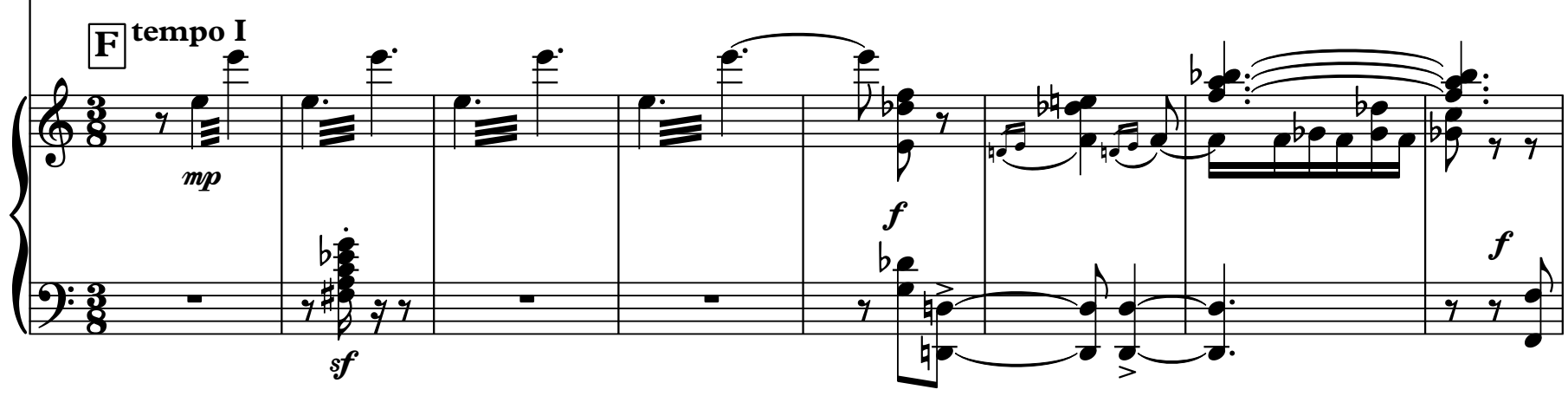



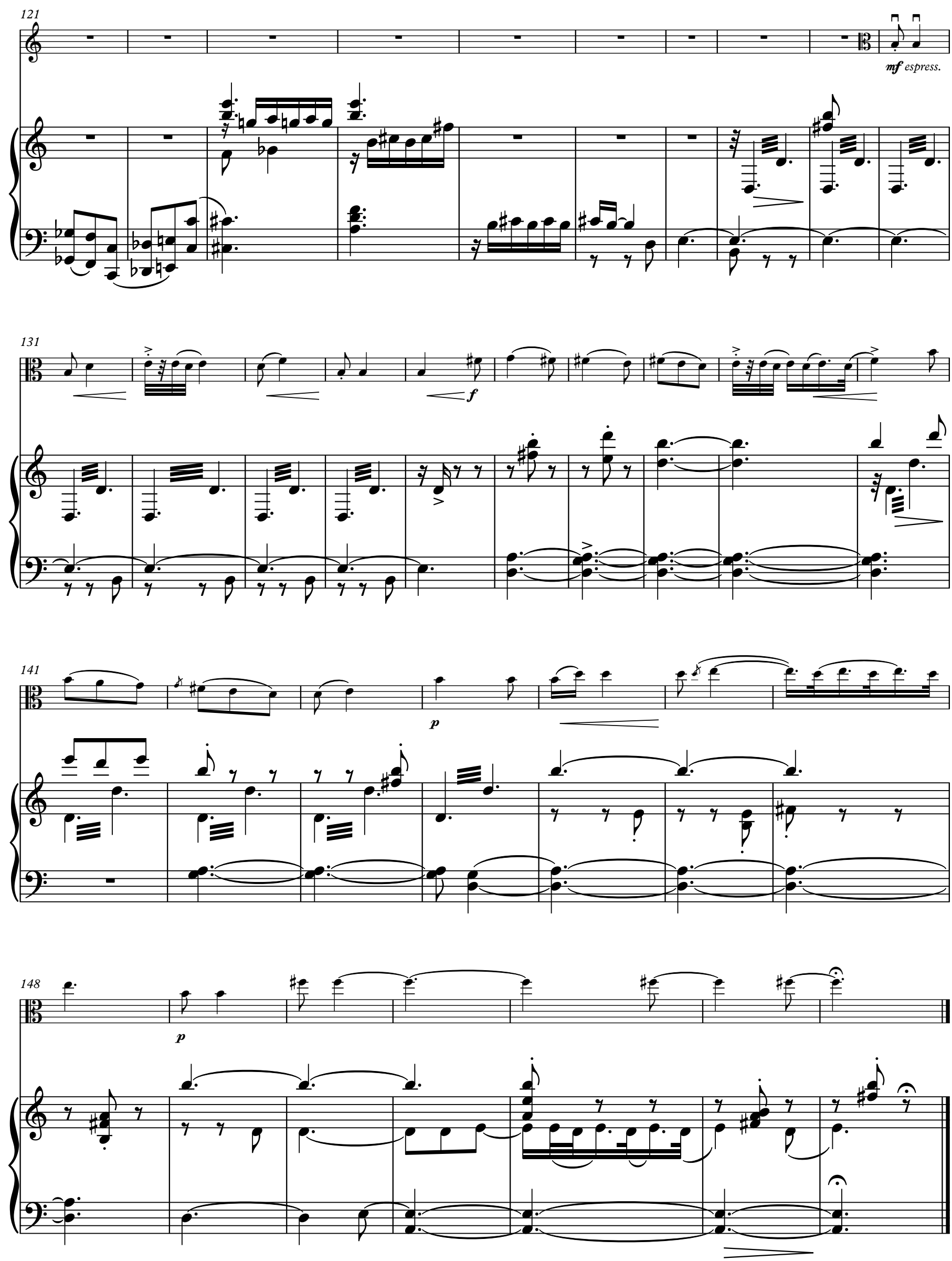


\section{III.}
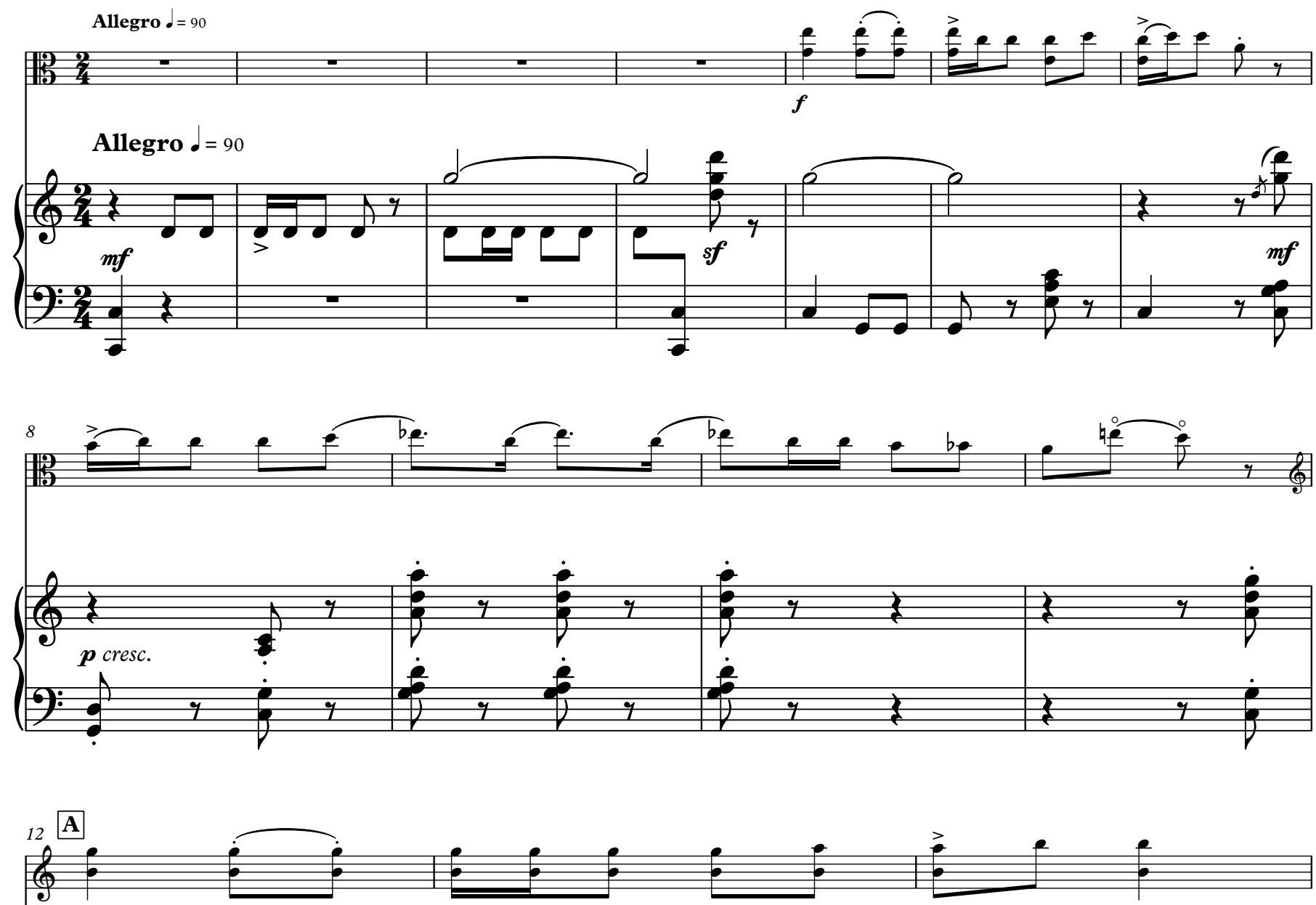

A
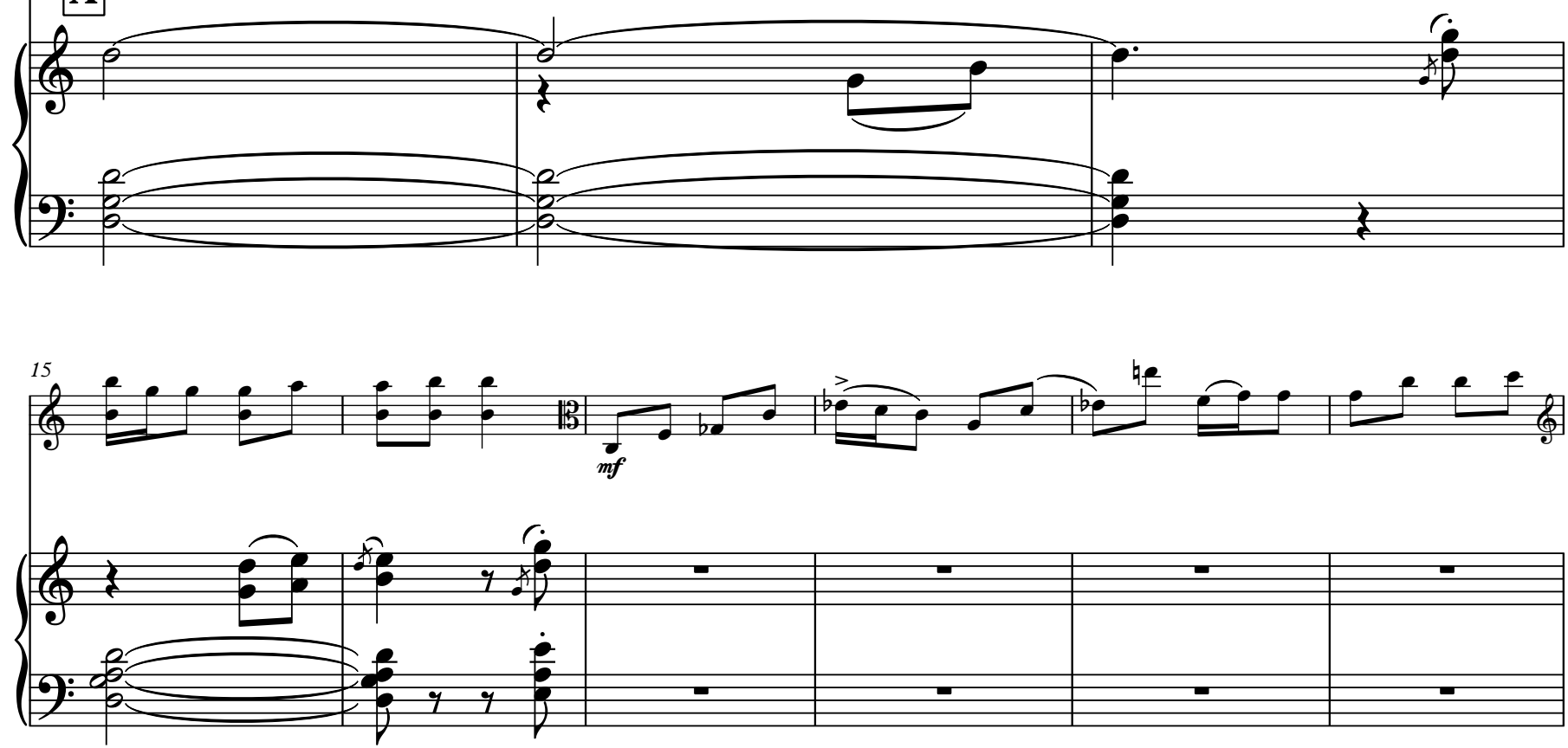

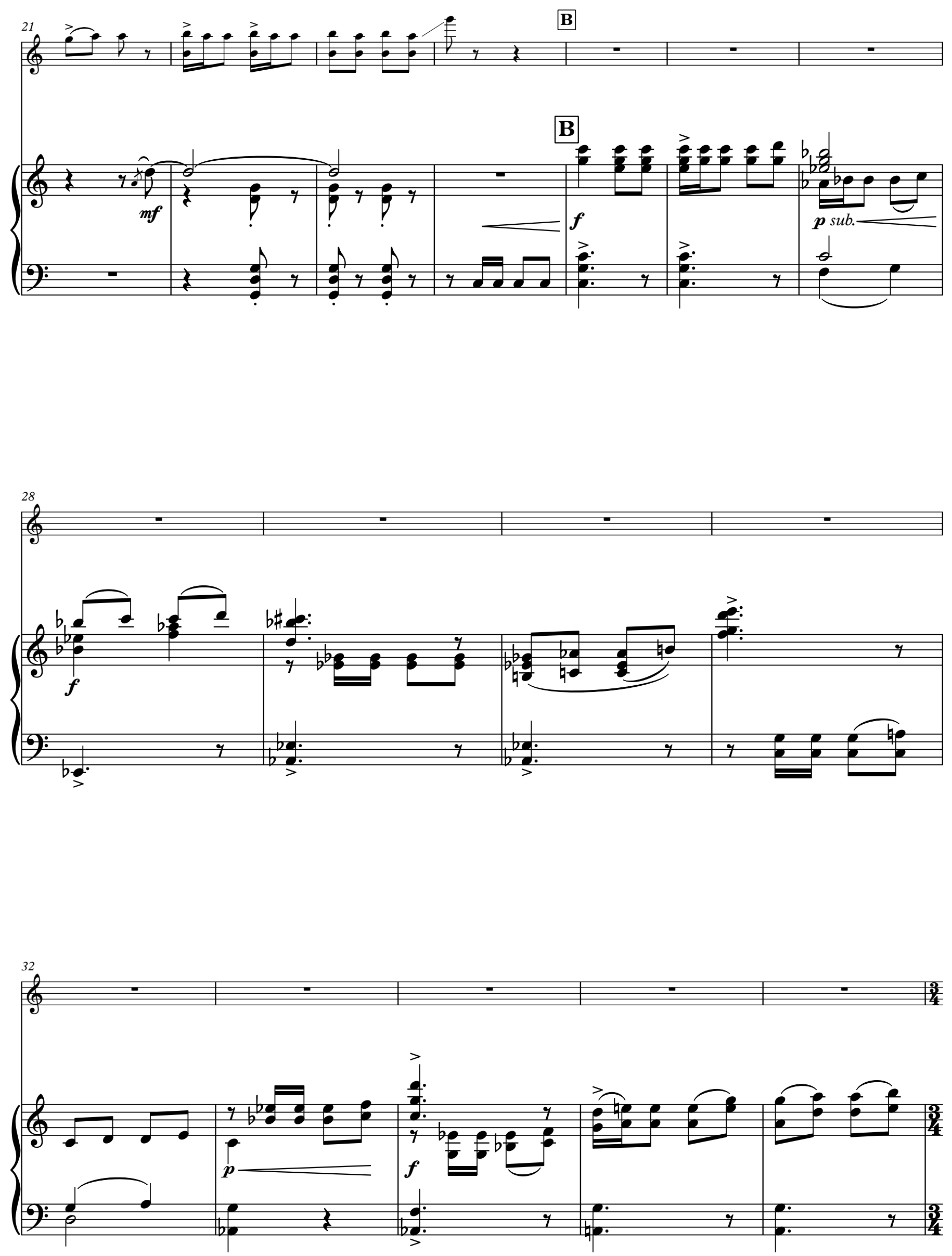

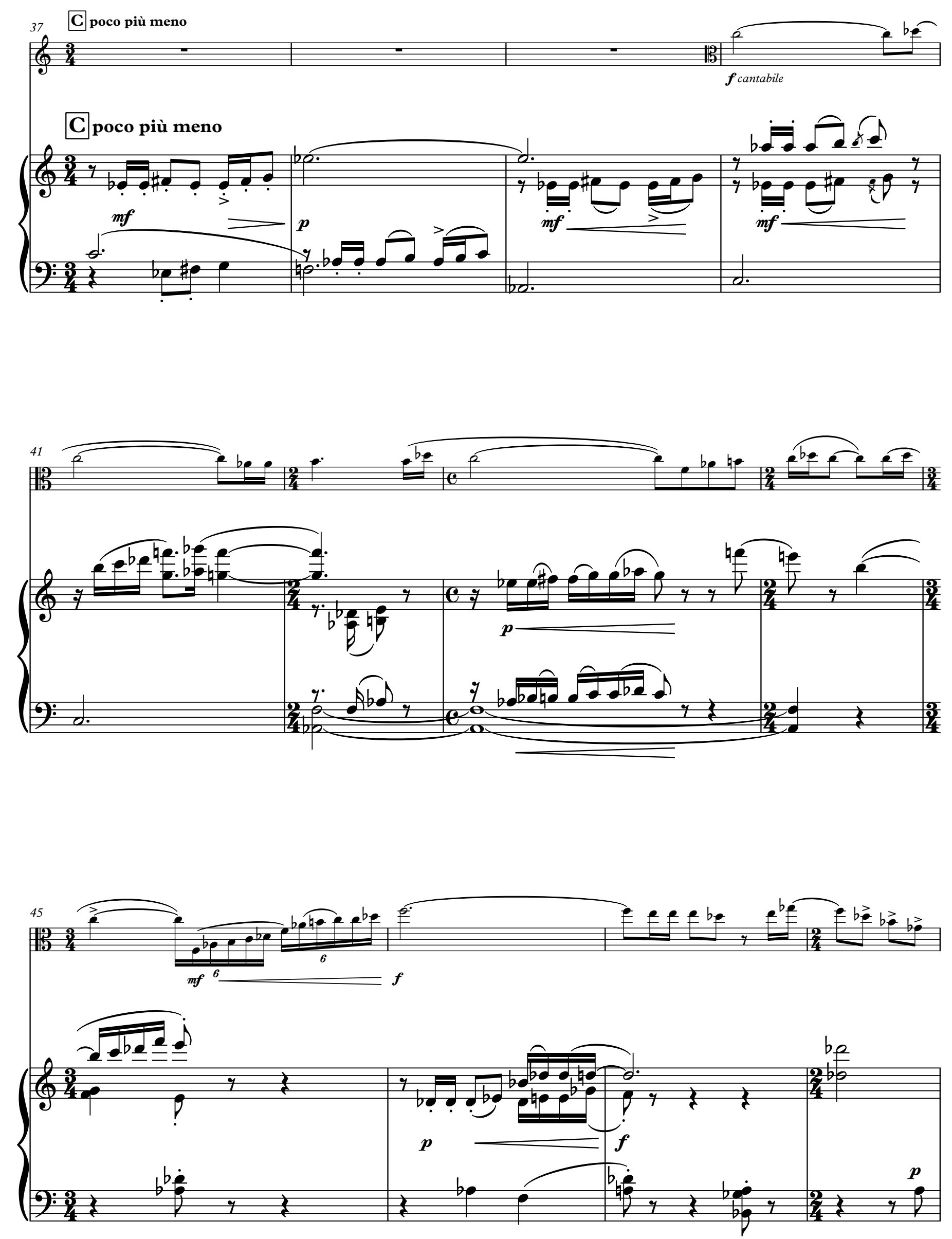

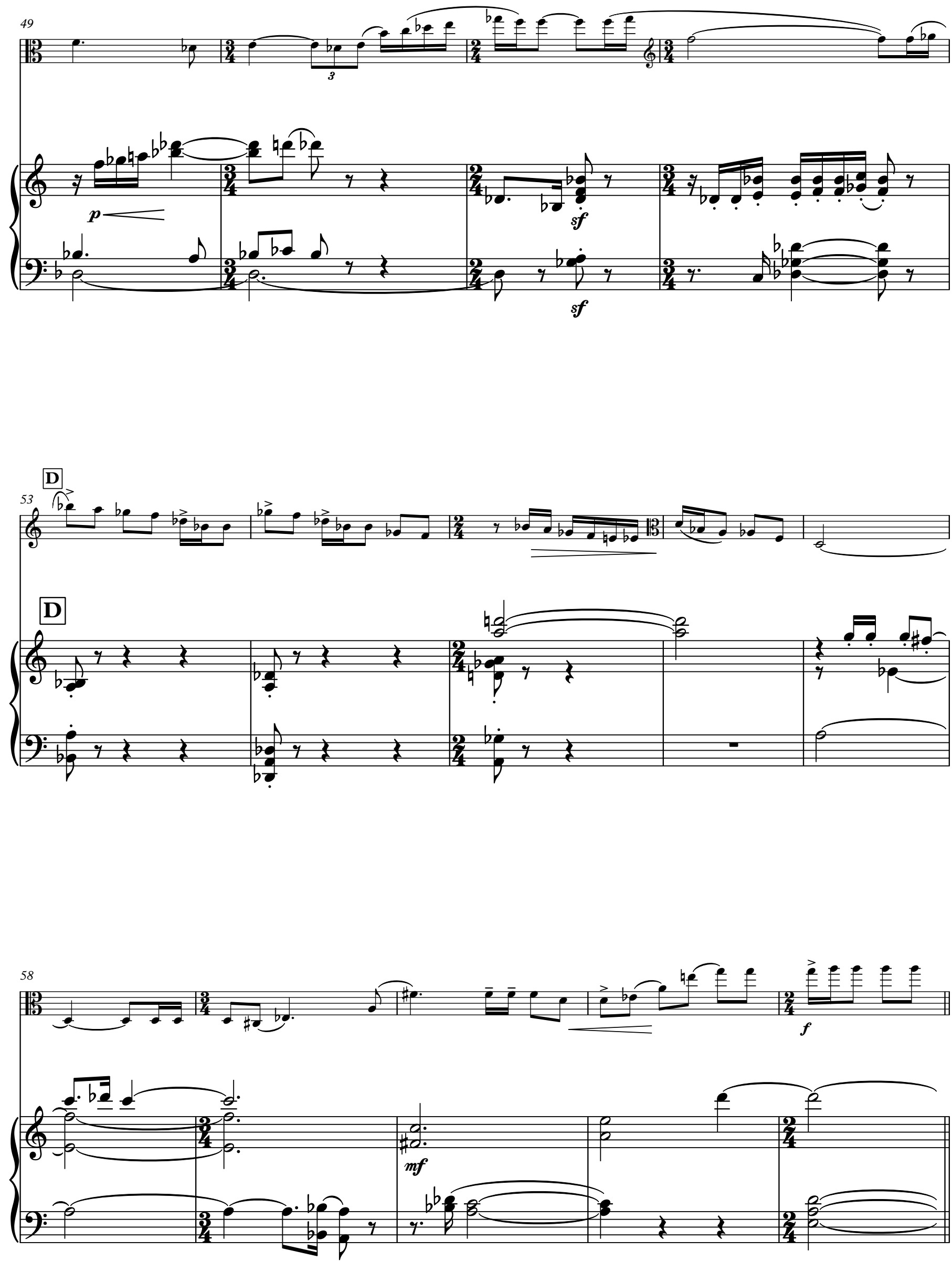

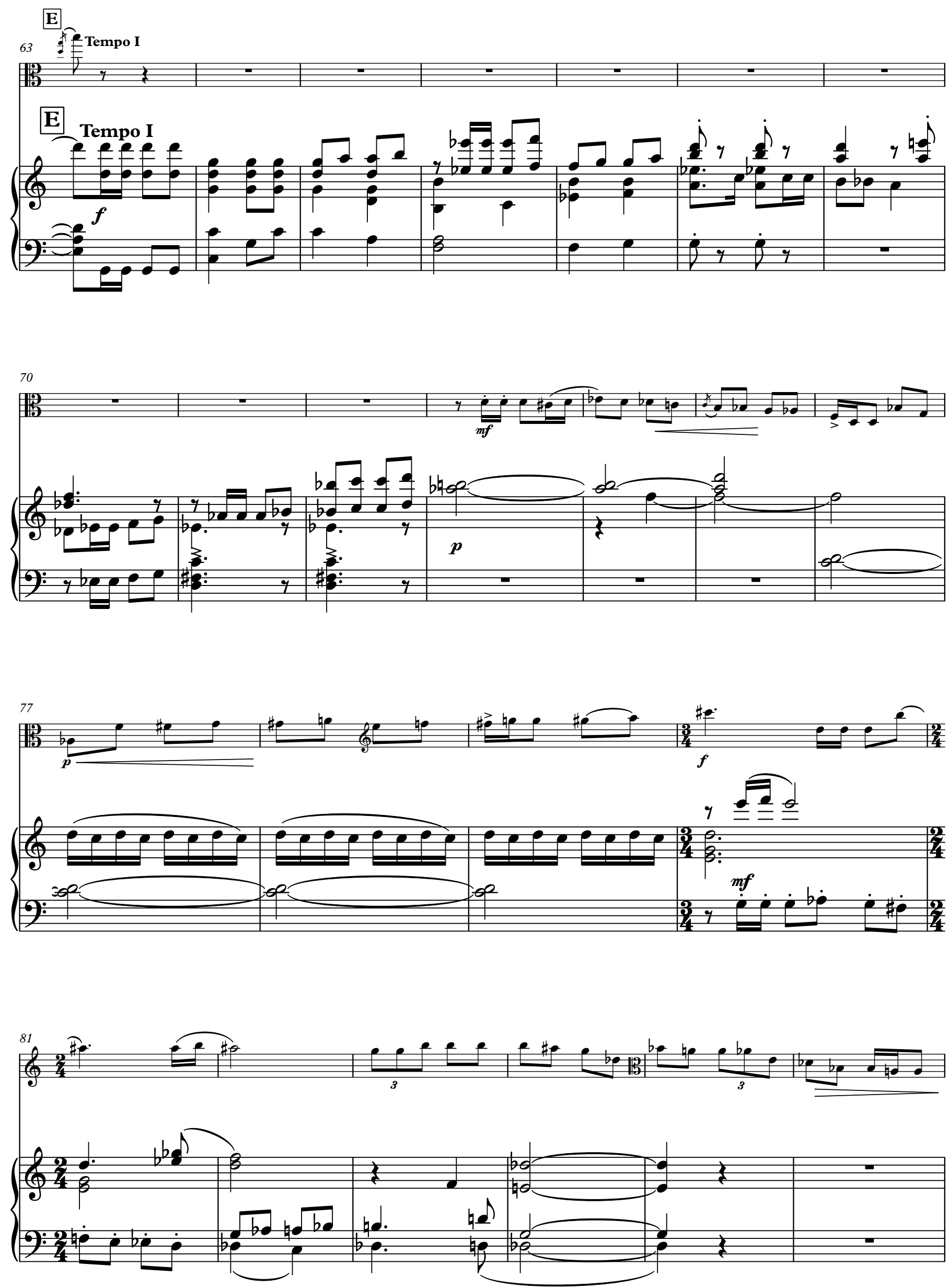

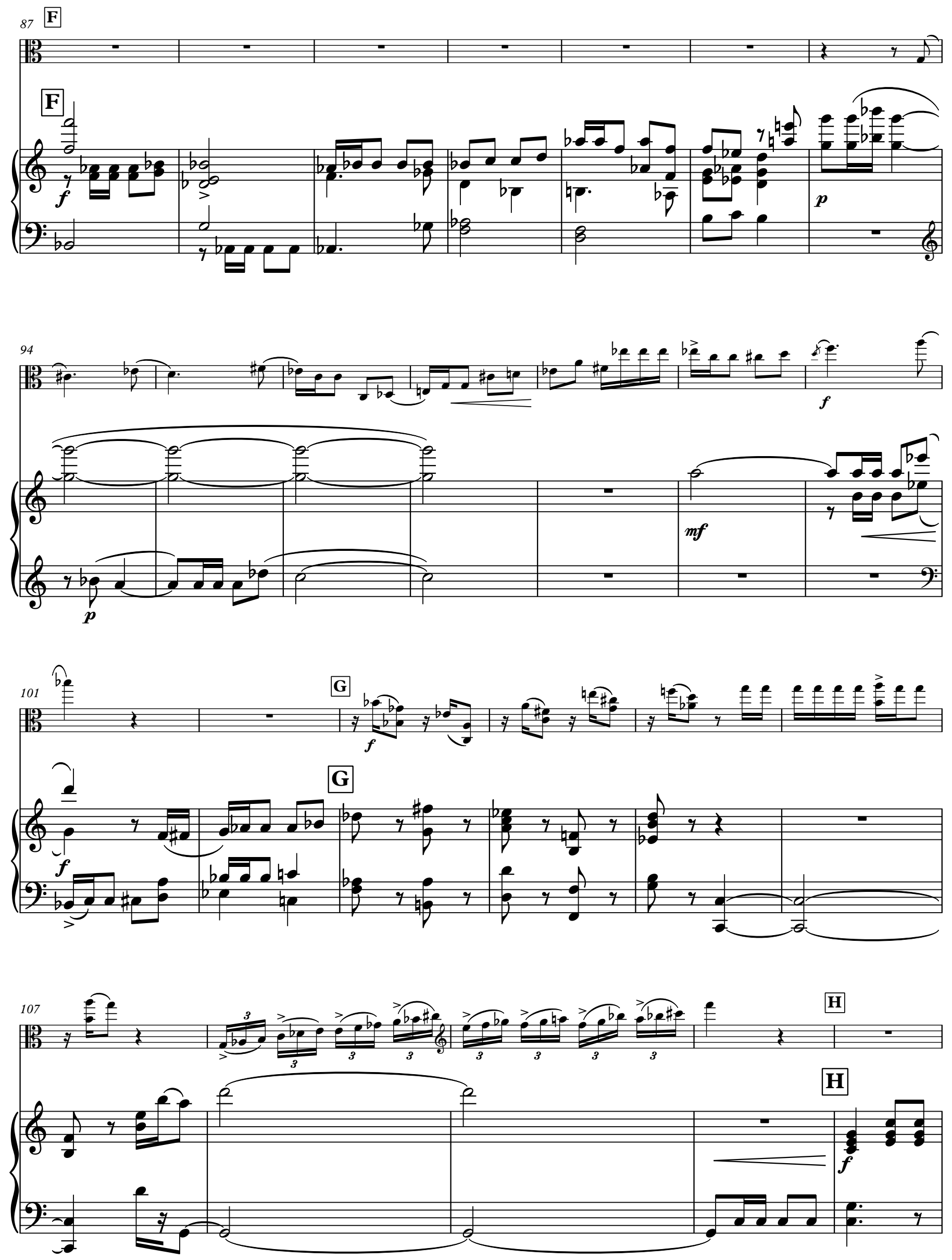

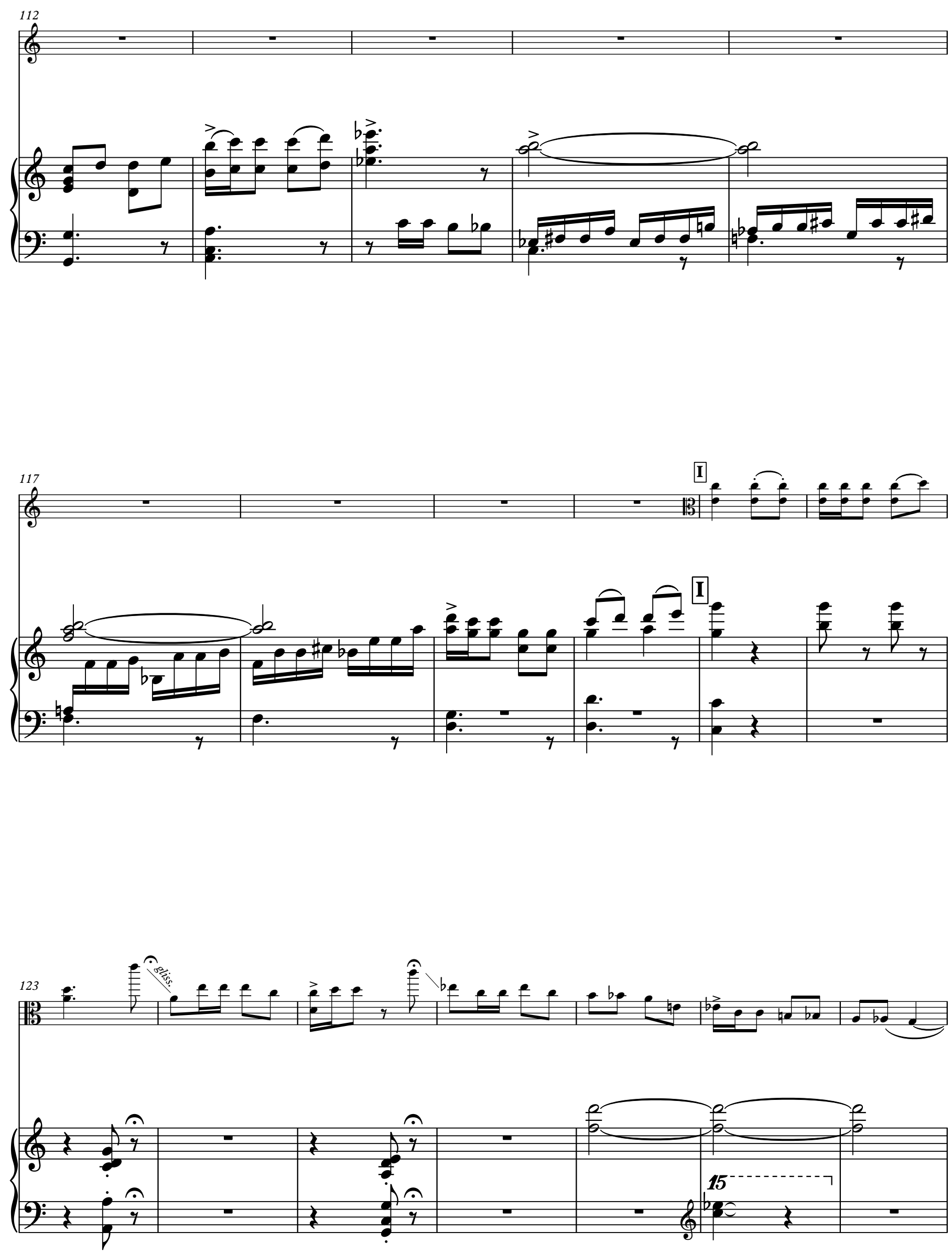

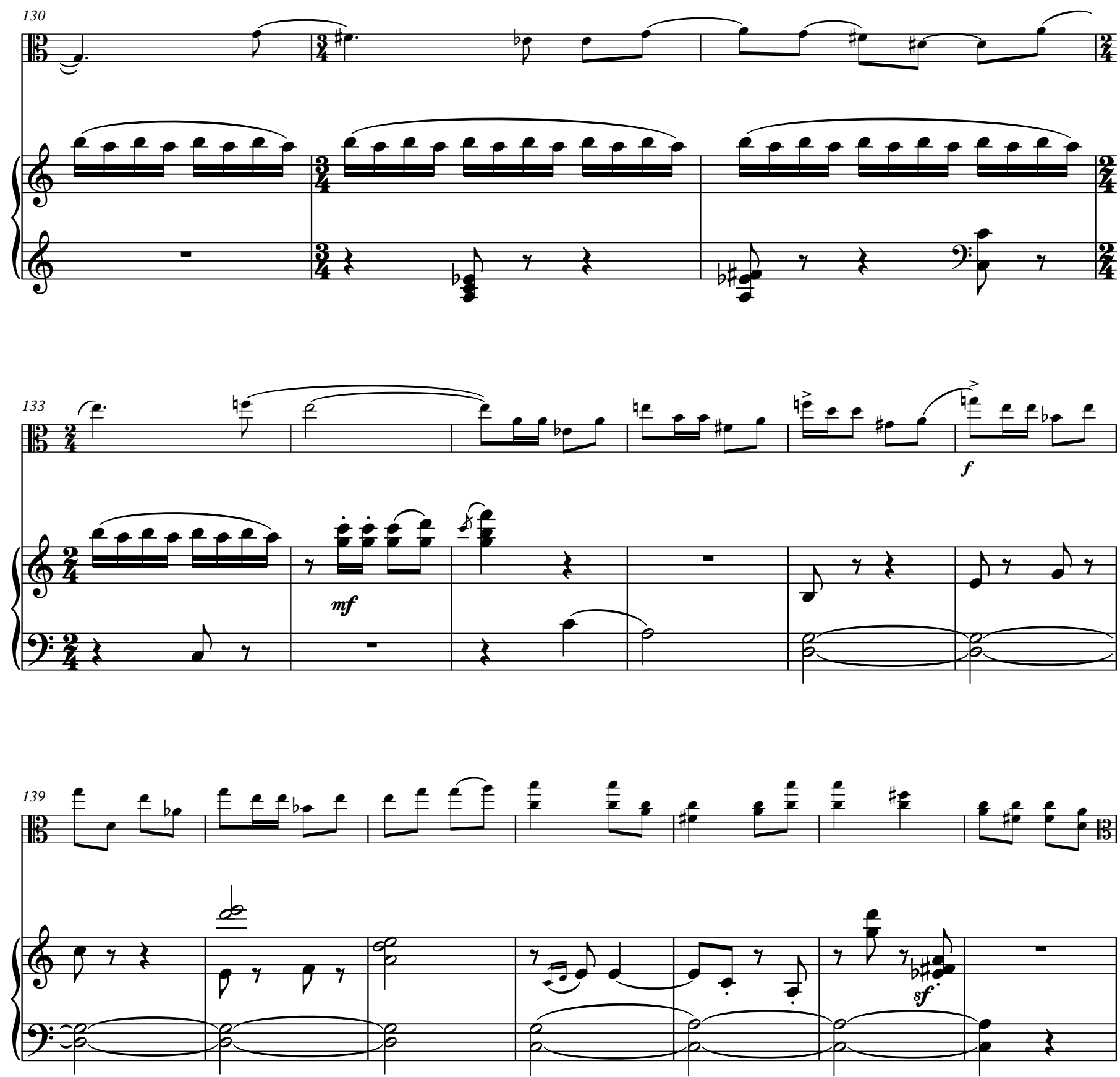

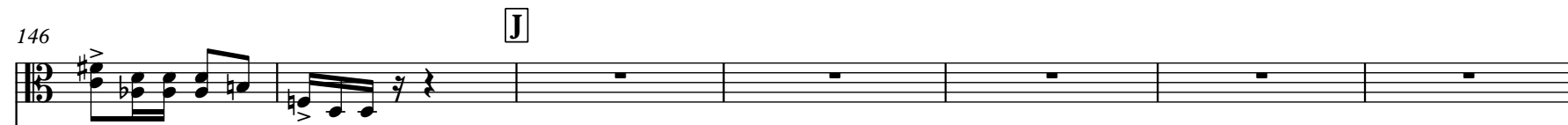

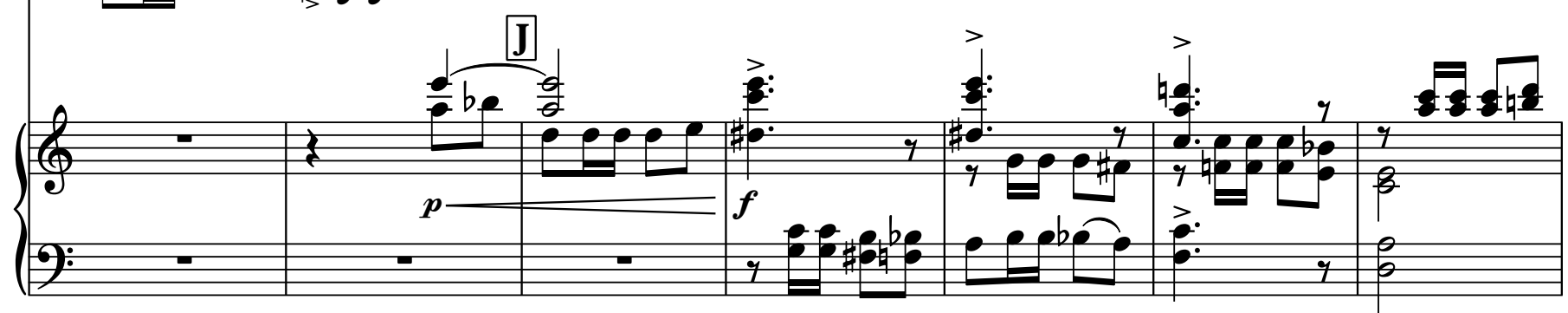



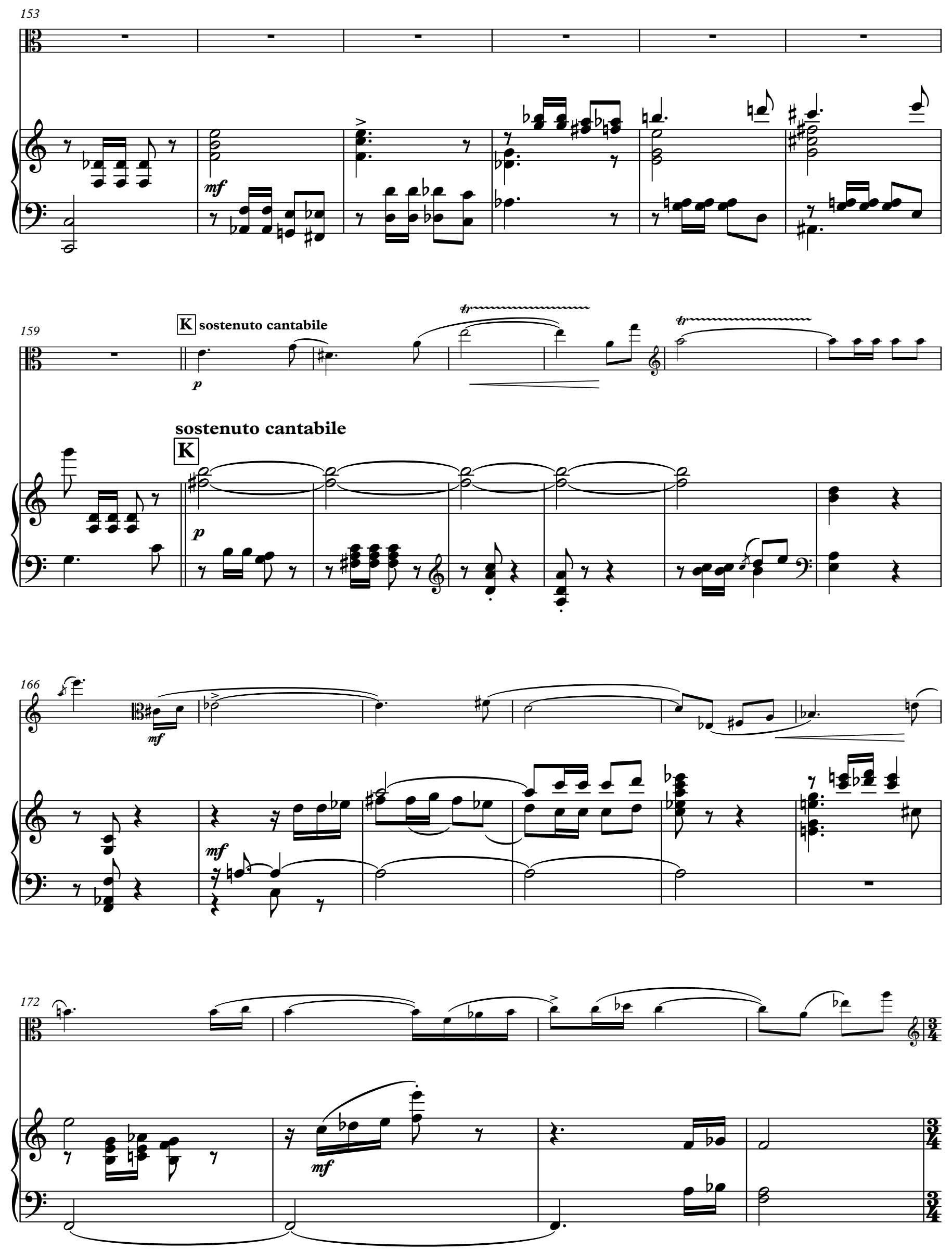

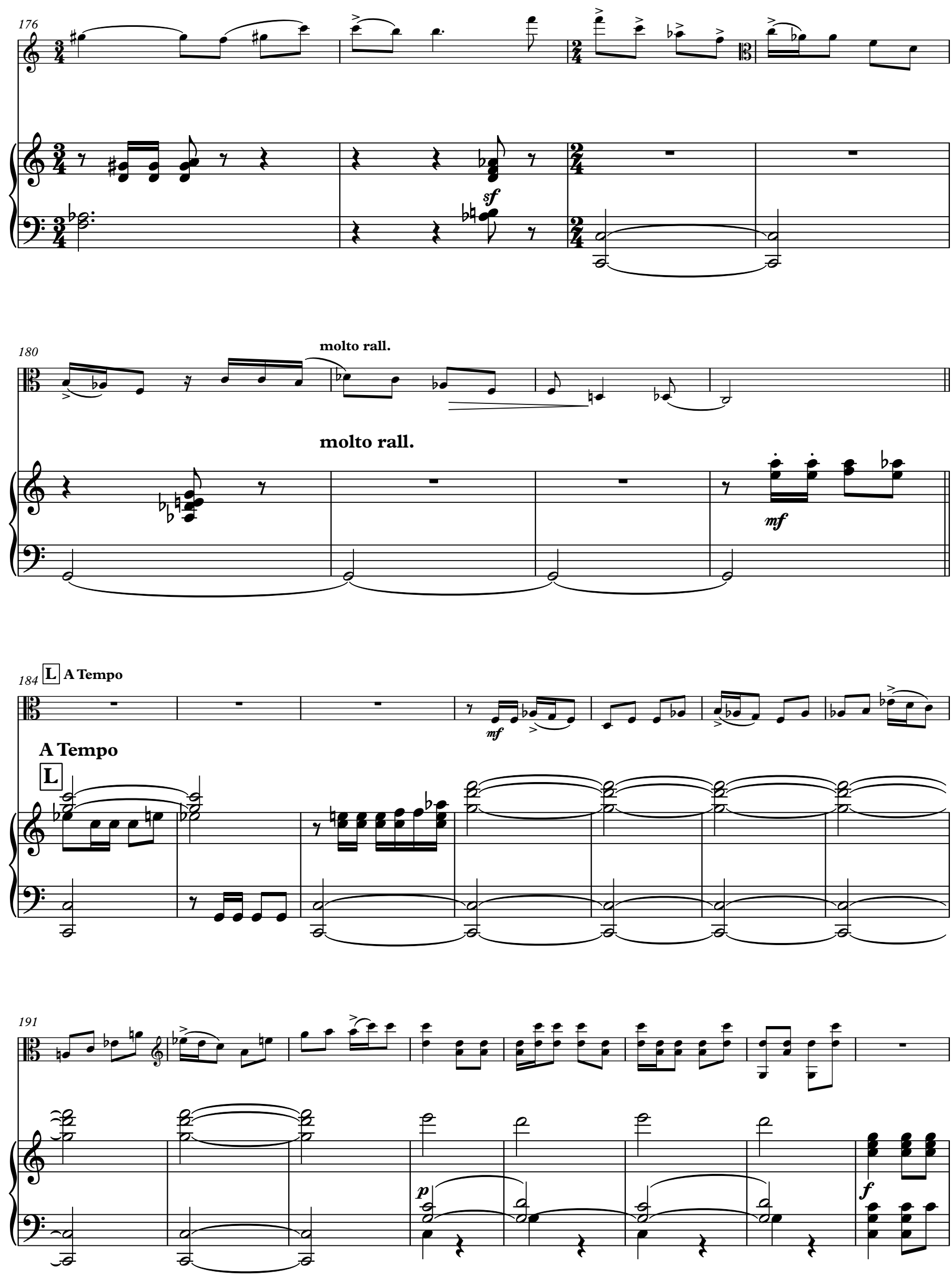

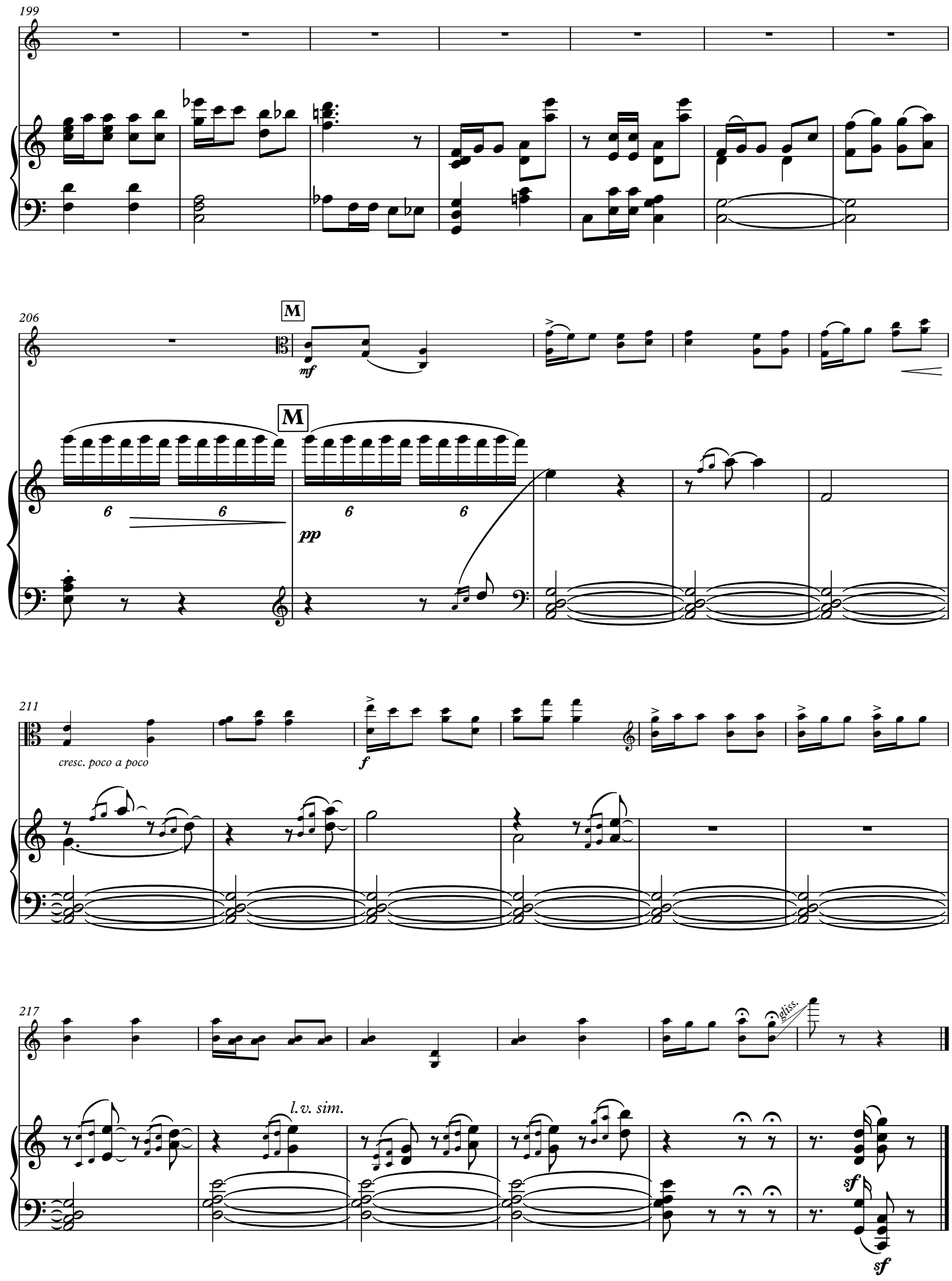


\title{
Dimitris Dragatakis
}

\section{Concerto for Viola and Orchestra}

\author{
$\underline{\text { Solo Viola }}$
}

Created by Elyse Dalabakis

Viola part edited by Elyse Dalabakis

Reduction and engraving by Brendan Agnew 

Concerto for Viola and Orchestra

I

Dimitris Dragatakis

\begin{tabular}{l|l} 
Moderato \\
$\mathbf{2}$
\end{tabular}

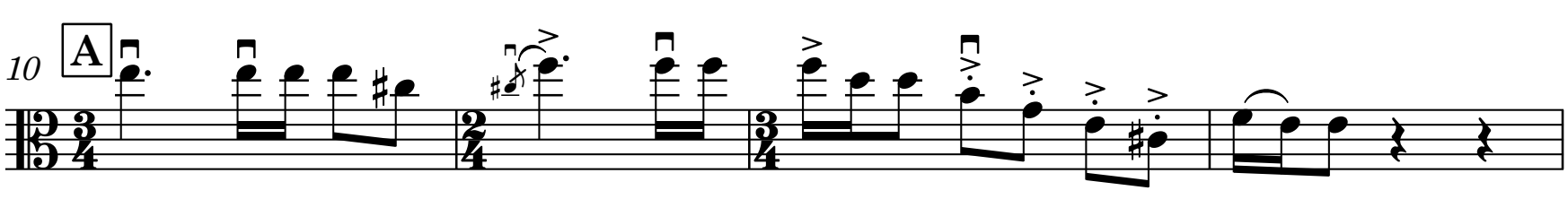

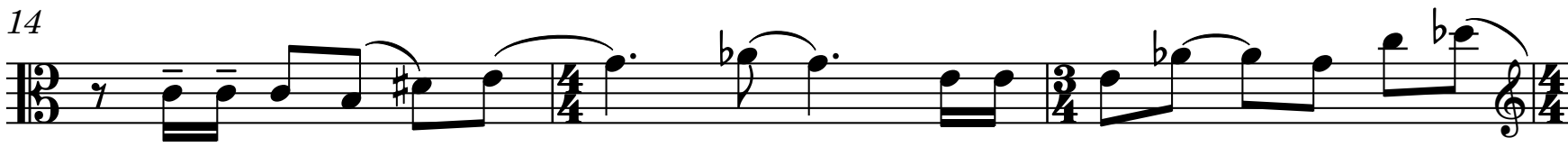

$60_{0}^{17}=b_{0}$

(6) largam.

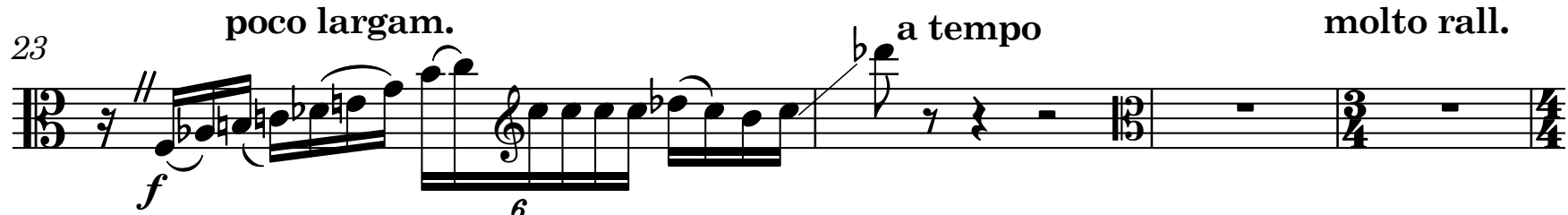

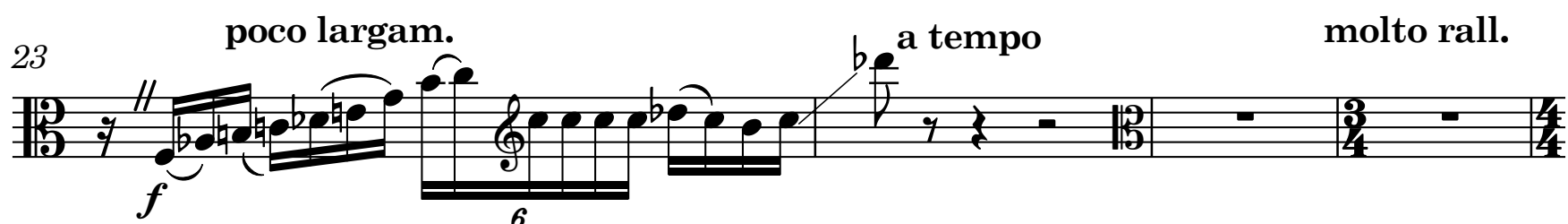

27 B a tempo

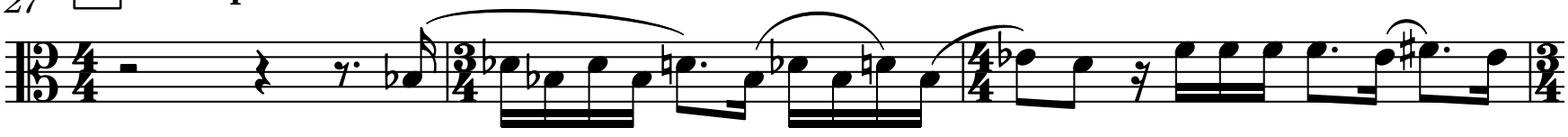

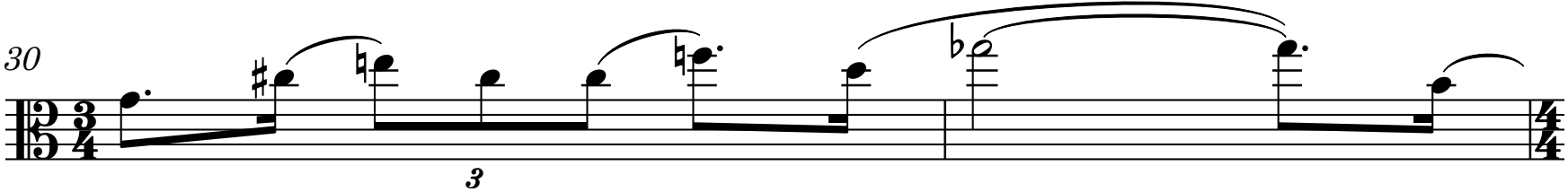

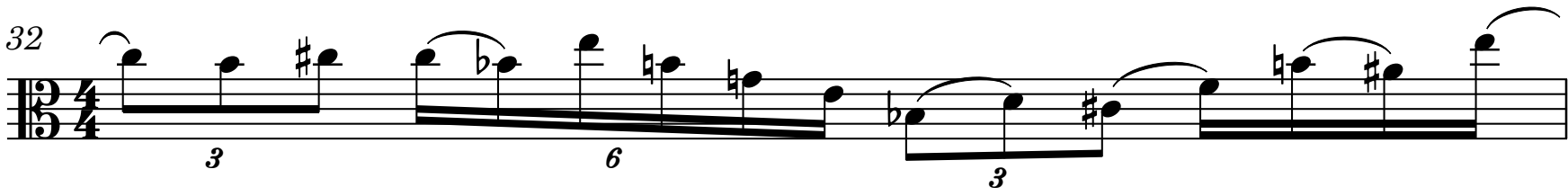

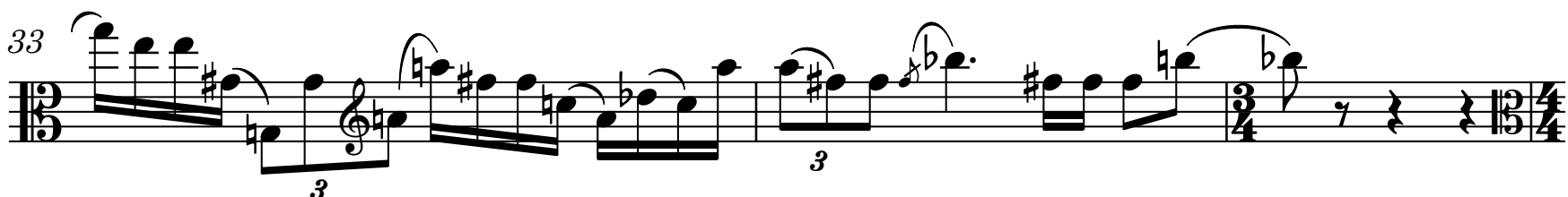


${ }_{36}$ C

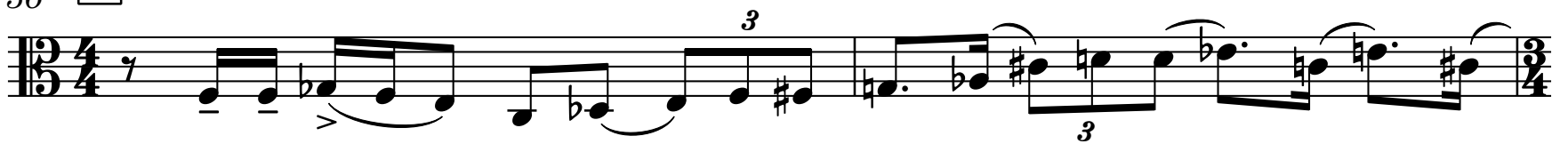

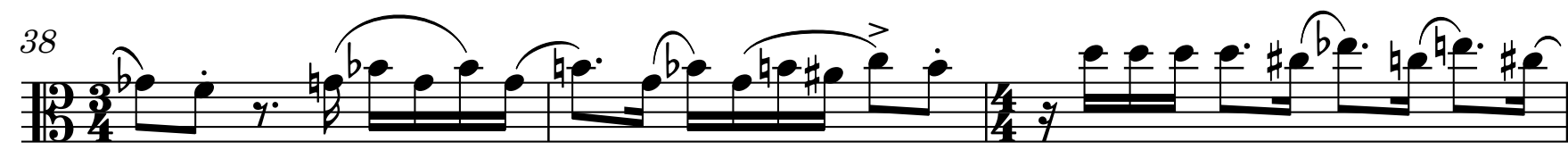

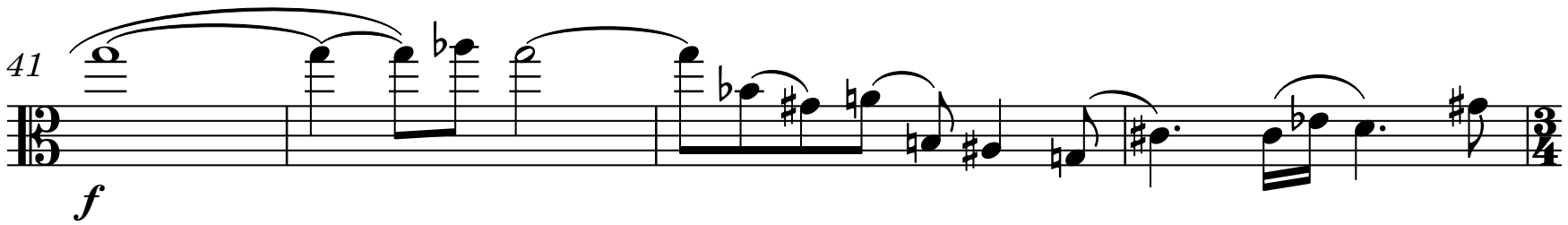

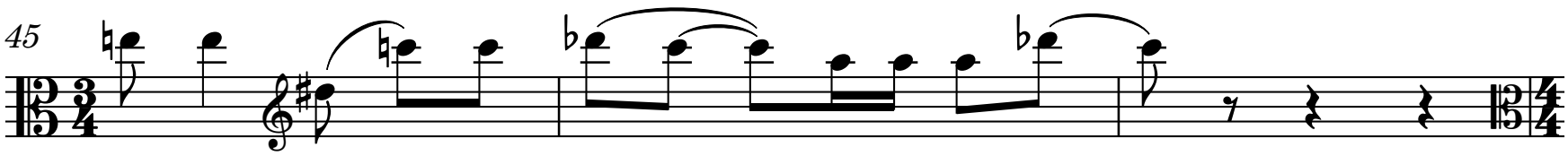

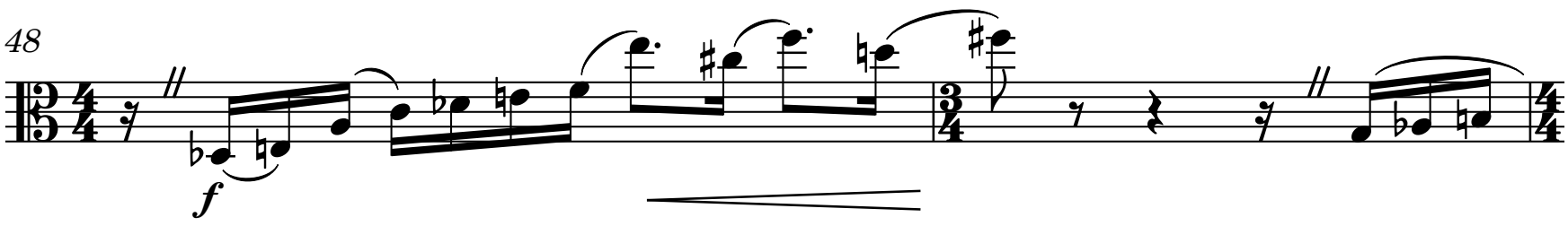

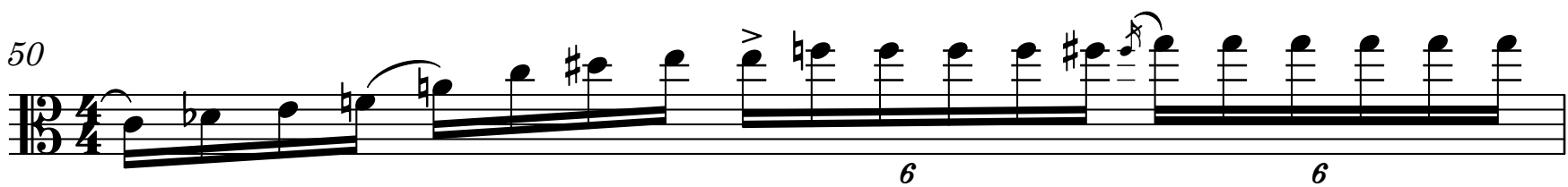
51 poco largam. ${ }_{54}$ Dpoco sostenuto 我, 61 E a tempo

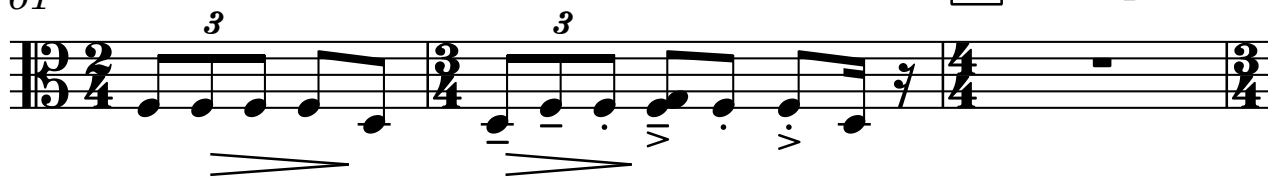




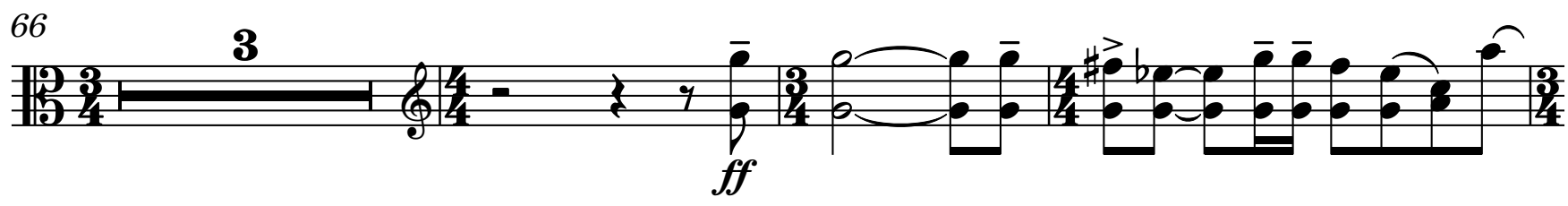
(9) ${ }_{77} \mathbf{F}$ poco largam.

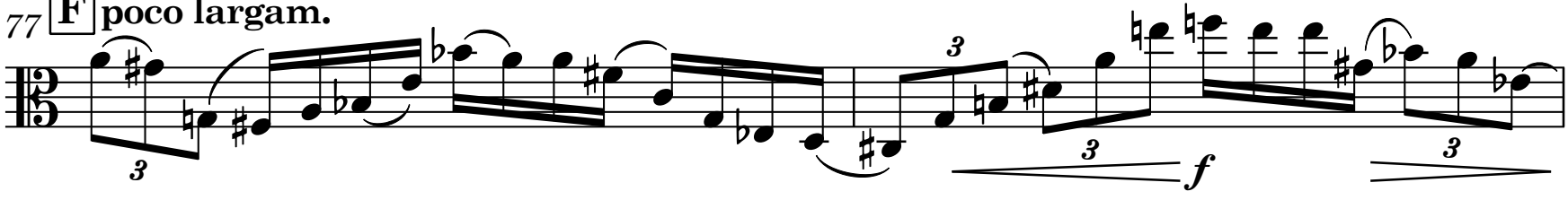

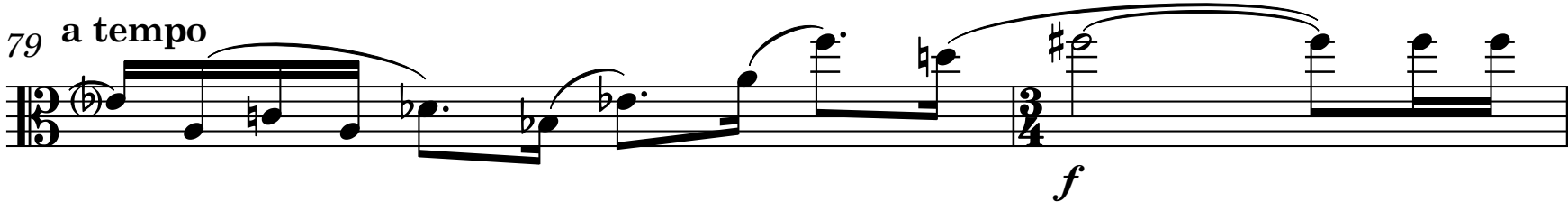

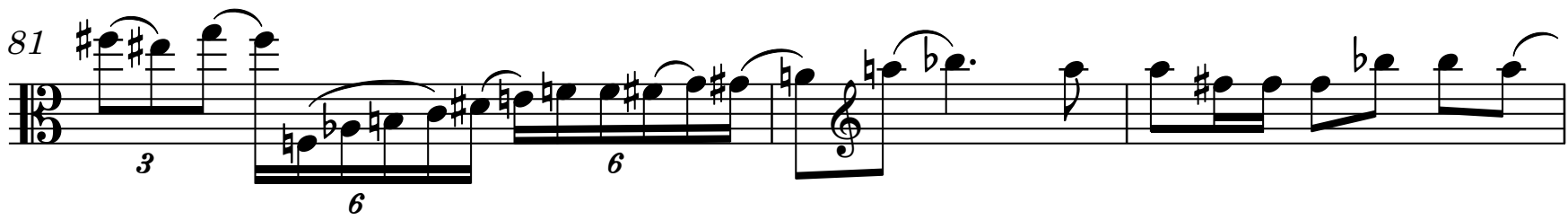

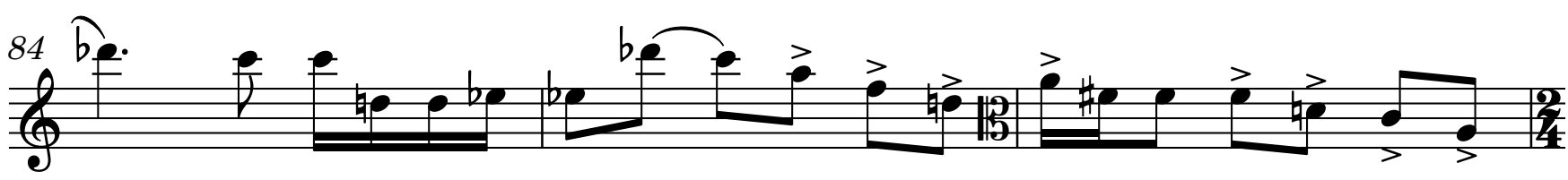

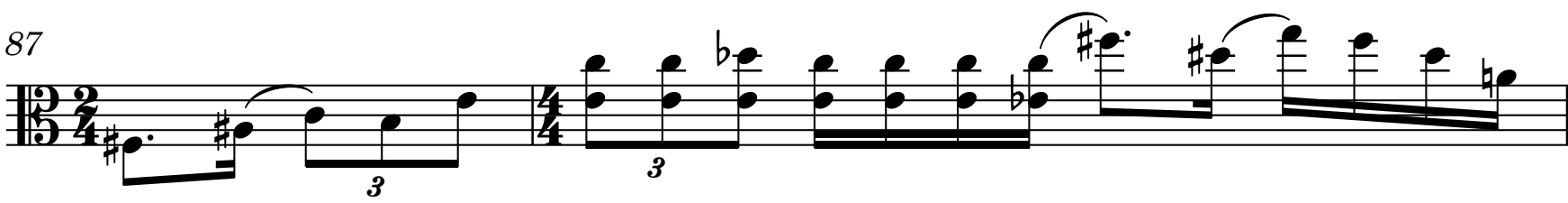

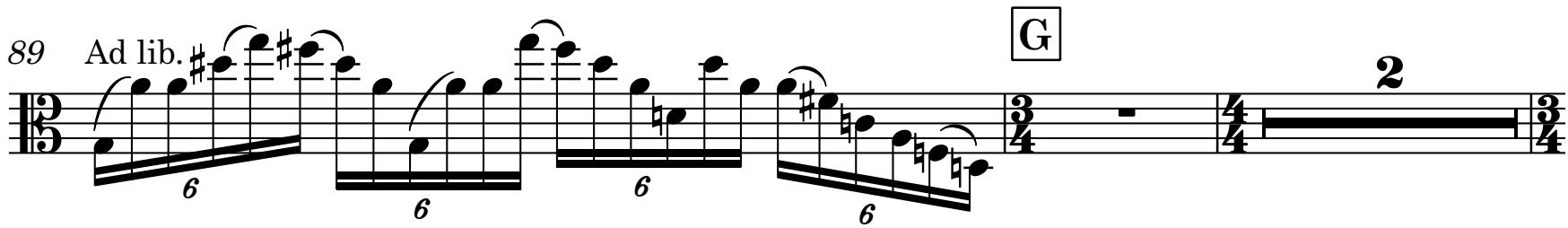
(2)

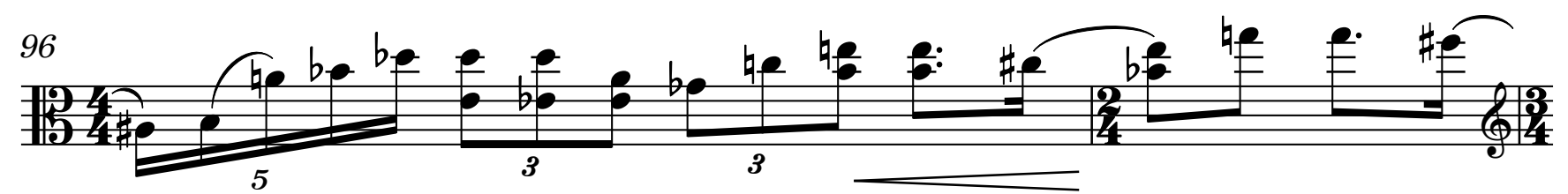



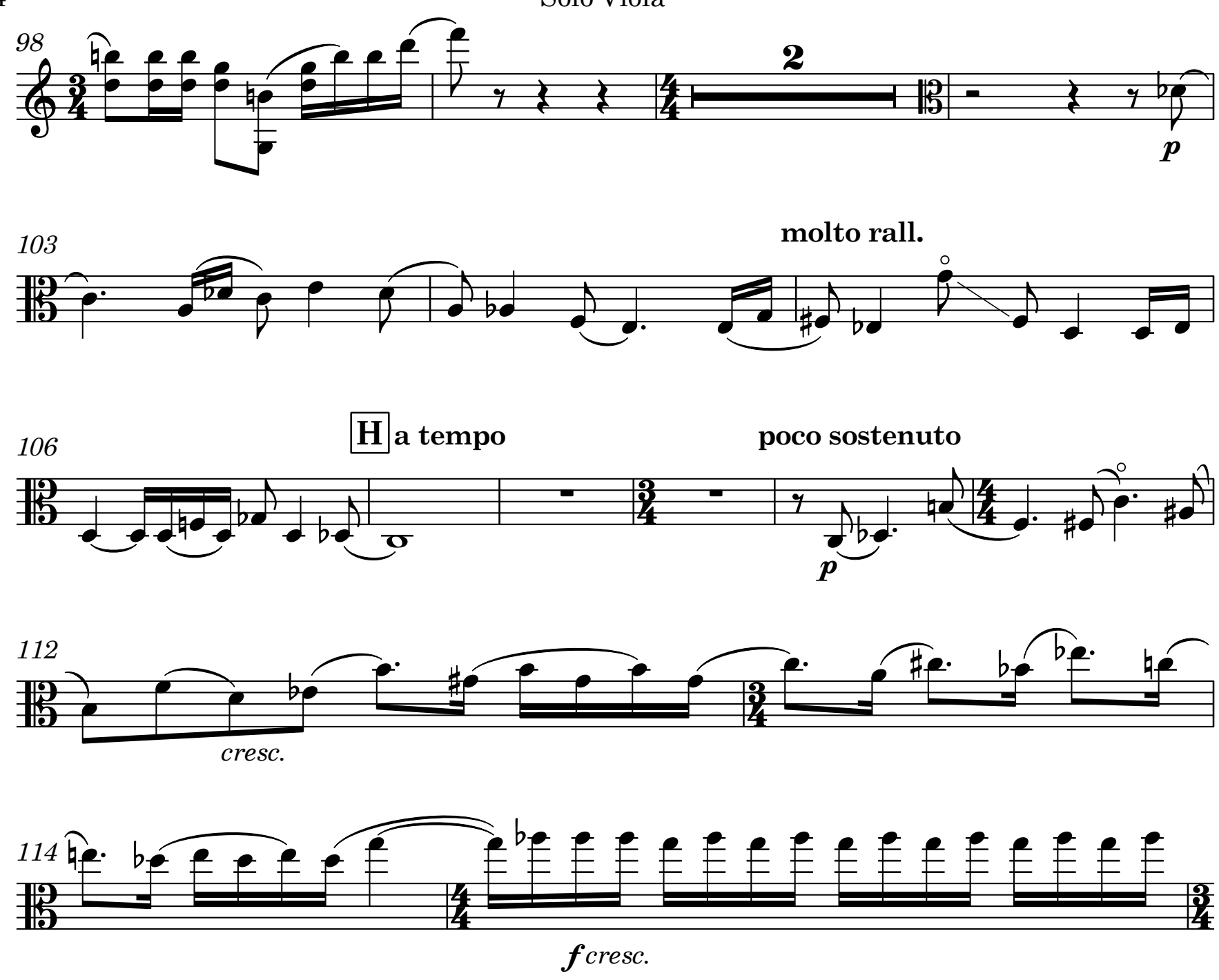

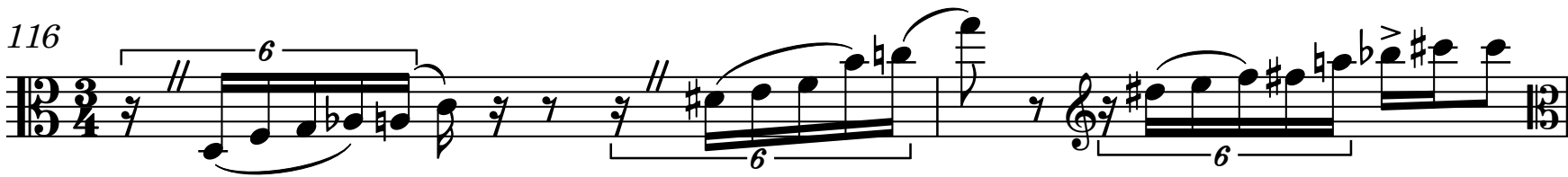
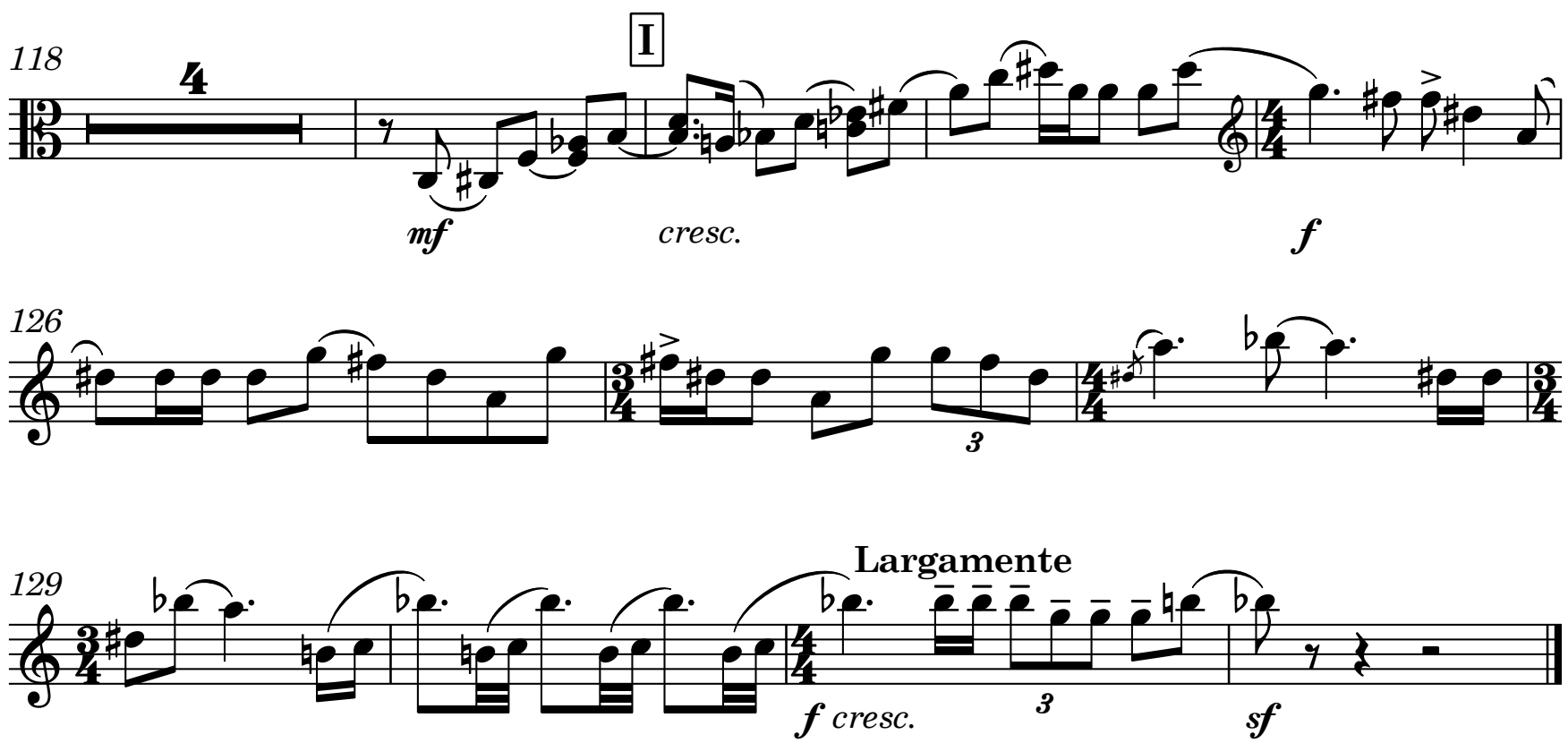


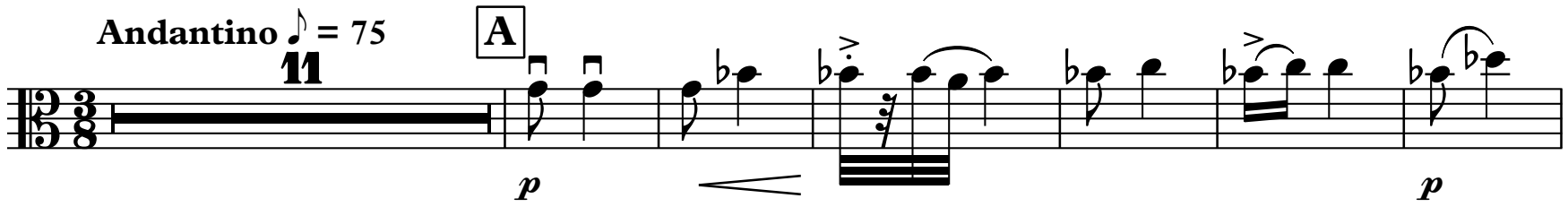

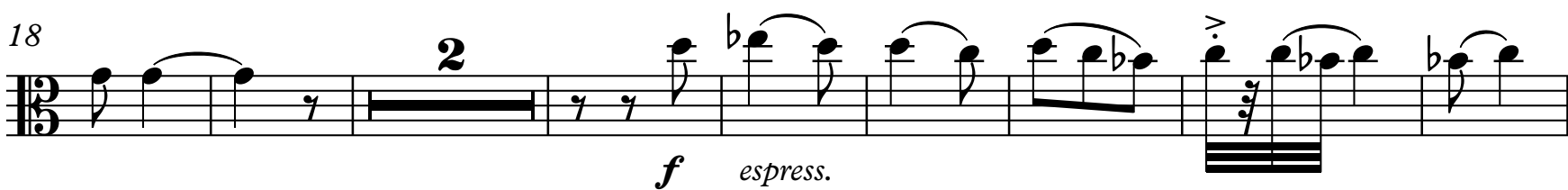

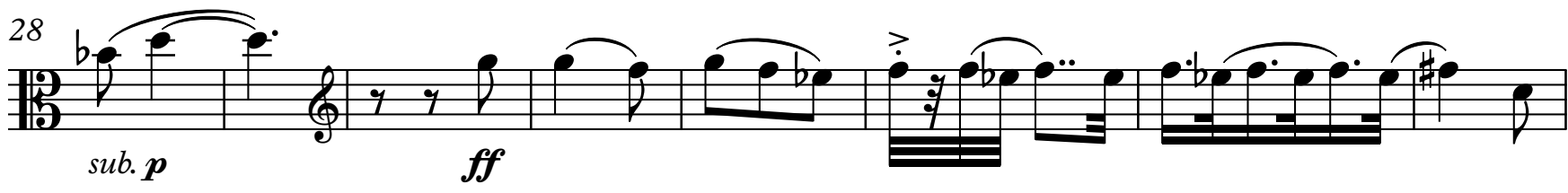

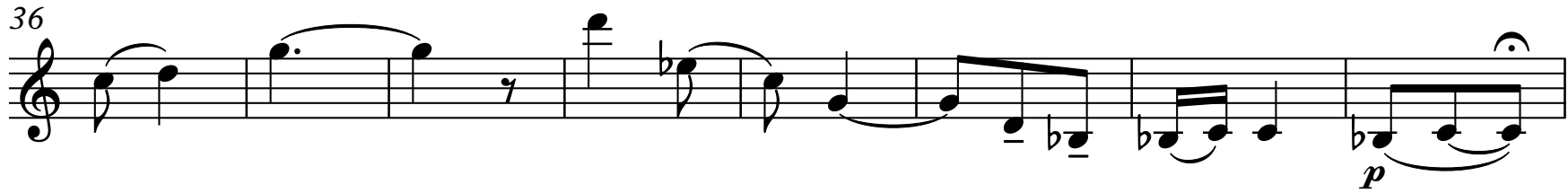

$\frac{44 \mathrm{~B}}{6}$ G e.e.e.e.

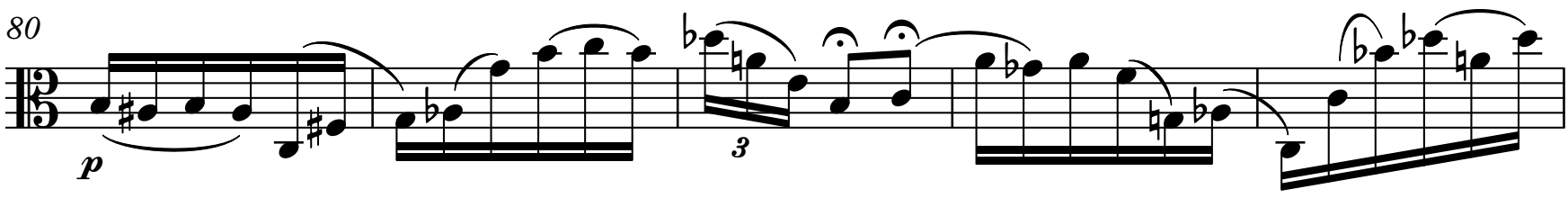

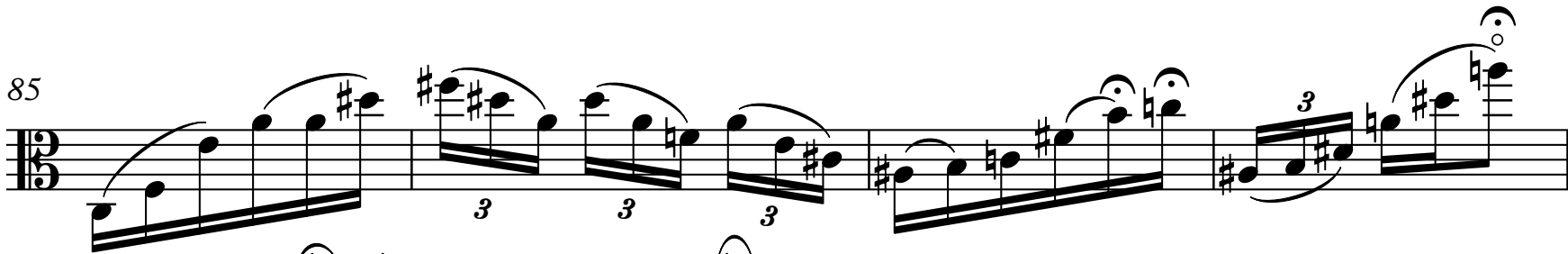

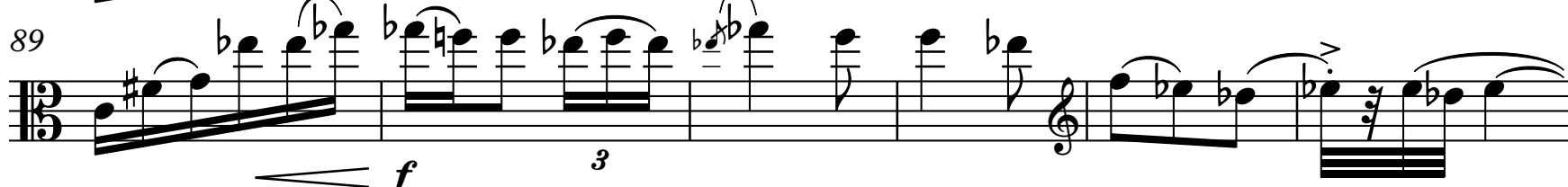

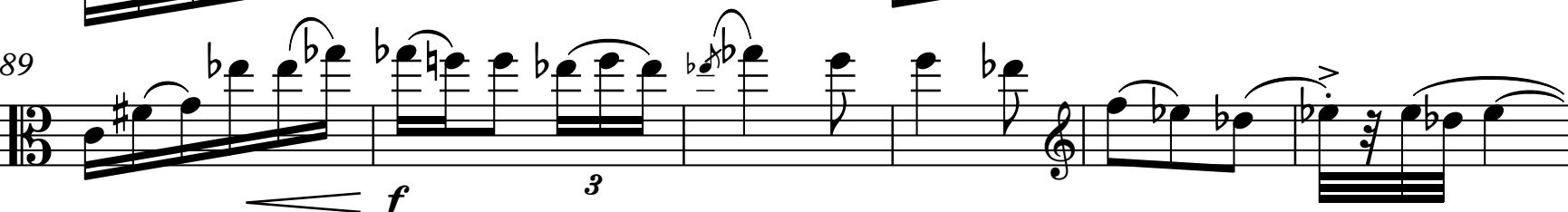
(9)

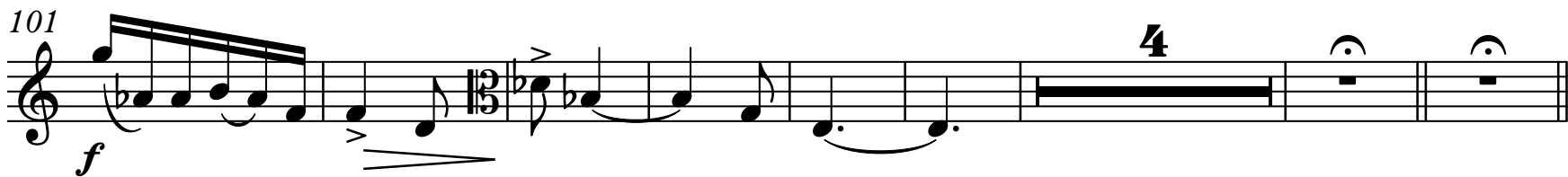


6

Eadenzz)

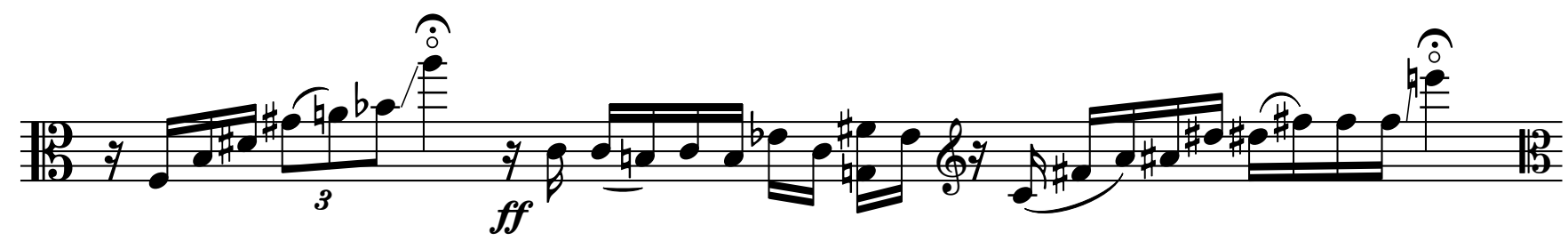

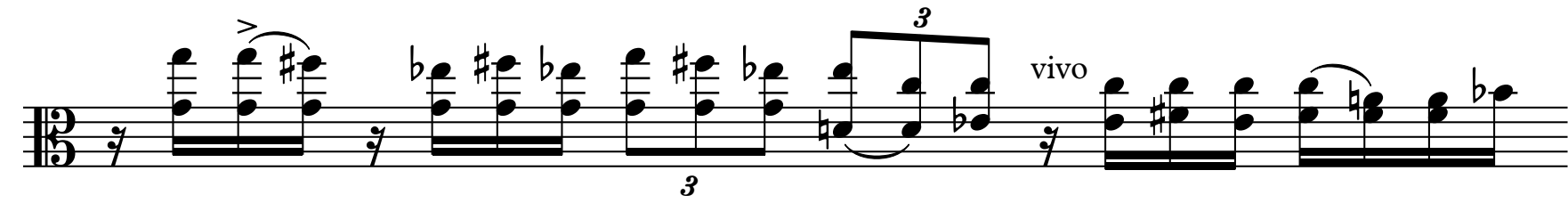

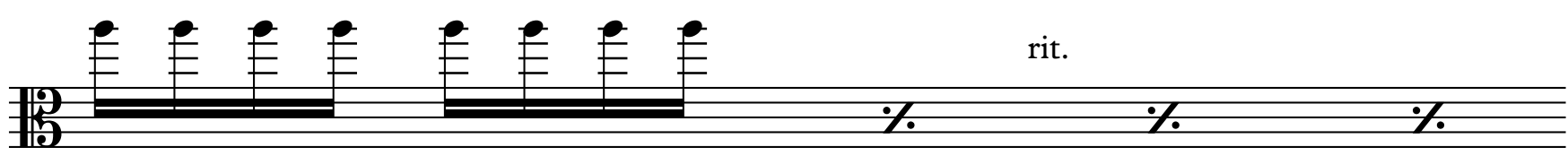

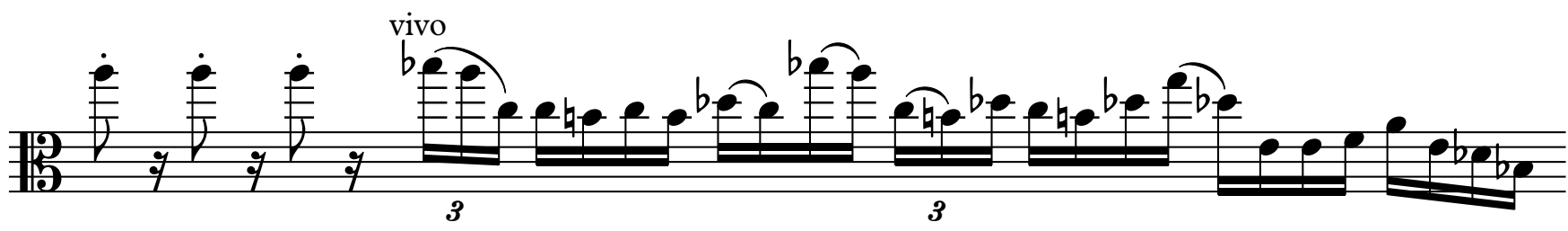

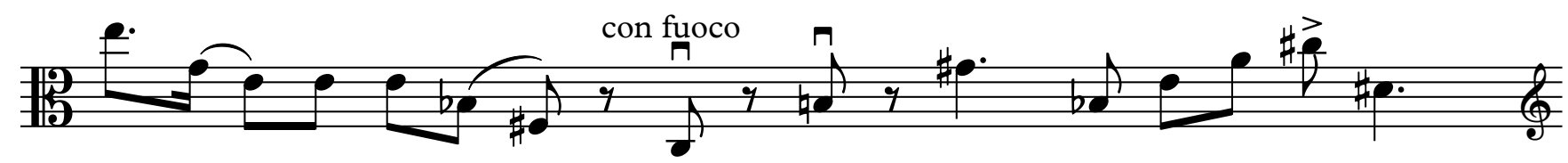
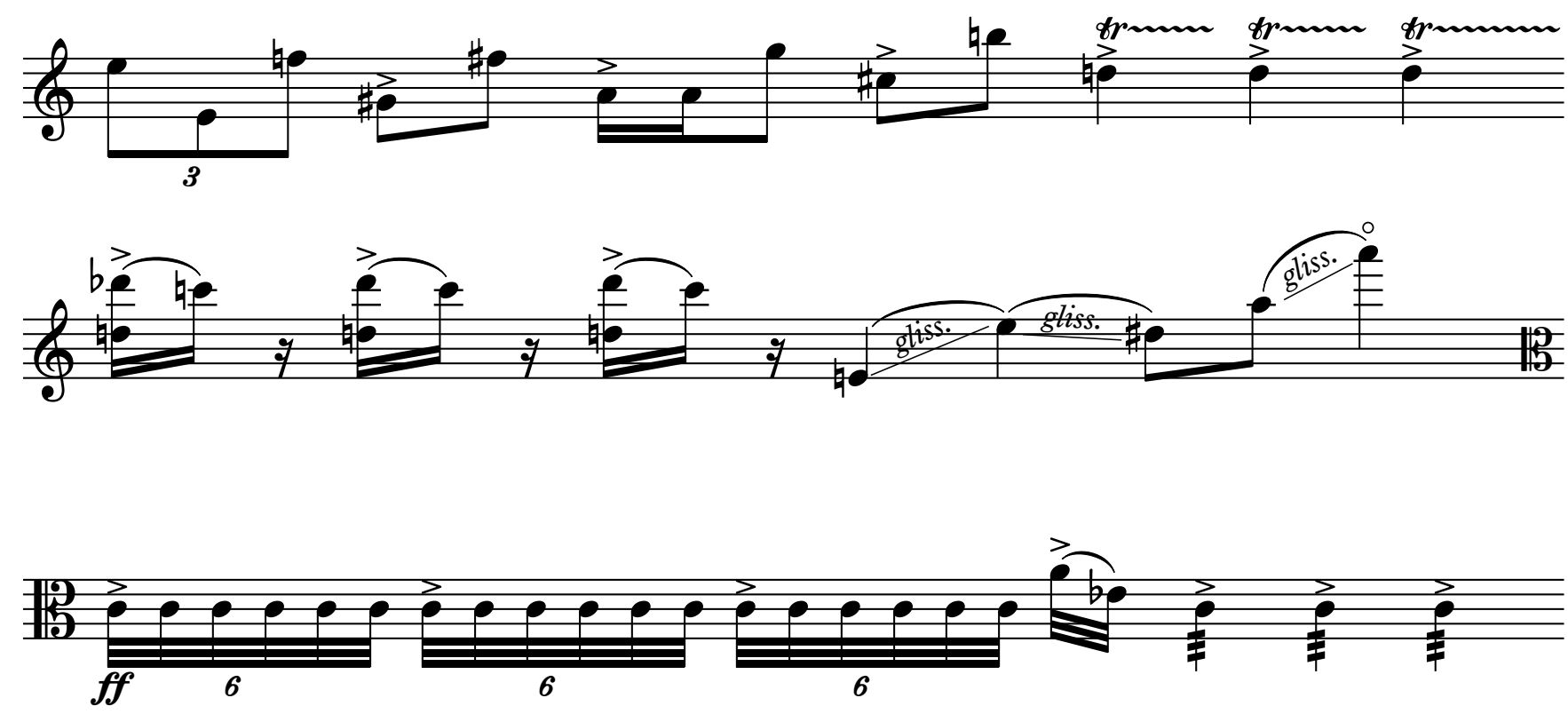

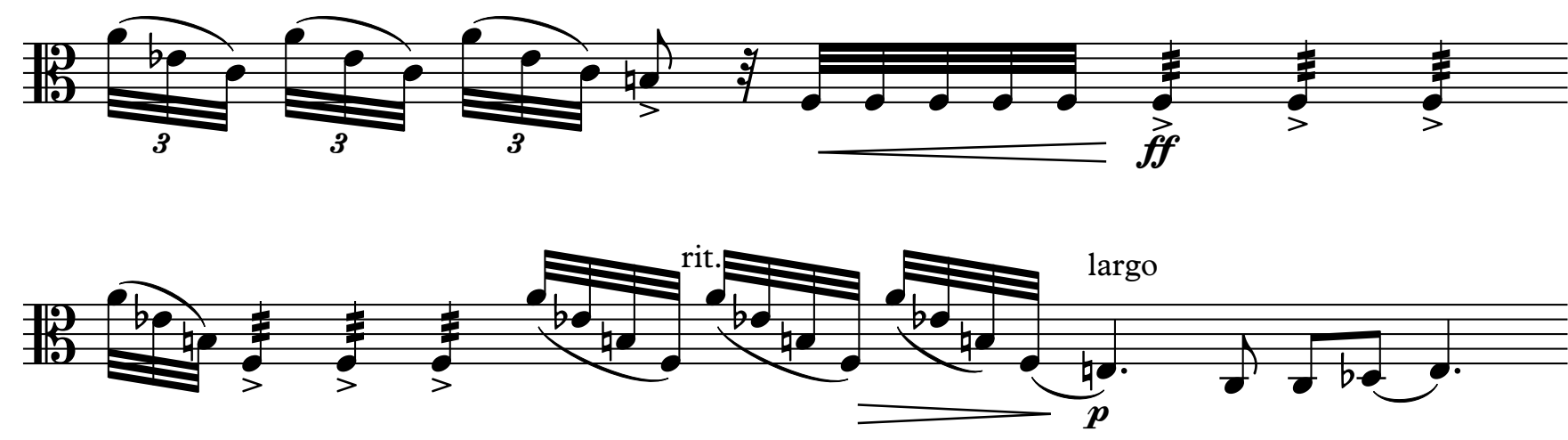

伤

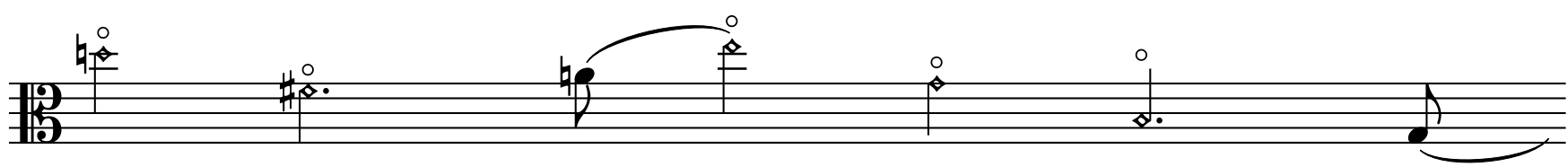

poco a poco accel

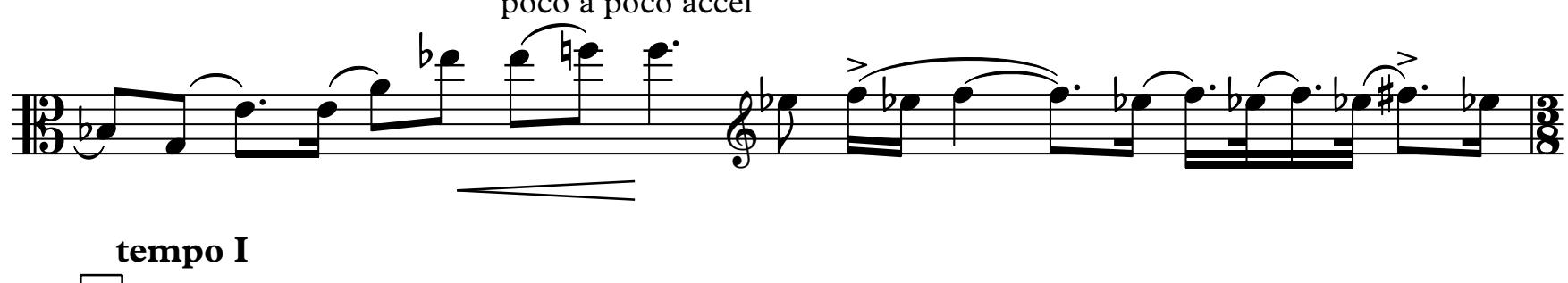

$80^{2}$

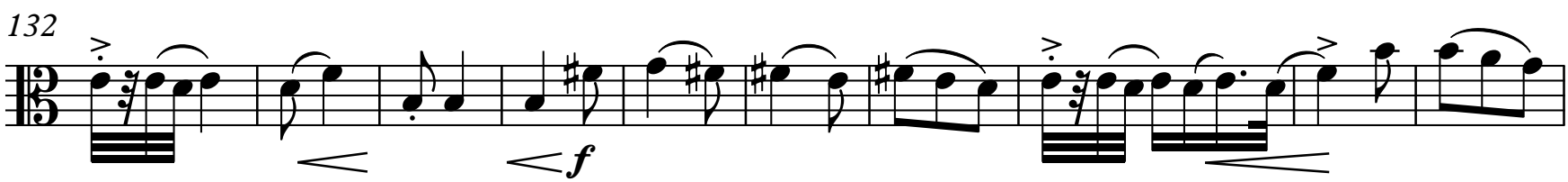
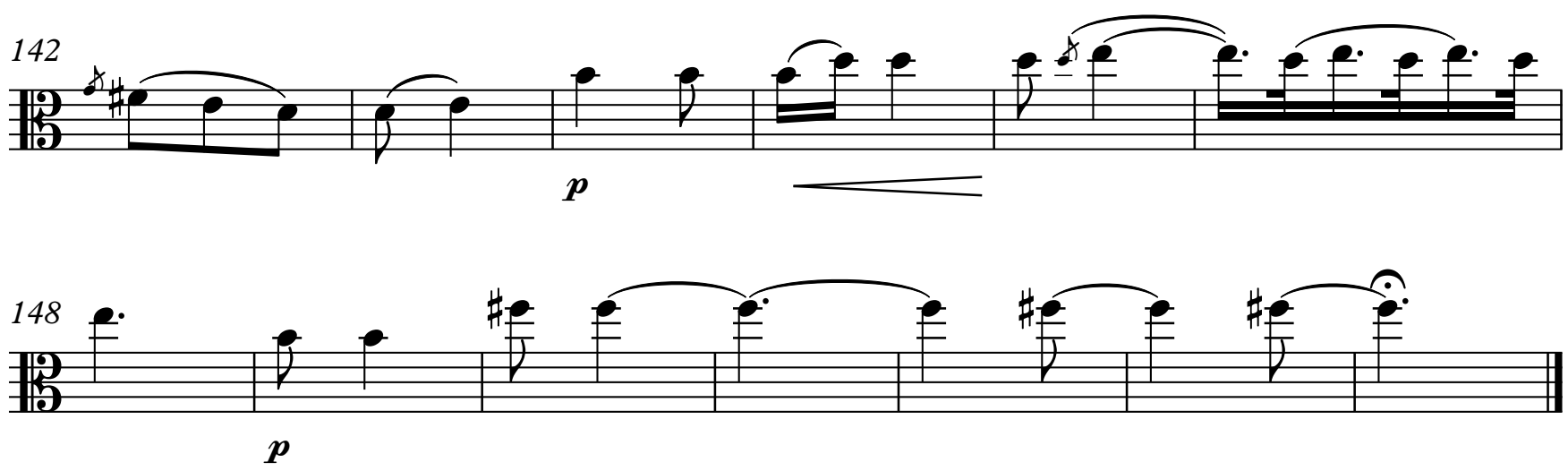
Solo Viola

III.

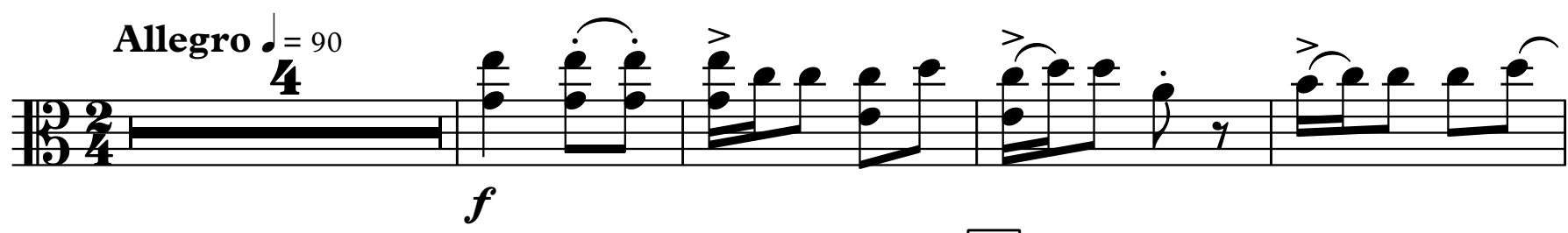

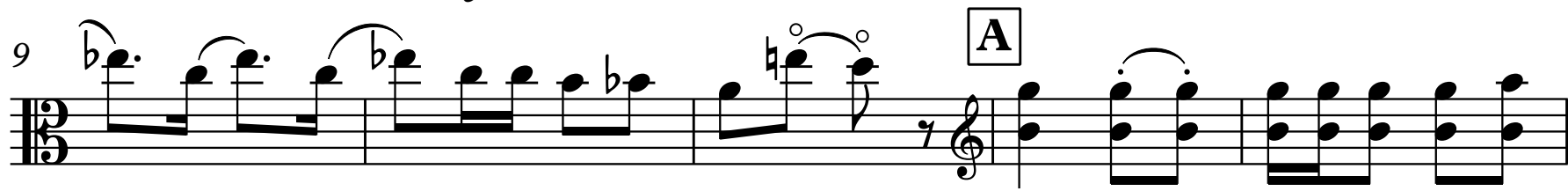

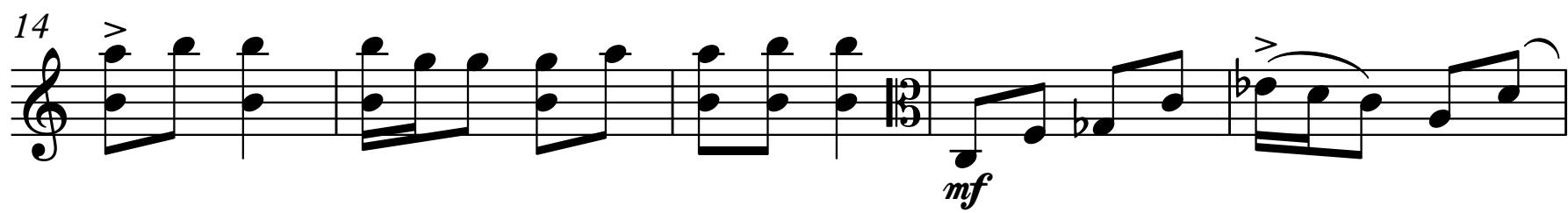

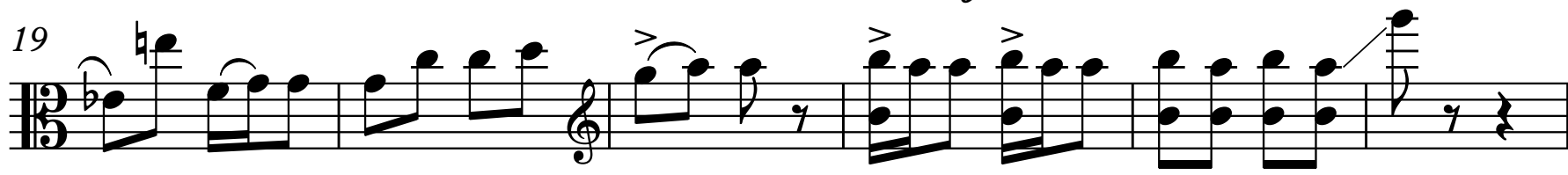
${ }_{25} \mathbf{B}$ ?

C poco più meno

123

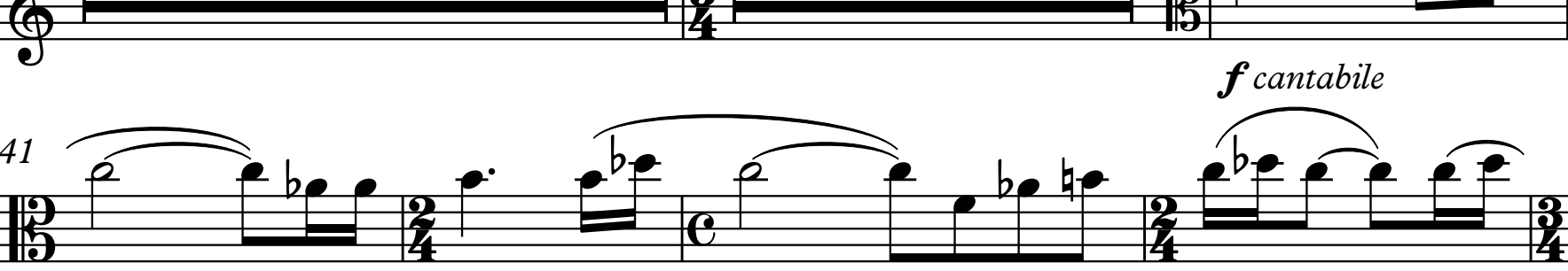

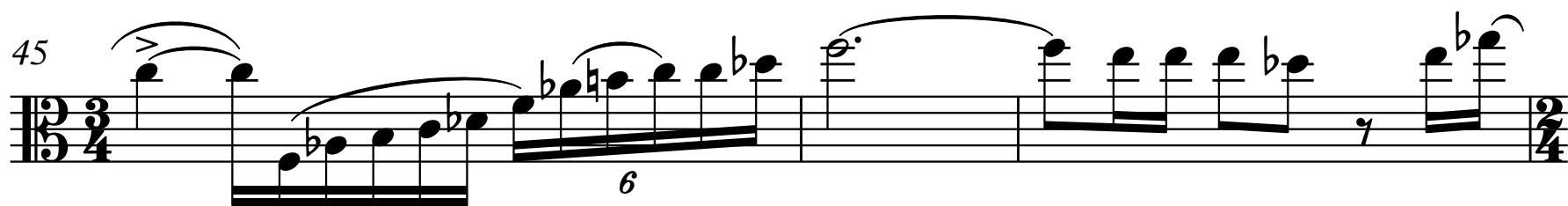

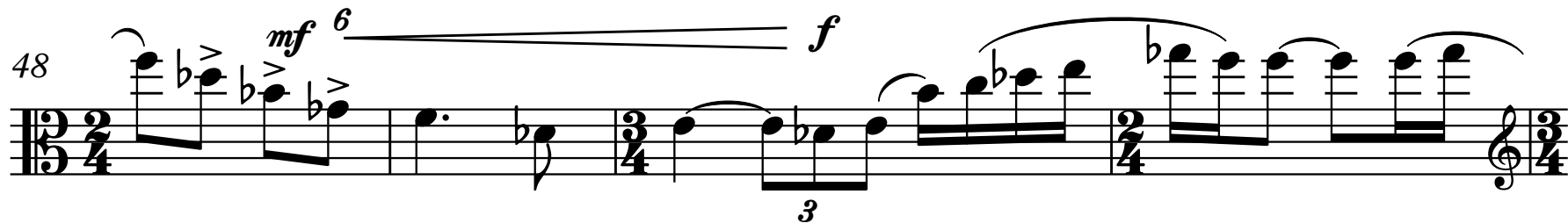

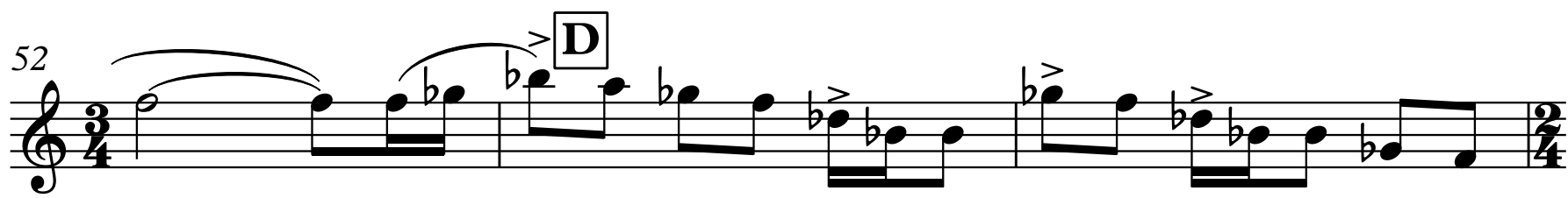


55

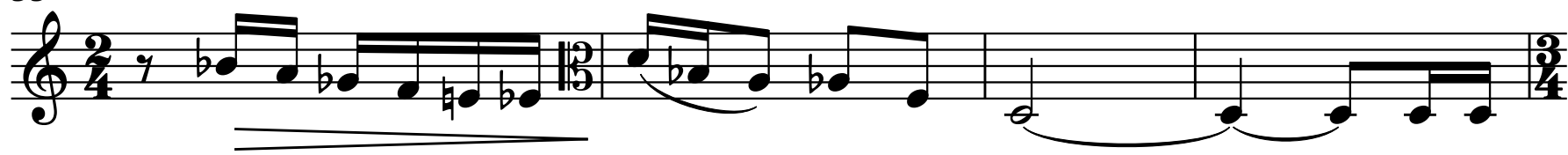

13\% 63 年

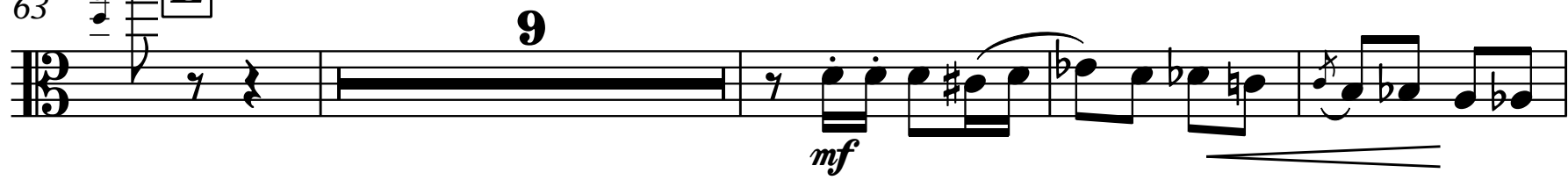
草-

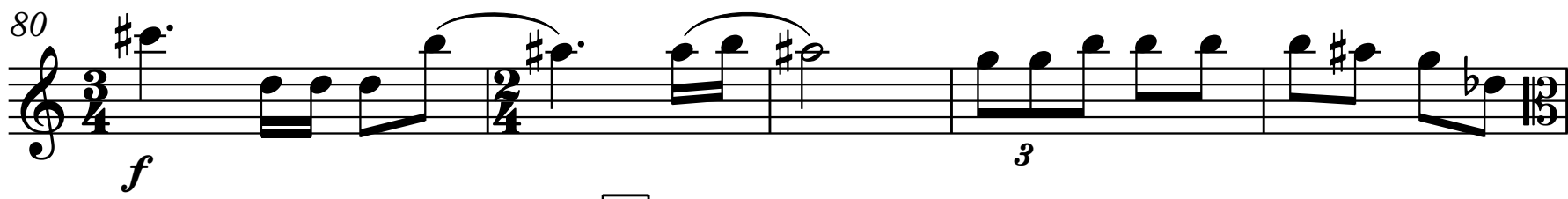

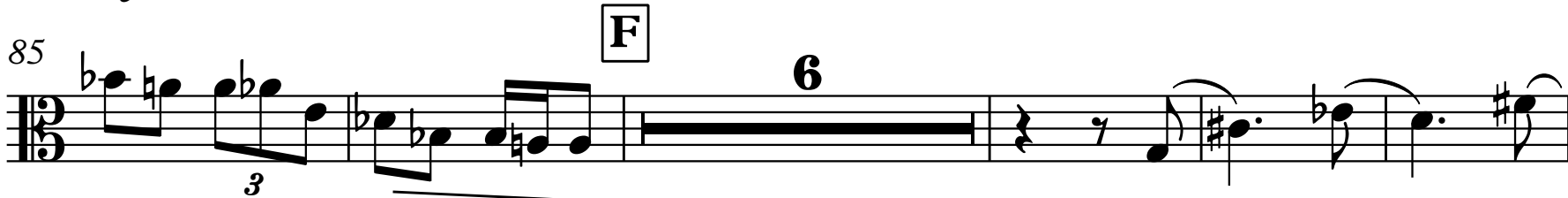

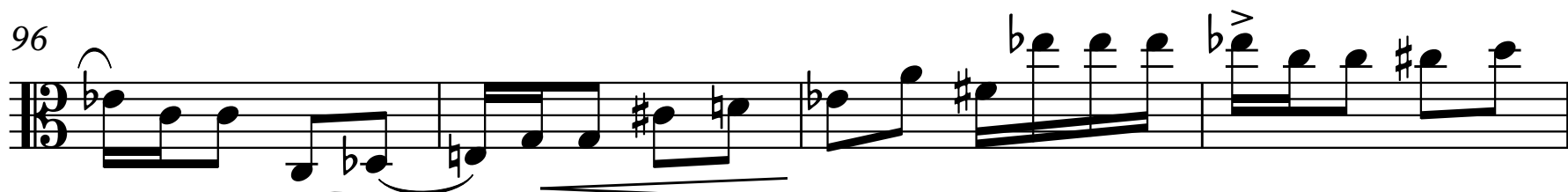

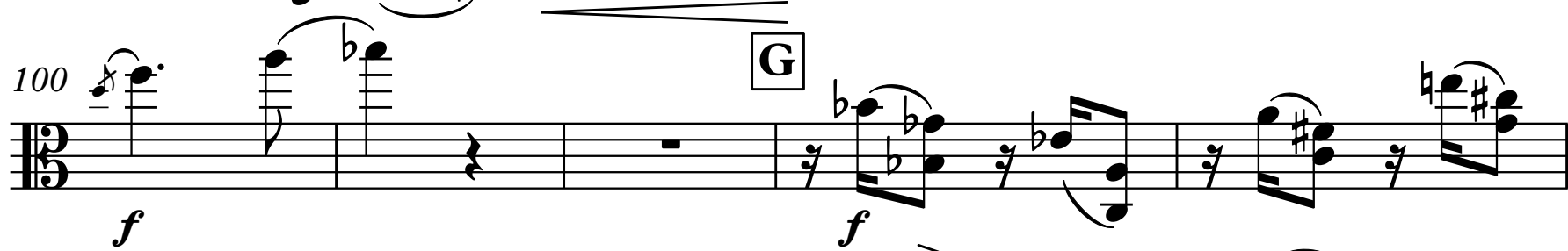

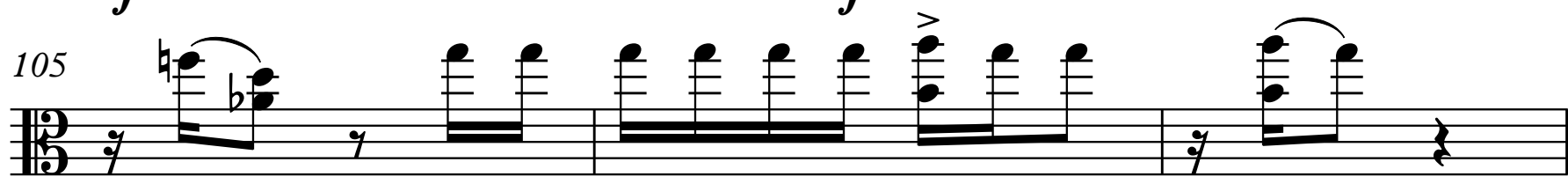

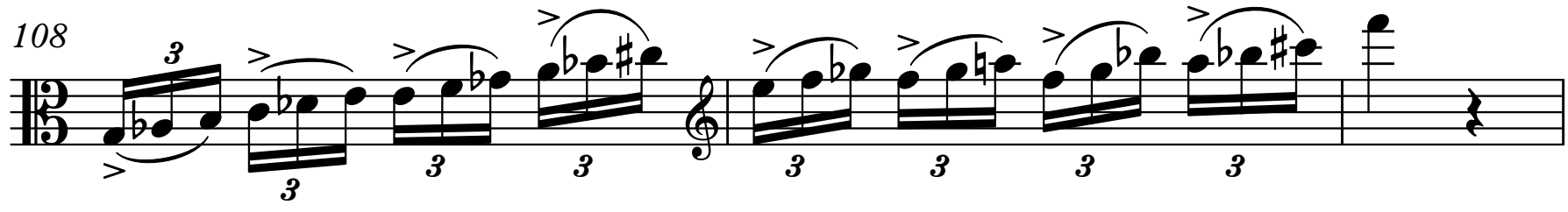


10
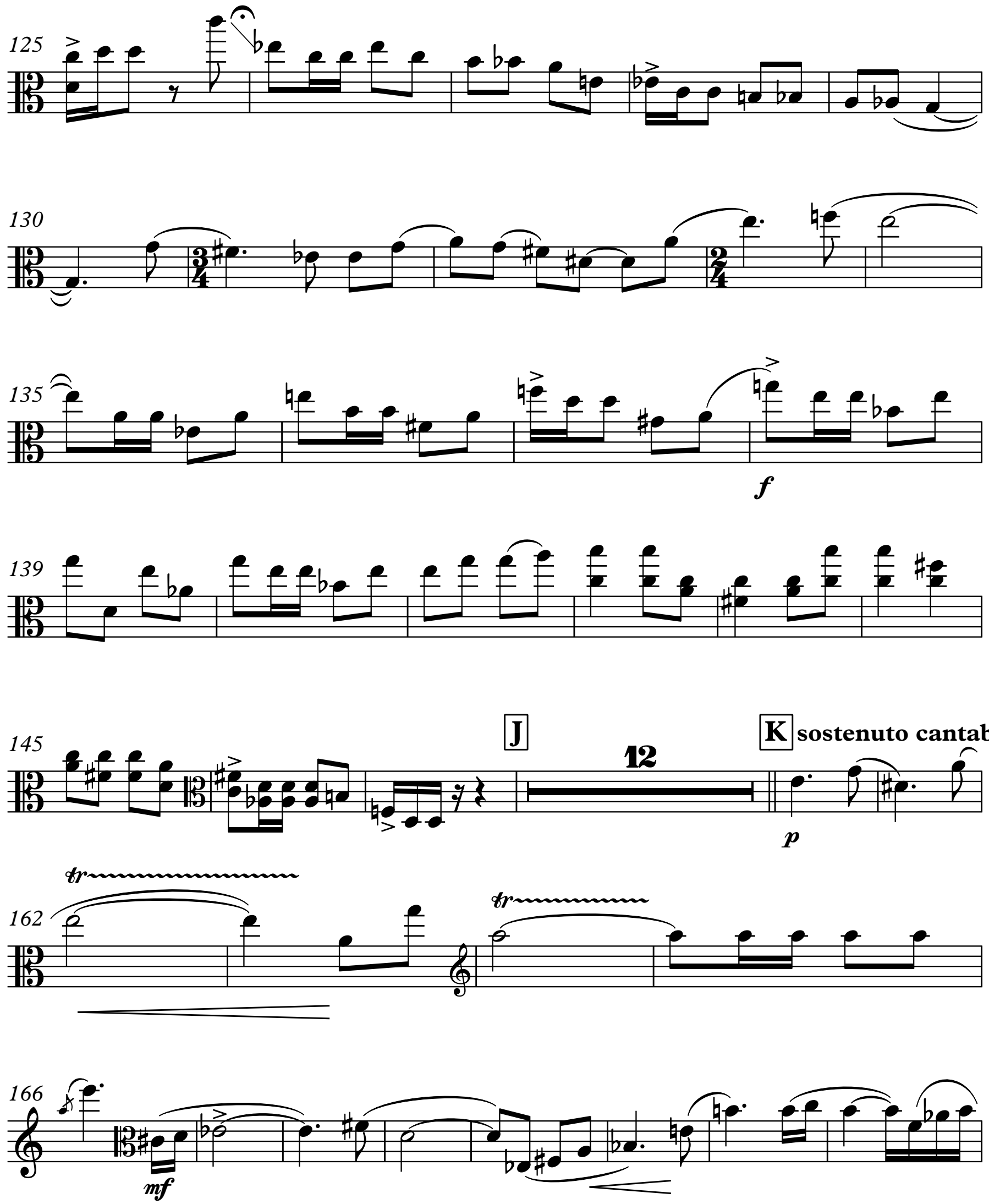
tys

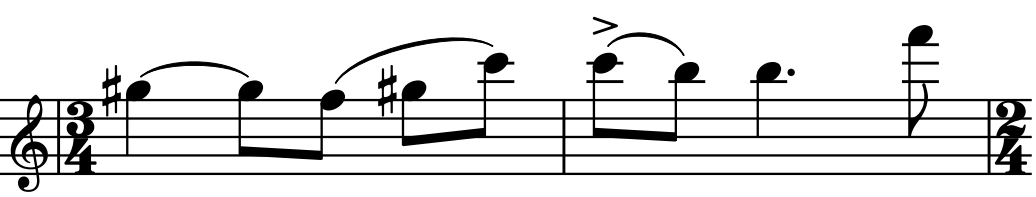

每

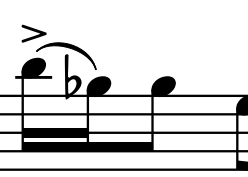

molto rall.

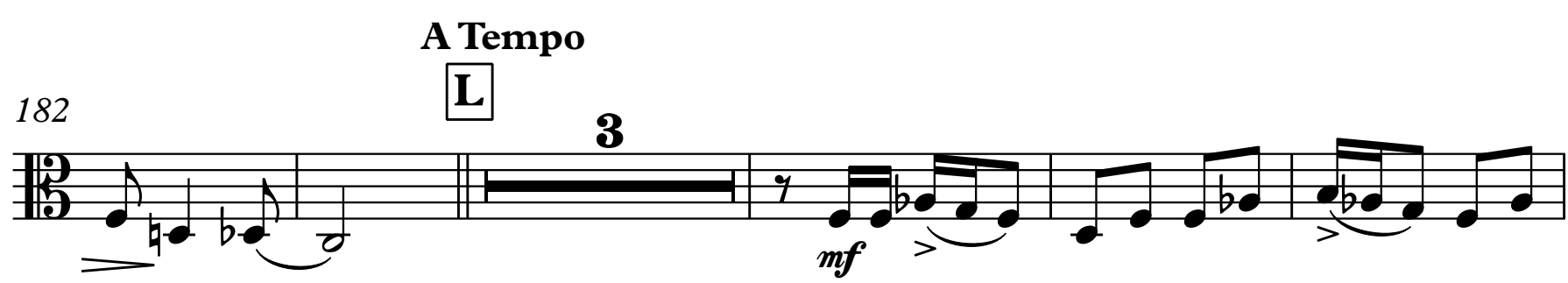

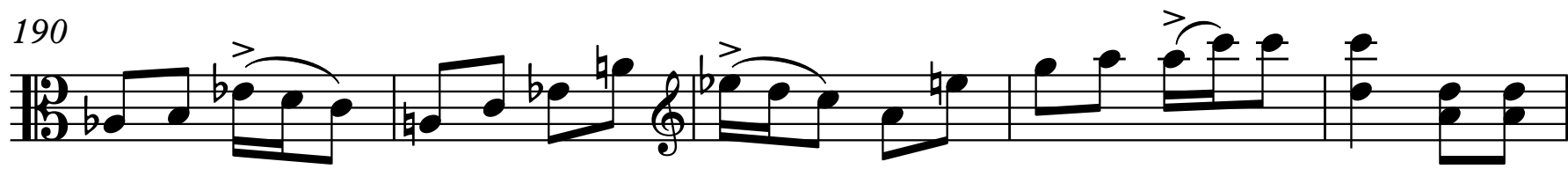
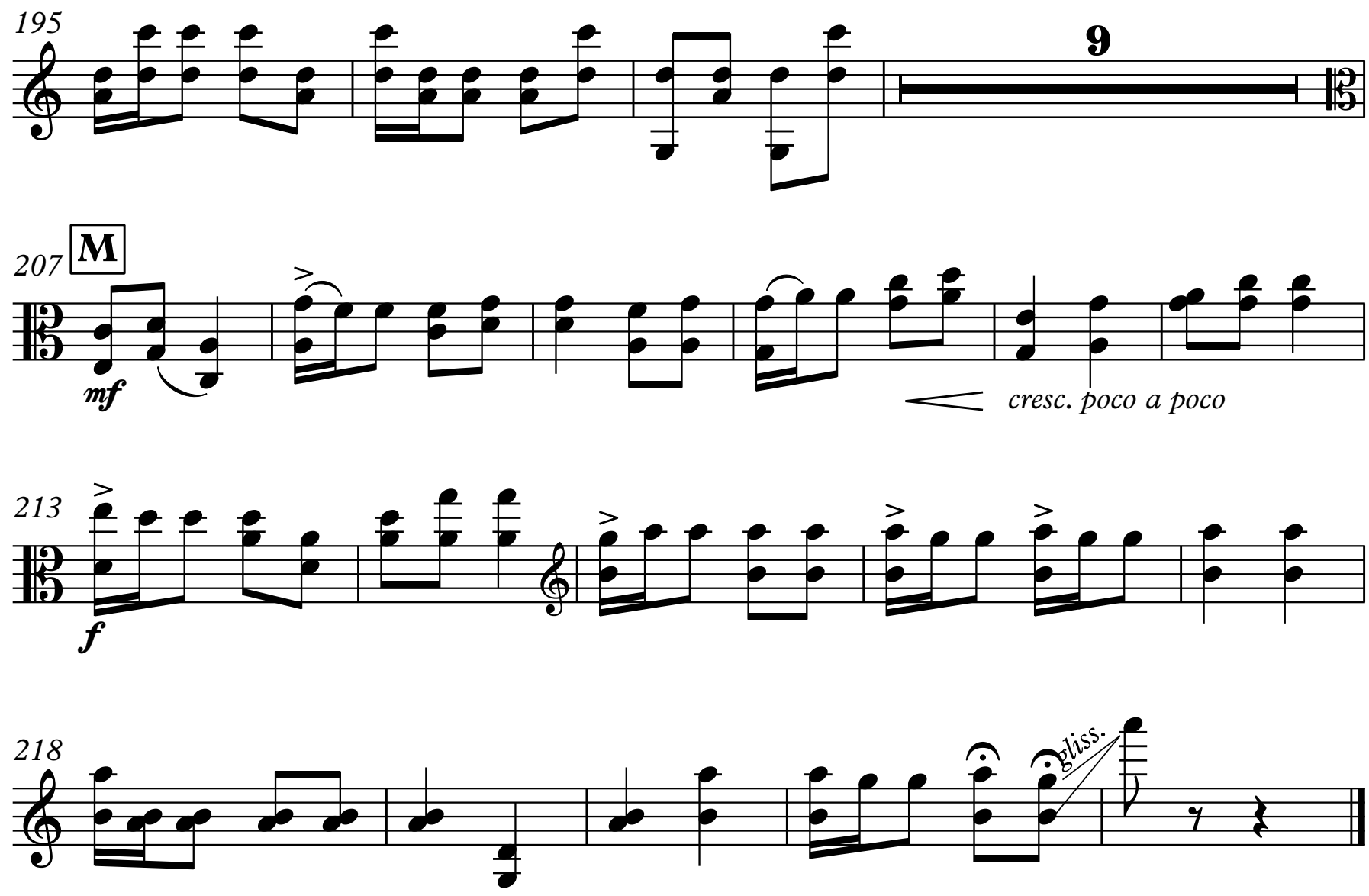


\subsubsection{New viola, piano, percussion quintet chamber music edition}

Throughout the researcher's and collaborative pianist rehearsal process the need for a percussive timbre became apparent. The soundscape of viola and piano together lacked the percussive qualities that distinguished the premiere recording, and indeed Dragatakis' compositional style in this work. Some of the essence of the piece was lost, in the researcher's opinion, without the percussion timbre. To mitigate this, a viola, piano, and percussion chamber music edition was created.

The percussion chamber music version was created from the orchestral score. The collaborative percussionist and engraver along with the researcher arranged the orchestral percussion parts to be playable by three players, and created a percussion score with three staves for performance purposes. No notes or instruments were changed from the original orchestra score - the percussion instrumentation is entirely maintained. The parts have been reduced to three staves to allow for three percussion players, making for a quintet chamber music version of the Concerto for Viola. In order to include the percussion parts on three staves, the collaborative percussionist had to work out from the orchestra score how the percussion section would be set up, how many players would be needed, and who could play what when in order to use three players.

Due to Dragatakis' style of writing, in which the orchestra/percussion and the viola soloist often trade musical phrases or themes instead of playing simultaneously, most of the dynamic markings can also be played - relative to the chamber ensemble - as originally marked in the orchestral score.

This version will aid future violists in playing and rehearsing this work. As it is quite difficult - and can be expensive - to get an entire orchestra together, this chamber music version offers players the ease of a small ensemble while also retaining much of the composer's originally intended soundscape. This new edition, along with the 
new stand-alone piano part, can also be used to rehearse in preparation for performing the work with orchestra.

The musical parts for the percussion chamber music version appear on the following page. To view the PDF please click on the link below.

Concerto for Viola - percussion chamber music version

https://drive.google.com/drive/folders/1IPoMLgrh PTPhFaN3VH4j9jMPziHVhTz?u sp=sharing 


\section{Dimitris Dragatakis}

\section{Concerto for Viola and Orchestra}

Chamber version for Viola, Percussion and Piano

\section{$\underline{\text { Score }}$}

Created by Elyse Dalabakis

Viola part edited by Elyse Dalabakis

Piano part edited by Gabriela Glapska

Percussion parts edited by Hannah Neman

Reduction and engraving by Brendan Agnew 

Full Score

\section{Concerto for Viola and Orchestra}

Chamber version for Viola, Percussion and Piano

I

Dimitris Dragatakis

Moderato $\_=70$
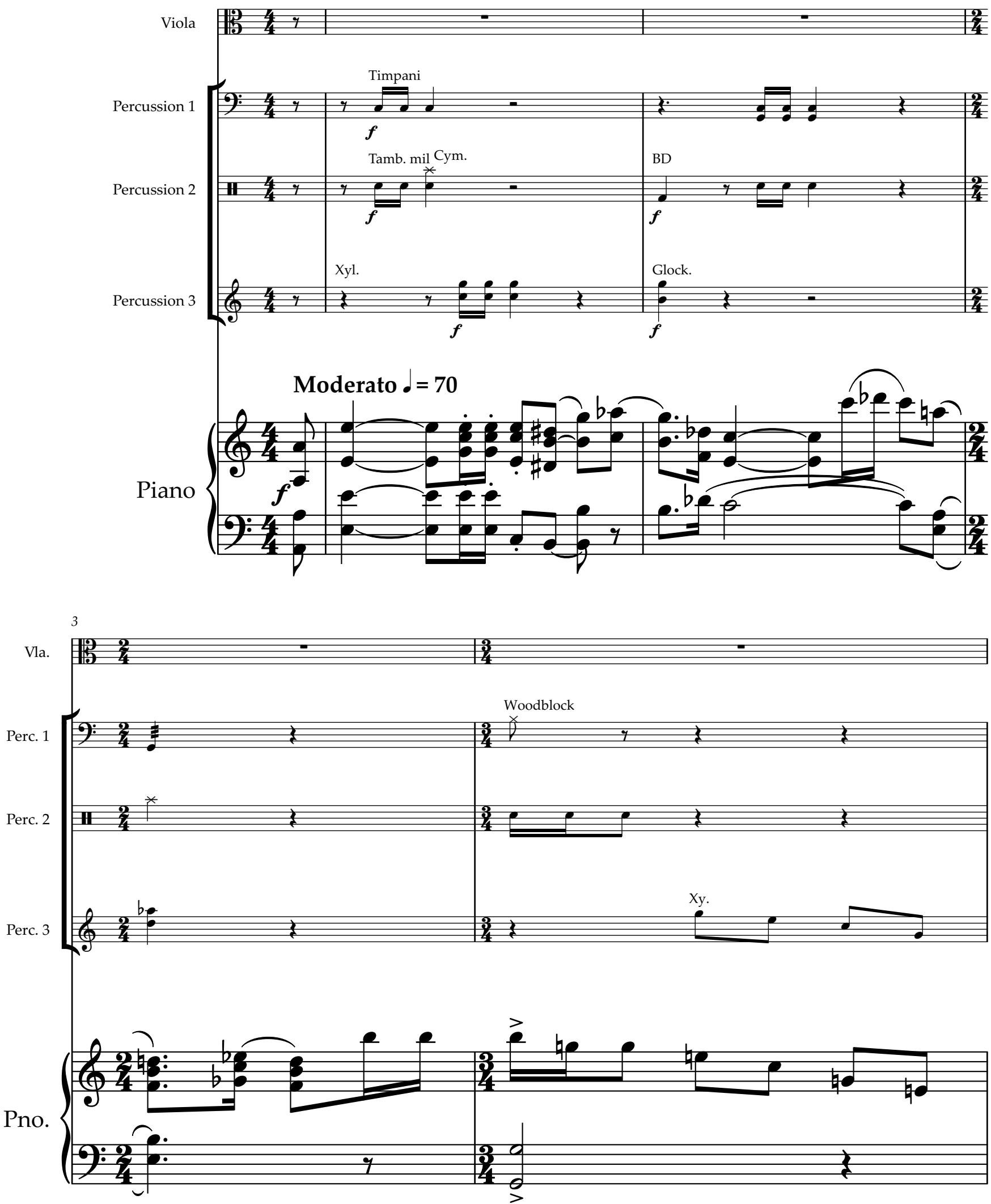

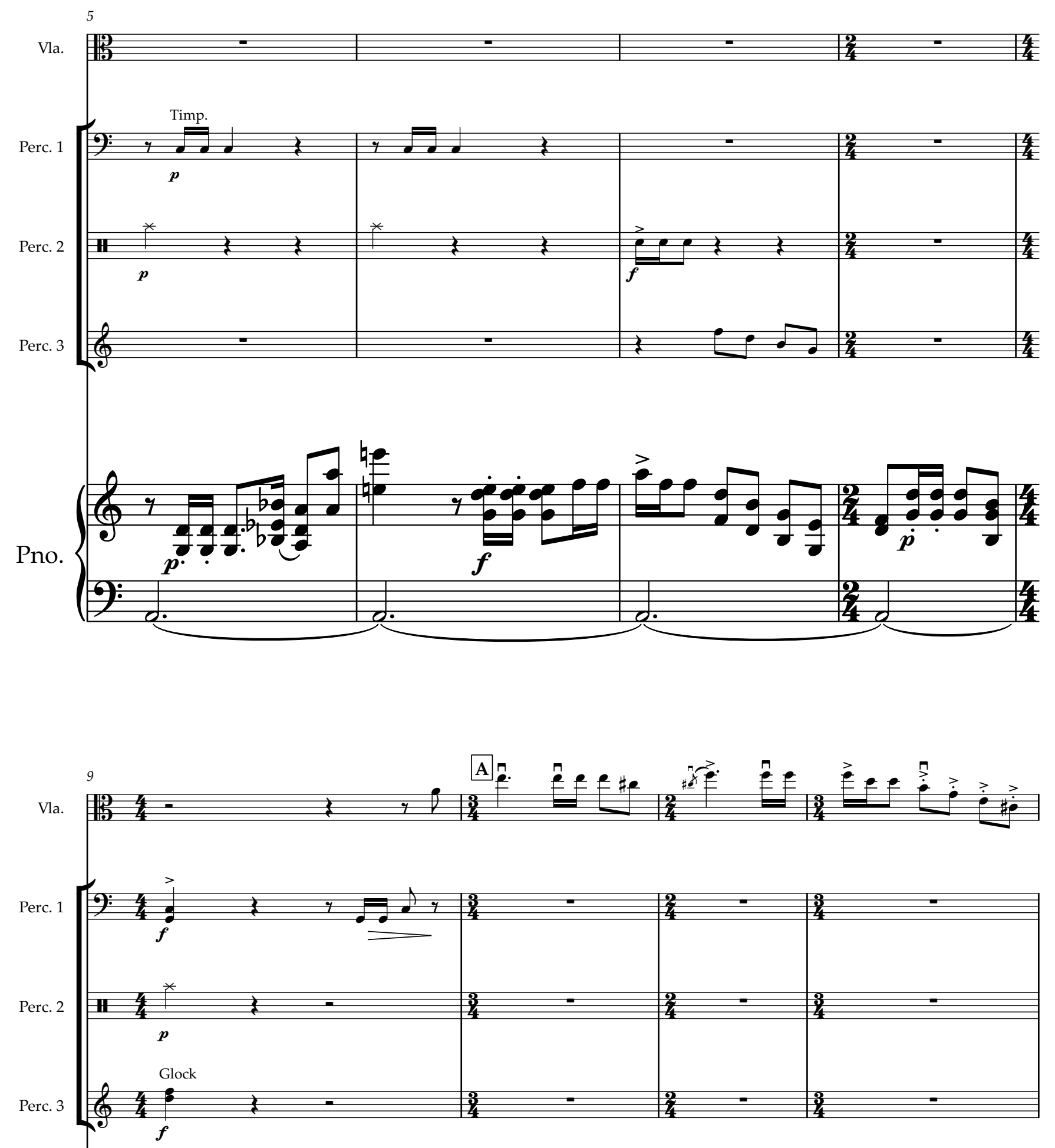

A

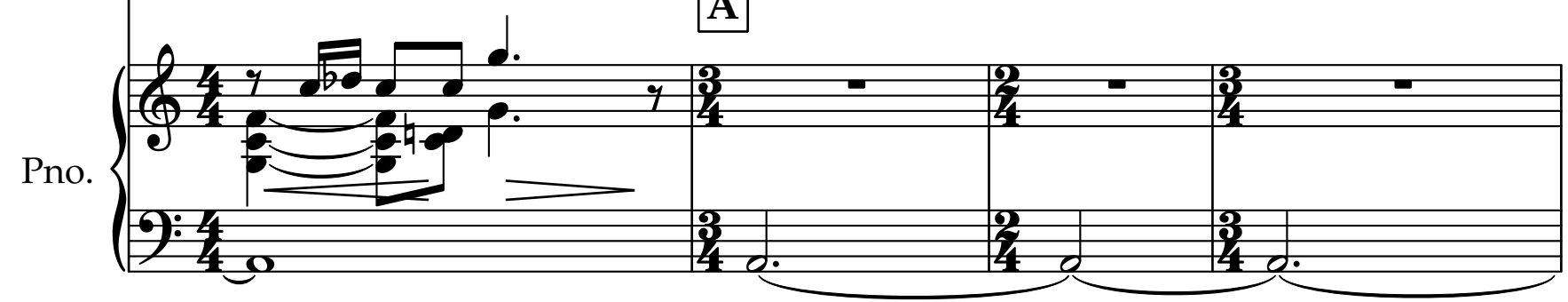



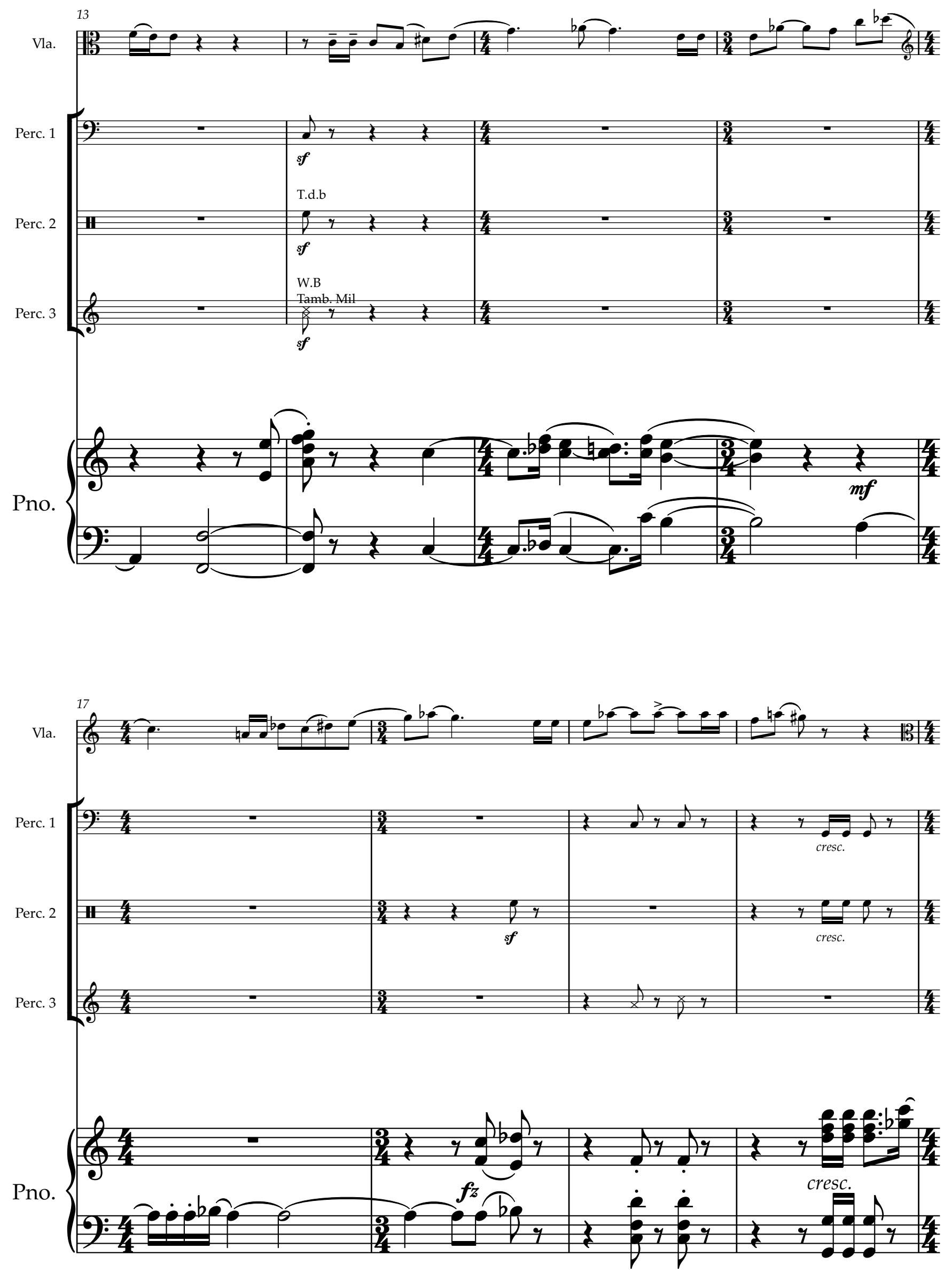

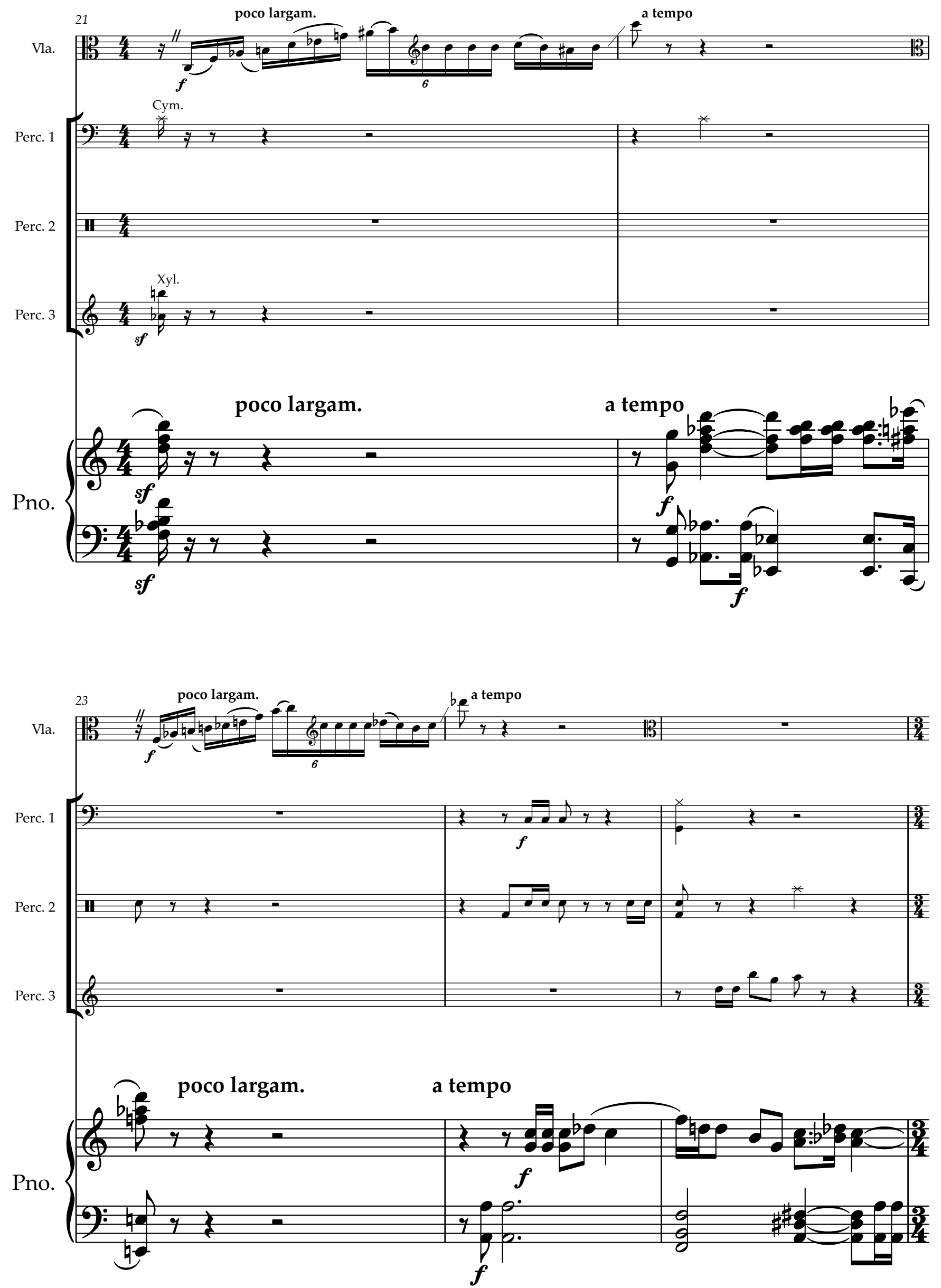

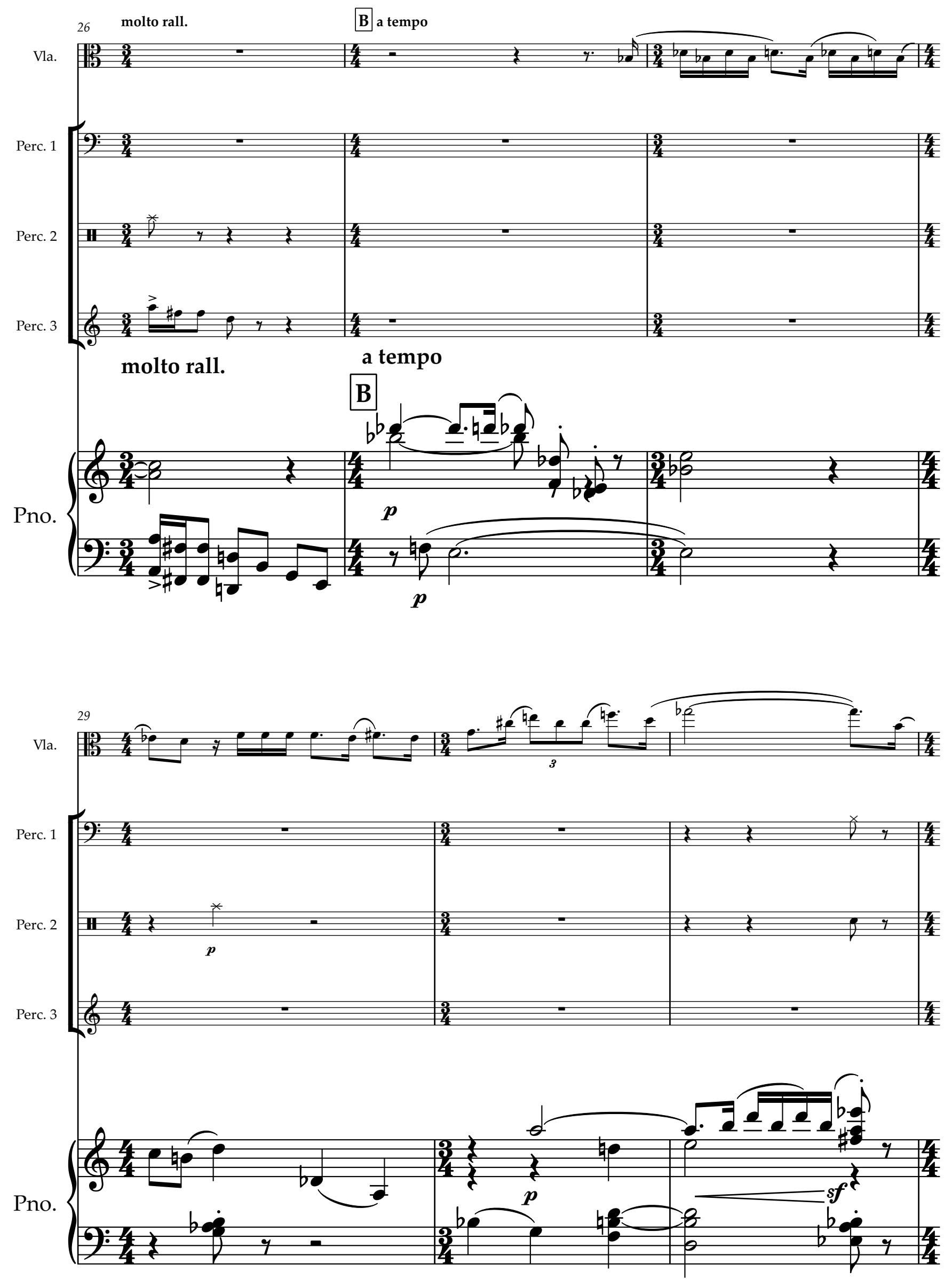

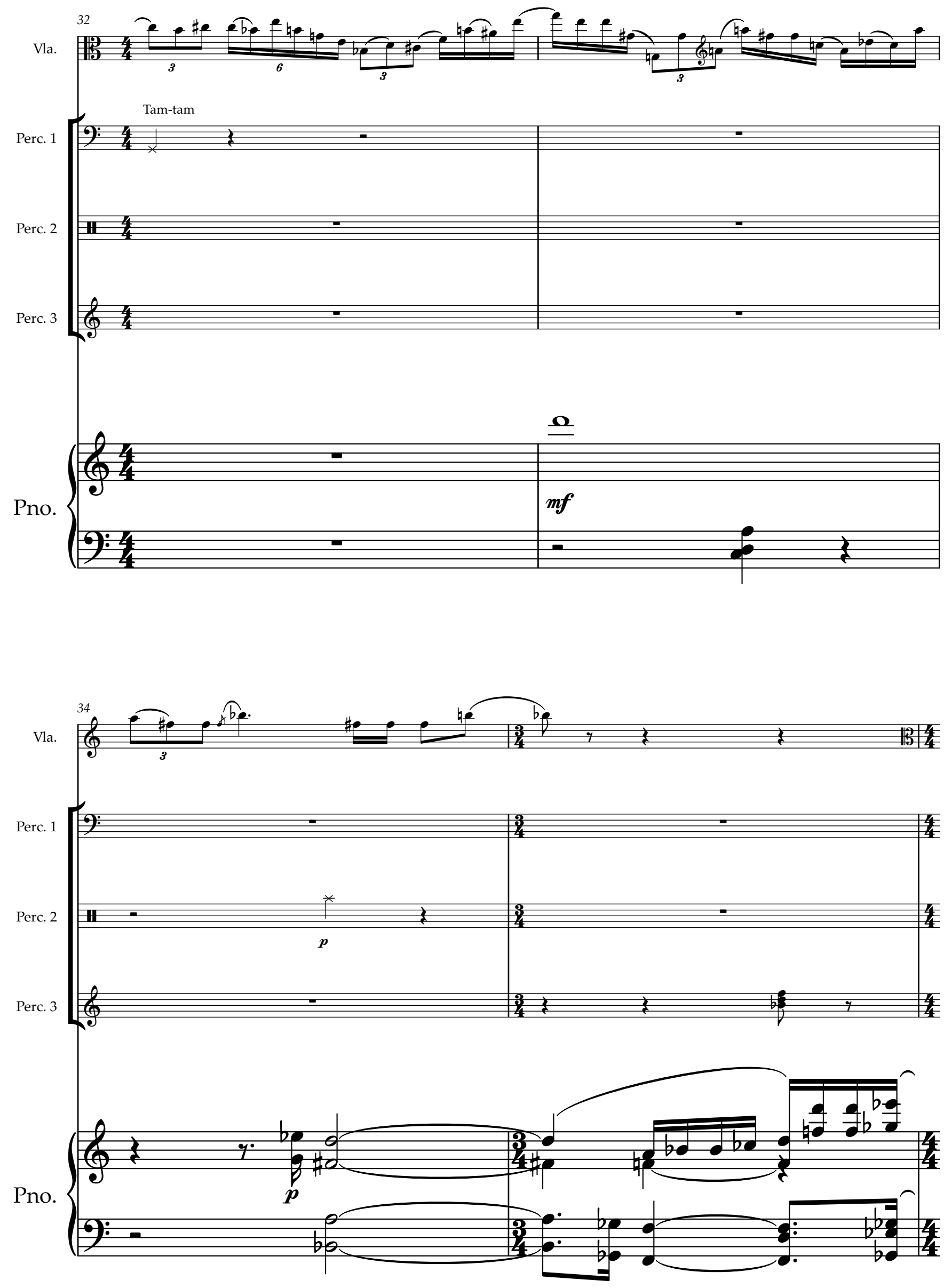

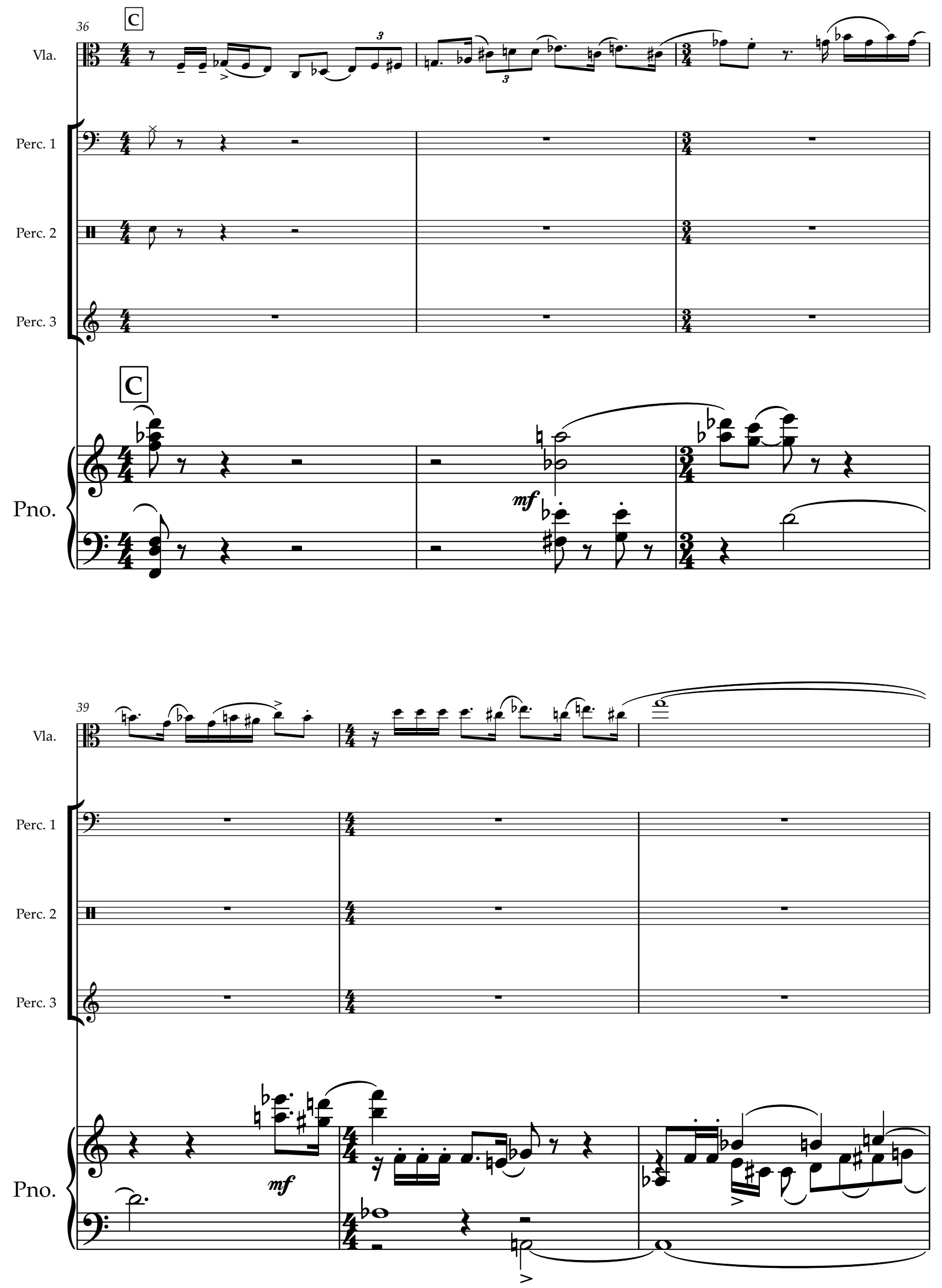

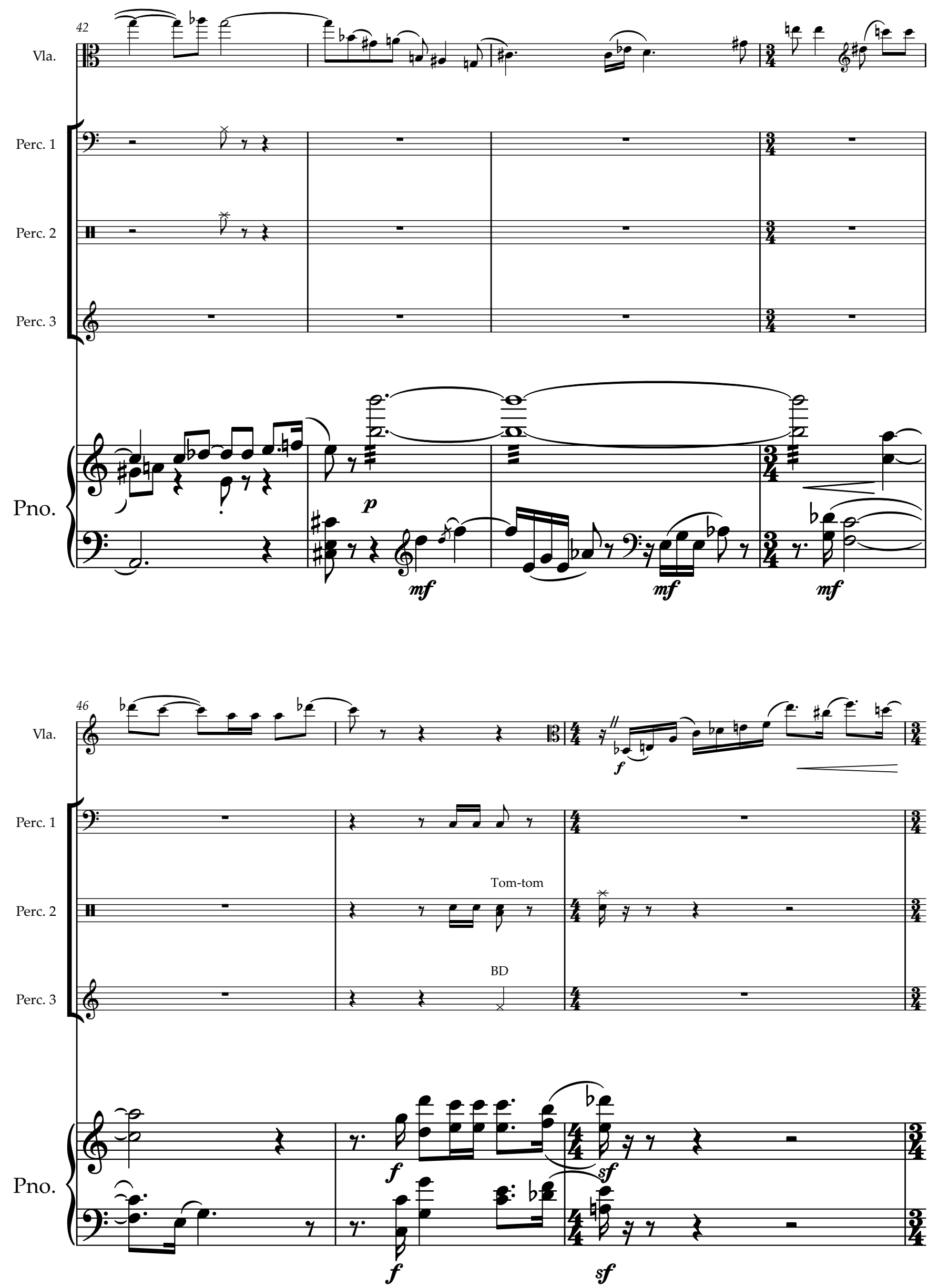

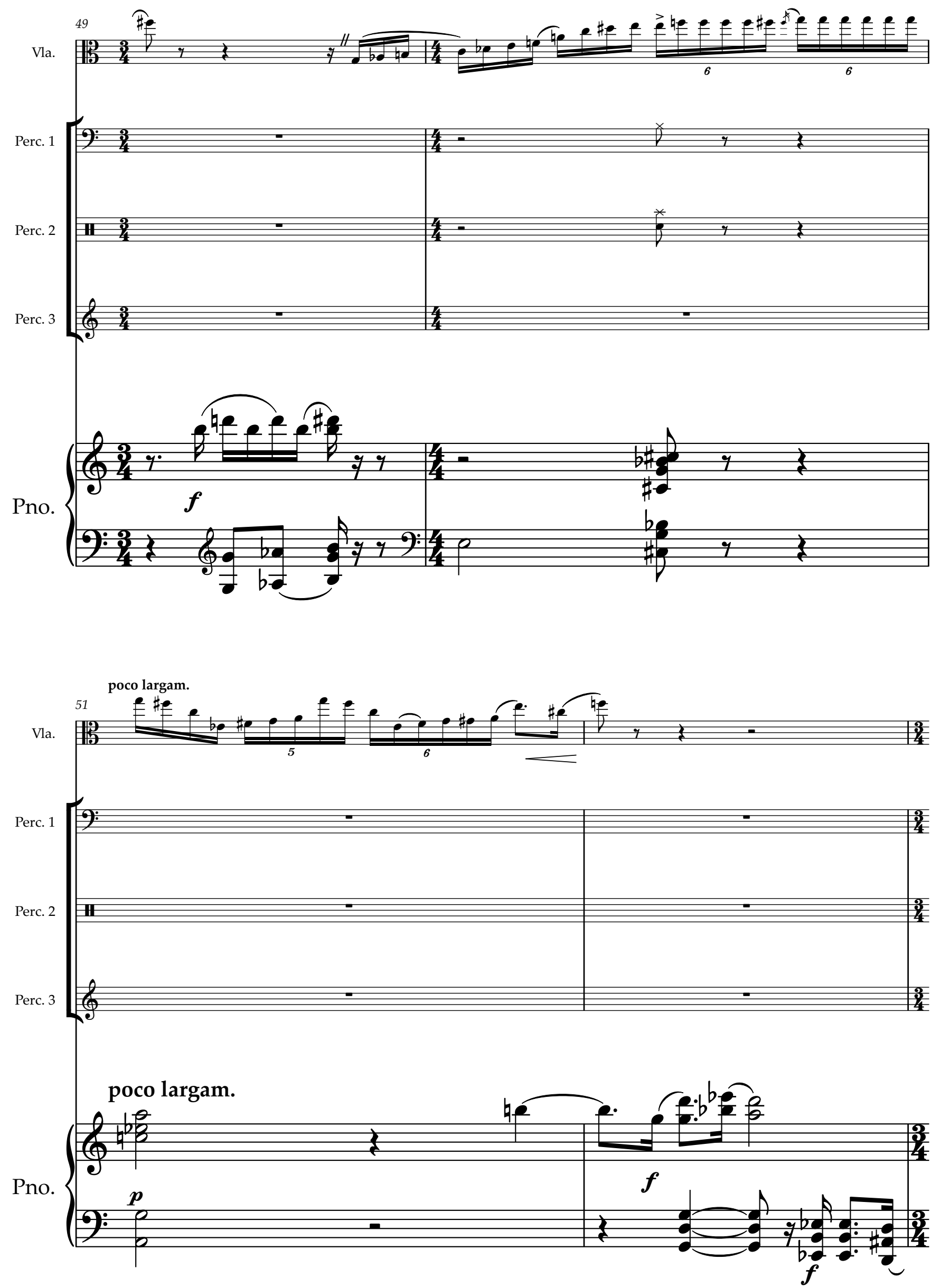

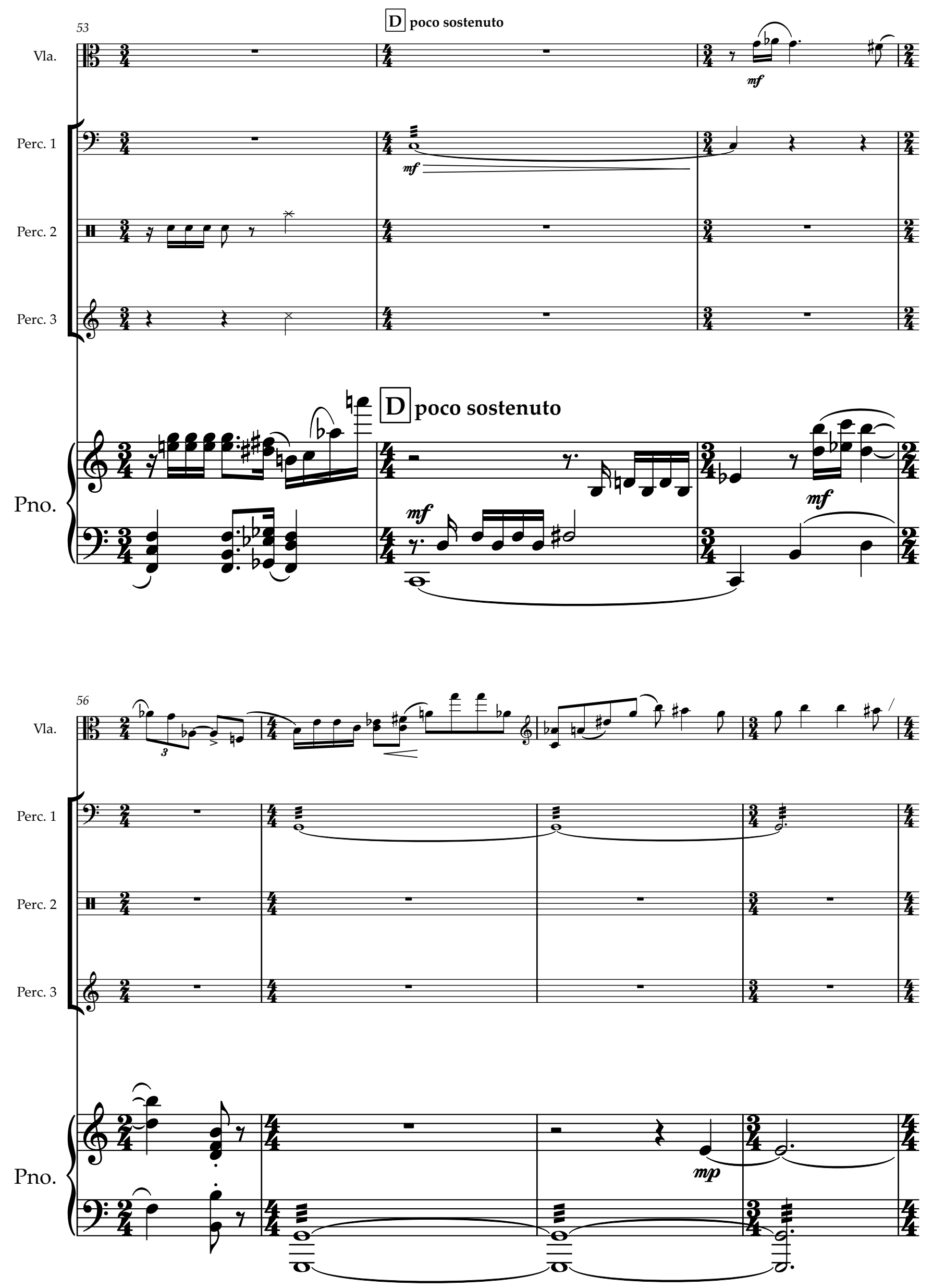

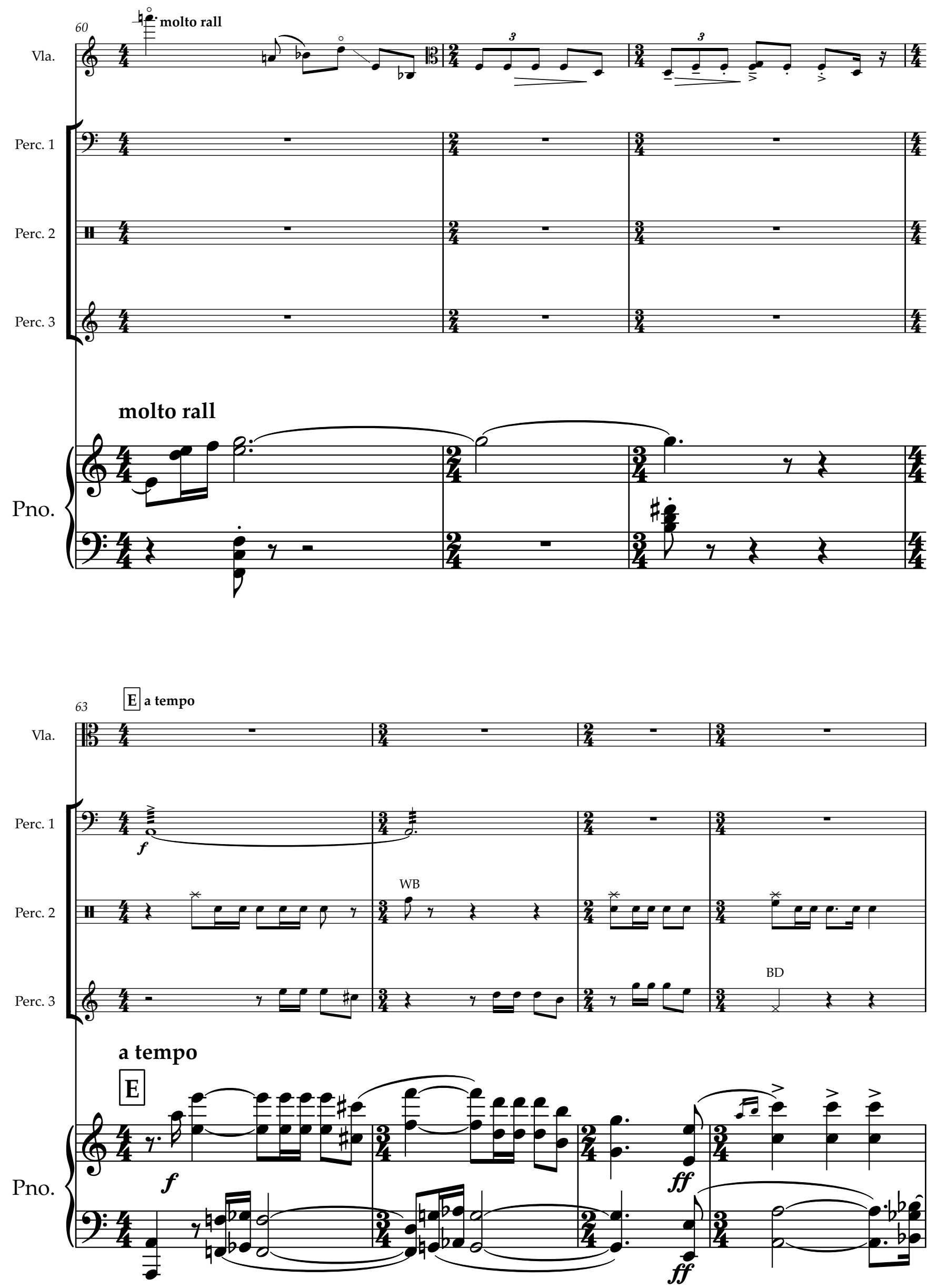

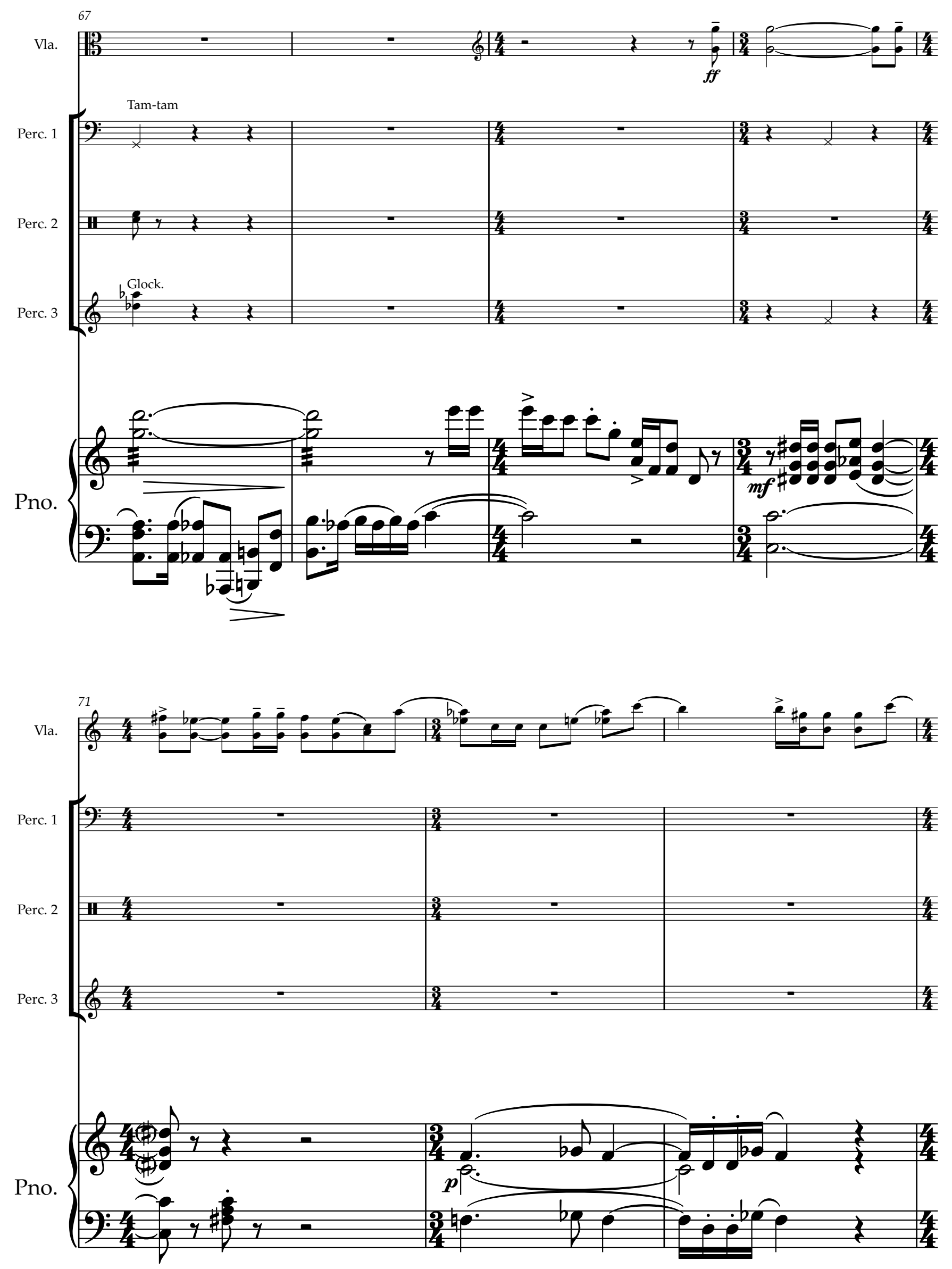

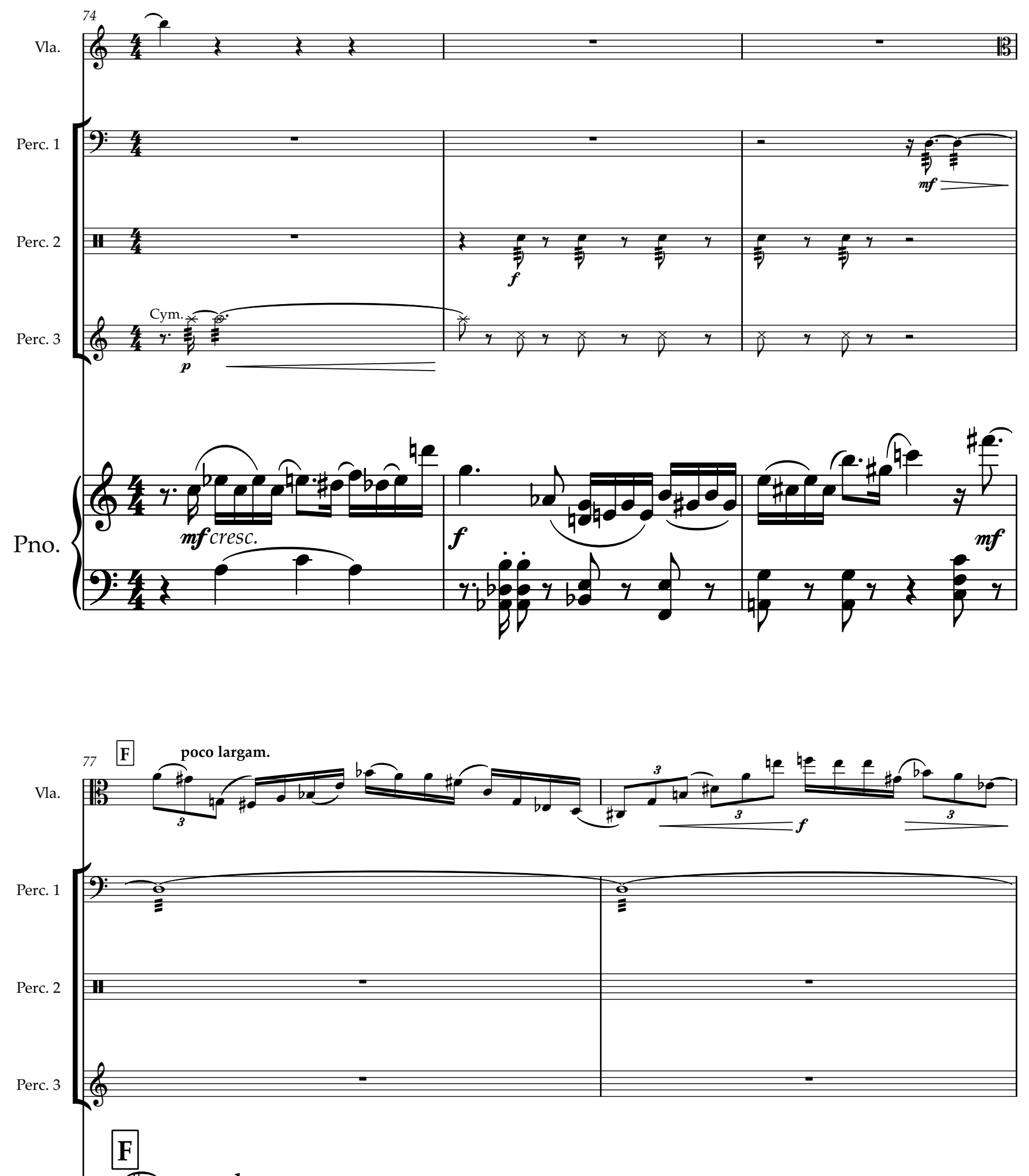

(\#) e.poco largam.

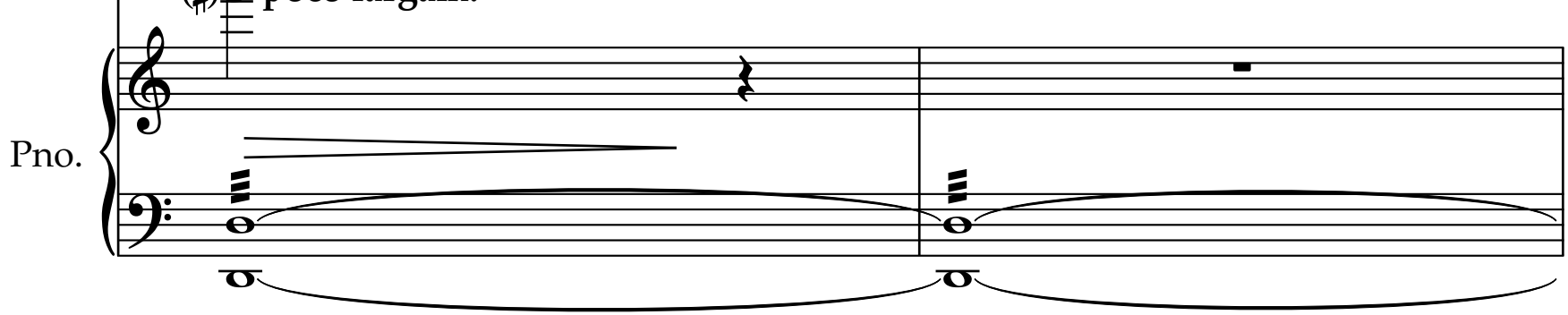



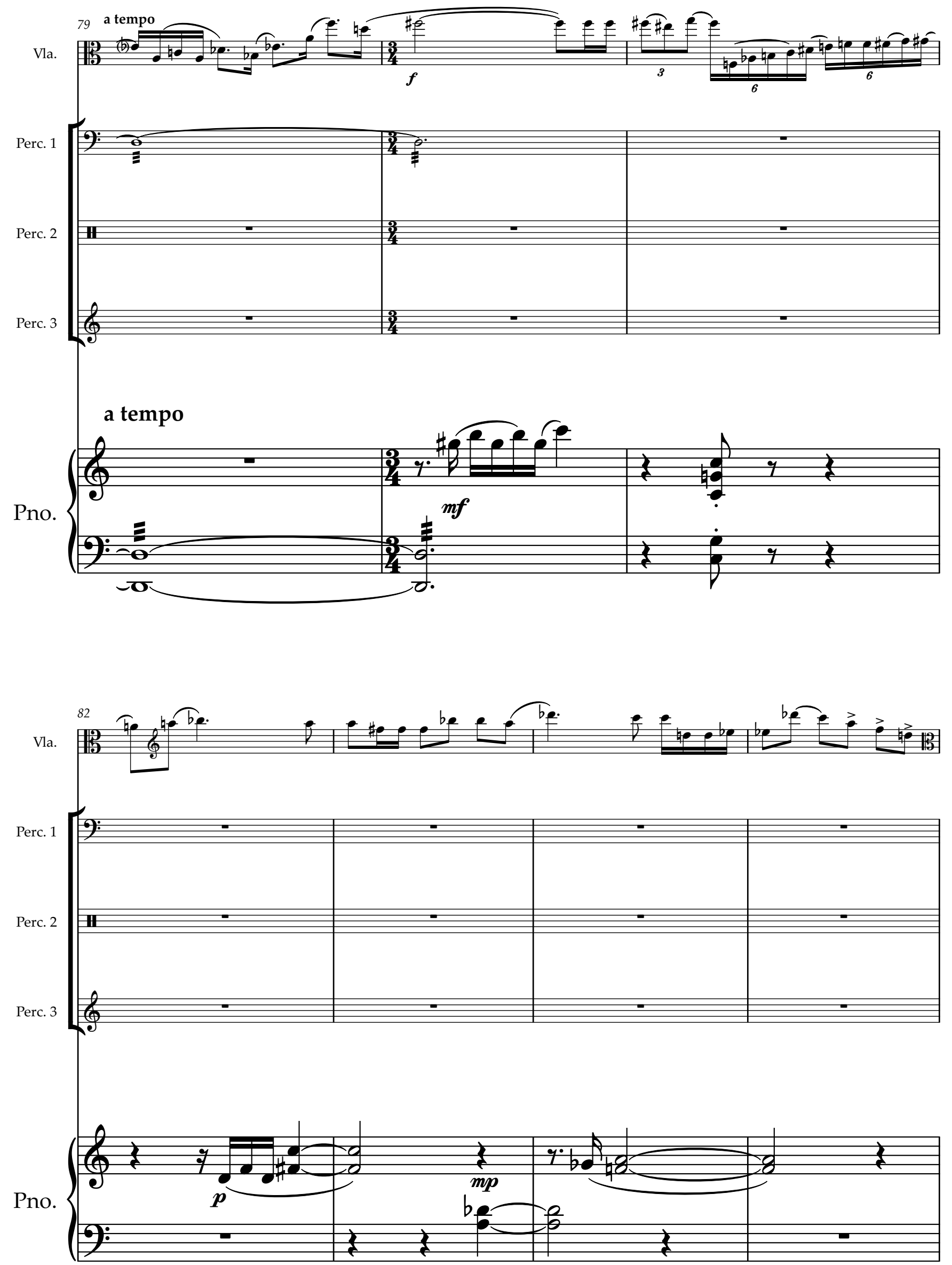

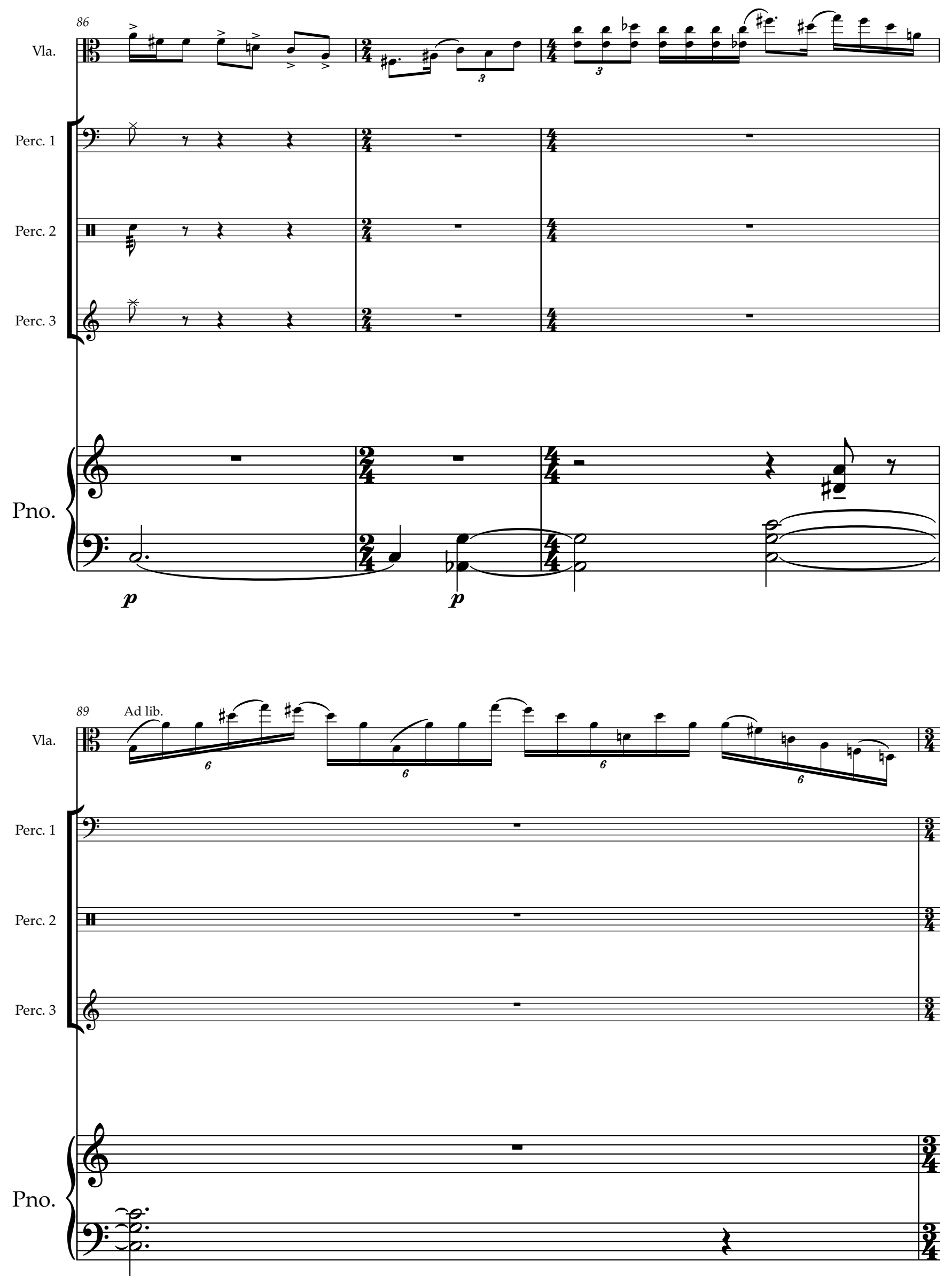

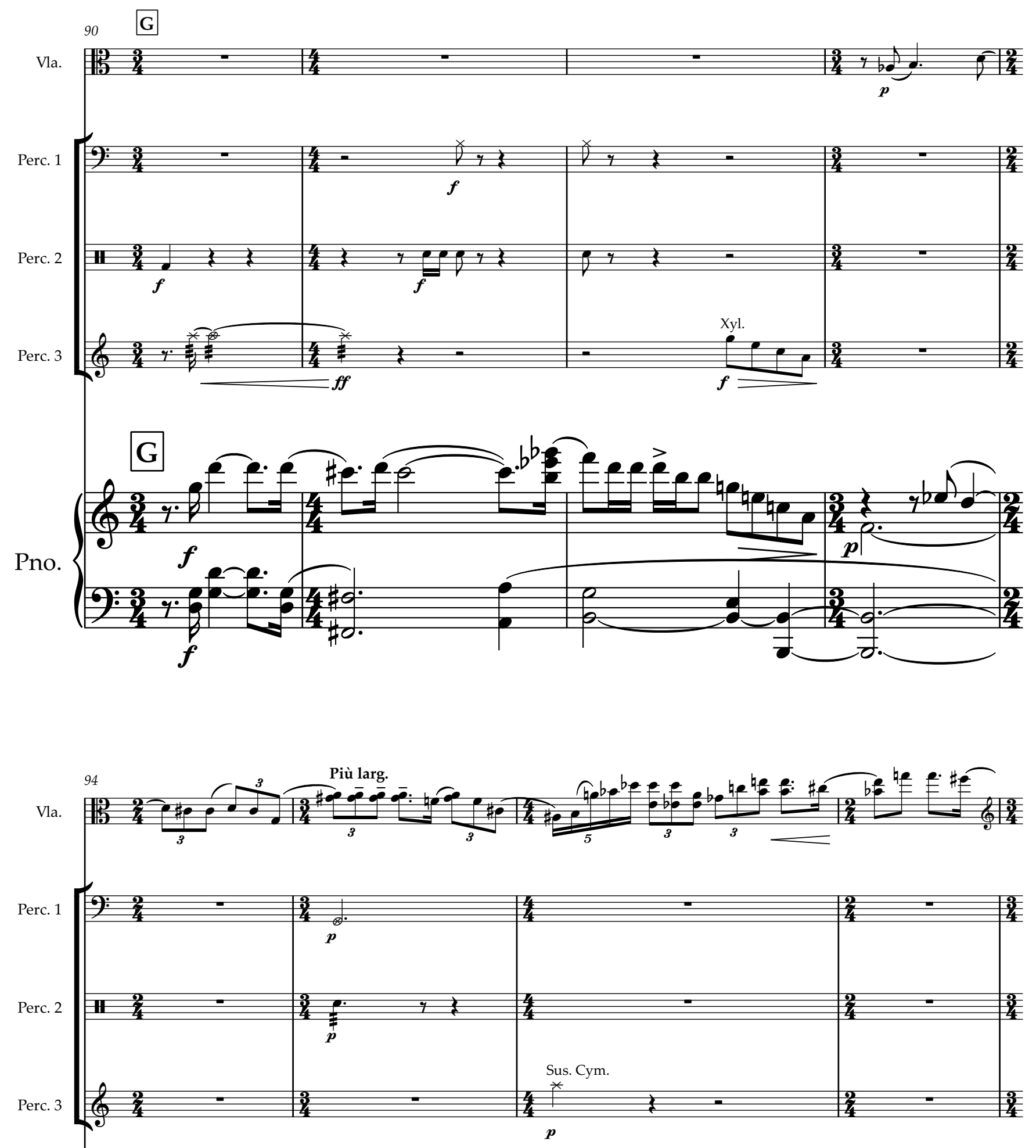

Più larg.

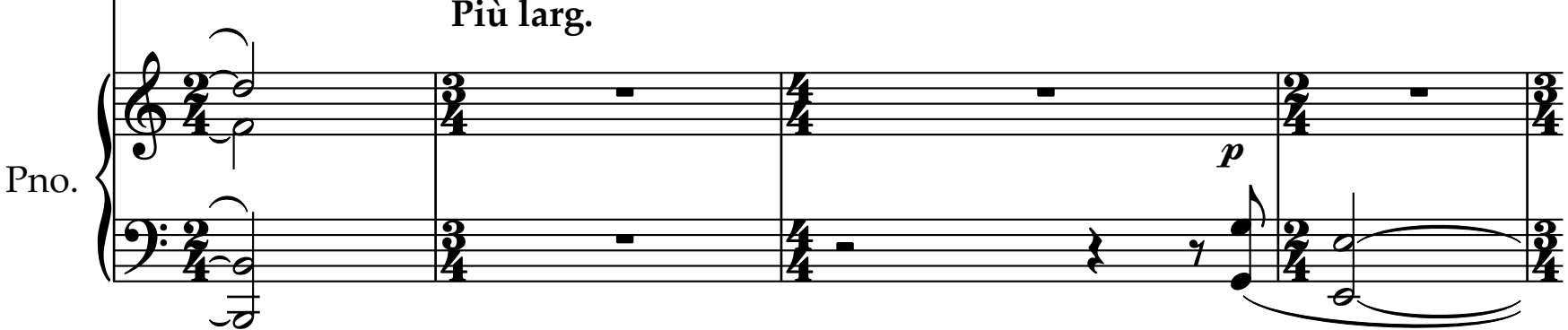




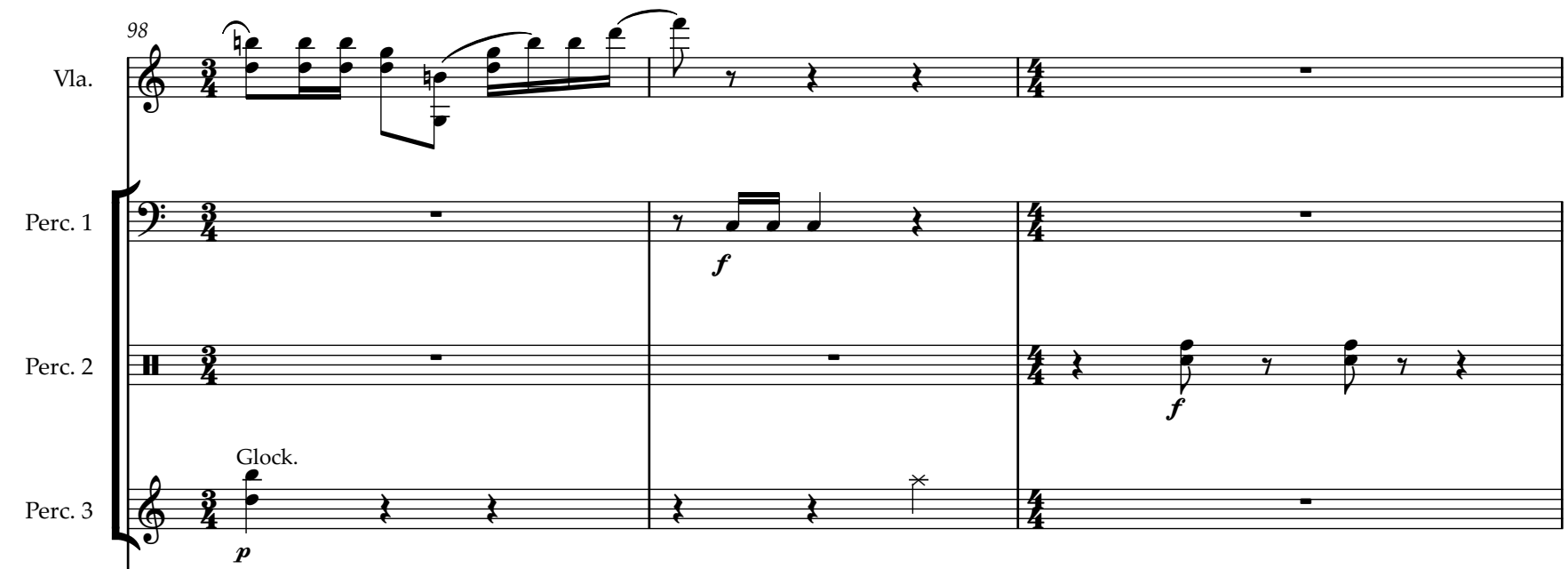

Pno.
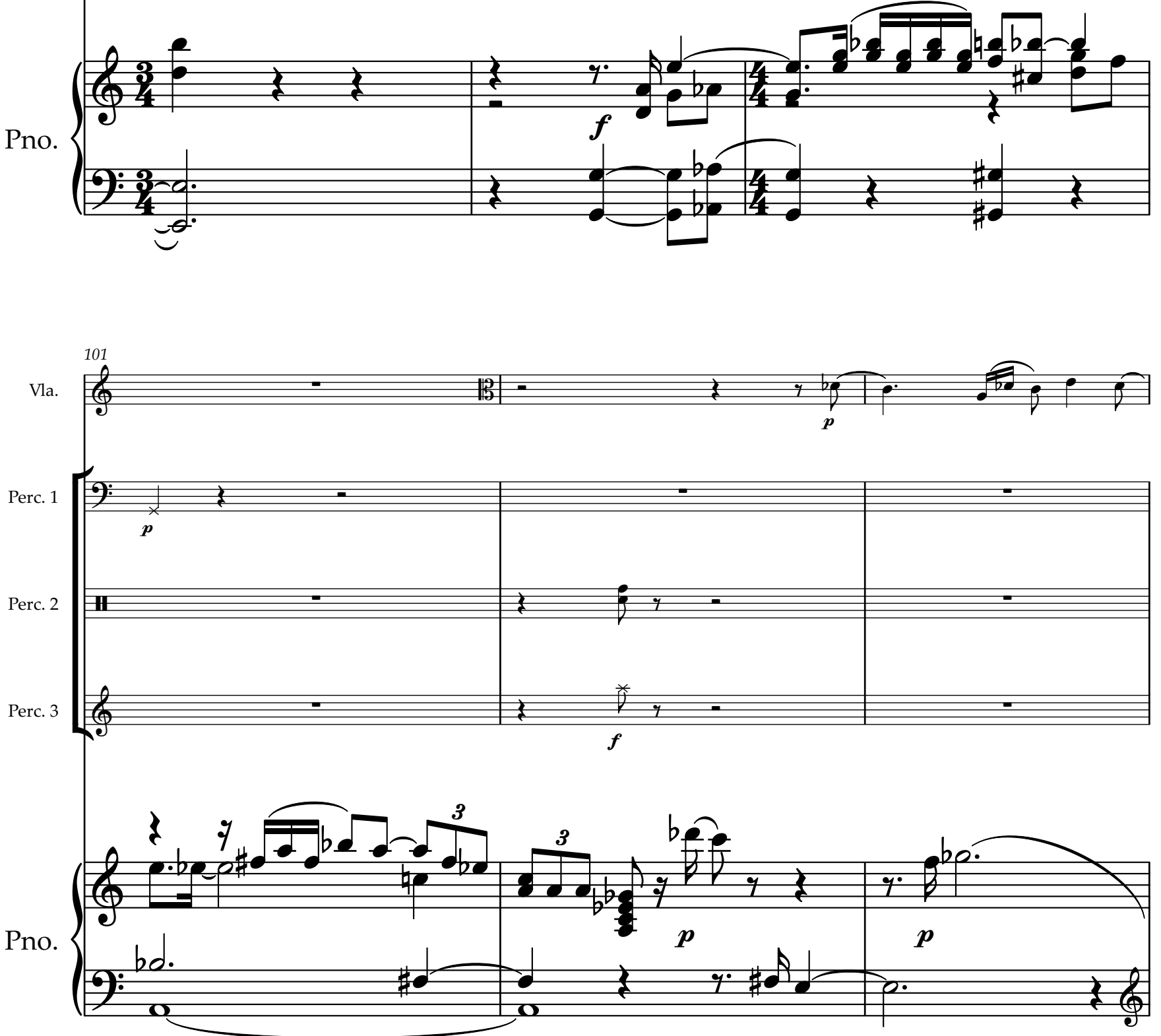

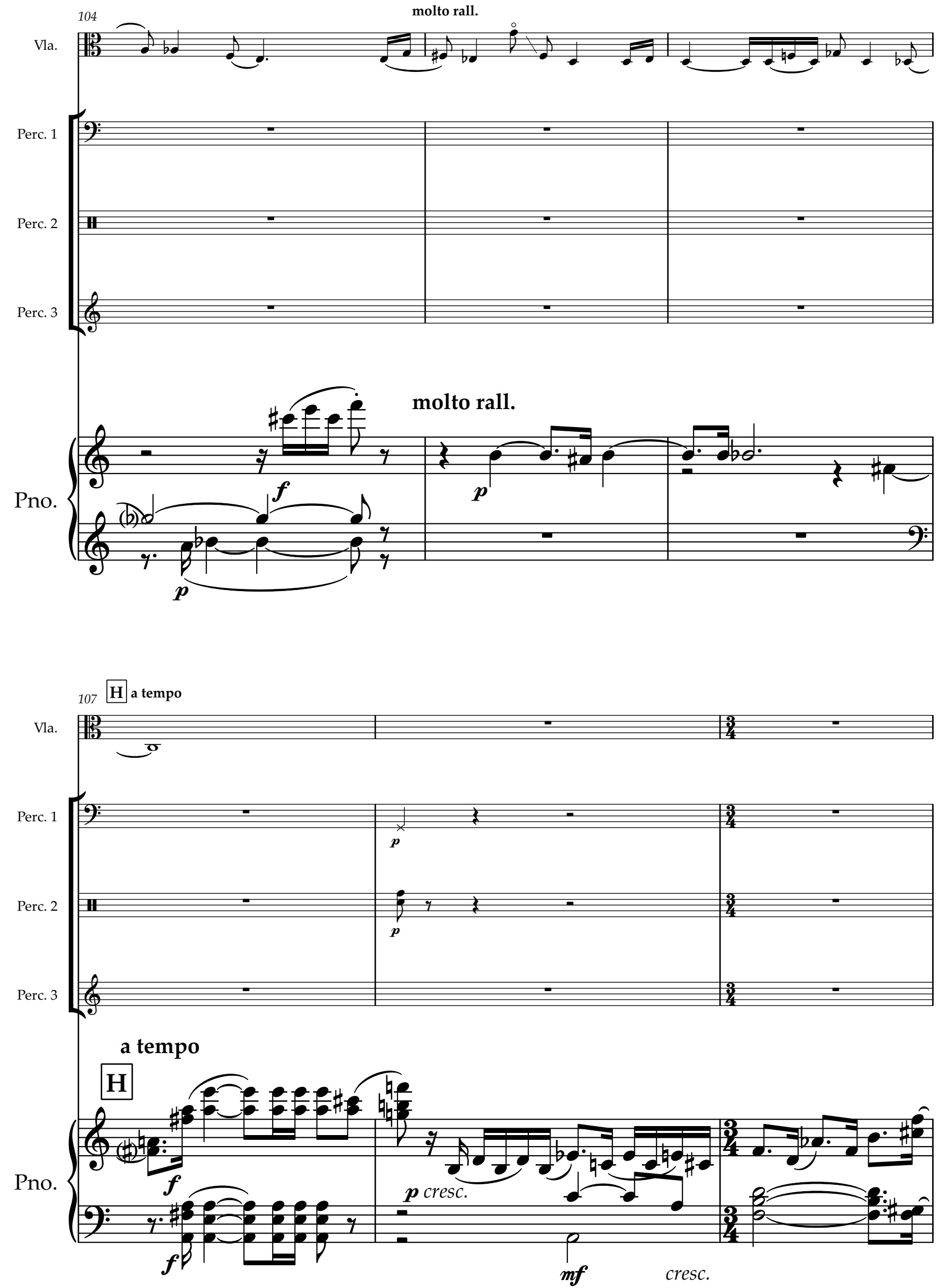

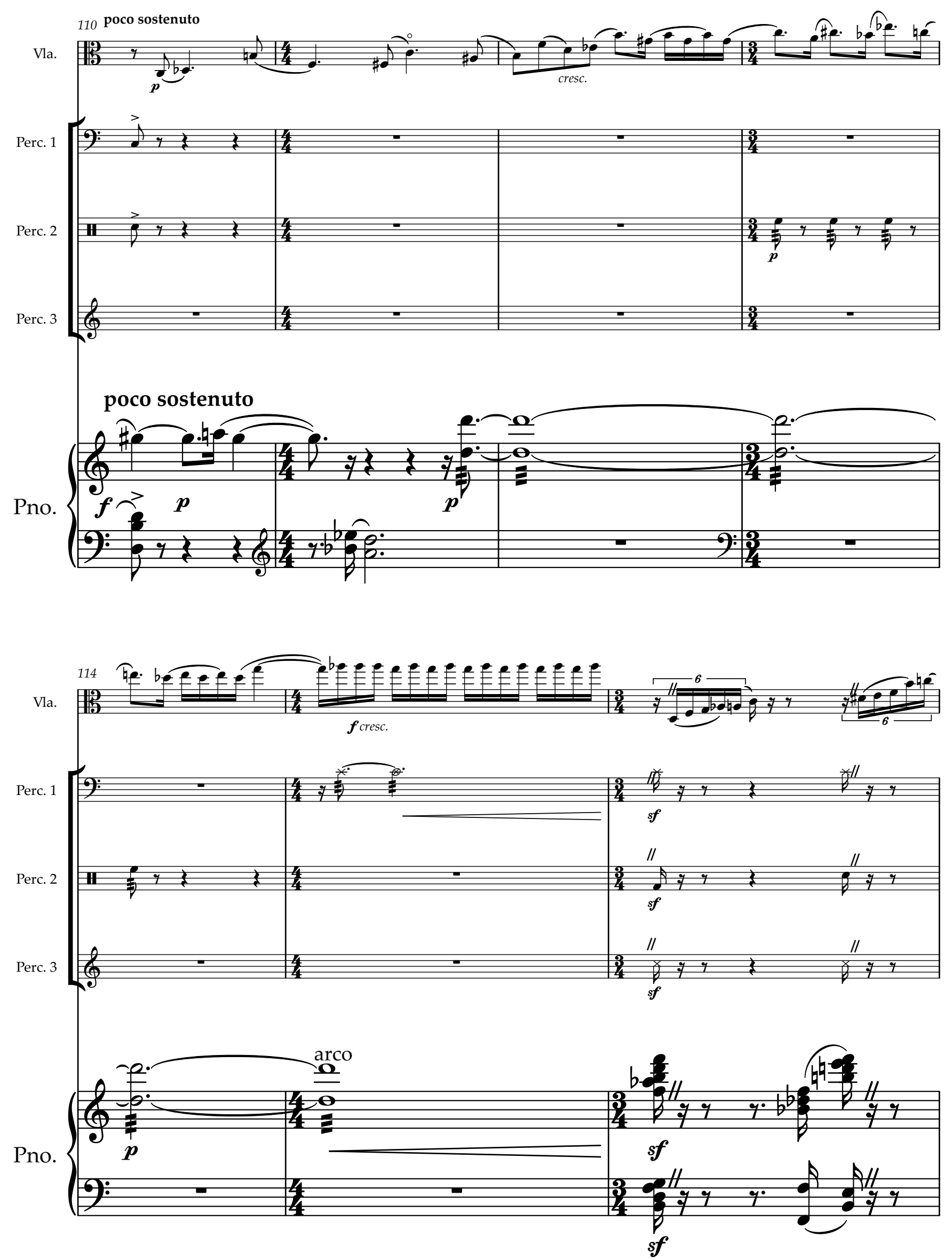

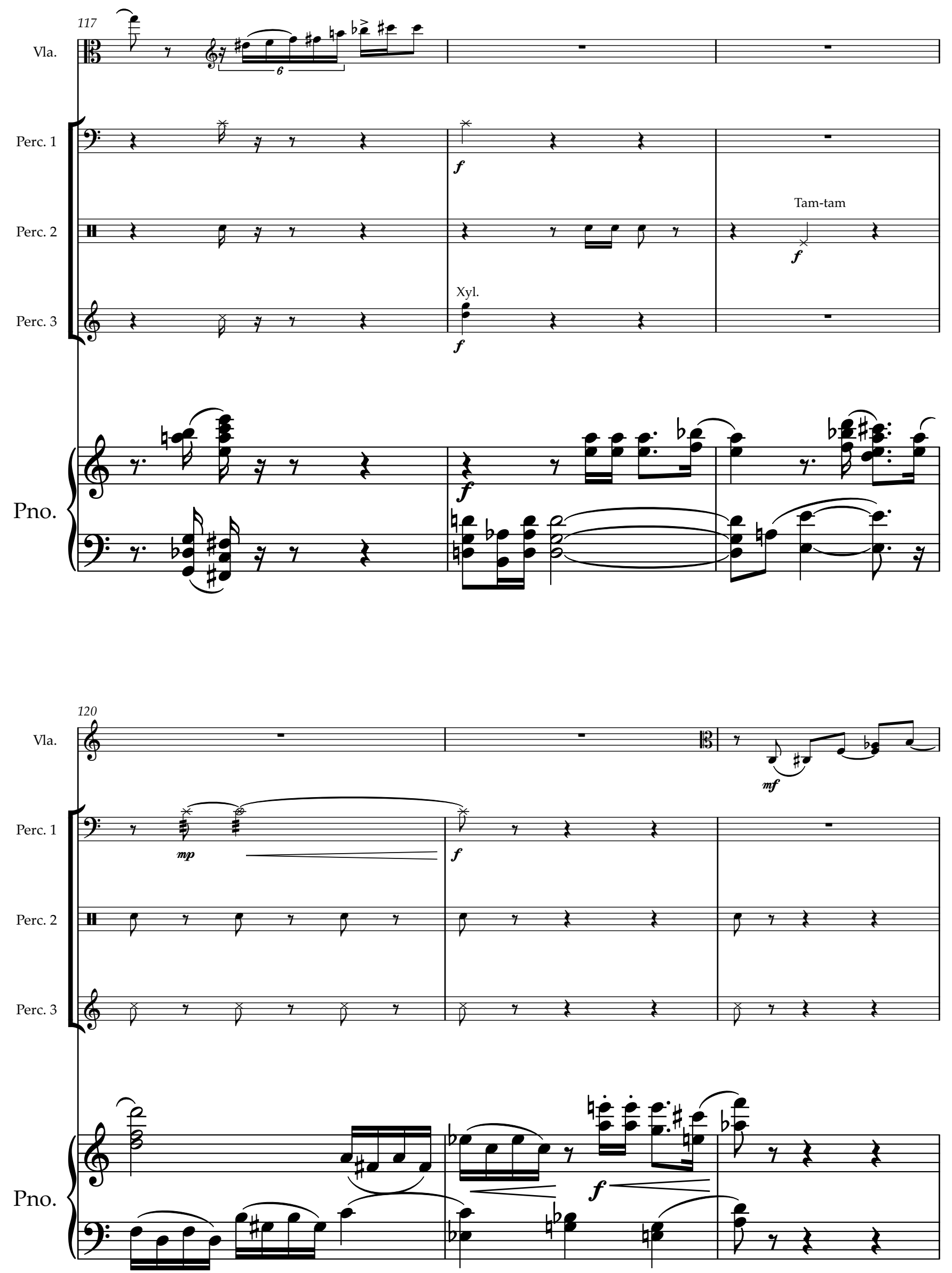

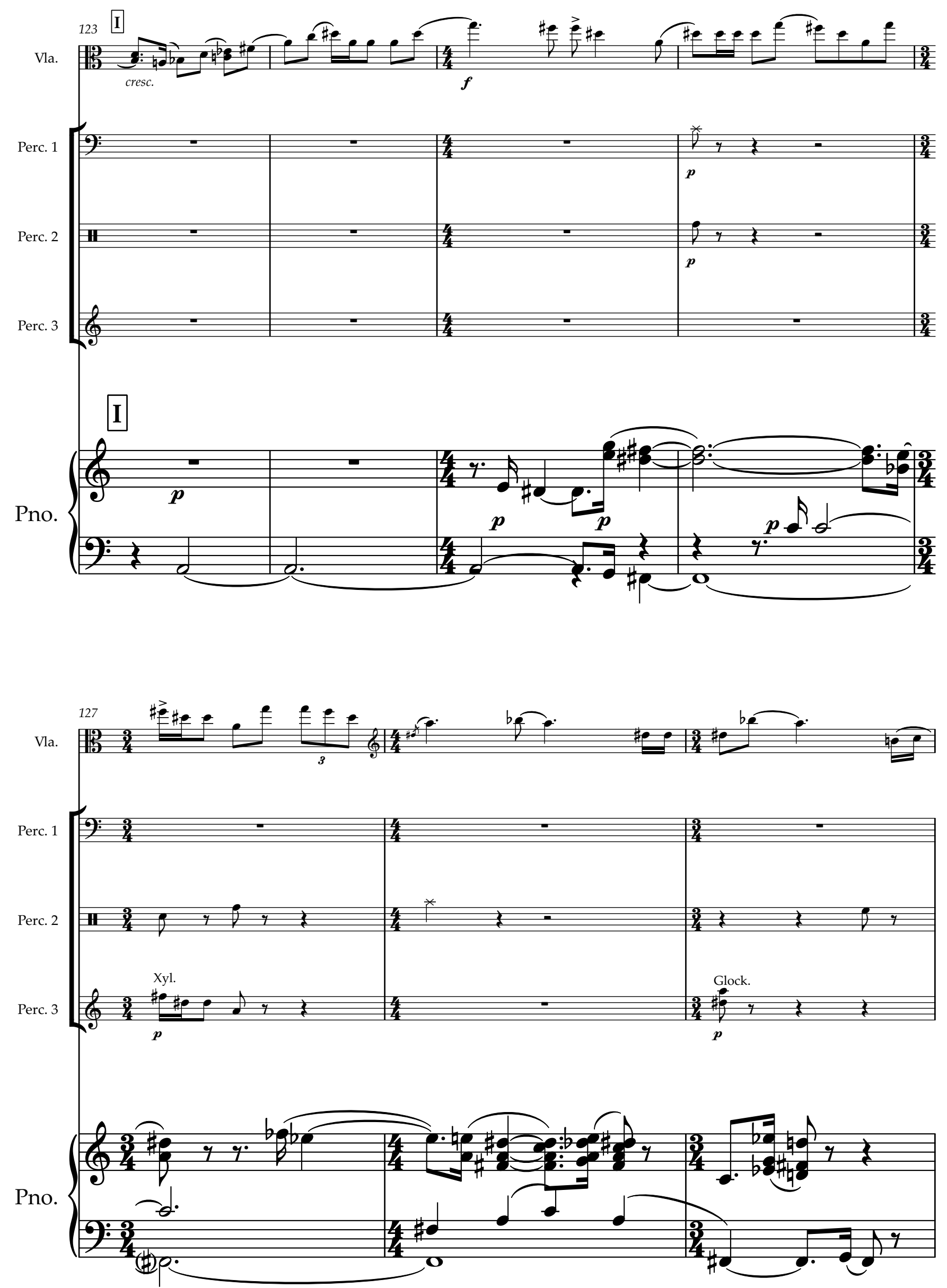

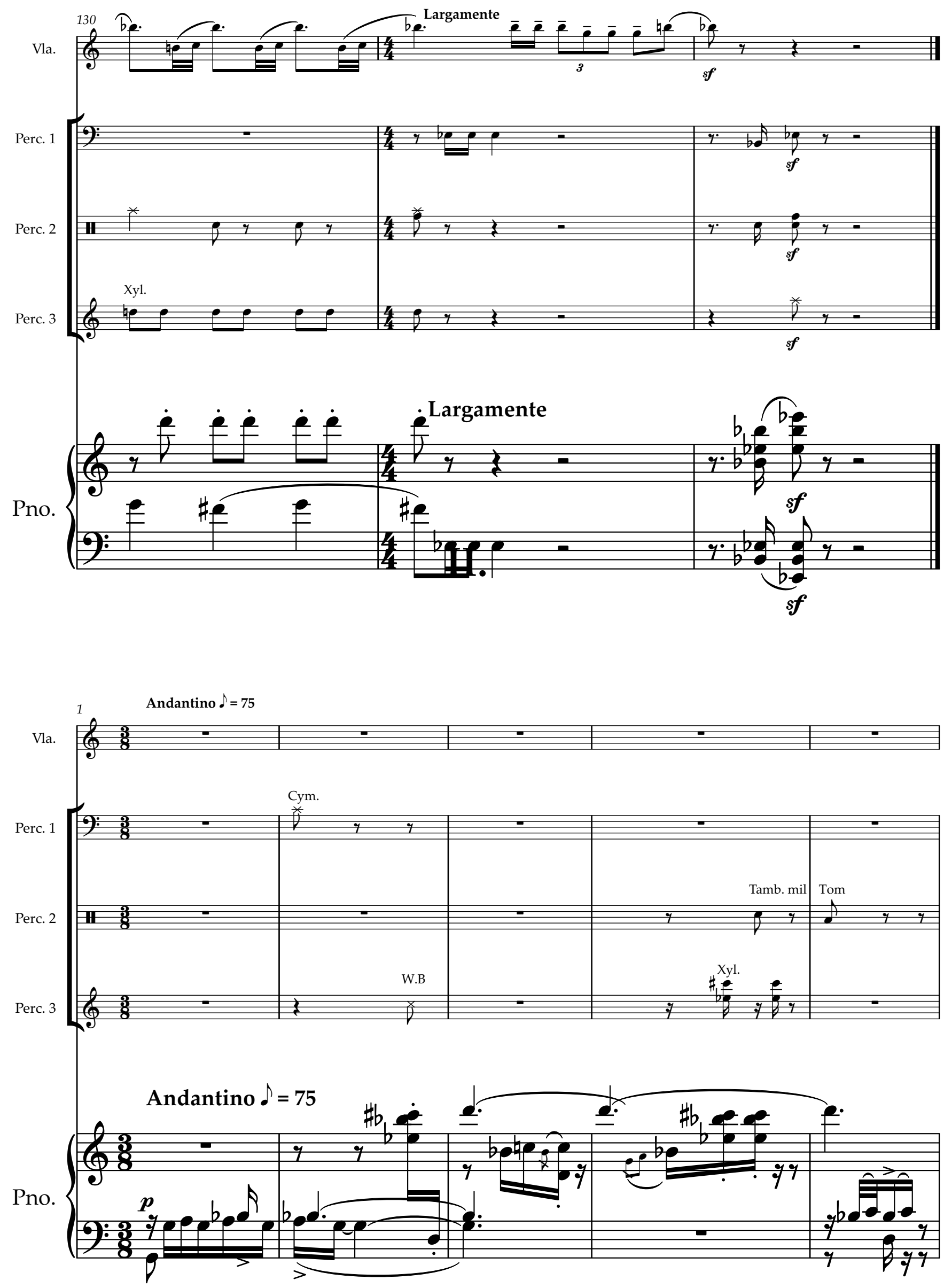

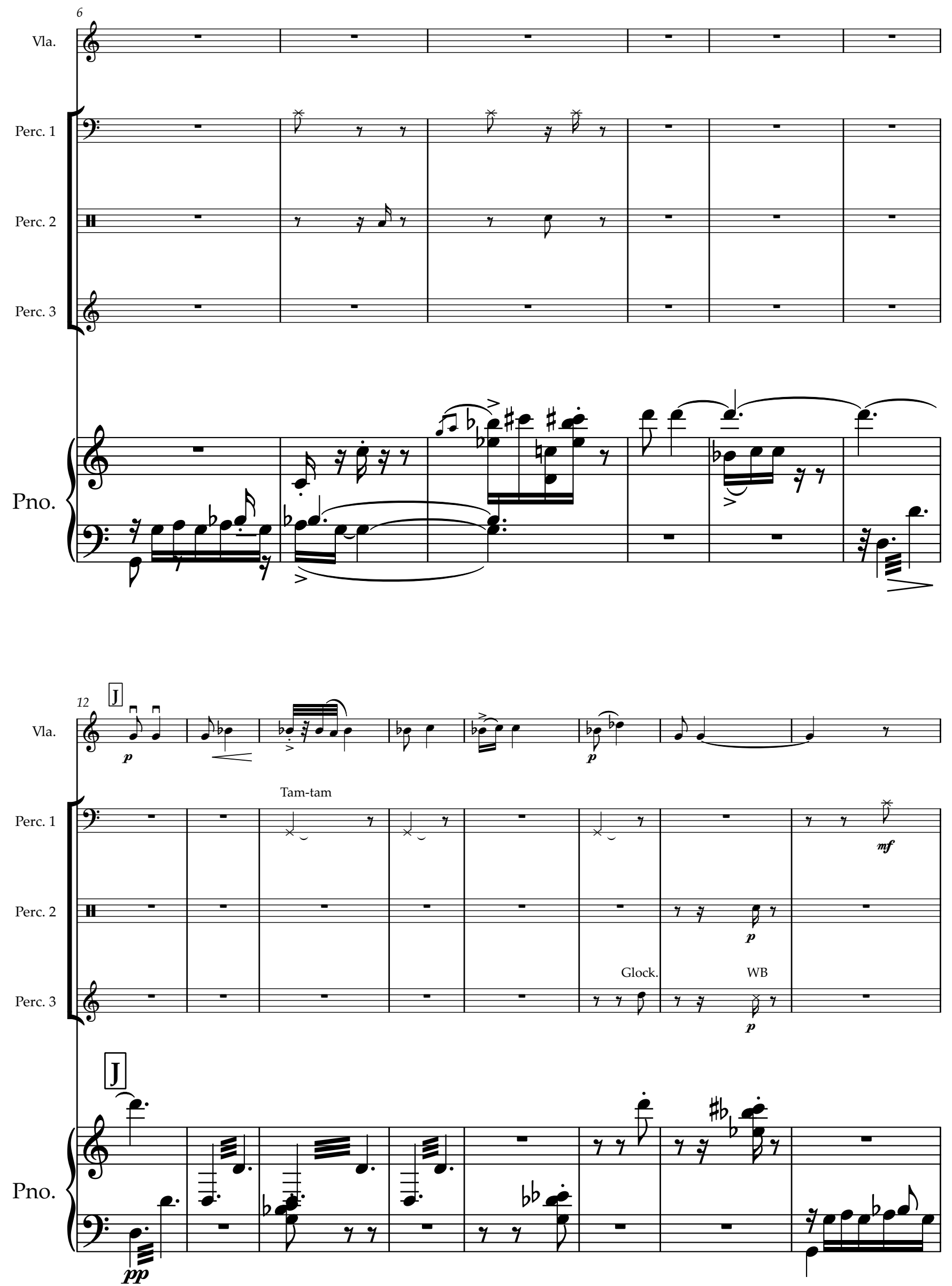

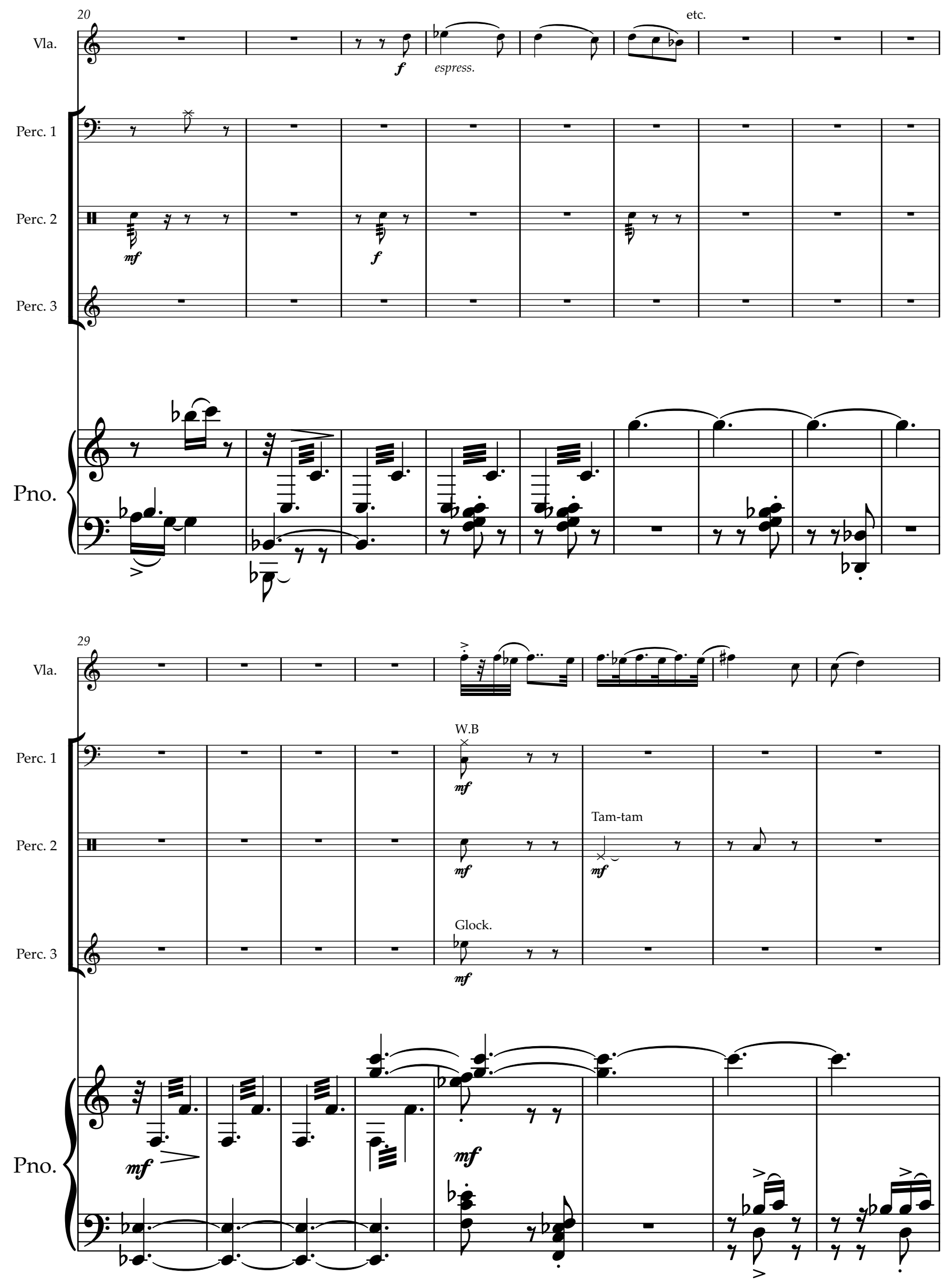

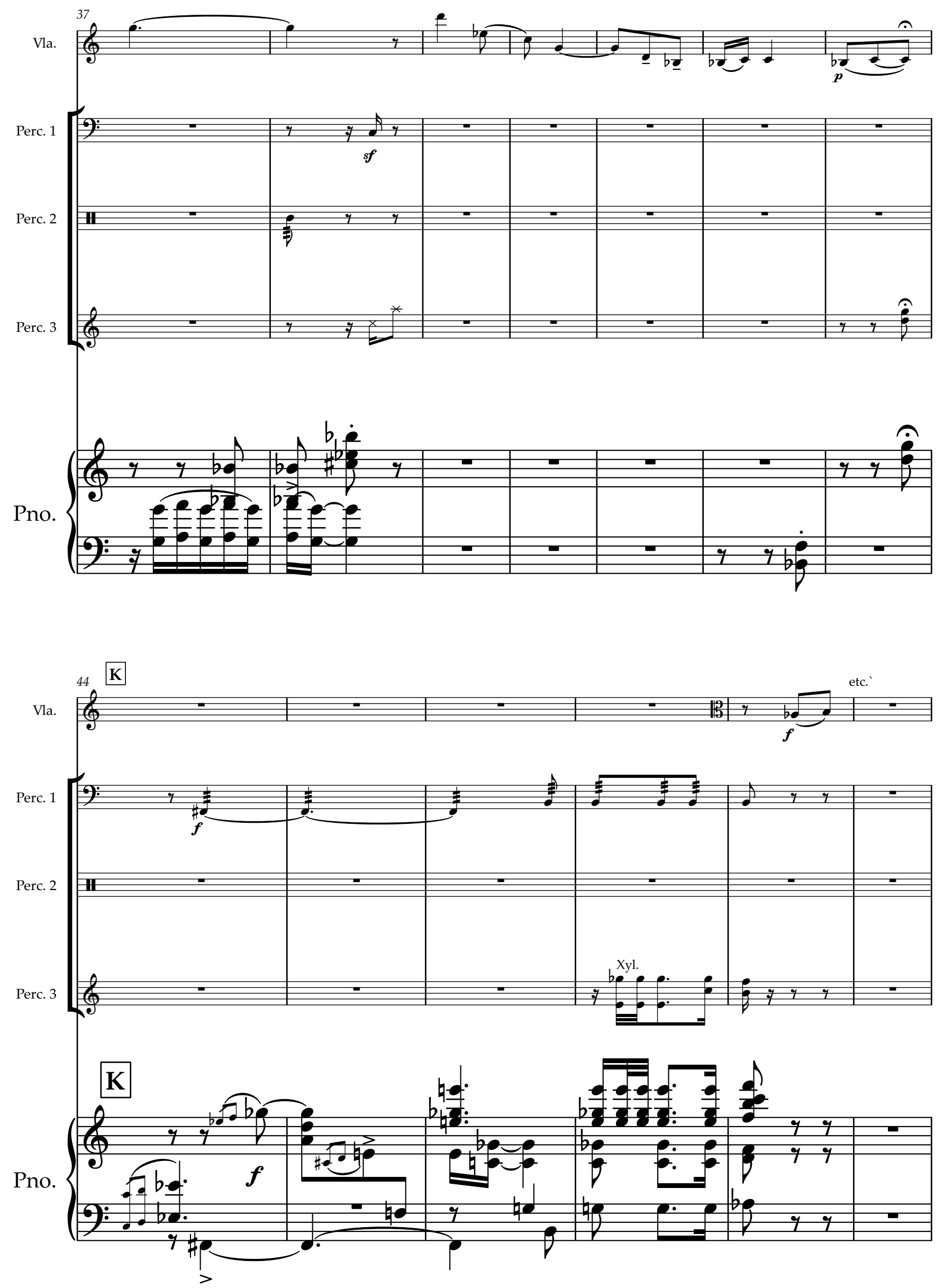

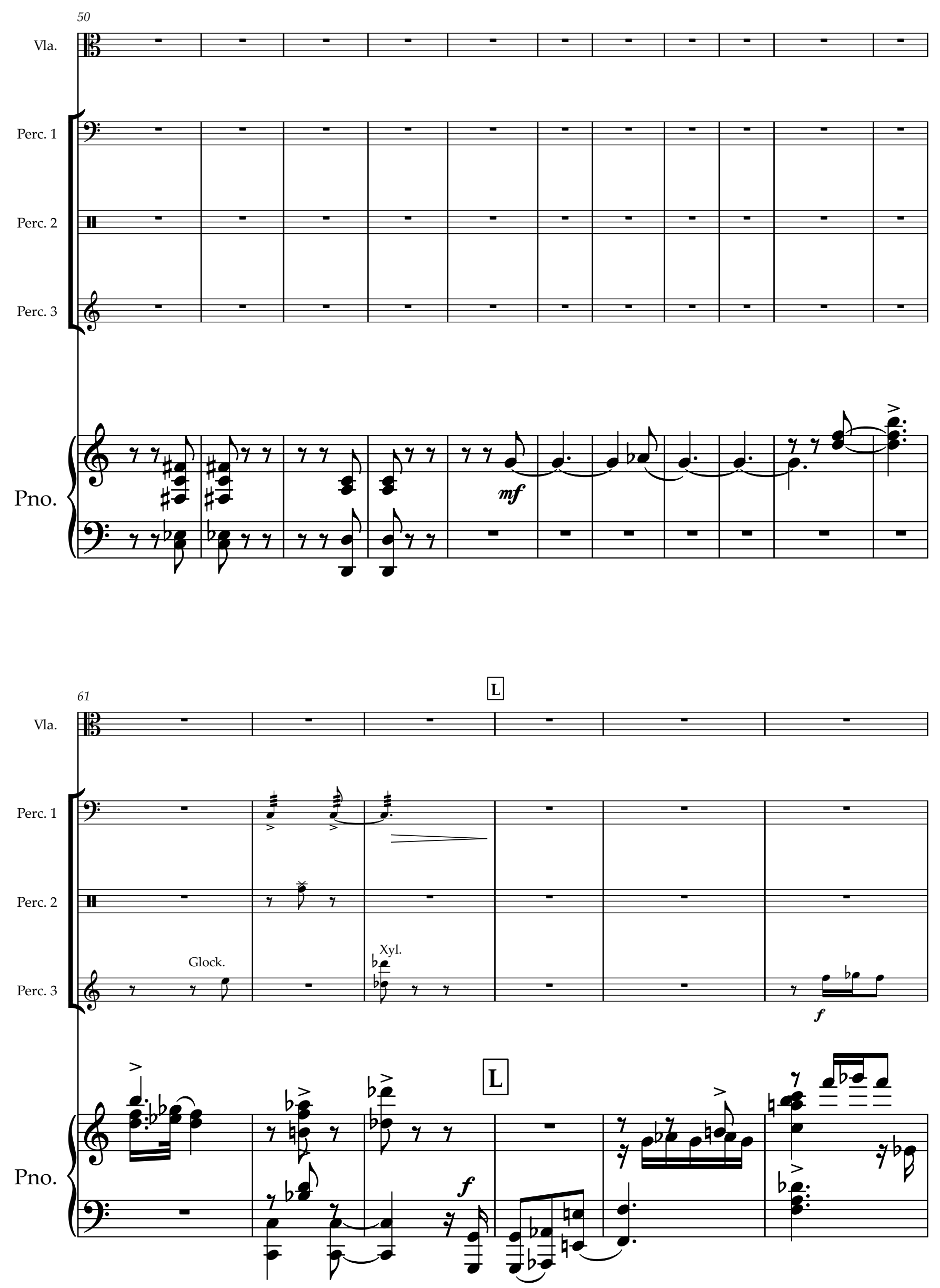

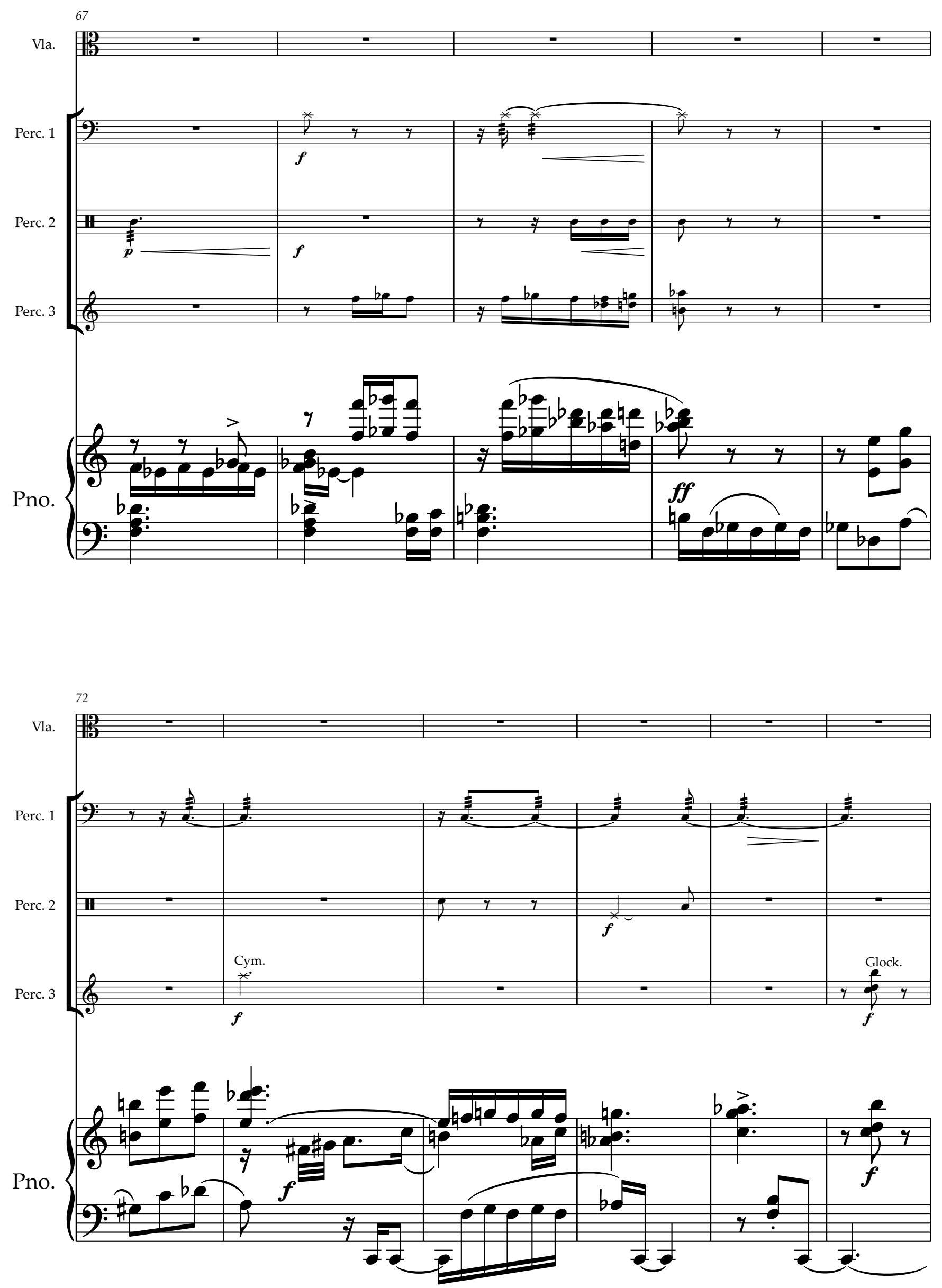

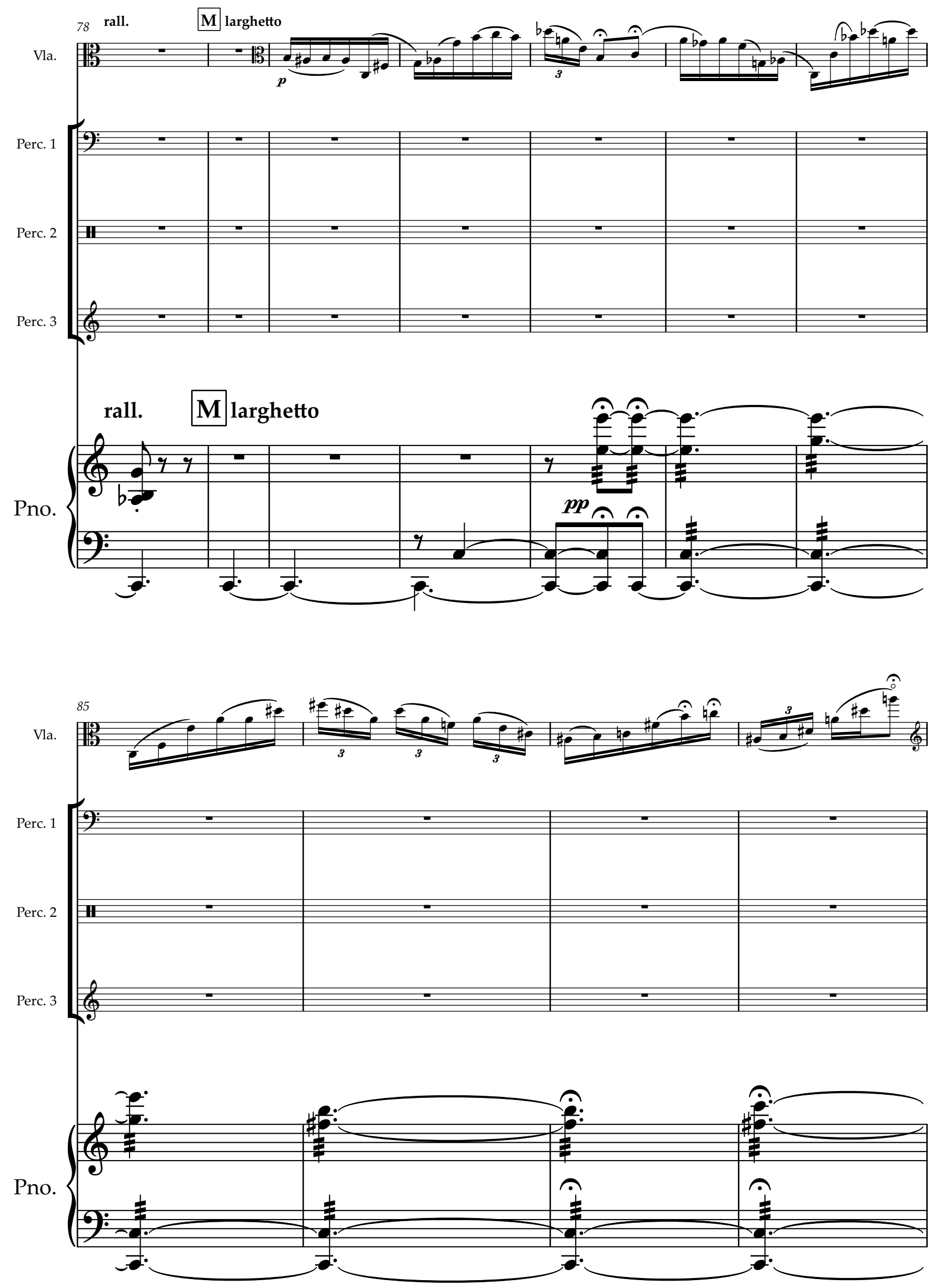

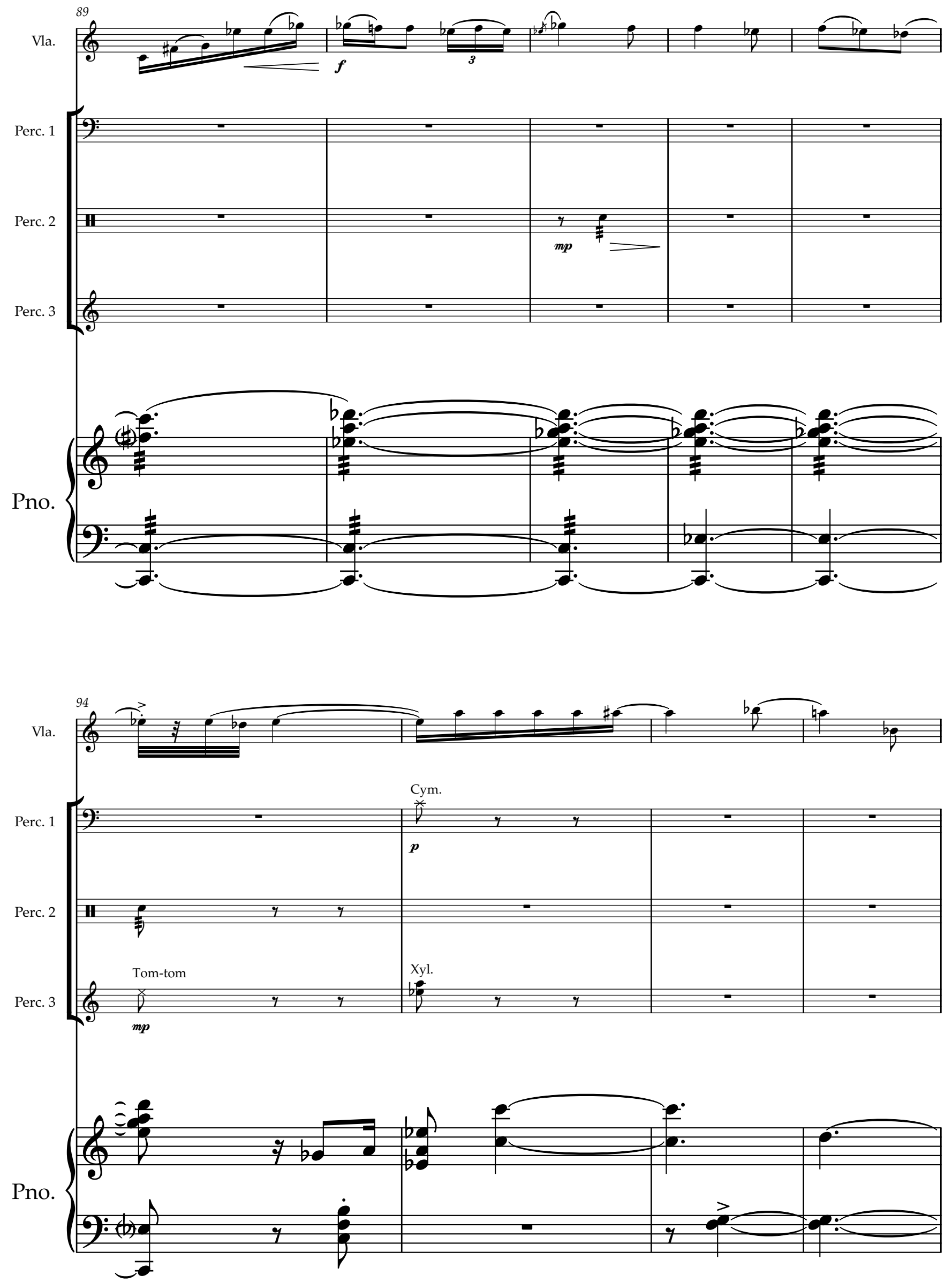

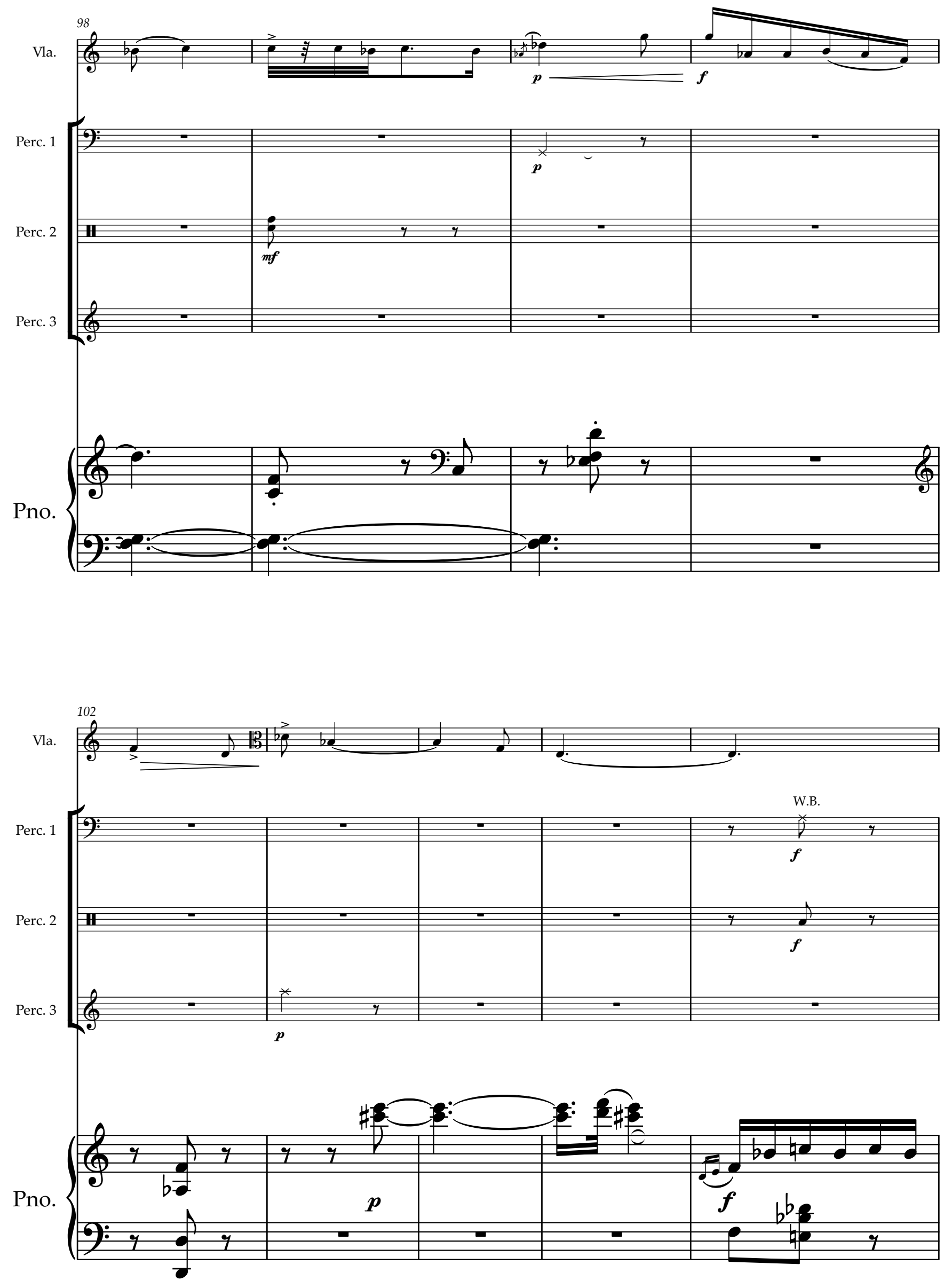

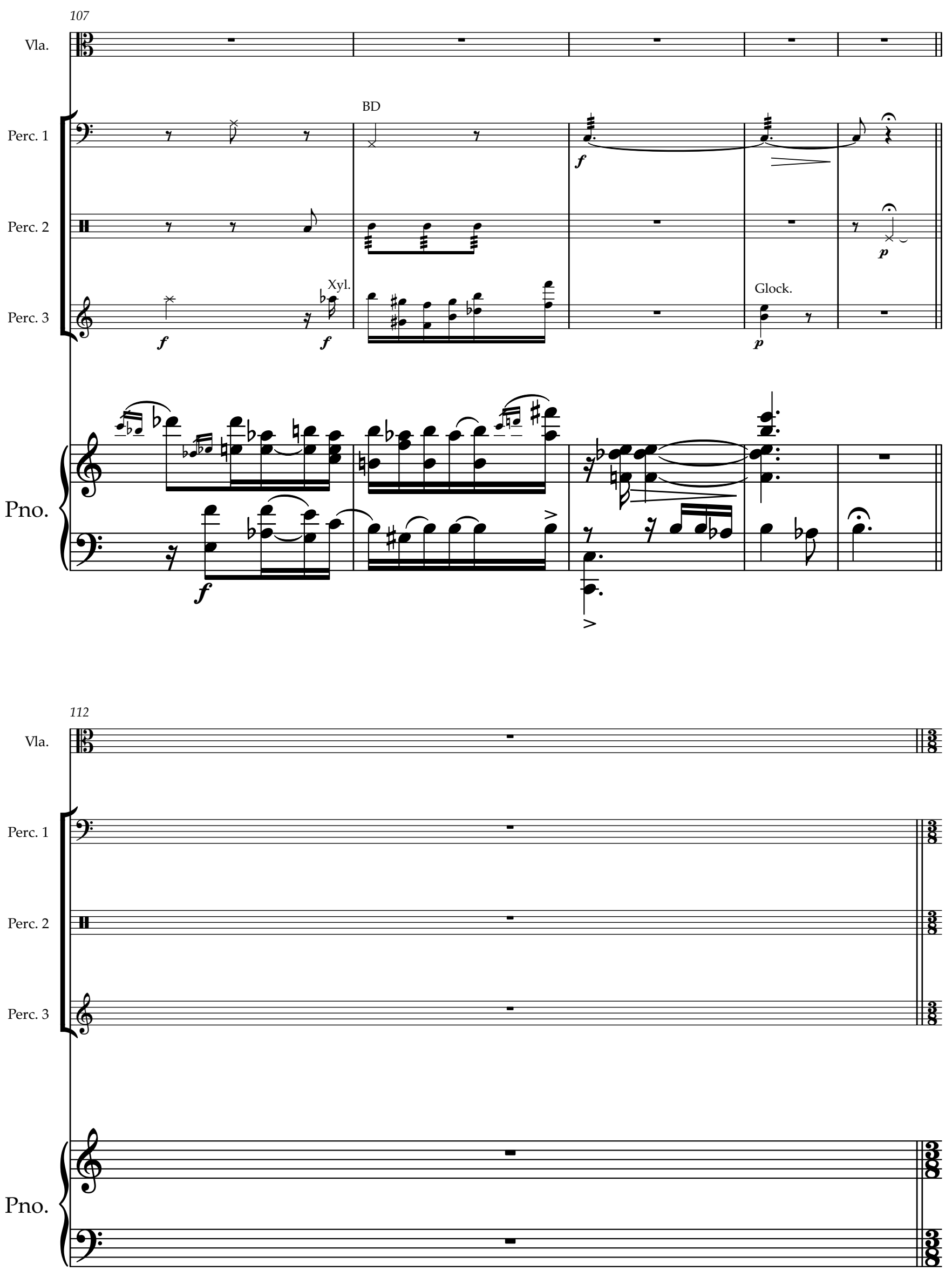

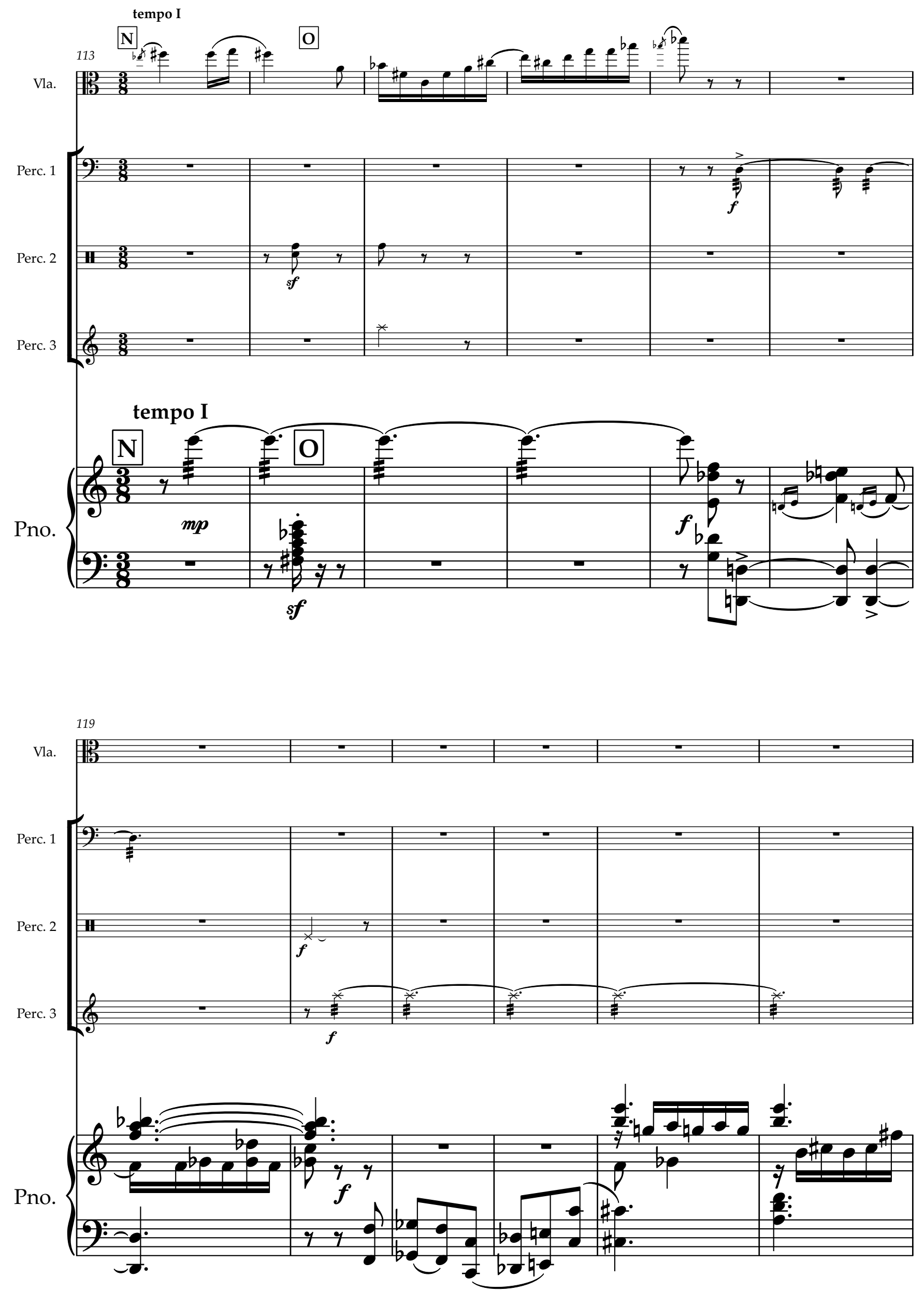

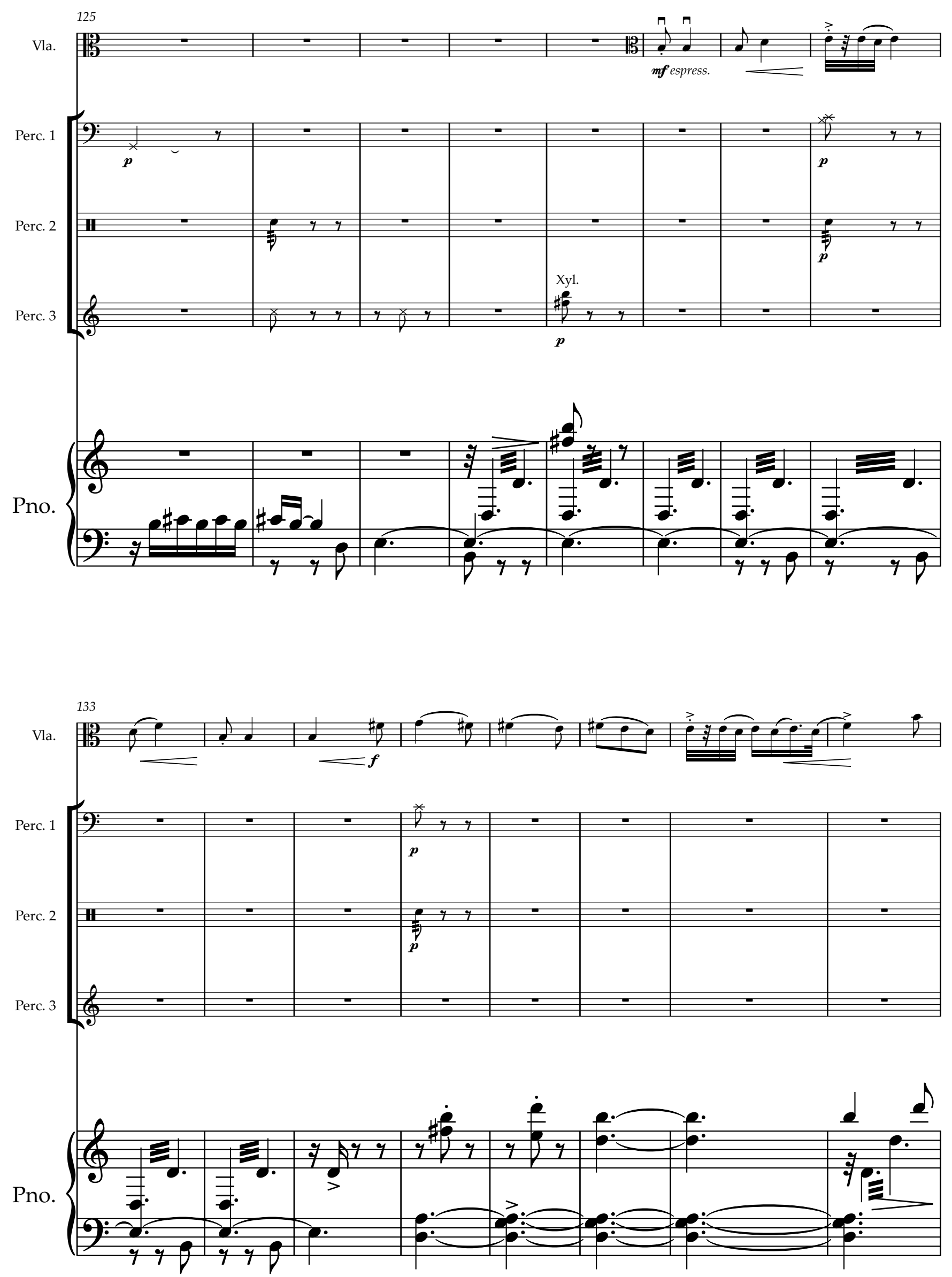

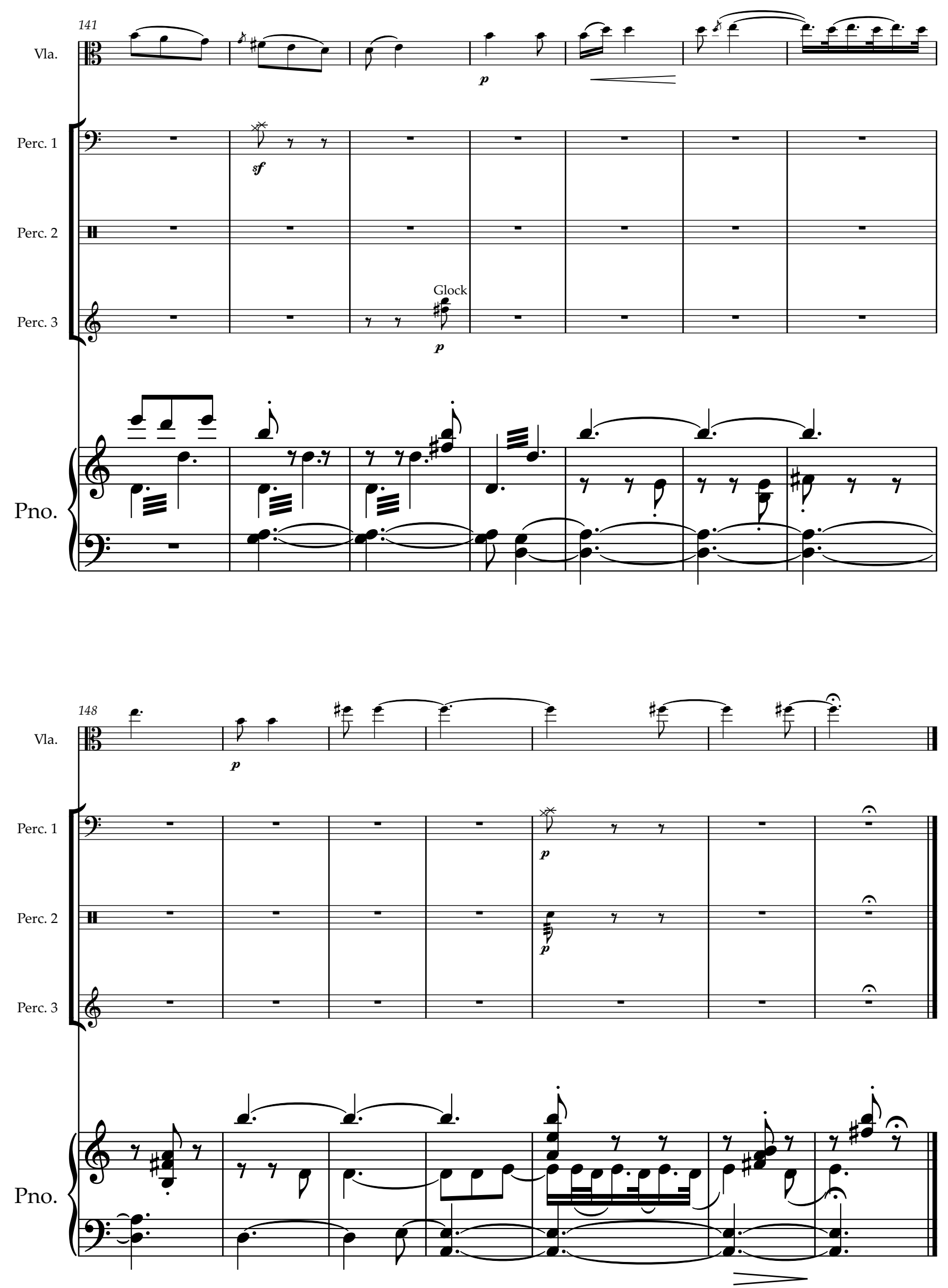


\section{III.}

Full Score

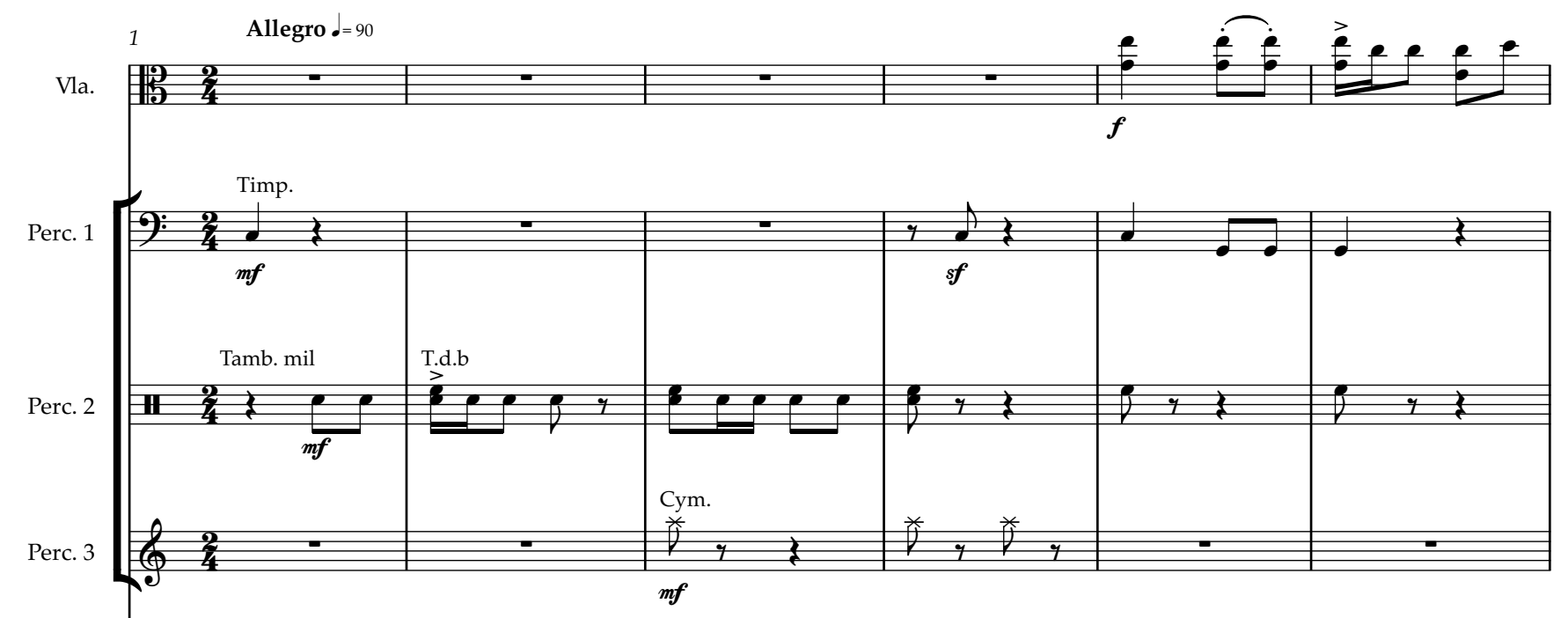

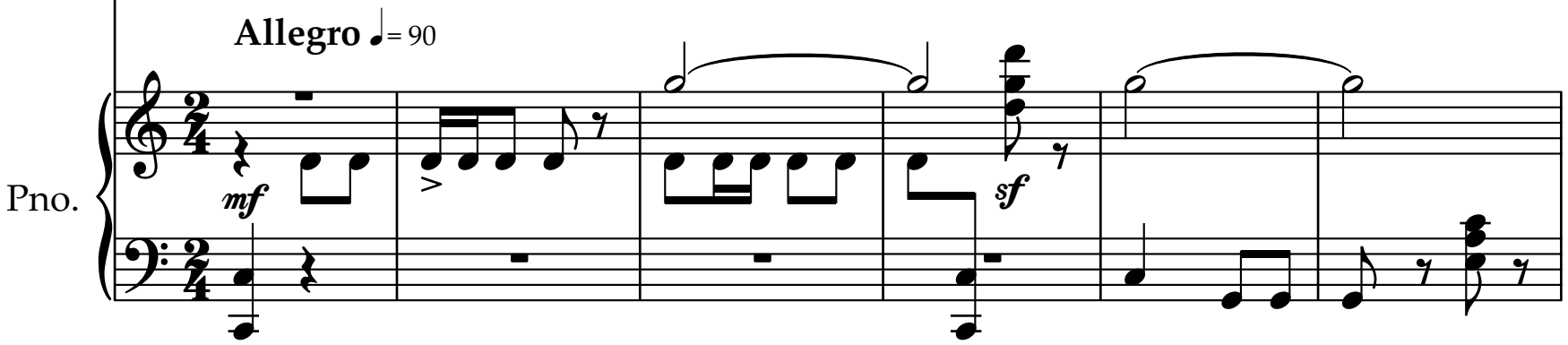

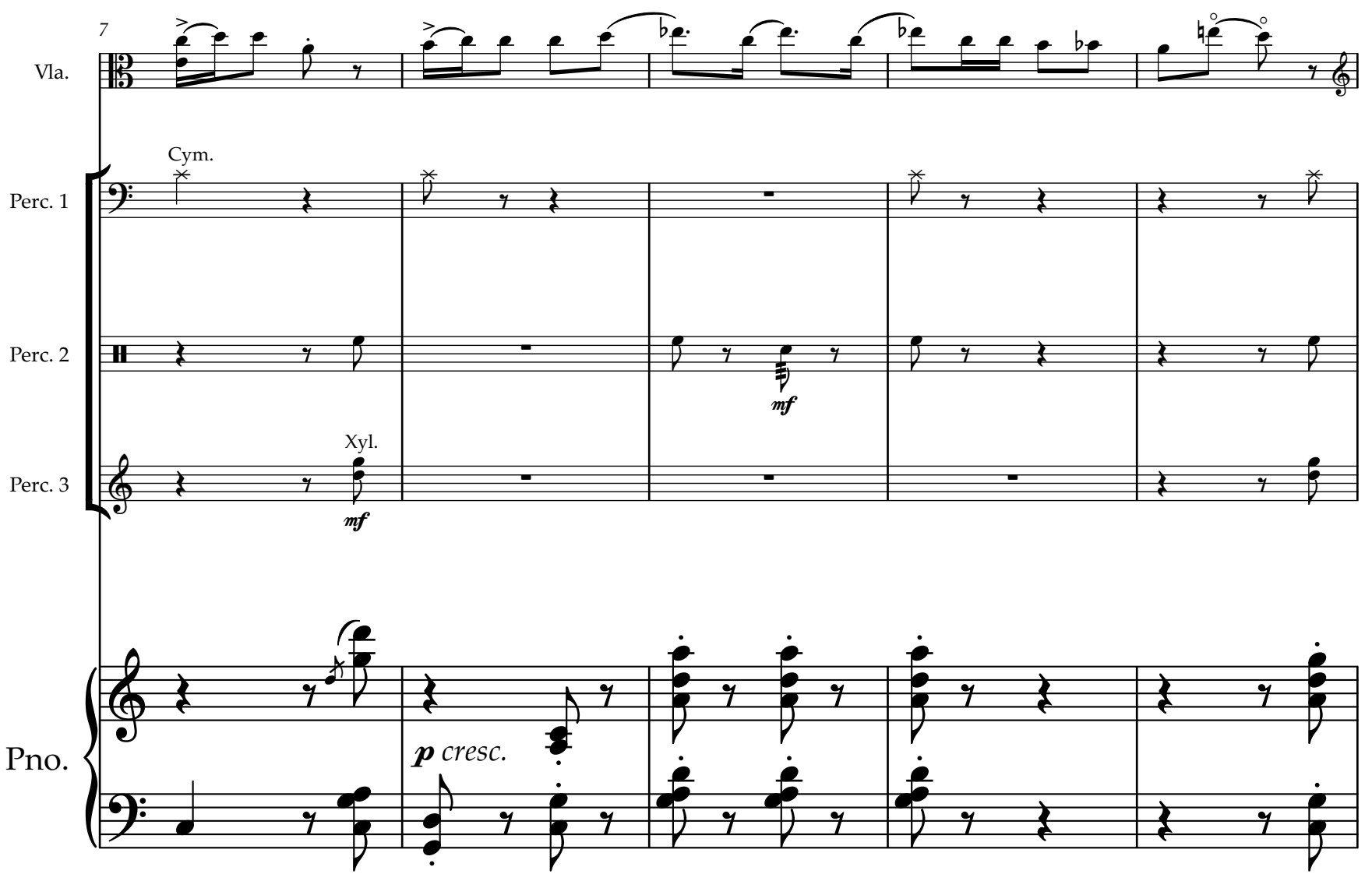



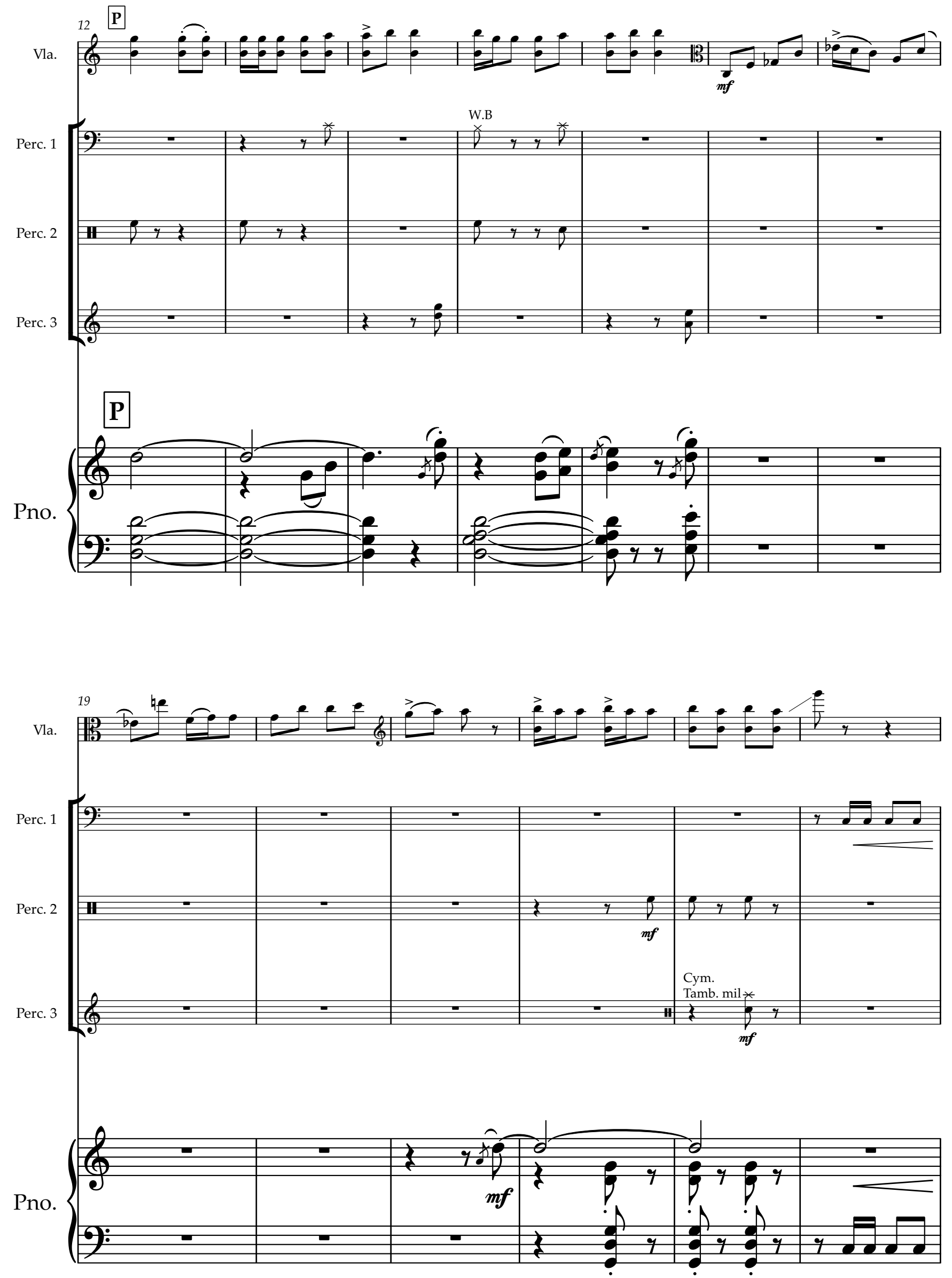

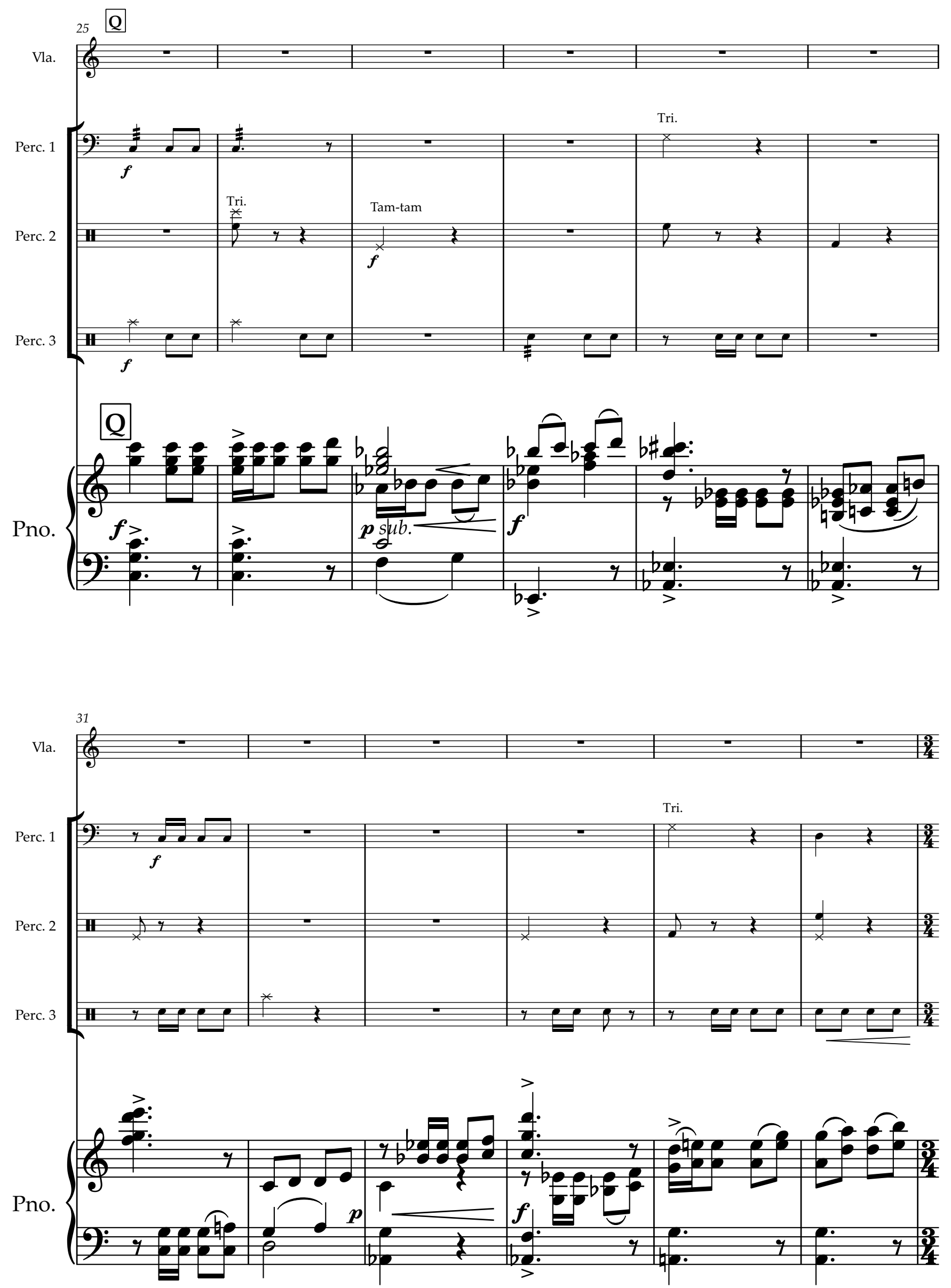

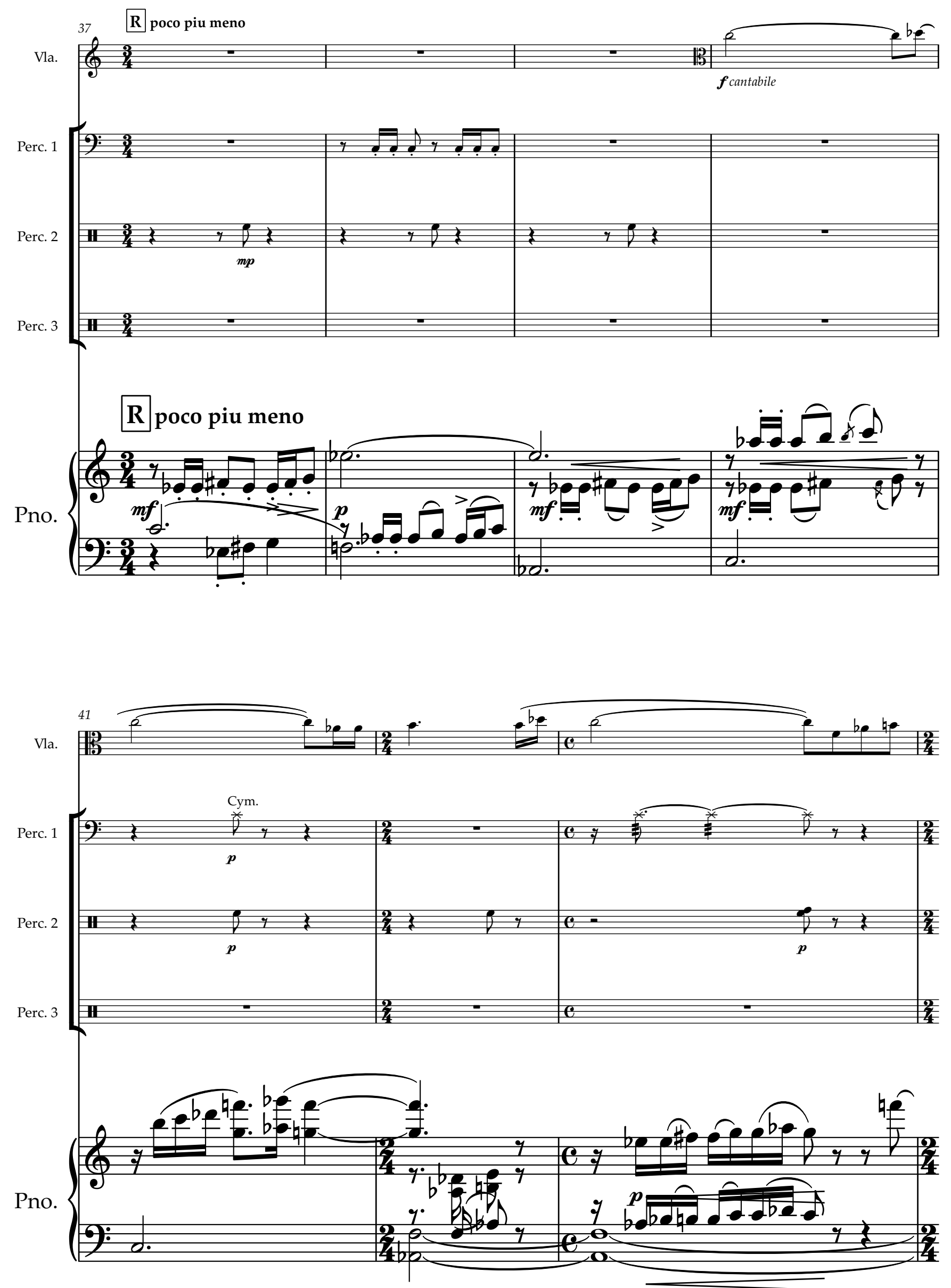

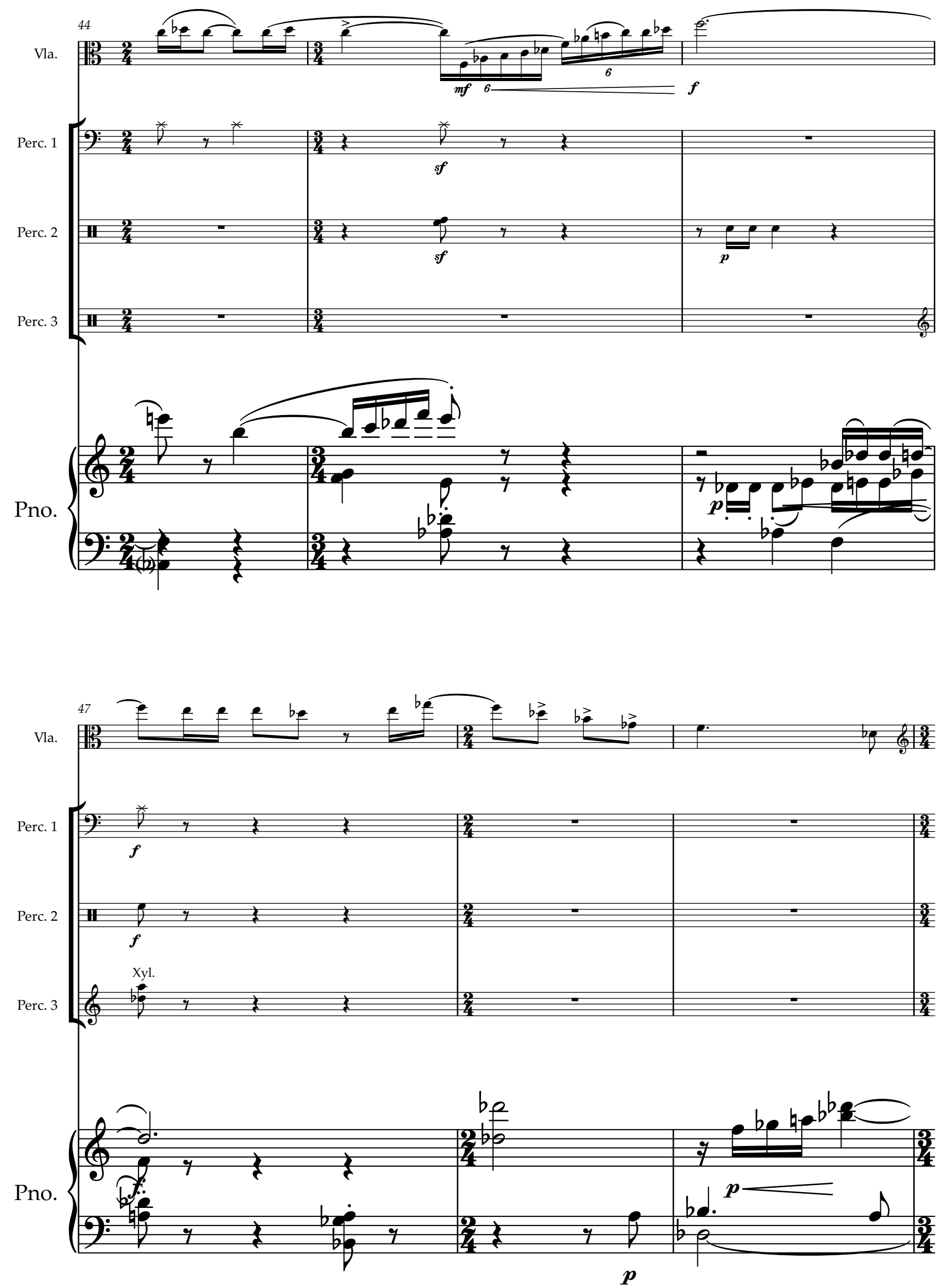

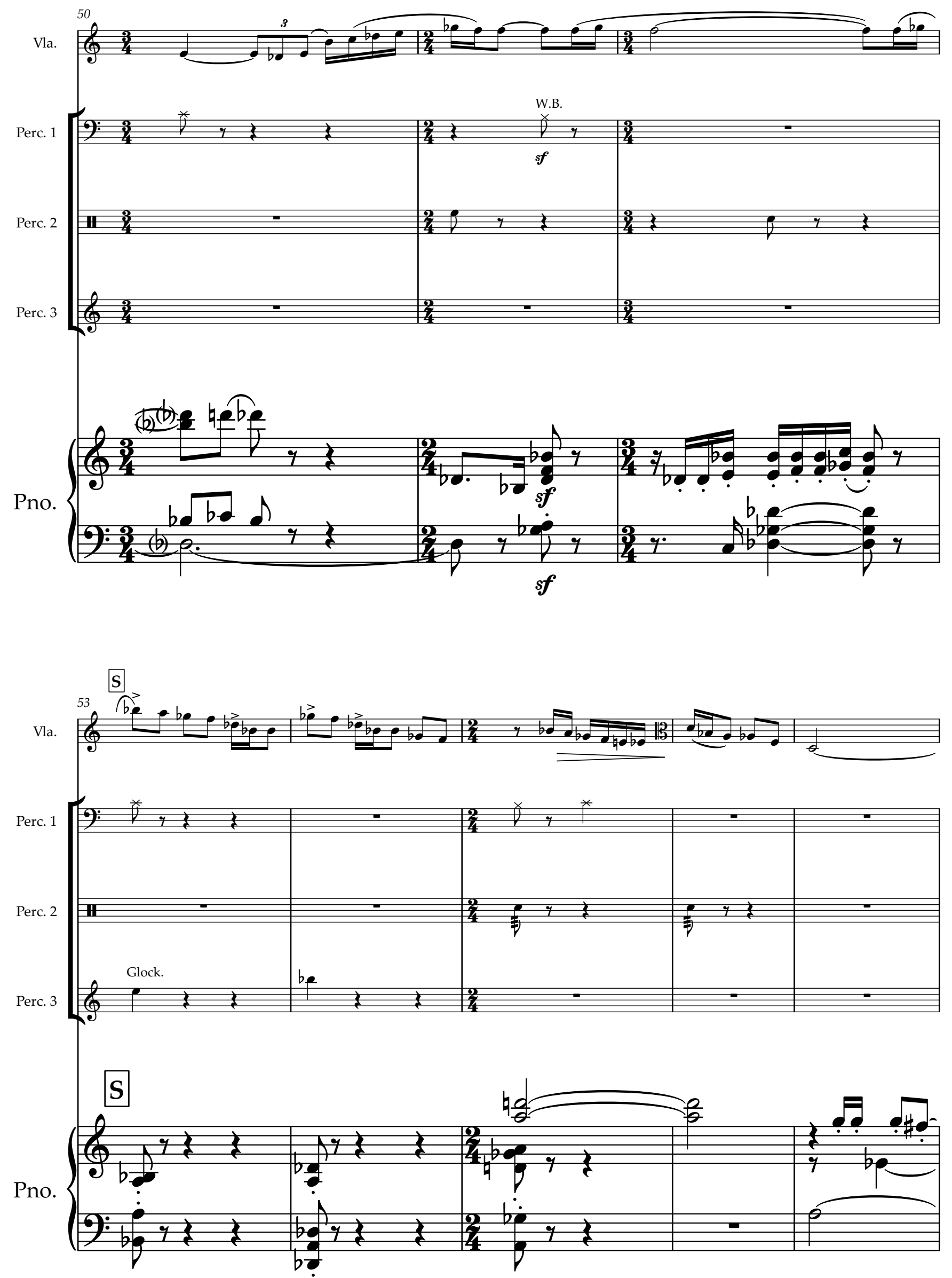

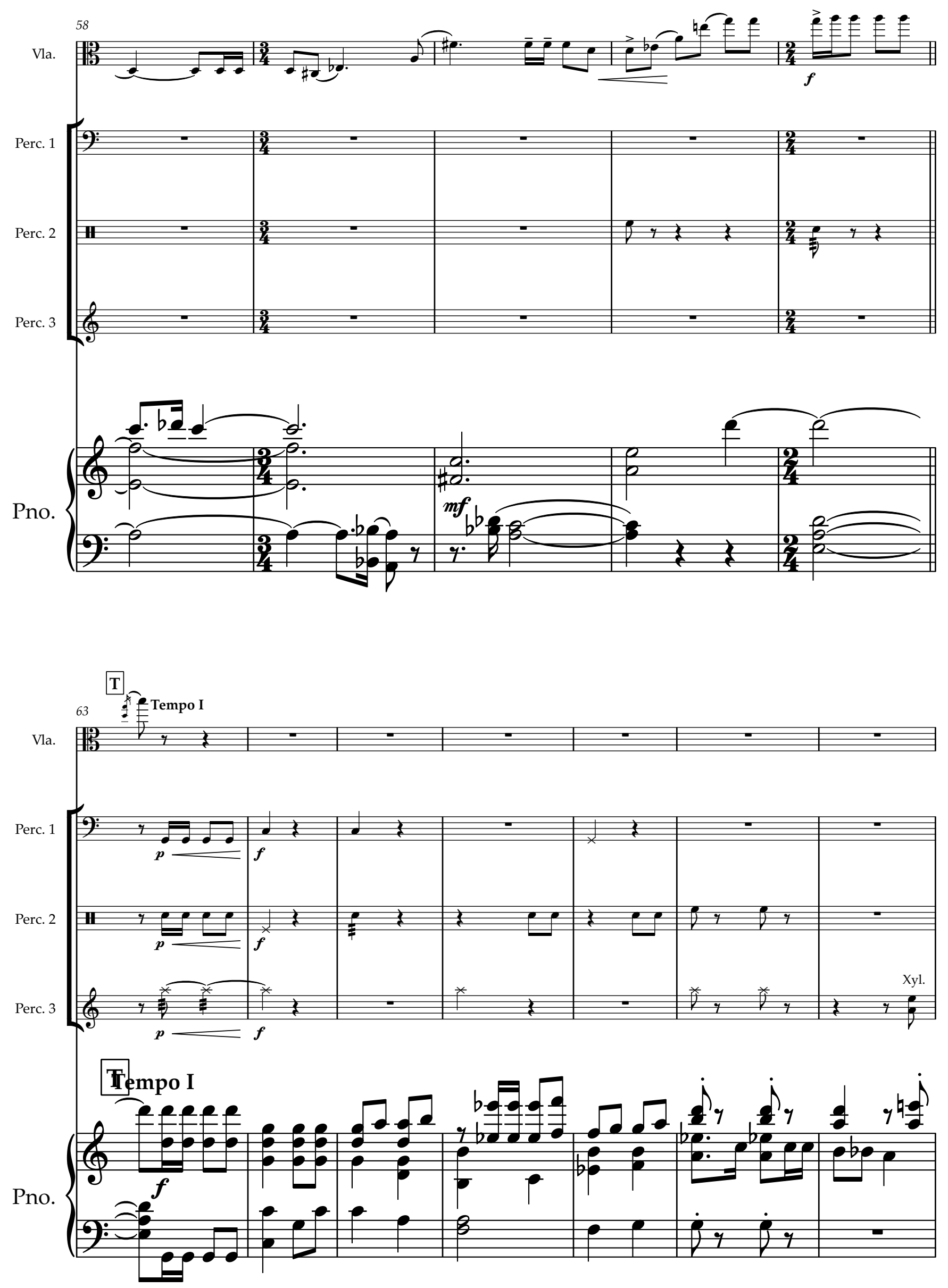

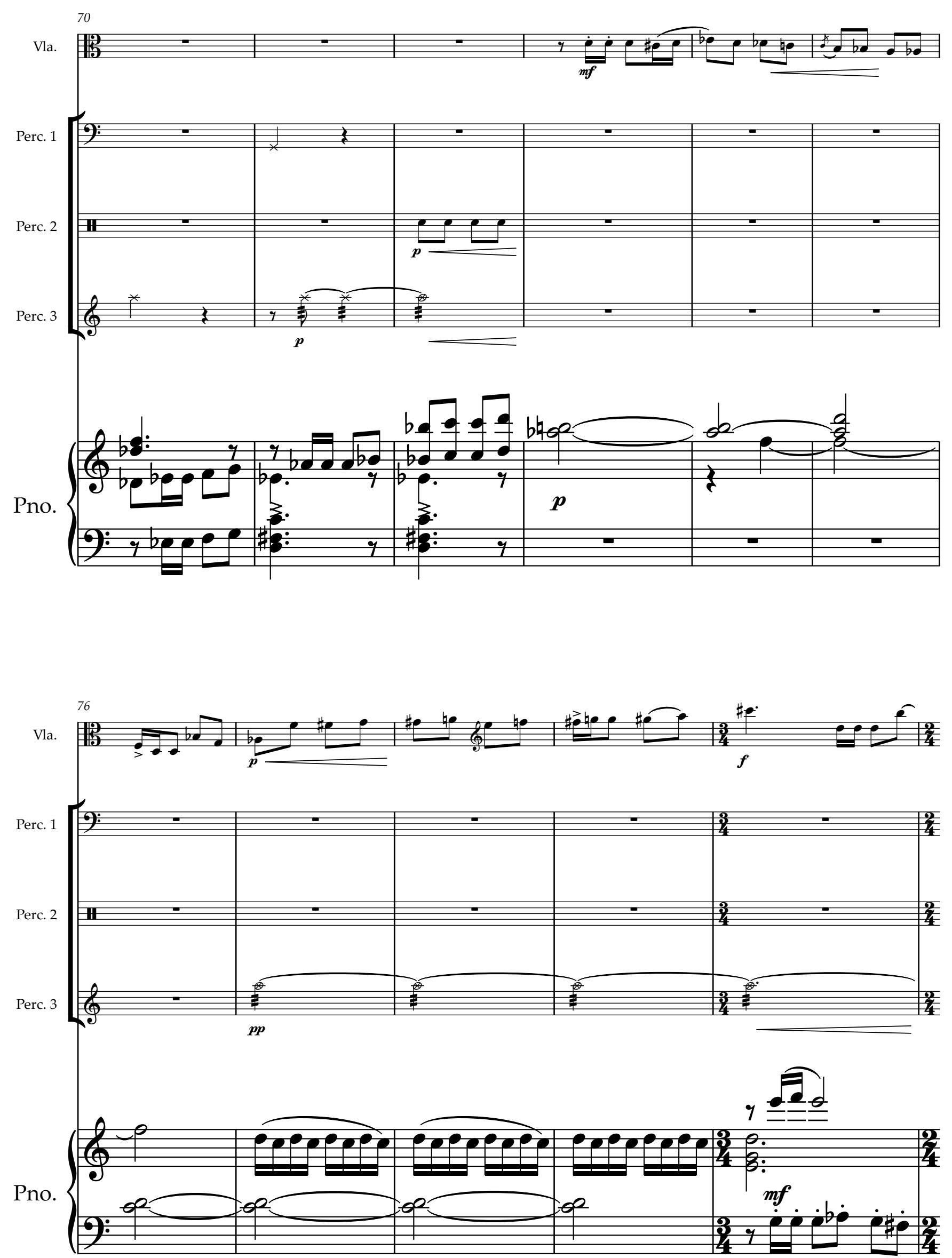


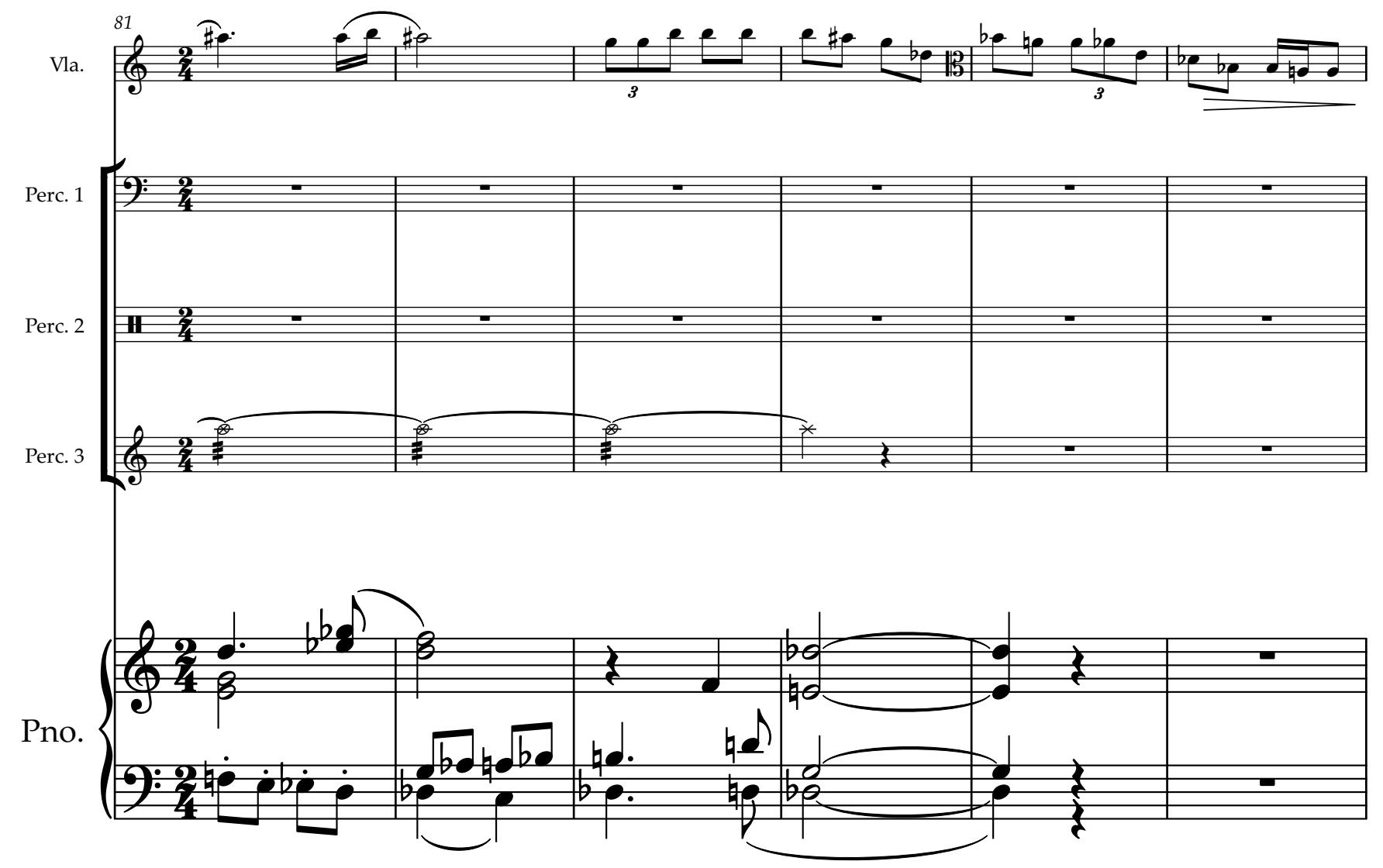

${ }_{87} \mathrm{U}$
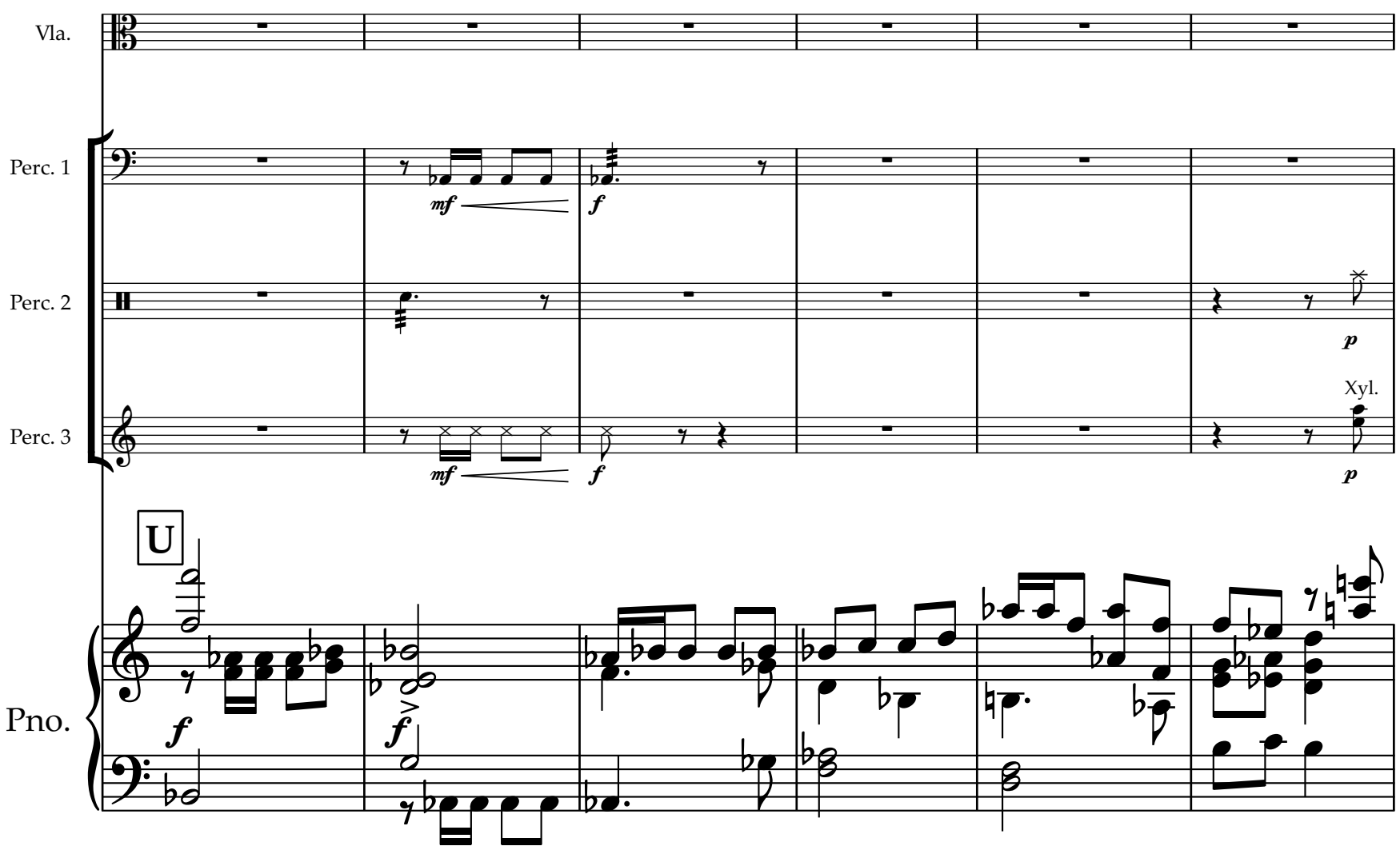

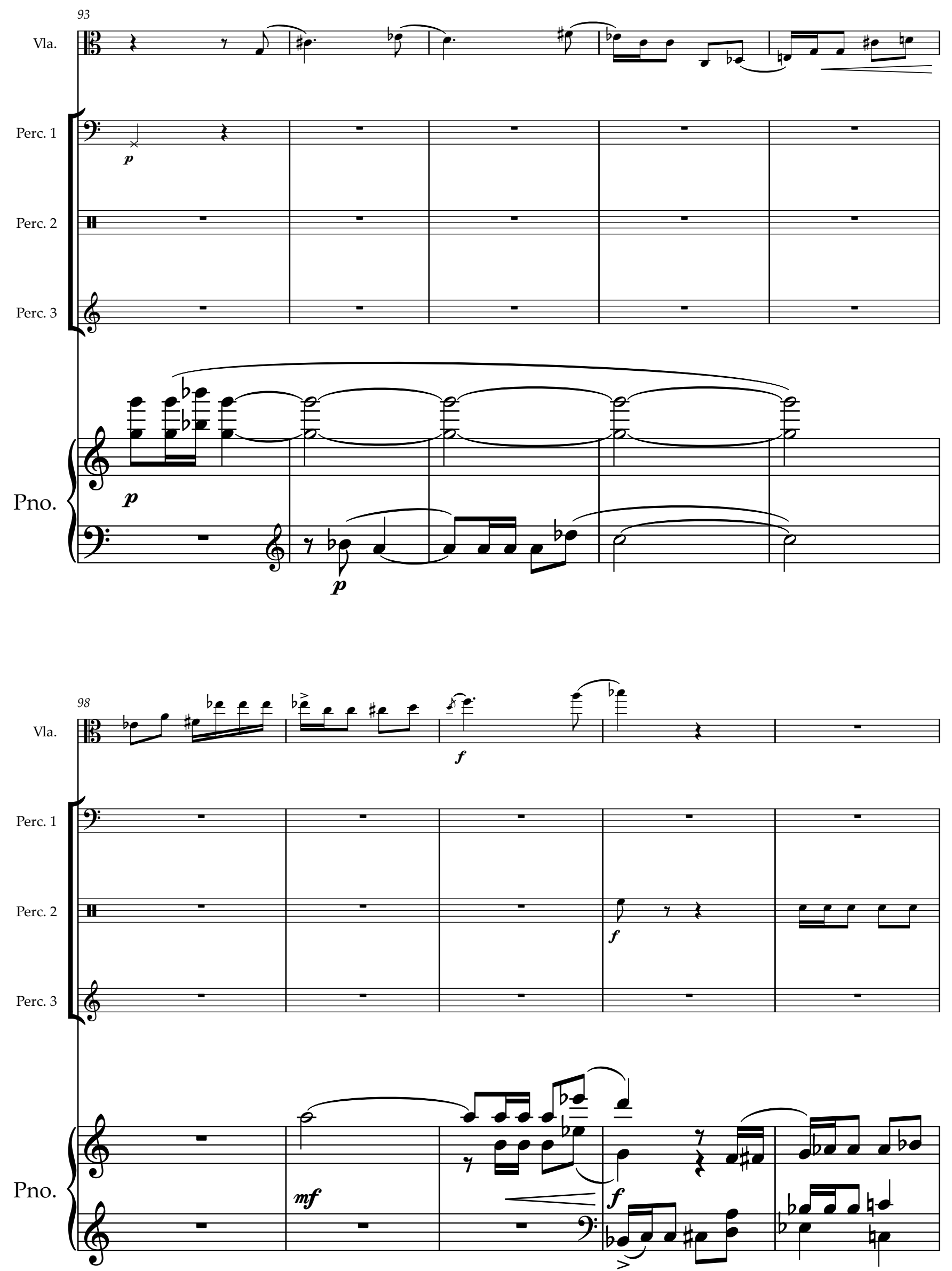

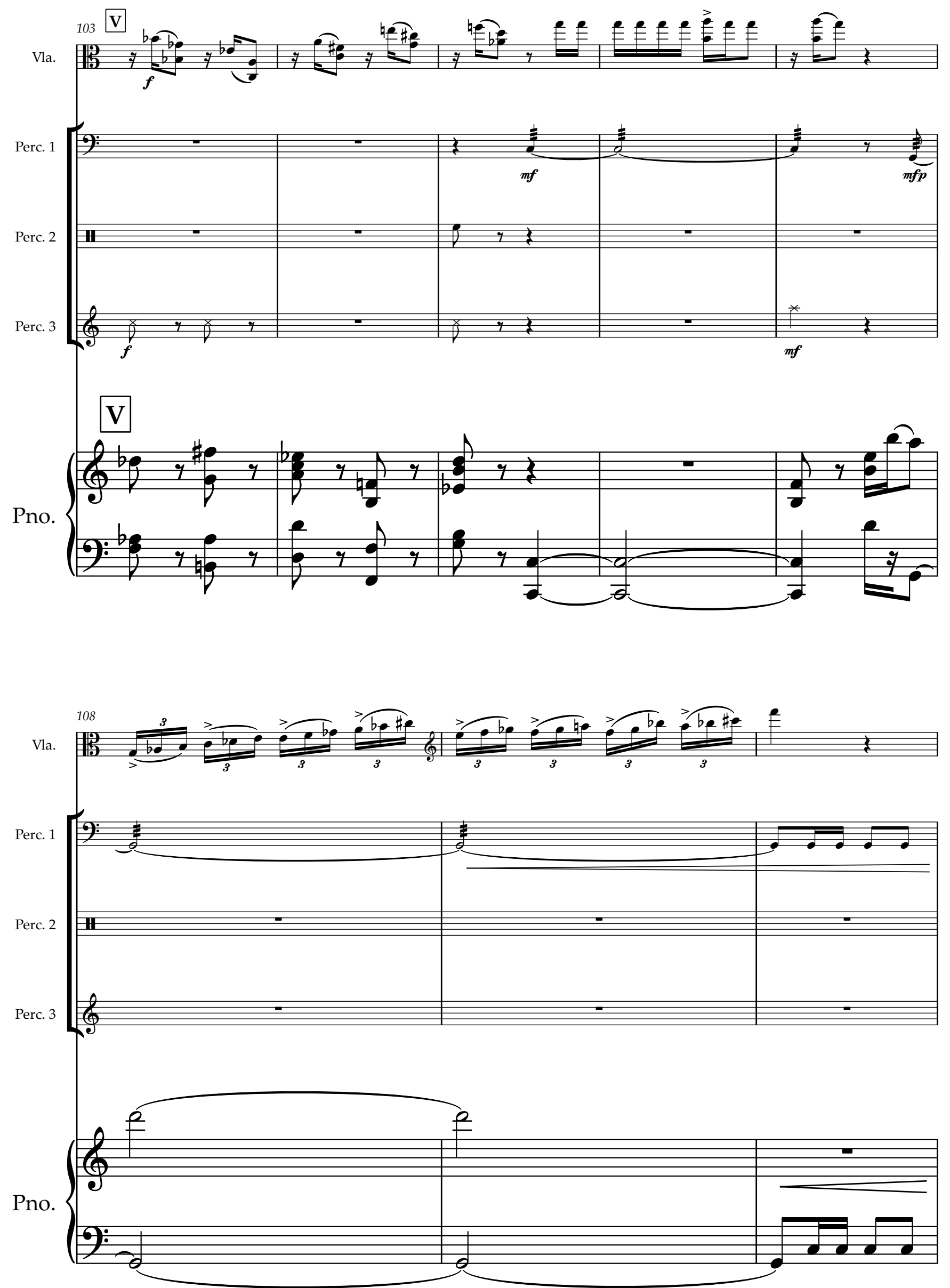

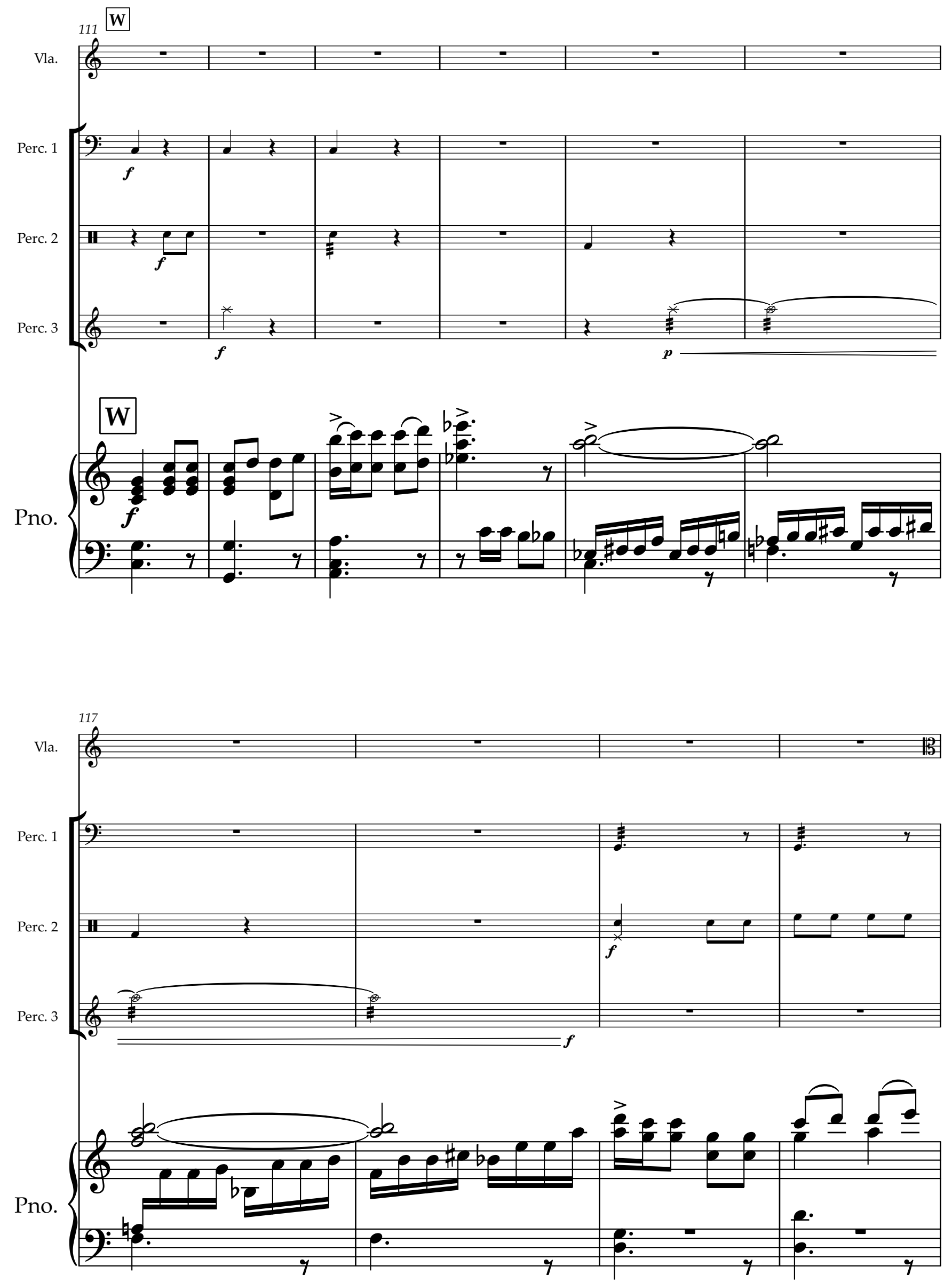

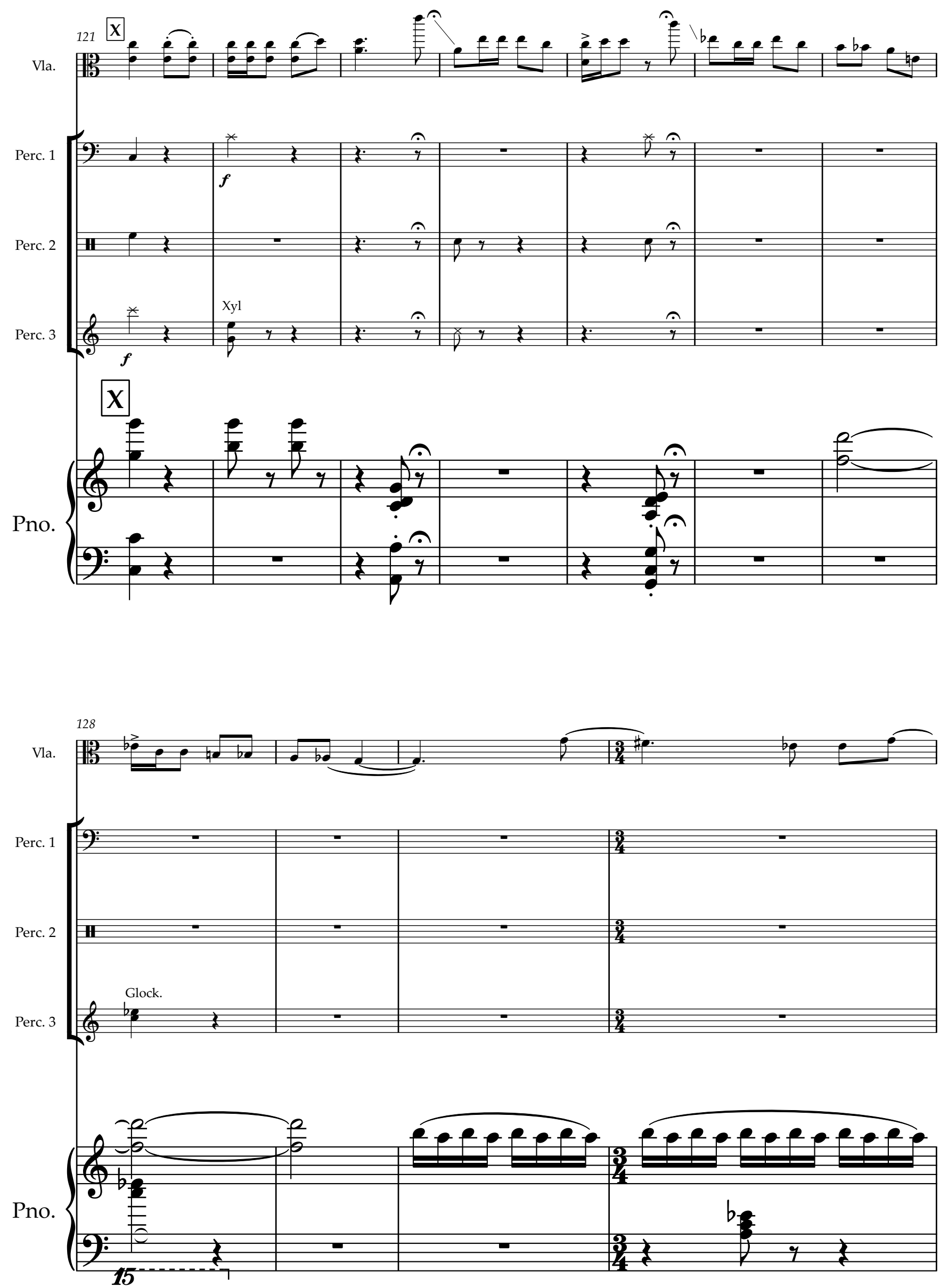

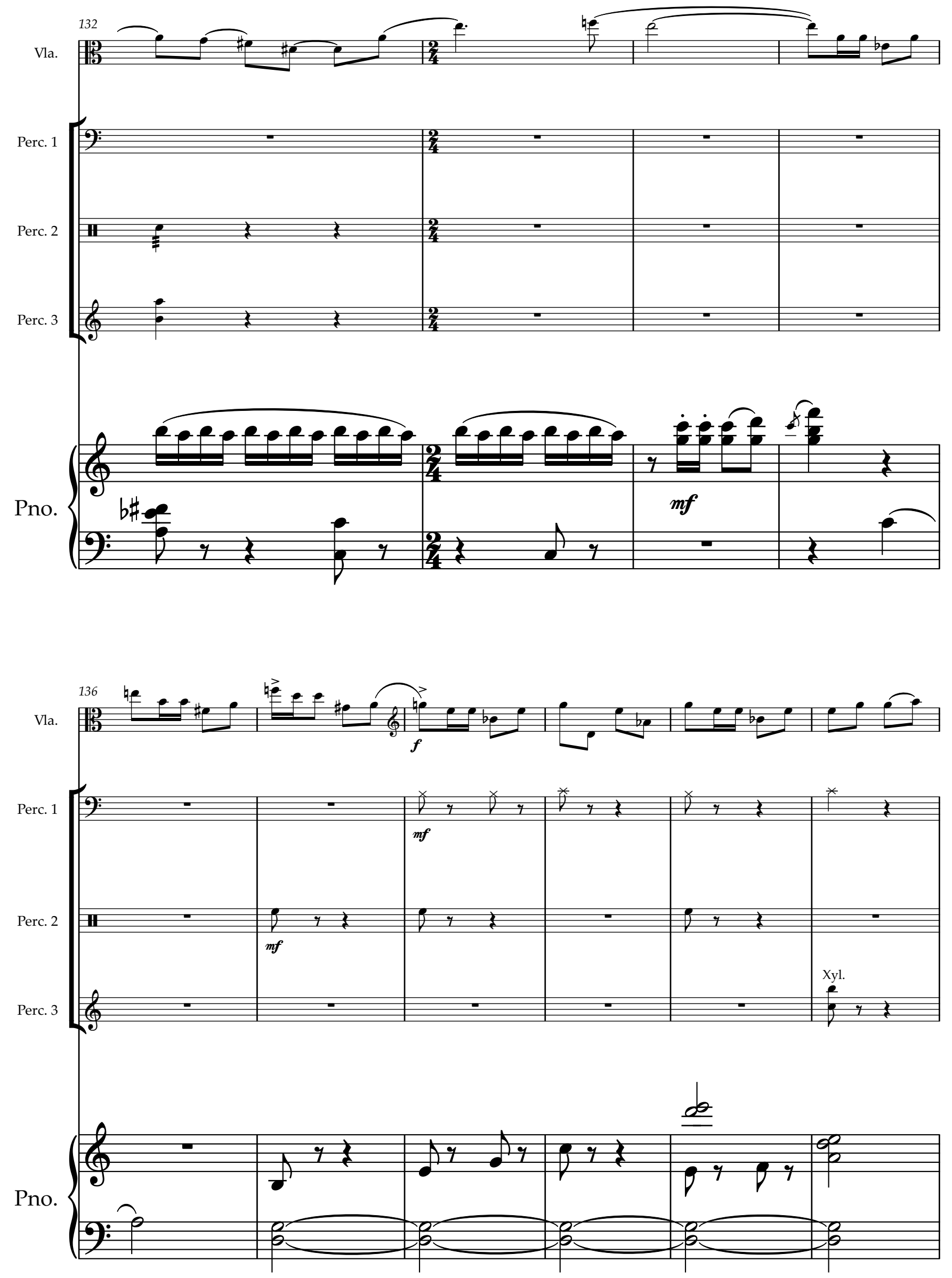

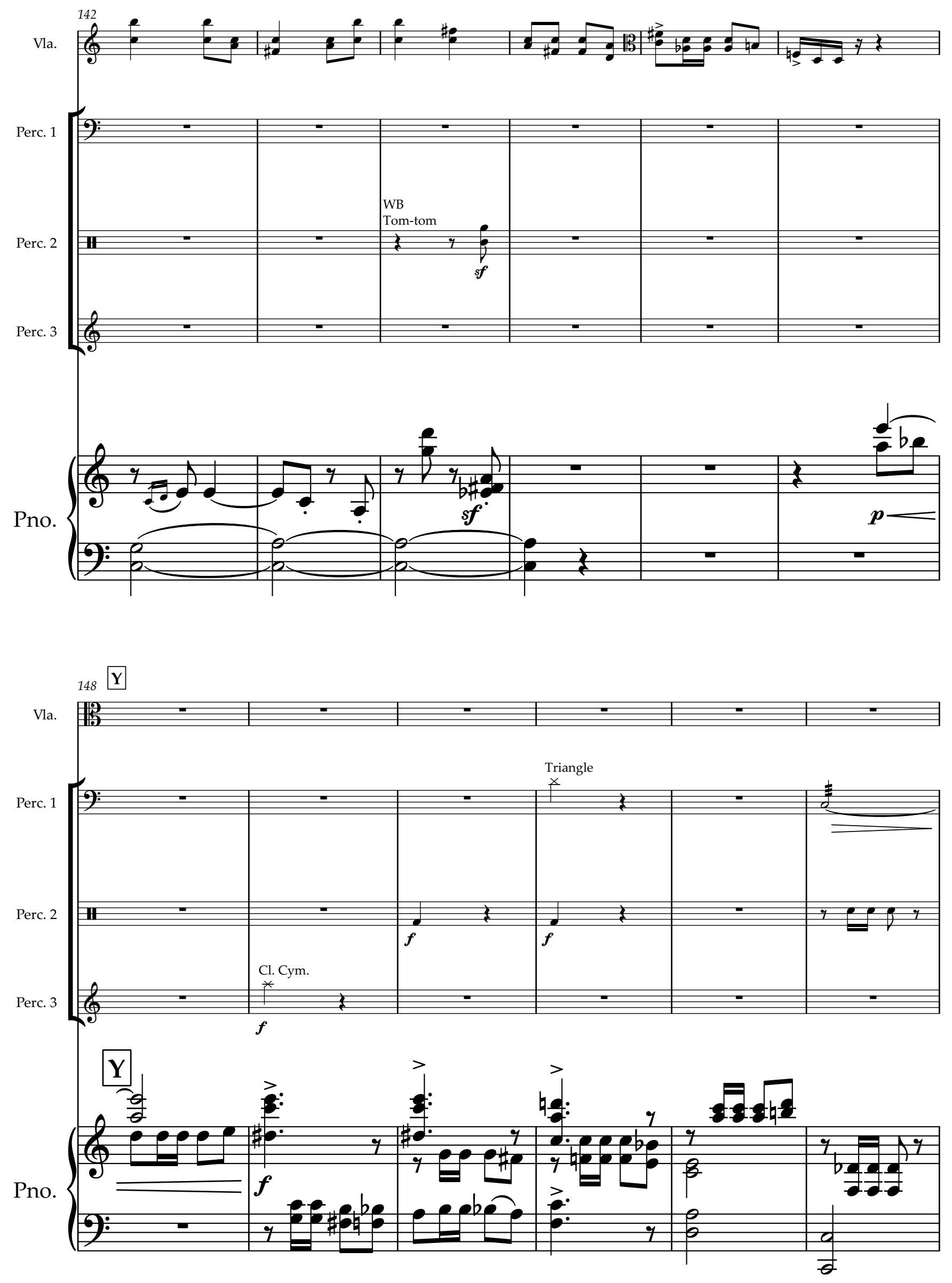

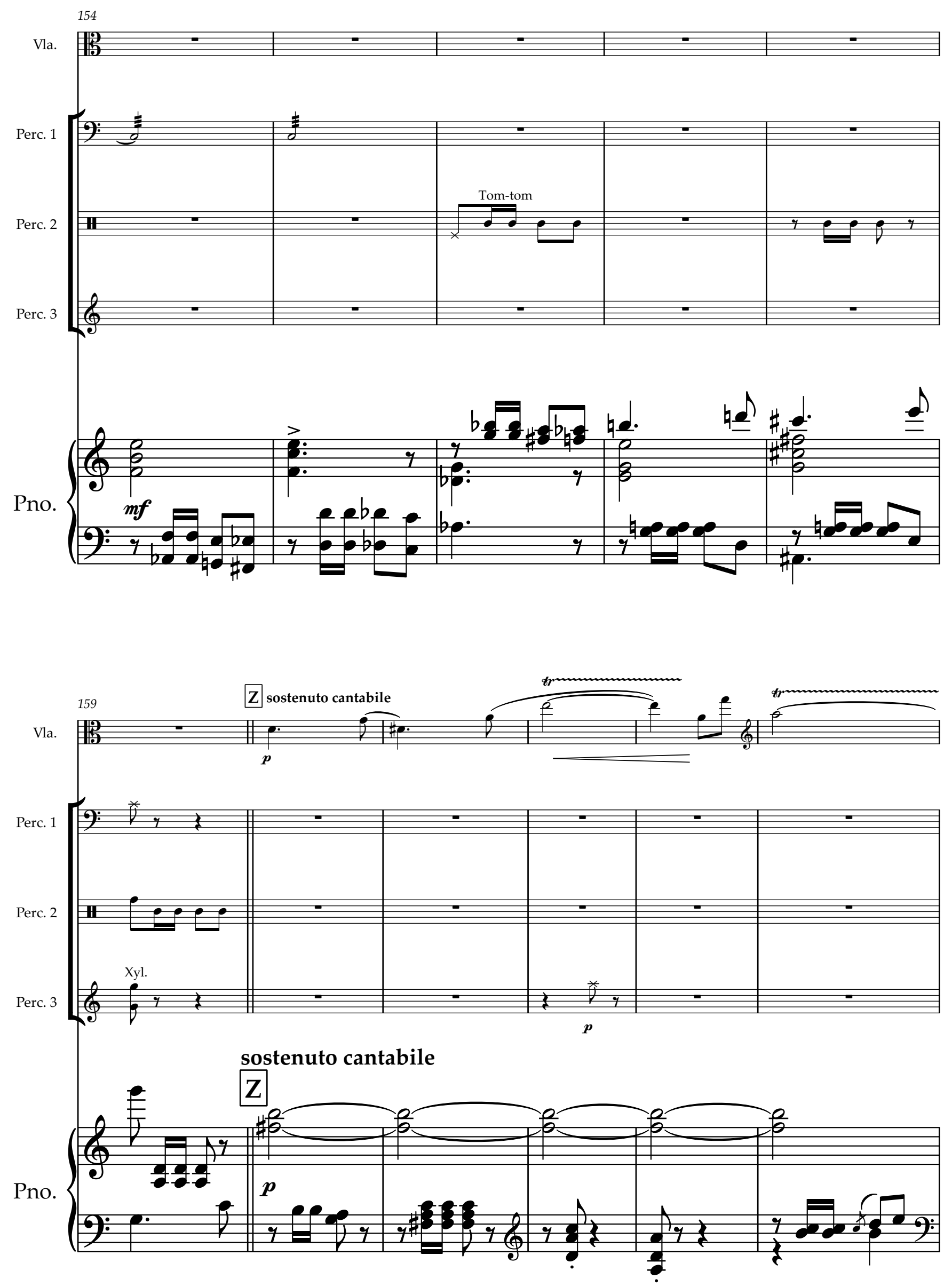

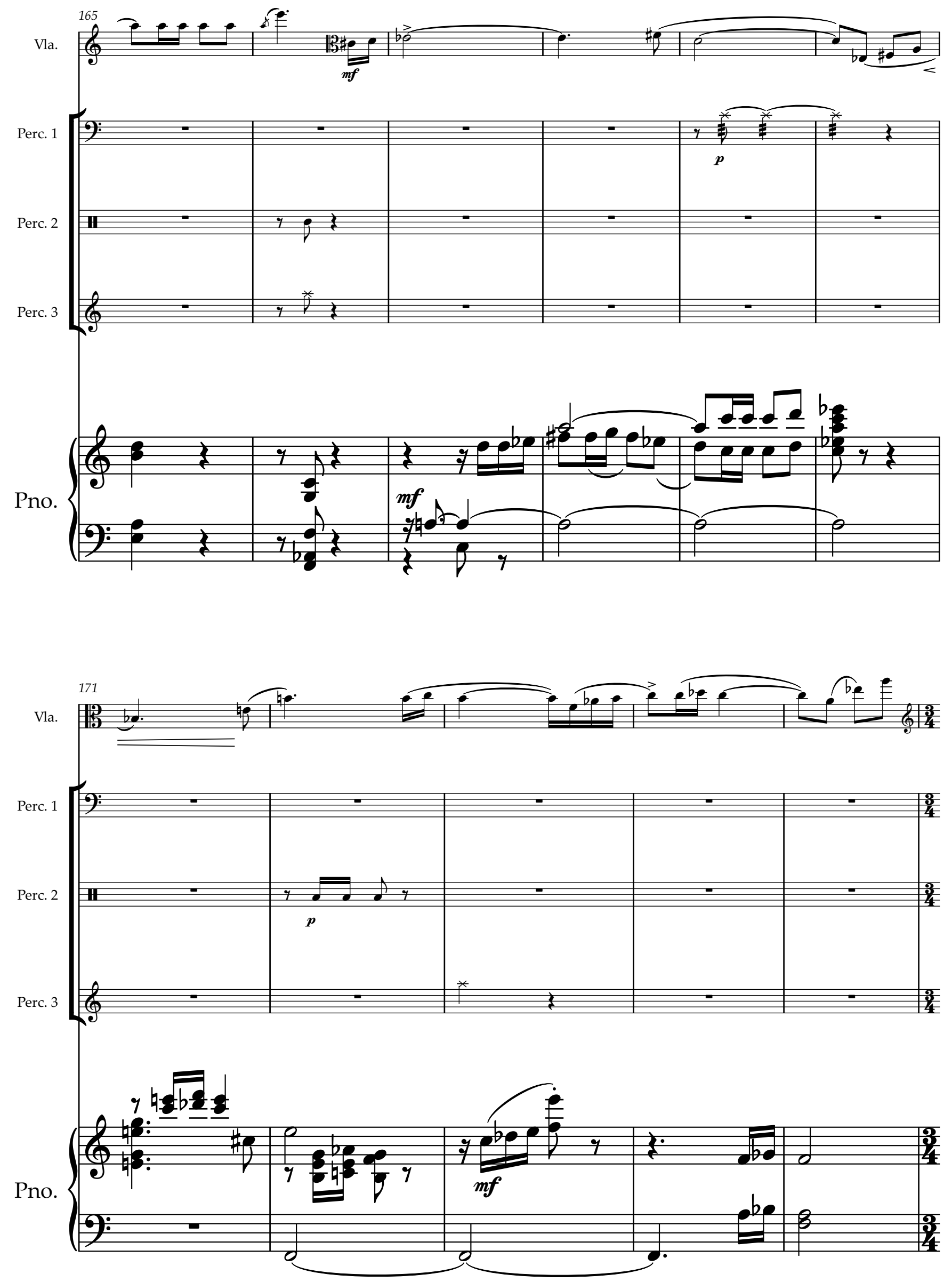

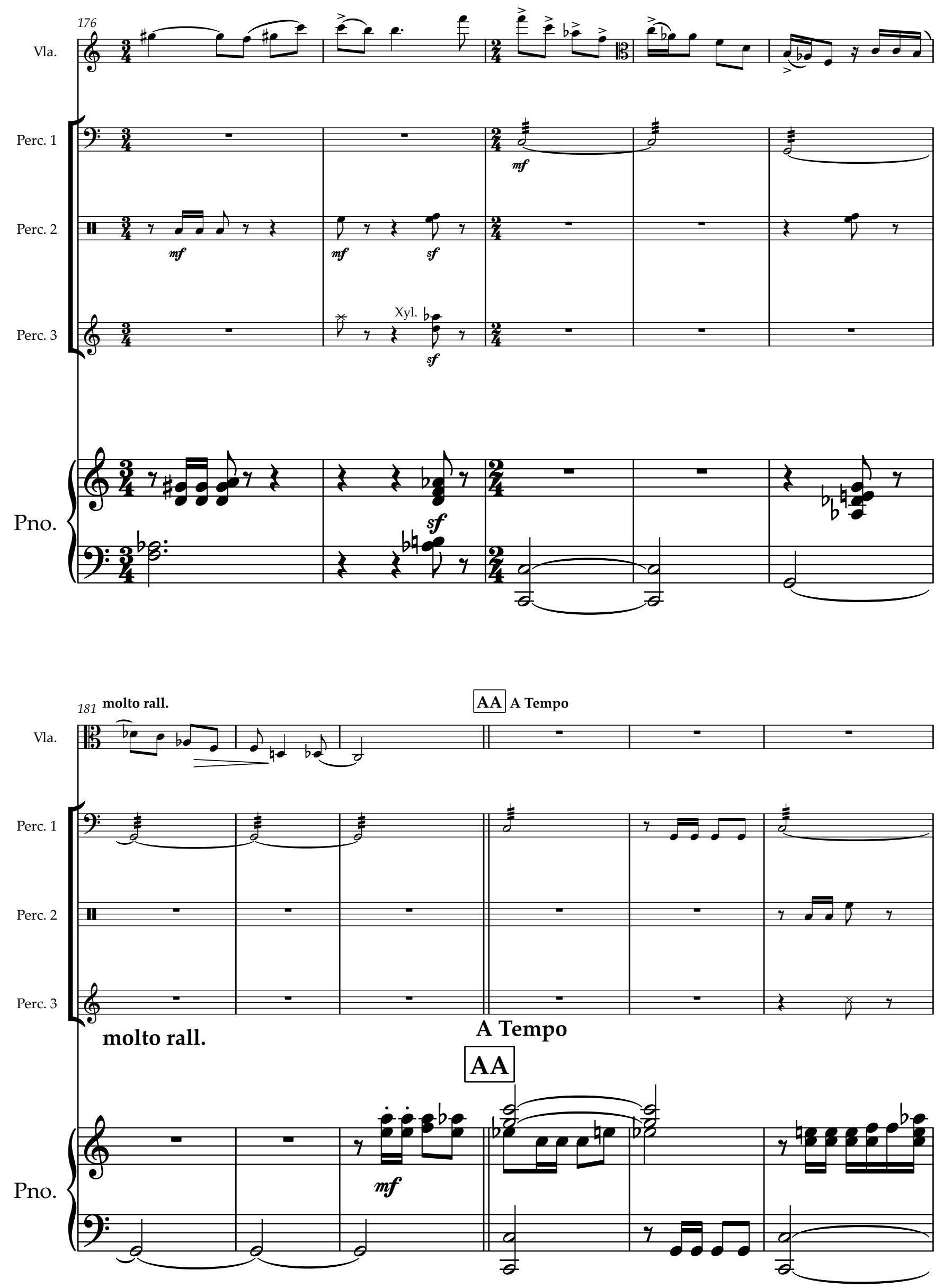

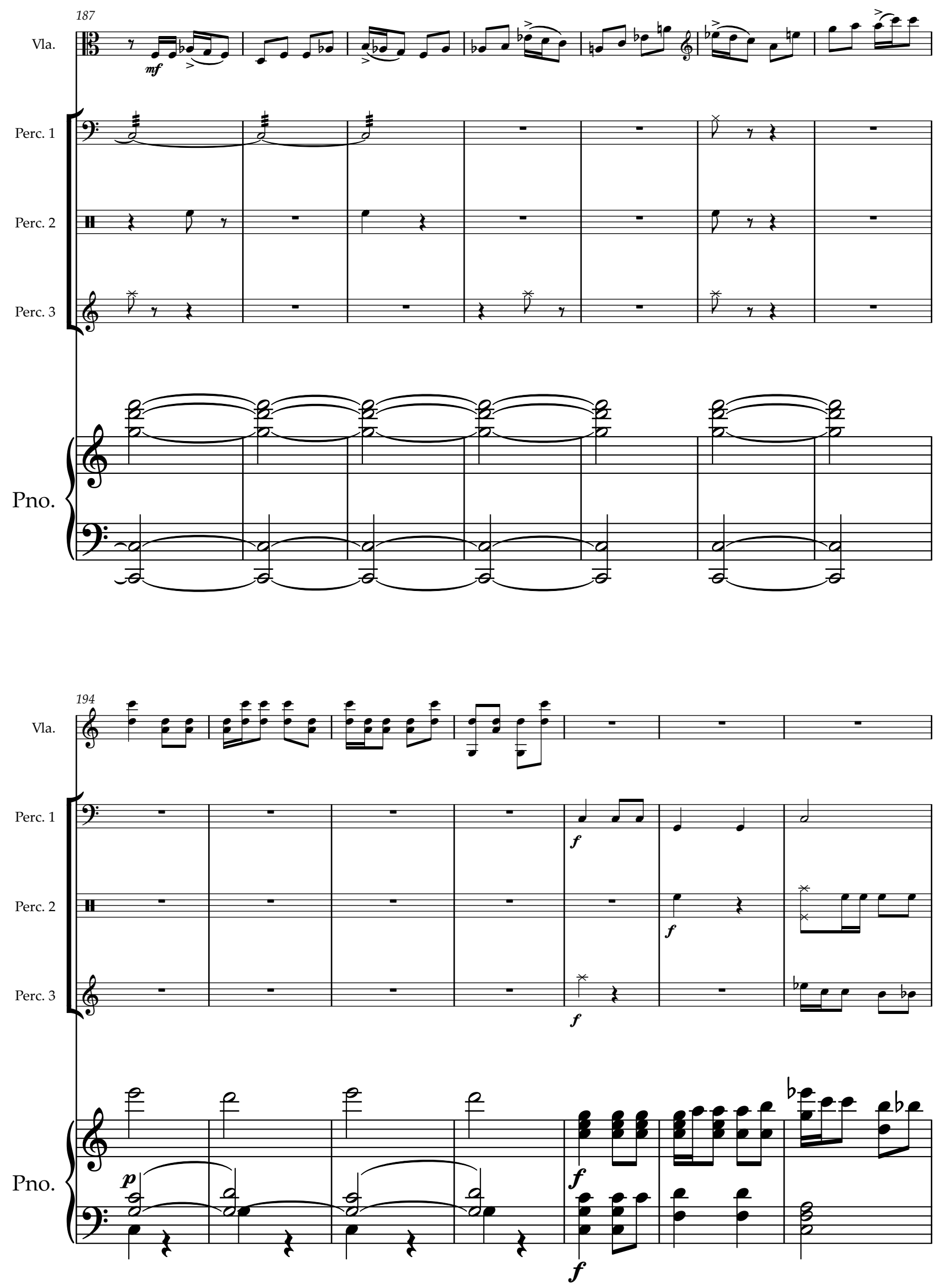

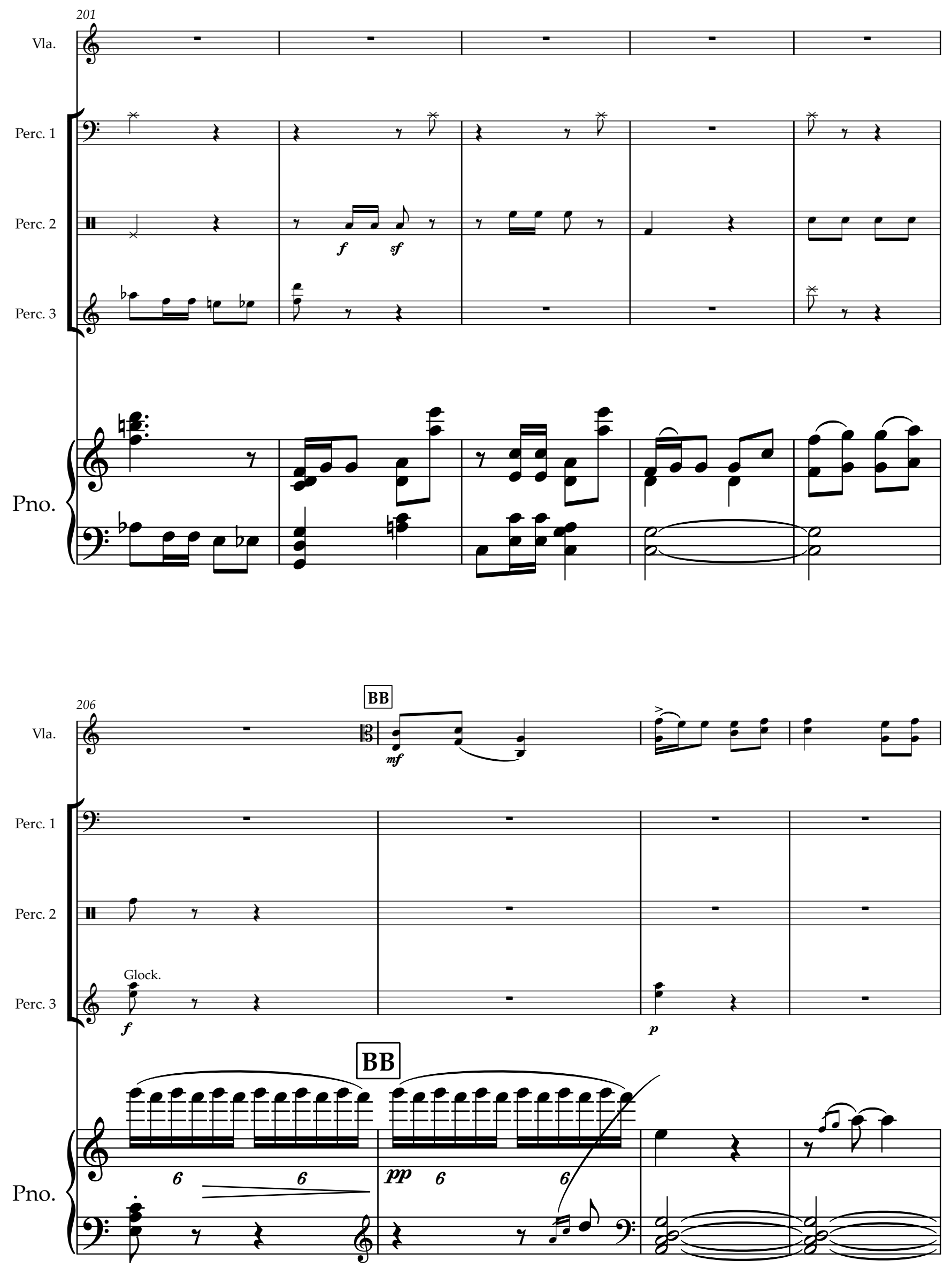

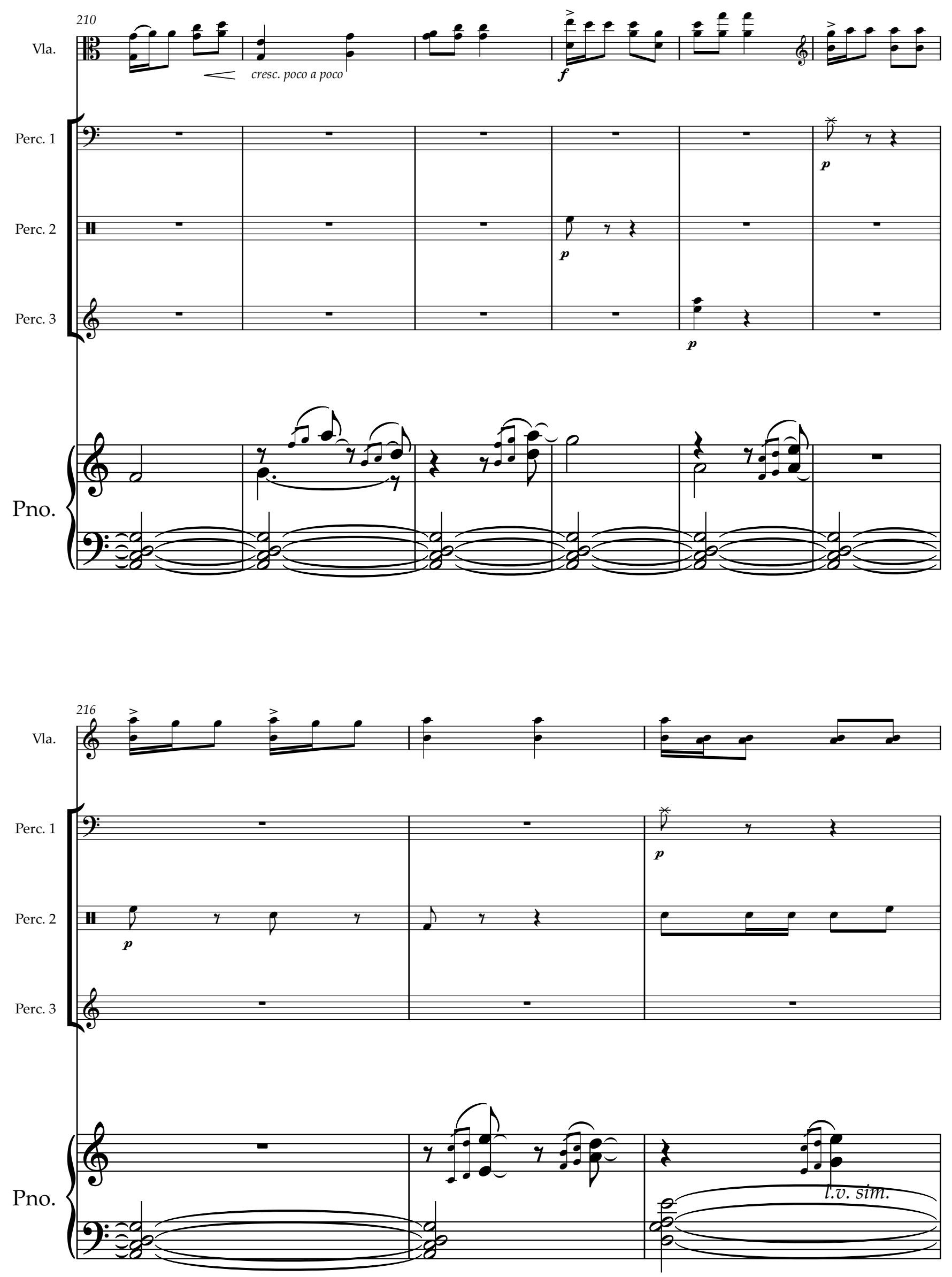


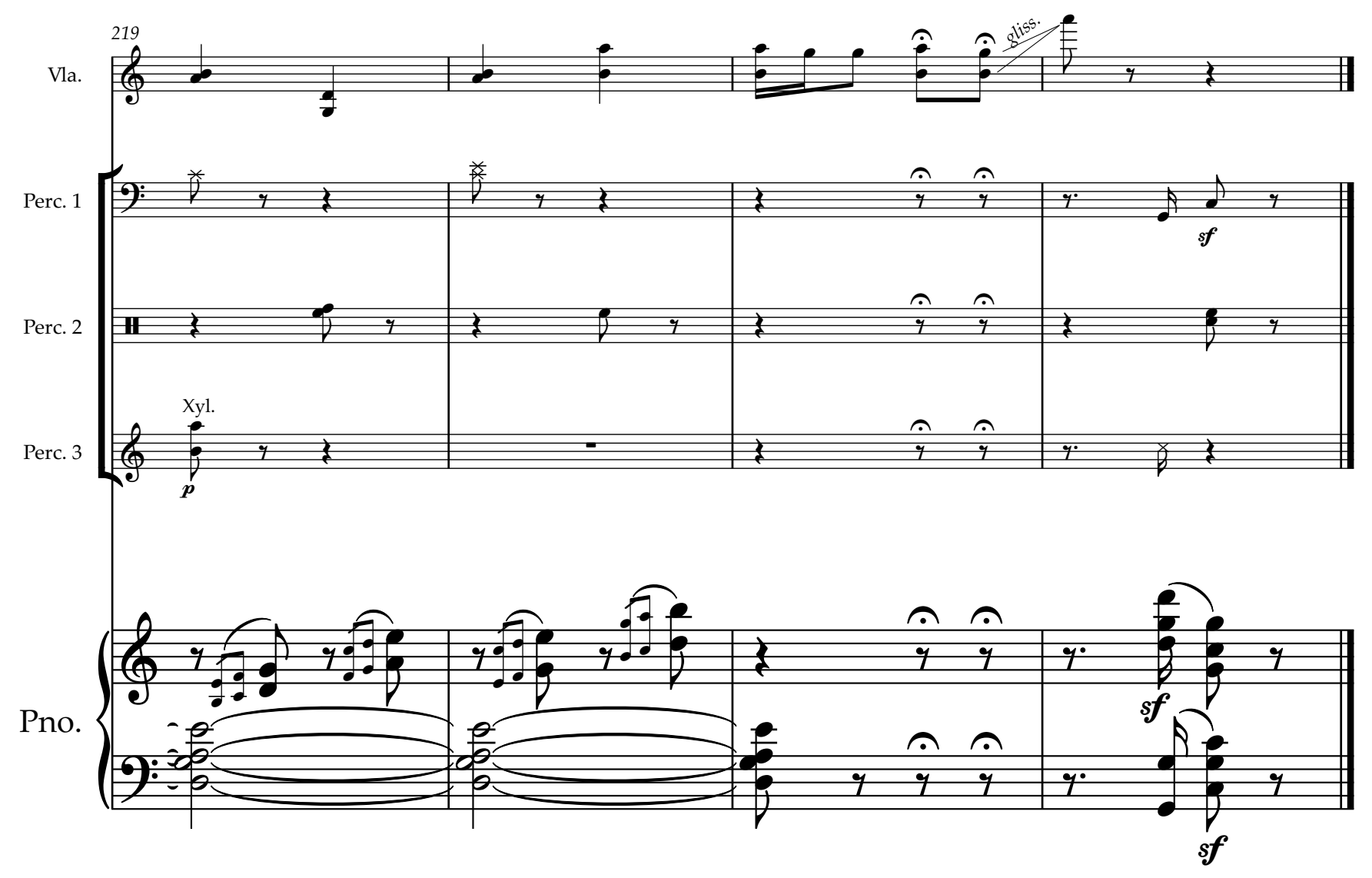




\section{Dimitris Dragatakis}

\section{Concerto for Viola and Orchestra \\ Percussion Score}

Created by Elyse Dalabakis

Percussion parts edited by Hannah Neman

Reduction and engraving by Brendan Agnew 

Percussion Score

\section{Concerto for Viola and Orchestra}
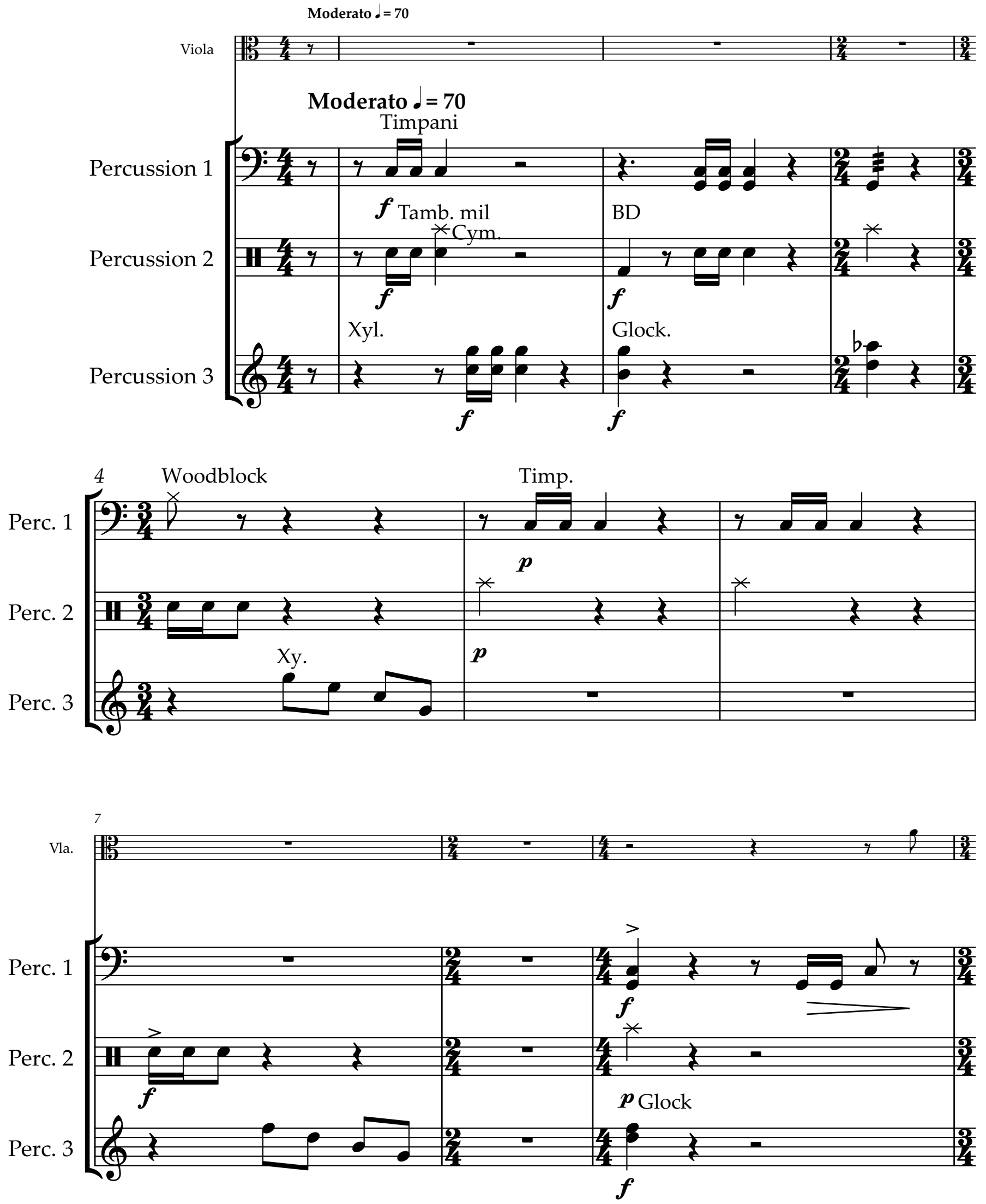

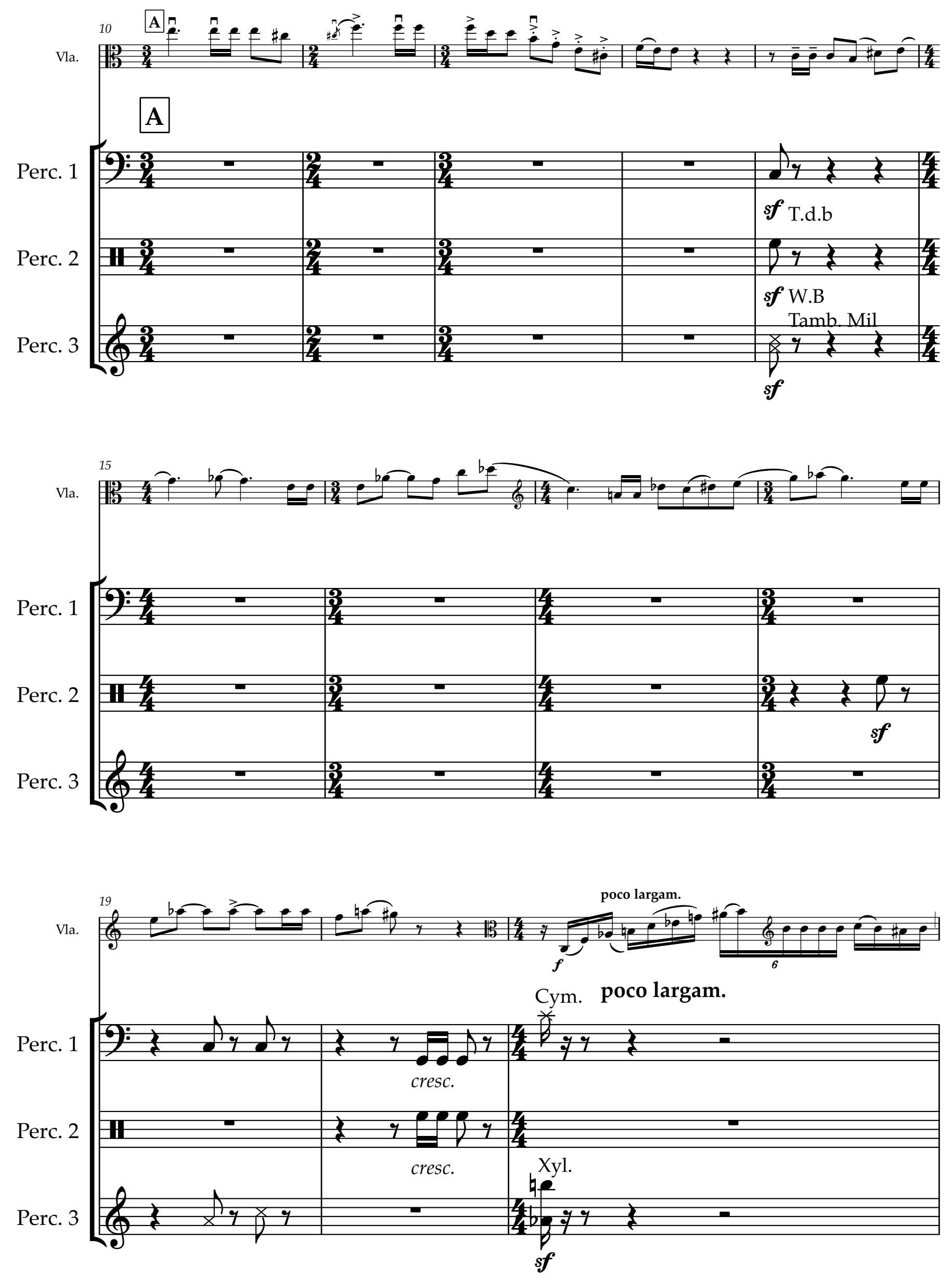

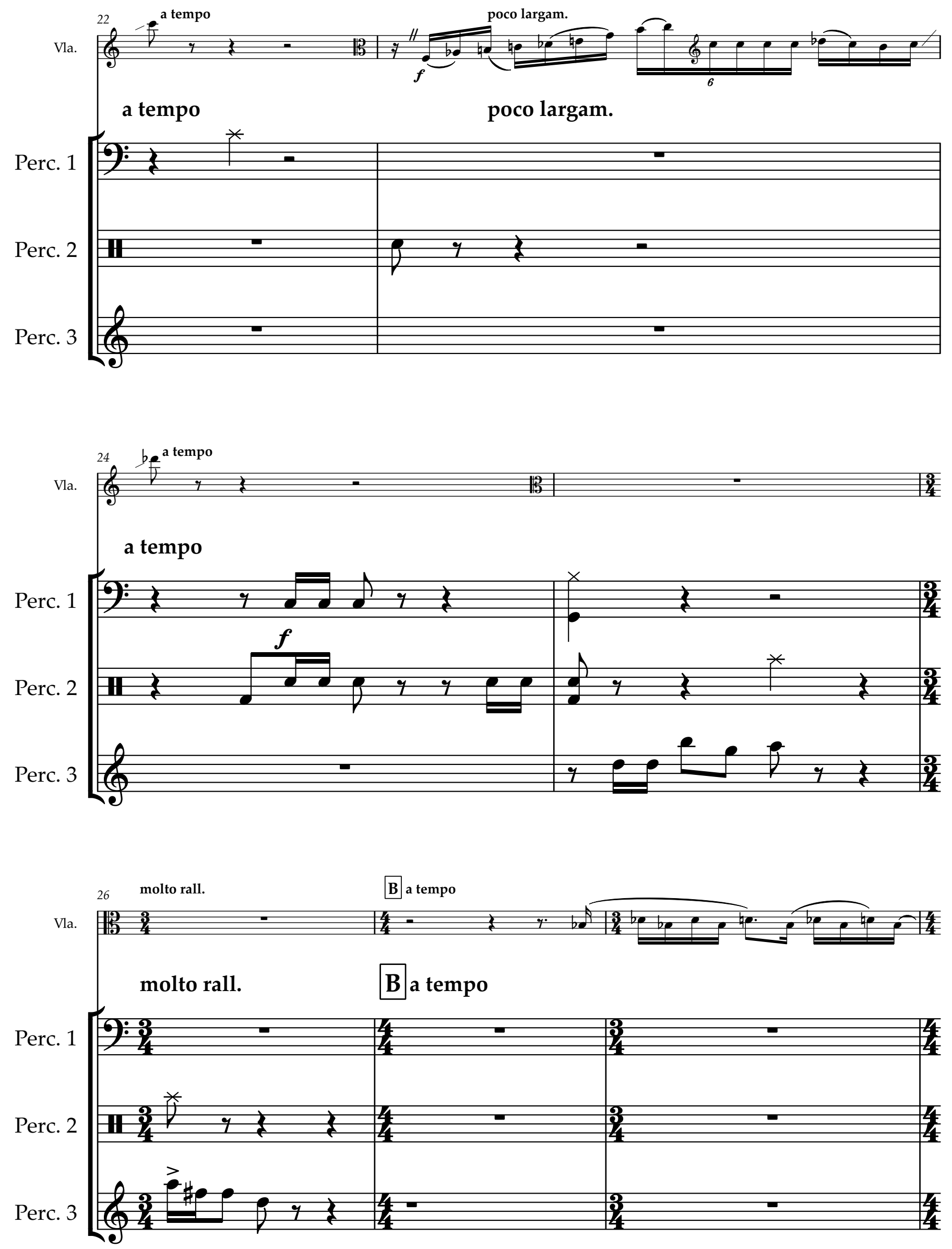

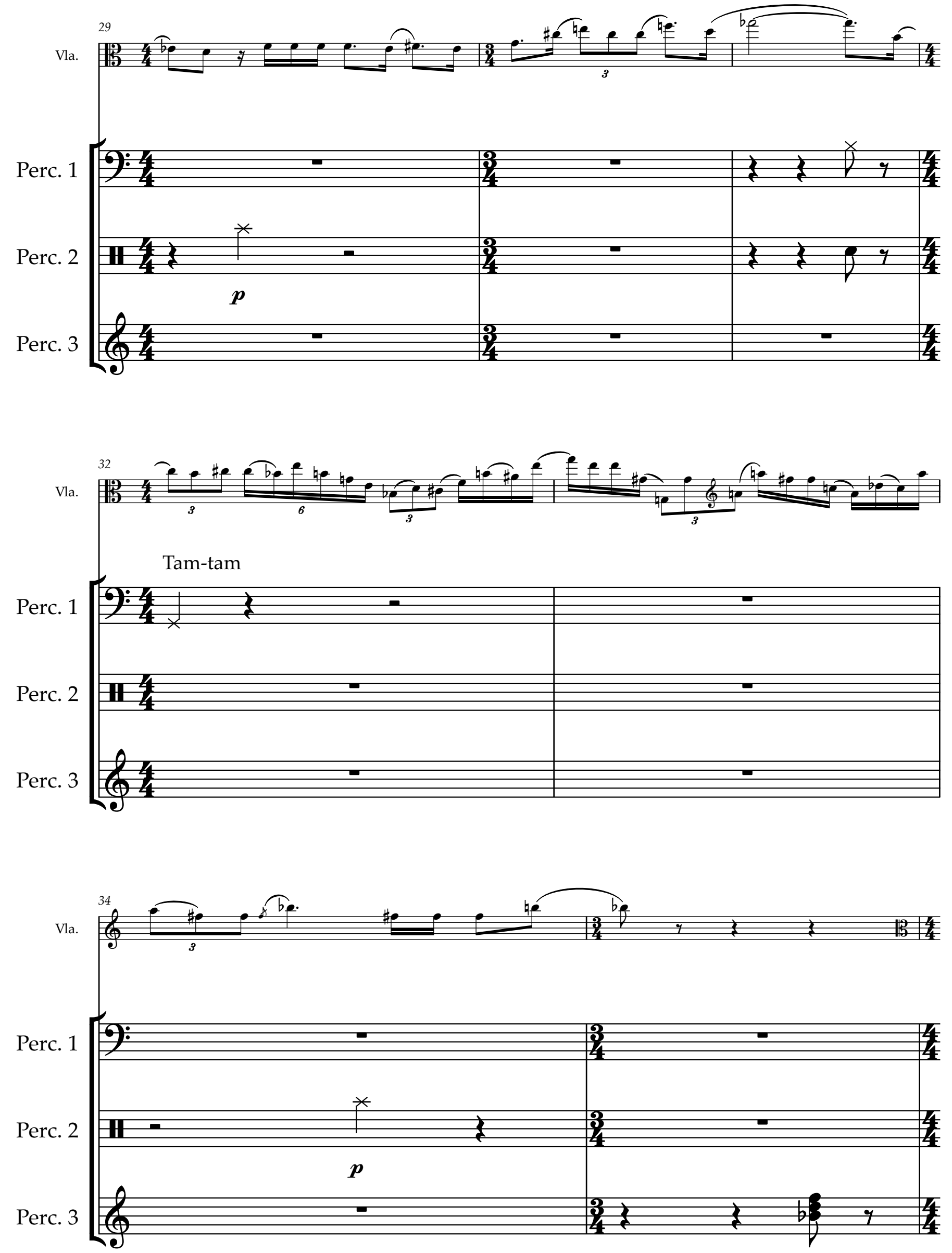

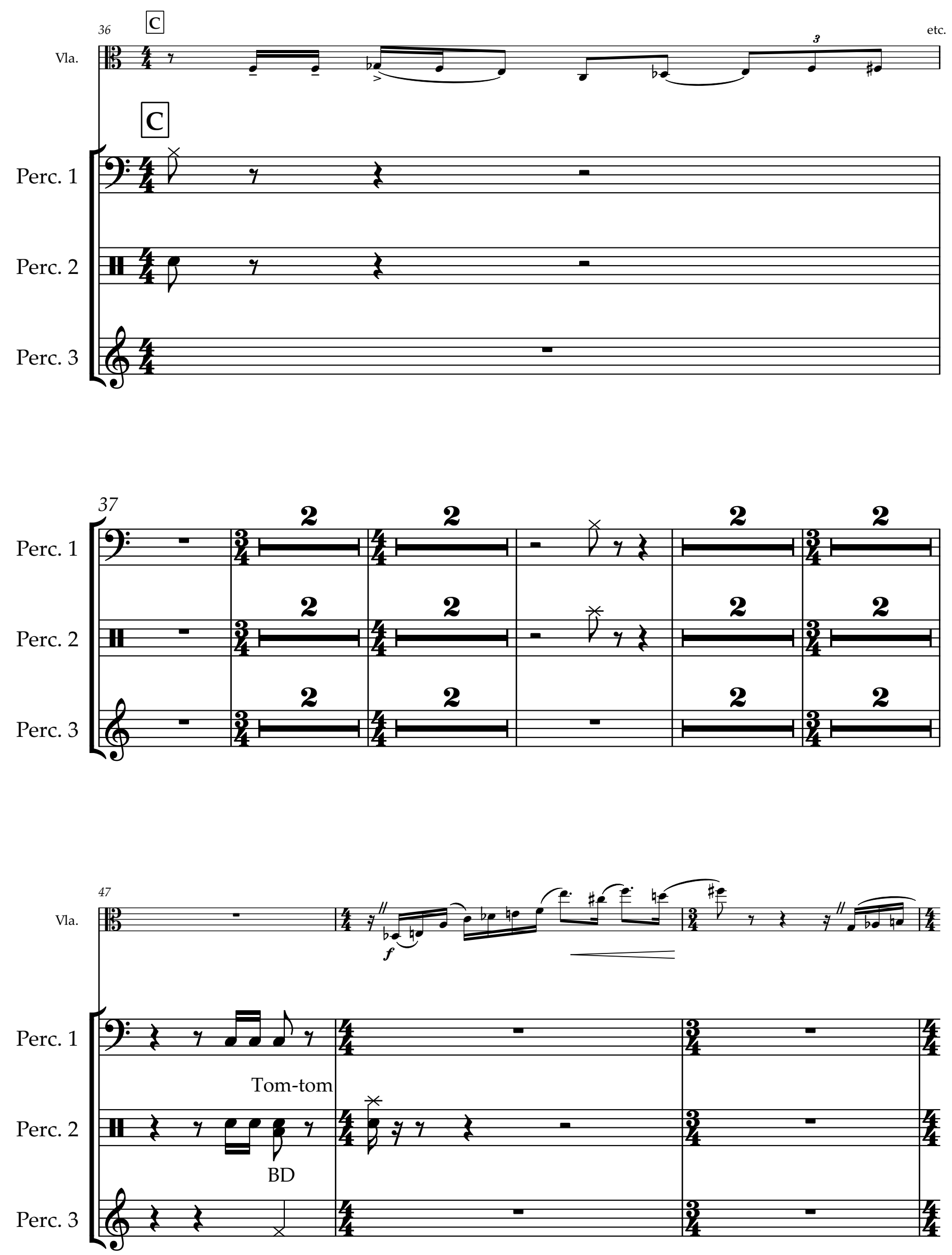

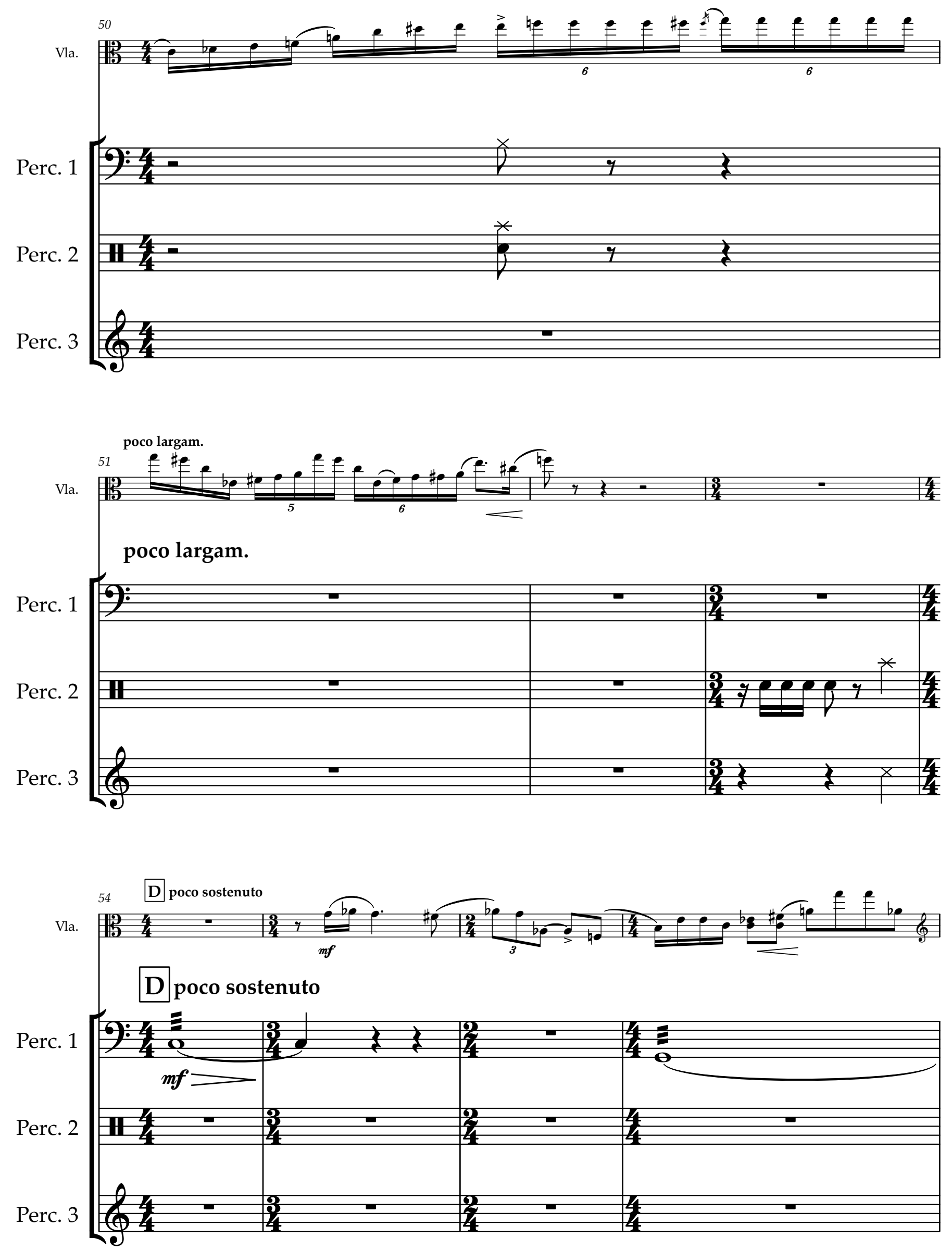


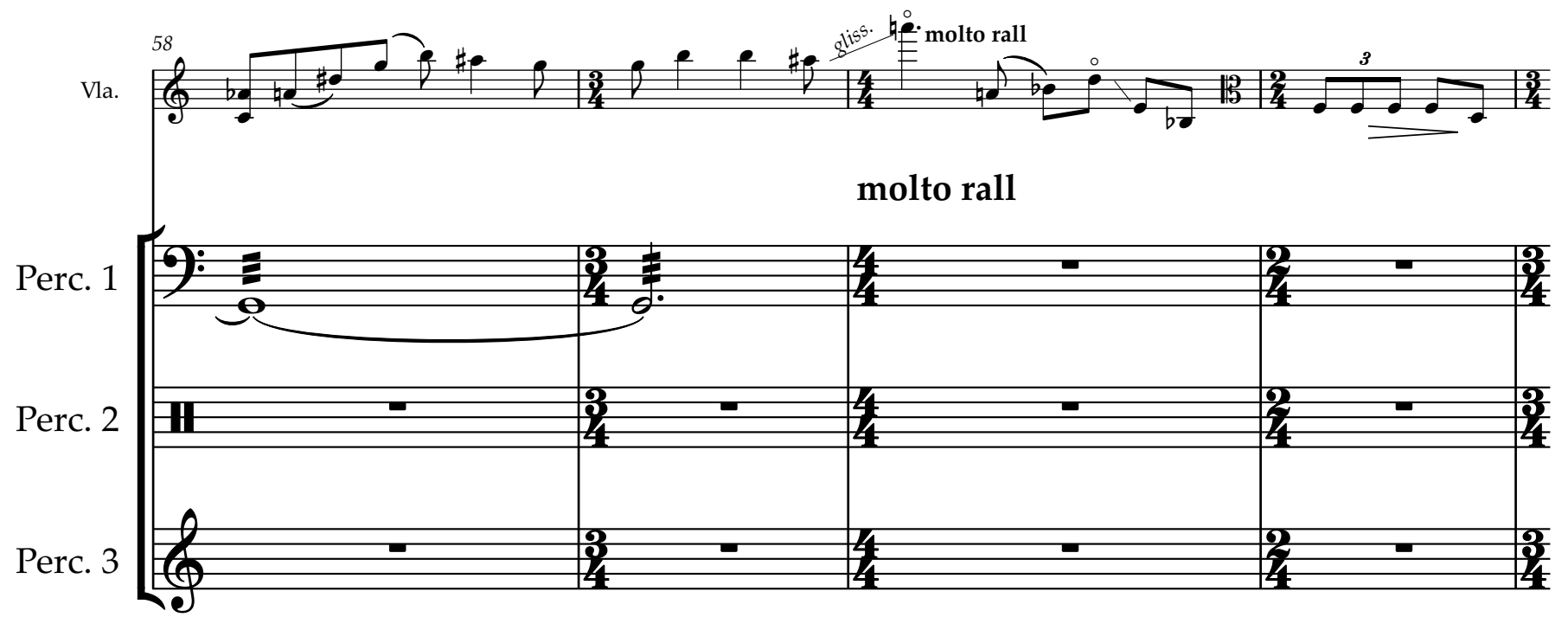



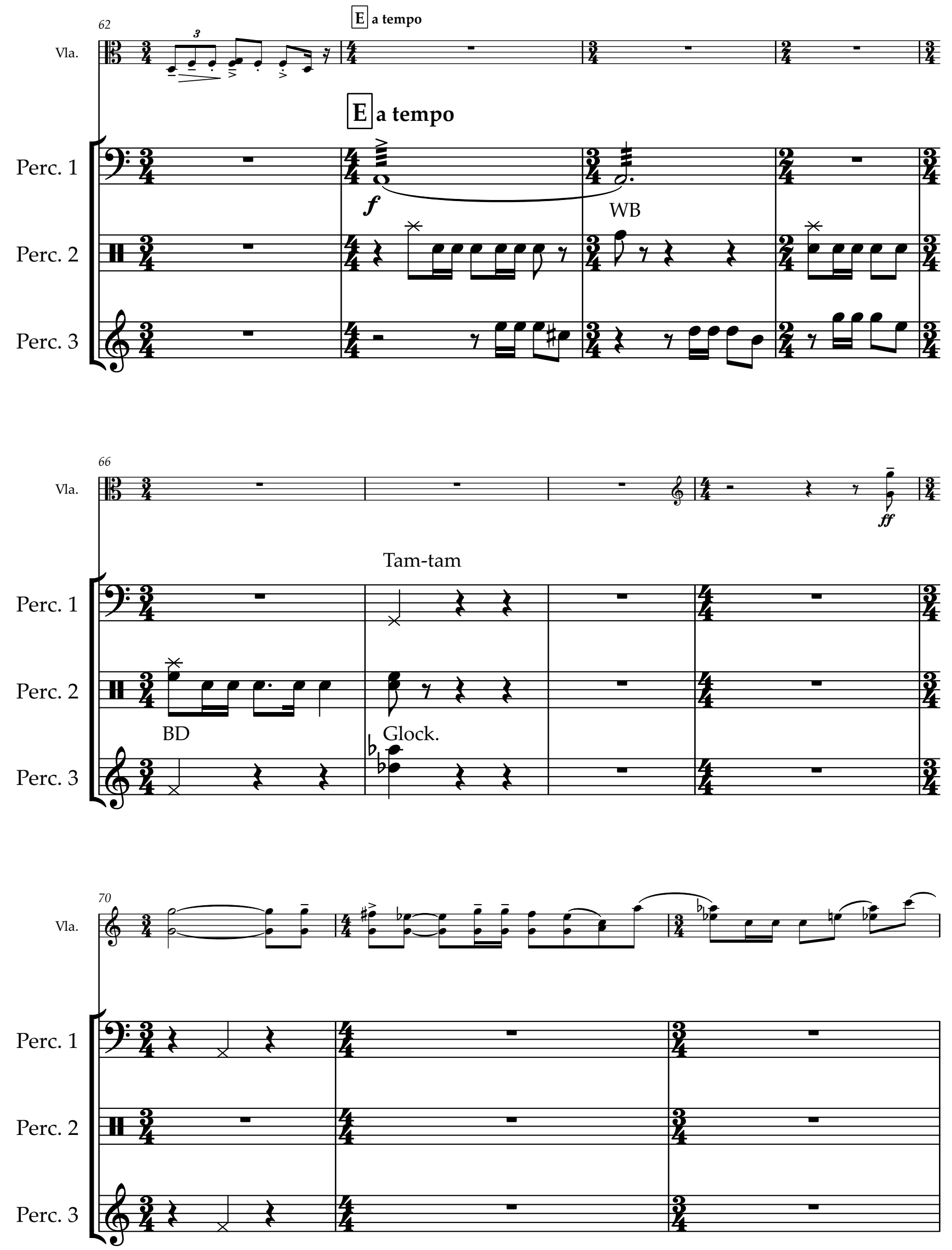

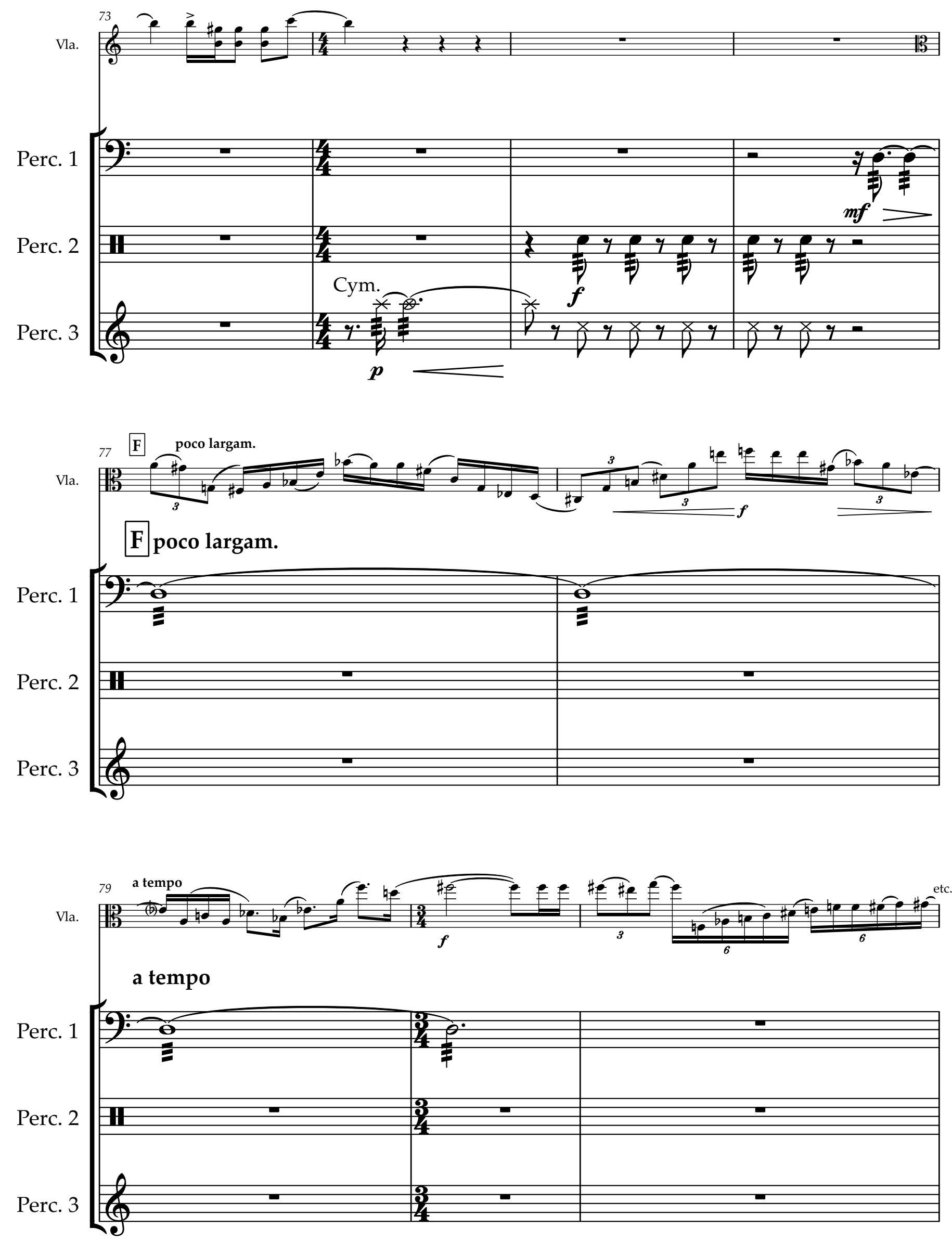

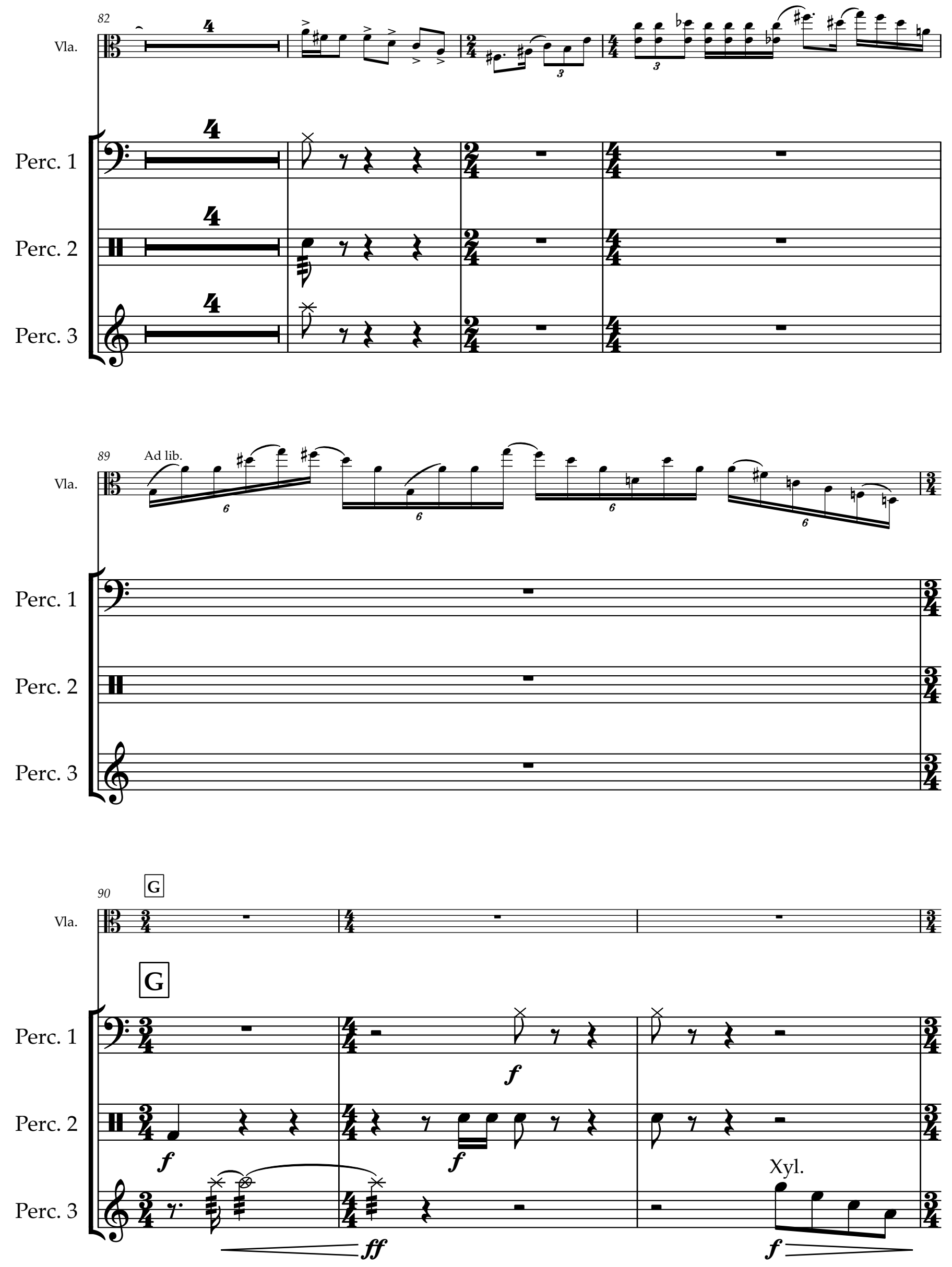

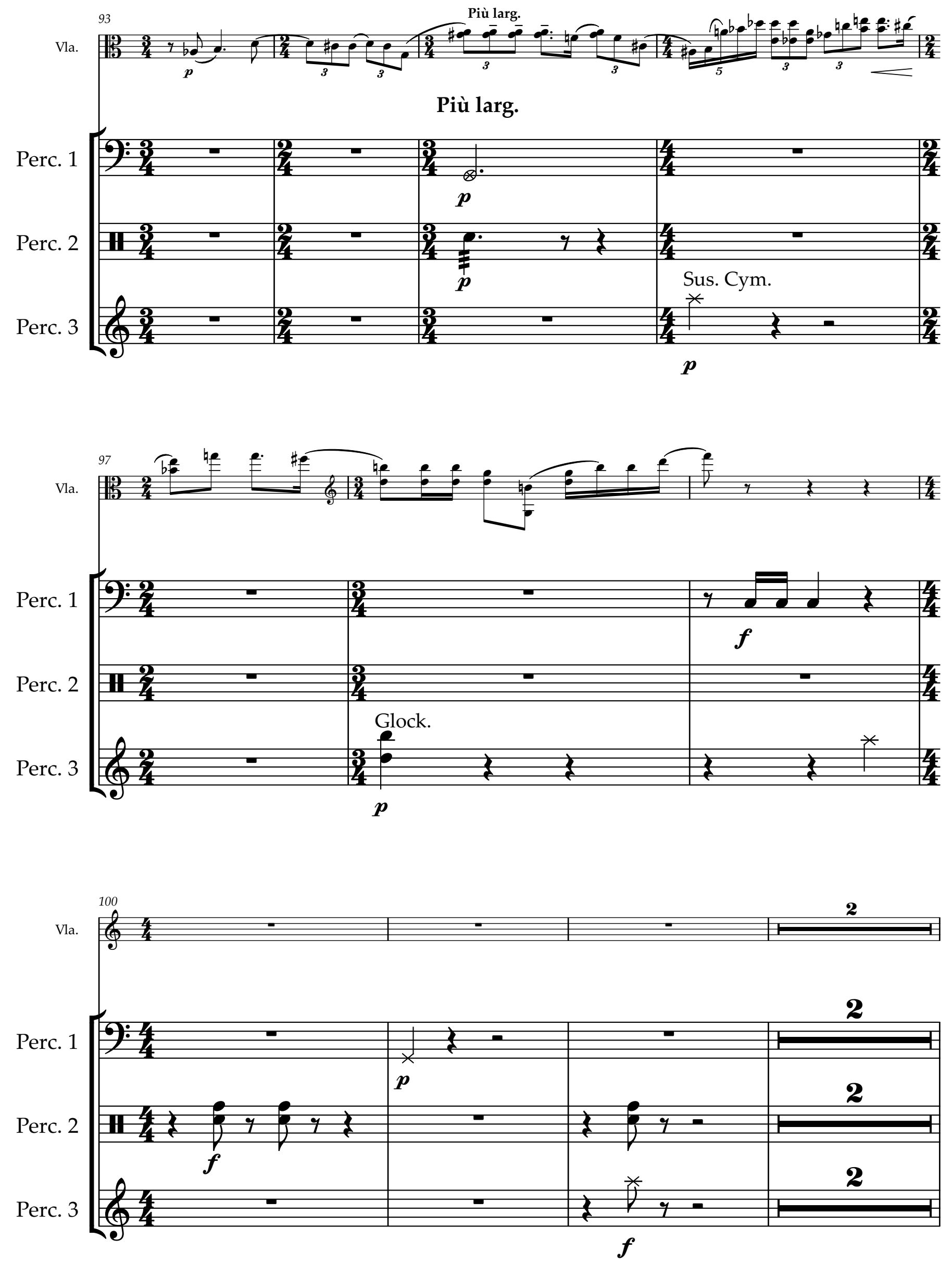

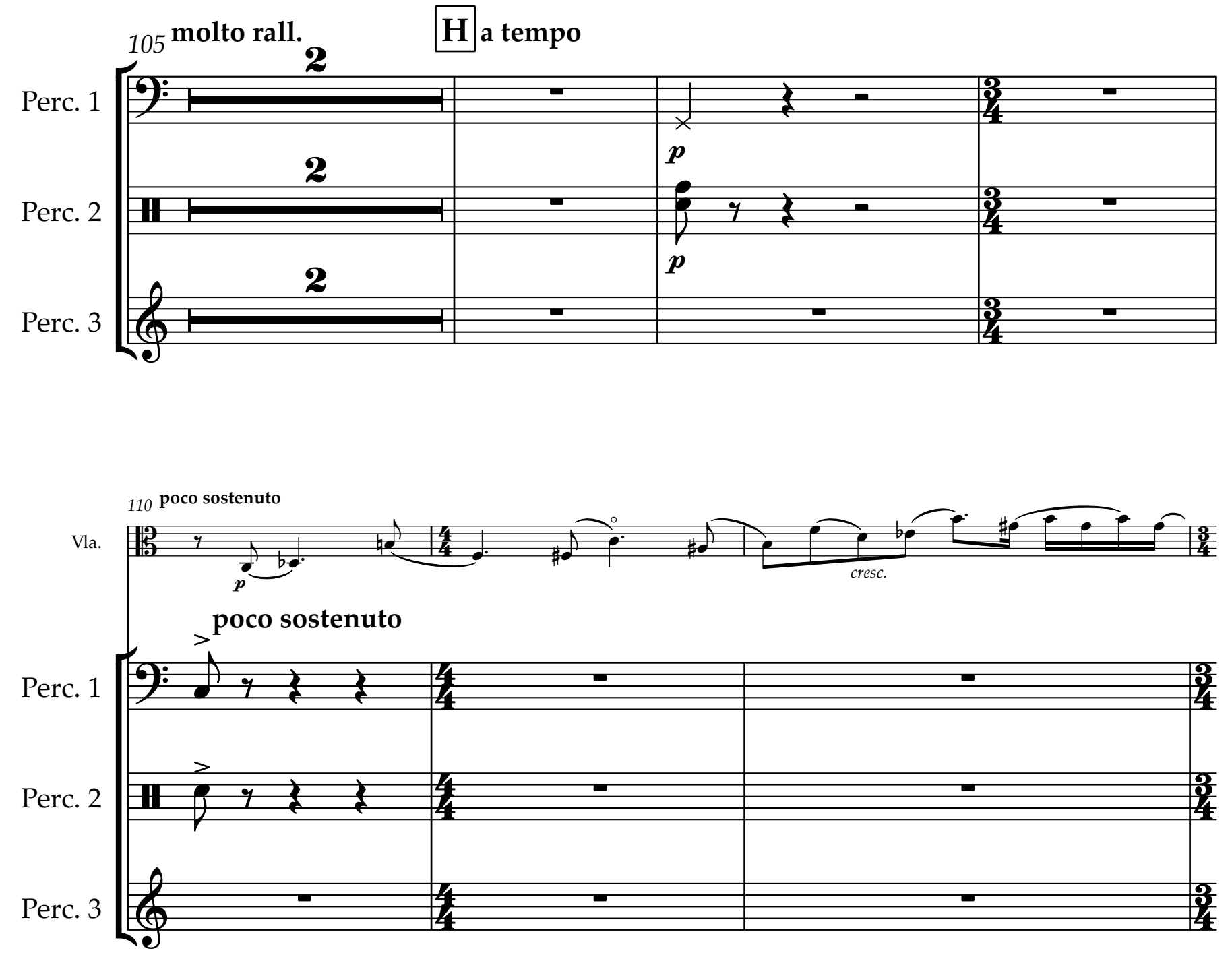

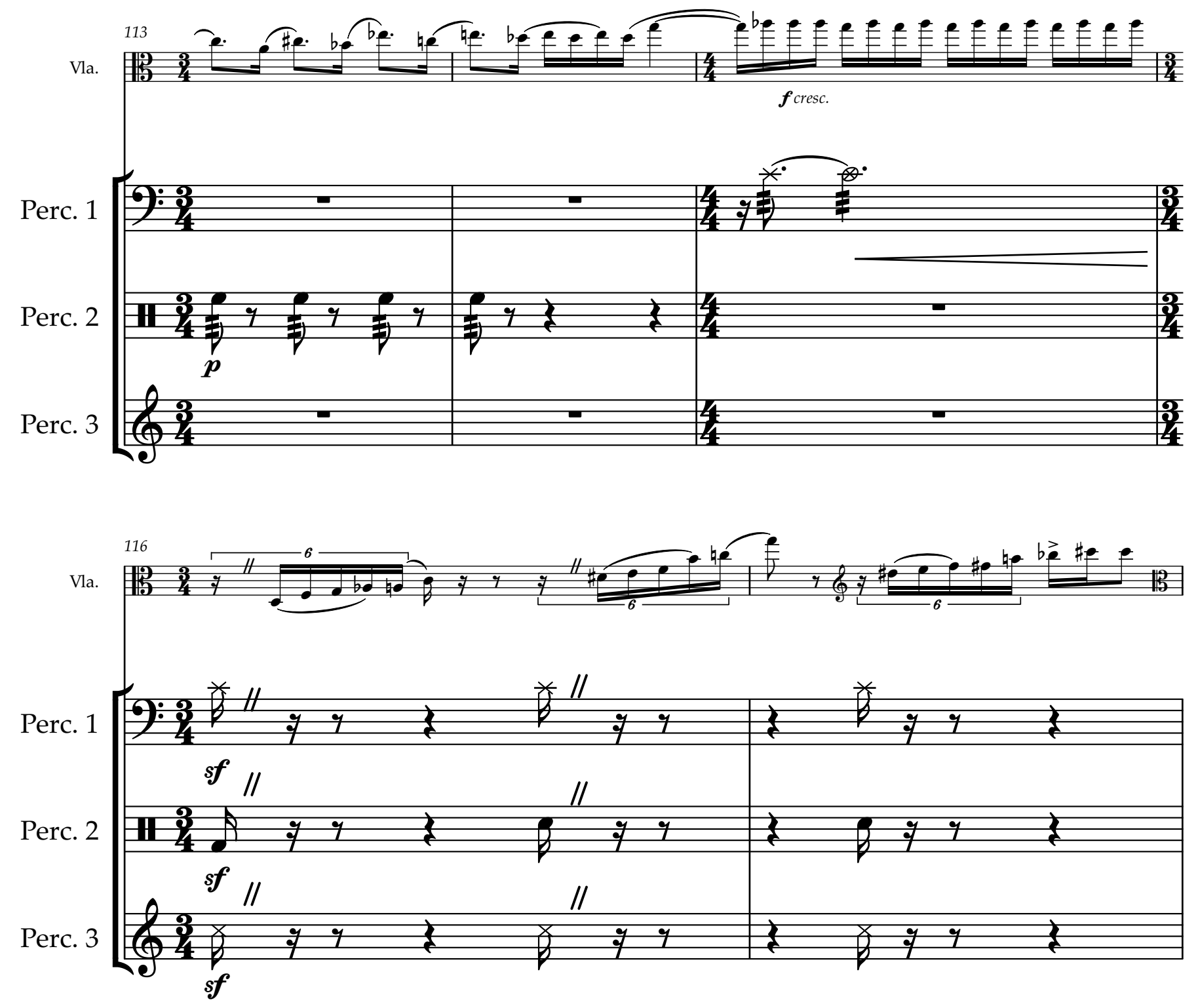

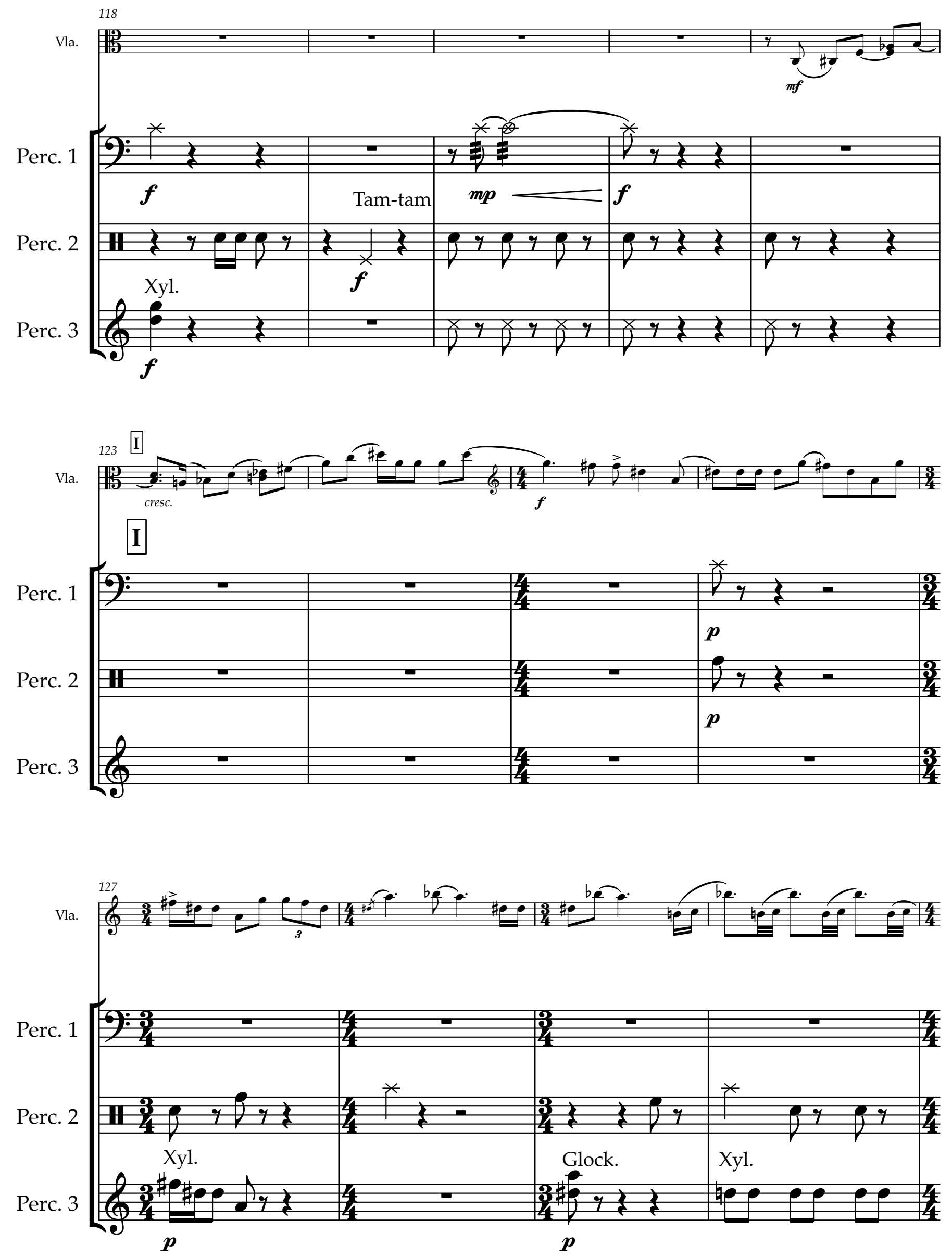


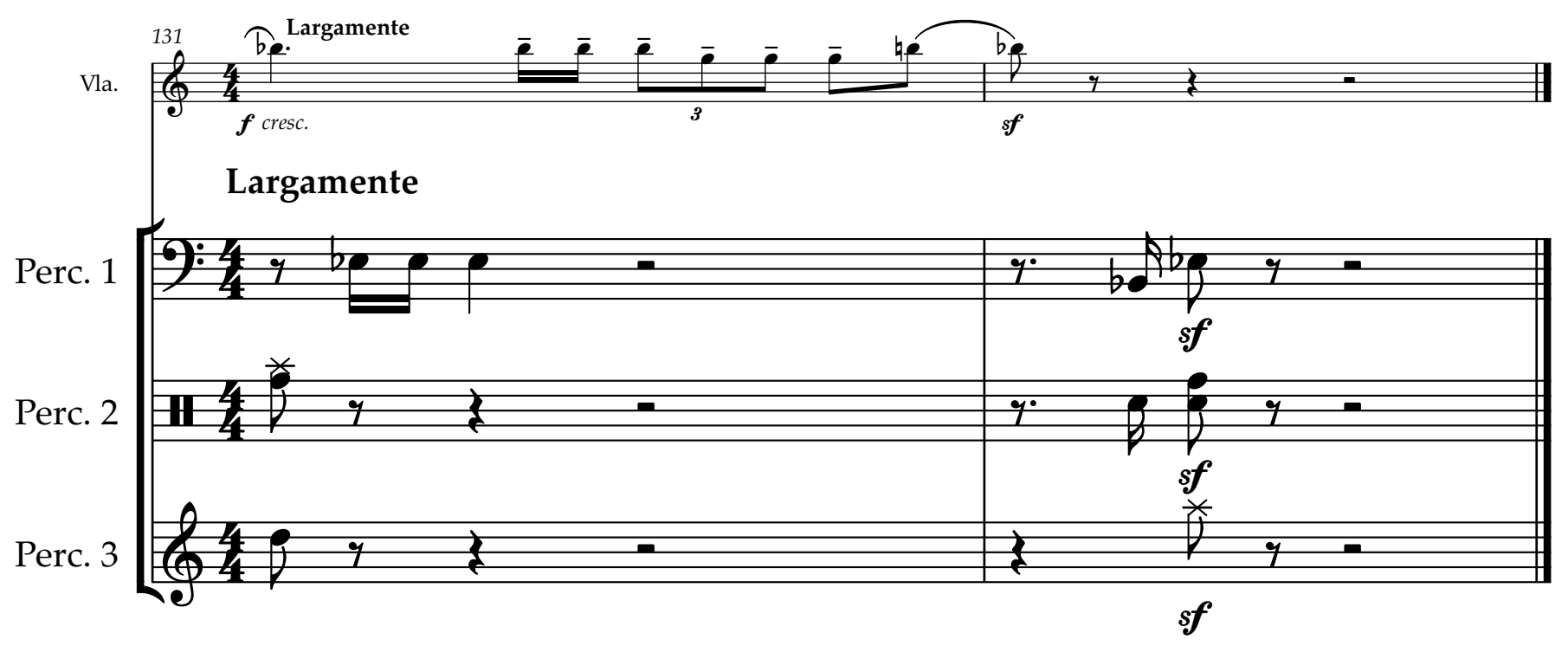



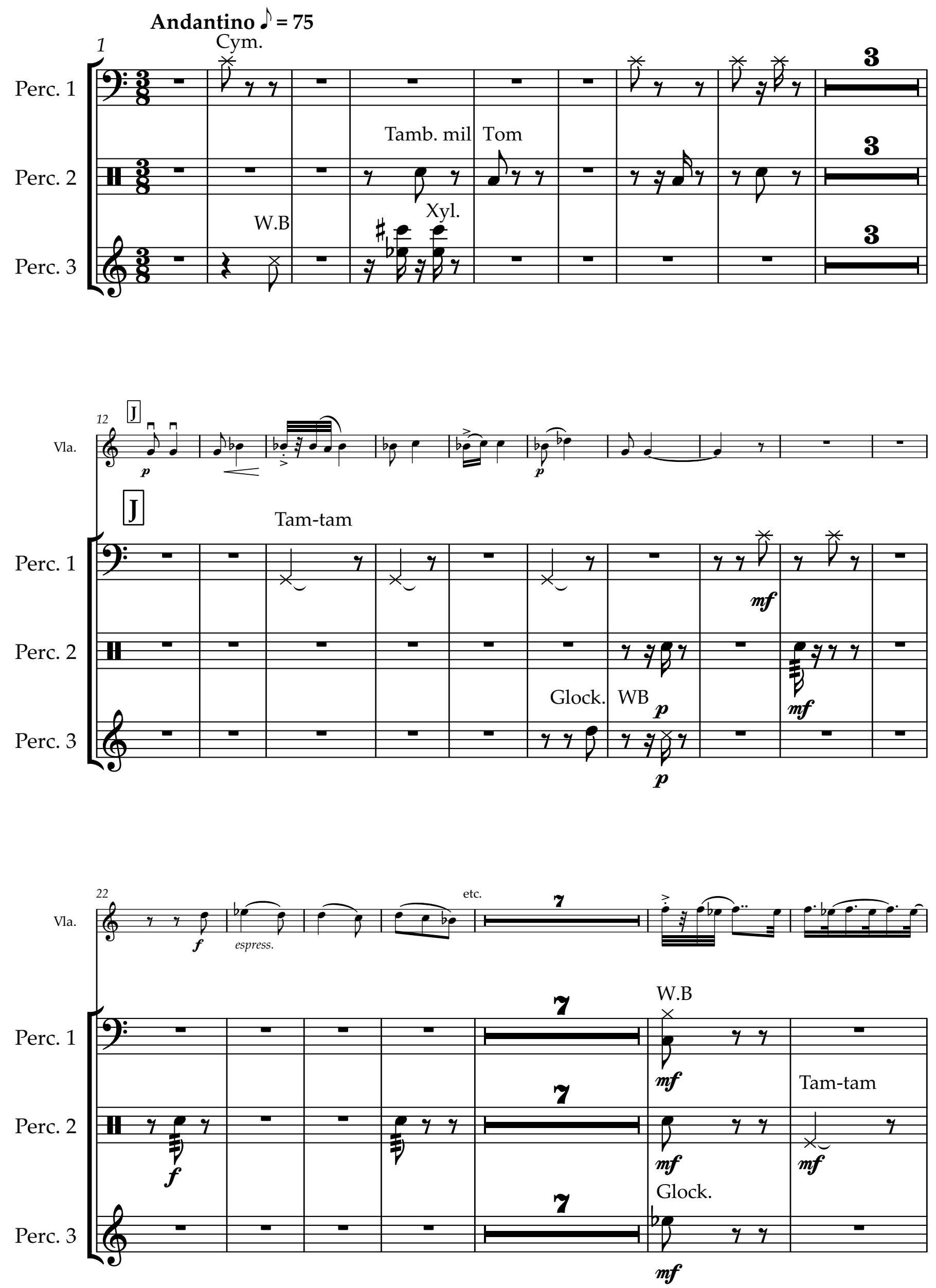

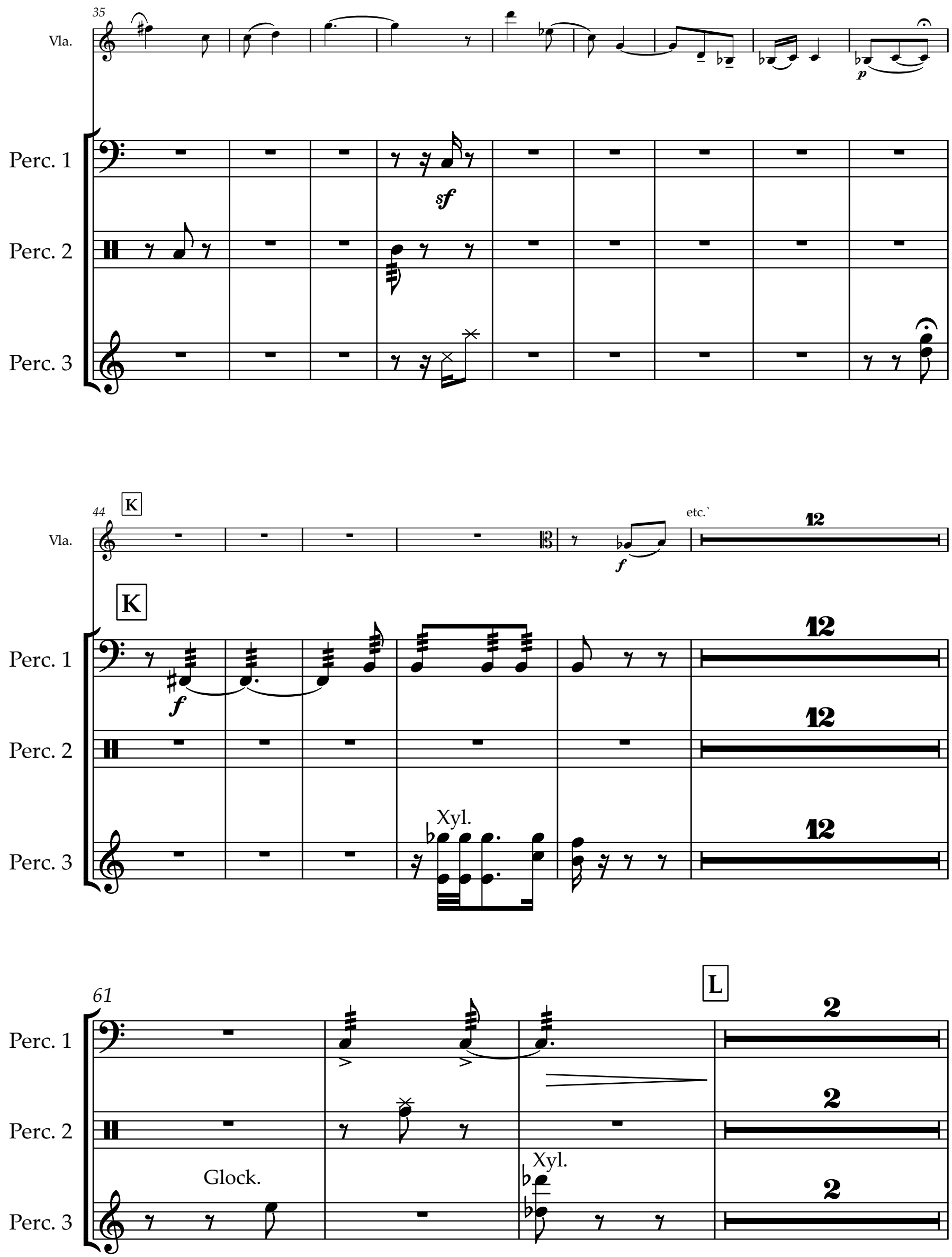

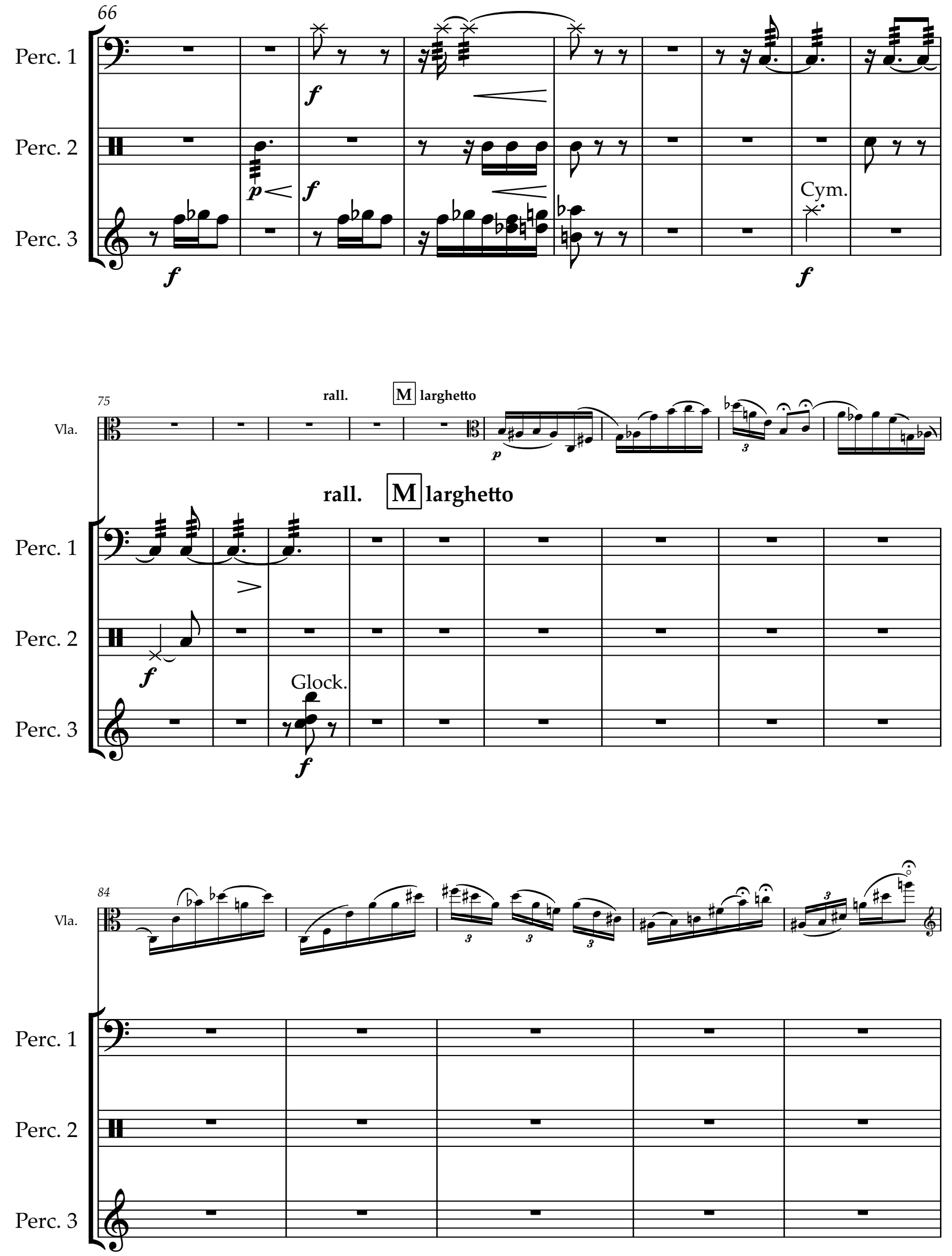

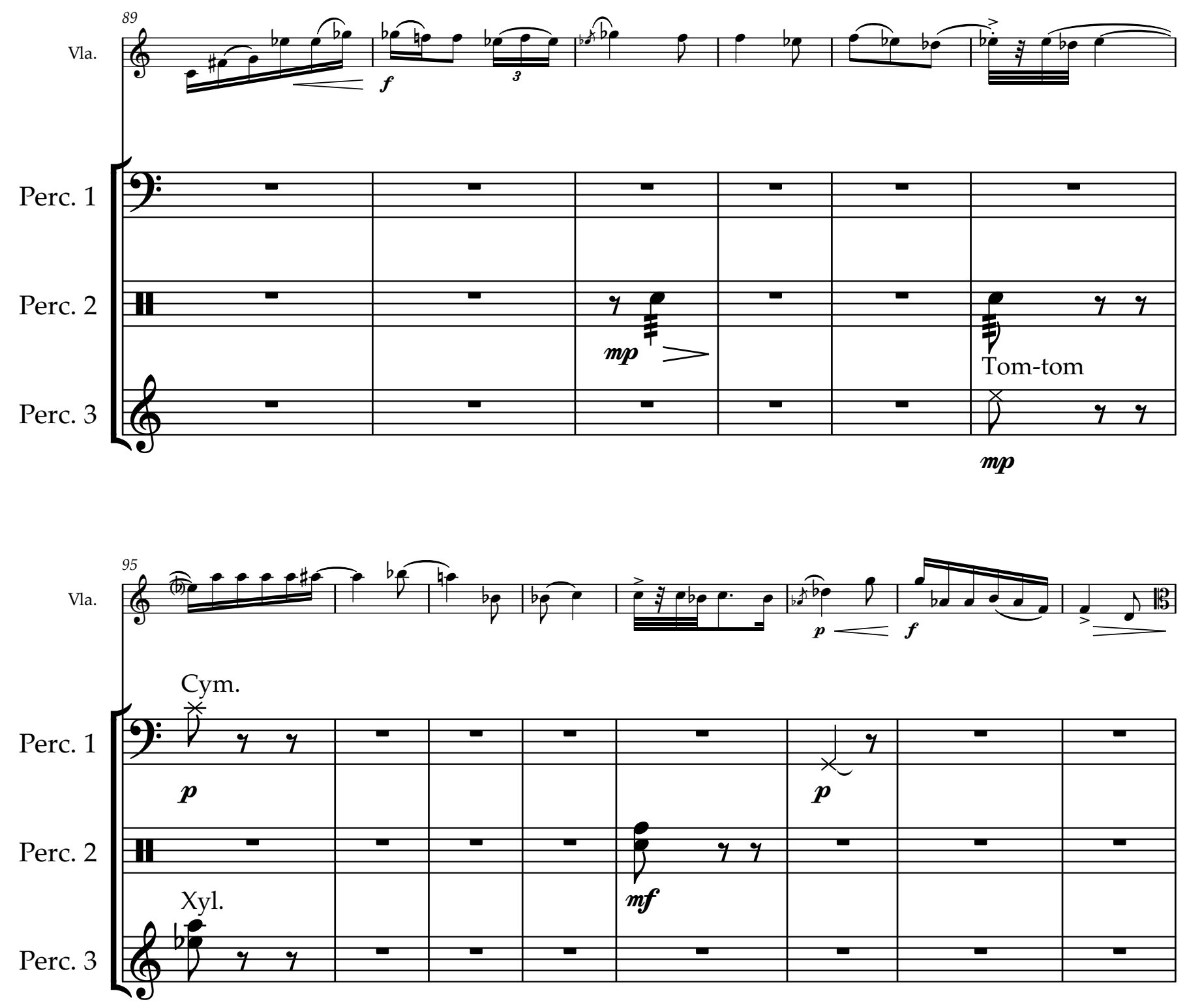

103

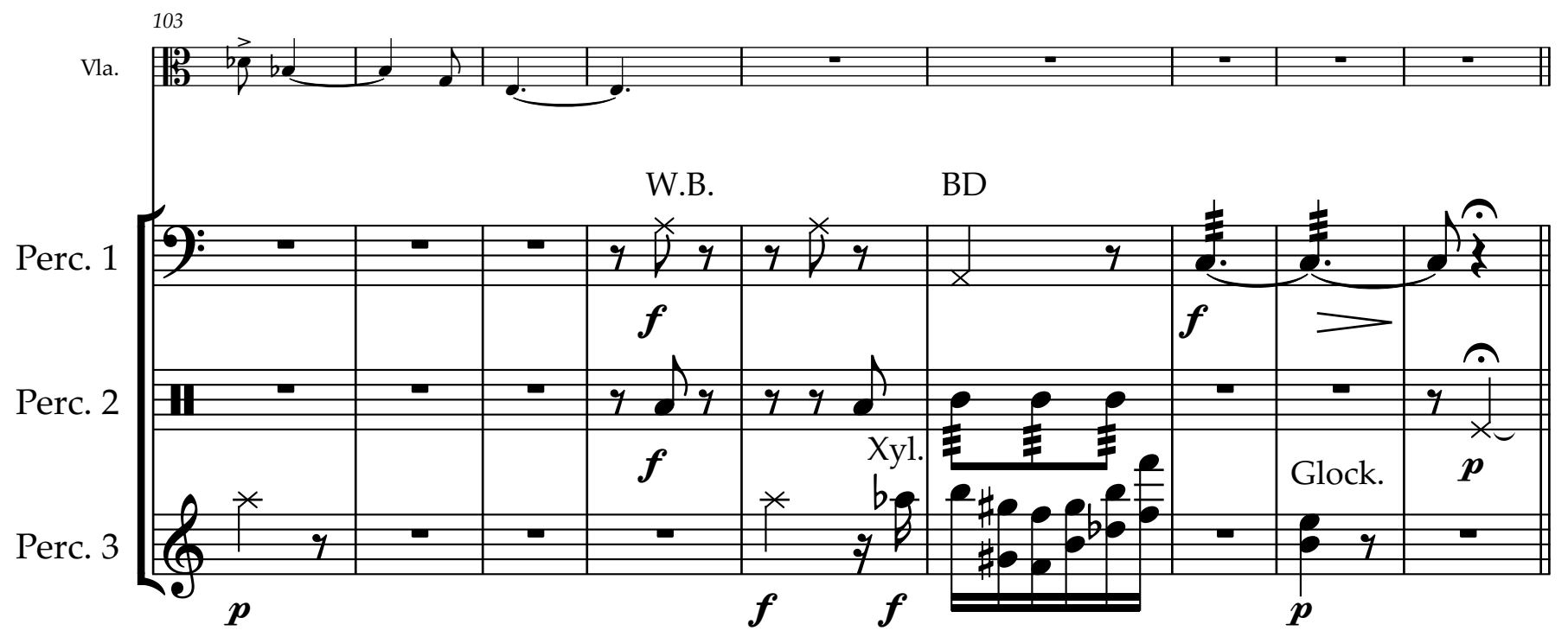



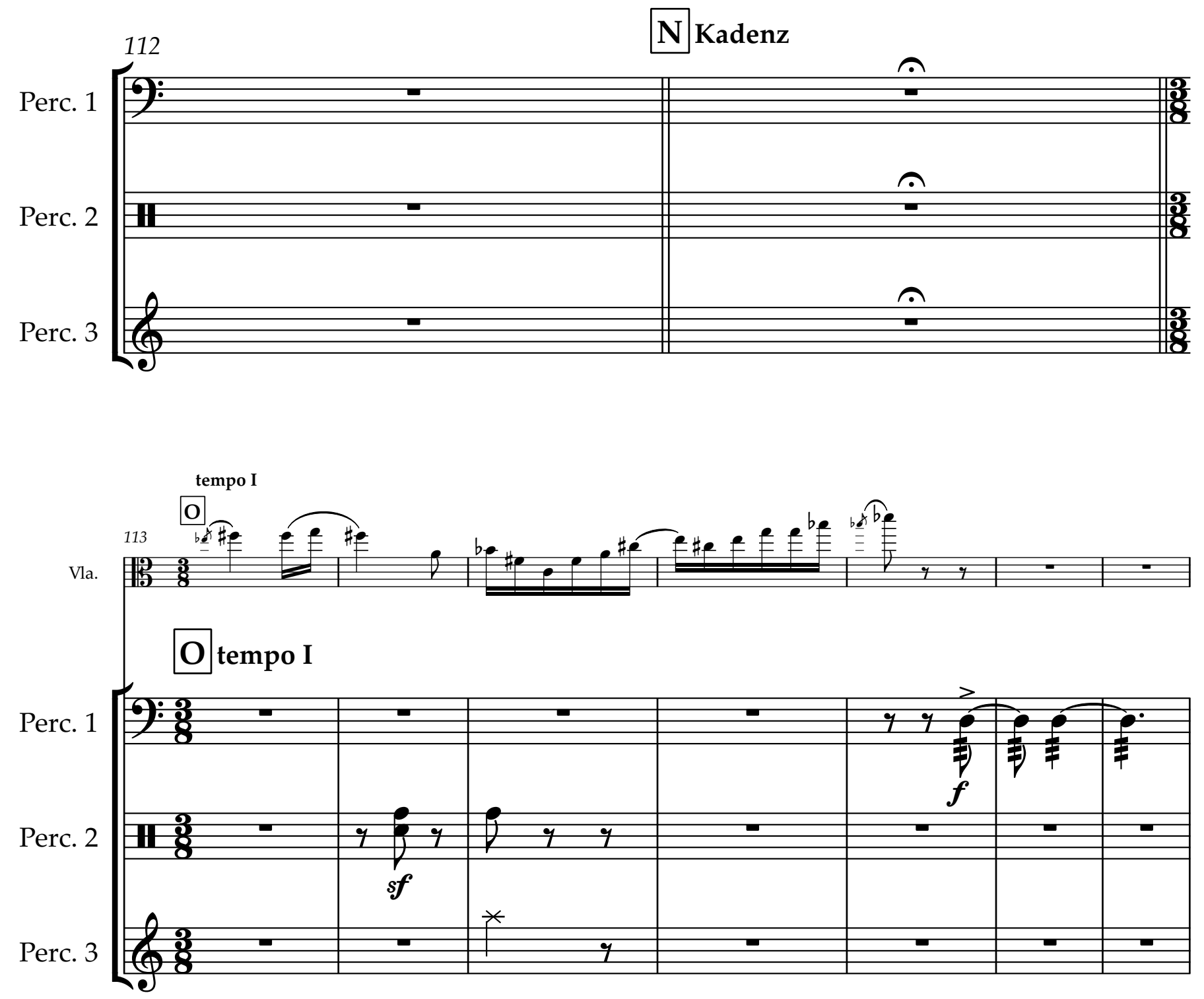

120

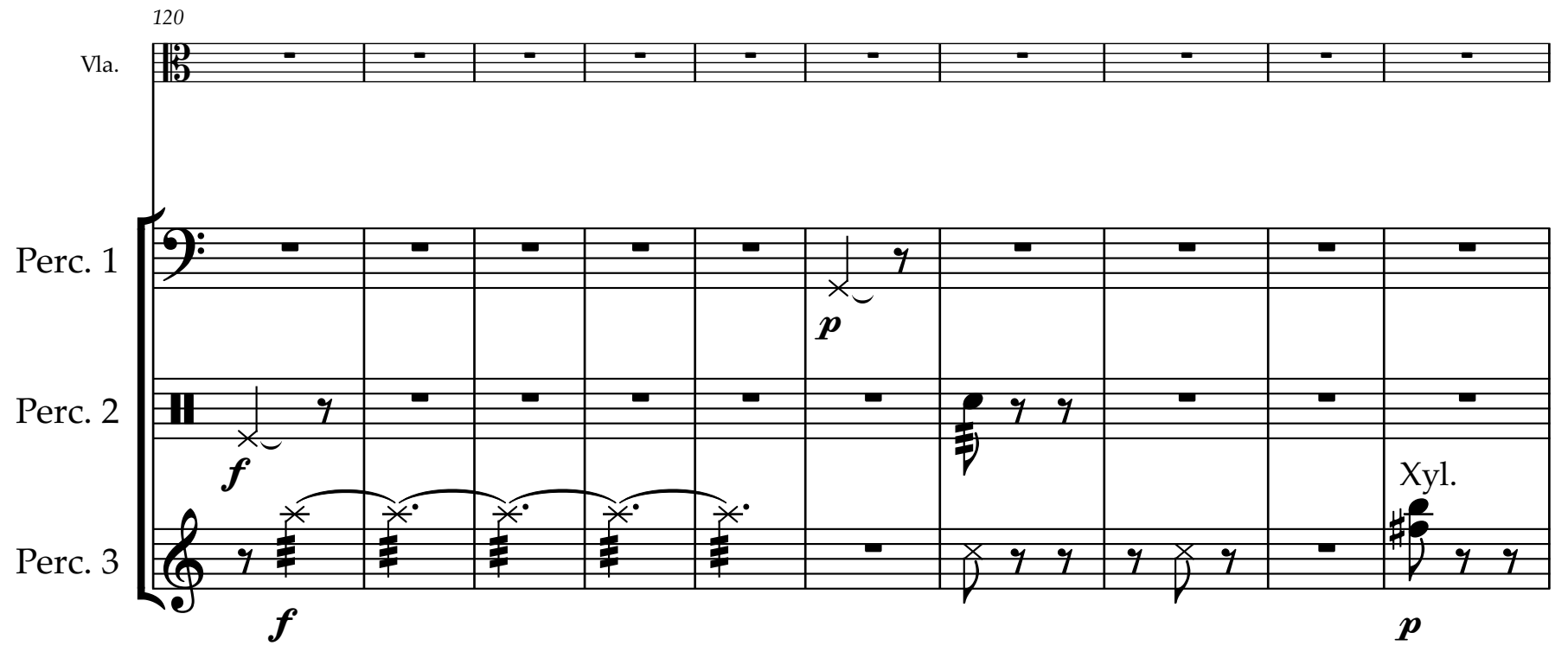



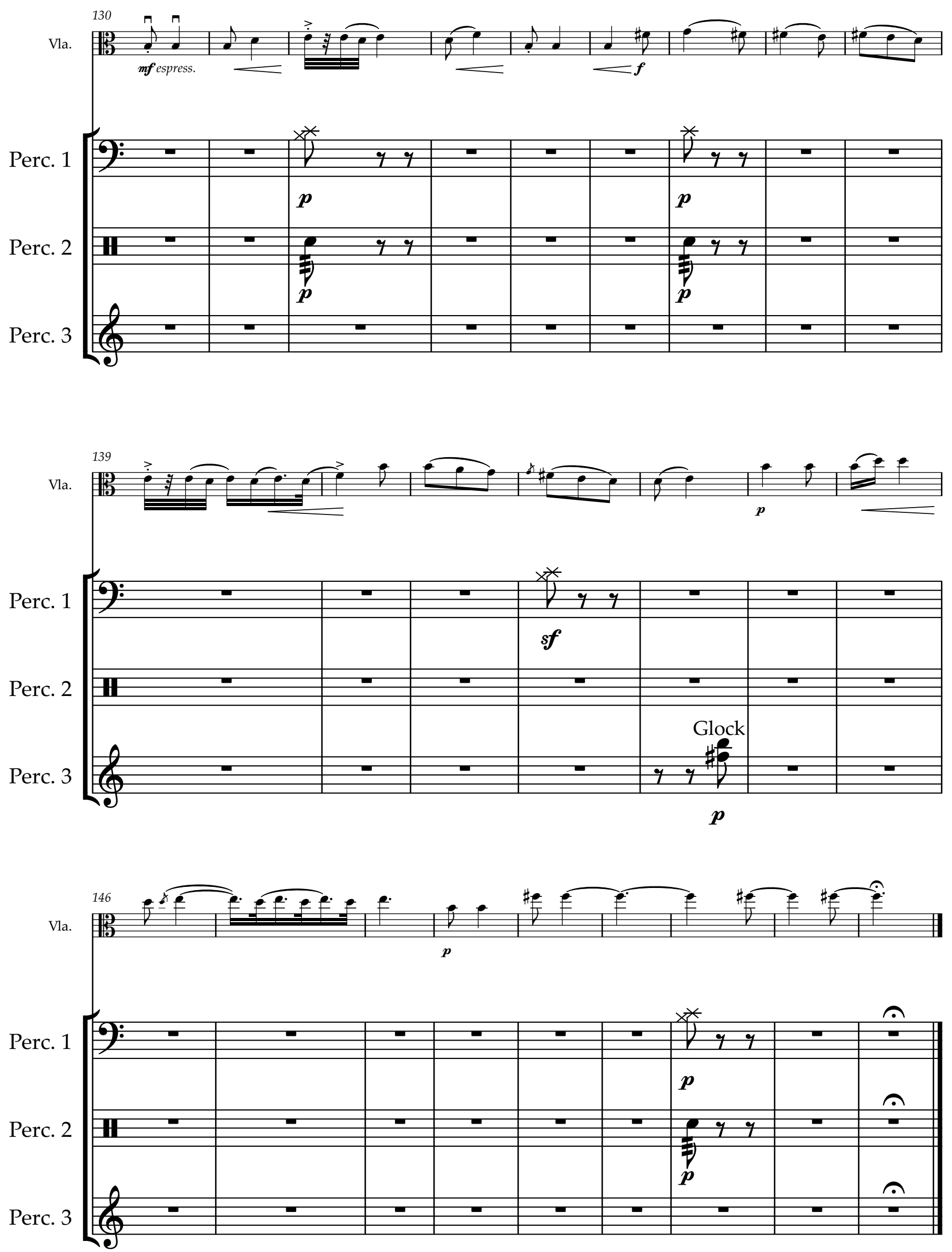


\section{III.}
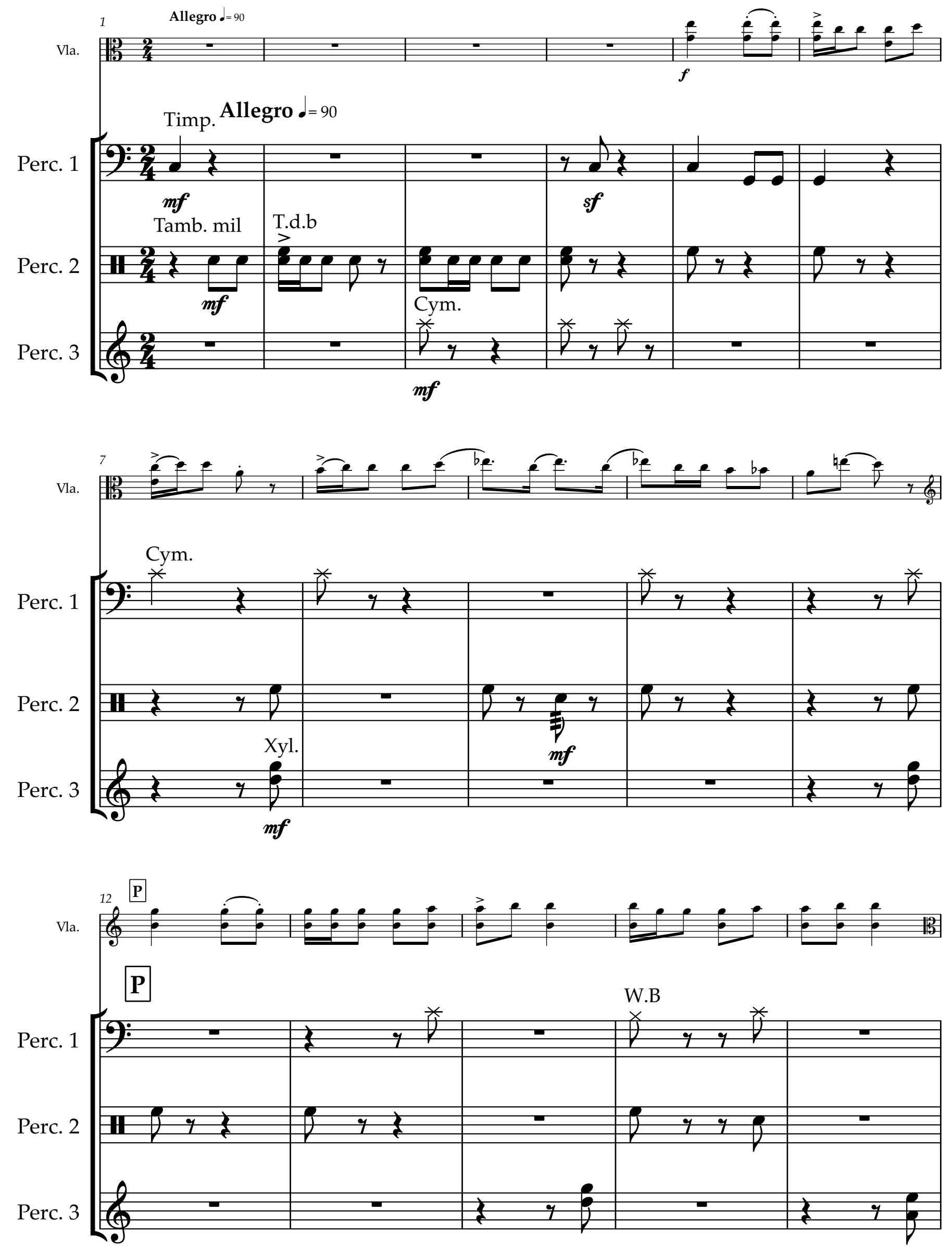


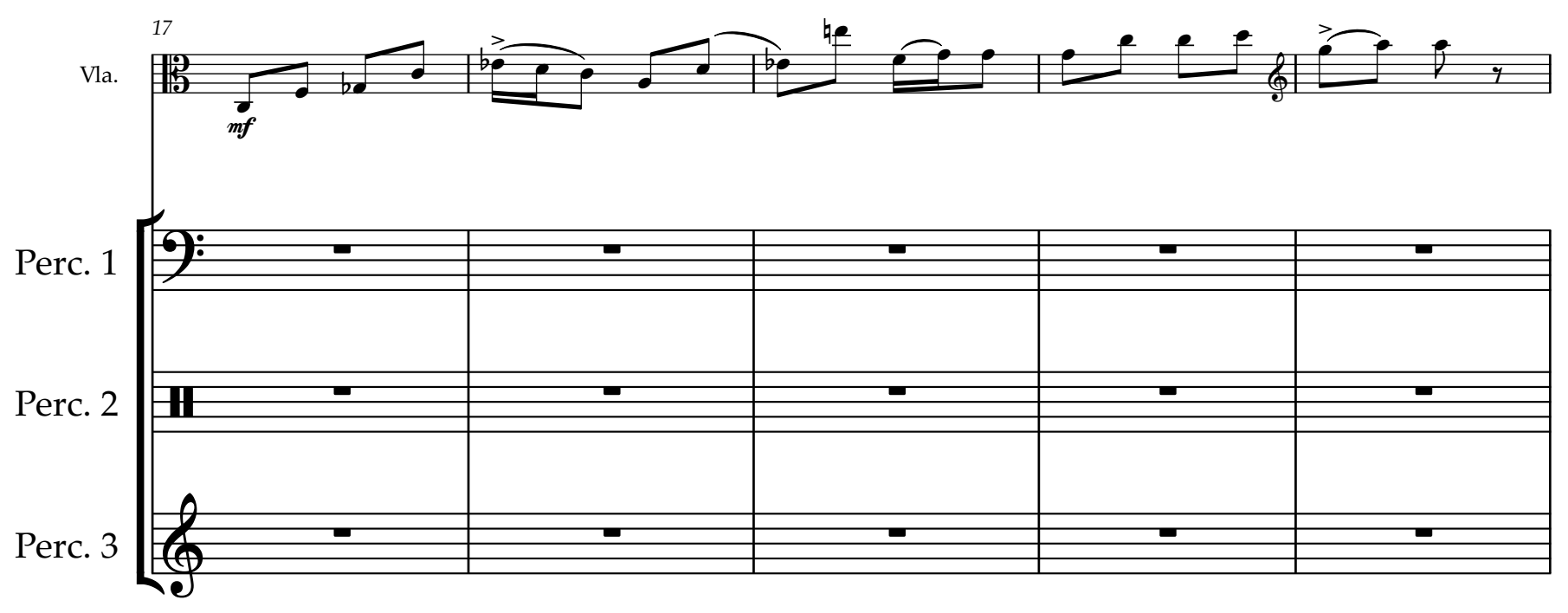



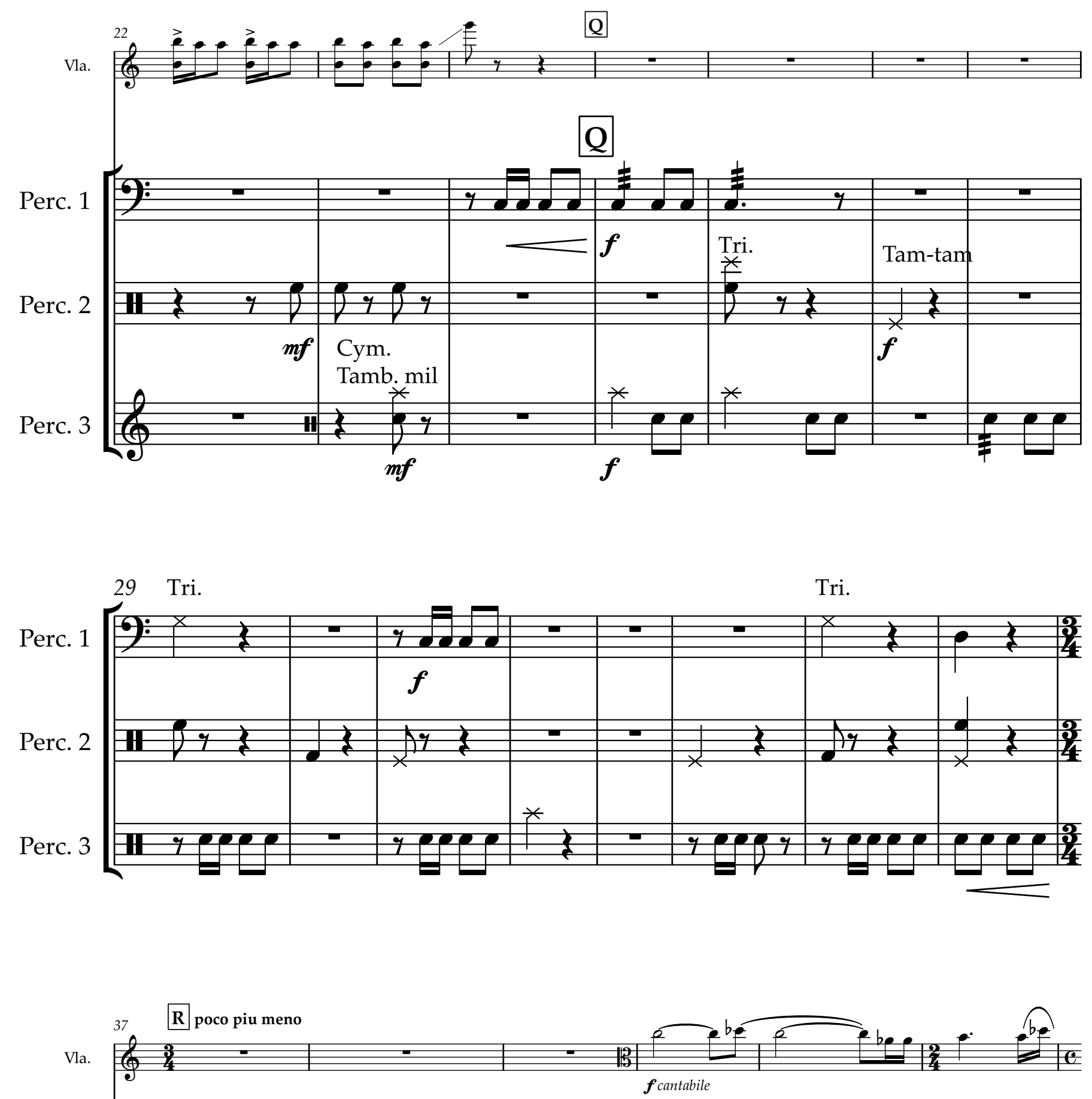

$\mathbf{R}$ poco piu meno

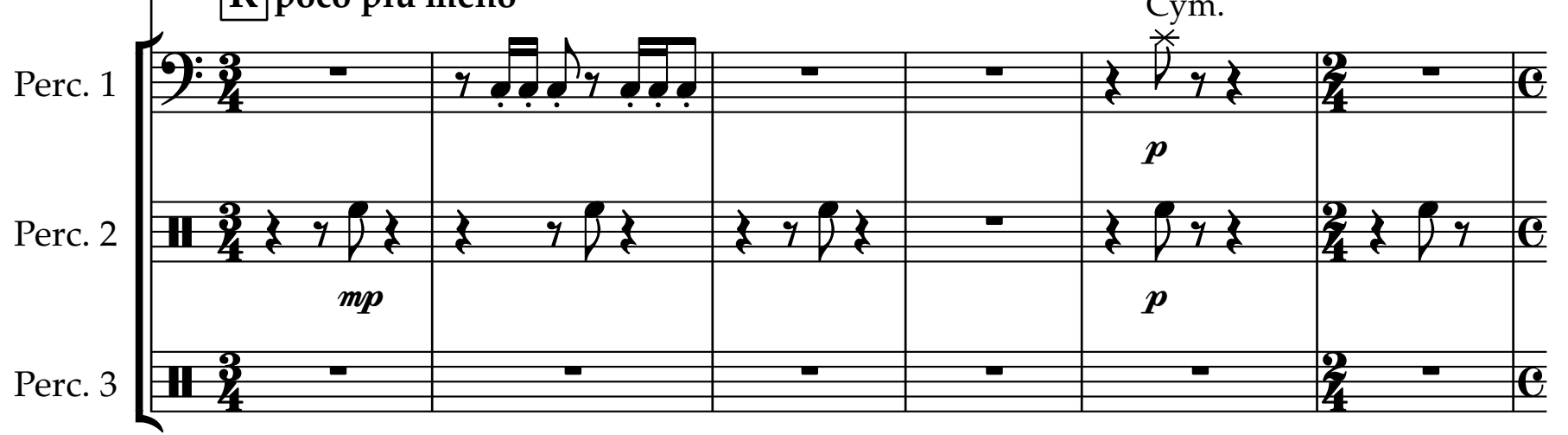



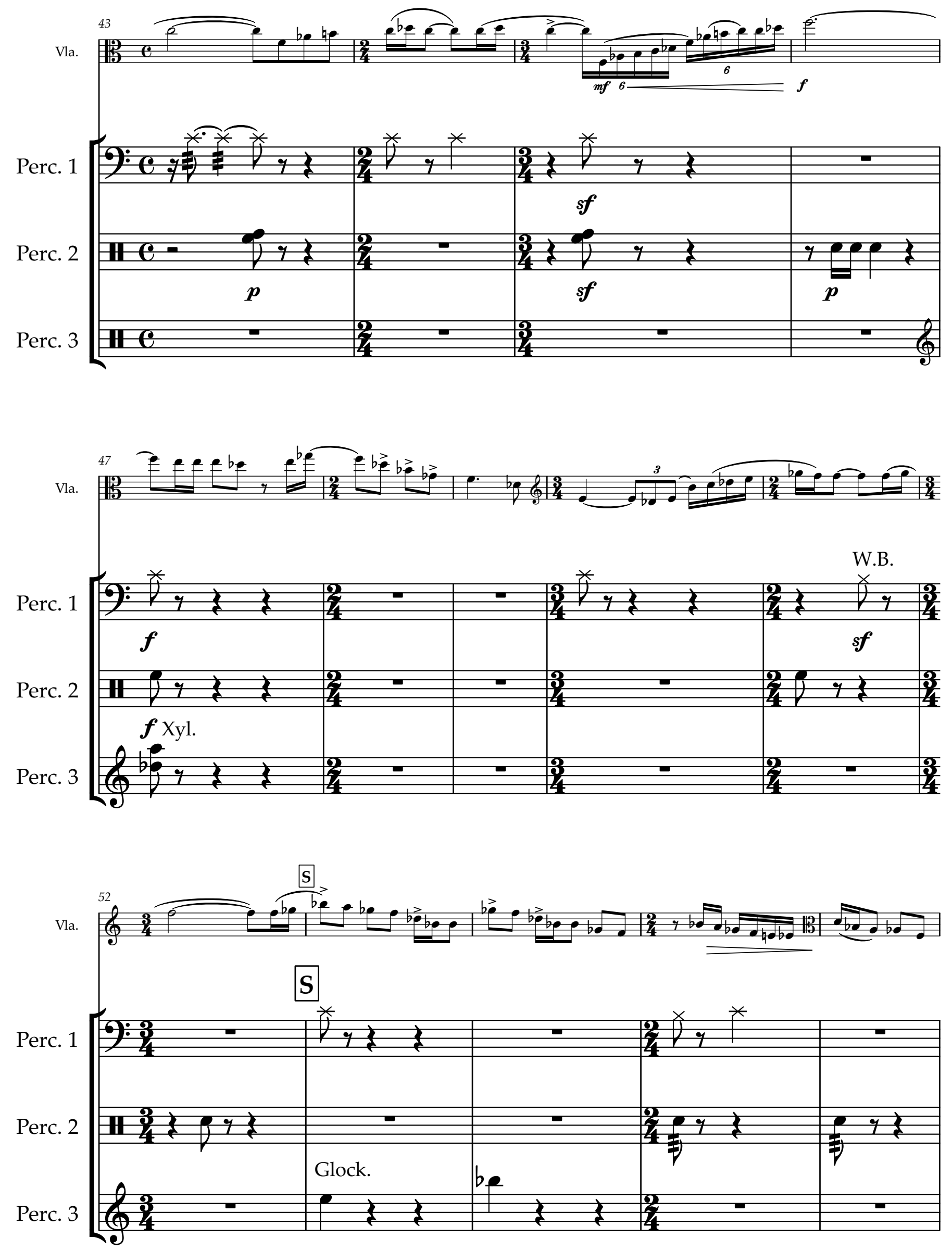

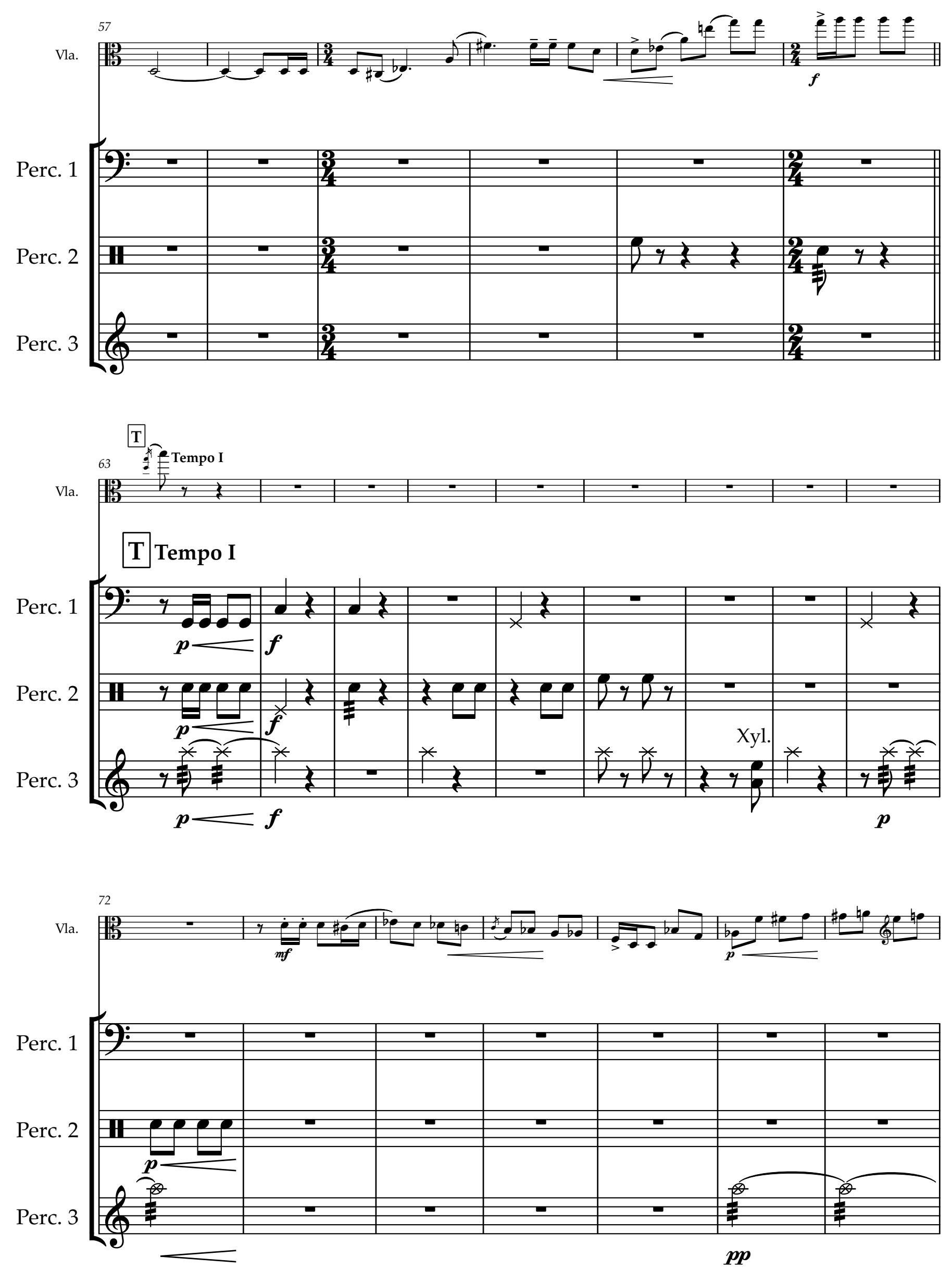

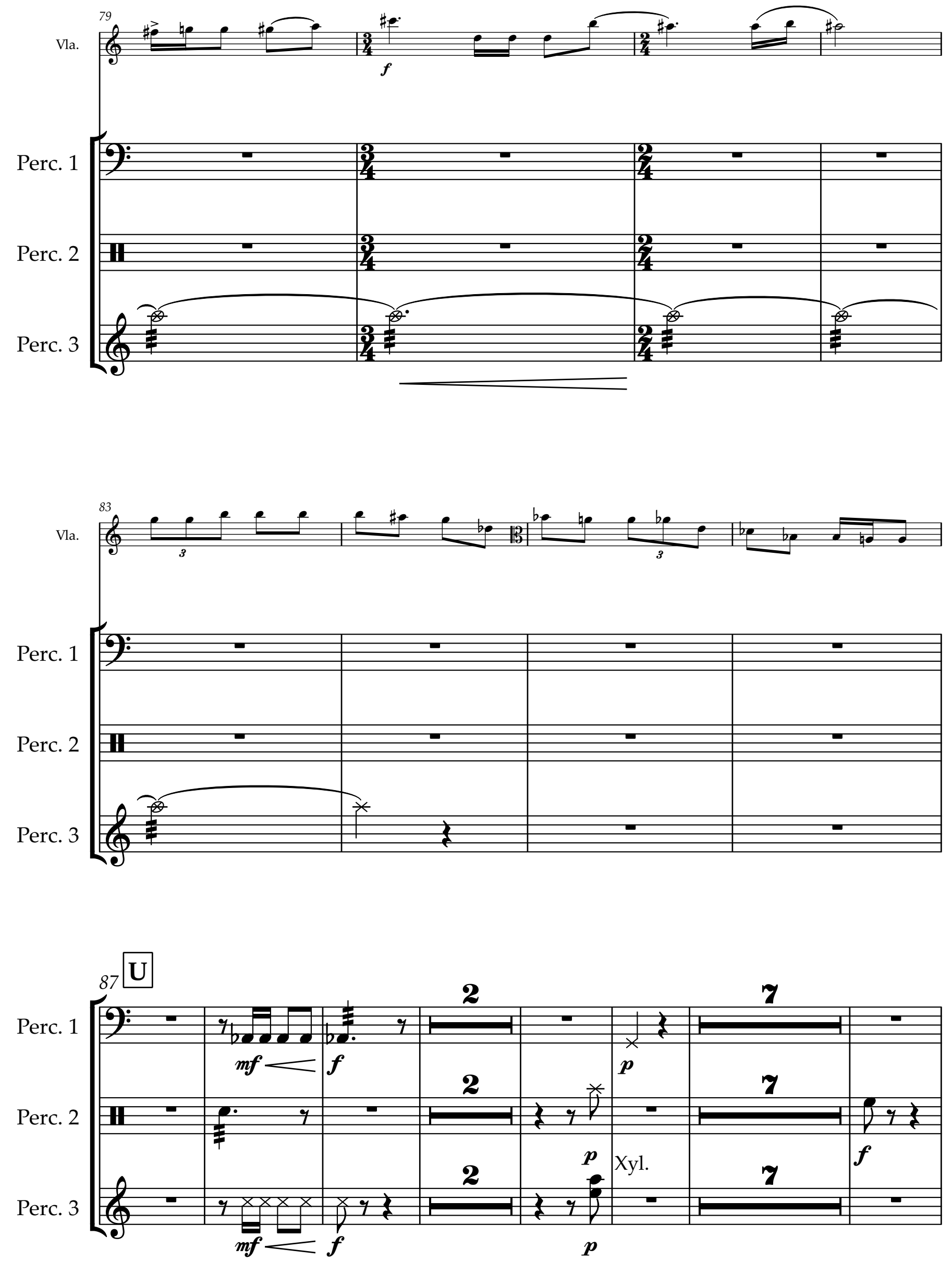

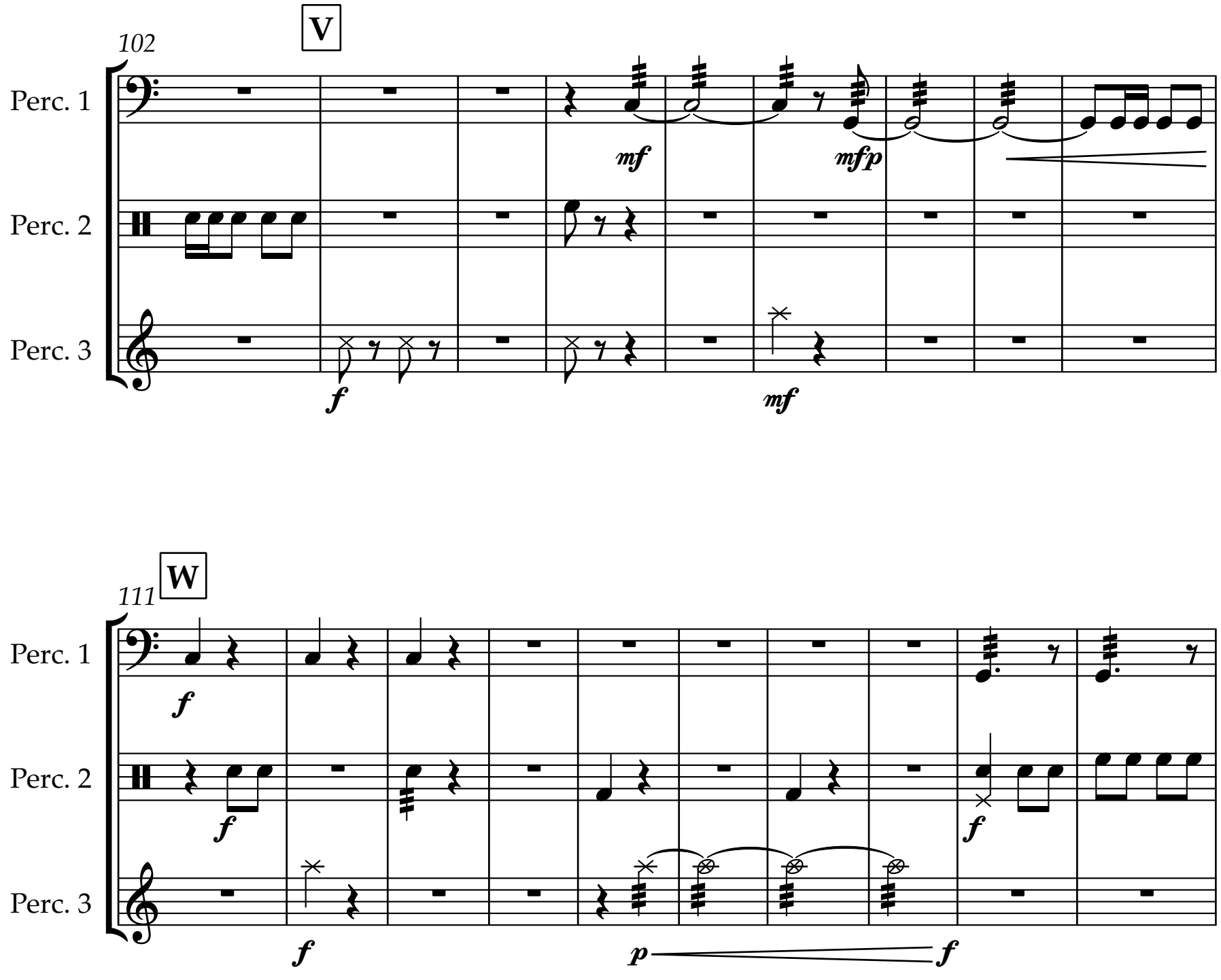

Vla. $\mathrm{x}$

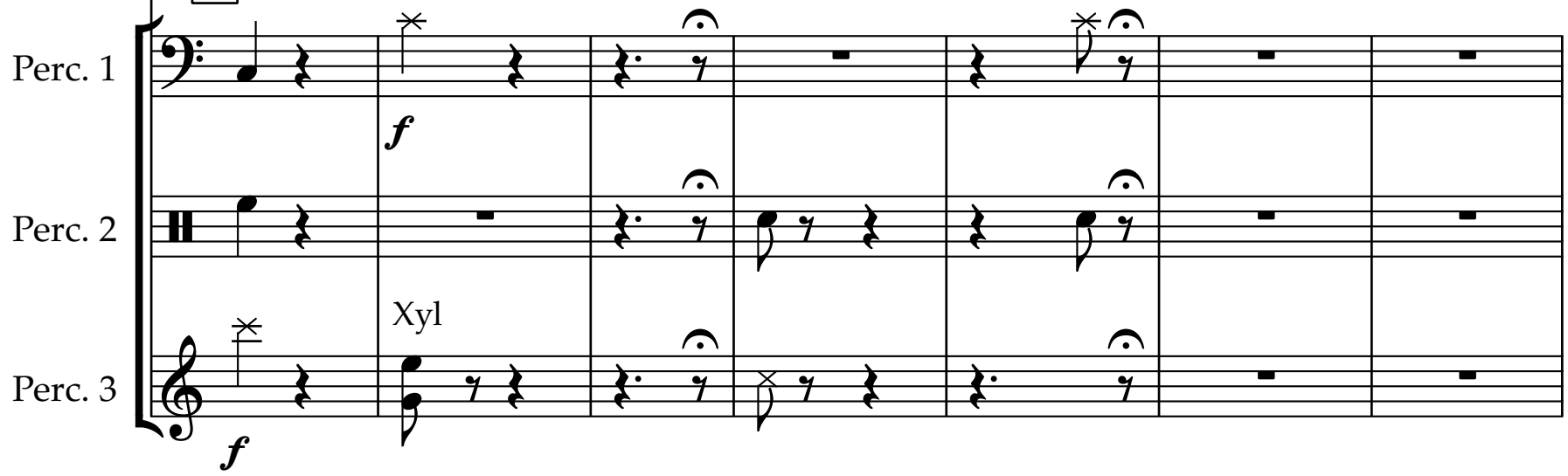



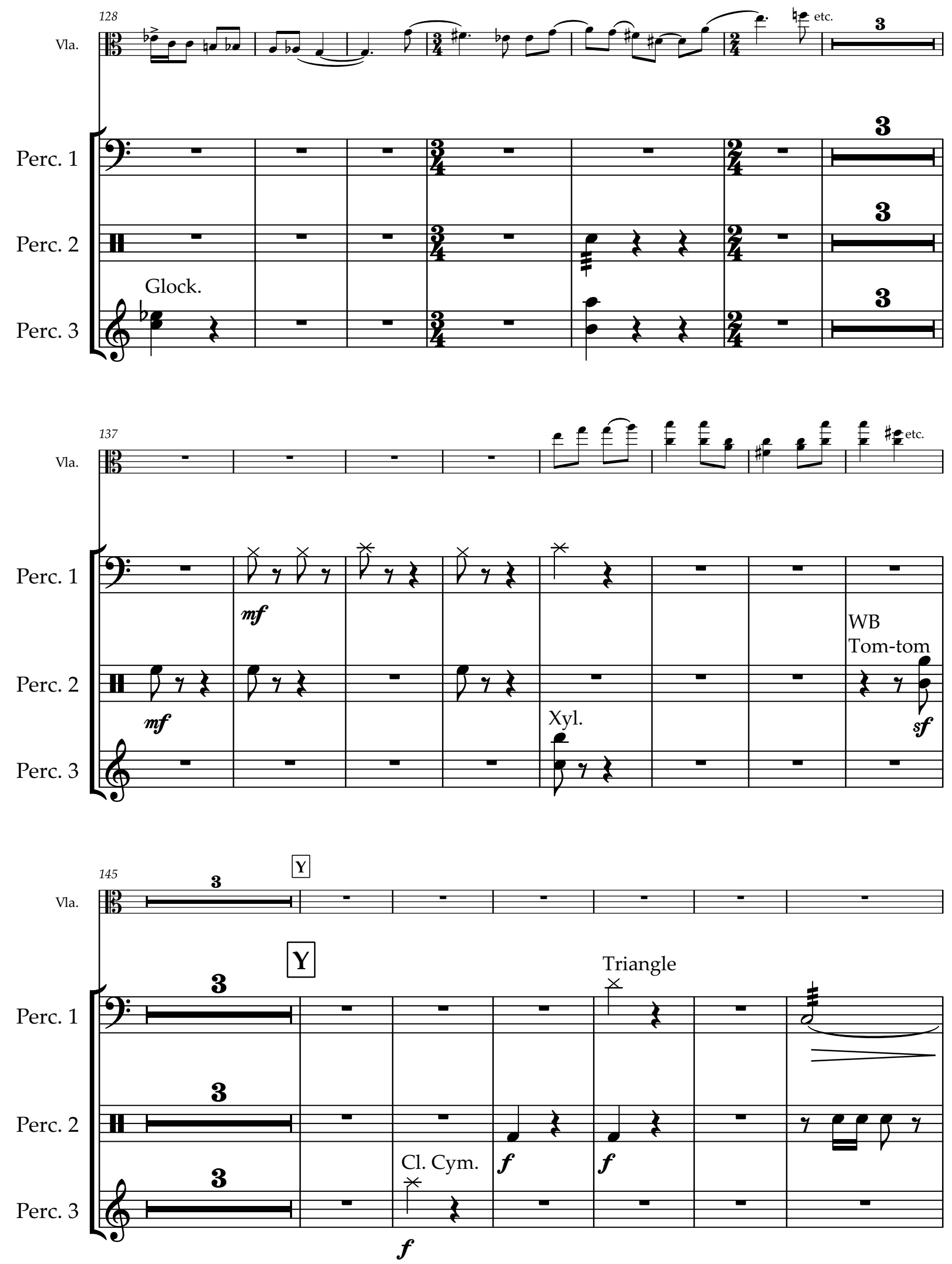

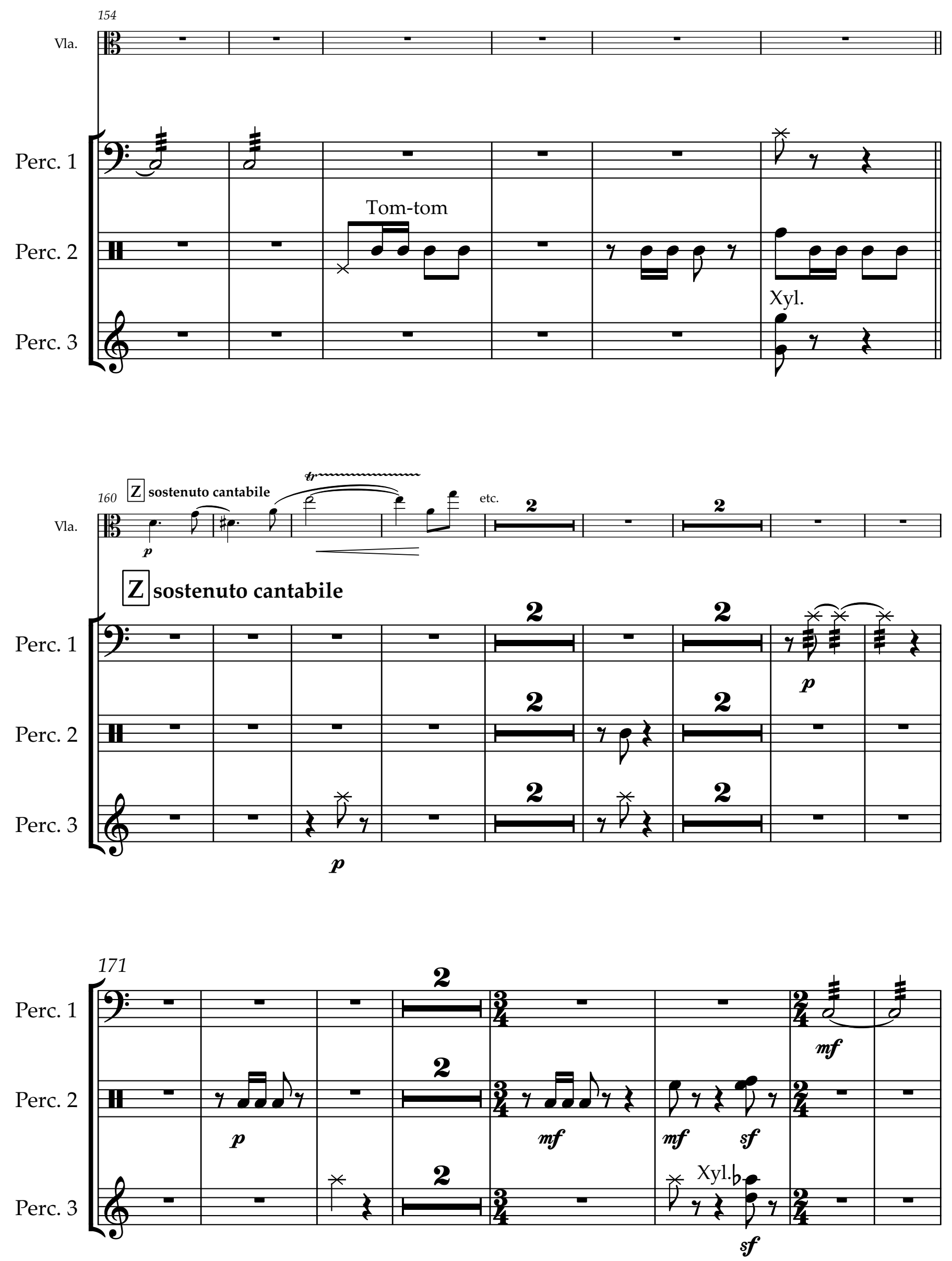

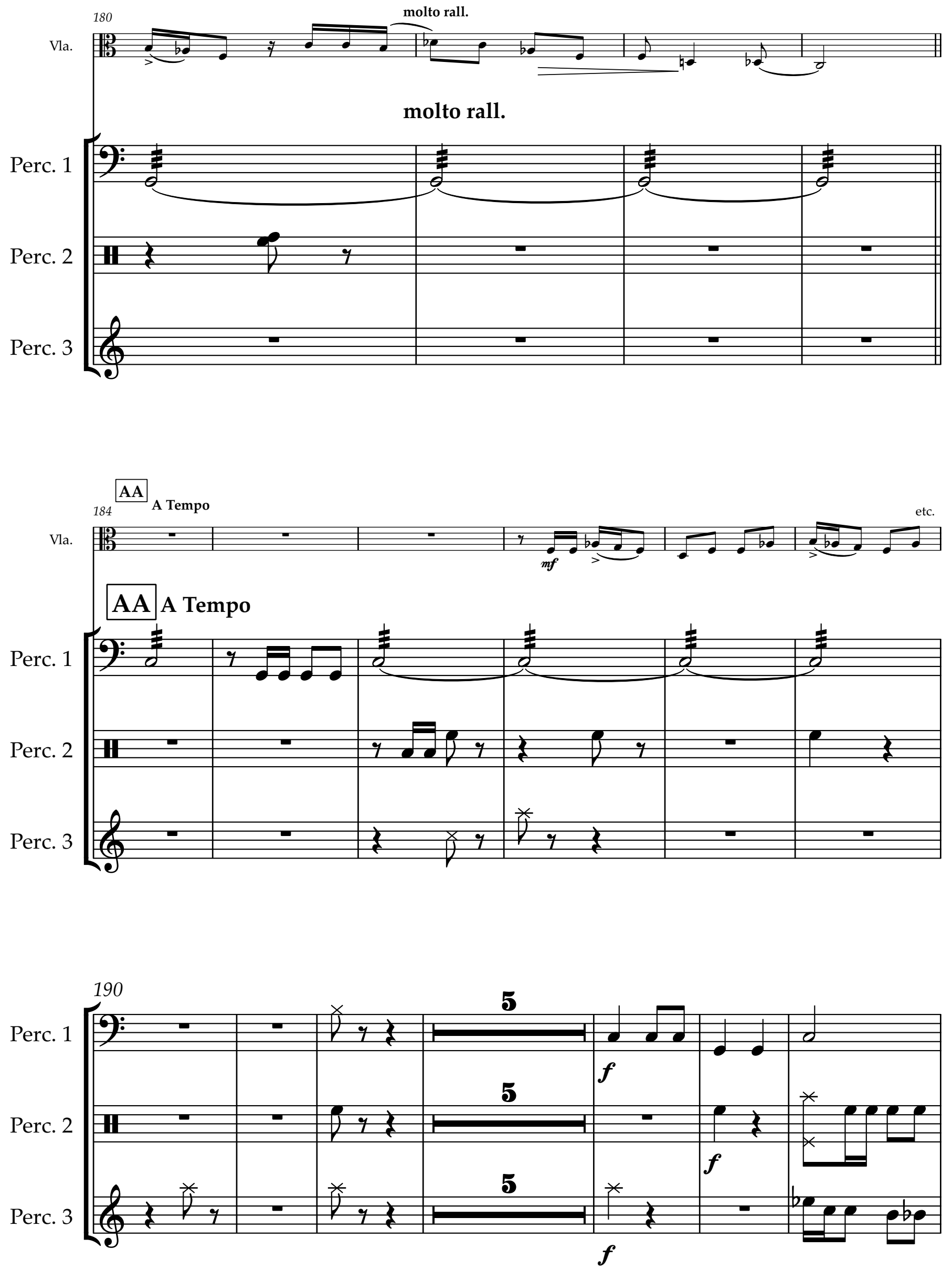

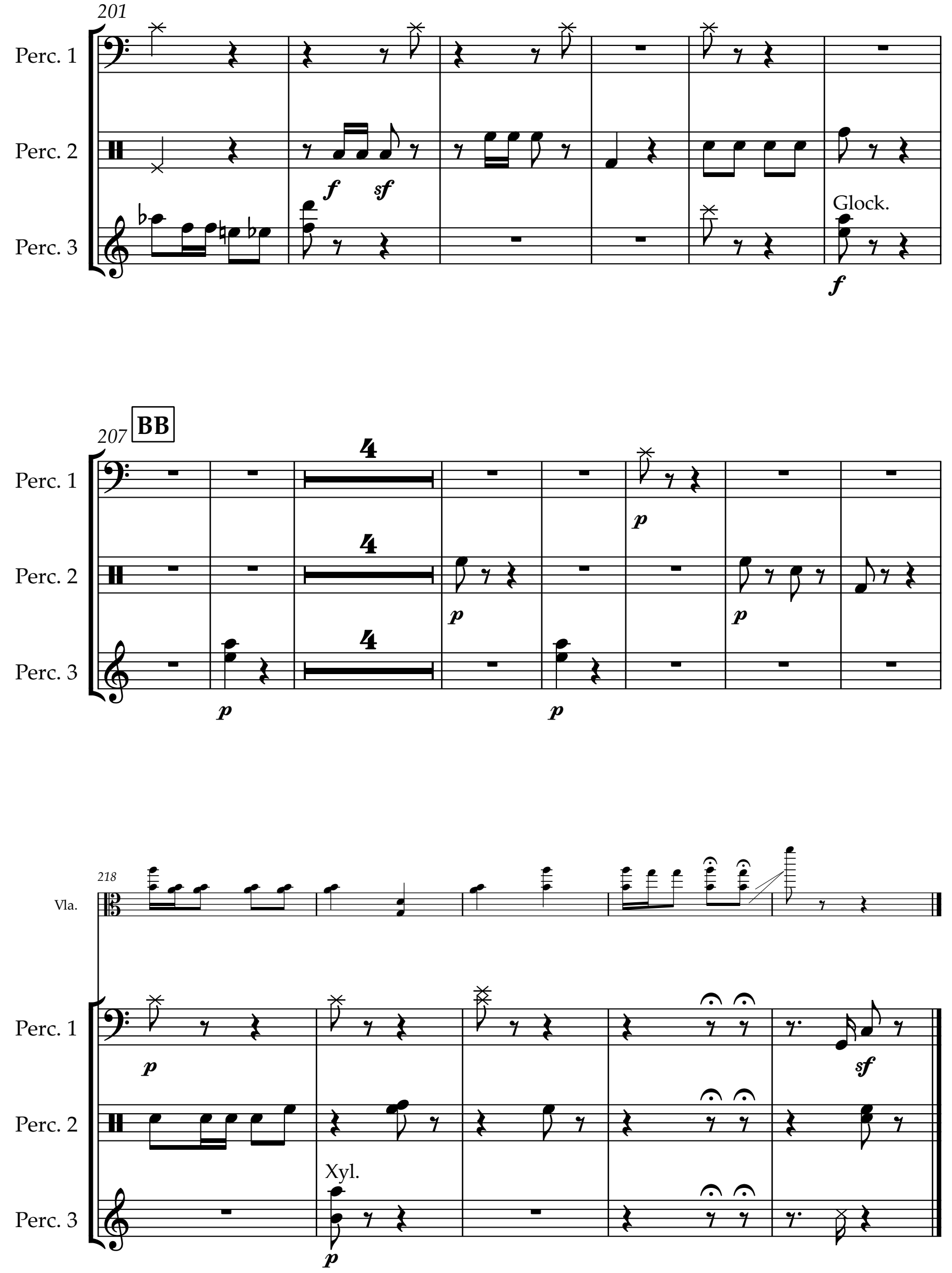


\section{Chapter 5: Dragatakis in 2020}

The following section discusses Dragatakis today, focusing on conference presentations, other presentations or exhibitions, performances of his works, and past and upcoming events. This section also discusses Dragatakis' reception in Greece and abroad and later how current performers and scholars can assist in advancing and preserving twentieth-century composers' legacies through digital tools and digital humanities.

\subsection{Dragatakis' reception in Greece and abroad}

This section examines Dragatakis' reception today while also providing digital statistics from the newly created digital platforms.

Within recent years, Naxos and Irida classical music record labels have released CDs of Dragatakis' work, which further shows the importance of his works even after his death. A discography created by Greek musicologist and archivist Thomas Tamvakos for the Dimitris Dragatakis Archive can be found on the digital database website here. $^{70}$

\section{https://www.dimitrisdragatakis.com/discography}

In addition to this, there are annual events that are held in his honour or feature his works. These events are outlined in the next section.

It is important to consider the IEMA database website - while the sources are difficult to access, the fact there are $800+$ listings pertaining to Dragatakis and his works speaks

\footnotetext{
70 Thomas Tamvakos, “Dimitris Dragatakis Discography,” Dimitris Dragatakis Archive Database and Website, accessed June 2020. https://www.dimitrisdragatakis.com/discography.
} 
volumes about his reception in Greece today. This alone shows Dragatakis' favourable reception within Greece and on a small international scale.

Today in Greece, Dragatakis is celebrated and remembered; however, abroad he is still relatively unknown and is considered a 'lesser-known' composer.

\subsubsection{Dragatakis events}

The following section outlines the relevant events that have been held for Dragatakis since his death, events that happen annually or biennially to assist in promoting and preserving his legacy, and upcoming events.

\subsubsection{Dragatakis Composition Competition and Friends of Dragatakis Society}

The Dimitris Dragatakis Composition Competition is a biennial competition established in 2004 in collaboration with the Greek Composers' Union and Friends of Dragatakis Society to honour Dimitris Dragatakis' legacy as a composer and teacher.

Apart from his work as a composer, Dimitris Dragatakis was an encouraging teacher and mentor who felt that music education was of the utmost importance, and sought to inspire and support his students at all times. The mission of the competition is to continue Dragatakis' teaching legacy while also giving up-and-coming composers the opportunity to distinguish themselves and their works.

A detailed list of past competitions can be found on the Dimitris Dragatakis Archive digital database website created by the researcher, here. $^{71}$

\section{https://www.dimitrisdragatakis.com/dragatakis-competition}

\footnotetext{
71 “Dimitris Dragatakis Competition," Dimitris Dragatakis Archive Database and Website, accessed June 2020. https://www.dimitrisdragatakis.com/dragatakis-competition.
} 
After Dimitris Dragatakis died in 2001, the Friends of Dragatakis Society was formed in 2003. The mission of the society is to honour Dimitris Dragatakis, preserve his works, and promote his legacy. ${ }^{72}$ The Board members and Members at Large are active in preserving the legacy of Dimitris Dragatakis. For more information about the society, see the Friends of Dragatakis Society page created by the researcher, here.

\section{https://www.dimitrisdragatakis.com/the-society}

\subsubsection{Dragatakis past events}

In recent years, there have been concerts and events dedicated to Dragatakis and his legacy. These events include concerts, public archive exhibitions, conference presentations, and book publications.

A list of 'past event highlights' created by the researcher in consultation with the Dimitris Dragatakis Archive can be found on the Past Events page of the Dimitris Dragatakis Archive database website, located here.

\section{https://www.dimitrisdragatakis.com/past-events}

\subsubsection{Conference presentations}

Dr Kalopana presents lectures and presentations about Dragatakis almost annually, and sometimes more frequently. ${ }^{73}$ She is a pillar of Dragatakis scholarship and has played a vital role in preserving and promoting Dragatakis' legacy in the twenty-first century. Specific past presentations Dr Kalopana has made can be found on the Past

\footnotetext{
72 "Friends of Dragatakis Society," Dimitris Dragatakis Archive Database and Website, accessed June 2020. https://www.dimitrisdragatakis.com/the-society.

73 "Past Events," Dimitris Dragatakis Archive Database and Website, accessed June 2020. https://www.dimitrisdragatakis.com/past-events.
} 
The 'past events' page of the Dimitris Dragatakis Archive database website created by the research is located here.

\section{https://www.dimitrisdragatakis.com/past-events}

The following section outlines the researcher's conference presentation at the 46th International Viola Congress in Poznan, Poland, regarding Dragatakis and his Concerto for Viola.

\subsubsection{46th International Viola Congress presentation}

This lecture was presented on 25 September 2019 in Poznan, Poland at the 46th International Viola Congress. ${ }^{74}$ The title of the lecture was "Dimitris Dragatakis (19142001): Concerto for Viola" and the lecture outlined the history of the Concerto, biographical information of Dragatakis, a live interview with Artur Paciorkiewicz, the viola soloist who premiered the work, and a listening session of the recording of the first movement from the 1993 premiere performance.

The lecture was 30-minutes and focused on reintroducing the Concerto back into the viola canon. After discussing Dragatakis' life, the researcher spoke about the concerto and then invited violist Artur Paciorkiewicz to be interviewed live and offer his thoughts on the work. The researcher then invited the audience of forty or more attendees to listen to the recording from the premiere performance in 1993. This listening session was the first time an audience had ever heard the recording of the 1993 premier performance. It is unclear whether this recording was ever broadcast on the local classical Greece radio channel, Third Programme - if it was broadcast this would be the only other audience to hear the work other than the physical audience

\footnotetext{
74 “46th International Viola Congress," Polish Viola Society website, accessed June 2020. http://ptal.art.pl/index.php/en/46th-viola-congress.
} 
at the premiere performance. The lecture was well received and garnered media attention as listed below.

To watch a video recording of this lecture, please click here: $\underline{46 t h}$ International Viola Congress presentation. ${ }^{75}$

https://www.youtube.com/watch?v=YDWZmo89GJA\&feature=youtu.be

\subsection{Presentation media}

The following three articles pertain to the researcher's lecture presentation.

\subsection{1 "Impressions from the 46th IVS"}

This is an article written by the researcher about the 46th International Viola Congress. It was published in the Australia New Zealand Viola Society Journal in December 2019. A copy of this can be found in Appendix 5. ${ }^{76}$

\subsection{Dutch Viola Society - Day 2 review}

This is a review posted by the President of the Dutch Viola Society. Part of the article reviews the researcher's lecture presentation. A copy of this can be found in Appendix $5 .{ }^{77}$

\footnotetext{
75 Elyse Dalabakis, “Dimitris Dragatakis: Concerto for Viola | 46th International Viola Congress Presentation," YouTube, accessed June 2020.

https://www.youtube.com/watch?v=YDWZmo89GJA\&feature=youtu.be.

${ }^{76}$ Elyse Dalabakis, 2019, "Impressions from the 46th IVS," Australian New Zealand Viola Society Journal. See also Appendix 5.

77 “IVC2019 Poznan - Day 2 review," Dutch Viola Society, 25 September 2019.

http://dutchviolasociety.nl/2019/09/ivc2019-poznan-blog-day-2/.
} 


\subsection{NZSM - Press release}

This is a press release written by the New Zealand School of Music about the researcher and her colleague, Xi Liu, as they both attended and presented at the 46th International Viola Congress together. A copy of this can be found in Appendix 5.78

\subsubsection{Book publication by Dr Magdalini Kalopana}

As mentioned in the literature review, Dr Magdalini Kalopana recently published a book outlining the complete life, works, and legacy of Dimitris Dragatakis. This book, Dimitris Dragatakis: Systematic and Bio-bibliographical works catalogue [Systēmatikos kai Bio-bibliographikos Katalogos Ergōn], has been published through Nakas Music Publishing House and offers an incredible new source of information about Dragatakis. ${ }^{79}$

Nearly twenty years since his passing, Greek publishing houses are still interested in publishing information about Dragatakis' life and works. This speaks volumes about his reception and reputation as one of Greece's most important modern composers.

\subsubsection{Dragatakis digital database and website statistics}

This section discusses the website and YouTube statistics and digital traffic since their creation in late 2019 and goes into detail about projected post-doctoral plans and the strategy for promoting the Dimitris Dragatakis Archive in future.

\footnotetext{
78 "NZSM PhD candidates launch their PhD research on the international stage," New Zealand School of Music, last modified 14 October 2019. https://www.wgtn.ac.nz/nzsm/about/news/2019news/1777998-nzsm-phd-candidates,-elyse-dalabakis-and-xi-liu,-have-launched-their-phdresearch-onto-the-international-stage.

${ }^{79}$ Kalopana, Dimitris Dragatakis: Systematic and Bio-bibliographical Works Catalogue.
} 
Since its creation, the digital database website has hosted 164 different users. It should also be noted that the website has not yet been advertised as it is being included as a component of this dissertation and is under examination until publication of the research. The 164 users are either personal family friends of the Dragatakis or Koronidi families or users who have found the page through search engines. The Google Analytics statistics also show the highest percentage of visitors find the website through a Google search, so visitors are not usually navigating to the page via a direct link (www.dimitrisdragatakis.com), which suggests some of the digital traffic has been organic engagement, or users not related to the Dragatakis or Koronidis families.

The Dimitris Dragatakis - Composer YouTube page is similar in that it has not been advertised yet; however, despite not being advertised, the page has had over 133 views.

Going forward, the strategy discussed with the Dragatakis Archive Directors involves targeting music schools and music libraries as they would like to make their father's musical materials accessible not only to the public, but also, more importantly, to students. As mentioned in nearly every interview, Dragatakis enjoyed the time he spent with his students and was a mentor to many of them. The logical step forward is to ensure his legacy and music can continue to impact music students and the first step in that is to ensure music libraries around the world have access to his music.

\subsection{Advancing twentieth-century composers' legacies through digital tools}

This research examines, among other things, the following questions: how can we use twenty-first-century tools to advance the legacy of and Concerto for Viola by Dimitris Dragatakis? How can we be proactive in this process for other living, or recently 
departed, composers? The research model can assist future scholars with similar projects beyond just the scope of Dimitris Dragatakis.

Living in the digital age allows us opportunities to preserve legacies and information in such a way that it is instantly accessible. For example, creating a digital database website - as soon as the 'publish' button is pressed, the domain is connected to the site, and SEO is implemented, the website and all its contents are accessible on the World Wide Web. In 2020 at the push of the button, we can preserve data collections instantly, advance resources through digitisation, and promote them across the globe.

Further to this, it can be asked 'how do digital tools change or advance reception? How can we measure reception with digital tools?' Other than the obvious answer of accessibility, with digital tools it is possible to track a website's engagement. This is easily done through Google Analytics or other analytics pages within social media platforms (e.g. Facebook insights, YouTube Analytics), which show statistics related to number of visitors, what pages/links have been clicked on, and how long someone was on a website, among others. While these statistics may not necessarily give information on what viewers are thinking or experiencing, as may be gleaned from a written review or standing-ovation at the end of a concert, it does show increased or decreased engagement over time, which then converts to 'online traffic' and further to an 'online audience'. Digital engagement and statistics can be used going forward in discussing a composer's or musical work's digital reception and engagement, which opens up an entirely new field of music scholarship.

As COVID-19 continues to rage around the world, establishing an online presence for a composer is imperative - it ensures the legacy and musical works are accessible in a 'contactless' and 'socially-distanced' environment, and are accessible when international travel is no longer an option. Utilising digital tools has become the norm, and understanding how to promote digital platforms has become imperative. 
Going forward, there are still many tasks to accomplish for the Dragatakis Archive, including but not limited to digitising all programme and print material; converting cassette tapes to digital files; releasing unreleased recordings; promoting the Dragatakis Archive website to institutions and music libraries across the globe; and the list goes on.

There is a strong need to continue this work for all modern Greek composers, as many of them remain well-known in Greece, yet lesser-known in other parts of the world. We need to provide these pillars of Greek art music with an accessible digital presence in order to preserve, advance, and promote their legacies.

Greece aside, there are many who may benefit from scholars and performers utilising twenty-first-century digital tools. It is likely lesser-known composers who lived before the twenty-first century would benefit from a digital presence. The need to develop and use these digital tools is now more important than ever in the wake of the global COVID-19 pandemic. It is apparent these digital tools must continue to be used by future performers and scholars to advance both performance and scholarship, and to assist in continued access to these invaluable resources. 


\section{Author Biography}

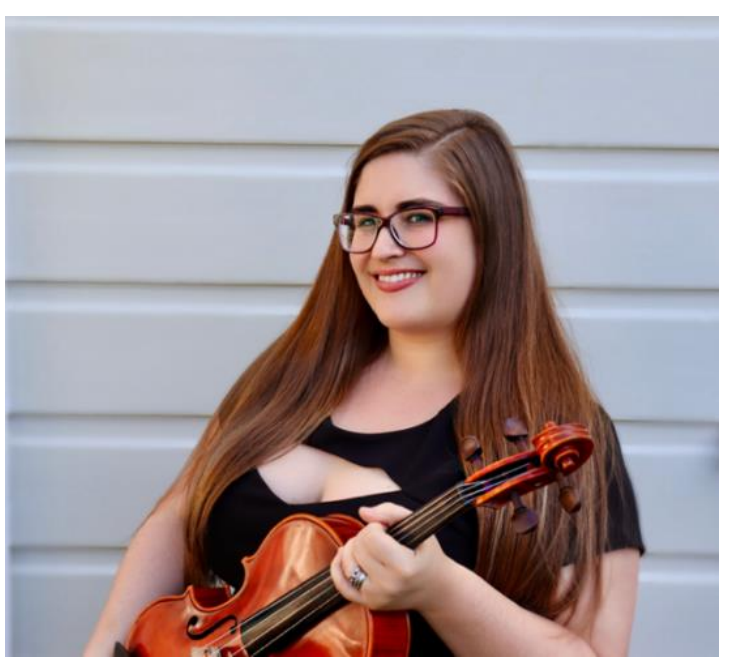

Figure 14. Author. Photo by Hannah Neman.
Greek-American violist Elyse Dalabakis is a multifaceted musician, performance scholar, and arts advocate who has earned a distinguished reputation as a solo, chamber, and orchestral musician and arts administrator throughout the USA and Australasia. Elyse records and performs often as a studio and pit musician, has presented multiple solo recitals in New Zealand and abroad, and plays regularly

with various regional New Zealand orchestras and casually with the New Zealand Symphony Orchestra. Elyse has performed in chamber series, festivals, and music academies around the world, most recently as faculty and violist in the Harikoa Collective for the inaugural edition of RimuFest New Zealand and Mexico (2020), and enjoys collaborating with other artists and performers across varied mediums.

In conjunction with her performance career, Elyse is a high-achieving and motivated performance scholar and has presented at the National Music Education Association conference in the USA as a student (2014), as well as the Viola Convention in Gosford, Australia (2015). She was an invited performer at the 45th International Viola Congress in Rotterdam (2018), an invited presenter and performer at the 46th International Viola Congress in Poznan (2019), and undertook an artist residency at the Greek Music Archives in Athens (2019). In January 2020, she was nominated and elected Treasurer of the International Viola Society board - an organisation that serves to promote and encourage the development of new viola repertoire, new insights into existing repertoire, and viola-related research. 
Elyse graduated with a Bachelor of Music in performance from the Florida State University (2014), and shortly thereafter relocated to Wellington, New Zealand, to pursue a Master of Music degree in performance (2016) and later PhD in Music degree from the New Zealand School of Music Victoria University of Wellington (2020). Elyse would like to recognise the Barbara Finlayson Scholarship and VUW JRC grants for their support towards this research project, without which it would not be possible. 


\section{Appendix 1: Digital materials}

\section{A.1.1 Table of links}

Below is a table of links. These are not all the links throughout the dissertation; however, they are the main or most important links.

\begin{tabular}{|c|c|c|}
\hline Name & Description & Link \\
\hline $\begin{array}{l}\text { Dragatakis archive list } \\
\text { of compositions (with } \\
\text { links) }\end{array}$ & $\begin{array}{l}\text { This is a list of compositions with interactive } \\
\text { links hosted on the Dragatakis Archive } \\
\text { website. }\end{array}$ & $\underline{\text { Link }}$ \\
\hline $\begin{array}{l}\text { Concerto for Viola } \\
\text { orchestra premiere } \\
\text { recording }\end{array}$ & $\begin{array}{l}\text { This is a link to the premiere recording of the } \\
\text { Concerto for Viola. The audio was provided by } \\
\text { the Dragatakis Archive and video was } \\
\text { created by researcher Elyse Dalabakis. }\end{array}$ & $\underline{\text { Link }}$ \\
\hline Playlist of interviews & $\begin{array}{l}\text { This is an unlisted YouTube playlist featuring } \\
\text { recorded interview audio. }\end{array}$ & $\underline{\text { Link }}$ \\
\hline $\begin{array}{l}\text { International Viola } \\
\text { Congress Presentation }\end{array}$ & $\begin{array}{l}\text { This is an unlisted YouTube link featuring the } \\
\text { researcher's presentations and lectures } \\
\text { pertaining to the research project at the 46th } \\
\text { International Viola Congress in Poznan, } \\
\text { Poland. }\end{array}$ & $\underline{\text { Link }}$ \\
\hline $\begin{array}{l}\text { NZSM PhD candidates } \\
\text { launch their PhD } \\
\text { research on the } \\
\text { international stage }\end{array}$ & $\begin{array}{l}\text { An article featured in the NZSM } \\
\text { DawnChorus about the researcher's } \\
\text { presentation at the } 46 \text { th International Viola } \\
\text { Congress. }\end{array}$ & $\underline{\text { Link }}$ \\
\hline $\begin{array}{l}\text { Dutch Viola Society } \\
\text { review }\end{array}$ & $\begin{array}{l}\text { A review of Day } 2 \text { of the } 46 \text { th International } \\
\text { Viola Congress by the Dutch Viola Society. }\end{array}$ & $\underline{\text { Link }}$ \\
\hline $\begin{array}{l}\text { Concerto for Viola } \\
\text { information page }\end{array}$ & $\begin{array}{l}\text { Link to Concerto for Viola information page on } \\
\text { Dragatakis website. }\end{array}$ & $\underline{\text { Link }}$ \\
\hline
\end{tabular}




\begin{tabular}{|l|l|l|}
\hline Piano and Viola parts & $\begin{array}{l}\text { This is a link to the musical parts for the } \\
\text { newly transcribed Concerto for Viola piano } \\
\text { part. }\end{array}$ & $\underline{\text { Link }}$ \\
\hline $\begin{array}{l}\text { Viola, Piano, and } \\
\text { optional percussion } \\
\text { parts }\end{array}$ & $\begin{array}{l}\text { This is a link to the musical parts for the } \\
\text { newly transcribed Concerto for Viola piano } \\
\text { part with optional percussion. }\end{array}$ & $\underline{\text { Link }}$ \\
\hline
\end{tabular}


A.1.2 PDF of digital database website

A PDF of the digital database and website is included after this page. The website is best viewed in an internet browser. The reader is encouraged to view this dissertation in Adobe and use the 'Bookmark' tab to the left-hand side to navigate through the dissertation. 


\section{DIMITRIS DRAGATAKIS}

ARCHIVE

Honoring one of Greece's most important modern composers

Request Music

dragatakis.info@gmail.com

\section{DIMITRIS DRAGATAKIS}

One of Greece's most important modern composers 


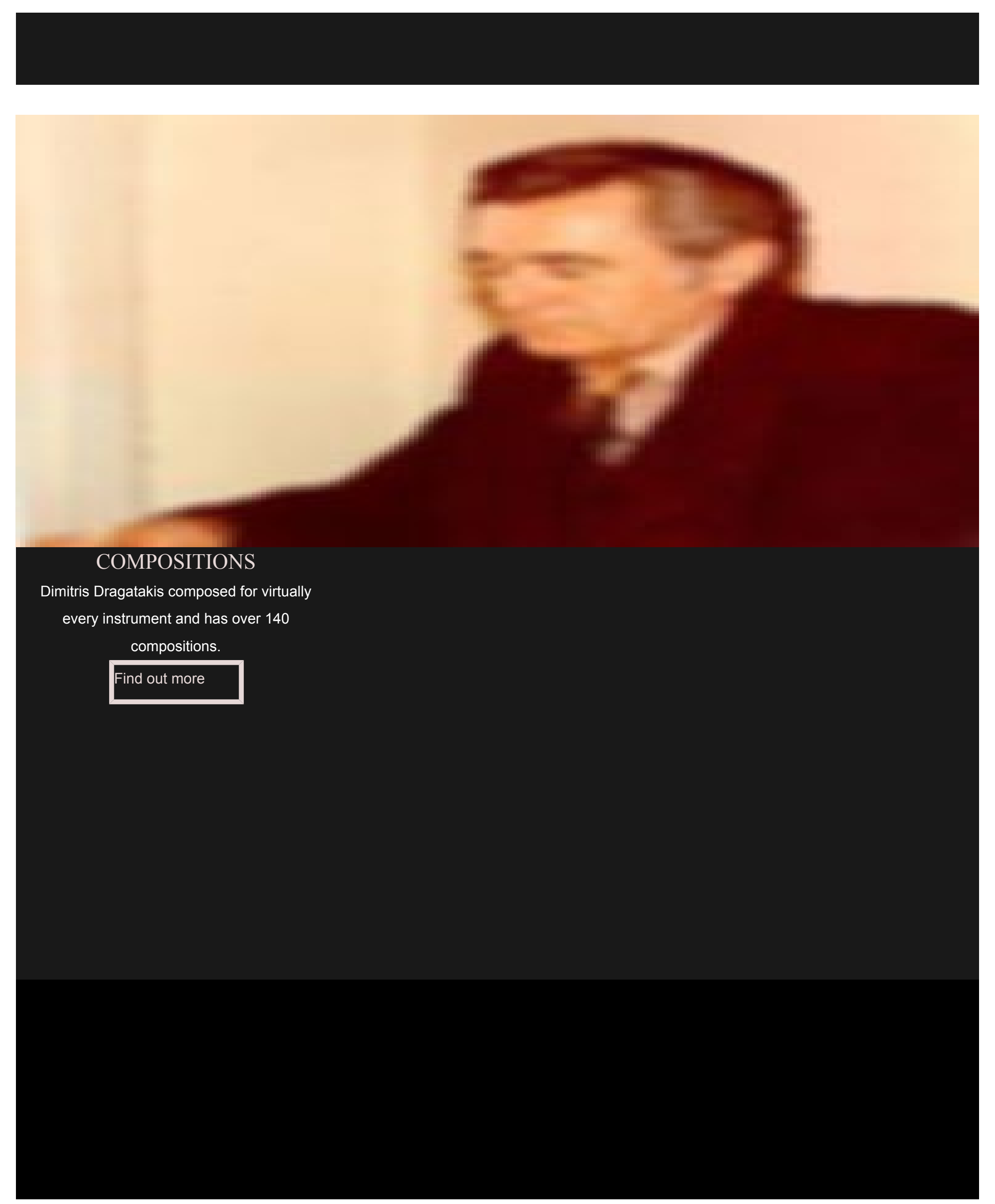




\section{DIMITRIS DRAGATAKIS}

Find out more about Dimitris Dragatakis,

an eminent modern Greek composer.

About Dimitris Dragatakis

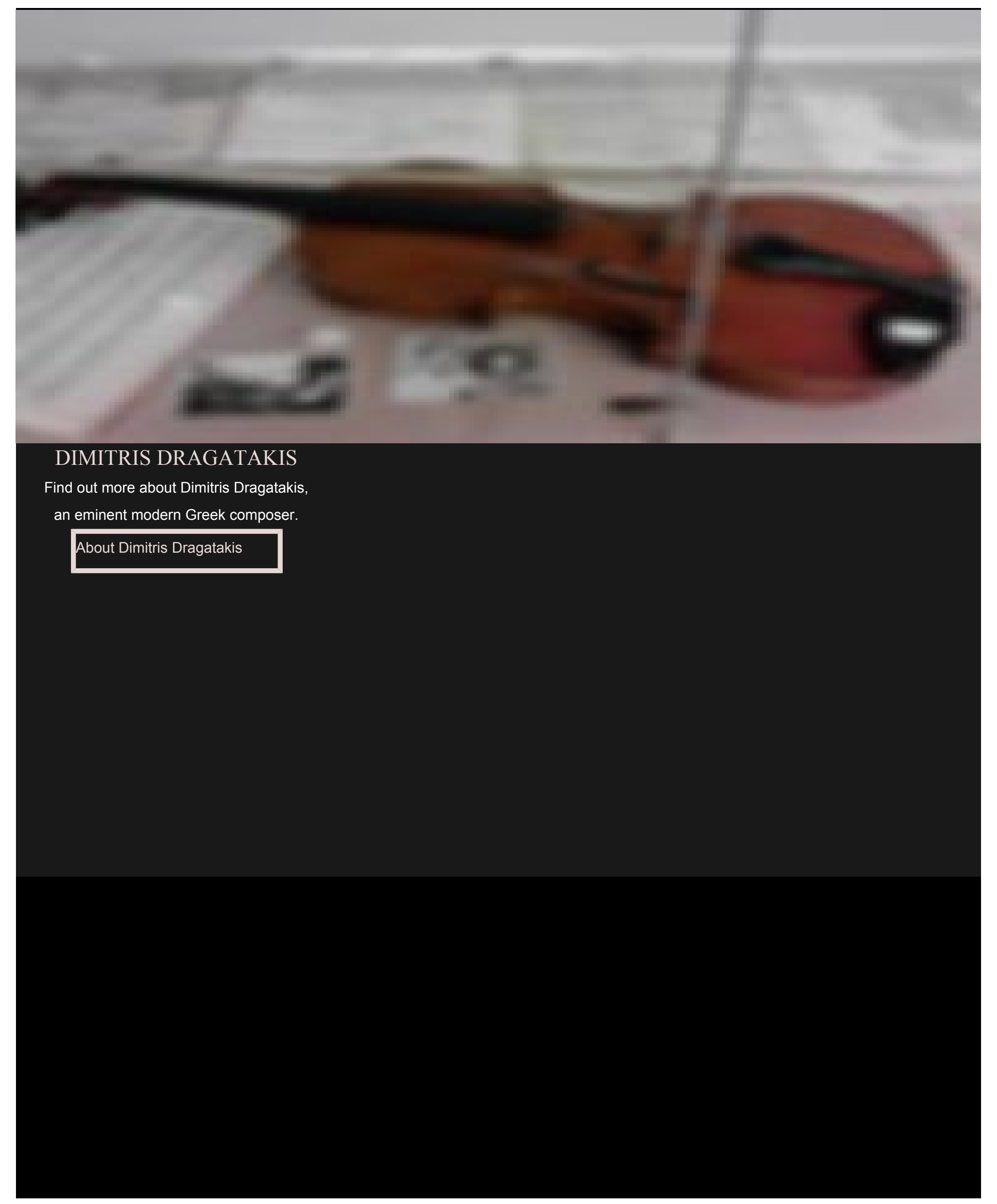




\section{FRIENDS OF}

\section{DRAGATAKIS SOCIETY}

Founded in 2003, the Friends of Dragatakis

Society's mission is to preserve, protect, and

promote the works and legacy of Dimitris

Dragatakis.

About the Society

\section{REQUEST MUSIC | GET IN TOUCH}

Looking for music or more information? Have comments or

questions? Fill out the form below.

To request music, please fill out the contact form below and one of

our team will get in touch with you.

If you're performing or presenting works by Dragatakis, please let us know on the form below - we'd be delighted to feature you on our website or social media platforms.

Athens, Greece

dragatakis.info@gmail.com

Name




\section{DIMITRIS DRAGATAKIS}

\section{ARCHIVE}

Honoring one of Greece's most important modern composers

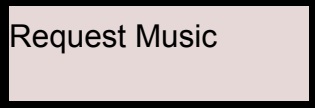

dragatakis.info@gmail.com

\section{REQUEST MUSIC | GET IN TOUCH}

Looking for music or more information? Have comments or questions? Fill out the form below.

To request music, please fill out the contact form below and one of our team will get in touch with you.

If you're performing or presenting works by Dragatakis, please let us know on the form below - we'd be delighted to feature you on our website or social media platforms.

Fist Name

Last Name

Email 


\section{dragatakis.info@gmail.com}

Athens, Greece 


\section{DIMITRIS DRAGATAKIS}

ARCHIVE

Honoring one of Greece's most important modern composers

Request Music

dragatakis.info@gmail.com

\section{COMPOSITIONS}

To find a specific piece, select the music type below. To view a complete list of works by Dragatakis click the button below. Dragatakis Archive - List of Works 

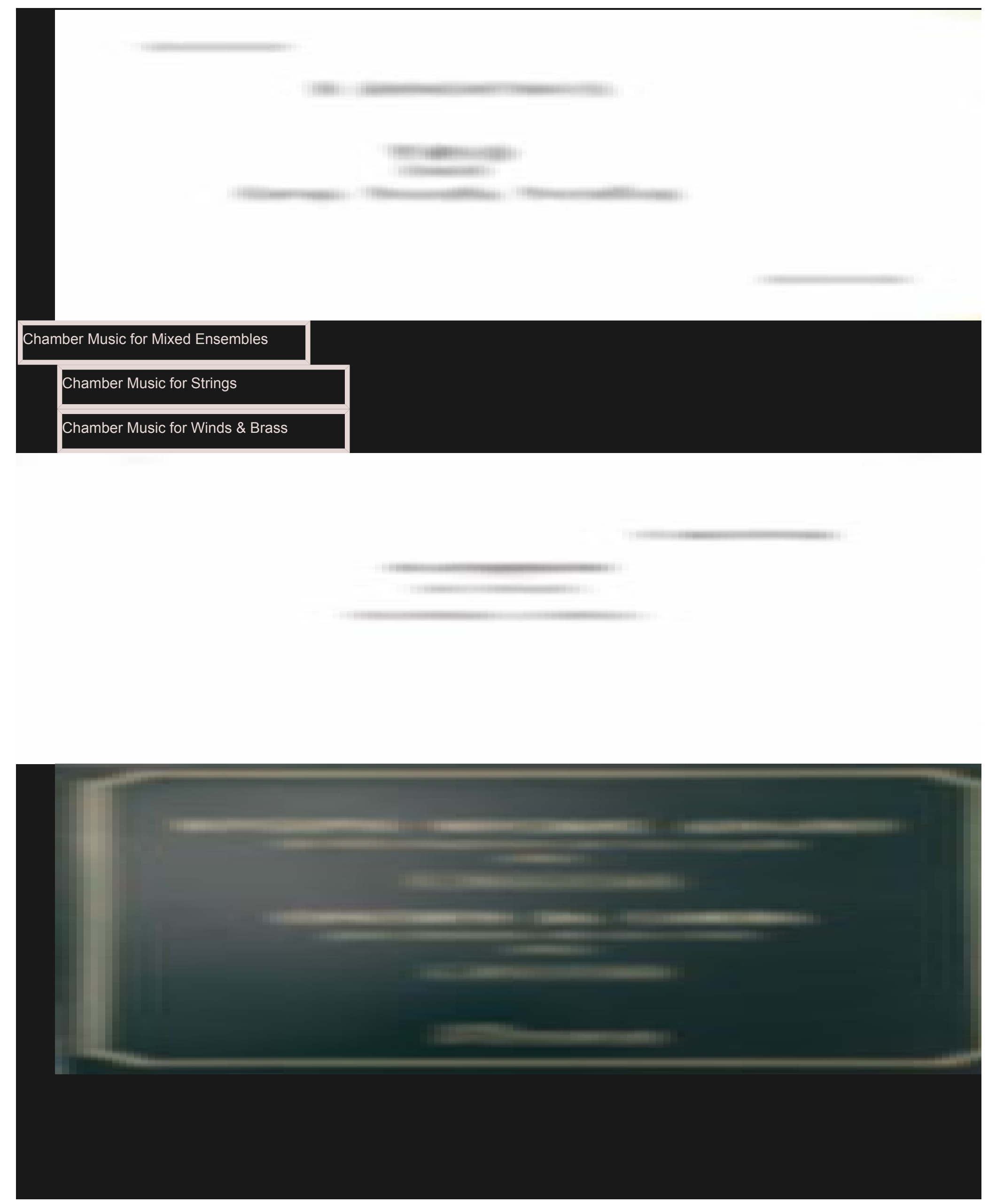


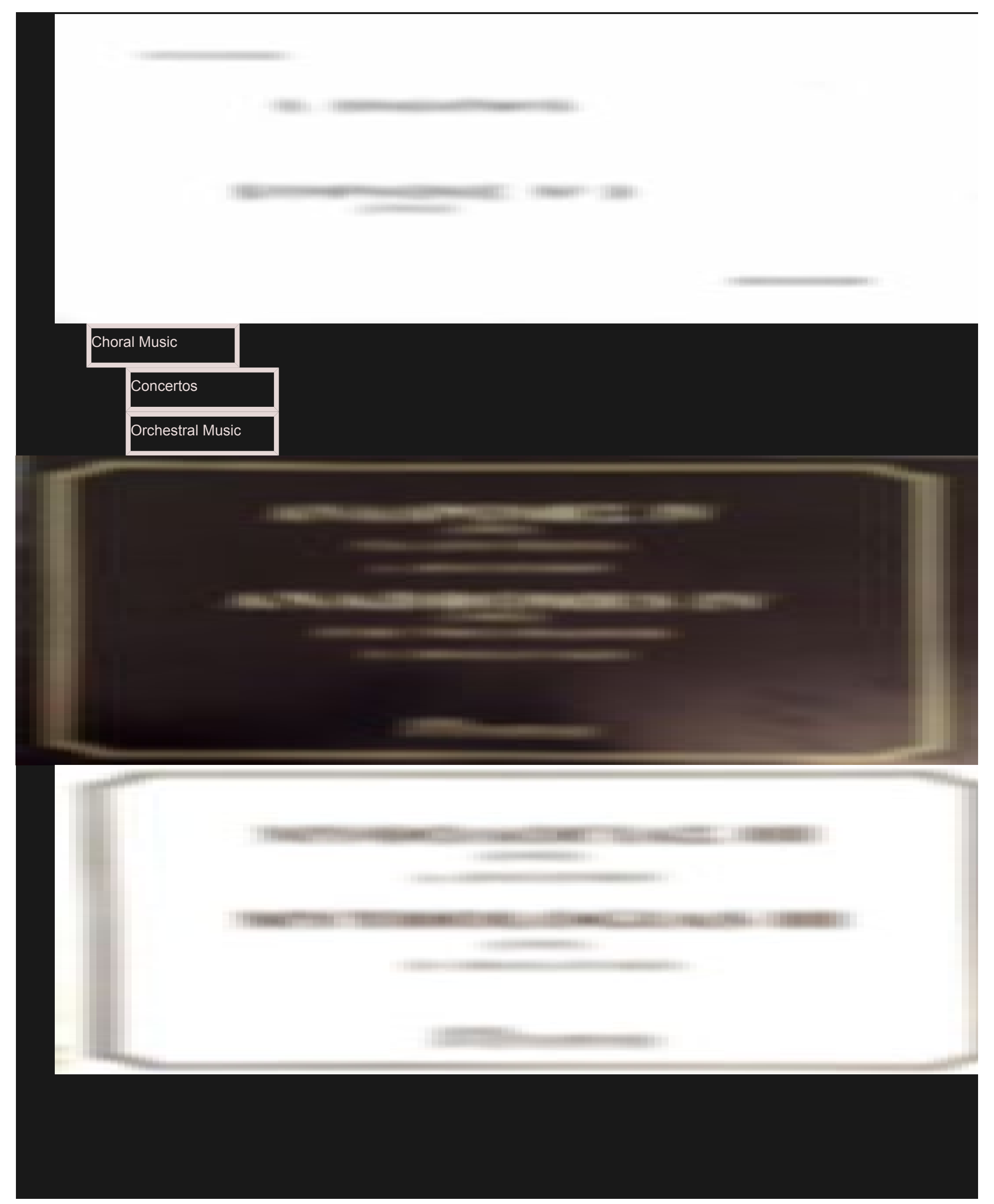




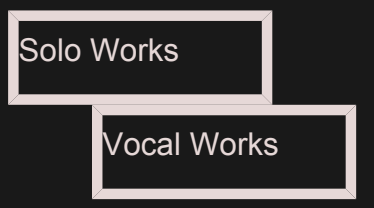

dragatakis.info@gmail.com

Athens, Greece

@2019 by the Dimitris Dragatakis Archive 


\section{DIMITRIS DRAGATAKIS}

ARCHIVE

Honoring one of Greece's most important modern composers

Request Music

dragatakis.info@gmail.com

\section{ABOUT}

Find out more about Dimitris Dragatakis, the Friends of Dragatakis Society, the Dimitris Dragatakis Composition Competition, and Greek Composer's Union. 


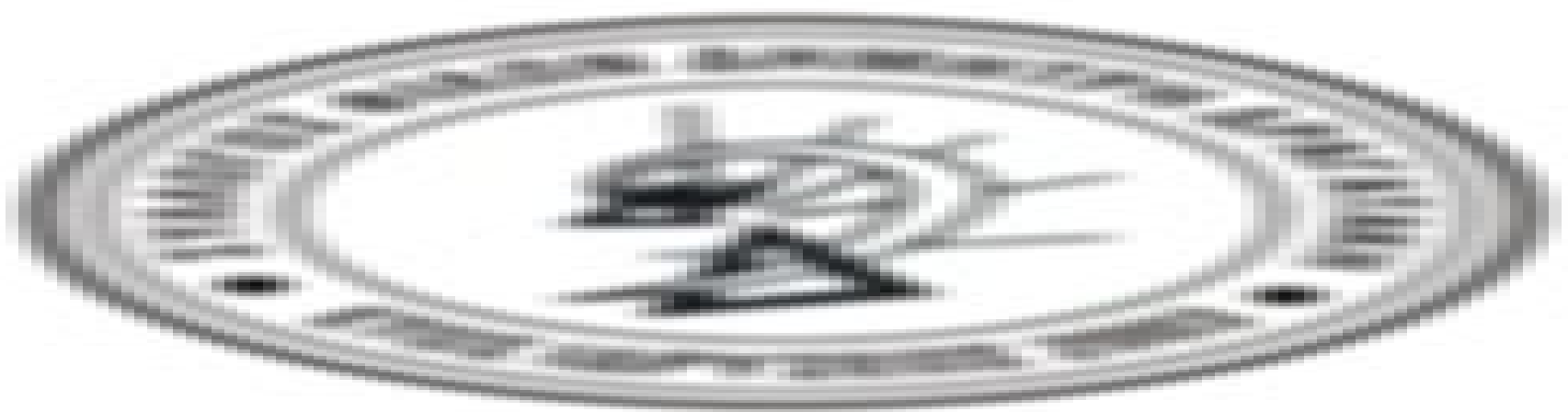

\section{FRIENDS OF}

DRAGATAKIS

\section{SOCIETY}

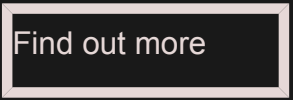

\section{DRAGATAKIS \\ COMPOSITION \\ COMPETITION}

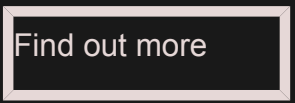




\section{dragatakis.info@gmail.com}

\section{Athens, Greece}


https://www.dimitrisdragatakis.com/the-society[19/06/20, 2:14:38 PM] 


\section{DIMITRIS DRAGATAKIS}

\section{ARCHIVE}

Honoring one of Greece's most important modern composers

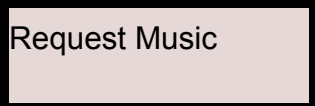

dragatakis.info@gmail.com

\section{CHAMBER MUSIC FOR MIXED ENSEMBLES}

Afieroma (Dedication), from a theme by M. Kalomiris for Mixed Octet (1963)

Diaphores (Differences) for Mixed Octet (1965)

Mousiki gia treis (Music for three) for Violin, Horn, and Piano (1969)

Anadromes I (Retrospections I) for Mixed Sextet (1976)

Anadromes III (Retrospections III) for Violin, Cello, and Piano (1978)

Praktiko 19 (Record 19) for Violin, Clarinet, Horn, Trumpet, and Piano (1979)

Trio for Clarinet, Percussion, and Piano (1986)

Chorikou Scholion (Choric's commentary) for Chamber Ensemble (1993) 


\section{dragatakis.info@gmail.com}

\section{Athens, Greece}




\section{DIMITRIS DRAGATAKIS}

\section{ARCHIVE}

Honoring one of Greece's most important modern composers

Request Music

dragatakis.info@gmail.com

\section{CHAMBER MUSIC FOR STRINGS}

Nanourisma (Berceuse) for Violin, Viola, or Cello and Piano or String Quartet

Choros (Dance) for Violin and Piano

Anamnisi (Remembrance) for Violin and Piano (1942)

String Quartet No. 1 (1957)

Sonata No. 1 for Violin and Piano (1958)

String Quartet No. 2 (1958)

Trio for two Violins and Viola (1960)

String Quartet No. 3 (1960) 


\section{DIMITRIS DRAGATAKIS}

\section{ARCHIVE}

Honoring one of Greece's most important modern composers

\section{Request Music}

dragatakis.info@gmail.com

\section{CHAMBER MUSIC FOR WINDS \& BRASS}

Trio for Oboe, Clarinet, and Bassoon (1962)

Trio for Trumpet, Horn, and Trombone (1962)

Woodwind Quintet (1964)

Epilogos (Epilogue) for Brass Quintet (1970)

Mousiki gia chalkina (Music for brass) for Brass Quartet (1971)

Dialogoi (Dialogues) for Woodwind Octet (1974)

Duo for Tuba and Clarinet (1977)

Duo for Clarinet and Piano (1981) 


\section{dragatakis.info@gmail.com}

\section{Athens, Greece}




\section{DIMITRIS DRAGATAKIS}

\section{ARCHIVE}

Honoring one of Greece's most important modern composers

Request Music

dragatakis.info@gmail.com

\section{CHORAL WORKS}

"Erot' anikite" ("Love invincible”), Sophocles, Antigone, third stasimon [1969]

"O choros" ("The chorus"), Euripides, The Heracleidae, fourth stasimon [1970]

"Taxidi” (“Journey”), G.Kotzioulas (1980)

"Thalassino" ("Marine”) (1980)

I treli rodia (The crazy pomegranate tree) (1981) and Mana (Mother) (1982)

“I lismonia” ("Forgetfulness) (1986)

"T' oneiro" (“The dream”), Chr. Apostolatou (1986)

"Efchi tis manas" (“The mother's wish") (1986) 


\section{DIMITRIS DRAGATAKIS}

\section{ARCHIVE}

Honoring one of Greece's most important modern composers

Request Music

dragatakis.info@gmail.com

\section{CONCERTOS}

Concerto for Viola and Piano (manuscript only) (1949-57)

Concertino for Clarinet (1962)

Concertino for Horn (1965)

Concerto for Violin (1969)

Adagio for solo viola (1969)

Concerto for Cello (1972)

Concerto for Oboe (1973)

Concerto for Piano (1975-7) 


\section{DIMITRIS DRAGATAKIS}

\section{ARCHIVE}

Honoring one of Greece's most important modern composers

Request Music

dragatakis.info@gmail.com

\section{ORCHESTRAL WORKS}

Treis Melodies (Three melodies)

Lyrika Skitsa (Lyric sketches) (1958)

Dokimio (Essay) (1958)

Symphony No. 1 (1959)

Symphony No. 2 (1960)

Symphony No. 3, Mikri (Little) (1964)

Symphony No. 4 (1966)

Tessera Skitsa (Four sketches) (1966-68) 


\section{dragatakis.info@gmail.com}

\section{Athens, Greece}




\section{DIMITRIS DRAGATAKIS}

\section{ARCHIVE}

Honoring one of Greece's most important modern composers

Request Music

dragatakis.info@gmail.com

\section{SOLO WORKS}

Petalouda (Papillon) for Solo Piano

Nostalgia (Nostalgia) for Solo Piano

Mikri Balanta (Petite Ballade) for Solo Piano (1949)

Sonatina No. 1 for Solo Piano (1961)

Sonatina No. 2 for Solo Piano (1963)

$\$ 1.00$

Antikes (Antiques) for Solo Piano (1972)

Anadromes II (Retrospections II) for Solo Piano (1977)

Spoudi I (Etude I) for Solo Piano (1981) 


\section{dragatakis.info@gmail.com}

\section{Athens, Greece}

@2019 by the Dimitris Dragatakis Archive 


\section{DIMITRIS DRAGATAKIS}

\section{ARCHIVE}

Honoring one of Greece's most important modern composers

Request Music

dragatakis.info@gmail.com

\section{VOCAL MUSIC}

'O tseligkas' (“The chief shepherd"), K. Krystallis (estimated 1942-9)

“Tachtarisma” (“Dandling song”) [on traditional verses] (estimated 1942-9)

“Tragoudi” (“Song”), M. Veloudis (estimated 1942-9)

“Tsakizo tis lianes elies" ("Cracking the thin olives"), V. Theodorou (1961)

"Enypnio" (“While Asleep"), D.Dragatakis (2000)

Anafora stin Ilektra (Reference to Electra), T. Roussos (1968)

Mythologias III (Mythology's III), Euripides (1985) 


\section{DIMITRIS DRAGATAKIS}

ARCHIVE

Honoring one of Greece's most important modern composers

Request Music 


\section{BIOGRAPHY}

Dimitris Dragatakis was born in the village of Platanousa in Epirus, Greece, on January 22nd, 1914. His parents, Leonidas Dragatakis and Eleni Zarkada, belonged to a generation which fully preserved the folk music tradition as an element of their daily lives.

Dimitris Dragatakis, the eldest son of a family of seven children, showed keen interest from a very young age in the natural sounds and the musical traditions of his birthplace. The perpetual drone of the river, Arahthos, situated at the base of the village, the echo of herd bells in the surrounding mountains, the improvised musical instruments along with the musical tradition of the area, critically sensitized him to these sounds and shaped his musical perception.

Following the completion of his basic education in his hometown as well as a series of violin lessons for one year in neighboring loannina, Dimitris Dragatakis' father took the initiative to take him to Athens in 1928 at the age of 14 along with his brother, Nikolaos, in order to study music at the National Conservatoire. Manolis Kalomiris, founder and director of the National Conservatoire, recognized his talent but at the same time understood the financial difficulties the brothers were facing and provided the primary aid and support in the completion of their studies. Dimitris Dragatakis studied violin under G. Psillas and he graduated in June 1938 receiving the Degree in Violin with Distinction, unanimously, as well as a prize from the Administration of the Conservatoire. Upon receiving the Degree he began teaching violin at the central National Conservatoire until 1947 and at annexes of the Conservatoire until 1941. At the same time he continued his studies in the Higher Theory of Music (in the class of Michalis Vourtsis) and received the Diploma of Harmony in June 1940 with Distinction and a prize. M. Kalomiris prompted Dragatakis to turn his focus on the viola and in May 1944 he was hired by the orchestra of the National Opera House, where M. Kalomiris was the Artistic Director. He worked there until 1947. In 1946 he married Iro Aivaliotis, who was also a violinist.

In 1949 he began lessons in Composition, Counterpoint and Fugue with L. Zoras and M. Kalomiris at the National Conservatoire from where he received the corresponding Diploma in June 1955. Additionally, from 1949 until 1957 he again teaches violin at the National Conservatoire. From 1951 he began his second period of collaboration with the orchestra of the

National Opera House which continued until 1969. In February 1952, Dragatakis becomes a member of the Greek Composers Union.

In 1977 a new collaboration between Dragatakis and the National Conservatoire begins, but now as a renowned composer, in the capacity of Professor of Higher Theoretical Studies, Superintendent of the School of Higher Theoretical Studies (19831995), member of the Artistic Commission (1983-2001) and of the Board of Directors of the Conservatoire (1985-2001). Since the spring of 1977 he also participated on the Board of Directors of the Greek Composers Union. In 1980 Dragatakis is designated as a member of the Special Concert Fund Organization (E.T.O.S.) of the Athens State Orchestra, a position he held until his death.

In 1995 Dragatakis becomes the Vice President of the Greek Composers Union (G.C.U.) until March 2001, when he is unanimously declared as the lifetime Honorary President of the Union. In 1997 he is presented with the "Maria Kallas" award from the National Greek Radio (the 3rd Program) and two years later with the award, "In Honor of G. Papaioannou" from the Academy of Athens. From February 1999 until his death, he serves as a member of the Board of Directors of the National Opera House as a representative of the Greek Composers Union.

Dimitris Dragatakis died suddenly on December 18th, 2001, amidst his creative activities. 


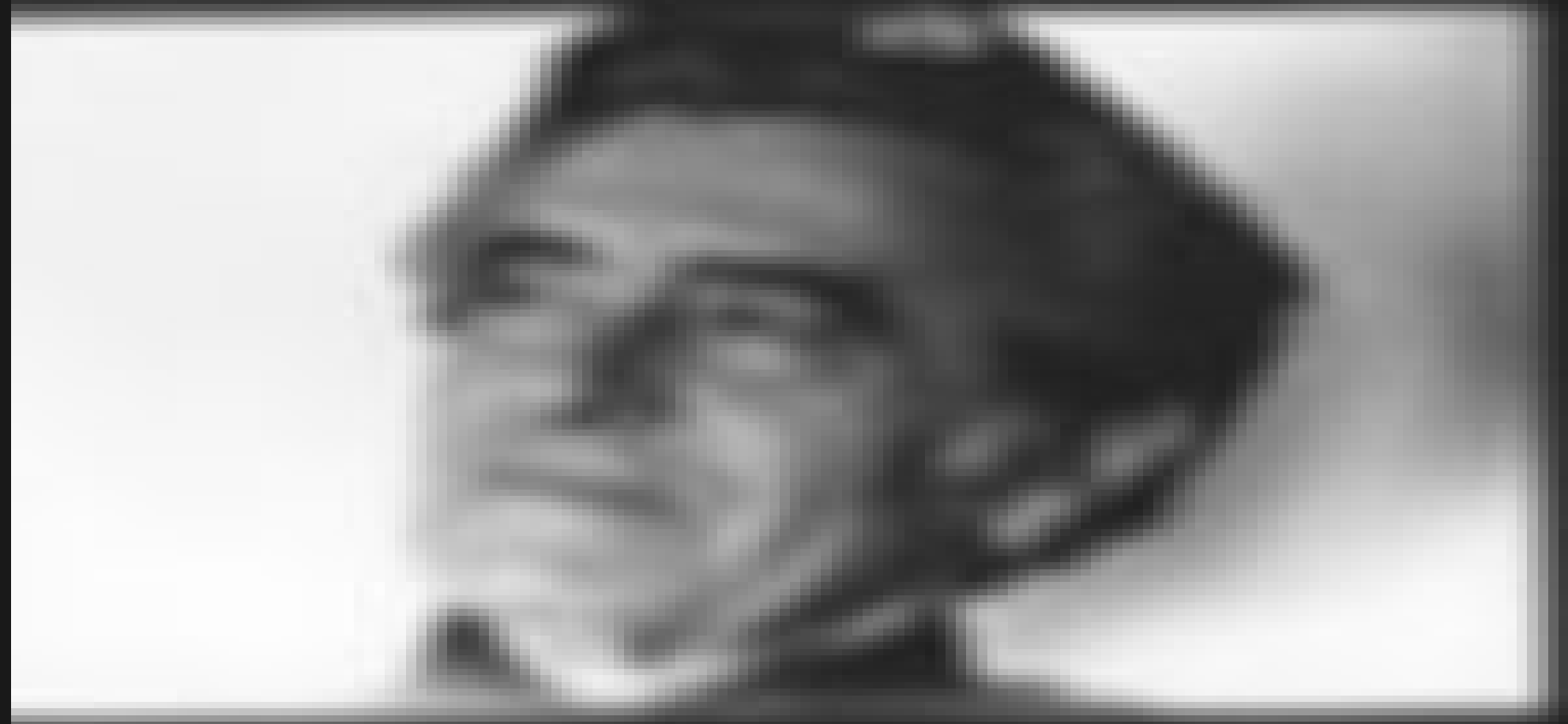

\section{LIFE AS A COMPOSER}

Dimitris Dragatakis was a very productive composer. He wrote music for most of the musical genres, with the total number surpassing 140 works. His first compositions are dated to before 1940 and his last being in 2001, the year of his death. His first dated work was the String Quartet No.1 in 1957, which had already carried the seal of maturity in composition. However, the fact that he began composing at a fairly older age (40-42 years of age) and he had already settled in a specific attitude

towards life, allowed him to preserve his Greek entity amidst the pioneering trends of the time. Since 1958, Dragatakis operates more intensely as a composer and composes regularly, of which many masterpieces are distinguished in National Competitions. He also monitors, through every possible means (radio, concerts, lectures), all the contemporary tendencies in composition which gradually lead him to approach contemporary musical trends.

Even though his initial studies were alongside L. Zoras and M. Kalomiris, he did not identify himself with the style that was representative of the National Music School. There are only few elements of this style observed in a small number of his primary compositions. On the contrary, he was a self-taught composer; the effects of the music in the region of his birthplace, the contemporary musical trends of his time (the musical pioneering of the 60's and 70's) and primarily his own personal perception of the art of music, are all the elements which essentially shaped his creative language.

The significance of Dragatakis' work is independent of the number of his works in itself or the number of distinctions he received during his lifetime. The acceptance and recognition his music gained is distinctly connected to the specific characteristics of the composer himself. Dragatakis was a modern composer, who embraced the messages of his time and expressed them through his music. He was also a composer deeply rooted in his Greek heritage, who constantly included the Greek folk musical traditions in his compositions and particularly the folk music of Epirus, the region of his birthplace. Finally, he was a humanitarian composer, who aspired for art to approach the average man and not only to address the musical "elite". 


\section{DISTINCTIONS \& DEDICATIONS}

Several of his works are distinguished in Panhellenic Competitions: String Quartet no.1 (1957): Honorable Mention in the First National Competition of Composition of the Greek Composers Union \{1958), Symphony no.1 (1959): 2nd Prize (category of symphonies) in the Panhellenic Competition of Composition of Serious Music of the Greek Radio Institution (G.I.R.) (1962), String Quartet no.3 (1960): 2nd Prize (category of chamber music) in the Panhellenic Competition of Composition of Serious Music of G.I.R. (1962), Trio for Oboe, clarinet and bassoon (1962): 1st Prize (unanimously) A' Panhellenic Composition Competition of the Greek Composers Union "M. Kalomoiri Prize" (1964), "Ulysses and Nafsika" - Ballet Suite no.2 (1964): p $t$ Prize in the Music Competition of the Panhellenic Ballet Competition, organized by the Greek Ballet theatre, the Touring Club and the magazine, "Tahidromos" (1965), Symphony no.S (1979-80): p t Prize (category of symphonies) of the A' Panhellenic

Composition Competition of Art Music from the Ministry of Culture (1981), Symphony no.6 (1989): 3rd Prize in the Competition of Symphony Compositions under the auspice of the Cultural Centre of the Municipality of Athens, with the theme of

National Paligenesis (1991).

In August 1988 the first honorary event for the composer, Dimitris Dragatakis, takes place and is organized by the Cultural Society of Platanousa, his hometown. In addition, in June 1988, a Commemorative Medal is presented to the composer and his wife for their participation in the National Resistance. There are tens of other honorary events that follow until today: 
Municipality of Nikaia (1991), French Institute of Athens - Greek Composers Union - Society of "M. Kalomiris" (1992), Society of Recognized Professors of Conservatoires (2001), Athens Concert Hall (2001), magazine Polyfonia (2002), National

Orchestra of Athens (2002), the magazine of Greek Composers Union "Mousikis Polytonon" (2006-7), etc. The year 2014 was declared by the Greek Composers Union and in collaboration with the Society of Friends of D. Dragatakis as the year of Dimitris Dragatakis", due to the 100 year anniversary of his birth. Many different agencies enthusiastically responded and organized events dedicated to his life and work throughout 2014 which included: Goethe Institute, Athens Concert Hall, Municipality of Northern Tzoumerka-Epirus, Municipality of Athens, Greek Musical Feast in Athens and Thessaloniki, etc.

\section{ESSENCE}

Dimitris Dragatakis belongs to those artists, who with faith in their creative instincts and tireless effort, overcome any adversity and realize their vision, often against all odds, therefore becoming a genuine model

for future generations.

Within the same context, lies Dragatakis' deep sensitization towards the new generation of composers. Believing creativity flourishes from the individual naturally and that essentially composition cannot be taught, being himself a "self-taught" 
composer, Dragatakis always encouraged his students to seek, and penetrating to reach a particular personal style, directly related to their era and its needs. As an avid believer and fighter of freedom of thought and expression, he always supported

anything new and pioneering, with the only condition being continuation and consistency. With these characteristics he became a model of a self-luminous artist; he not only incarnated his vision of a musical creation free from rules and systems and focused on the understandable expression of space and time, but he also showed the way for the younger generations of composers, who with faith in their goals can pursue their artistic self-realization, but always with a humanitarian focus.

The key element of Dimitris Dragatakis' contribution to Greek music lies in the strict consistency of his worldview and the high caliber and quality of his creations. Furthermore, in his perception and the lessons in life and his artistic career lie the possibility of renegotiating our own values and goals, not only individually but also socially.
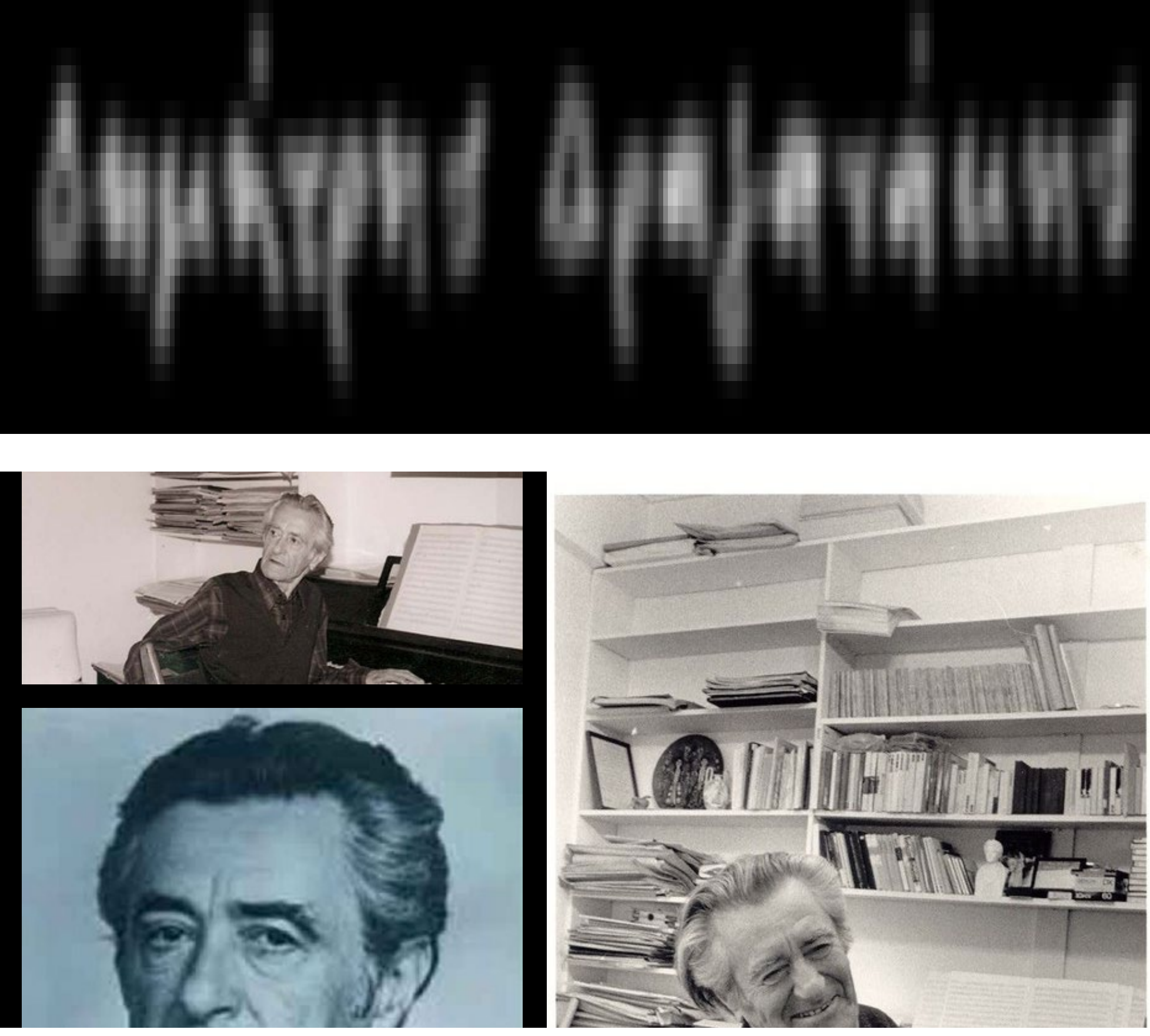

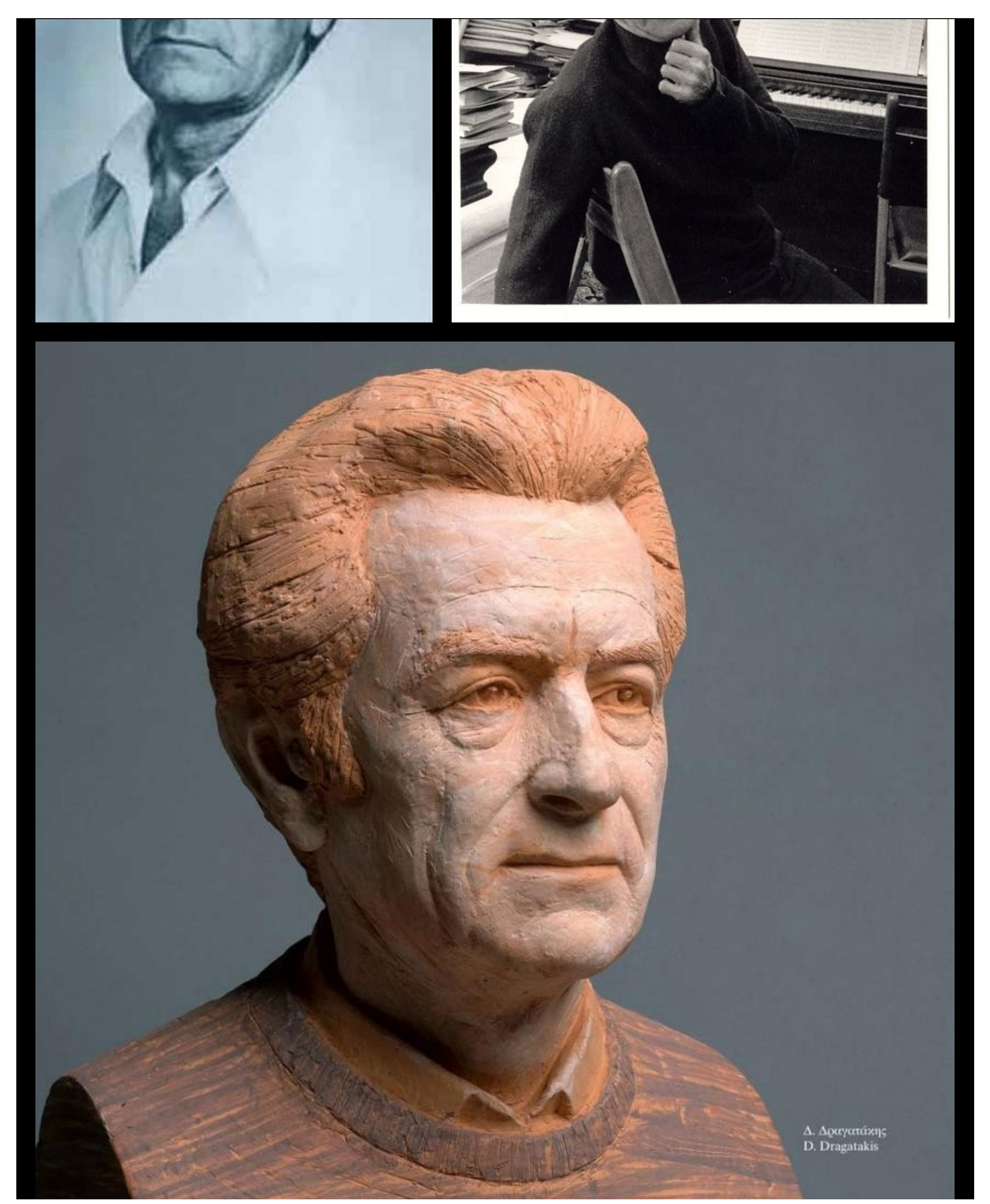
Many thanks to Dr Magdalini Kalopana for the biography notes, Mandy Dragatakis for the translation of the notes, and Kelly Dragatakis for editing the translation which were taken from the Dimitris Dragatakis: String Quartets CD.

Kalopana, Magdalini. Dragatakis, Mandy (trans.). Dragatakis, Kelly (ed.). Biography liner notes to Dimitris Dragatakis: The String Quartets, New Hellenic Quartet, IRIDA 022, CD, 2019.

\section{Athens, Greece}




\section{DIMITRIS DRAGATAKIS}

\section{ARCHIVE}

Honoring one of Greece's most important modern composers

Request Music

dragatakis.info@gmail.com

\section{DIMITRIS DRAGATAKIS COMPOSITION COMPETITION}

Continuing Dimitris Dragatakis' teaching legacy and inspiring up-and-coming composers

The Dimitris Dragatakis Composition Competition is a biennial competition established in 2004 in collaboration with the Greek Composers' Union and Friends of Dragatakis Society to honour Dimitris Dragatakis' legacy as a composer and teacher.

Apart from his work as a composer, Dimitris Dragatakis was an encouraging teacher and mentor, felt music education was of the utmost importance, and sought to inspire and support his students at all times. The mission of the competition is to continue Dragatakis' teaching legacy while also giving up-and-coming composers the opportunity to distinguish themselves and their works. 


\section{HISTORY OF THE COMPETITION}

\section{ST COMPETITION}

Call for compositions announced during 2003

Winning works performed on 2 November 2004 at the Goethe Institute, Athens

1st Prize: G. Sakallieros, Lament for " $D$ " - A String Quartet for string quartet and digital tape

2nd Prize: L. Kanaris, Hommage a Dimitris Dragatakis for string quartet

3rd Prize: A. Agrafiotis, Quartetto d 'archi for string quartet

2ND COMPETITION

Call for compositions announced 2005

Winning works performed on 31 October 2006 at the Goethe Institute, Athens

1st Prize: D. Doxakis, String Quartet

2nd Prize: Ant. Anestis, Concertino for instrumental ensemble

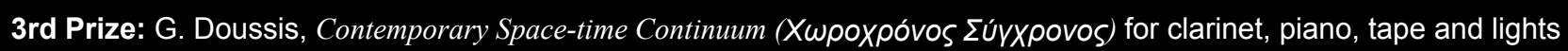
3RD COMPETITION

Call for compositions announced 2007

Winning works performed on 15 January 2009 at the Megaron - D. Mitropoulos Hall, Athens

1st Prize: A. Loufopoulos \& M. Korkokiou, Behaviours for flute and tape

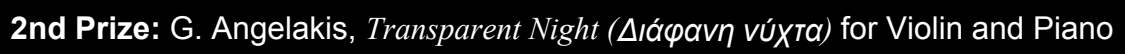

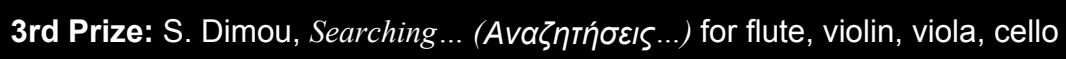




\section{TH COMPETITION}

Call for compositions announced 2009

Winning works performed on 12 January 2011 at the F. Nakas Conservatory, Athens

1st Prize: G. Zambaklis, In memoriam...

2nd Prize: Chr. Dovas, Luminous Interval...

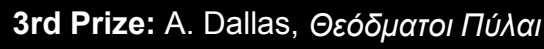

\section{TH COMPETITION}

Call for compositions announced 2011

Winning works announced in 2014 (no concert presentation)

1st Prize: G. Angelakis, Dödsdansen (Dance of death) for clarinet, bass clarinet, piano, violin and cello

2nd Prize: A. Rouvelas, Semi-impulsive spasm for two violins, viola, cello, double bass, piano

3rd Prize: V. Kourti-Papamoustou, Dance Suite for solo piano

\section{TH COMPETITION}

Call for compositions announced 2013

Winning works announced in 2015 (no concert presentation)

1st Prize: S. Avramidou, Skin for string quartet

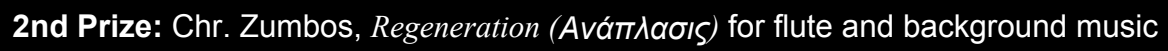

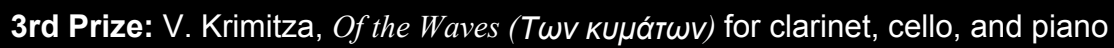

\section{TH COMPETITION}

Call for compositions announced 2015

No concert presentation for winning works

1st Prize: Chr. Dovas, Memory for flute, clarinetto, violin, viola, cello, piano

2nd Prize: Theodore Gougousoudis, Invisible Obstacle for flute and piano

3rd Prize: Theofilos Bikos, Stupefaction for oboe, two violins, viola, and cello

\section{TH COMPETITION}

Call for compositions announced 2017

Winning works performed on 18 December 2018 at the Goethe Institute, Athens

1st Prize: Chr. Dovas, Symbiosis for string quartet

2nd Prize: X. Constantinidou, Assimilations // for string quartet

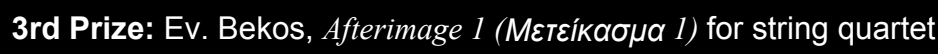


The information above was compiled by the Greek Composers' Union and musicologist Dr Magdalini Kalopana, PhD.

dragatakis.info@gmail.com

Athens, Greece

@2019 by the Dimitris Dragatakis Archive 


\section{DIMITRIS DRAGATAKIS}

ARCHIVE

Honoring one of Greece's most important modern composers

Request Music

dragatakis.info@gmail.com

The Greek Composers' Union was founded on June 8th 1931. Its' main aims are the protection and promotion of the

Greek musical creations, the development of solidarity between the Greek composers, and the protection of their professional and artistic rights. Since 1931, the Union has not relented in pursuing these goals, even during the Second World War.

Its members include the most distinguished Greek composers such as Dimitris Mitropoulos, Manolis Kalomiris, Nikos Skalkottas, Antiochos Evangelatos, lannis Xenakis, Jani Christou, George Sisilianos and Theodore Antoniou.

From 1989 until 2018 the president of the Greek Composers' Union was Theodore Antoniou, Academician, composer, director and professor at the Boston University. During his presidency, the G.C.U. has expanded its activities considerably. Besides the organization of many concert series, the Greek Composers Union organizes two Pan - Hellenic composition competitions: "Yiannis A. Papaioannou" competition and "Dimitris Dragatakis" competition. Moreover, it organizes young composers' workshops, lectures and congresses, and promotes the publication and release of different scores and CDs featuring contemporary music. 
Since 2003 the Greek Composers' Union has its own magazine “music Polytonon”, a bimonthly publication, whose main aim is to promote and disseminate Greek and international contemporary music to the wider public. The magazine also serves as an information and communication channel between the Greek musical community.

Greek Composers' Union is a member of the International Society for Contemporary Music (I.S.C.M.) since 2002.

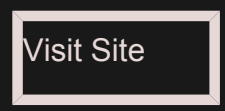




\title{
DIMITRIS DRAGATAKIS
}

\section{ARCHIVE}

Honoring one of Greece's most important modern composers

\author{
Request Music
}




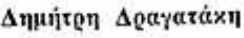 \\ D. DRAGATAKIS \\ A $\Phi$ IEP $\Omega M A$ \\ Dedication}

(1963) 


\section{Afieroma (Dedication), from a theme by M. Kalomiris for} Mixed Octet (1963)

Afieroma (Dedication), variation on a theme by M. Kalomiris for Mixed Octet Composed in 1963

Instrumentation: Flute, oboe, clarinet, trumpet, two violins, cello, and piano

\section{dragatakis.info@gmail.com \\ Athens, Greece}

@2019 by the Dimitris Dragatakis Archive 


\section{DIMITRIS DRAGATAKIS}

\section{ARCHIVE}

Honoring one of Greece's most important modern composers

Request Music 


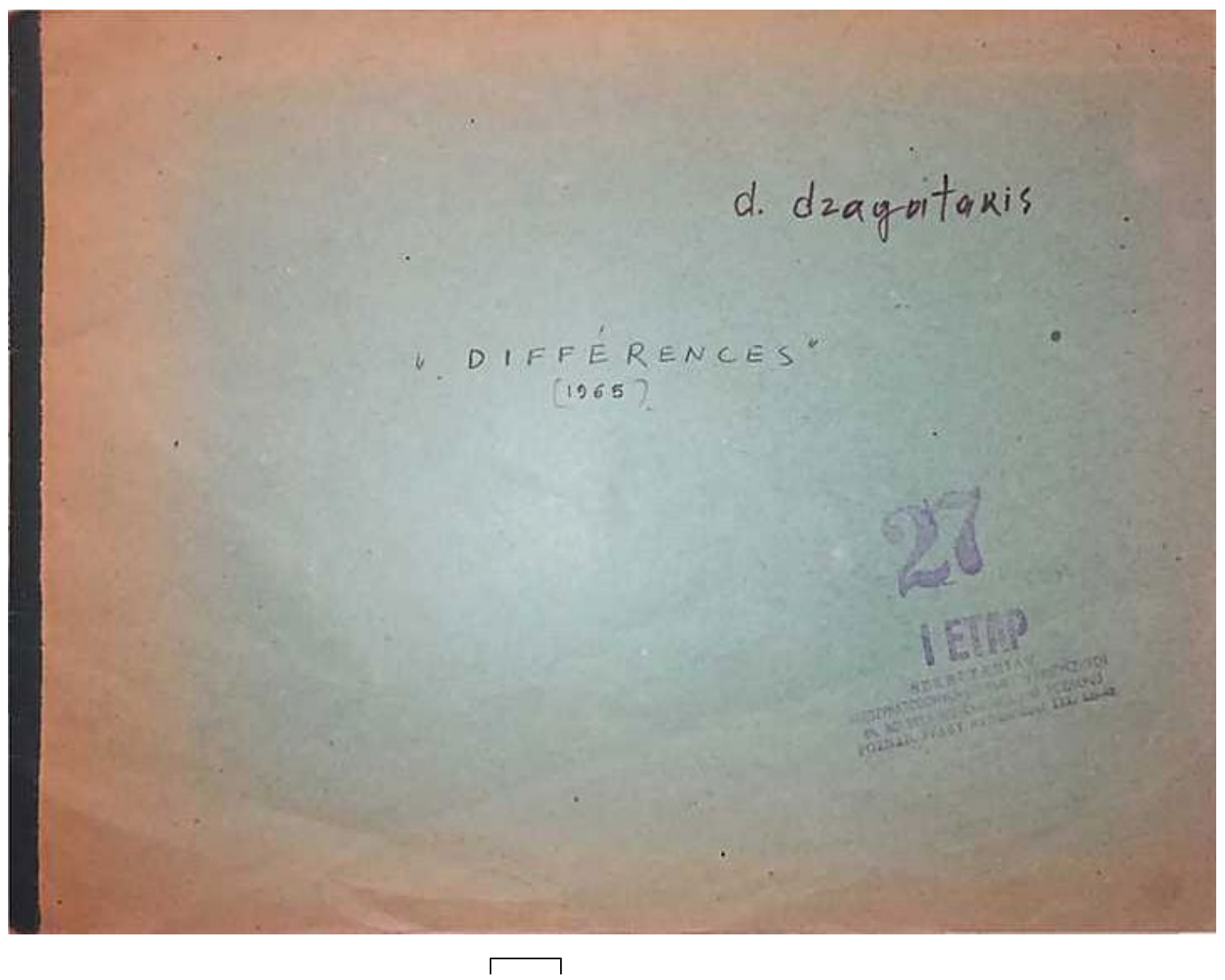

https://www.dimitrisdragatakis.com/product-page/diaphores-differences-for-mixed-octet-1965[19/06/20, 2:15:33 PM] 


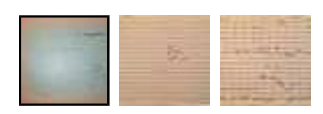

\section{Diaphores (Differences) for Mixed Octet (1965)}

Diaphores (Differences) for Mixed Octet

Composed in 1965

This work exists in manuscript form only.

Instrumentation: Flute, oboe, clarinet, horn, timpani, percussion, violin, and cello

\section{dragatakis.info@gmail.com}

\section{Athens, Greece}




\section{DIMITRIS DRAGATAKIS}

\section{ARCHIVE}

Honoring one of Greece's most important modern composers

Request Music 


\title{
A. $\Delta \varrho \alpha \gamma \alpha \tau \dot{\alpha} \chi \eta \zeta$
}

\section{Dragatakis}

\section{Music for three}

\author{
(Violino - Corno - Piano)
}

(1969) 


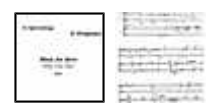

Mousiki gia treis (Music for three) for Violin, Horn, and Piano (1969)

Mousiki gia treis (Music for three) for Violin, Horn, and Piano

Composed in 1969

Instrumentation: Violin, horn, and piano 


\section{DIMITRIS DRAGATAKIS}

\section{ARCHIVE}

Honoring one of Greece's most important modern composers

Request Music 


\section{ANA $\triangle P O M E \Sigma$ I}

ANADROMES I

r. NAKA YOYZRKOZ OMCOI
MANERIITHMIOY 44 (ITEO) AORNAI
G. NAKAS

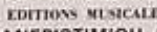
PANEPISTIMIOU 4 


\section{Anadromes I (Retrospections I) for Mixed Sextet (1976)}

Anadromes I (Retrospections I) for Mixed Sextet

Composed in 1976

Instrumentation: Flute, guitar, tuba, cello, doublebass, and piano 


\section{DIMITRIS DRAGATAKIS}

\section{ARCHIVE}

Honoring one of Greece's most important modern composers

Request Music 


\section{"ANADPOME III"}

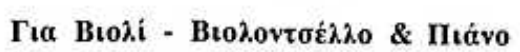
(1978)

\section{"ANADROMES III"}

For Violin - Violoncello \& Piano

(1978) 


\section{Anadromes III (Retrospections III) for Violin, Cello, and} Piano (1978)

Anadromes III (Retrospections III) for Violin, Cello, and Piano

Composed in 1978

Instrumentation: Violin, Cello, and Piano

\section{dragatakis.info@gmail.com \\ Athens, Greece}

@2019 by the Dimitris Dragatakis Archive 


\title{
DIMITRIS DRAGATAKIS
}

\section{ARCHIVE}

Honoring one of Greece's most important modern composers

\author{
Request Music
}


Uwi iudobu

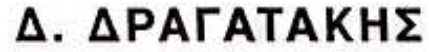 \\ $=$ ПрактIKó $19=$ \\ (1979)

\section{D.DRAGATAKIS} \\ = PRACTIKO $19=$ \\ (1979)
}




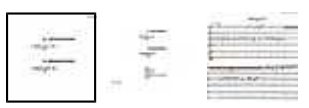

Praktiko 19 (Record 19) for Violin, Clarinet, Horn, Trumpet, and Piano (1979)

Praktiko 19 (Record 19) for Violin, Clarinet, Horn, Trumpet, and Piano

Composed in 1979

Instrumentation: Violin, Clarinet, Horn, Trumpet, and Piano

\section{dragatakis.info@gmail.com \\ Athens, Greece}

@2019 by the Dimitris Dragatakis Archive 


\section{DIMITRIS DRAGATAKIS}

\section{ARCHIVE}

Honoring one of Greece's most important modern composers

Request Music 


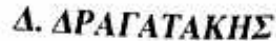

\section{DRAGATAKIS}

- TRIO.

(

(1986)

- TRIO -

(for C clarinet, piano and percussion)

(1986) 


\section{Trio for Clarinet, Percussion, and Piano (1986)}

Trio for Clarinet, Percussion, and Piano

Composed in 1986

Instrumentation: Clarinet, Percussion, and Piano

\section{dragatakis.info@gmail.com}

\section{Athens, Greece}




\section{DIMITRIS DRAGATAKIS}

\section{ARCHIVE}

Honoring one of Greece's most important modern composers

Request Music 


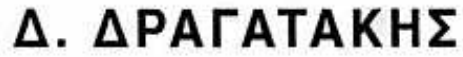

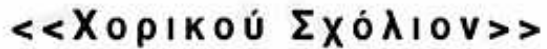 \\ (1993)

\section{D.DRAGATAKIS} \\ $\ll$ CHORICS COMMENTARY $>$ \\ (1993)
}




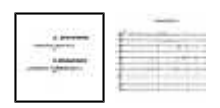

\section{Chorikou Scholion (Choric's commentary) for Chamber} Ensemble (1993)

\section{Chorikou Scholion (Choric's commentary) for Chamber Ensemble}

Composed in 1993

Instrumentation: Flute, Clarinet, Horn, Trumpet, Violin, Cello, Timpani, Percussion, and Piano

\section{dragatakis.info@gmail.com}

\section{Athens, Greece}

@2019 by the Dimitris Dragatakis Archive 


\section{DIMITRIS DRAGATAKIS}

\section{ARCHIVE}

Honoring one of Greece's most important modern composers

Request Music 


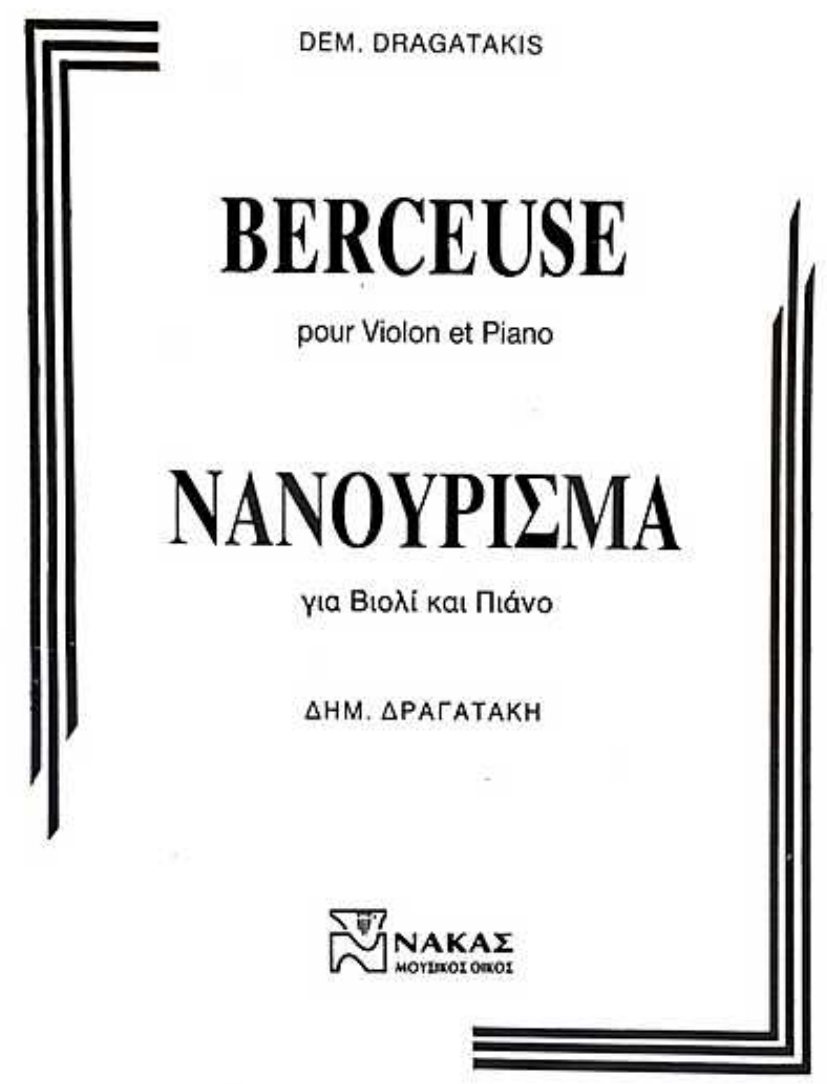




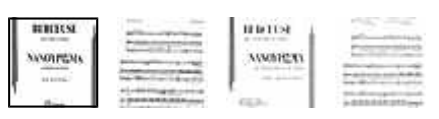

Nanourisma (Berceuse) for Violin, Viola, or Cello and Piano or String Quartet

Nanourisma (Berceuse) for Violin, Viola, or Cello and Piano

Composition year is estimated between 1942 and 1949

Instrumentation: Violin and piano, viola and piano, cello and piano, or string quartet

Listen here:

For Violin and Piano

For Cello and Piano 


\section{DIMITRIS DRAGATAKIS}

\section{ARCHIVE}

Honoring one of Greece's most important modern composers

Request Music 


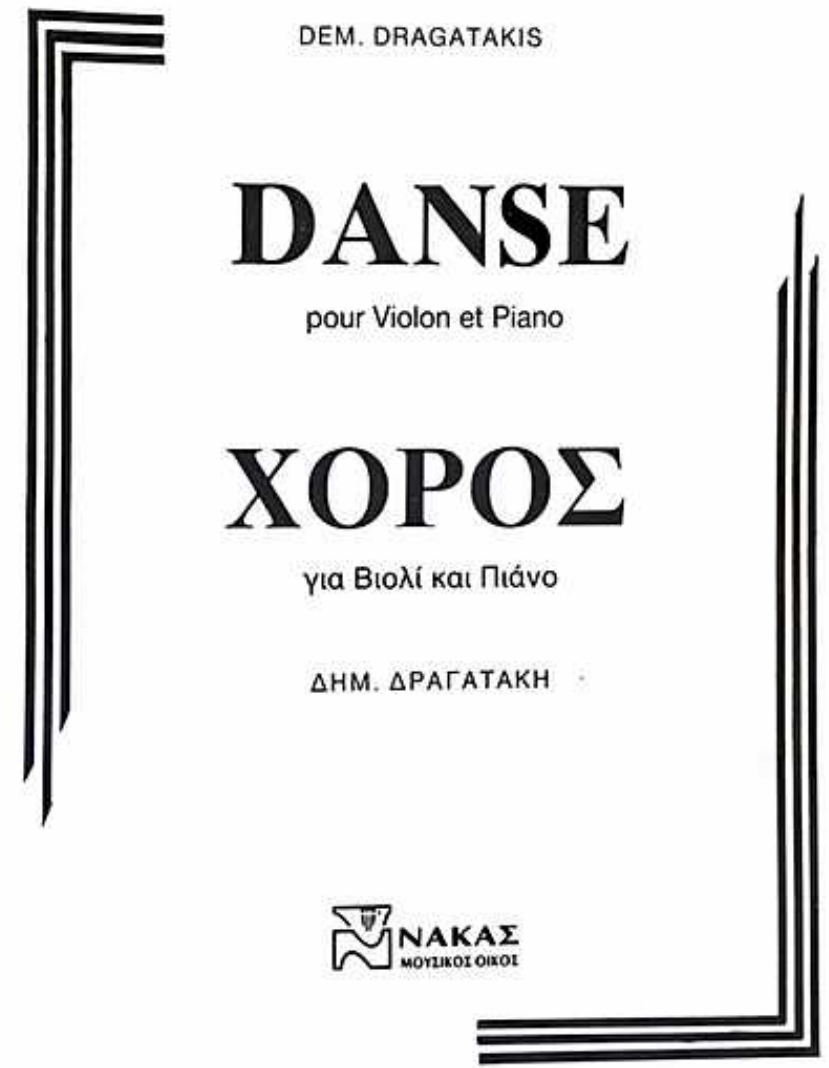




\section{Choros (Dance) for Violin and Piano}

\section{Choros (Dance)}

Composition year is estimated between 1949 and 1957

Instrumentation: Violin and piano 


\section{DIMITRIS DRAGATAKIS}

\section{ARCHIVE}

Honoring one of Greece's most important modern composers

Request Music 


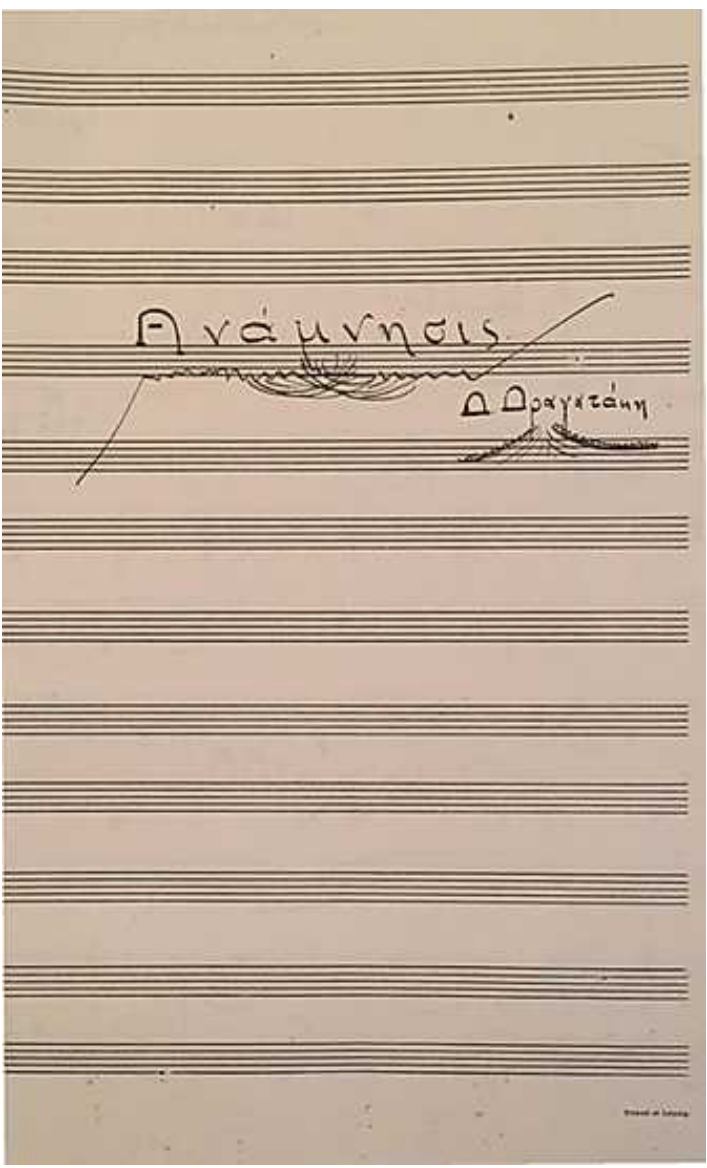

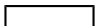




\section{Anamnisi (Remembrance) for Violin and Piano (1942)}

Anamnisi (Remembrance) for Violin and Piano

Composed in 1942

Instrumentation: Violin and piano

\section{dragatakis.info@gmail.com}

\section{Athens, Greece}




\section{DIMITRIS DRAGATAKIS}

\section{ARCHIVE}

Honoring one of Greece's most important modern composers

Request Music 
O). Ukararáuns

Quartetto:
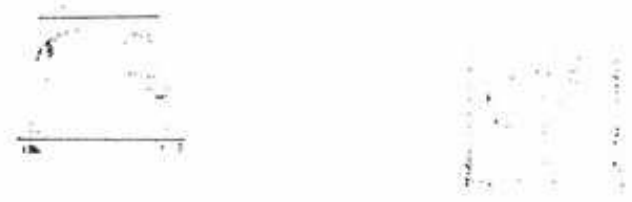

https://www.dimitrisdragatakis.com/product-page/string-quartet-no-1-1957[19/06/20, 2:16:32 PM] 


\section{String Quartet No. 1 (1957)}

\section{String Quartet No. 1}

Composed in 1957

Instrumentation: String quartet

Listen here:

i. Allegro

ii. Allegro

iii. Andantino

iv. Vivo 


\section{DIMITRIS DRAGATAKIS}

\section{ARCHIVE}

Honoring one of Greece's most important modern composers

Request Music 


\section{EONATA No1 \\ TIA BIONI \& MIANO}

\section{SONATA N01}

FOR VIOLIN \& PIANO 


\section{Sonata No. 1 for Violin and Piano (1958)}

Sonata No. 1 for Violin and Piano

Composed in 1958

Instrumentation: Violin and piano

Listen now:

i. Allegro moderato

ii. Andantino

iii. Allegro vivo

\section{Athens, Greece}




\section{DIMITRIS DRAGATAKIS}

\section{ARCHIVE}

Honoring one of Greece's most important modern composers

Request Music 


\section{\. $\triangle P A Г A T A K H \Sigma$}

\section{Kочарте́то ар. 2}

(1958)

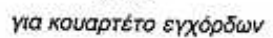

\section{DRAGATAKIS}

\section{Quartetto No. 2}

(1958)

for String Quartet 


\section{String Quartet No. 2 (1958)}

\section{String Quartet No. 2}

Composed in 1958

Instrumentation: String quartet

Listen now:

i. Allegro vivo

ii. Allegro moderato

iii. Andante

iv. Presto

\section{dragatakis.info@gmail.com}

\section{Athens, Greece}




\section{DIMITRIS DRAGATAKIS}

\section{ARCHIVE}

Honoring one of Greece's most important modern composers

Request Music 


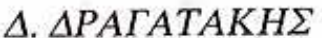

Toío

(1960)

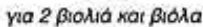

D. DRAGATAKIS

Trio

(1960)

for 2 violins and viola 


\section{Trio for two Violins and Viola (1960)}

Trio for two Violins and Viola

Composed in 1960

Instrumentation: Two violins and viola 


\section{DIMITRIS DRAGATAKIS}

\section{ARCHIVE}

Honoring one of Greece's most important modern composers

Request Music 


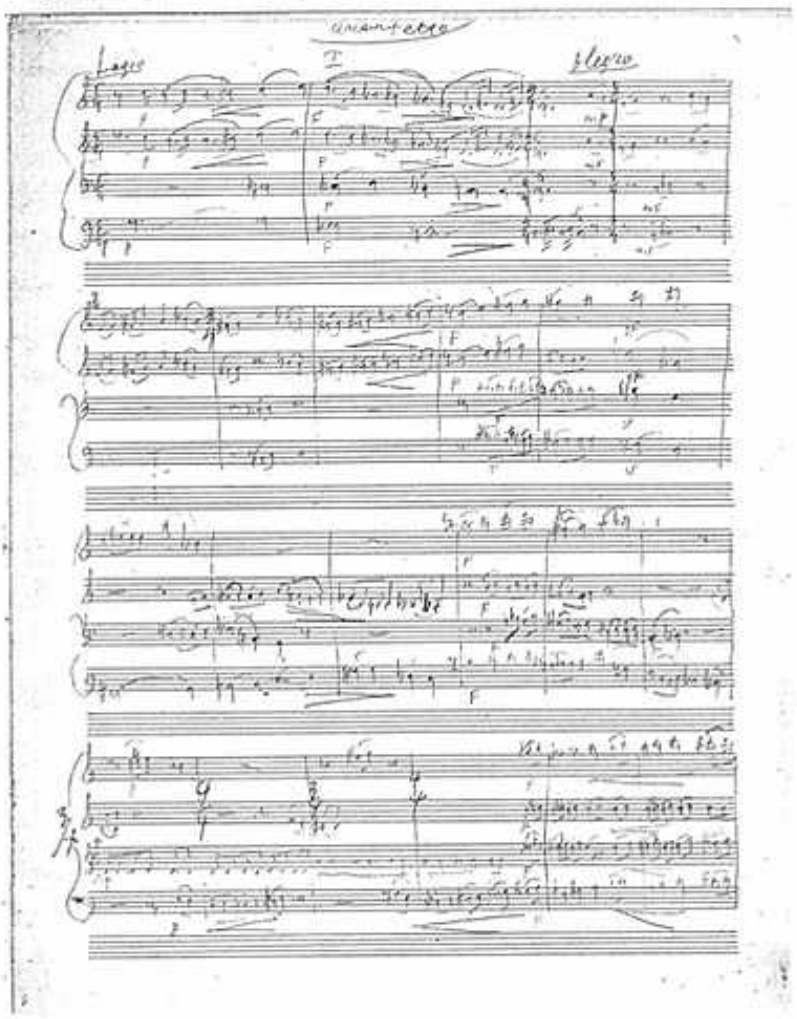

https://www.dimitrisdragatakis.com/product-page/string-quartet-no-3-1960[19/06/20, 2:17:02 PM] 


\section{String Quartet No. 3 (1960)}

String Quartet No. 3

Composed in 1960

Instrumentation: String quartet

Listen now:

i. Largo

ii. Marcia (Moderato)

iii. Andante

iv. Allegro

\section{dragatakis.info@gmail.com}

\section{Athens, Greece}




\section{DIMITRIS DRAGATAKIS}

\section{ARCHIVE}

Honoring one of Greece's most important modern composers

Request Music 


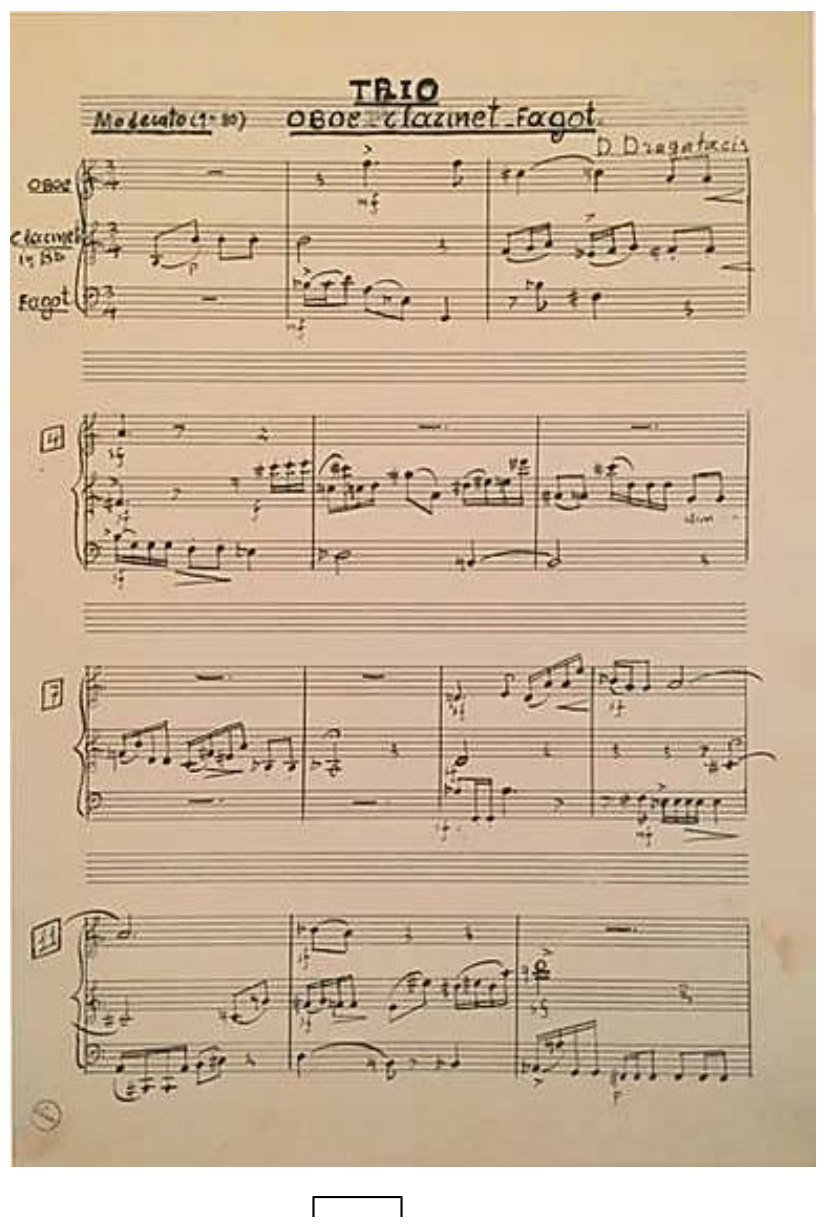

https://www.dimitrisdragatakis.com/product-page/trio-for-oboe-clarinet-and-bassoon-1962[19/06/20, 2:17:06 PM] 


\section{Trio for Oboe, Clarinet, and Bassoon (1962)}

Trio for Oboe, Clarinet, and Bassoon

\section{Composed in 1962}

This work exists in manuscript form only.

Instrumentation: Oboe, Clarinet, and Bassoon

Listen here:

i. Moderato

ii. Pestissimo

iii. Grave

iv. Animato

\section{Athens, Greece}




\section{DIMITRIS DRAGATAKIS}

\section{ARCHIVE}

Honoring one of Greece's most important modern composers

Request Music 


\section{DRAGATAKIS}

\section{TRIO}

(1962)

Corno Tromba Tromboni 


\section{Trio for Trumpet, Horn, and Trombone (1962)}

Trio for Trumpet, Horn, and Trombone

Composed in 1962

Instrumentation: Trumpet, horn, and trombone 


\section{DIMITRIS DRAGATAKIS}

\section{ARCHIVE}

Honoring one of Greece's most important modern composers

Request Music 


\section{D. $\triangle P A T A T A K H E$ \\ D. Dragatakis}

\section{Quintetto}

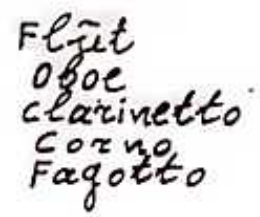




\section{Woodwind Quintet (1964)}

Woodwind Quintet

Composed in 1964

Instrumentation: Flute, oboe, clarinet, bassoon, and horn

Listen here:

i. Largo

ii. Presto-Meno-Presto

iii. Adagio

iv. Allegro

\section{dragatakis.info@gmail.com}

\section{Athens, Greece}




\section{DIMITRIS DRAGATAKIS}

\section{ARCHIVE}

Honoring one of Greece's most important modern composers

Request Music 


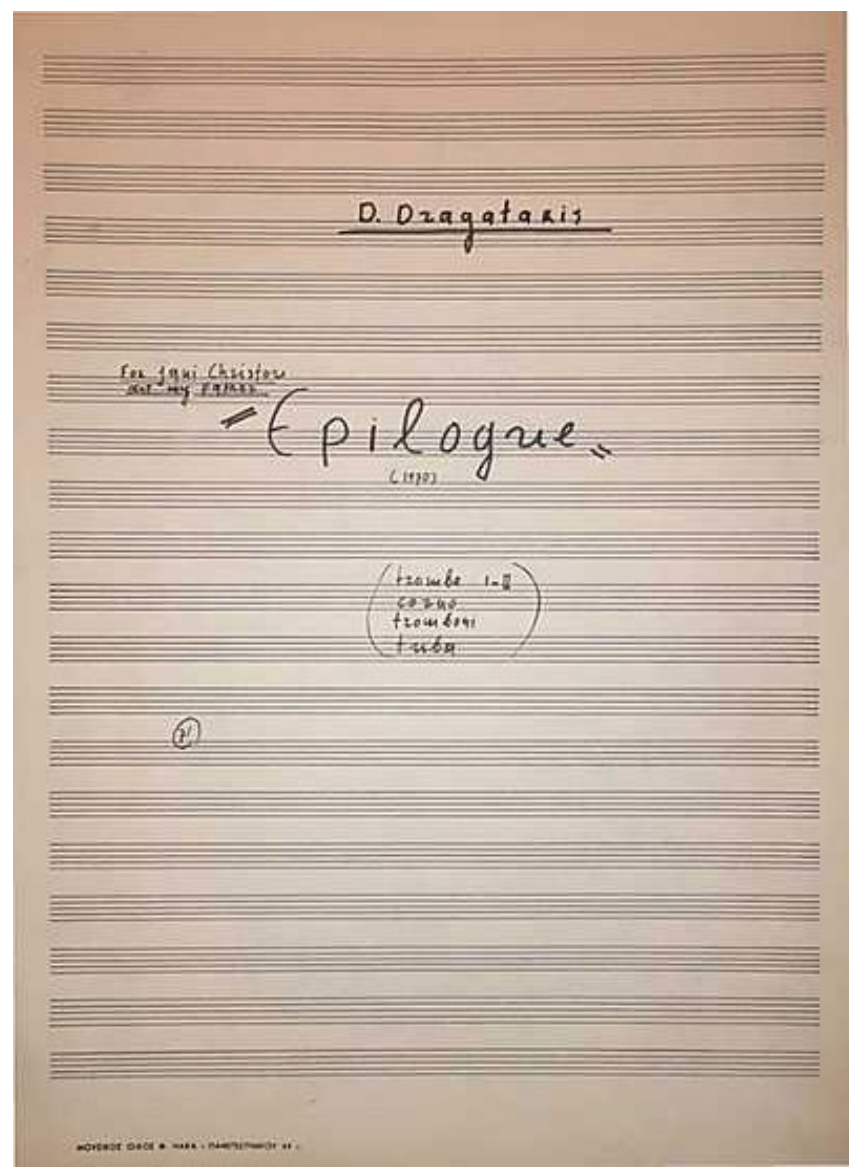

https://www.dimitrisdragatakis.com/product-page/epilogos-epilogue-for-brass-quintet-1970[19/06/20, 2:17:21 PM] 


\section{Epilogos (Epilogue) for Brass Quintet (1970)}

Epilogos (Epilogue) for Brass Quintet

Composed in 1970

This work exists in manuscript form only.

Instrumentation: Two trumpet, horn, trombone, and tuba

\section{dragatakis.info@gmail.com}

\section{Athens, Greece}




\section{DIMITRIS DRAGATAKIS}

\section{ARCHIVE}

Honoring one of Greece's most important modern composers

Request Music 

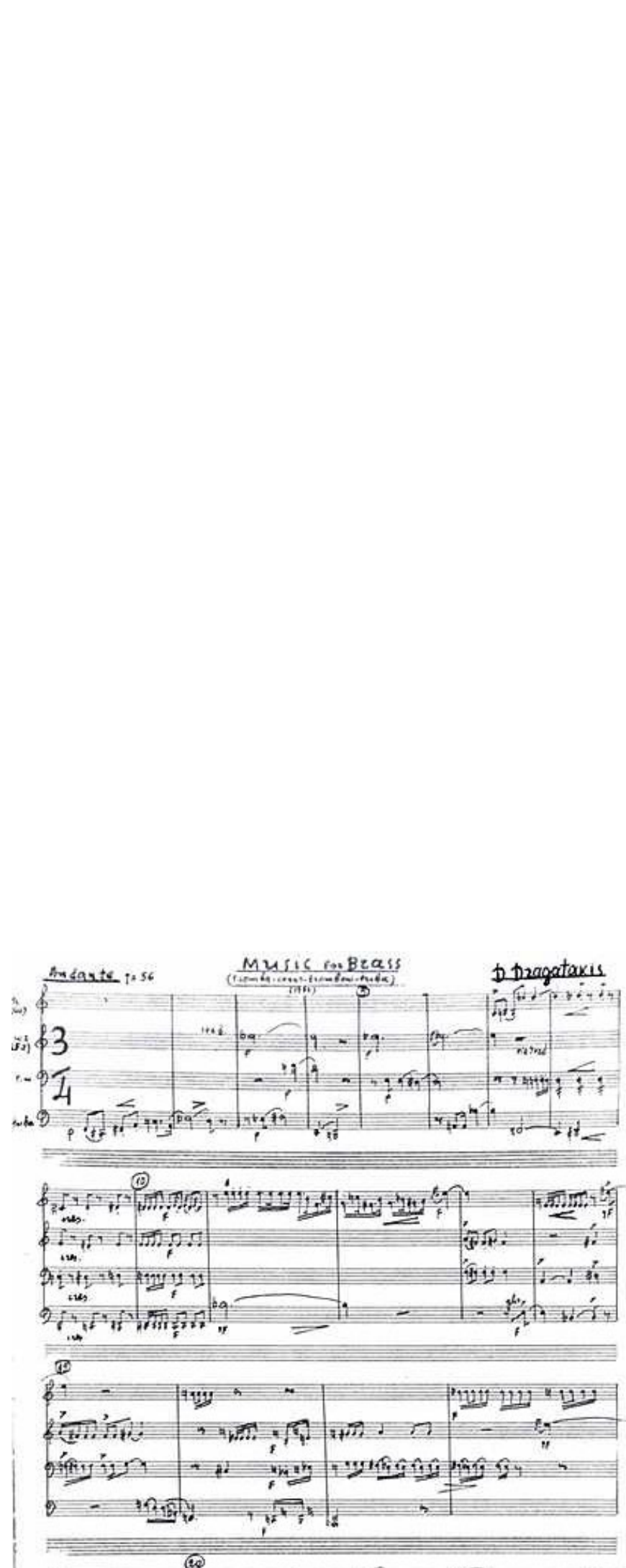


\section{Mousiki gia chalkina (Music for brass) for Brass Quartet} (1971)

Mousiki gia chalkina (Music for brass)

Composed in 1971

This work exists in manuscript form only.

Instrumentation: Trumpet, horn, trombone, and tuba

\section{dragatakis.info@gmail.com \\ Athens, Greece}




\section{DIMITRIS DRAGATAKIS}

\section{ARCHIVE}

Honoring one of Greece's most important modern composers

Request Music 


\section{Dragatakis}

«Dialogues*

1974

fot 2 wiod quartets
(cosi-Clarinets - Fafoti - Conti)

A. dearatásus

"Àáhoyous"

1974

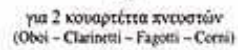

https://www.dimitrisdragatakis.com/product-page/dialogoi-dialogues-for-woodwind-octet-1974[19/06/20, 2:17:30 PM] 


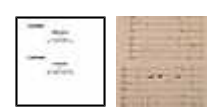

\section{Dialogoi (Dialogues) for Woodwind Octet (1974)}

Dialogoi (Dialogues) for Woodwind Octet

Composed in 1974

Instrumentation: Two woodwind quartets (2 ob, $2 \mathrm{cl}, 2$ bn, 2 hn)

Listen here:

i. Largo

ii. Allegro

iii. Adagio

iv. Allegro 


\section{DIMITRIS DRAGATAKIS}

\section{ARCHIVE}

Honoring one of Greece's most important modern composers

Request Music 


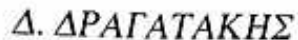

\section{«NToúo»}

1977

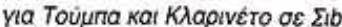

D. DRAGATAKIS

\section{"Duo"}

1977

for Tuba and Clarinet in Bb 


\section{Duo for Tuba and Clarinet (1977)}

Duo for Tuba and Clarinet

Composed in 1977

Instrumentation: Clarinet and tubo

\section{dragatakis.info@gmail.com}

\section{Athens, Greece}




\section{DIMITRIS DRAGATAKIS}

\section{ARCHIVE}

Honoring one of Greece's most important modern composers

Request Music 


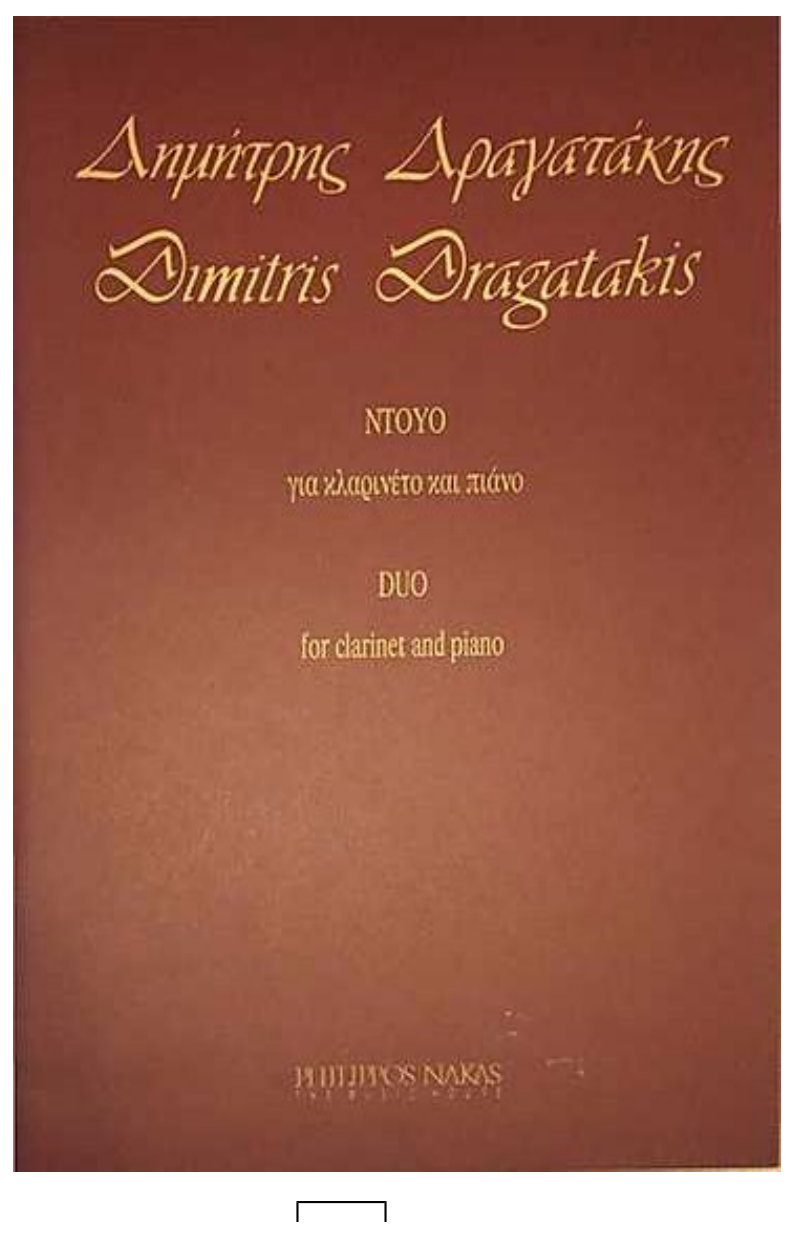

https://www.dimitrisdragatakis.com/product-page/duo-for-clarinet-and-piano-1981[19/06/20, 2:17:38 PM] 


\section{Duo for Clarinet and Piano (1981)}

\section{Duo for Clarinet and Piano}

Composed in 1981

Instrumentation: Clarinet and piano

Listen now 


\section{DIMITRIS DRAGATAKIS}

\section{ARCHIVE}

Honoring one of Greece's most important modern composers

Request Music 


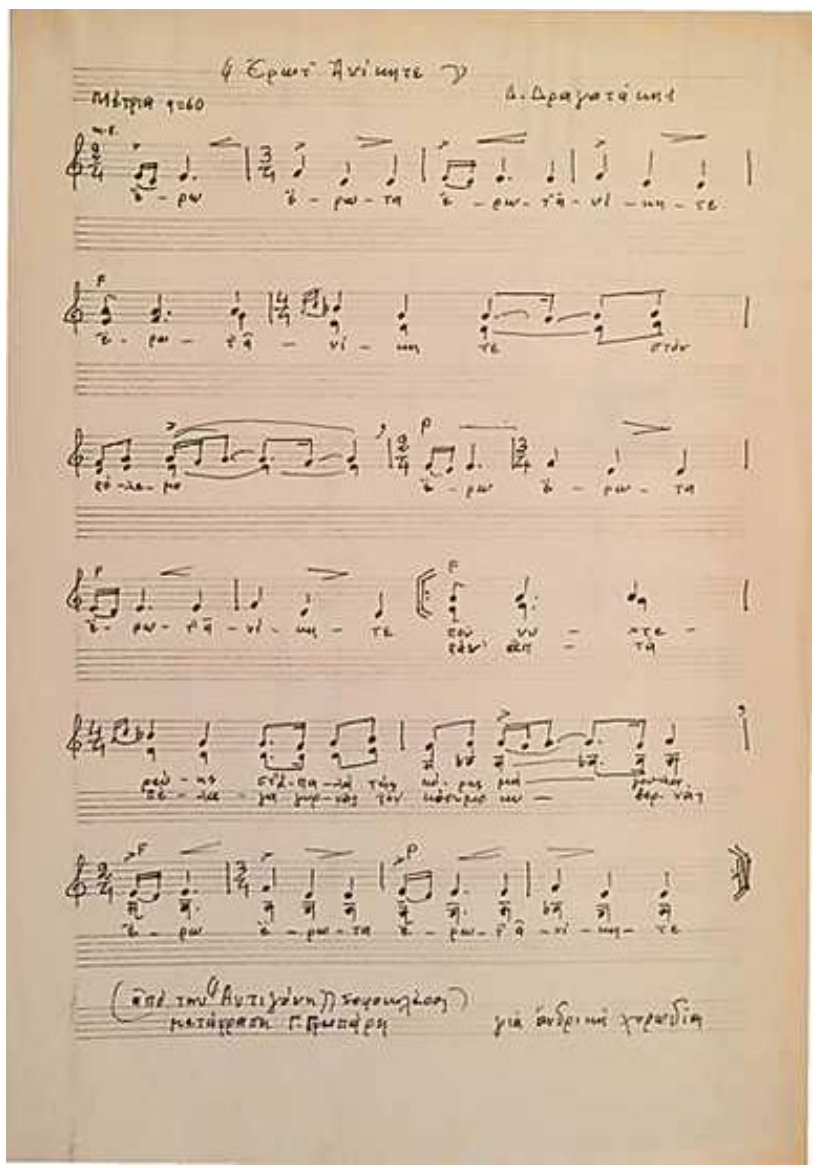

https://www.dimitrisdragatakis.com/product-page/erot-anikite-love-invincible-sophocles-antigone-third-stasimon-1969[19/06/20, 2:17:43 PM] 


\section{"Erot' anikite" ("Love invincible"), Sophocles, Antigone,} third stasimon [1969]

"Erot' anikite" ("Love invincible"), Sophocles, Antigone, third stasimon

Composed in 1969

This work exists in manuscript form only.

Instrumentation: Male choir

\section{dragatakis.info@gmail.com \\ Athens, Greece}

(C2019 by the Dimitris Dragatakis Archive 


\section{DIMITRIS DRAGATAKIS}

\section{ARCHIVE}

Honoring one of Greece's most important modern composers

Request Music 


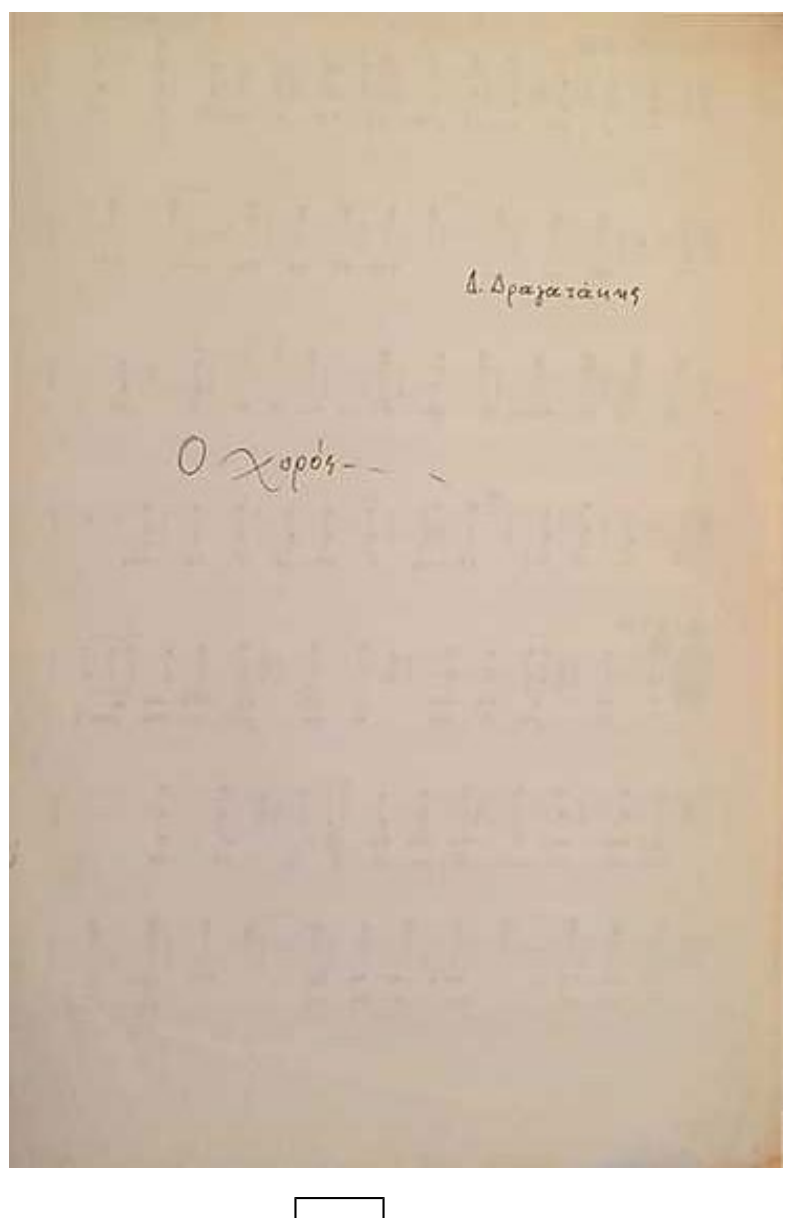

https://www.dimitrisdragatakis.com/product-page/o-choros-the-chorus-euripides-the-heracleidae-fourth-stasimon-1970[19/06/20, 2:17:49 PM] 


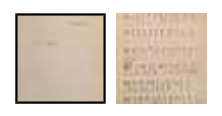

"O choros" ("The chorus"), Euripides, The Heracleidae, fourth stasimon [1970]

"O choros" ("The chorus"), Euripides, The Heracleidae, fourth stasimon Composed in 1970

This work exists in manuscript form only.

Instrumentation: Male choir

\section{dragatakis.info@gmail.com}

\section{Athens, Greece}

@2019 by the Dimitris Dragatakis Archive 


\section{DIMITRIS DRAGATAKIS}

\section{ARCHIVE}

Honoring one of Greece's most important modern composers

Request Music 


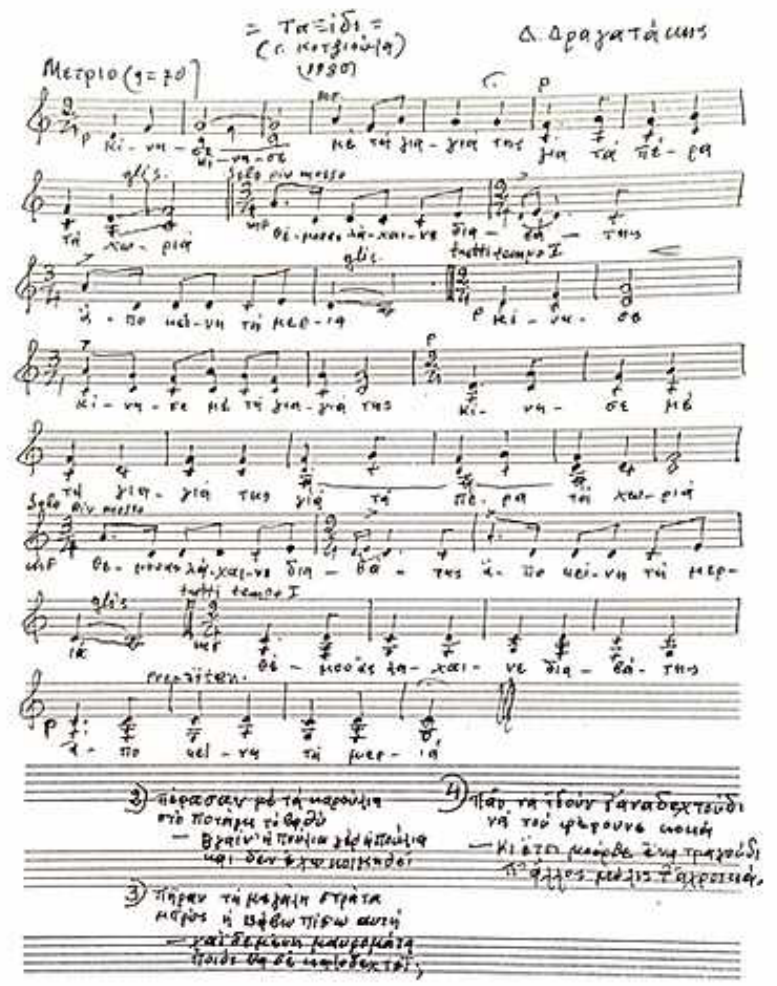




\section{“Taxidi” (“Journey”), G.Kotzioulas (1980)}

"Taxidi” (“Journey"), lyrics by G.Kotzioulas

Composed in 1980

Instrumentation: Choir 


\section{DIMITRIS DRAGATAKIS}

\section{ARCHIVE}

Honoring one of Greece's most important modern composers

Request Music 


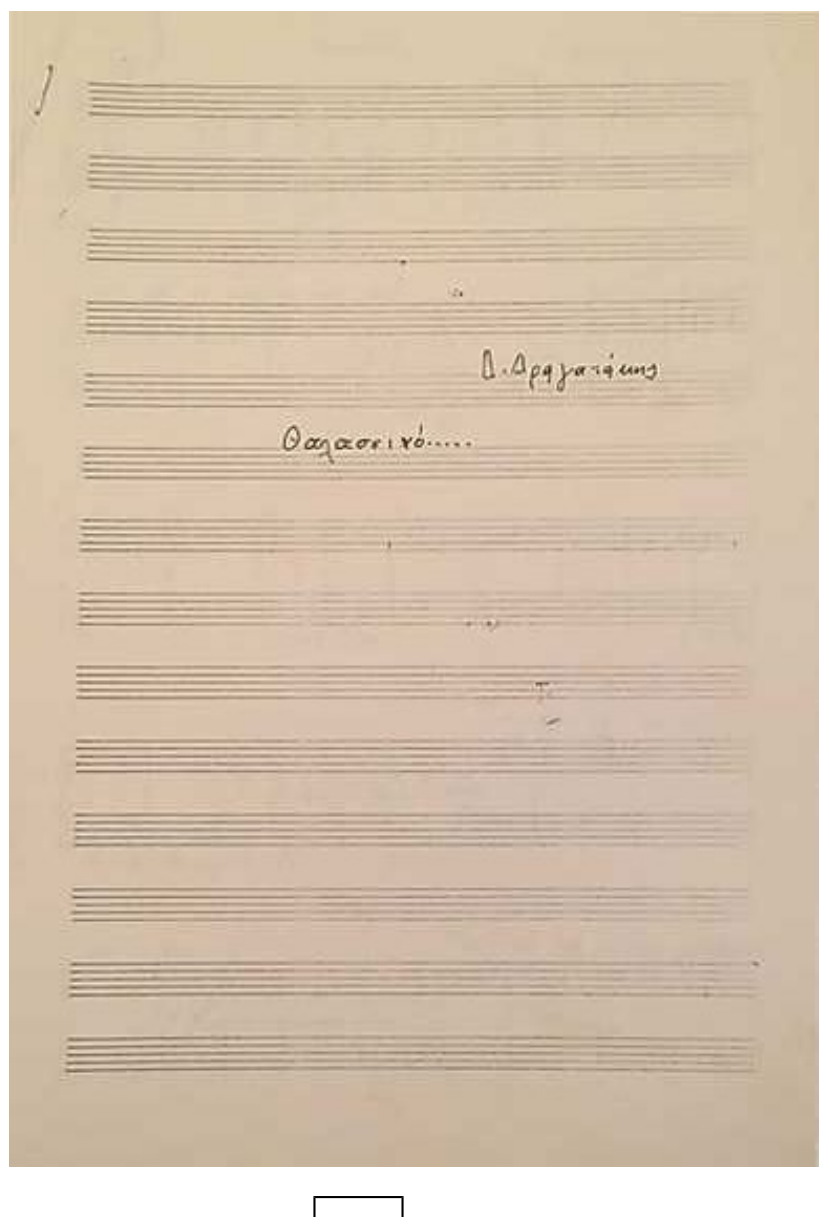

https://www.dimitrisdragatakis.com/product-page/thalassino-marine-1980[19/06/20, 2:17:57 PM]

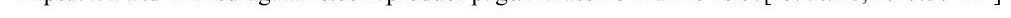




\section{“Thalassino" ("Marine") (1980)}

\section{"Thalassino" ("Marine")}

\section{Composed in 1980}

This work exists in manuscript form only.

Instrumentation: Choir

\section{dragatakis.info@gmail.com}

\section{Athens, Greece}




\section{DIMITRIS DRAGATAKIS}

\section{ARCHIVE}

Honoring one of Greece's most important modern composers

Request Music 


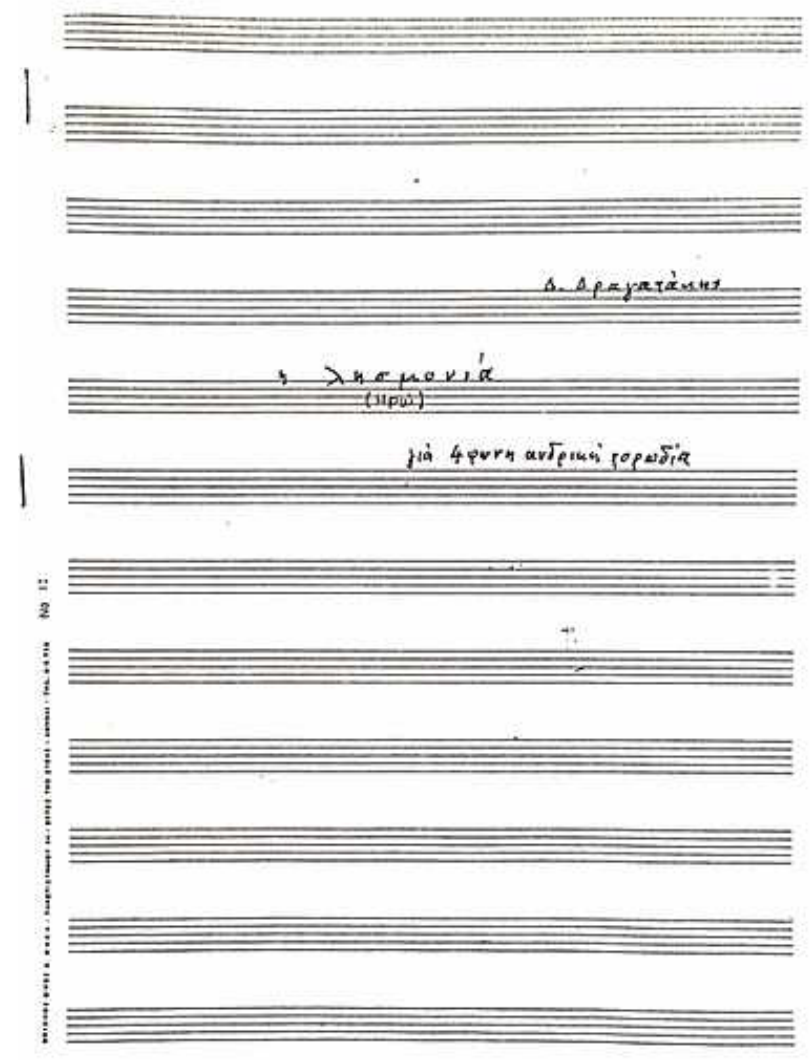

https://www.dimitrisdragatakis.com/product-page/i-lismonia-oblivion-1986[19/06/20, 2:18:02 PM] 


\section{"I lismonia" ("Forgetfulness) (1986)}

\section{"I lismonia” (“Oblivion”)}

\section{Composed in 1986}

This work exists in manuscript form only.

Instrumentation: Choir

\section{dragatakis.info@gmail.com}

\section{Athens, Greece}




\section{DIMITRIS DRAGATAKIS}

\section{ARCHIVE}

Honoring one of Greece's most important modern composers

Request Music 


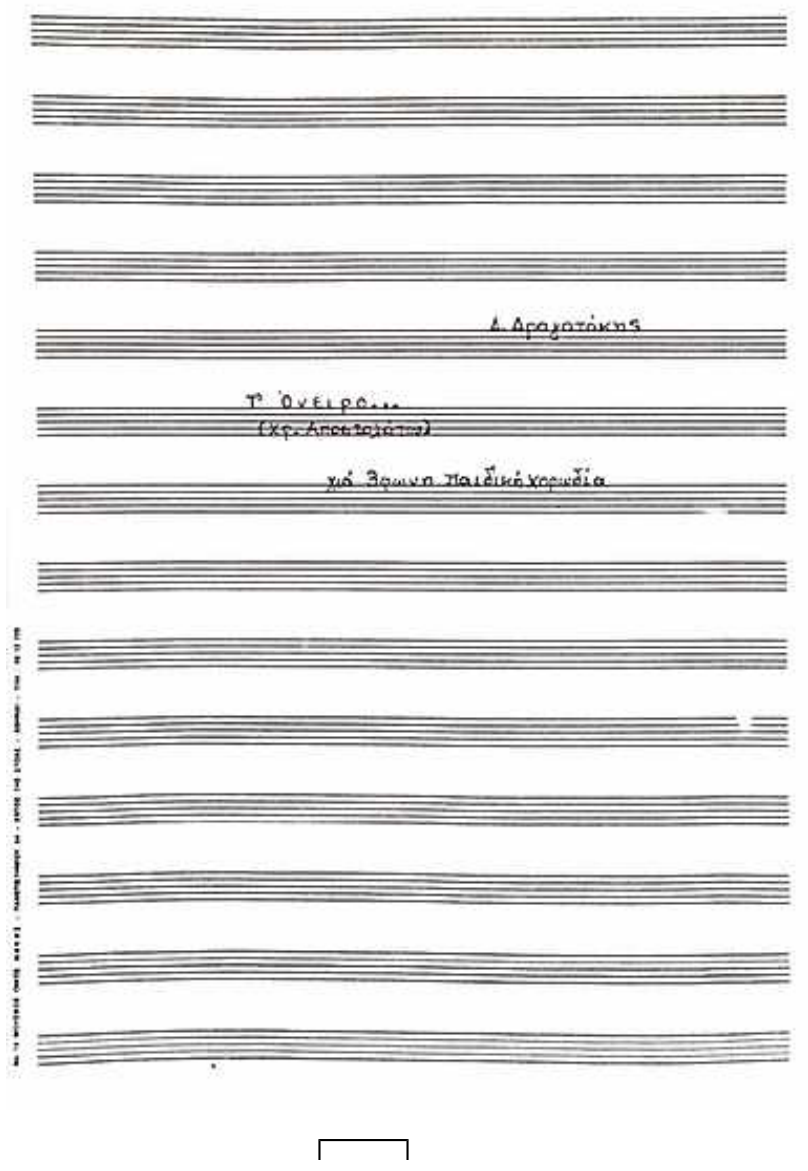

https://www.dimitrisdragatakis.com/product-page/t-oneiro-the-dream-chr-apostolatou-1986[19/06/20, 2:18:06 PM] 


\section{“T' oneiro" ("The dream"), Chr. Apostolatou (1986)}

"T' oneiro" ("The dream"), lyrics by Chr. Apostolatou

\section{Composed in 1986}

This work exists in manuscript form only.

Instrumentation: Choir

\section{dragatakis.info@gmail.com}

\section{Athens, Greece}




\section{DIMITRIS DRAGATAKIS}

\section{ARCHIVE}

Honoring one of Greece's most important modern composers

Request Music 


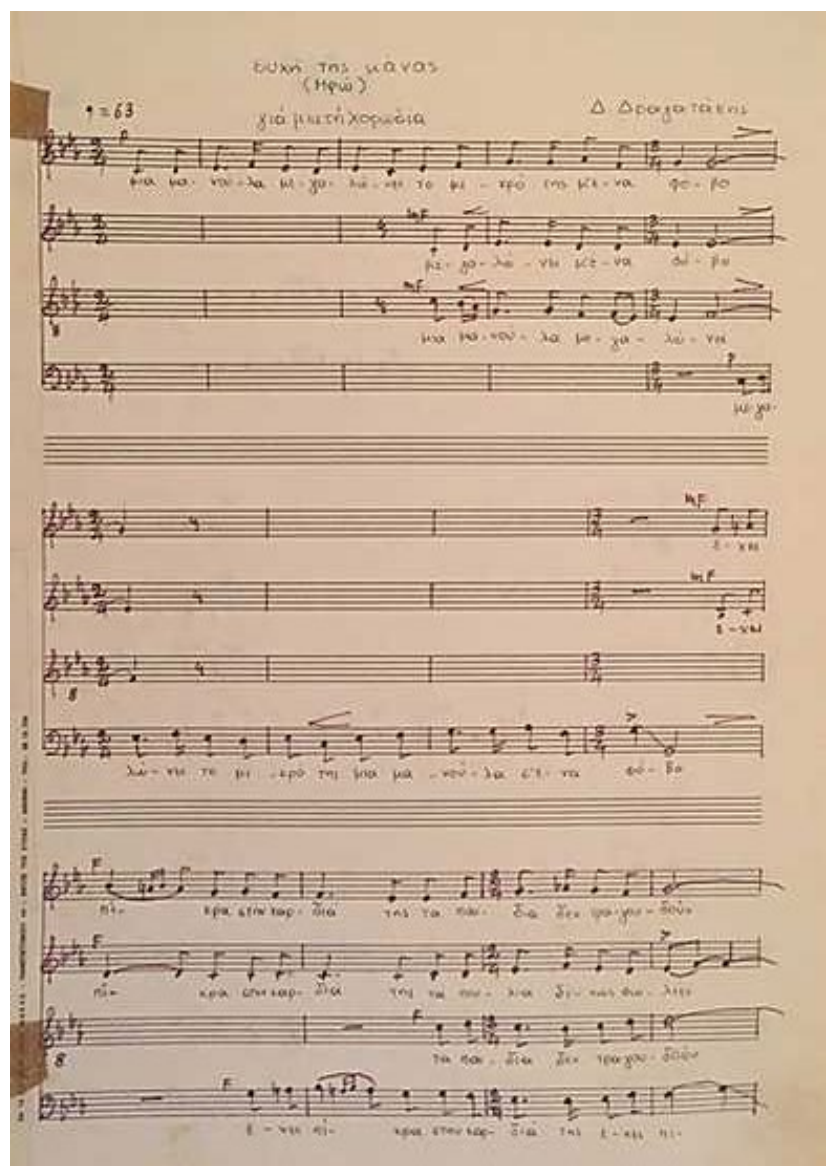

https://www.dimitrisdragatakis.com/product-page/efchi-tis-manas-the-mother-s-wish-1986[19/06/20, 2:18:11 PM] 


\section{"Efchi tis manas" (“The mother's wish") (1986)}

"Efchi tis manas" ("The mother's wish")

Composed in 1986

This work exists in manuscript form only.

Instrumentation: Choir 


\section{DIMITRIS DRAGATAKIS}

\section{ARCHIVE}

Honoring one of Greece's most important modern composers

Request Music 


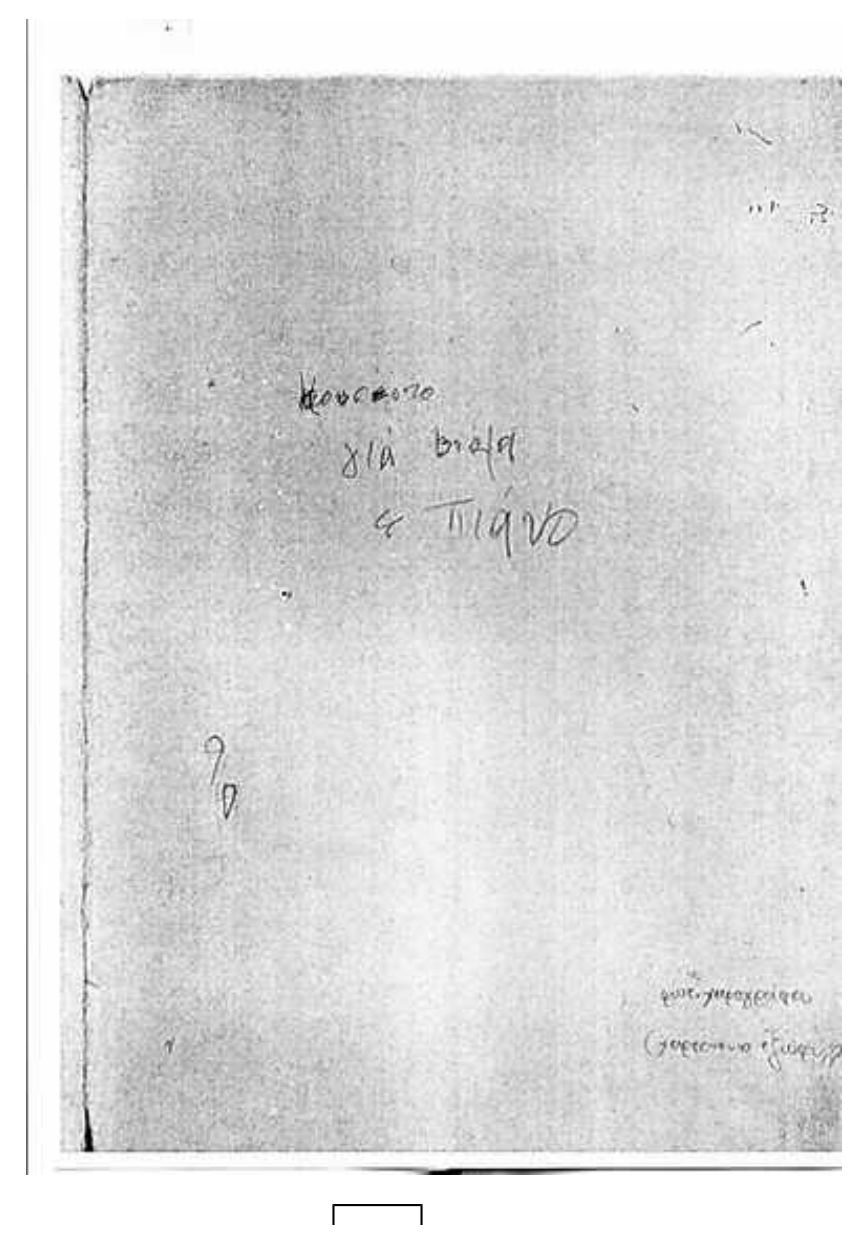

https://www.dimitrisdragatakis.com/product-page/concerto-for-viola-and-piano-manuscript-only-1949-57[19/06/20, 2:18:16 PM] 


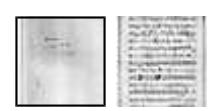

\section{Concerto for Viola and Piano (manuscript only) (1949-57)}

Concerto for Viola

Composed in 1949-57

This work exists in manuscript form only.

Instrumentation: Viola and piano

\section{dragatakis.info@gmail.com}

\section{Athens, Greece}

@2019 by the Dimitris Dragatakis Archive 


\section{DIMITRIS DRAGATAKIS}

\section{ARCHIVE}

Honoring one of Greece's most important modern composers

Request Music 


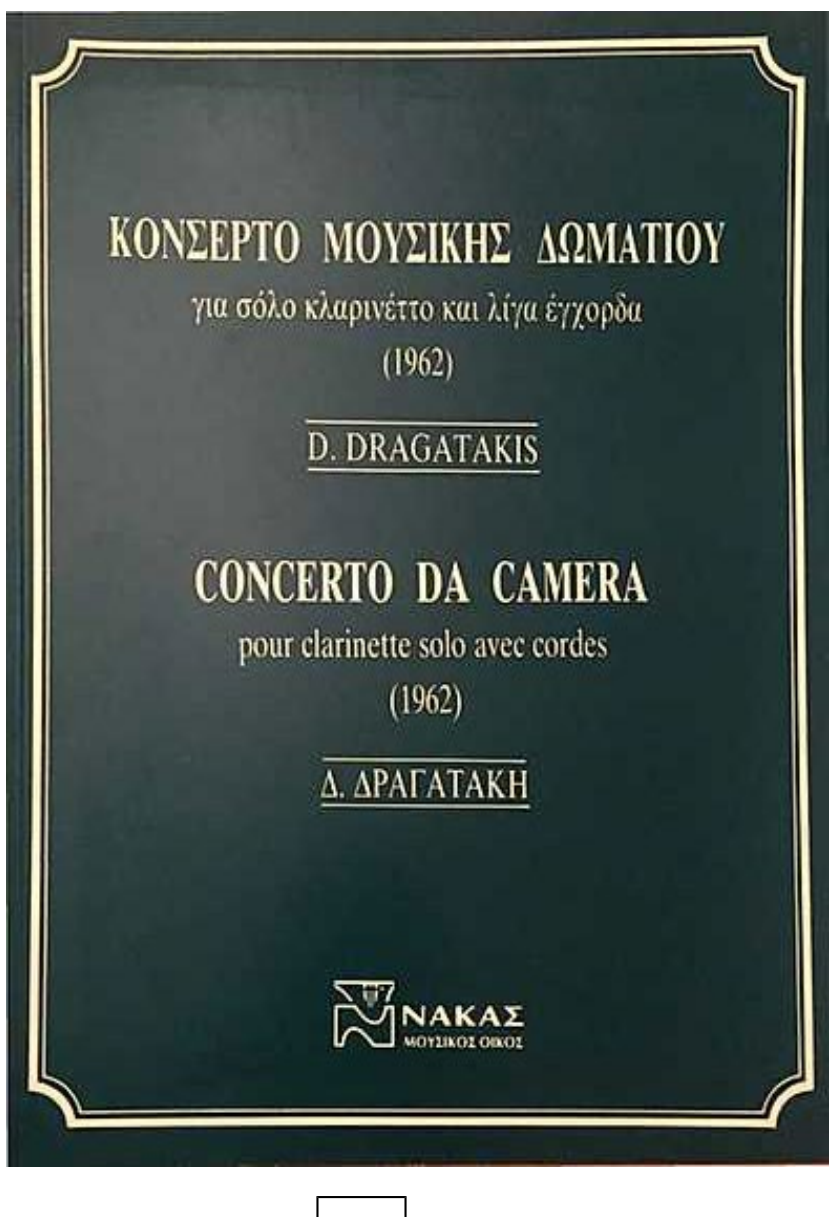




\section{Concertino for Clarinet (1962)}

Concertino for Clarinet

Composed in 1962

Instrumentation: clarinet, string orchestra 


\section{DIMITRIS DRAGATAKIS}

\section{ARCHIVE}

Honoring one of Greece's most important modern composers

Request Music 
D. DRAGATAKIS

\author{
CONCERTINO \\ (1965)
}

For Orchestra and Solo Freuch-HORN

https://www.dimitrisdragatakis.com/product-page/concertino-for-horn-1965[19/06/20, 2:18:26 PM] 


\section{Concertino for Horn (1965)}

\section{Concertino for Horn}

Composed in 1965

Instrumentation: horn, instrumental ensemble 


\section{DIMITRIS DRAGATAKIS}

\section{ARCHIVE}

Honoring one of Greece's most important modern composers

Request Music 
D. DRAGATAKIS

\section{CONCERTO}

\section{for Violino Solo \& orchestra \\ (1969)}




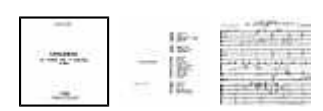

\section{Concerto for Violin (1969)}

Concerto for Violin

Composed in 1969

Instrumentation: violin, string orchestra

\section{Listen now}

Purchase from Nakas Music House (violin and orchestra)

Purchase from Nakas Music House (violin and piano, arranged by Stylianos

Tsakalidis)

\section{dragatakis.info@gmail.com}

\section{Athens, Greece}




\section{DIMITRIS DRAGATAKIS}

\section{ARCHIVE}

Honoring one of Greece's most important modern composers

Request Music 


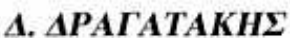

\section{DRAGATAKIS}

\section{Adagio \\ (for string orchestra, Piano}

and Viola Solo)

(1969)

https://www.dimitrisdragatakis.com/product-page/adagio-for-solo-viola-1969[19/06/20, 2:18:35 PM] 


\section{Adagio for solo viola (1969)}

Adagio for solo viola

Composed in 1969

Instrumentation: viola, piano, string orchestra

\section{dragatakis.info@gmail.com}

\section{Athens, Greece}




\section{DIMITRIS DRAGATAKIS}

\section{ARCHIVE}

Honoring one of Greece's most important modern composers

Request Music 


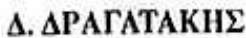

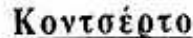

(1972)

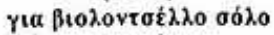

xat oexírea

\section{DRAGATAKIS}

\section{Concert}

(1972)

for V.cello Solo and Orchesira 


\section{Concerto for Cello (1972)}

Concerto for Cello

Composed in 1972

Instrumentation: cello, orchestra

\section{dragatakis.info@gmail.com}

\section{Athens, Greece}




\section{DIMITRIS DRAGATAKIS}

\section{ARCHIVE}

Honoring one of Greece's most important modern composers

Request Music 


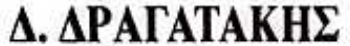

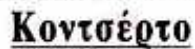 \\ (1973) \\ үıа $0 \mu \pi о \varepsilon$ бódo xat Oexíorea exxópdor}

\section{DRAGATAKIS}

\section{Concert}

(1973)

for Oboe solo

and Siring Orchestra 


\section{Concerto for Oboe (1973)}

Concerto for Oboe

Composed in 1973

Instrumentation: oboe, orchestra

Listen here:

i. Andante

ii. Presto 


\section{DIMITRIS DRAGATAKIS}

\section{ARCHIVE}

Honoring one of Greece's most important modern composers

Request Music 


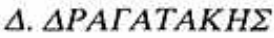

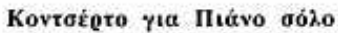

xat oexíareส

(1975.1977)

\section{D.DRAGATAKIS}

\section{Concert for Piano solo}

and orchestra

(1975.197n) 


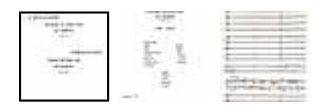

\section{Concerto for Piano (1975-7)}

\section{Concerto for Piano}

Composed in 1975-7

Instrumentation: piano, orchestra

\section{dragatakis.info@gmail.com}

\section{Athens, Greece}




\section{DIMITRIS DRAGATAKIS}

\section{ARCHIVE}

Honoring one of Greece's most important modern composers

Request Music 


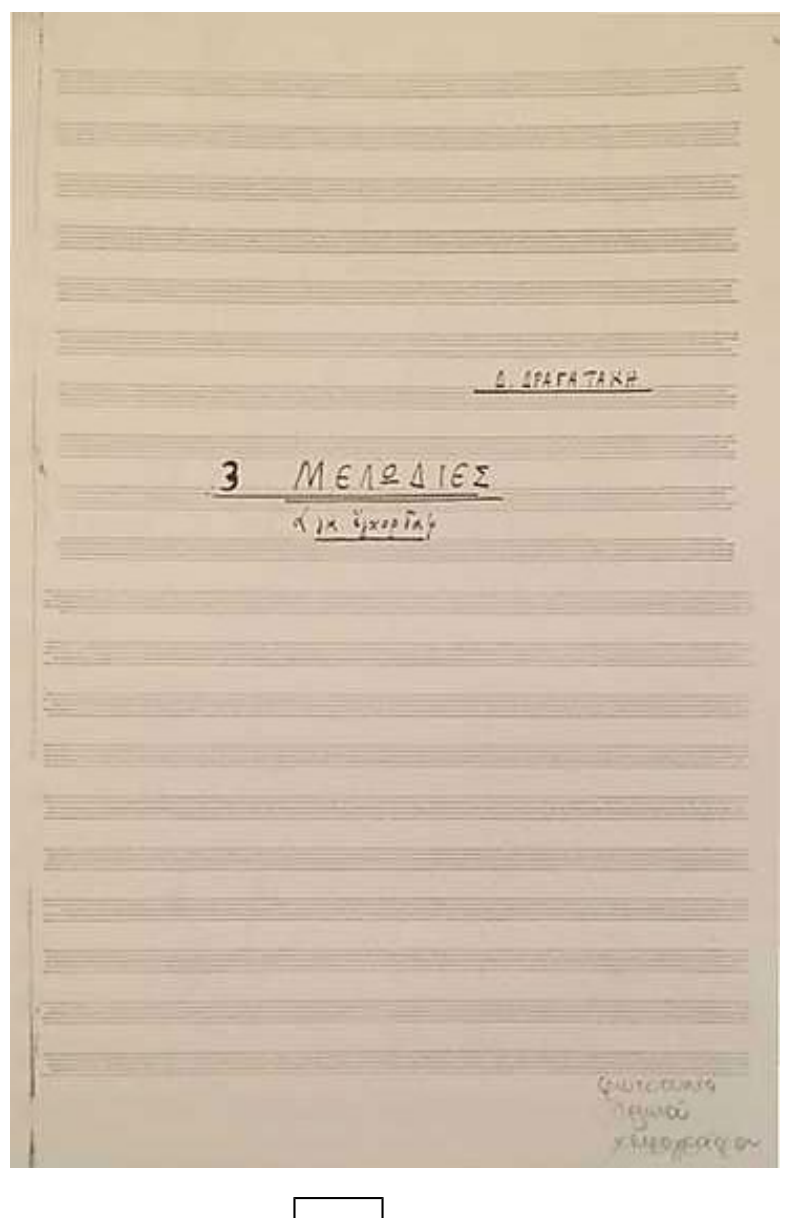

https://www.dimitrisdragatakis.com/product-page/treis-melodies-three-melodies[19/06/20, 2:18:53 PM] 


\section{Treis Melodies (Three melodies)}

Treis Melodies (Three melodies)

Year of composition is estimated between 1949 and 1957

This work exists in manuscript form only.

Instrumentation: String orchestra

\section{dragatakis.info@gmail.com}

\section{Athens, Greece}




\section{DIMITRIS DRAGATAKIS}

\section{ARCHIVE}

Honoring one of Greece's most important modern composers

Request Music 


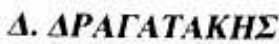

\section{DRAGATAKIS}

- AYPIKA EKITEA -

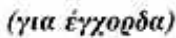

(195s) 


\section{Lyrika Skitsa (Lyric sketches) (1958)}

Lyrika Skitsa (Lyric sketches)

Composed in 1958

Instrumentation: String orchestra

\section{dragatakis.info@gmail.com}

\section{Athens, Greece}




\section{DIMITRIS DRAGATAKIS}

\section{ARCHIVE}

Honoring one of Greece's most important modern composers

Request Music 


\section{$\triangle O K I M I O$}

(1983)

TIA OPXHXTPA

D. Dragatakis

ESSAY

(1958)

HOR ORCHESTRA

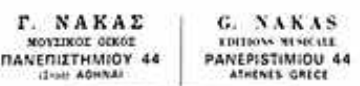

https://www.dimitrisdragatakis.com/product-page/dokimio-essay-1958[19/06/20, 2:19:02 PM] 


\section{Dokimio (Essay) (1958)}

\section{Dokimio (Essay)}

Composed in 1958

Instrumentation: orchestra 


\section{DIMITRIS DRAGATAKIS}

\section{ARCHIVE}

Honoring one of Greece's most important modern composers

Request Music 
A. DPATATAKHI

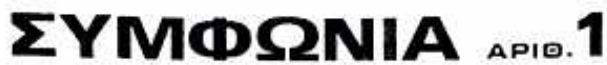

(10se).

- -

D. DRAGATAKIS

\section{SYMPHONY no 1}

r. NAKAE C. NAKAS

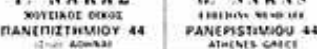

https://www.dimitrisdragatakis.com/product-page/symphony-no-1-1959[19/06/20, 2:19:06 PM] 


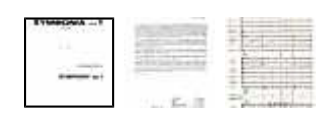

\section{Symphony No. 1 (1959)}

Symphony No. 1

Composed in 1959

Instrumentation: orchestra

\section{Listen now}




\section{DIMITRIS DRAGATAKIS}

\section{ARCHIVE}

Honoring one of Greece's most important modern composers

Request Music 


\section{Dragatakis}

\section{SYMPHONY NO 2}

$$
\text { แมด }
$$

ANDลNIE-SOSTENuto ALIECRETHO- MSOERATO

tento-atiegso

(1)




\section{Symphony No. 2 (1960)}

Symphony No. 2

Composed in 1960

Instrumentation: orchestra

\section{dragatakis.info@gmail.com}

\section{Athens, Greece}




\section{DIMITRIS DRAGATAKIS}

\section{ARCHIVE}

Honoring one of Greece's most important modern composers

Request Music 
D. DRAGATAKIS

\section{SYMPHONIE № 3 (1964)}




\section{Symphony No. 3, Mikri (Little) (1964)}

Symphony No. 3, Mikri (Little)

Composed in 1964

Instrumentation: orchestra 


\section{DIMITRIS DRAGATAKIS}

\section{ARCHIVE}

Honoring one of Greece's most important modern composers

Request Music 


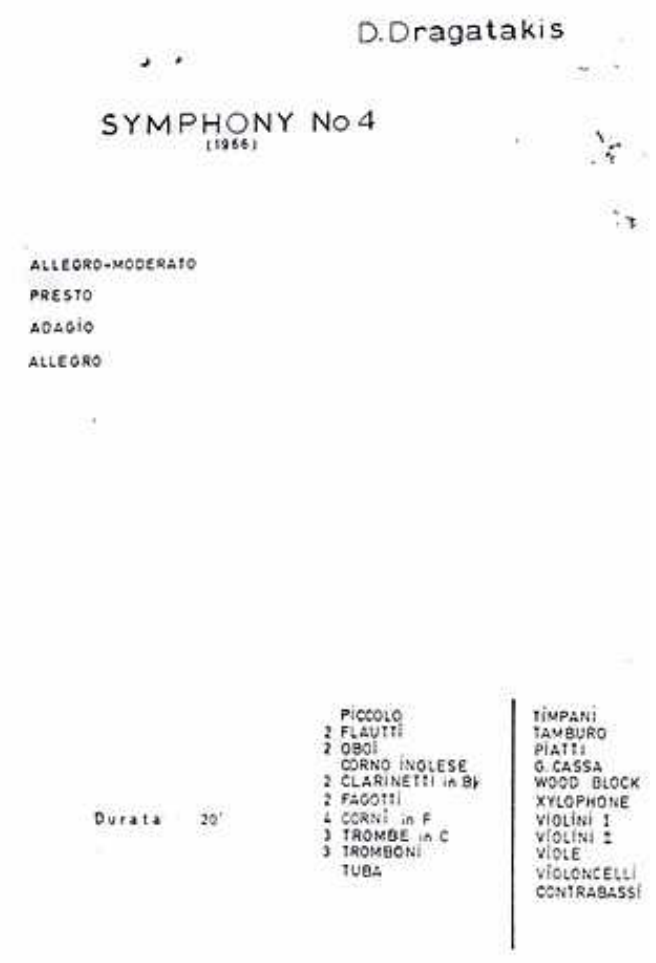

https://www.dimitrisdragatakis.com/product-page/symphony-no-4-1966[19/06/20, 2:19:22 PM] 


\section{Symphony No. 4 (1966)}

Symphony No. 4

Composed in 1966

Instrumentation: orchestra

\section{dragatakis.info@gmail.com}

\section{Athens, Greece}




\section{DIMITRIS DRAGATAKIS}

\section{ARCHIVE}

Honoring one of Greece's most important modern composers

Request Music 


\section{DRAGATAKIS}

\section{D. АРАГАТАKH $\Sigma$}

\section{FOUR SKETCHES}

\section{FOR THREE STRING GROUPS}

(1966-1968) 


\section{Tessera Skitsa (Four sketches) (1966-68)}

Tessera Skitsa (Four sketches)

Composed in 1966-68

Instrumentation: String orchestra (divided in three parts) 


\section{DIMITRIS DRAGATAKIS}

\section{ARCHIVE}

Honoring one of Greece's most important modern composers

Request Music 


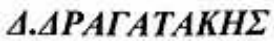

\section{IETAAOYAA \\ (mpo rov 1957)}

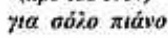

\section{D.DRAGATAKIS}

\section{PAPILLON}

(before 1957)

for solo piano

https://www.dimitrisdragatakis.com/product-page/petalouda-papillon-for-solo-piano[19/06/20, 2:19:31 PM] 


\section{Petalouda (Papillon) for Solo Piano}

Petalouda (Papillon) for Solo Piano

Composition year estimated before 1940

Instrumentation: Solo piano 


\section{DIMITRIS DRAGATAKIS}

\section{ARCHIVE}

Honoring one of Greece's most important modern composers

Request Music 


\section{NOETANTIA}

IIA IIANO

r. NAKAE | C. NAKAS

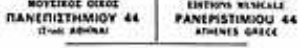




\section{Nostalgia (Nostalgia) for Solo Piano}

Nostalgia (Nostalgia) for Solo Piano

Composition year estimated to be 1940

Instrumentation: Solo piano

\section{Listen now}

\section{Purchase from Nakas Music House (Nostalgia)}

Purchase from Nakas Music House (Complete Solo Piano Works)

\section{dragatakis.info@gmail.com}

\section{Athens, Greece}




\section{DIMITRIS DRAGATAKIS}

\section{ARCHIVE}

Honoring one of Greece's most important modern composers

Request Music 


\title{
$\triangle$. $\triangle$ PAГATAKH
}

\section{MIKPH}

\section{MחA $\triangle A$ ANTA}

\author{
IIA IIANO
}

\section{PETITE BALLADE \\ POUR. PIANO}

PAR D. DRAGATÁKIS

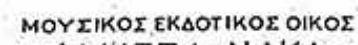

DINITITA NAKA

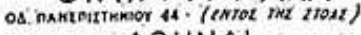

- AOHNAI - 


\section{Mikri Balanta (Petite Ballade) for Solo Piano (1949)}

Mikri Balanta (Petite Ballade) for Solo Piano

Composed in 1949

Instrumentation: Solo piano

\section{Listen now}




\section{DIMITRIS DRAGATAKIS}

\section{ARCHIVE}

Honoring one of Greece's most important modern composers

Request Music 


\section{$\triangle . \triangle$ РАГАТАKH}

\section{SONATINA \\ № 1}

POUR PIANO

()

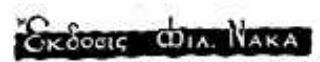

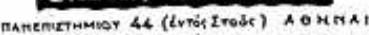




\section{Sonatina No. 1 for Solo Piano (1961)}

Sonatina No. 1 for Solo Piano

Composed in 1961

Instrumentation: Solo piano

Listen here:

i. Moderato

ii. Larghetto

iii. Allegro

Purchase from Nakas Music House (Complete Solo Works for Piano)

\section{dragatakis.info@gmail.com \\ Athens, Greece}

(C2019 by the Dimitris Dragatakis Archive 


\section{DIMITRIS DRAGATAKIS}

\section{ARCHIVE}

Honoring one of Greece's most important modern composers

Request Music 


\section{SOWATINA NO 2}

For piano solo

https://www.dimitrisdragatakis.com/product-page/sonatina-no-2-for-solo-piano-1963[19/06/20, 2:19:50 PM] 


\section{Sonatina No. 2 for Solo Piano (1963)}

Sonatina No. 2 for Solo Piano

Composed in 1963

Instrumentation: Solo piano

Listen here:

i. Allegro - Moderato - Allegro

ii. Largo

iii. Vivo

Purchase from Nakas Music House (Sonatina No. 2)

Purchase from Nakas Music House (Complete Solo Piano Works)

$\$ 1.00$

dragatakis.info@gmail.com

Athens, Greece

@2019 by the Dimitris Dragatakis Archive 


\section{DIMITRIS DRAGATAKIS}

\section{ARCHIVE}

Honoring one of Greece's most important modern composers

Request Music 


\section{ANTIKES}

For solo piano 


\section{Antikes (Antiques) for Solo Piano (1972)}

Antikes (Antiques) for Solo Piano

Composed in 1972

Instrumentation: Solo piano

Listen here:

i. Largo

ii. Allegretto

iii. Allegro

iv. Moderato

v. Molto sostenuto

vi. Allegretto

vii. Presto

viii. Adagio 


\section{DIMITRIS DRAGATAKIS}

\section{ARCHIVE}

Honoring one of Greece's most important modern composers

Request Music 


\section{ANA $\triangle P O M E \Sigma$ \\ II \\ (ANADROMES II) \\ (B97)}

Solo Piano 


\section{Anadromes II (Retrospections II) for Solo Piano (1977)}

Anadromes II (Retrospections II) for Solo Piano

Composed in 1977

Instrumentation: Solo piano

\section{Listen now}

\section{Purchase from Nakas Music House (Anadromes II)}

Purchase from Nakas Music House (Complete Solo Piano Works)

\section{dragatakis.info@gmail.com}

\section{Athens, Greece}




\section{DIMITRIS DRAGATAKIS}

\section{ARCHIVE}

Honoring one of Greece's most important modern composers

Request Music 


\section{ETUDE No 1 Enowsin No 1}

SOLO PIANO

https://www.dimitrisdragatakis.com/product-page/spoudi-i-etude-i-for-solo-piano-1981[19/06/20, 2:20:03 PM] 


\section{Spoudi I (Etude I) for Solo Piano (1981)}

Spoudi I (Etude I) for Solo Piano

Composed in 1981

Instrumentation: Solo piano

\section{Listen now}

\section{Purchase from Nakas Music House (Spoudi I)}

Purchase from Nakas Music House (Complete Solo Piano Works)

\section{dragatakis.info@gmail.com}

\section{Athens, Greece}




\section{DIMITRIS DRAGATAKIS}

\section{ARCHIVE}

Honoring one of Greece's most important modern composers

Request Music 


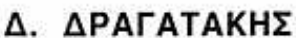

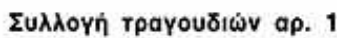

( $\mu \varepsilon$ cuvossia mávou) 


\section{Collection of Songs, op. 1 (2020)}

This collection of songs was put together before Dimitris Dragatakis passed away in 2001. The edition is meant to be published by Nakas in 2020. Please get in touch if you'd like individual works listed below or the Dragatakis edition of the collection of songs.

“Dyo peristeria perasan” (“Two doves passed by”), D. Dragatakis (1980) - voice and piano “Echei apops' ena fengari” (“There’s a moon tonight”), K. Kontoulēs (1979 ) - voice and piano

"Isoun mikri" ("You were [a] young" [girl]), V. Theodorou (1982) - voice and piano

"Piano nero" (“Holding water”), V. Theodorou (1982) - voice and piano

“T’ Aprili to fengari” (“April's moon”), V. Theodorou (1982) - voice and piano

"Mana" ("Mother"), V. Theodorou (1981) - voice and piano

"I treli rodia" ("The crazy pomegranate tree"), Od. Elytis (1981) - voice and piano

"Ochi ta roda" ("Not the roses"), G. Drosinis (1971) - voice and piano

"De thelo tou kissou” (“I don't want the ivy's" [deceiving height]), G. Drosinis (1971) voice and piano

"Me poia lachtara" (“With which longing”), G. Drosinis (1971) - voice and piano

"Na se prosmeno" (“To await for you"), G. Drosinis (1971) - voice and piano

"I balanta tis Gkouentolin" (“Gwendolin’s ballad”), J. Anouilh, Becket (1968) - voice and piano, guitar, or lute

"Nanourisma" (“Lullaby”), D. Dragatakis (1980) - voice and piano

“Poulia ein' ta chronia” ('Years are like birds'), F. Angoules (1961) - voice and piano

"Vithleem” (“Bethlehem”), D. Dragatakis (1980) - bass and piano

"Tsakizo tis lianes elies" (“Cracking the thin olives"), V. Theodorou (1961) - voice and piano

'Ta prot'asteria' (“The first stars”), F. Angoules (1961) - voice and piano

Monologos ar. 1 (Monologue no.1), D. Dragatakis (1979) - acapella voice

“Vithleem” (“Bethlehem”), D. Dragatakis (1980) - for baritione and piano 


\section{dragatakis.info@gmail.com}

\section{Athens, Greece}

@2019 by the Dimitris Dragatakis Archive 


\section{DIMITRIS DRAGATAKIS}

\section{ARCHIVE}

Honoring one of Greece's most important modern composers

Request Music 


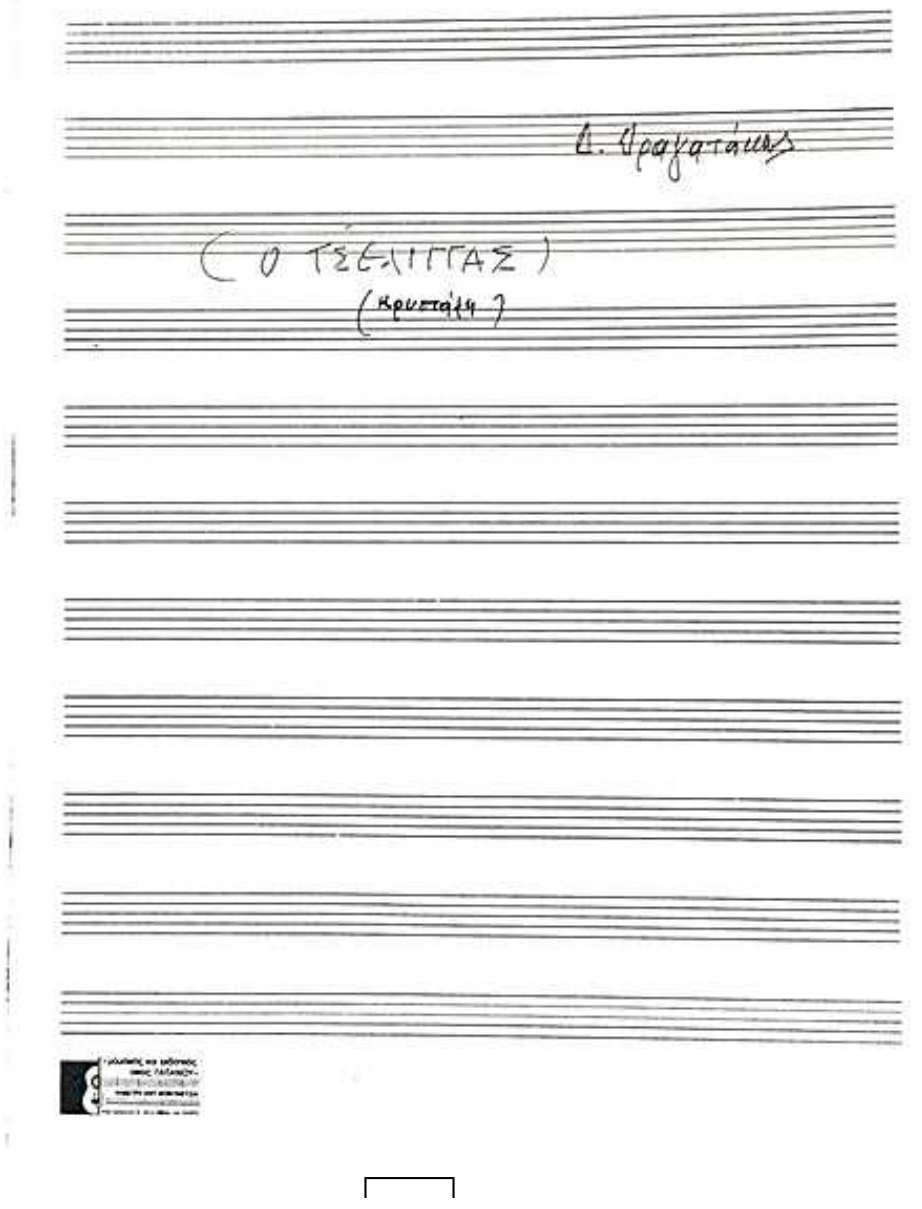

https://www.dimitrisdragatakis.com/product-page/o-tseligkas-the-chief-shepherd-k-krystallis-estimated-1942-9[19/06/20, 2:20:14 PM] 


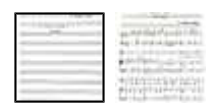

'O tseligkas' (“The chief shepherd”), K. Krystallis (estimated 1942-9)

'O tseligkas' ("The chief shepherd"), K. Krystallis

Year of composition is estimated between 1942-49

This work exists in manuscript form only.

Instrumentation: voice and piano

\section{dragatakis.info@gmail.com}

\section{Athens, Greece}

@2019 by the Dimitris Dragatakis Archive 


\section{DIMITRIS DRAGATAKIS}

\section{ARCHIVE}

Honoring one of Greece's most important modern composers

Request Music 


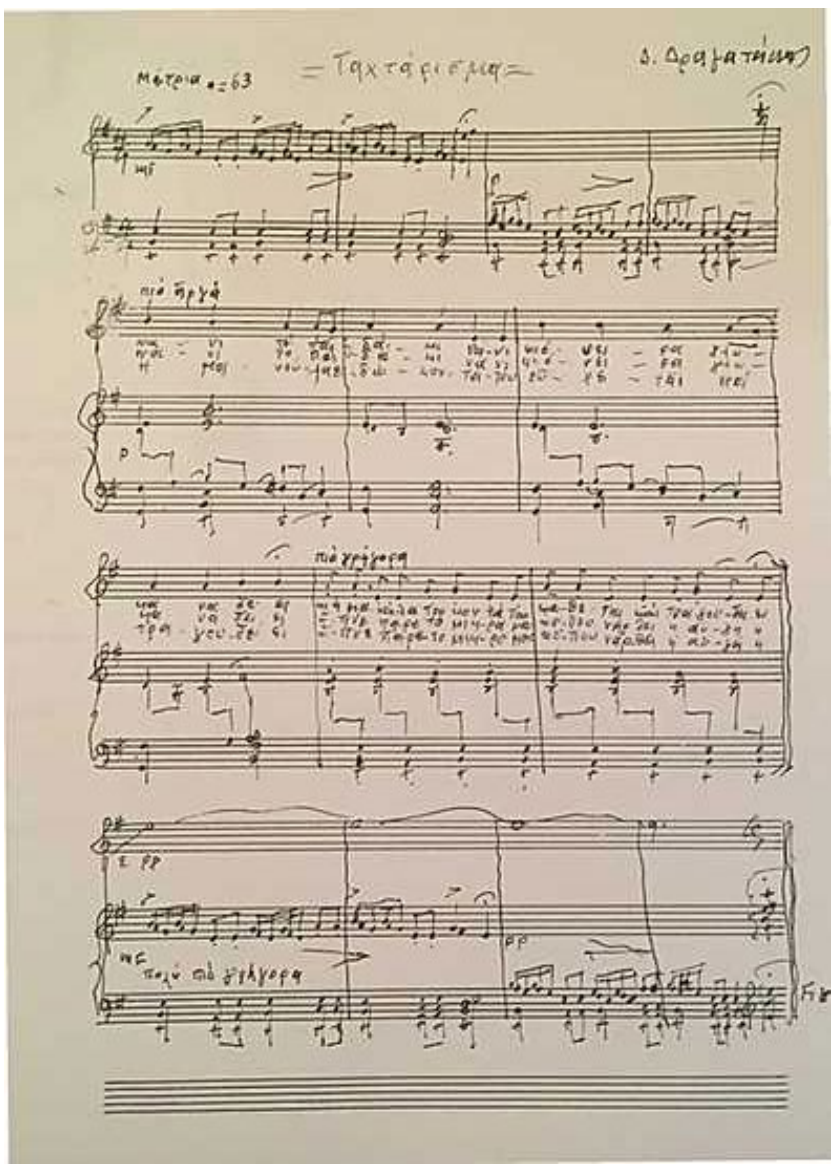




\section{"Tachtarisma" ("Dandling song") [on traditional verses]} (estimated 1942-9)

"Tachtarisma" ("Dandling song") [on traditional verses]

Year of composition is estimated between 1942-49

This work exists in manuscript form only.

Instrumentation: voice and piano

\section{dragatakis.info@gmail.com \\ Athens, Greece}

(C2019 by the Dimitris Dragatakis Archive 


\section{DIMITRIS DRAGATAKIS}

\section{ARCHIVE}

Honoring one of Greece's most important modern composers

Request Music 


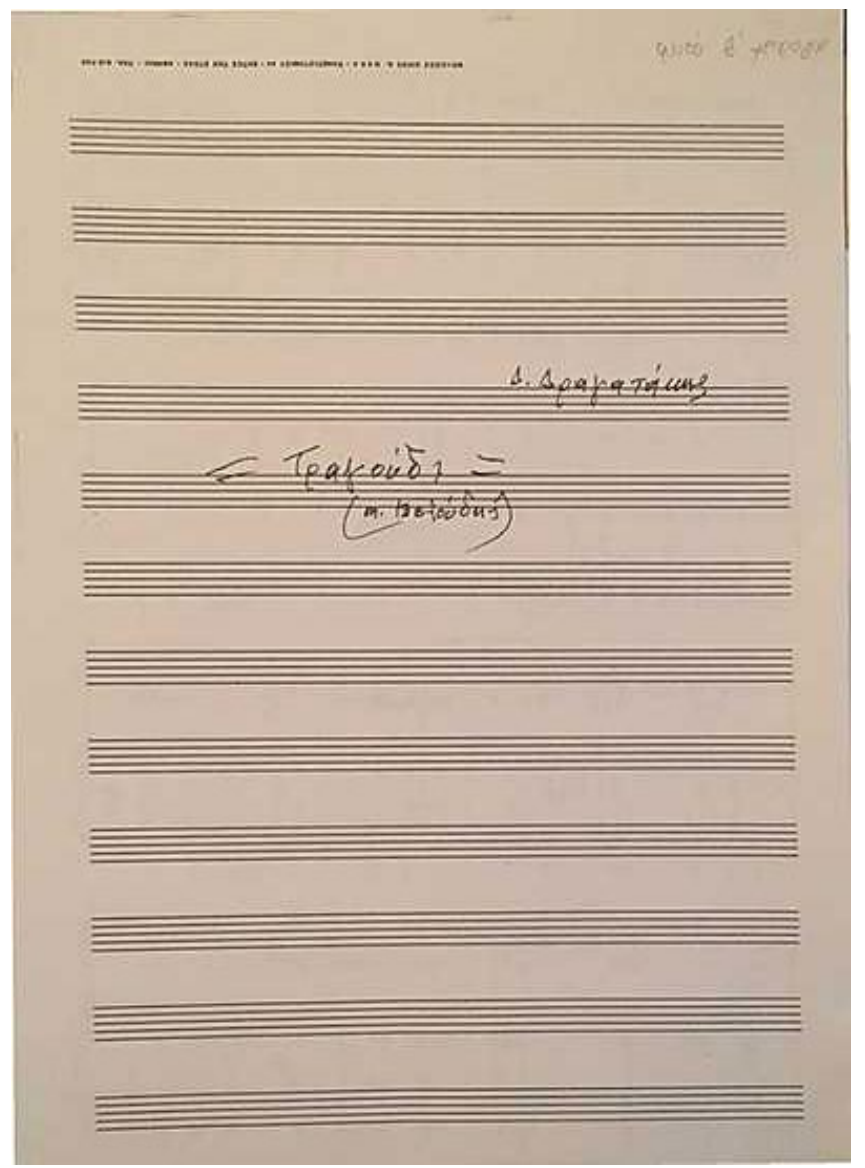

https://www.dimitrisdragatakis.com/product-page/tragoudi-song-m-veloudis-estimated-1942-9[19/06/20, 2:20:23 PM]

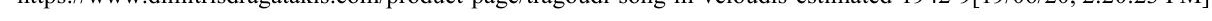




\section{“Tragoudi” (“Song”), M. Veloudis (estimated 1942-9)}

"Tragoudi" ("Song"), M. Veloudis

Year of composition is estimated between 1942-49

This work exists in manuscript form only.

Instrumentation: voice and piano

\section{dragatakis.info@gmail.com}

\section{Athens, Greece}




\title{
DIMITRIS DRAGATAKIS
}

\section{ARCHIVE}

Honoring one of Greece's most important modern composers

\author{
Request Music
}




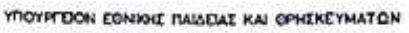

MOTEIKAN EKSOCEII

\section{5}

EAAHNIKA TPAГOYAIA

TIA TPATOYAI KAI MIANO

AQHNAI 1967 


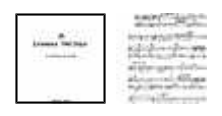

"Tsakizo tis lianes elies" ("Cracking the thin olives"), V. Theodorou (1961)

"Tsakizo tis lianes elies" ("Cracking the thin olives"), V. Theodorou Composed in 1961

Instrumentation: Voice and piano

\section{dragatakis.info@gmail.com \\ Athens, Greece}

○2019 by the Dimitris Dragatakis Archive 


\section{DIMITRIS DRAGATAKIS}

\section{ARCHIVE}

Honoring one of Greece's most important modern composers

Request Music 

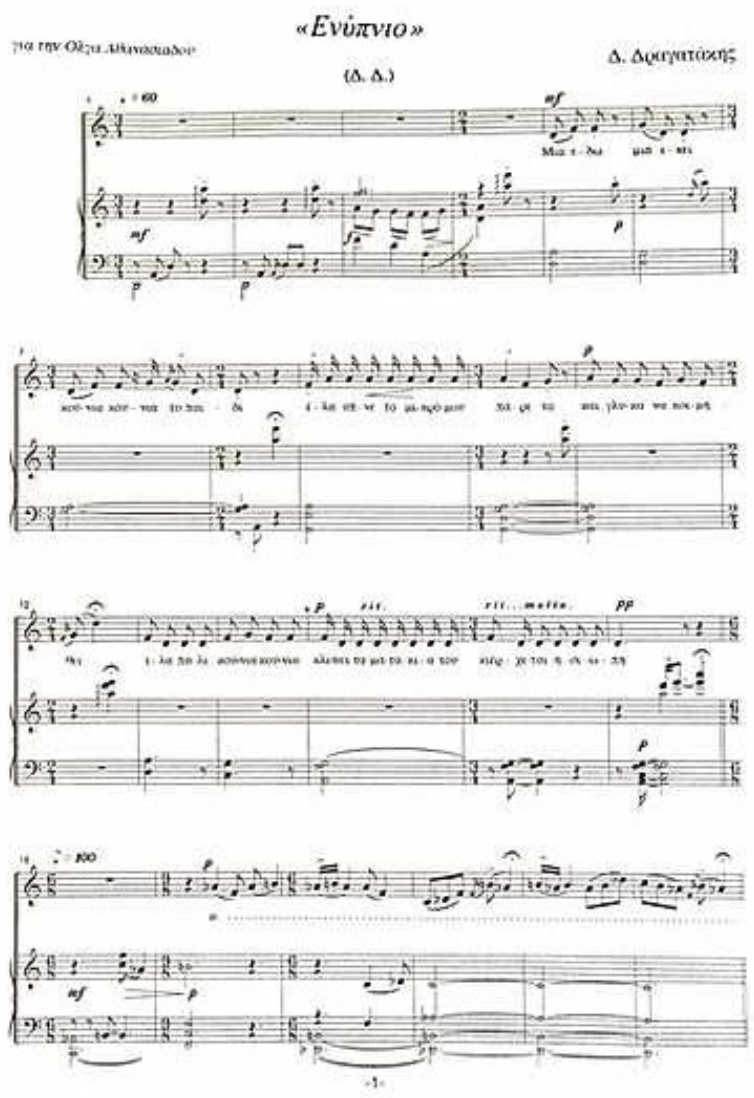


\section{"Enypnio" (“While Asleep"), D.Dragatakis (2000)}

"Enypnio" (“While Asleep”), D.Dragatakis

Composed in 2000

Instrumentation: voice and piano

\section{dragatakis.info@gmail.com}

\section{Athens, Greece}

@2019 by the Dimitris Dragatakis Archive 


\section{DIMITRIS DRAGATAKIS}

\section{ARCHIVE}

Honoring one of Greece's most important modern composers

Request Music 


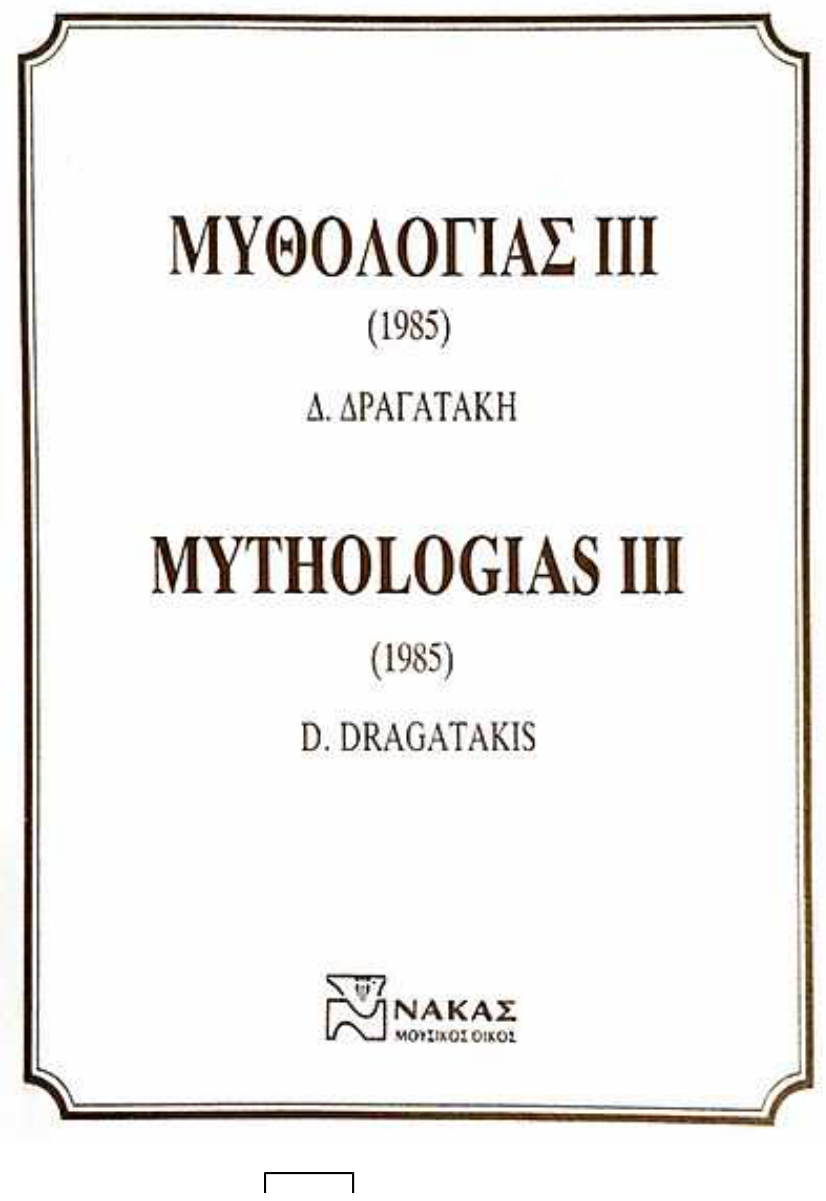




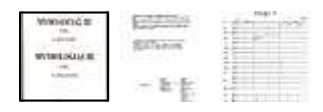

\section{Mythologias III (Mythology's III), Euripides (1985)}

Mythologias III (Mythology's III), Euripides

Composed in 1985

Instrumentation: Soprano and orchestra 


\section{Appendix 2: Concerto for Viola manuscripts}

This appendix includes the manuscripts for the Concerto for Viola's orchestra score and piano reduction. There are links below if the reader would like to access these PDFs separately.

Concerto for Viola orchestra manuscript

https://drive.google.com/file/d/1qcQ8Qy1ua8UhtzJ4quSoFsPkyaX4 WbL/view?usp= sharing

Concerto for Viola piano reduction manuscript

https://drive.google.com/file/d/1V414DLKQPUFYp7I FD8CA6yaRWkeD4xZ/view?u $\underline{s p=s h a r i n g}$ 


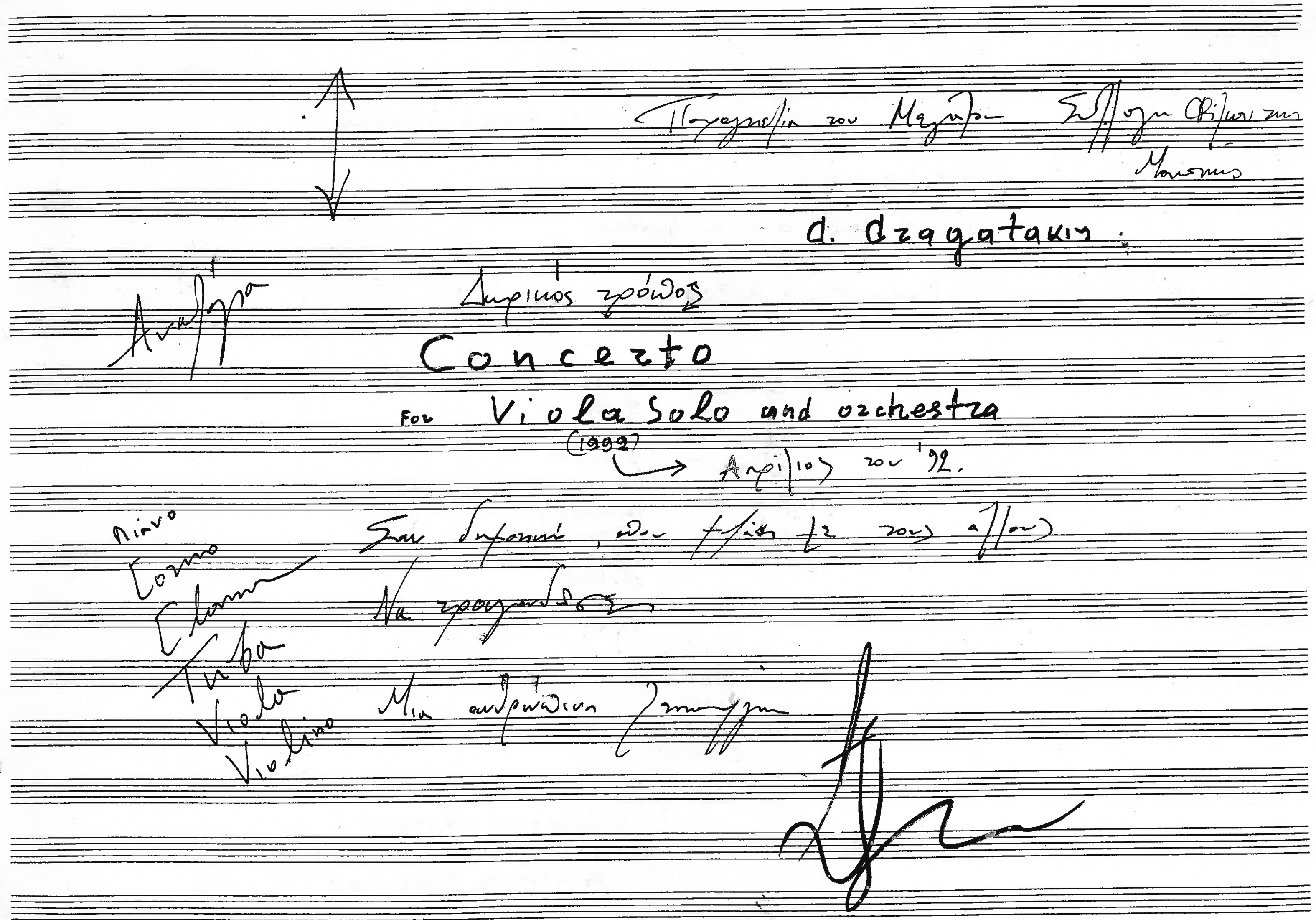




\section{Dragentakis}

\section{Concerto}

\section{Fon Violor 30 lo and ozchestra}

\section{Moderoto - indentino - freeg=o}

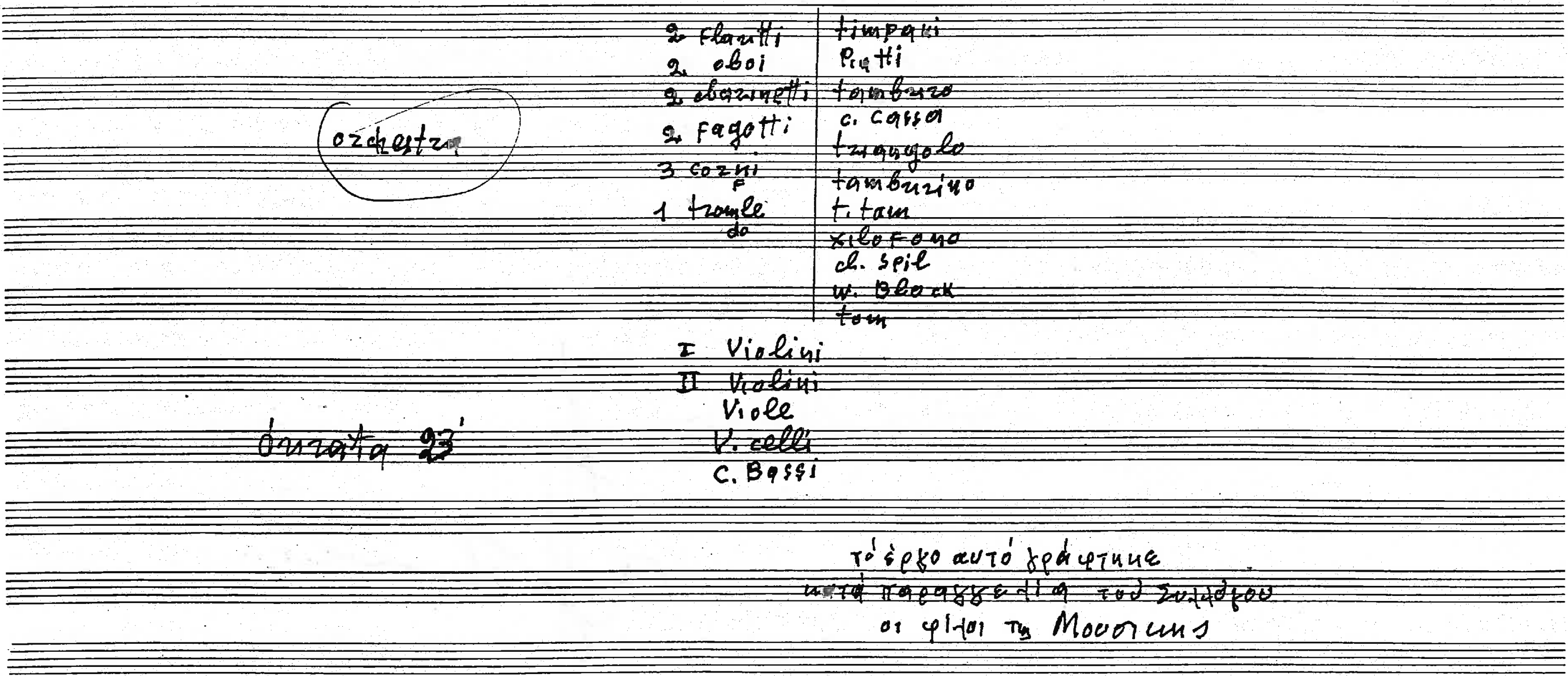




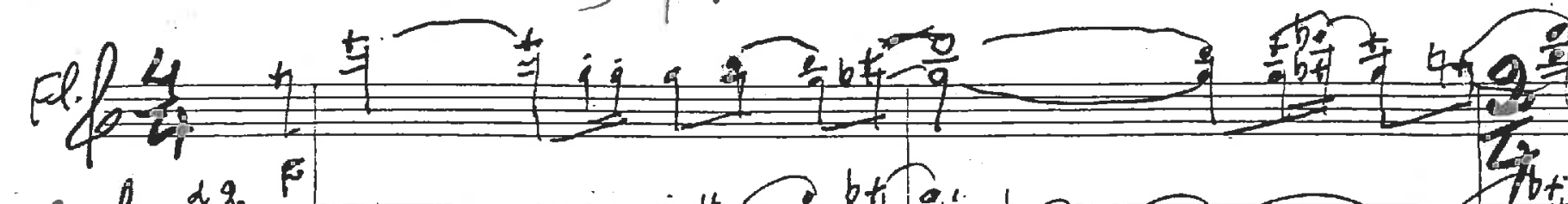
$x_{6+6}$

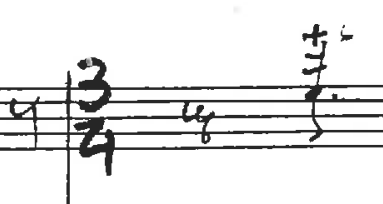
t. $2 q \frac{5}{2}$

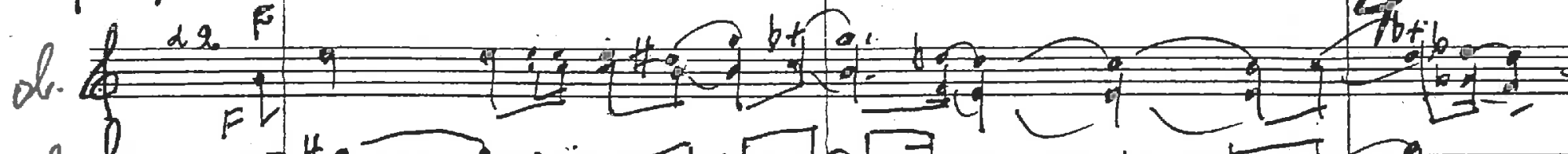
$l_{B} F_{2}$

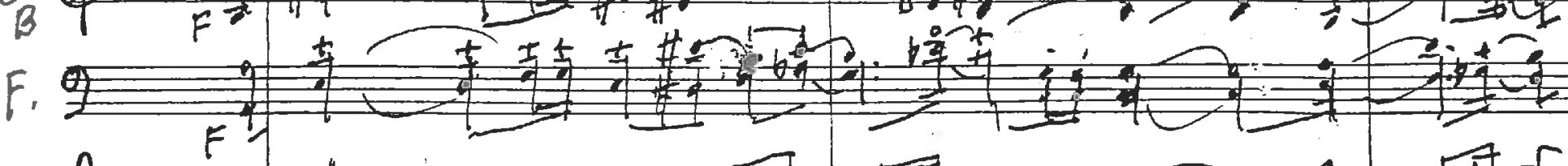
cor. $t_{d 0}$

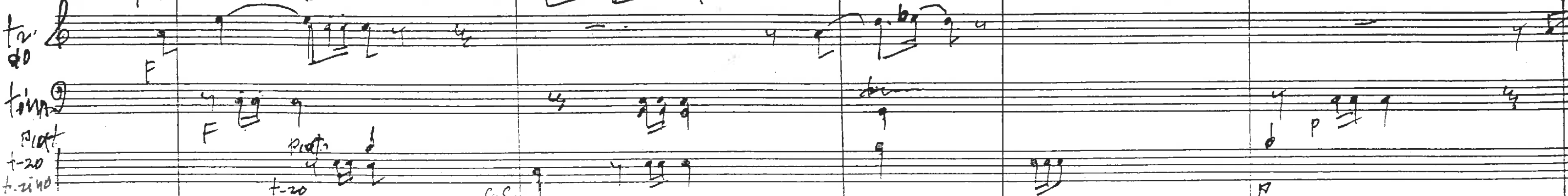

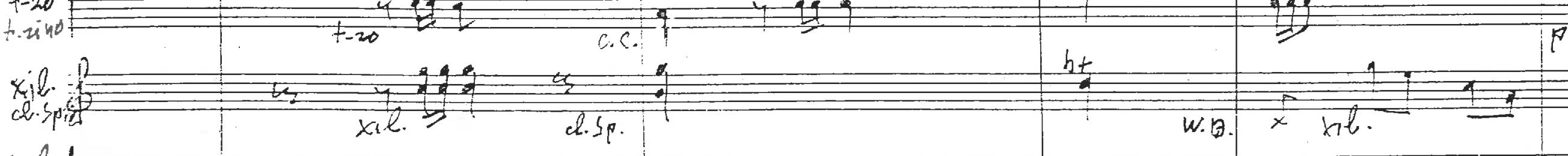
Sedo

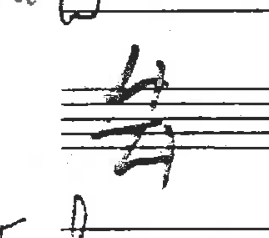

I , .

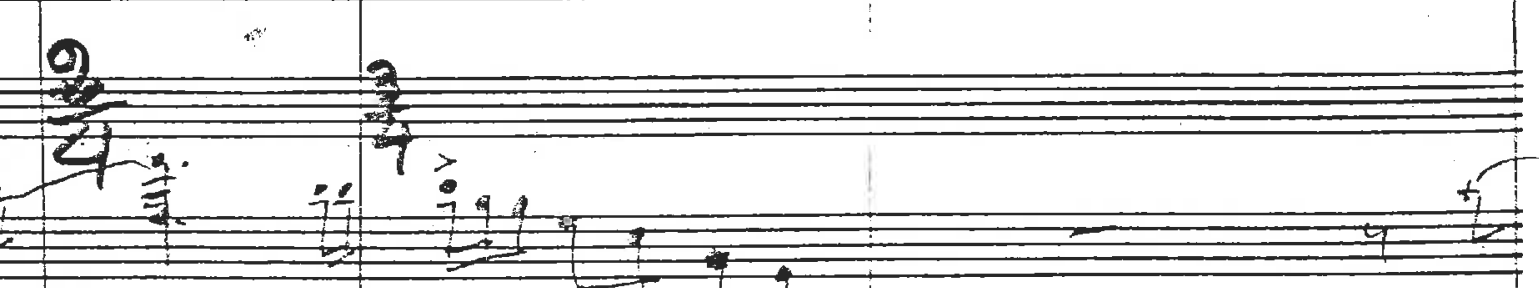

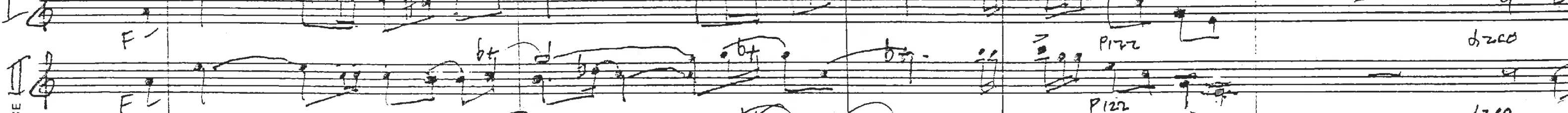

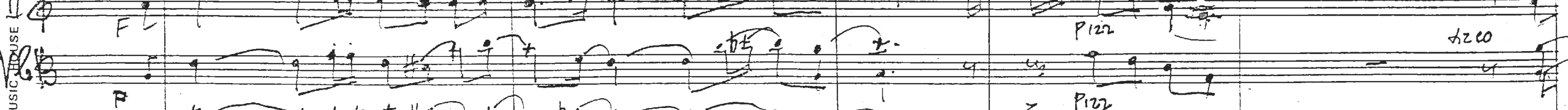

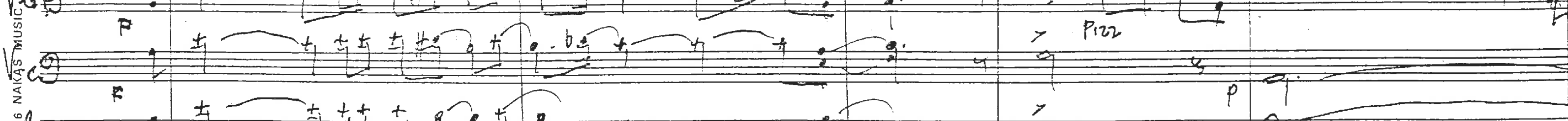

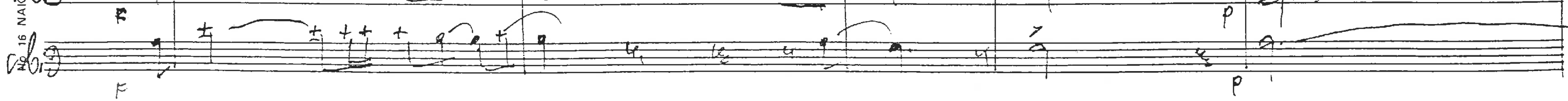




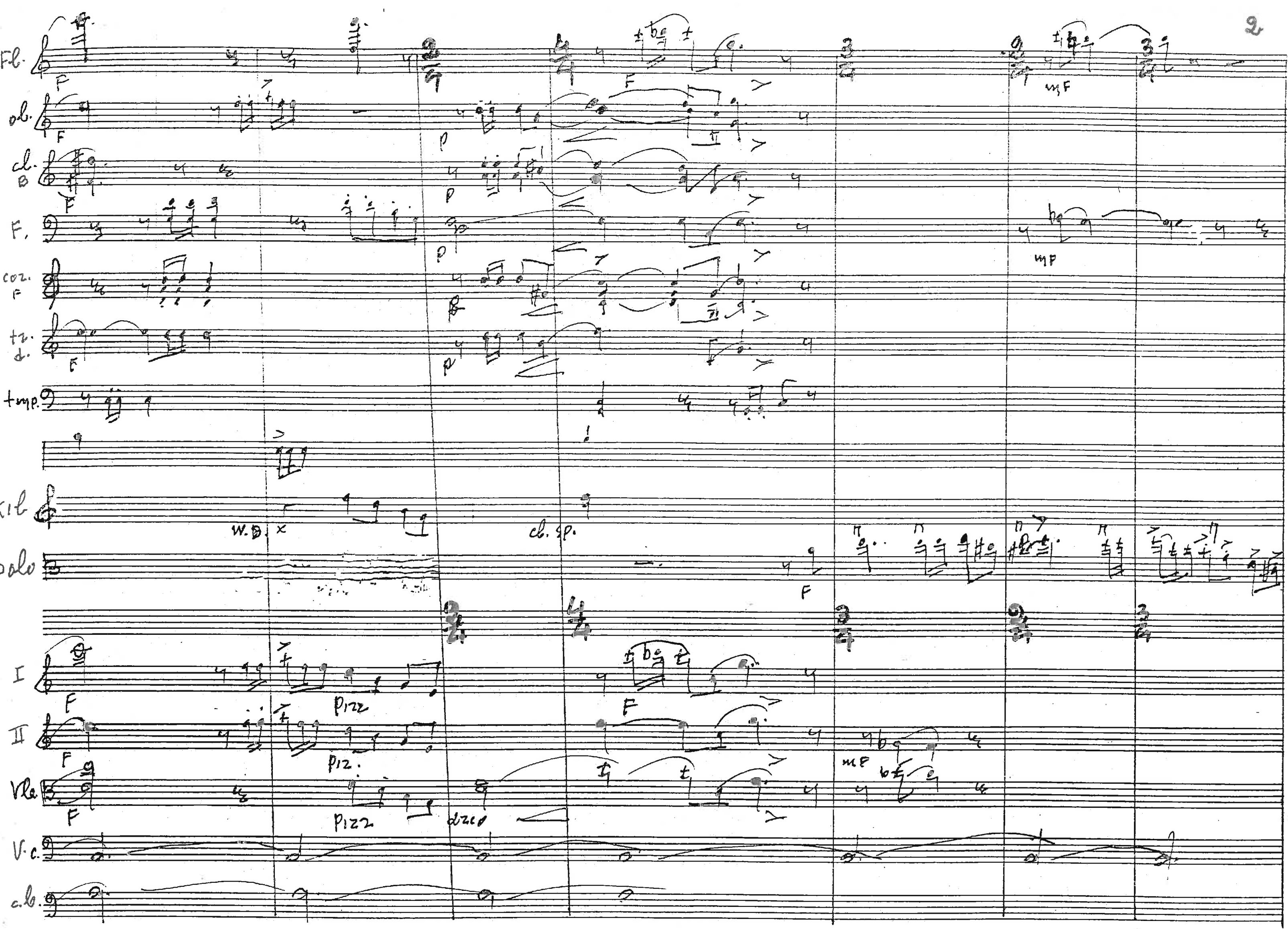




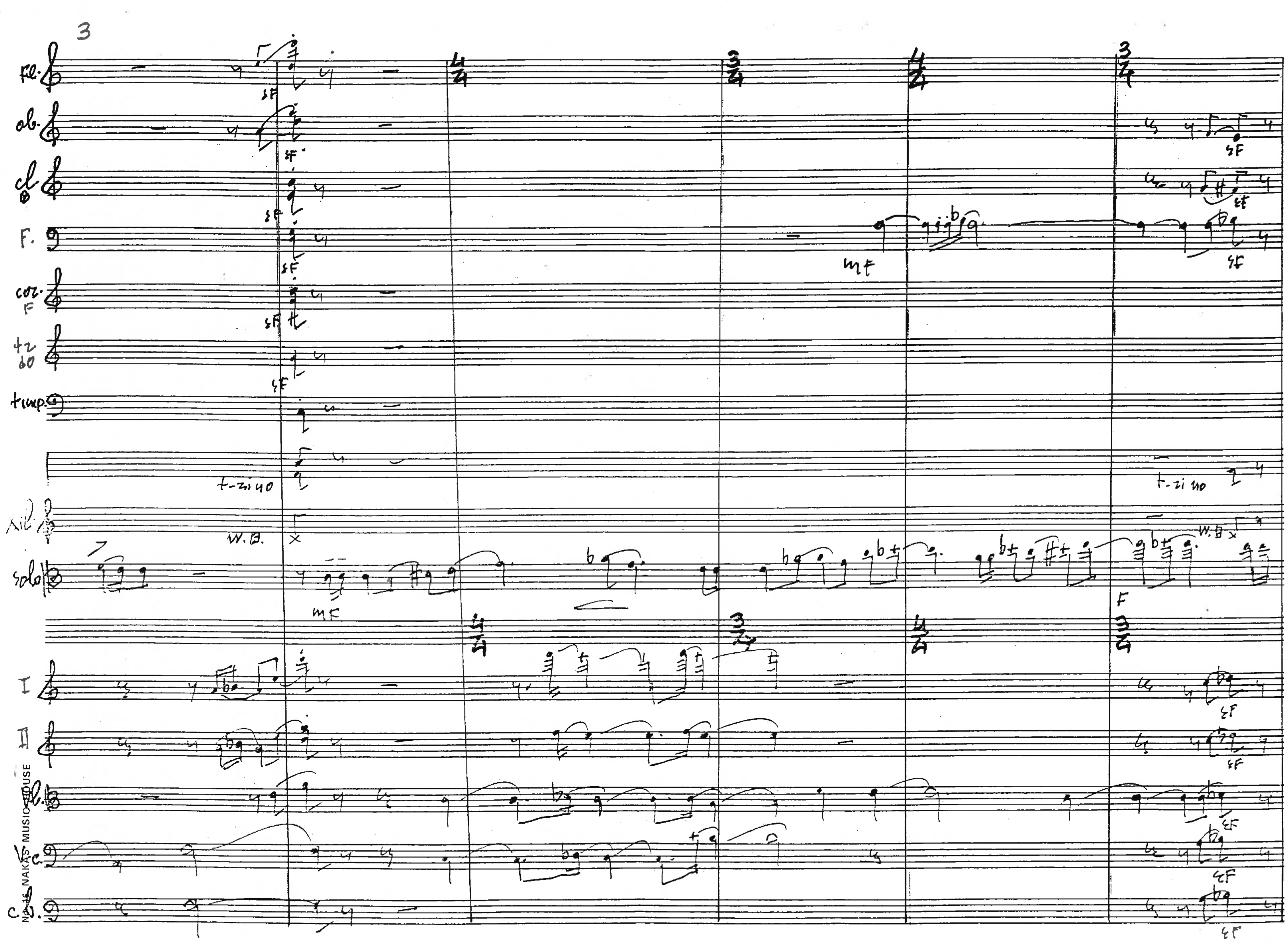


$F b+$ ob. $\frac{\mathrm{C}}{42}$ ८.

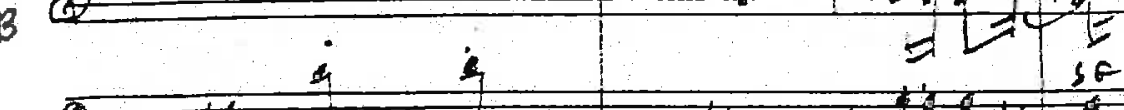

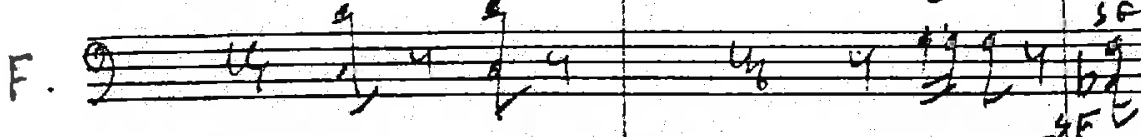

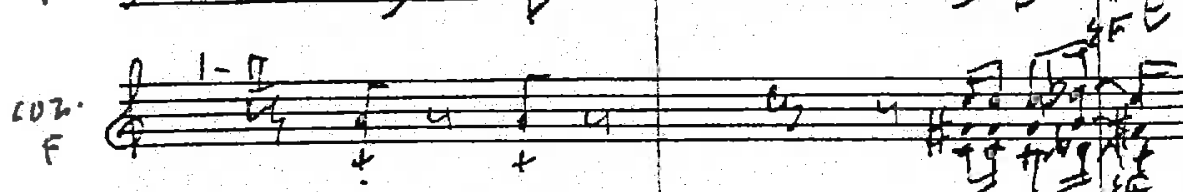
t

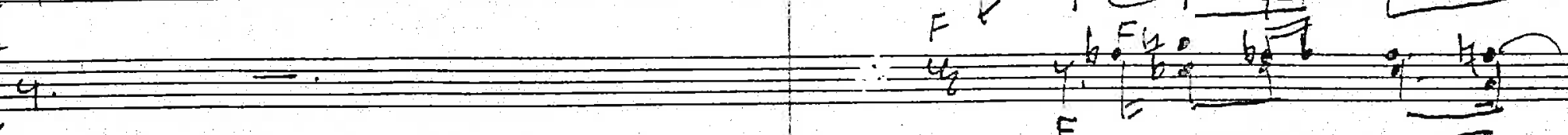
do 45

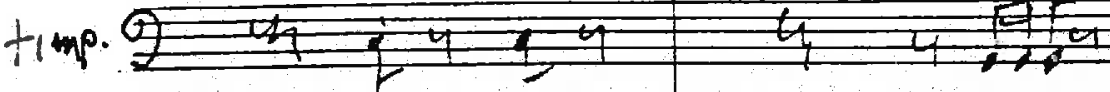

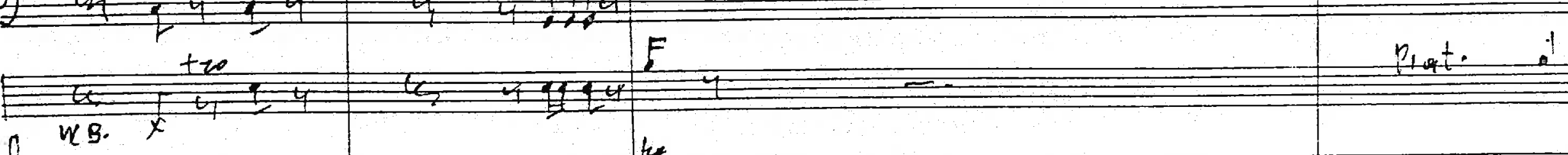

Nib.

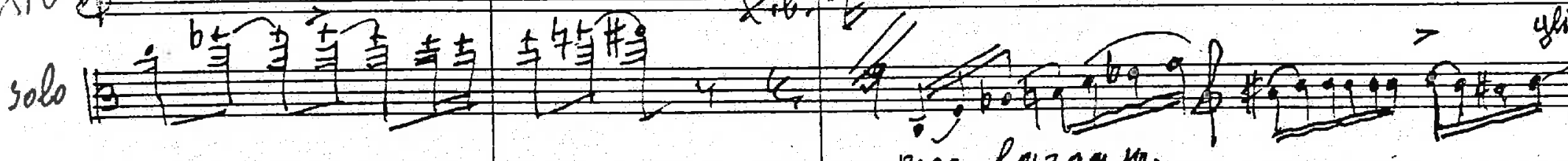

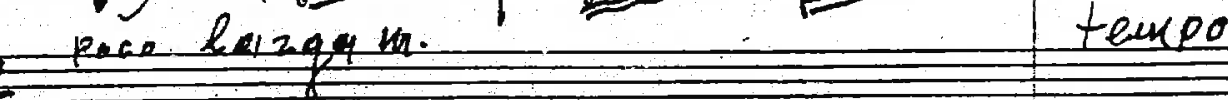

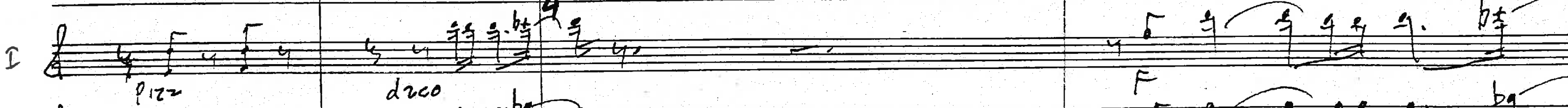

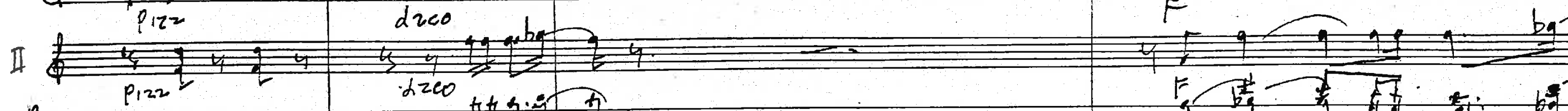

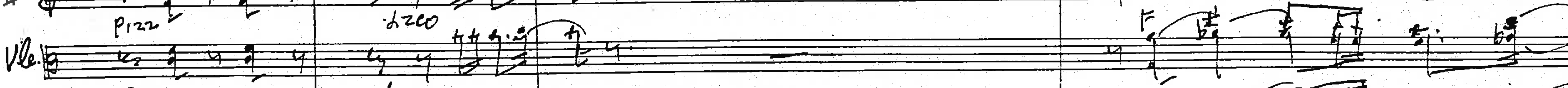

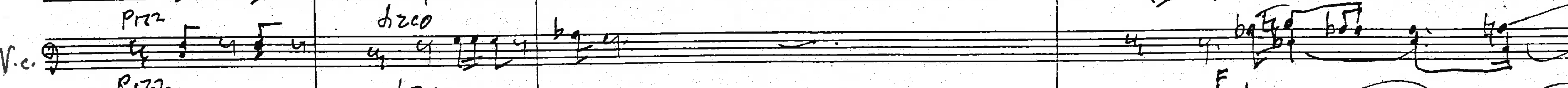

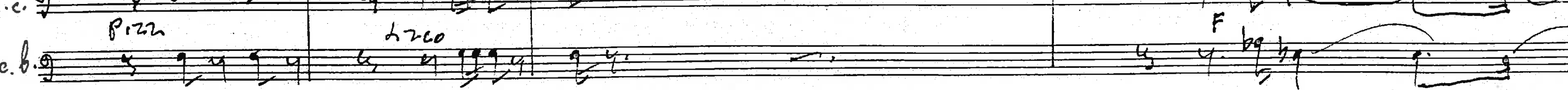




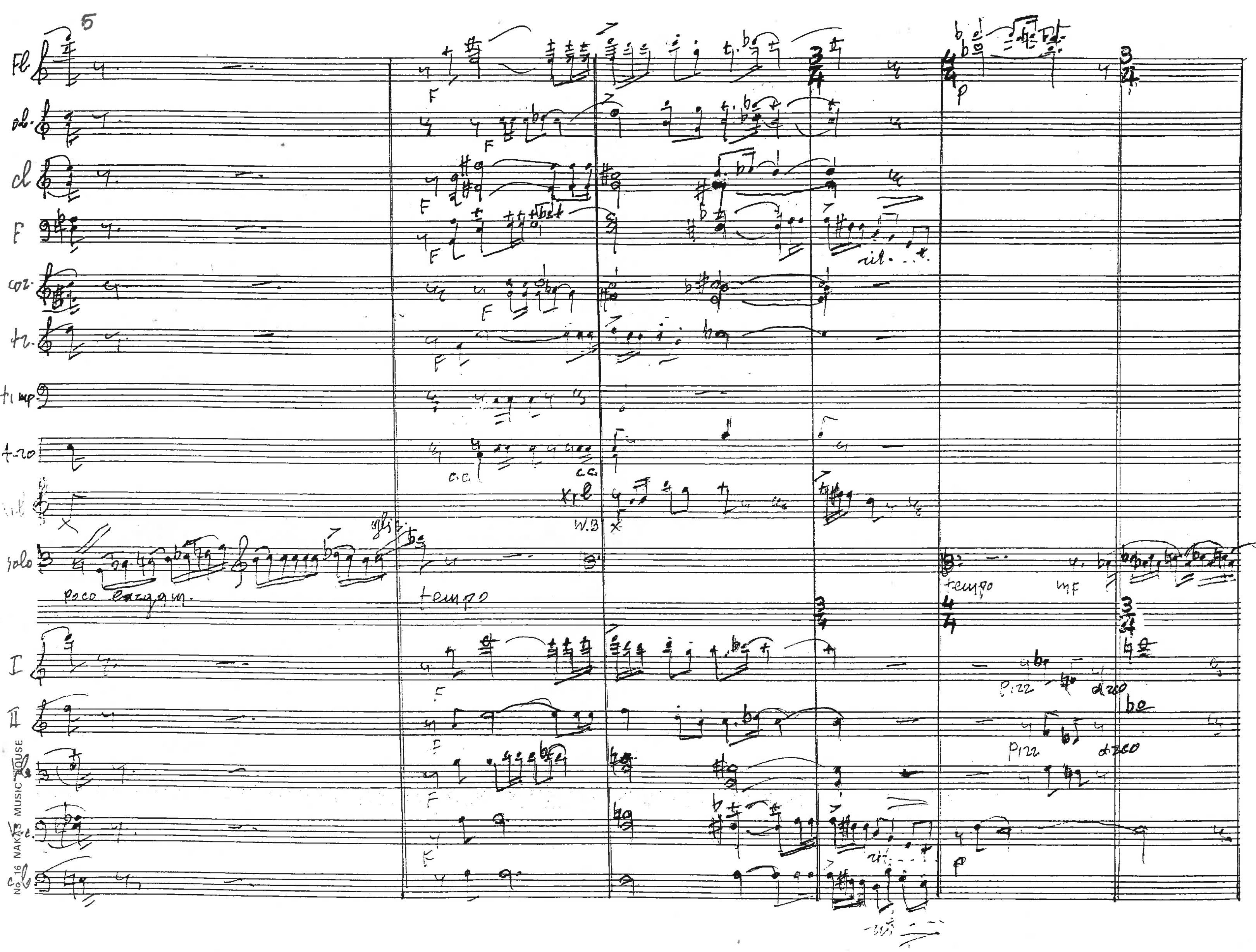




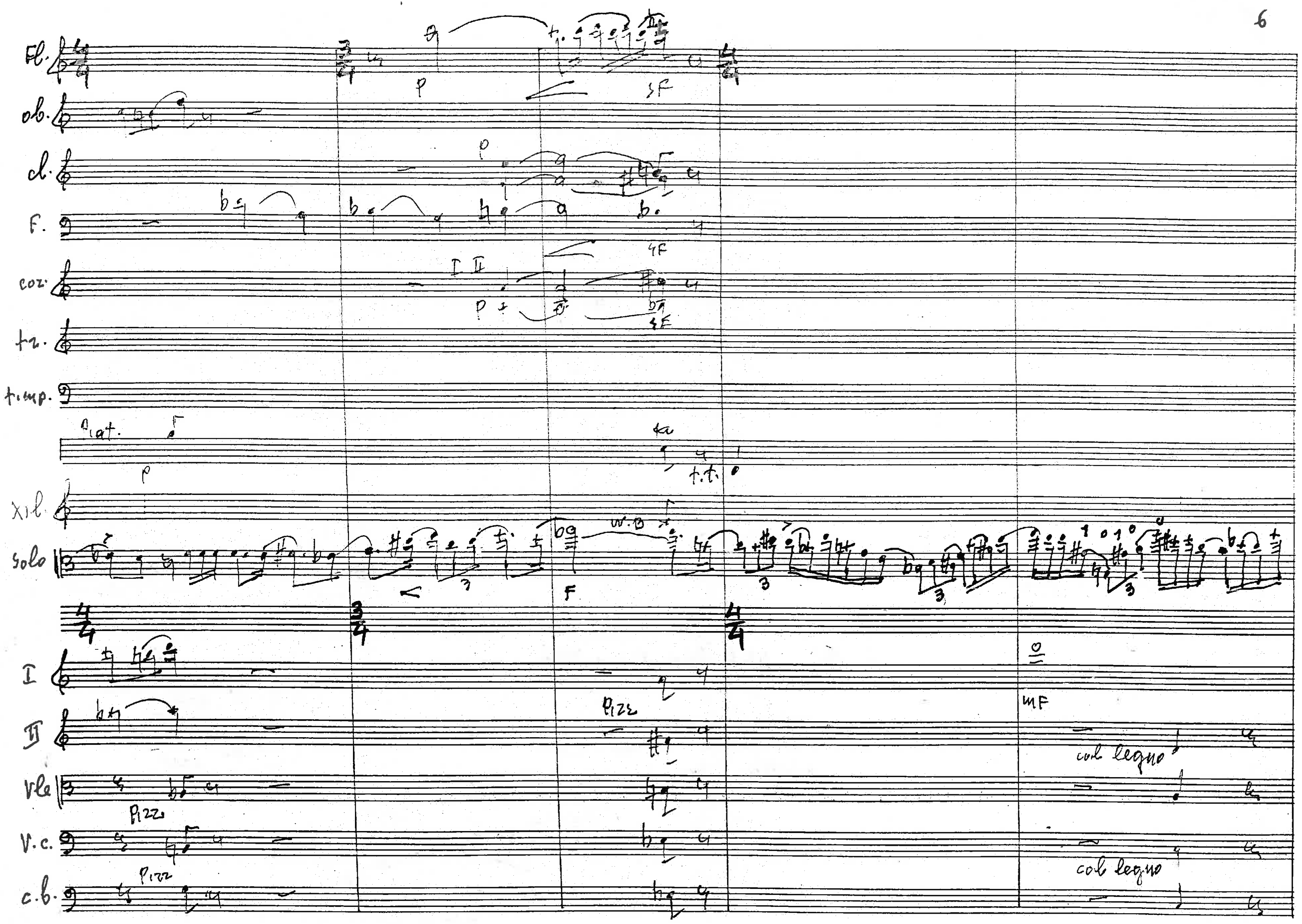




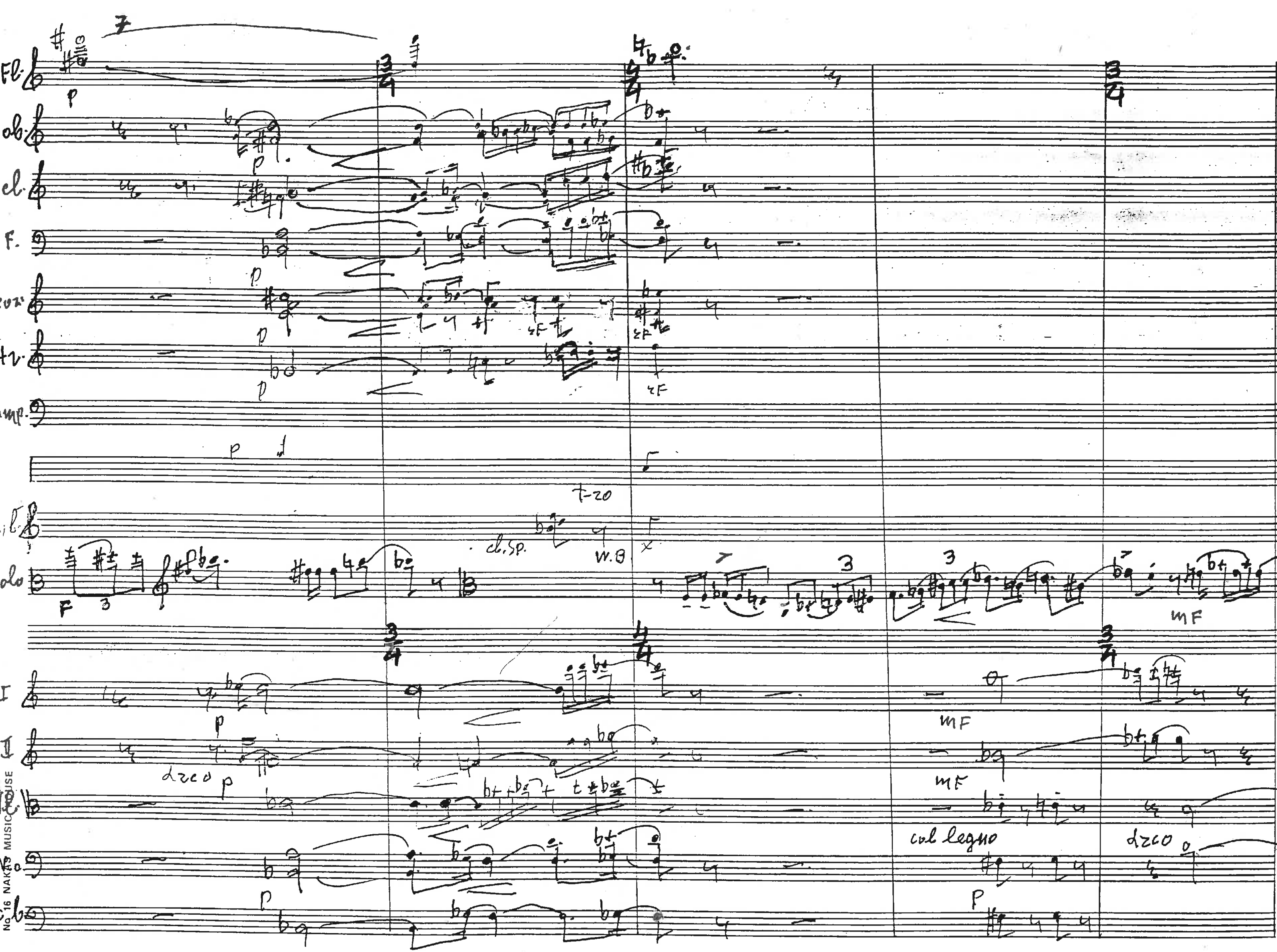


$\mathrm{Fl}$ $o b \frac{M E+1+\frac{1}{4}}{M E}$

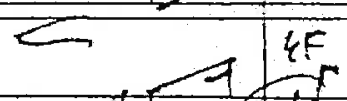
$\frac{4 F}{4}=$ $\mathrm{d}$ F. Lo2. $+q \cdot$ timp.

$x \cdot 6 \cdot 6$

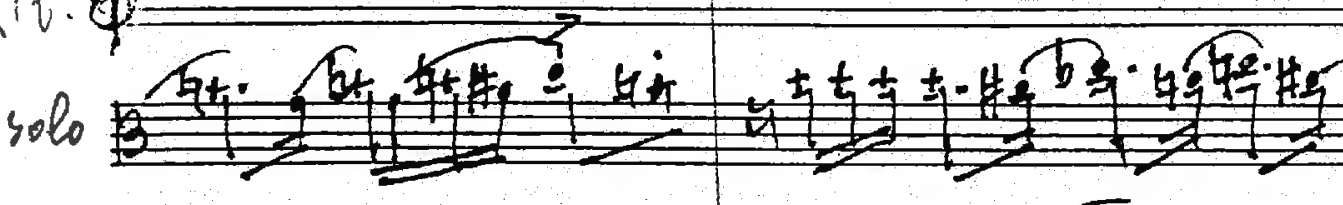

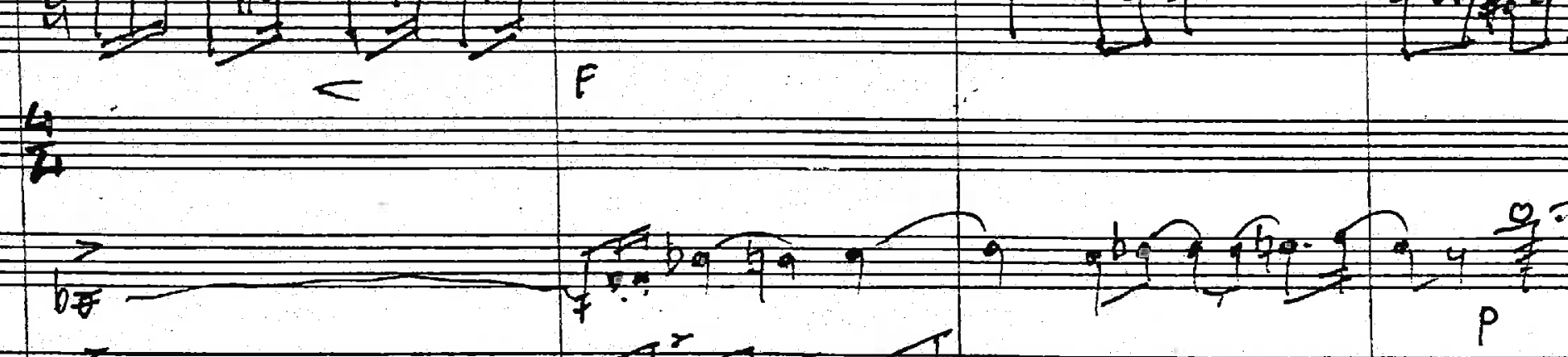
Solo 1 II Vhe r.c. c. b.

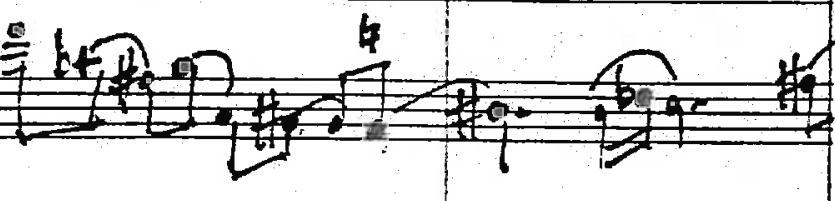

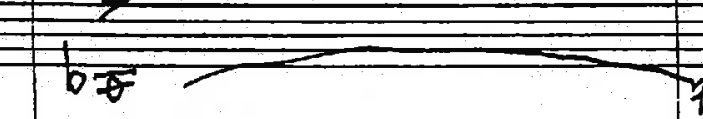
17. ${ }_{122}^{2} d x_{00}$

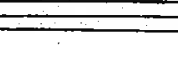
$\frac{5}{x}$

\section{1} o 12 
$\mathrm{Fl}$

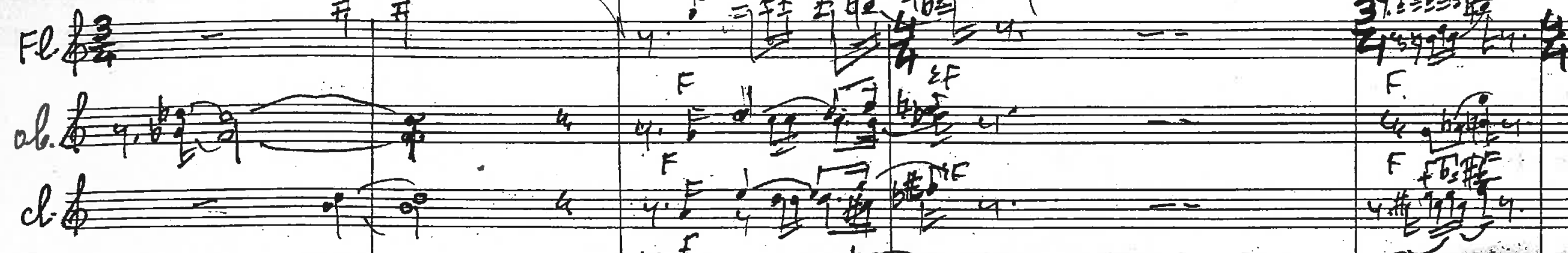
F. CO2.

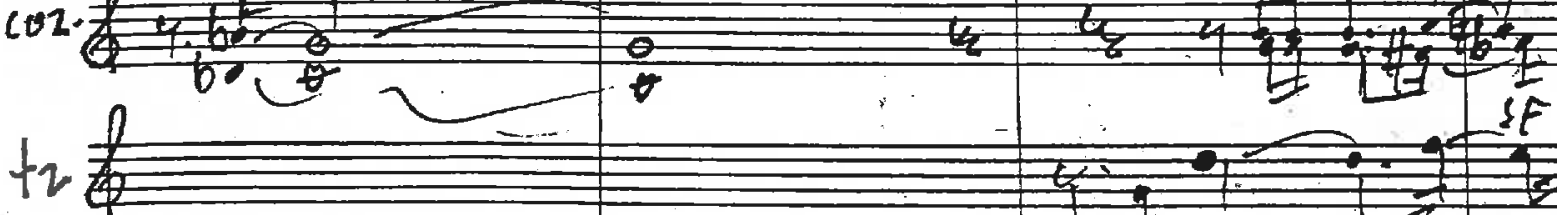
fiw 1

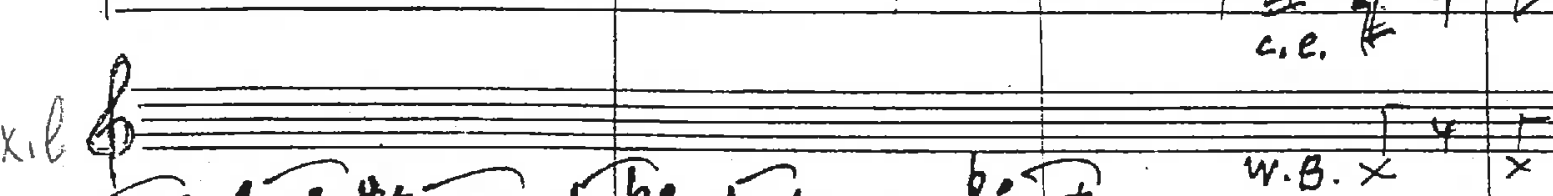
2.

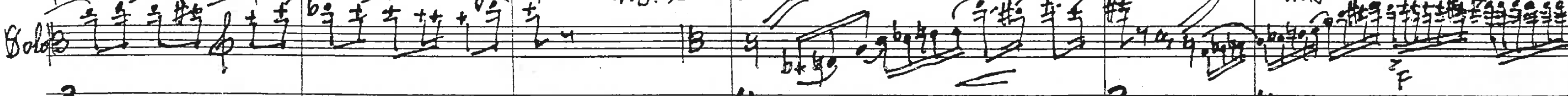
$\frac{3}{4}$

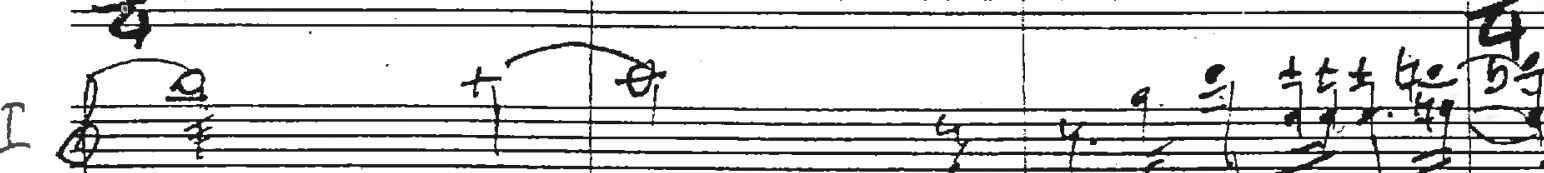
II (2) L

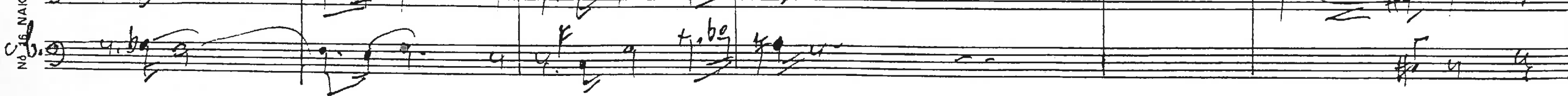


11

Fl.

ob.

$d \cdot$

F.

cor:

tr

$\operatorname{trm} \frac{+2}{02}$

en

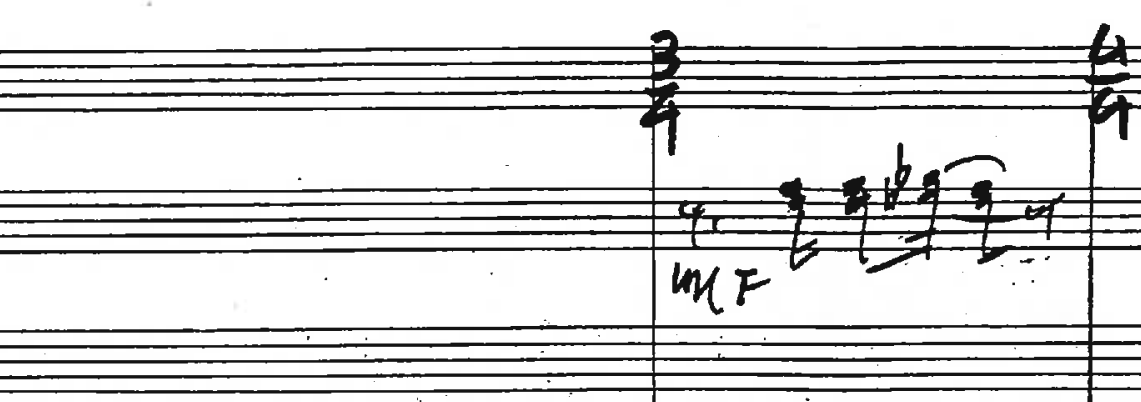

$x_{i} b$ xib $x_{0}$

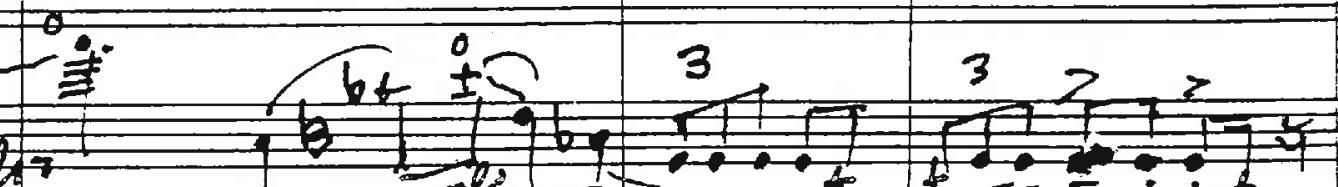

I

I

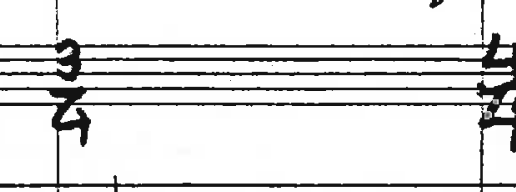

molo ut. gll $_{4}$

谛

up
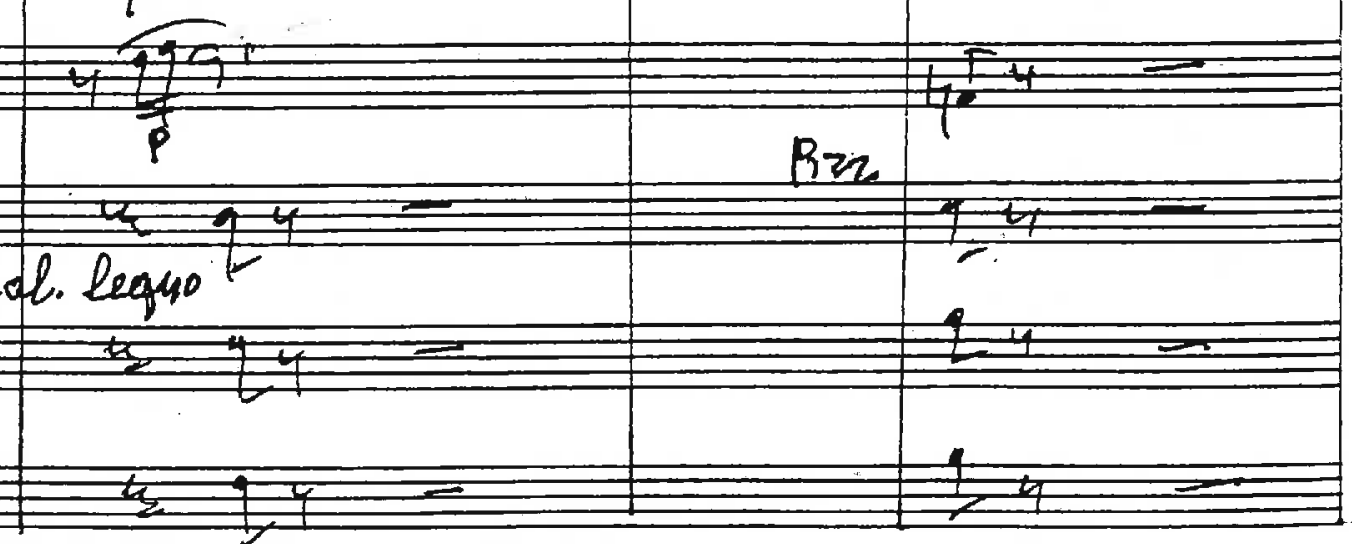


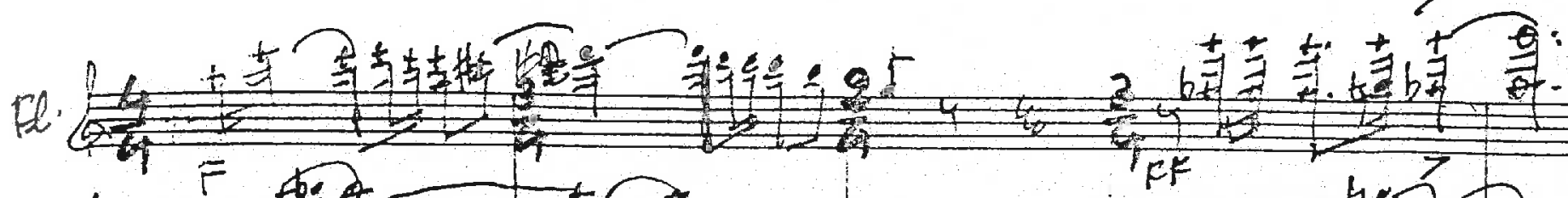
totis

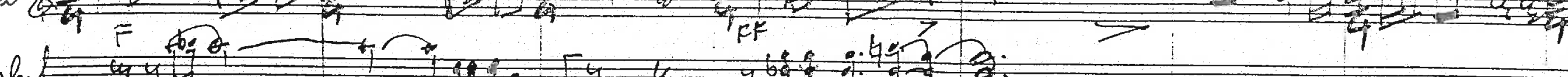
ob.

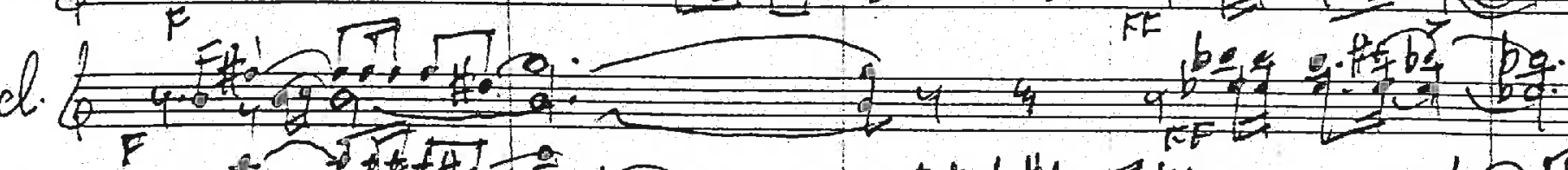

F. cor. +2. $\operatorname{timp} 0$

$4 \frac{1}{1}$

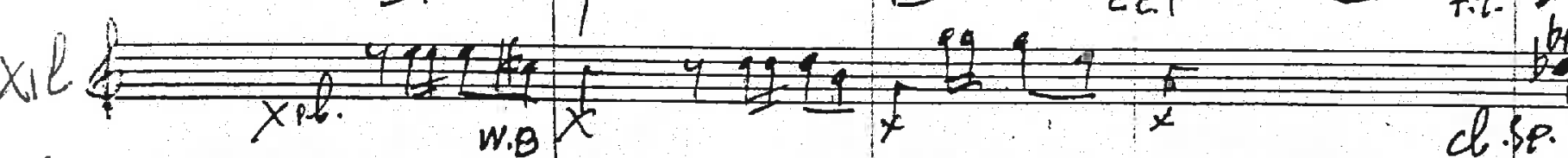
solo

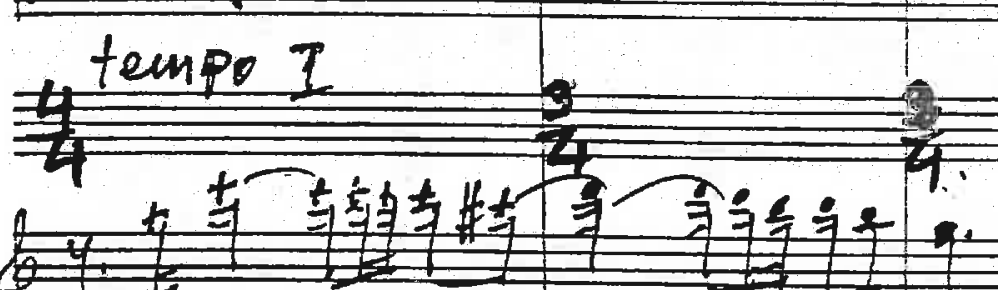

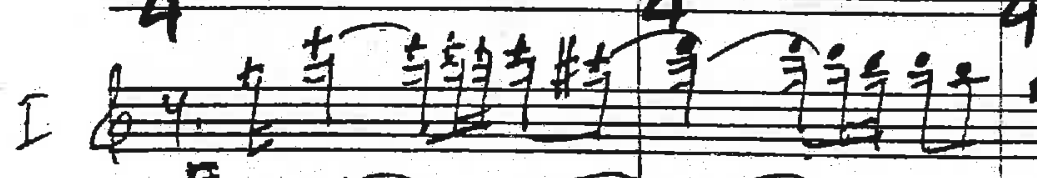

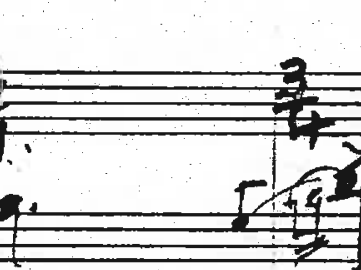
$P+7 F$ (1) 을. 2 20? VR

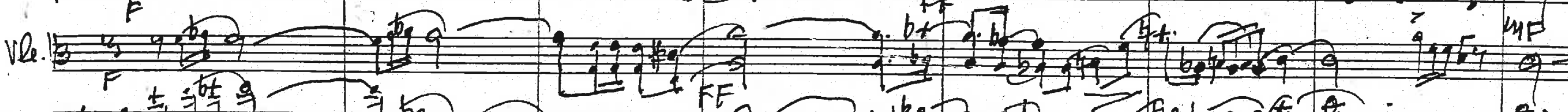
V.e. b. Q. c.6. 
$f l \frac{4}{4}$

ob.

$c=\frac{4}{4}$

f.

con

tr.

timp

5

xit)

Solo bat

I. II

\%

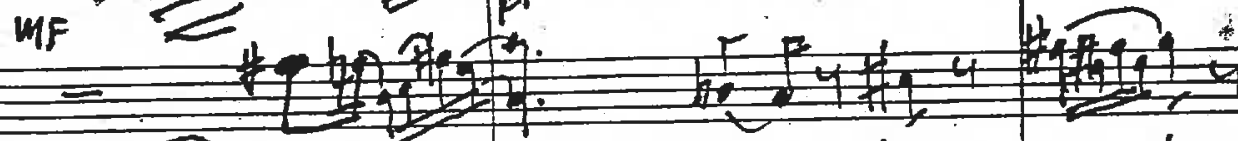

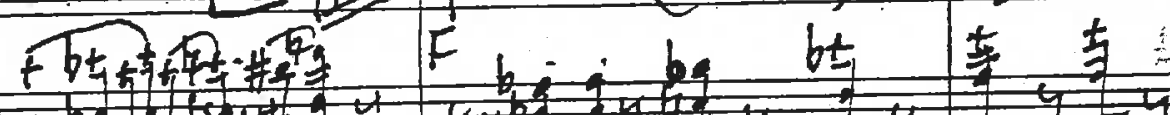

$\frac{4}{4}$

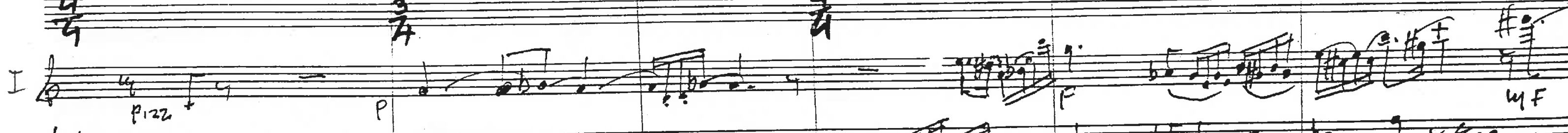
II 尊 年

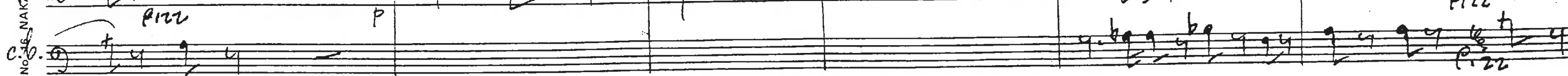




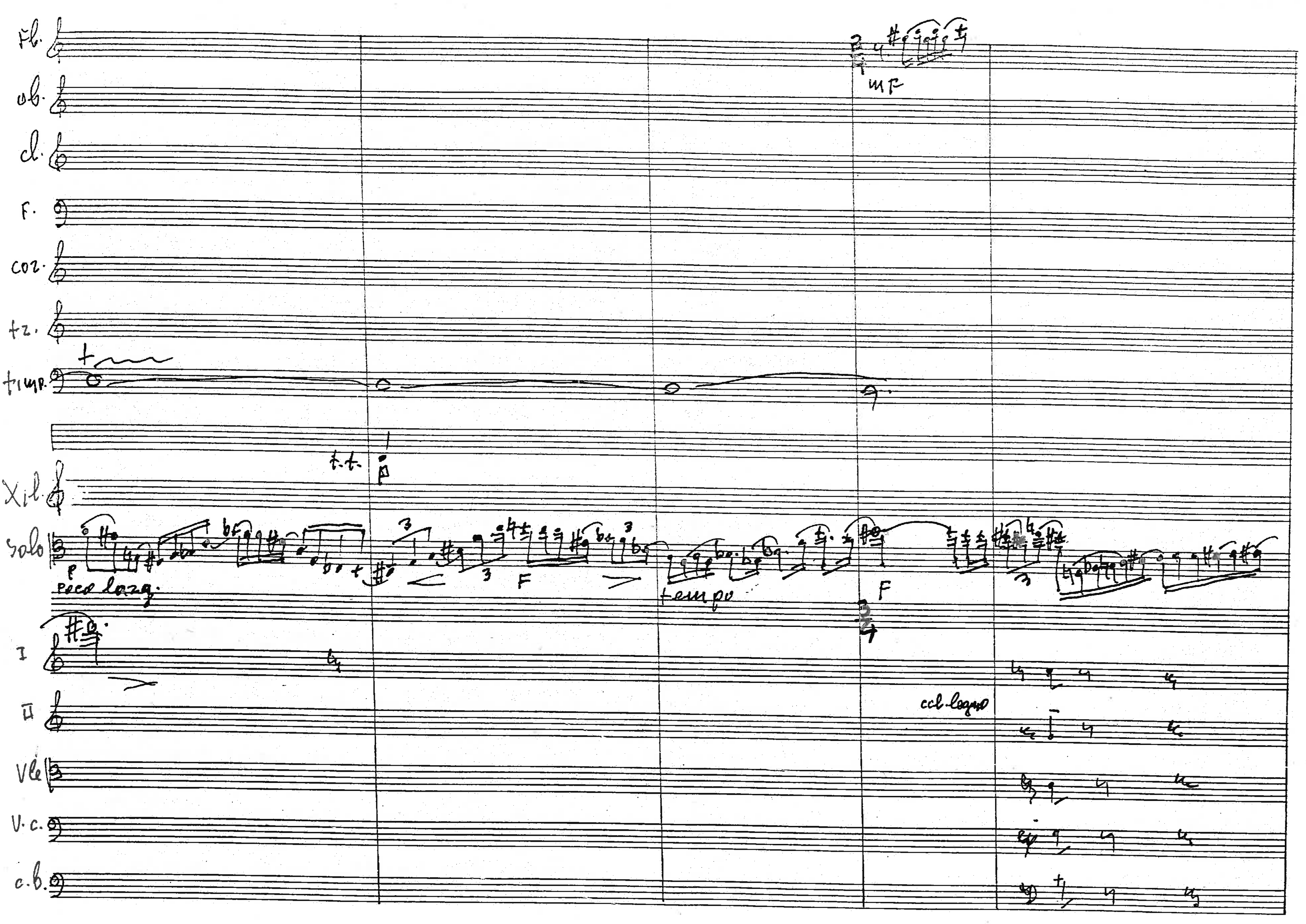


of

2.

con:

th.

$1-\pi$

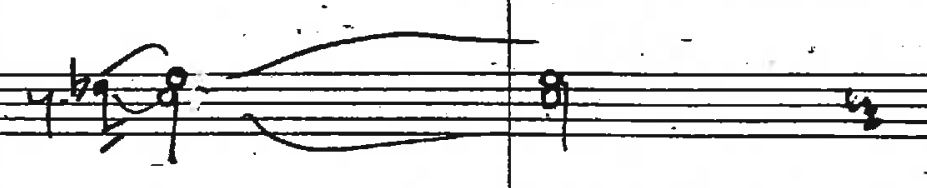

I

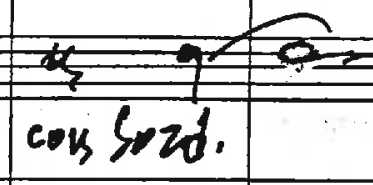

tomp

xi和

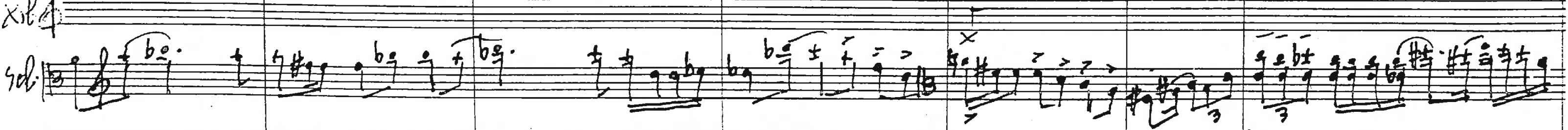

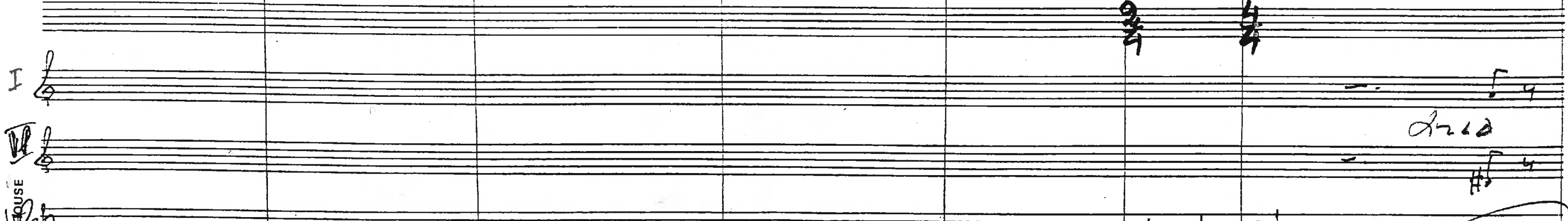

(

(1)

是

?

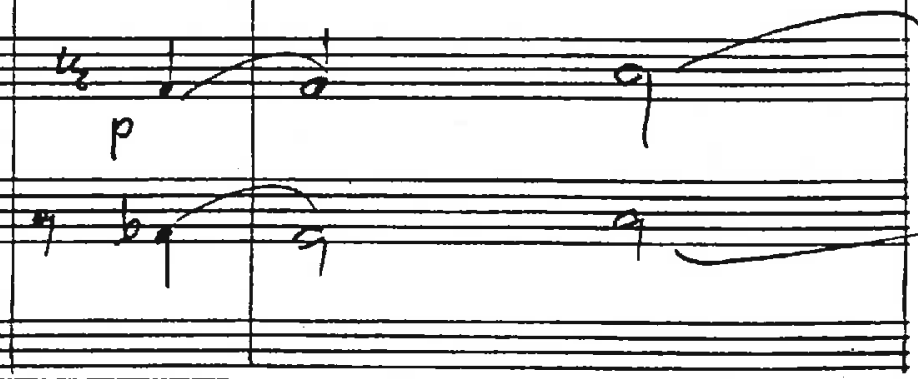


ab.

ti2

党

F.

cor 2

III

$\frac{3+2}{k+7.1}$

$\pm 7 .+9$.

$+6 \div$

$t q \cdot$

VIKSord:FO

tim. $F=2$. $\circ>$

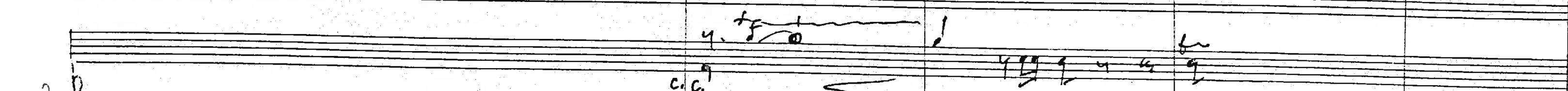
Solo 20 ?

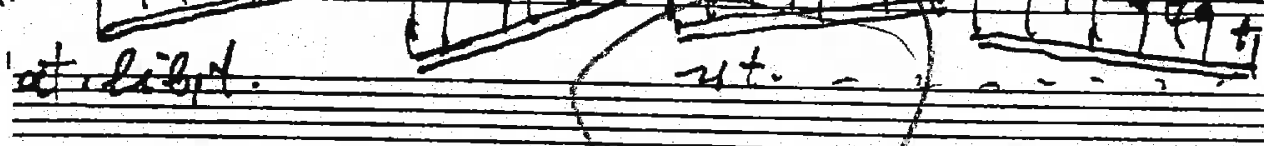

$I$

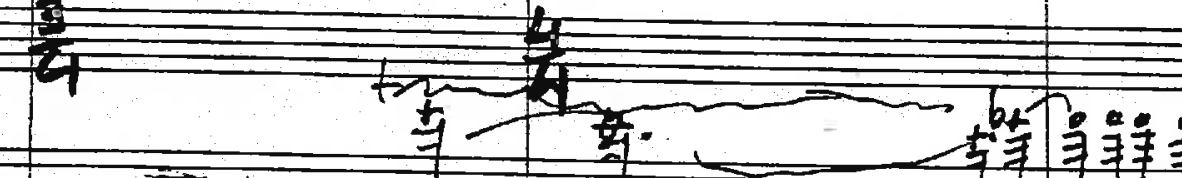

II

ve

V.c. 占寺

$c . b$.

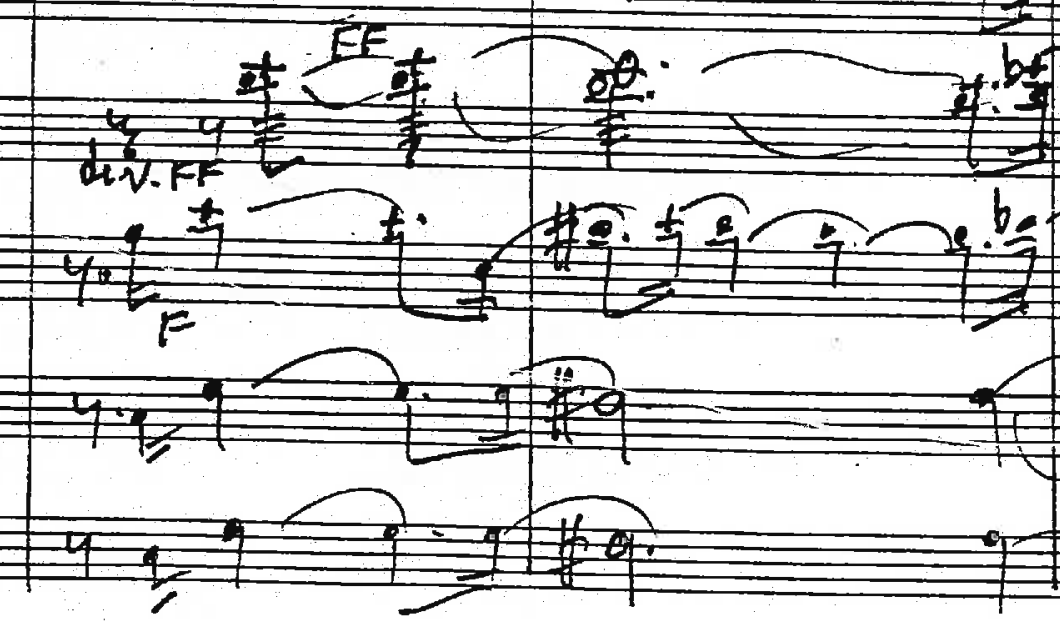

$\frac{1}{x_{1}}+1$

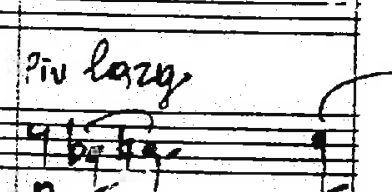

$p=9$

9

$01 P_{0}$

$\frac{0=19-2}{P}$ . $p$ 


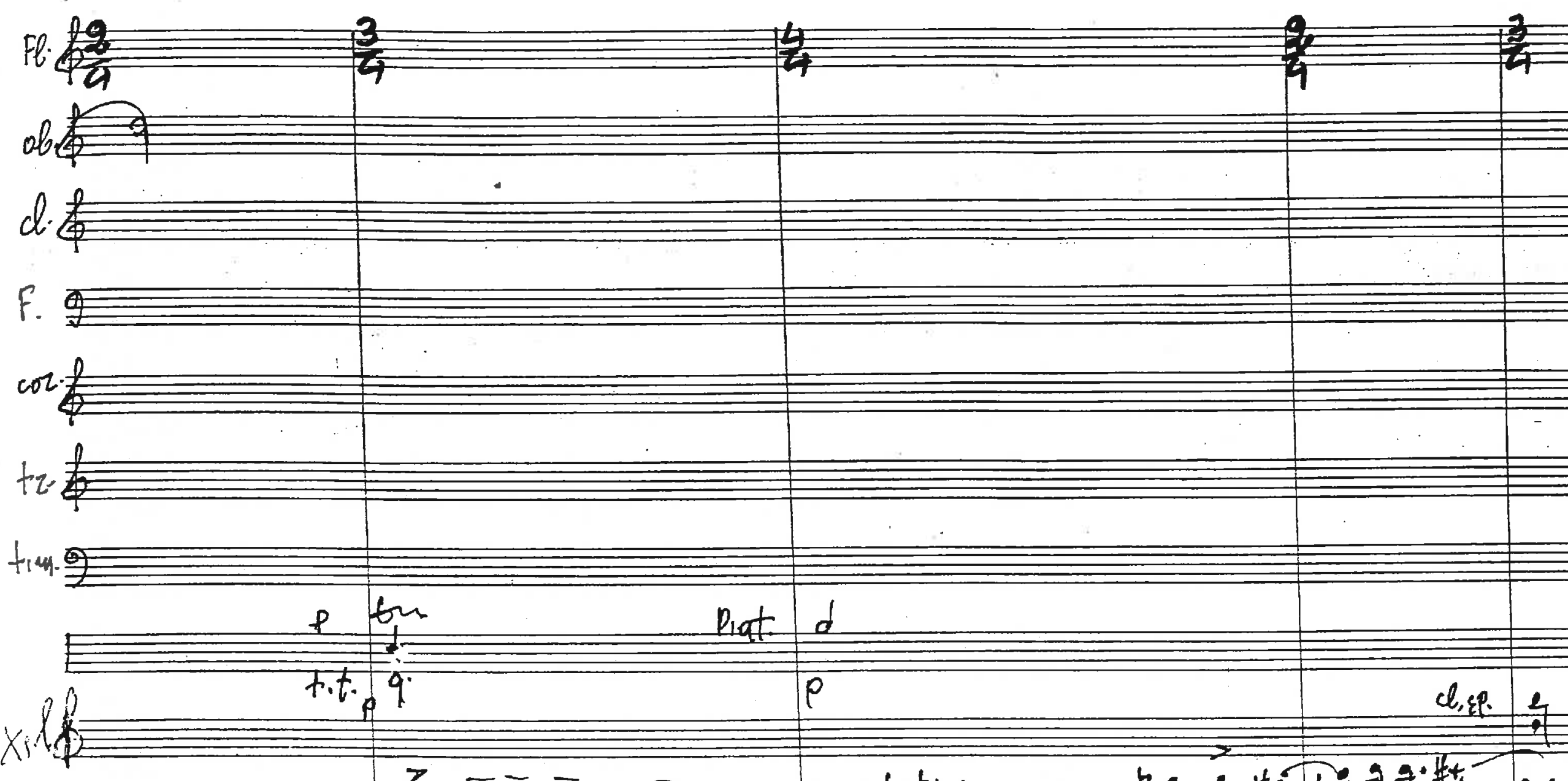
15olo $I 3$ II 9

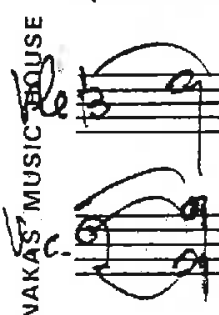
:

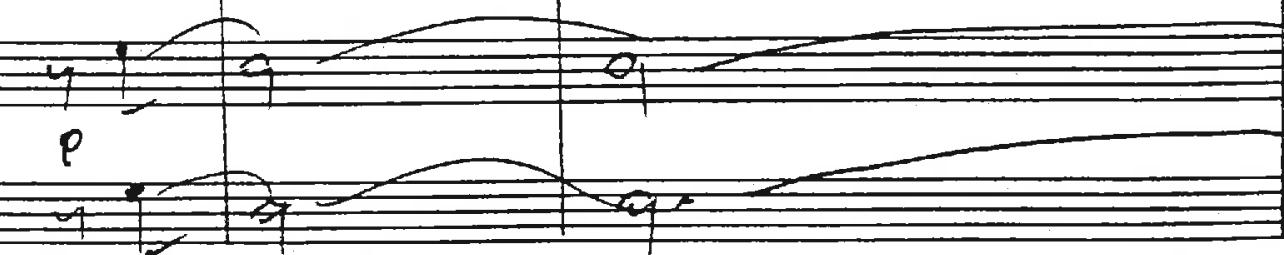


of

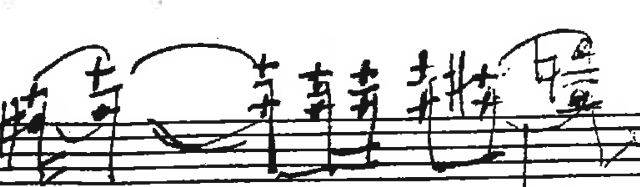

o.

Q.

$F .20$

Cor 2010

†r.

tim

E0

w

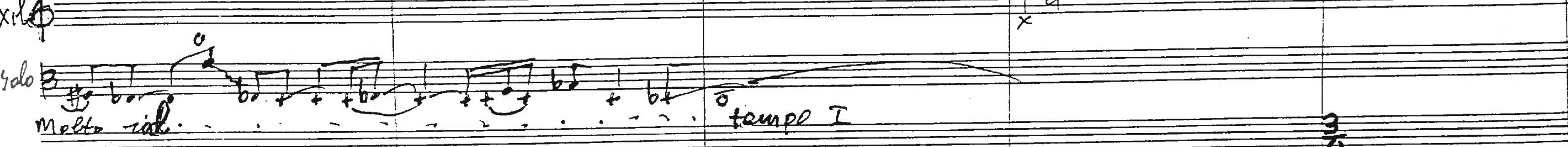

I

II



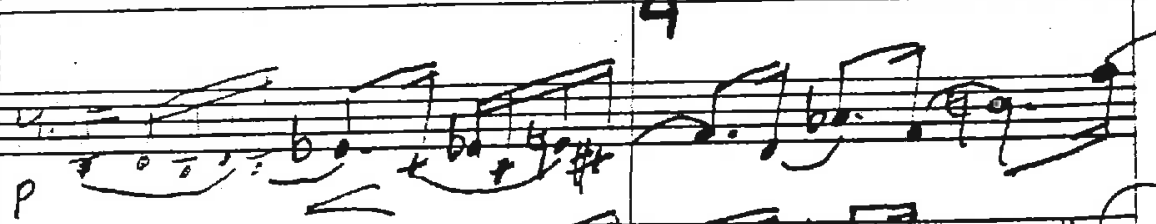

.

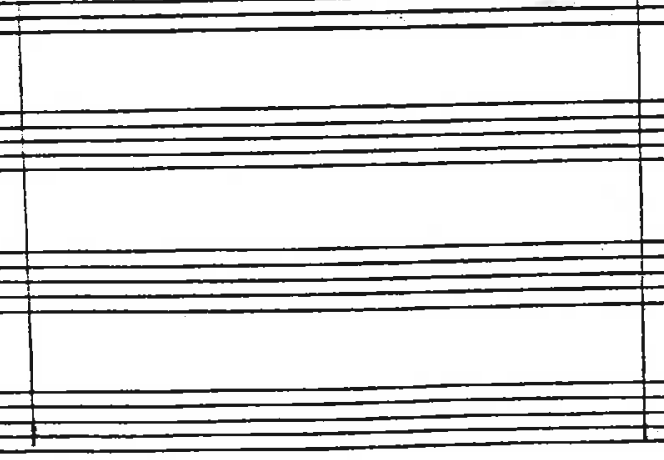

$p<<+1+C$

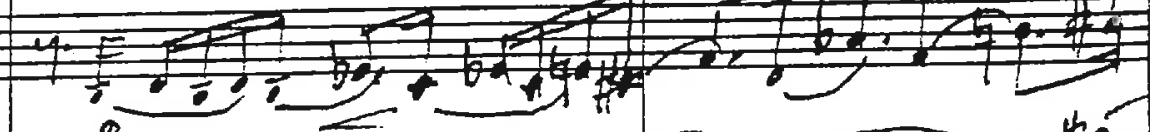

$p=0+1+1$

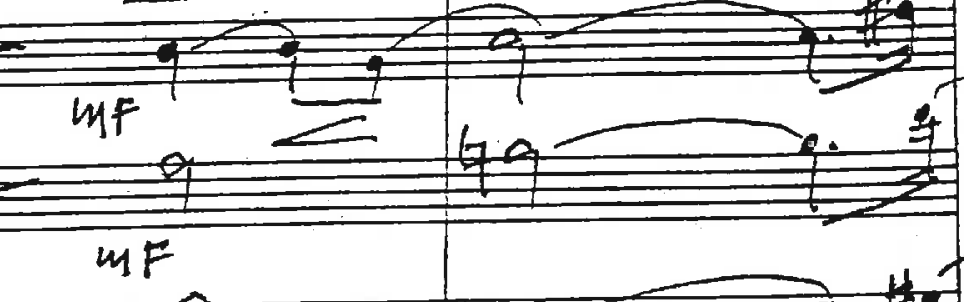




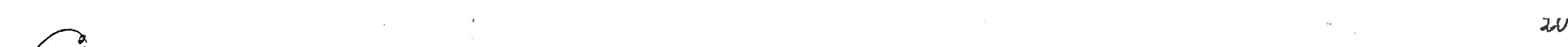

H. $\frac{2}{4}=$

ob. $\frac{1}{4-5}$

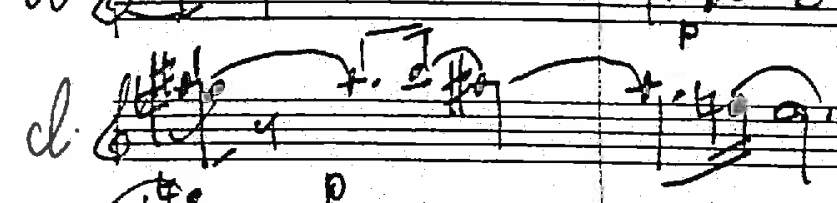

F.

6.2

+2.

$\operatorname{tin} \frac{2 \sqrt{4}=2}{4}$

xil.

44

Solocosost

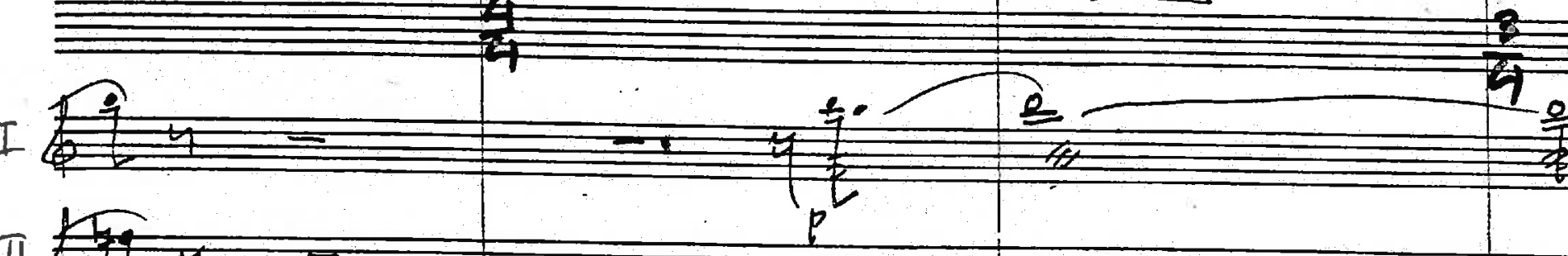

II Whe 4

$V_{c} \frac{9}{4}$

c.6. $\frac{2}{2}$

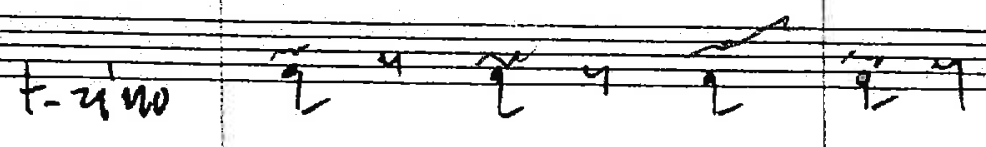

으.

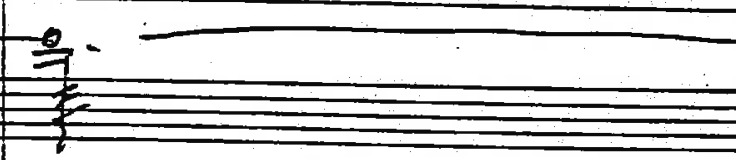

4

collegul 4923 4 be 


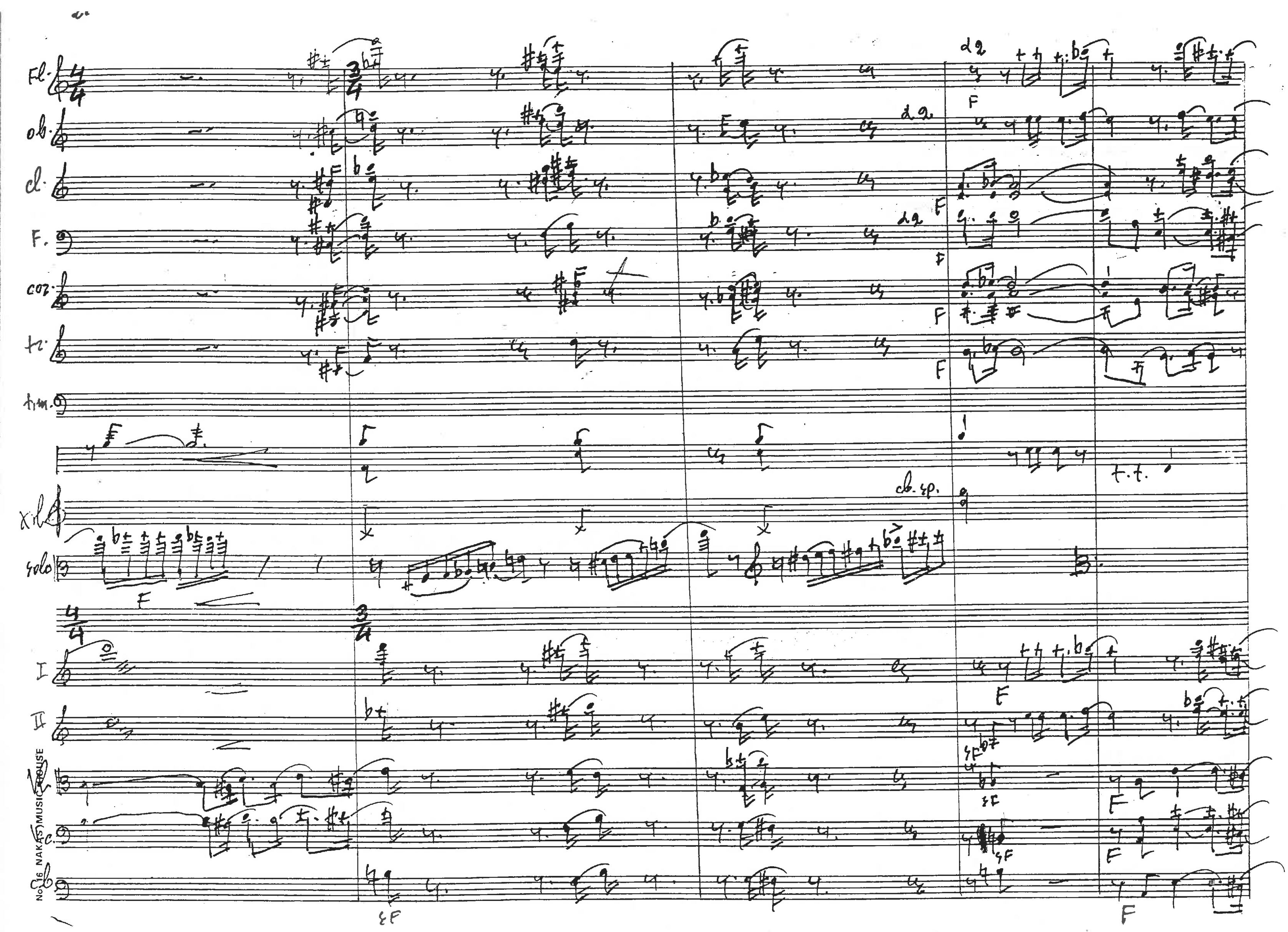




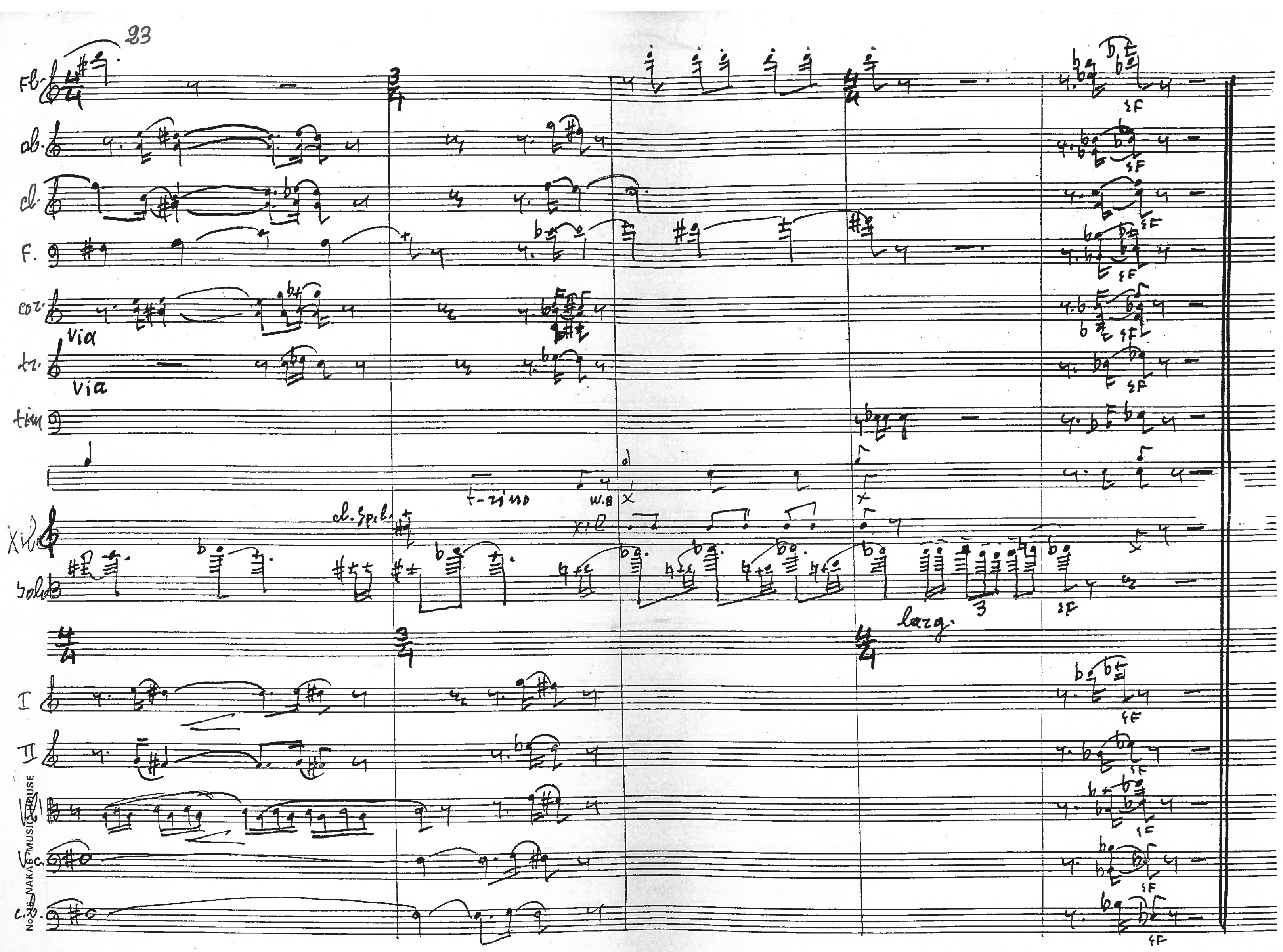


ob

b.

$F . \quad \dot{q}_{2}+4: 4$

$7=$

cotn 1 III

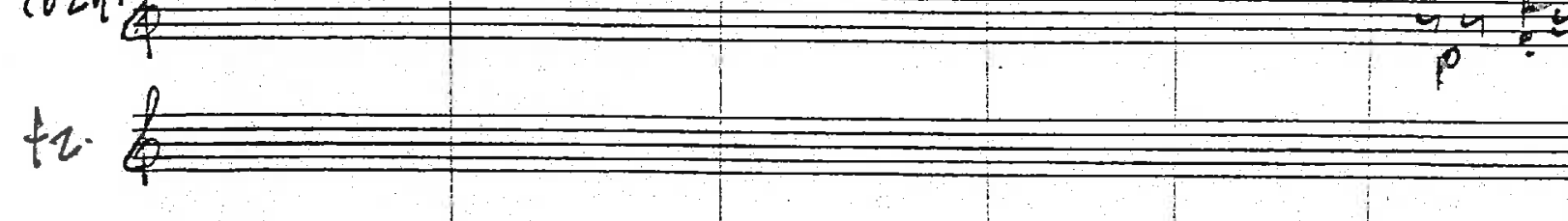

timp.

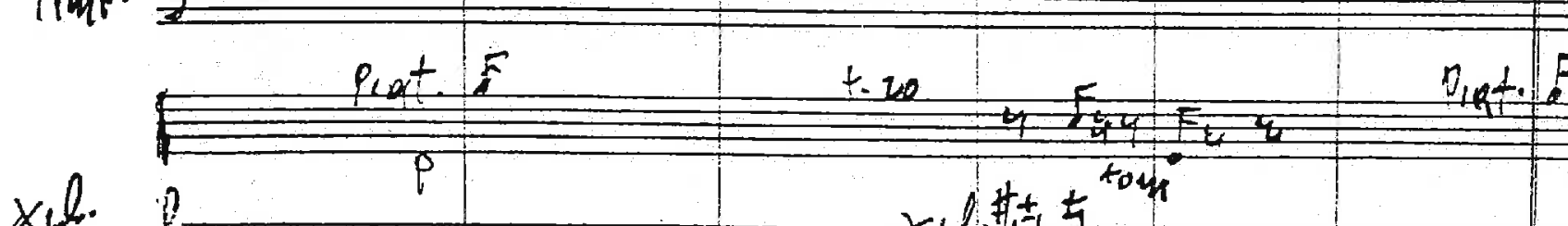

ce.se. 0

solo

$\frac{1,454}{4}$ Tou
W. $B^{*}$ $0^{x} \times e^{2}$

\begin{tabular}{r|c|c|c|c|c|}
\hline \\
\hline
\end{tabular}

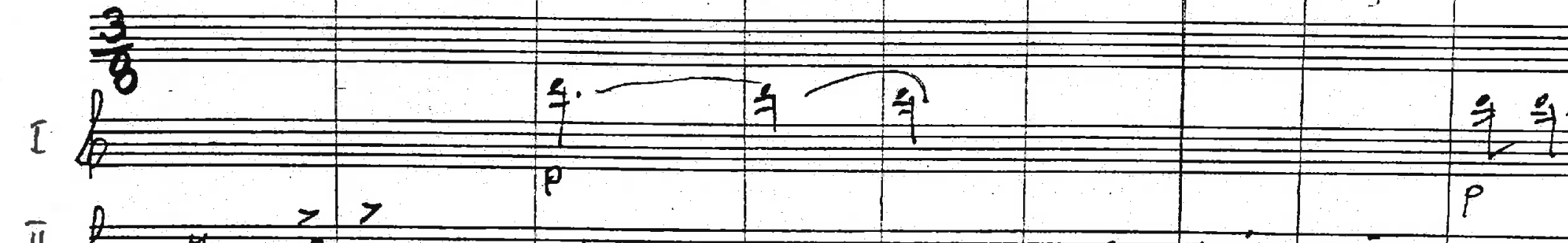

II $\frac{>>}{p}$

Vhe $p$

\begin{tabular}{ll}
\hline \\
\hline$P_{12}$
\end{tabular}

v. b.

P122.

to 19े की के etopen $\frac{7}{4}$

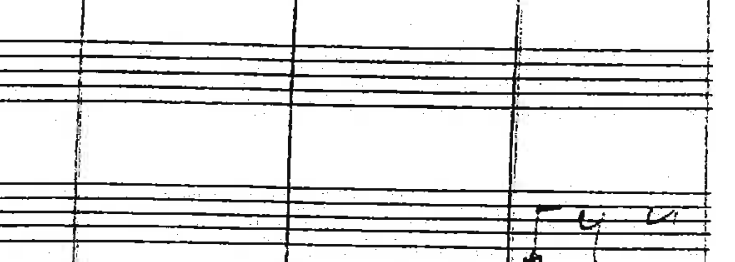

$+$
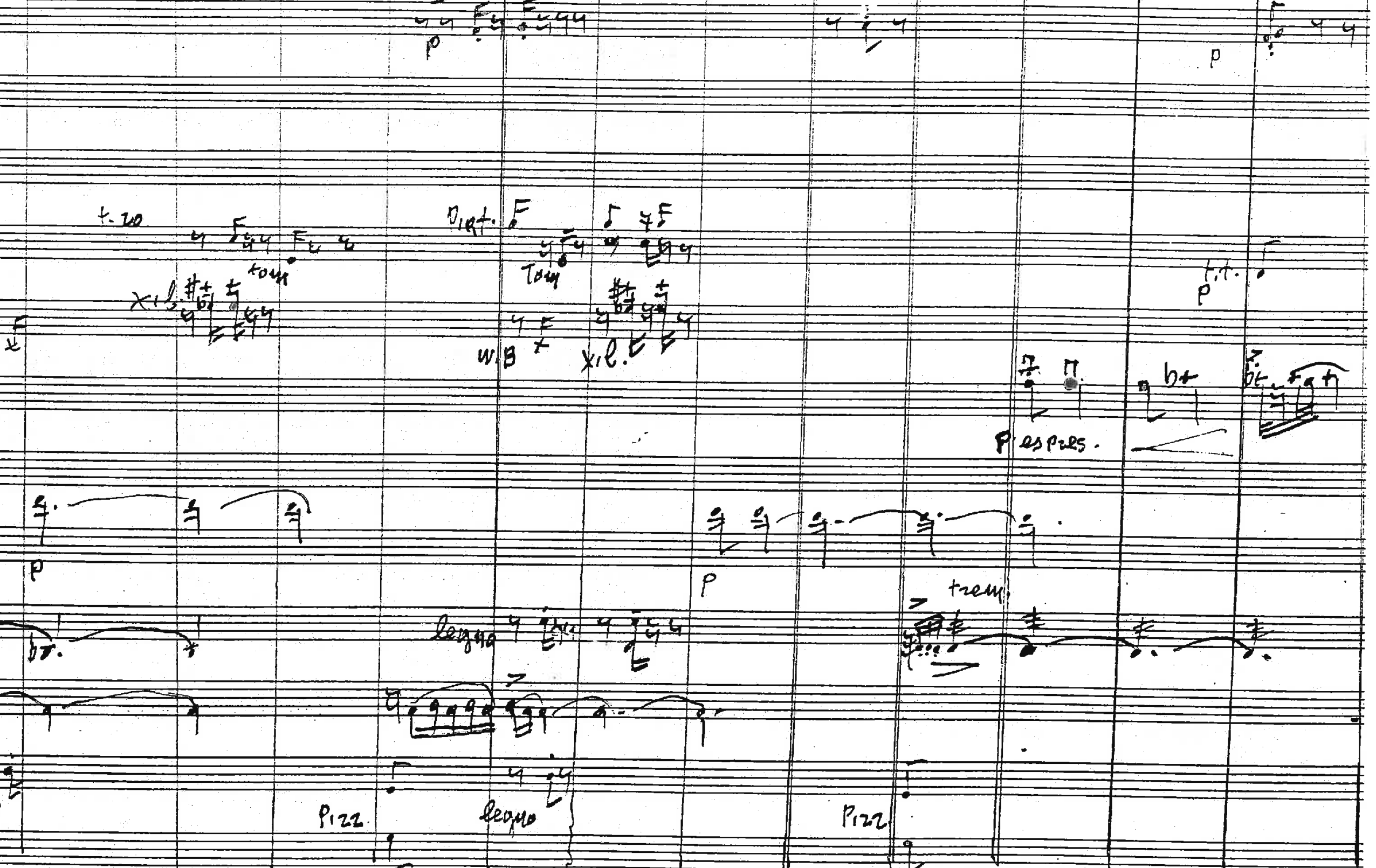

?
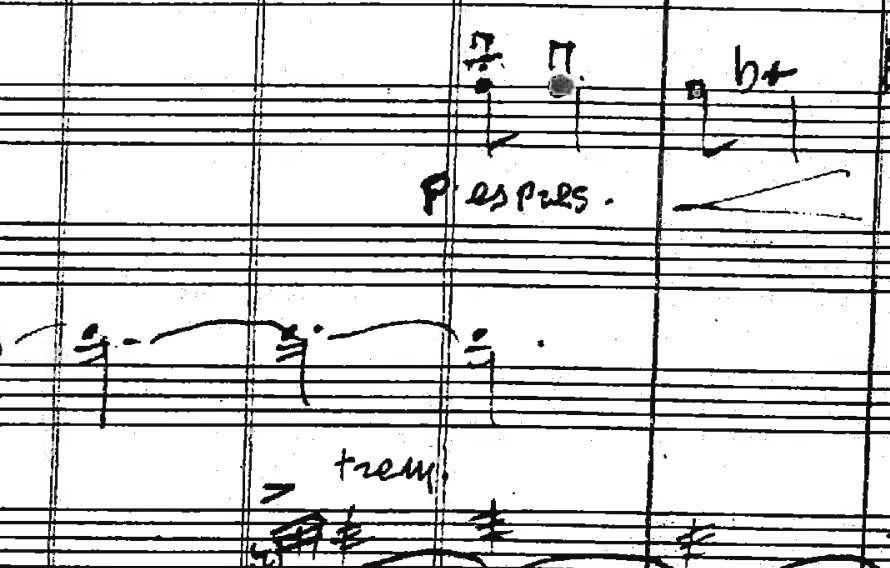

ivat

P) espres.

$\dot{1}$

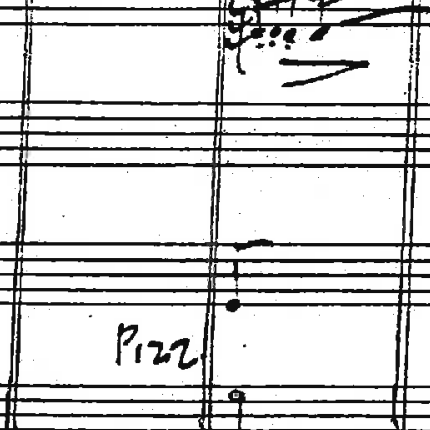

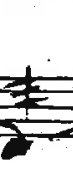

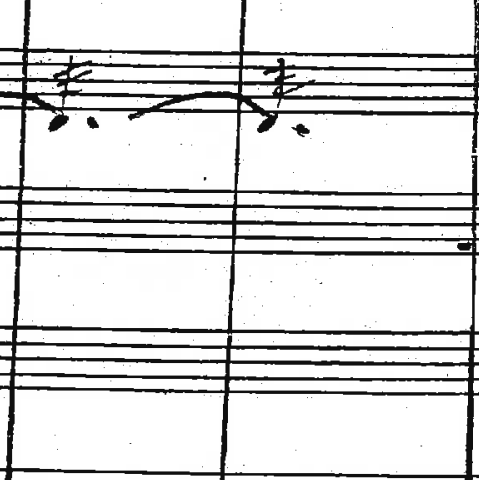




\section{5}

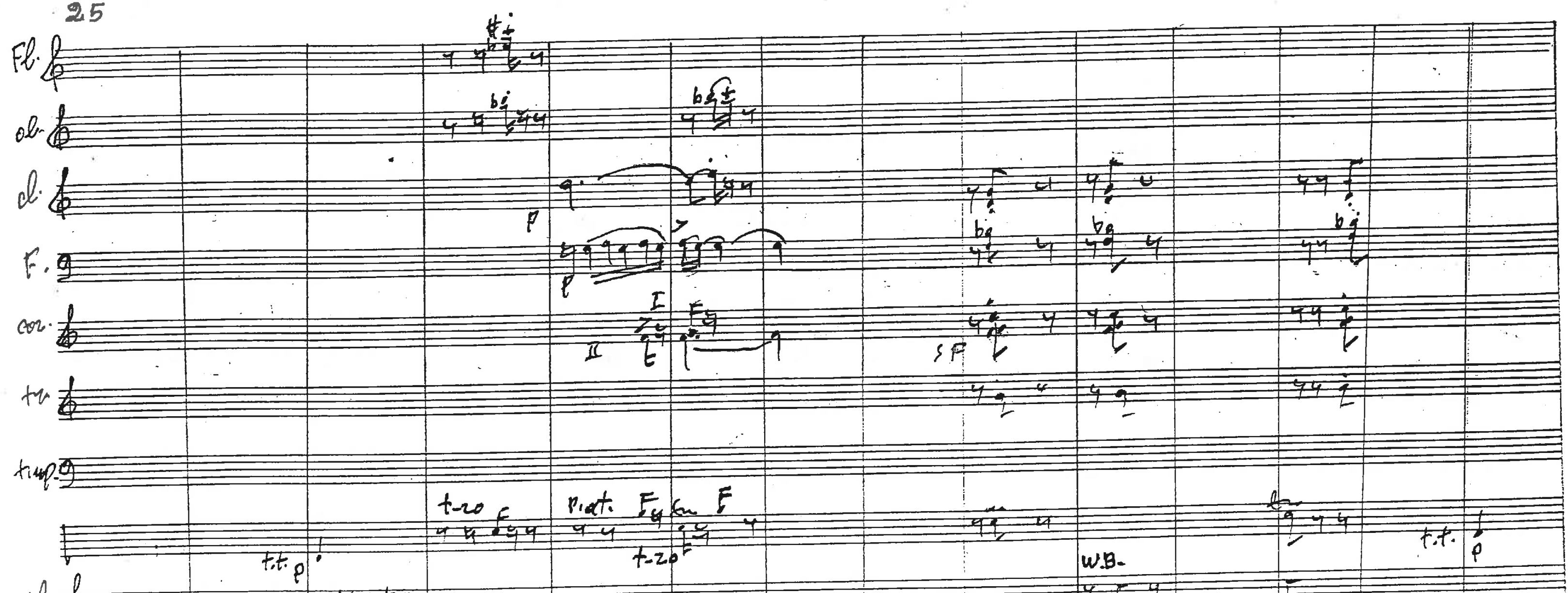

Vil alo

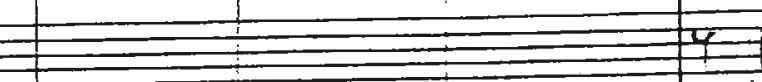

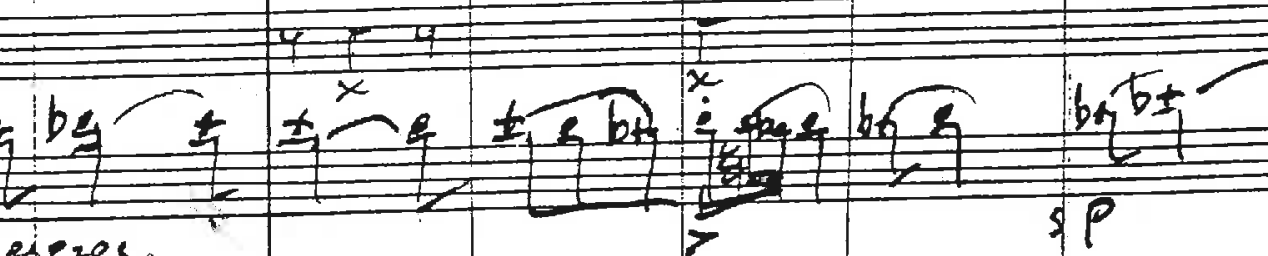
Fespres.

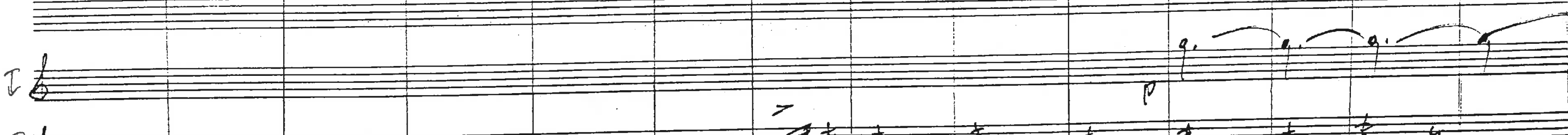
II

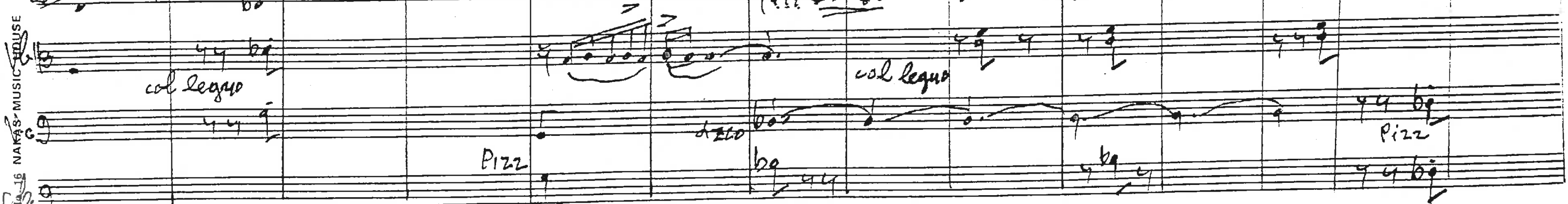
( 


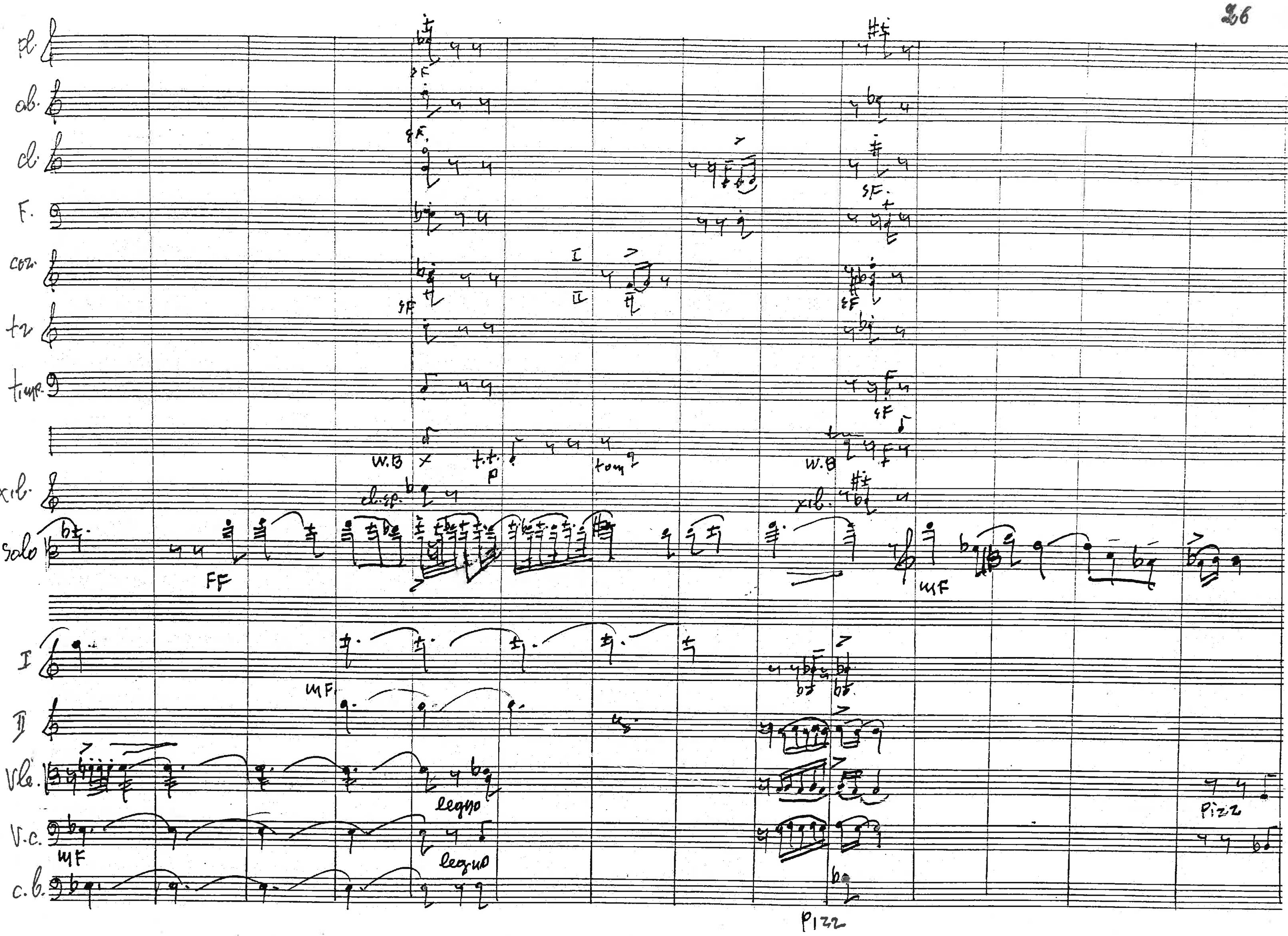


ob.

di \begin{tabular}{l|l|}
\hline & $F$ \\
\hline
\end{tabular}

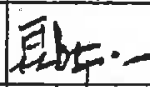

F.

$b_{t}+2+5$

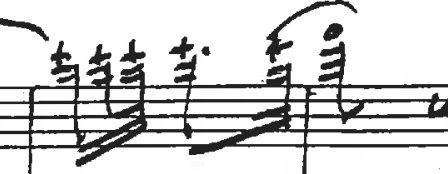

be: $: 5$

$F$

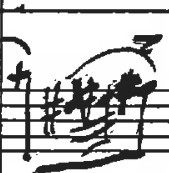

(1)

cor. F:工再-

tr.

tim

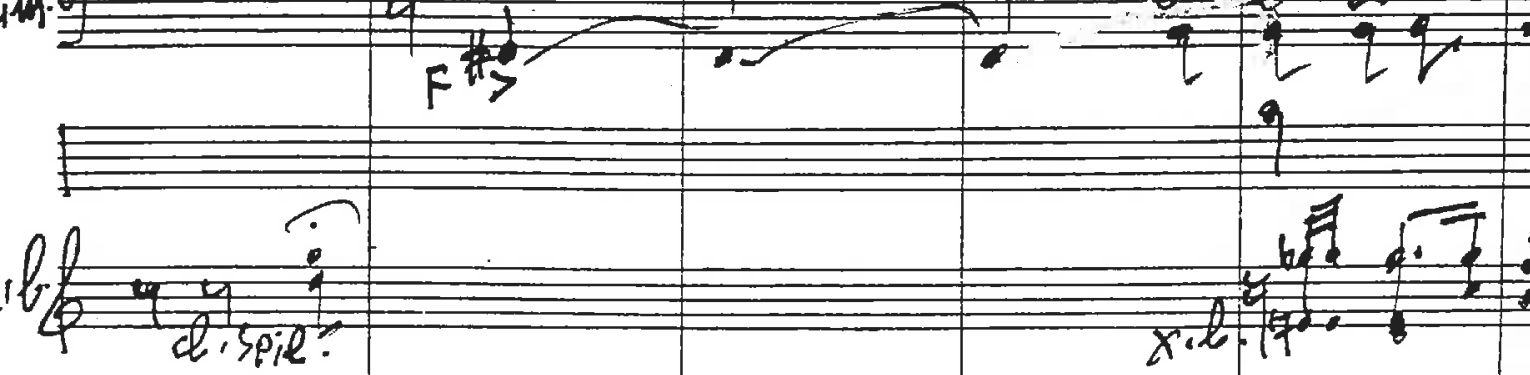

ols ?<smiles>C#C</smiles>

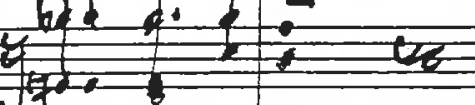

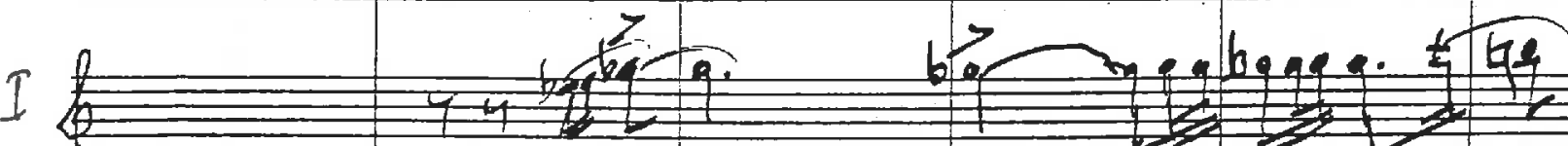
$1+\frac{1}{2}$

II

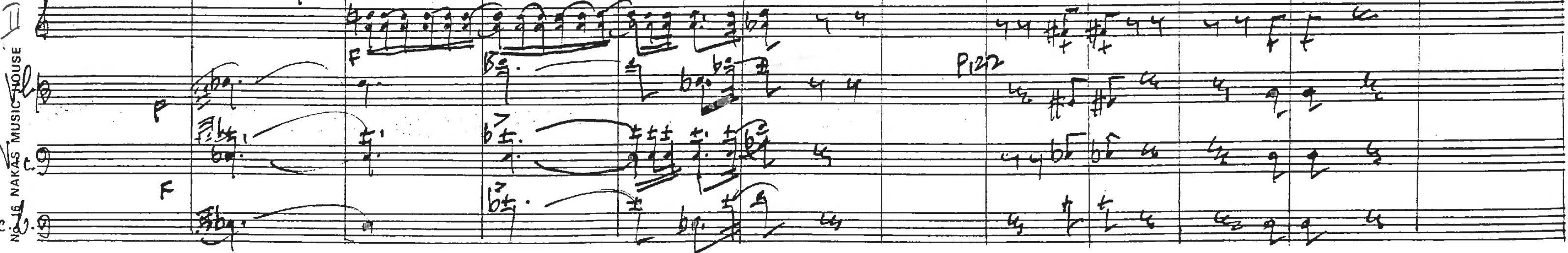




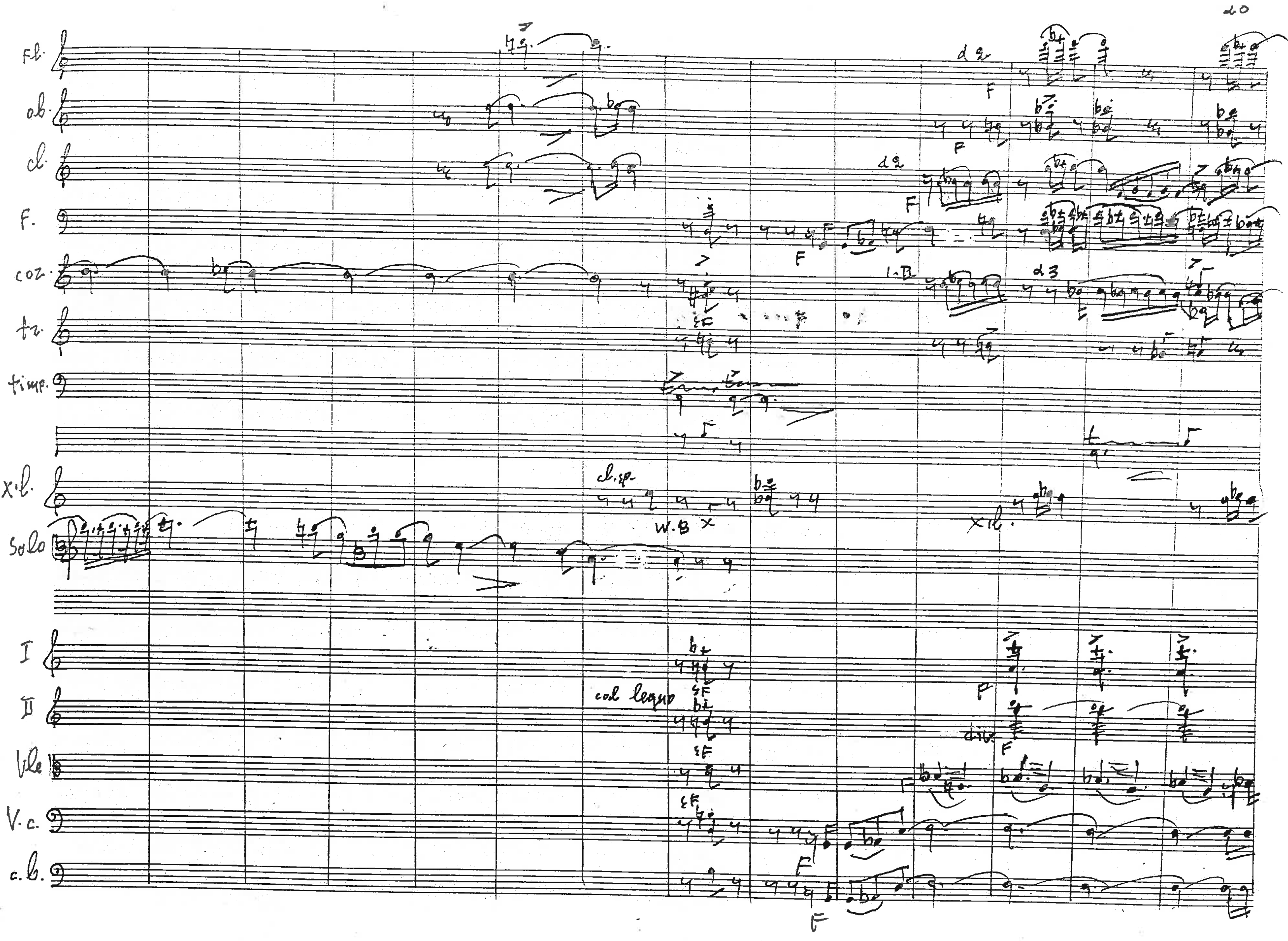




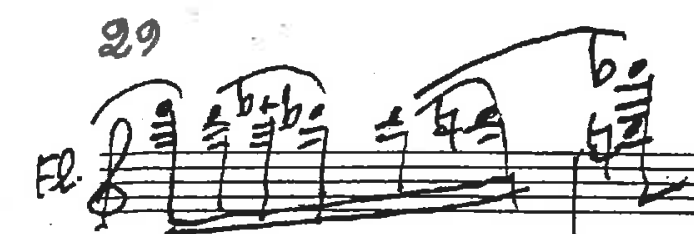

ob. abab bt be a

o.

F.

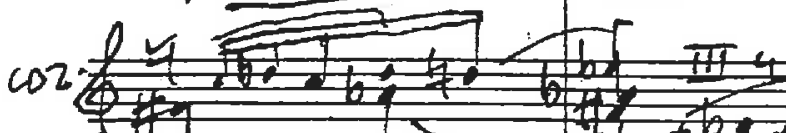

11015919

tr.

tim

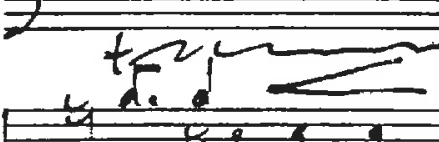

ib.

$x=4=4$

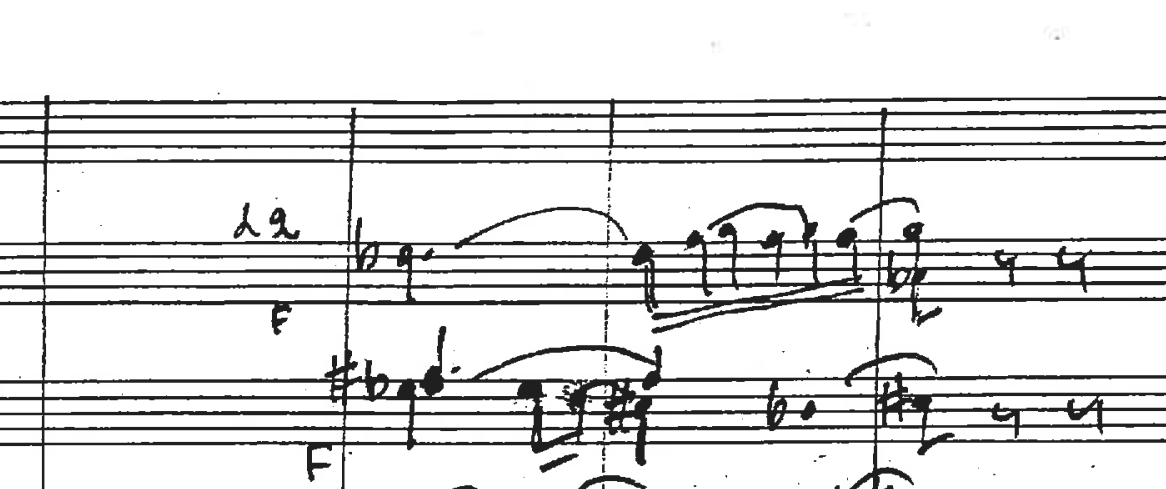

$4=$

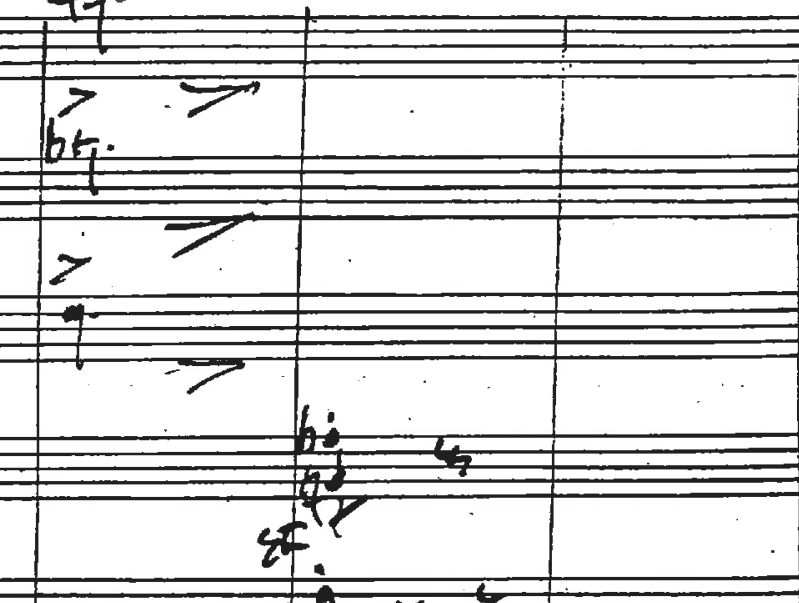

$1-2$ $=2$

IIf

be be

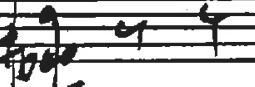

a

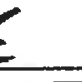

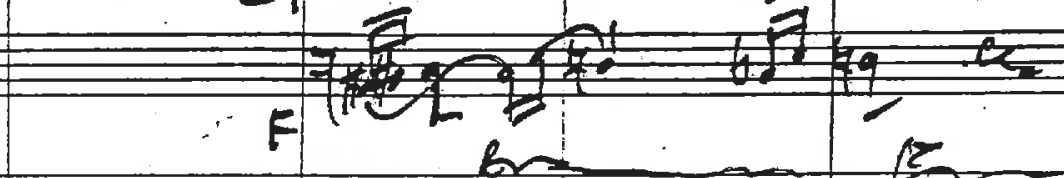

on

$2+\frac{1}{2+2}$

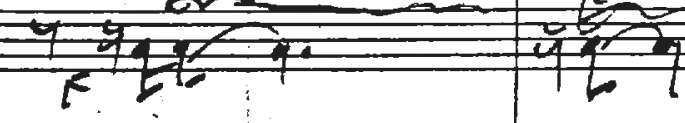

6

41

Solo

f $74^{6}=345$

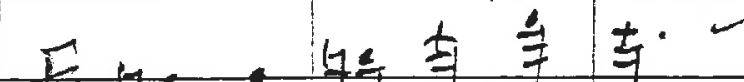
$+9+2$

$1+\frac{1}{t a}$ be the mis

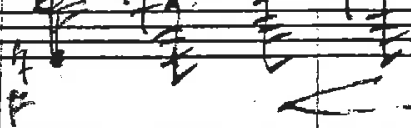

II

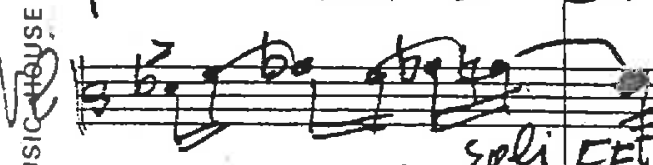

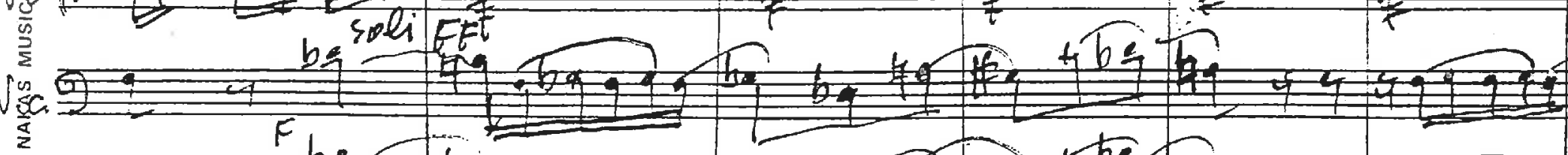

t.t. tom

fom $\quad w .\left.\right|^{x}$

$7=$

chepter

政

, 12
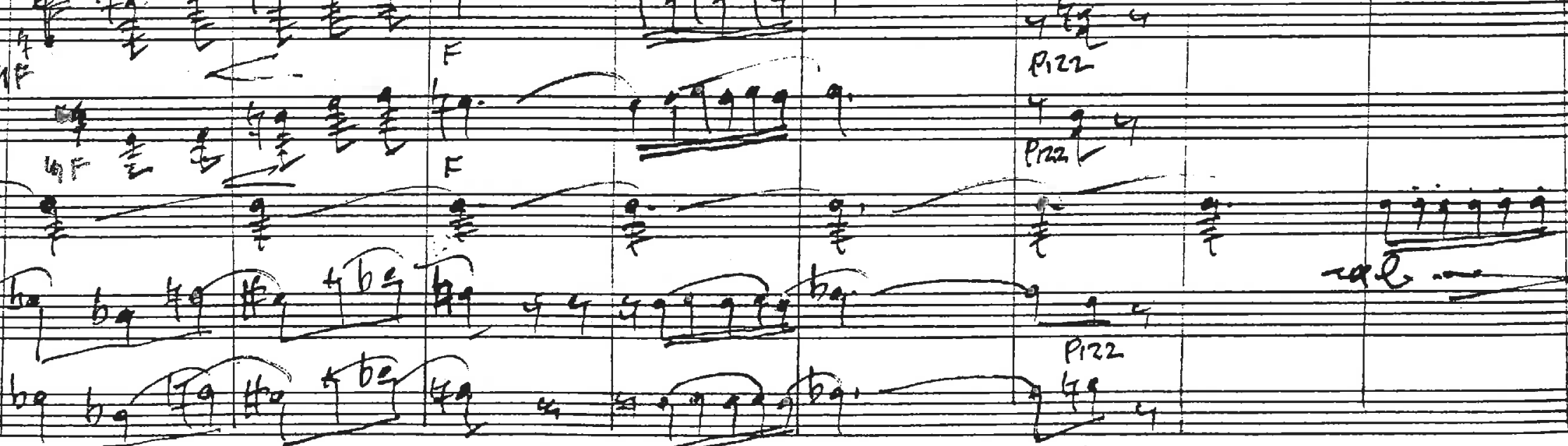


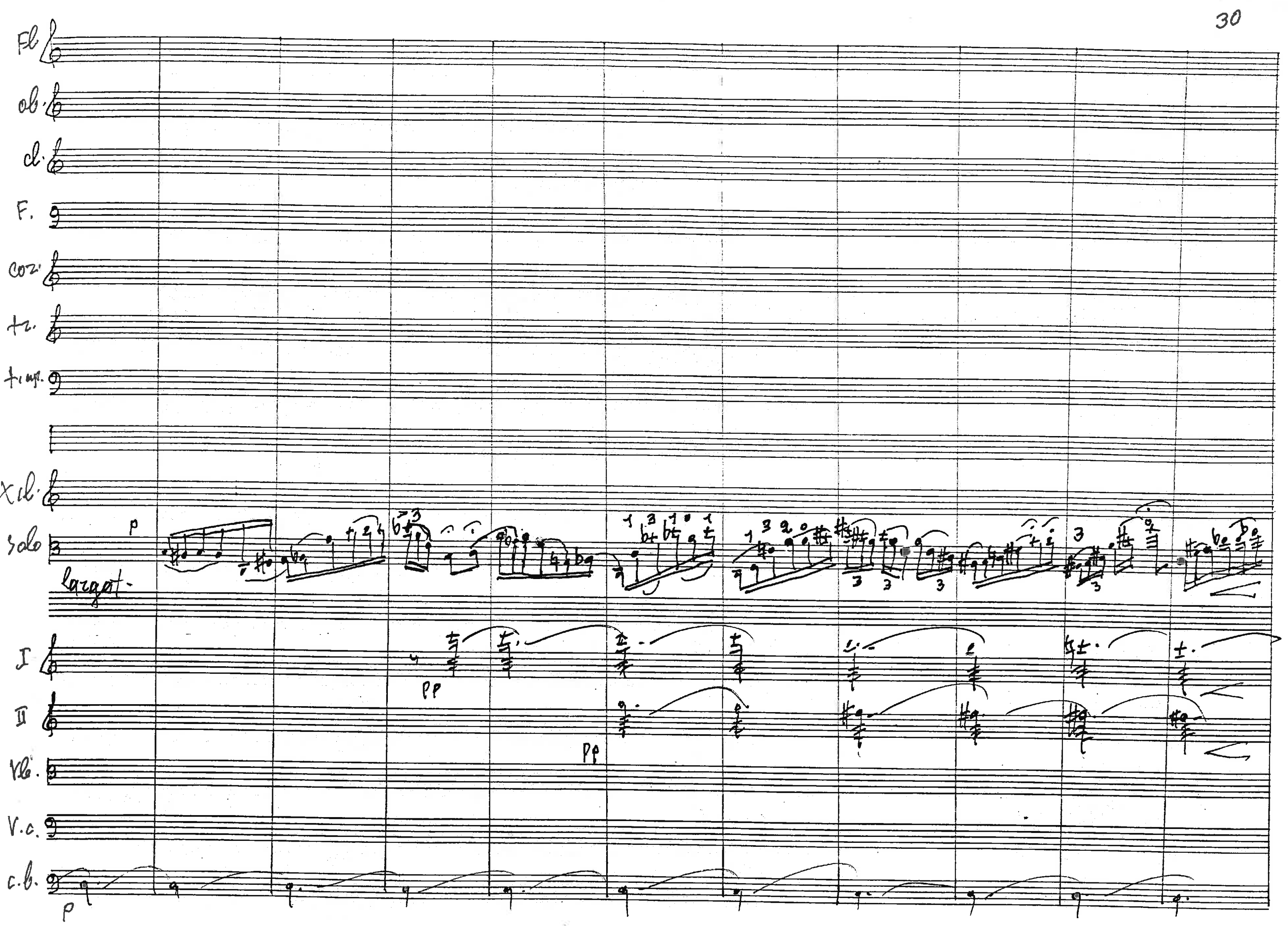




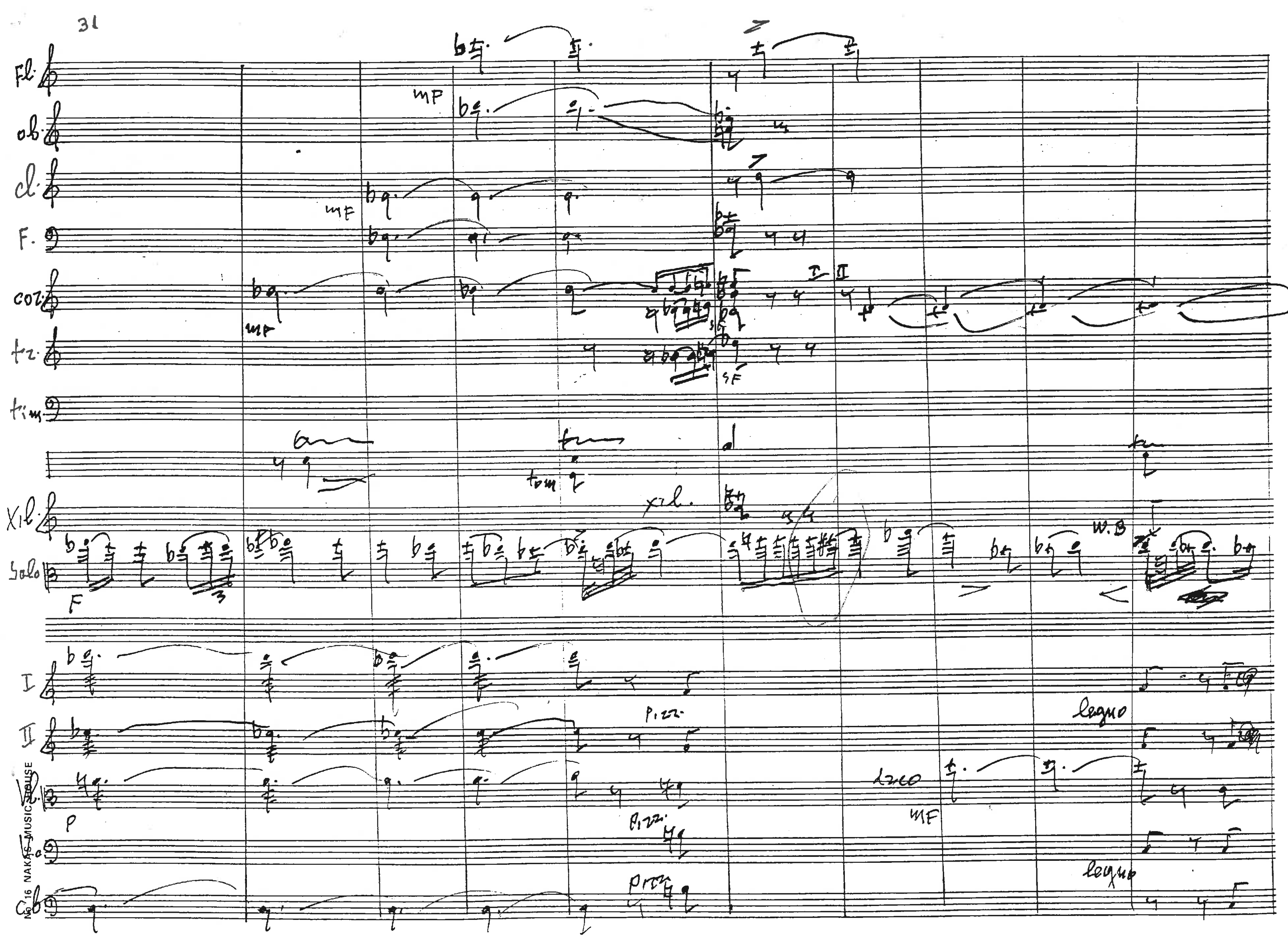


$\mathrm{Fl} .2$

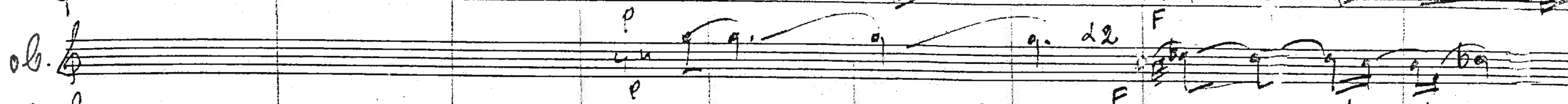

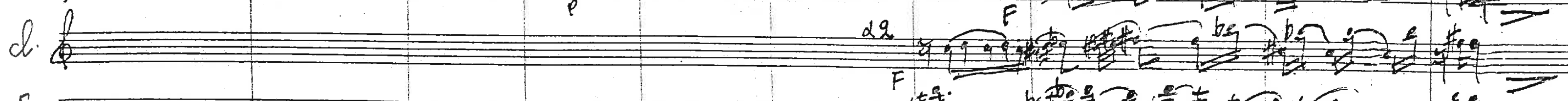

F.

cor. F憬 $42 \cdot$ timp

$\alpha 3$ $F$

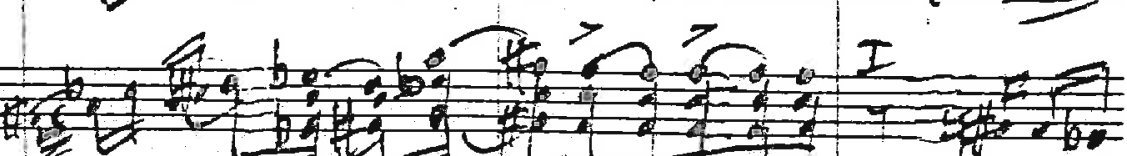
F $242+2$ F 212

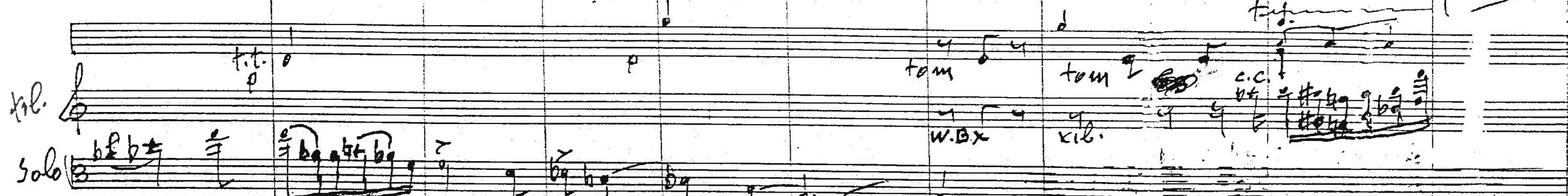
Solo

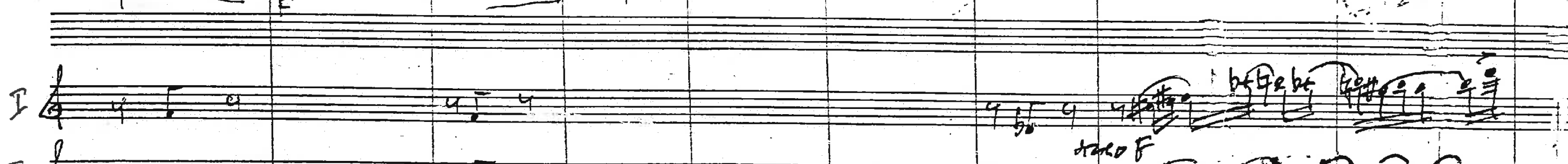
II velegno

V.C. c.b.

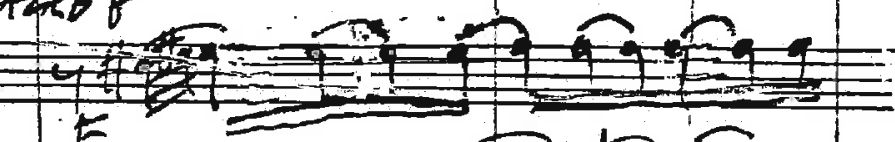

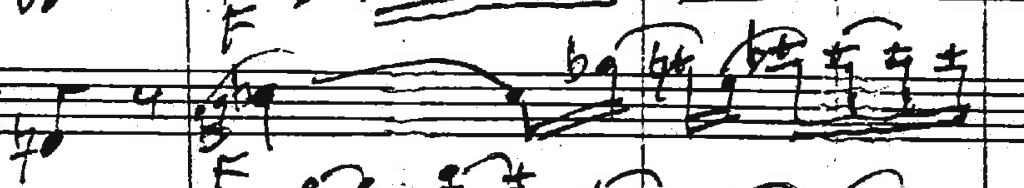
IF or a t 4

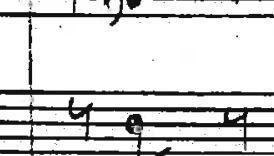

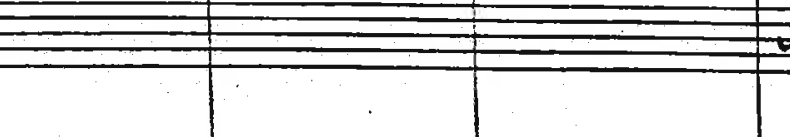

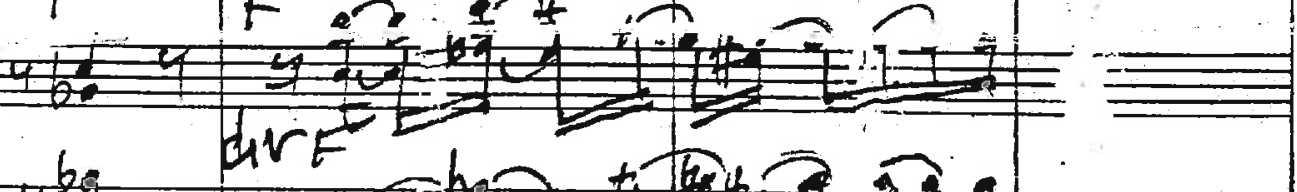

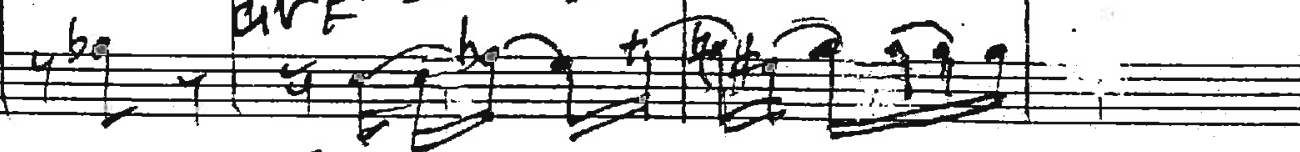


$\frac{1}{12}$

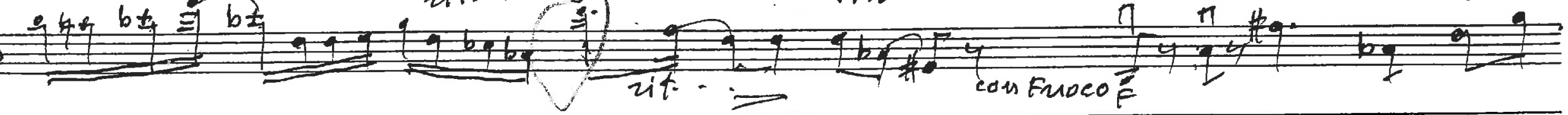

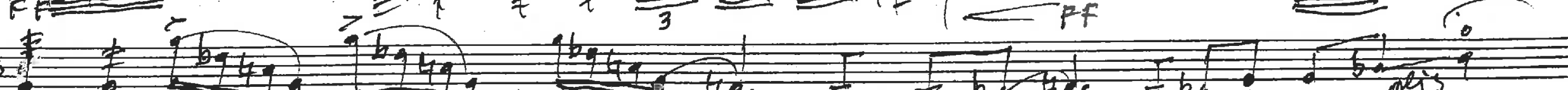
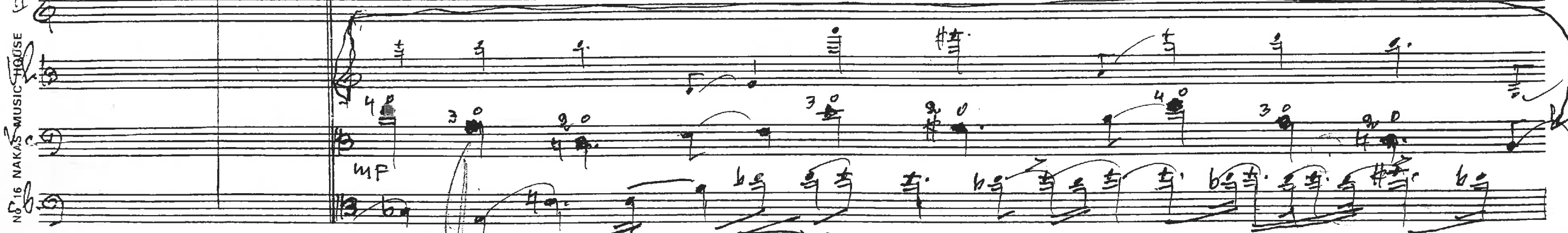


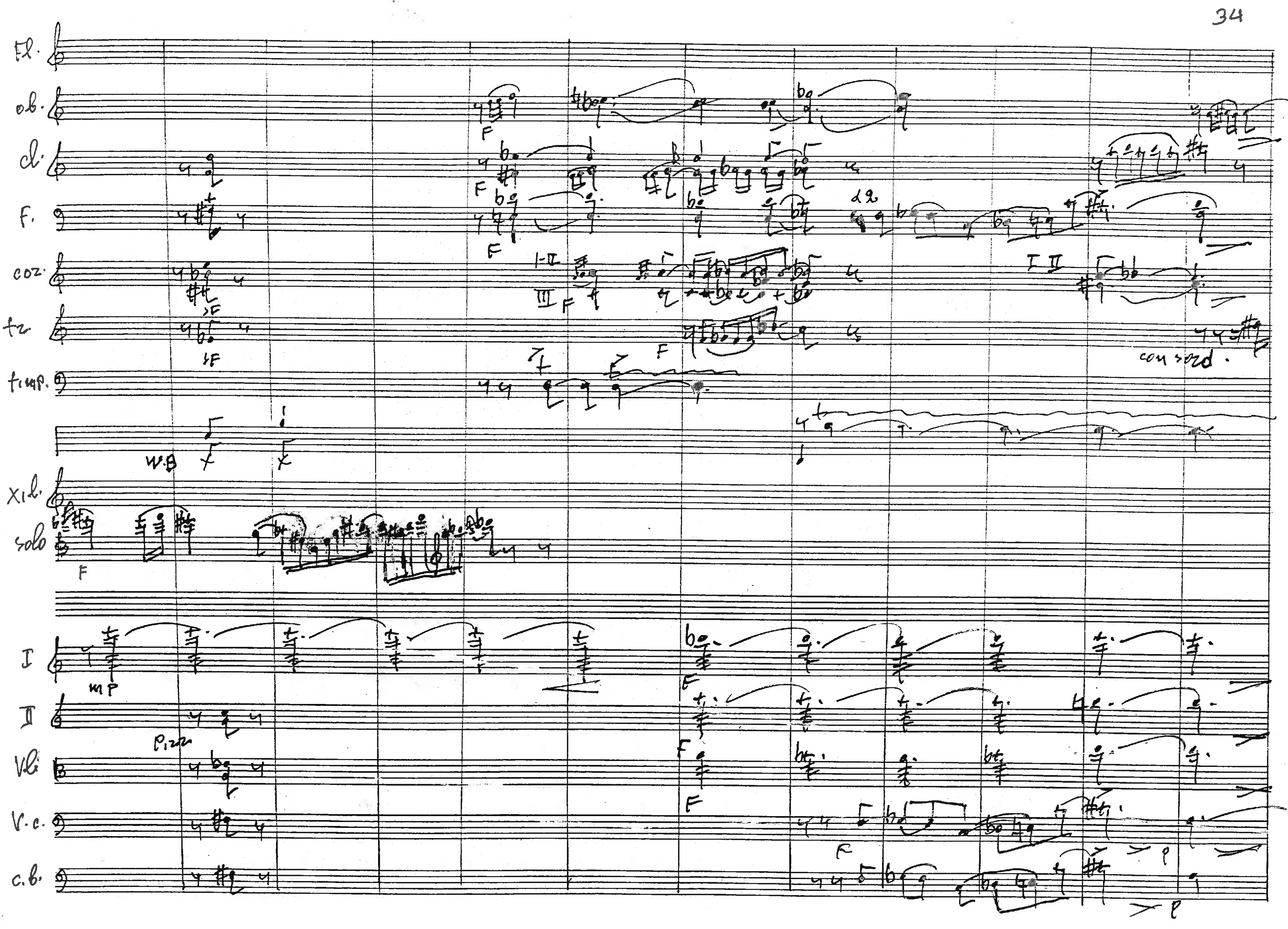




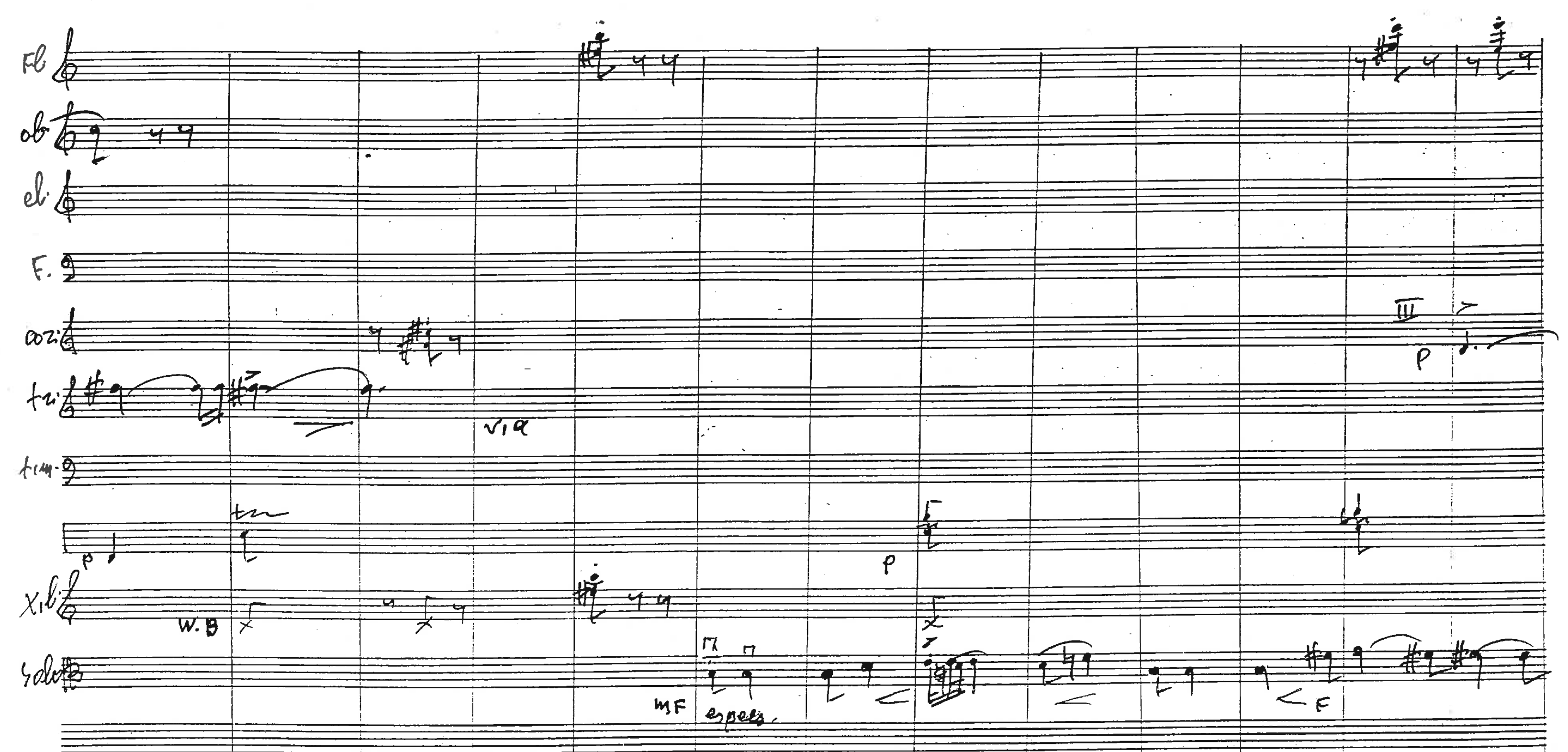

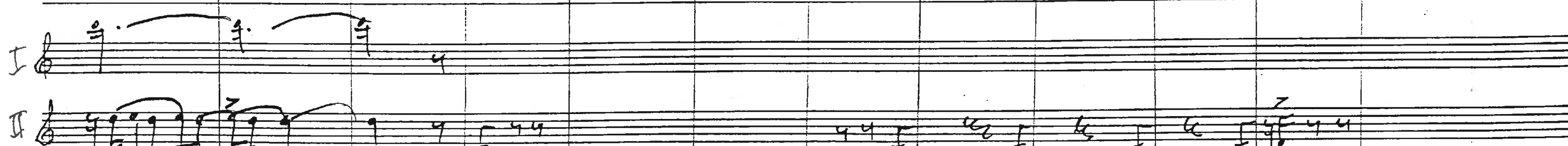

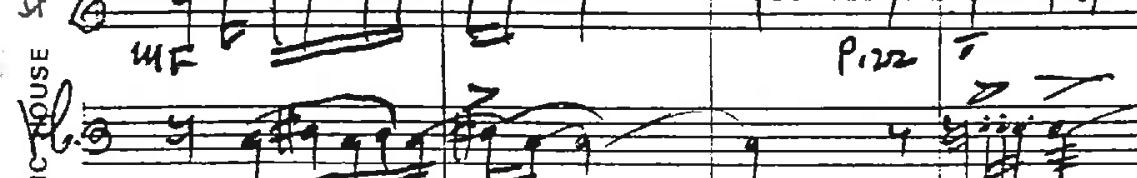

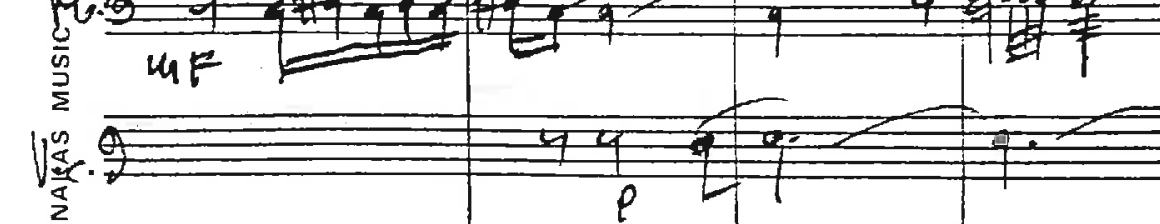

c. 124 $P_{122}$

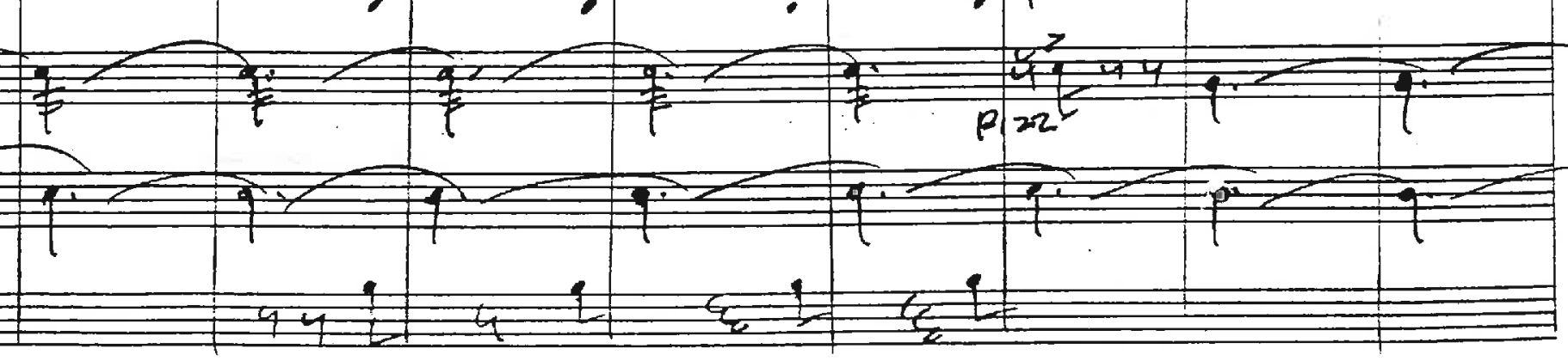


.

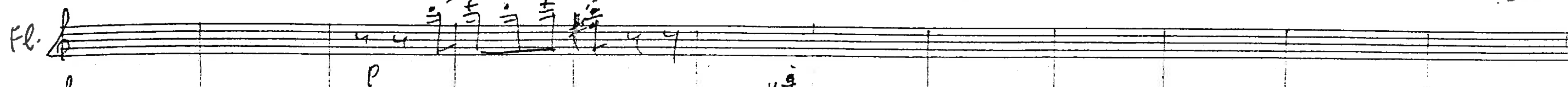
or

d.

F.

$\operatorname{cor} \frac{1}{9 ! 2}$

$\imath_{\imath} \cdot 1$

timp.

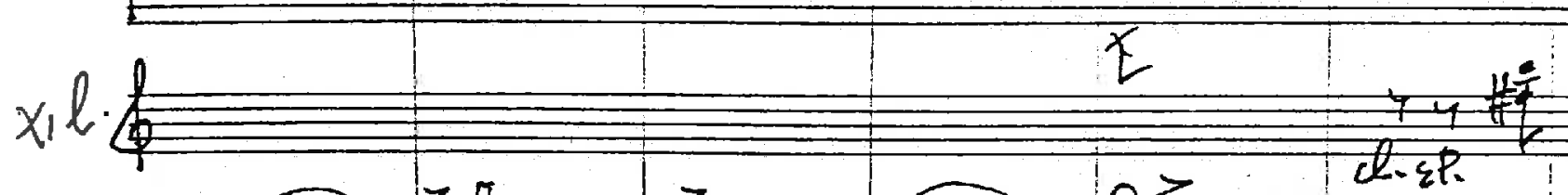

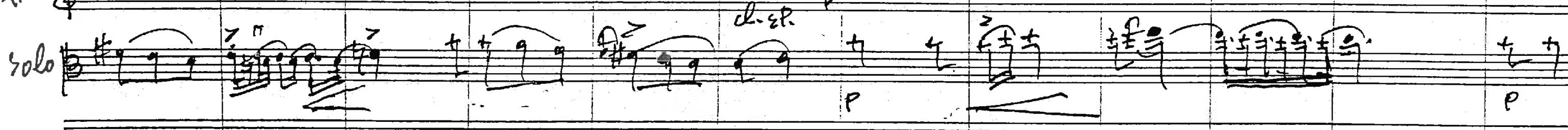

I

D

vle

v.c.

c.b.

1

9.

i. $9-79$

$4-19-7$.

a.

7
$\square$

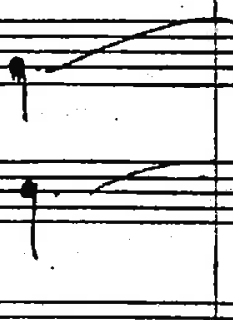

2

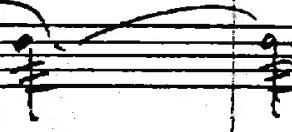

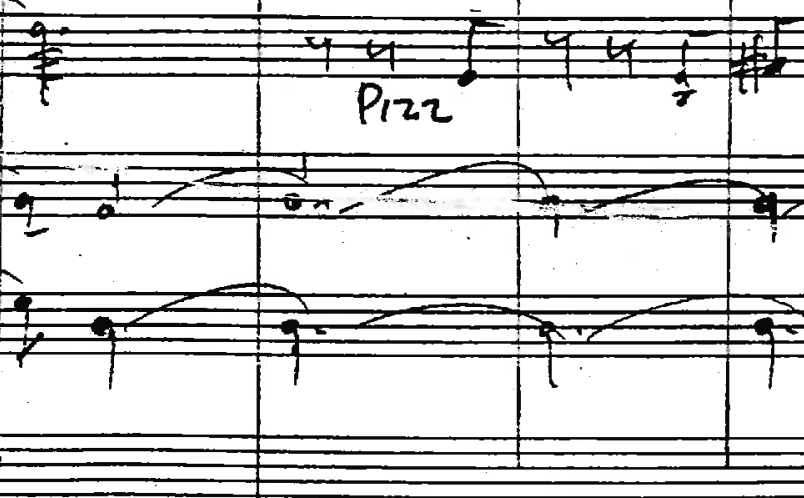

4
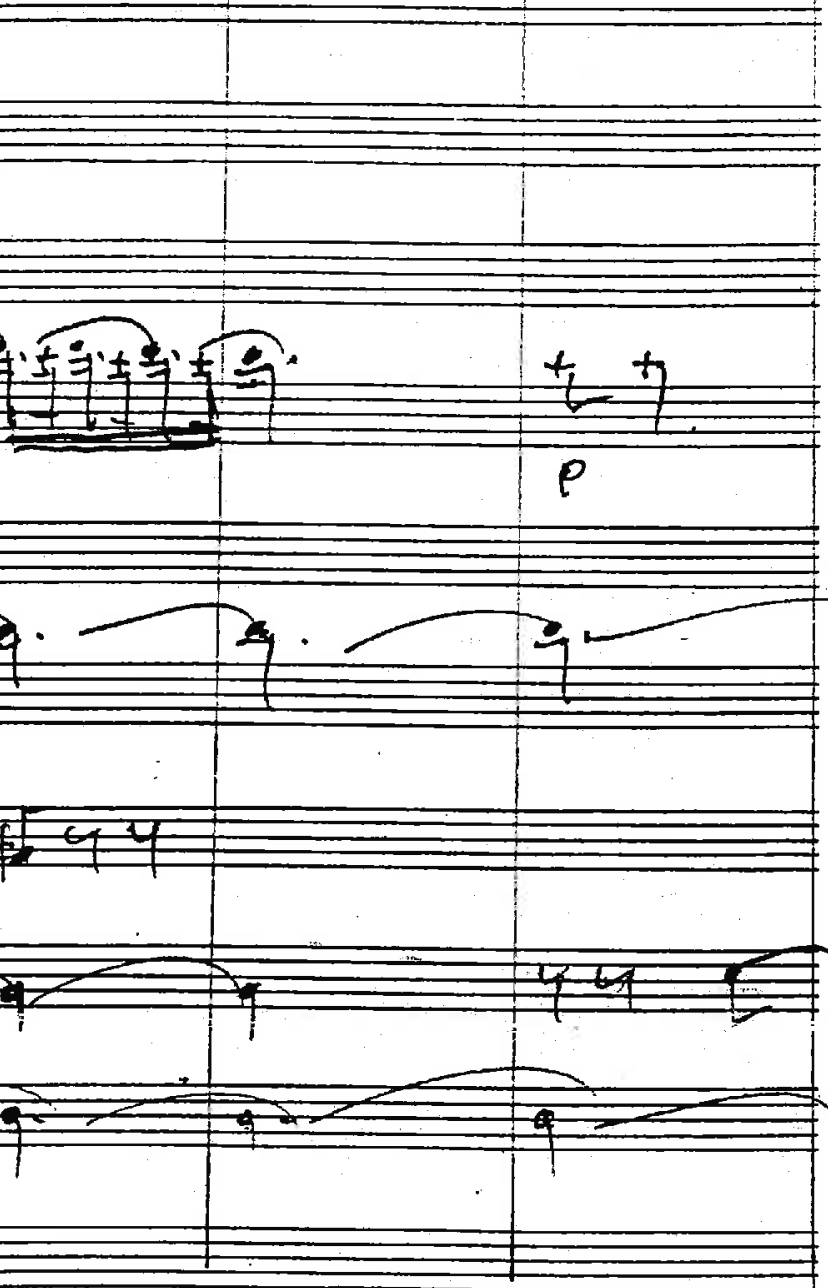
Allog $20 ;=90$
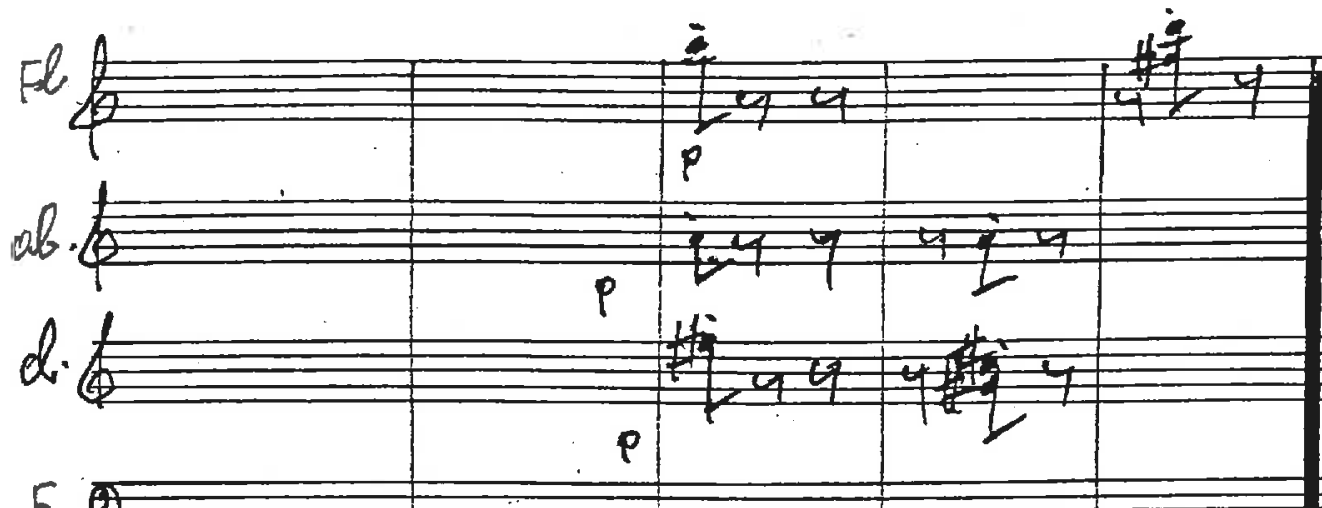

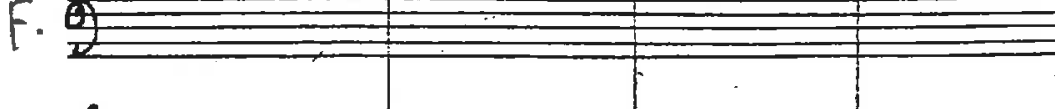

$\infty$

to

tin

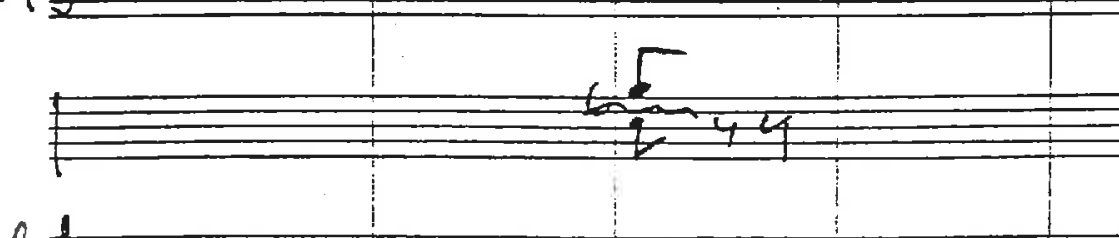

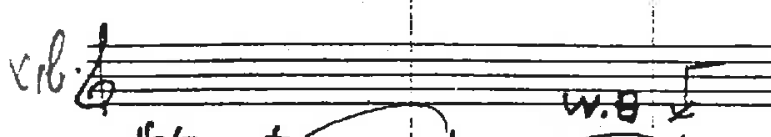

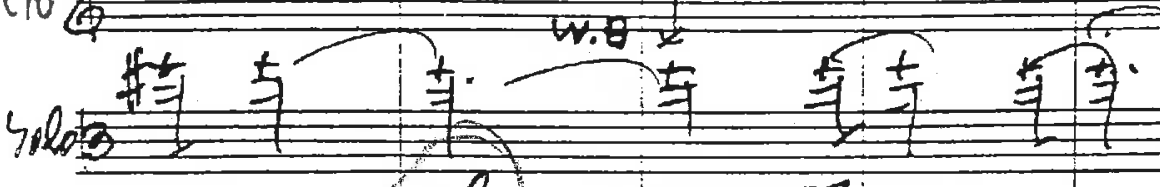
$(7 a h) \cdot \because \rightleftharpoons$

$I \frac{9-1}{2+1}$

P122

II

(I)

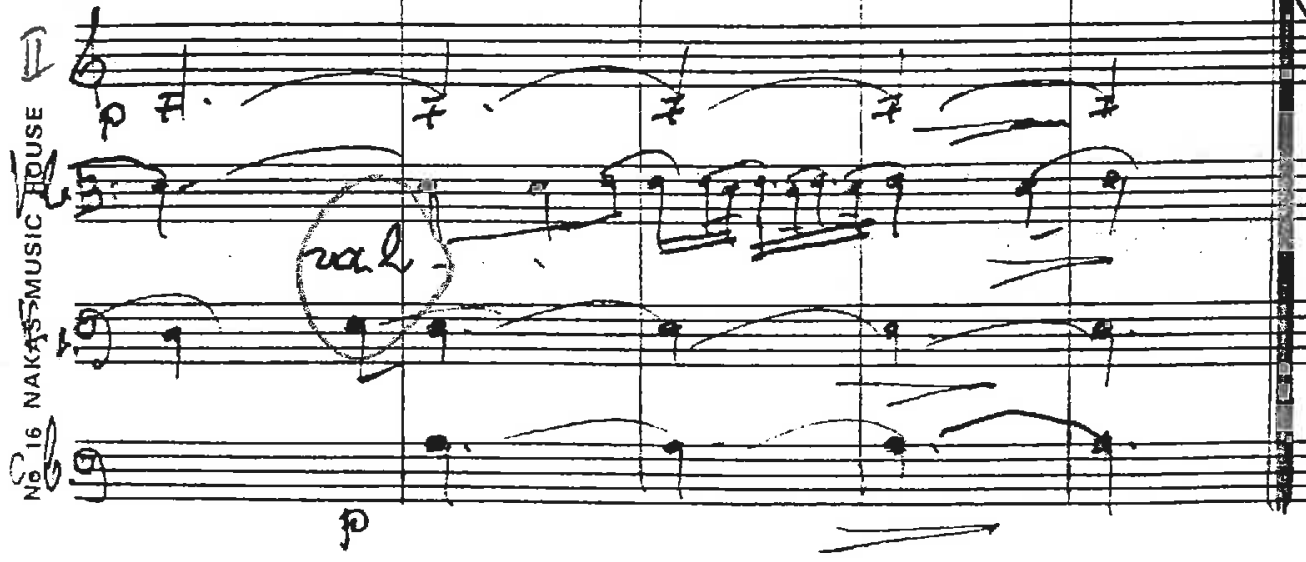

attaca

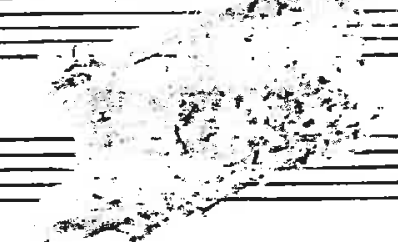

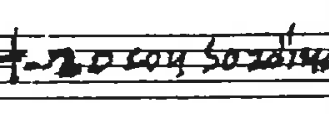
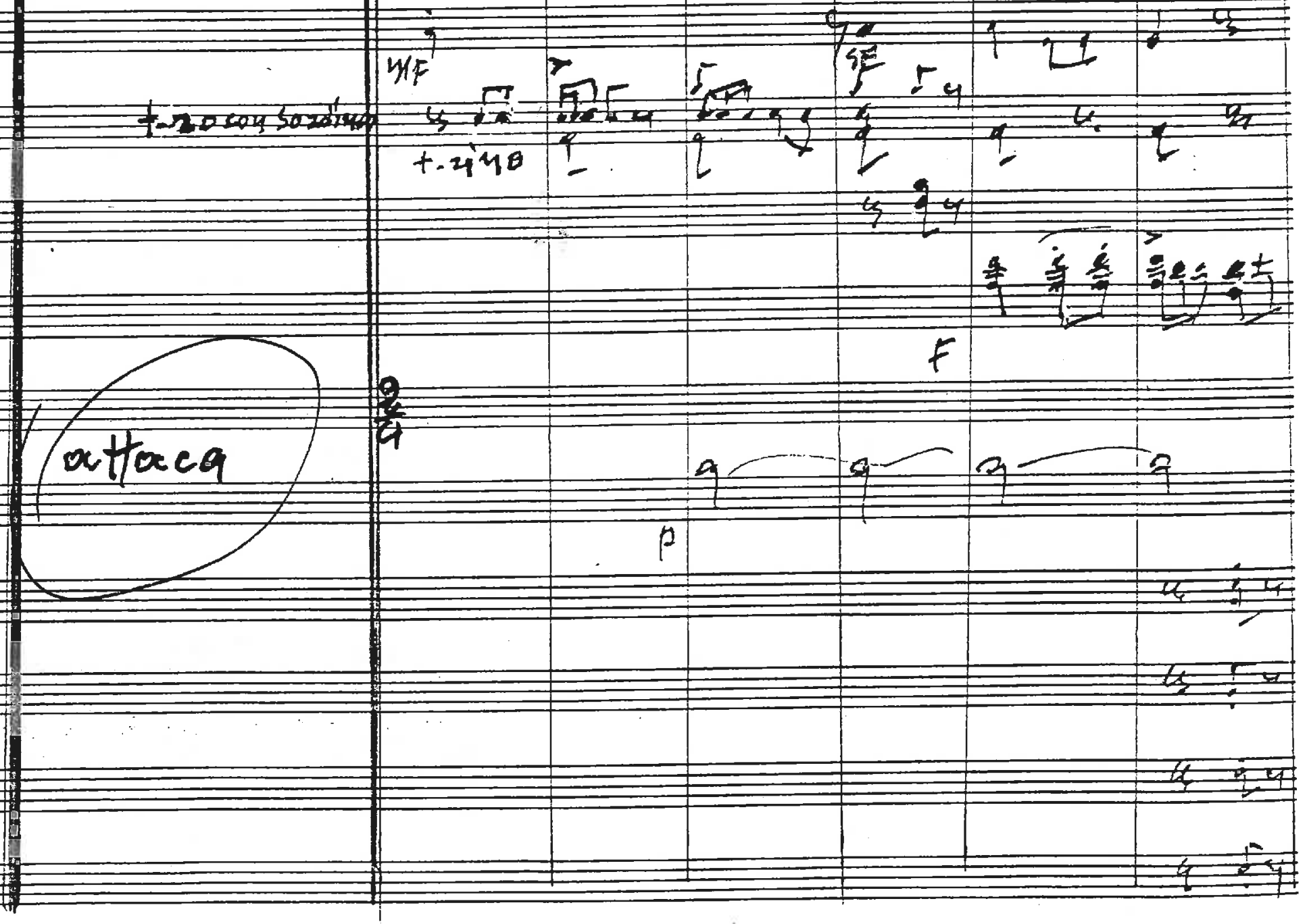
咴 $\infty$ d

\& wo 地

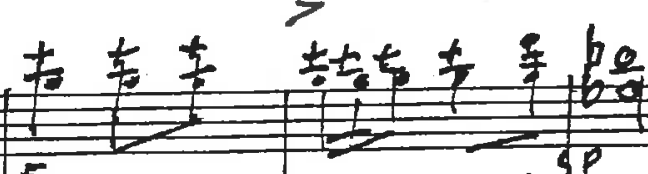

व.

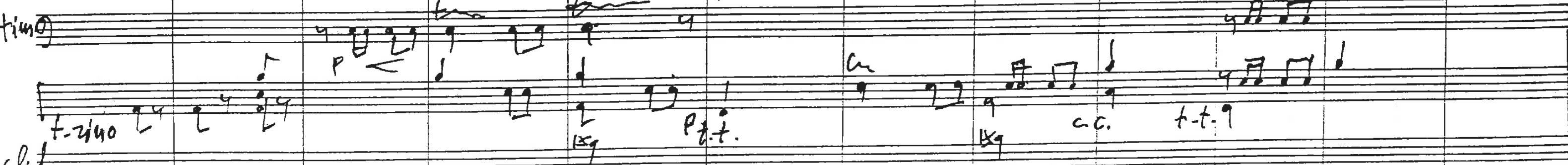

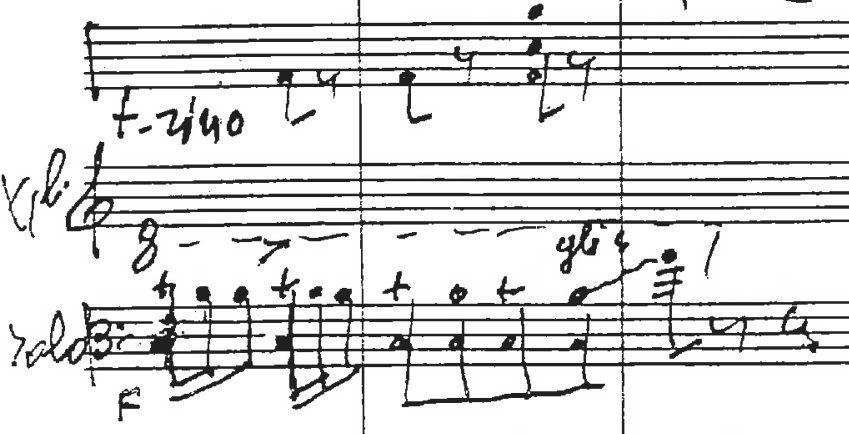

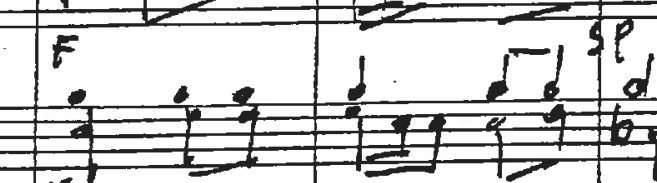

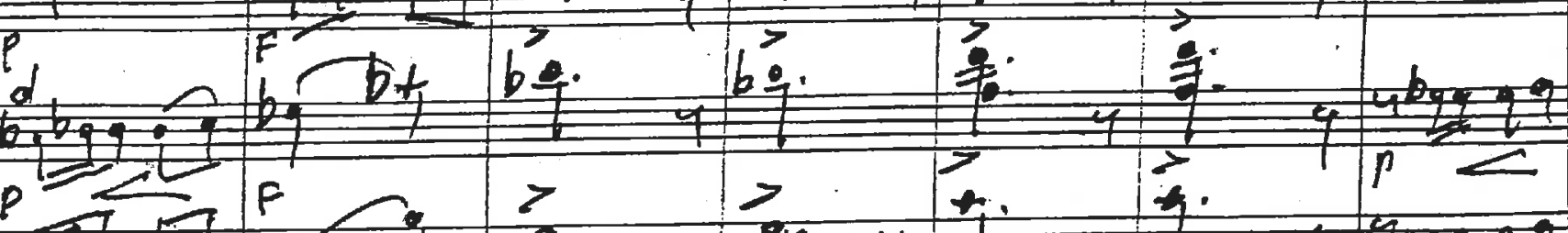

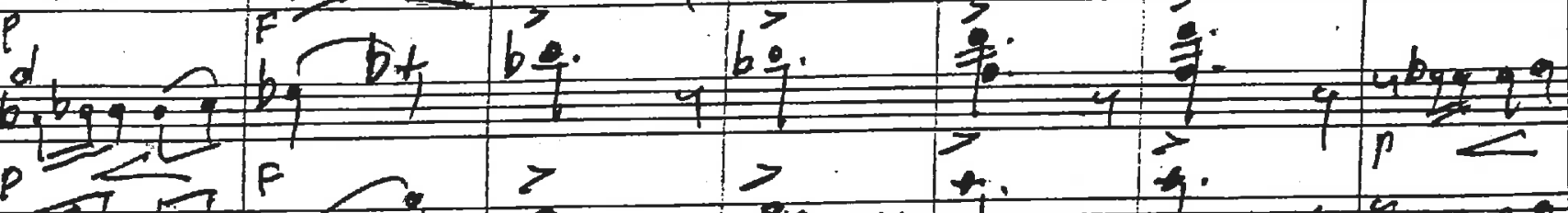

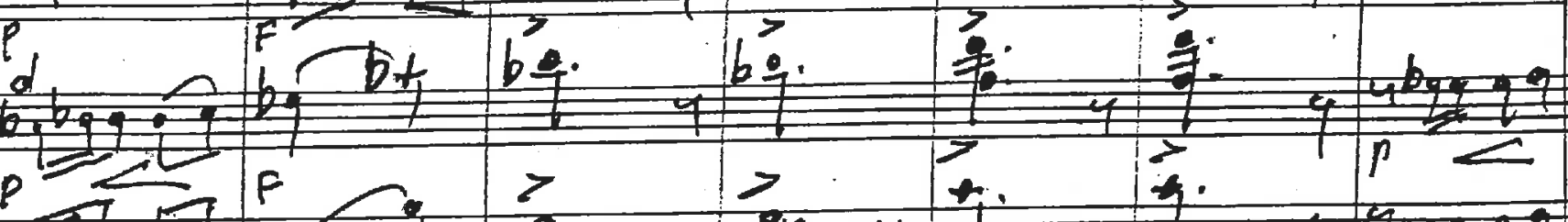

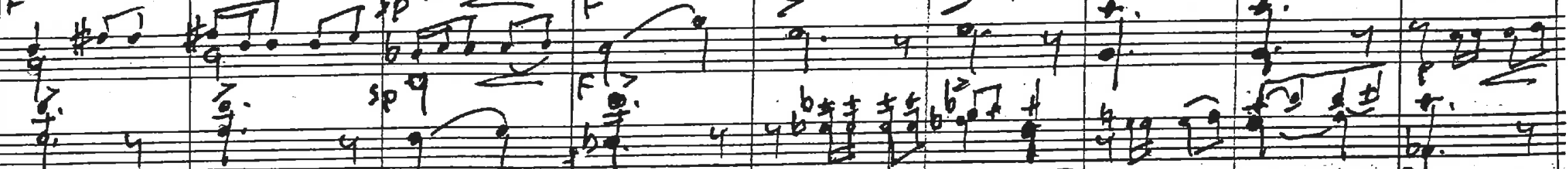

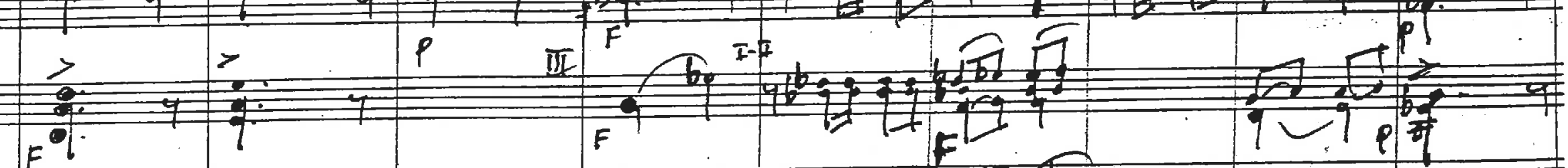
\%

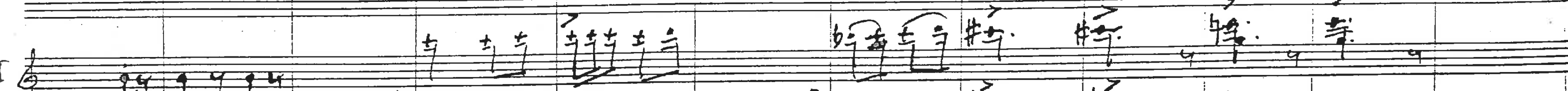

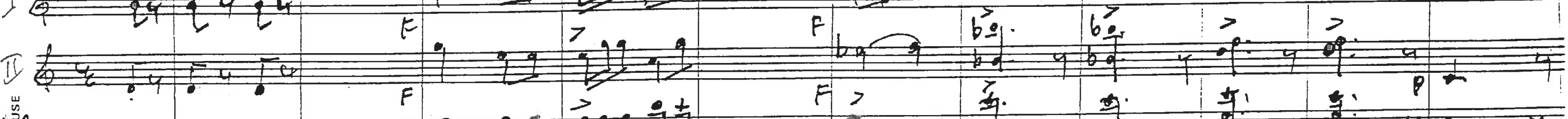
(1) F

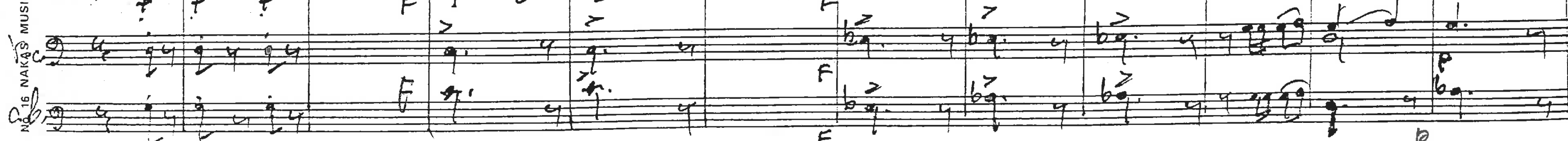
क 


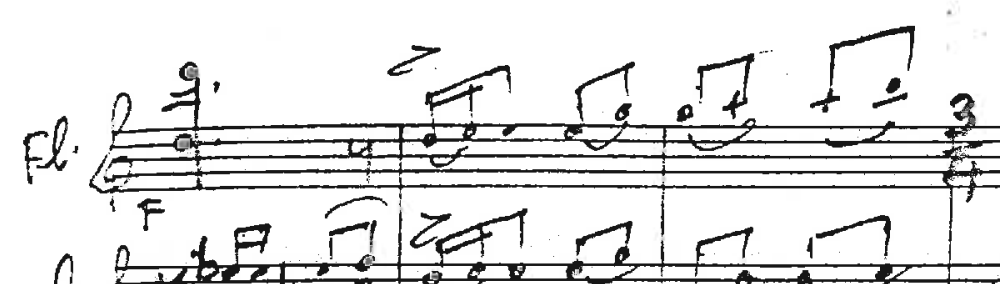

40

ob. l. $F$

d.

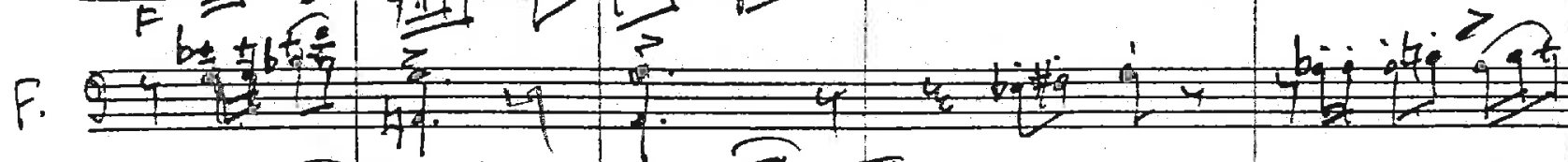

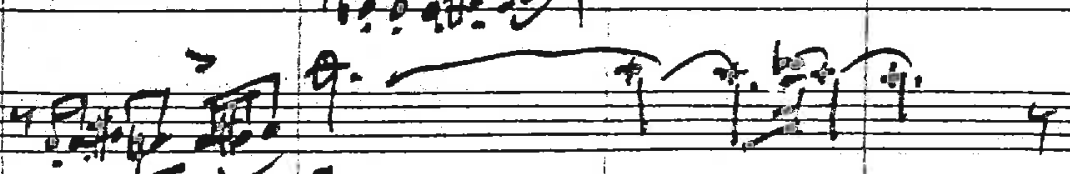

$\cot _{0}$

的

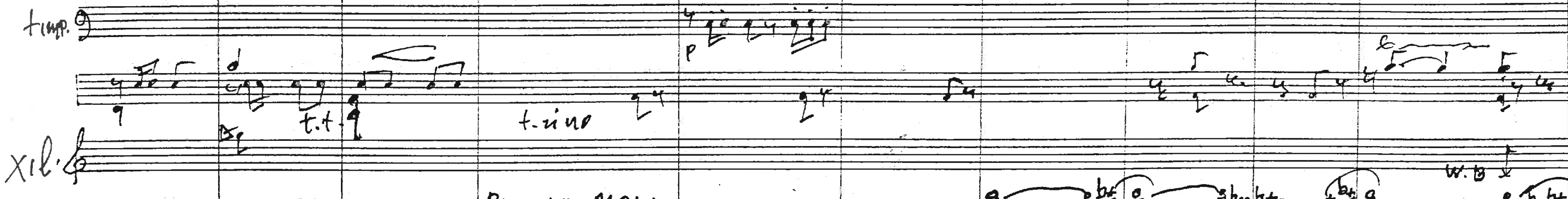
solos

I

Preopin meno

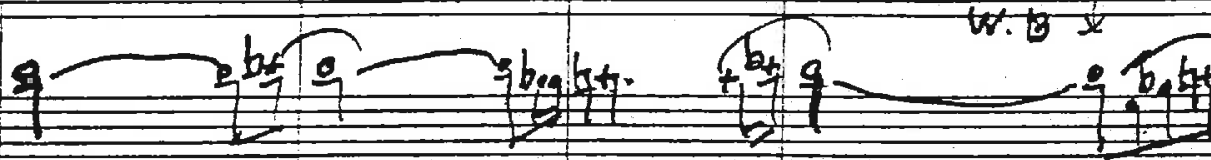

II 12

Wh

V.c.

$F$

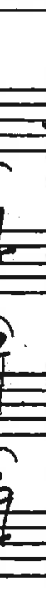

4

F contab. 


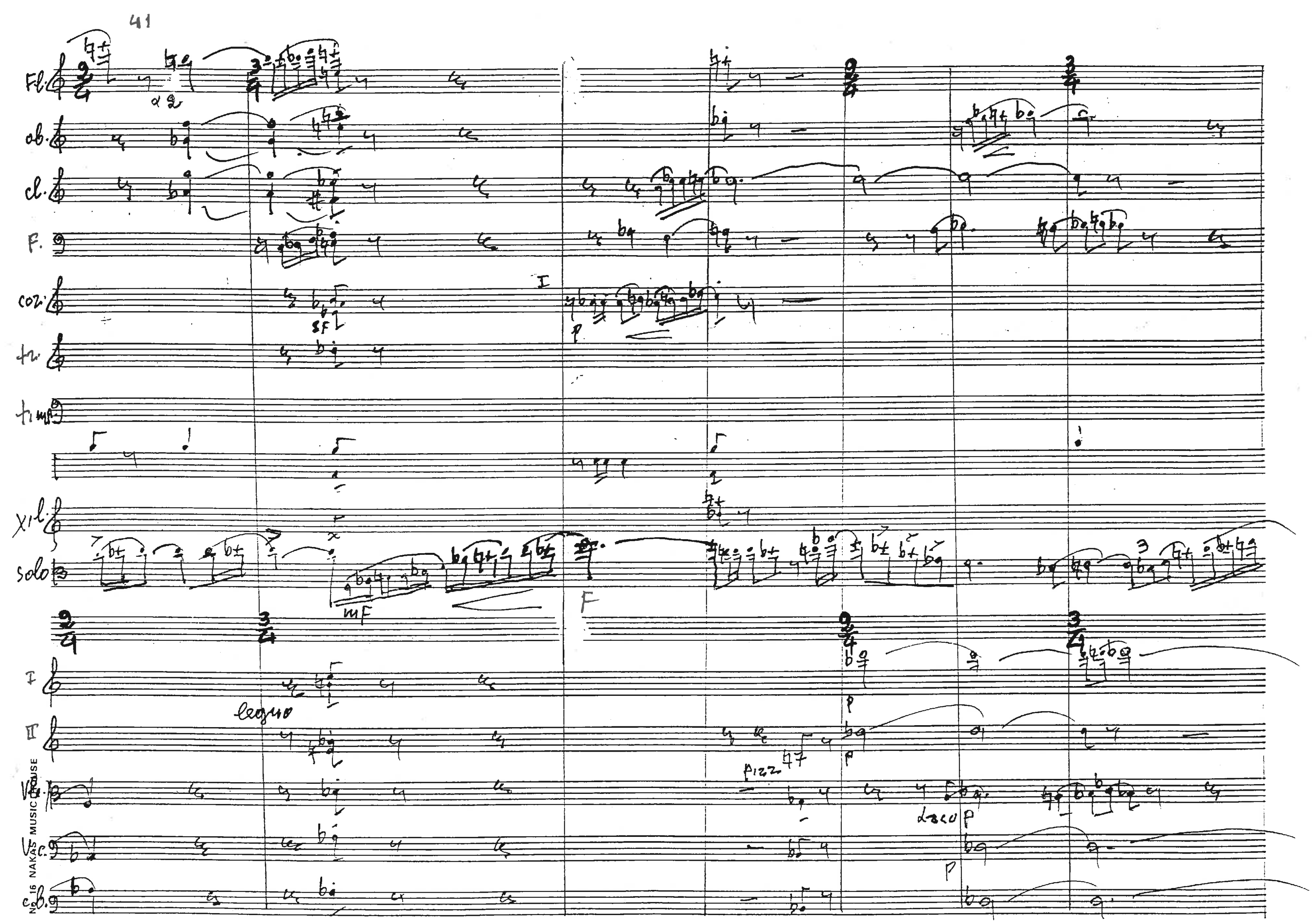




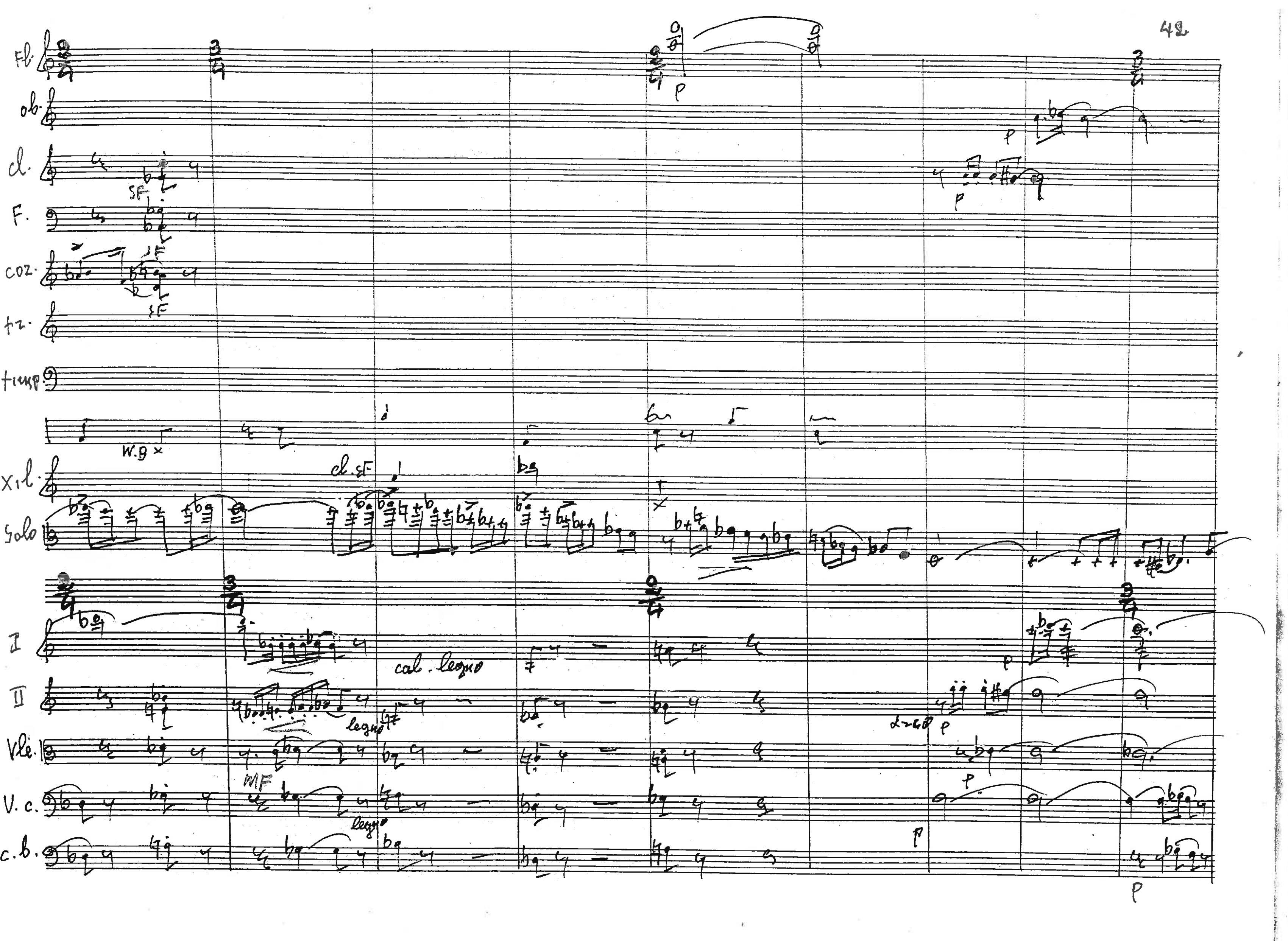




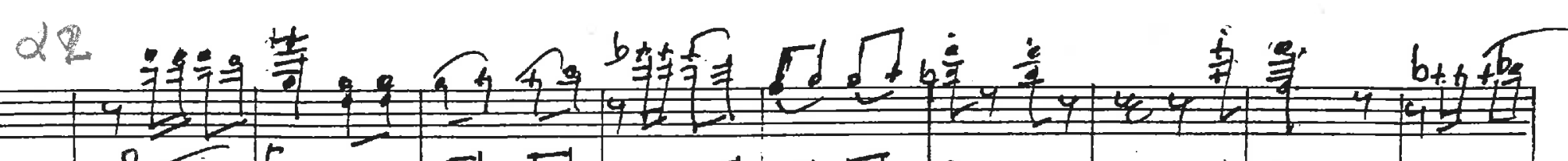

a.

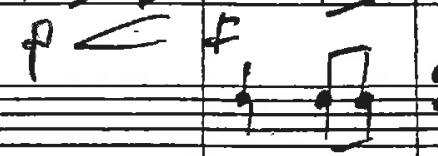

$d$

F.

IIII

$\operatorname{cor} \frac{40+0,2}{m F}=$

fr. $M F=$

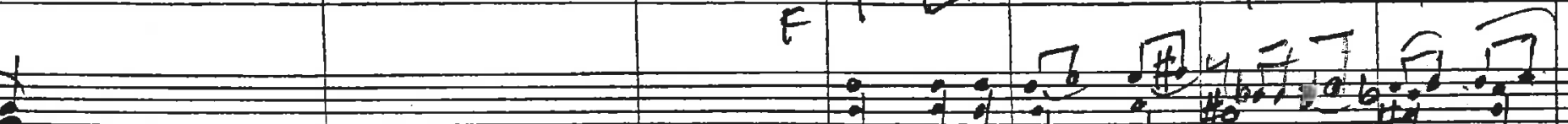

(1)

\begin{tabular}{ll}
\hline \\
\hline
\end{tabular}

x俻

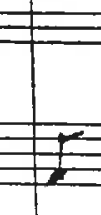

\begin{tabular}{l|l|l|} 
& & \\
\hline
\end{tabular}

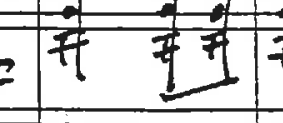

\#

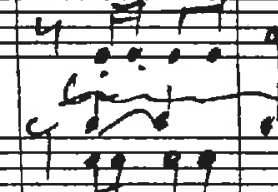

2

of 2.
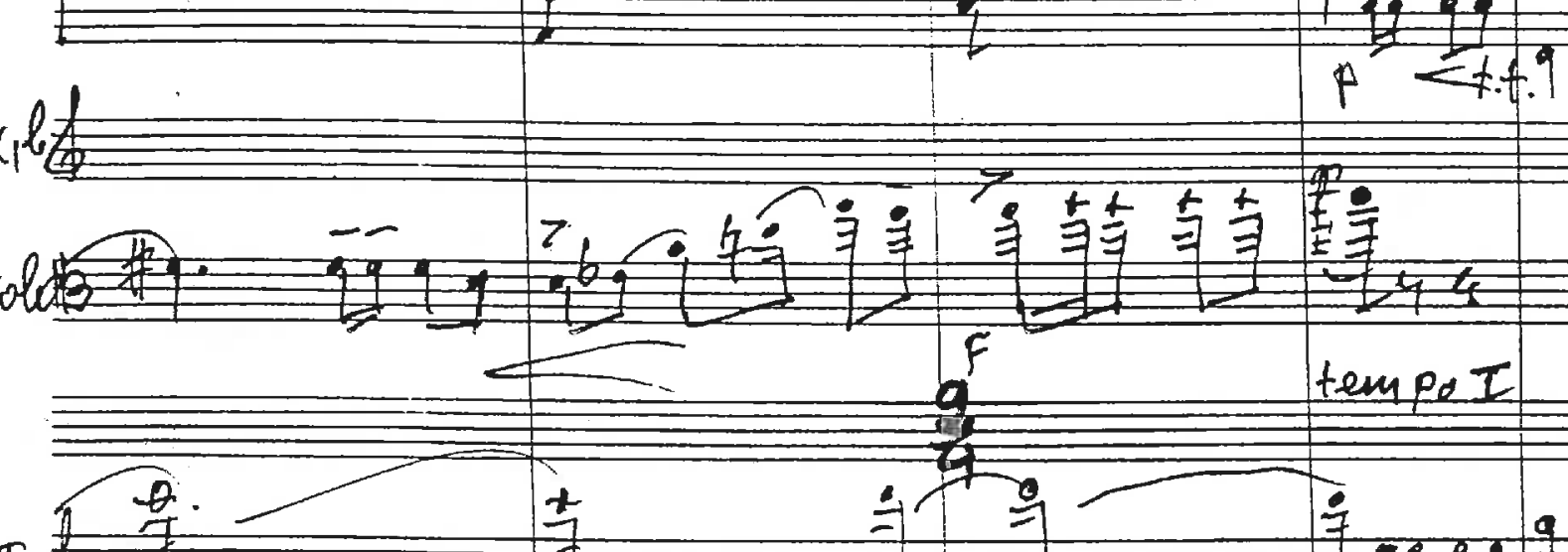

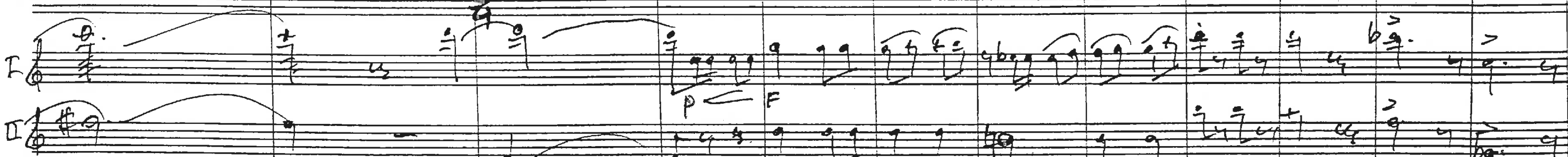

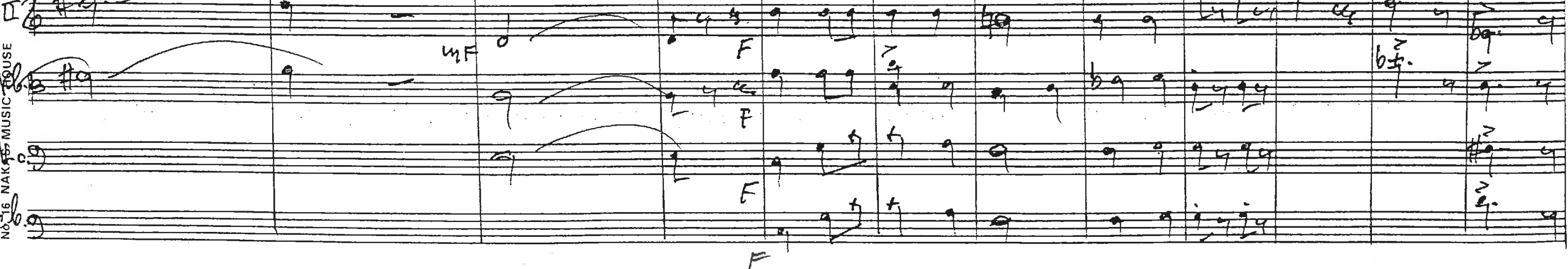




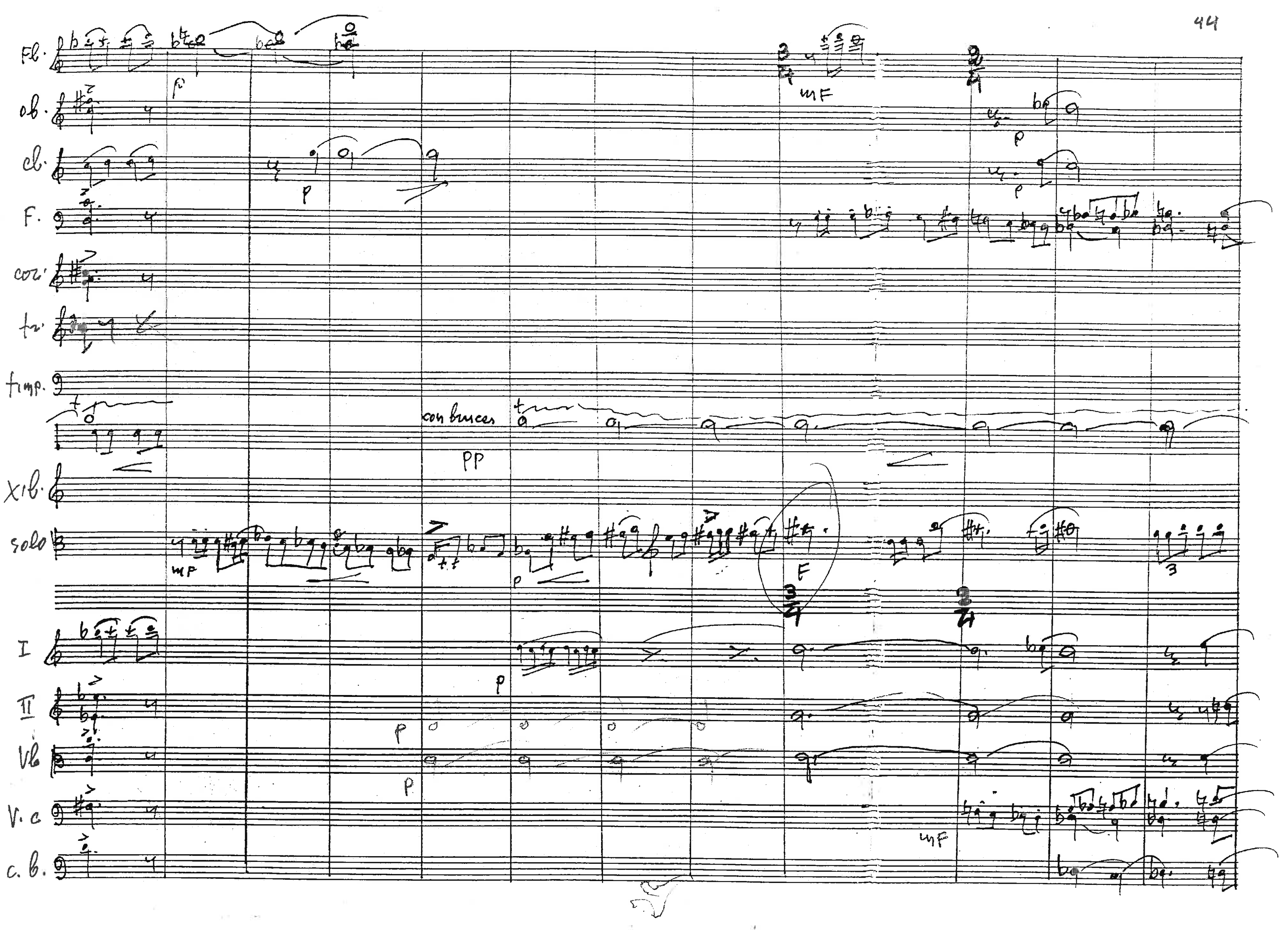


Ab

ob

$d \cdot \frac{2}{21}$

F.

$\cos 2$

巾

$\lim _{4}$

$\times 0$

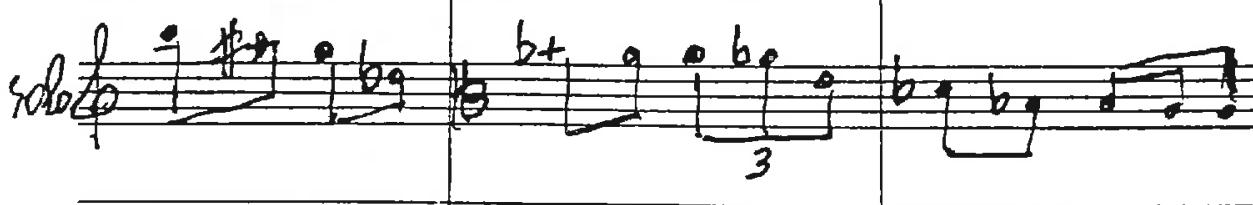

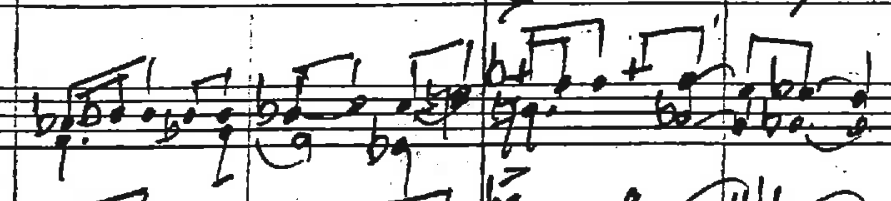

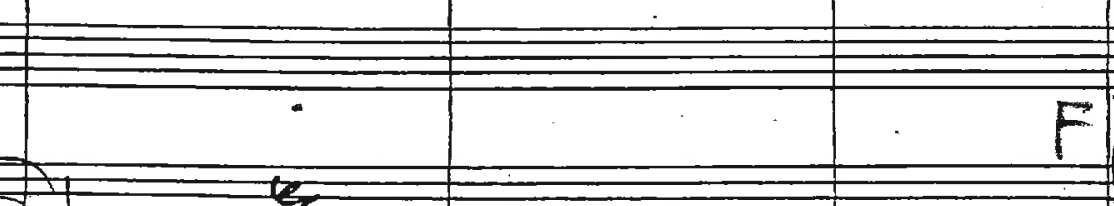

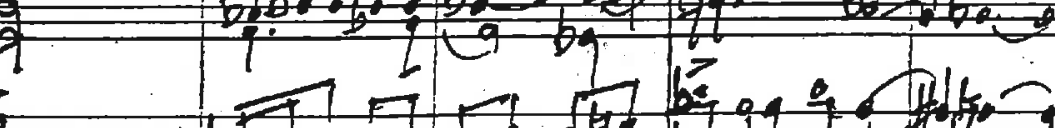

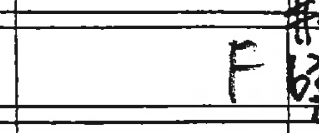

$60 \quad 6 \sqrt{5 !} \sqrt{6} 65 \sqrt{5}$

प⿺辶⿻

it 1

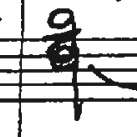

metent

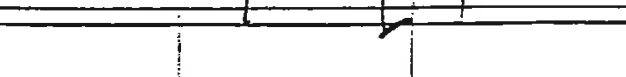

114

$p$ 2

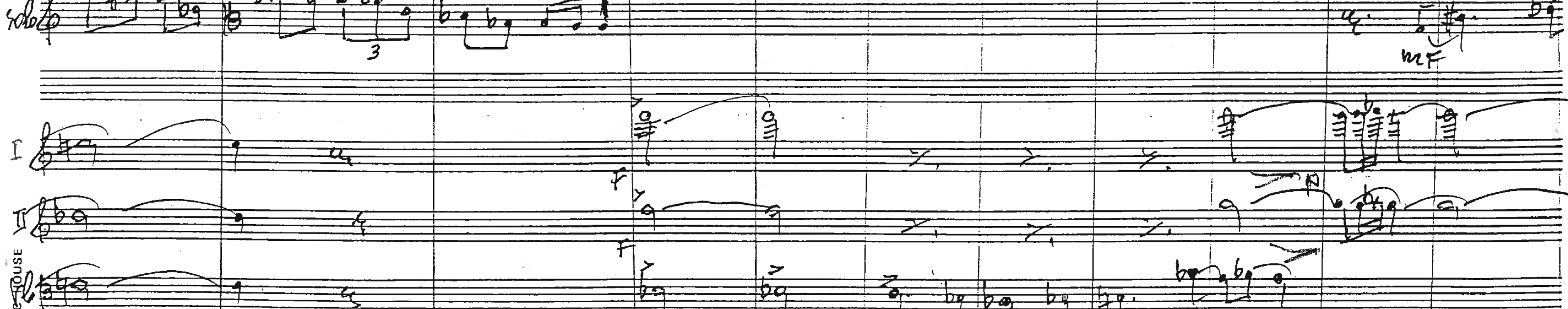
be $\longrightarrow$ 2 $\frac{1}{2}$

c
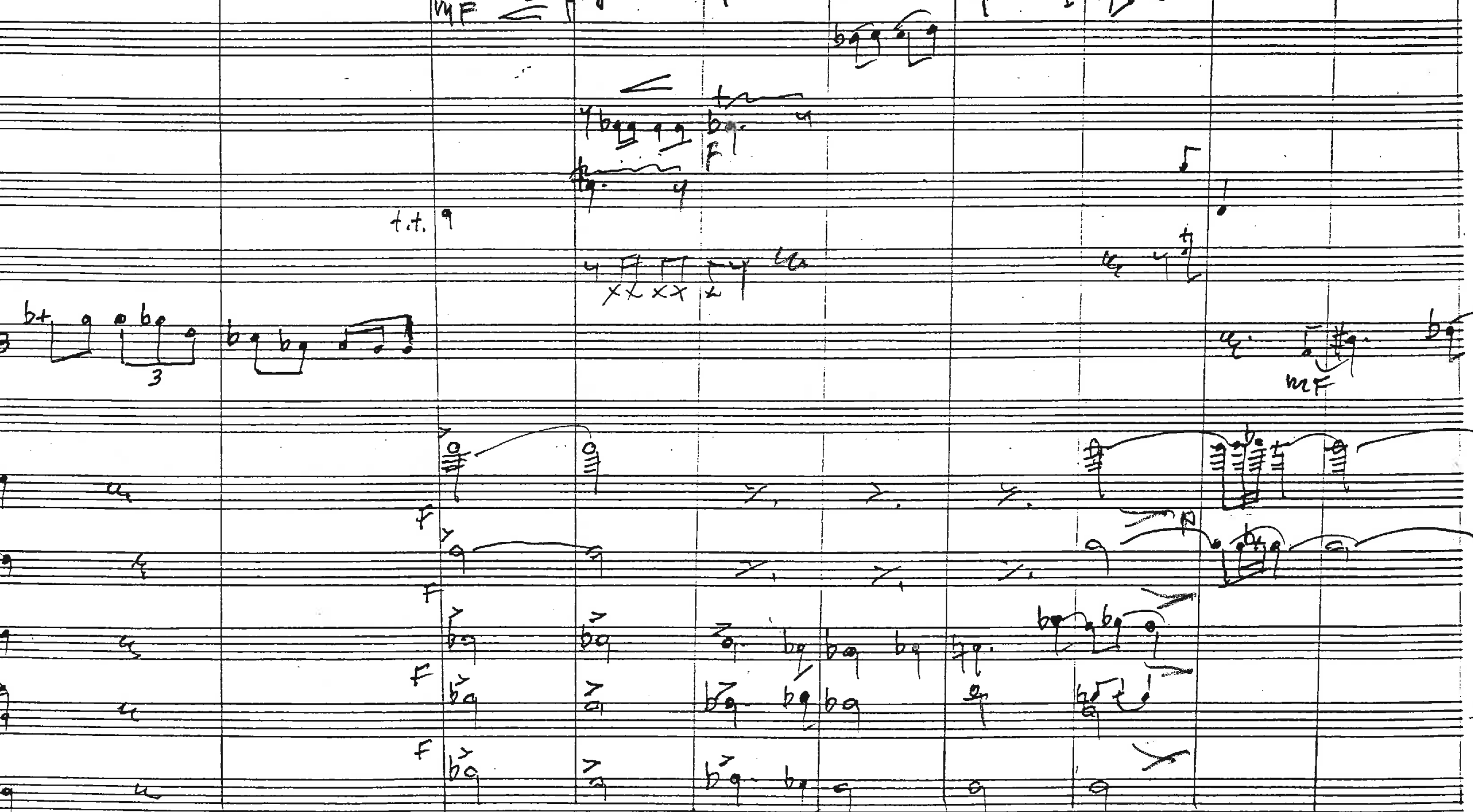


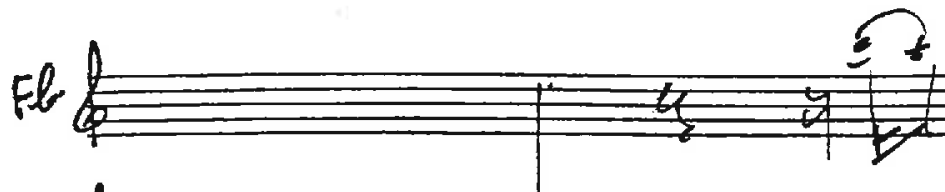
$c$ F. : $\cos$ th. time \begin{tabular}{l|l}
\hline \hline$\sum$ & 4 \\
\hline \hline
\end{tabular} $\frac{4}{4}$ $x<$ Solo

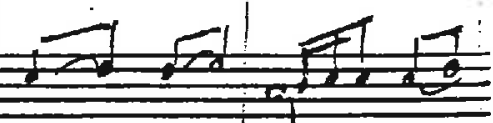
席 $+2 \sqrt{2} \sqrt{2}+2$ L

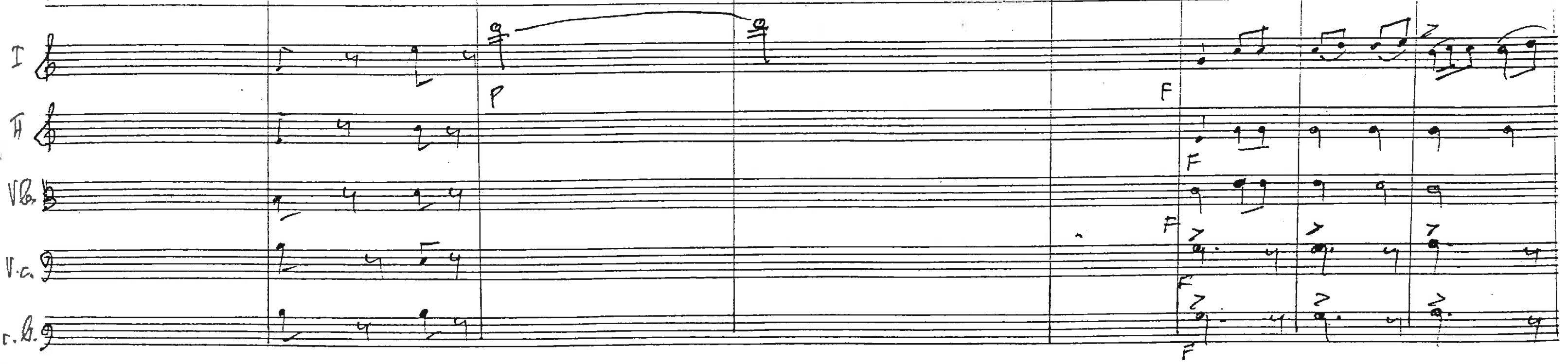




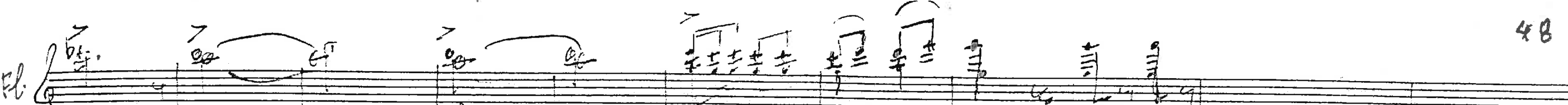

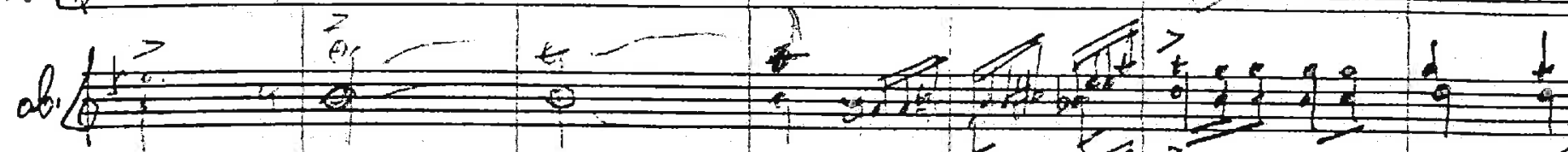

l.

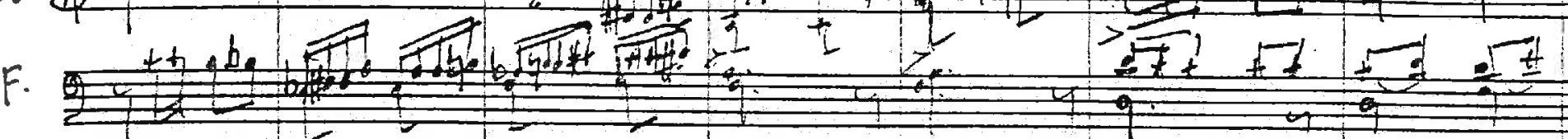

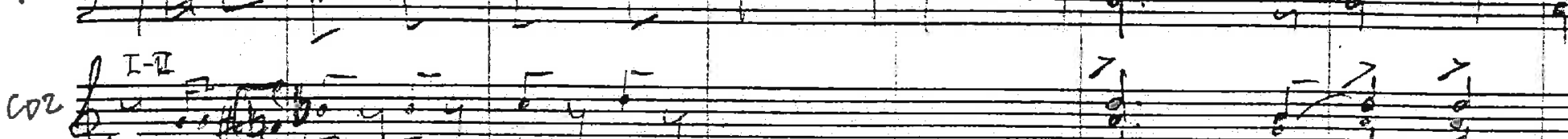

的.

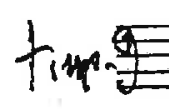

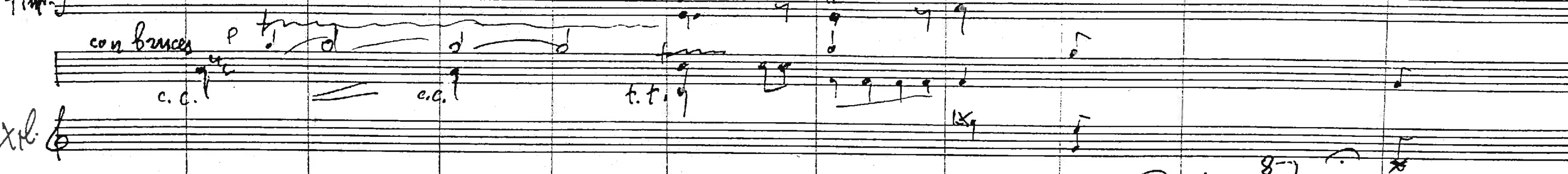

Solo

2

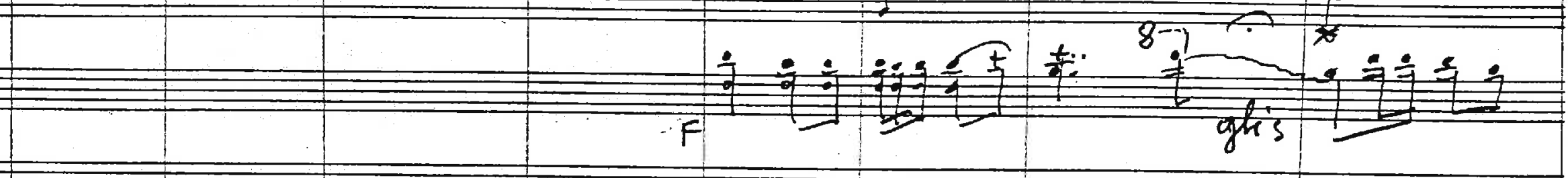

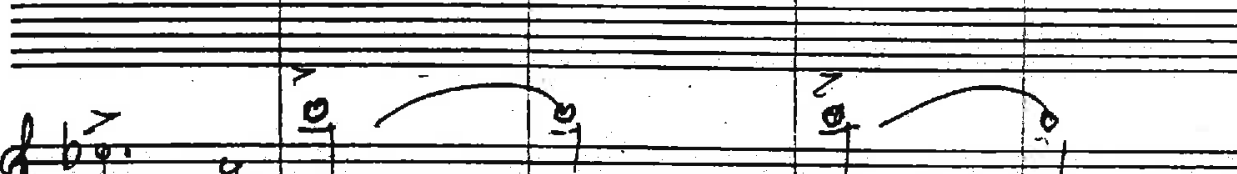

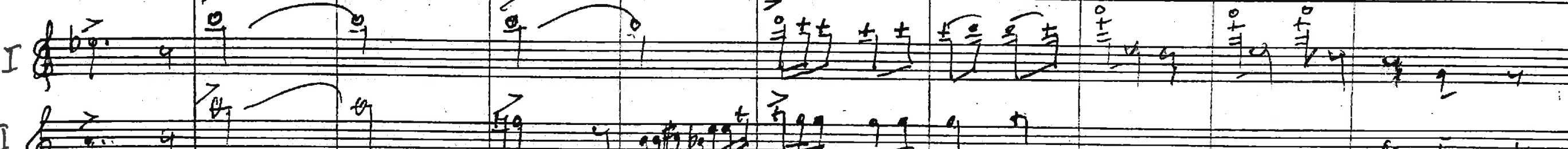

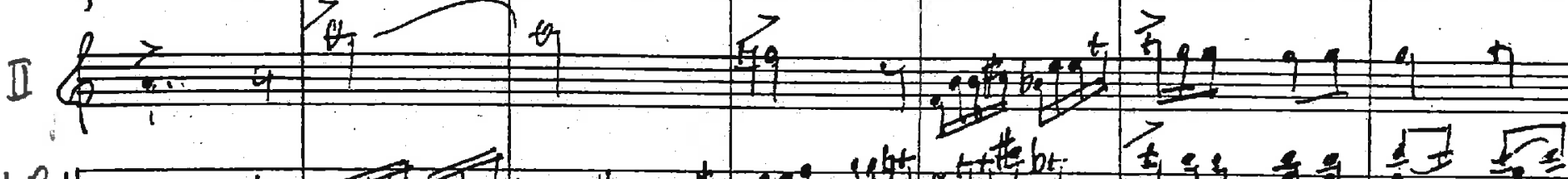

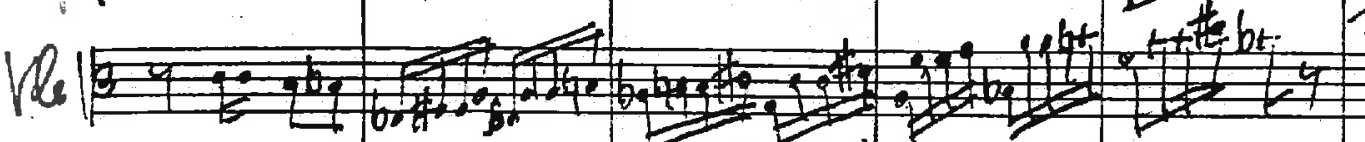

+ + be

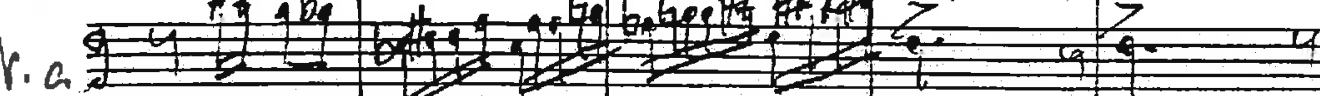

6.63

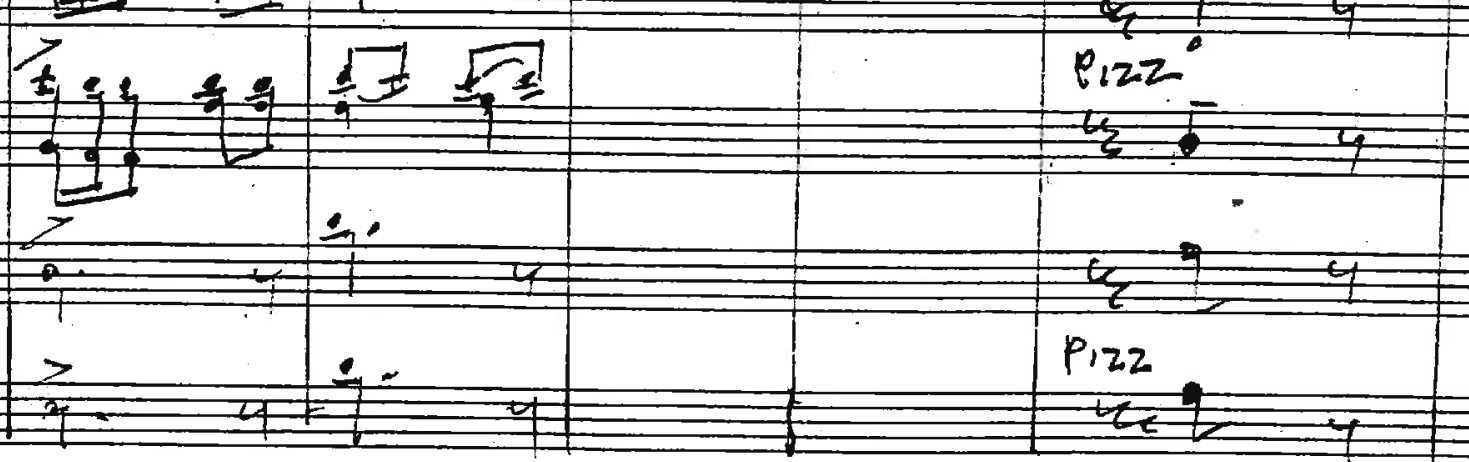


$F l$.

ob.

$d \quad 4$

$F . \frac{S P}{S F}$

iा

th

tw

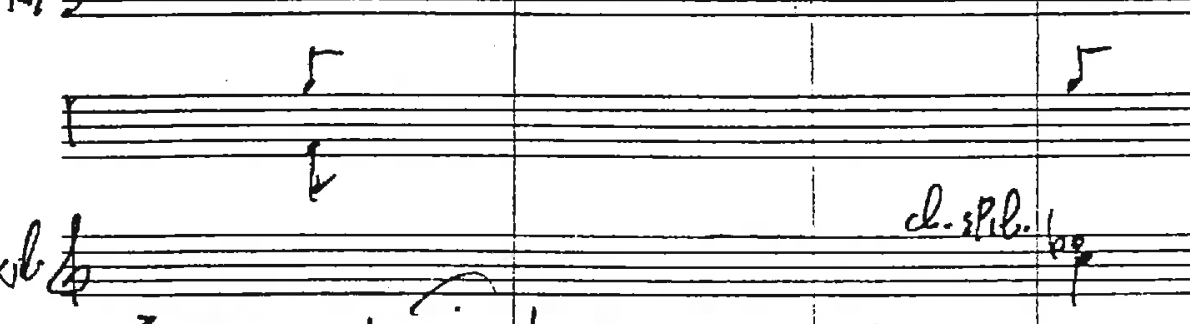

Sol

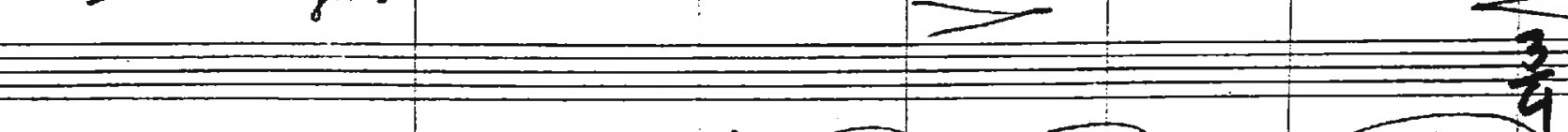
$I+2$ I) c.6. 


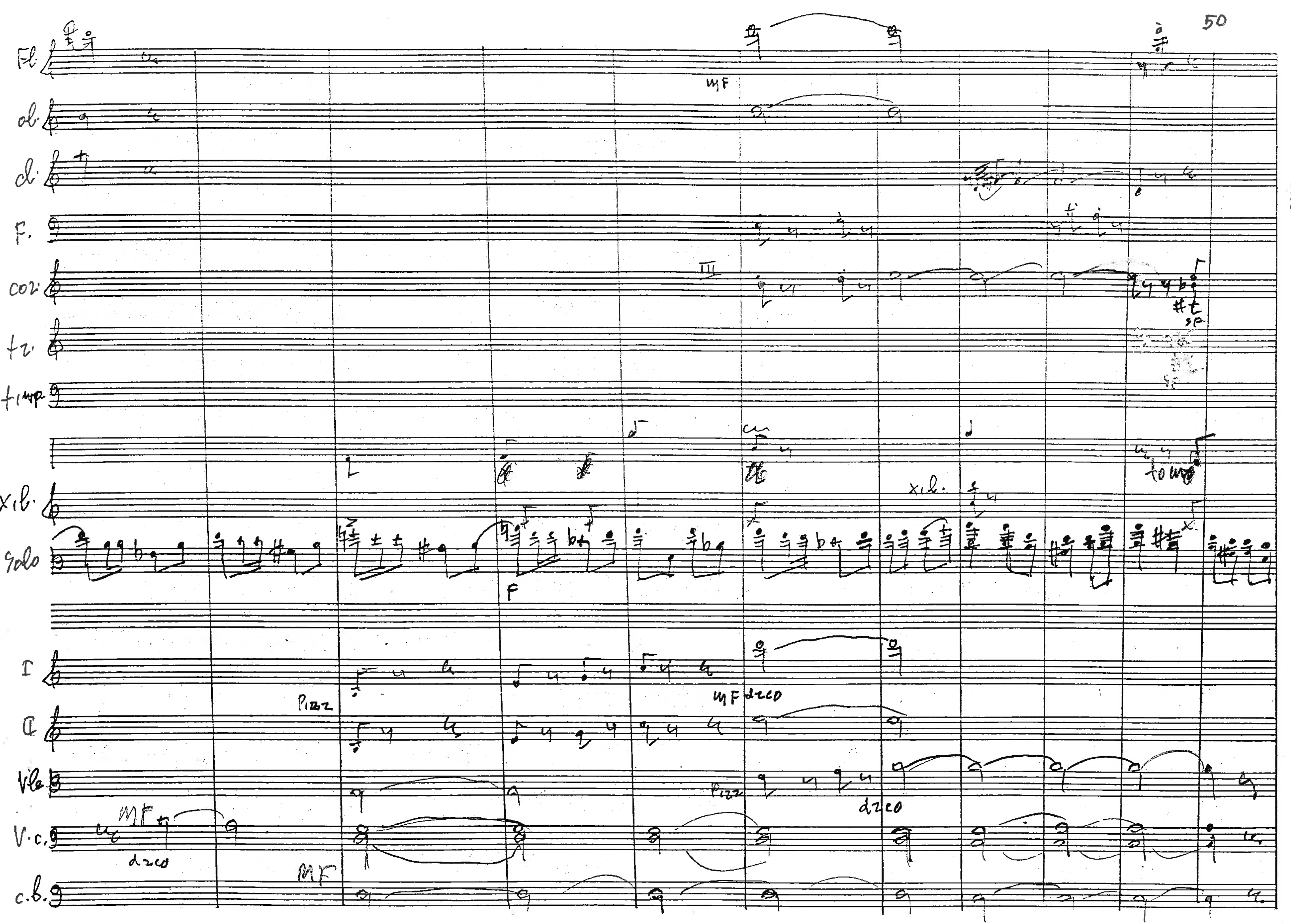




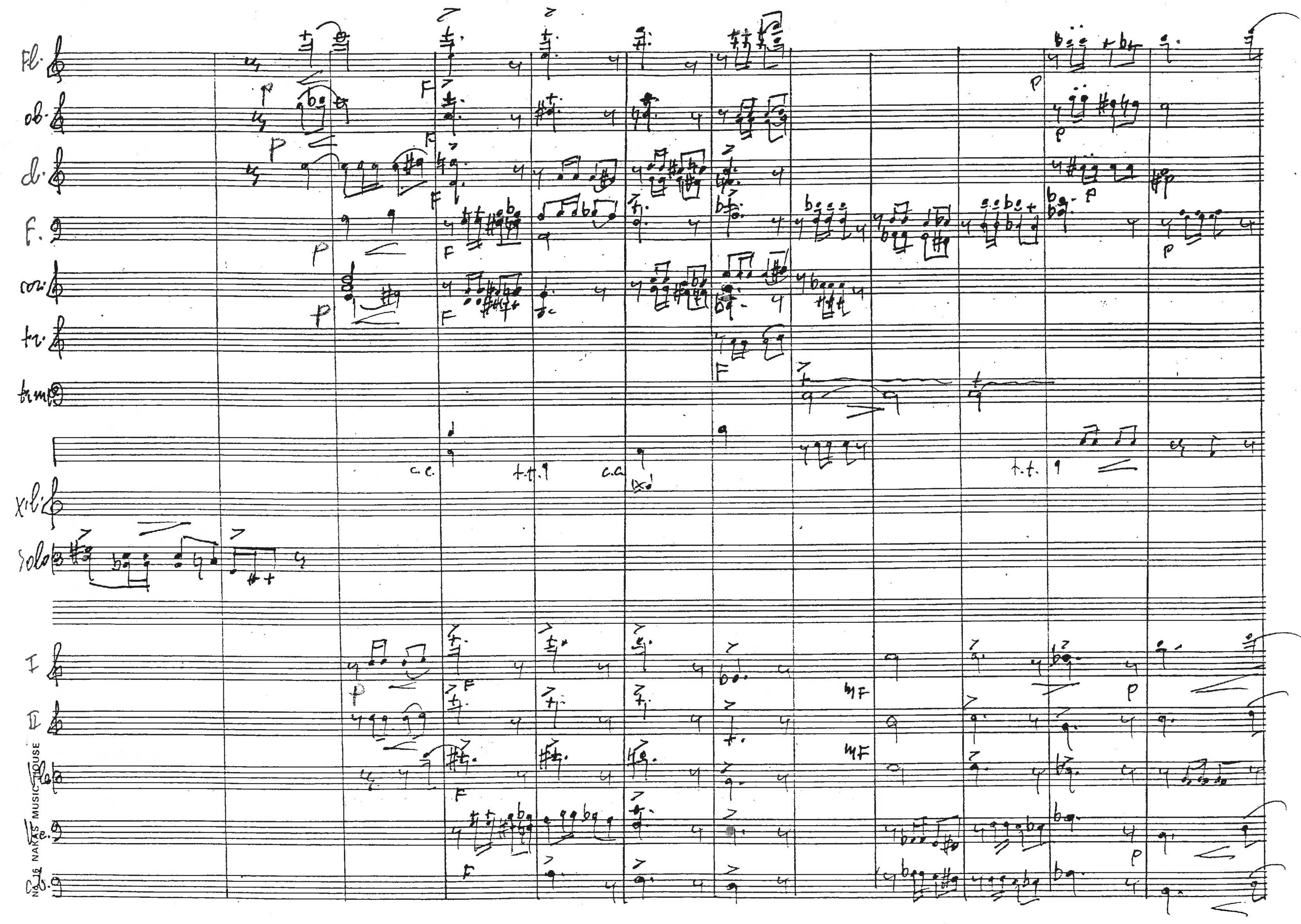




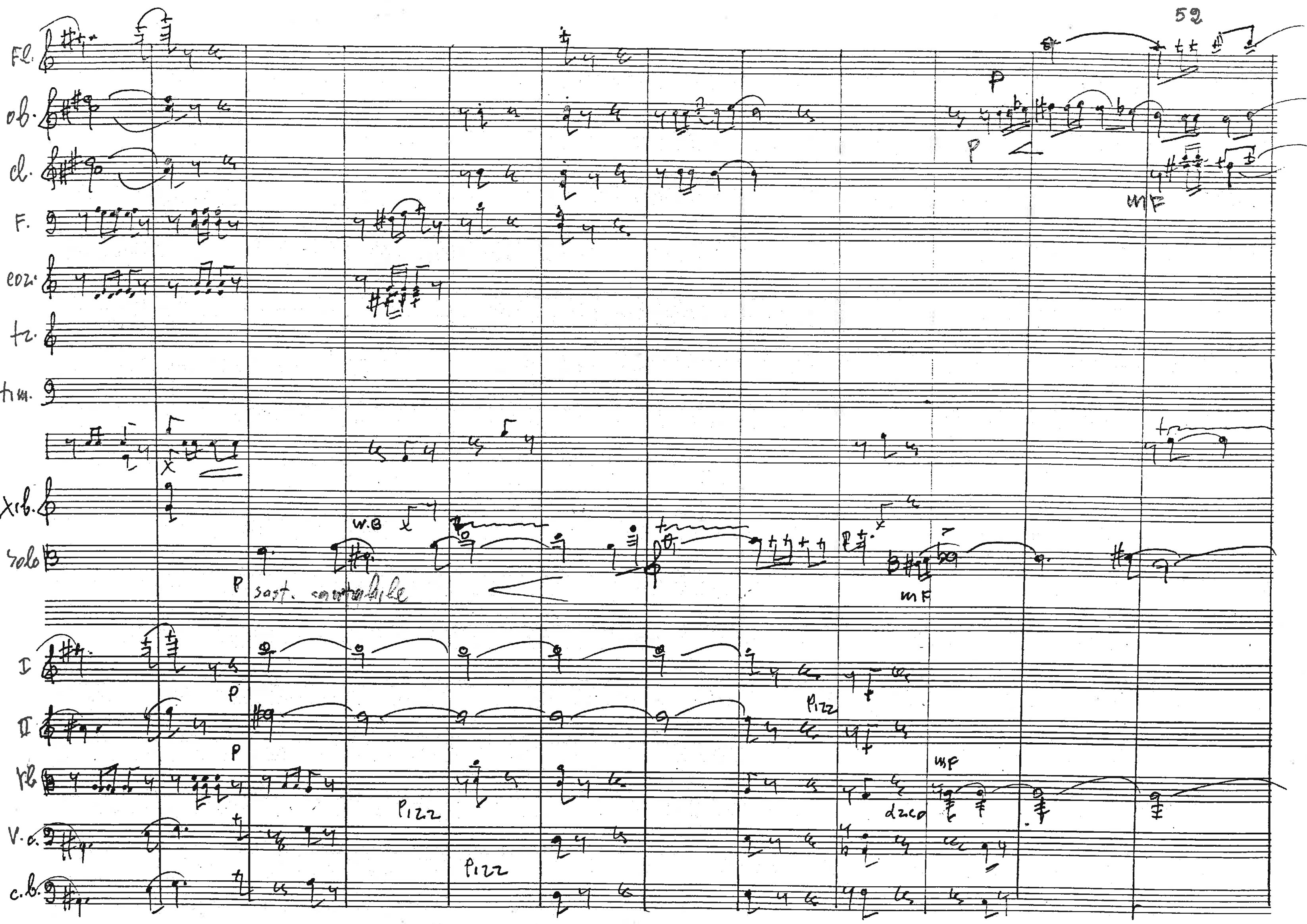




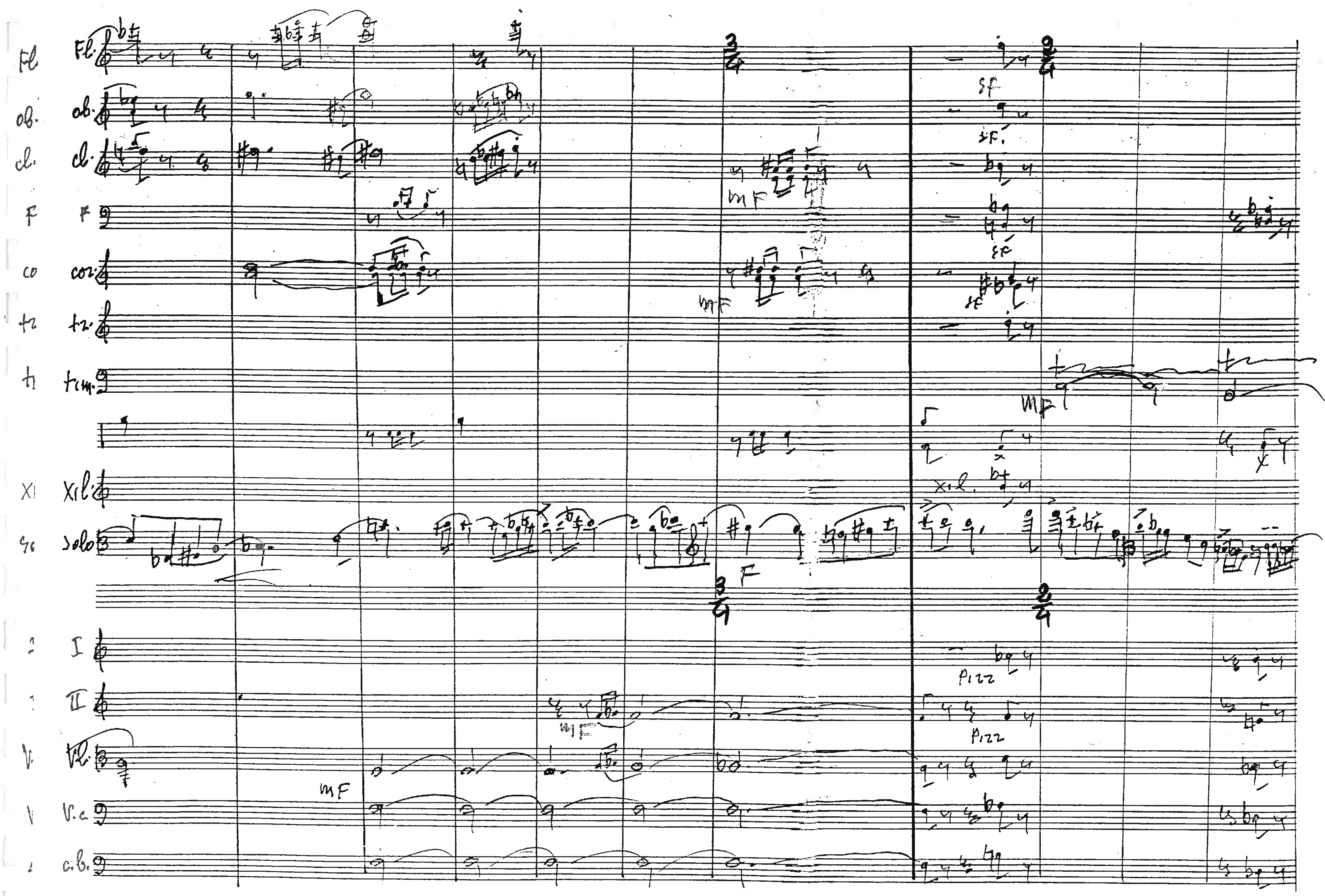




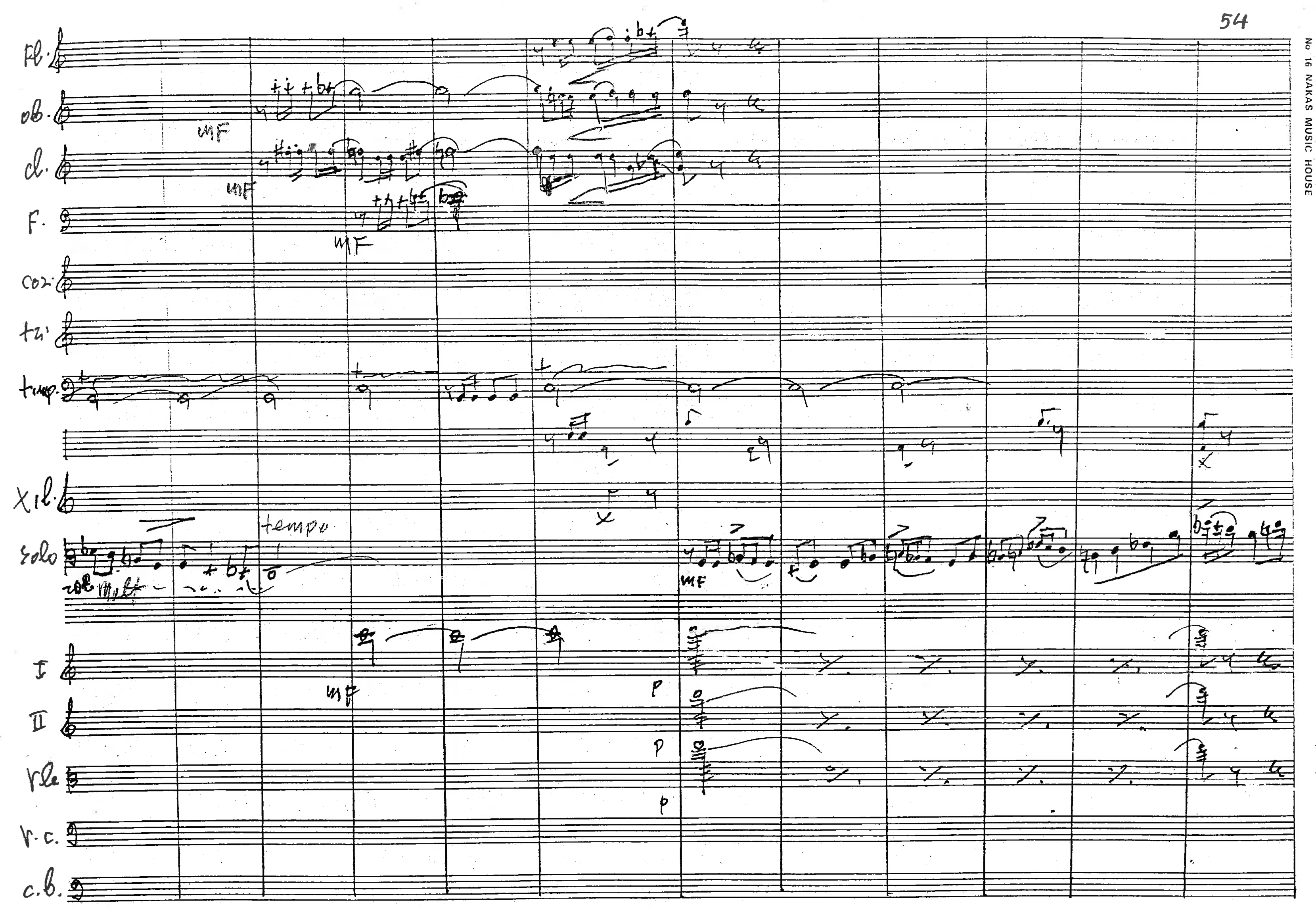




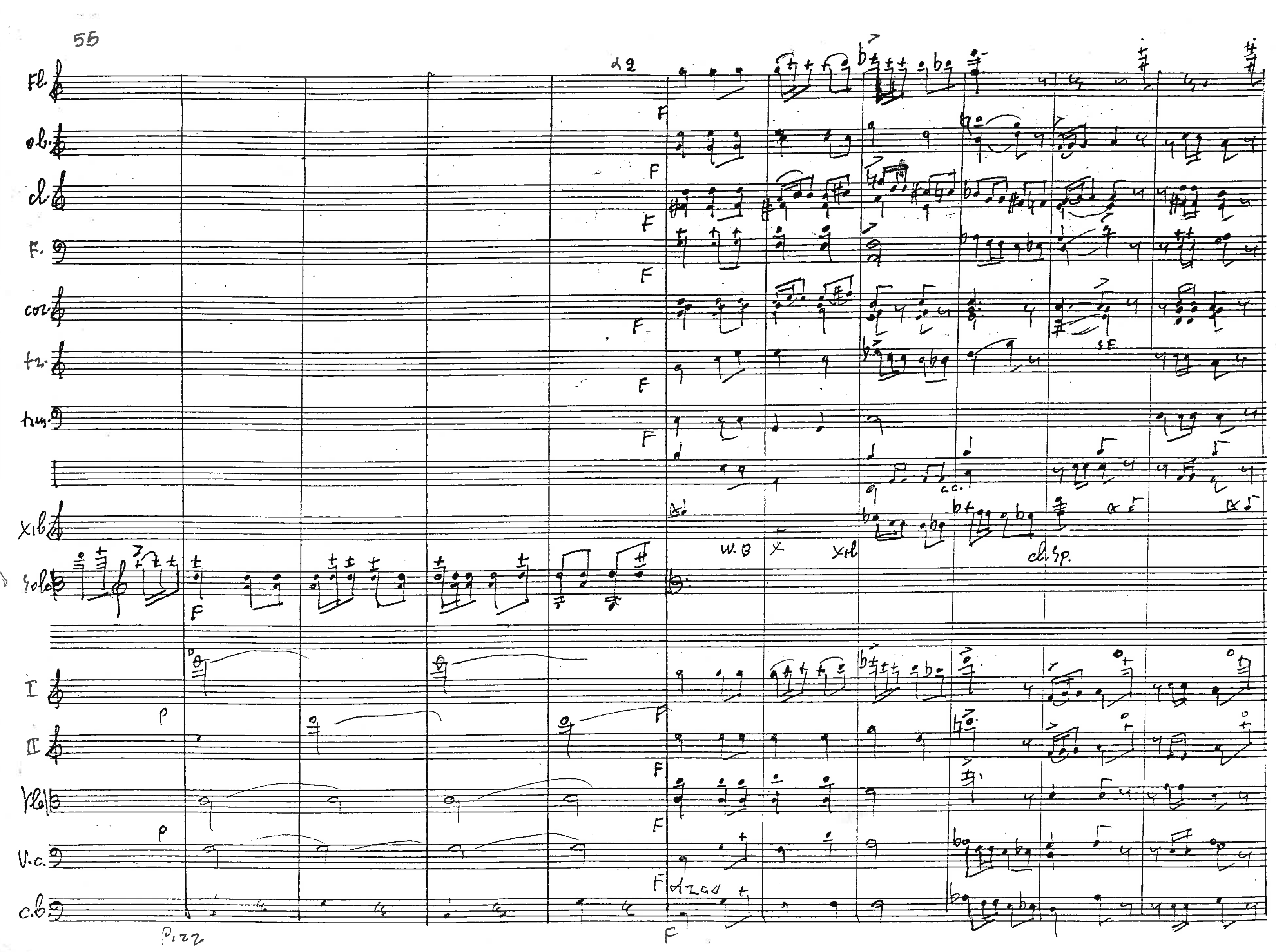




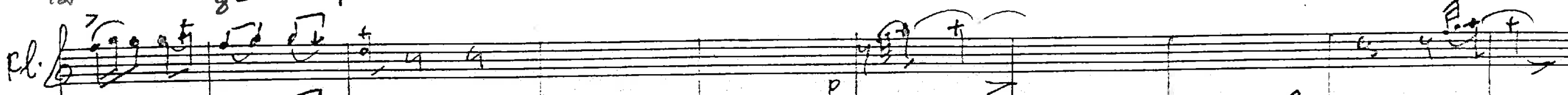
ob.

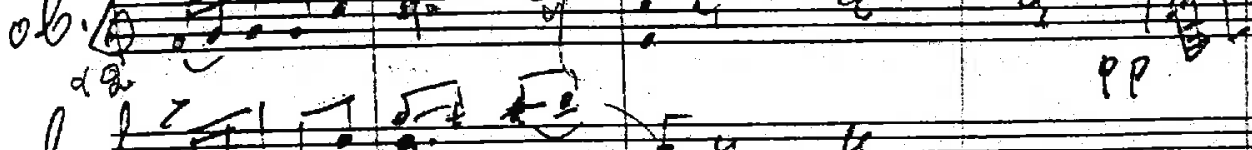
d. F. $\operatorname{col} \frac{1>}{10}$ tr.

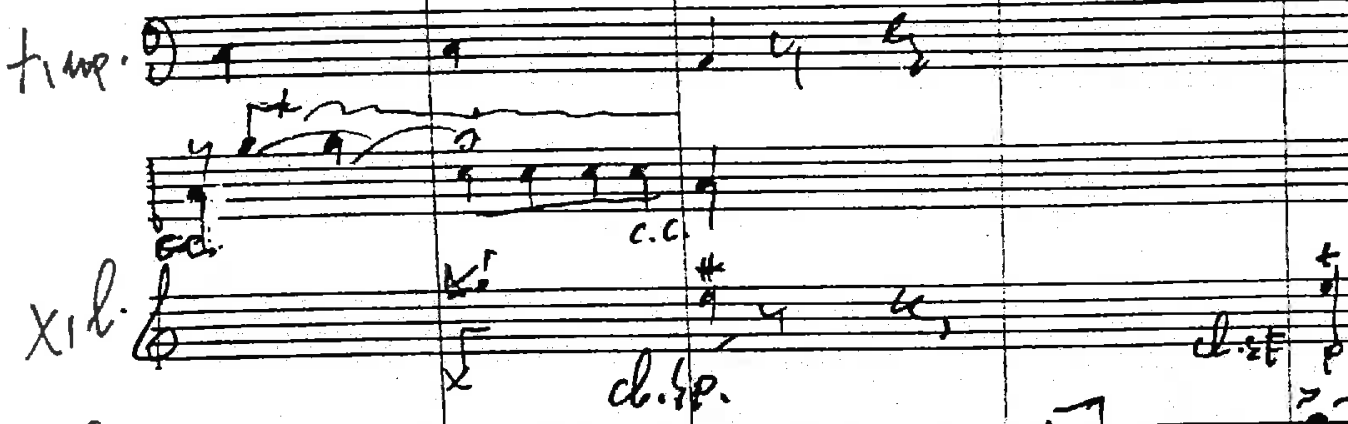
sabo

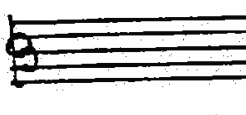
$<$ d.sp. I 1.12 (3) I 70 .t.

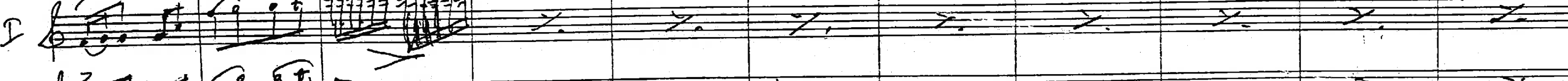
II $120 \%$ hlo V.c. c.b. \begin{tabular}{c|c|c|}
$>$ & $P P$ \\
\hline & 4 & $P P$
\end{tabular}

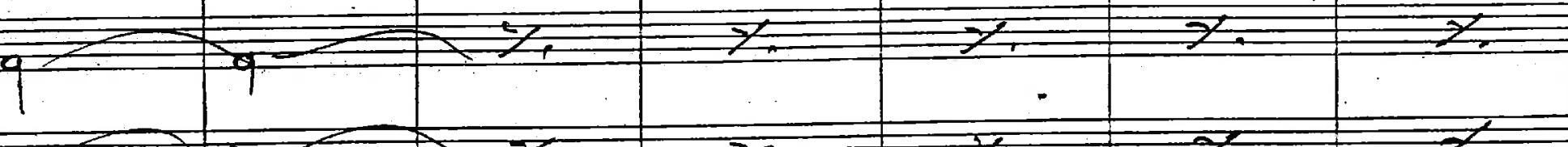
$4 \not 2 \not z \ldots$ p 




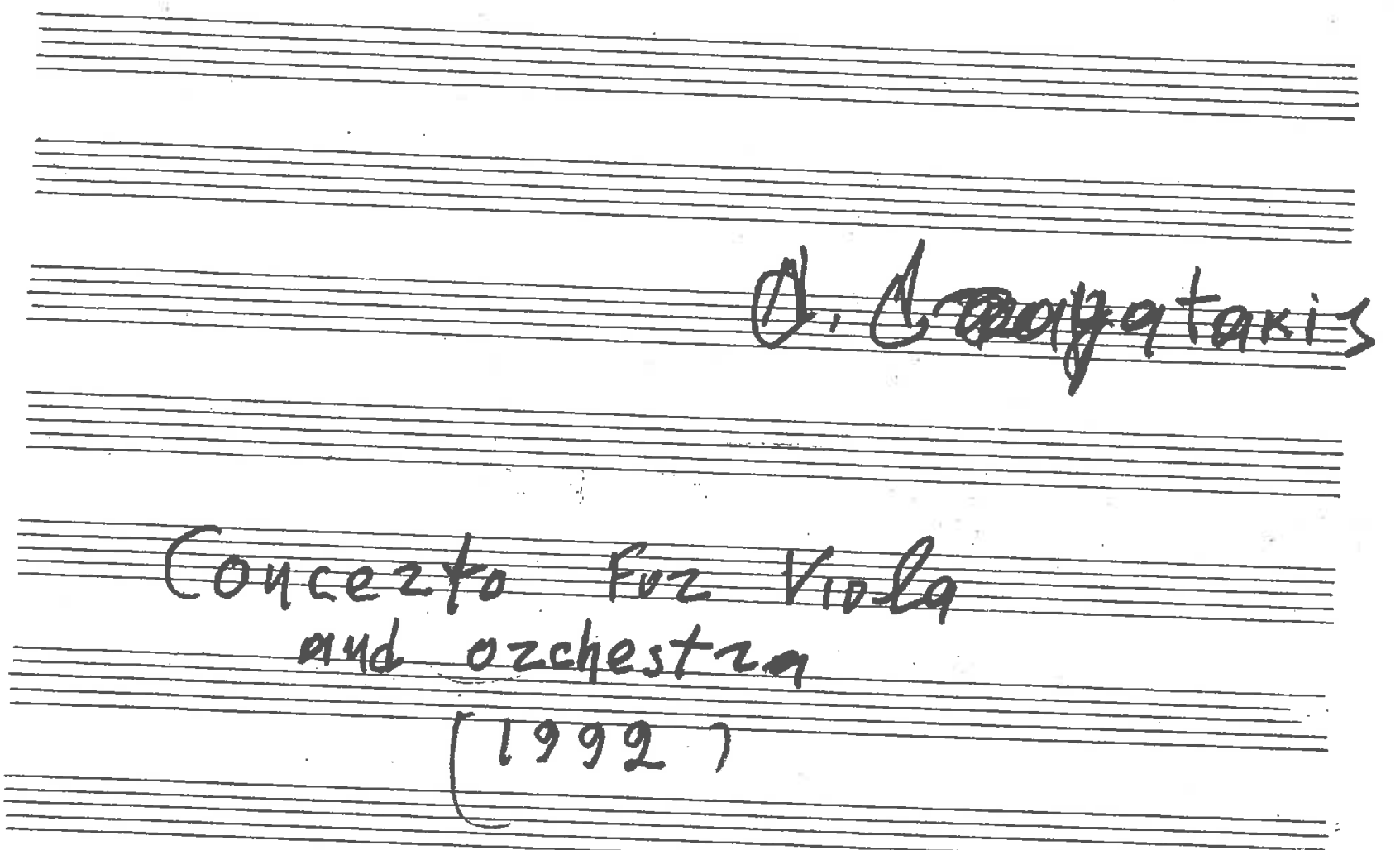

$$
\begin{gathered}
\text { Goucezto fuz toba } \\
\text { and ozchestra } \\
(1992)
\end{gathered}
$$


Moderite (pocofort) $\quad q=70$

$I$

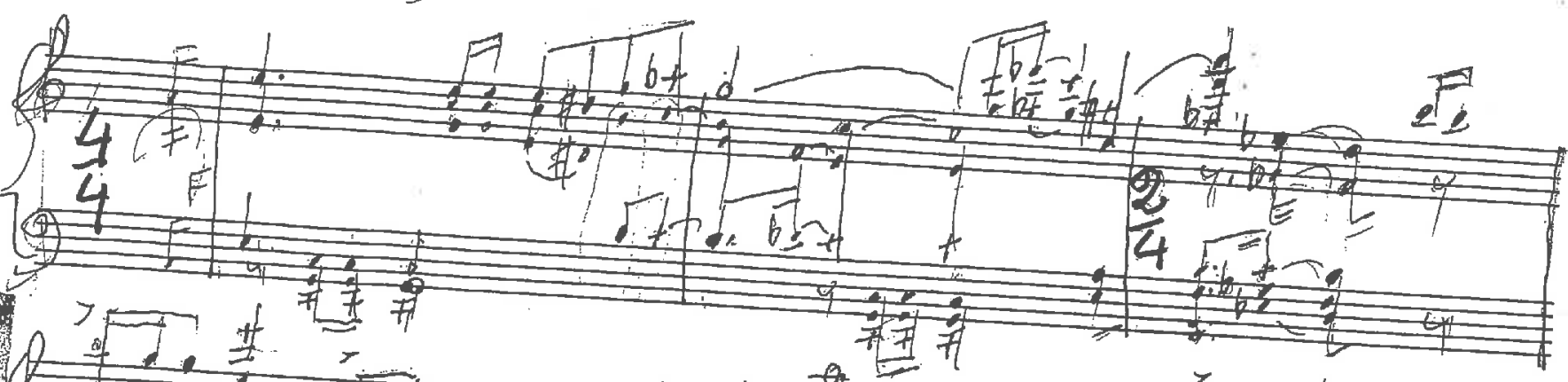

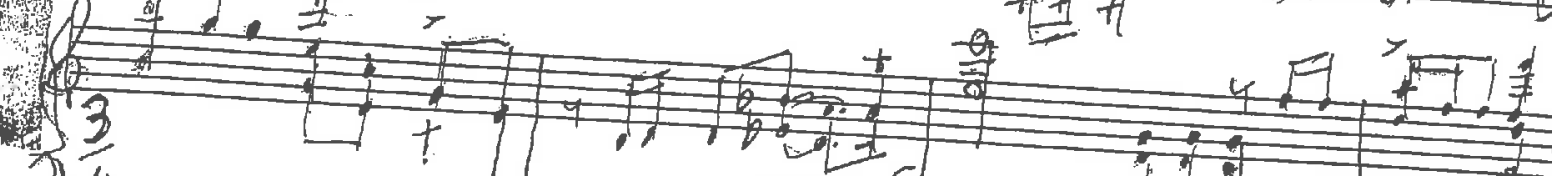

$\pi$

型

0

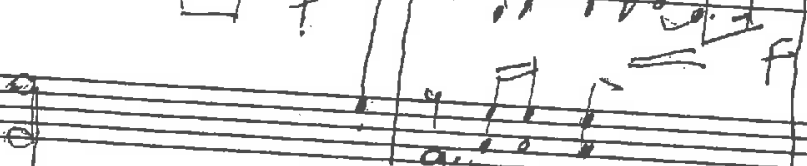

$4+5 ! 10$

2

p

$9 x^{2}+2+1$

$9=2+20$

$9+2$

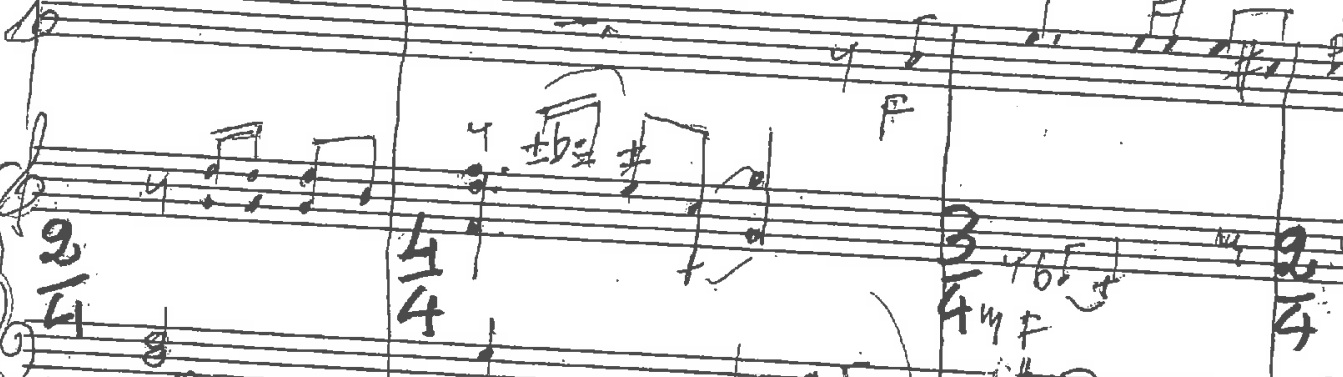

$=9$

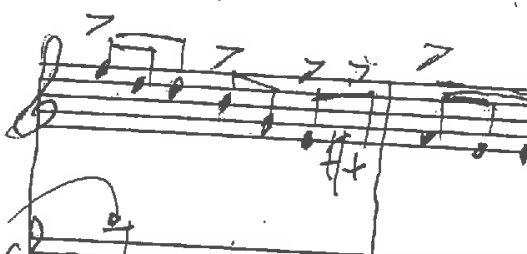

$1 \frac{3}{4}$

7

2

$-1$

If

增

t9!

451 


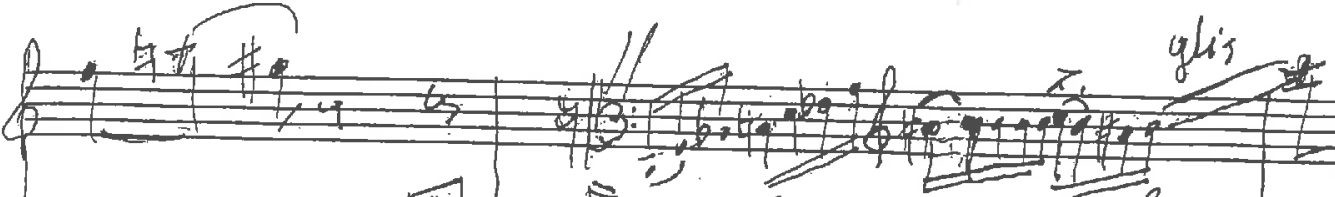

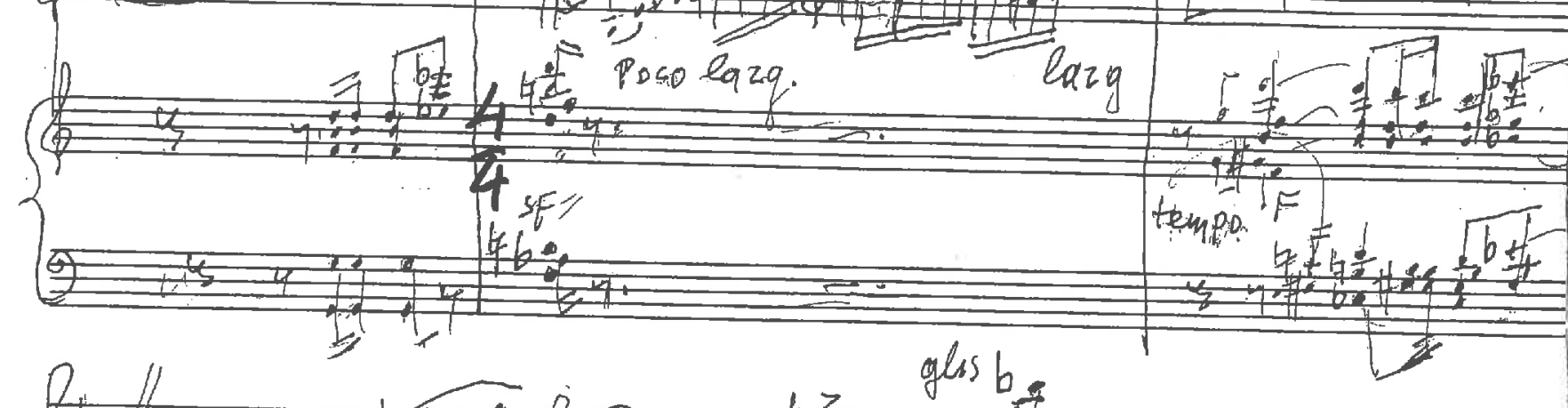

$\quad$ gls $\quad$

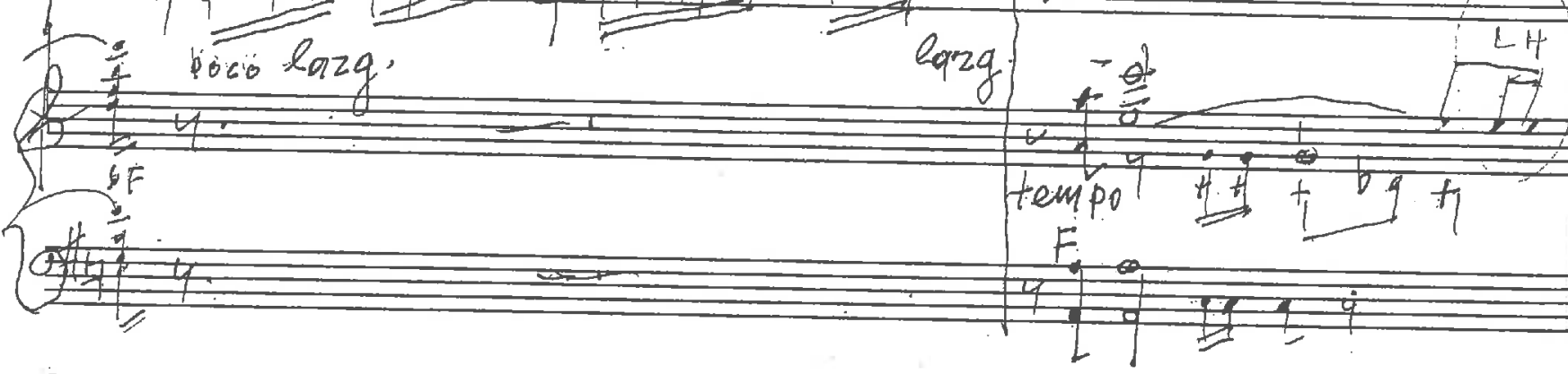

b

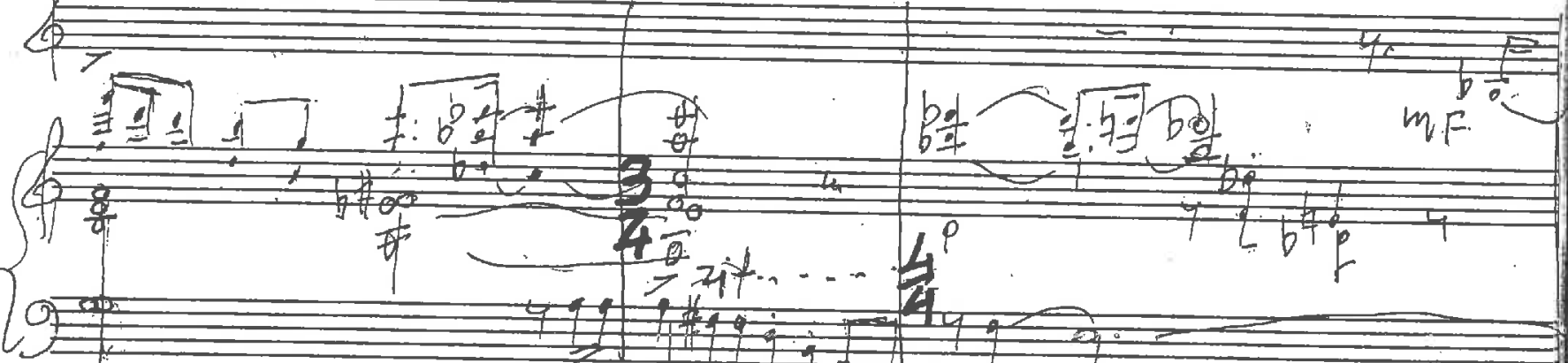

W

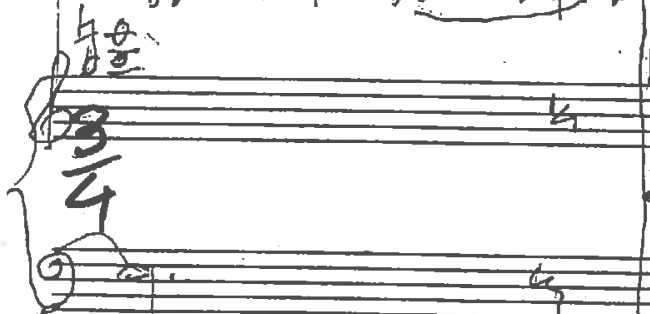
$6+647$

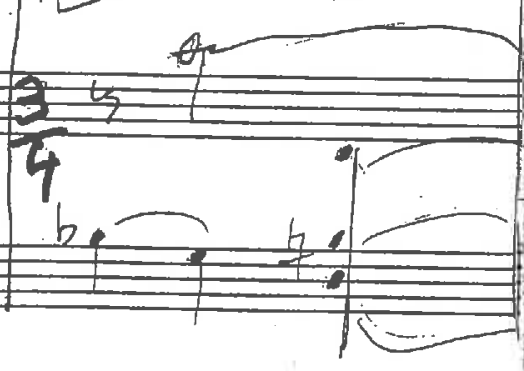




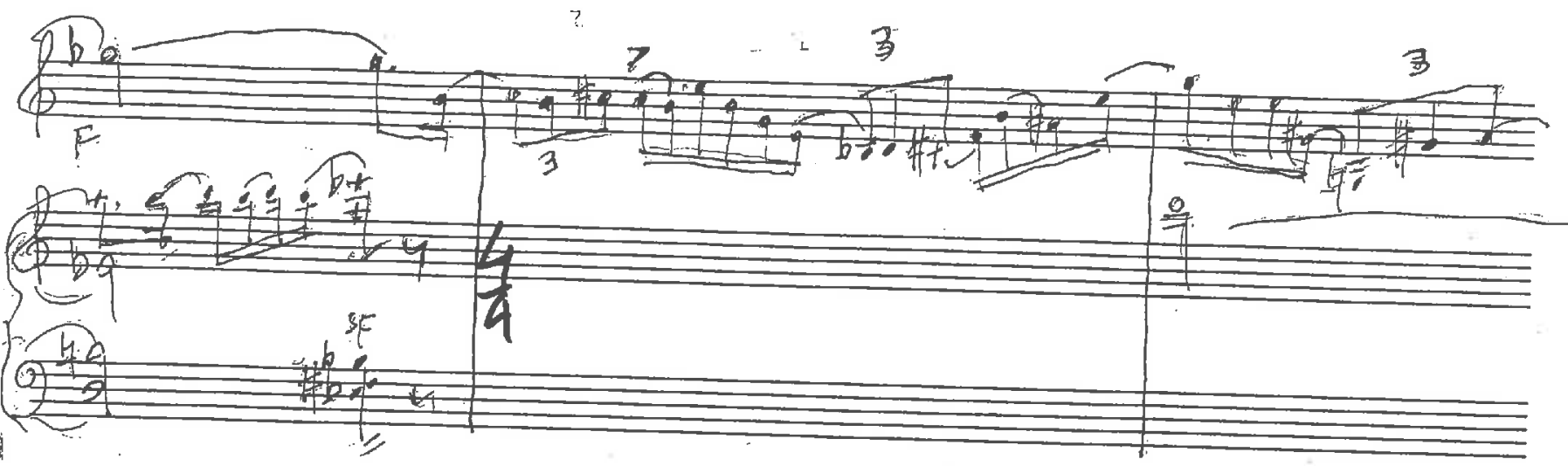

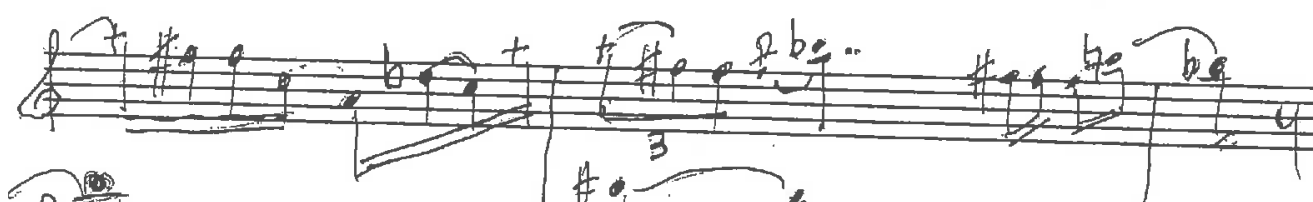

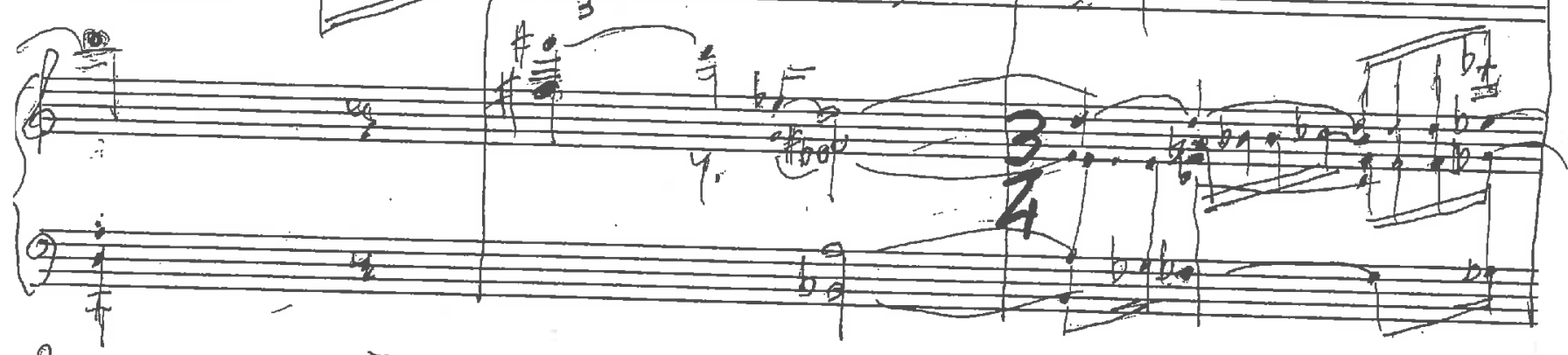
(4)

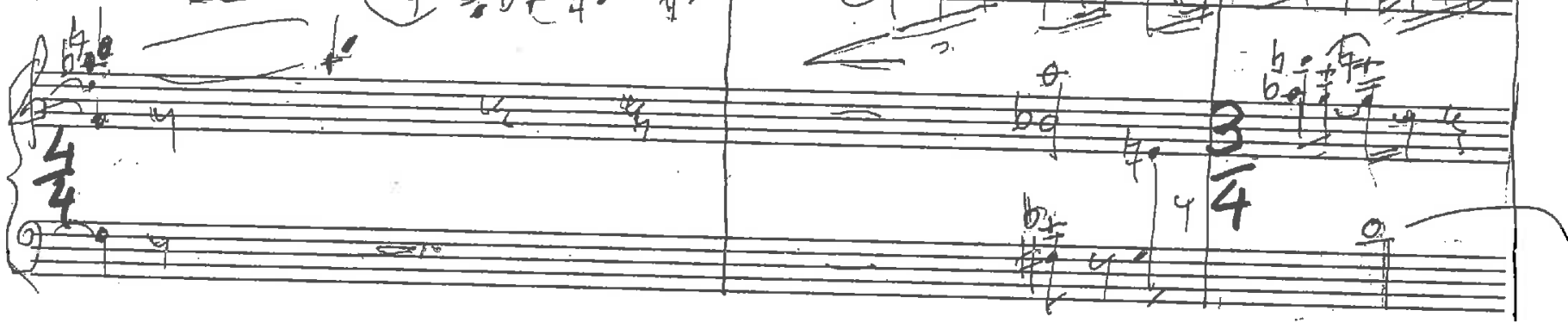

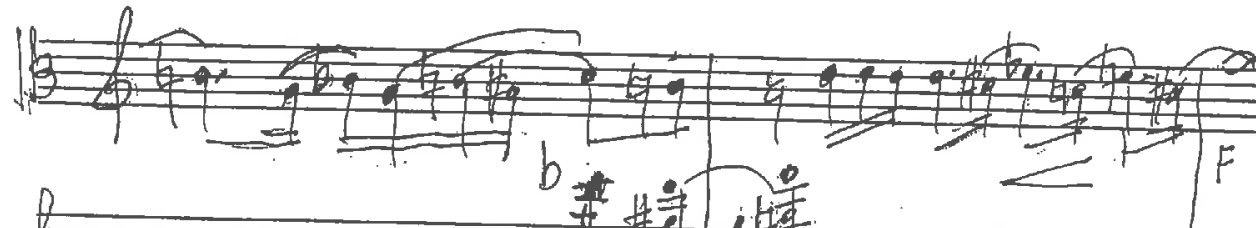
(2) 


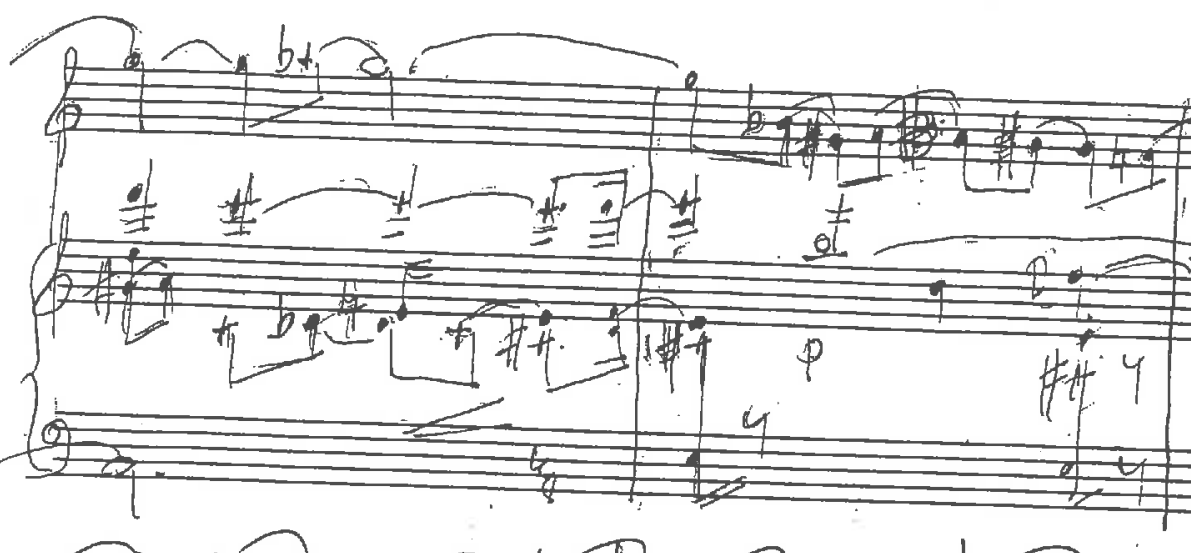
25?

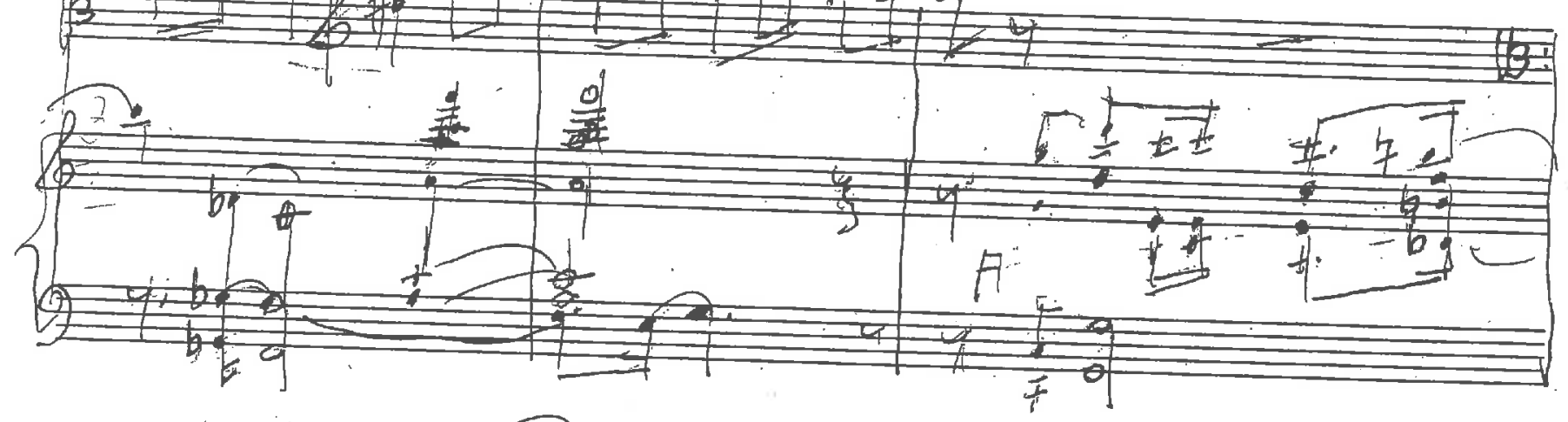

W
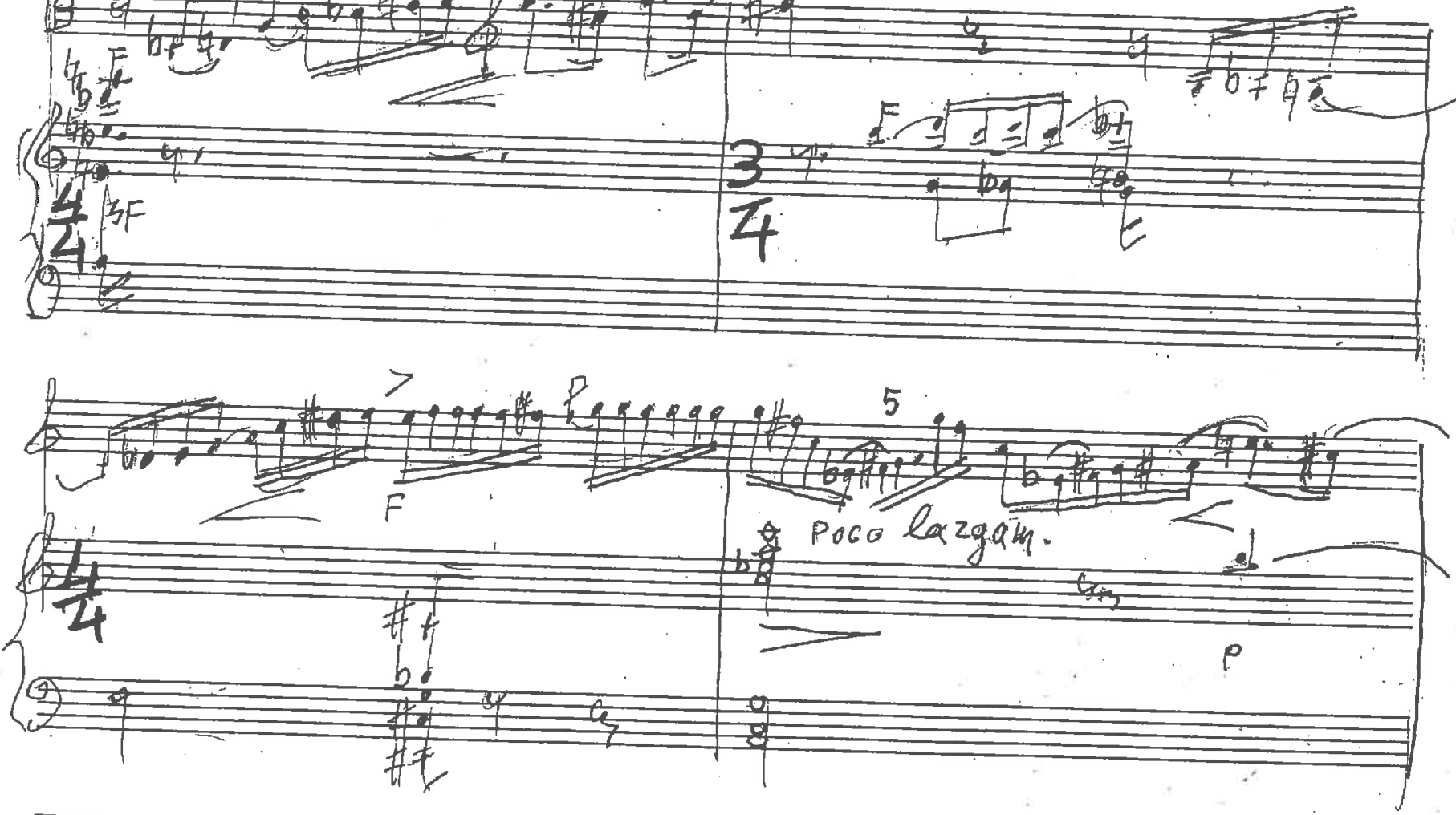
$\pi$

番-

$\left\{\frac{1}{F_{0}^{2}}\right.$ W

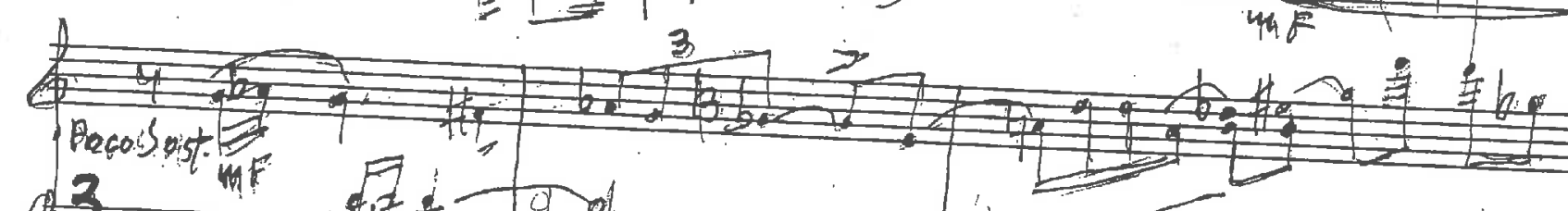

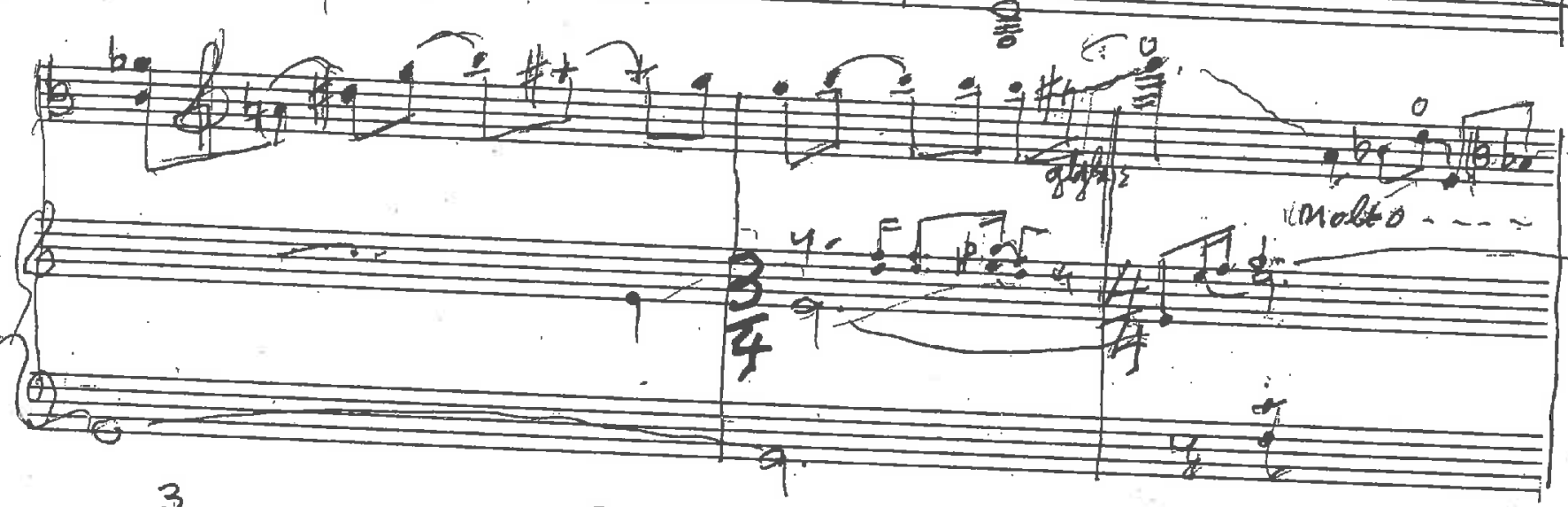

3

(1) 


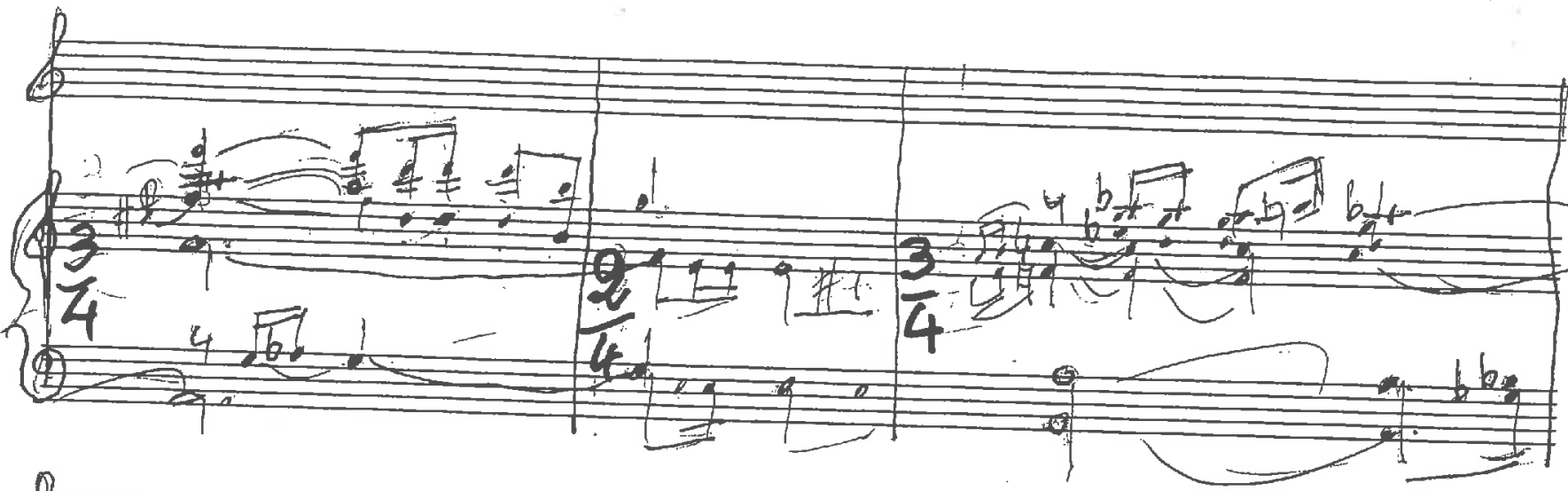

8

1)

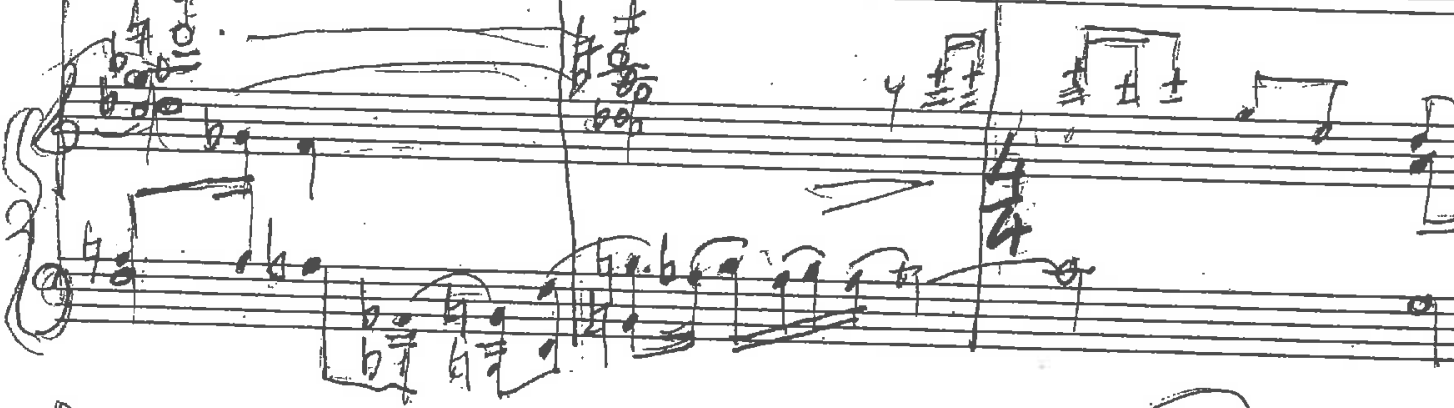

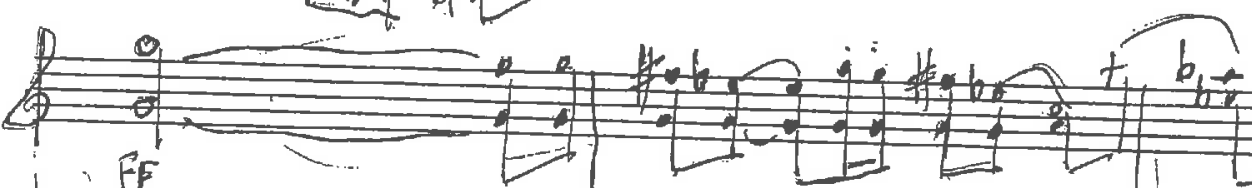

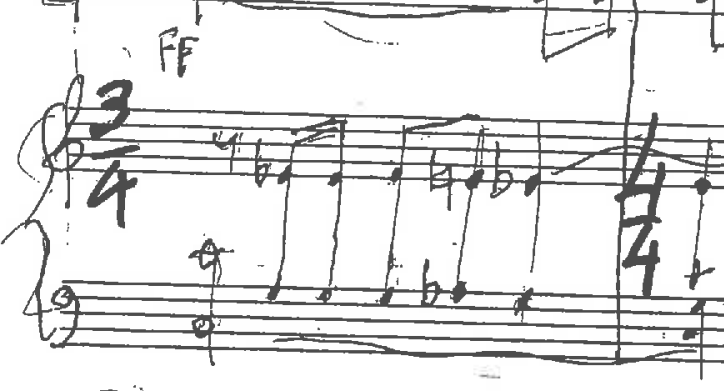

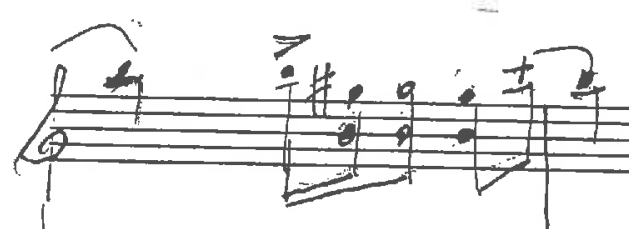

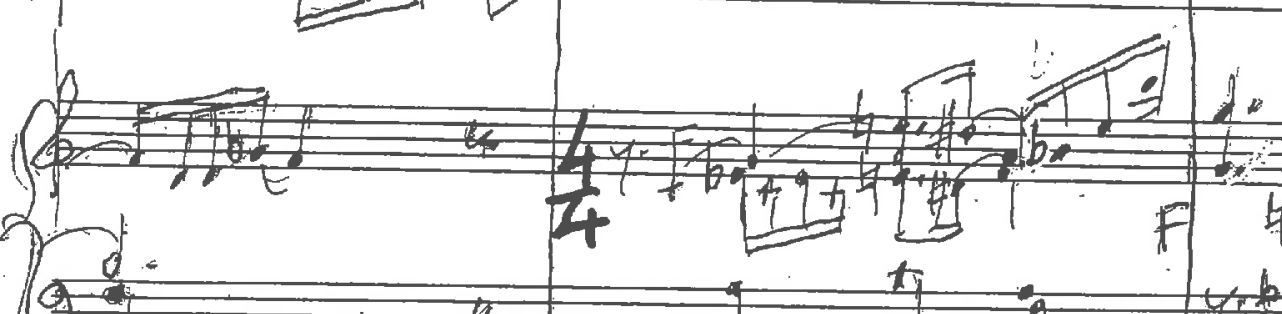
$\frac{0}{20}$

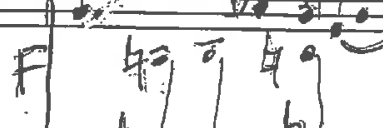 $\frac{1}{2}=$

bot? 
Pós lazgam.

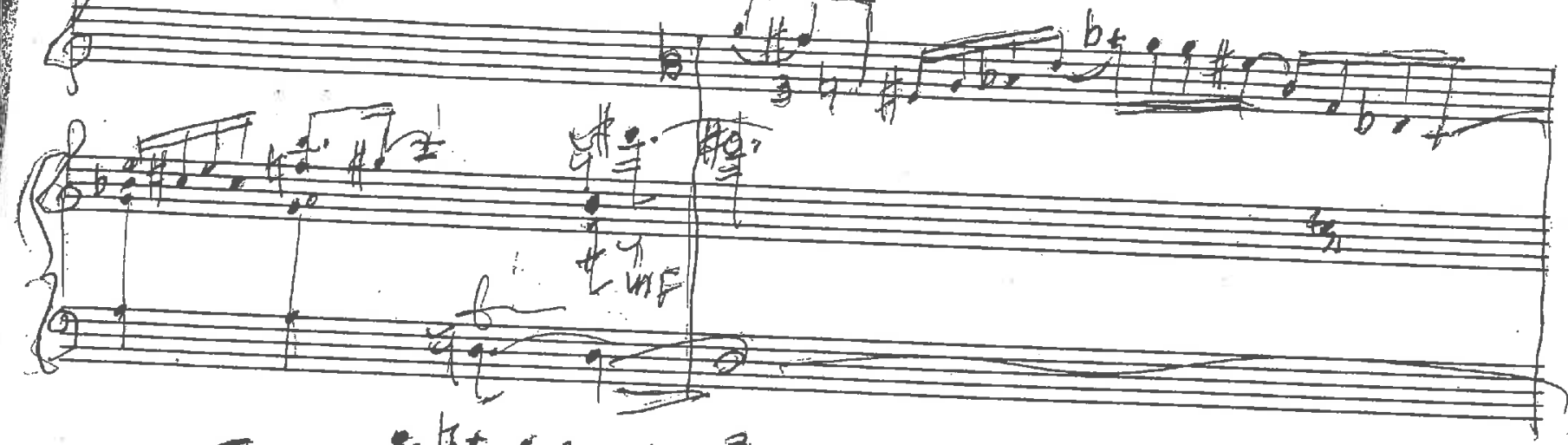

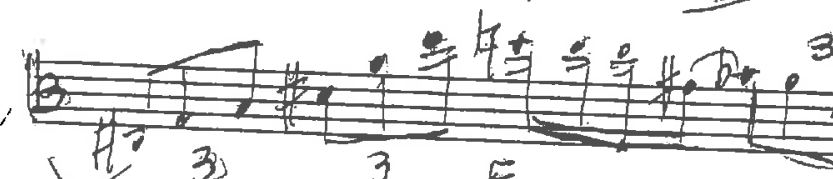

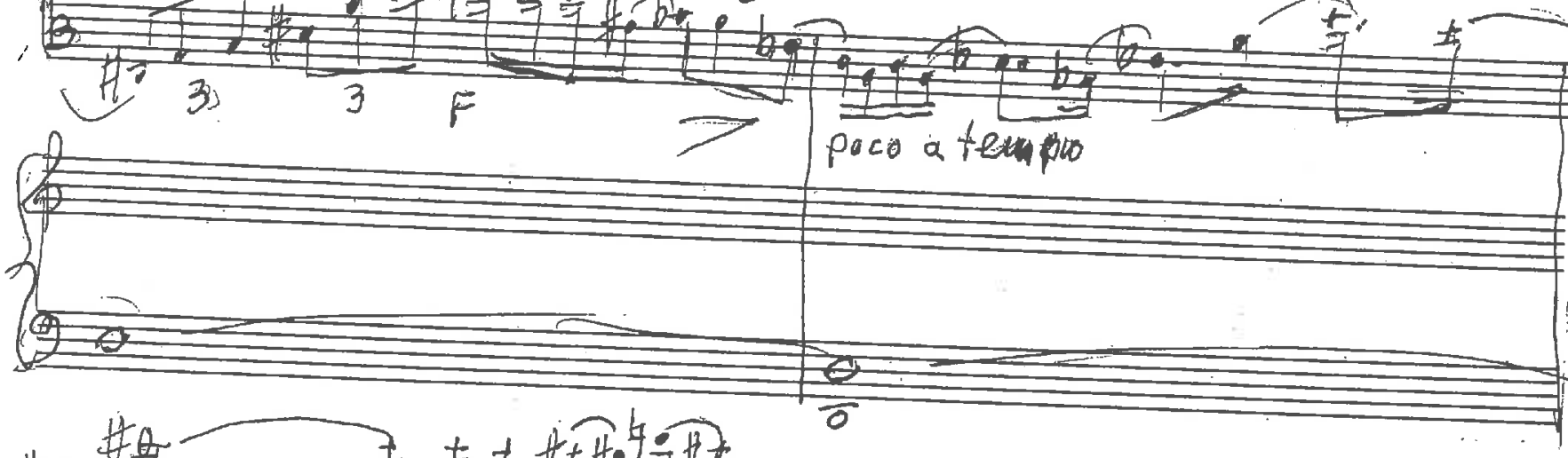

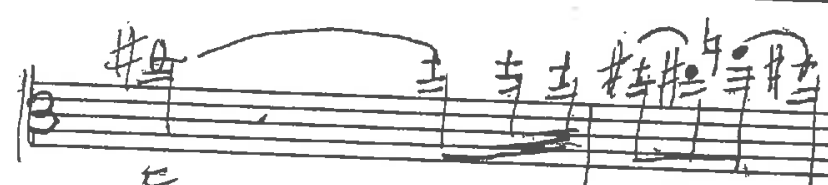

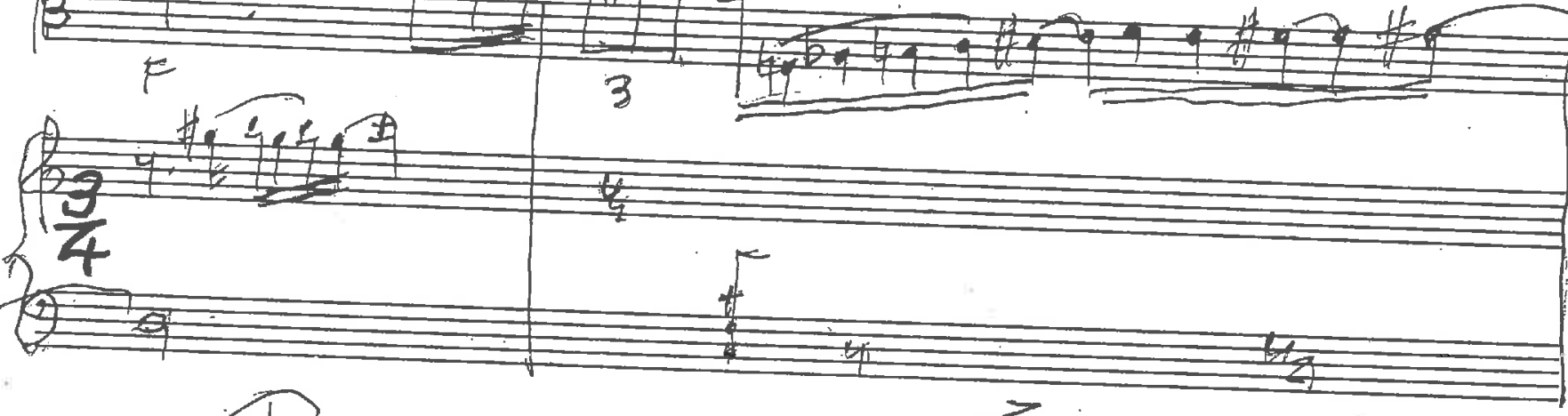




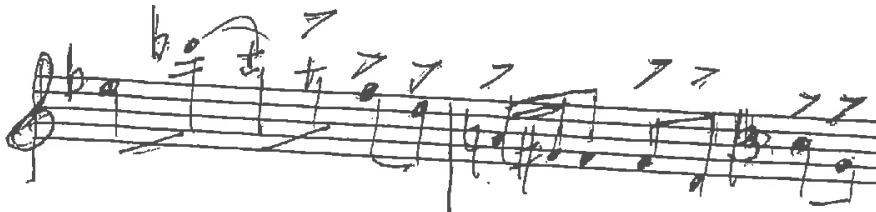

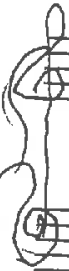
$\frac{4}{3}$

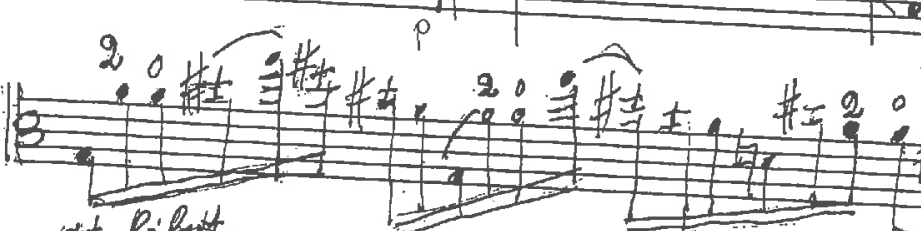

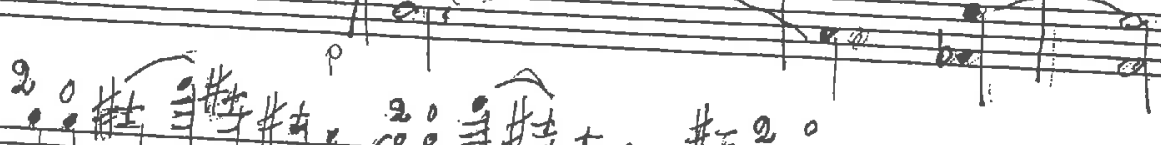

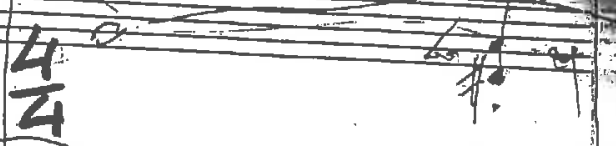

8 bat.libtit.

$x_{2}$ $2 x+\ldots+195$
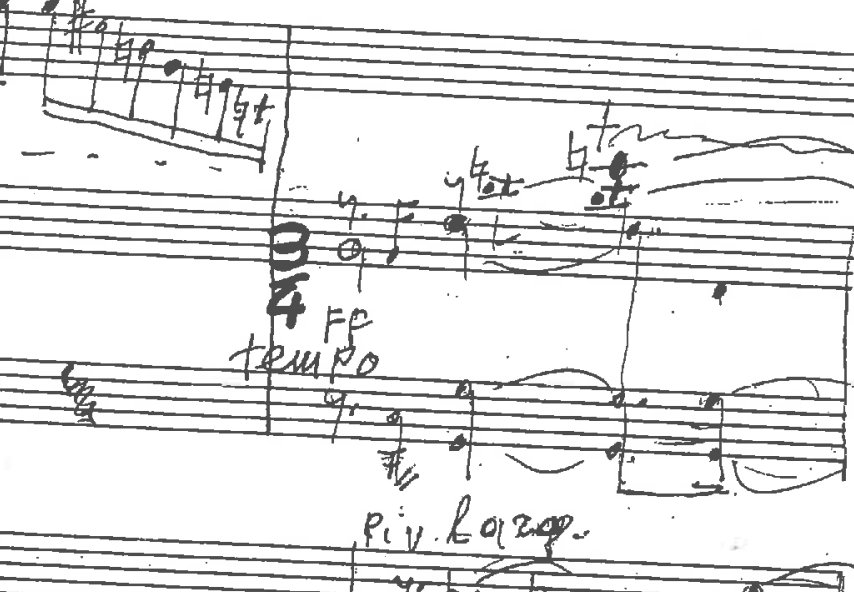

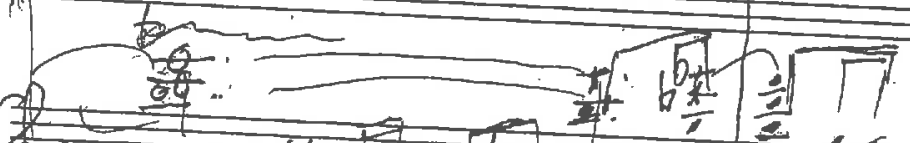

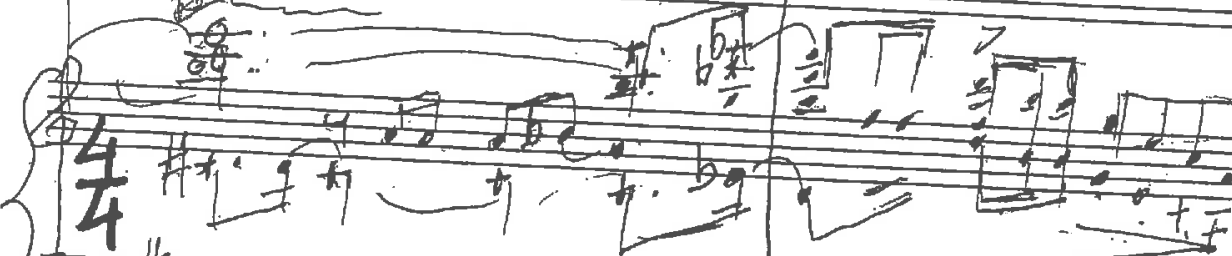

8

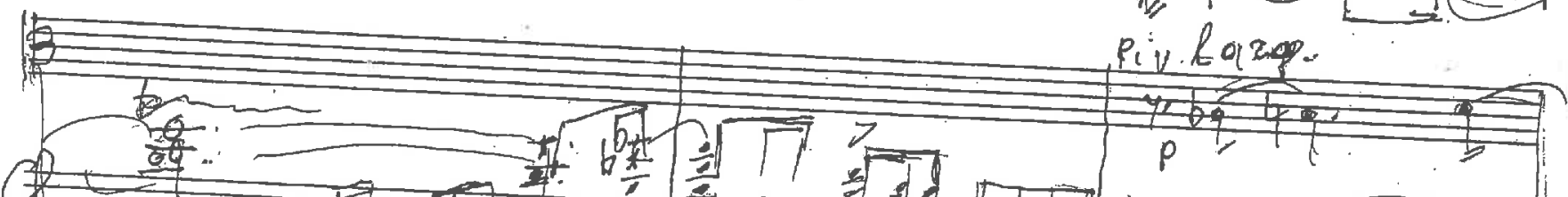

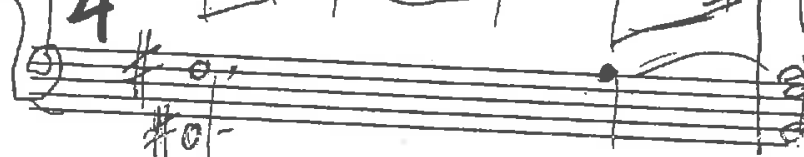

$\therefore+4^{2} P$

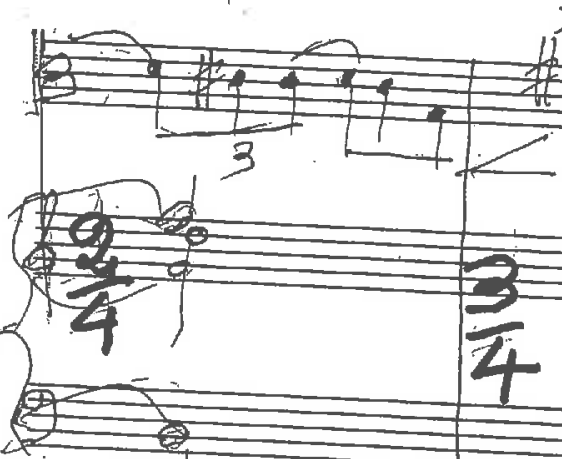

$\frac{7+2}{3}$

3 
9

1
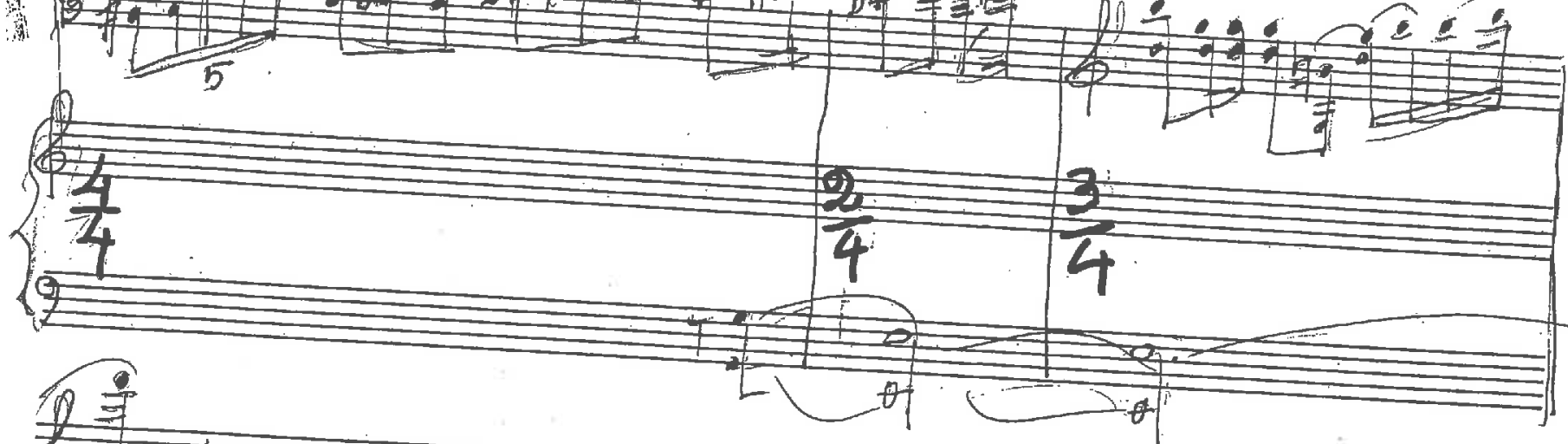

1\%

(2)

1.

$27 \quad 5 \quad 10$

a

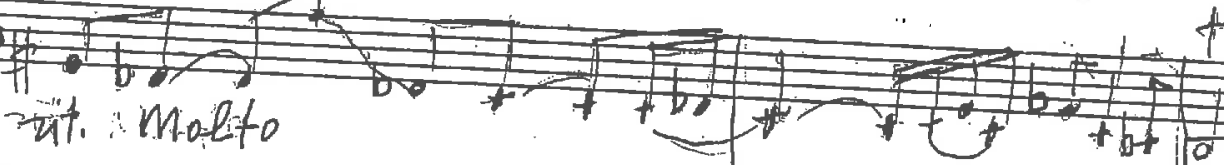

2 2012

) 17. 


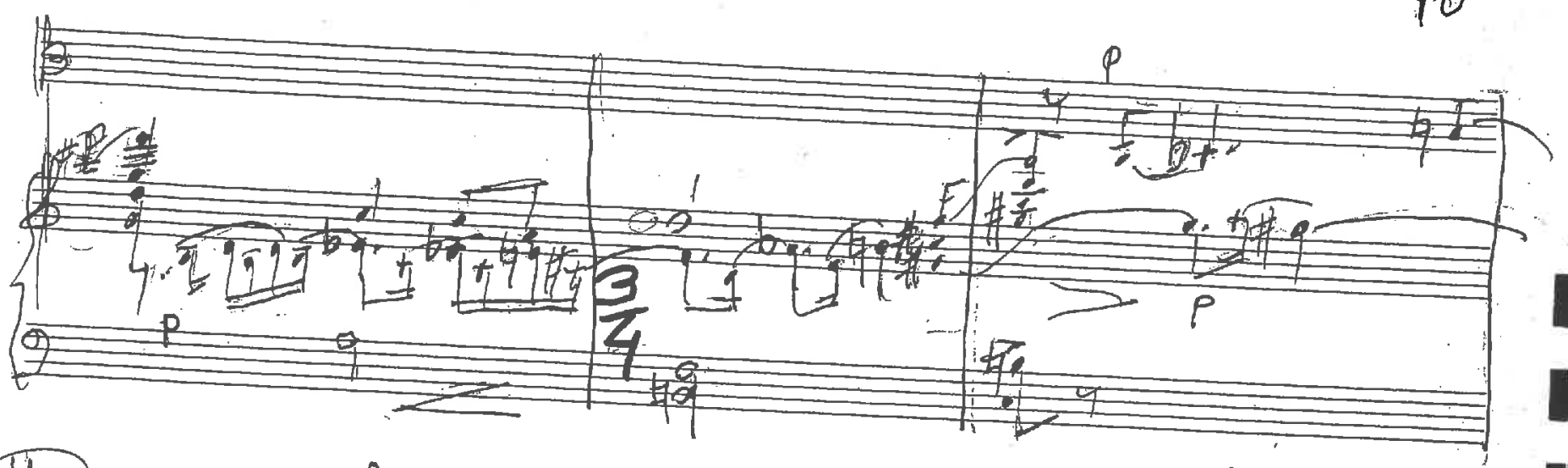

1. 0 .

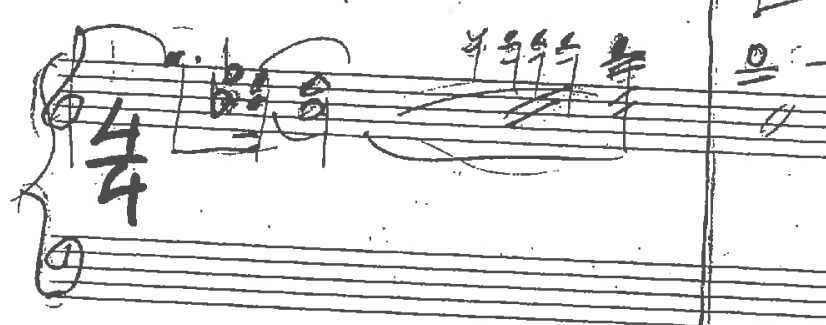

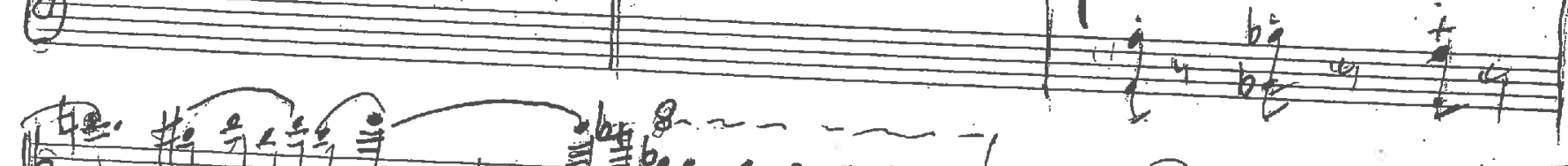

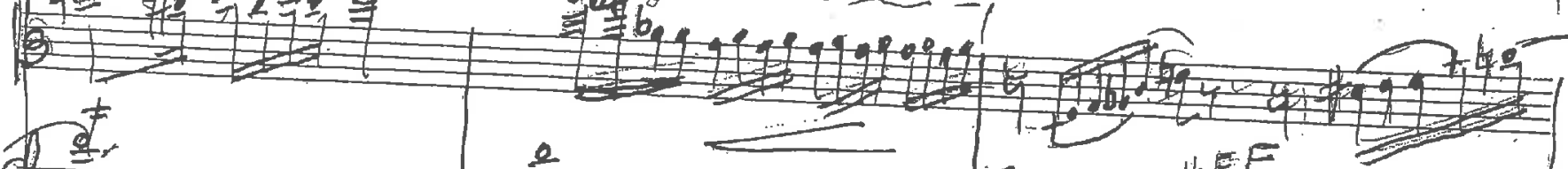

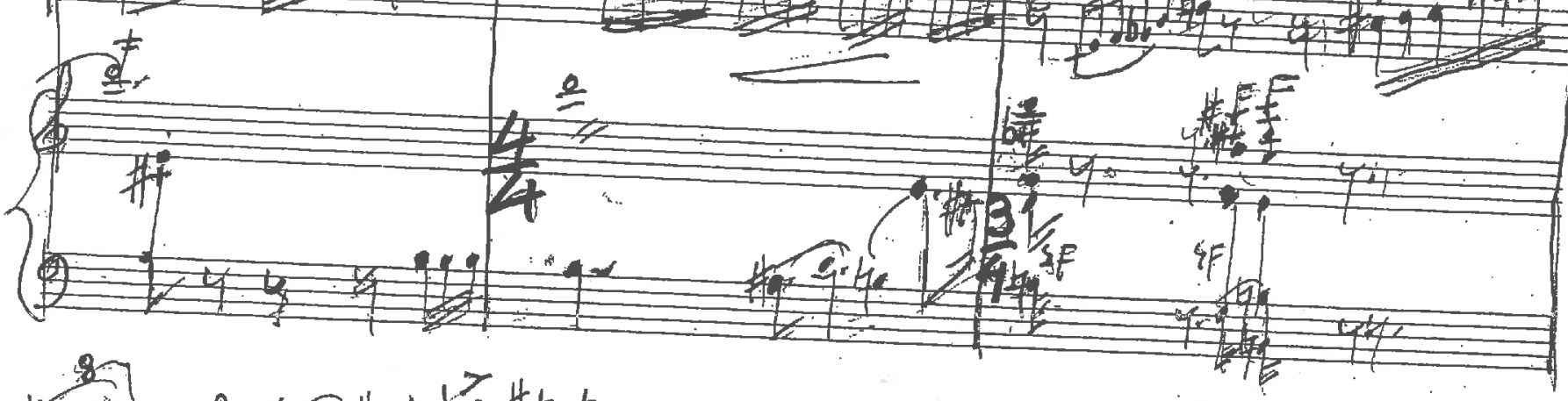

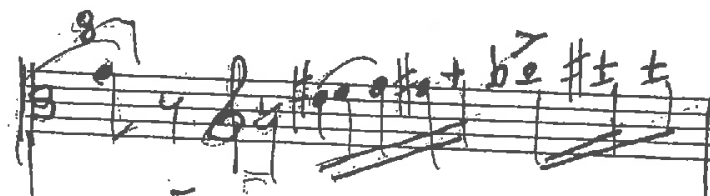

$\left\{\frac{F+\frac{F}{2}}{F}\right.$

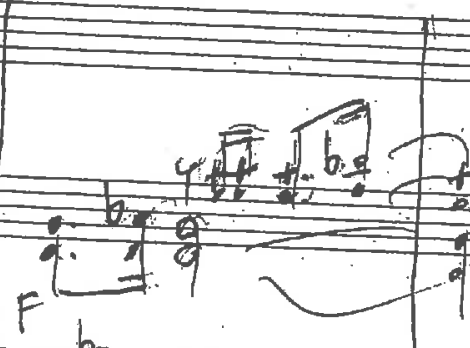

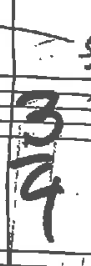




\section{1}

\&

1)

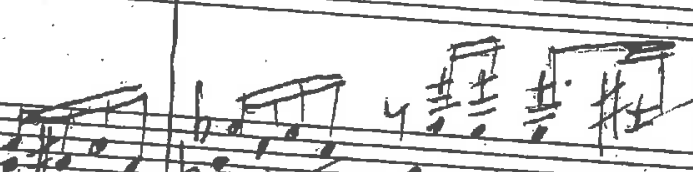

11.1

1.1.1.4.

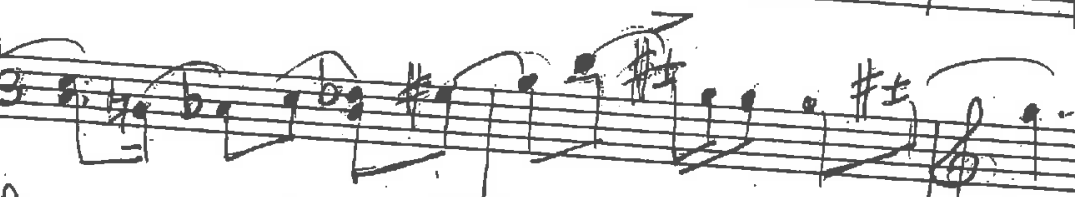

$3 \quad 2$

$\frac{4}{4}$

(1)

4

$17>2$

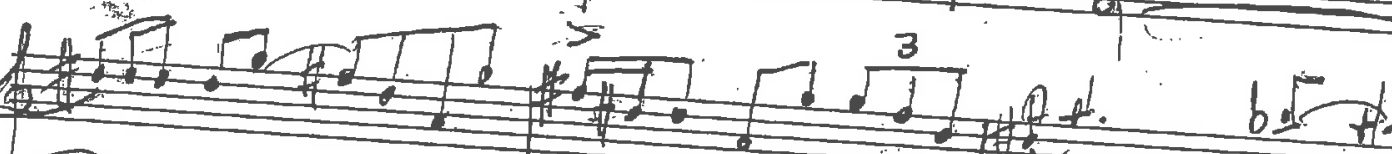

井至

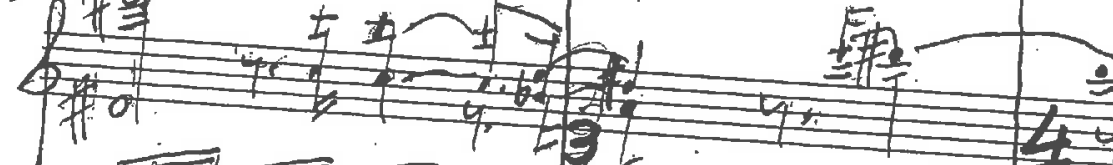

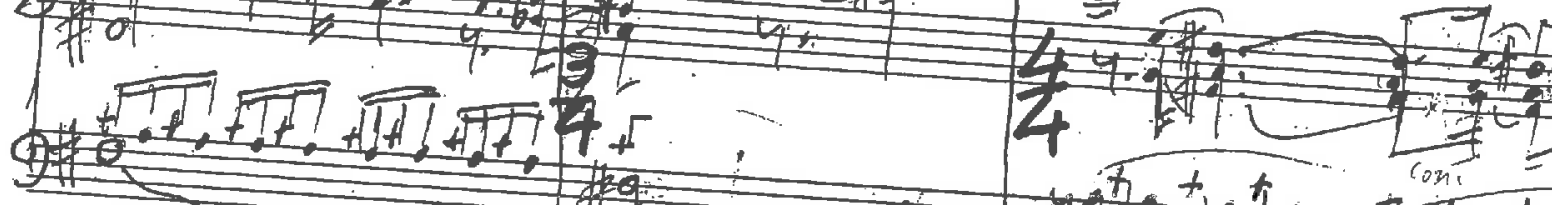
1.1919

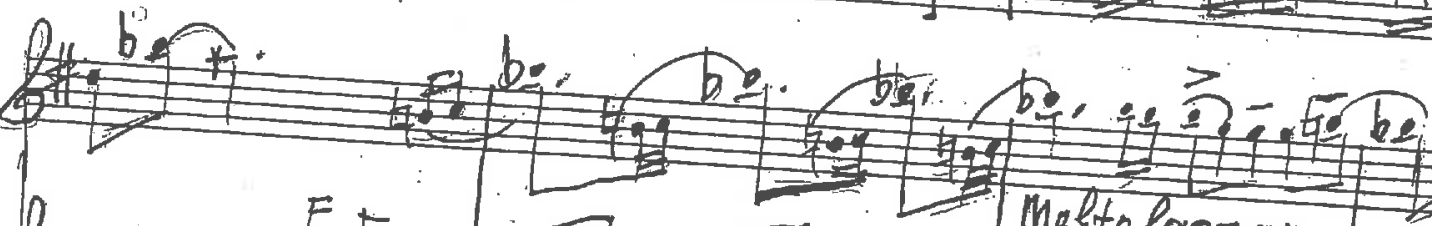

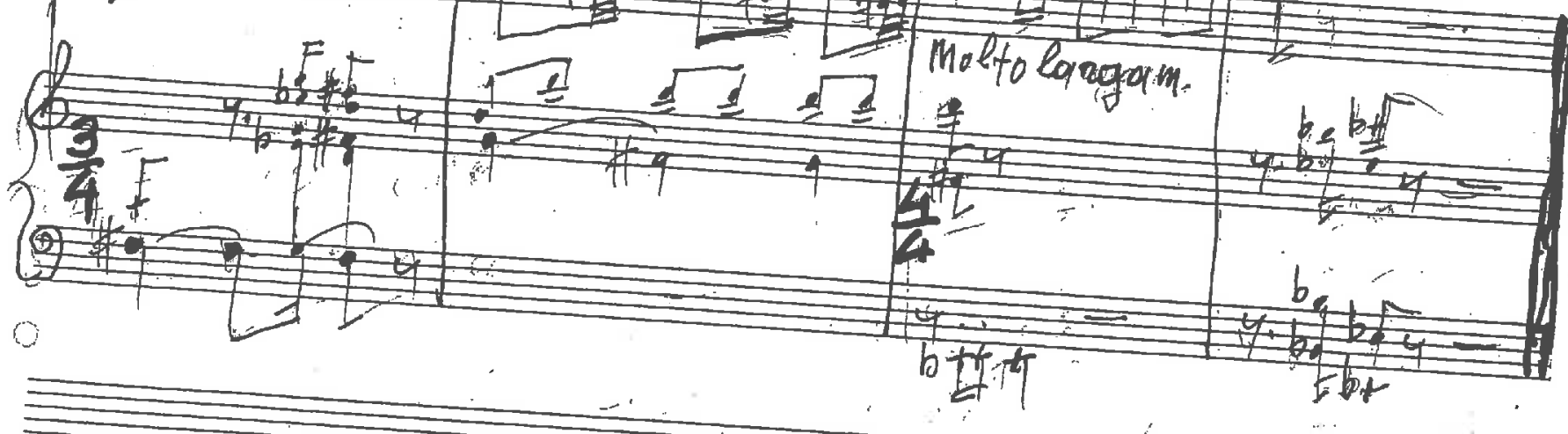


t:

然 I.

安.

$\pm$

27

6

bert<smiles>C#CCCCC#[Si]</smiles>

tot

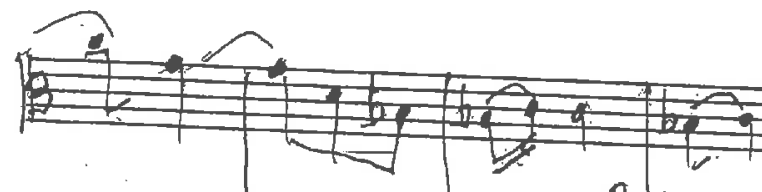

$f^{\prime}$

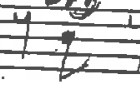

可

12

雨
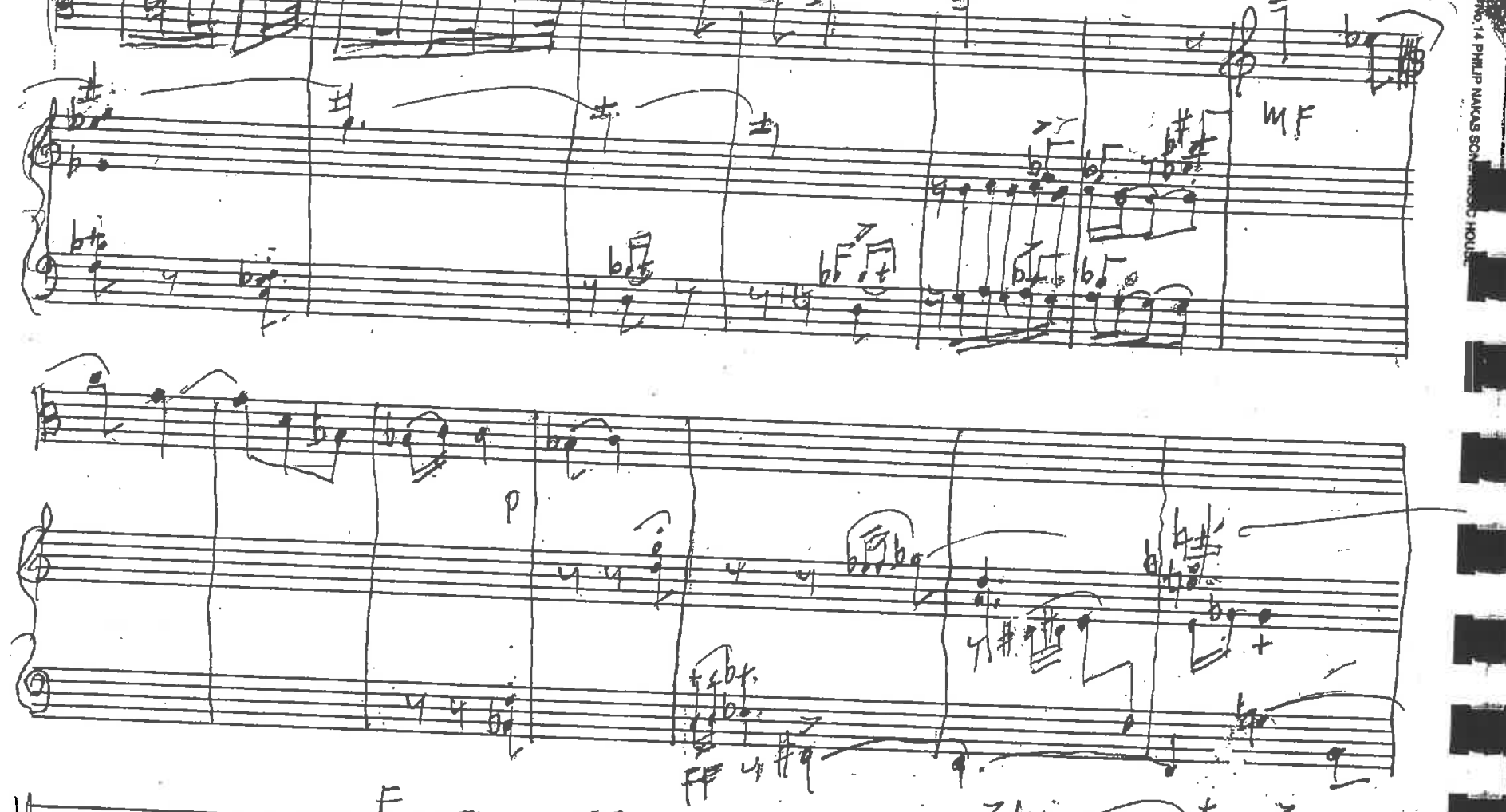

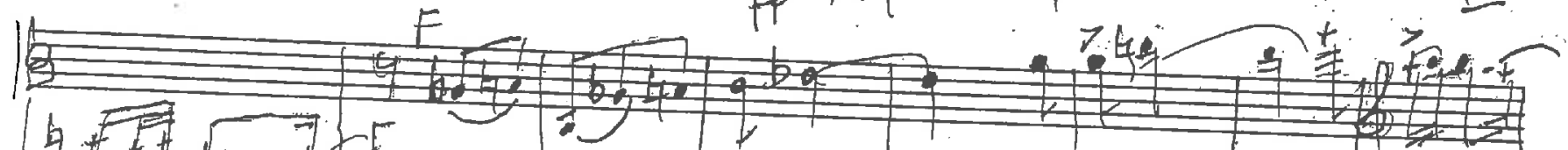

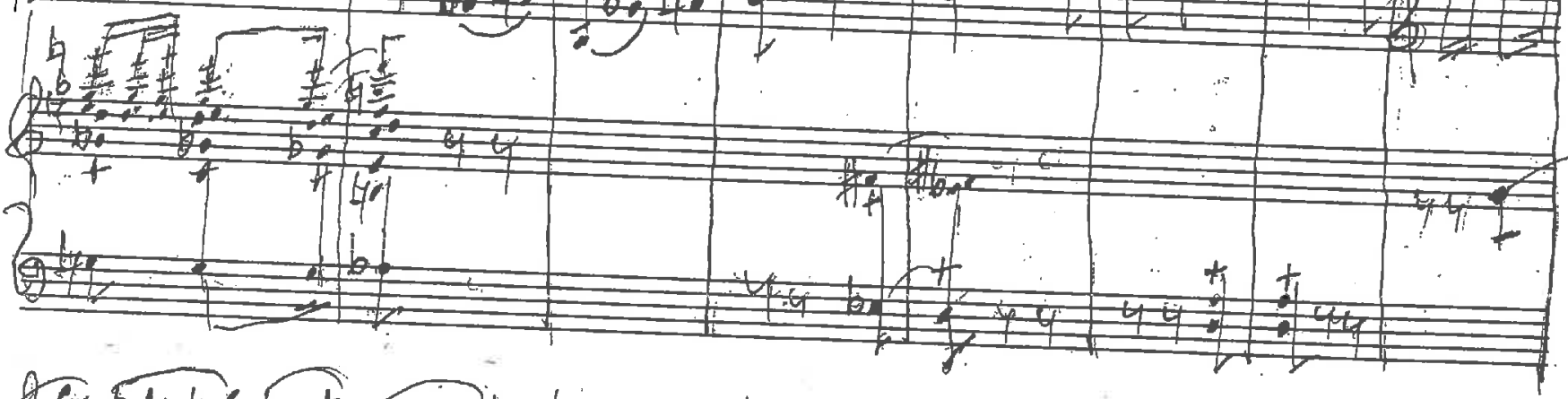

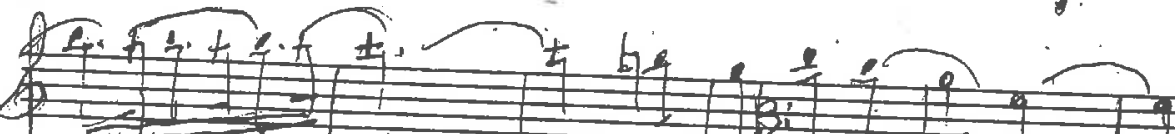

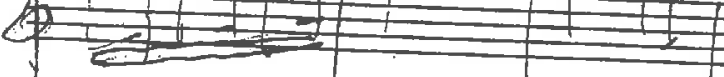

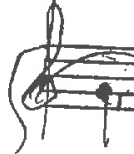

䒠
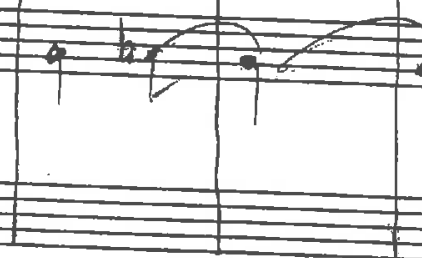

54

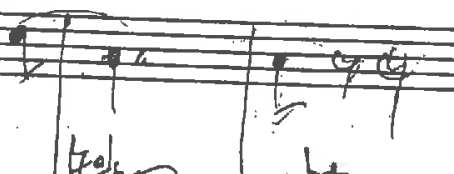

2

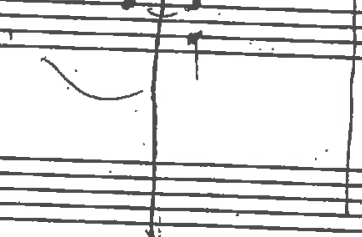

$+2$ 4 

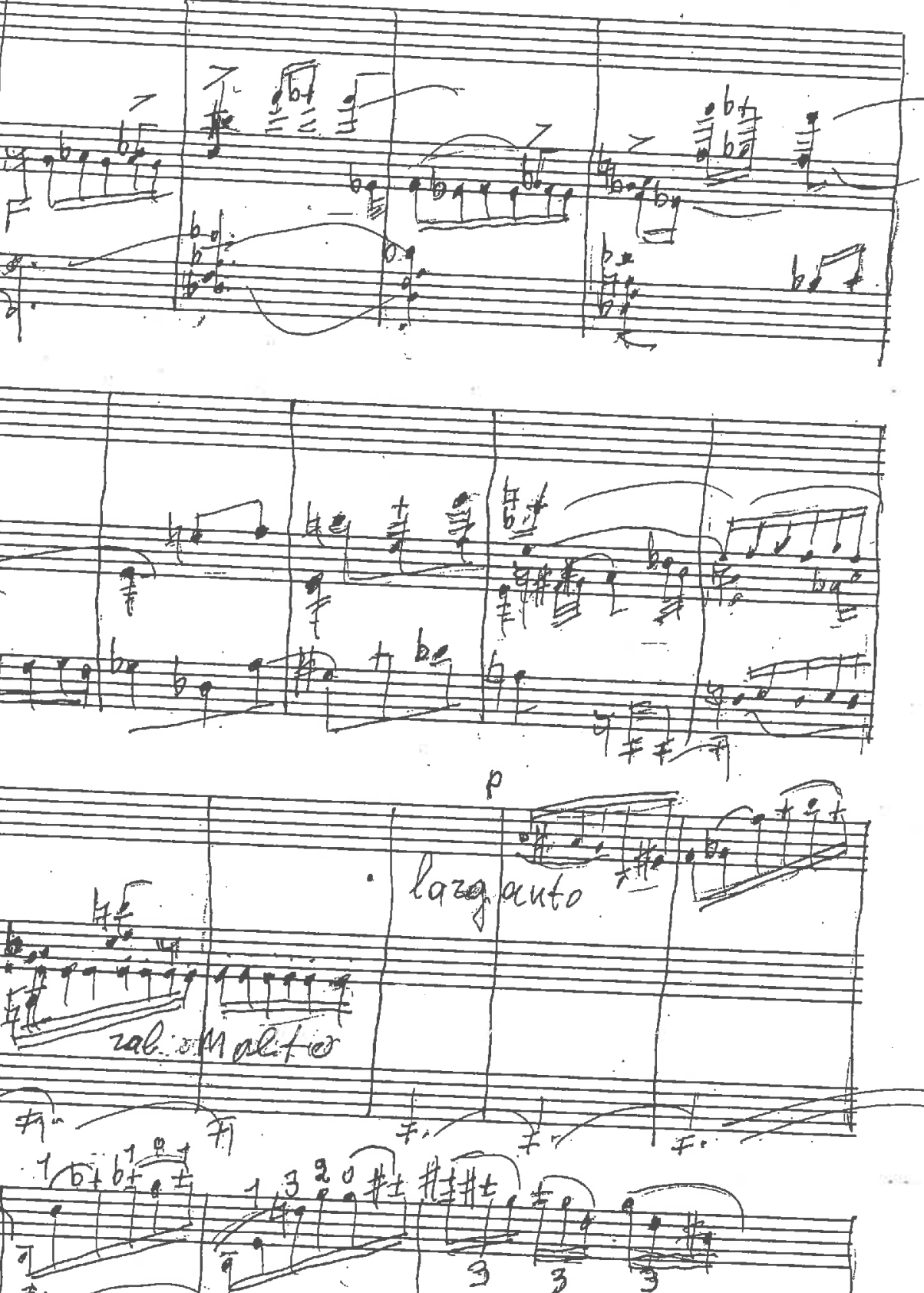


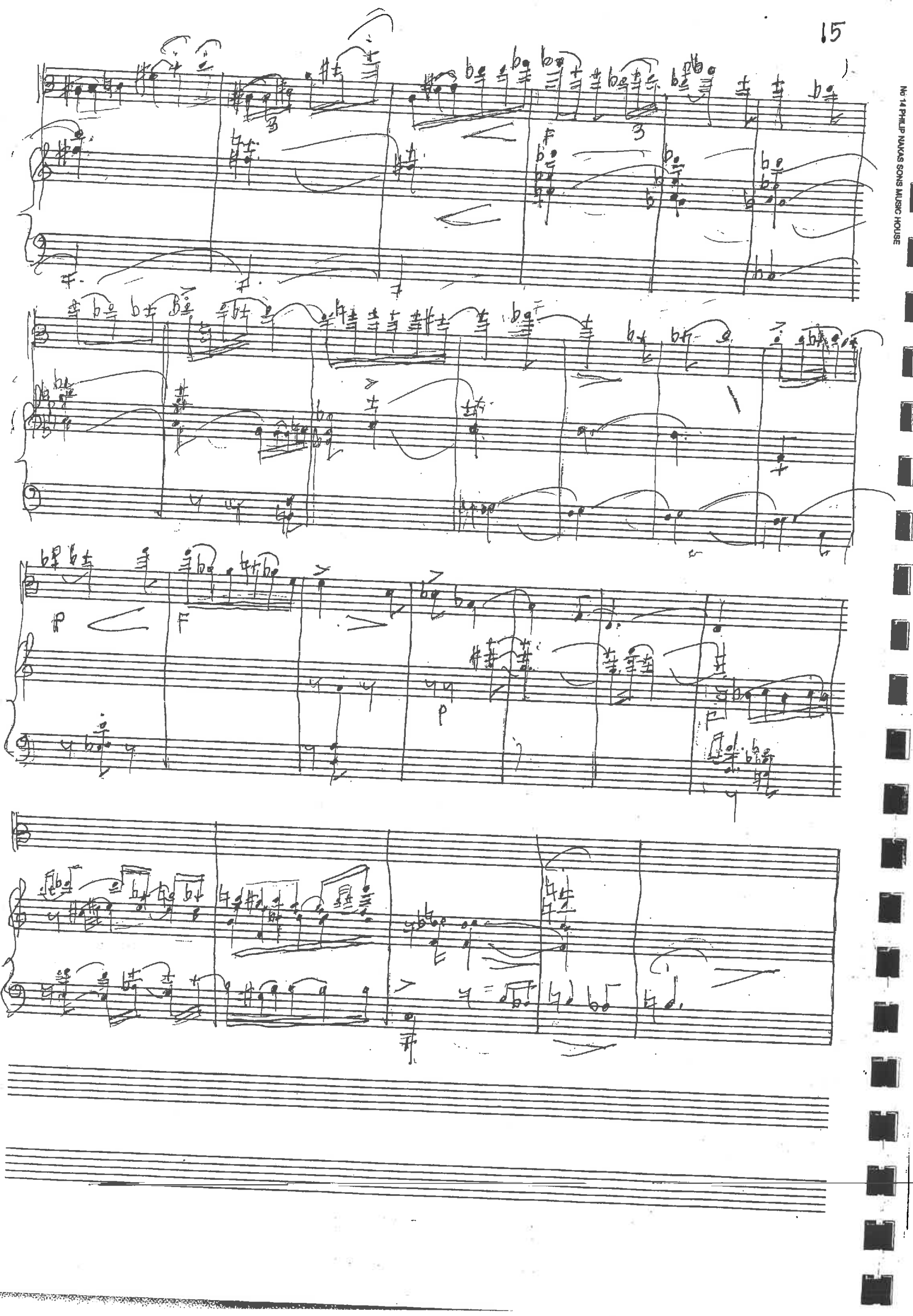




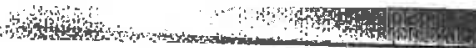

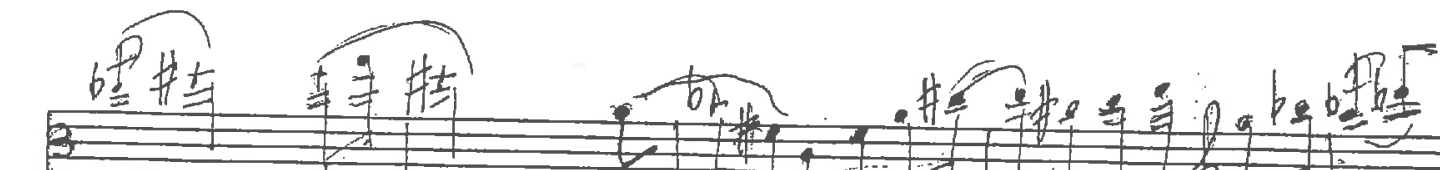
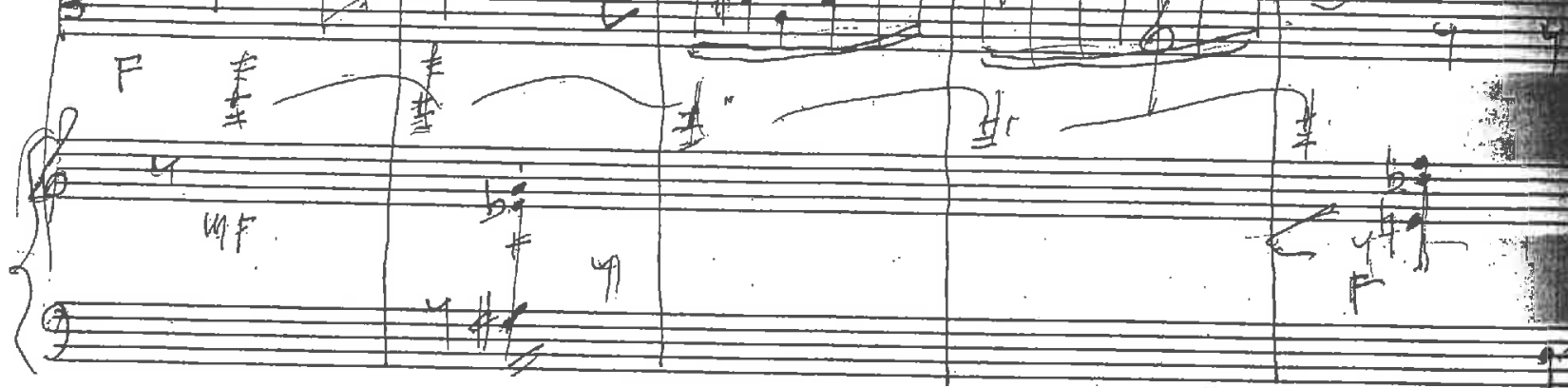

$=$

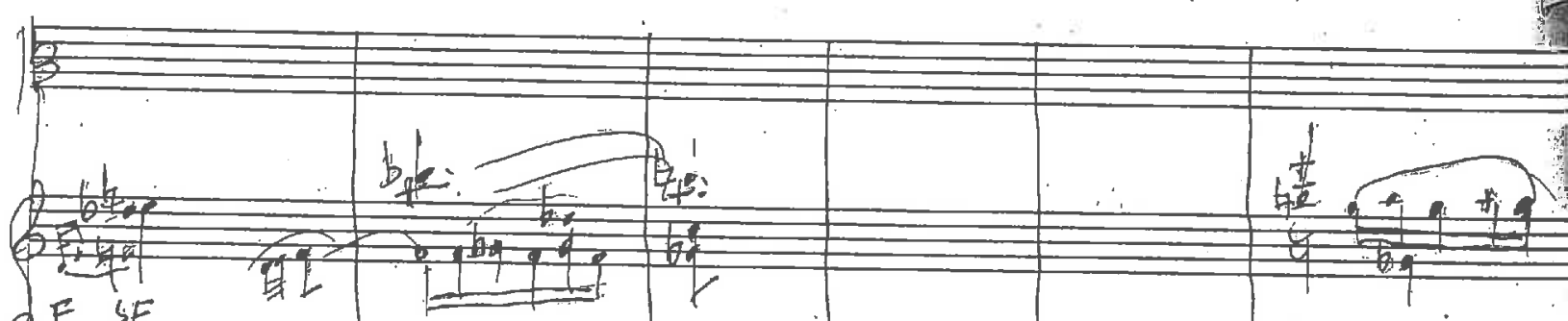

- F SF

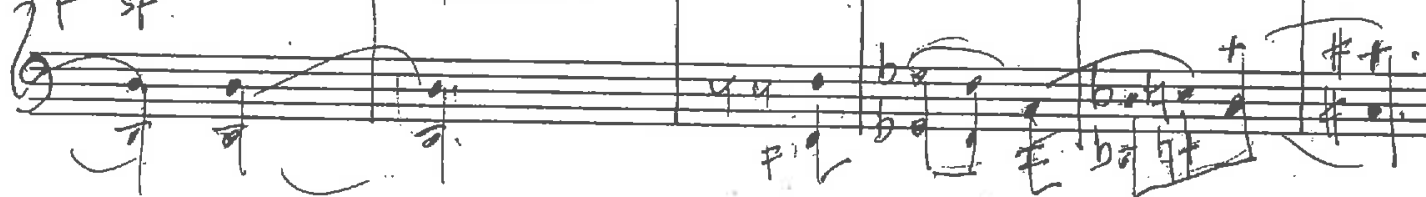

\begin{tabular}{llll}
\hline \\
\end{tabular}

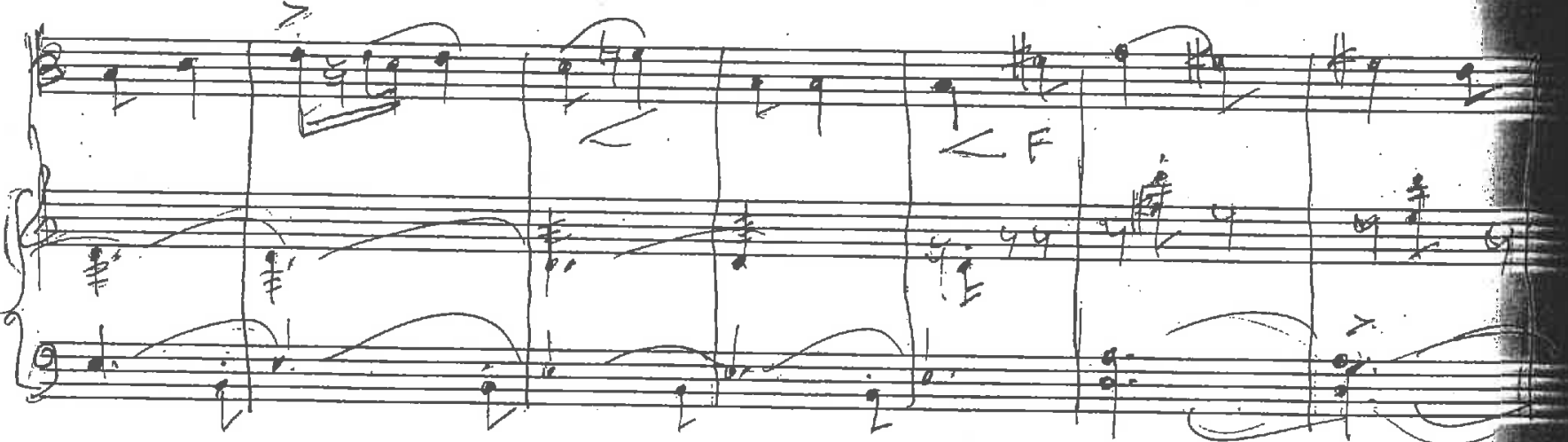

西

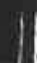




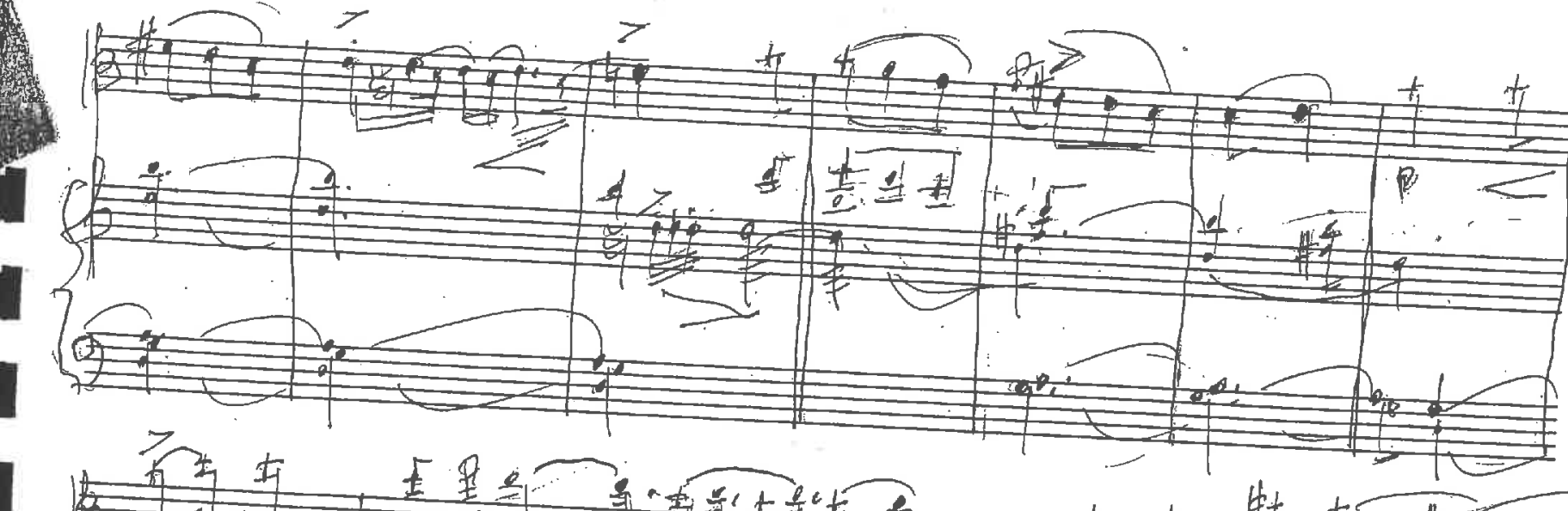

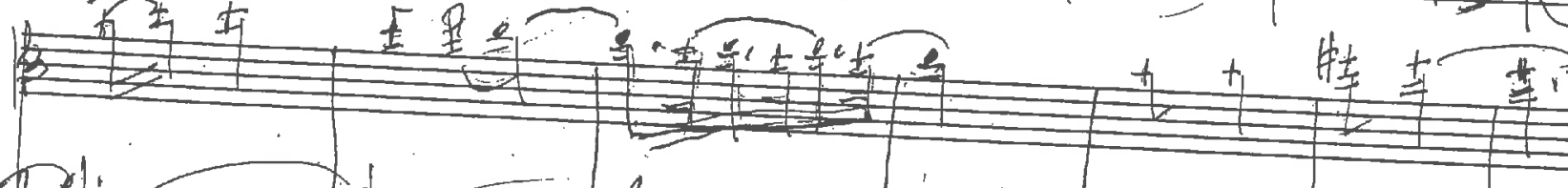

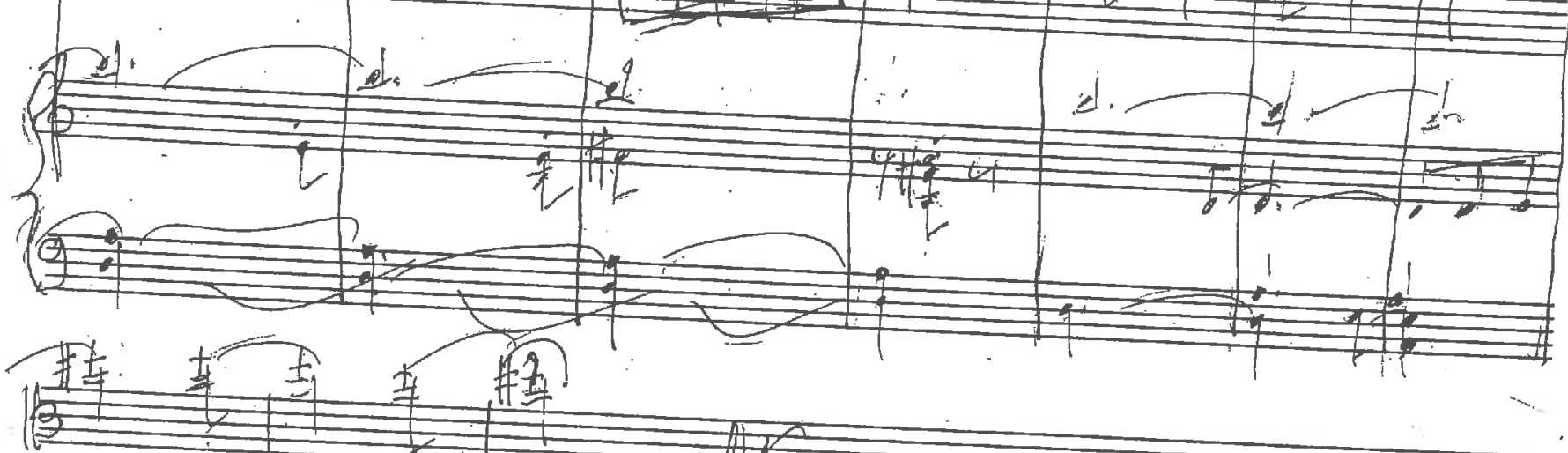

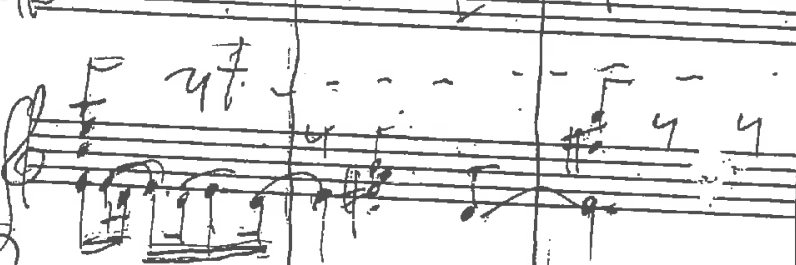
$3+2$ $\leq 2$ 1 
19
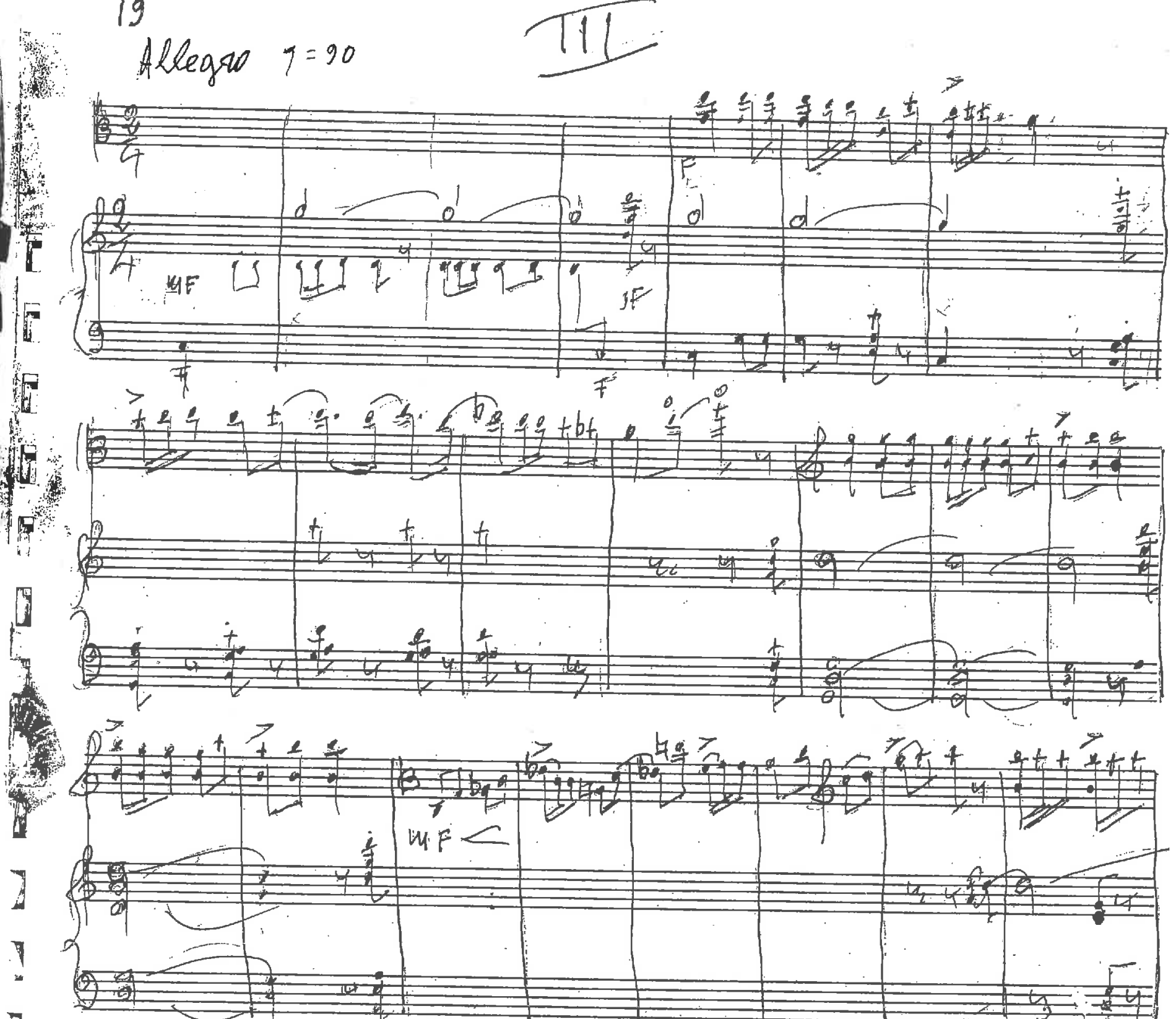

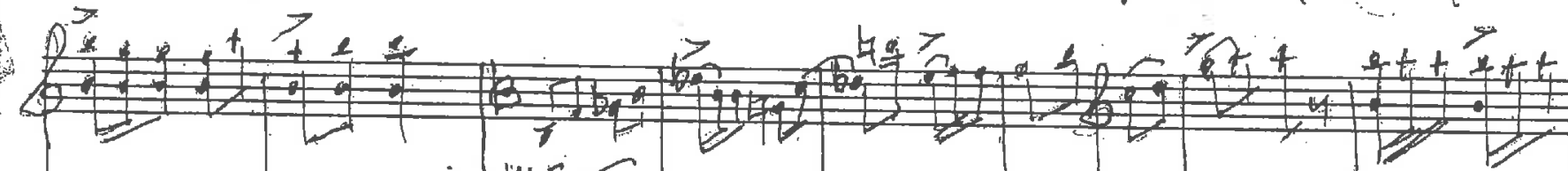
$2 \quad$ i $4 \%<$

$\{2$

$\underset{2+2+2+2}{2}$

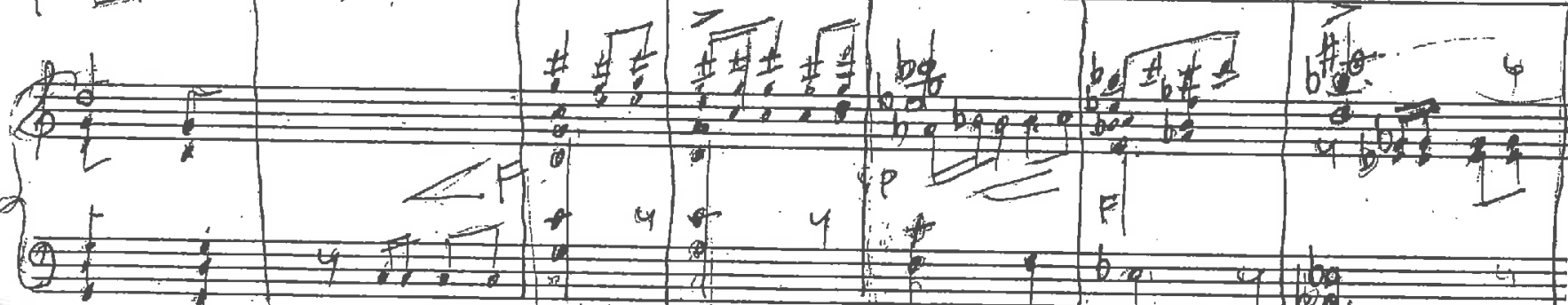

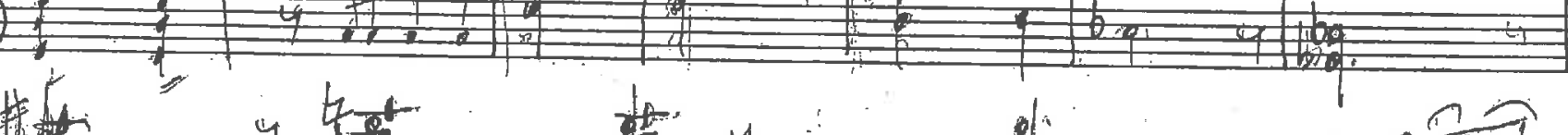

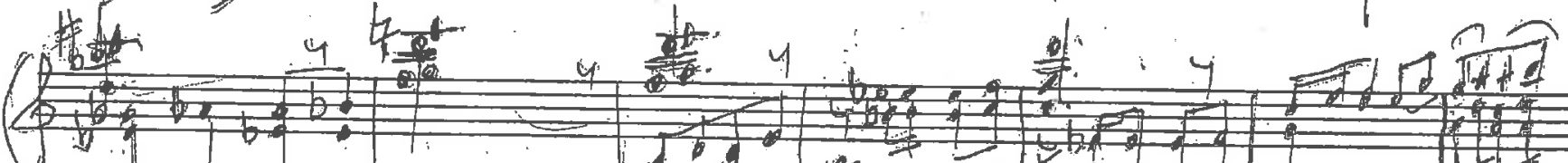
3 (1)

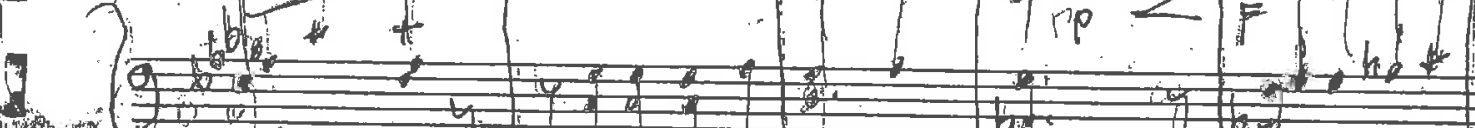


40.

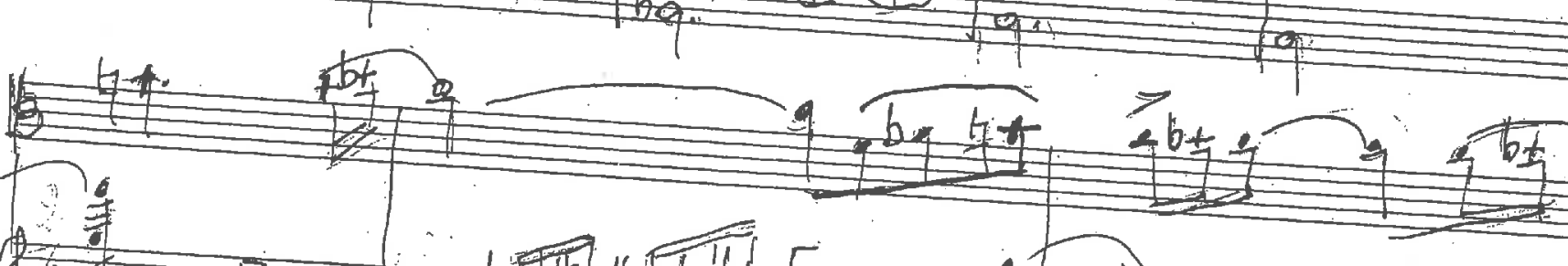

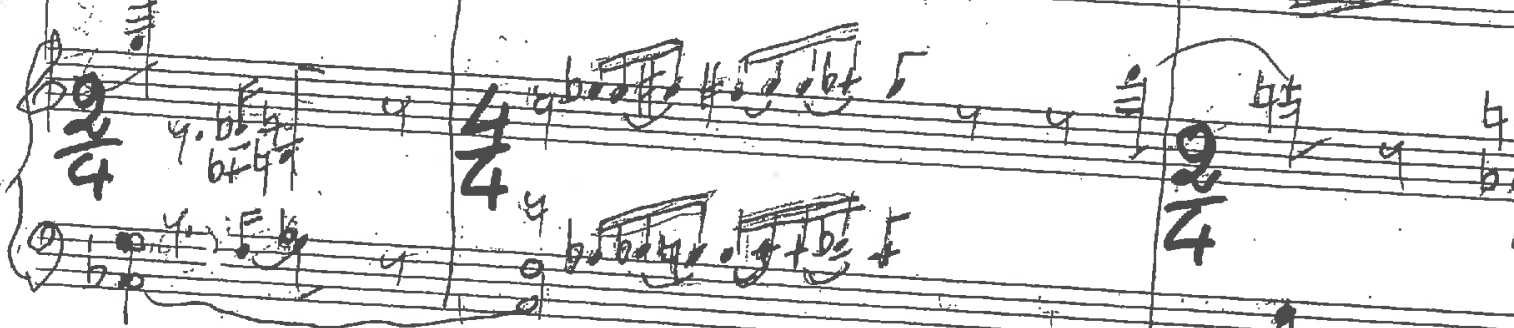

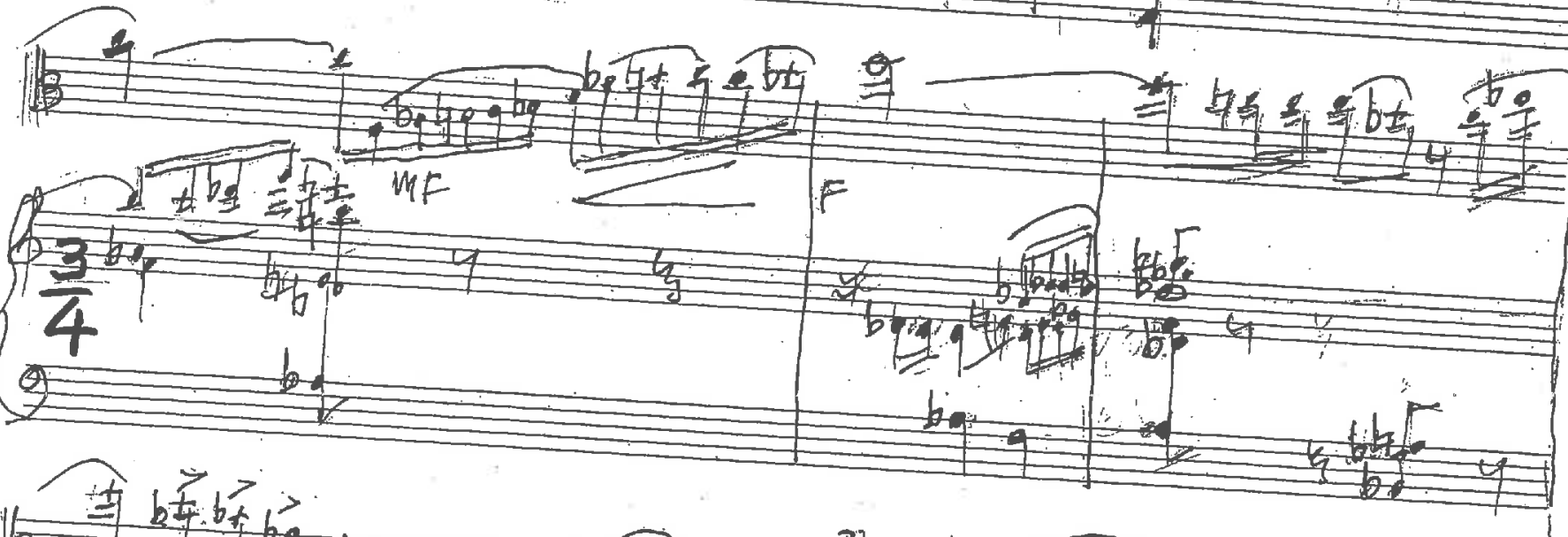

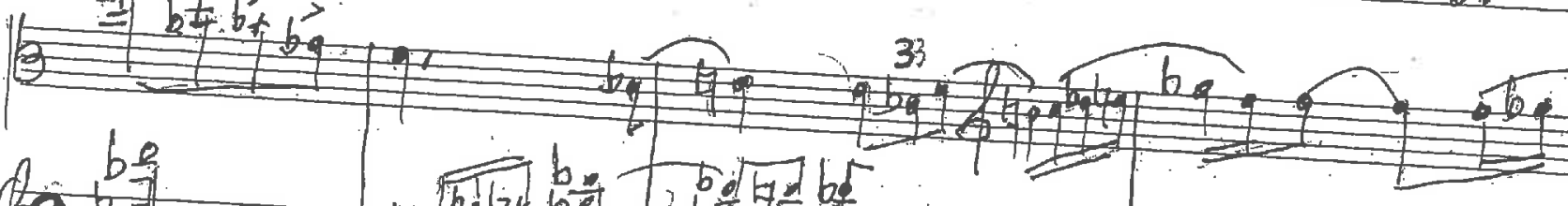

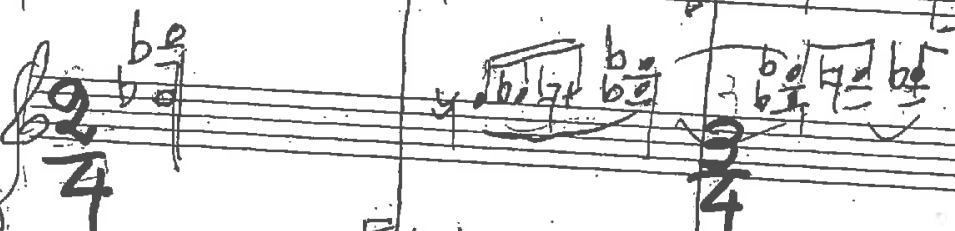

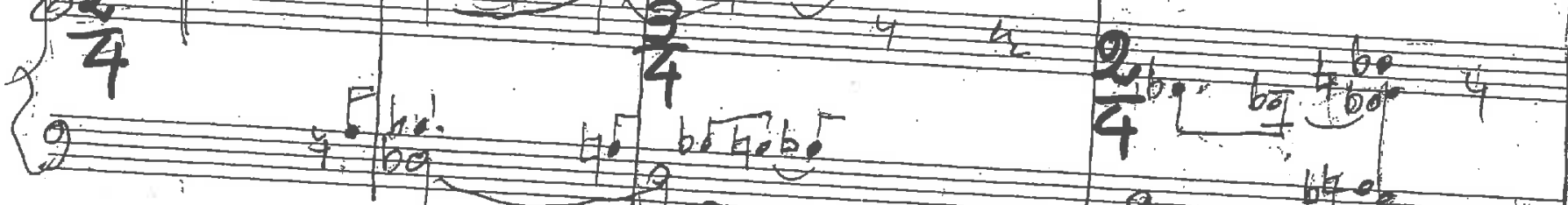




\section{1}

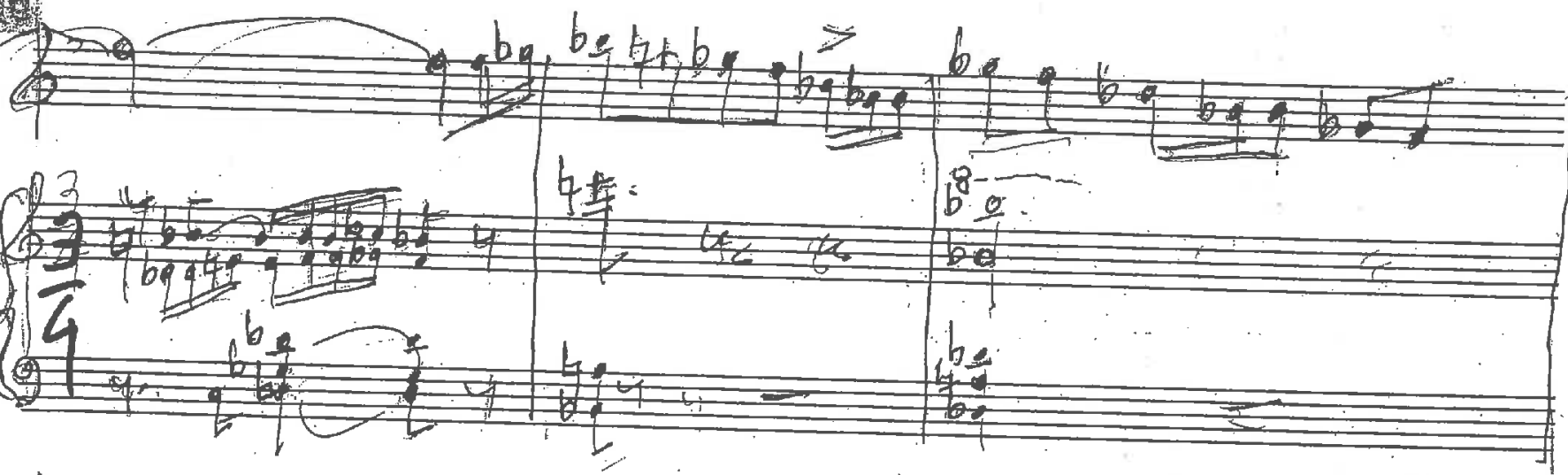

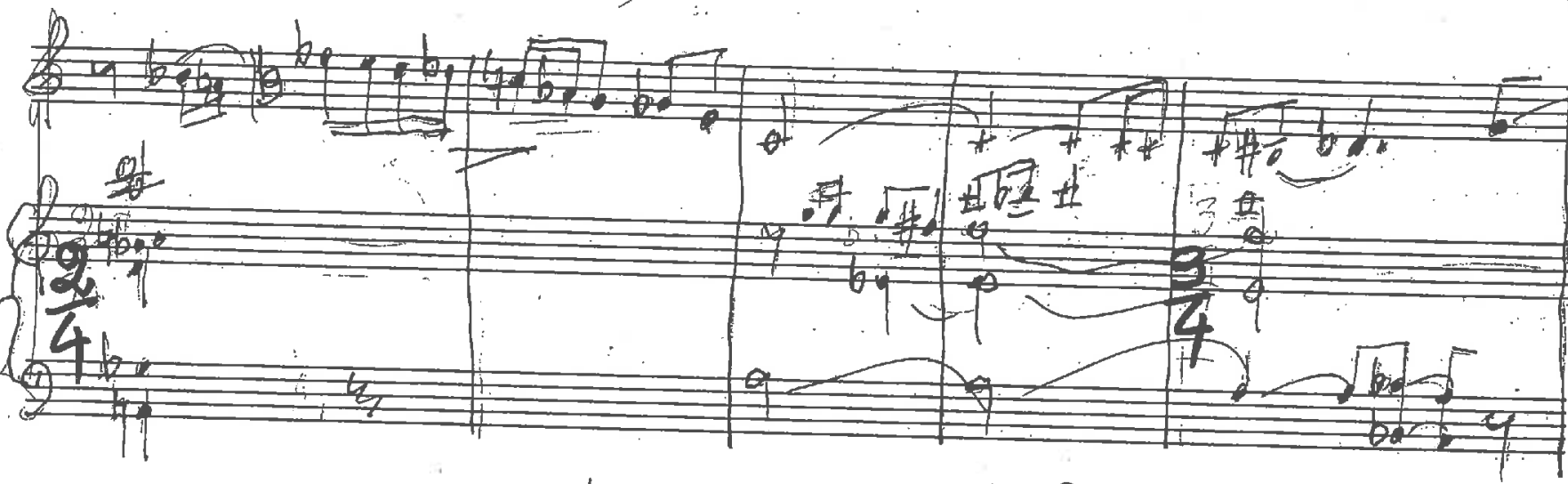
(1)

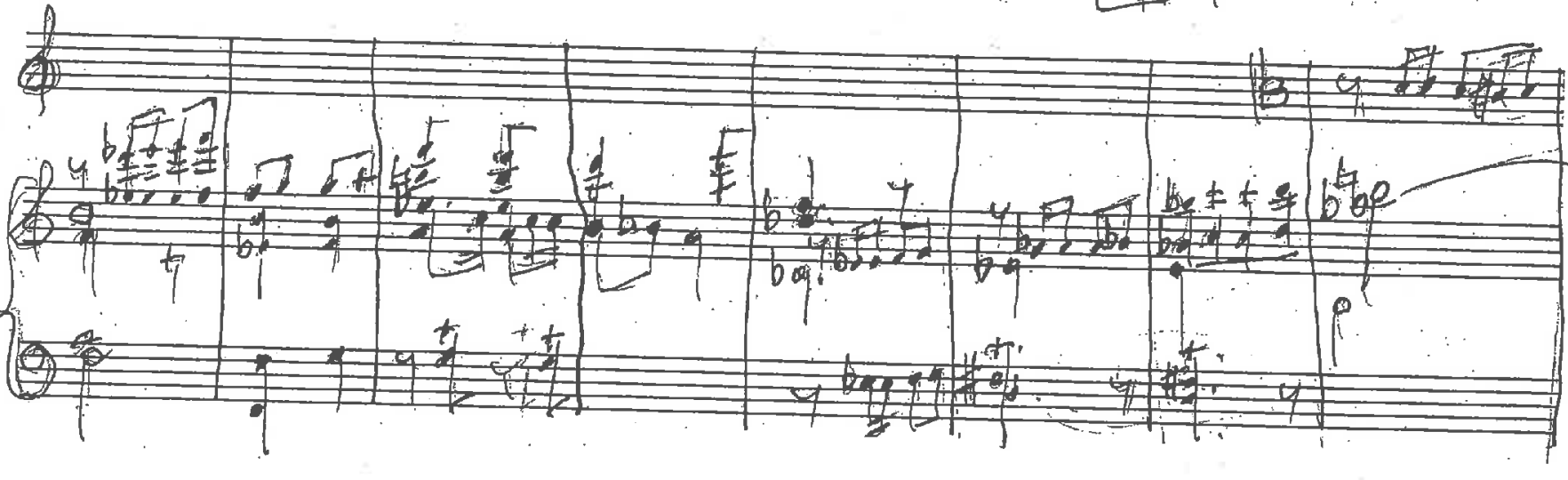




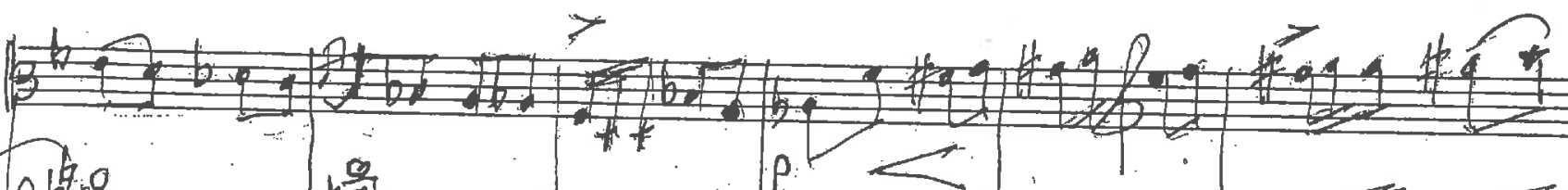

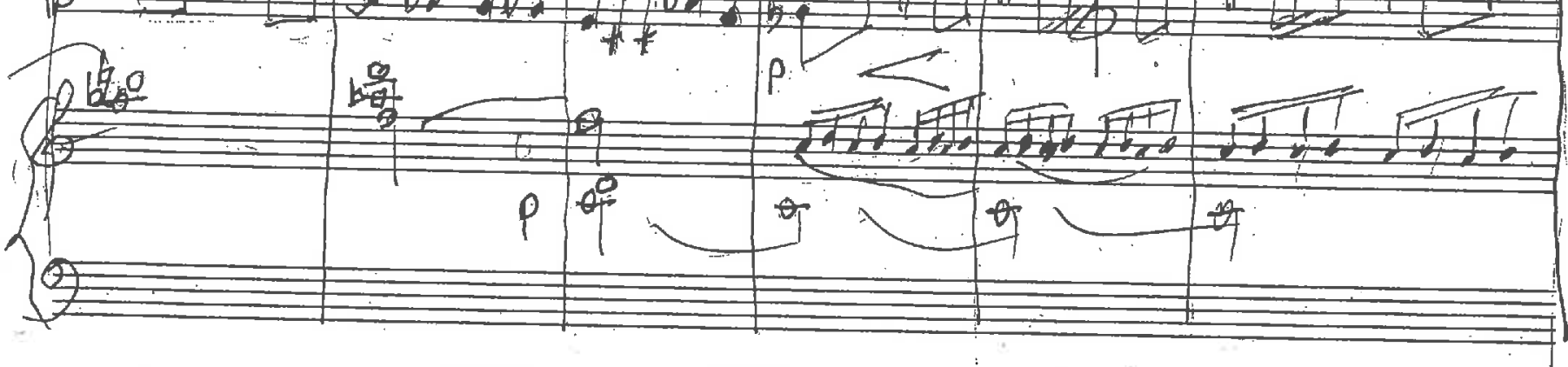

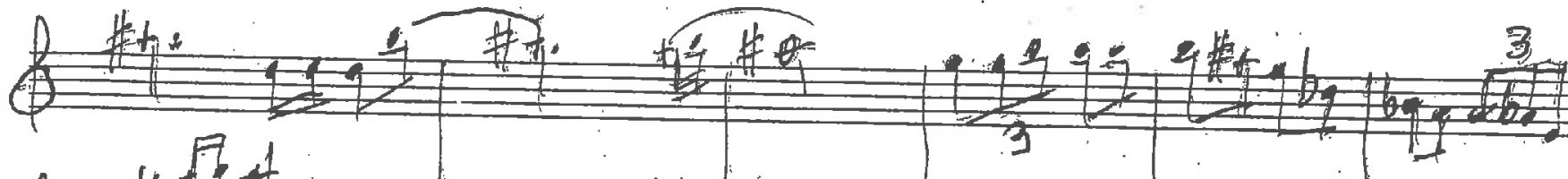

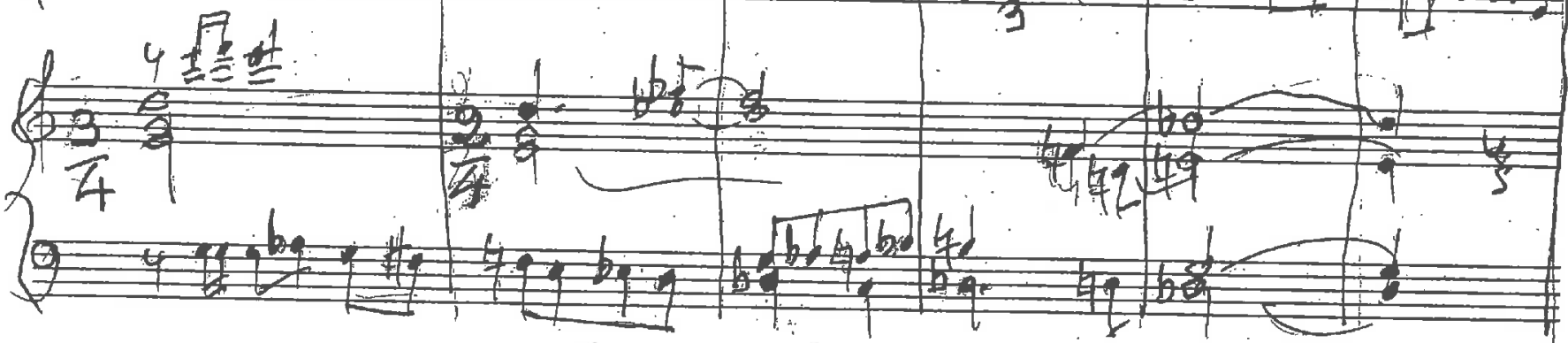
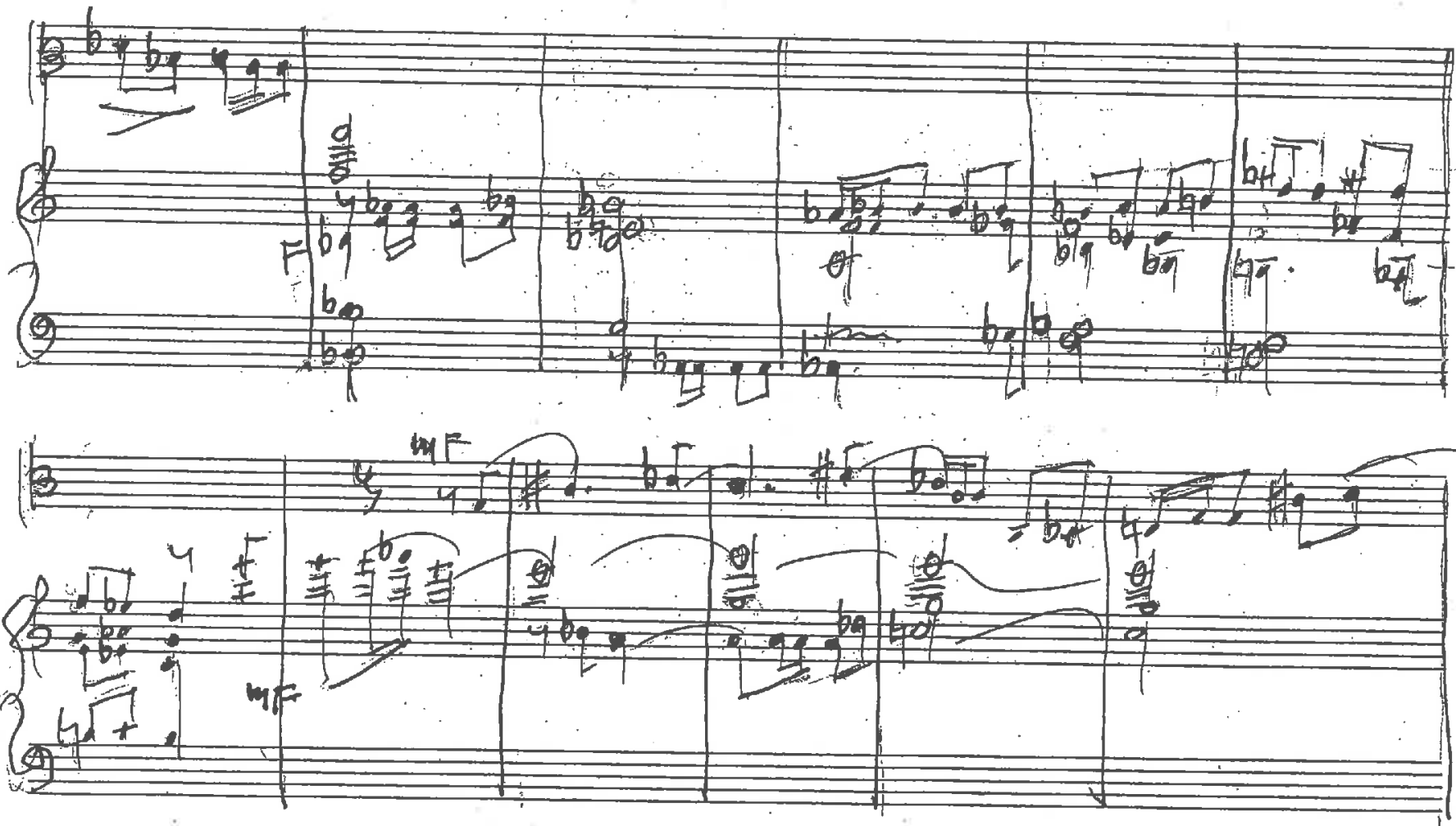


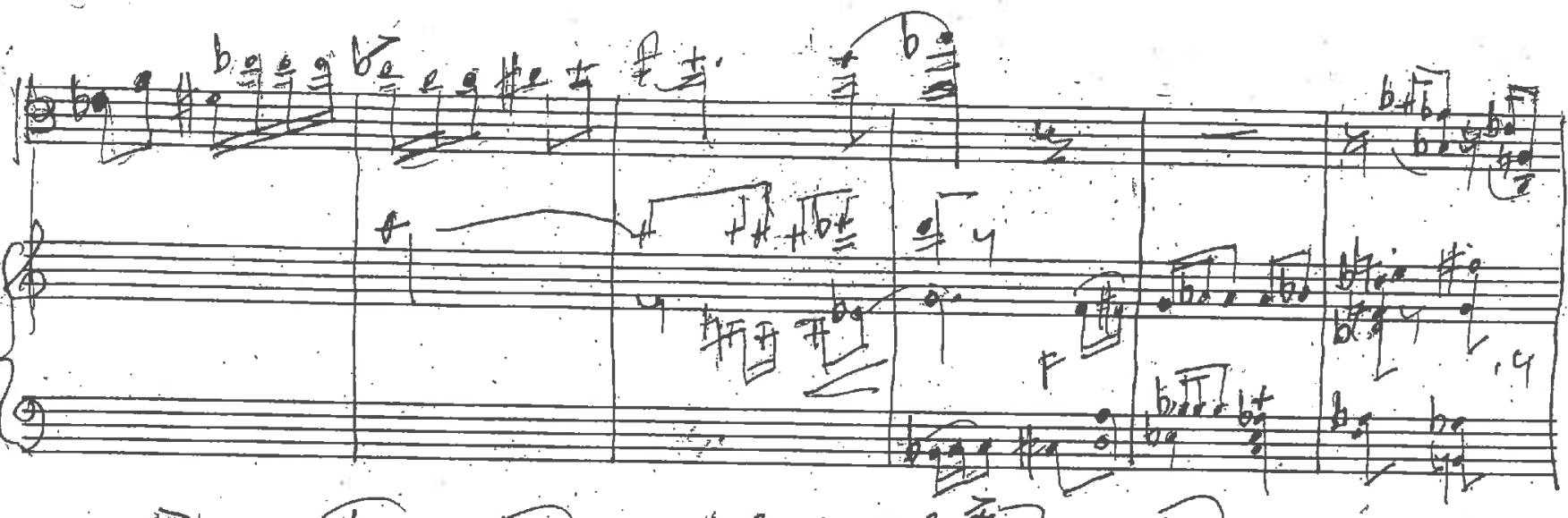

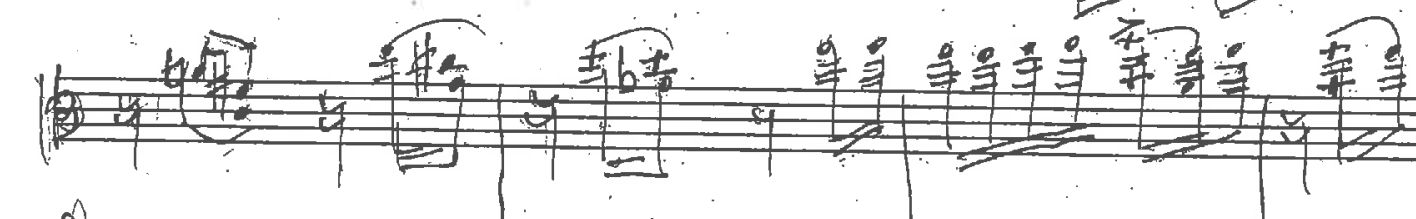

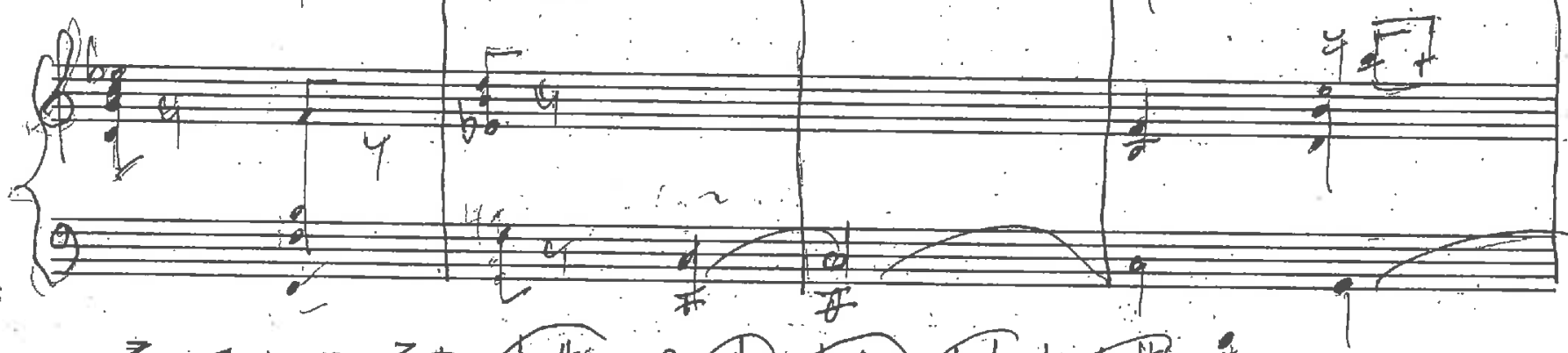

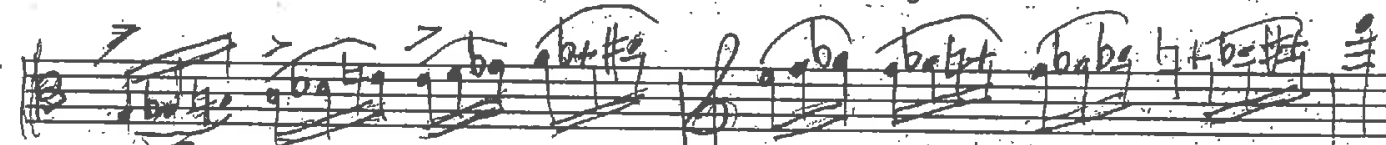
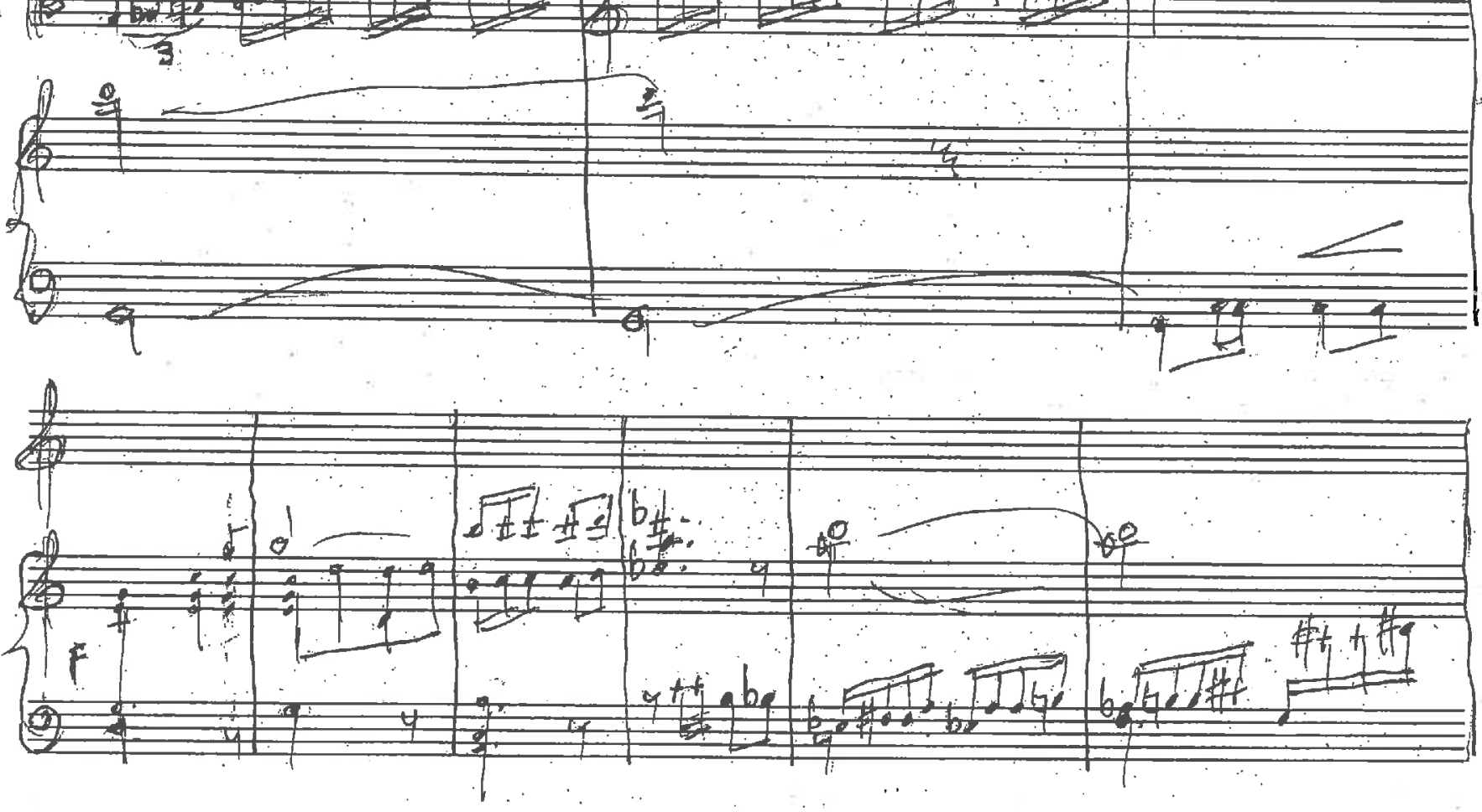


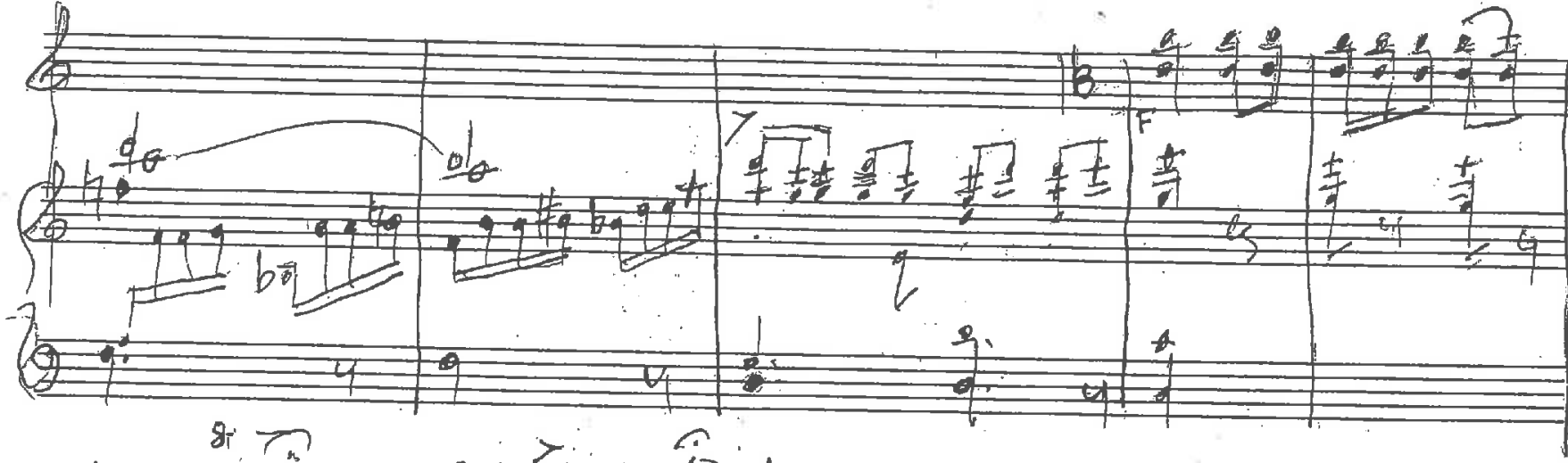

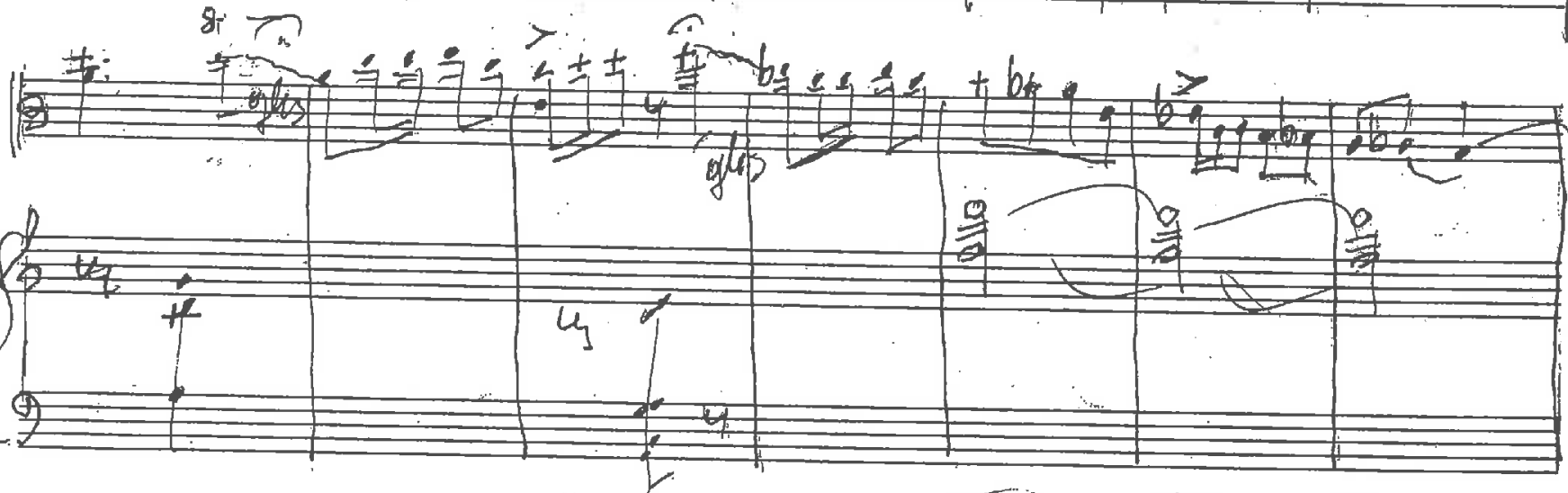

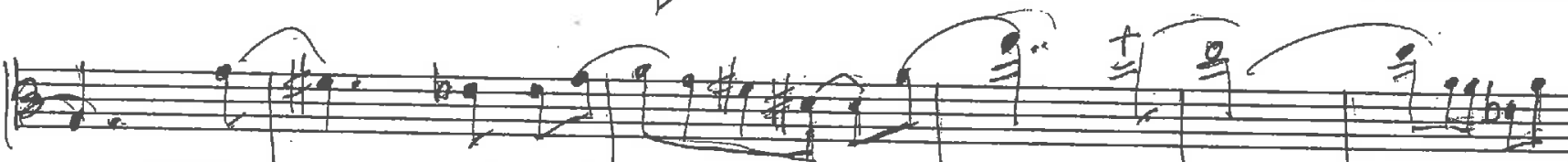
(4)

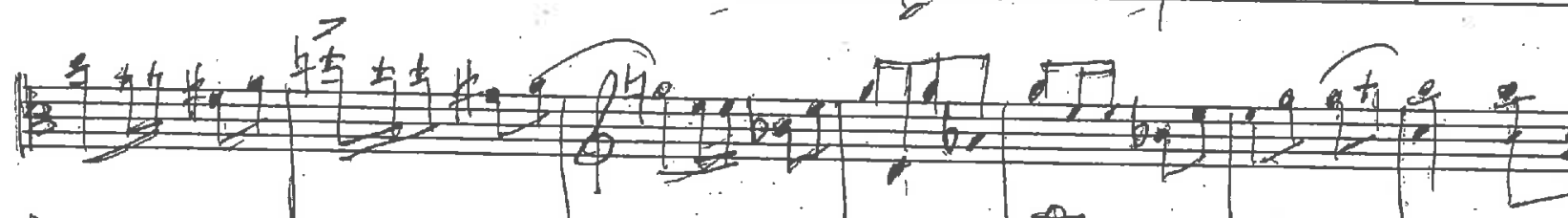
\begin{tabular}{|c|c|c|c|c|c|}
\hline & & & \\
\hline \\
\hline
\end{tabular} 

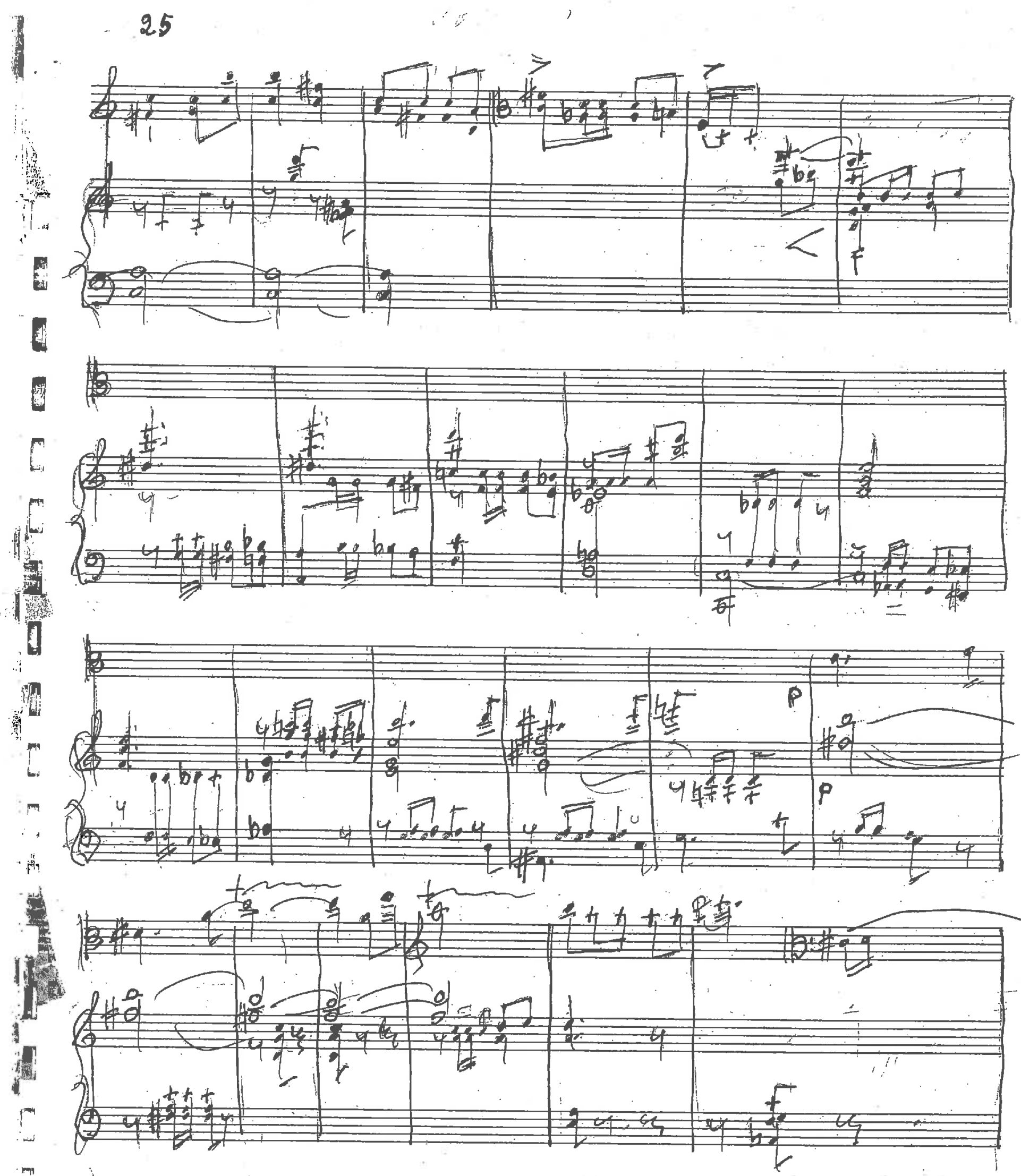

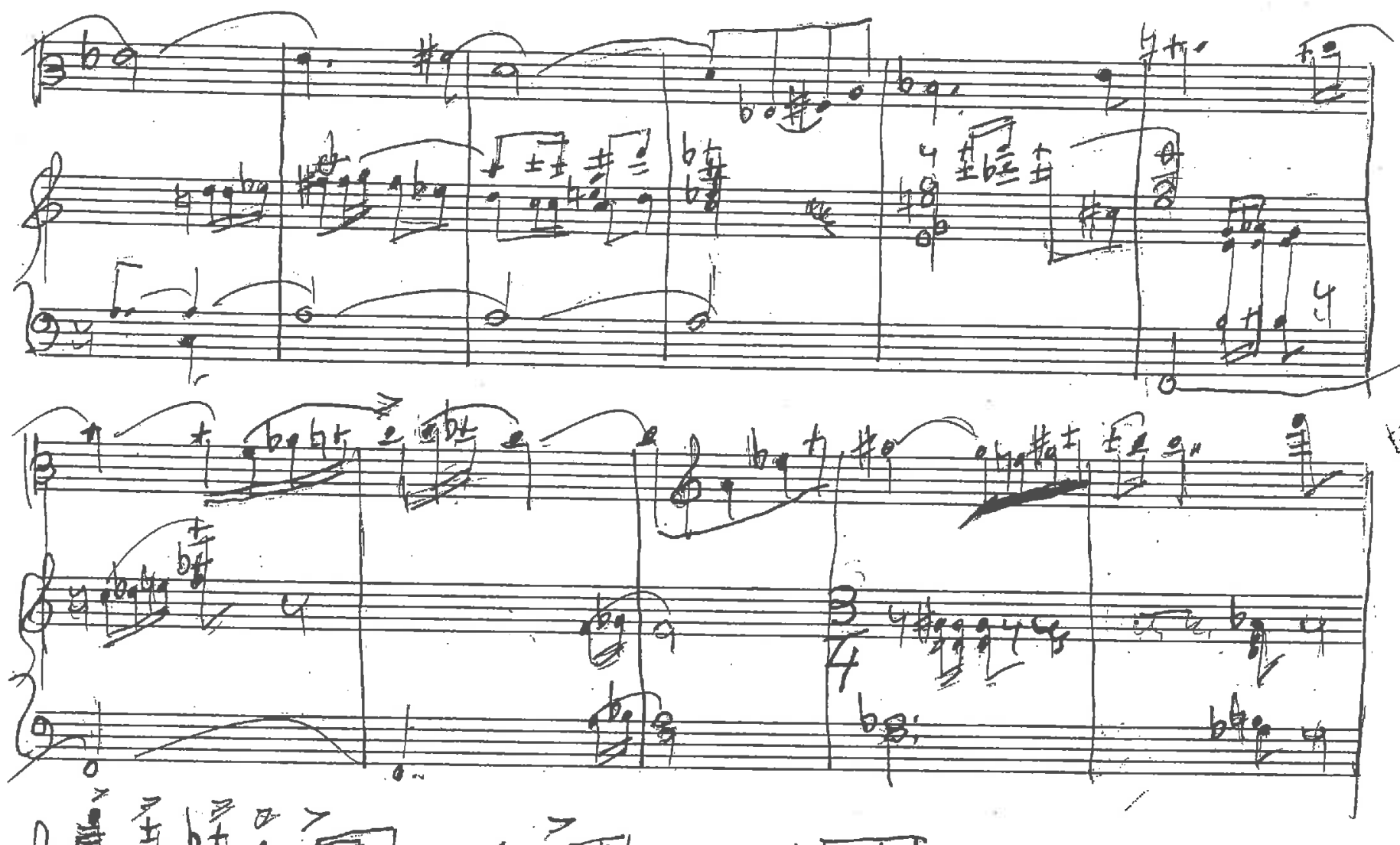

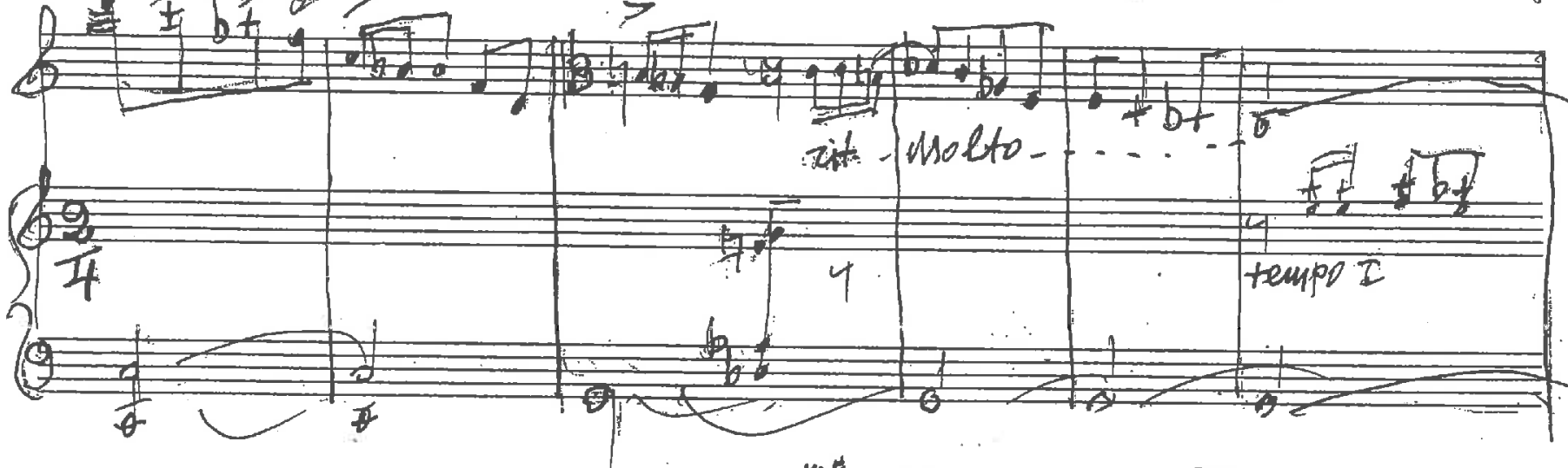

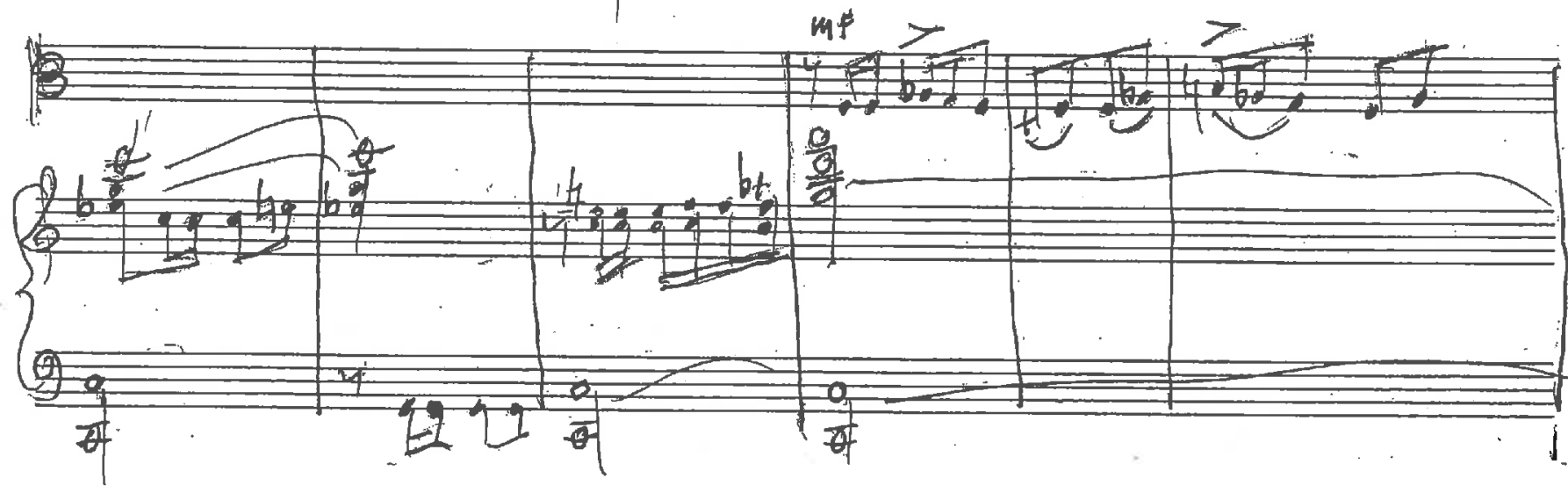


27 2 $\quad 2$

2

$\frac{1}{30.0}$

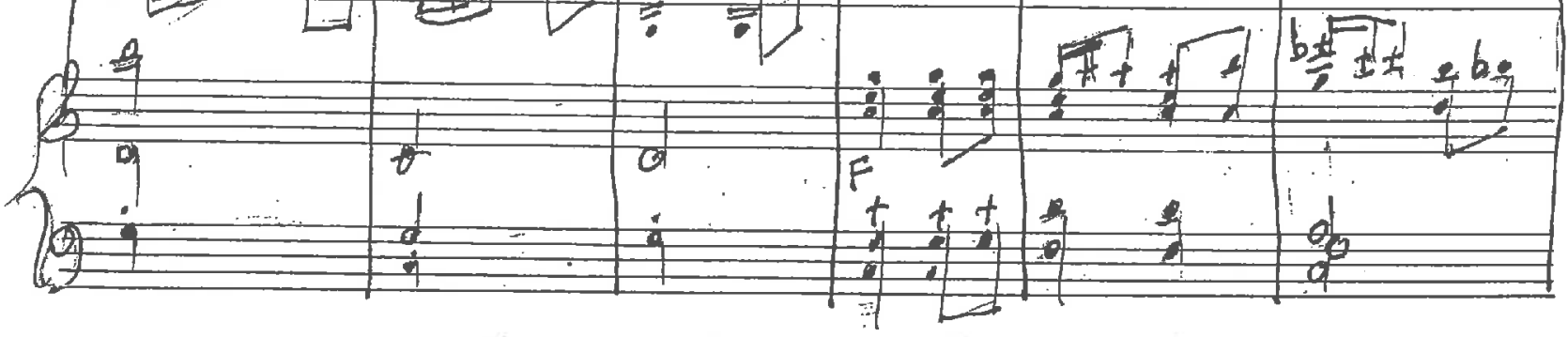

9

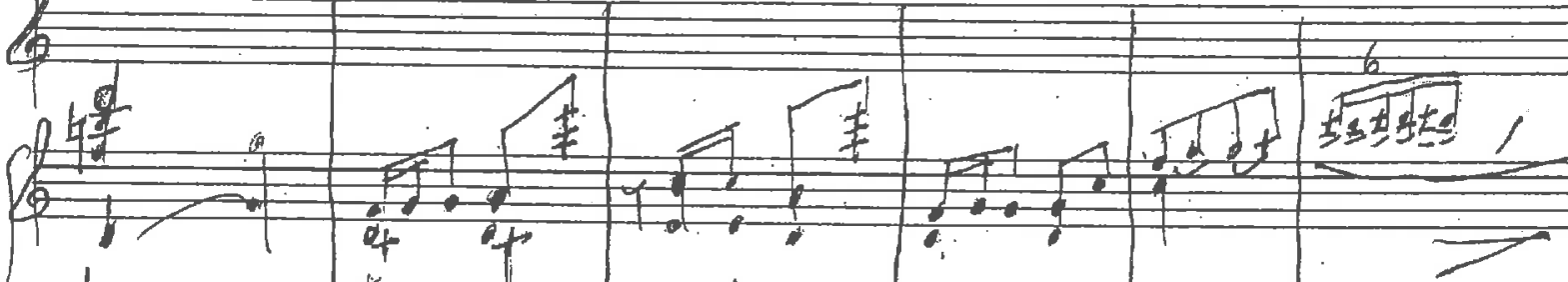
1\%?

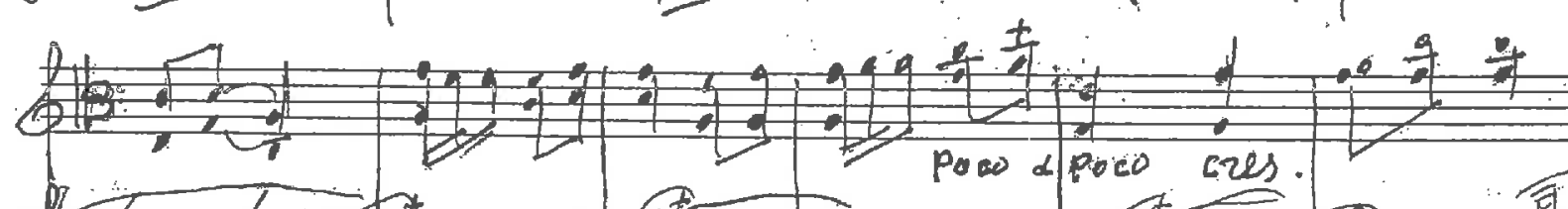
19

(9)

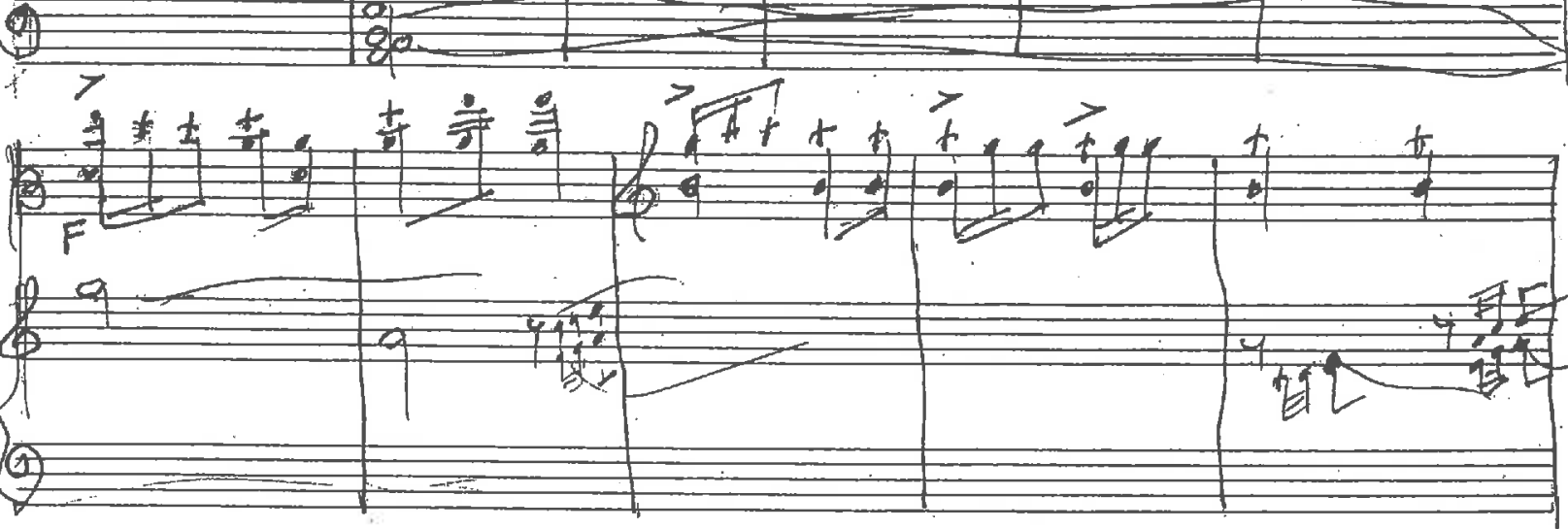



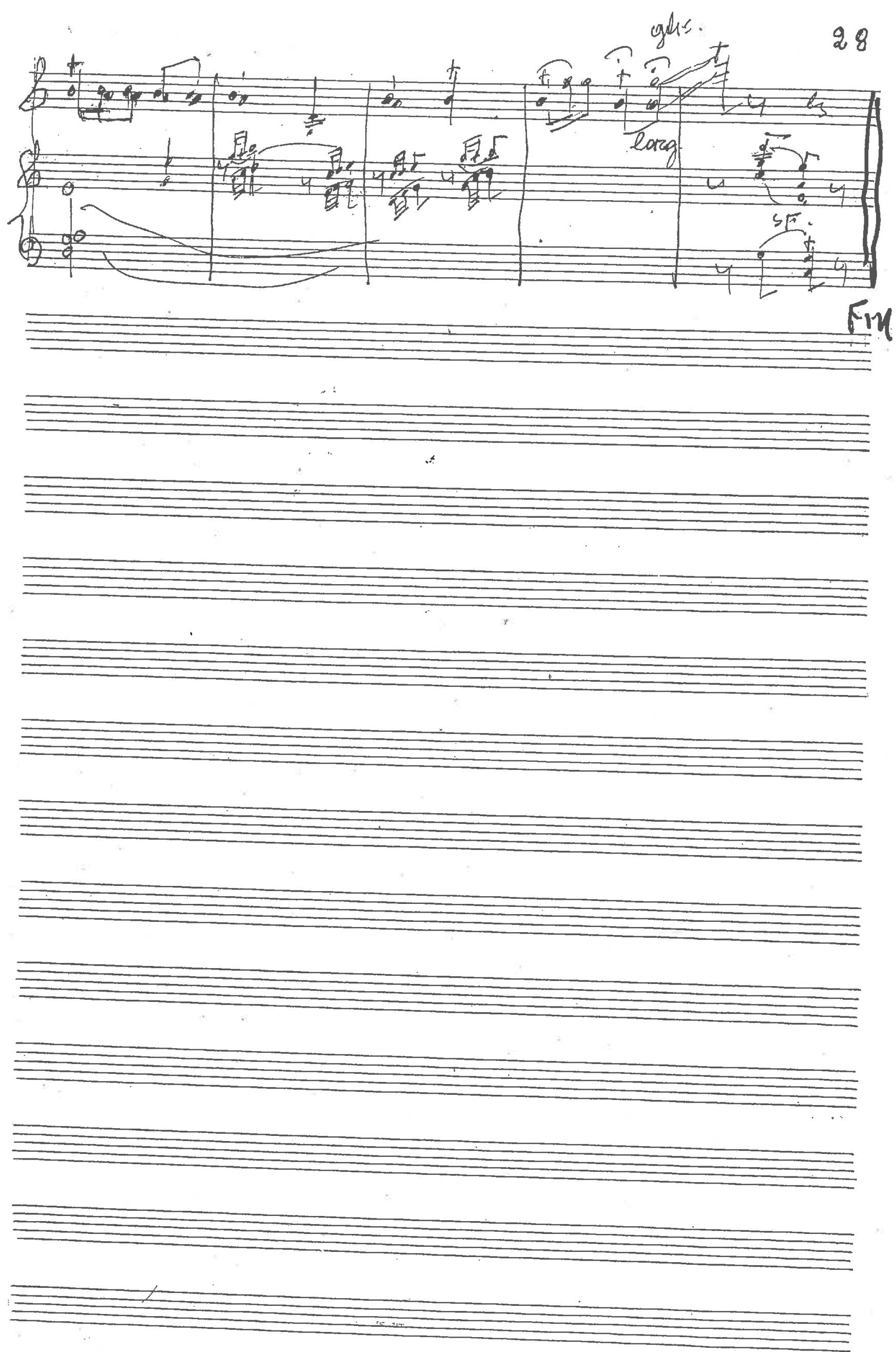
Appendix 3: Concerto for Viola 1993 performance part and score This appendix includes the 1993 performance part and score, which was generously scanned and sent to the researcher by Artur Paciorkiewicz, the violist who premiered the work. There are links below if the reader would like to access these PDFs separately.

Concerto for Viola orchestra score 1993

https://drive.google.com/file/d/15KI-

8NFwbPrXXkrREi6cKanHMX1Ch3Ag/view?usp=sharing

Concerto for Viola solo viola part 1993

https://drive.google.com/file/d/1EKweyzamsdC76yl QZwgwNwZIpdbg_p3/view?u sp=sharing 
1.

A.APAГATAKH
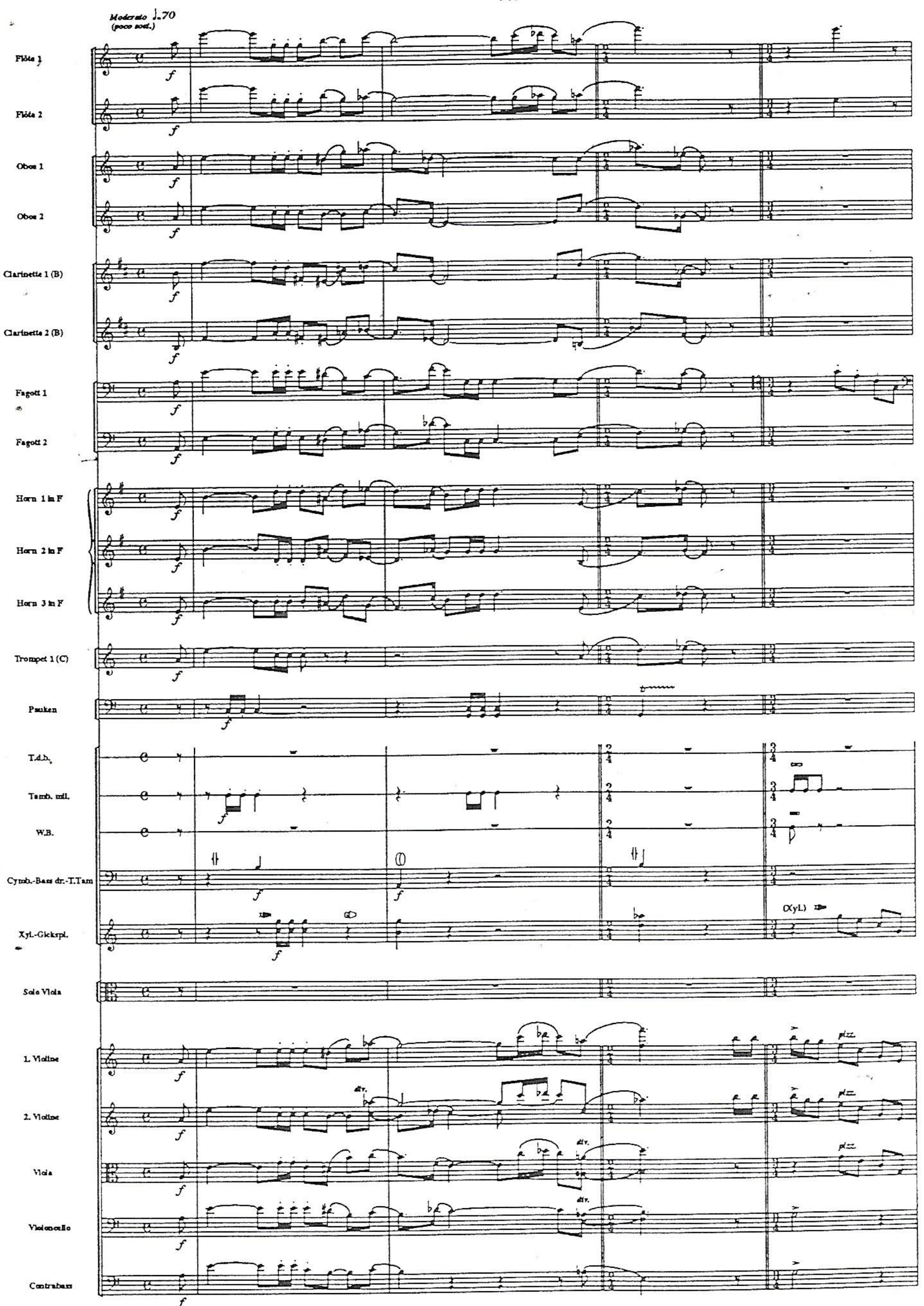


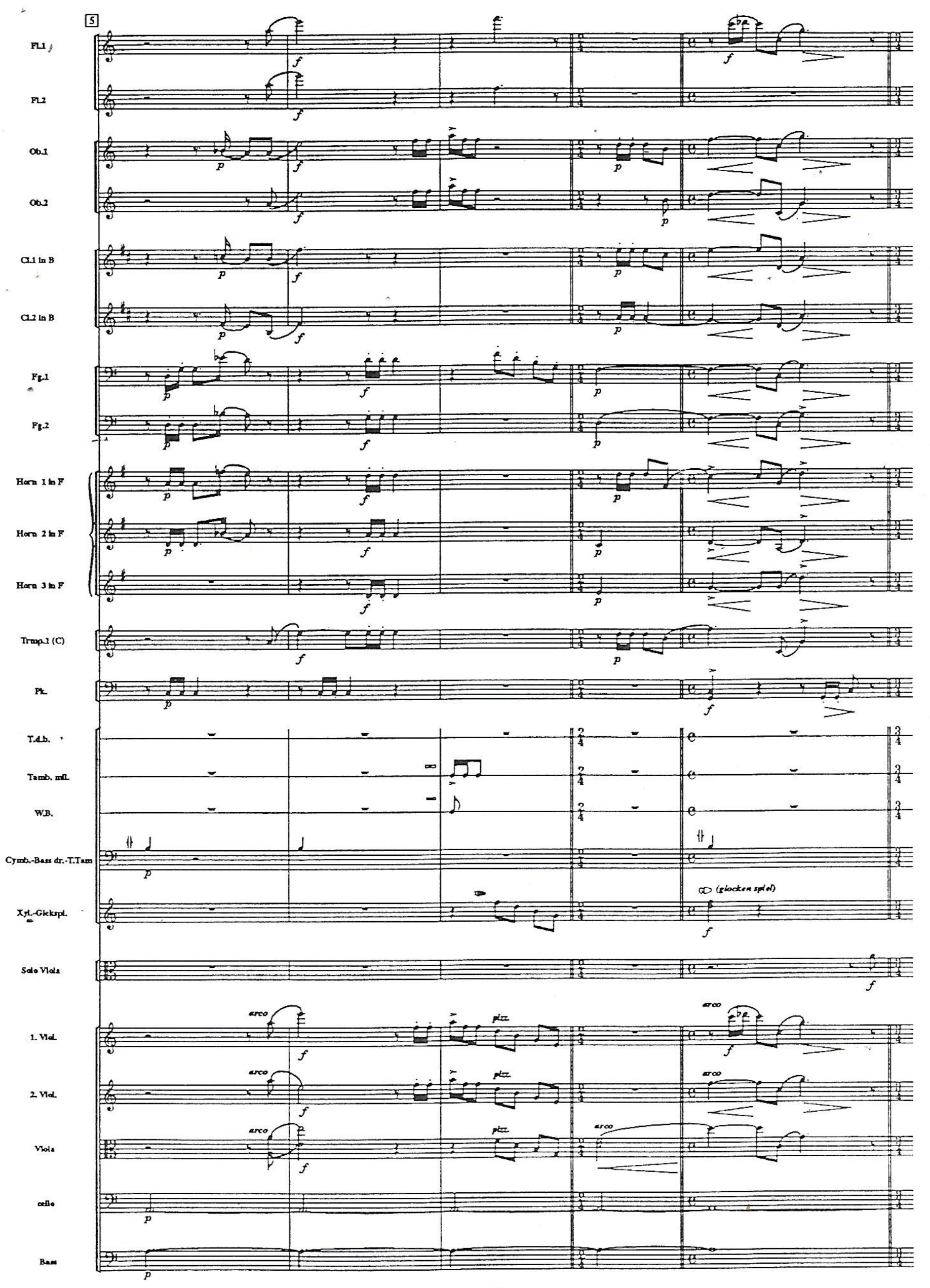




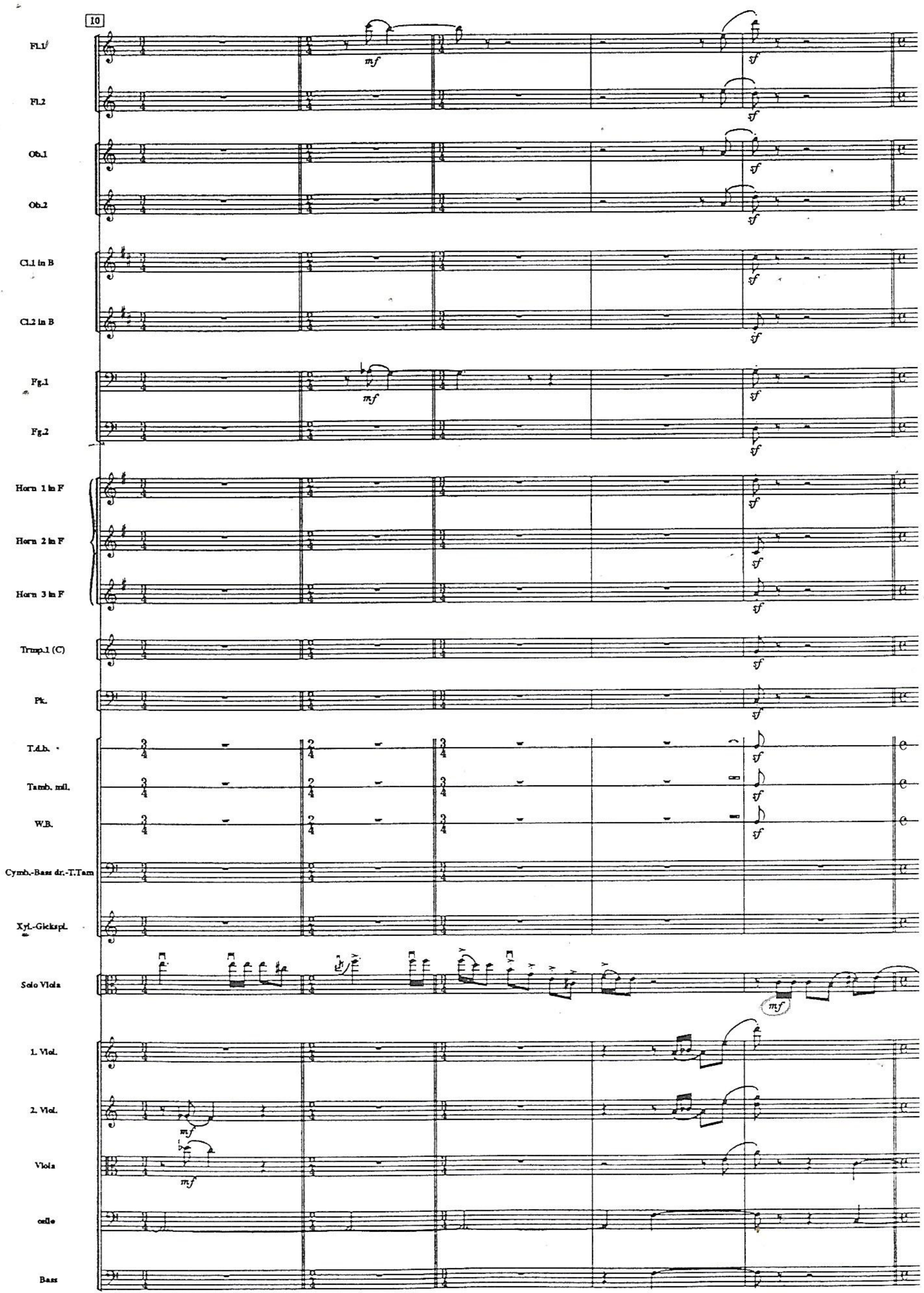


15
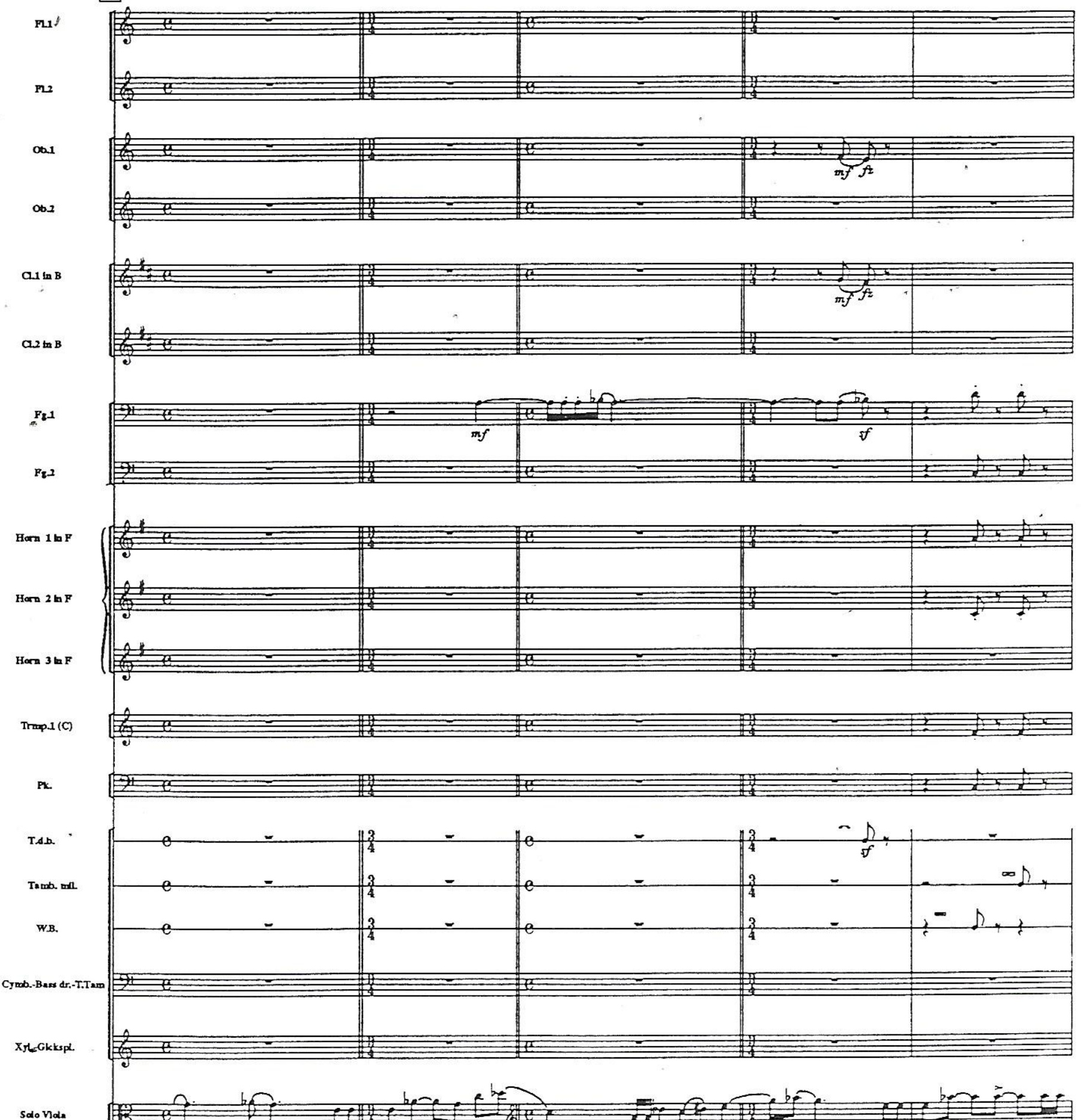

Solo ท人a.

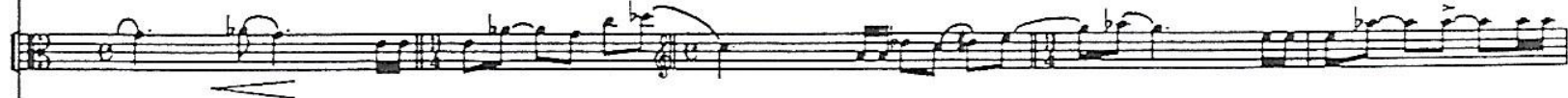

swe

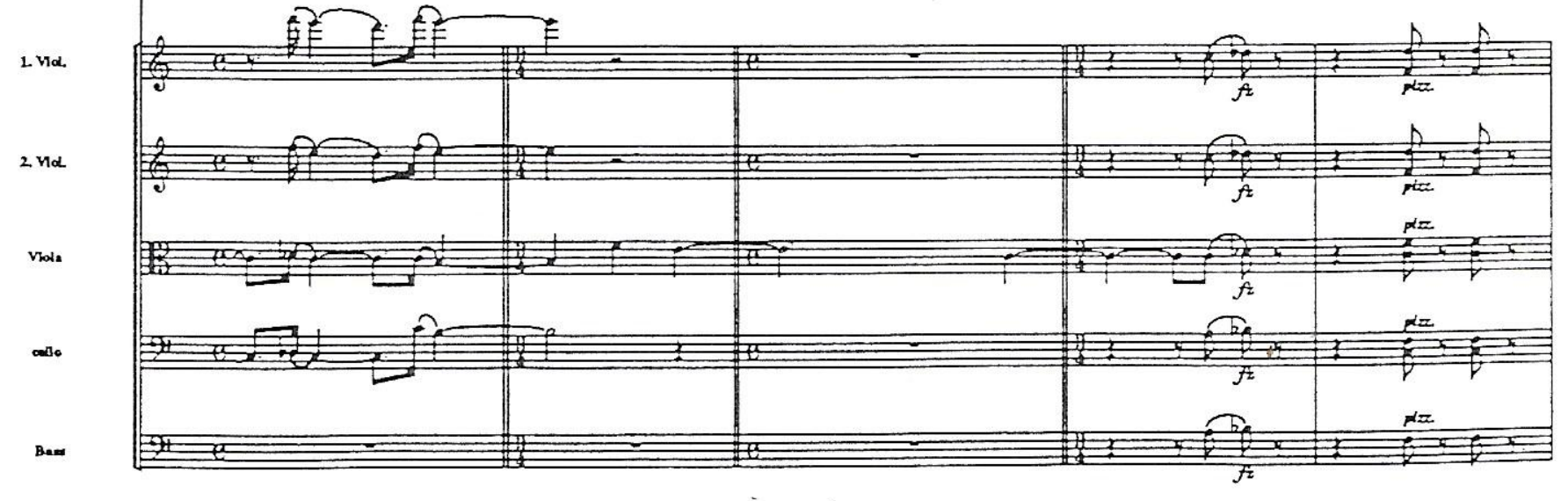




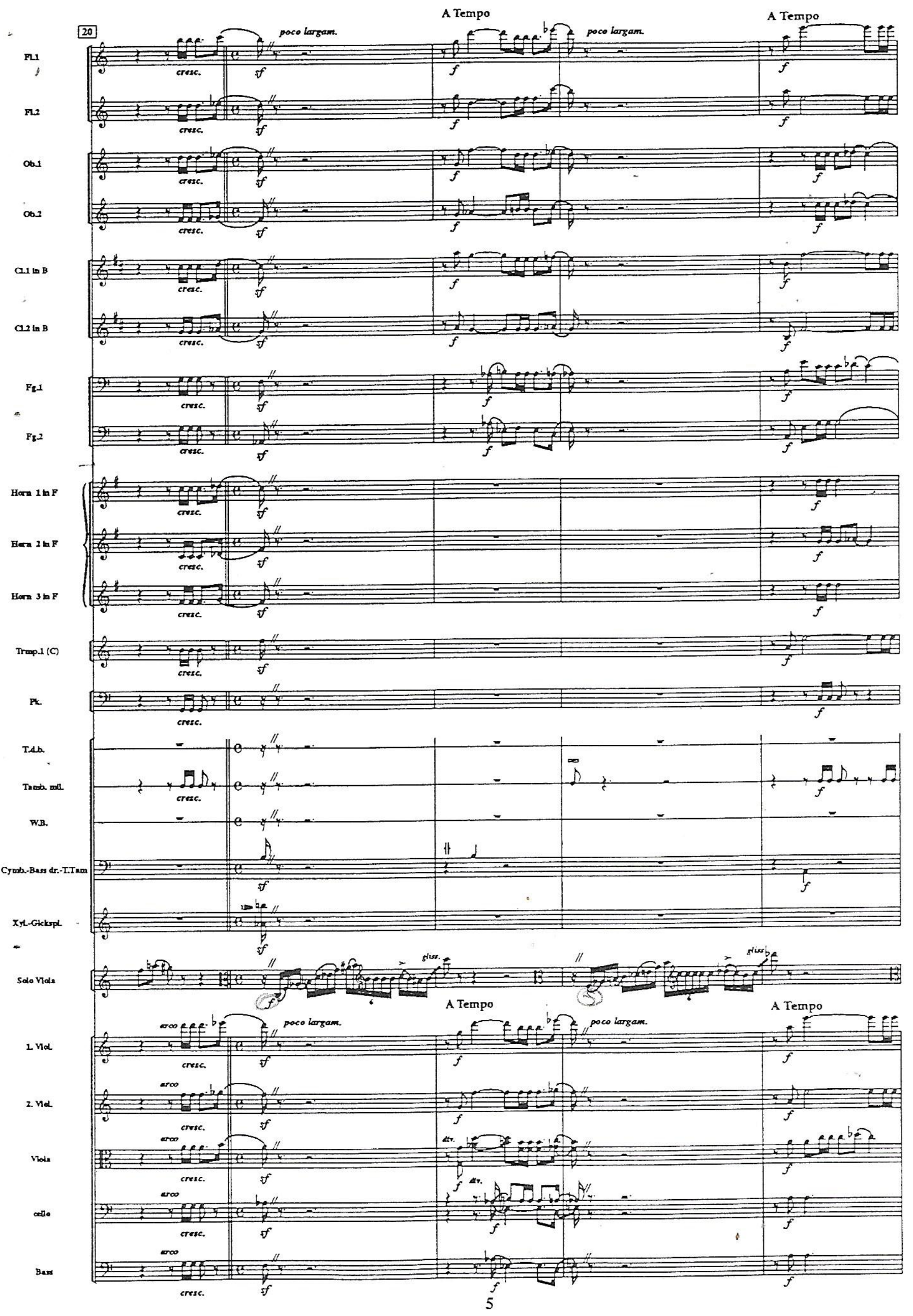




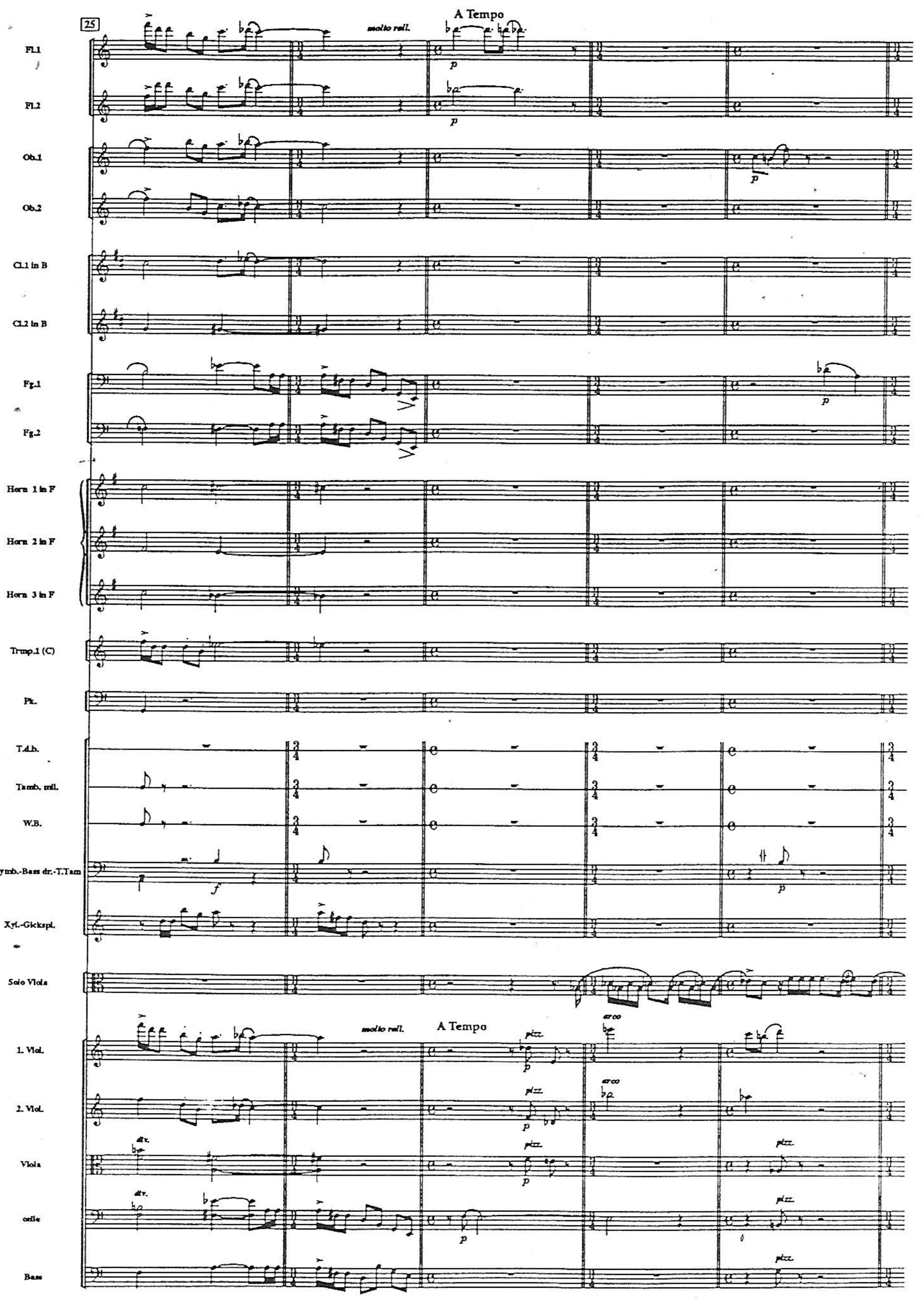




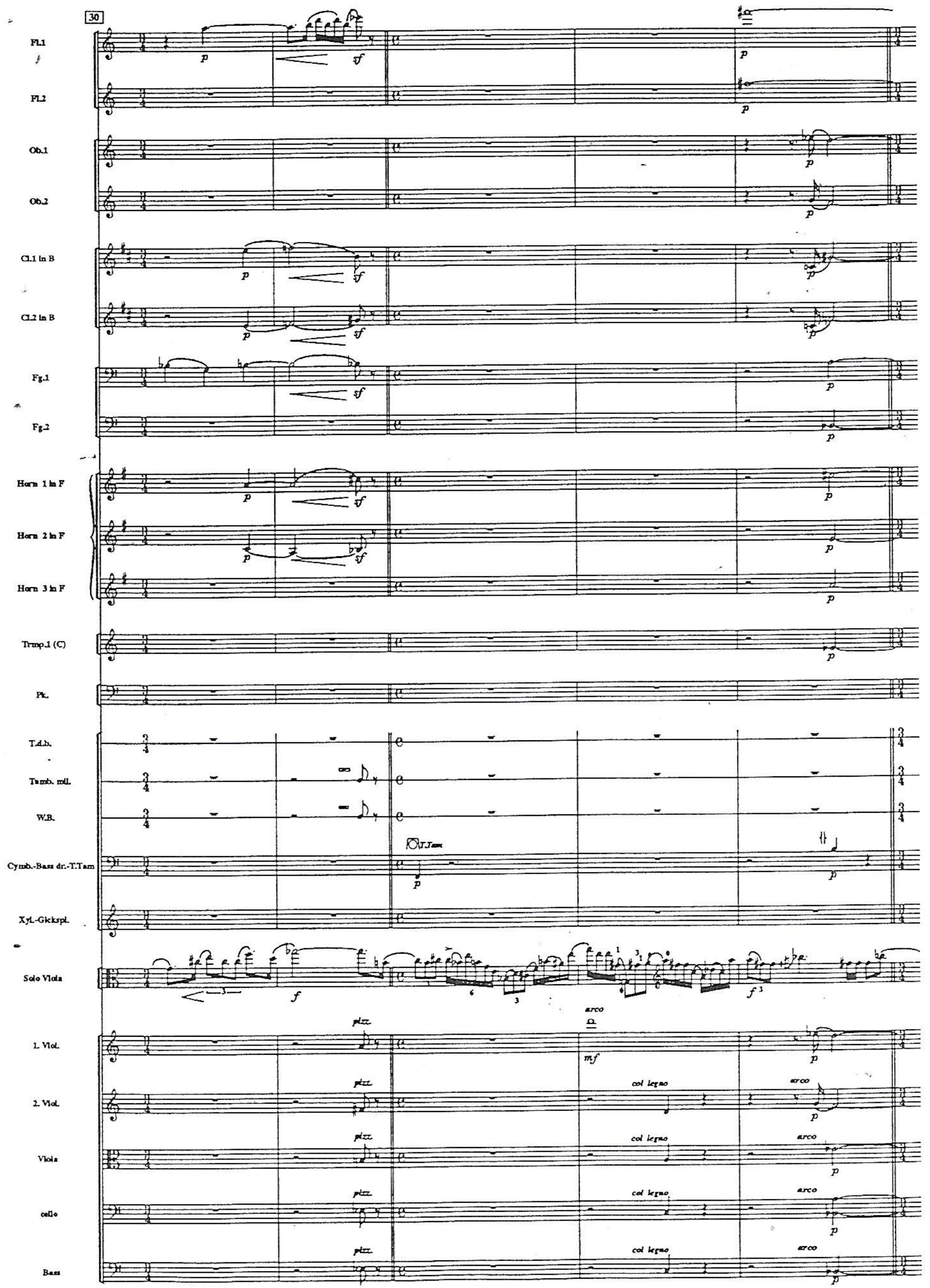




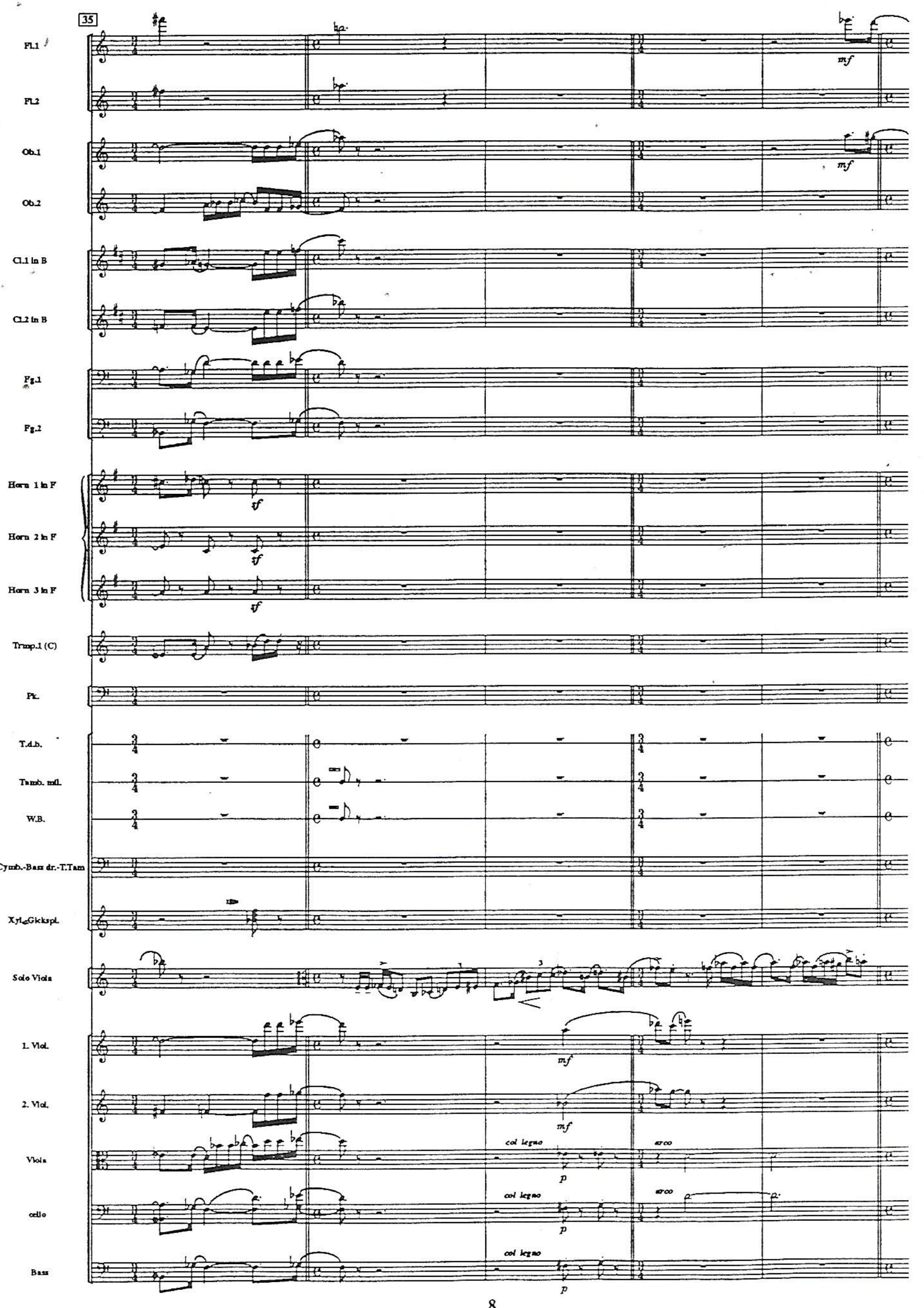




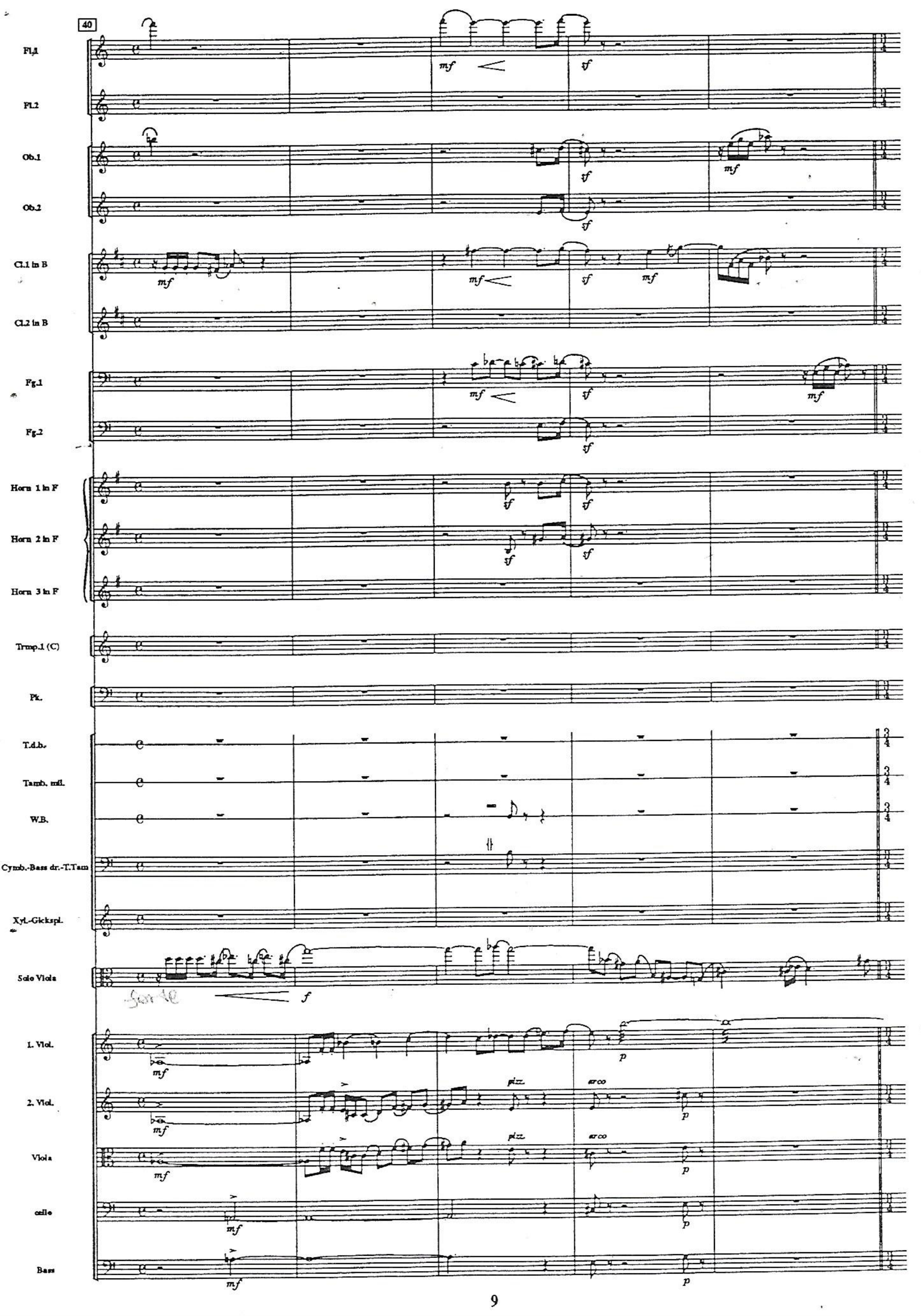




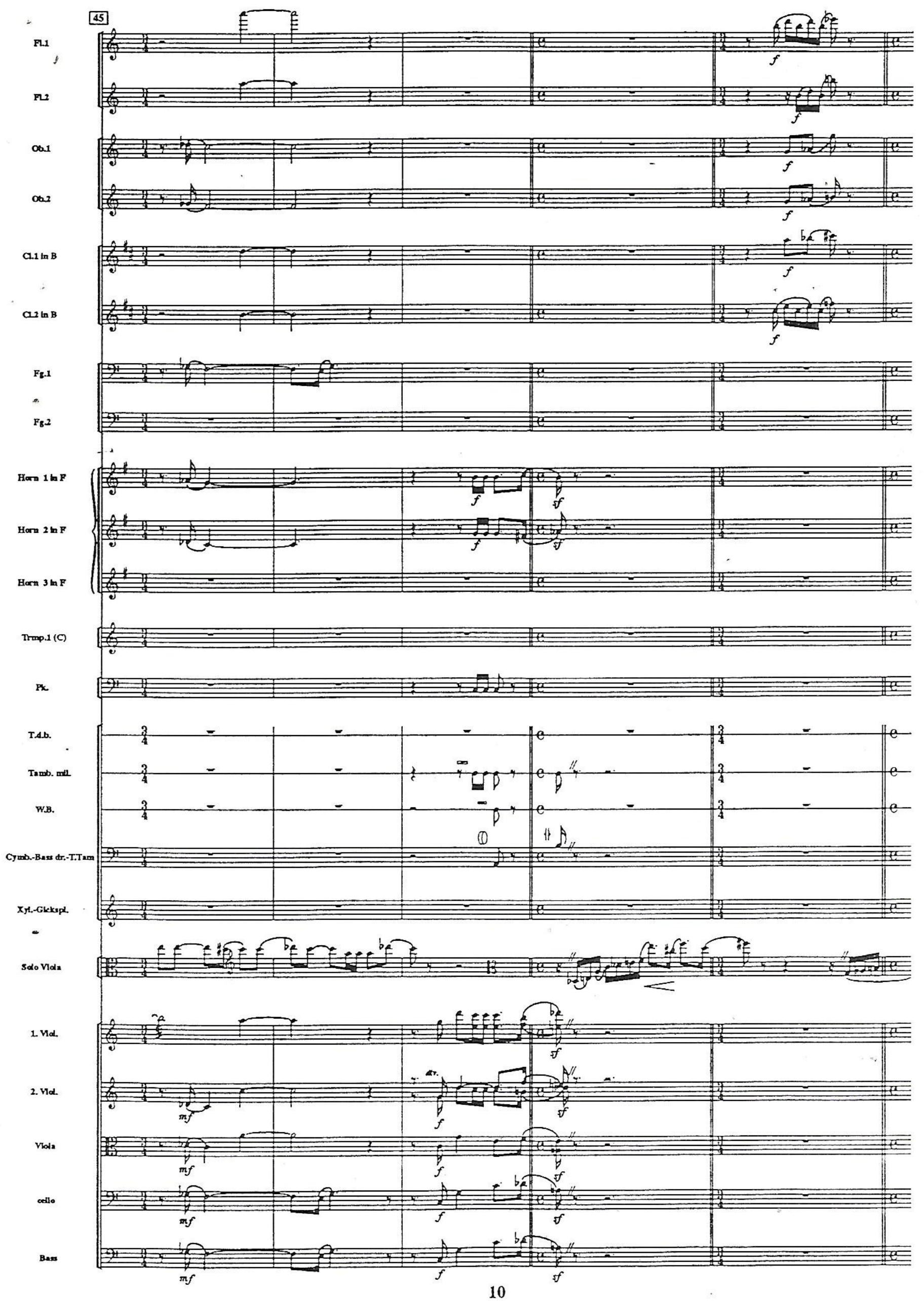




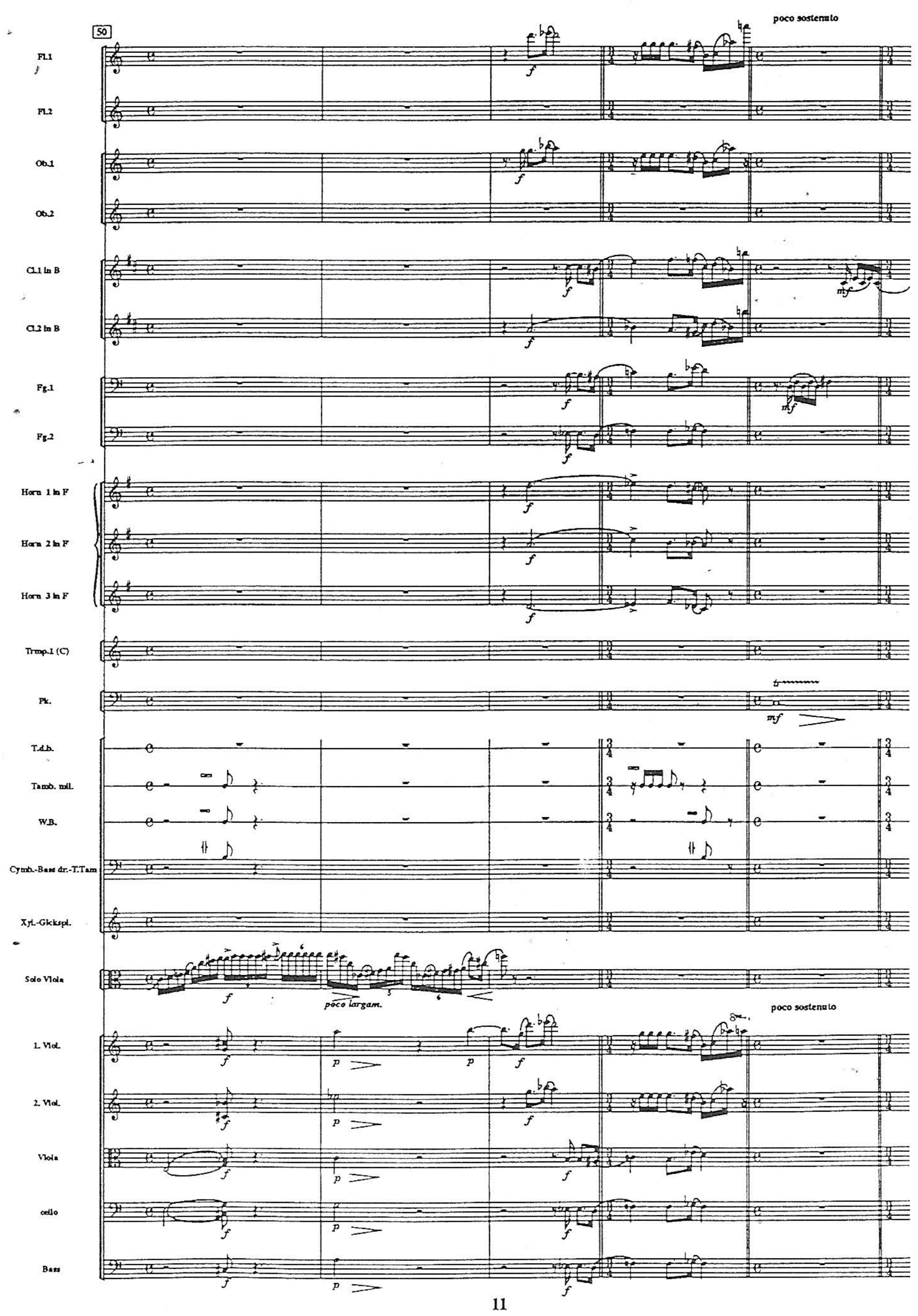




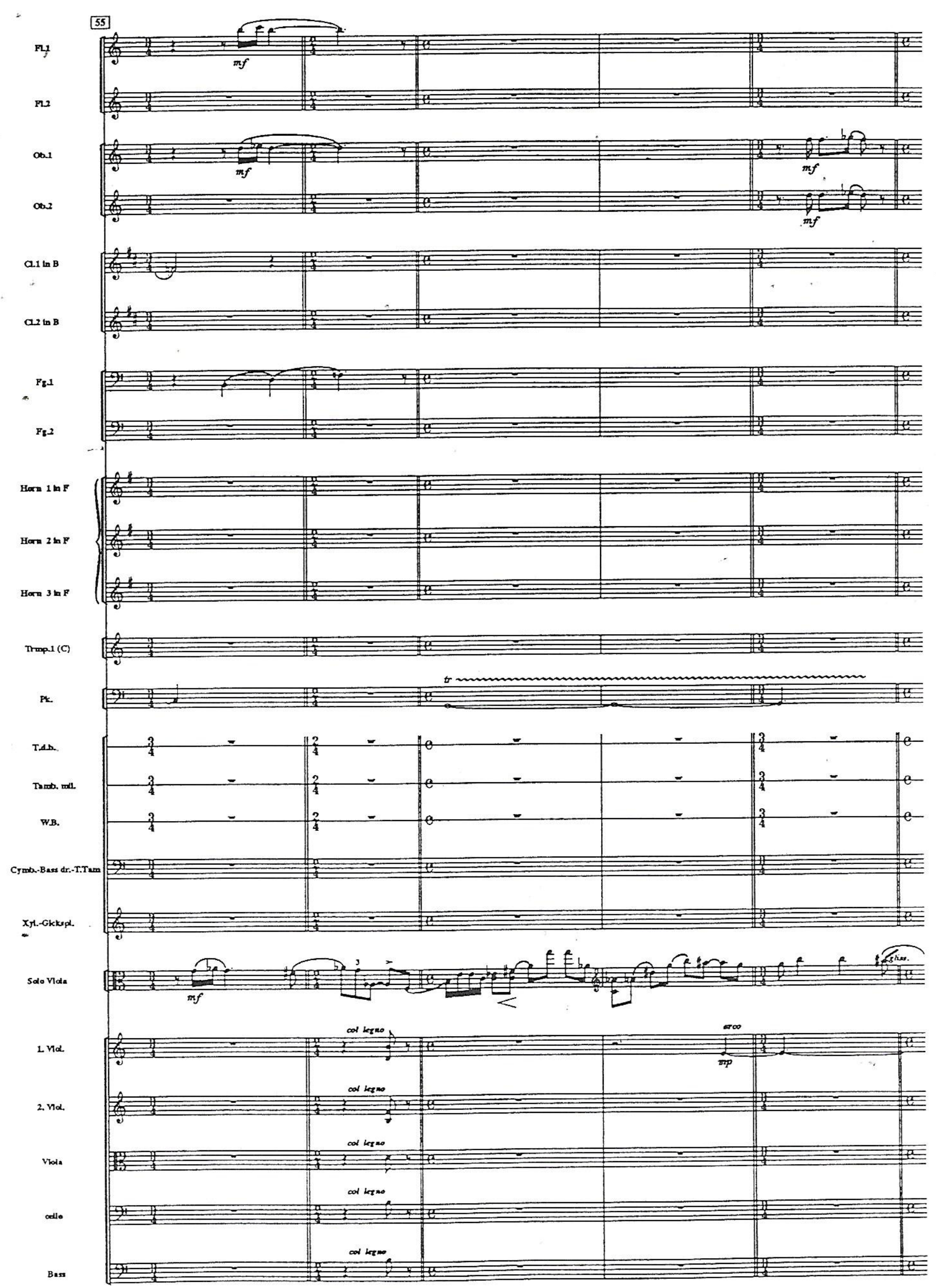




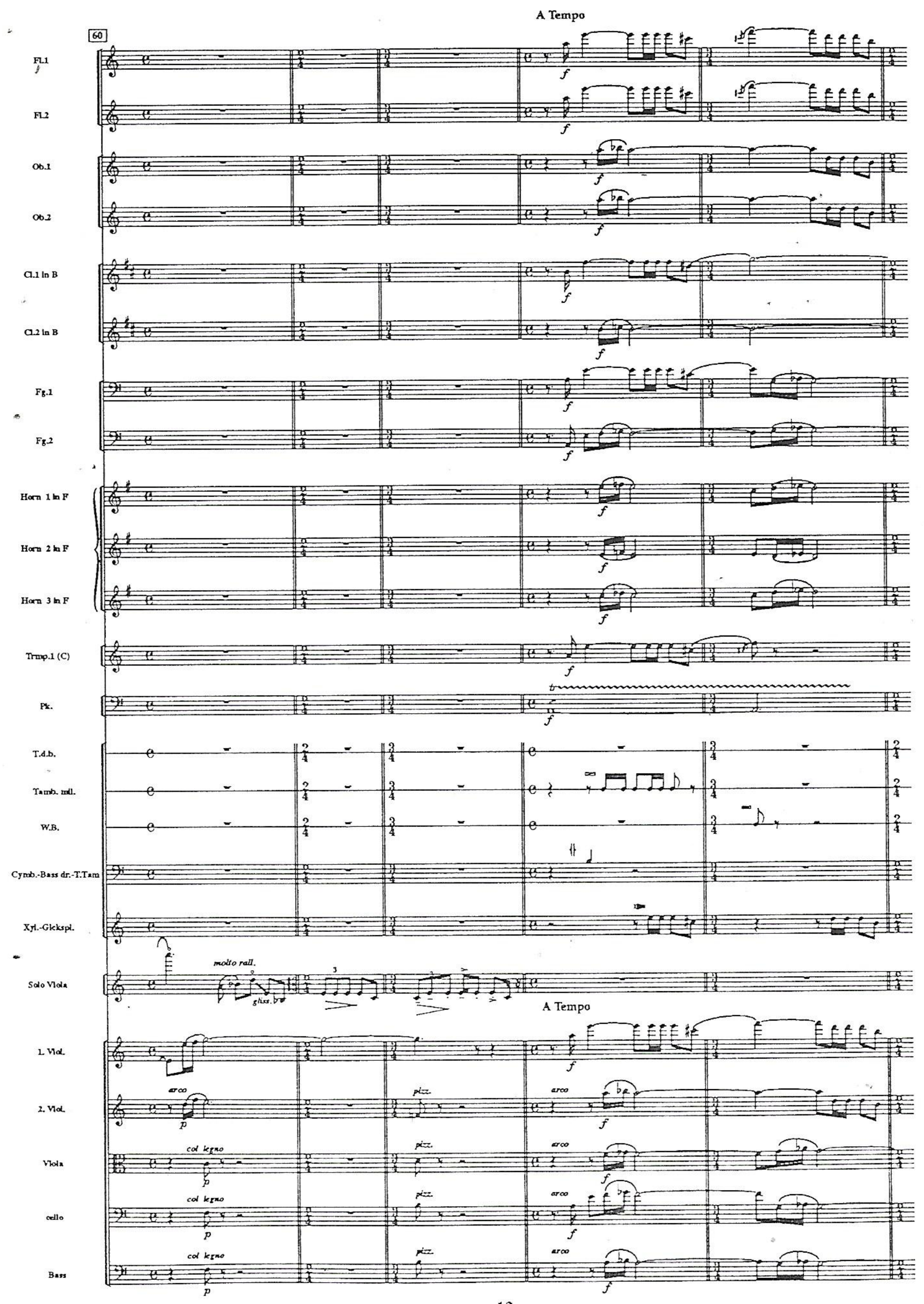




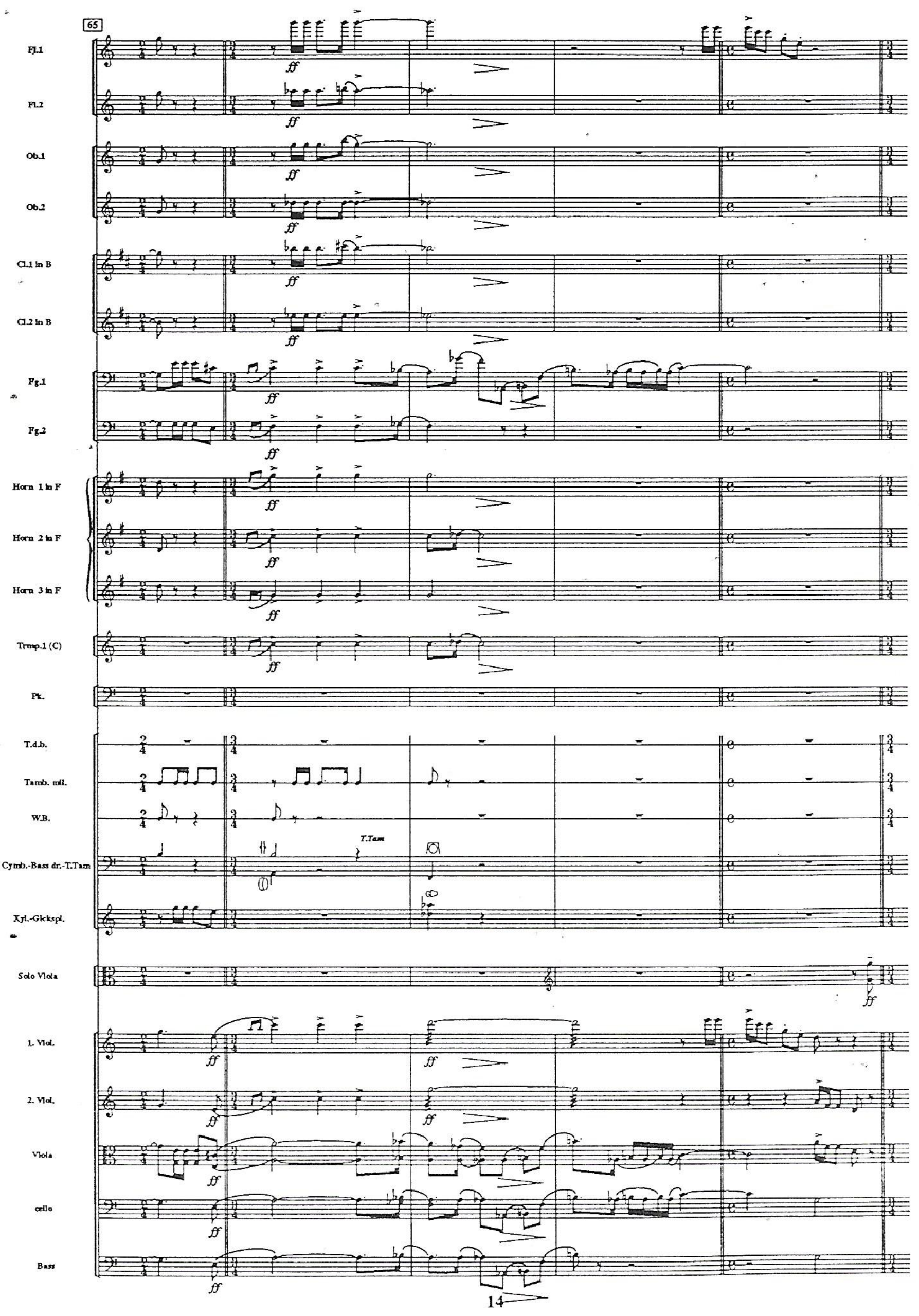


70
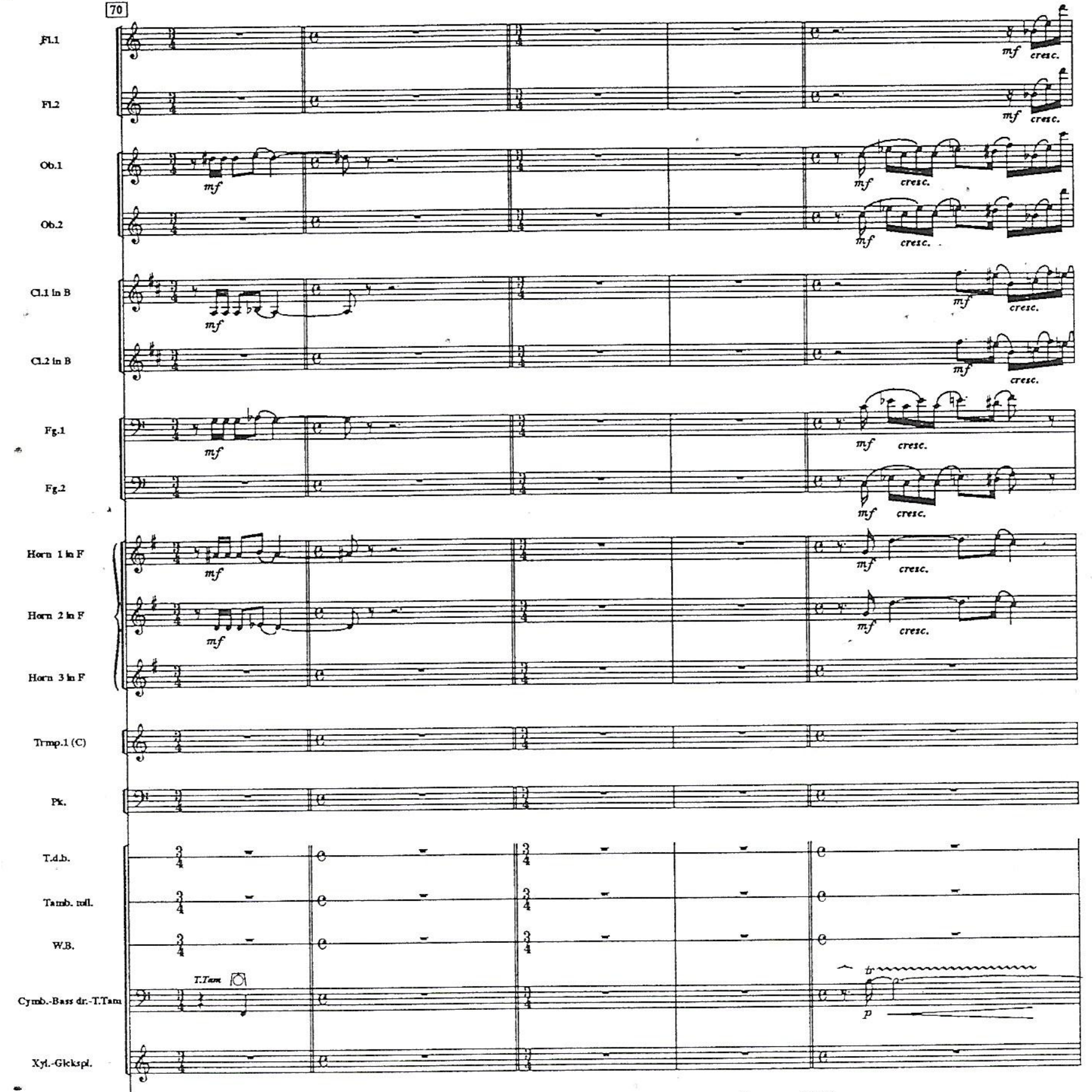

Solo Vlola

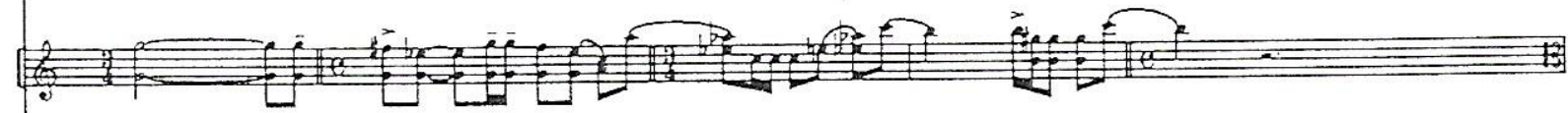

$1 \mathrm{n} \alpha$.

2. no.

Yhol

codio

Bass

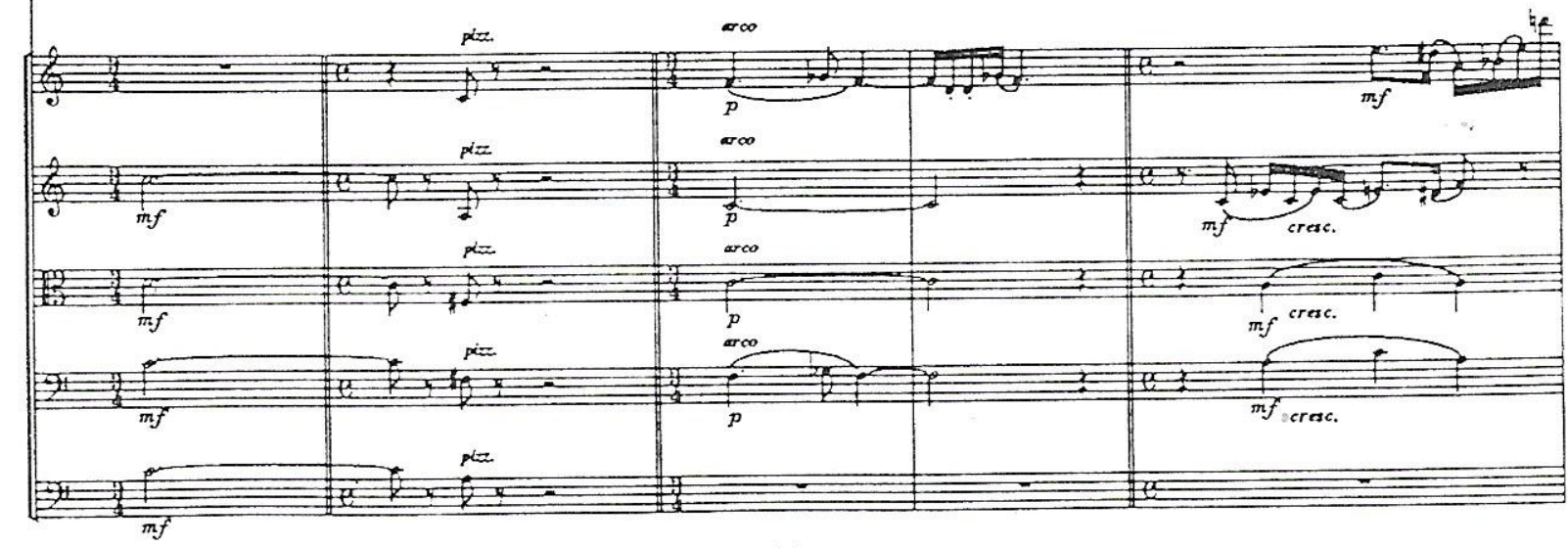




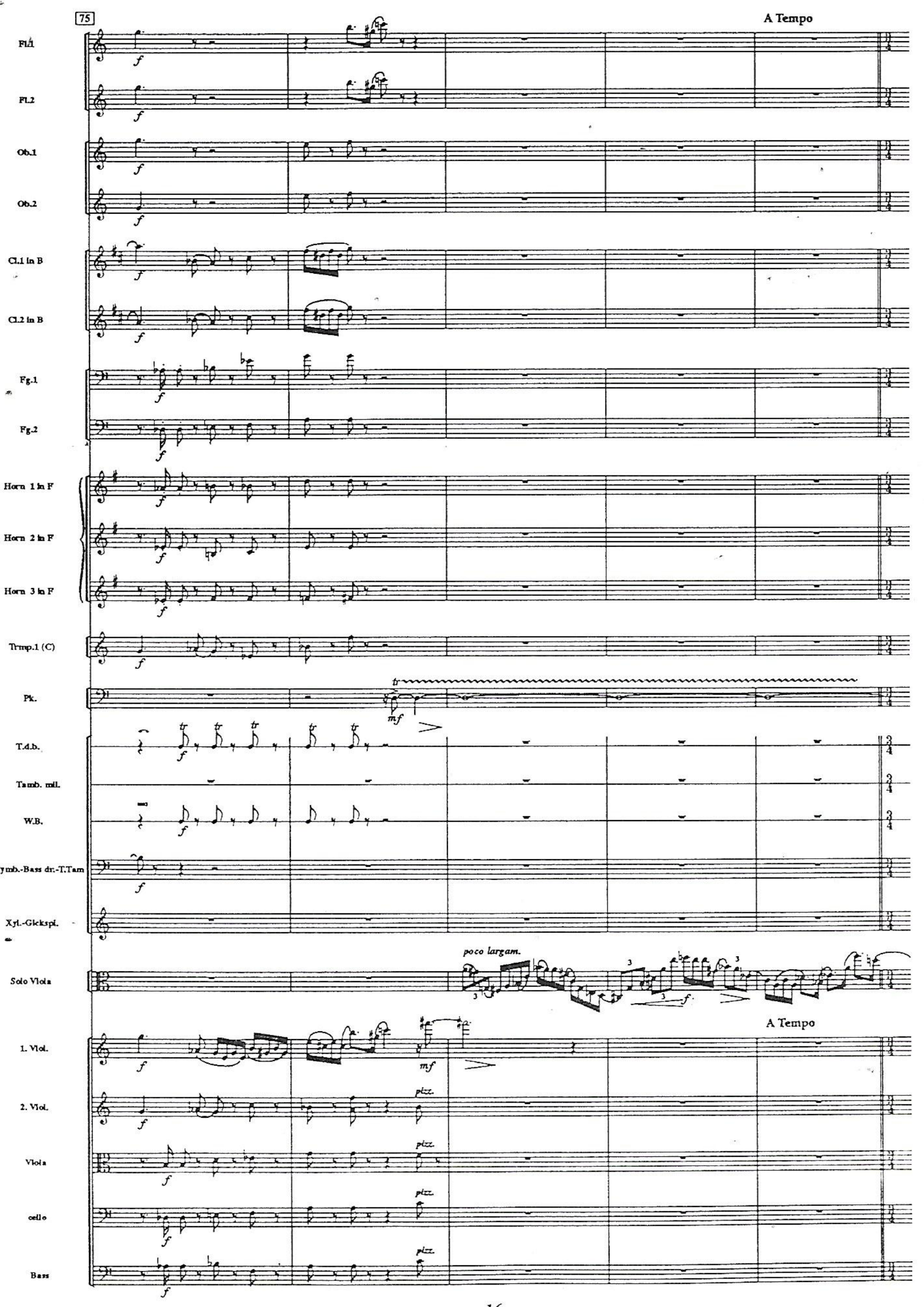




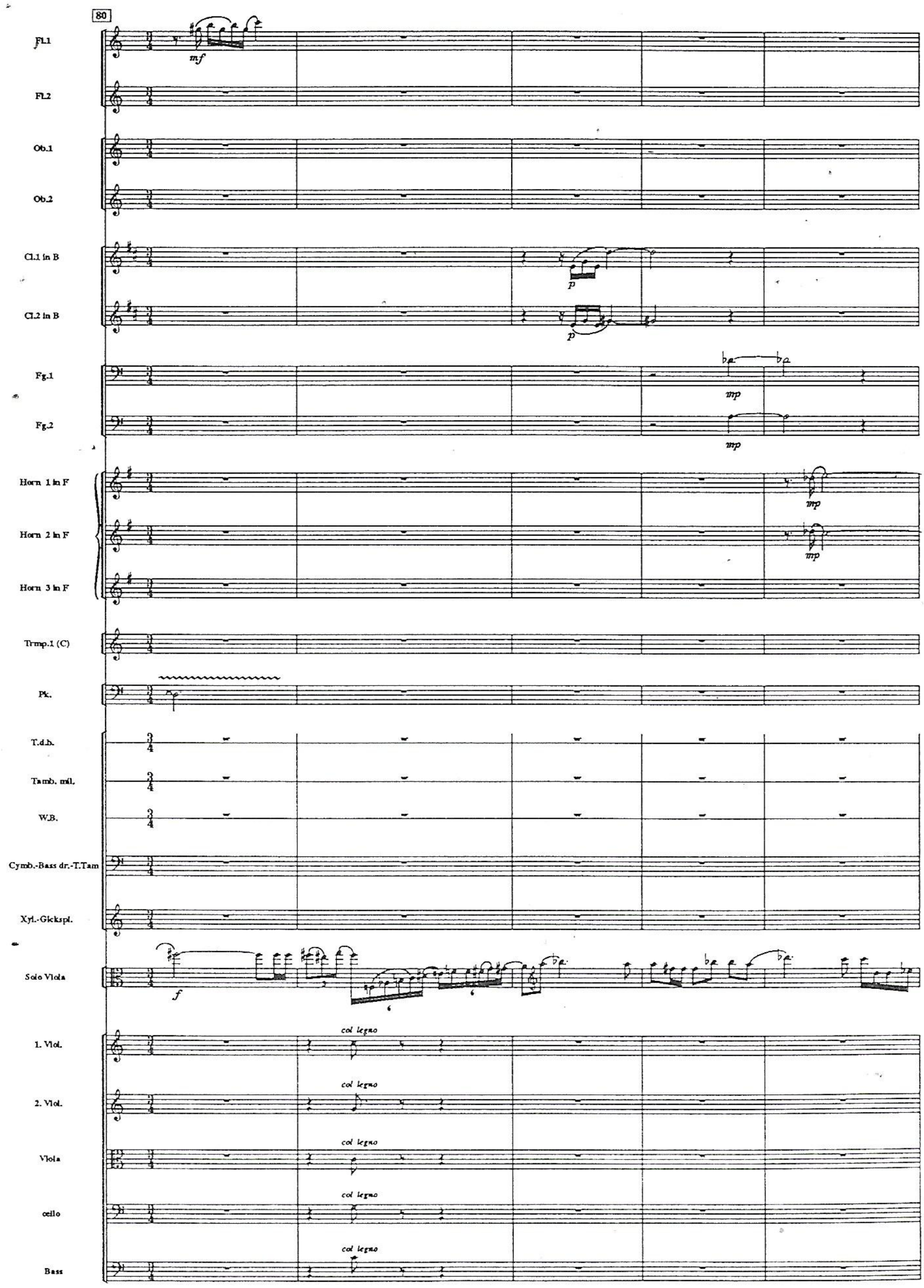


85
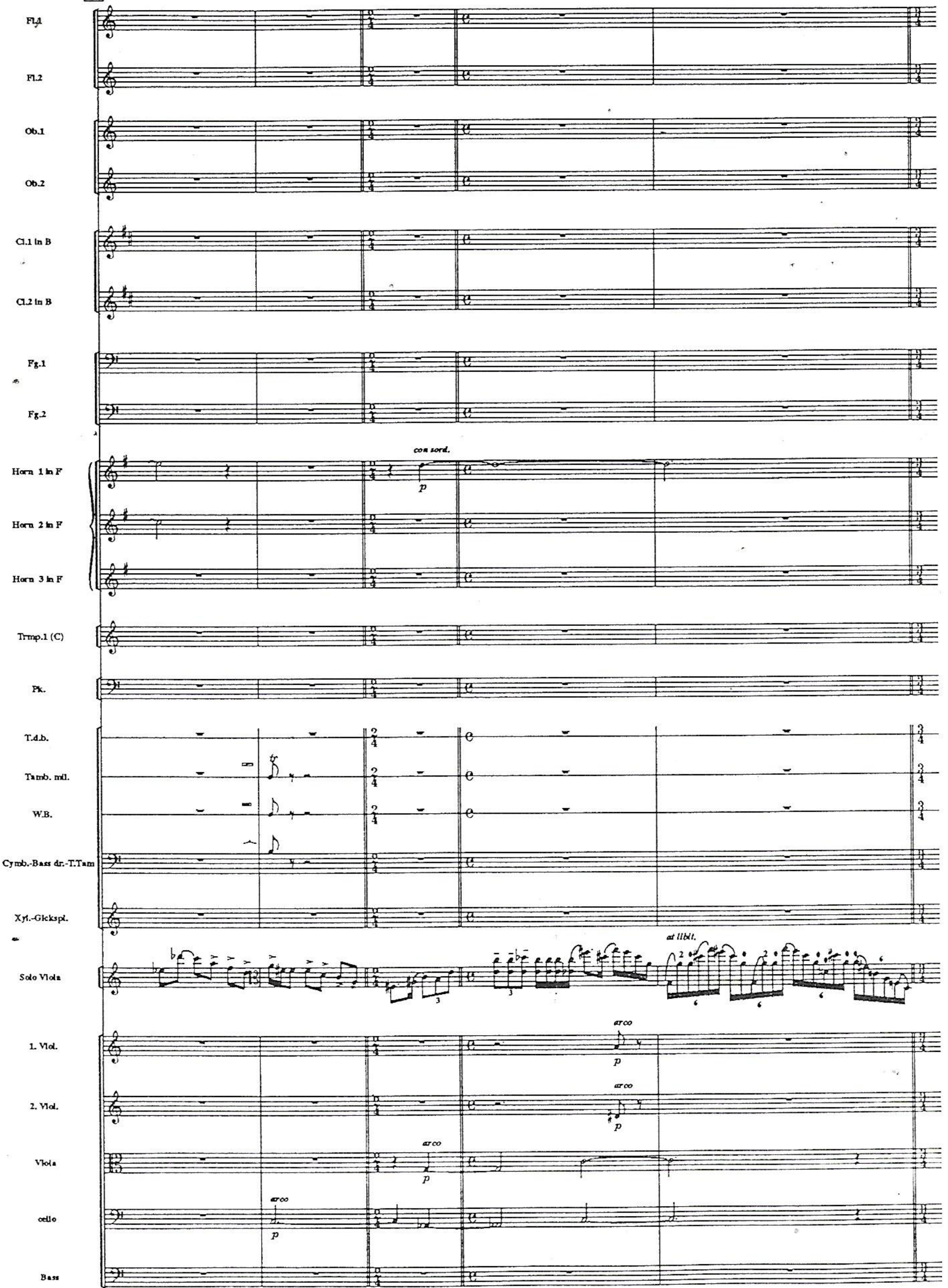


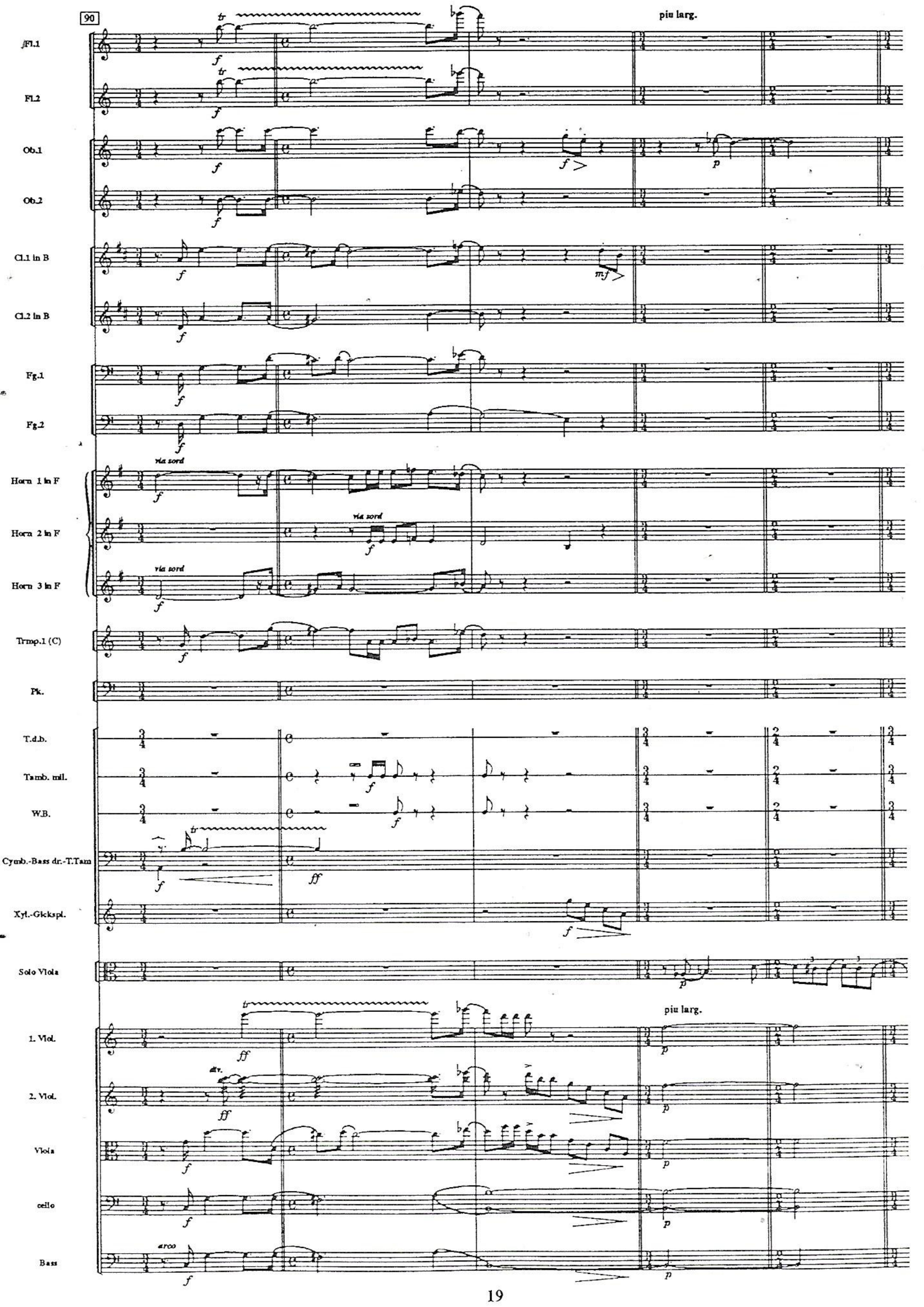


[95]
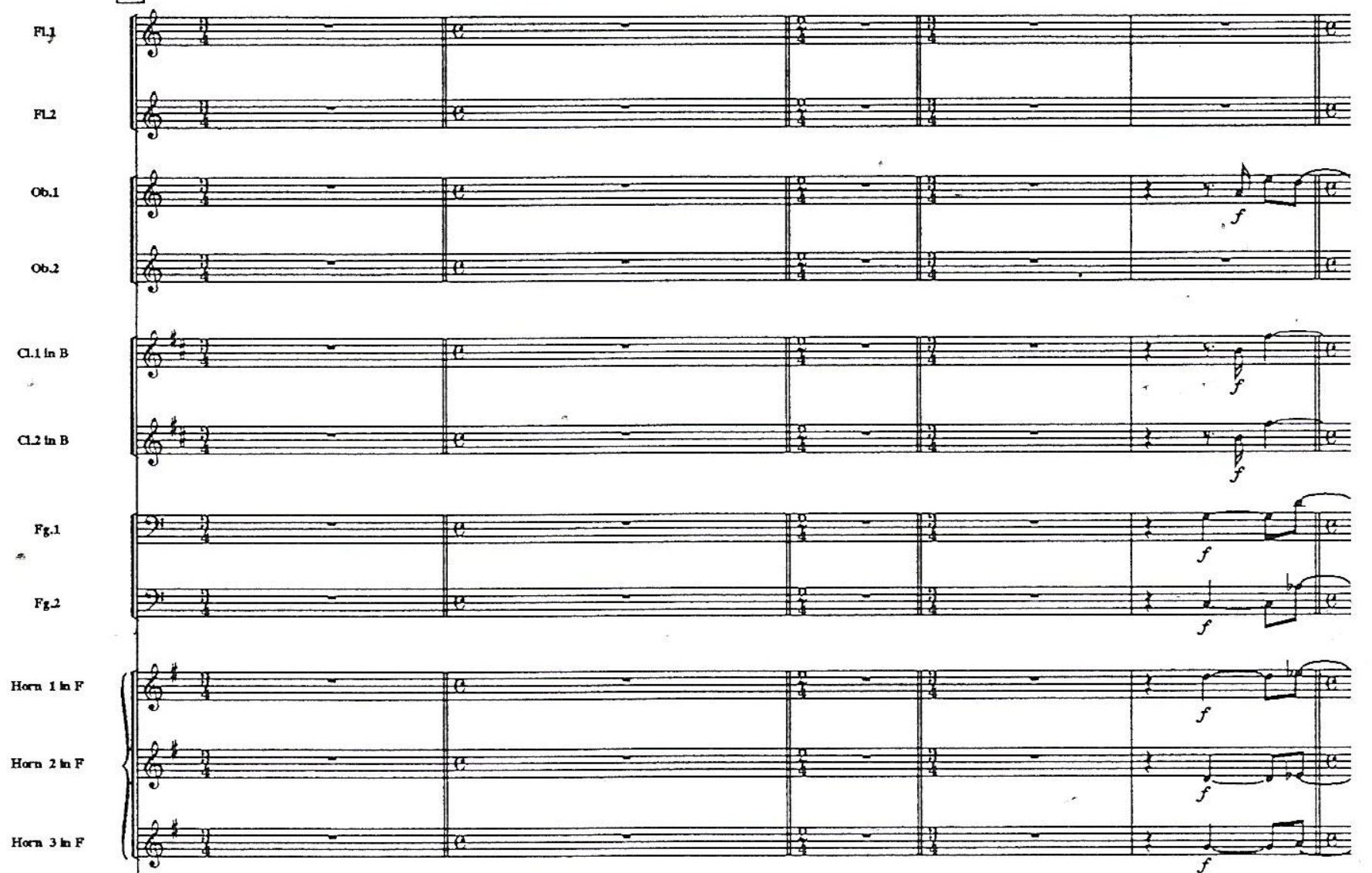

Trmp.1(C)
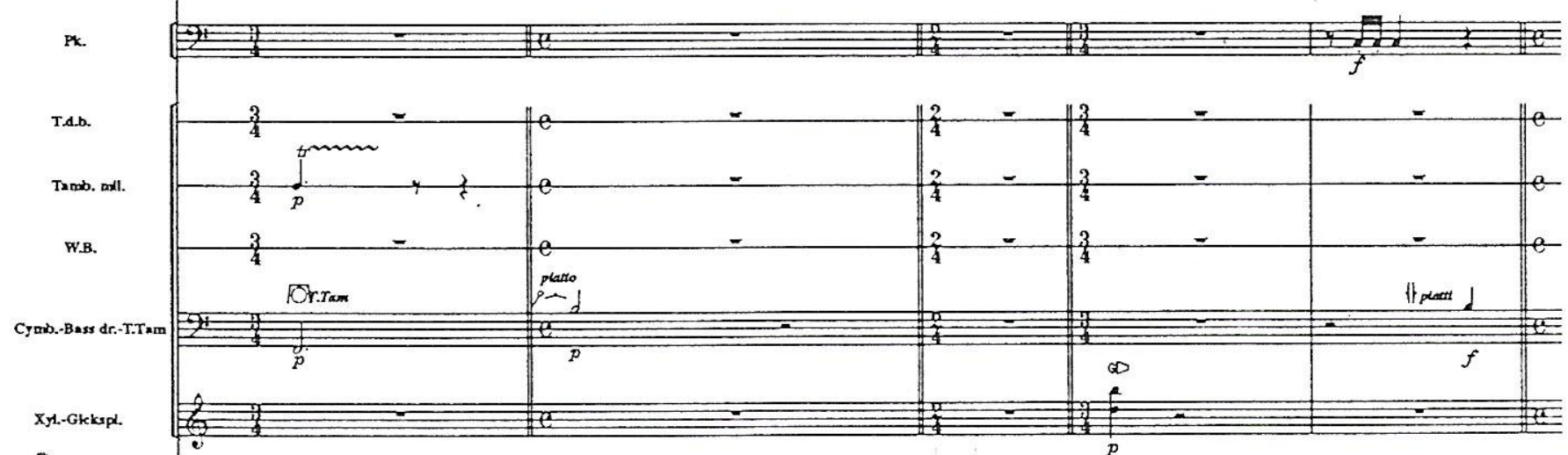

Sodo V1/

2. ท1.

vhow

cello

B.s
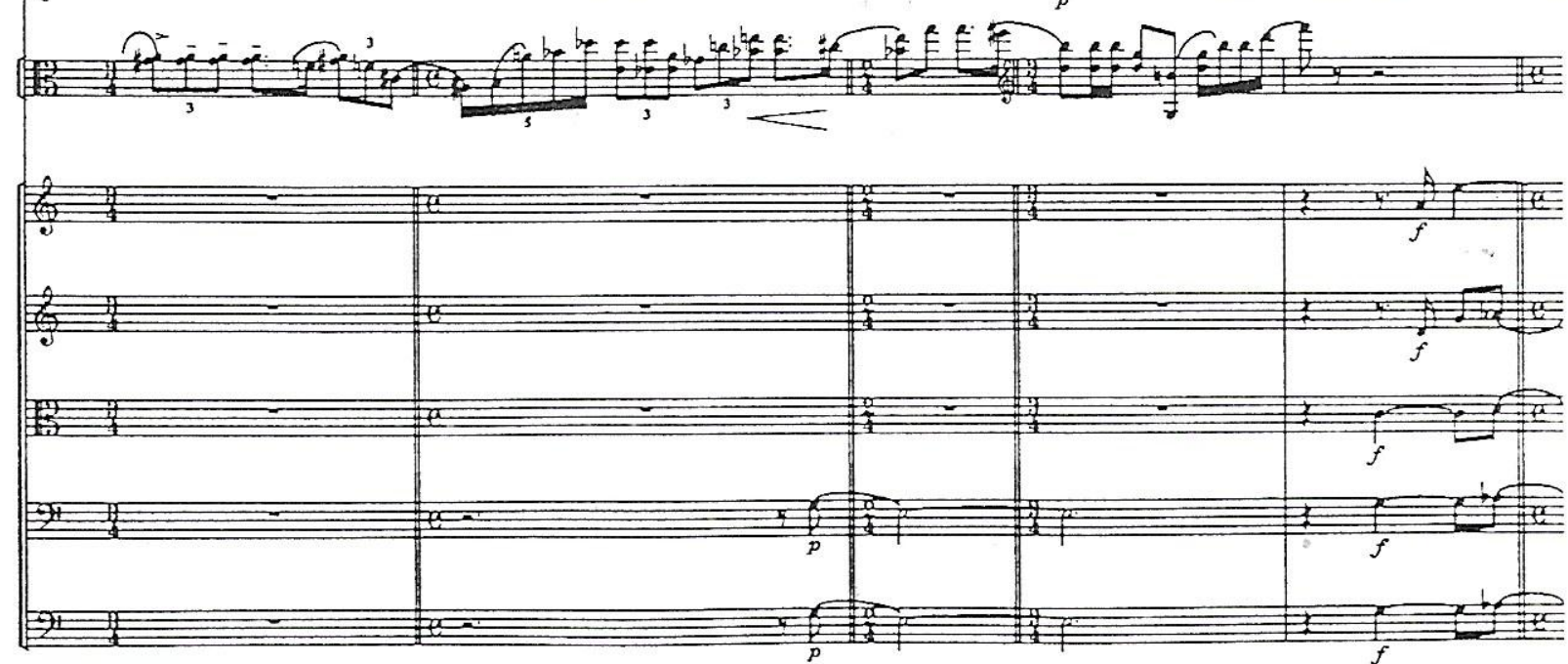


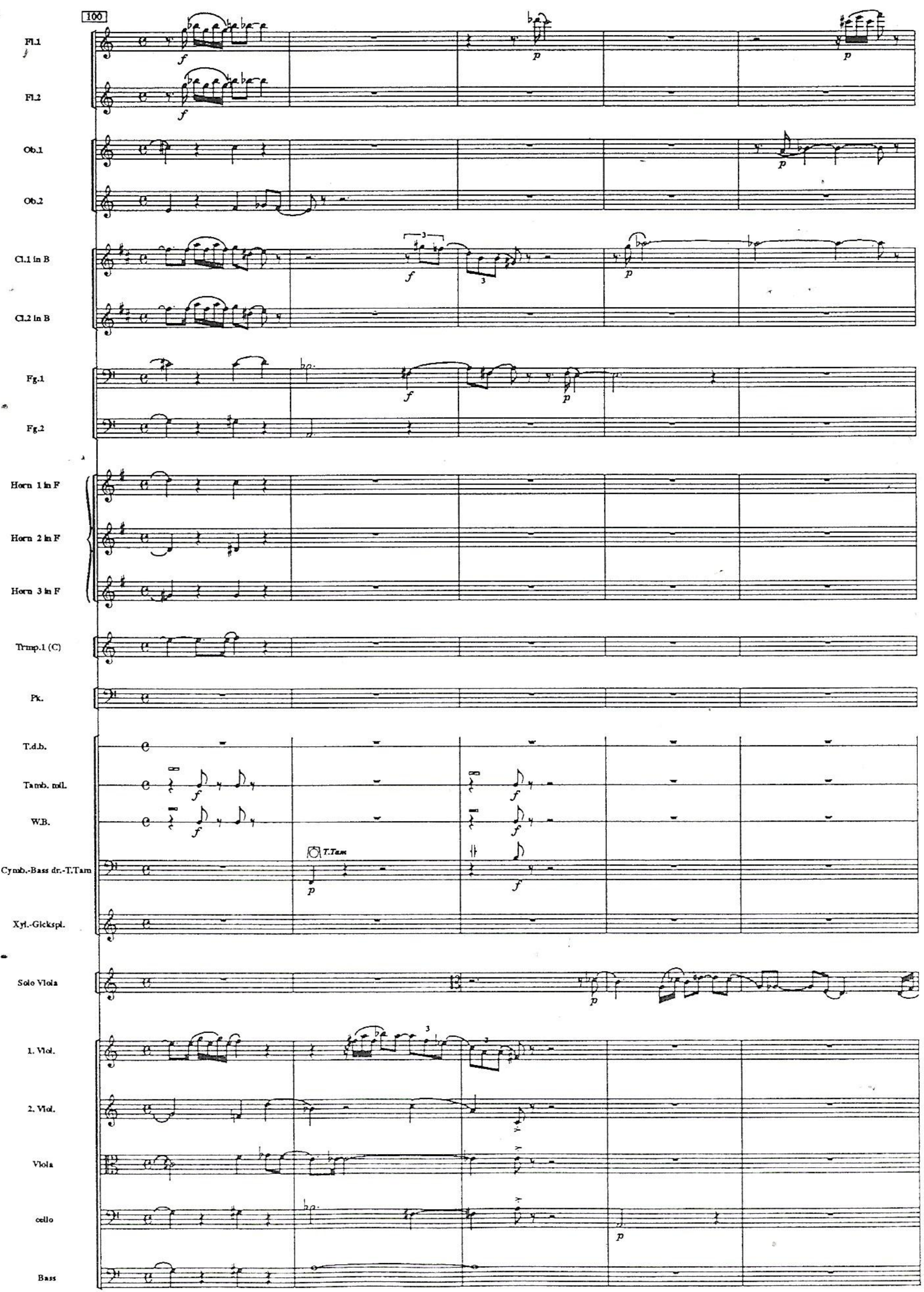



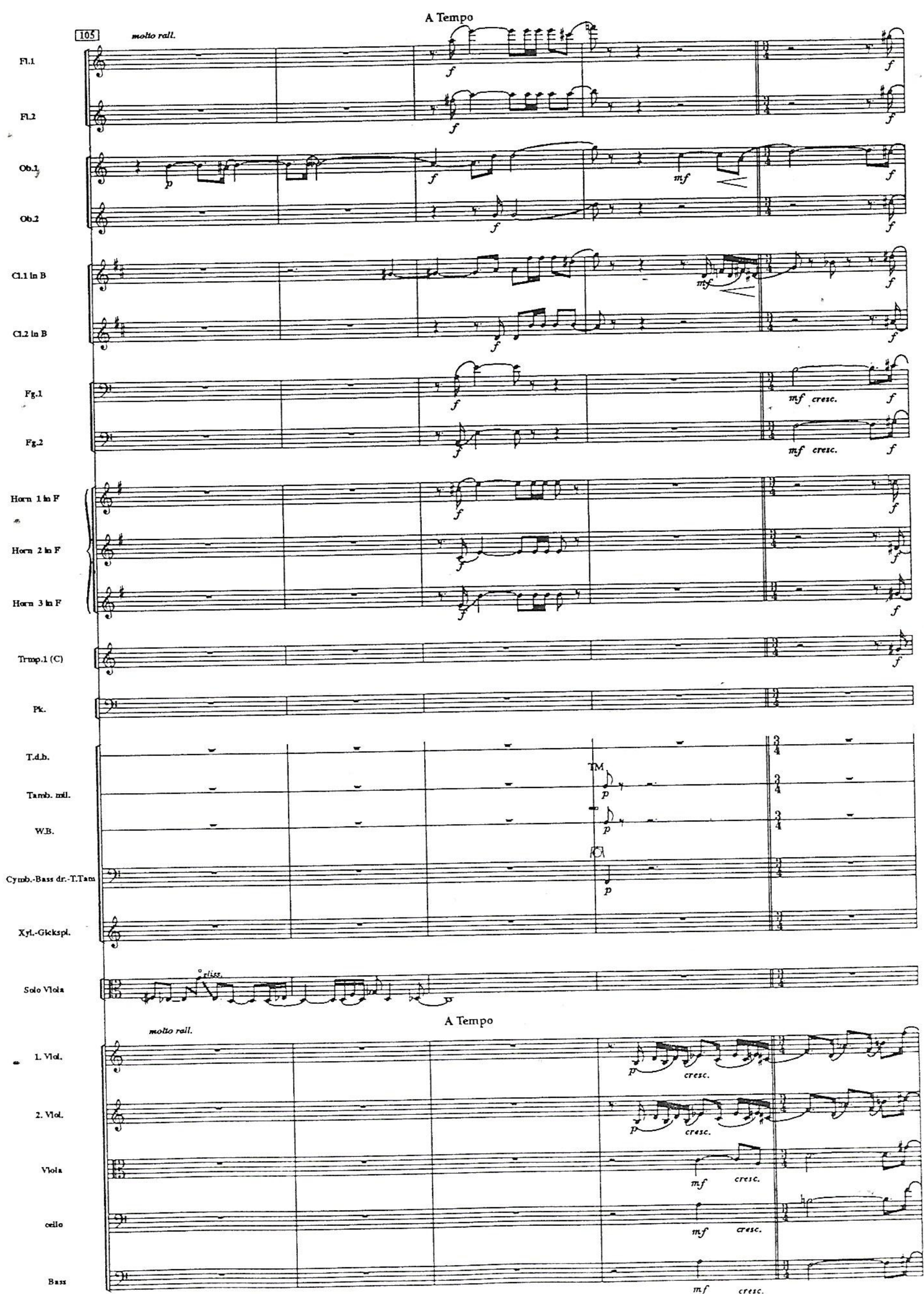


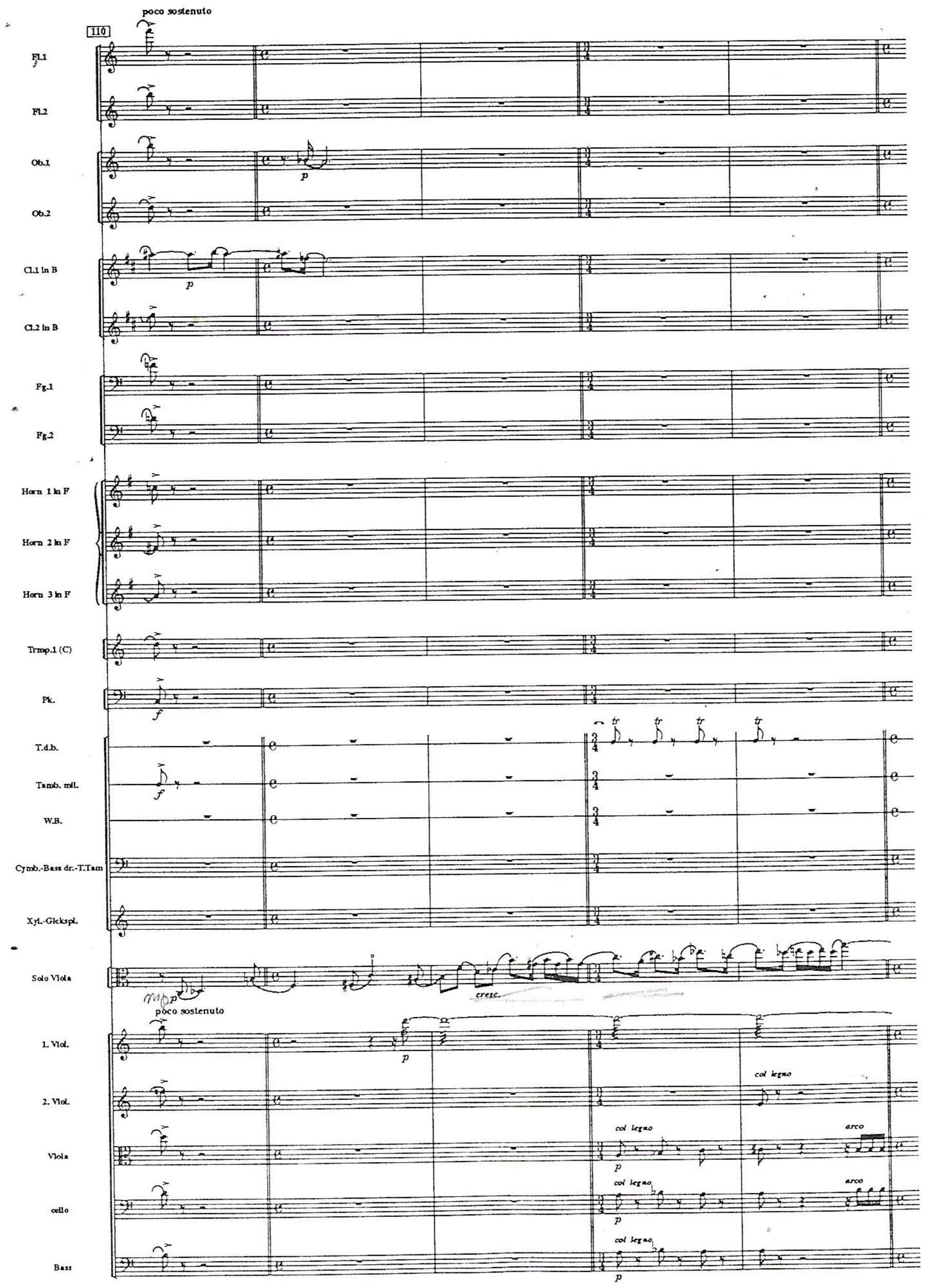




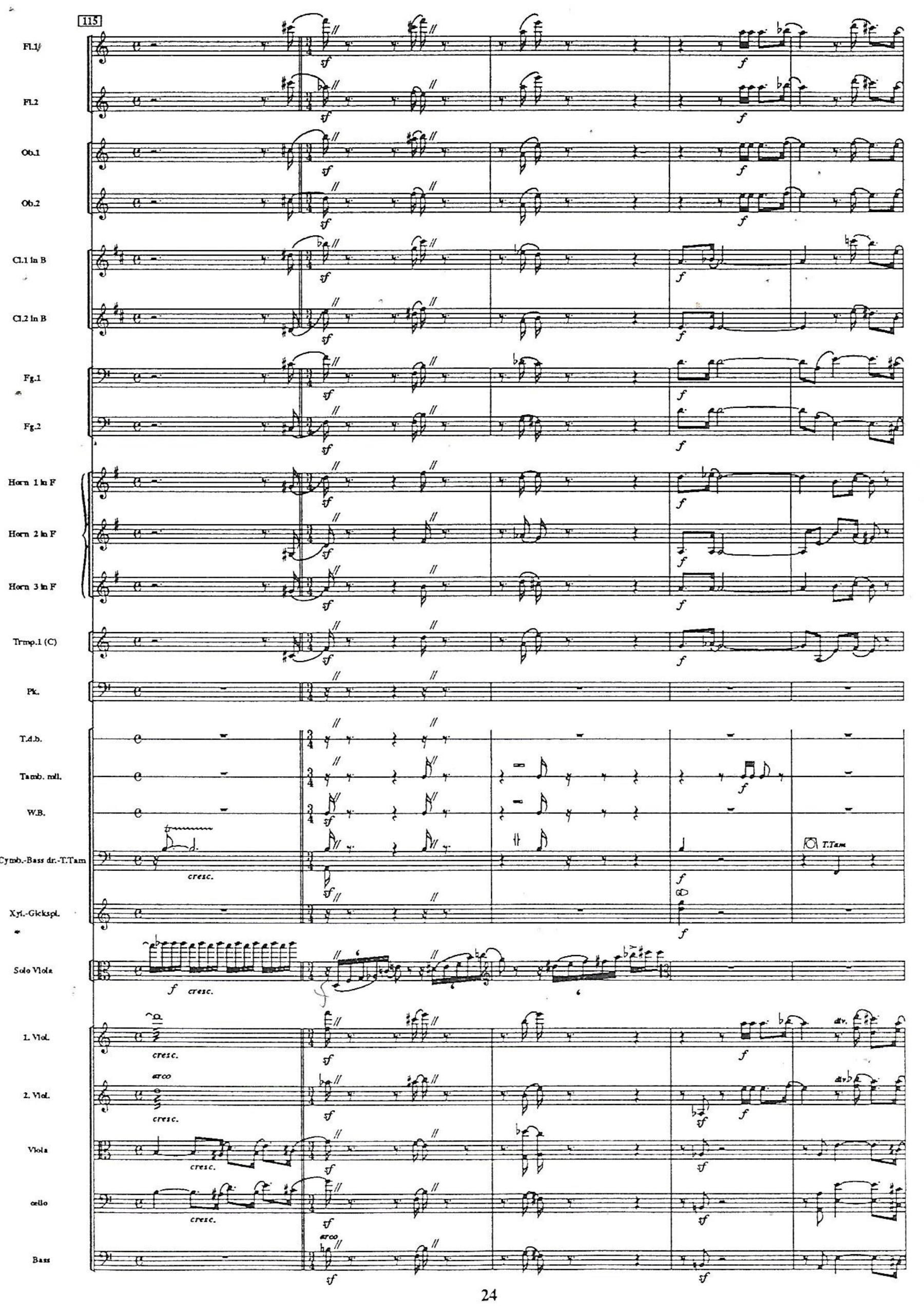




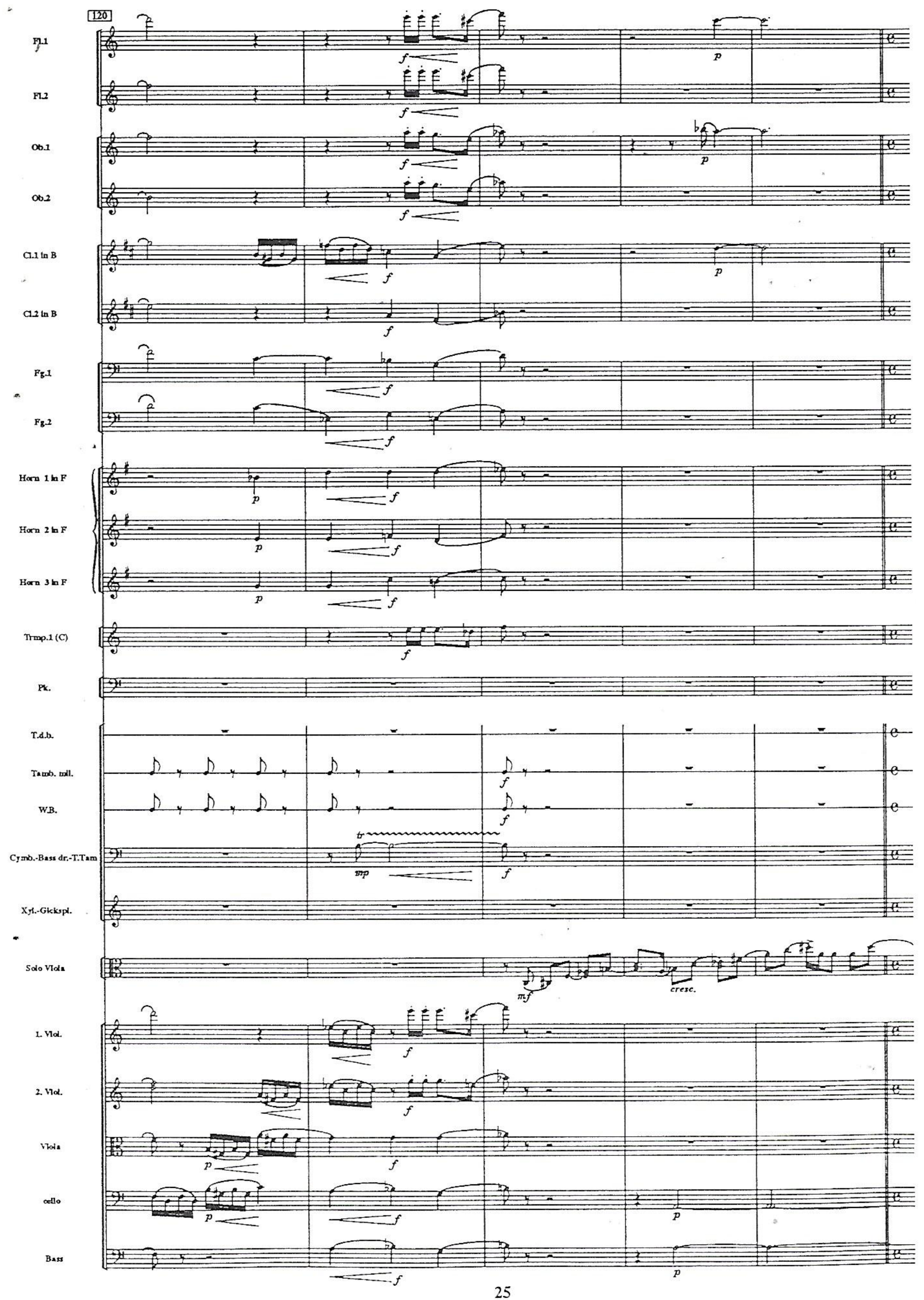




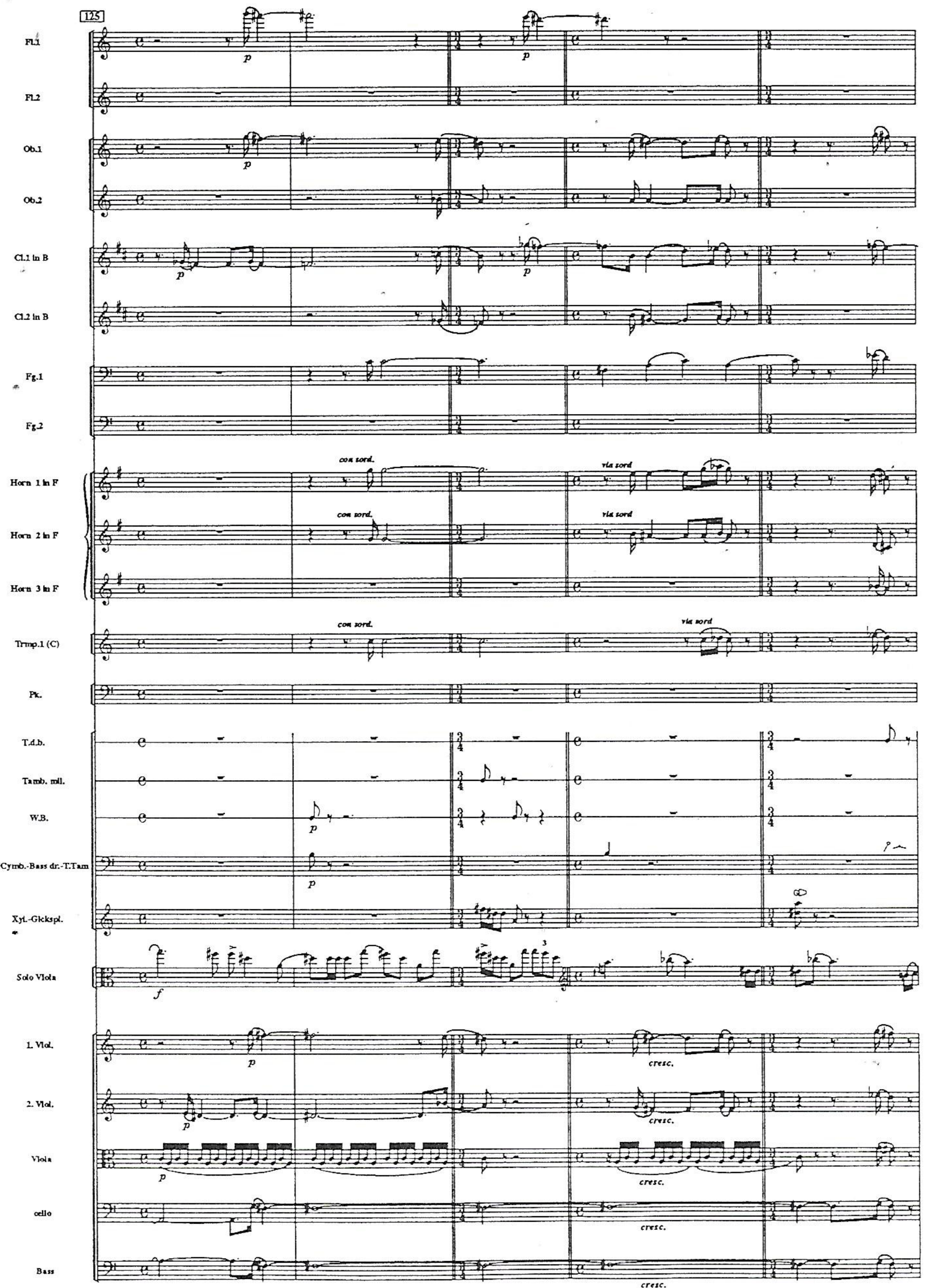




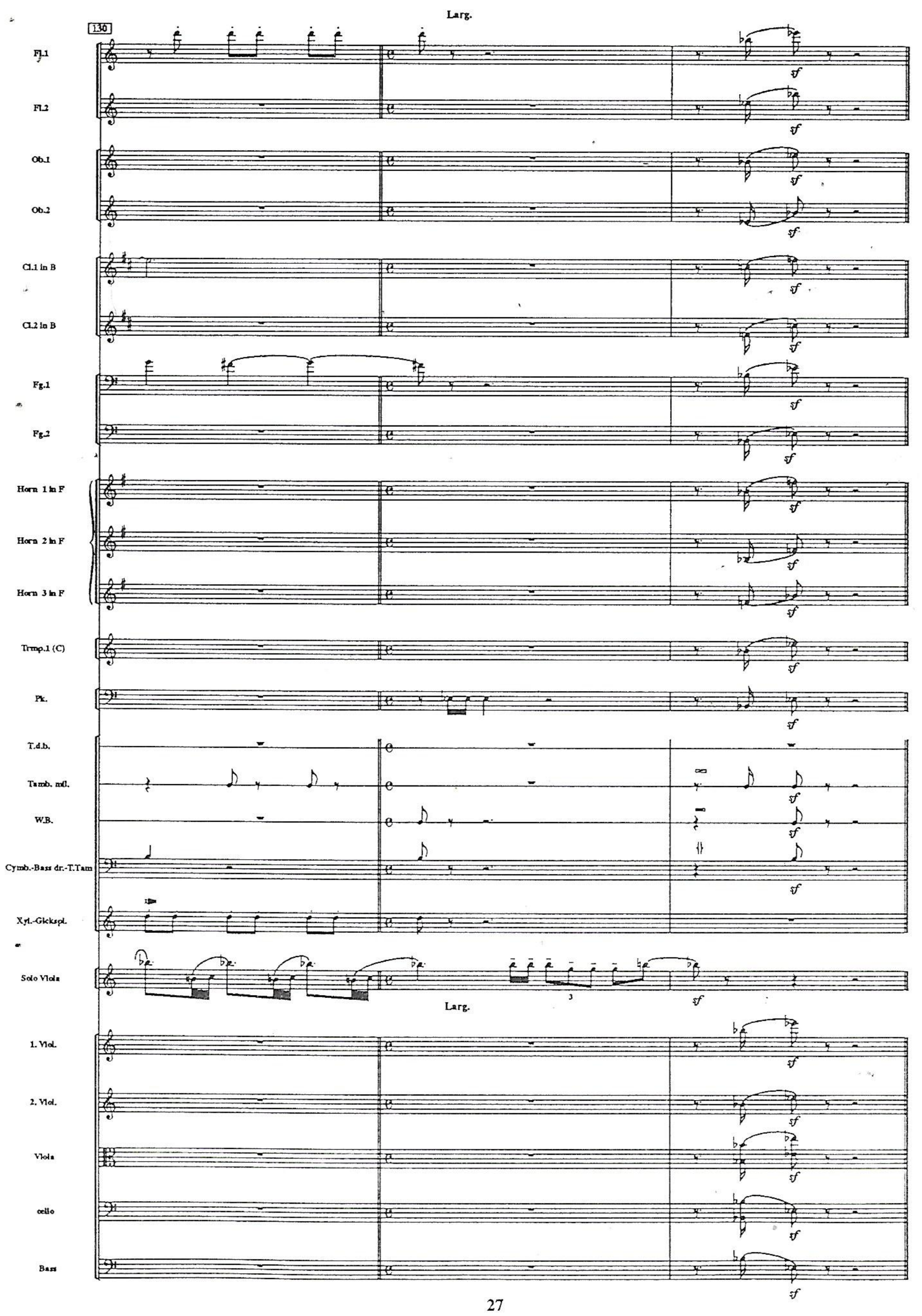



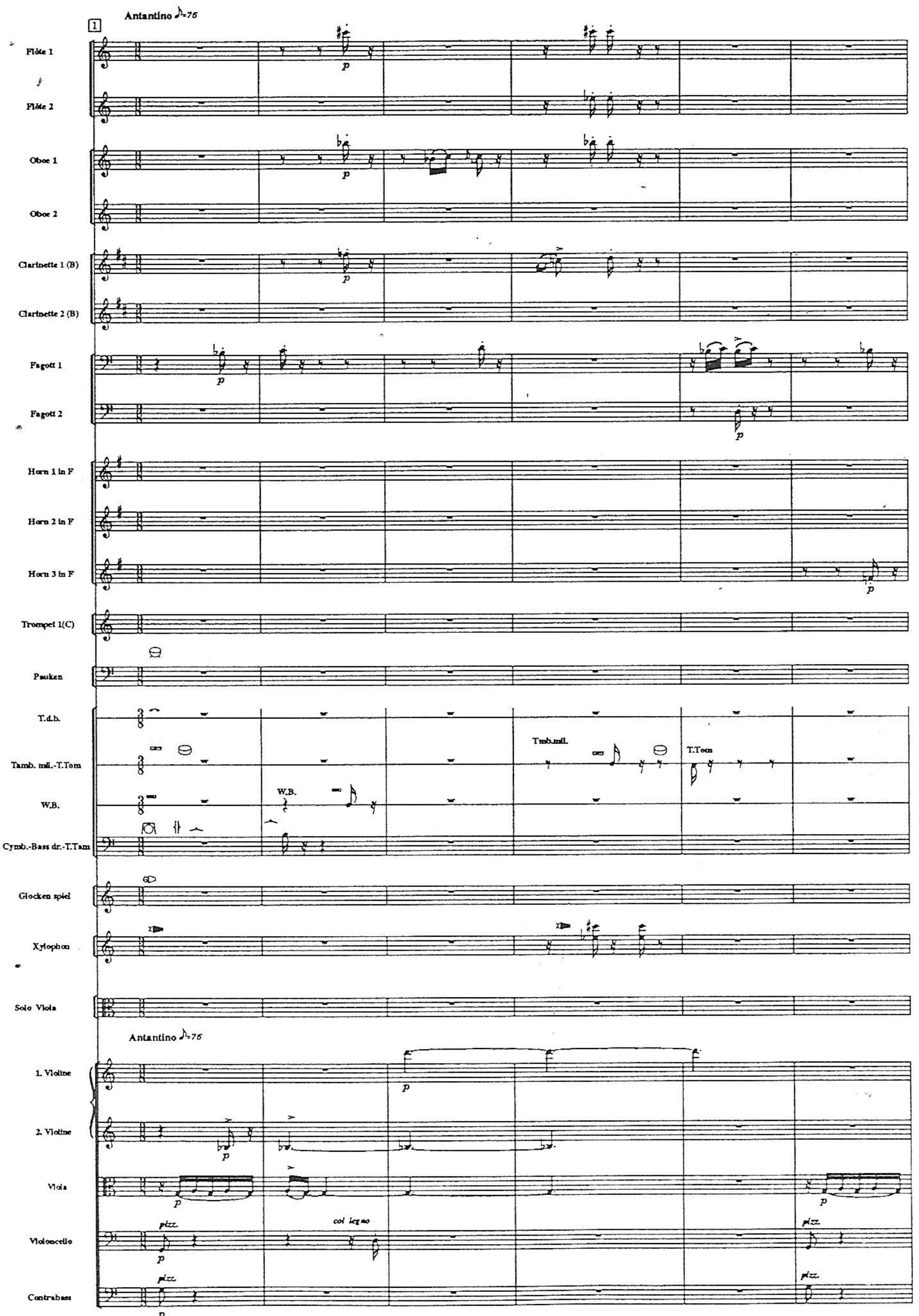


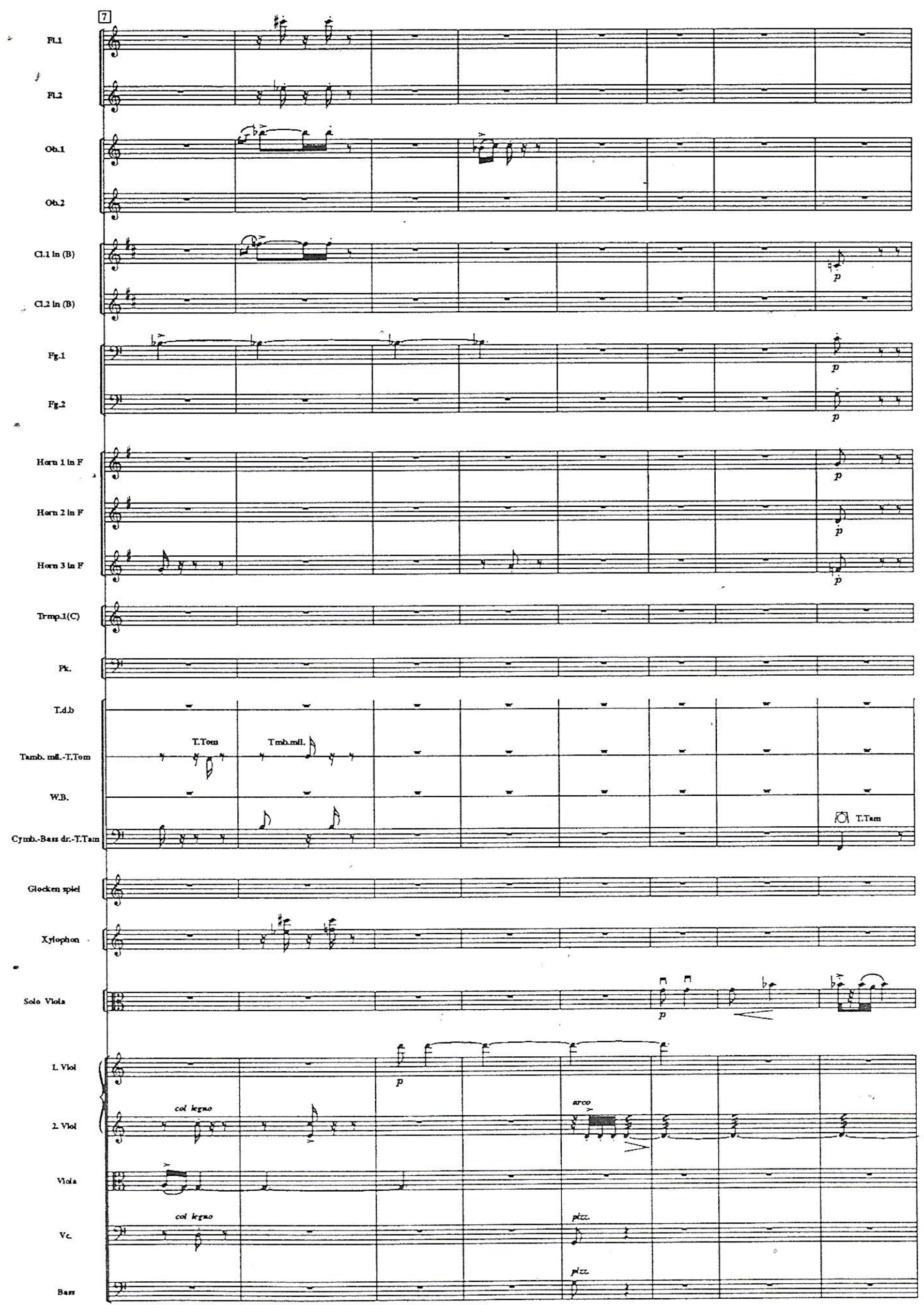




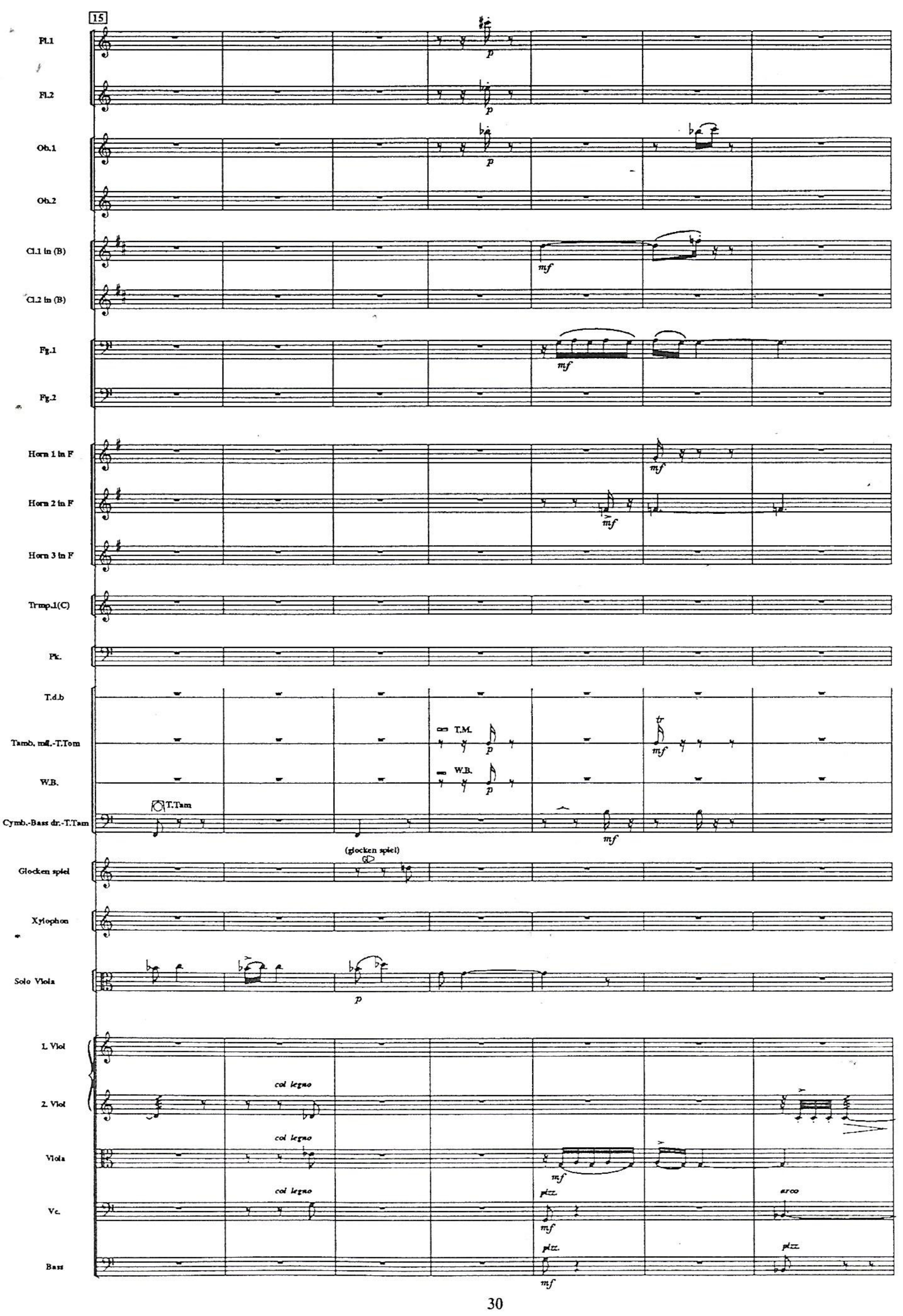




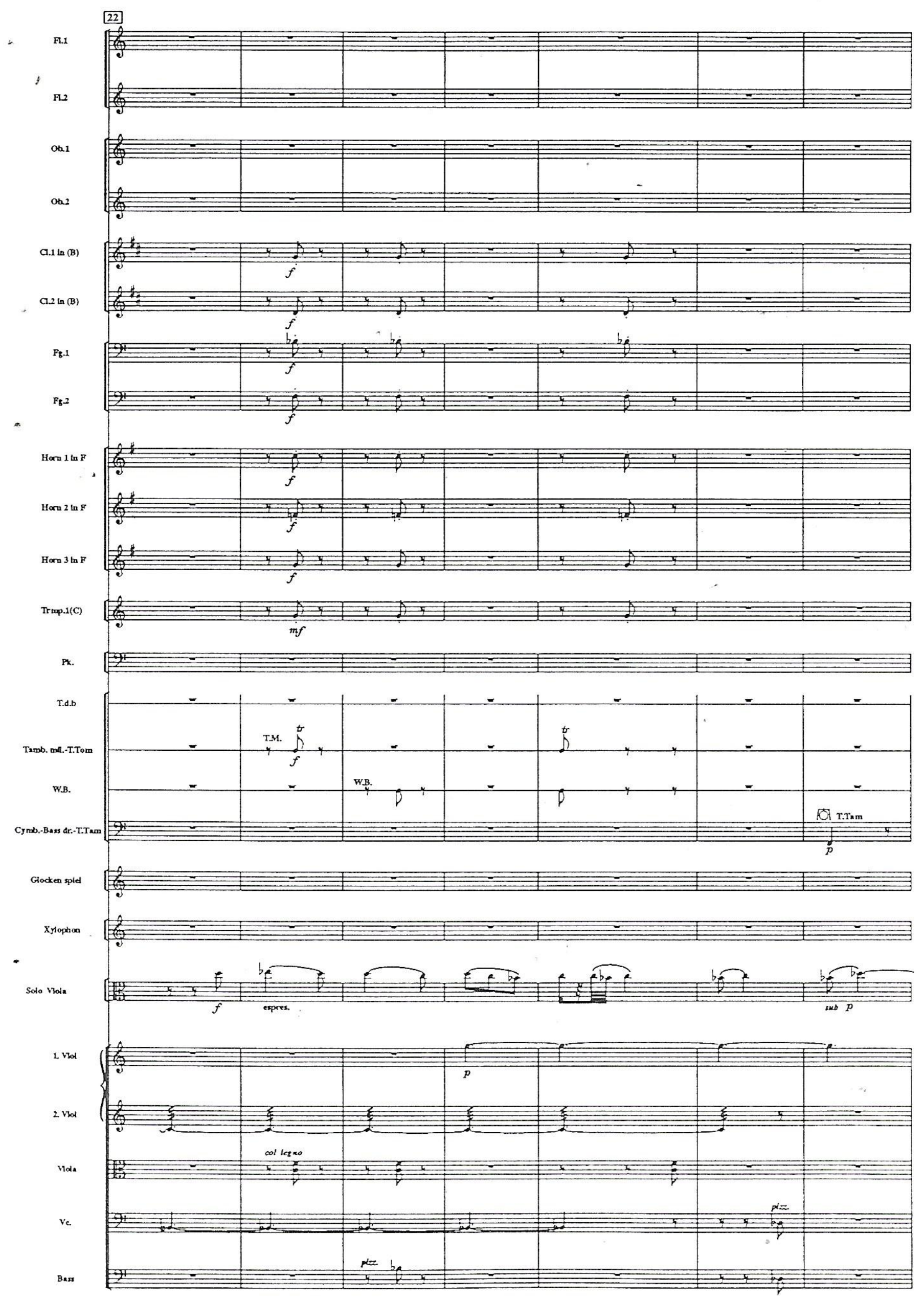




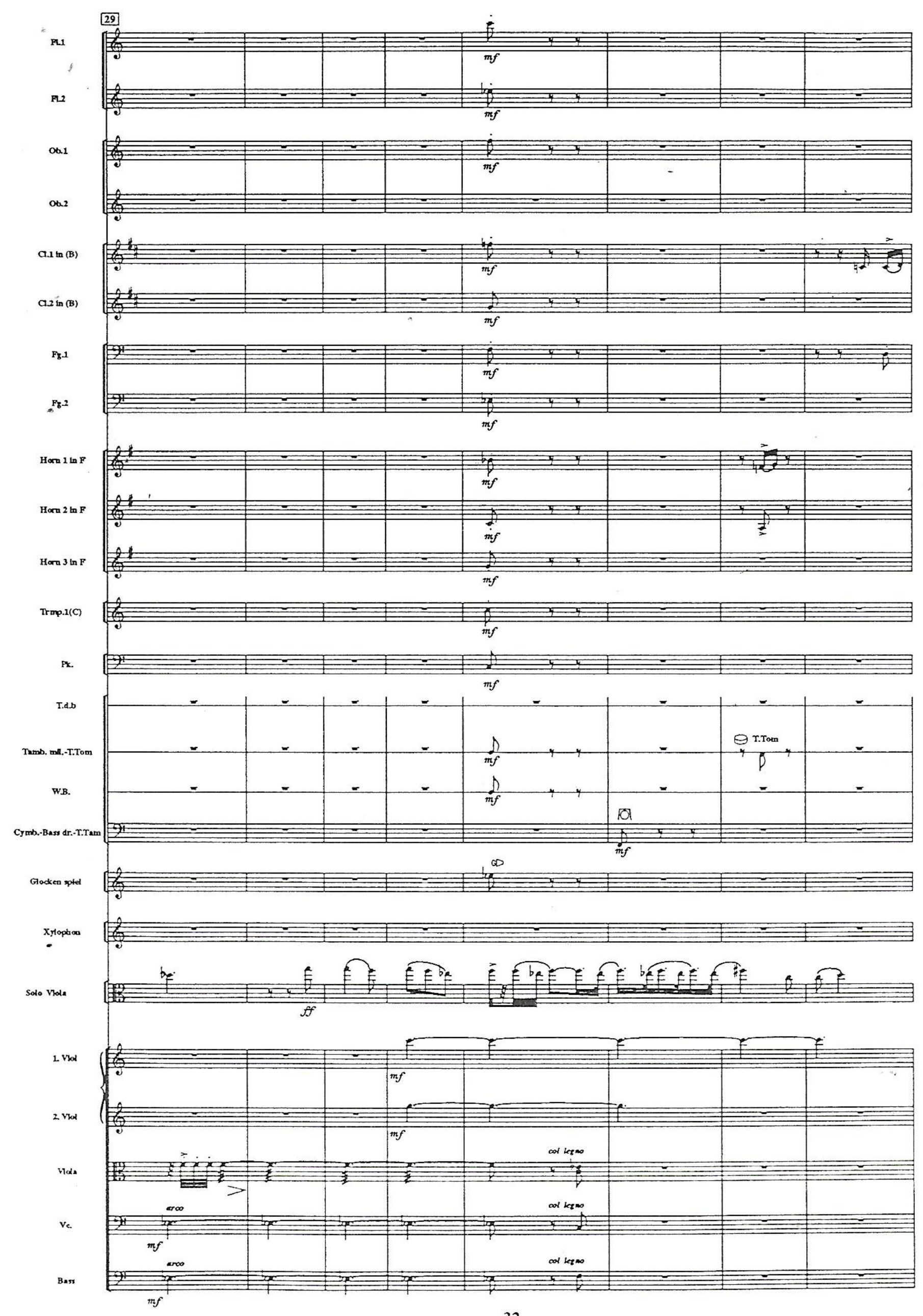




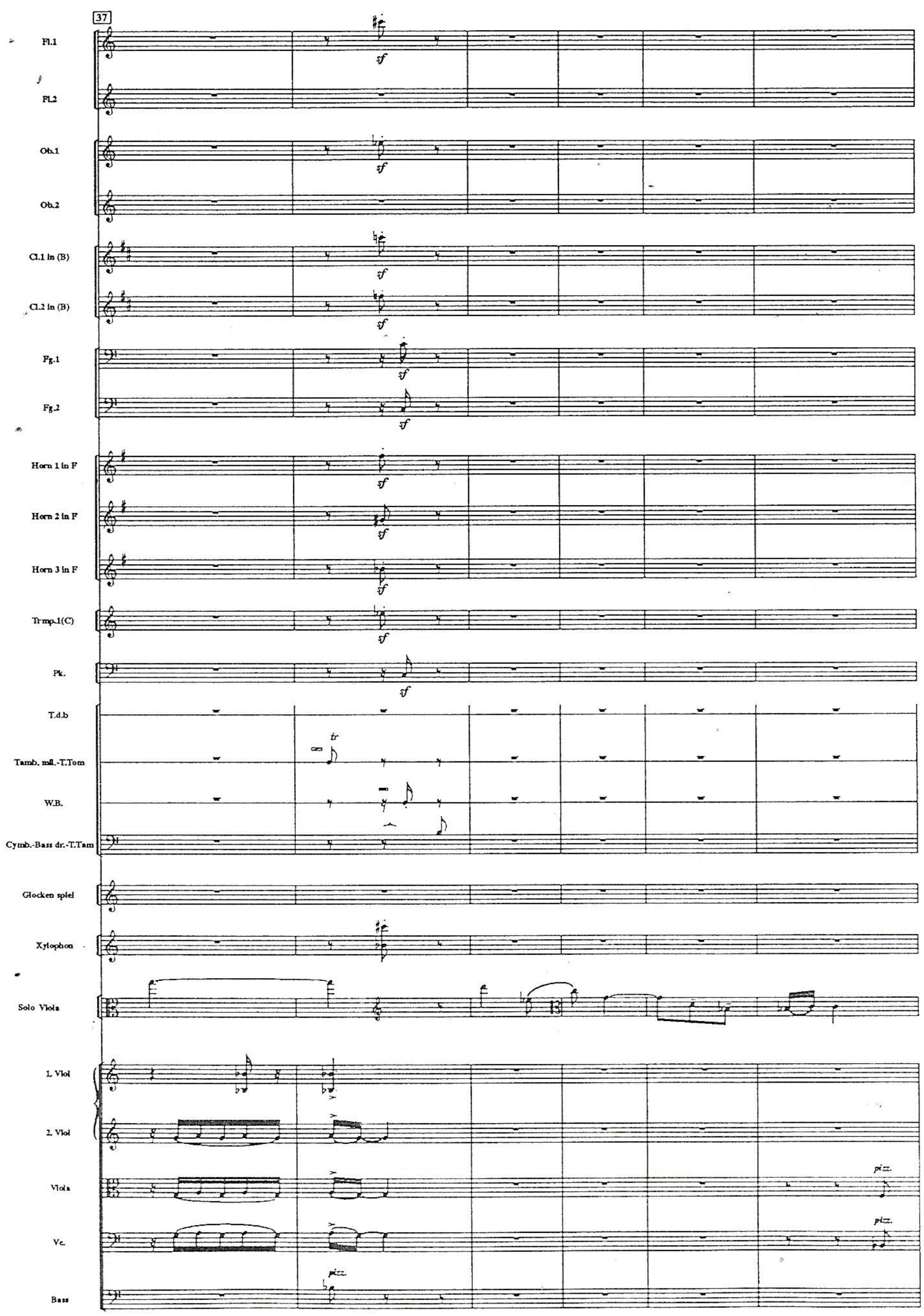




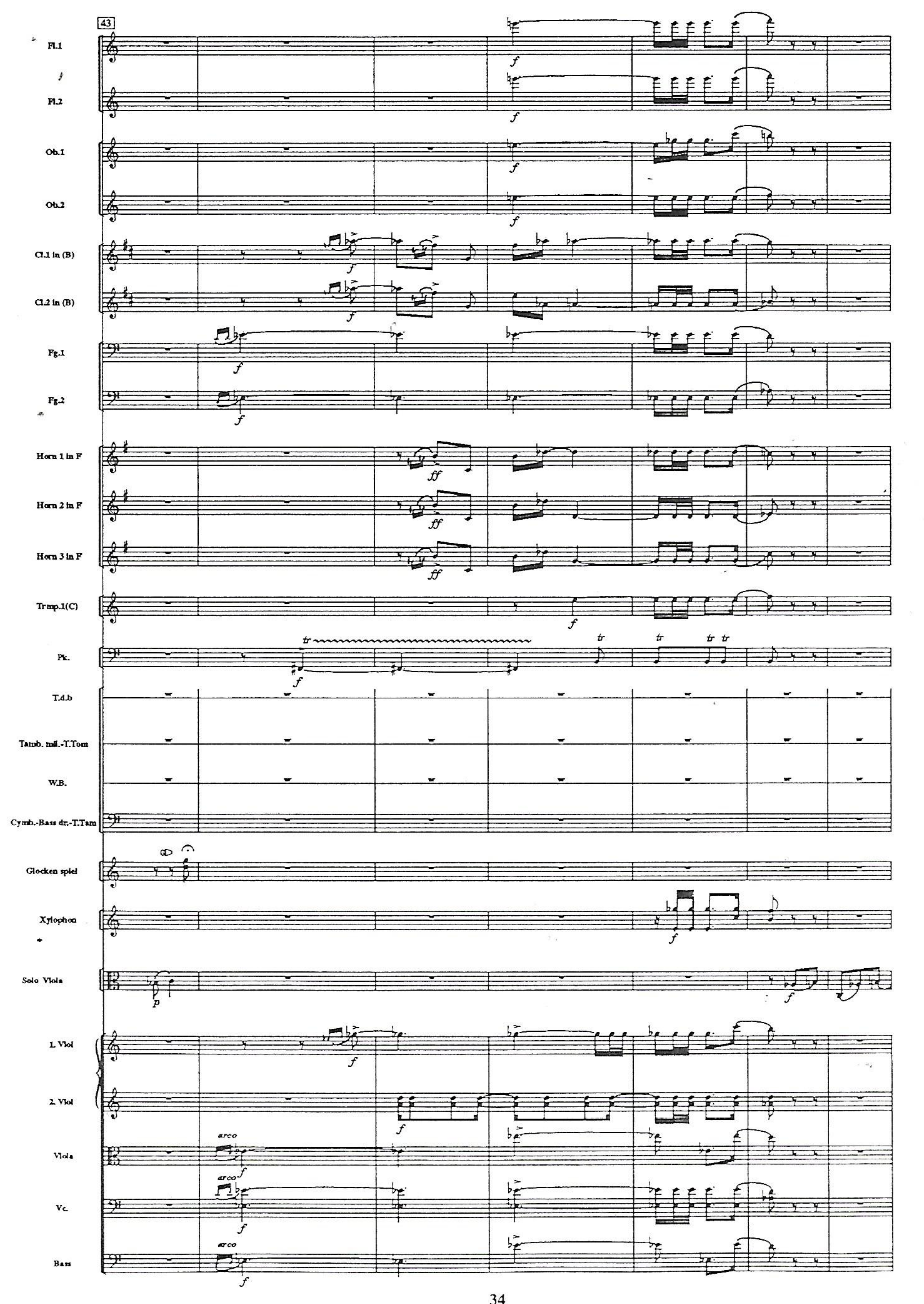




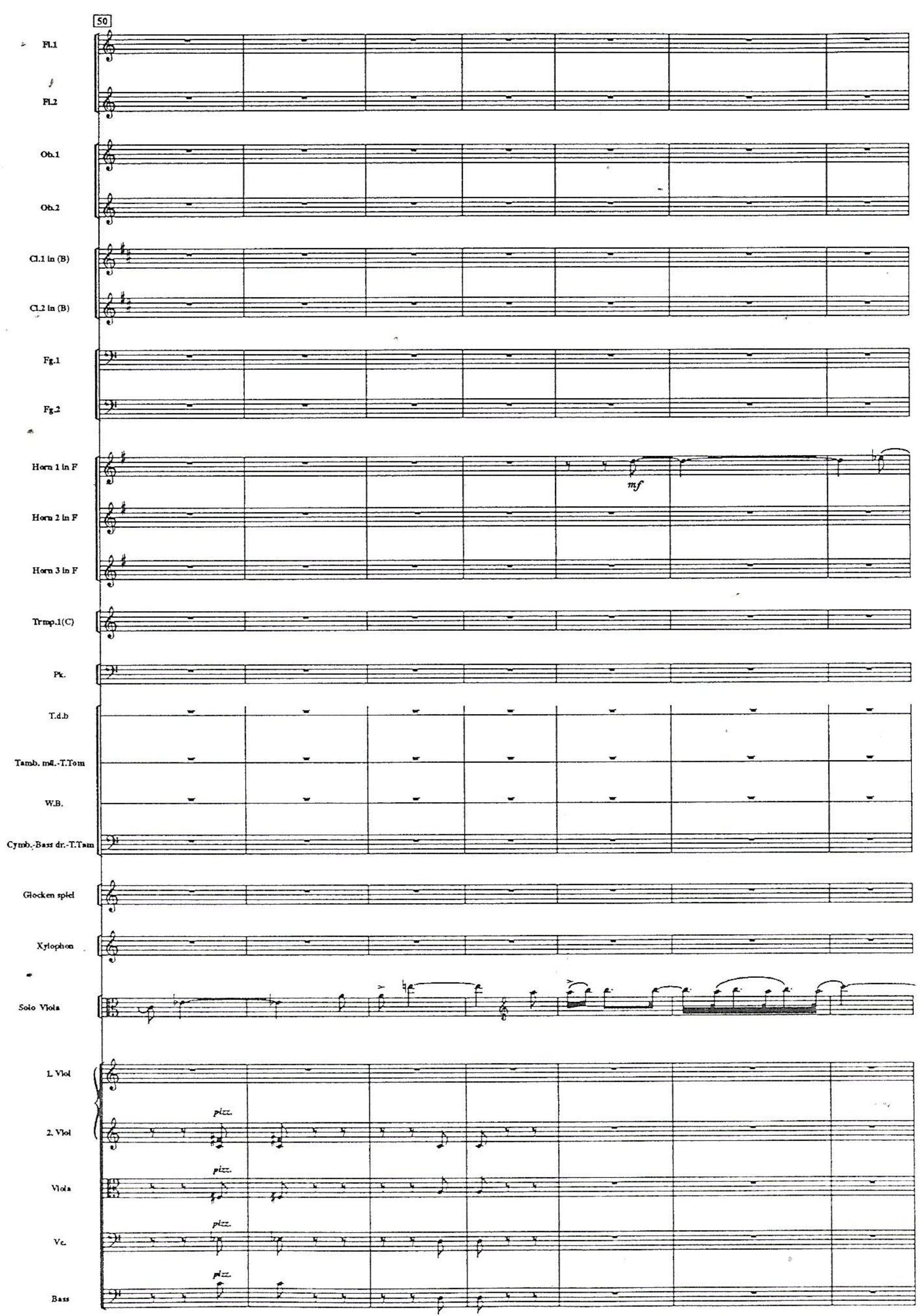




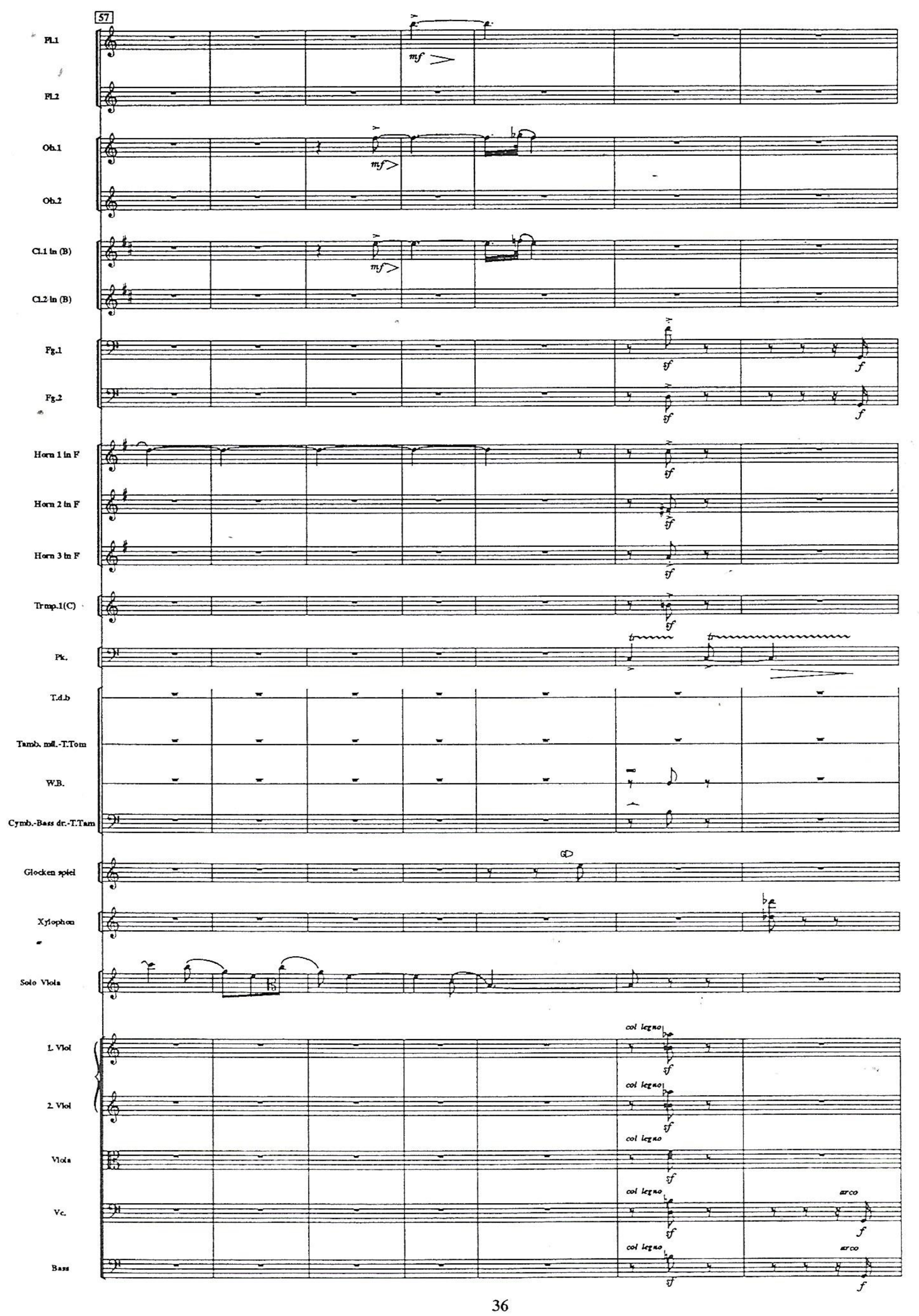




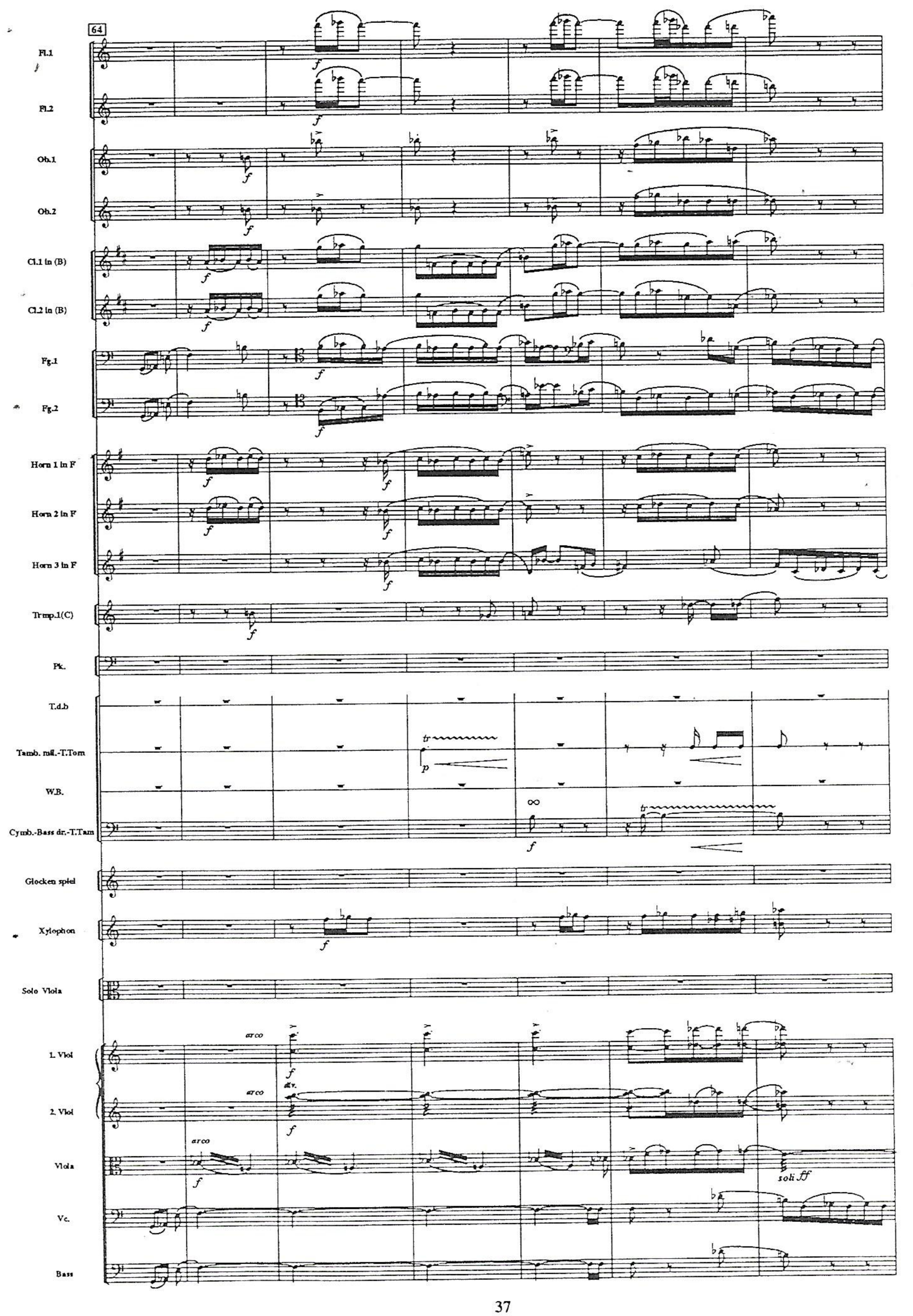




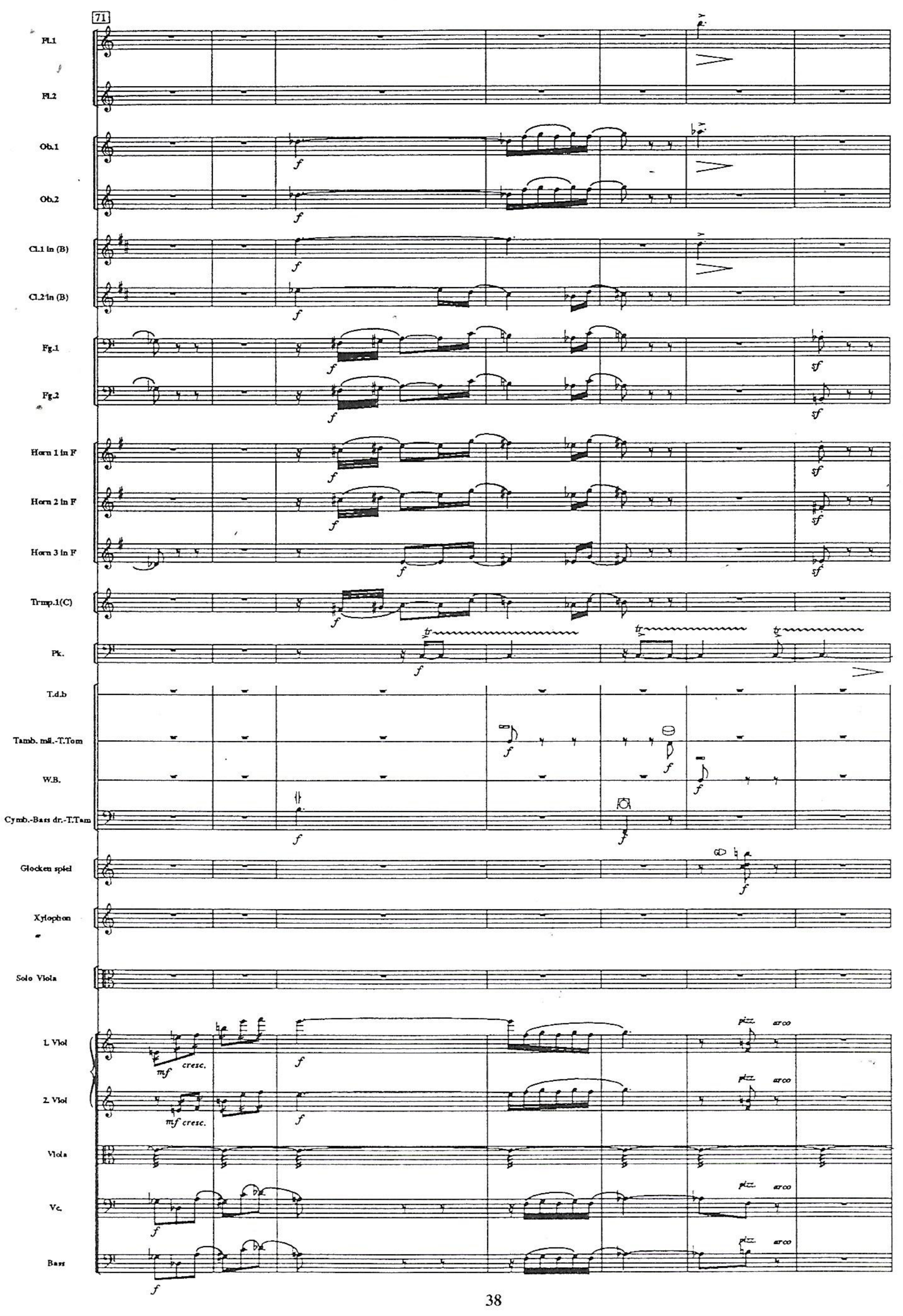




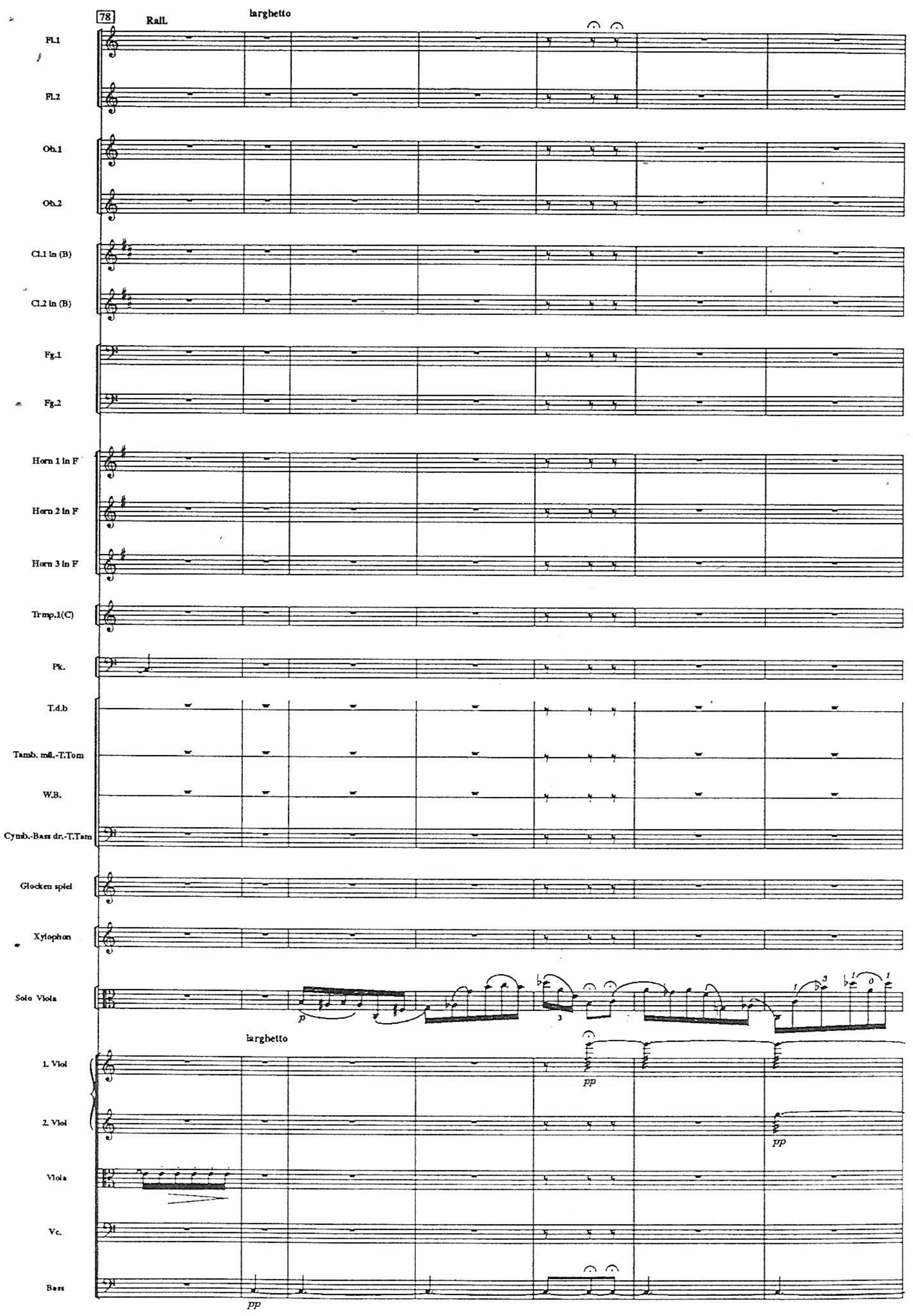




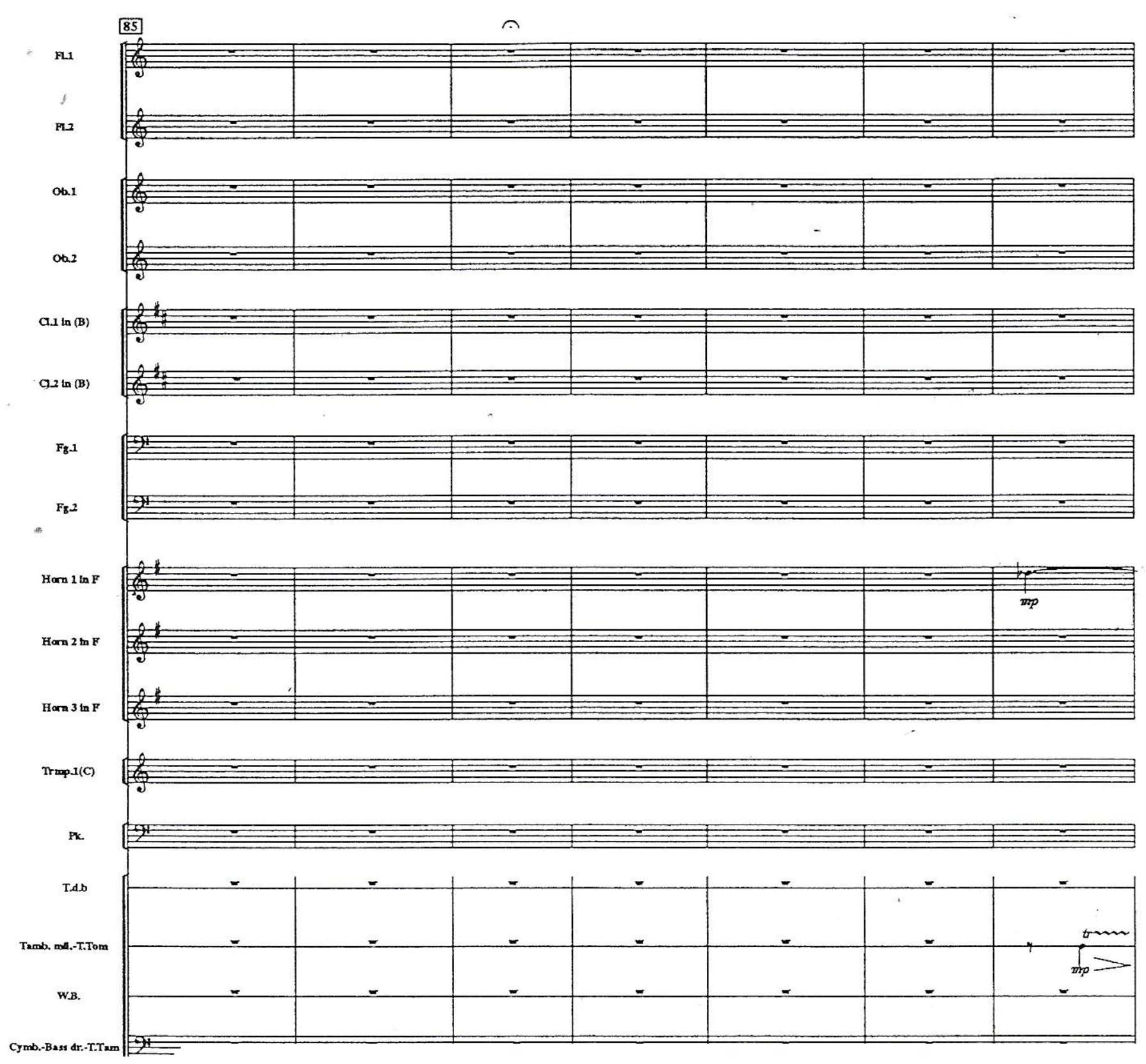




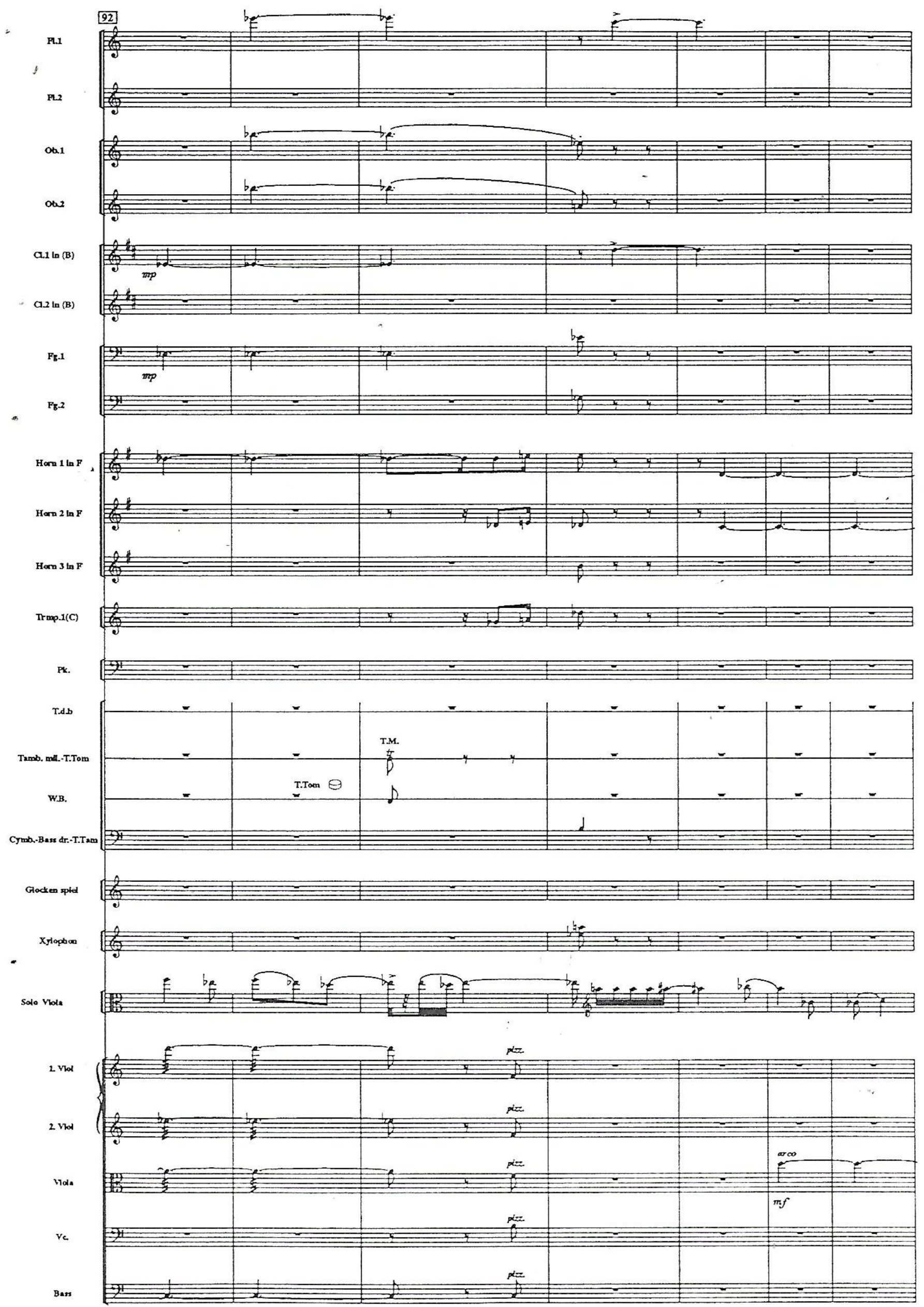




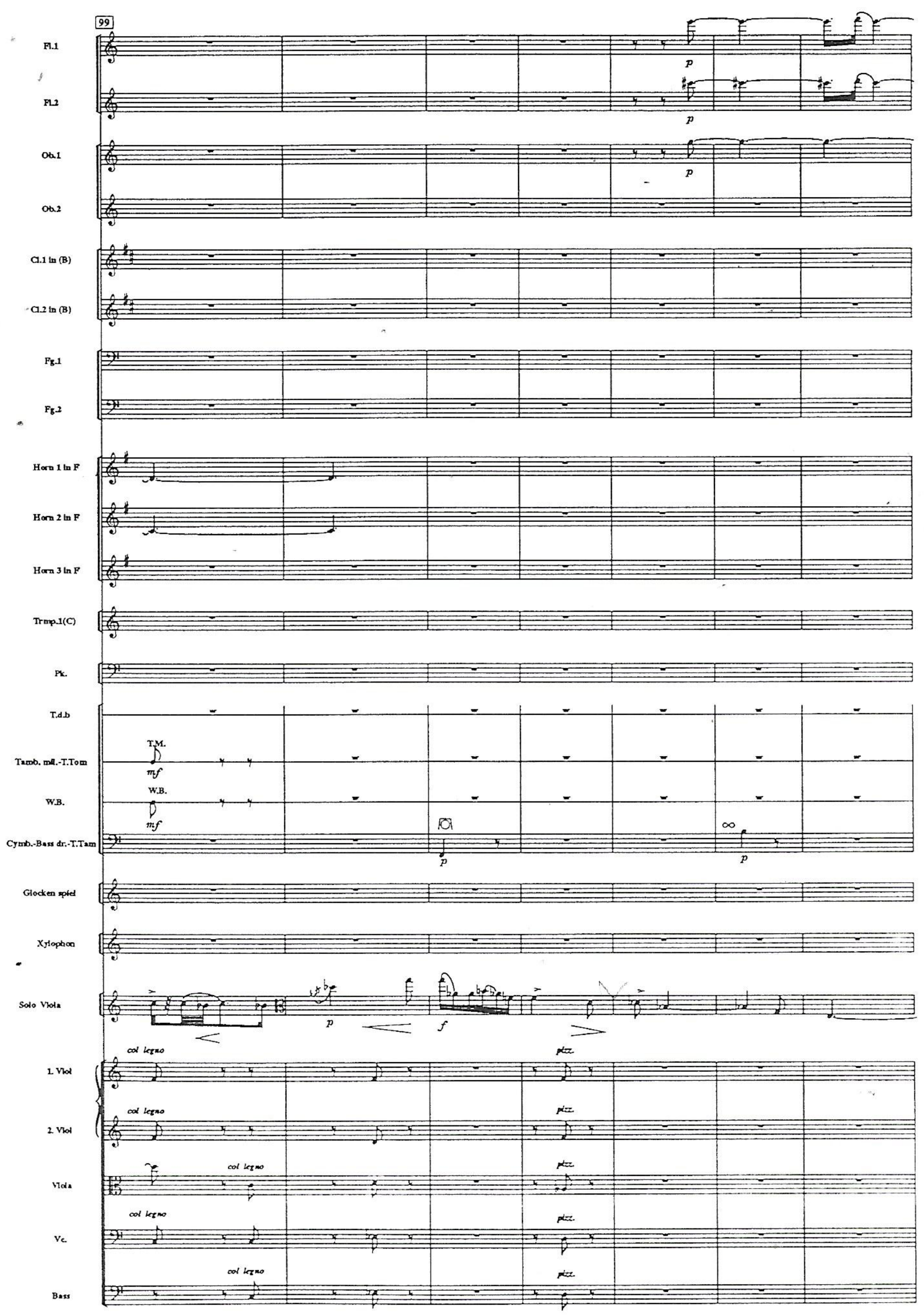




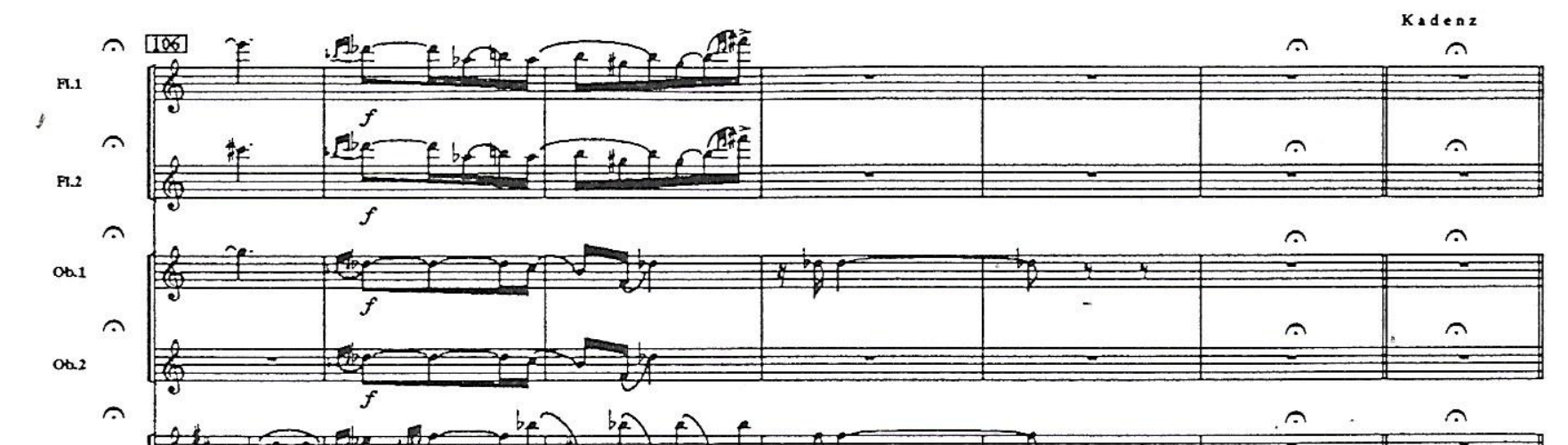

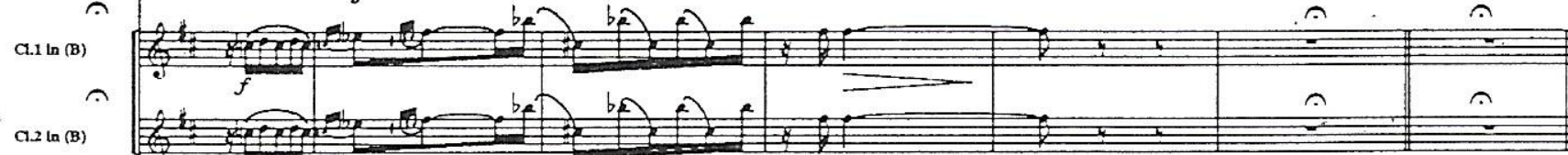

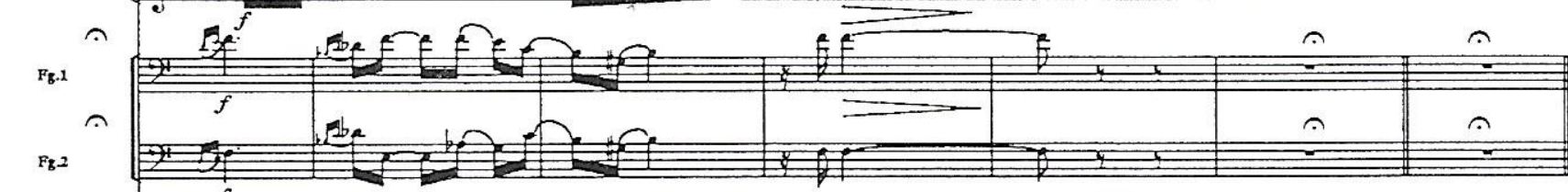

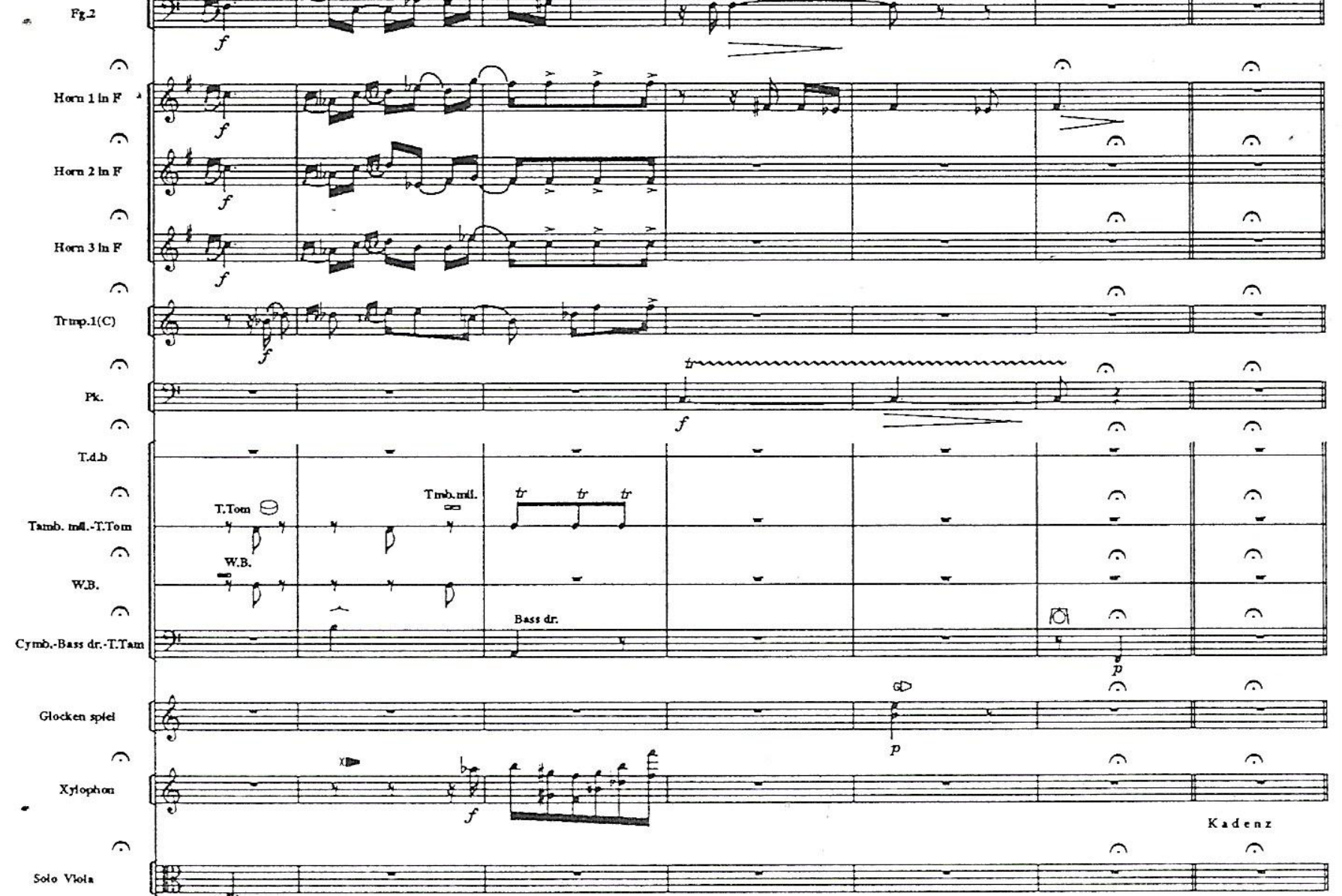

Solo Votet

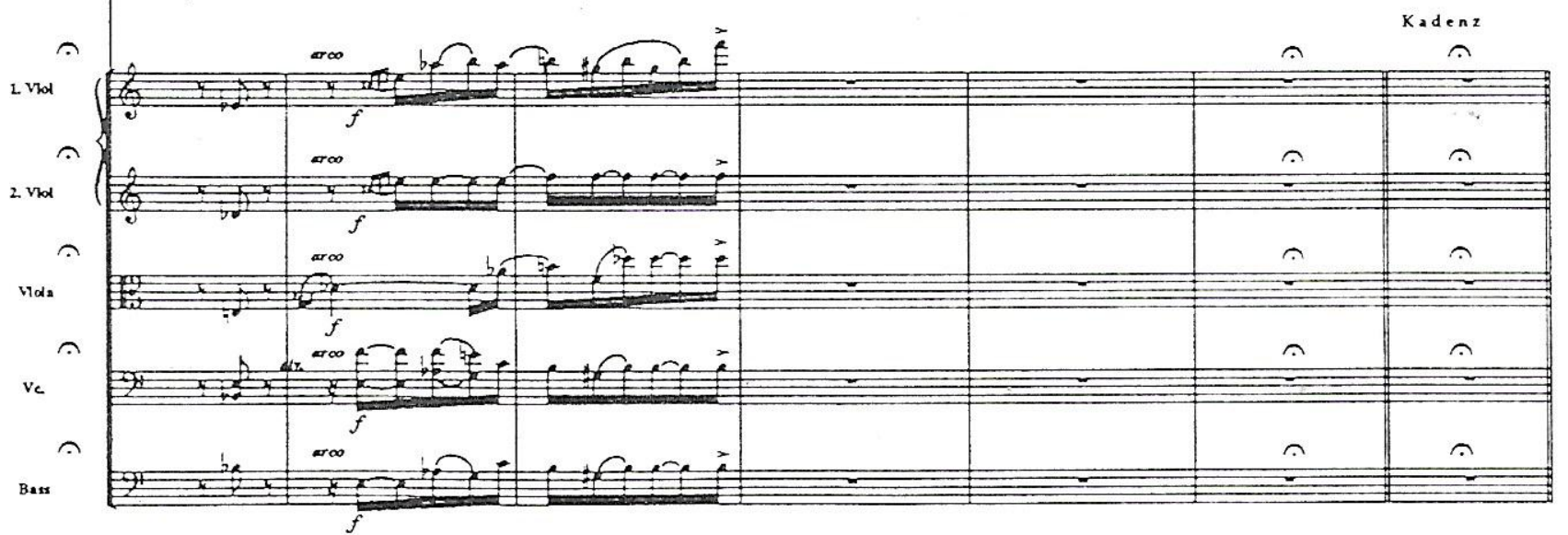


I

Kadenz

(Solo)

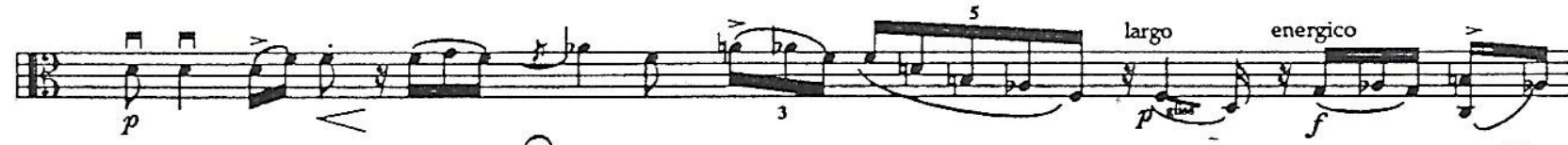

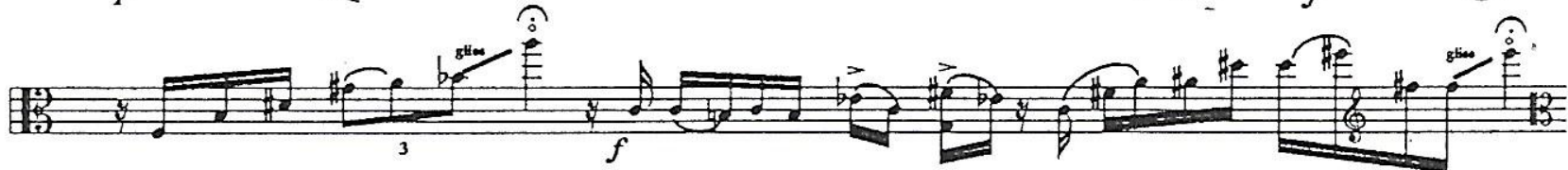
$\frac{\underbrace{2}_{\text {ri }} \%}{3}$

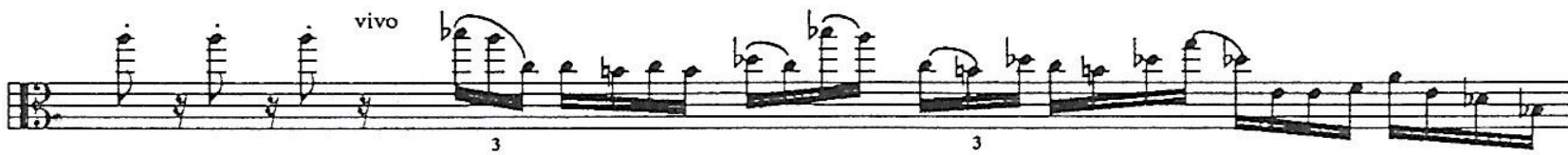
(n)

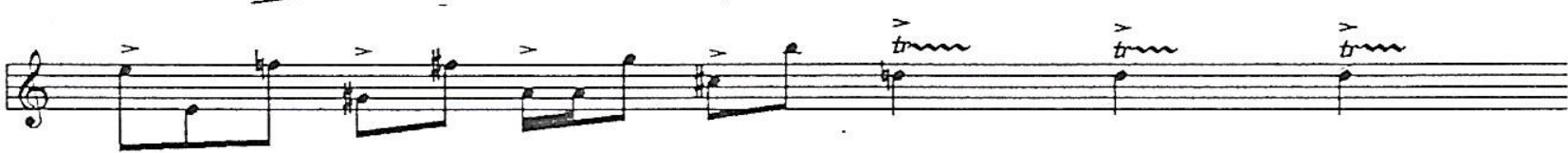
(II

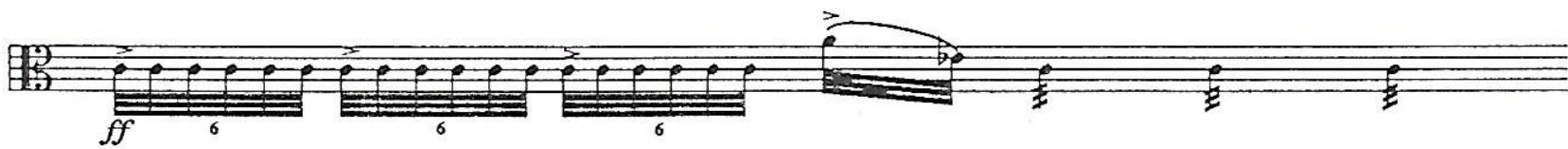

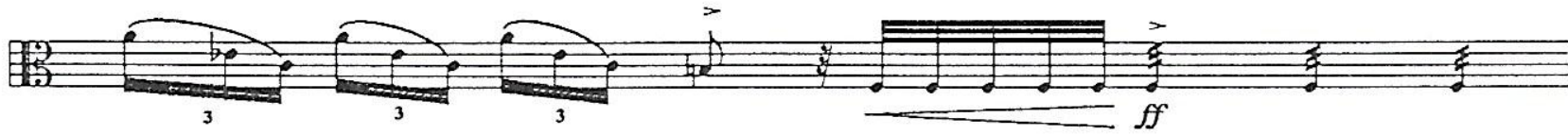

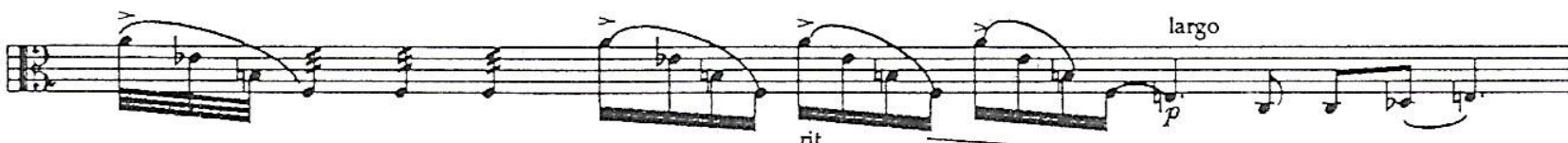
of 事

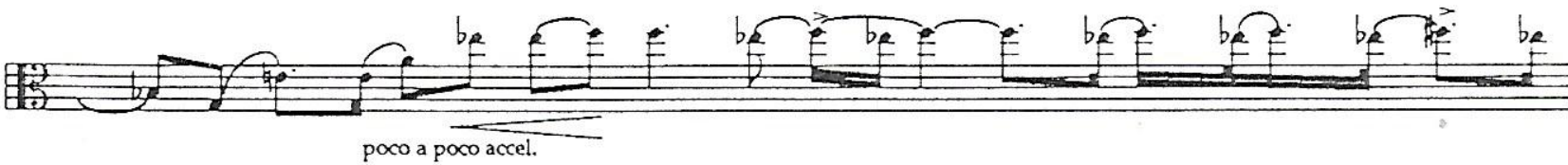
(43) 


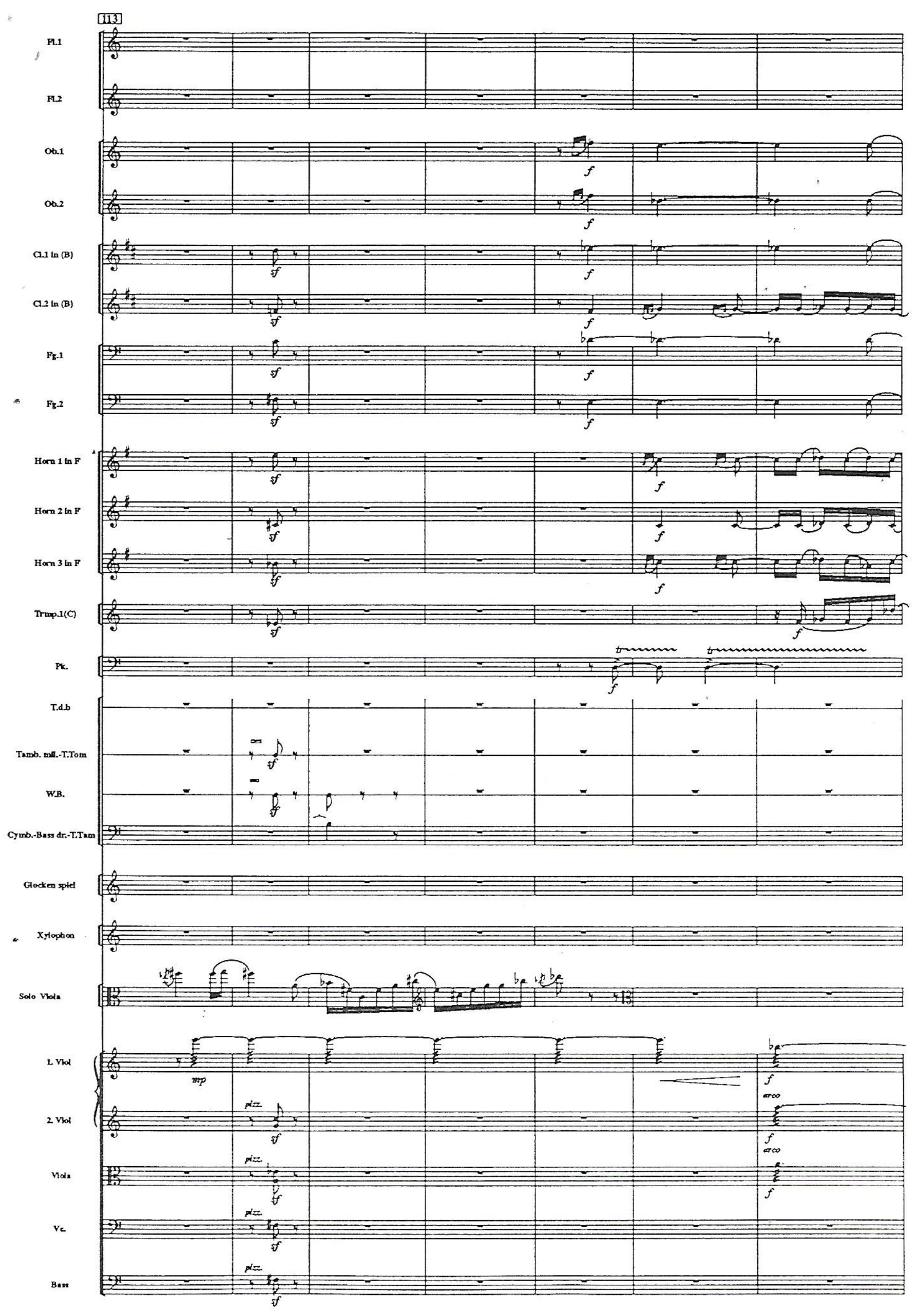




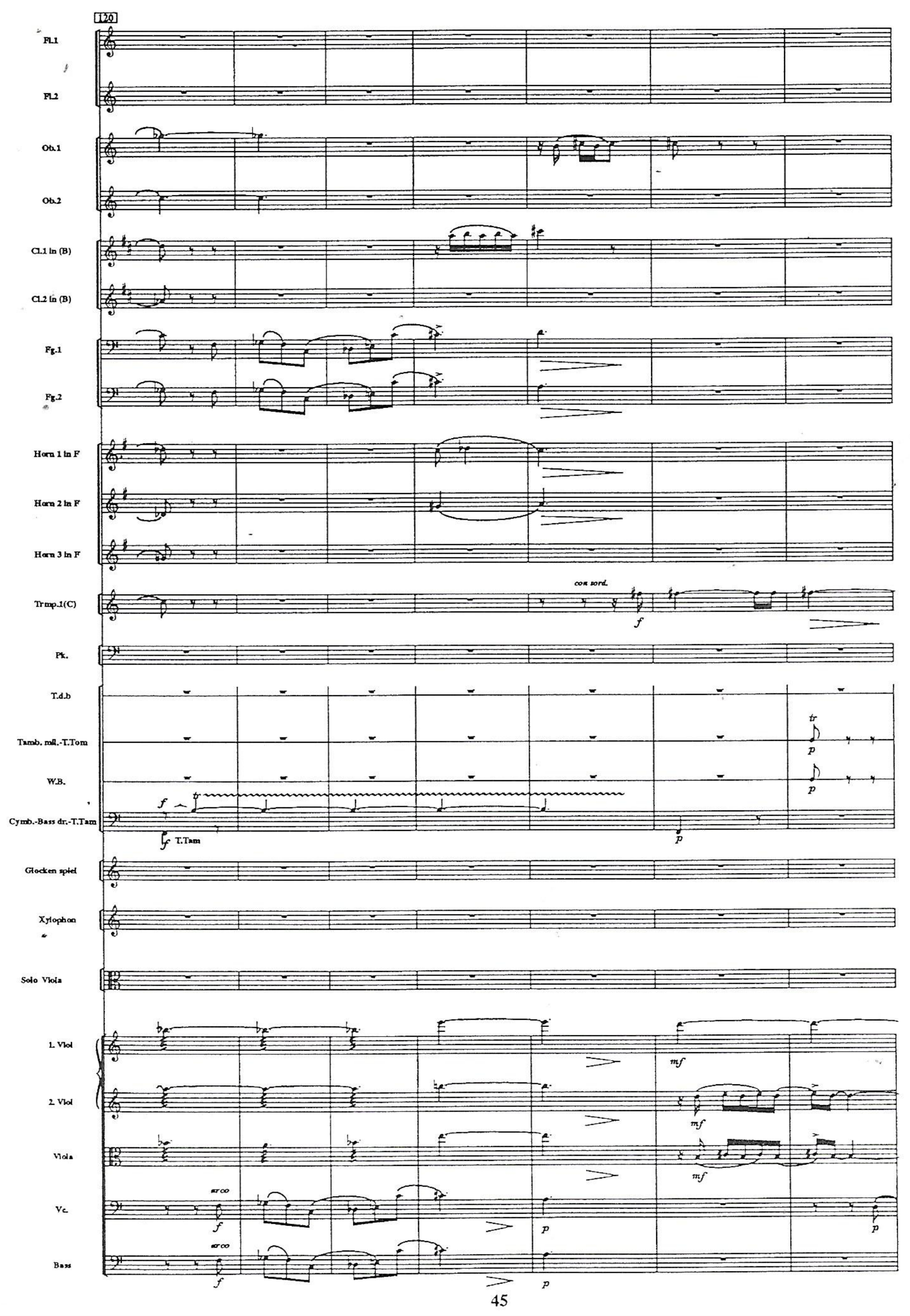




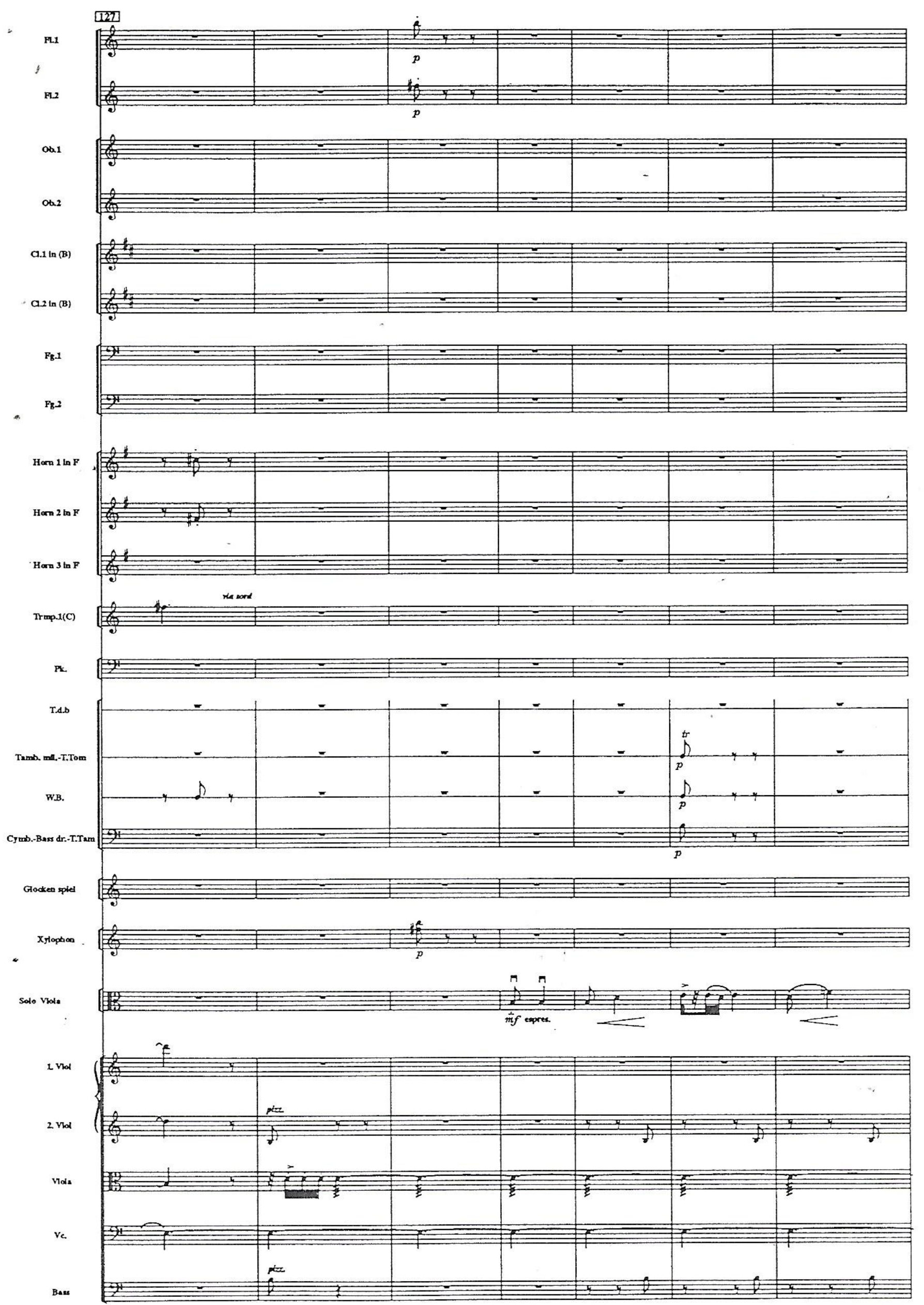




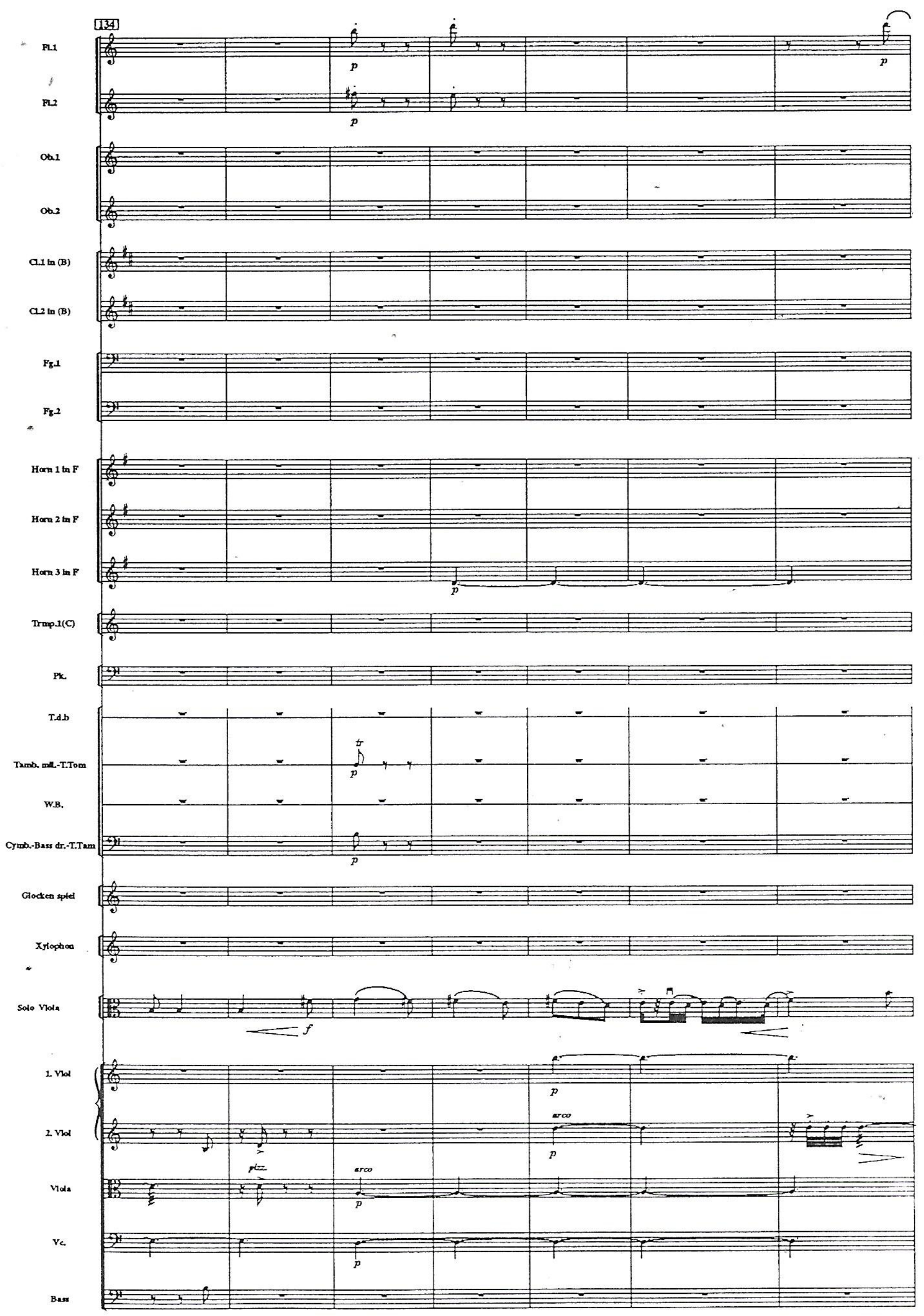




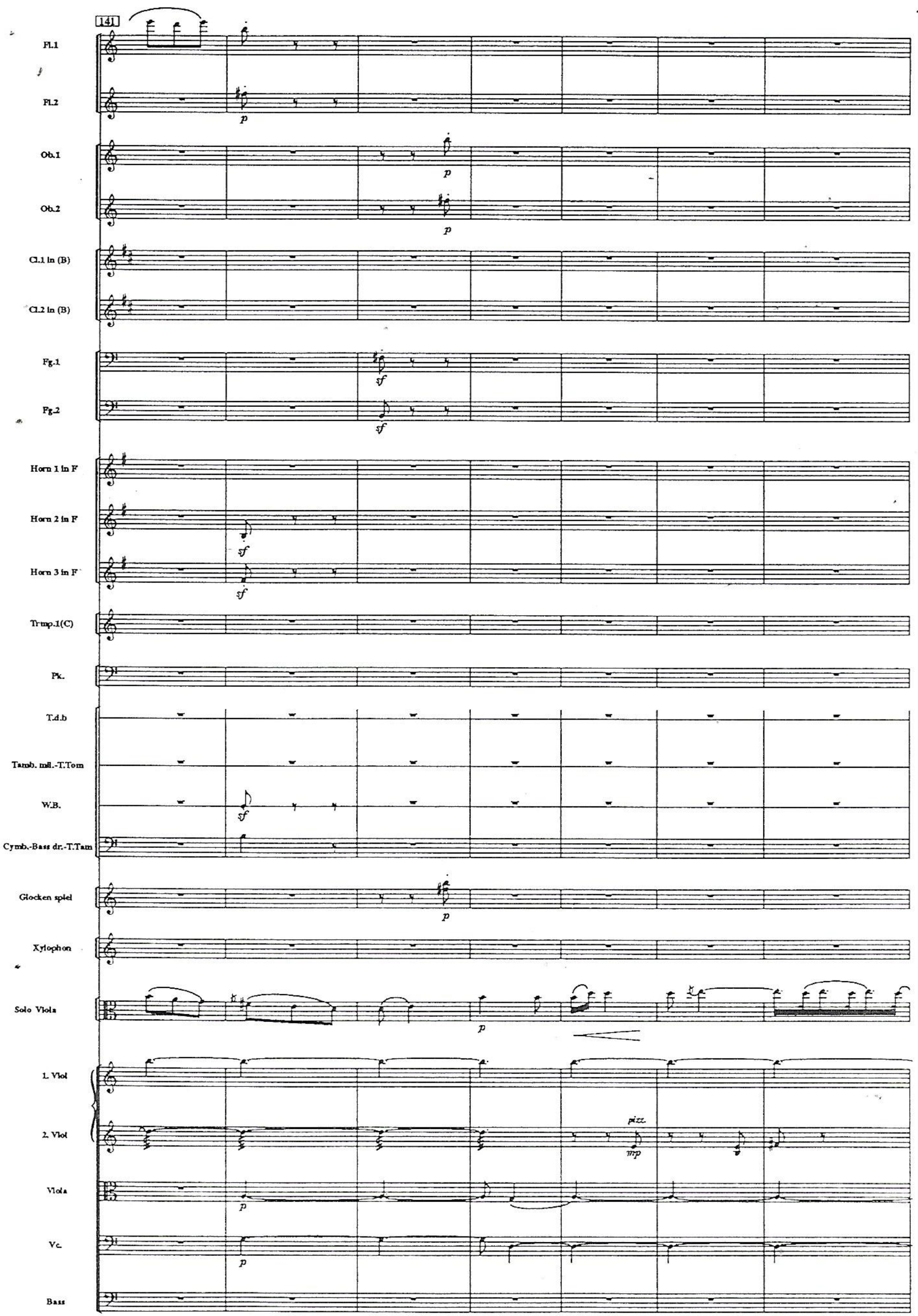




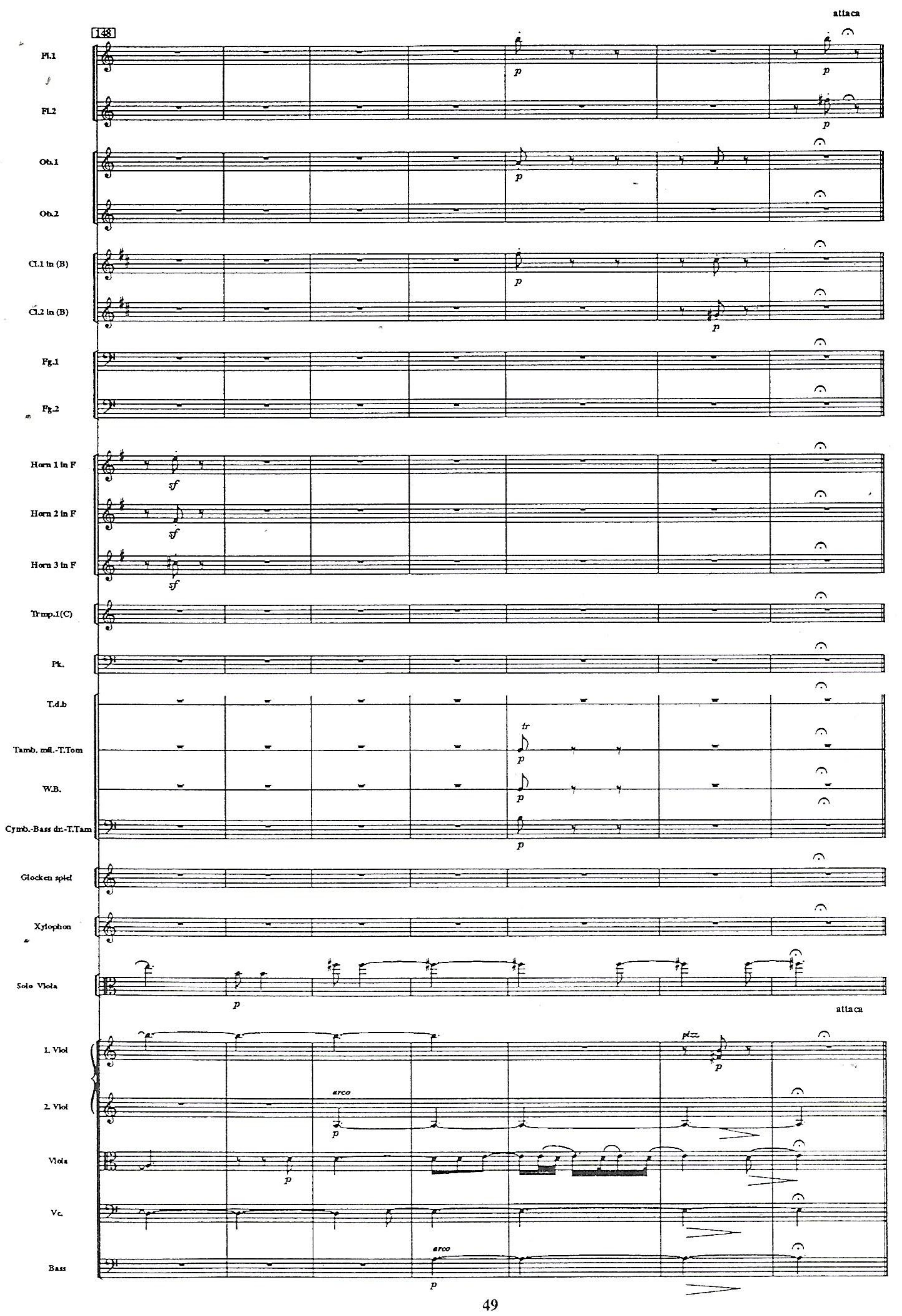




\section{Satz}

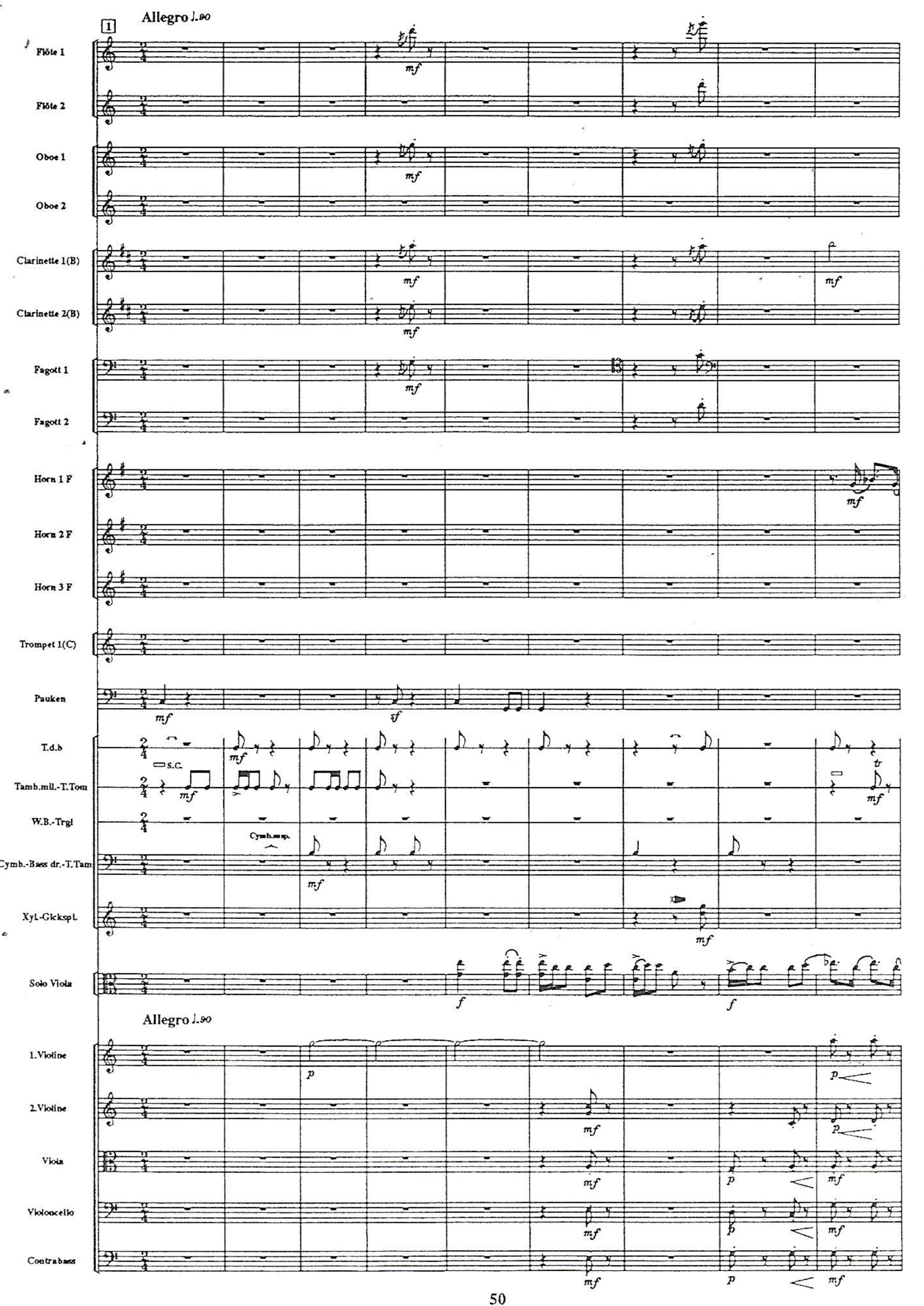




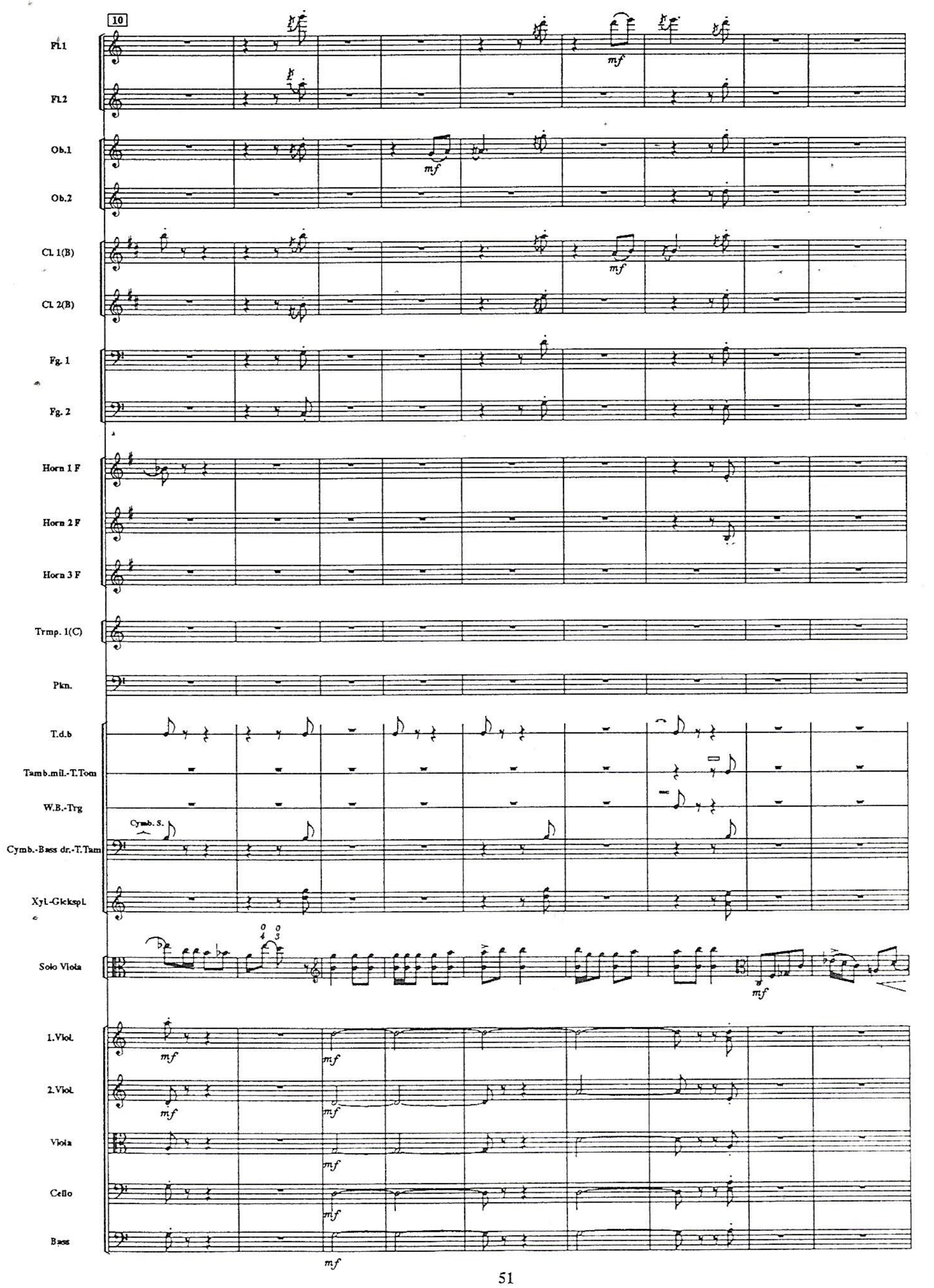




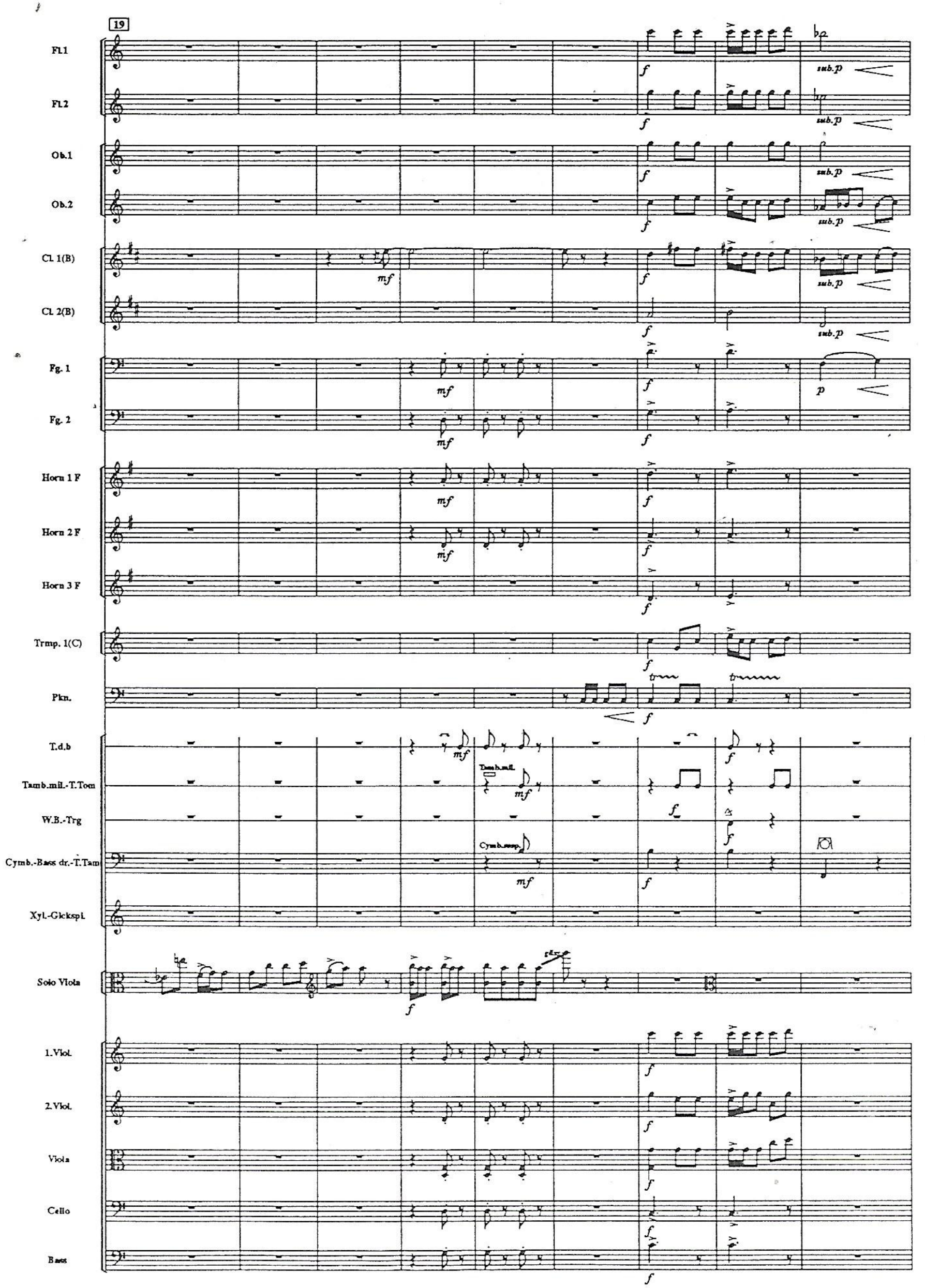




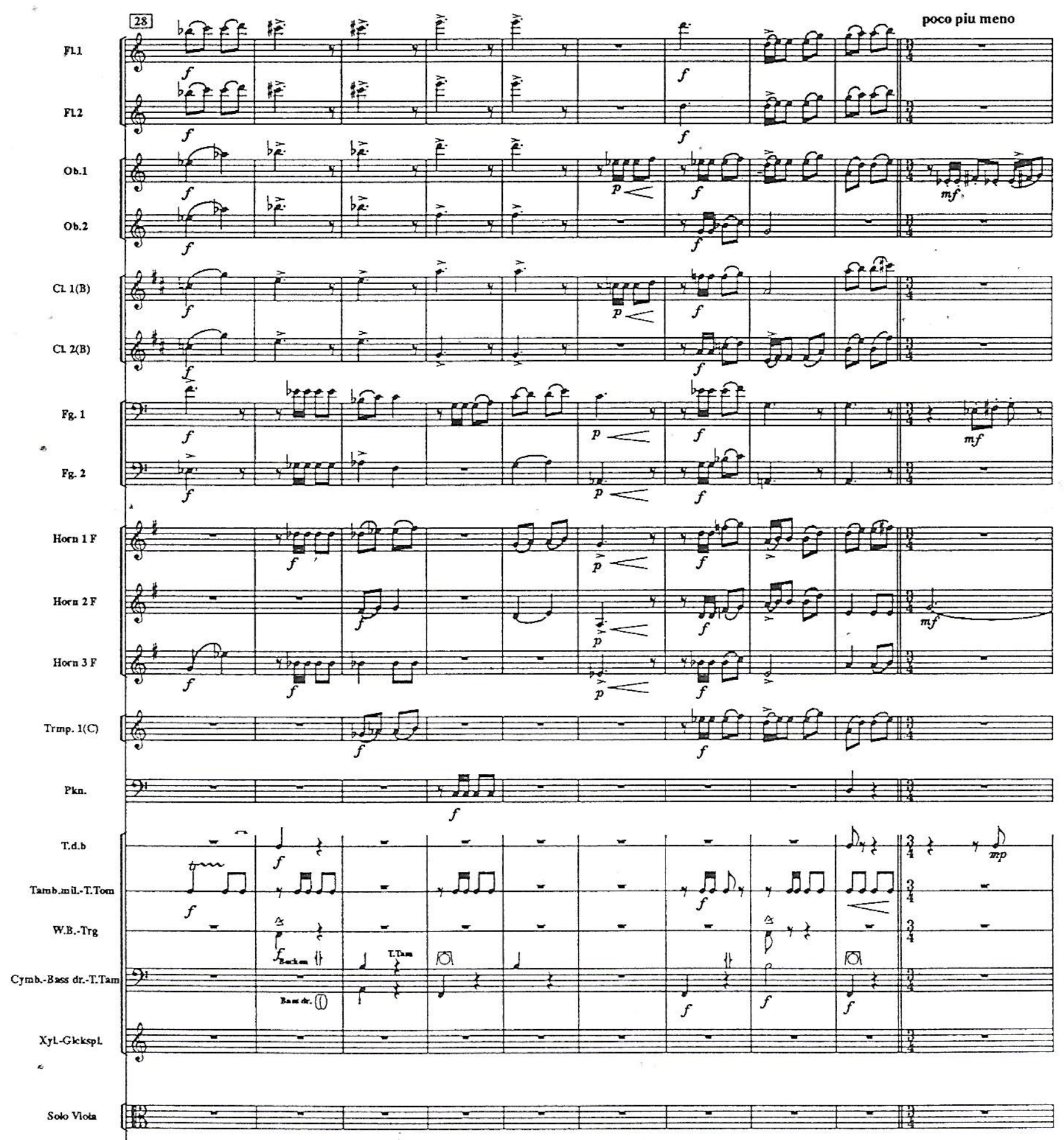




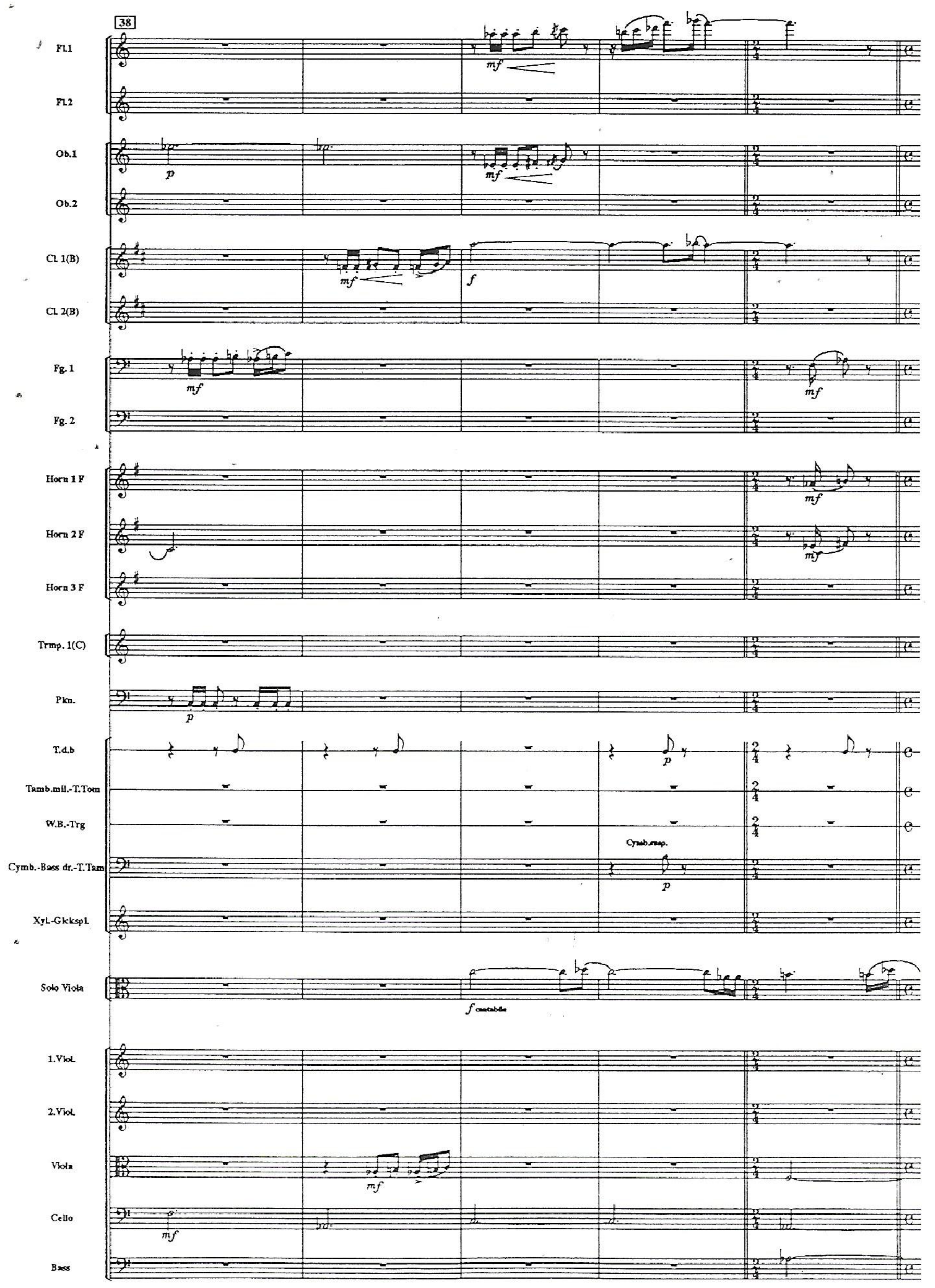




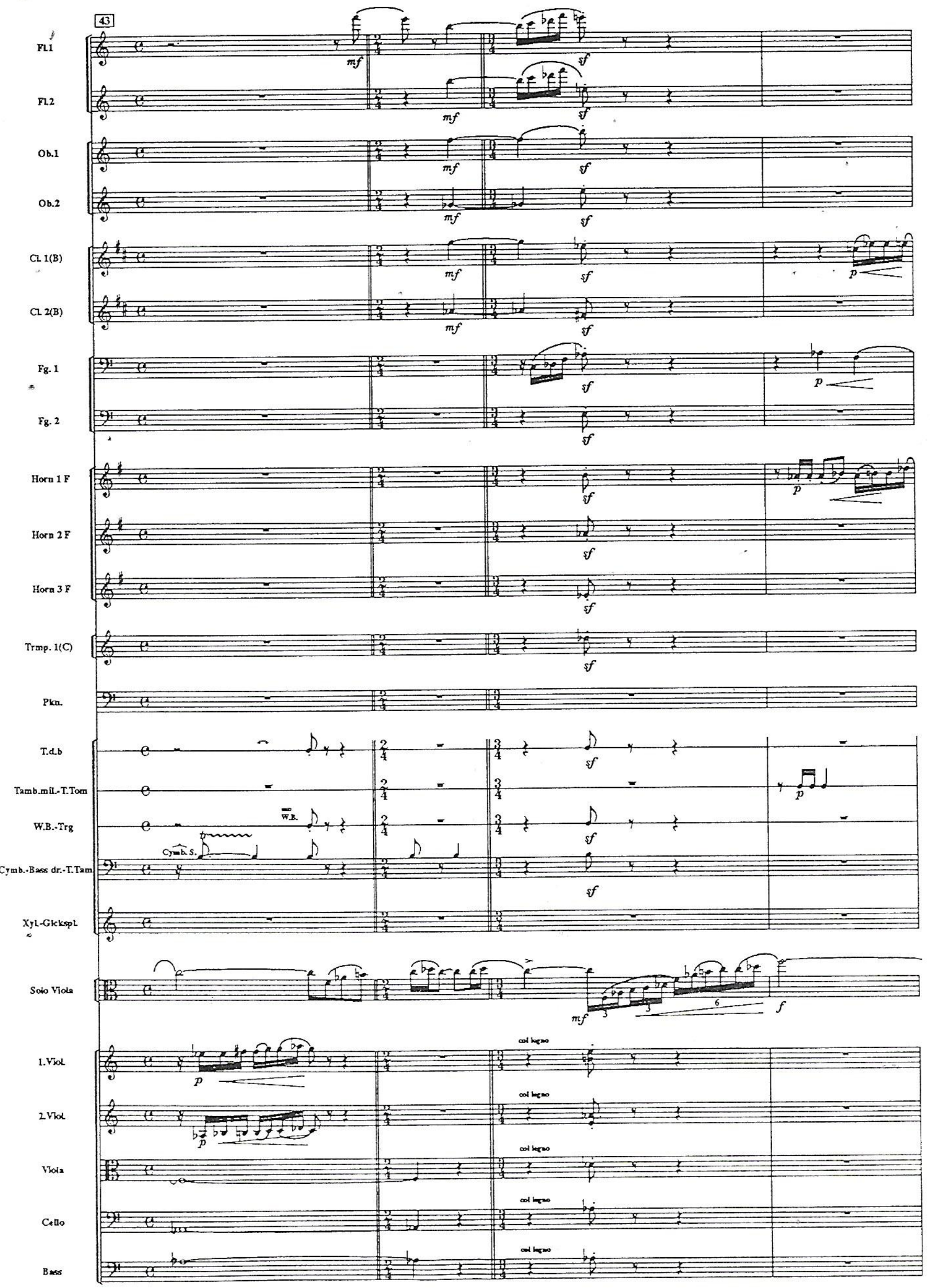




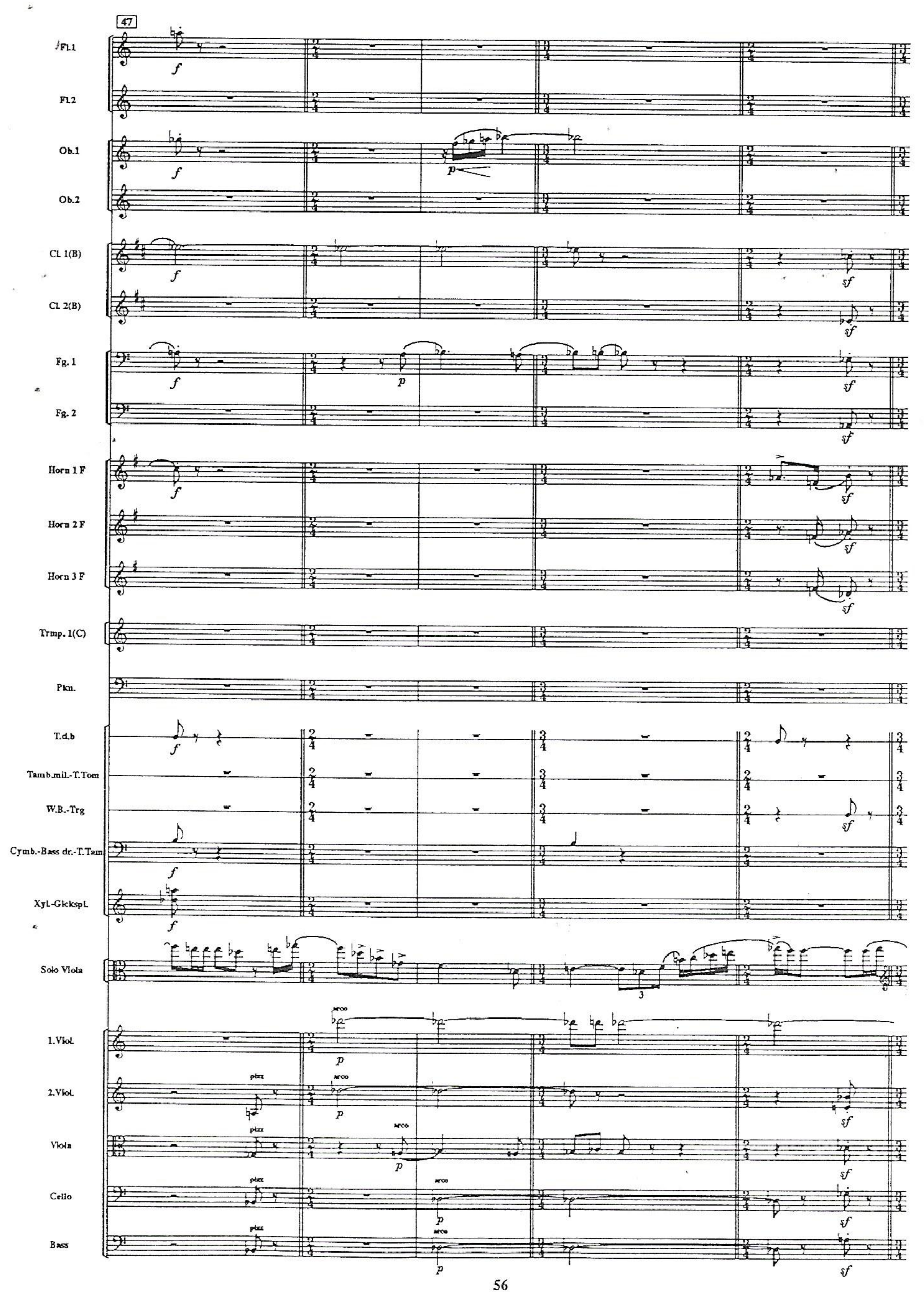




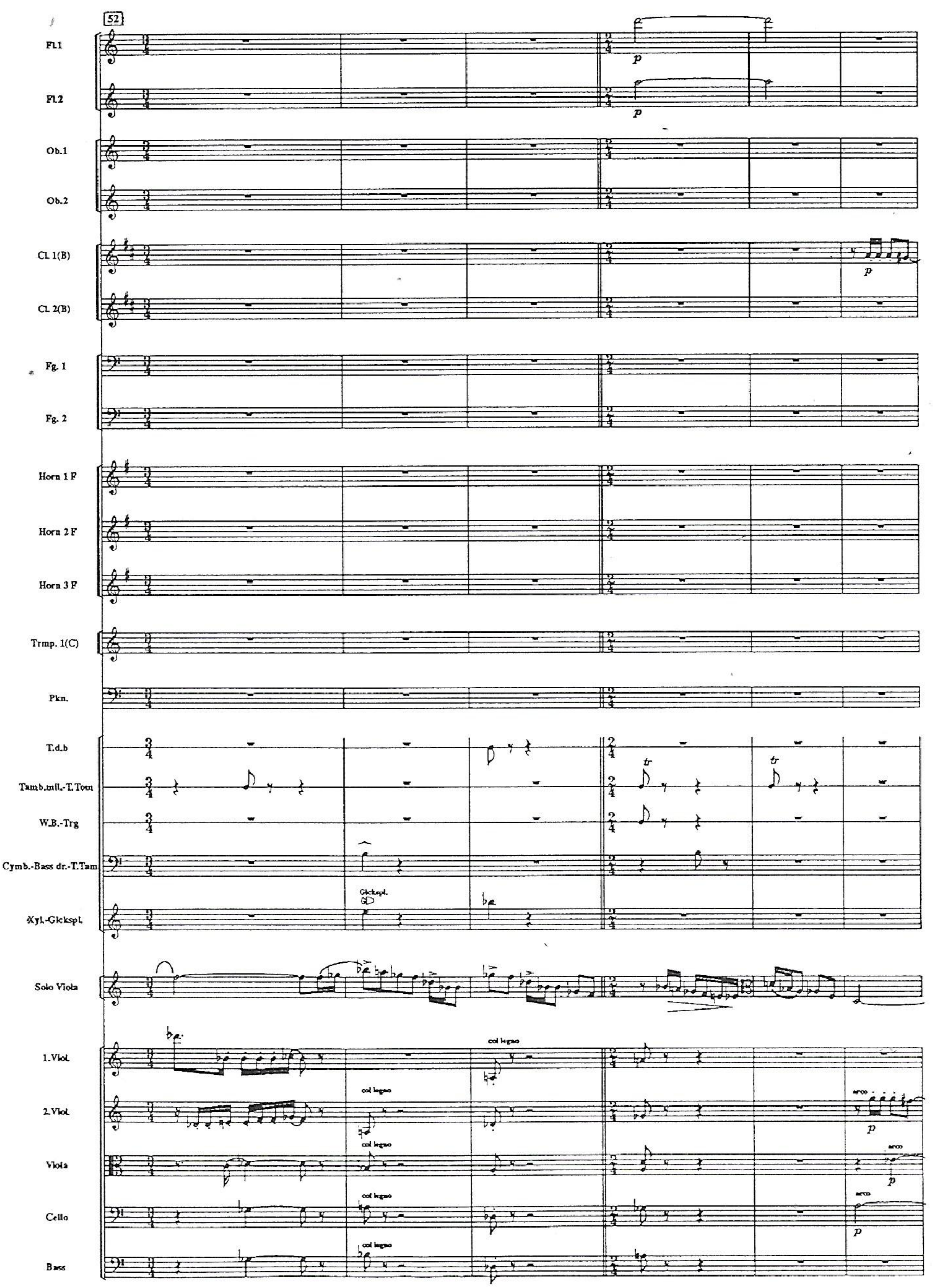




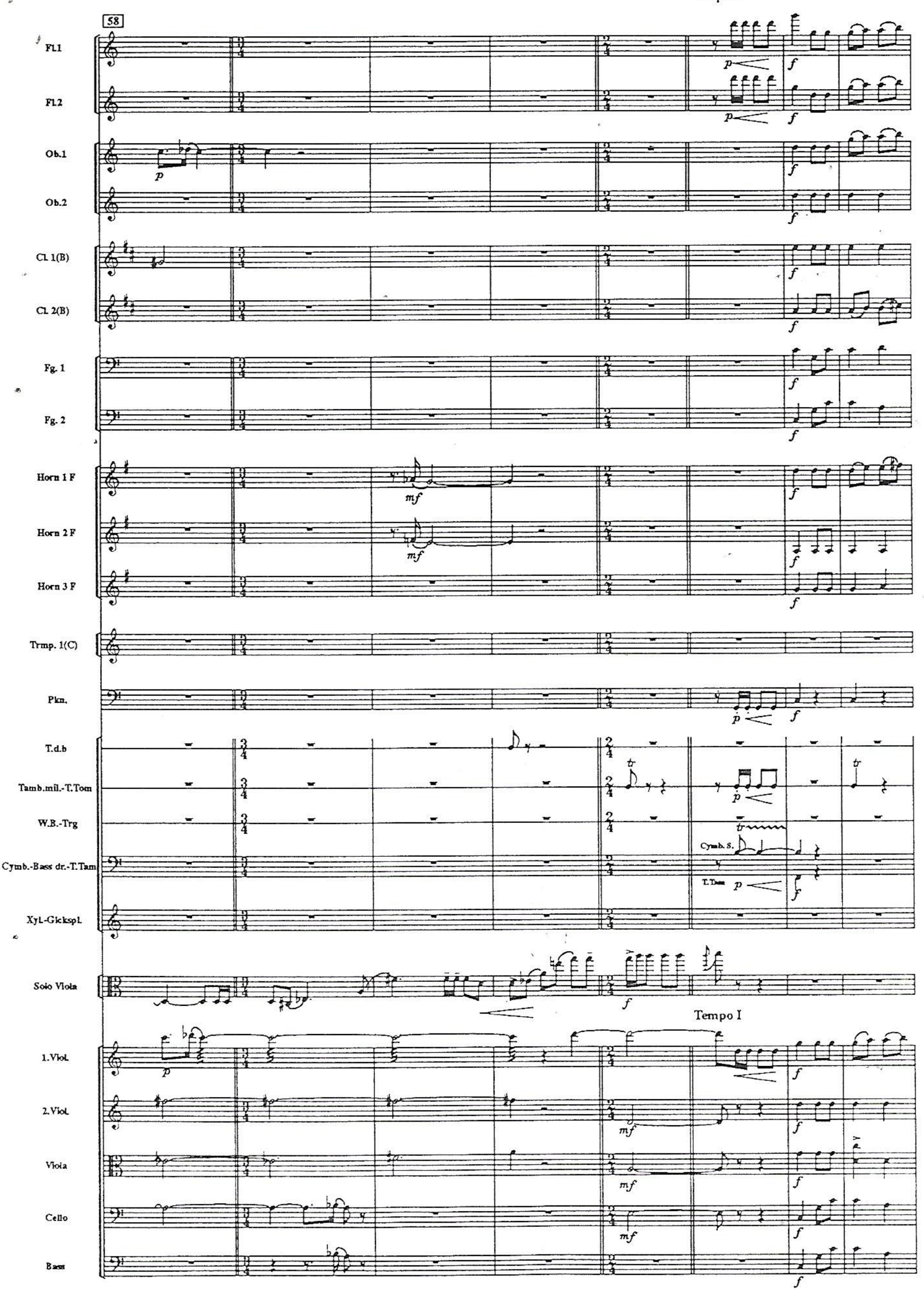




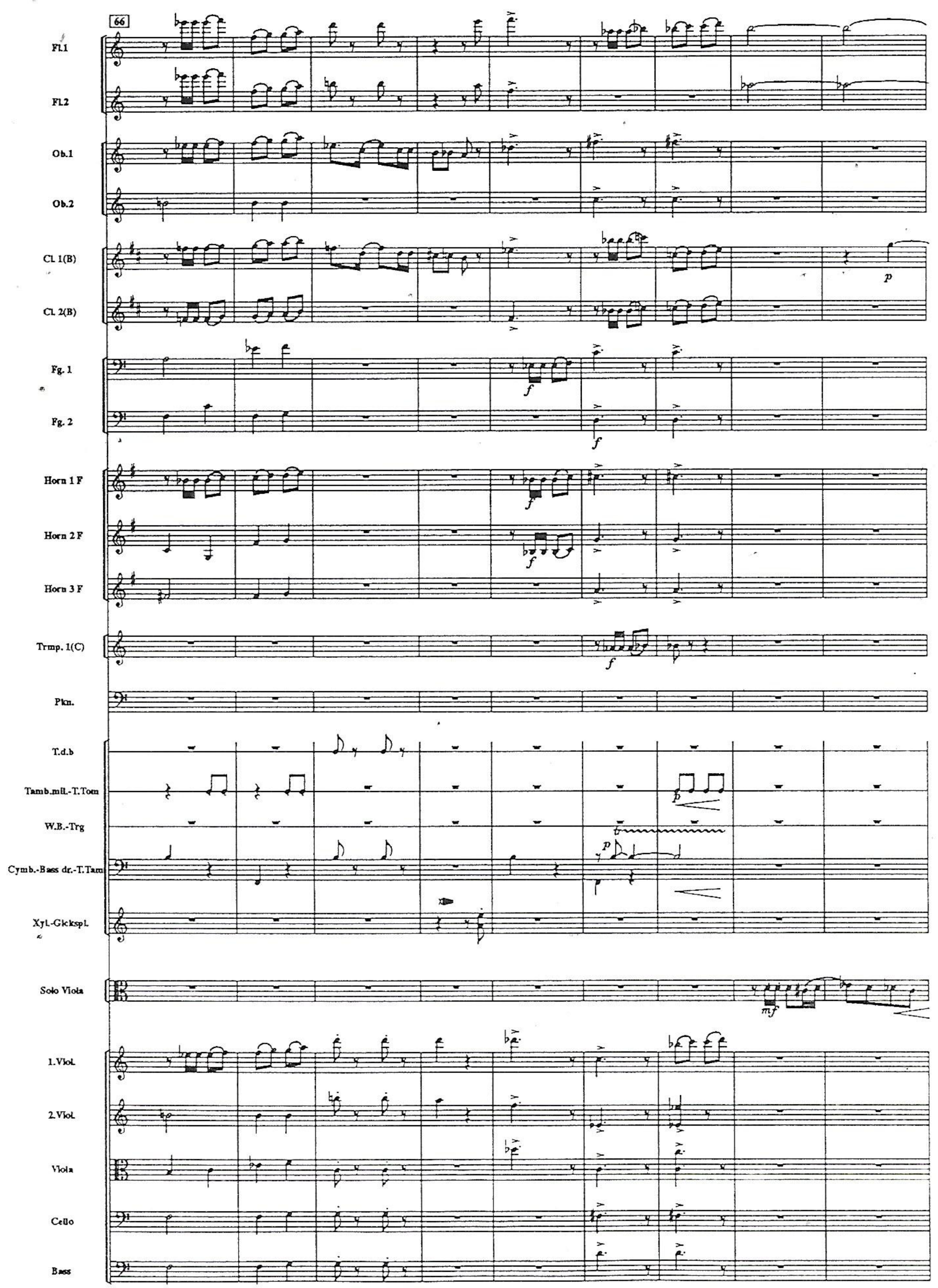




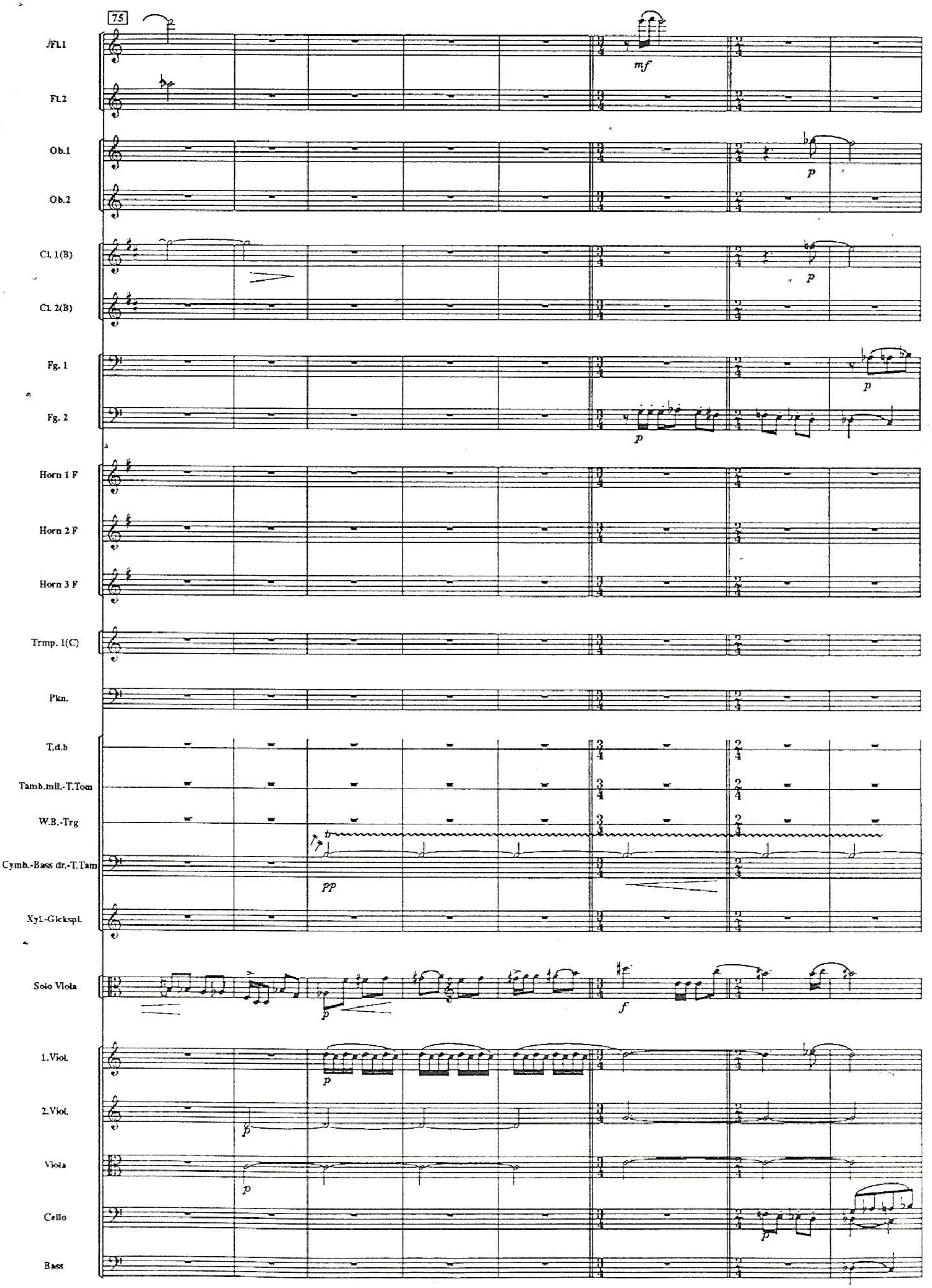




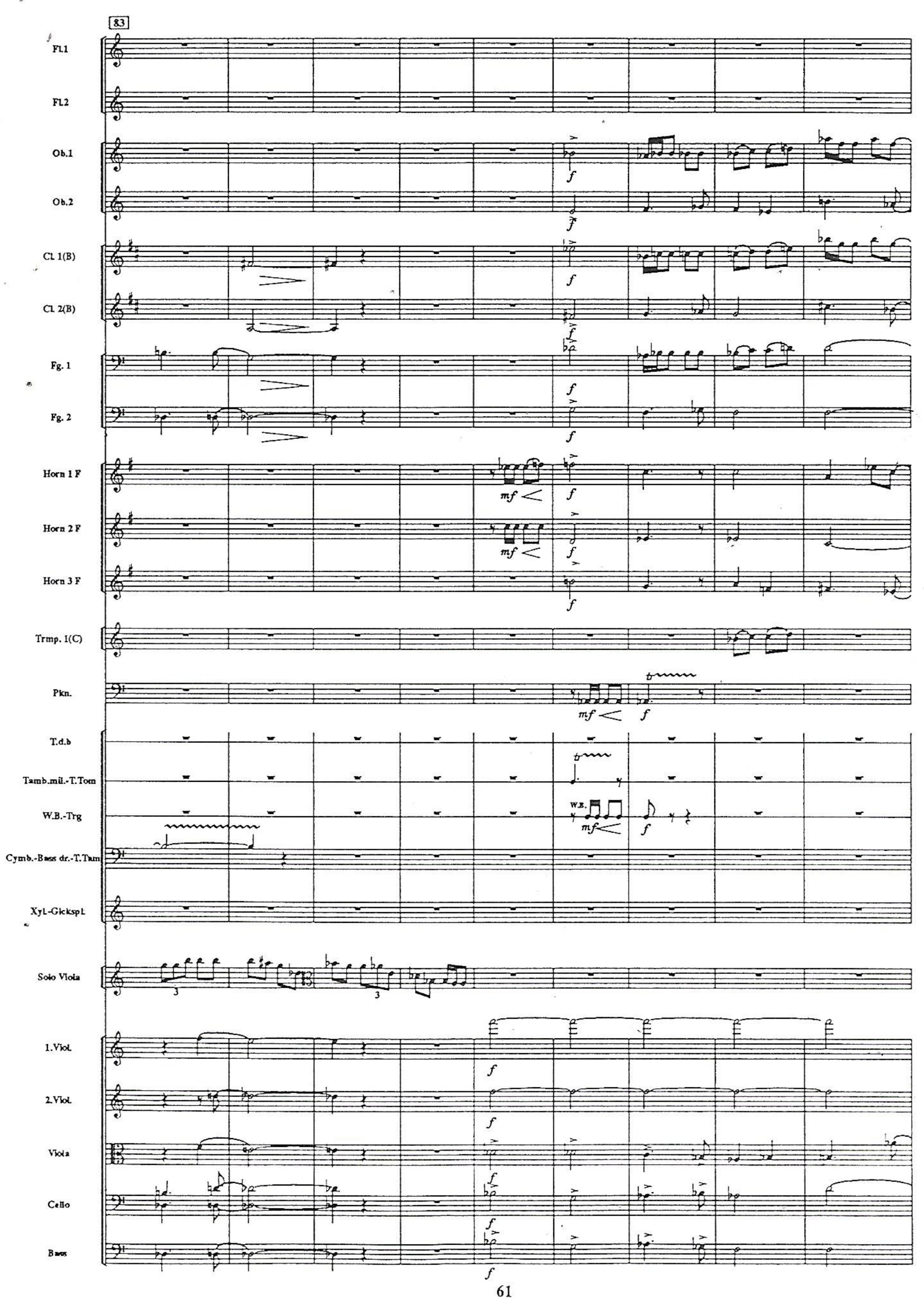




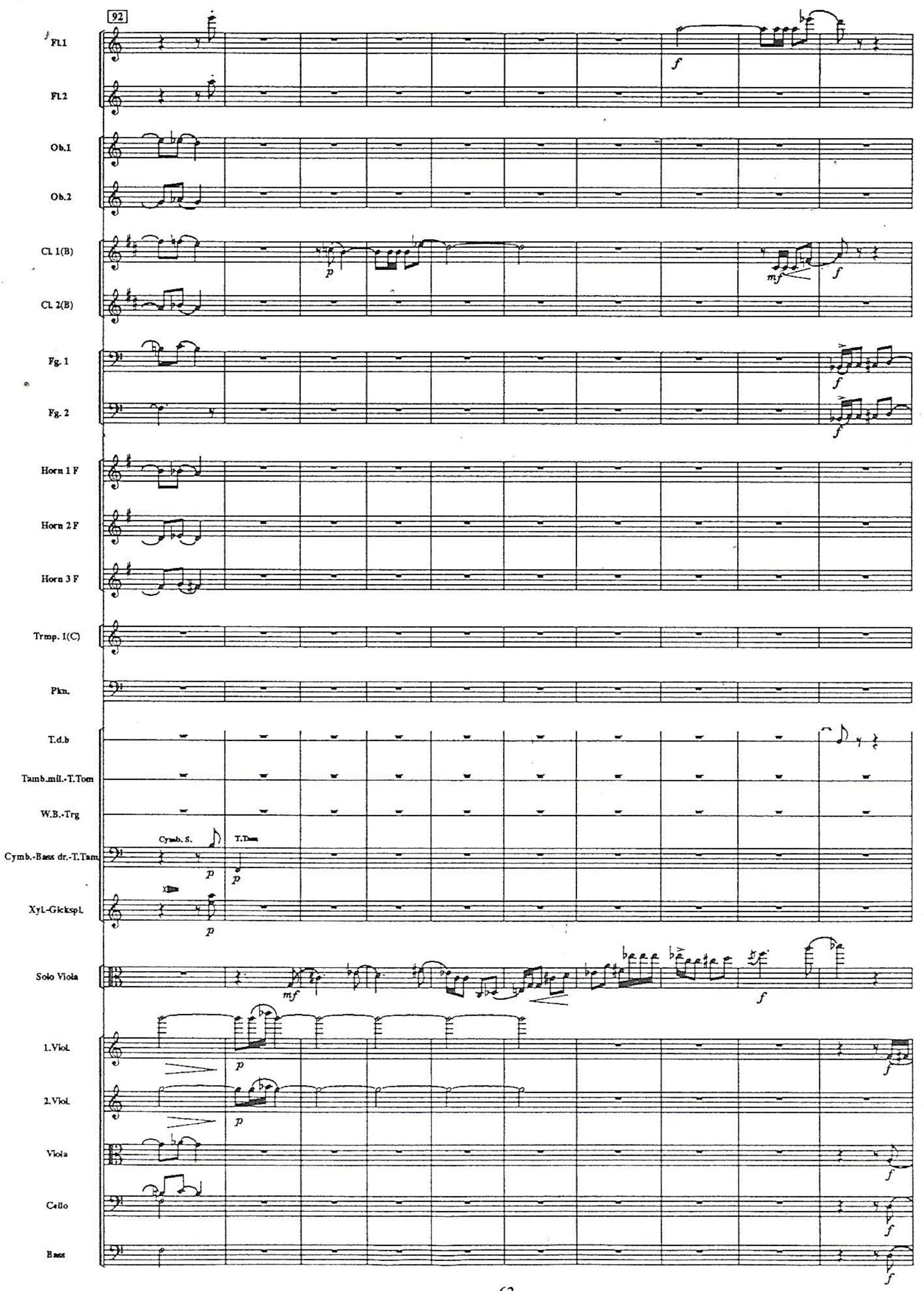




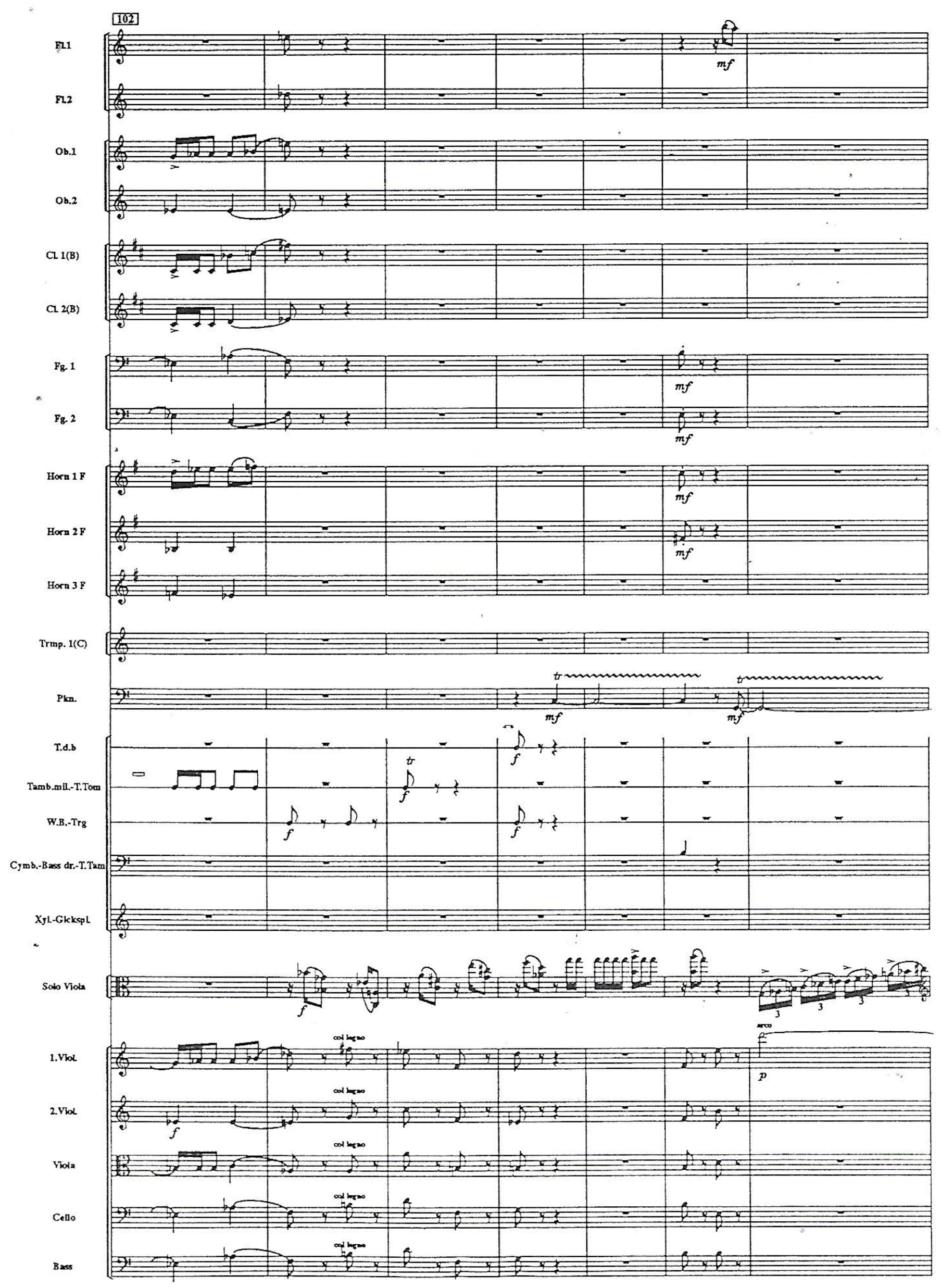



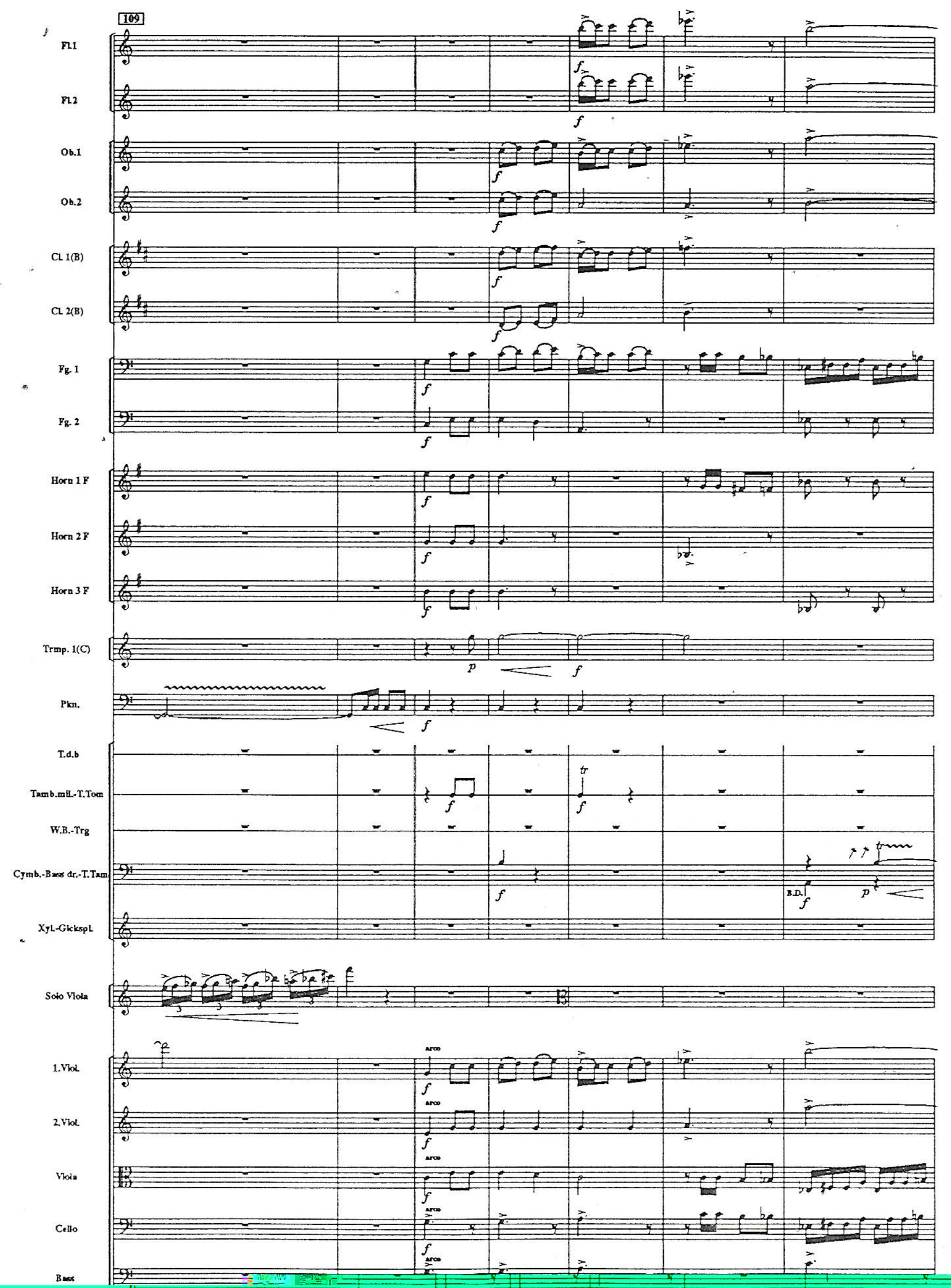


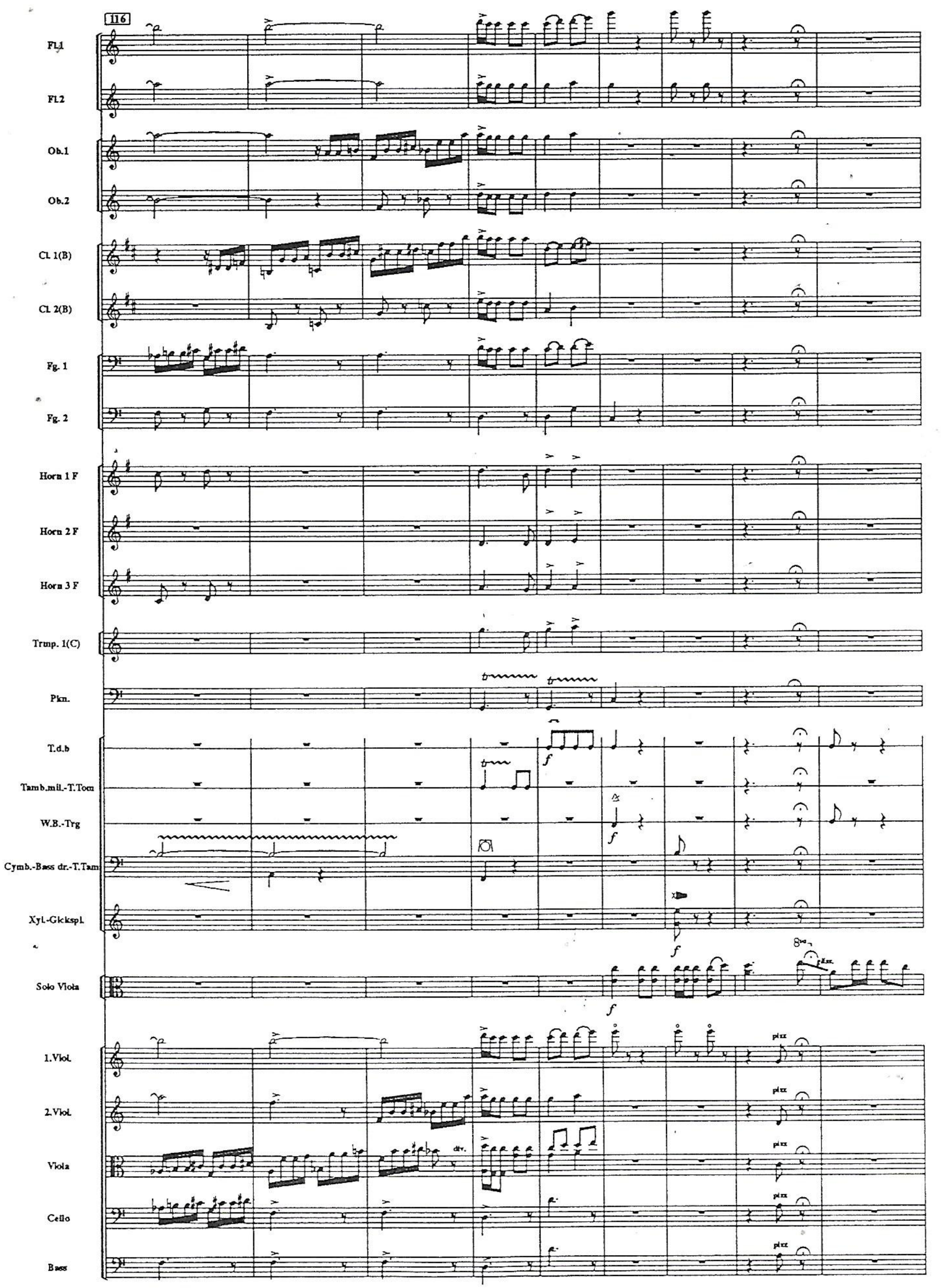




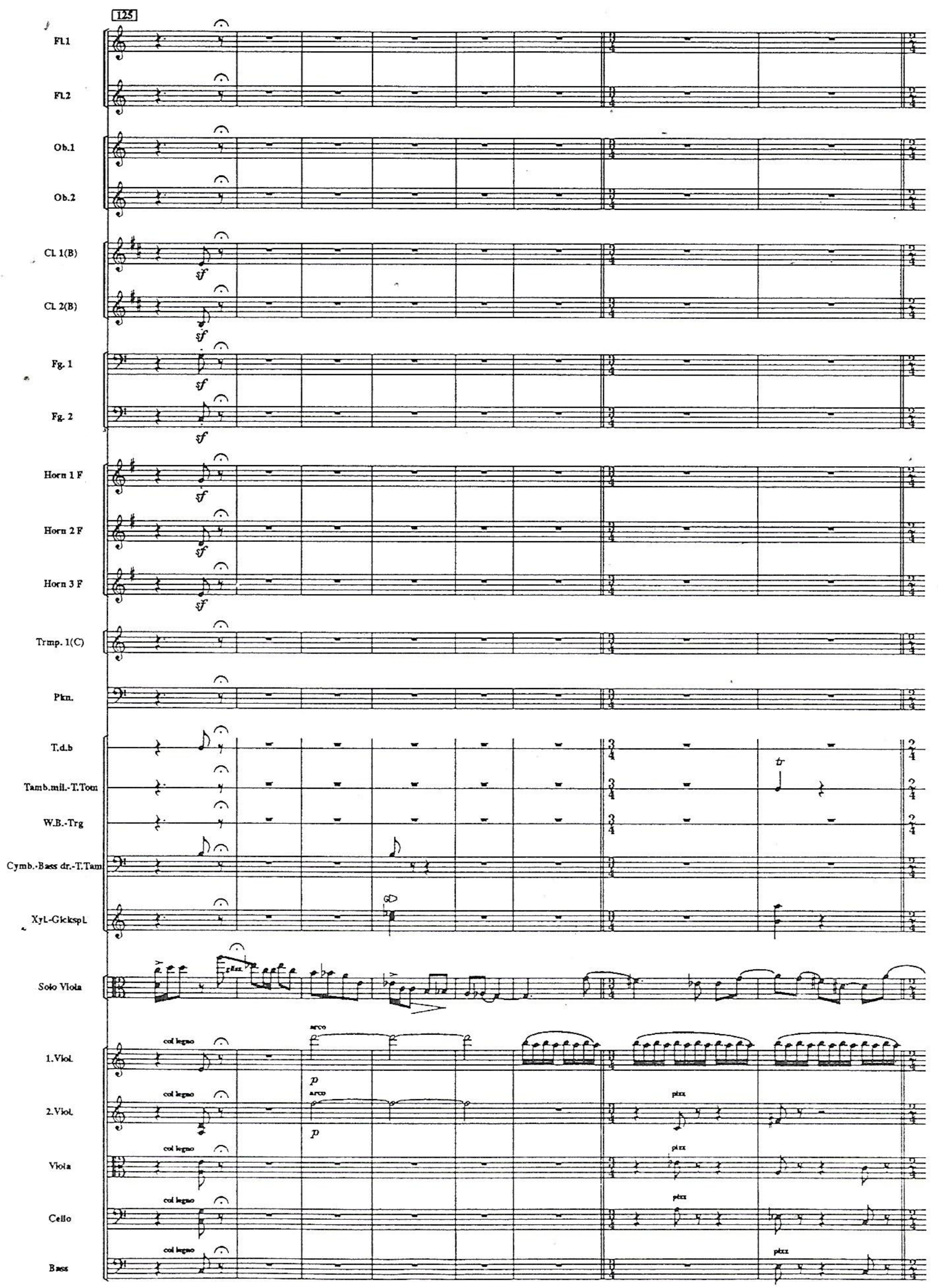



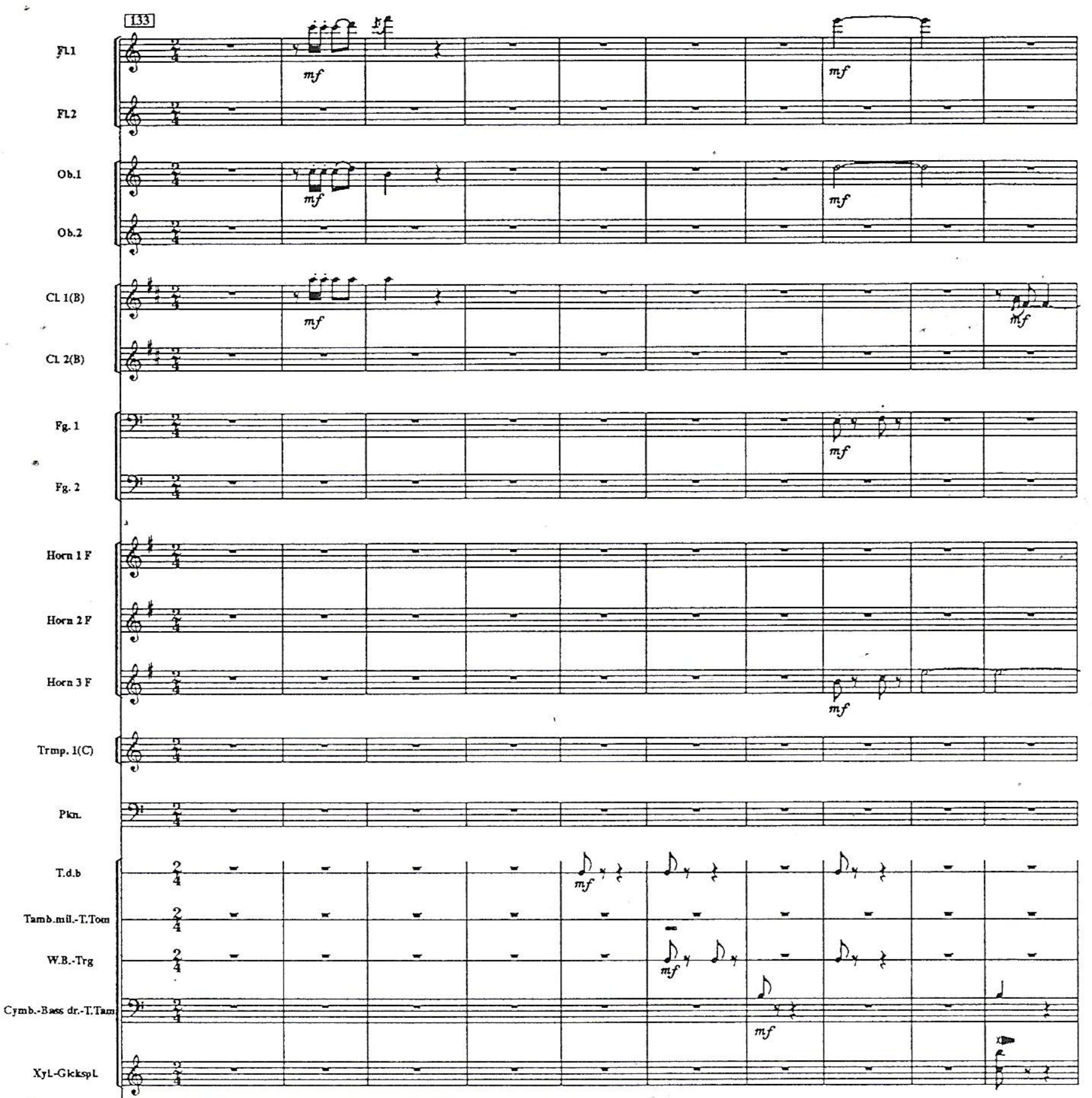

Solo Vio

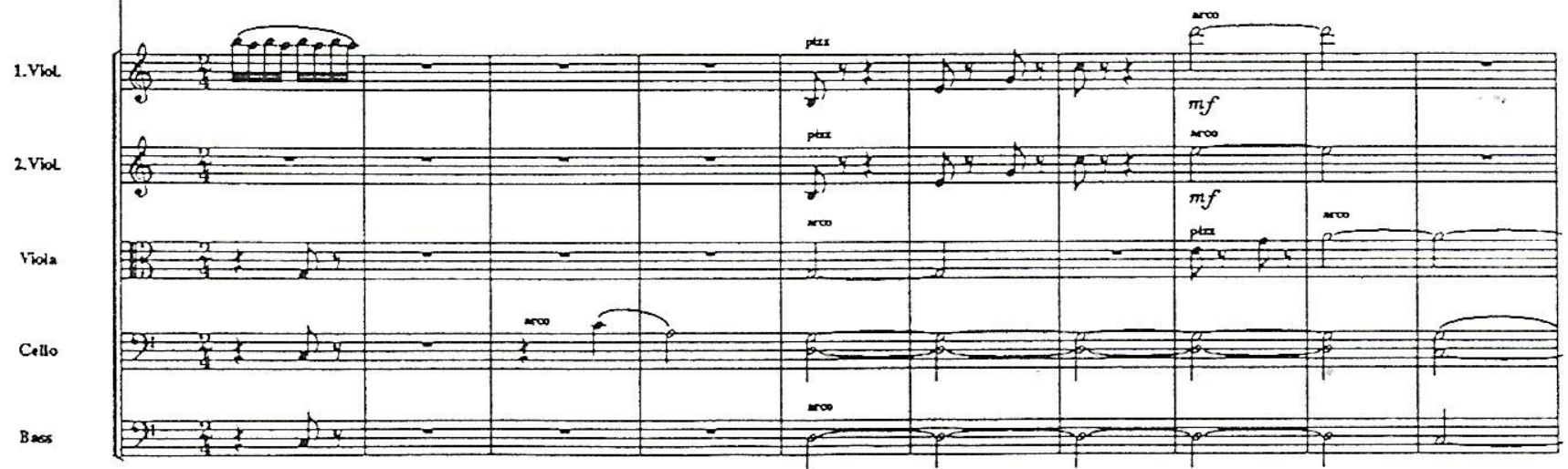




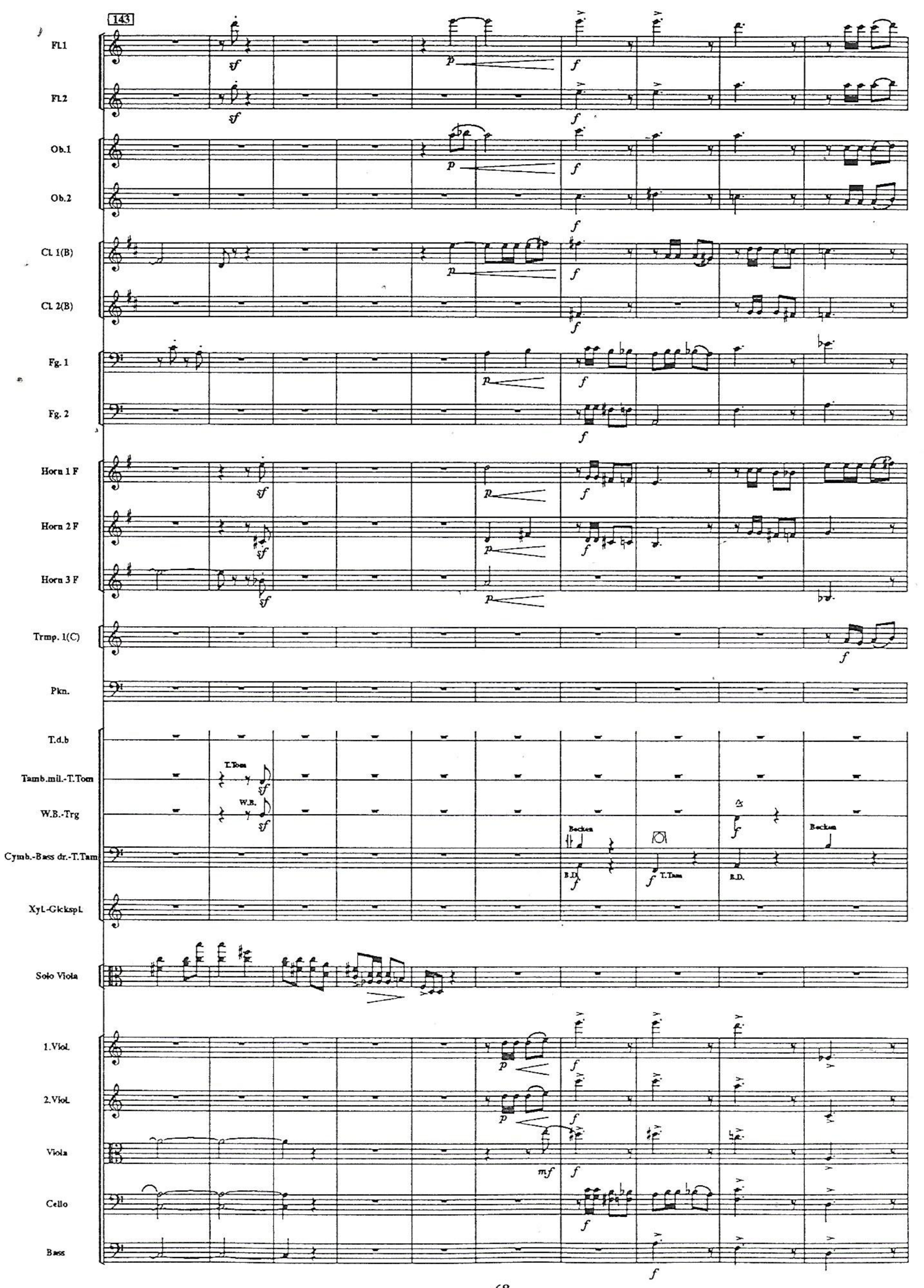




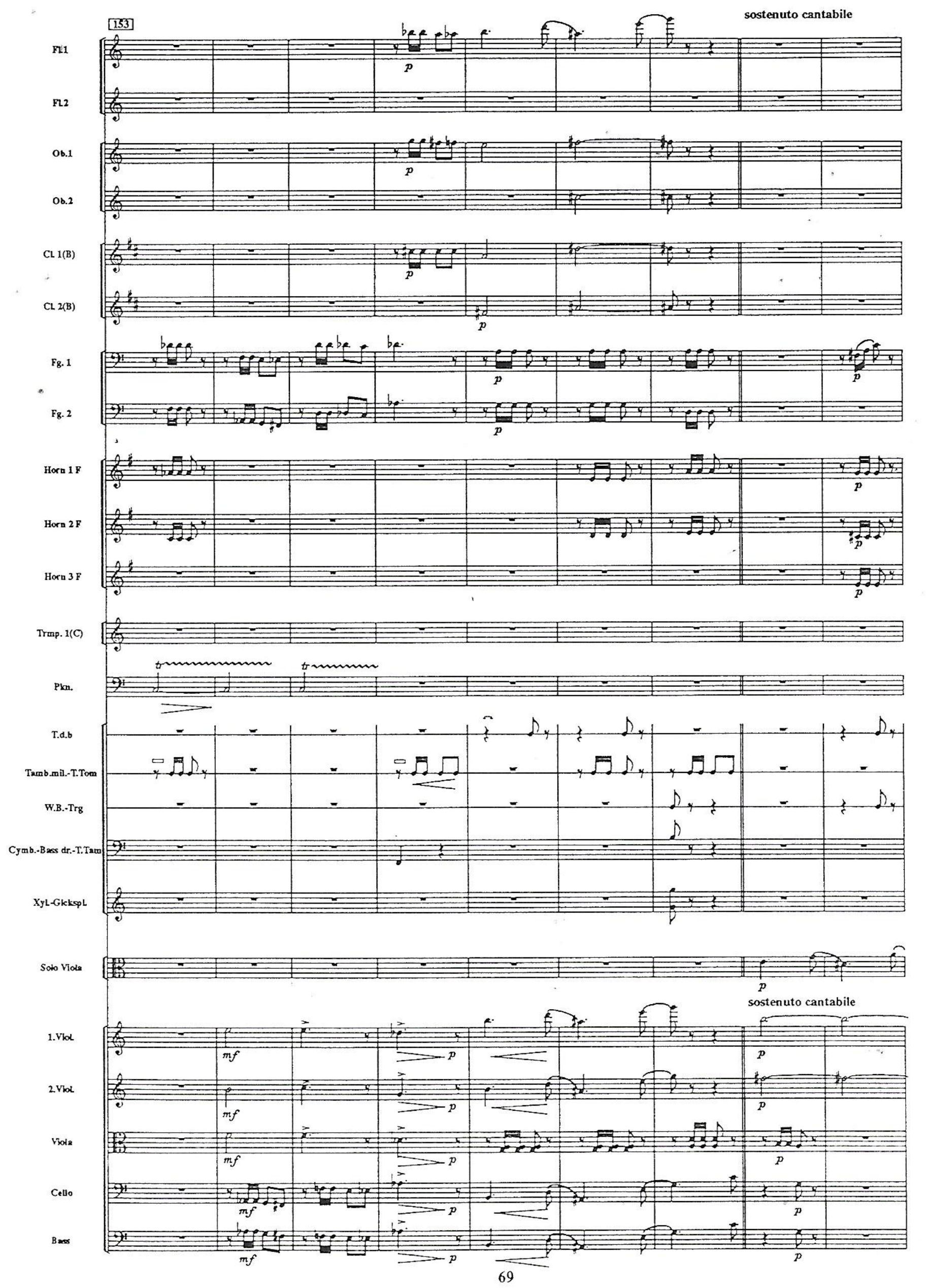




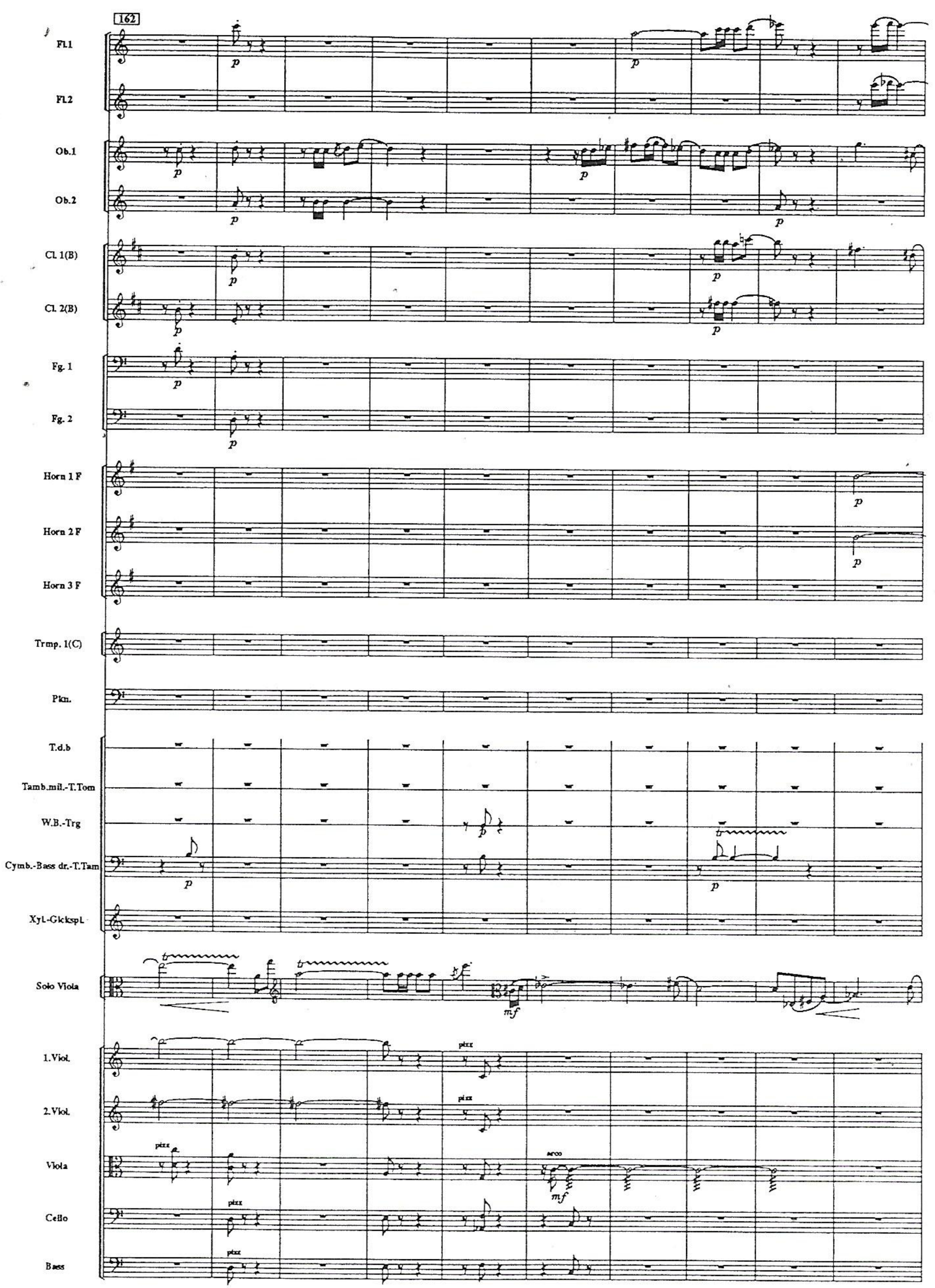




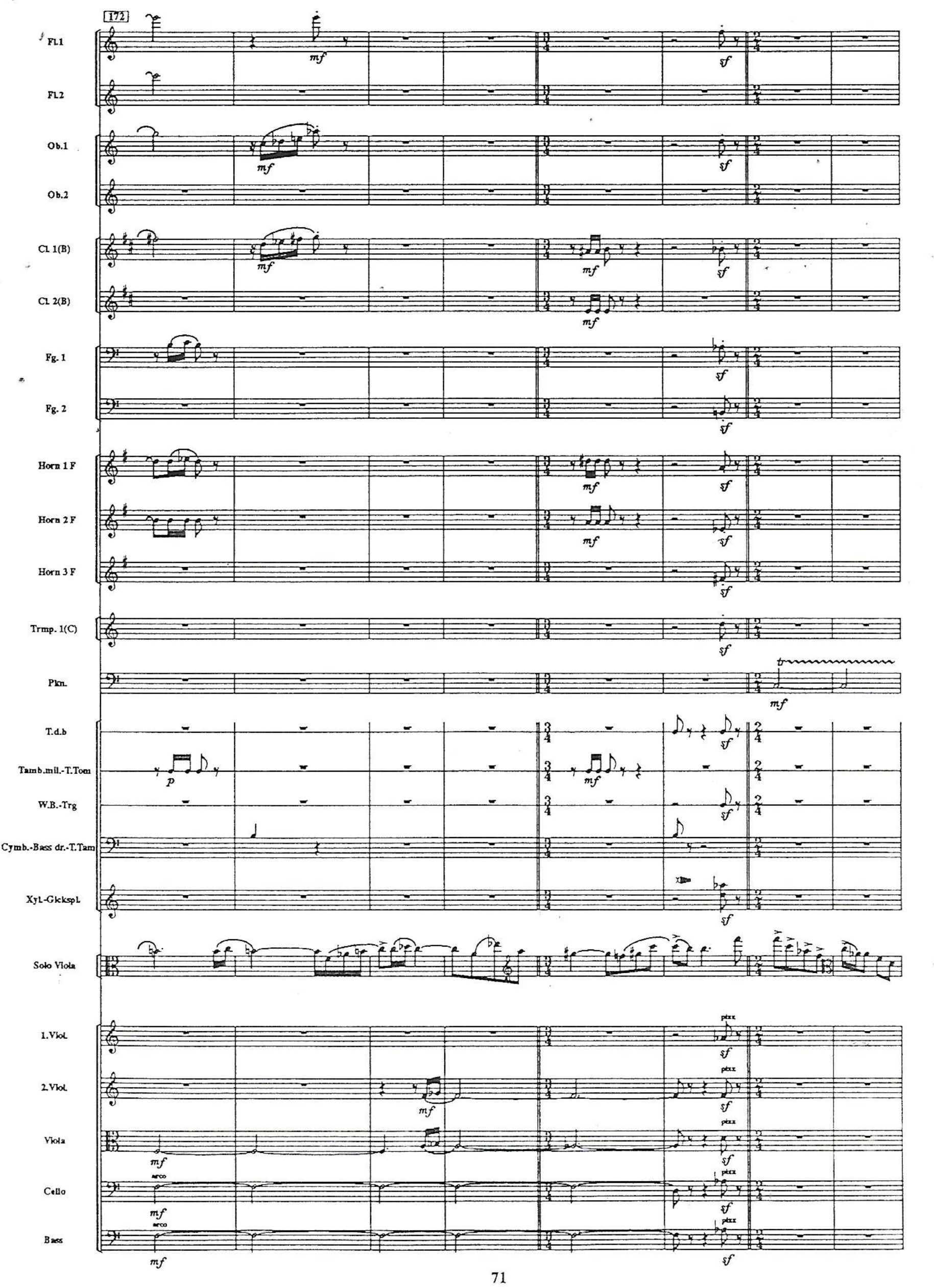




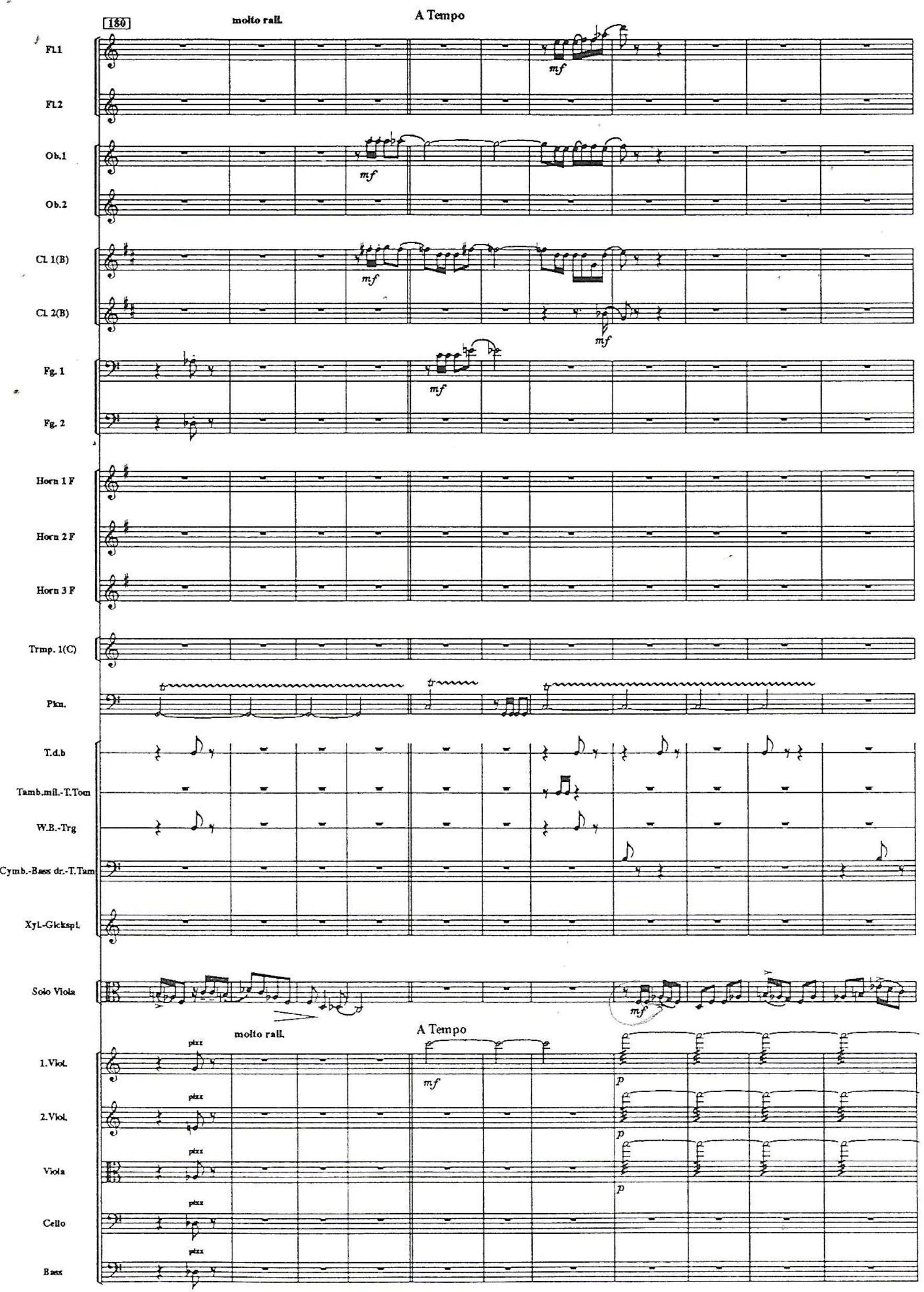




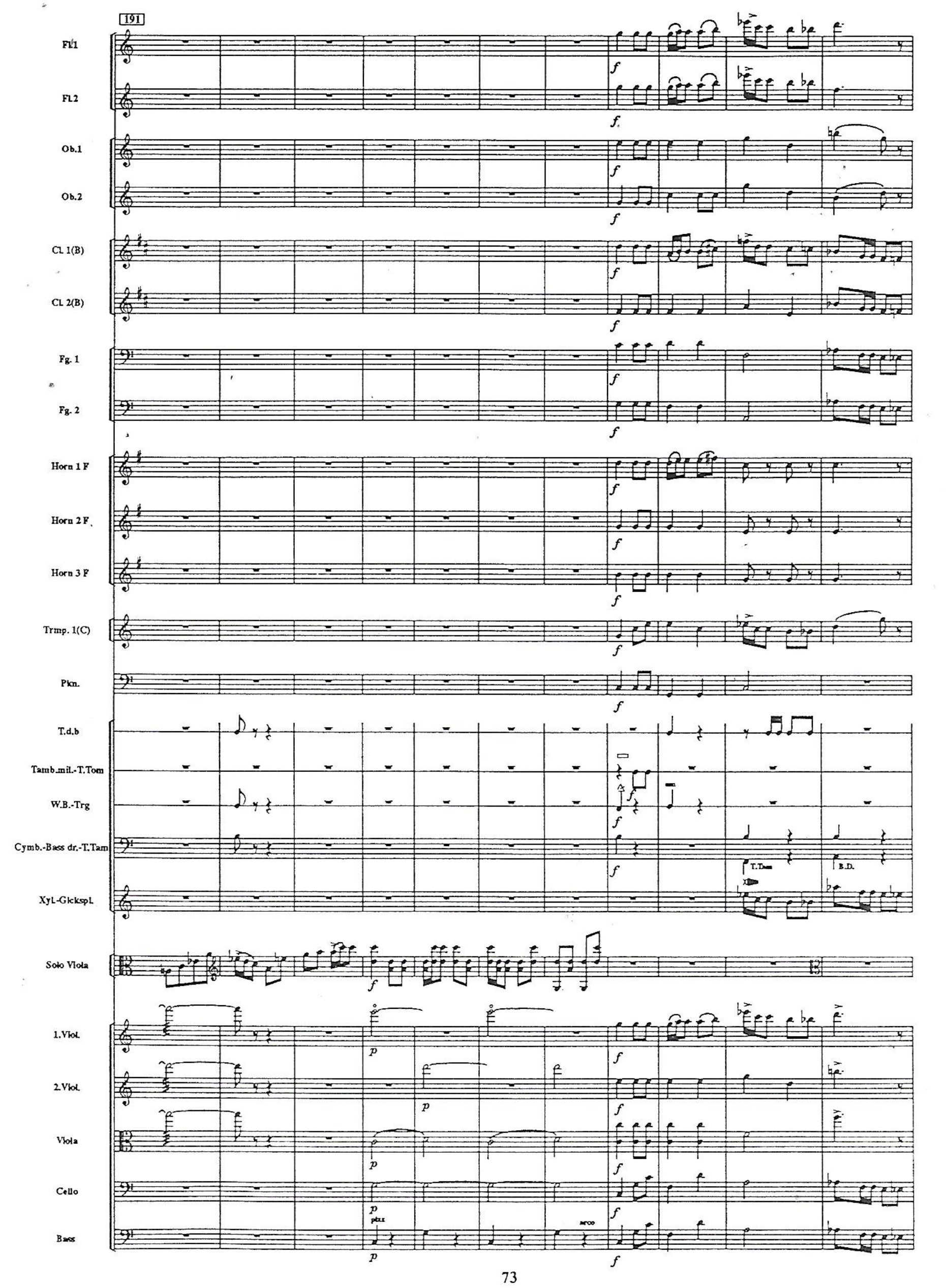




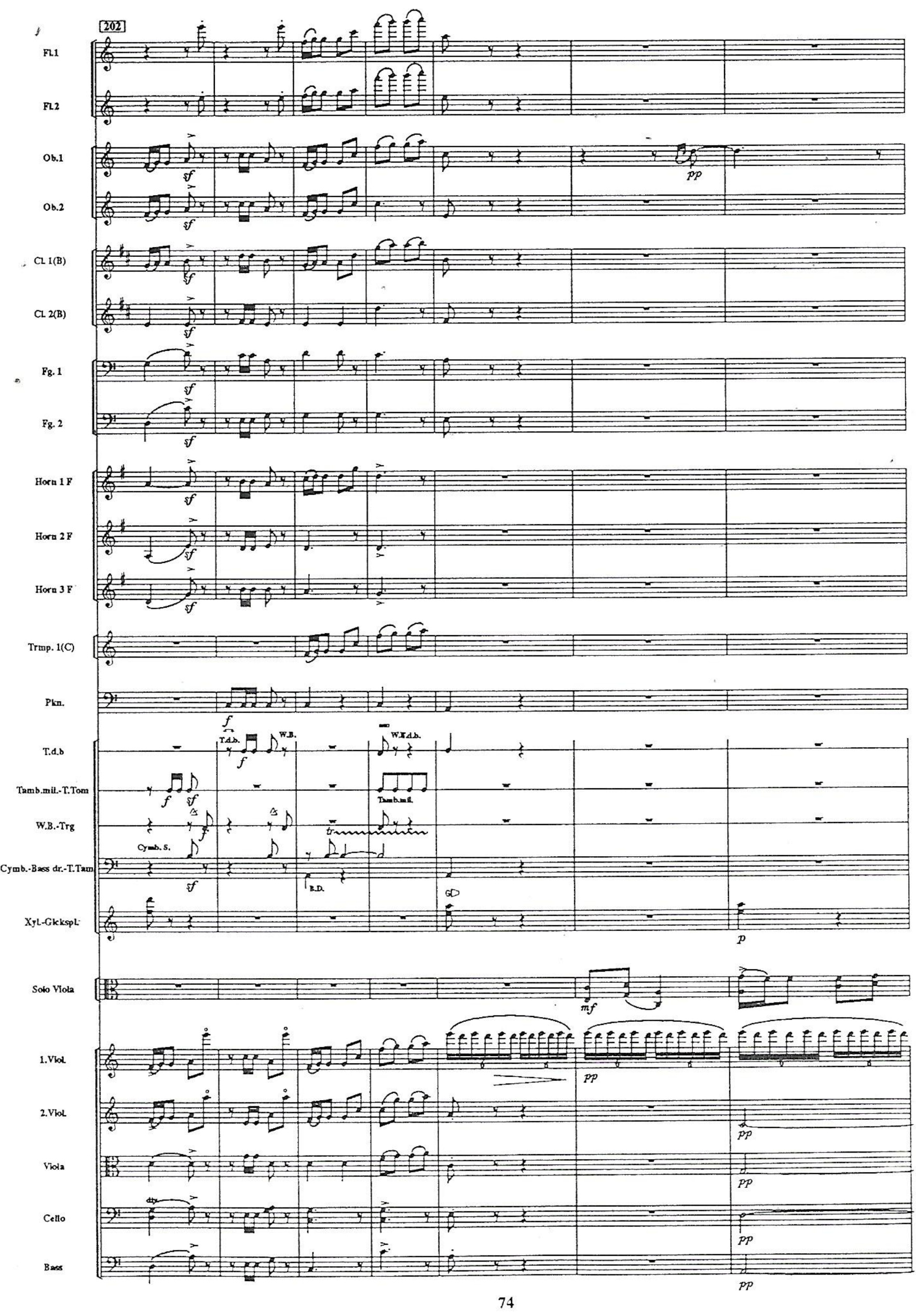




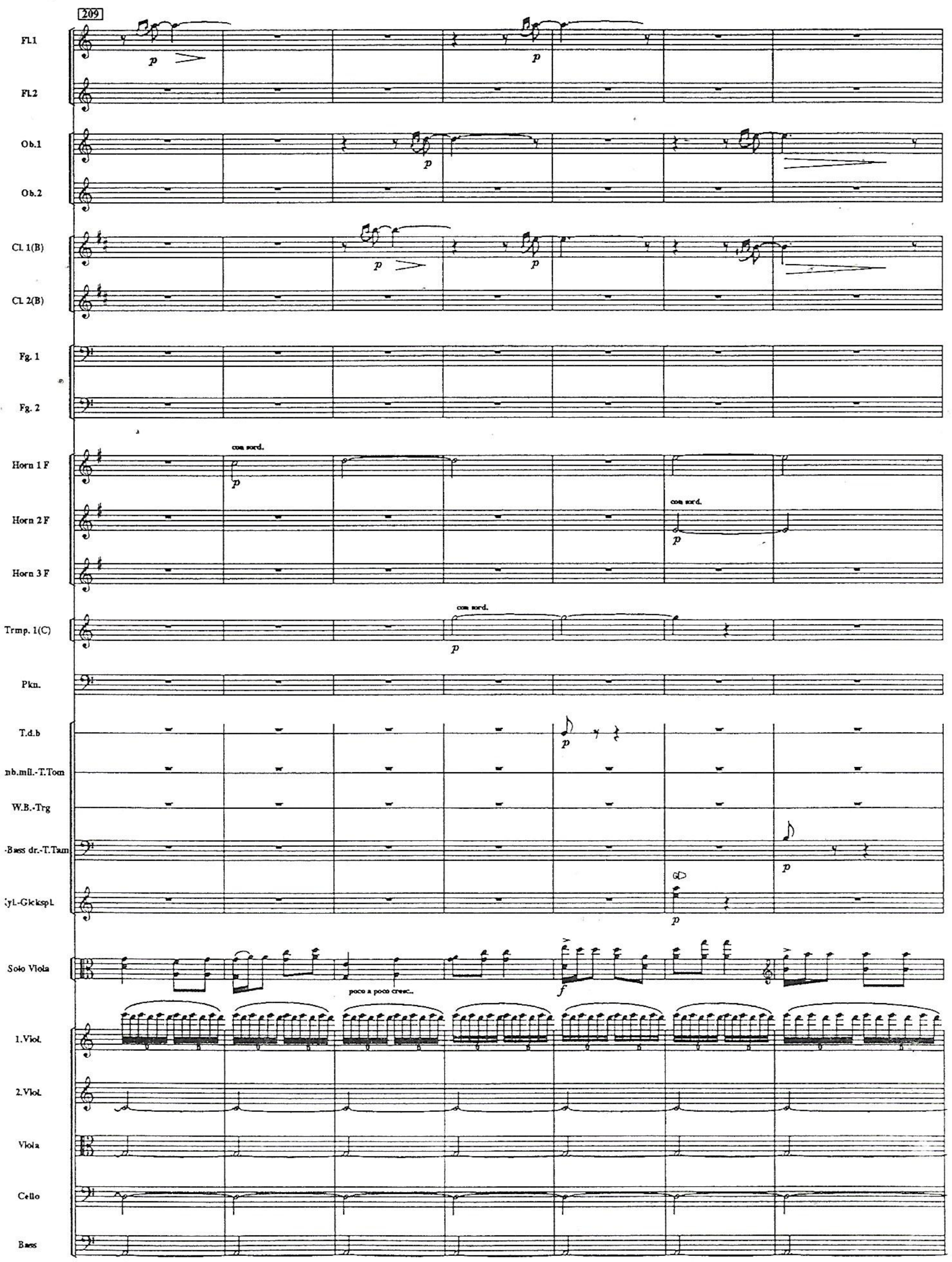



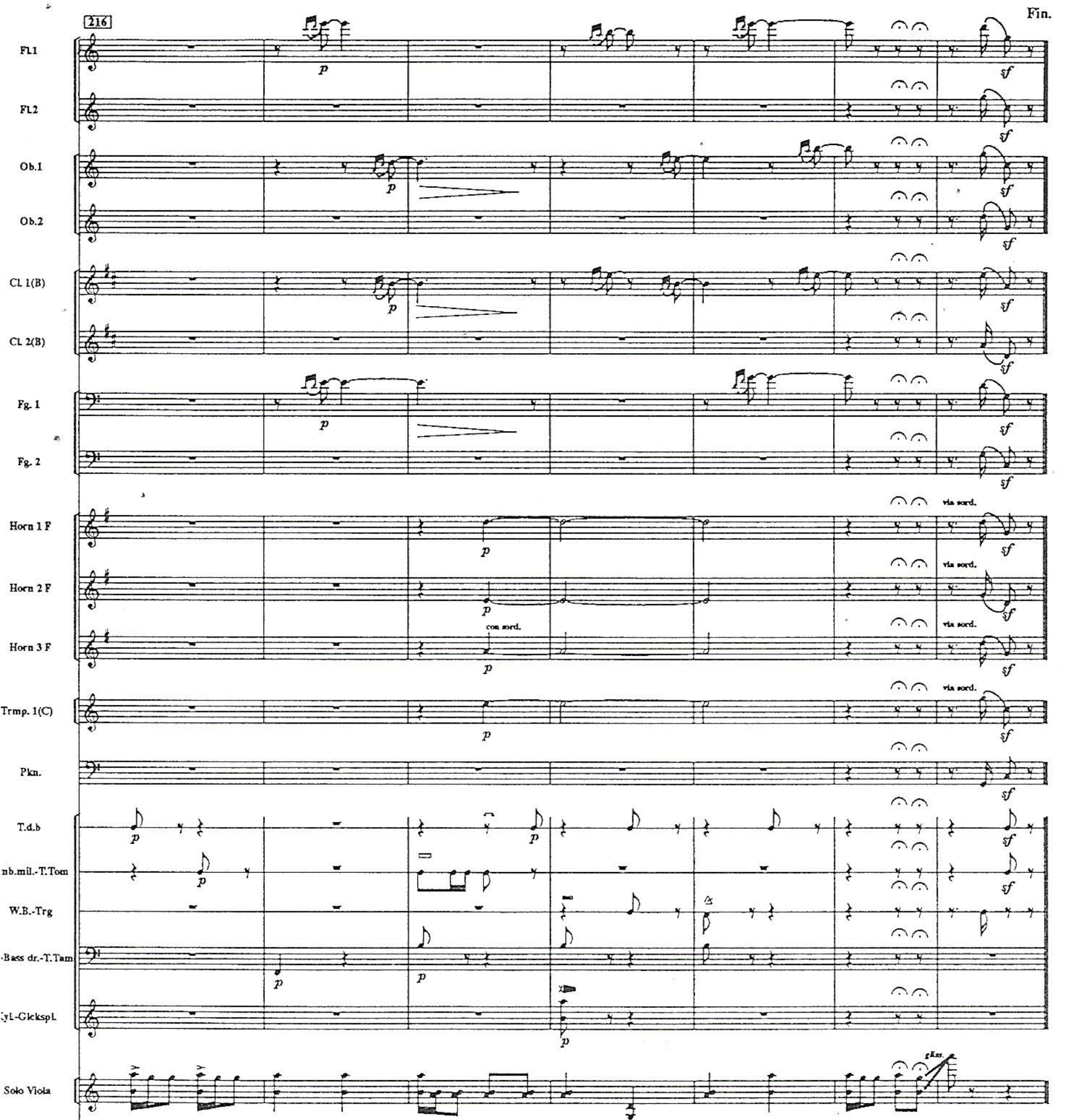
CONCERTO FOR VIOLA AND ORCHESTRA

Solo Viola Moderato $\quad d=70$

$\triangle . \triangle \mathrm{PAГАTAKH} \Sigma$

(poco sost.)

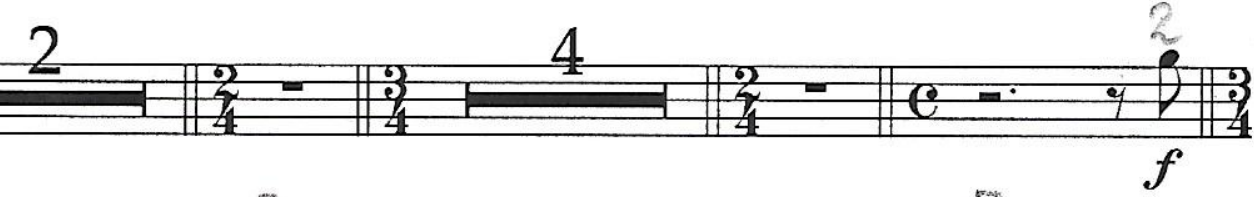

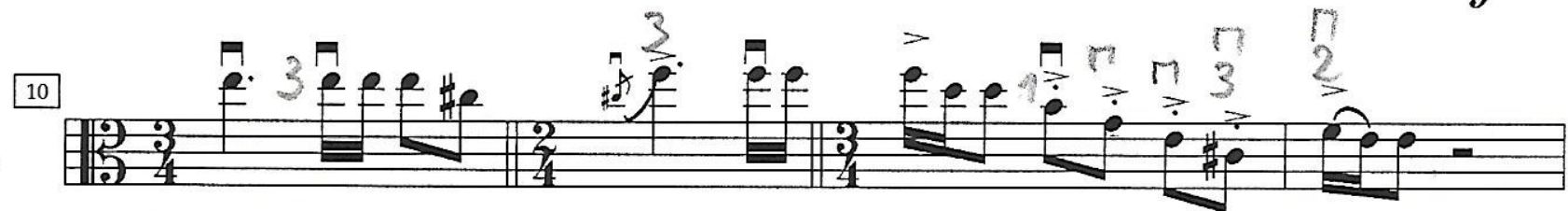

14

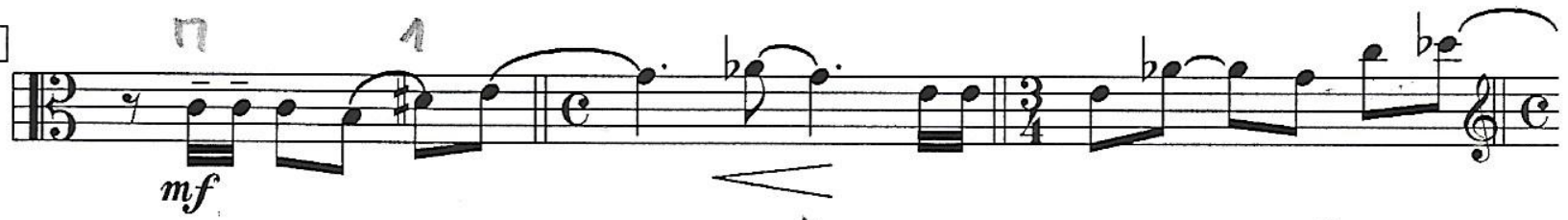

17 $0_{0}^{2} e^{2}$ 20

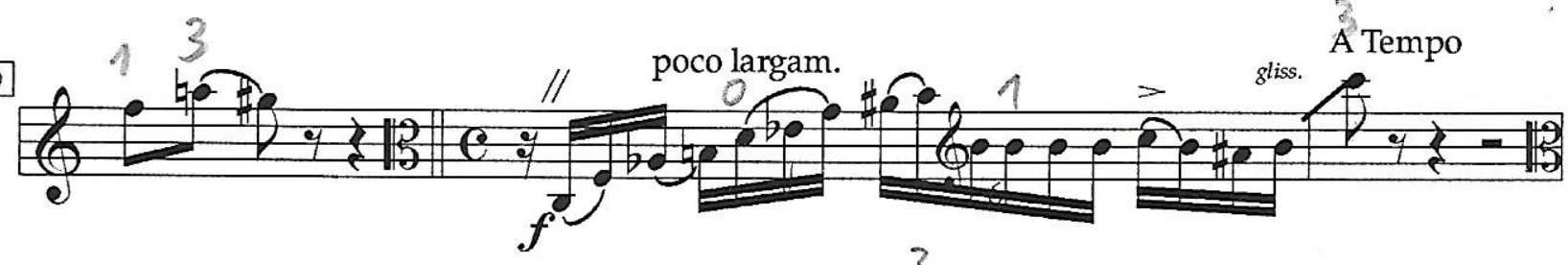
23 // poco largam.

27. (1)

30

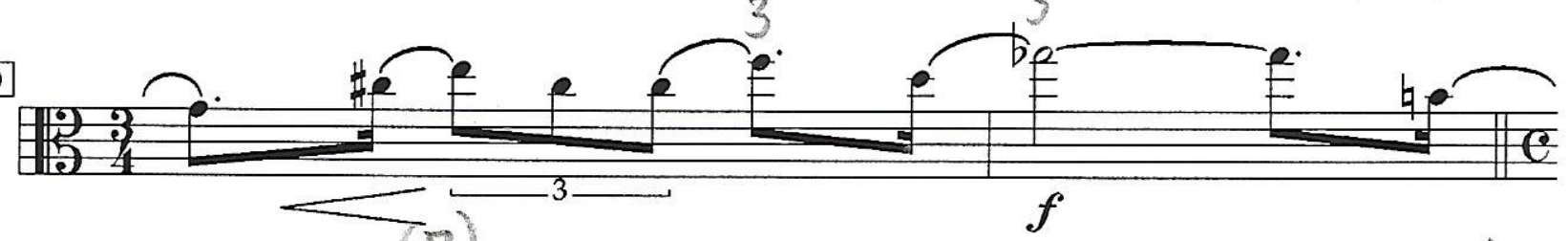

32

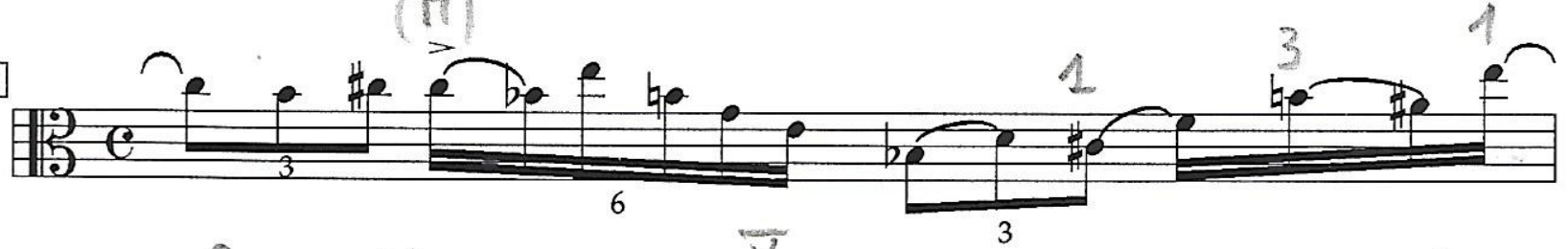

33

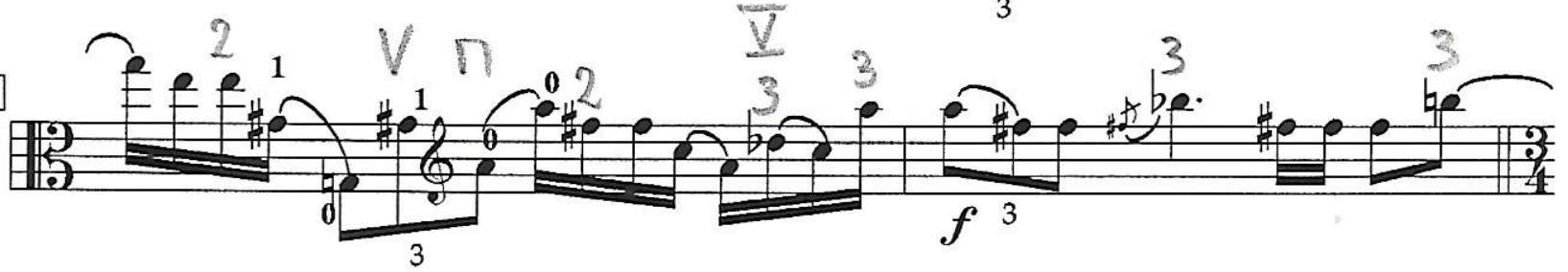


35

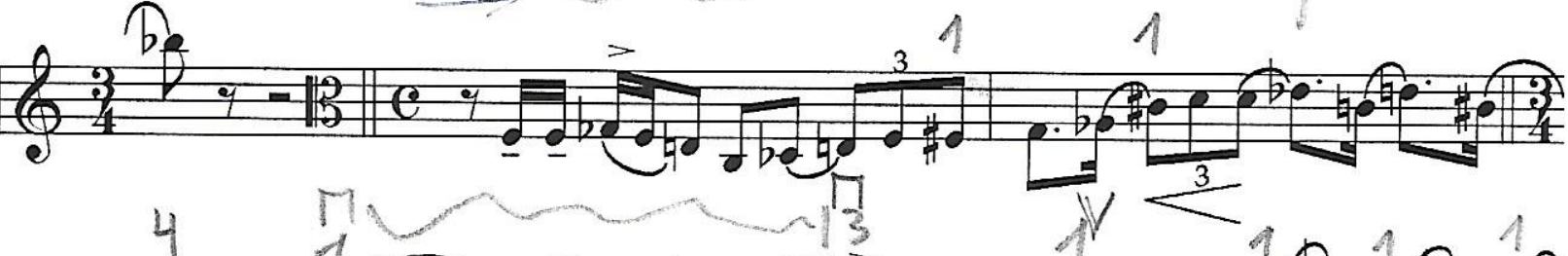

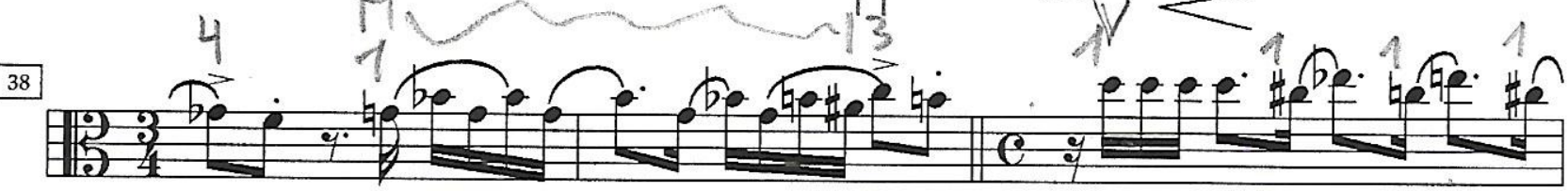

41

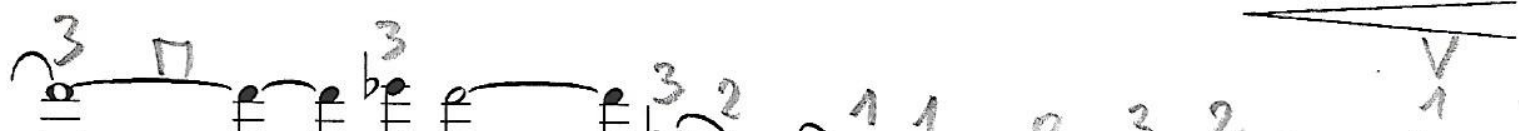

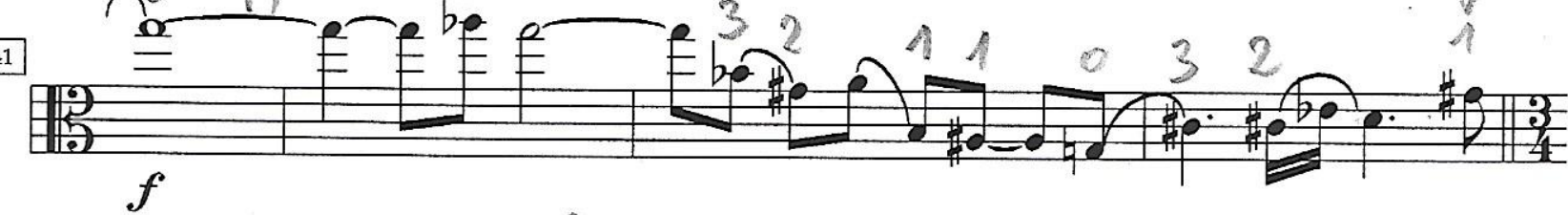

45

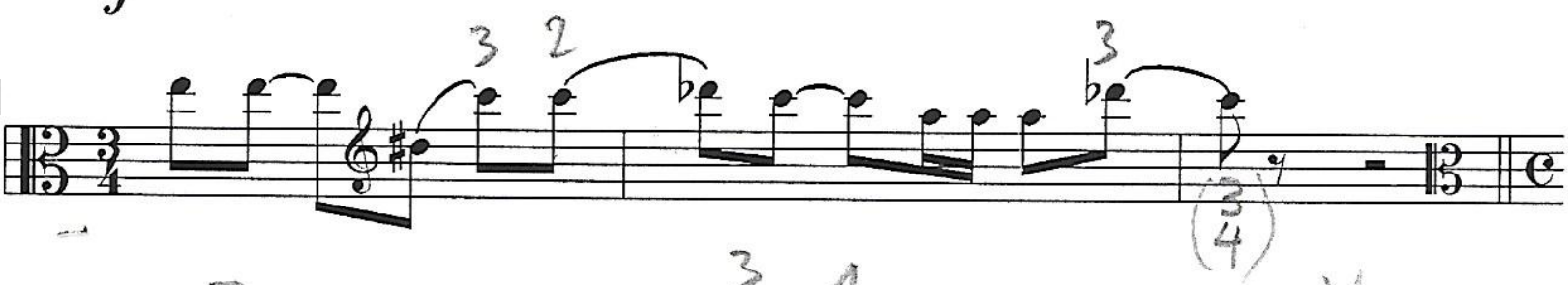

48

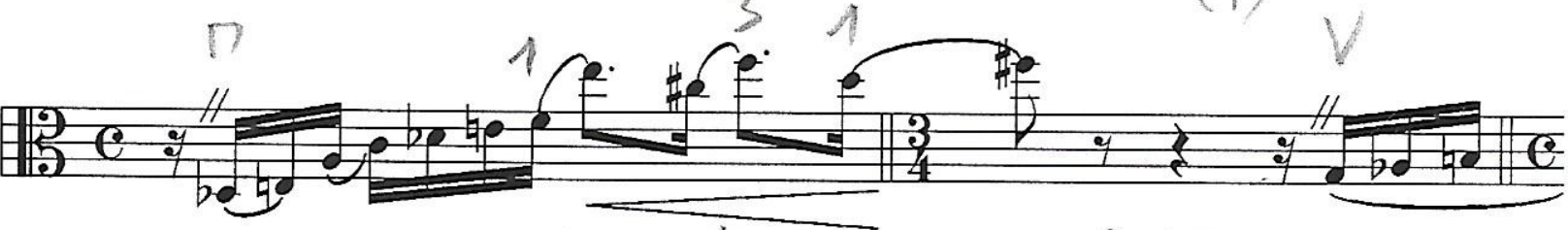

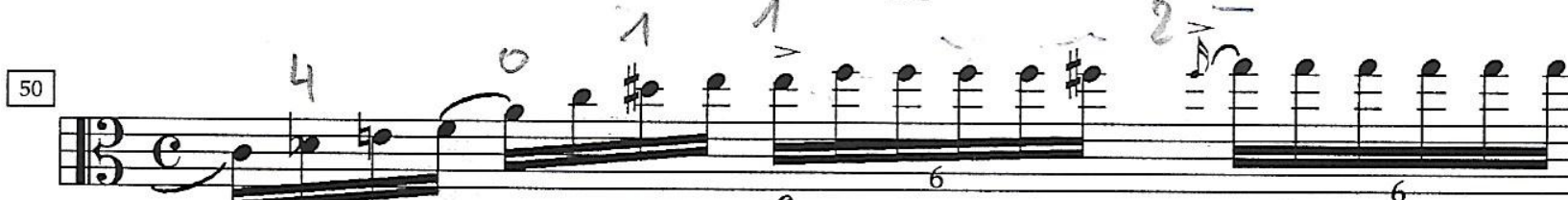

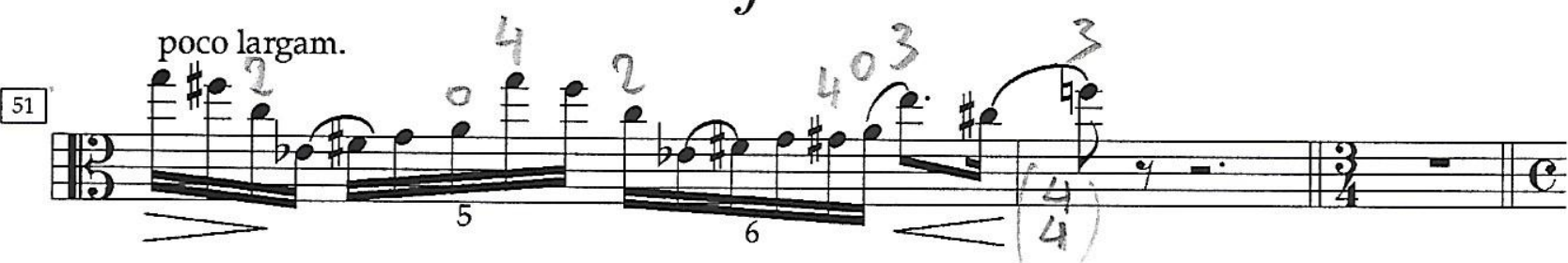

-

n

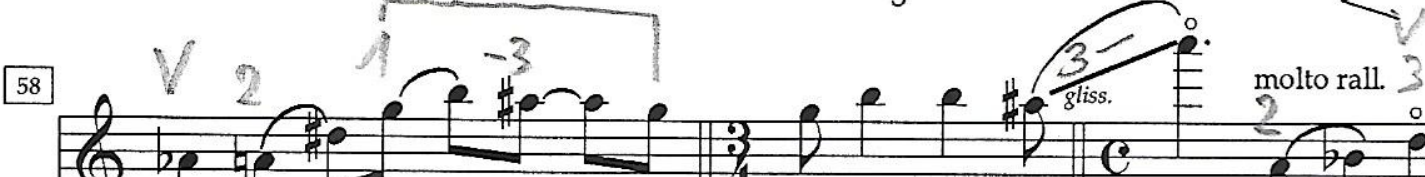

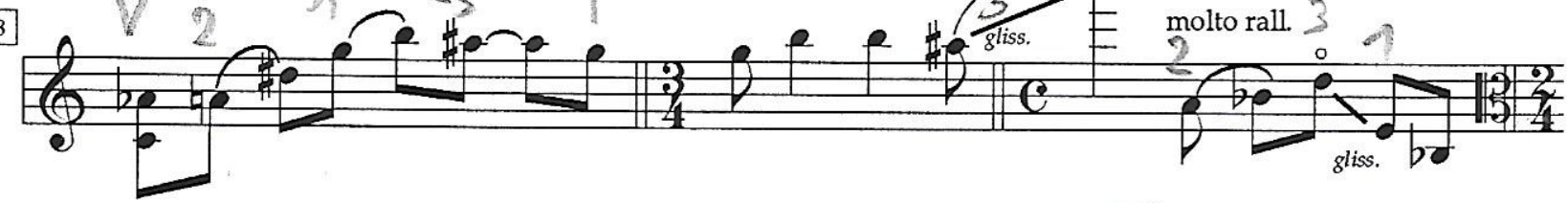

61

A Tempo !

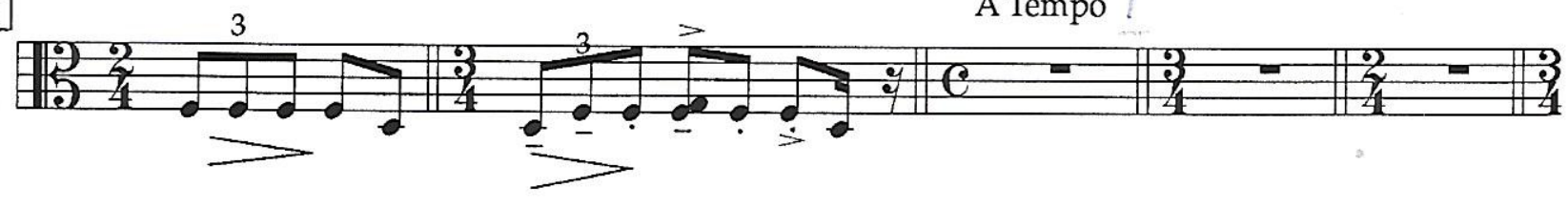


66

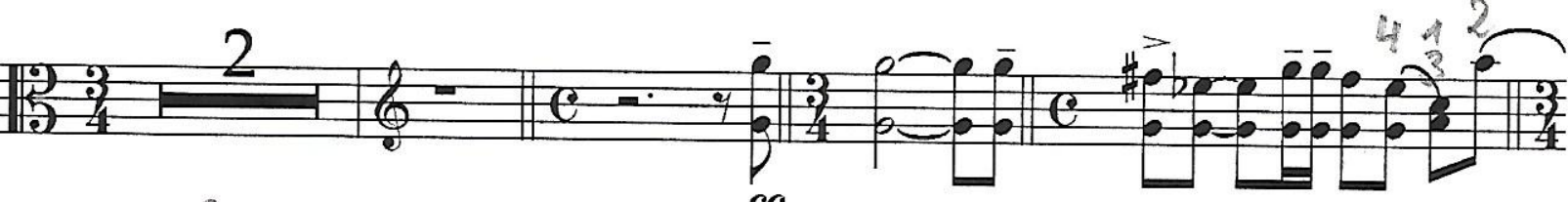

72

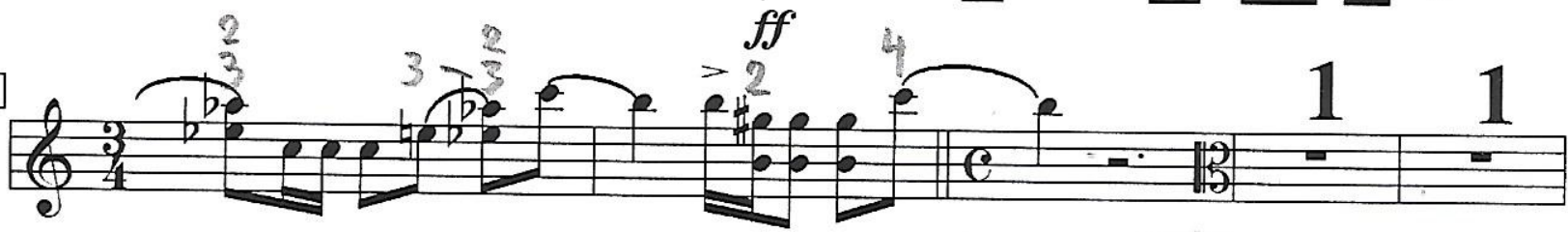

77

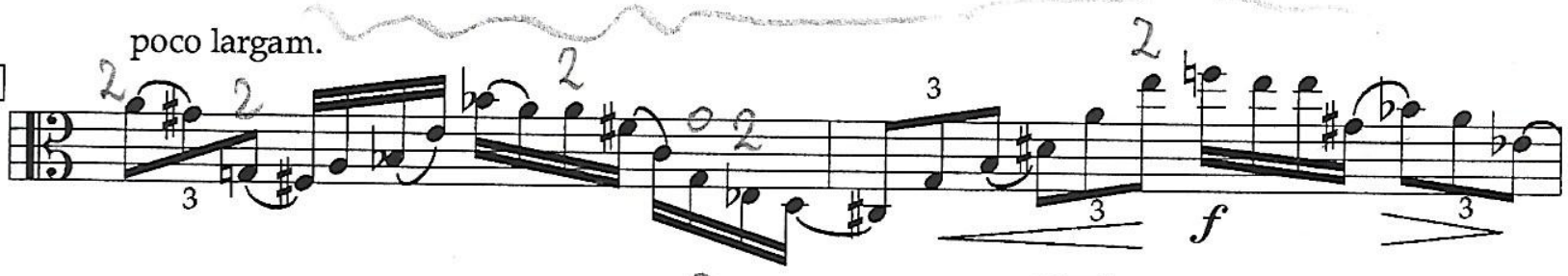

79

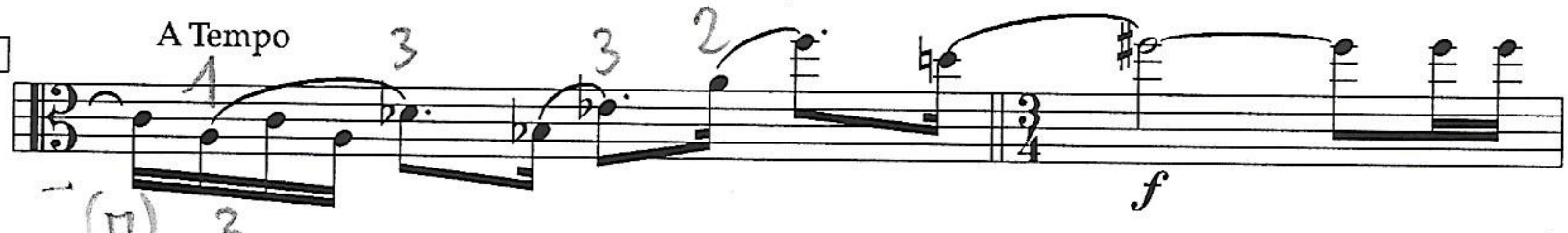

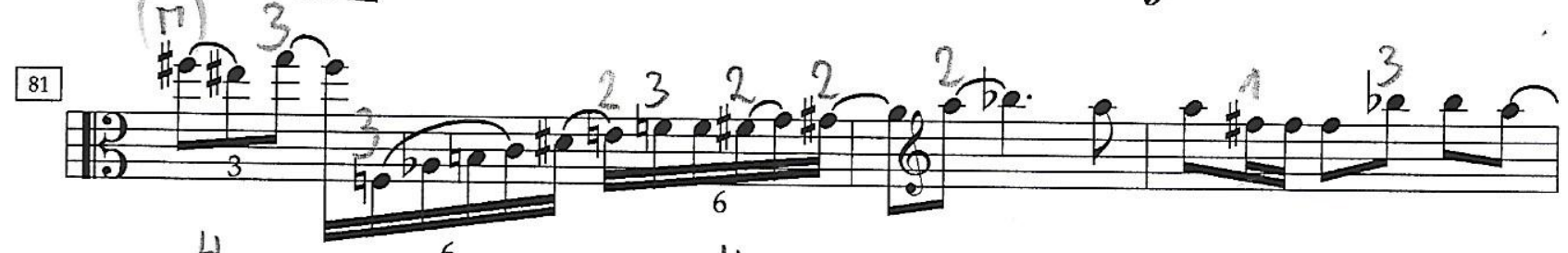

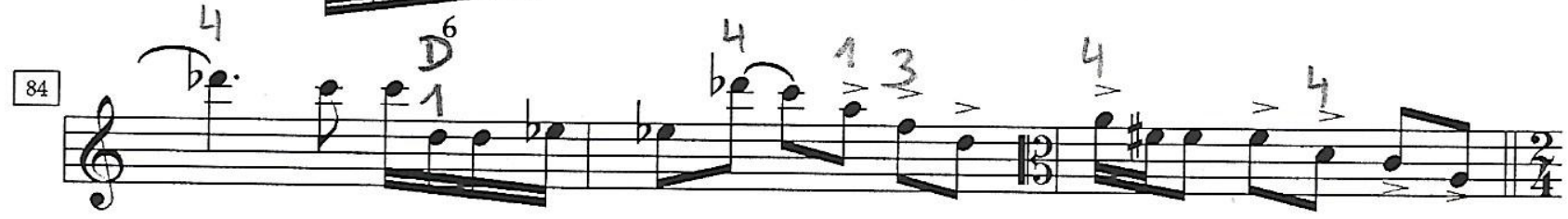

87

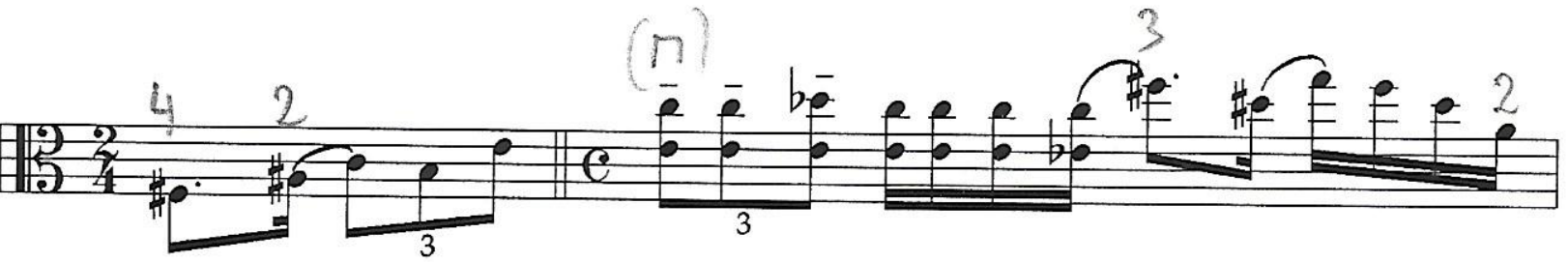

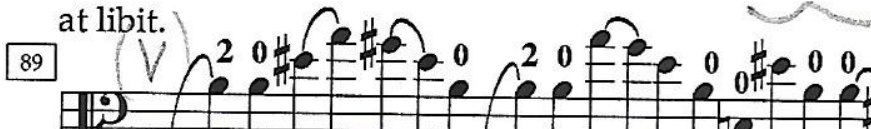

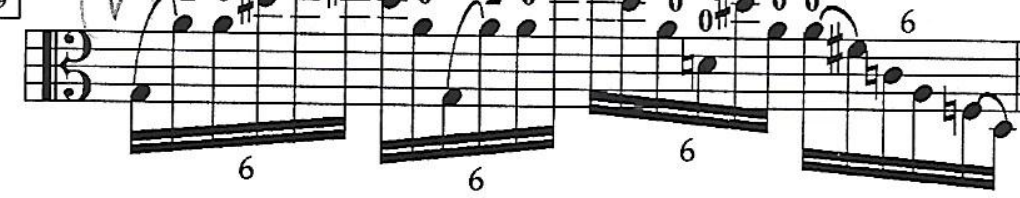
93 piu larg.V $12=2$

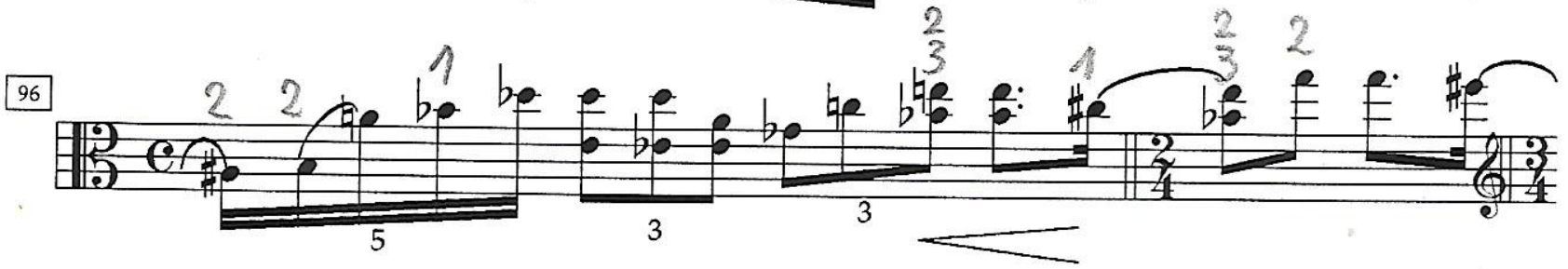




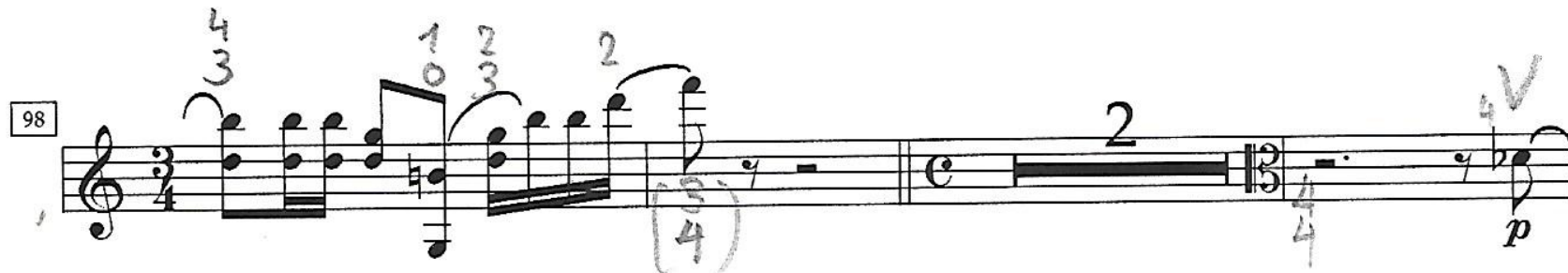

103

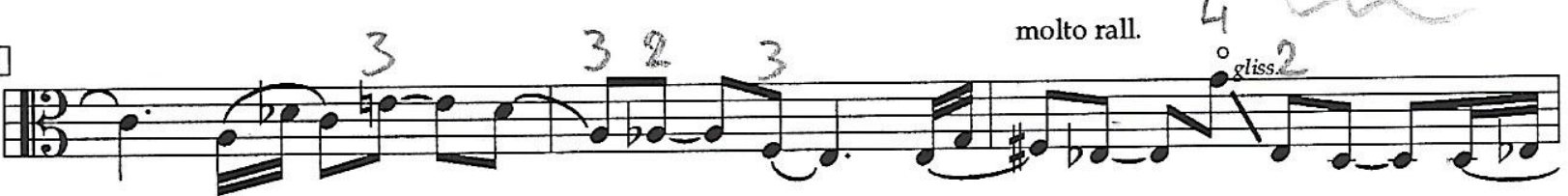
106 A Tempo

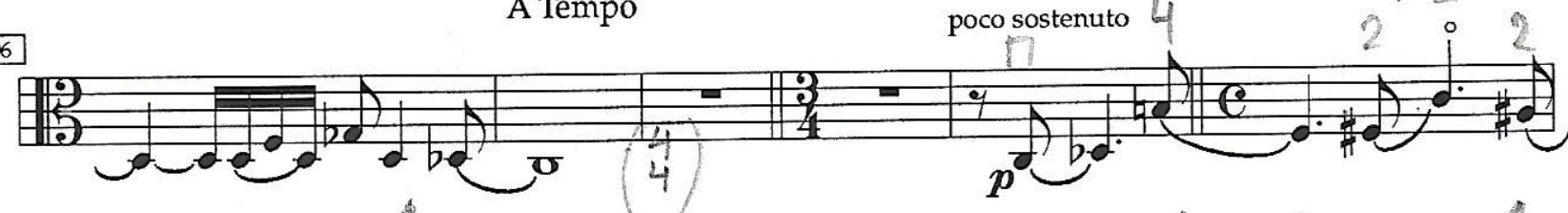

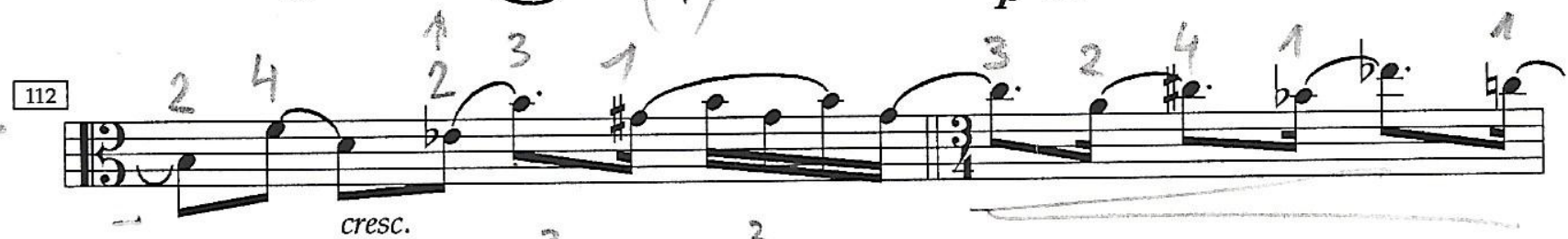

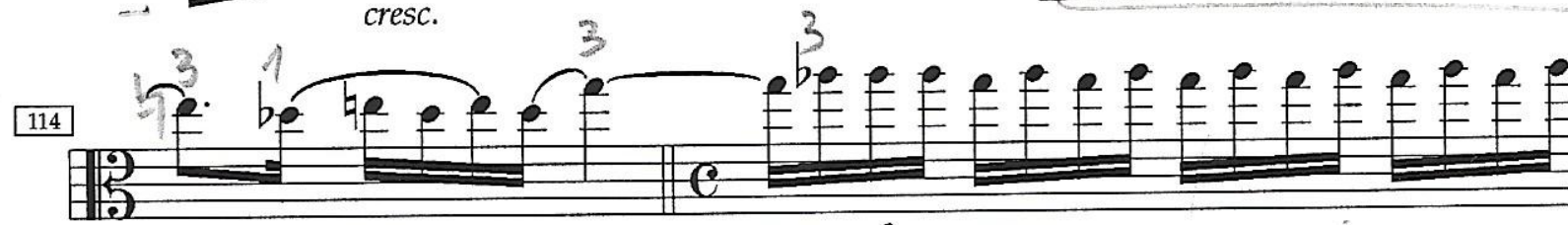
f cresc.

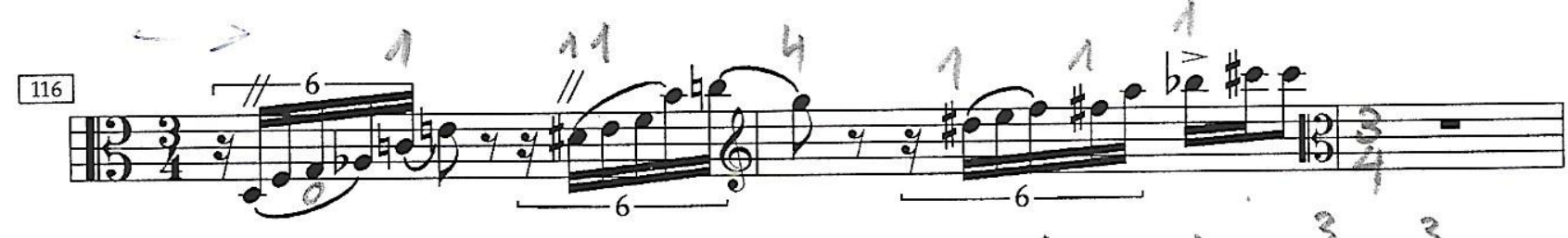
(119

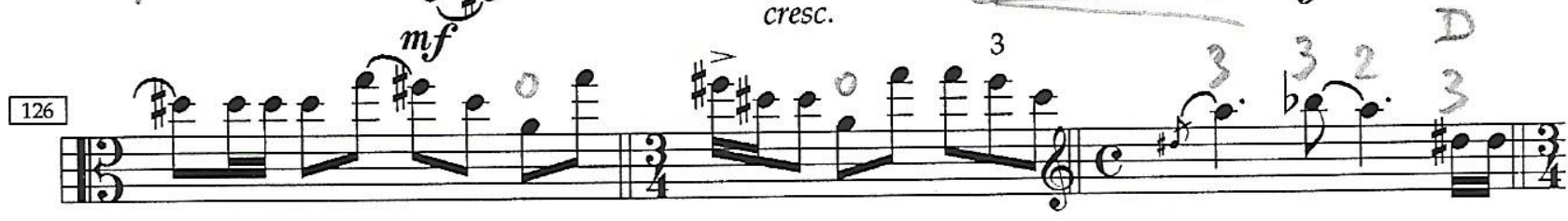

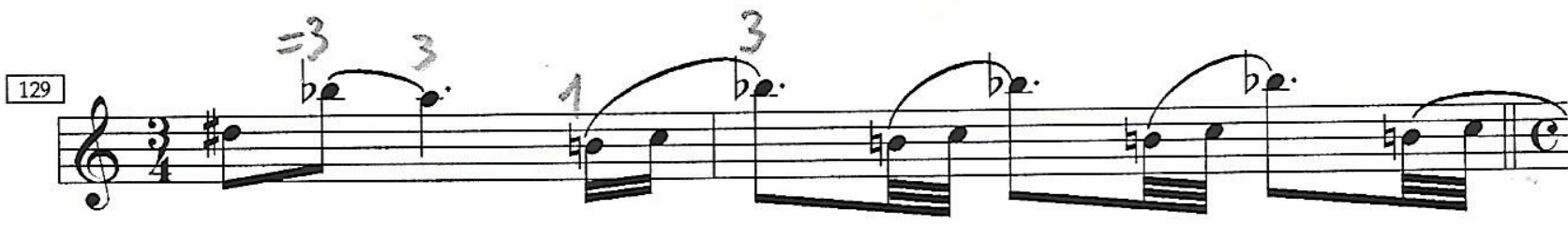

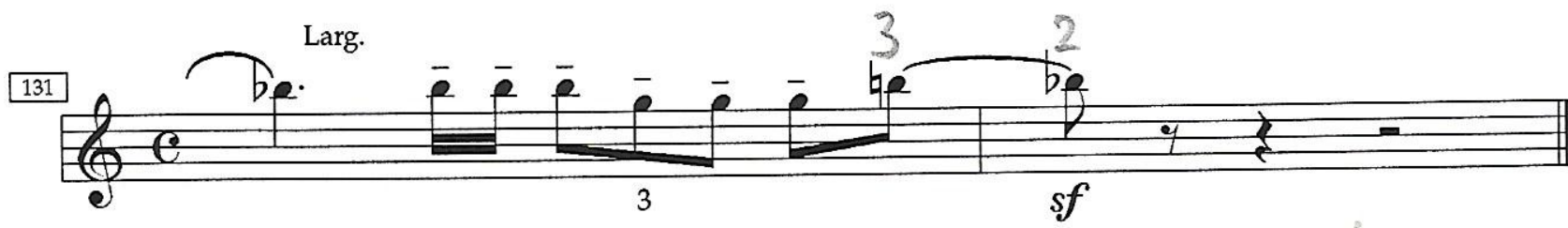


Andantino

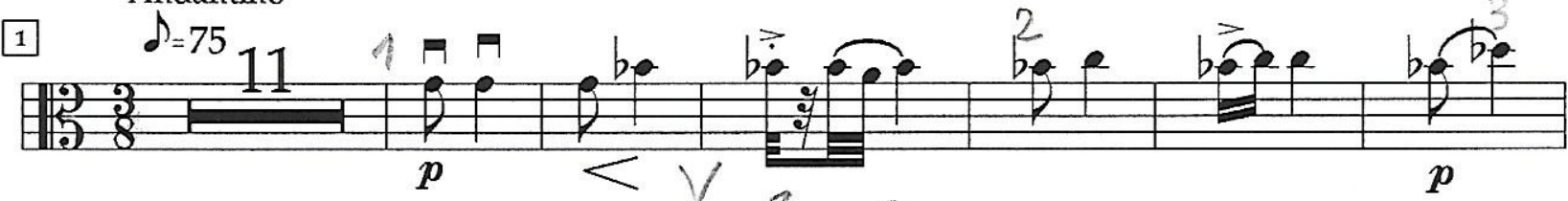

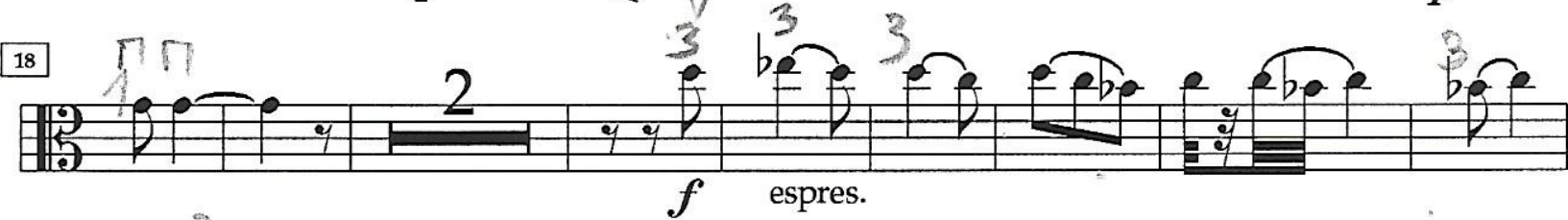
sub.p

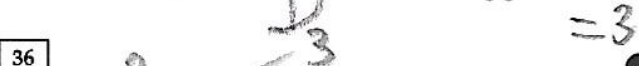

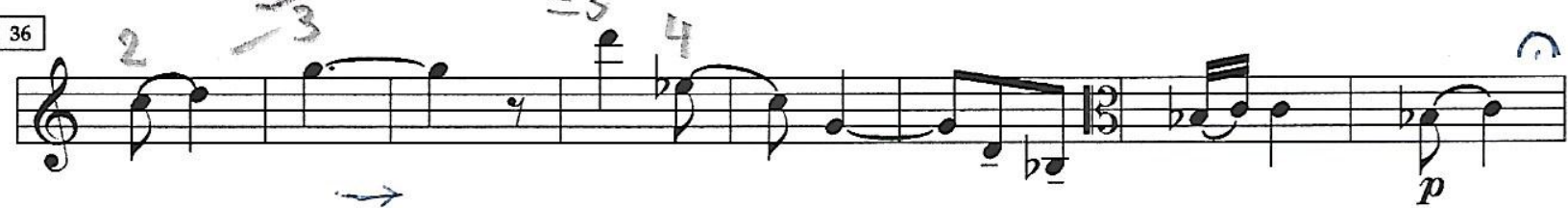
肼 $(05$ e.e.e.

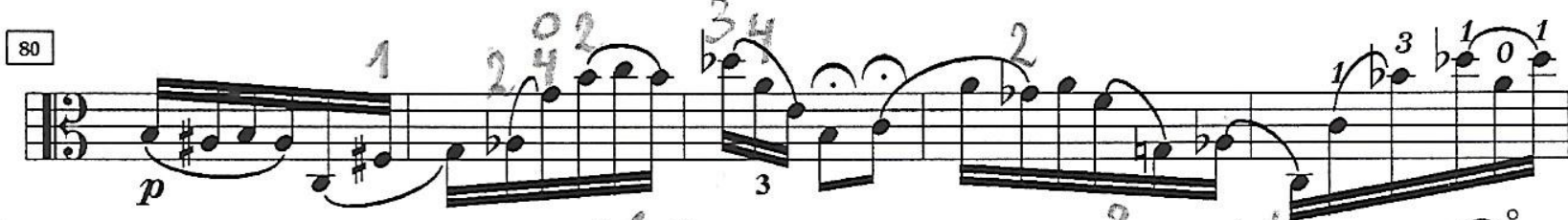
85

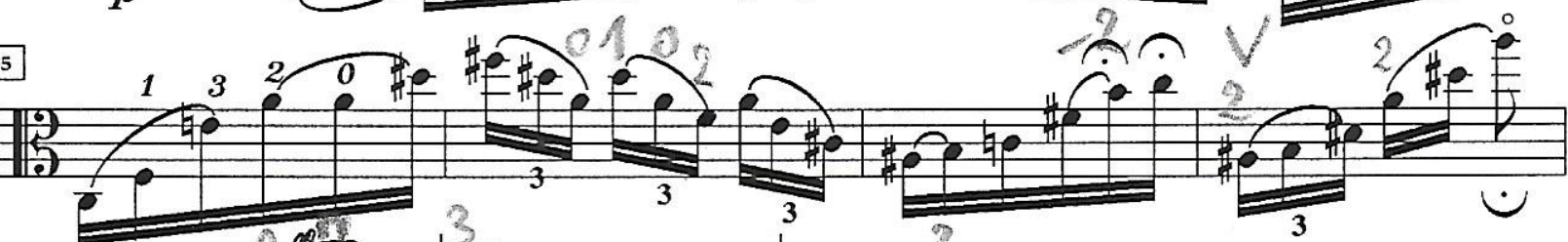
$89 \mathrm{aV}$ befoe bepebefe bobe e le be

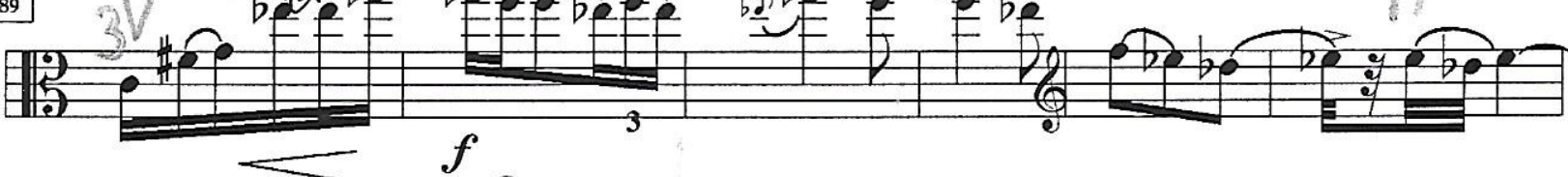

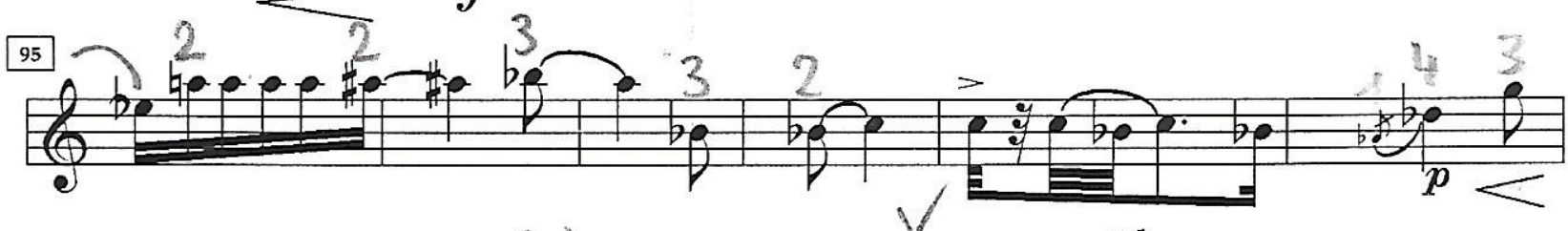

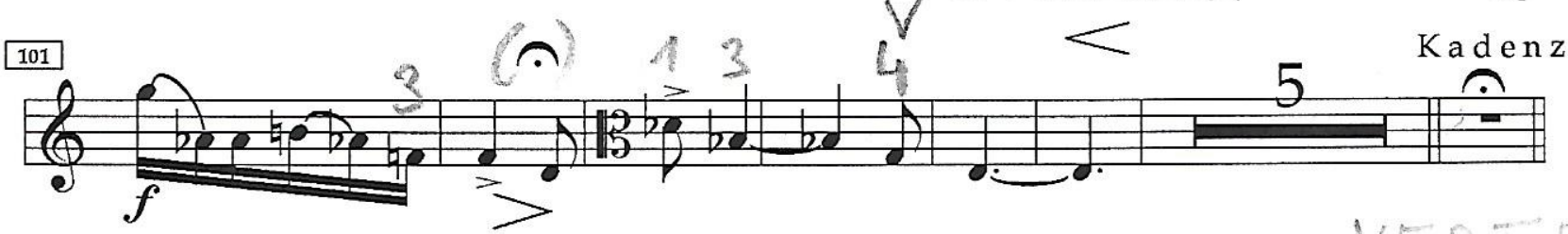


senza misura

Solo VIOLA

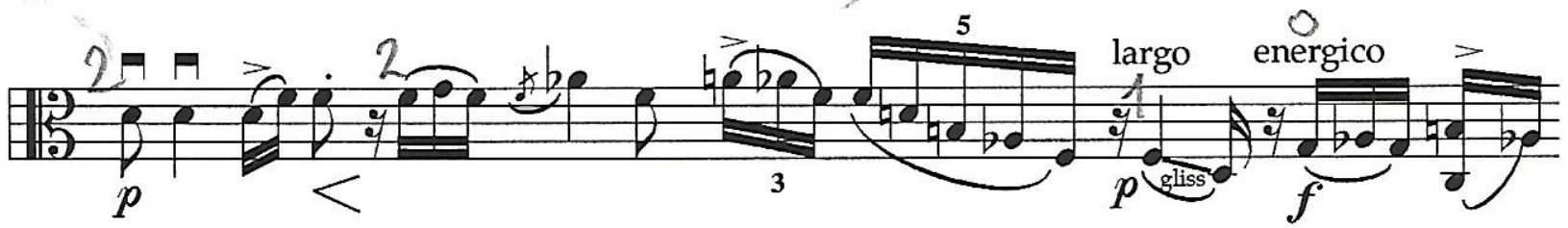

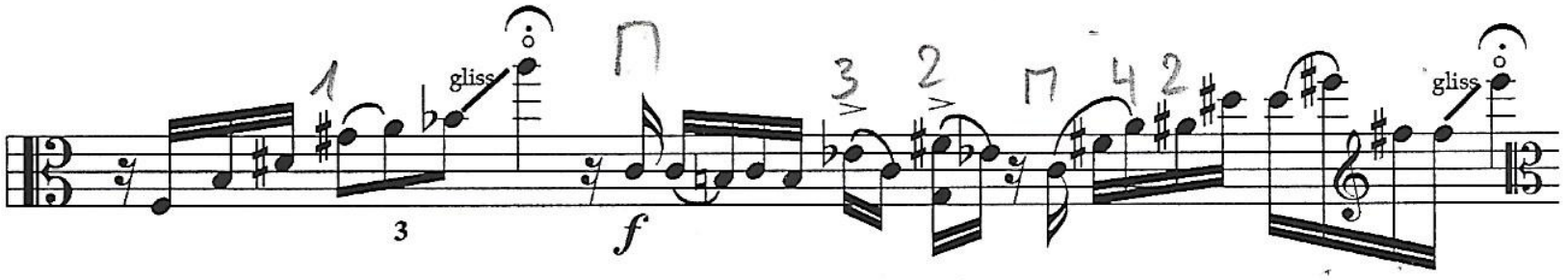
$\frac{n^{3}}{3}$

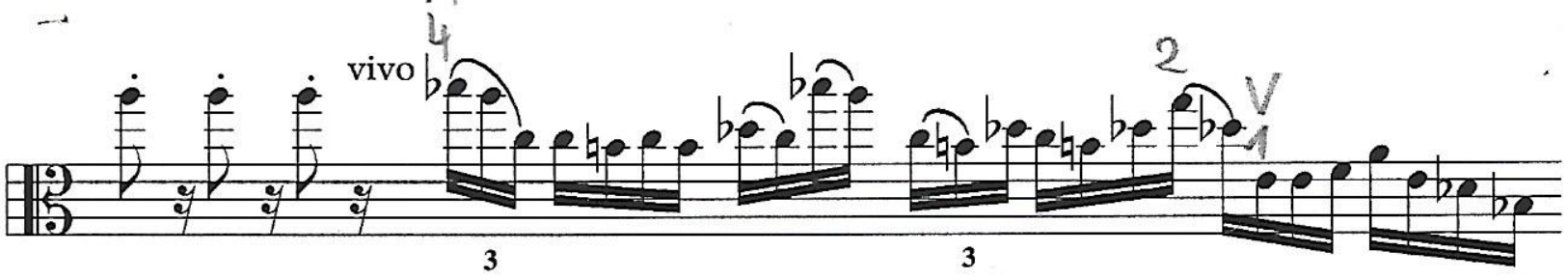
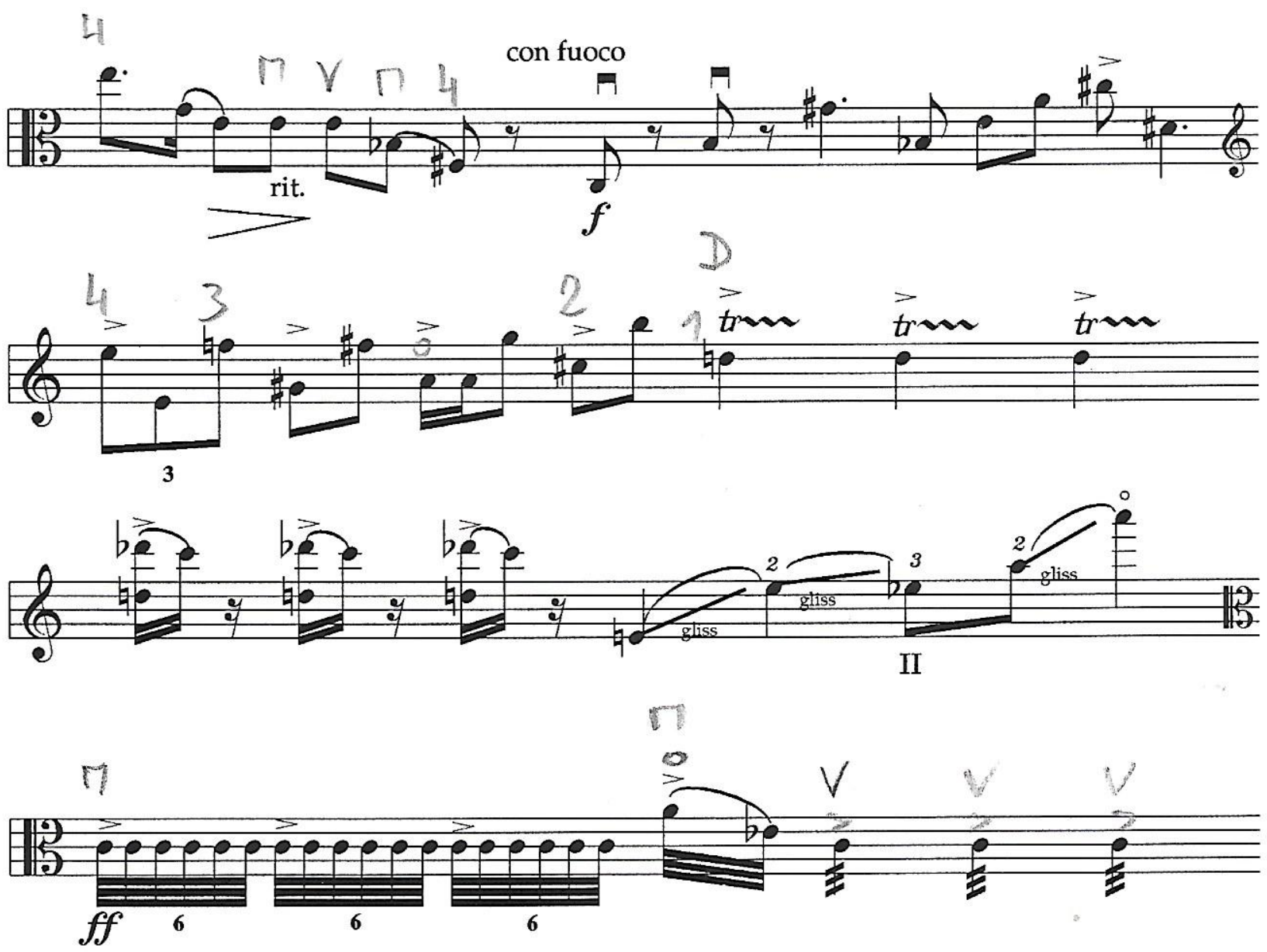


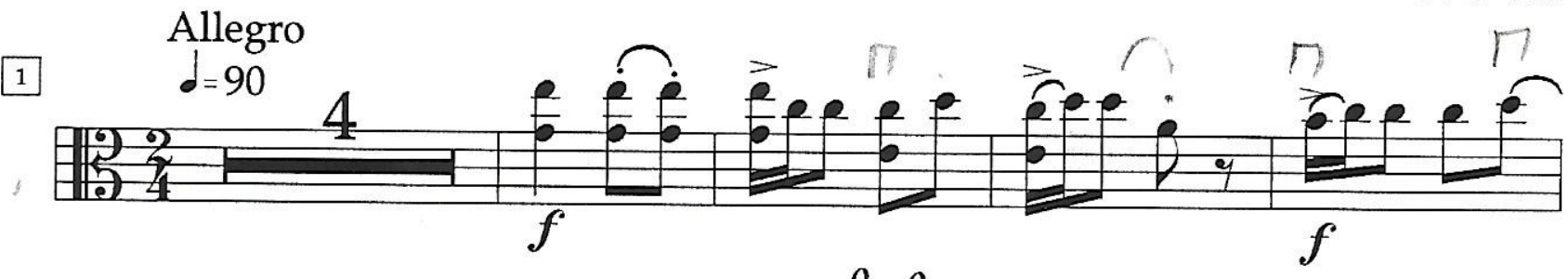

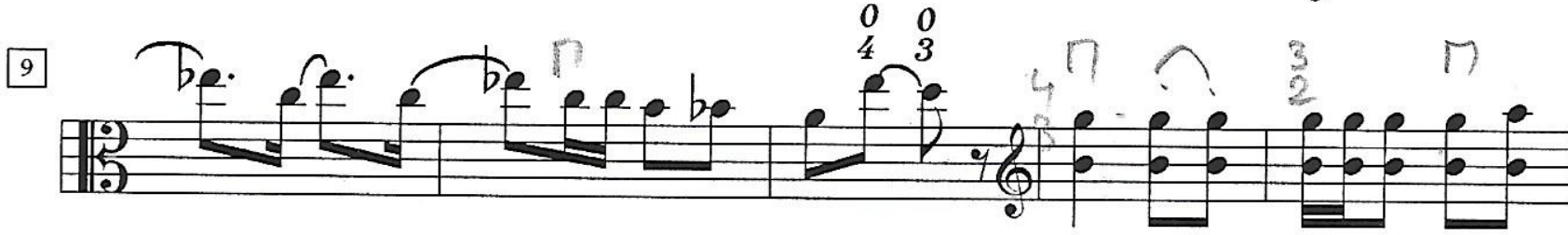

14

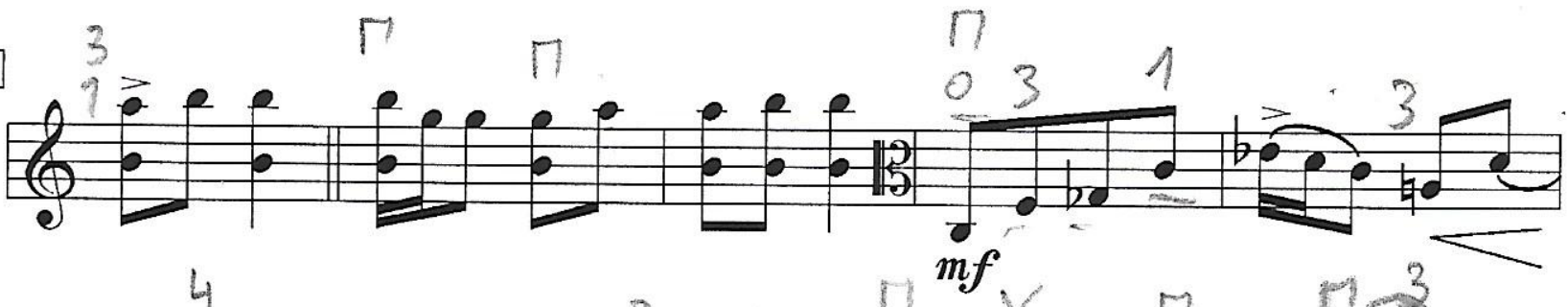

19

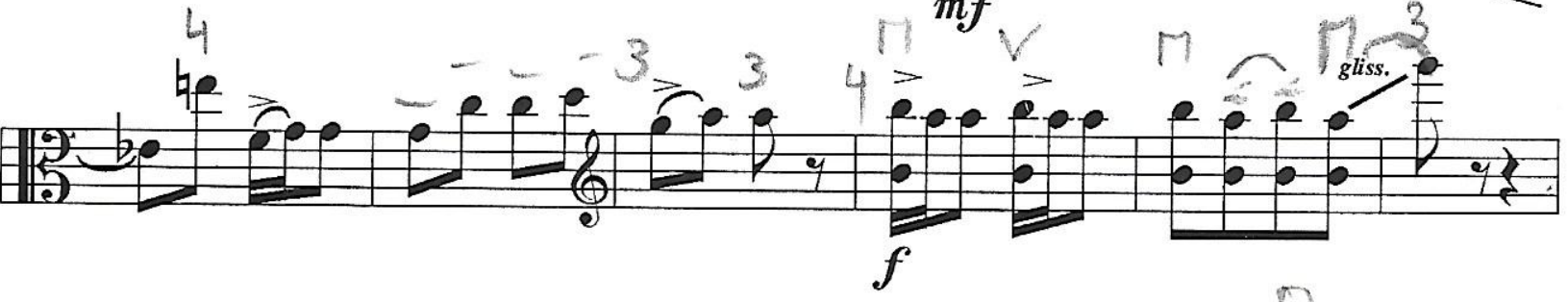

25

$\frac{2}{4} \frac{2}{0}$

10

poco piu meno

3

e te be

$\boldsymbol{f}_{\text {cantabile }}$

41

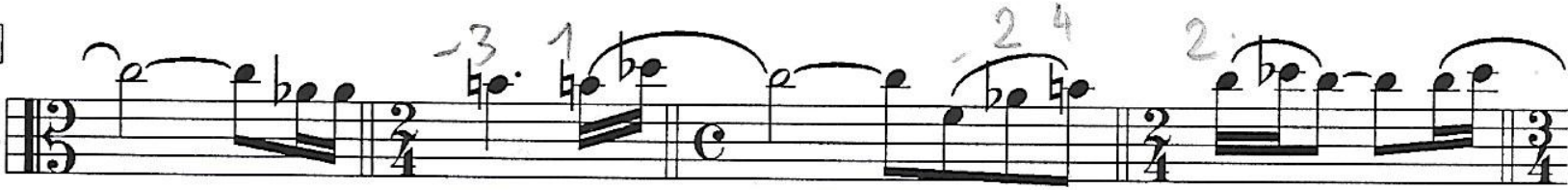

45

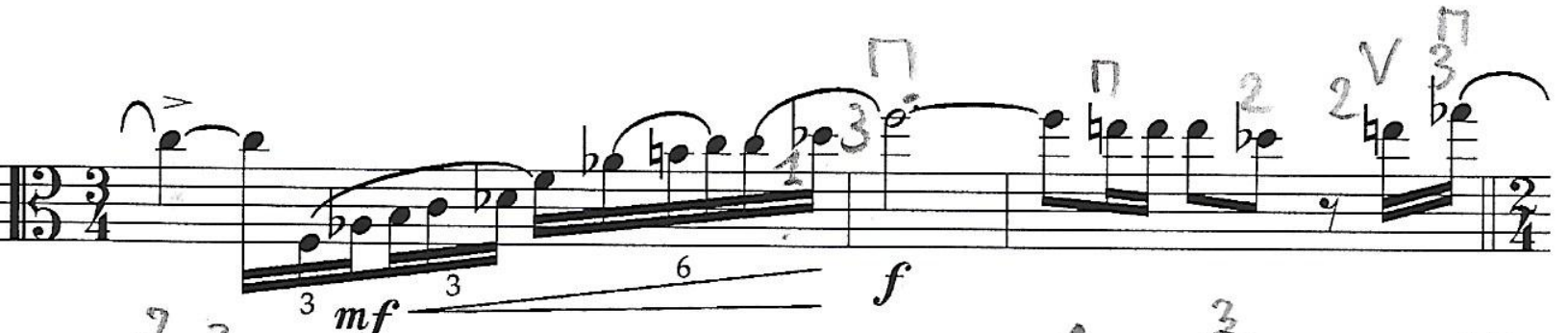

48 $n^{2} 3^{3}$

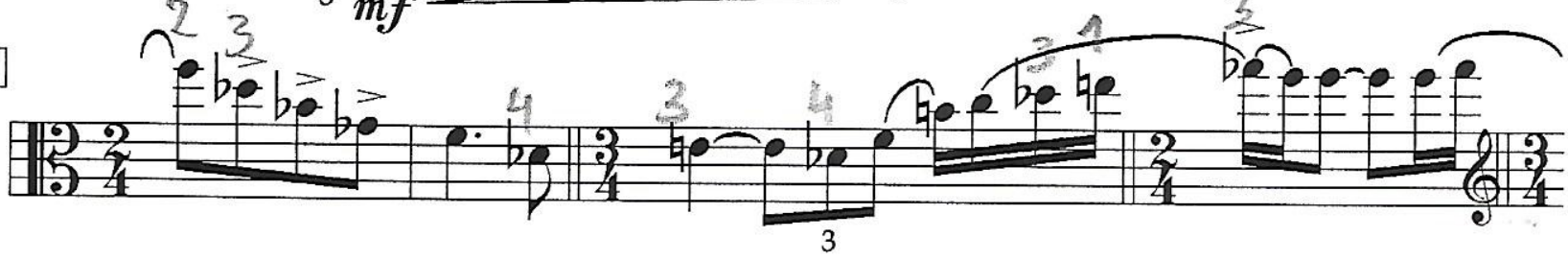

52

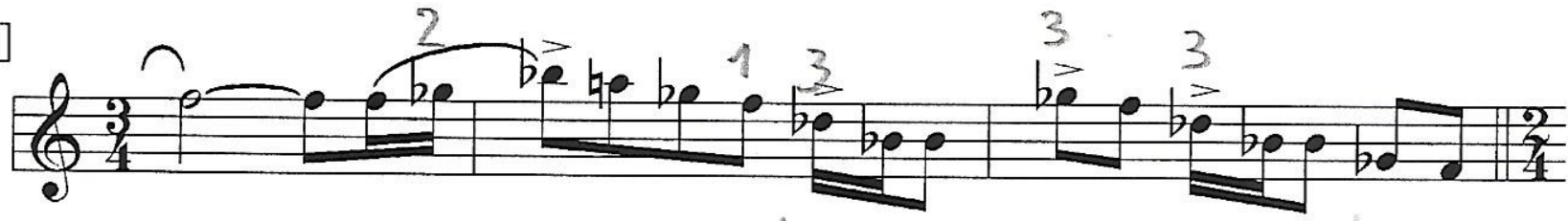


55

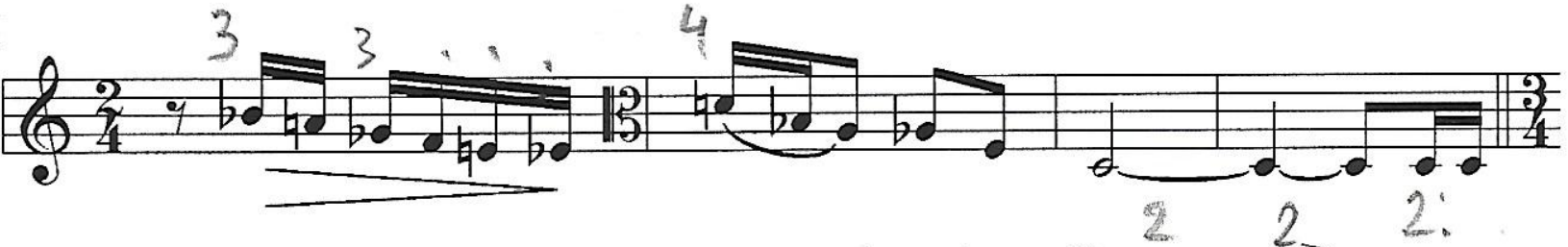

59

63

193

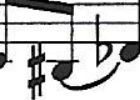

Tempo I

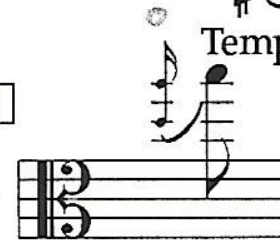

2 日

76

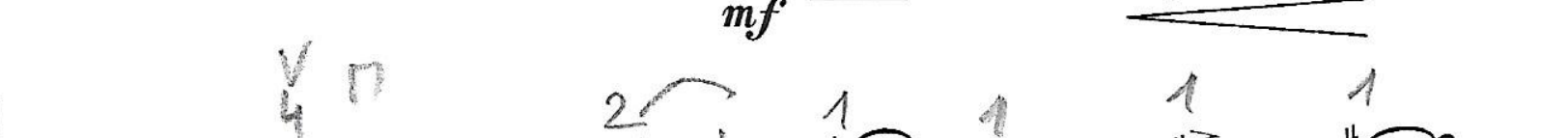

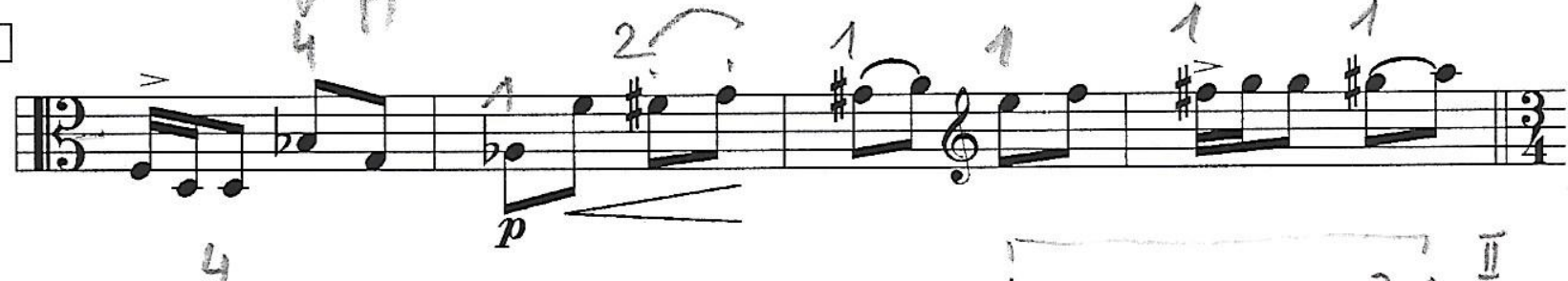

80

9

7
2

$f \longrightarrow$

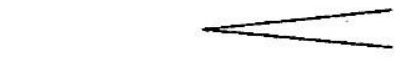




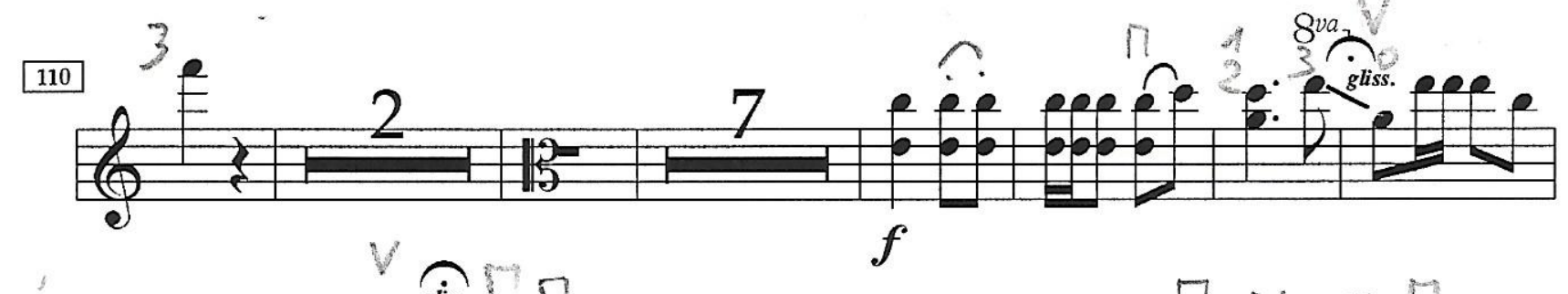

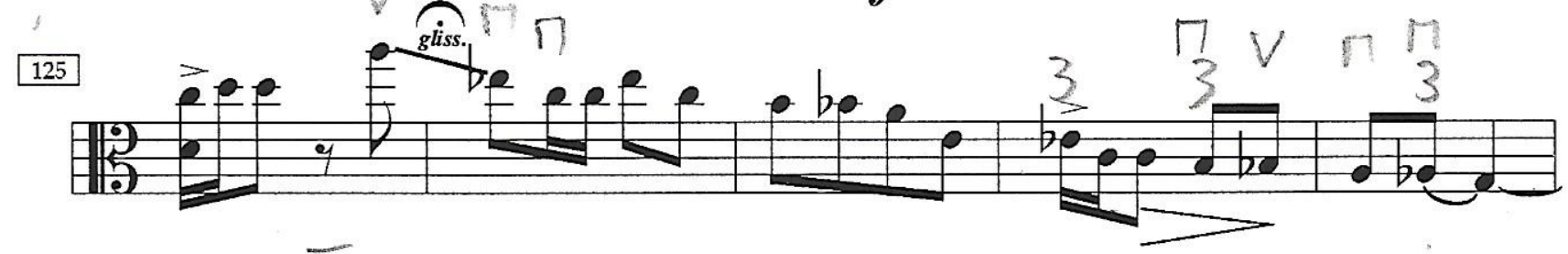

130
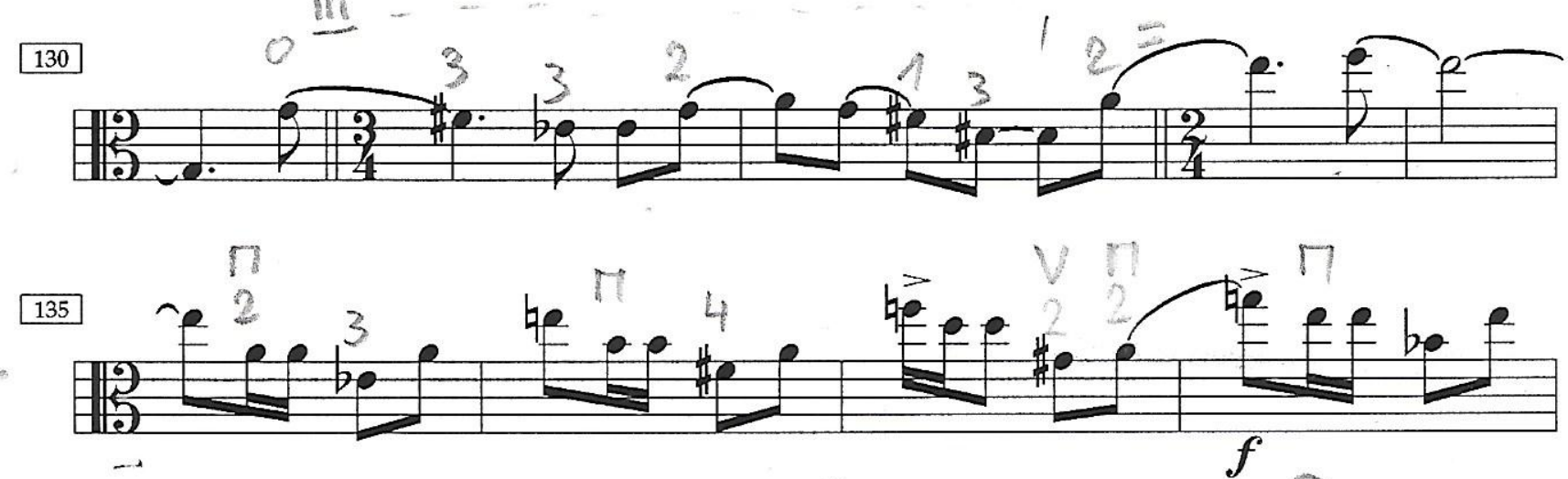

139
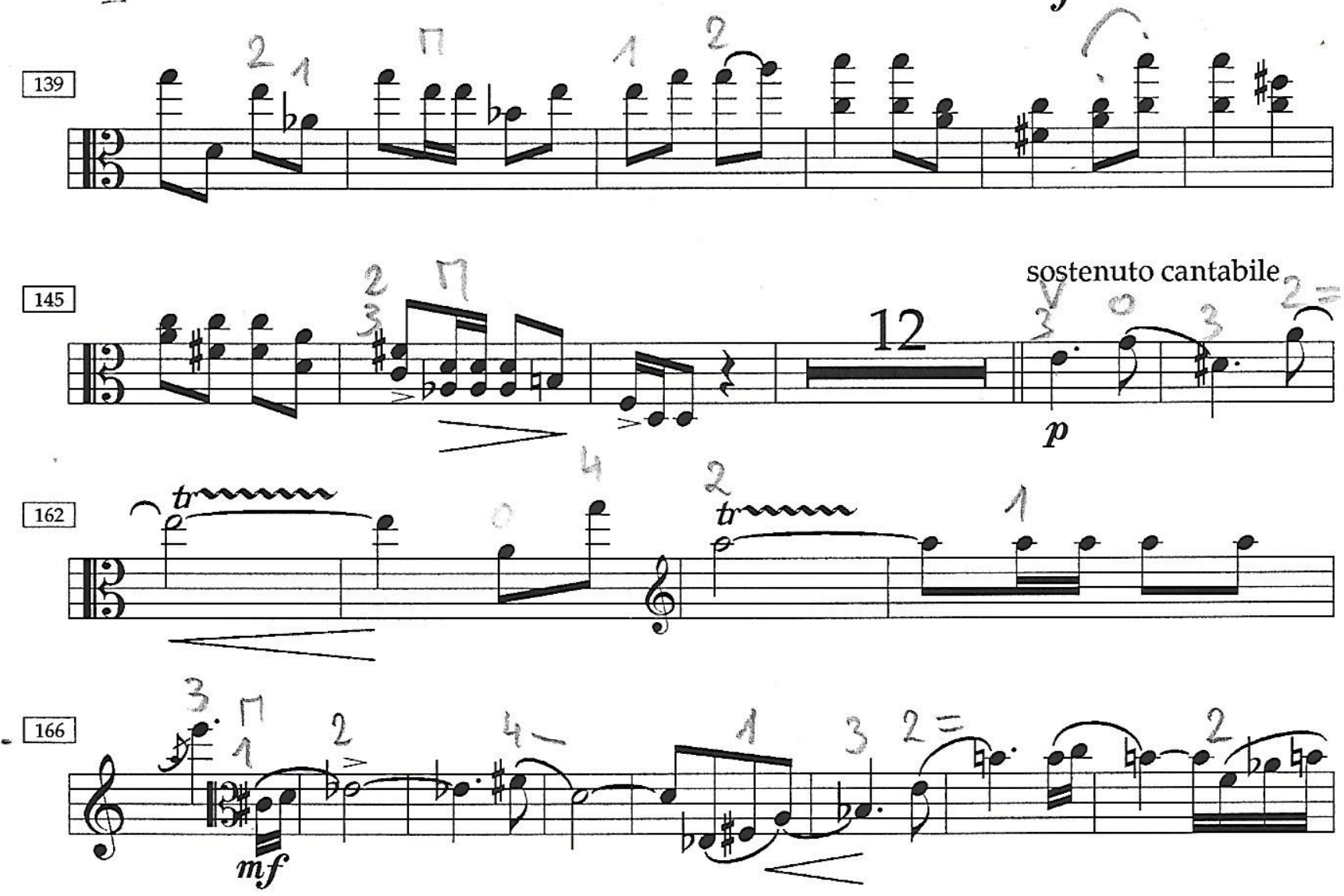


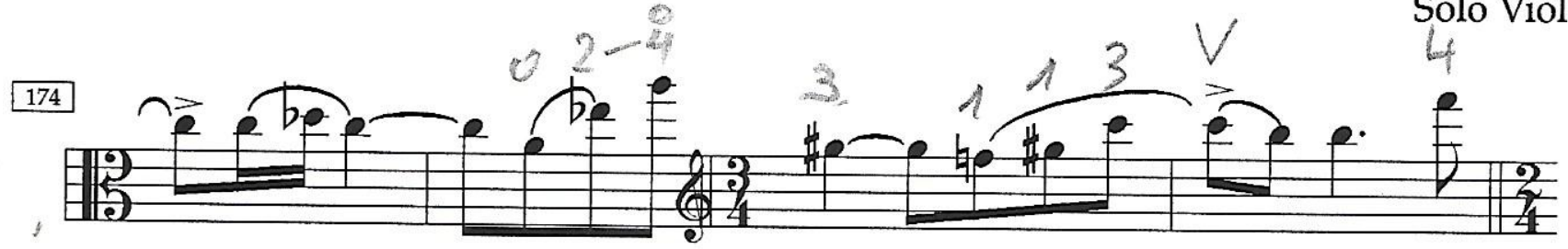
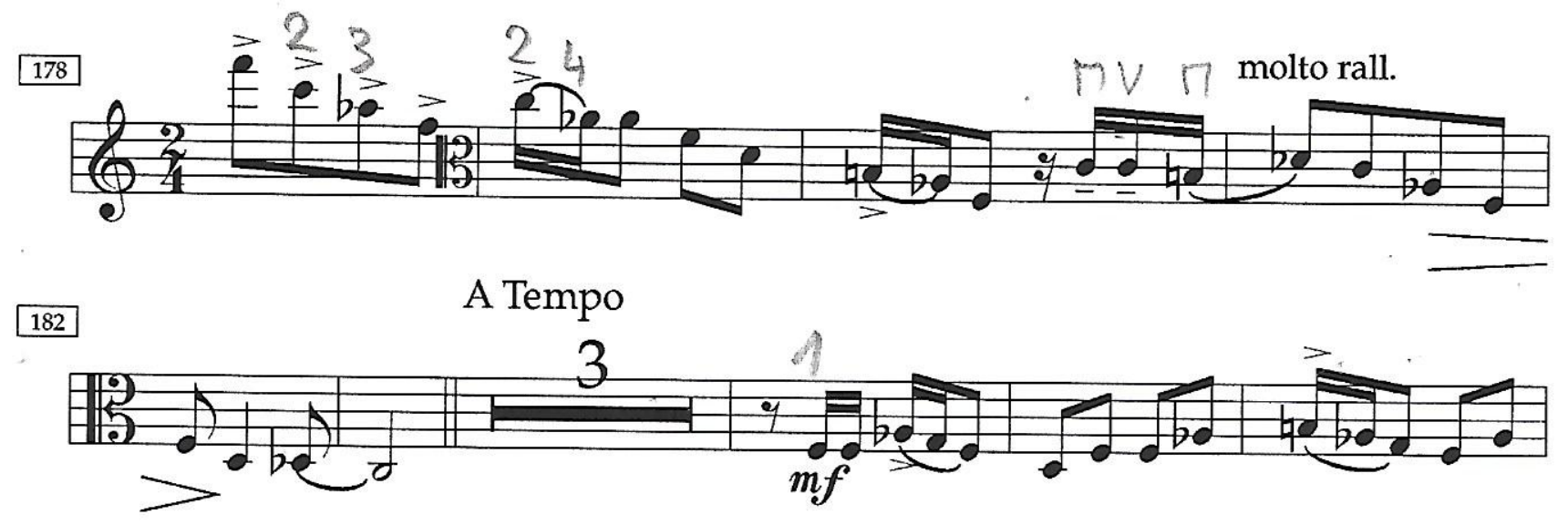

190

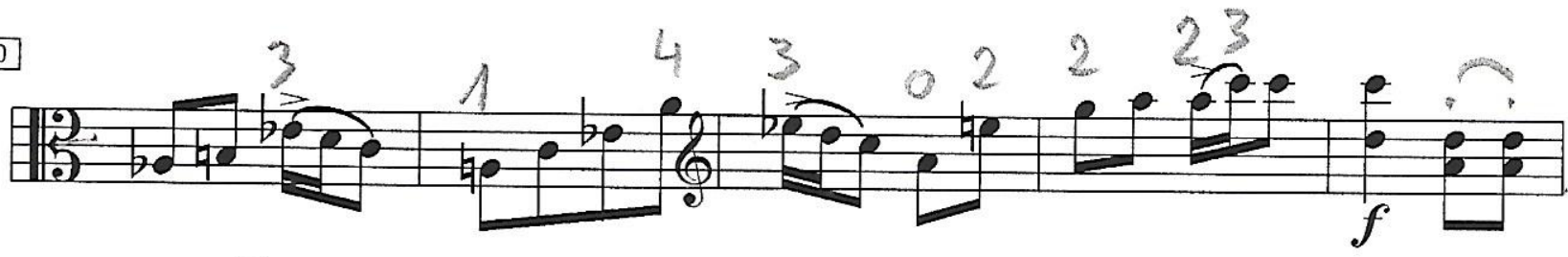

195

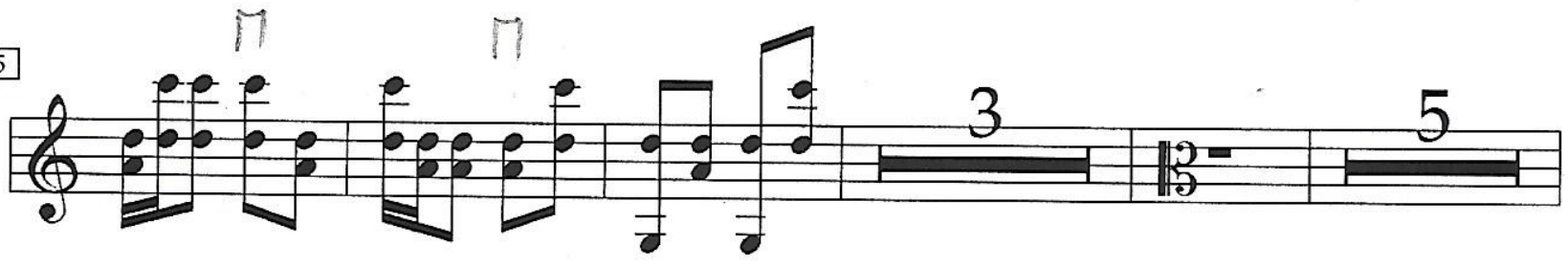

207

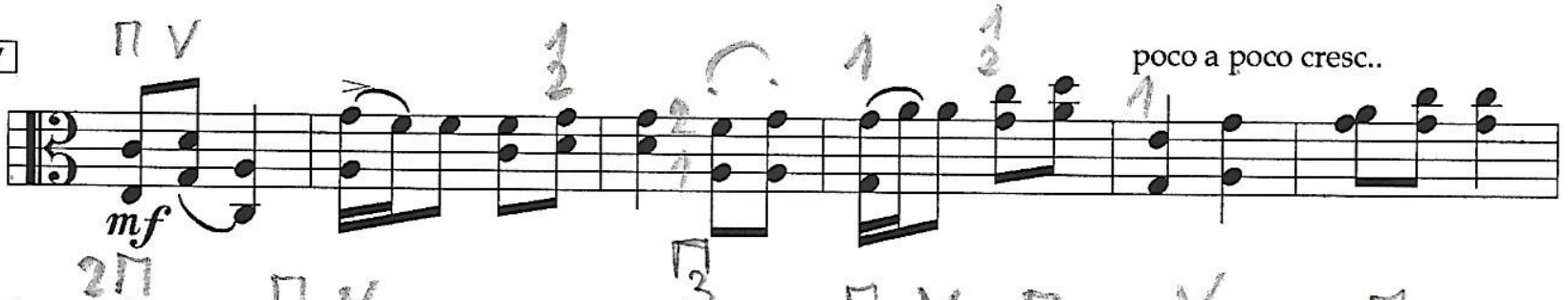

213

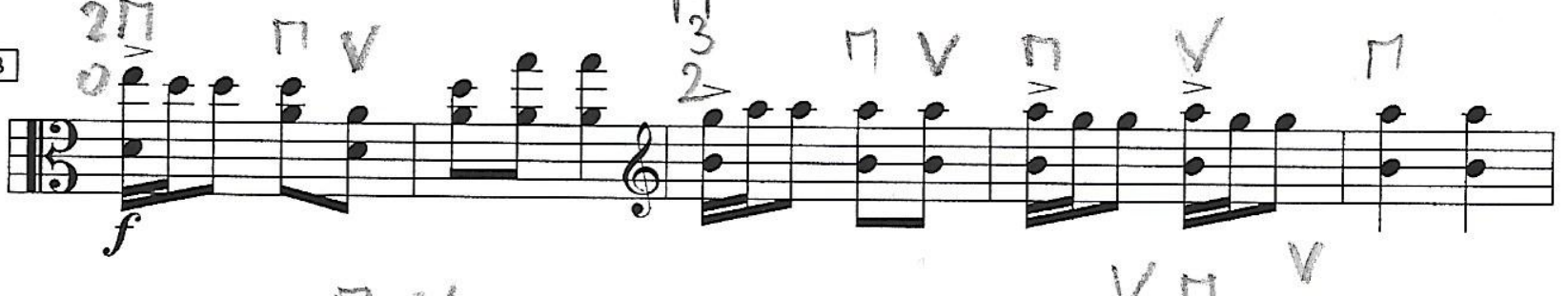

218

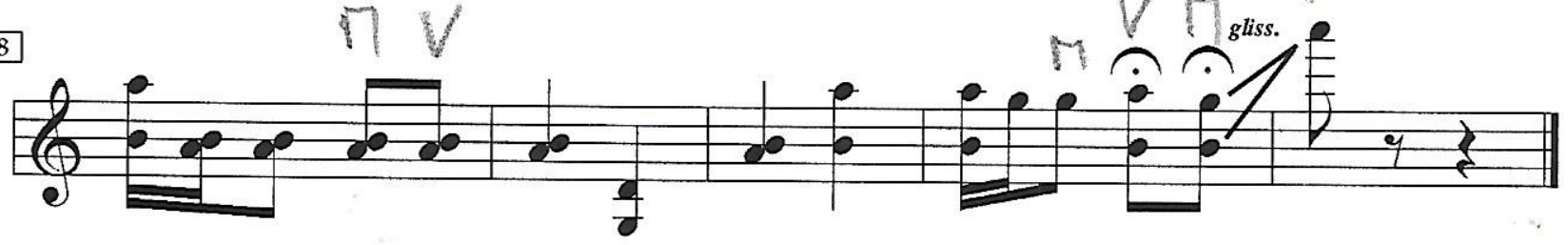


Appendix 4: Correspondence and interview materials

Email from Artur Paciorkiewicz

Included on the next page is an email referred to in the dissertation, which was sent by Artur Paciorkiewicz on November 16, 2017 to the researcher and the primary supervisor. 


\section{This content is unavailable}

\section{Fwd: Dmitris Dragatakis}

\section{This content is unavailable}

Fri, Nov 17, 2017 at 7:30 AM

Begin forwarded message:

This content is unavailable

Dear Donald,

I am fine, thank you.

First of all I would like to correct a date and a place of my world premiere of the viola concerto of Dimitris Dragatakis. It was 31 of January 1993 in Athens during the International Music Festival. The conductor was Jerzy Swoboda and Philharmonic Orchestra from Kraków.

The day before was concert with "Polish Requiem" of Krzysztof Penderecki and he was conducting it also. So, he was next day the listener of my concert.

He felicitated me and Dragatakis also and said that the concerto is very good, specially first and second movement.

In the same day of the concert I recorded the concerto. Dmitris Dradakatis was very satisfied. I asked about copy of the recording but it was impossible.

I do not know if it is any publication of the concerto. Enclose you will find scan of solo part and the score.

I wish you good luck for the future

Artur 


\section{Questionnaires}

Valia Koronidi

\section{QUESTIONNAIRE}

1. In which city were you born? What was your experience in school life - social, sports, academic subjects, music? Can you tell us a bit more about yourself, your career, and passions? Why have you taken on the director position of the archive?

2. Please tell me about your family (mother, family, brothers, sisters, children) and the careers they have pursued? What can you tell me about your brother or other siblings?

3. Where did your grandparents come from (Epirus?), birth and death? Did your grandparents have any background in music? Were your grandparents, or their parents, impacted by the Greek-Turkish population exchange in the 1920s or earlier political events after Greece's independence?

4. Where did your parents meet each other? Can you tell me more about them, their relationship, and your mother?

5. Was your father involved with music before he moved to Athens?

6. Was he exposed to western music, Greek traditional music, or both before travelling to Athens to study music?

7. Did someone teach him violin in Epirus before he moved to Athens?

8. Did he play any other instruments before his formal studies?

9. Did your father start composing before he started formal lessons at the Athens Conservatoire?

10. Your father witnessed many major political events in Greece in the 1940s and beyond. How did these events impact his life, school, music? How were his political views situated at this time? Were his views also popular among the majority of Greek people? 
11. Was it your father's intention to become a composer? Or did he find his career in composition through violin and viola playing? Through the university/education system?

12. Are there any particular memories that stand out in your mind of him as a father? How did he balance a busy career in composition, performing, teaching, and parenting?

13. Did your father think of relocating to other parts of Europe to pursue his career? Or did he always intend to reside in Athens? Is there a reason for that, or coincidence?

14. What is classical music, or contemporary classical music, like in Greece today? Is it accepted and encouraged? How is it received by audiences?

15. How is your father's music and status viewed today in Greece?

16. What was your father's approach to teaching composition? Was it with a western style only? Or more like his own style and influenced by many things (e.g. Greek music, music trends of the 1960s and 1970s)?

17. After your father retired from the Greek National Orchestra, did he continue to play violin and viola? Did he prefer violin or viola, or both equally, do you know? Did the Greek National Orchestra ever perform his works?

18. Did your father enjoy travelling much? Would you say he kept in touch with what was going on in the music scene internationally?

19. Did your father return to Epirus? Did his parents live the rest of their lives there?

20. Was there a reason the Krakow Philharmonic Orchestra premiered the Concerto for Viola in 1993? Is there a reason it wasn't premiered by the Greek National Orchestra? Was it more prestigious to have a foreign orchestra premiere your work at the time?

21. Did your father work with any violists in particular in Greece or internationally? Did he write the Concerto for Viola, or other works including viola, for anyone in particular? Did he write any works with dedications? 
22. Did your father have a preferred type of composition (e.g. symphony, chamber work, concerto)?

23. Did your father ever mention any specific western influences?

24. What was the balance of commissioned and non-commissioned work by your father?

25. Were there any moments your father felt were highlights in his career? Any low points?

26. Is there any else you'd like to add regarding your father and other topics we've discussed?

Thanos Koronidi

IMPROMPTU QUESTIONNAIRE

Leonidas Dragatakis

\section{QUESTIONNAIRE}

1. In which city were you born? What was your experience in school life - social, sports, academic subjects, music? Can you tell us a bit more about yourself, your career, and passions? Why have you taken on the director position of the archive?

2. Please tell me about your family (mother, family, brothers, sisters, children) and the careers they have pursued?

3. Where did your parents meet each other? Can you tell me more about them, their relationship, and your mother?

4. Your father witnessed many major political events in Greece in the 1940s and beyond. How did these events impact his life, school, music? How were his political views situated at this time? Were his views also popular among the majority of Greek people? 
5. Are there any particular memories that stand out in your mind of him as a father? How did he balance a busy career in composition, performing, teaching, and parenting?

6. What is classical music, or contemporary classical music, like in Greece today? Is it accepted and encouraged? How is it received by audiences?

7. What was your father's approach to teaching composition? Was it with a western style only? Or more like his own style and influenced by many things (e.g. Greek music, music trends of the 1960s and 1970s)?

8. Did your father enjoy travelling much? Would you say he kept in touch with what was going on in the music scene internationally?

9. Did your father ever mention any specific western influences?

10. Were there any moments your father felt were highlights in his career? Any low points?

11. Is there any else you'd like to add regarding your father and other topics we've discussed?

Kelly Dragatakis

IMPROMPTU QUESTIONNAIRE

Ismini Koronidi

\section{QUESTIONNAIRE}

1. In which city were you born? What was your experience in school life - social, sports, academic subjects, music? Can you tell us a bit more about yourself, your career, and passions?

2. Please tell me about your family (mother, family, brothers, sisters, children) and the careers they have pursued?

3. Can you tell me more about your grandfather and grandmother?

4. Are there any particular memories that stand out in your mind of him as a grandfather? 
5. Can you tell me more about theory lessons with your grandfather?

6. What was your grandfather's approach to teaching music theory?

7. Did your grandfather ever mention any specific western influences?

8. Is there any else you'd like to add regarding your grandfather and other topics we've discussed?

Iro Koronidi

\section{QUESTIONNAIRE}

1. In which city were you born? What was your experience in school life - social, sports, academic subjects, music? Can you tell us a bit more about yourself, your career, and passions?

2. Please tell me about your family (mother, family, brothers, sisters, children) and the careers they have pursued?

3. Can you tell me more about your grandfather and grandmother?

4. Are there any particular memories that stand out in your mind of him as a grandfather?

5. Can you tell me more about theory lessons with your grandfather?

6. What was your grandfather's approach to teaching music theory?

7. Did your grandfather ever mention any specific western influences?

8. Is there any else you'd like to add regarding your grandfather and other topics we've discussed?

Magdalini Kalopana

QUESTIONNAIRE

1. In which city were you born?

2. How old were you when you started studying music? What was your experience in school life - social, sports, academic subjects, music? Can you tell us a bit more about yourself, your career, and passions? Why have you taken on the curator position of the archive? 
3. Please tell me about your relationship with Dragatakis? How did you come to know each other?

4. What was Dragatakis like as a friend and colleague? Are there any particular memories that stand out in your mind of Dragatakis? How did he balance a busy career in composition, performing, teaching, and parenting?

5. Was Dragatakis involved with music before he moved to Athens? Was he exposed to western music, Greek traditional music, or both before travelling to Athens to study music? Did someone teach him violin in Epirus before he moved to Athens? Did he play any other instruments before his studies?

6. Did Dragatakis start composing before he started formal lessons at the Athens Conservatoire?

7. Dragatakis witnessed many major political events in Greece in the 1940s and beyond. How did these events impact his life, school, music? How were his political views situated at this time? Were his views also popular among the majority of Greek people?

8. Was it Dragatakis' intention to become a composer? Or did he find his career in composition through violin and viola playing? Through the university/education system?

9. Did Dragatakis think of relocating to other parts of Europe to pursue his career? Or did he always intend to reside in Athens? Is there a reason for that, or coincidence?

10. What is classical music, or contemporary classical music, like in Greece today? Is it accepted and encouraged? How is it received by audiences?

11. Artur, the violist who premiered the Concerto for Viola, mentioned Yuri Bashmet was originally contracted to perform the work. I noticed this was also mentioned in a quote in your catalogue. Do you know why Bashmet had to cancel or have any other insight into this?

12. How is Dragatakis received today in Greece? 
13. What was Dragatakis' approach to teaching composition? Was it with a western style only? Or more like his own style and influenced by many things (e.g. Greek music, music trends of the 1960s and 1970s)?

14. When Dragatakis retired from the Greek National Orchestra, did he continue to play violin and viola after he retired? Did he prefer violin or viola, or both equally, do you know? Did the Greek National Orchestra ever perform his works?

15. Did Dragatakis enjoy travelling much? Would you say he kept in touch with what was going on in the music scene internationally?

16. Did Dragatakis return to Epirus? Did his parents live the rest of their lives there?

17. Was there a reason the Krakow Philharmonic Orchestra premiered the Concerto for Viola in 1993? Is there a reason it wasn't premiered by the Greek National Orchestra? Was it more prestigious to have a foreign orchestra premiere your work at the time?

18. Did Dragatakis work with any violists in particular in Greece or internationally? Did he write the Concerto for Viola, or other works including viola, for anyone in particular? Did he write any works with dedications?

19. Did Dragatakis have a preferred type of composition (e.g. symphony, chamber work, concerto)?

20. Did Dragatakis ever mention any specific western influences?

21. Do you have any advice for other pianists or musicians looking to perform his works?

22. What was the balance of commissioned and non-commissioned work by Dragatakis?

23. Were there any moments Dragatakis felt were highlights in his career? Any low points?

24. Who were his Greek contemporaries? 
25. Is there any else you'd like to add regarding Dragatakis and other topics we've discussed? 
Permission slips

Signed permission slips from each interviewee are included on the next page. 
- I would like a copy of the transcript of my interview: Yes No

- I would like a summary of my interview: $\quad$ Yes No

- I would like to receive a copy of the final report and have added my email Yes No address below.

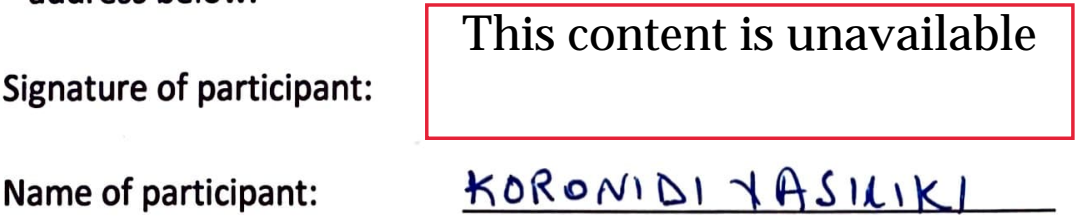

Date:

11/10/2019

Contact details:

This content is unavailable 
- I would like a copy of the transcript of my interview:

- I would like a summary of my interview:

- I would like to receive a copy of the final report and have added my email address below.

Signature of participant:

Name of participant:

This content is unavailable

Date:

Contact details:

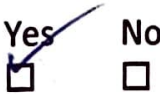

Yes No

No

iv 


\section{Human Ethics Committee information}

If you have any concerns about the ethical conduct of the research you may contact the Victoria University HEC Convenor: Dr Judith Loveridge. Email hec@vuw.ac.nz or telephone +64-4-463 6028.

\section{CONSENT TO INTERVIEW}

This consent form will be held for 5 years.

Researcher: Elyse Dalabakis, New Zealand School of Music, Victoria University of Wellington.

- I have read the Information Sheet above and the project has been explained to me. My questions have been answered to my satisfaction. I understand that I can ask further questions at any time.

- I agree to take part in a video/audio recorded interview.

I understand that:

- I may withdraw from this study at any point before 31 October 2019, and any information that I have provided will be returned to me or destroyed.

- The identifiable information I have provided will be destroyed on 31 December 2020.

- Any information I provide will be kept confidential to the researcher, the supervisor, and the transcriber.

- The findings may be used for a PhD dissertation.

- The observation notes/recordings will be kept confidential to the researcher and the supervisor and the transcriber.

- I consent to information or opinions which I have given being attributed to me in any reports on this research:

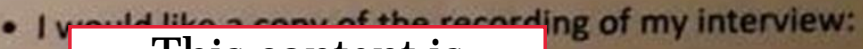

This content is unavailable 


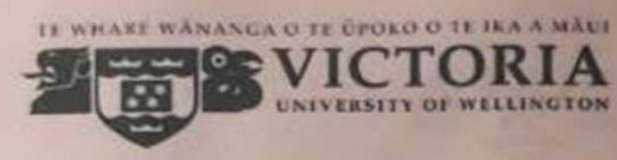

- I would like a copy of the transcript of my interview:

- I would like a summary of my interview:

- I would like to receive a This content is unavailable email Yes No address below.

Signature of participant:

Name of participant:

I ATHANASIOS KORONIDES

Date:

Contact details:

10-June-2020

This content is unavailable 


\section{Interview}

2 messages

Dear Leo and Kelly,

\section{This content is unavailable}

7 Dalabakis (\#300339538) - Information and Consent sheet - 0000027941.pdf $364 \mathrm{~K}$

\section{This content is unavailable}


This content is unavailable

respond, we will give our permission by just stating, 'please consider this as my electronic signature,' as you idicated in your email.

\section{This content is unavailable}




\section{Human Ethics Committee information}

If you have any concerns about the ethical conduct of the research you may contact the Victoria University HEC Convenor: Dr Judith Loveridge. Email hec@vuw.ac.nz or telephone +64-4-463 6028.

\section{CONSENT TO INTERVIEW}

This consent form will be held for 5 years.

Researcher: Elyse Dalabakis, New Zealand School of Music, Victoria University of Wellington.

- I have read the Information Sheet above and the project has been explained to me. My questions have been answered to my satisfaction. I understand that I can ask further questions at any time.

- I agree to take part in a video/audio recorded interview.

I understand that:

- I may withdraw from this study at any point before 31 October 2019, and any information that I have provided will be returned to me or destroyed.

- The identifiable information I have provided will be destroyed on 31 December 2020.

- Any information I provide will be kept confidential to the researcher, the supervisor, and the transcriber.

- The findings may be used for a PhD dissertation.

- The observation notes/recordings will be kept confidential to the researcher and the supervisor and the transcriber.

- I consent to information or opinions which I have given being attributed to me in any reports on this research:

Yes No

- I would like a copy of the recording of my interview: 
- I would like a copy of the transcript of my interview: Yes No

- I would like a summary of my interview: $\quad$ Yes No

- I would like to receive a copy of the final report and have added my email Yes No address below.

Signature of participant:

Name of participant:

This content is unavailable

Date:

Isminikoronidi

$10|6| 2020$

Contact details: 


\section{Interview permission slip}

\begin{tabular}{|c|c|}
\hline Iro Koronidi & $\begin{array}{c}\text { This content is } \\
\text { unavailable }\end{array}$ \\
\hline \hline
\end{tabular}

Wed, Oct 14, 2020 at 8:18 PM

This content is unavailable

"I consent, this is my electronic signature" .

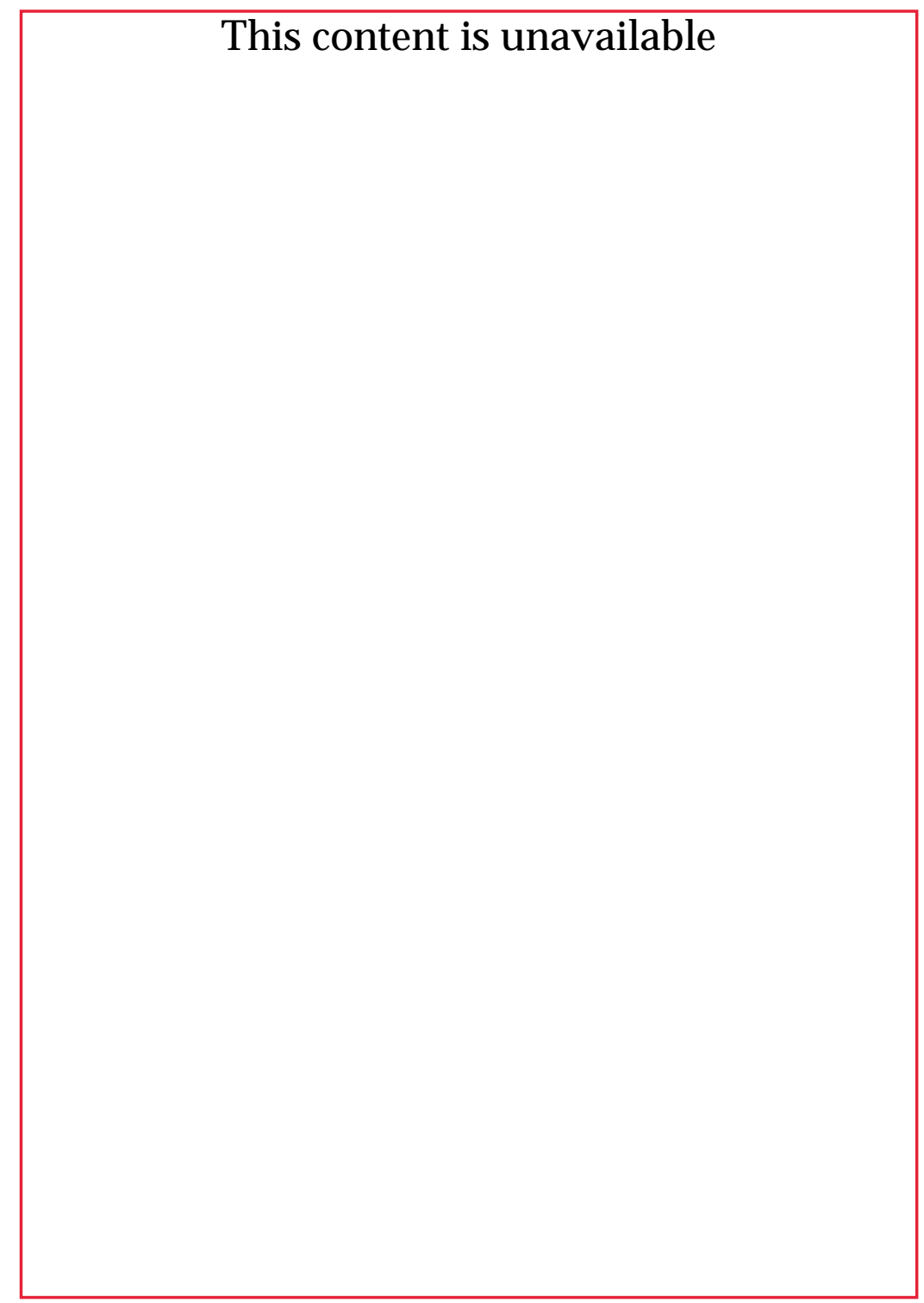


Appendix 5: Research residency and IVC presentation

Included in the next section are the IVC media proceedings mentioned in the final chapter. Some of these media proceedings are in print only and the reader would not otherwise have access to them. 


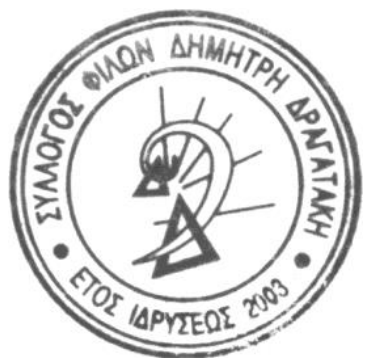

Dear Elyse,

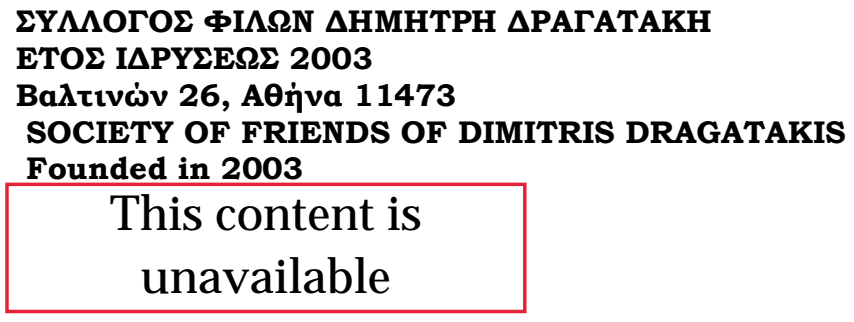

Athens, February 20, 2019

Thank you for your recent visit to the Dragatakis Music Archives in Athens, Greece. It was a pleasure to meet you and to see your energy, passion, and enthusiasm about what you want to accomplish and we believe a lot of good things will come out of this project.

Following on from our discussion, it would be wonderful if you were able to return to Athens in 2019 to create an online presence for Dimitris Dragatakis as well as the ongoing work at the Dragatakis Music Archive. Your expertise in digital communication and general online content design will be invaluable to this project. In addition to the creation of an online presence, there would be a number of archival tasks to be further developed within the Dragatakis archive in which we'd like for you to play a significant role. We believe this will have a direct connection with and will support your PhD research project.

During your residency in Athens, we will be able to provide you with full access to all the materials you need and would like to meet regularly to discuss the progress of your PhD and archival tasks. We predict the time needed for these tasks could be between two to three months.

Due to the nature of the Dragatakis Music Archives and its status as a non-profit organization, the Society of Friends of Dimitris Dragatakis would not be able to compensate you for your time; however, we hope this letter of invitation will assist you in obtaining the necessary funding for travel and living expenses to make this possible. Please pass on our contact details to your potential funding agencies if they should require any further information.

We enthusiastically await your return to Athens and look forward to working together in the near future.

Sincerely,

Magdalini Kalopana | Dragatakis Archive Curator

$$
\begin{gathered}
\text { This content is } \\
\text { unavailable }
\end{gathered}
$$
Valia Koronidis Dragatakis | Dragatakis Archive Director, Secretgantafthn Canintw
of Friends of Dimitris Dragatakis and Dimitris Dragatakis' daugh This content is 
http://dutchviolasociety.n1/2019/09/ivc2019-poznan-blog-day-2/

\section{IVC2019 Poznan blog - Day 2}

Posted on $\underline{26 / 09 / 2019}$ by DVS

The 46th International Viola Congress takes place in Poznan (Poland) from Sept. 24th - 28th, 2019. Your intrepid bloggers Karin Dolman and Kristofer Skaug bring fresh reports daily from this temporary hotspot of the viola universe.

\section{Day 2: Wednesday, September 25th, 2019}

I must be getting old, as attending viola ensemble rehearsal at 8am (a daily session aptly titled "Everyone is Eager", in the early drafts of the programme) proved to be an impossible challenge this morning, after late-night blogging work. Apparently 3 die-hards showed up... but I'm not too ashamed, because without that extra sleep I would have been unconscious at this point, unable to complete this blog in time. Hang on for the full report of a very long and action-packed day...!

The 9am lecture session kicked off with a "food-for-thought" session by Myrna Layton (representing the Primrose International Viola Archive - PIVA) with the title "Building your public: attracting and retaining the Millenial and iGen(eration) audience". She started out elaborating a number of thesis statements:

- Performers needs to build an audience if they want to have an audience

- Players need to ask themselves about their relationship to their audiences

- All musicians should be able to address audiences confidently

- Understanding the "iGen" means understanding the future (audience) As a result, a "list of things to think about" emerged, however it remains more a list of questions than ready-served answers (that would be too easy!). I wonder if we can figure out how the iGen audiences work before the next hard-to-reach generation emerges...!

Next up was an interesting presentation by Elyse Dalabakis, concerning the viola concerto by the Greek composer Dimitris Dragatakis. This is part of her Ph.D. research under guidance of prof. Donald Maurice, in Wellington (NZ). She travelled to Athens to perform archive research for this work, and was also introduced to Artur Paciorkiewicz, the Polish violist who did the premiere performance and recording in 1993. 


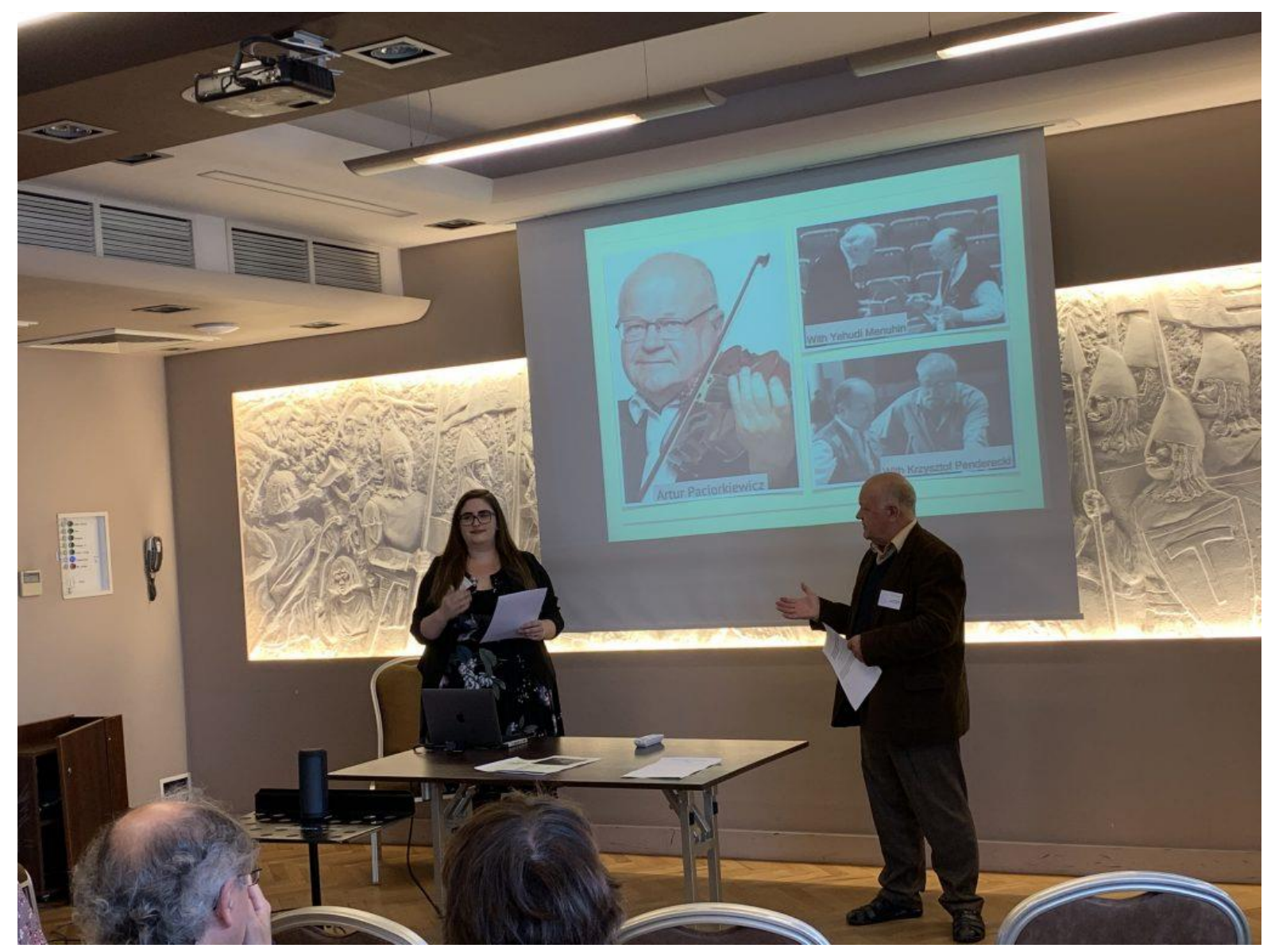

By no coincidence whatsoever, mr. Paciorkiewicz was present in the room, and was subjected to a (prepared-translation) interview about the process of rehearsing and performing this work. The composer (Dragatakis) was apparently unusually pleased with the premiere performance, the first movement of which we were given to hear the actual recording (reportedly a premiere sounding as such). It is indeed a fascinating work!

At 10am we hurried over to the POSM recital hall, where Maxim Rysanov was giving a master class. The DVS "Sister Act" (Sunniva and Ursula Skaug) were fortunate to go first, with a half-hour lesson on the Lutoslawski Bucolics. He easily squeezed out some extra mileage in dynamics, phrasing, tempi, and even re-arranging the octave choices in various places. After this there were some very interesting lessons on the Bach solo suites, the names of the students unfortunately escaped me.

The programme "An oriental bridge" by Baris Kerem Bahar (Turkey) featured various solo viola pieces written mostly for (and even by) himself. On the whole his compositions are neither modern in style nor very virtuosic, but quite sweet and melodic music (quote: "I'm a romantic guy!"). The ornaments and sounds are really oriental, but with a very classical trained scale work.

Unfortunately, he was unable to perform his programmed pieces by Tsintsadze and Khachaturian, because there was no pianist (wtf 1st degree). Instead he took more time for a Q\&A session, and told us about an emerging genre referred to as "Turkish classical music", which bridges traditional oriental and classical styles, making a specific use of e.g. 
vibrato, sul tasto, ponticello, and quarter-tone adjustments on conventional scales. For more information you can visit his website: www.bariskerembahar.com

The Swiss IVC delegation summed up in one person, Viacheslav Dinerchtein brought an interesting lecture-recital about Mieczysław Weinberg's solo sonatas for viola. Born in a Polish-Jewish family in pre-WW2 Warsaw, the talented pianist Weinberg fled (as only survivor of his family) when the German invasion came, and ended up in Minsk (Belarus), where he entered the Conservatory. Particularly notable is his discovery of, and eventual friendship with Shostakovich. They were both very prolific composers, and it seems clear that they influenced each other musically. Case in point, Dinerchtein postulated with confidence that Fjodor Druzhinin's performance of Weinberg's viola sonatas must have given Shostakovich the spark to write his own viola sonata. In the other direction, Shostakovich fervently and publicly defended Weinberg's music against bans and official State beratements.

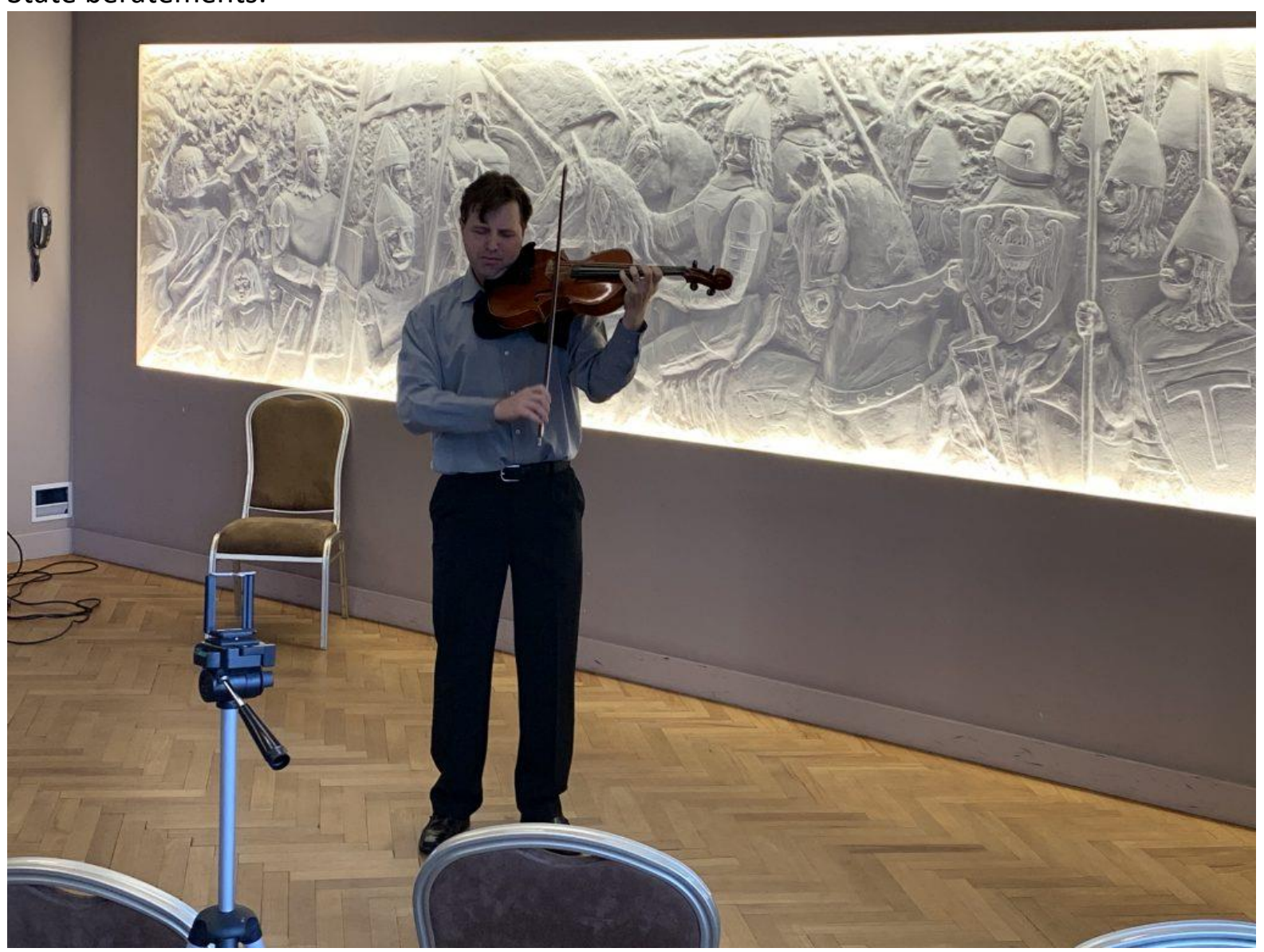

Dinerchtein played the 1st Weinberg solo sonata for us by heart (!), a very complex work, and deeply impressive. I (Karin) definitely could hear the influences of Shostakovich here, but I also felt a touch of Britten - one of his string quartets sounds nearly like a quotation from this Weinberg viola solo sonata.

Lunch break - so we eat our lunchbag sandwiches, with not-too-cheap coffee from the Hotel Ikar restaurant. Outside it has started raining, quite a lot actually. So we're happy to stay inside and visit the stands at Music4Viola and Gems Music publishers, where lots of interesting repertoire for viola ensembles is on display. 
We end up buying a healthy stack of fresh sheet music, for further enjoyment at home. After the break, Aneta Dumanowska and Barbara Papierz performed (as "teacher-student" duo) the Lament for two Violas by Frank Bridge, bringing out some pleasing whole-bodied confluences of sound, which are richly latent in this possibly most famous piece of the viola duo repertoire. It is nearly a symphony in itself, well written technically for the viola, a delight to play and also today to listen to.

Next, Annette-Barbara Vogel and Jutta Puchhammer-Sedillot take on the Sonata for violin and viola (1945) by Mario Castelnuovo-Tedesco (1895-1968): A piece with significant challenges in articulation and sound production. Not to be taken lightly! 1st movement (con brio) is very cheerful and bright. It made me (Karin) think of Reger's trios for flute, violin and viola - even in dynamics. Then there are also the Rollaisms, i.e. violin and viola happily agreeing about everything.

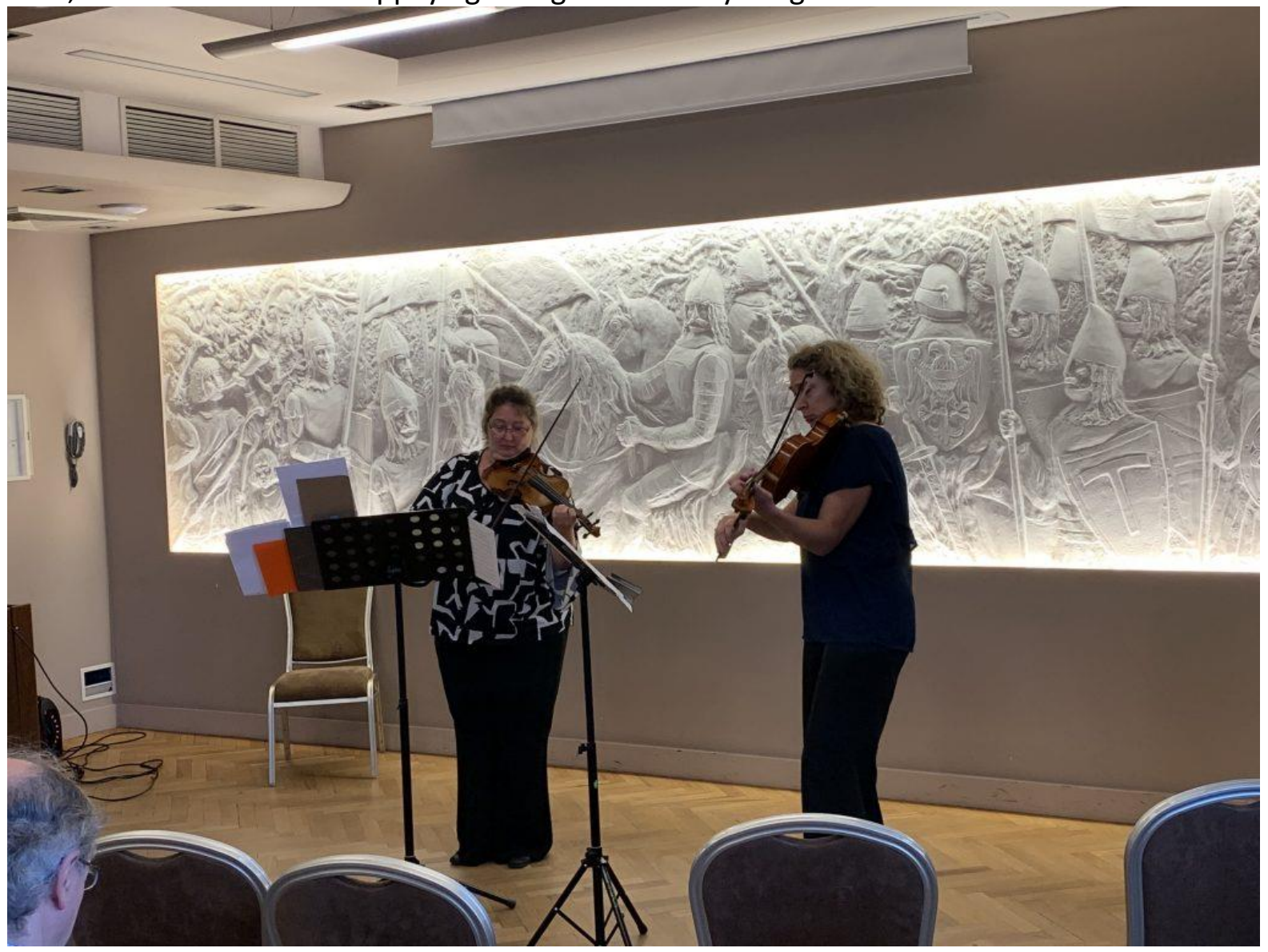

The 2nd movement introduces a more reflective theme, which is fed into a series of variations. The interplay of violin and viola voices is varied and imaginative. The melody initially stays in the viola, and the violin adds Schubertian high variations. And then suddenly this beautiful waltzer followed by an heroic theme in both instruments accompanied by daunting arpeggios. The movement ends with a rich fugue (reminding us why we have to practice thirds!). Beautiful!

The ensuing virtuosic Scherzo - Rondo movement is very enjoyable music (an intersection of waltzer and tarantella), and very well played too! 
An extra cheer from the crowd: The Portuguese delegation has finally arrived, after a harrowing double-delayed travel of 26 hours without sleep! And just in time for Jorge Alves to bring his contribution to this recital: Two contemporary viola solo pieces. The first piece, Dedans-Dehors by Miguel Azguime (b. 1960), is anchored in deep accentuated Enotes on the C-string, with excursions through glissandi and harmonics all over the place, full of surprising twists. It evokes a feeling of timelessness...

The next work by Armando Santiago (b.1932) bears the title "Neume III, en huit strophes" (the programme booklet had it badly misspelled). The music is challenging for the performer as well as the listener: Likened to "a crazy person talking", there are undulating, shifting notes and odd, erratic pizzicato outbursts, as well as movements hard to describe with words, except perhaps "you had to be there"...

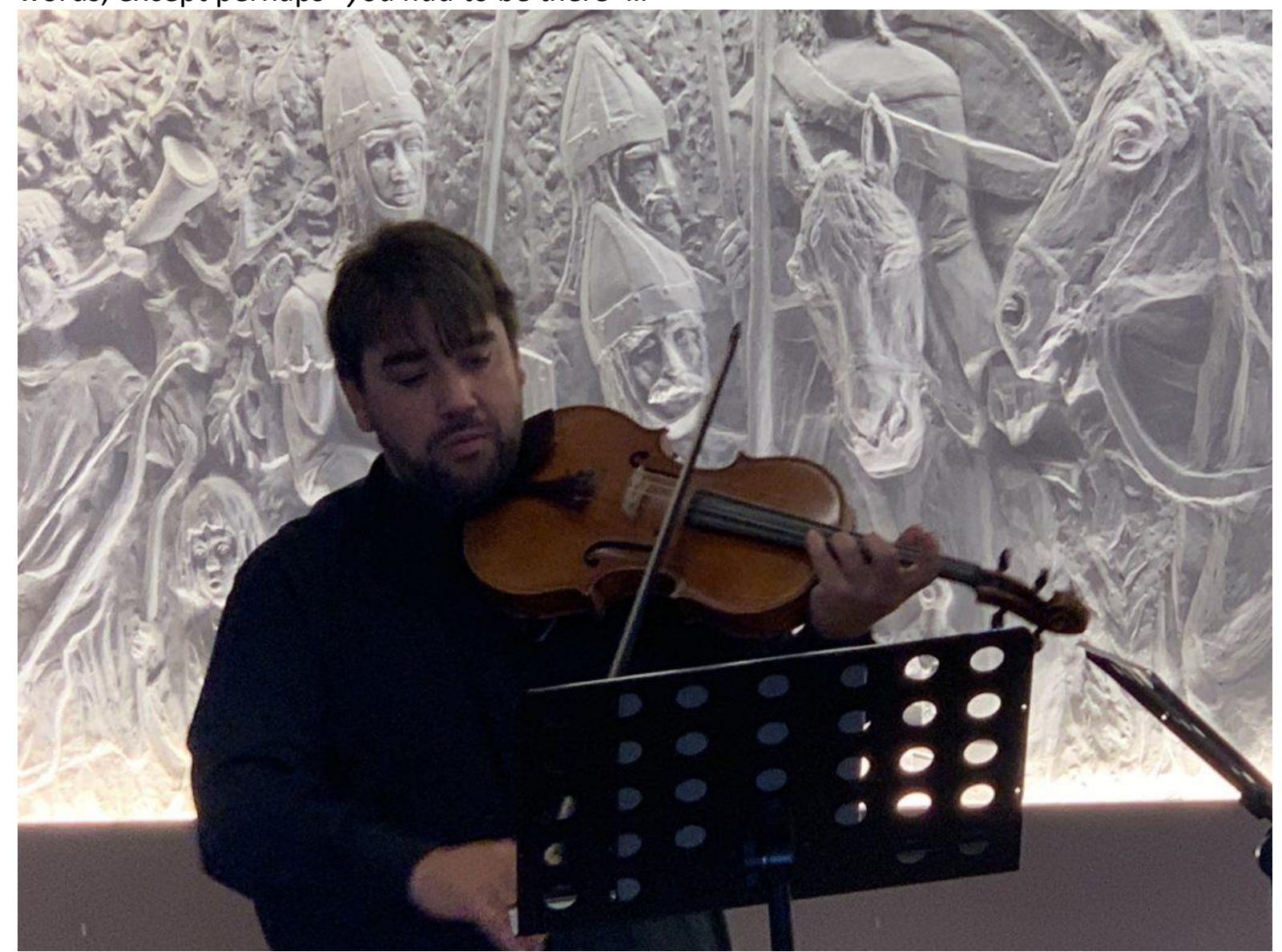

Following a rather wet walk through historical downtown Poznan, we entered the house of the Henryk Wieniawski Music Society, in an alley behind the beautiful Market square. There's a living-room concert venue with an old white Calisia grand piano (glad there aren't more IVC attendees, as they would have had to listen outside, in the rain!).

Due to the transit time, we unfortunately missed the lecture about the viola compositions of Tadeusz Paciorkiewicz, but we were on time to hear his viola sonata being executed by Błażej Maliszewski (with Paweł Rydel on the white piano stool).

The next program concerns classical cello sonata transcriptions. Prof. Leszek

Brodowski explained his affinity to transcriptions by the shortage of (readily available) viola solo repertoire when he graduated from conservatory, 40 years ago; so he started writing 
his own transcriptions of classical works - Mozart, Mendelssohn, Schubert. He then performed a transcription of Beethoven's Cello Sonata op. 5 no. 2 in g minor, which indeed sounded like a very convincing option for viola - not least by the visible pleasure that prof. Brodowski took in playing Beethoven here, in this chamber music room, where the spirit of Wieniawski is all around.

Krzysztof Komendarek-Tymendorf followed suit with his very own transcription of Brahms' Cello Sonata no.1 op.38 in E minor. Together with pianist Mirosława Sumlinska he brought the "transcription" themed concert to a very passionate culmination. Unrelated to the skilled performance, however, one can't help missing Brahms' powerful cello notes deep down.

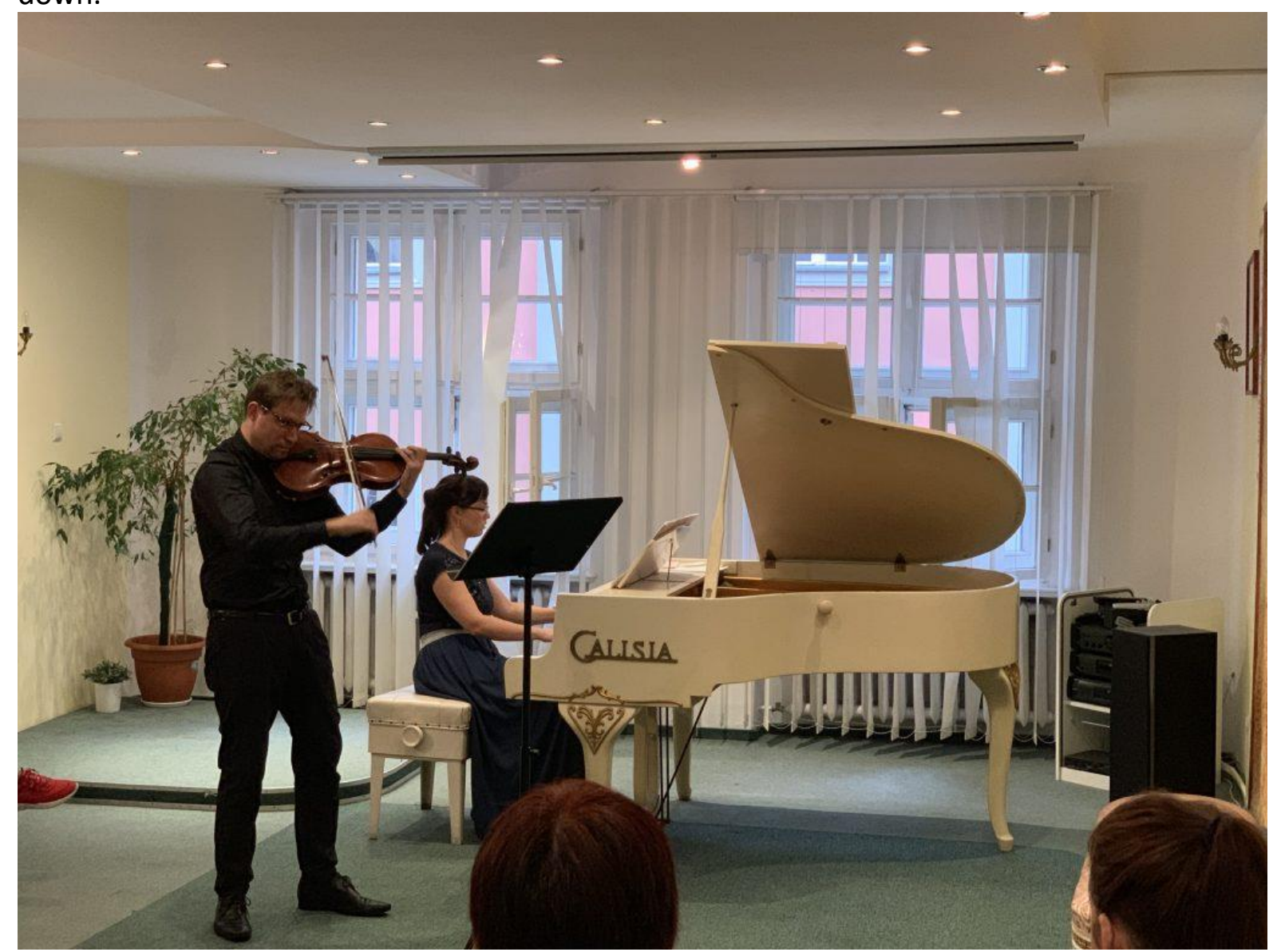

Tymendorf's proverbial encore was an actual world premiere of the piece "Waldteufel und Nixe" by Artur Andrzejewski, more of a miniature, tonal in construction in spite of the 1965 
birth year of the composer. Very enjoyable - and noted on the wishlist!

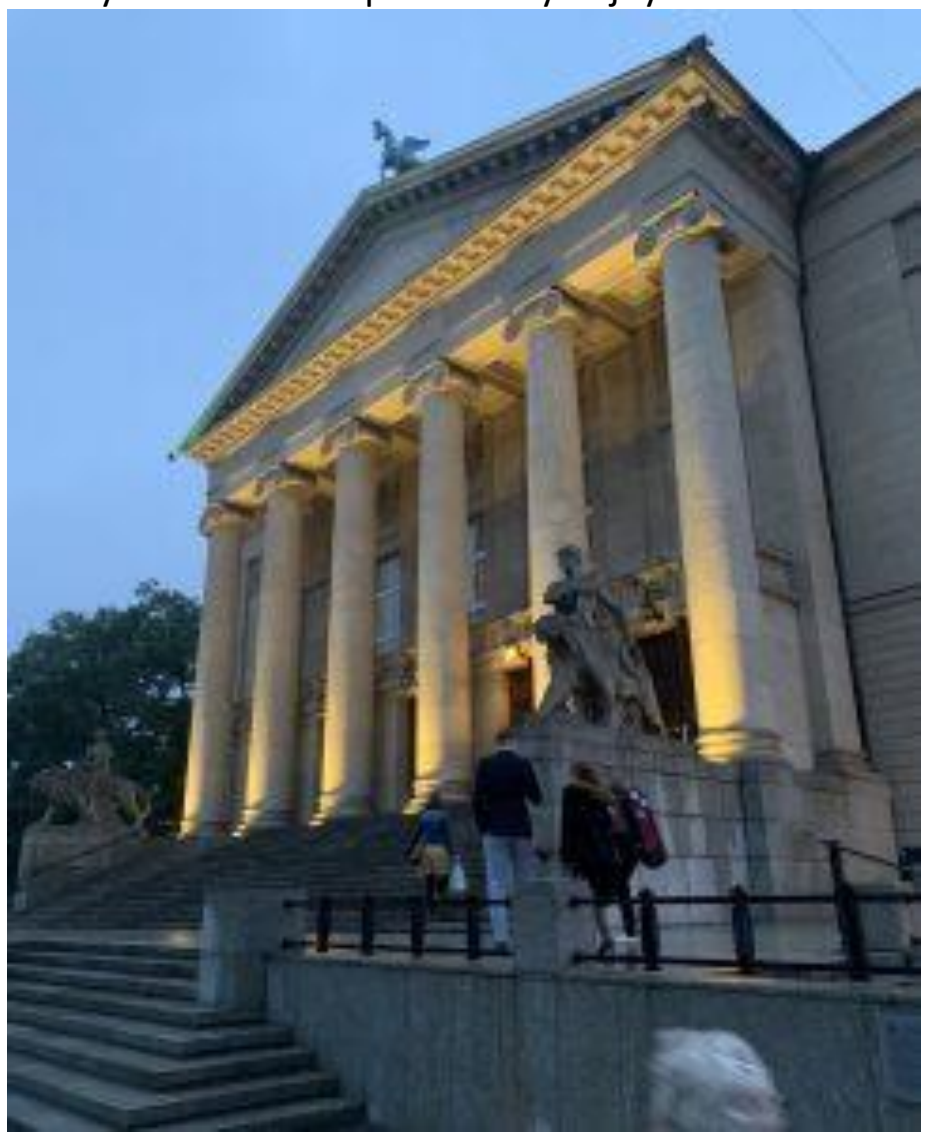

This leaves us with 90 minutes of rest for the ears, and other restorative activities, before we head to tonight's evening concert in the Poznan Grand Theatre, a quite spectacular building and beautiful opera/concert hall. The Poznan Grand Theatre Symphony

Orchestra has taken the stage, with Katarzyna Tomala-Jedynak at the baton. No less than FOUR concertos are programmed, 2 solid hours of viola concertos binge-listening without an intermission! OMG...

After a short welcome and introduction from our hosts as well as IVS president Carlos Maria Solare ("what's-all-this-Viola-Congress-stuff-then?", for the broader audience), we are all set for the Anton Wranitzky double-concerto in C, with grand old man Jerzy Kosmala playing together with his own 17-year-old grandson (!) Stefan Kosmala-Dahlbeck. Although both are currently living in the U.S., their roots in Poland are strong. 


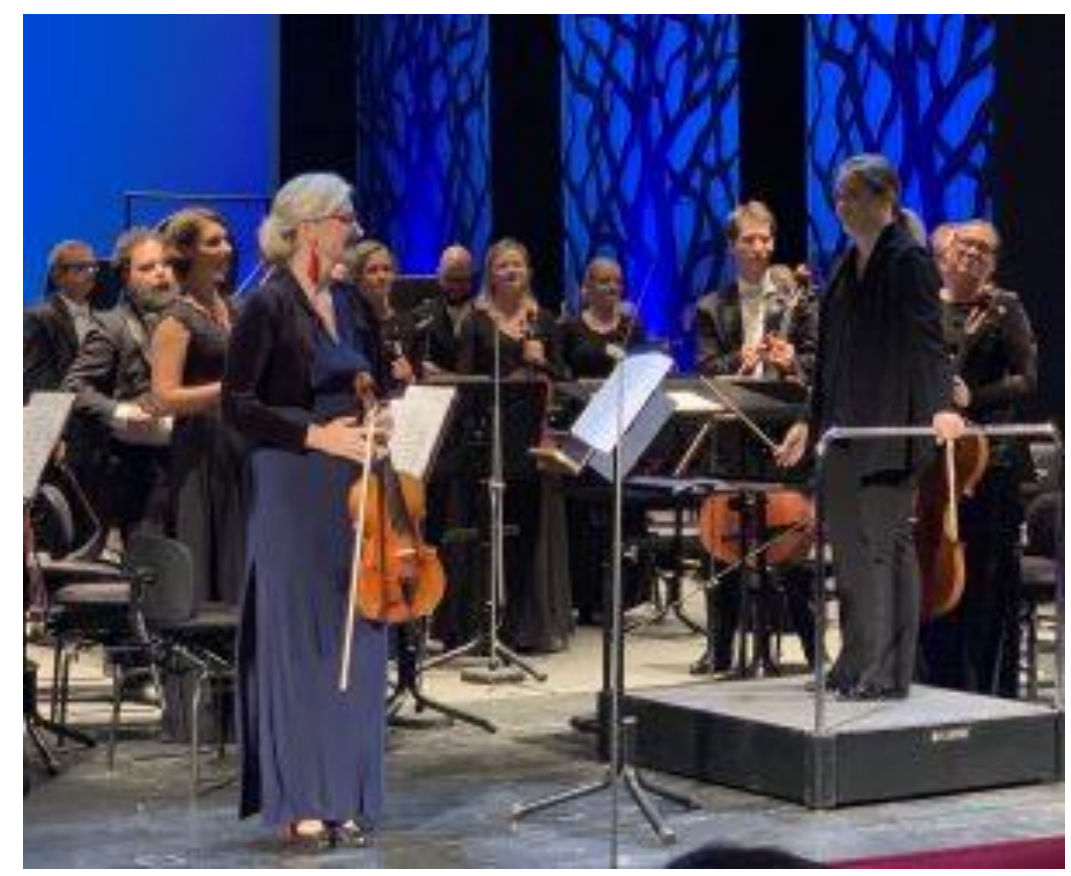

The second concerto on the programme this evening was composed in 2016 by the young Ewa Fabiańska-Jelińska (b.1989), and performed by our congress co-host Ewa Guzowska. It is a refreshing contrast to the Wranitzky concerto, and Guzowska adds a lot of energy to the performance, with beautiful tone qualities. Her viola speaks easily through the string orchestra accompaniment.

Similarly for viola and strings is the concerto by Marek Stachowski, interpreted by Tomasz Rosinski. The latter is audibly and visibly a first-rate violist, but the "script" he gets to work with is a bit on the meager side here. There is significant repetition, long periods of soloist inactivity, and not enough material to keep things cooking for the (too long) duration of the piece.

The opposite would be true for the 1968 concerto of Grażyna Bacewicz (mentioned in yesterday's blog): in the hands of violist Paweł Riess, and joined by a fully instrumented symphony orchestra (except - oddly, the viola section is vacated!), this piece turns into a truly impressive work. The slow movement is of great beauty, and the finale is explosive and furious. Compliments to the soloist, conductor, and the orchestra alike! 


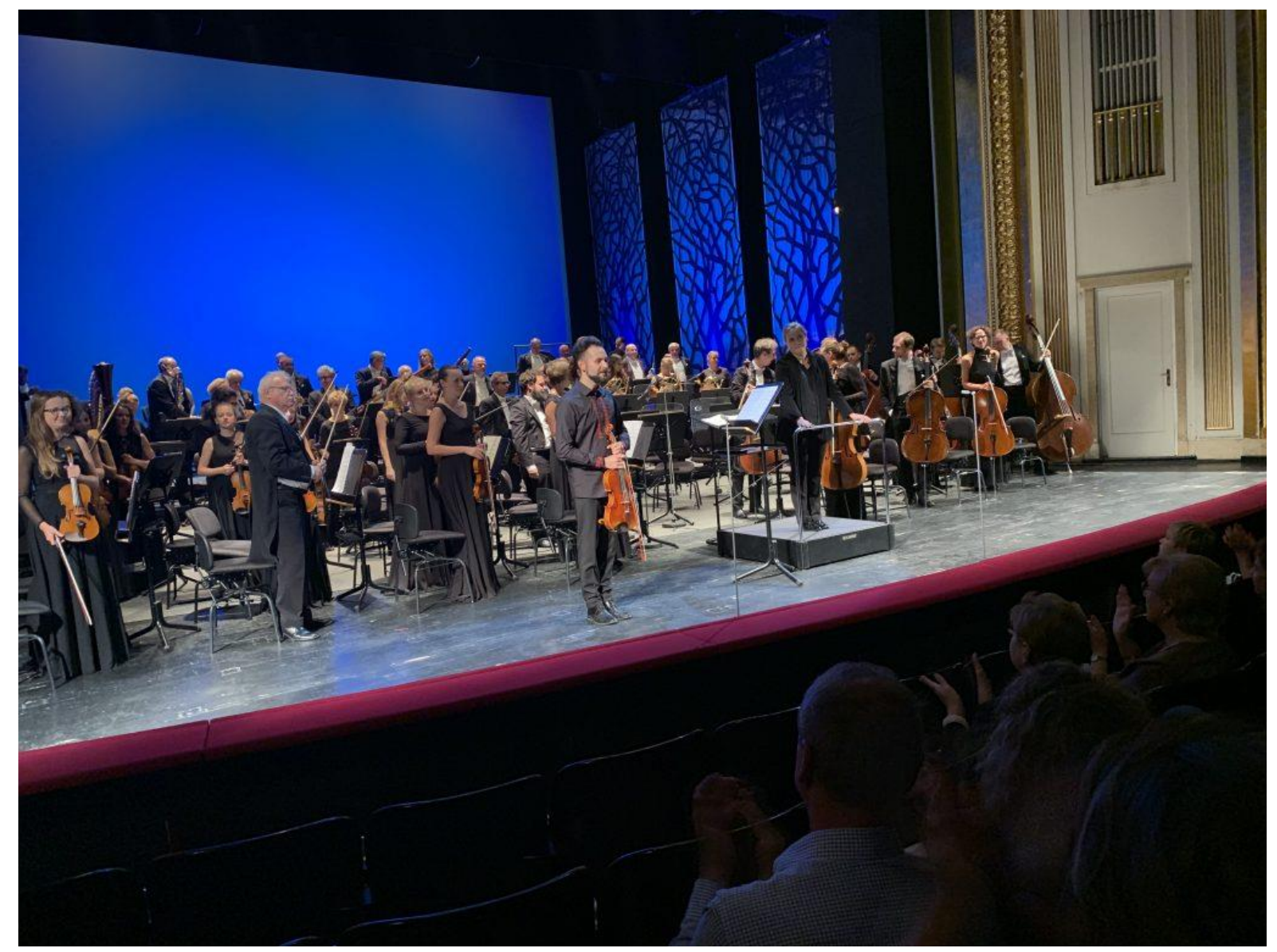

I could say more, but this blog is already long enough, and I am really Eager to make it to Viola Ensemble practice tomorrow at 8am! So that's it folks - tune in again tomorrow...

- Karin \& Kristofer 


\section{NZSM PhD candidates launch their $\mathrm{PhD}$ research on the international stage}

Elyse Dalabakis and Xi Liu (Lucy), two NZSM PhD candidates and violists, launched their $\mathrm{PhD}$ research onto the international stage through presentations and performances at the 46th International Viola Congress (IVC) - the largest annual conference centered around the viola - in September in Poznan, Poland.

\section{October 2019}

One of the major purposes of the International Viola Society is to promote everincreasing standards of excellence in viola performance through the annual congresses and associated competitions. International Viola Congress have been held since 1973 and have been hosted twice in Wellington. The 44th International Viola Congress was held in Wellington in 2017 and was co-hosted by Professor Donald Maurice and Associate Professor Gillian Ansell and managed by Elyse Dalabakis. The first IVC in Wellington was hosted by Donald Maurice in 2001 and was the first-ever IVC to be held in the southern hemisphere.

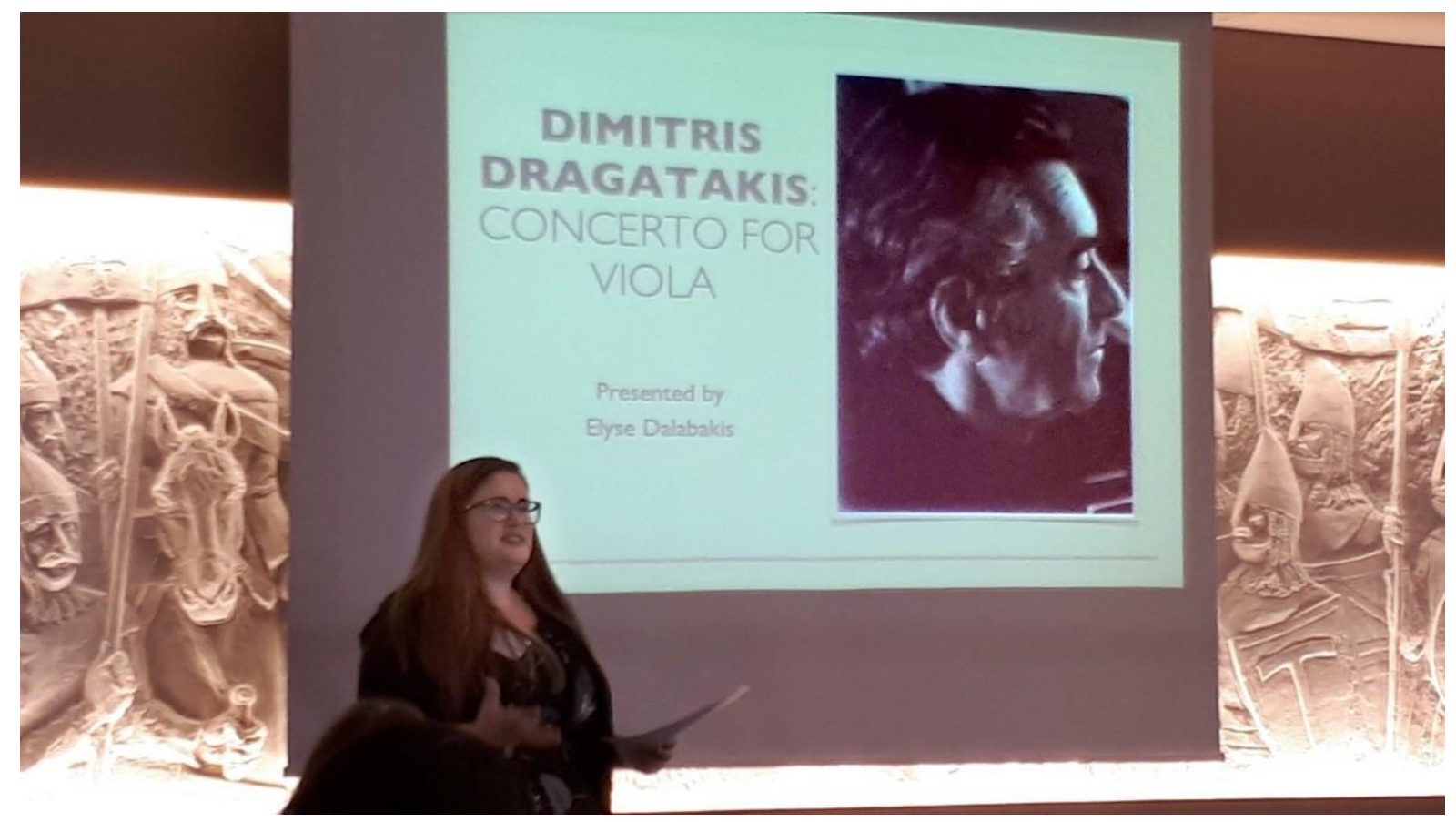

Elyse Dalabakis presented her PhD research on modern Greek composer Dimitris Dragatakis (1914 - 2001) and his Concerto for Viola. Interestingly, Artur Paciorkiewicz, the violist who premiered the concerto in 1993, was present for the lecture and was invited to speak about performing the concerto and working with Dragatakis - a component which made her lecture stand out during the week. The premiere recording from 1993 was unearthed from the Dragatakis archive only earlier this year. During her presentation, she played the recording from the premiere performance - a world 
https://www.wgtn.ac.nz/nzsm/about/news/2019-news/1777998-nzsm-phd-candidates,-elysedalabakis-and-xi-liu,-have-launched-their-phd-research-onto-the-international-stage

premiere in itself as the work had not been heard for 26 years. Violists, professors, and educators in attendance described her lecture as a 'Congress highlight and fascinating'.

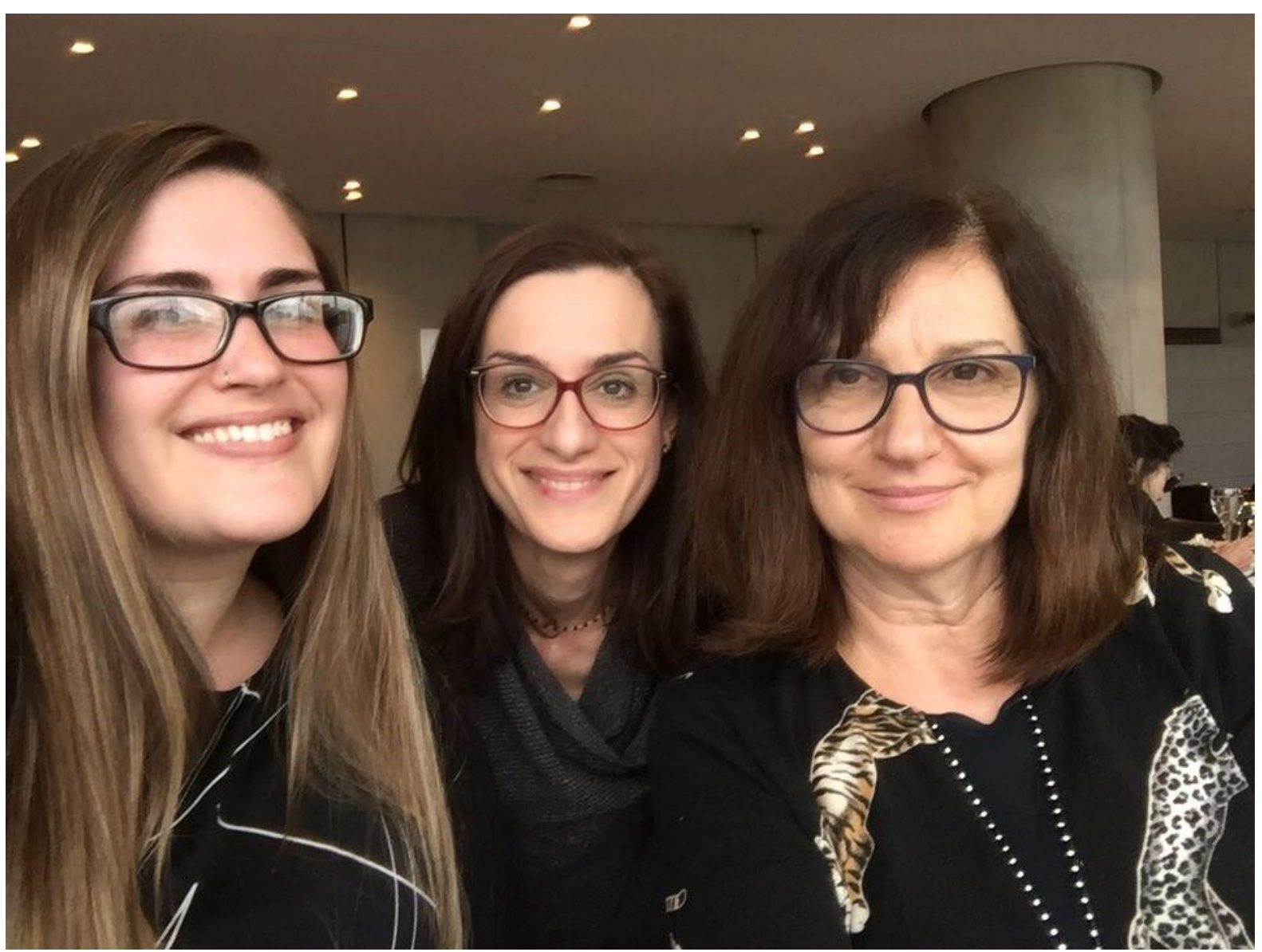

After the Congress in Poland, Elyse headed to Athens, Greece to undertake an artist residency at the Dragatakis Archive at the Greek Music Archives for the month of October, working closely with the Director, Valia Koronidi, and Curator, Magdalini Kalopana. Accompanying Elyse's PhD dissertation submission will be the publication and recording of the Concerto for Viola and piano reduction (which only previously existed in manuscript form). 


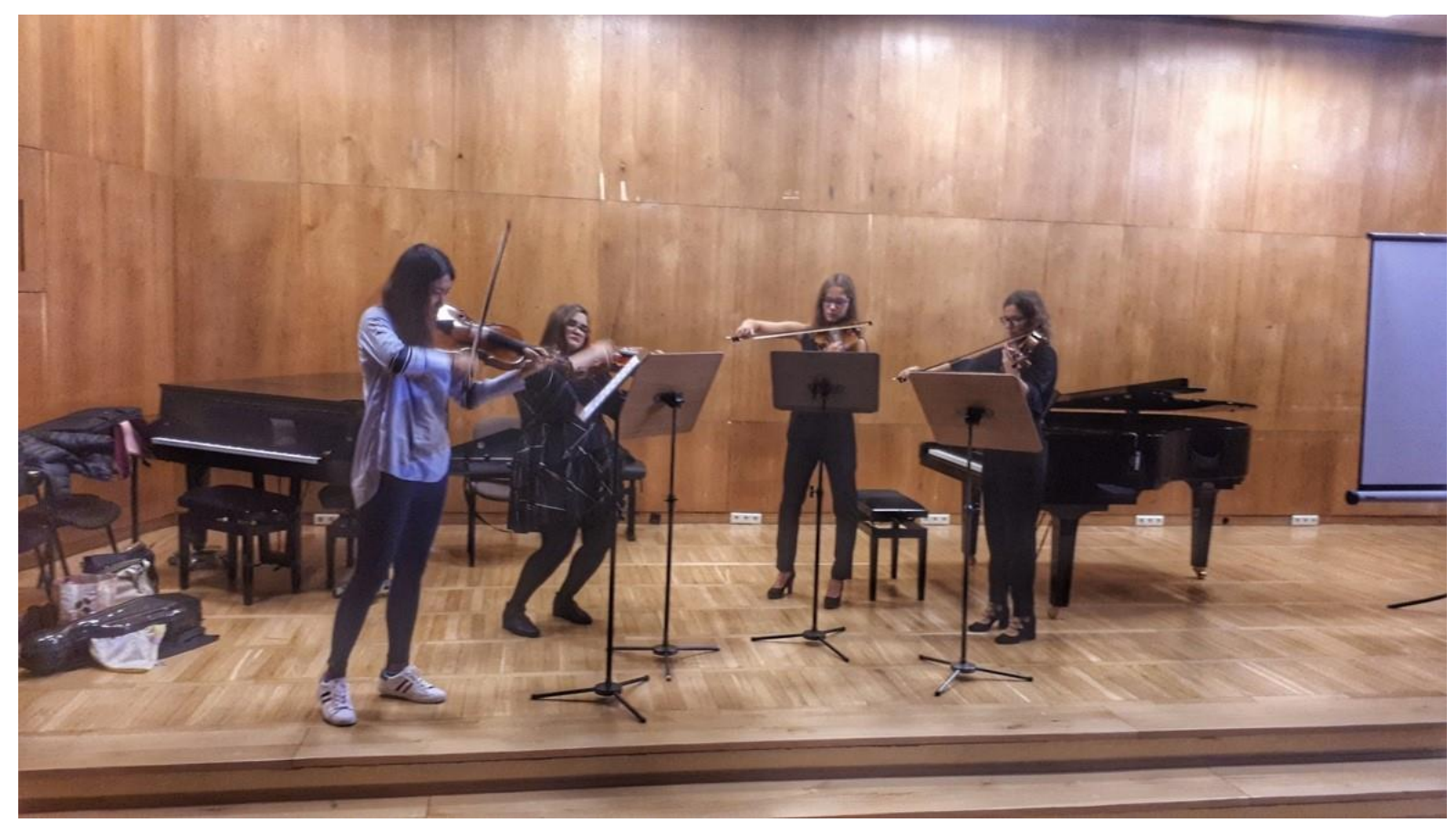

$\mathrm{Xi}$ "Lucy" Liu also presented her PhD research in a lecture recital which focused on Israeli composer Boris Pigovat (b. 1953) and performing his Sonata for Viola and Piano, and the world premiere of a new arrangement by Pigovat of his work Nigun for viola quartet. Performers were Lucy and Elyse who were joined by Marianna Kalicka and Aleksandra Ruciak, viola students of Professor Marcin Murawski from the Academy of Music. I.J. Paderewski: The performance of Nigun was very well received at the Congress with many attendees asking at the end of the lecture where they could purchase the music. 
https://www.wgtn.ac.nz/nzsm/about/news/2019-news/1777998-nzsm-phd-candidates,-elysedalabakis-and-xi-liu,-have-launched-their-phd-research-onto-the-international-stage

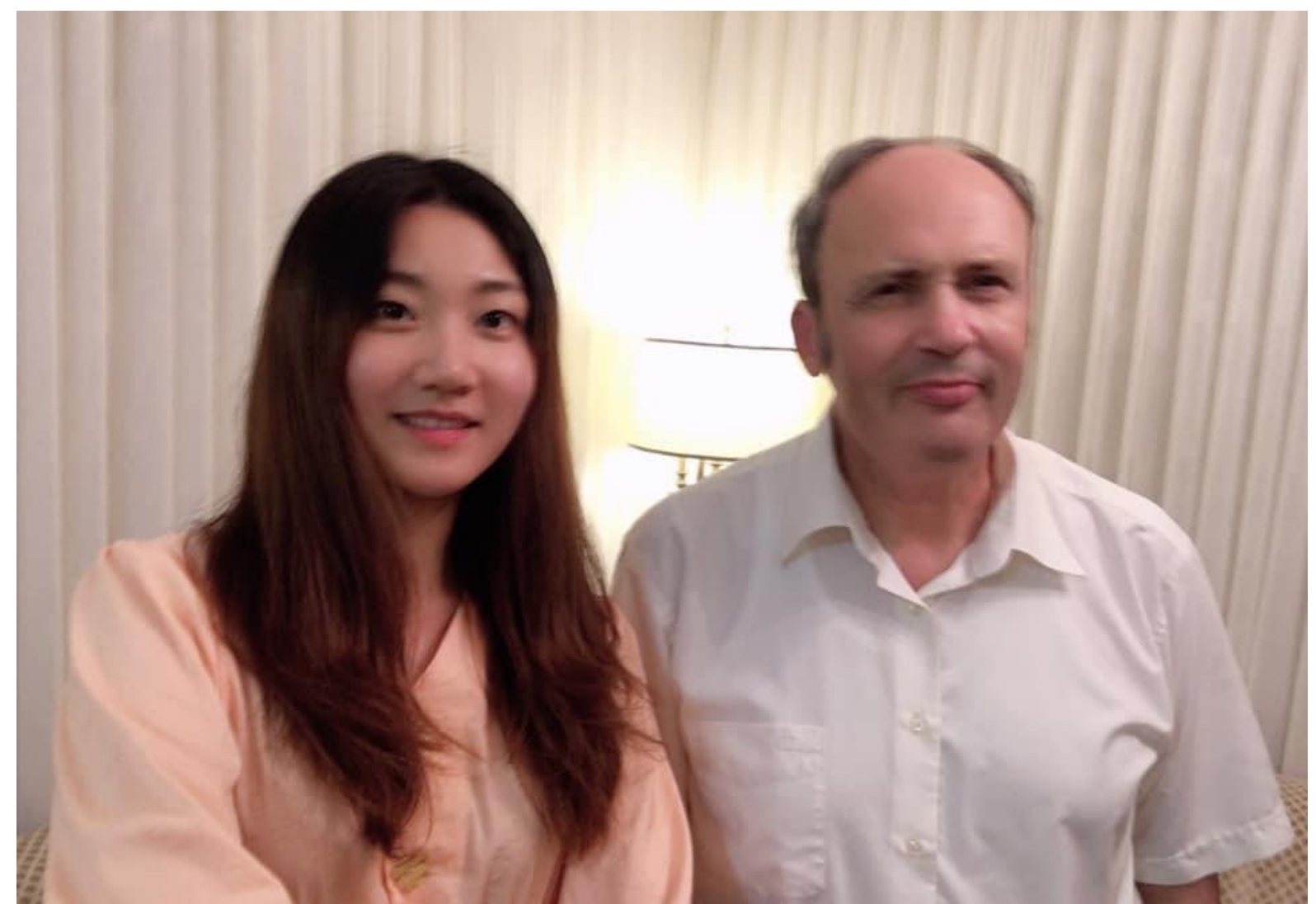

Before the Congress in Poznan, Lucy visited Boris Pigovat in Israel where she conducted a series of interviews which will be included in her $\mathrm{PhD}$.

Elyse and Lucy are very grateful to VUW's Joint Research Committee for their support in both of these presentations. We look forward to seeing Elyse's and Lucy's successes in the months to come and wish them the best with their dissertation submissions. 
Appendix 6: New orchestra score and complete orchestra parts Below is the newly typeset orchestra score and orchestra parts. Currently, the orchestra score and parts do not exist outside the archive. This material adds a valuable contribution to topics surrounding Dragatakis, but also to viola scholarship and digital humanities. The reader can also access these materials via the link below.

Link to orchestra score and complete parts

https://rive.google.com/drive/folders/1Wt5YQVMBB3lIqckpm5LTRxcA1VhNiP8E? $\underline{\text { usp=sharing }}$ 


\title{
Dimitris Dragatakis
}

\section{Concerto for Viola and Orchestra}

\author{
$\underline{\text { Full Score }}$
}

Created and edited by Elyse Dalabakis

Percussion parts edited by Hannah Neman

Engraved by Brendan Agnew 



\section{Concerto for Viola and Orchestra}

I.

Dmitris Dragatakis Horn 2in

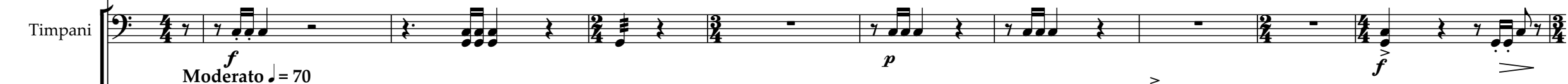

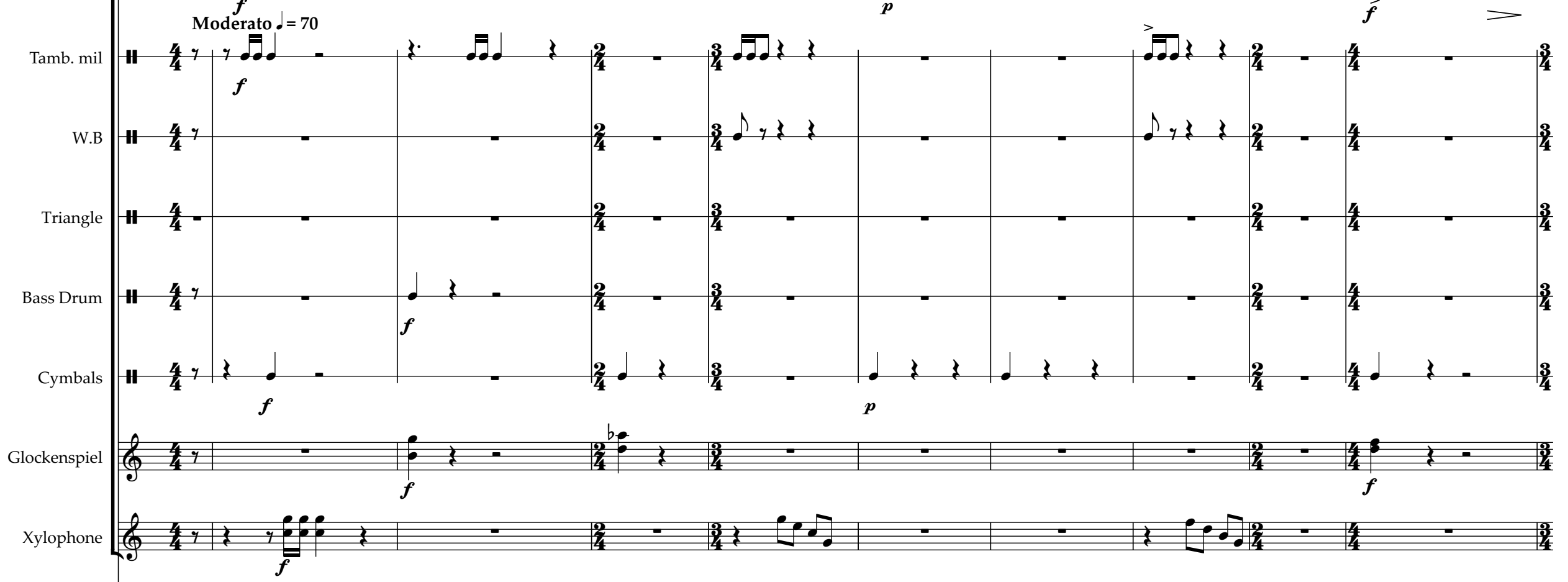

Solo Viola $1 \mathrm{~F}_{3}^{4}$

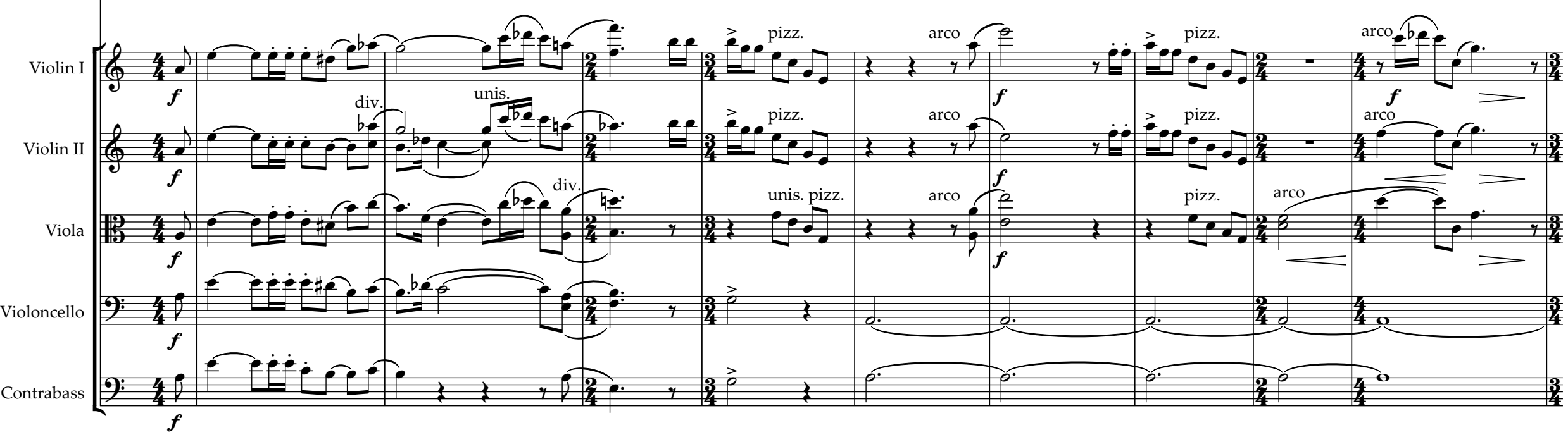



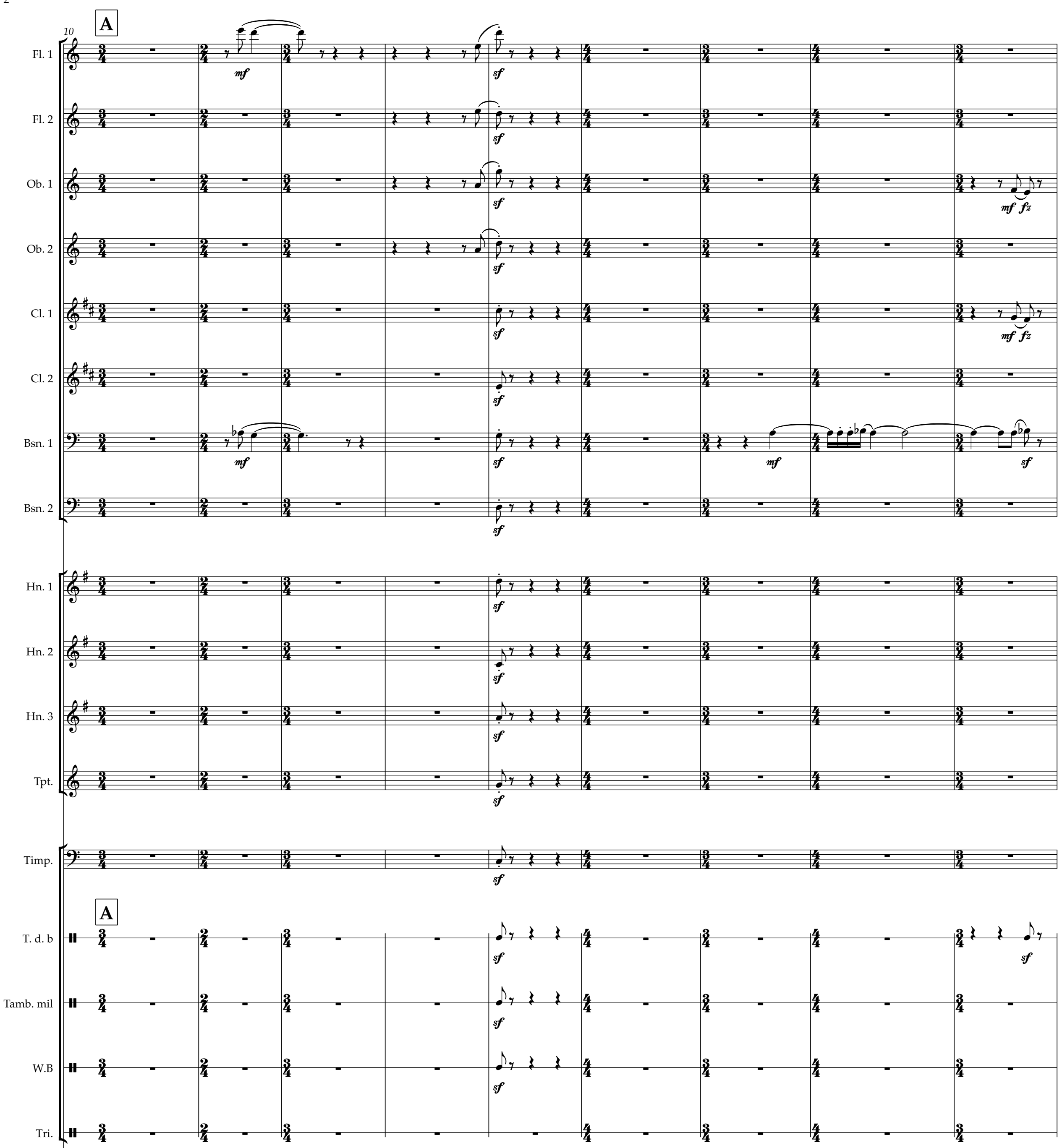

Solo Viola

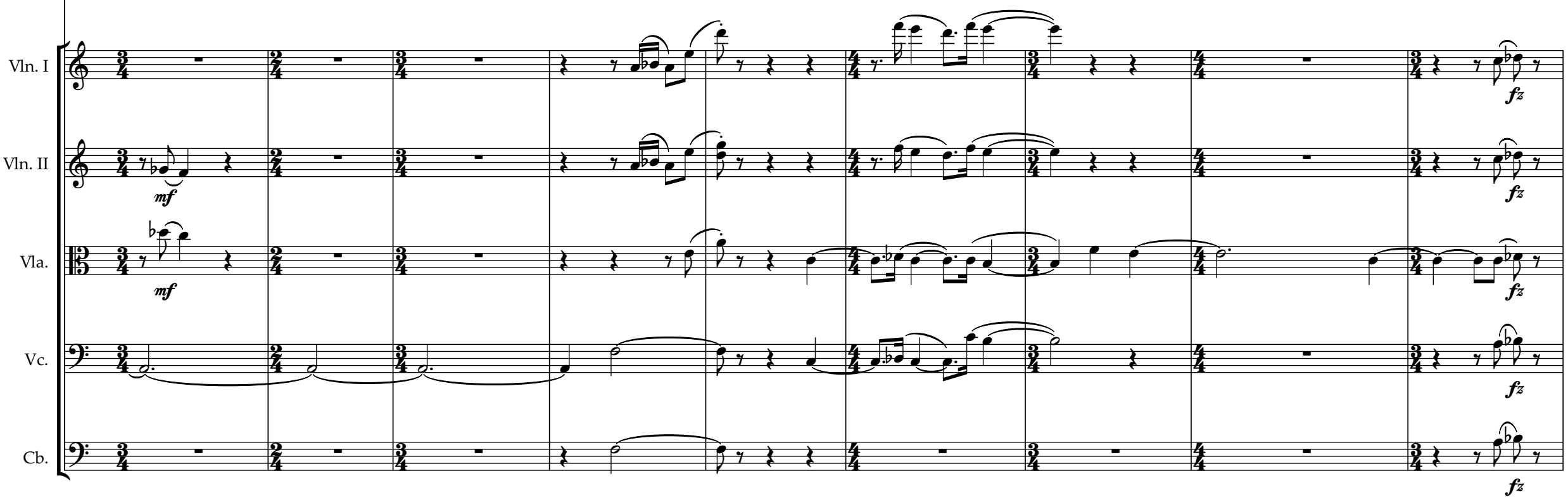



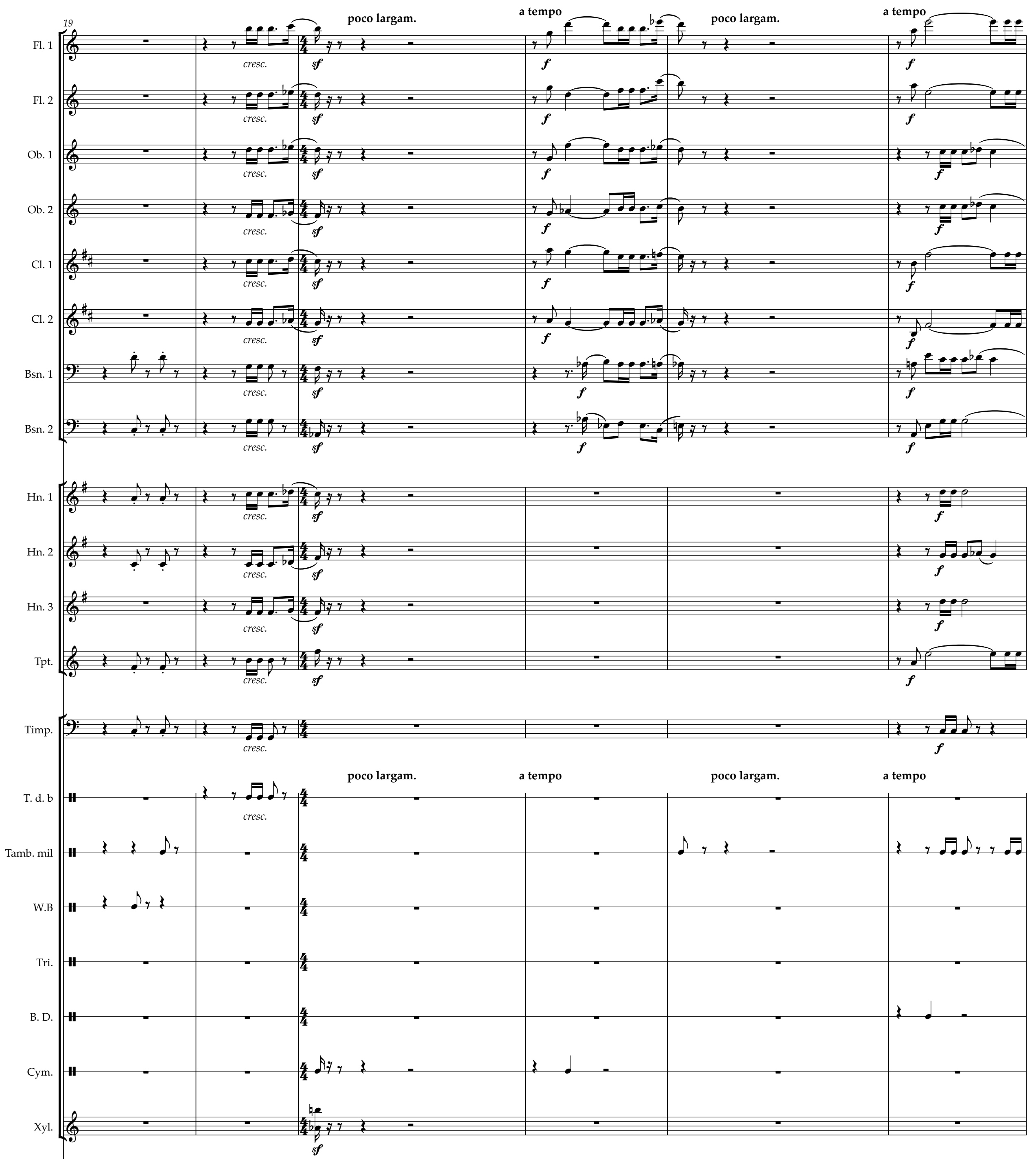

Solo Viola $\oint_{2}$ Cb. 


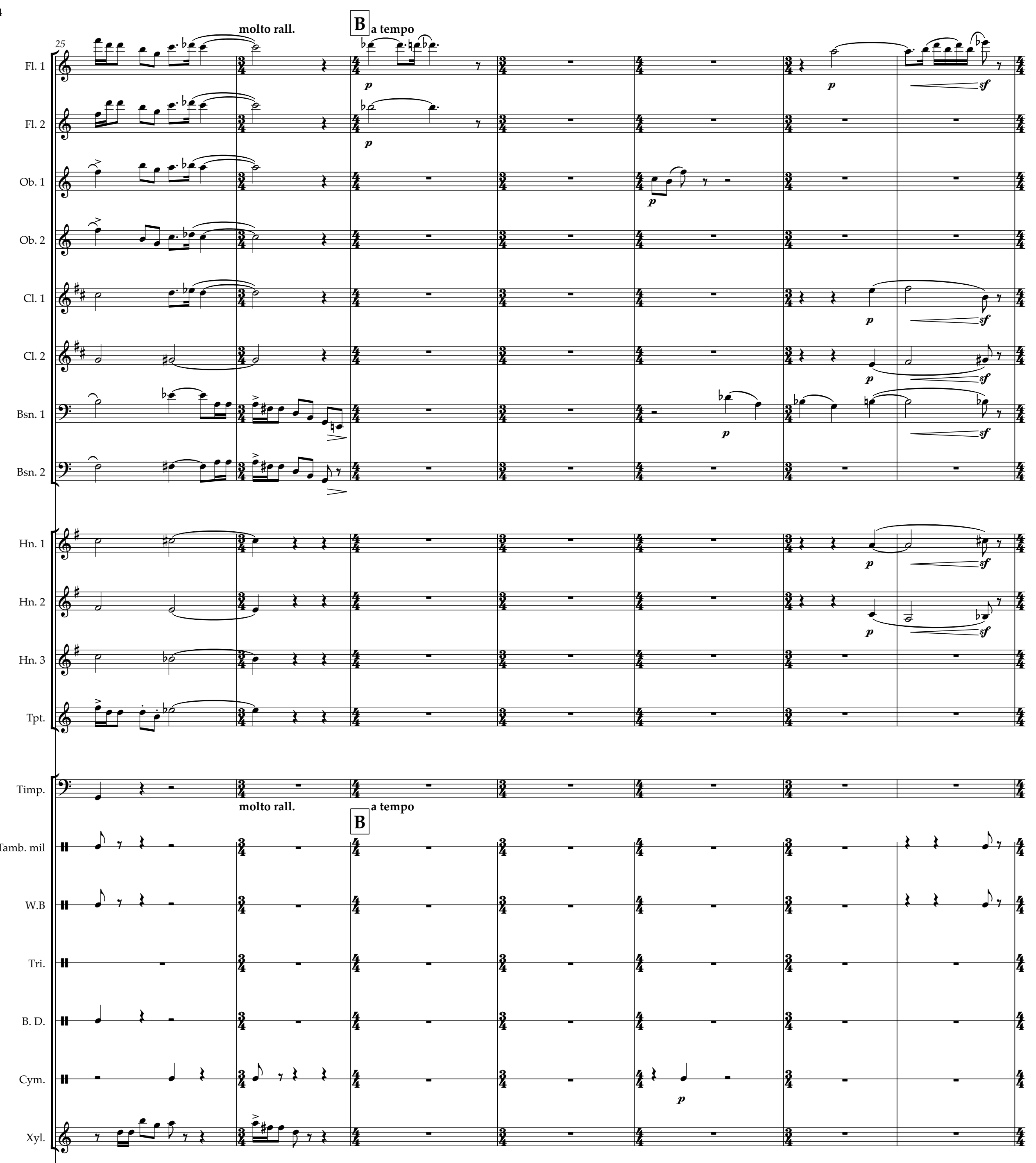

Solo Viola C.. 

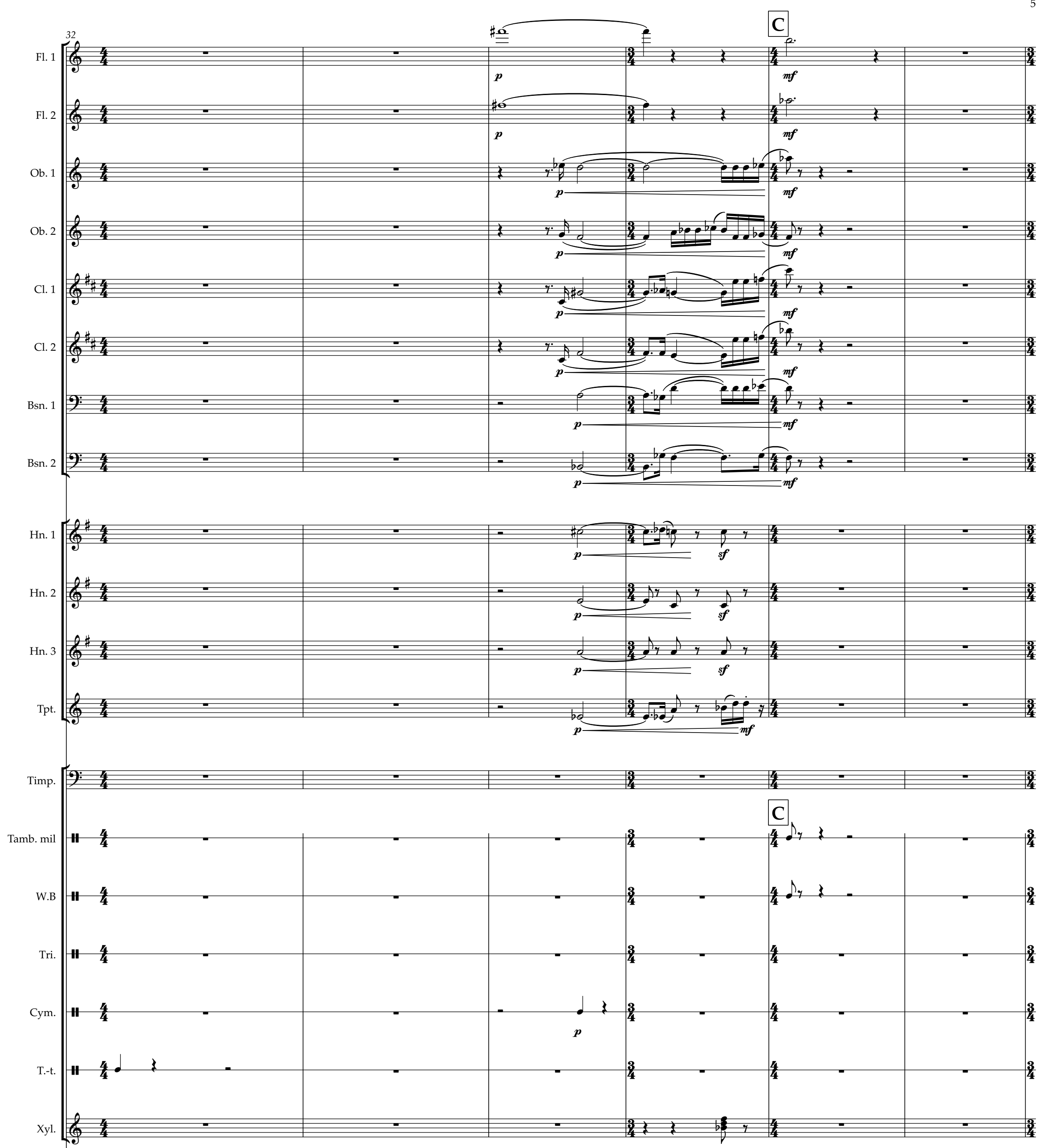

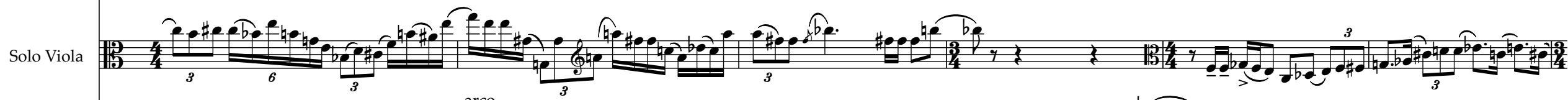

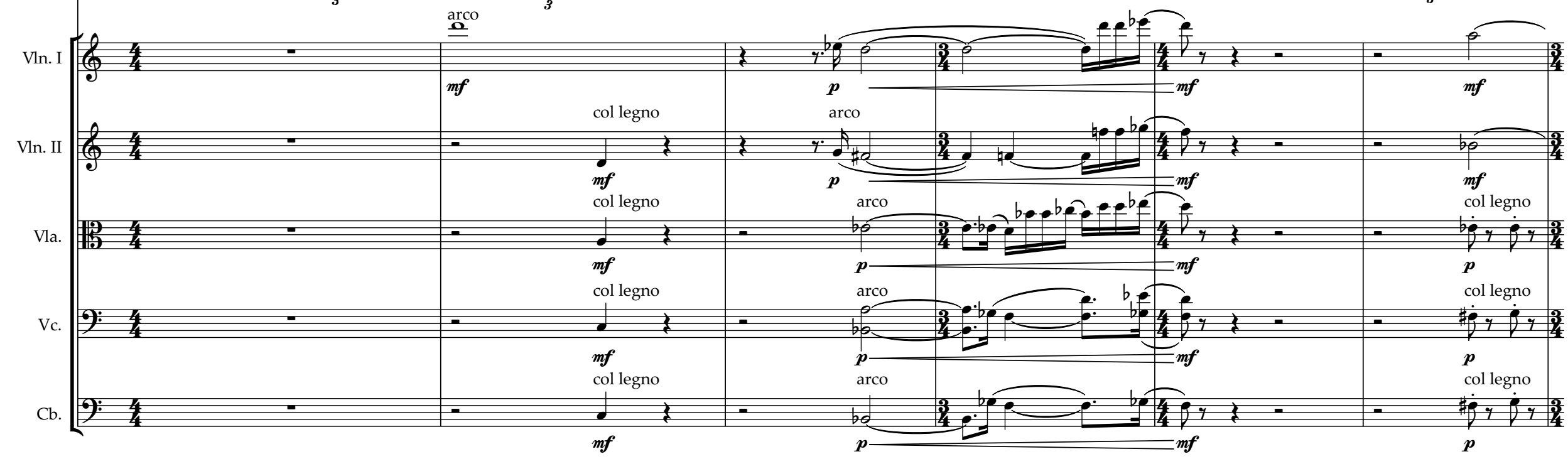



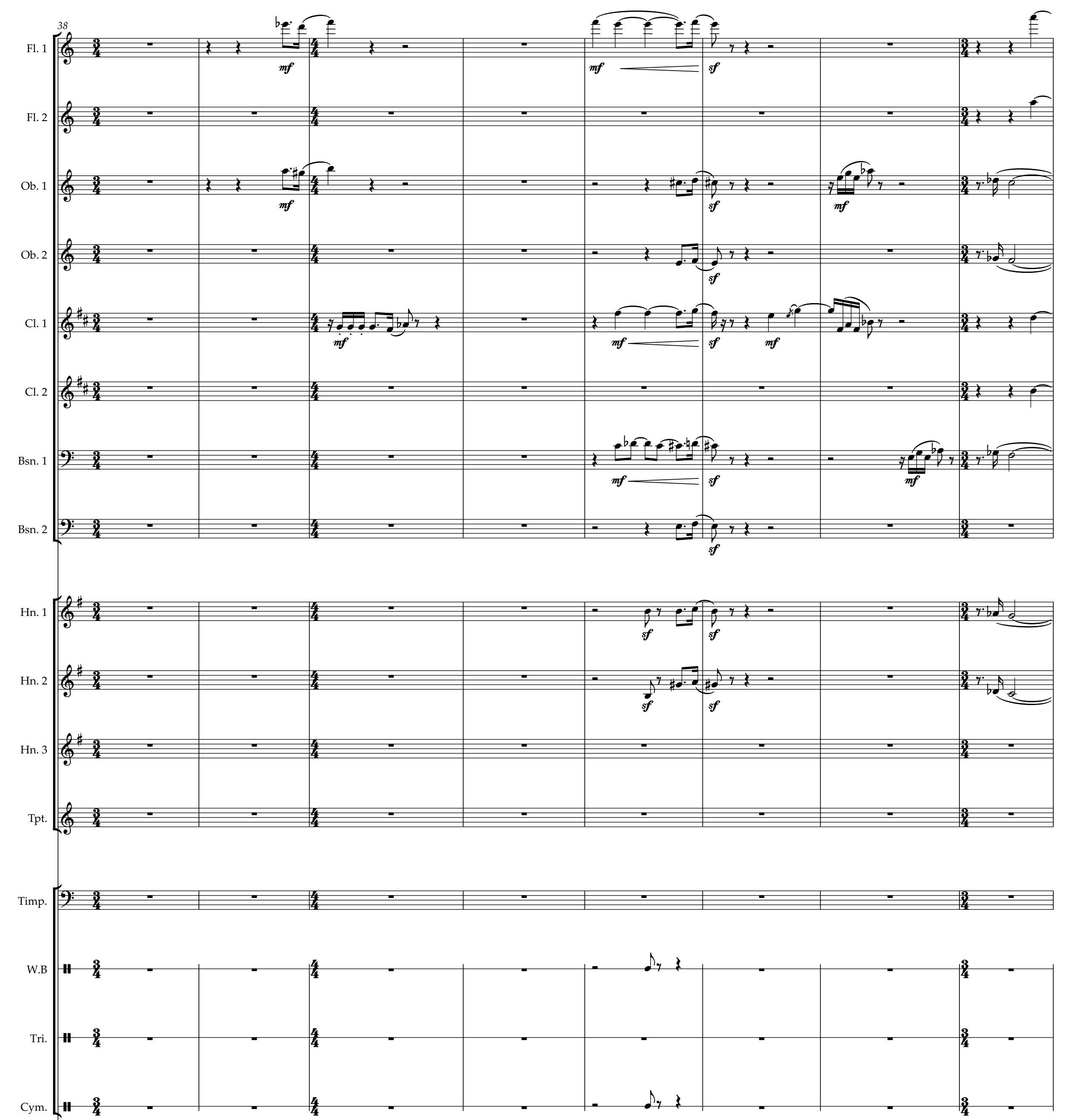

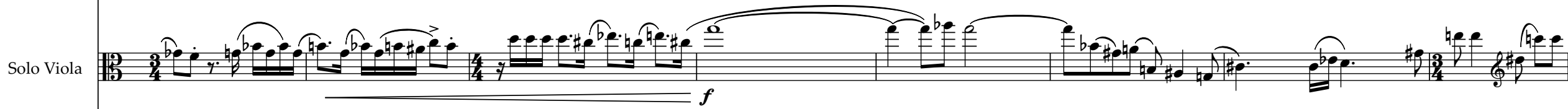

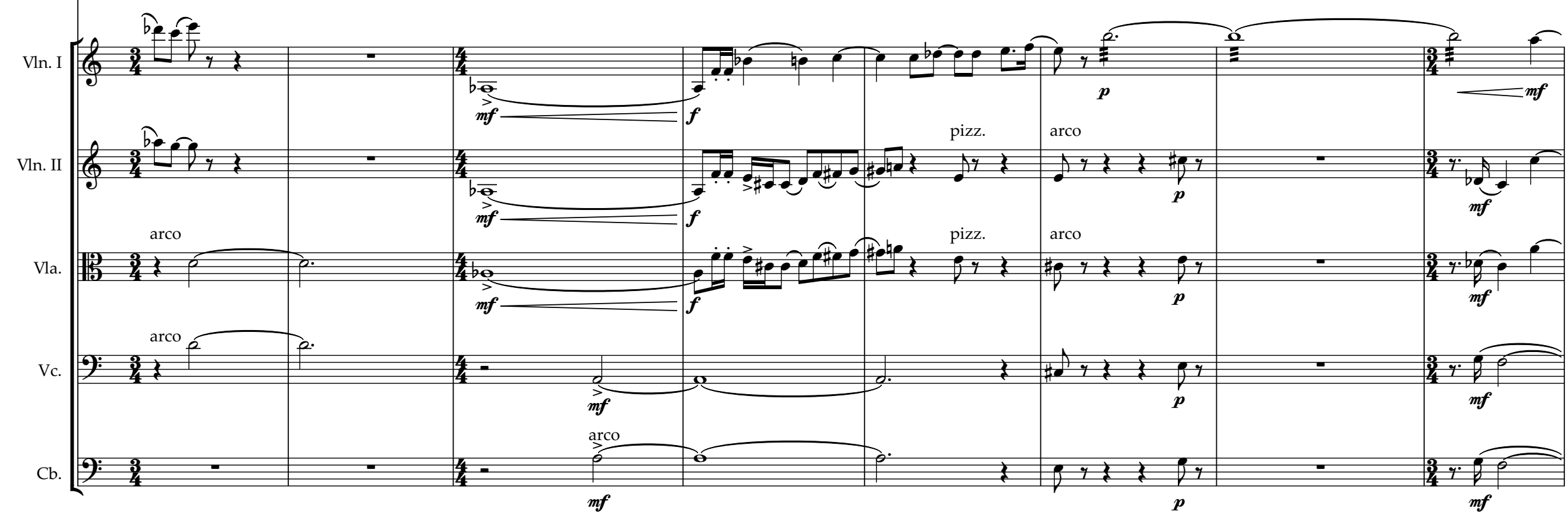



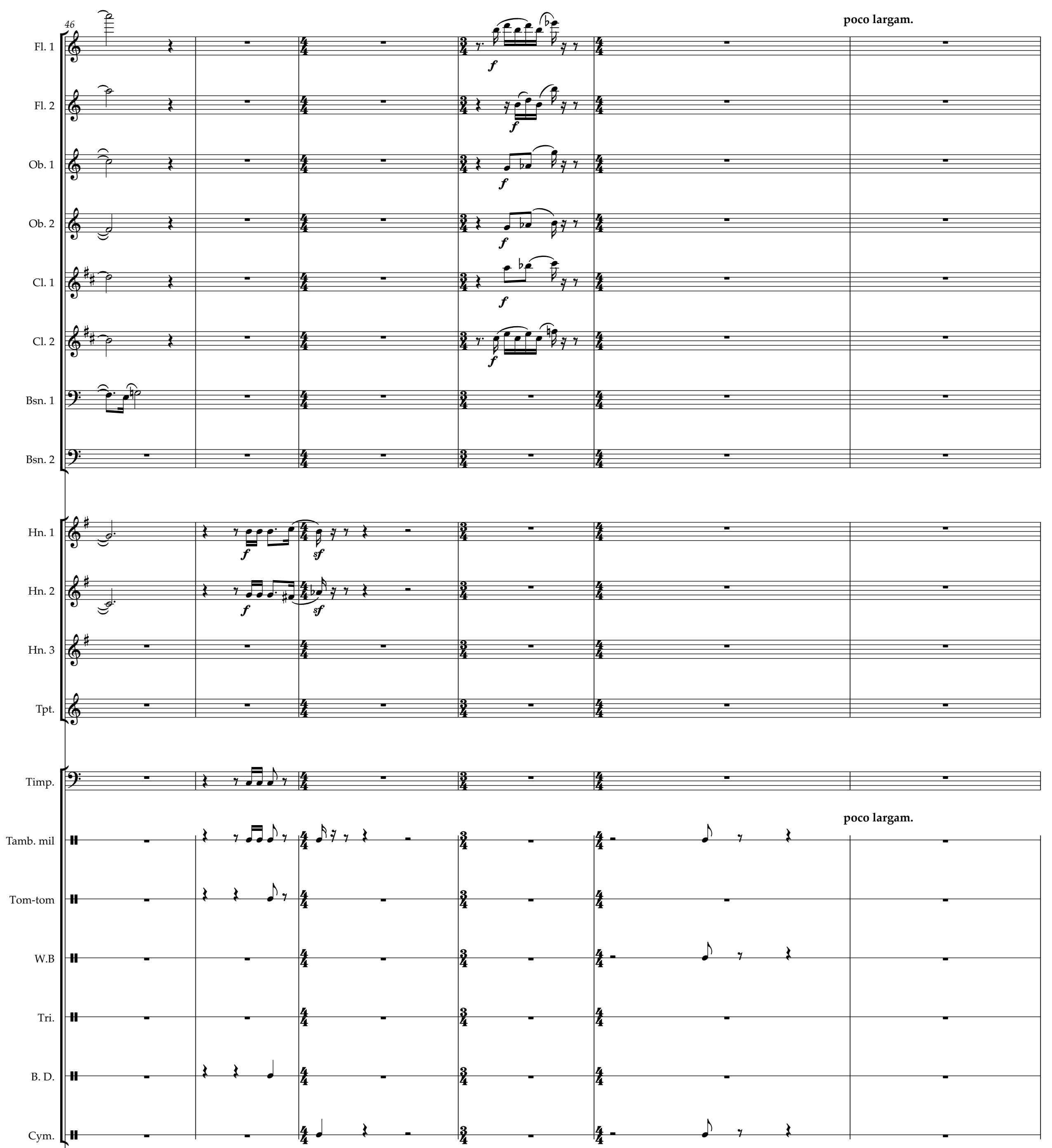

Solo Viola $\oint^{2}$

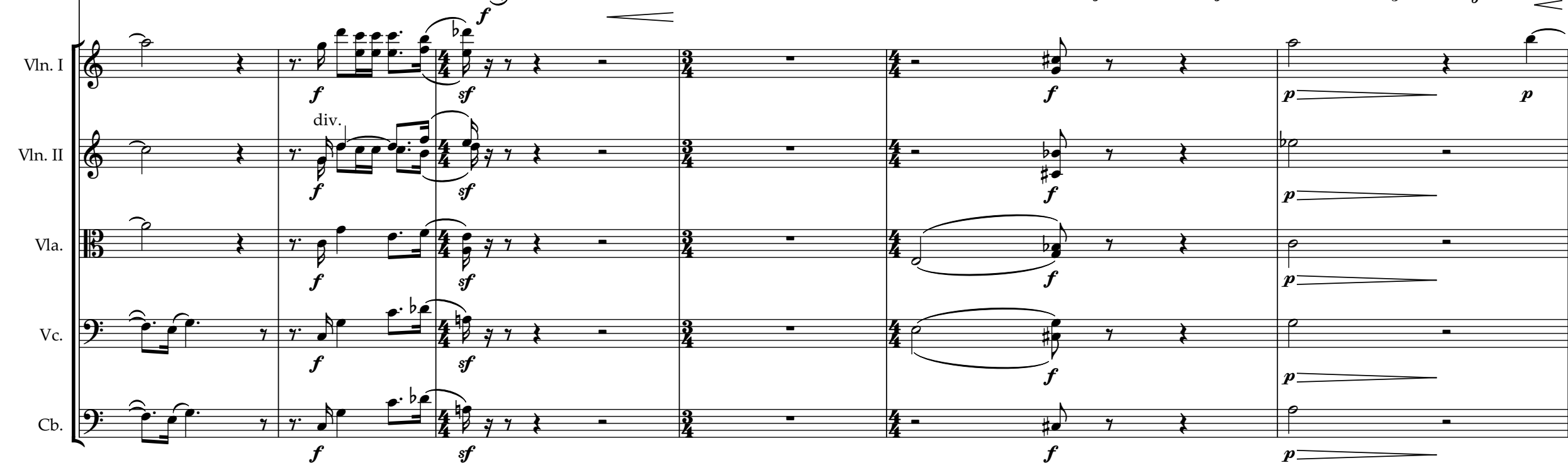



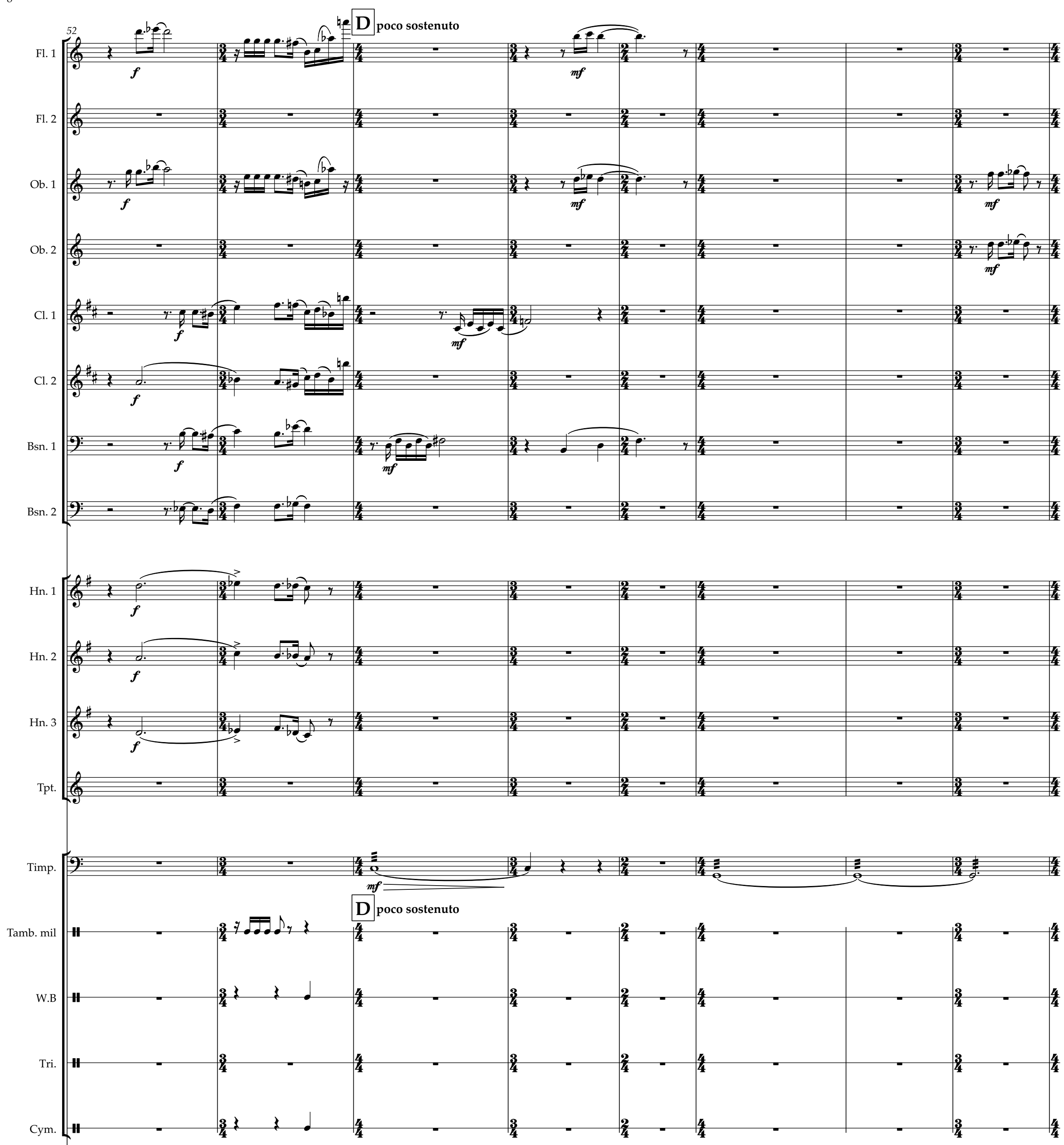

Solo Viola

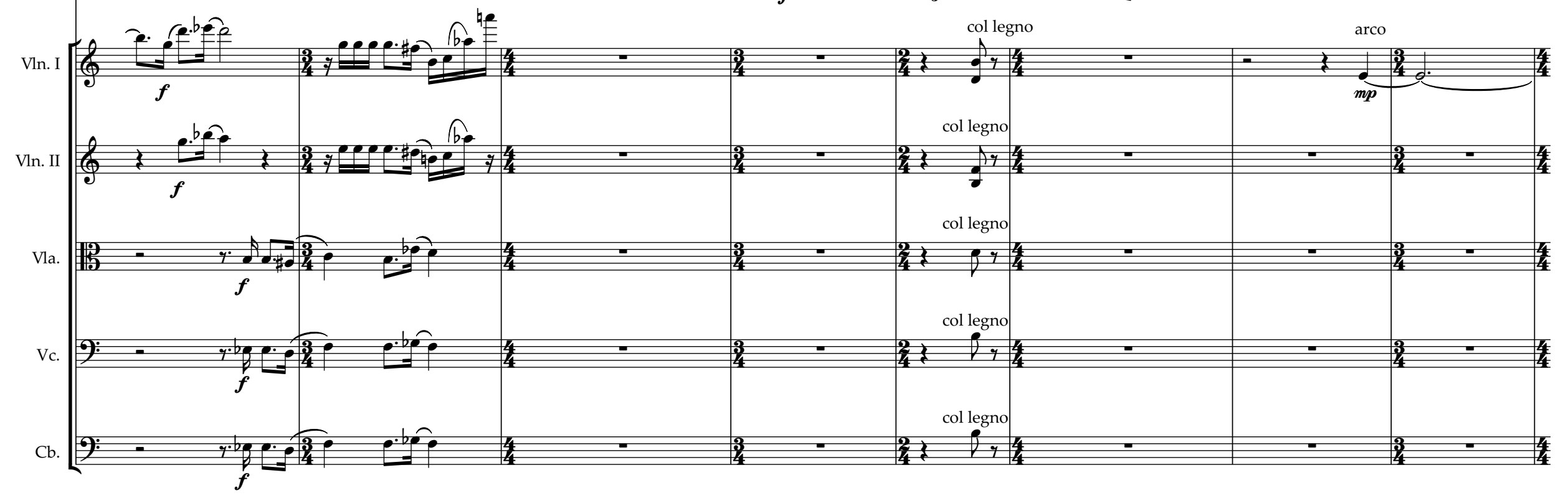



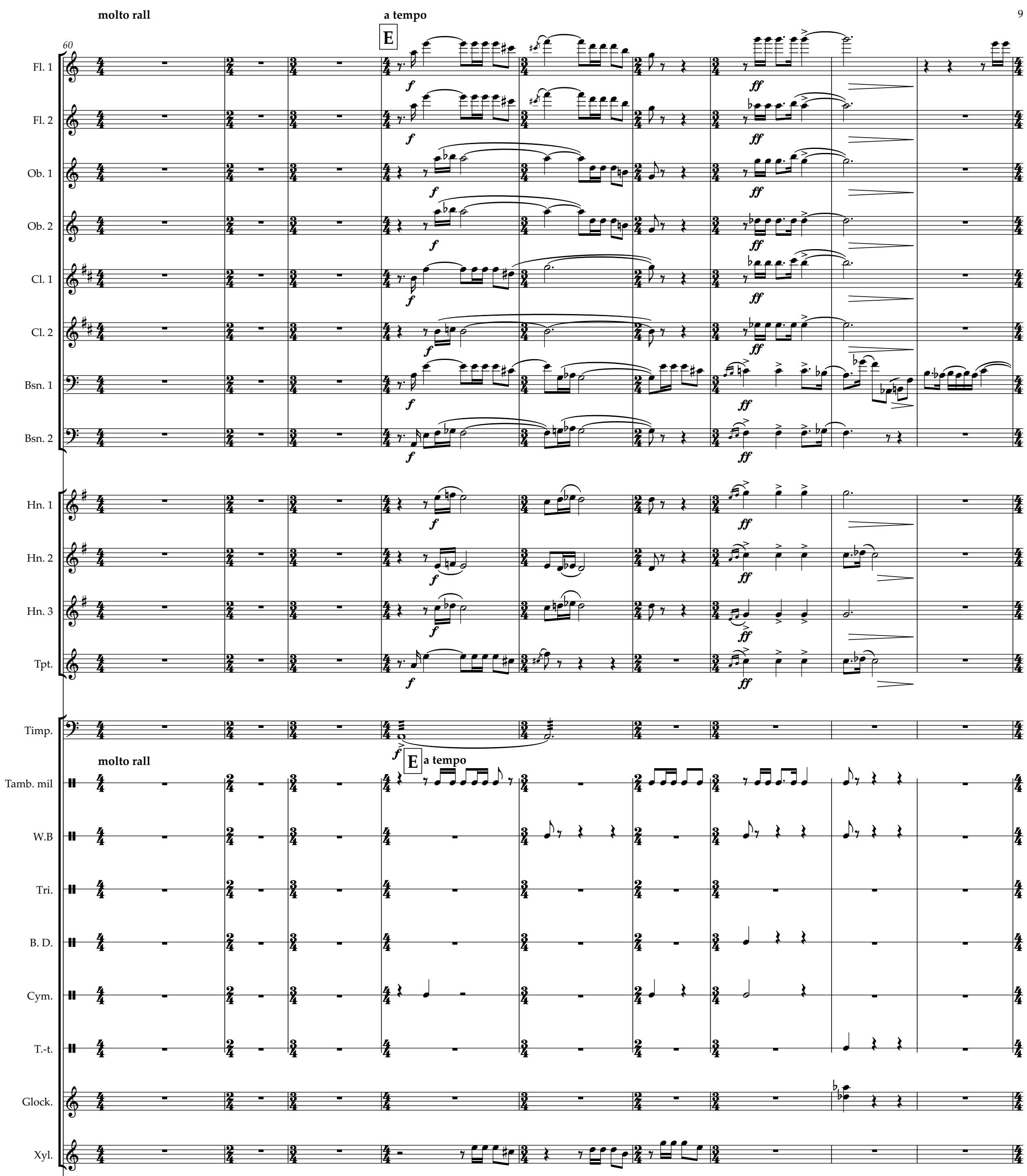

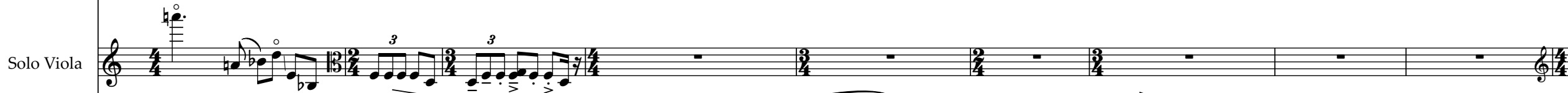

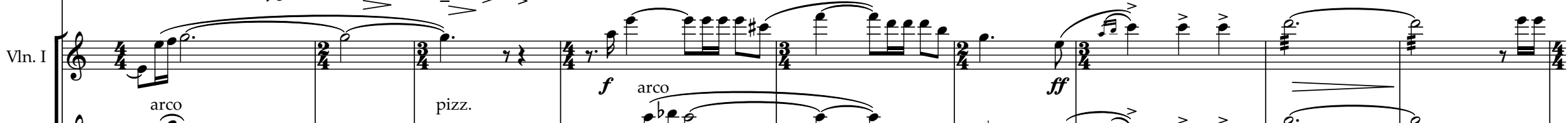
Vn. II $\oint_{0} \int_{\text {col legno }}^{\text {arco }}$ Va.

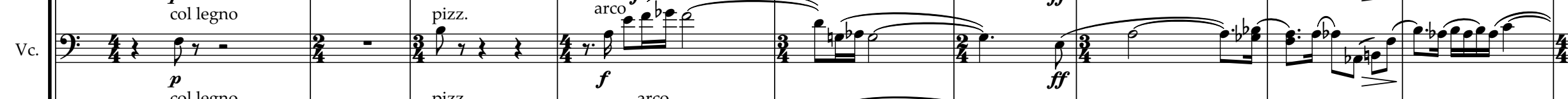

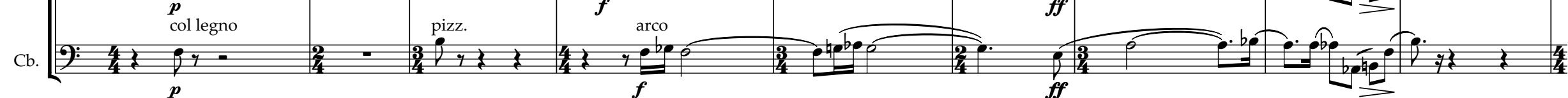



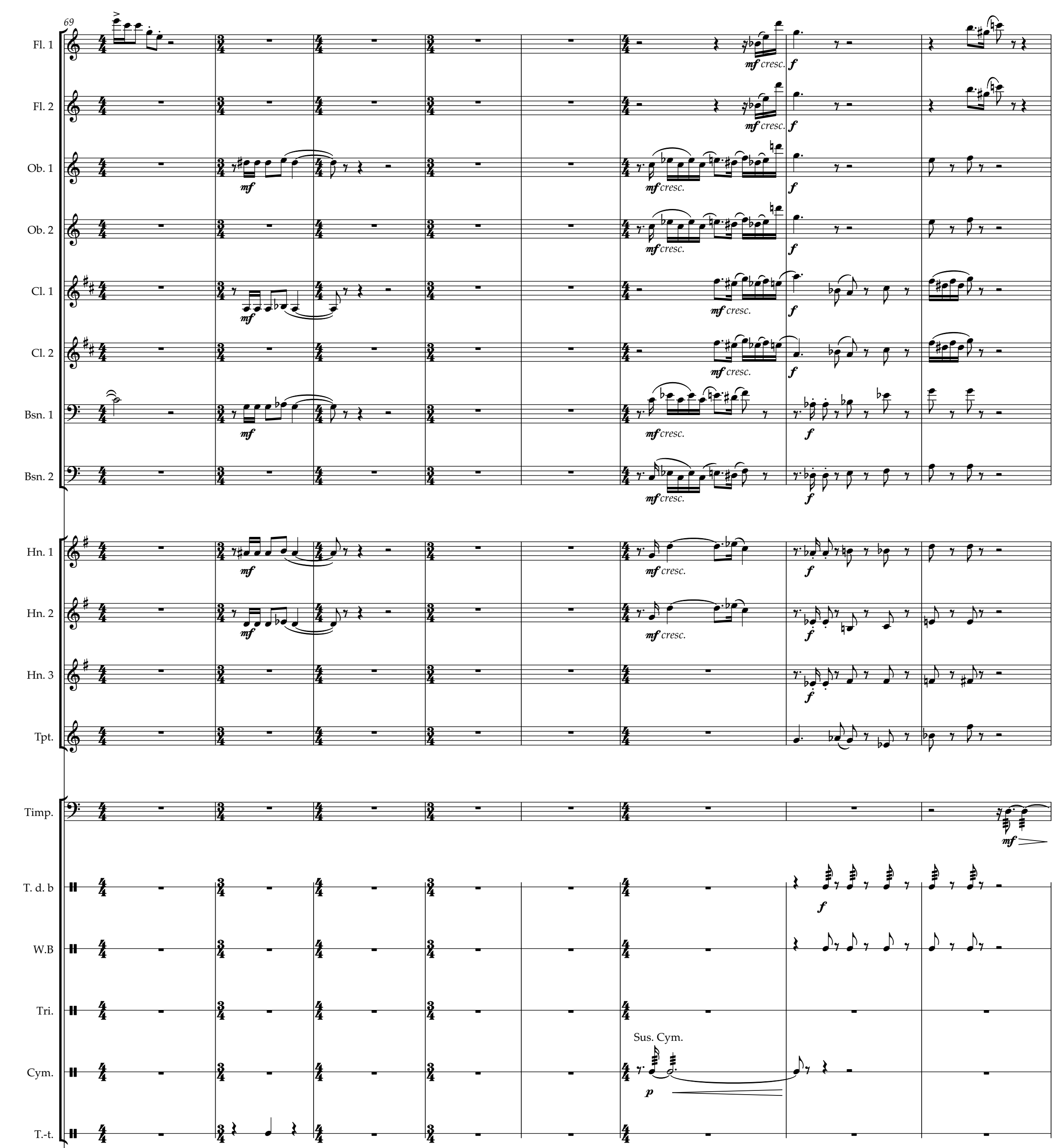

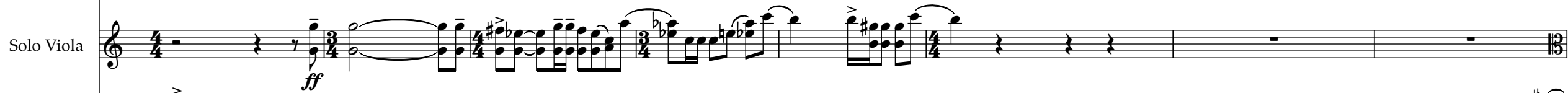
C.. 

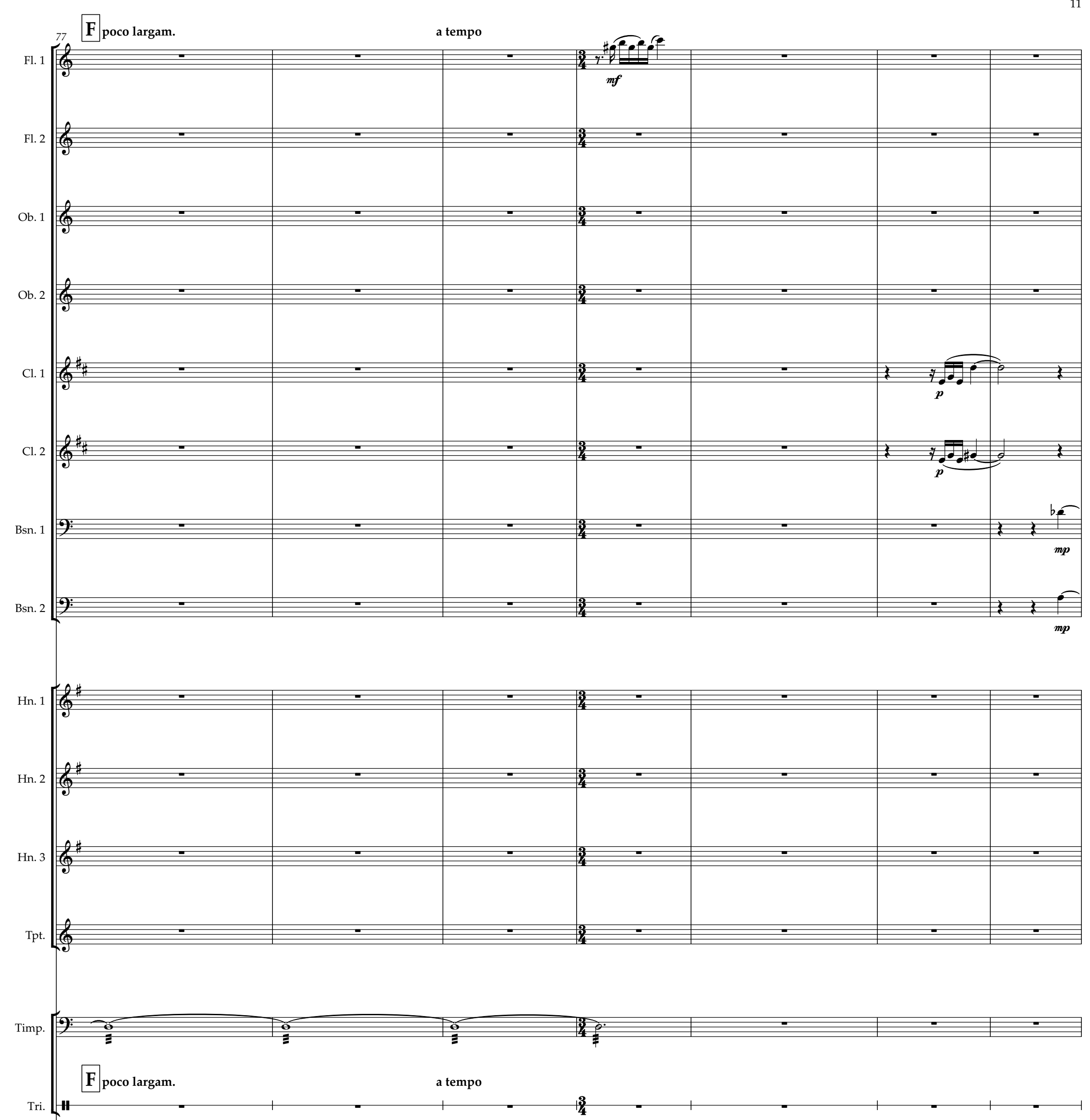

Solo Viola

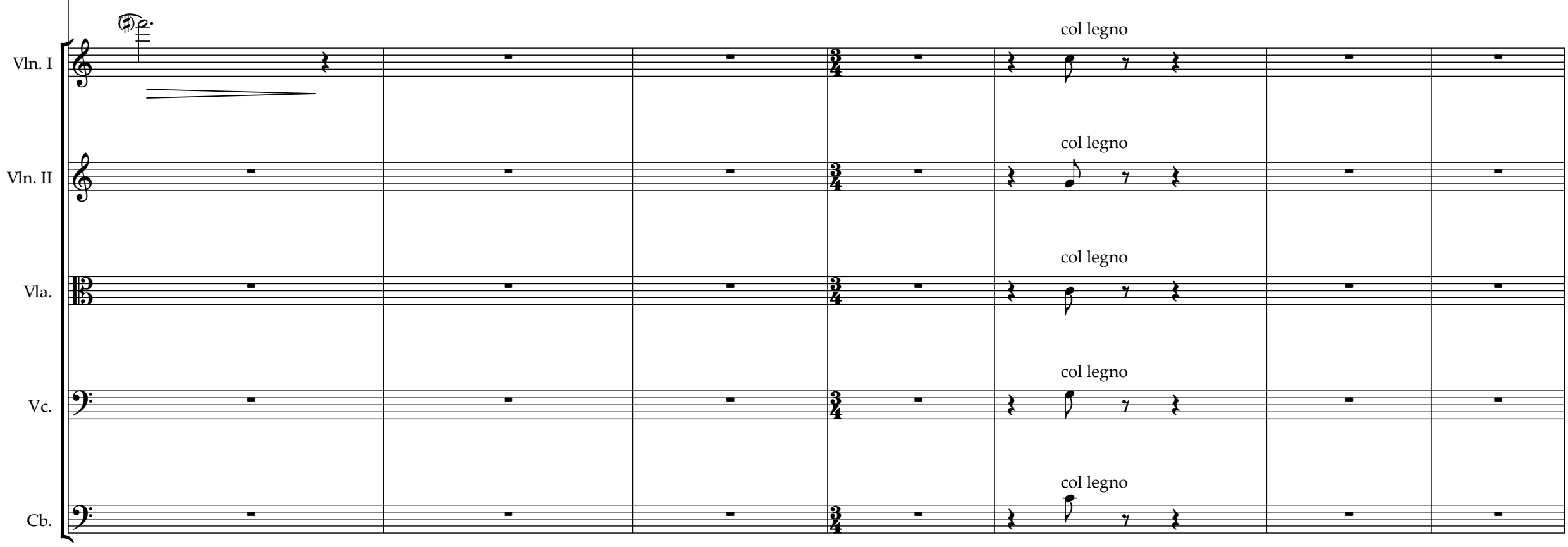


12
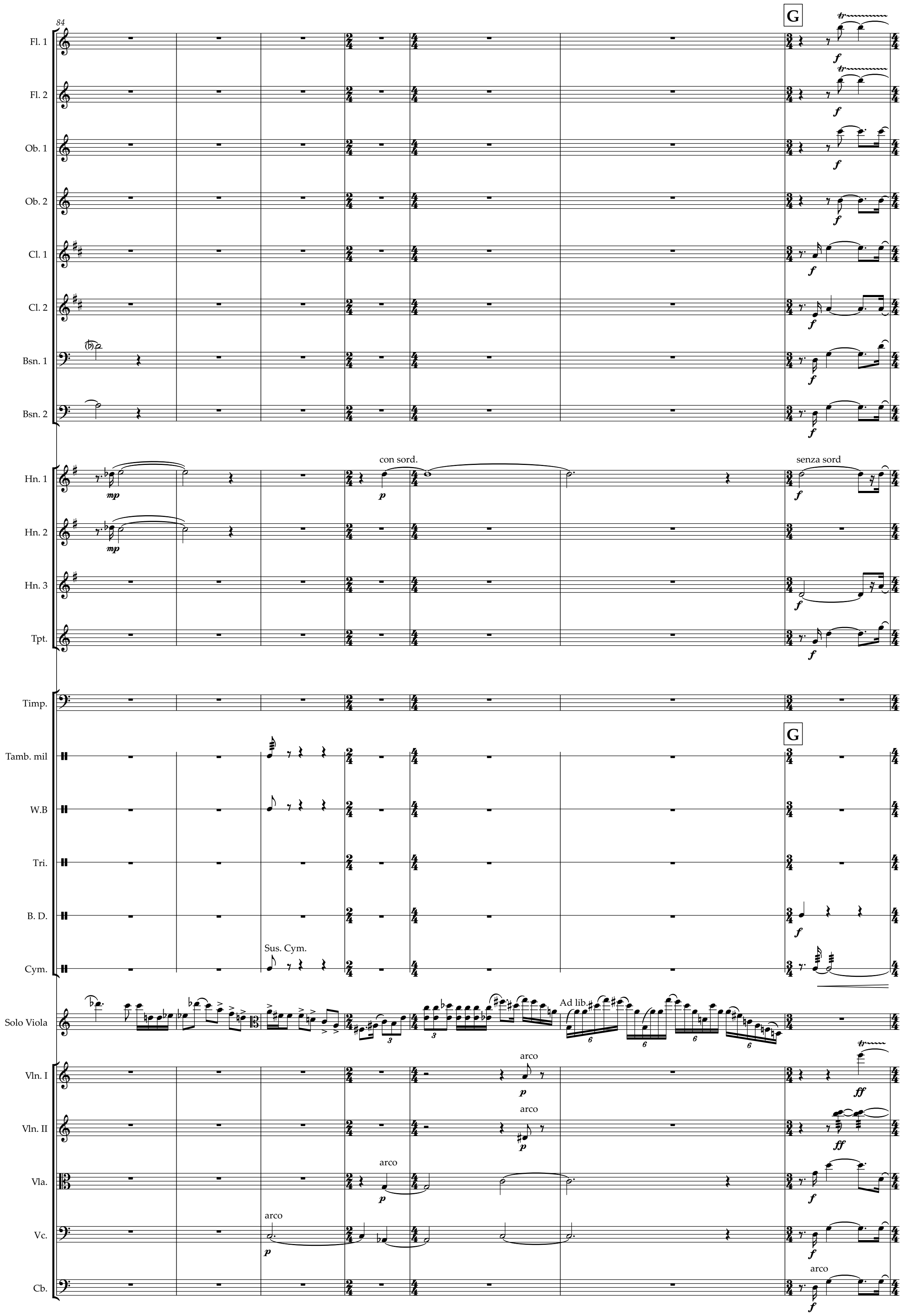

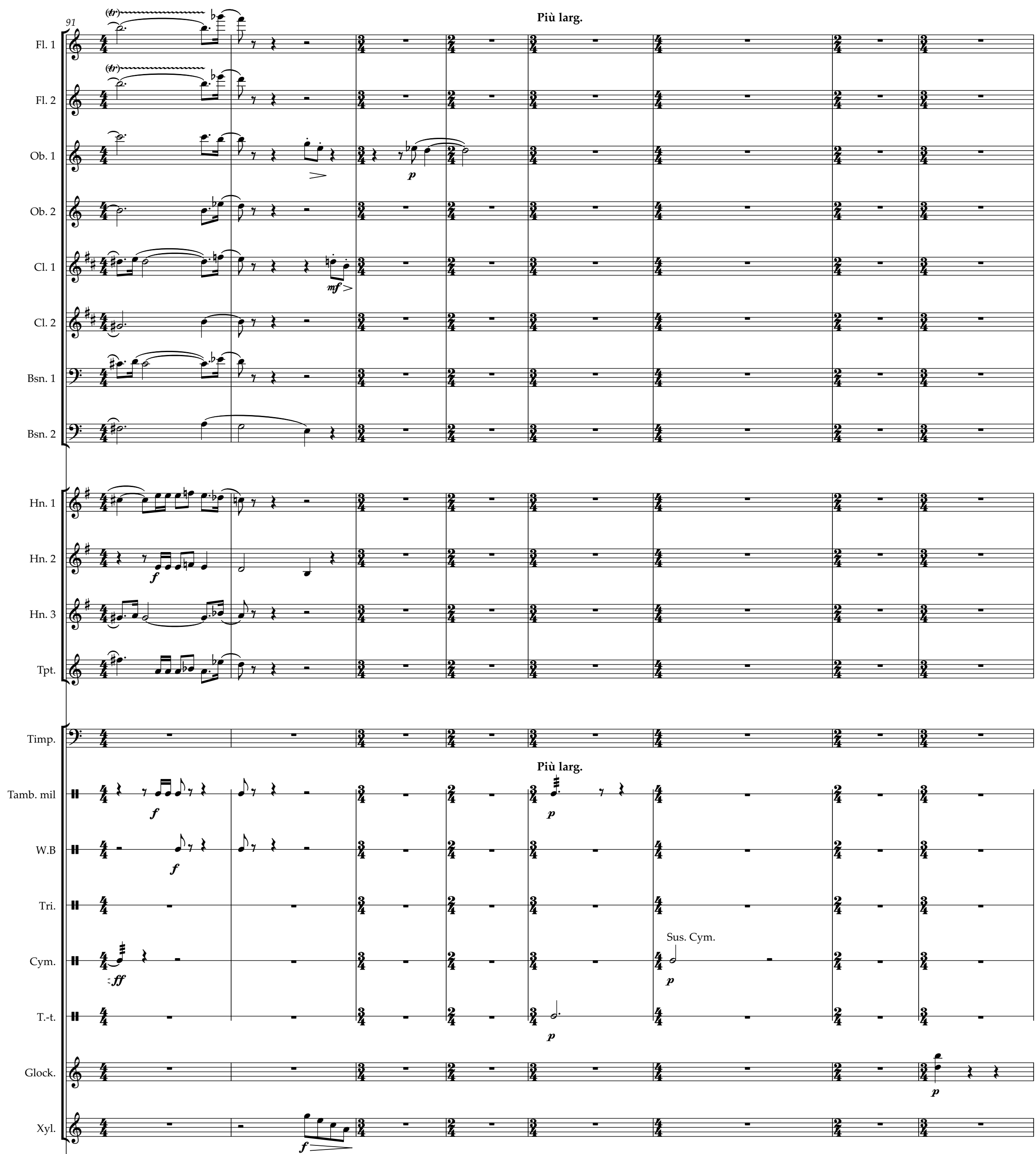

Solo Viola C.. 
14
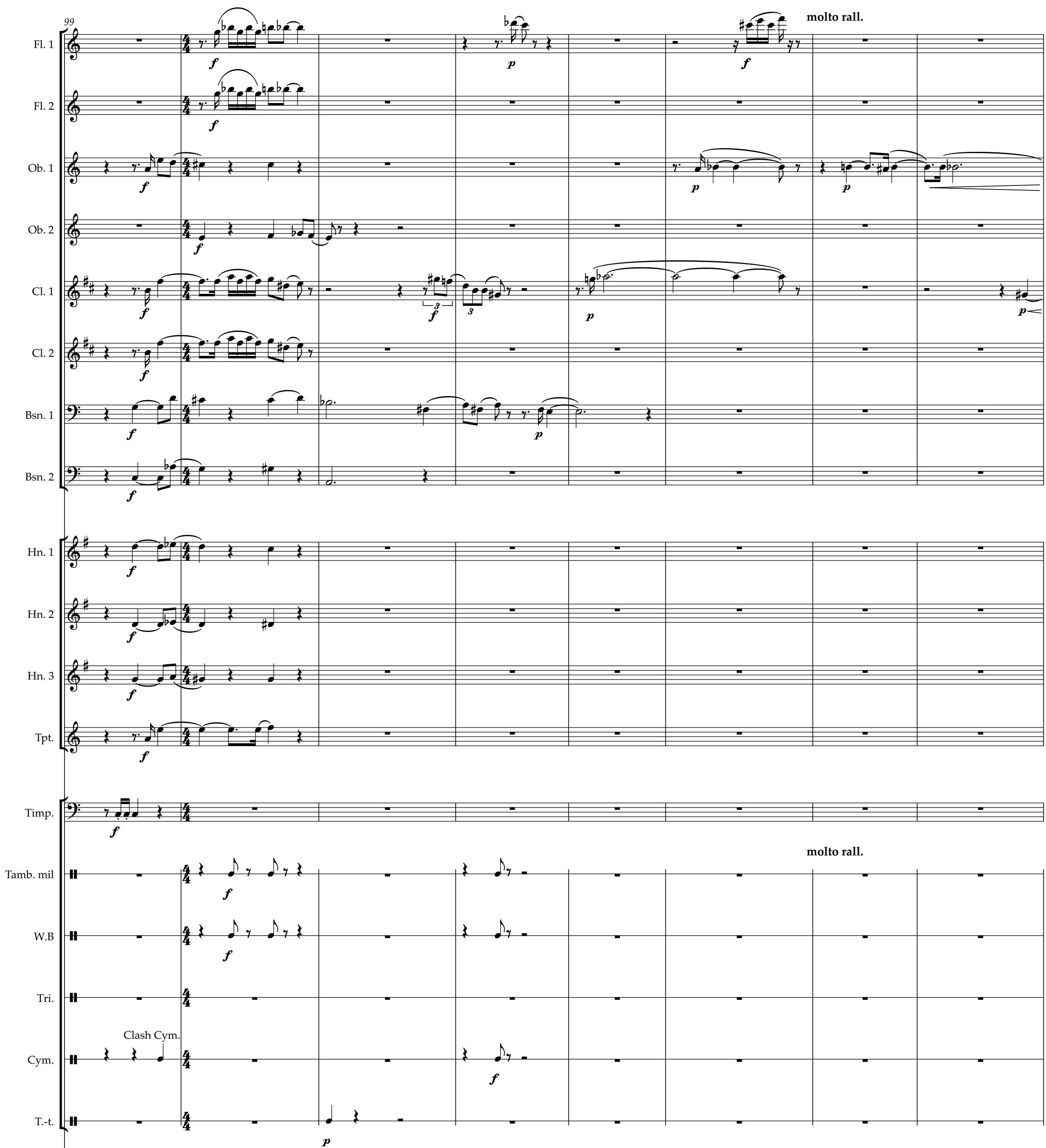

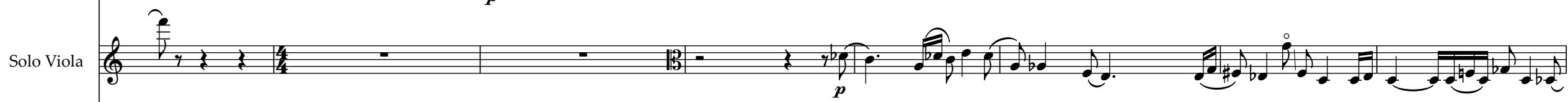

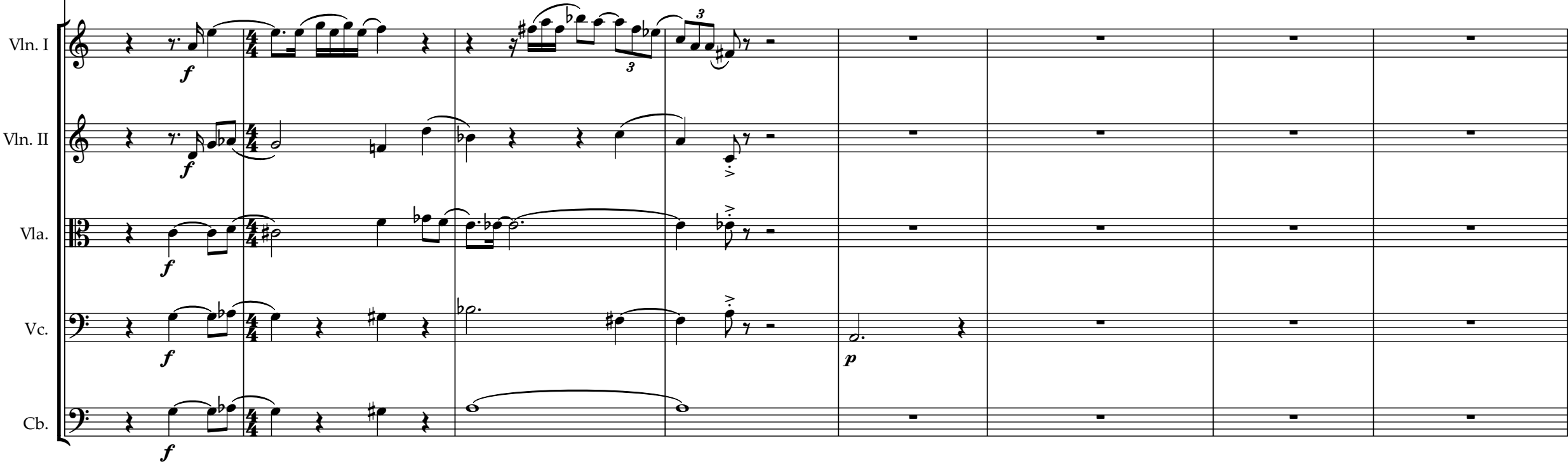



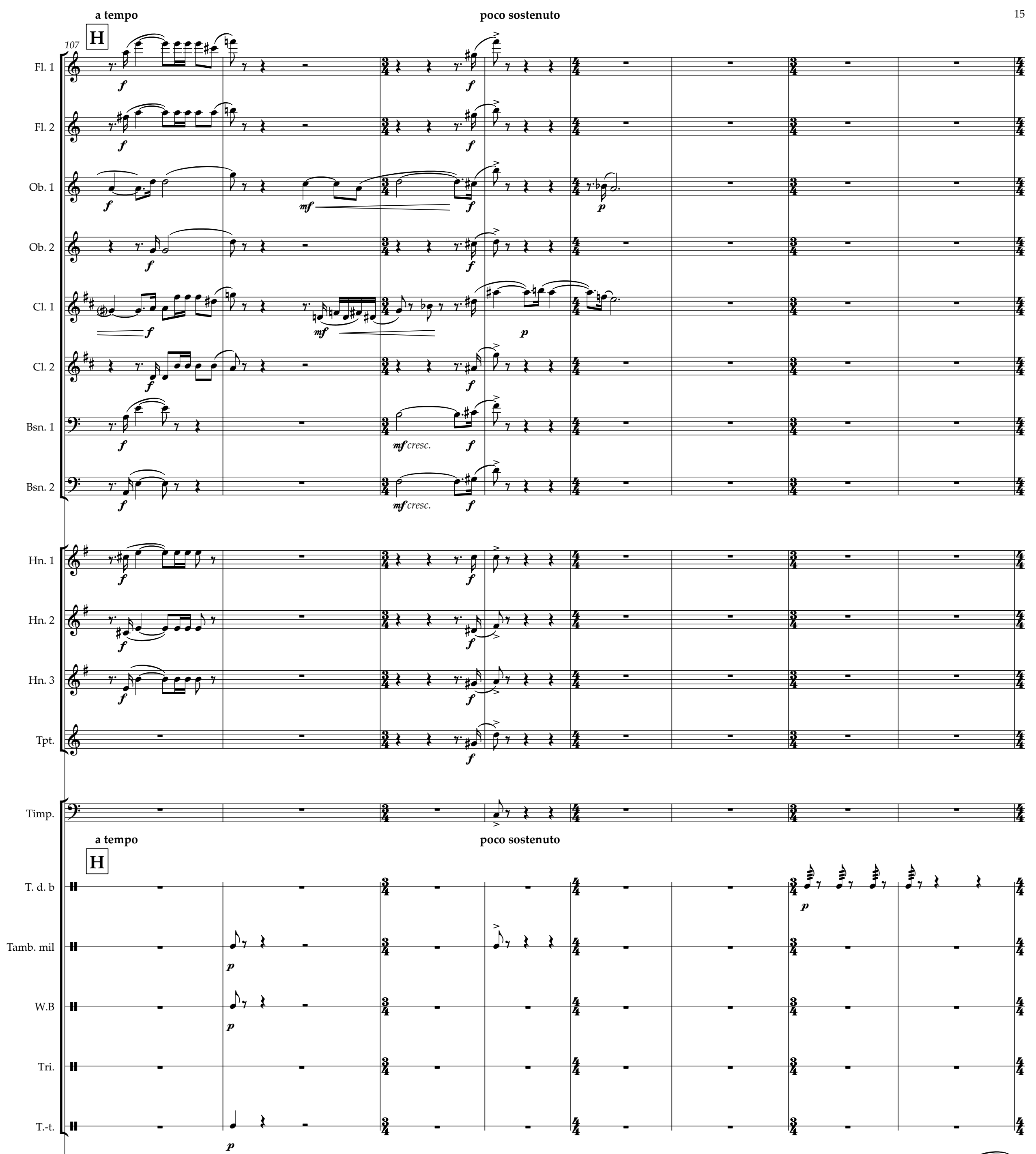

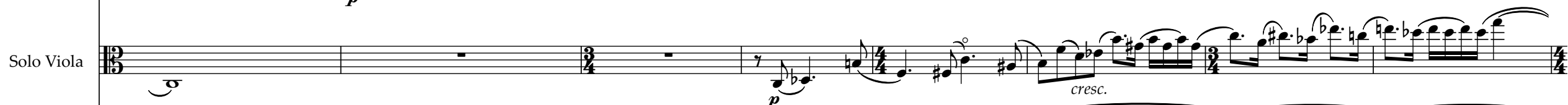

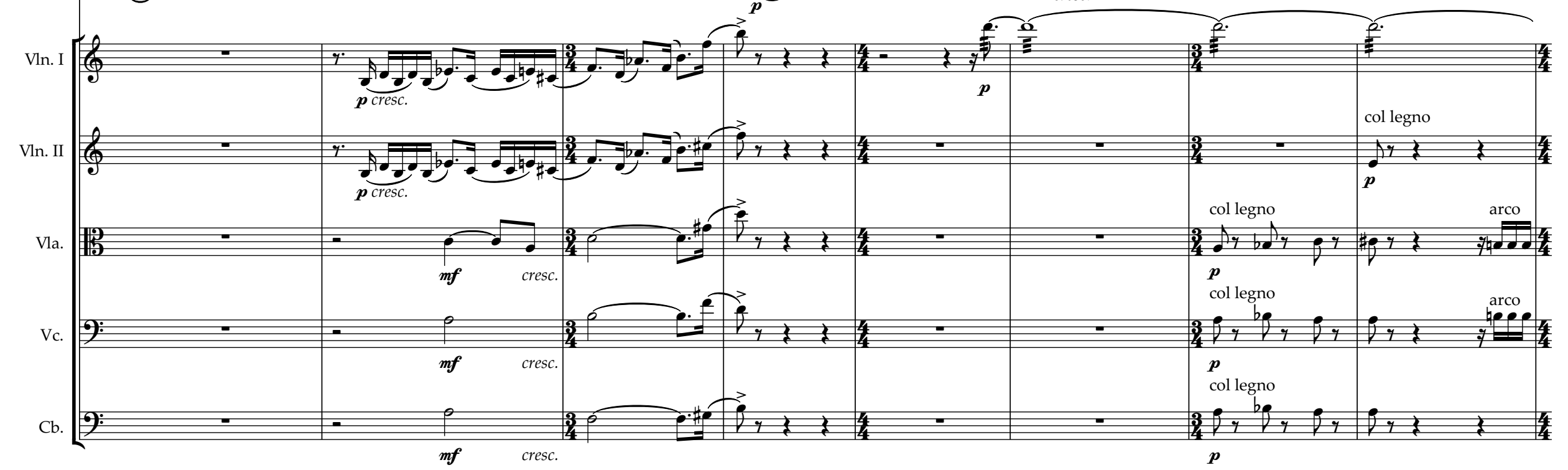


16

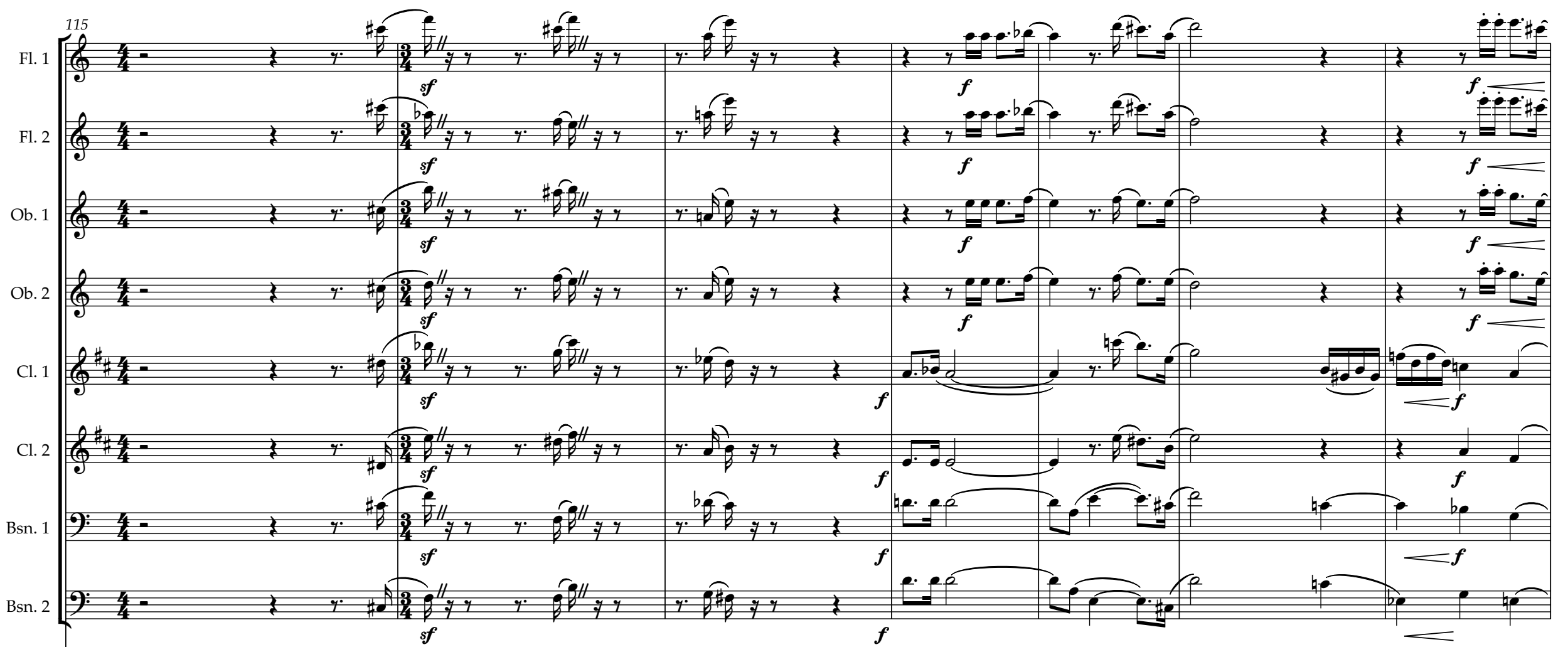

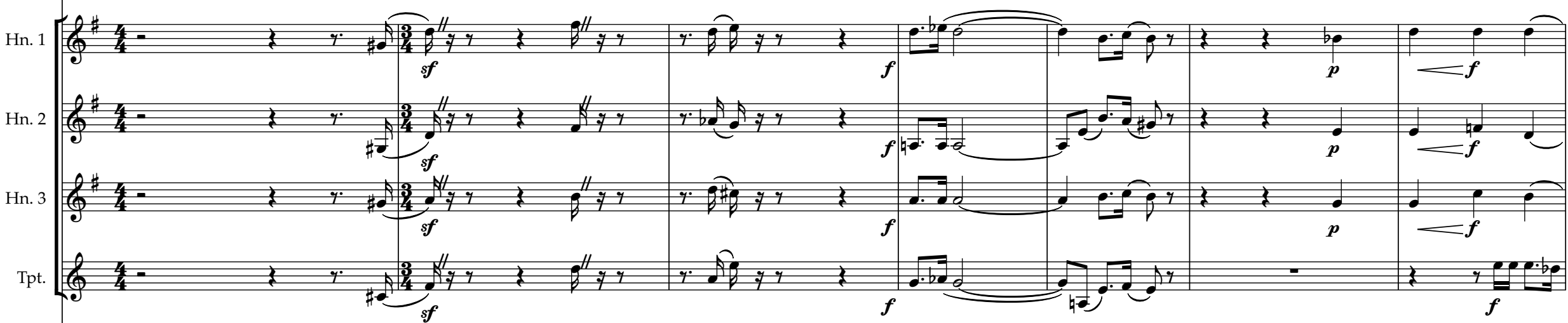

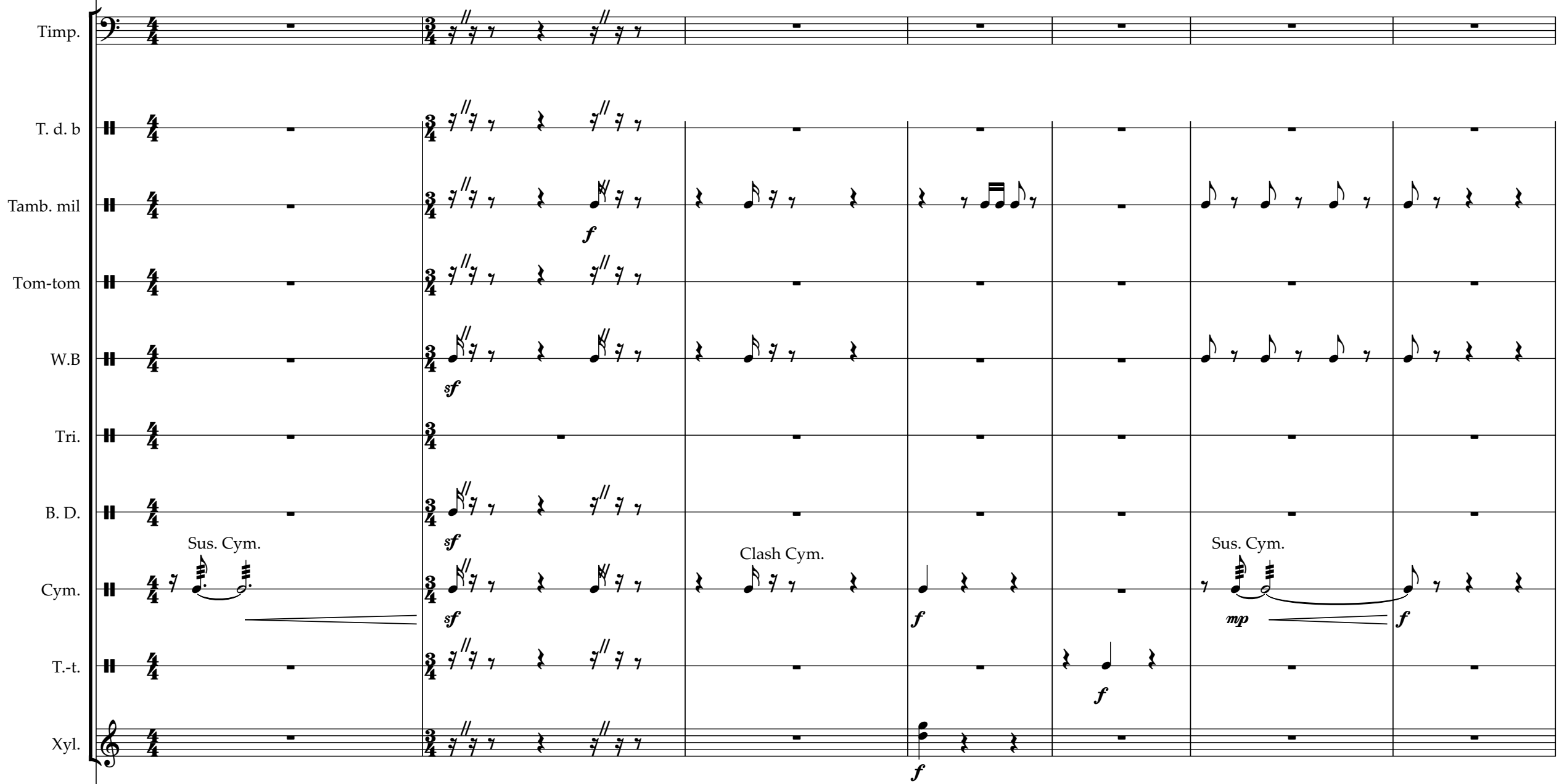
Solo Viola Cb. 

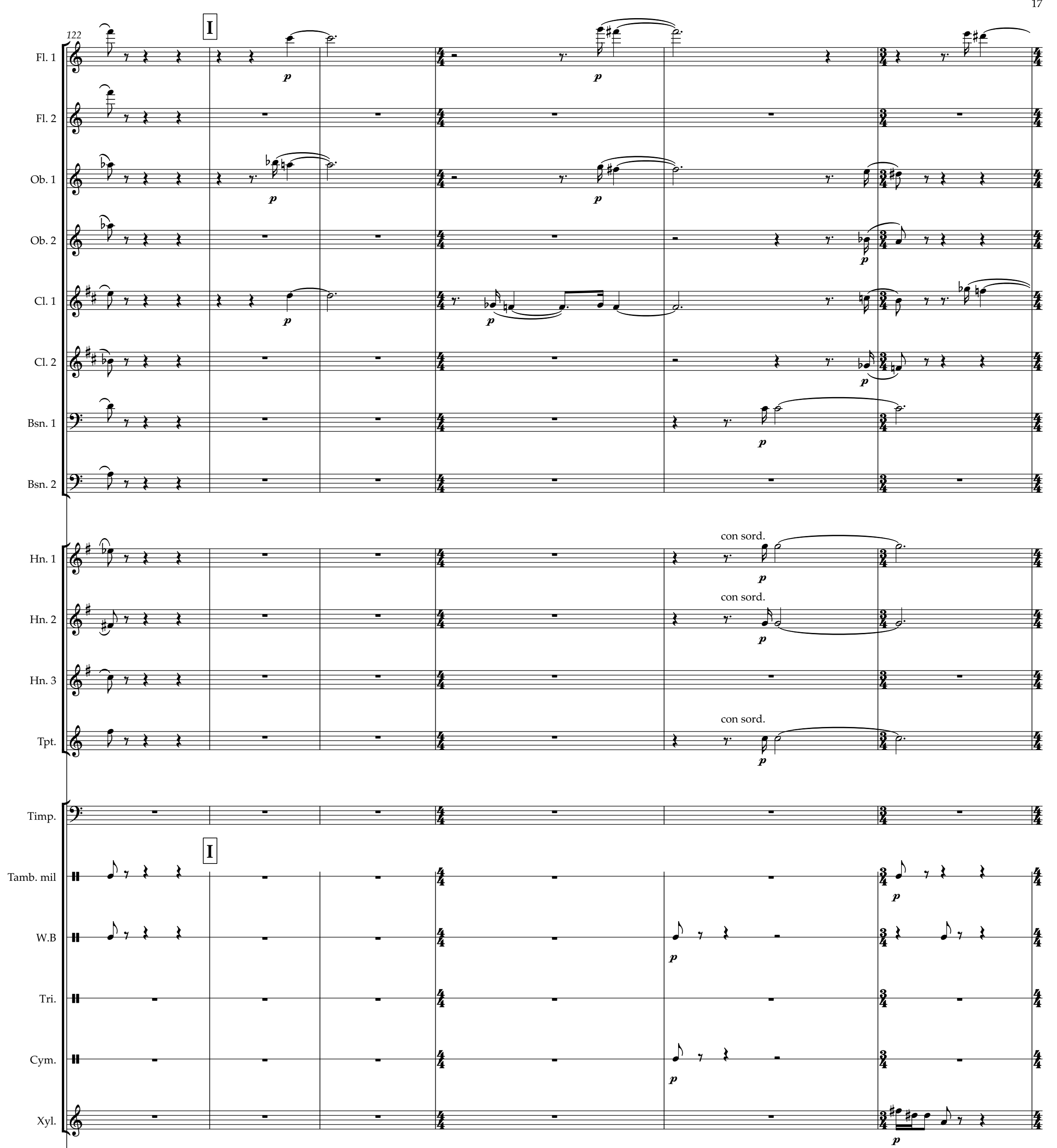

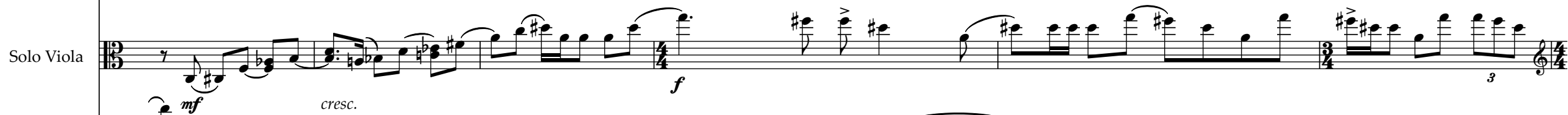
(II.II 

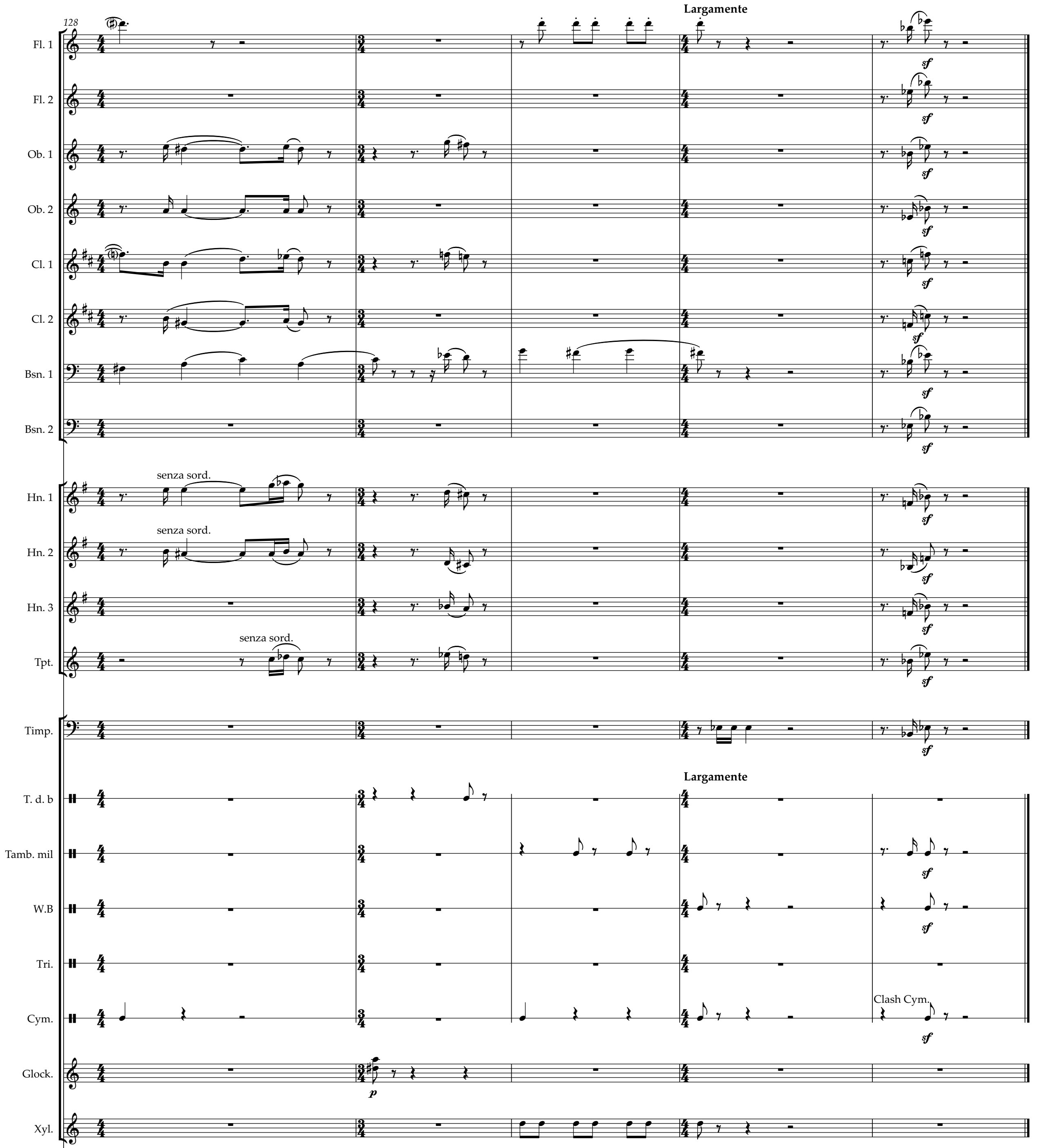

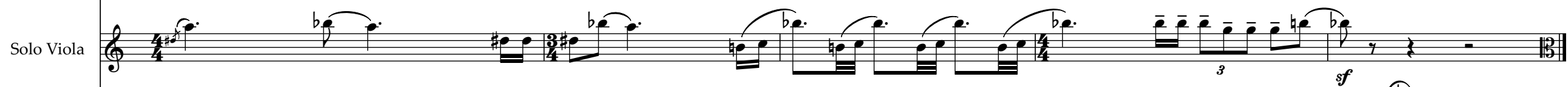

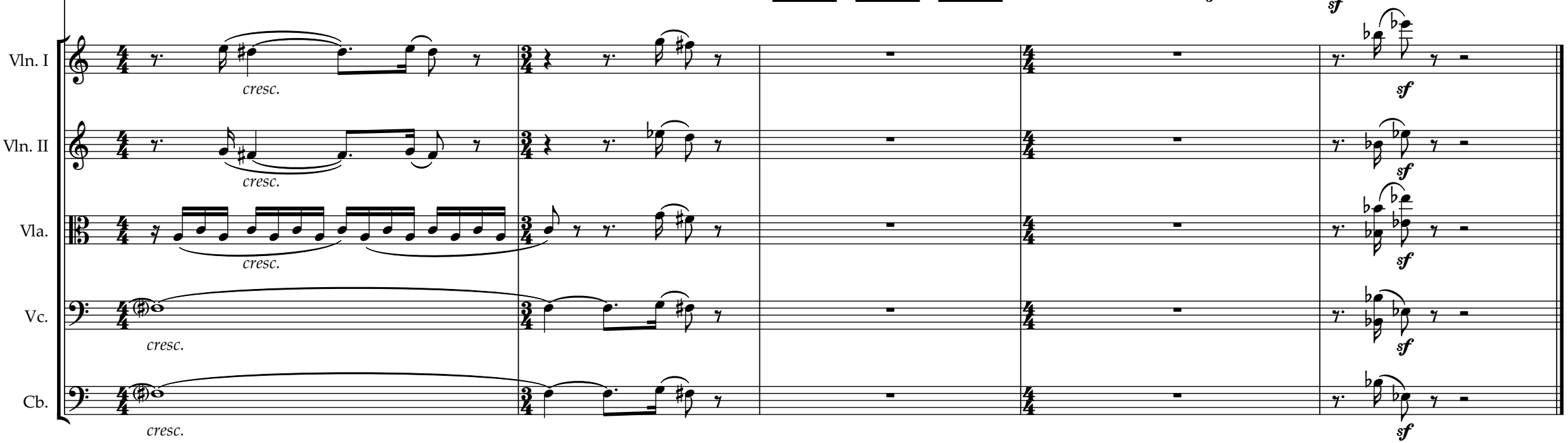



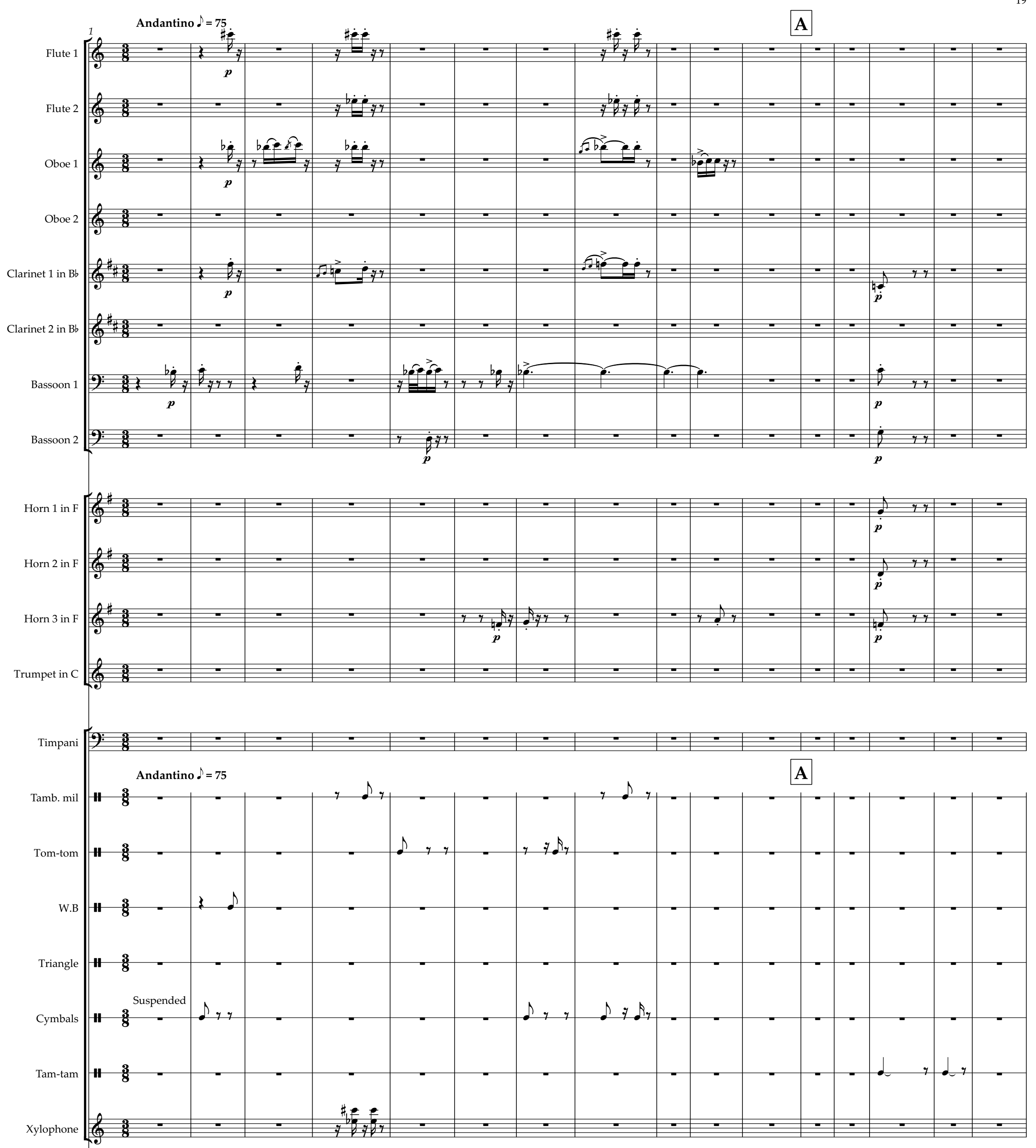

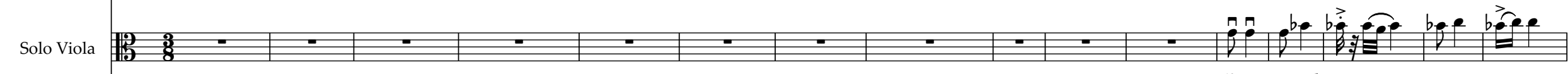

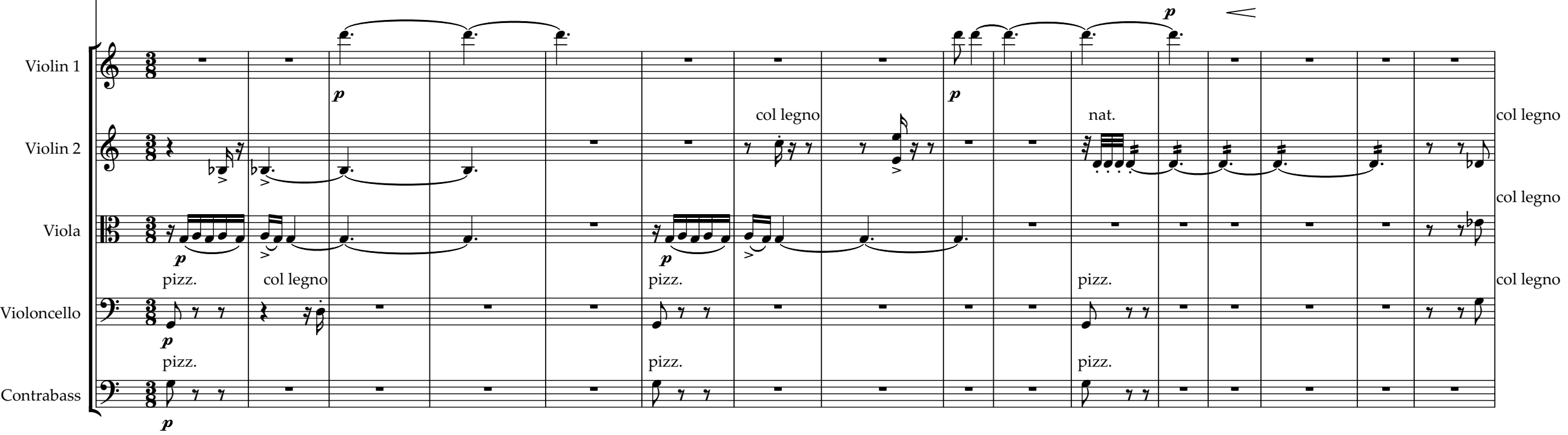



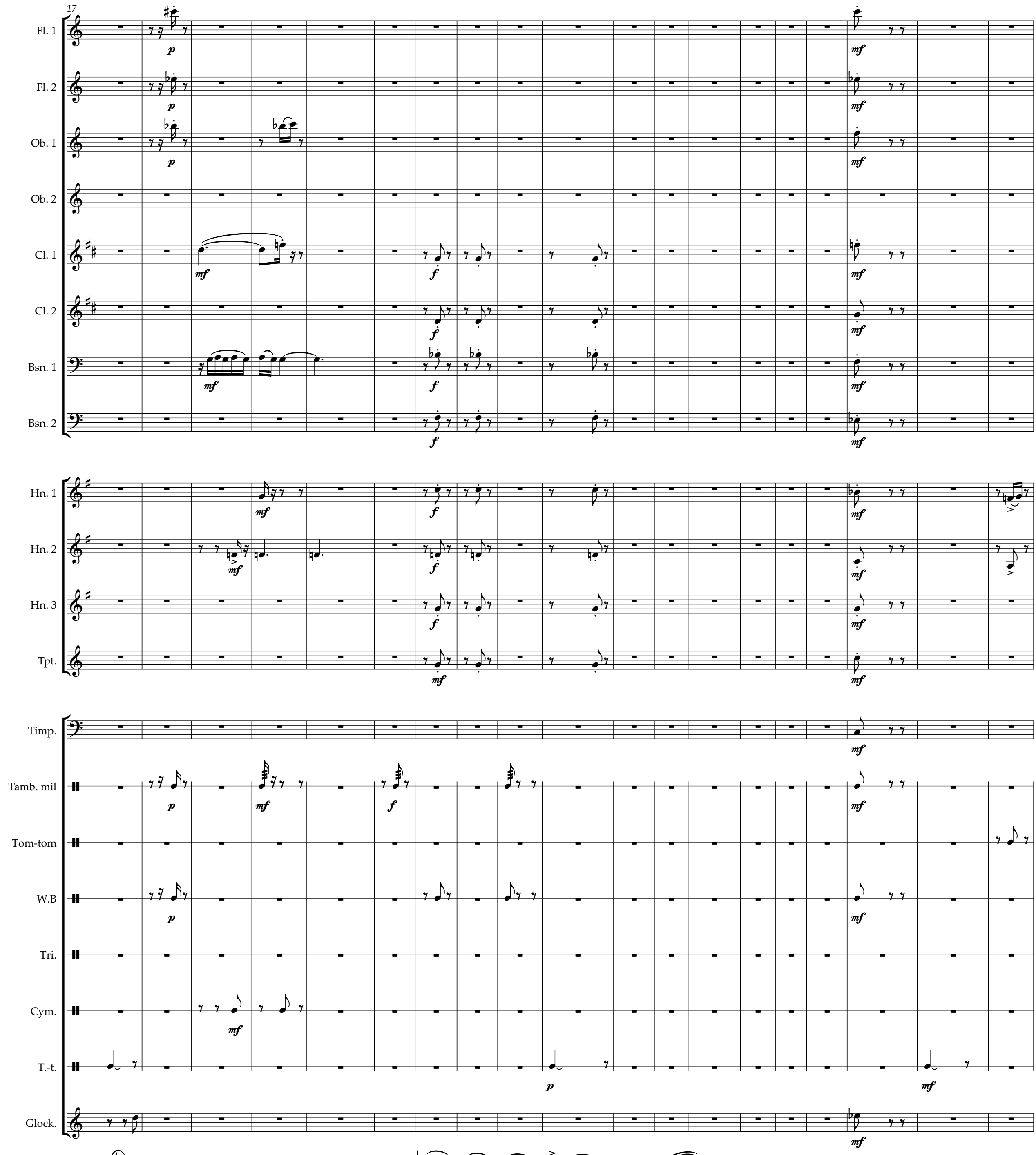

Solo Viola

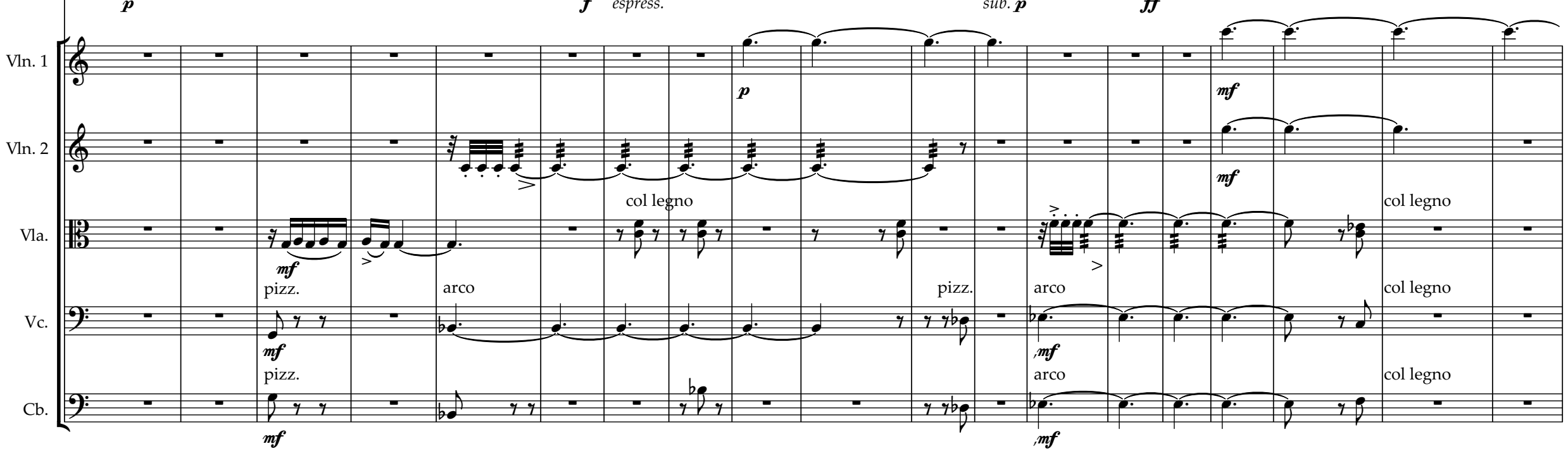



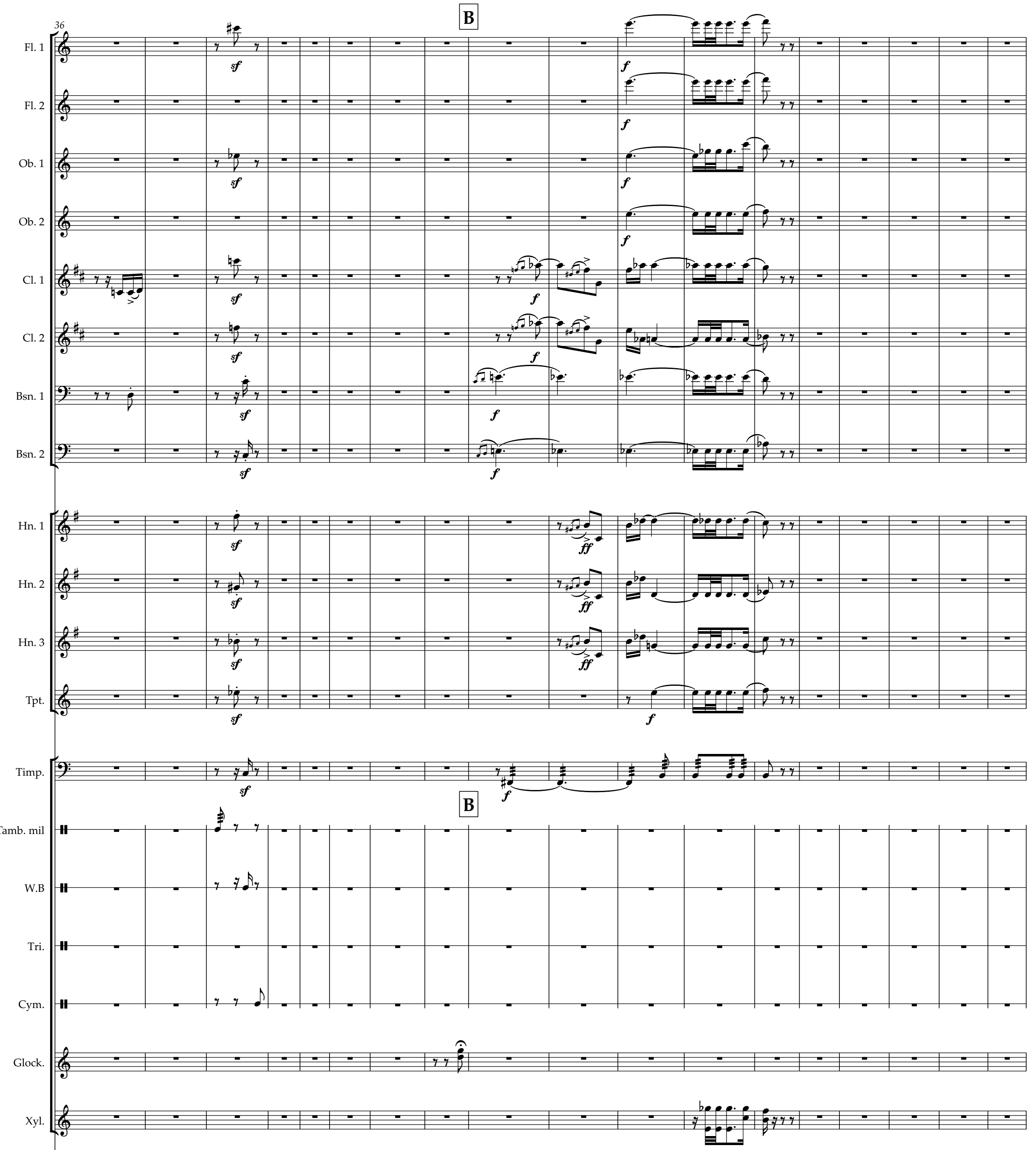

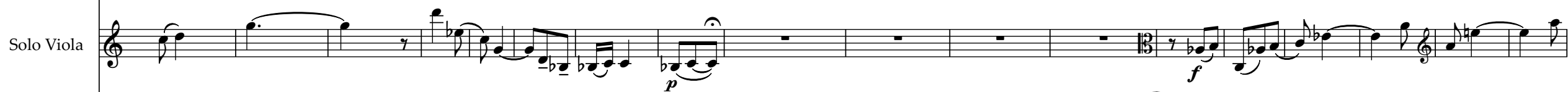

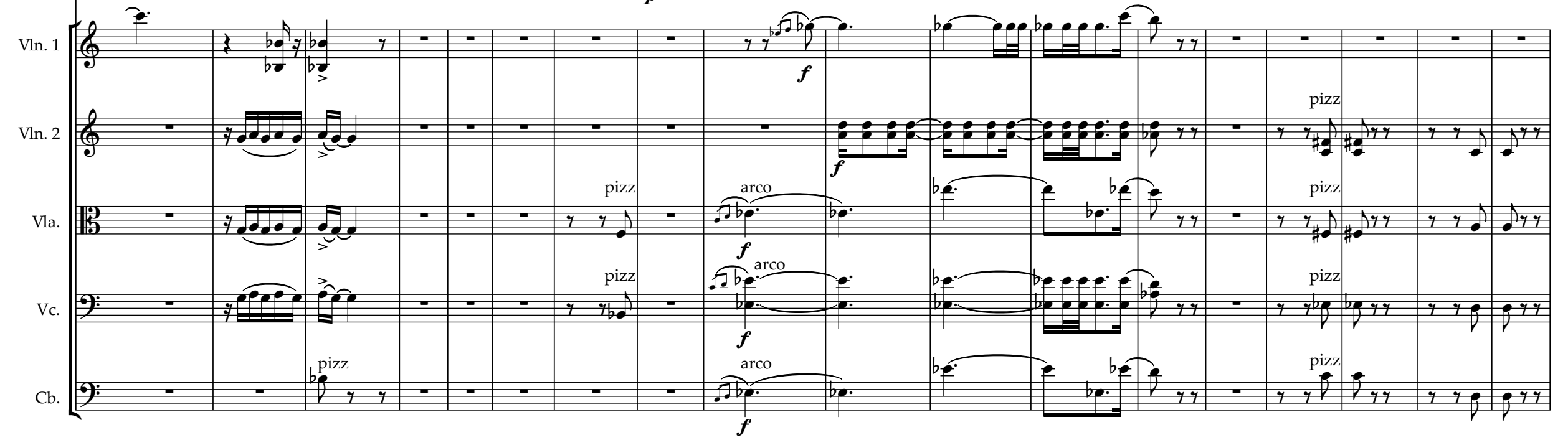




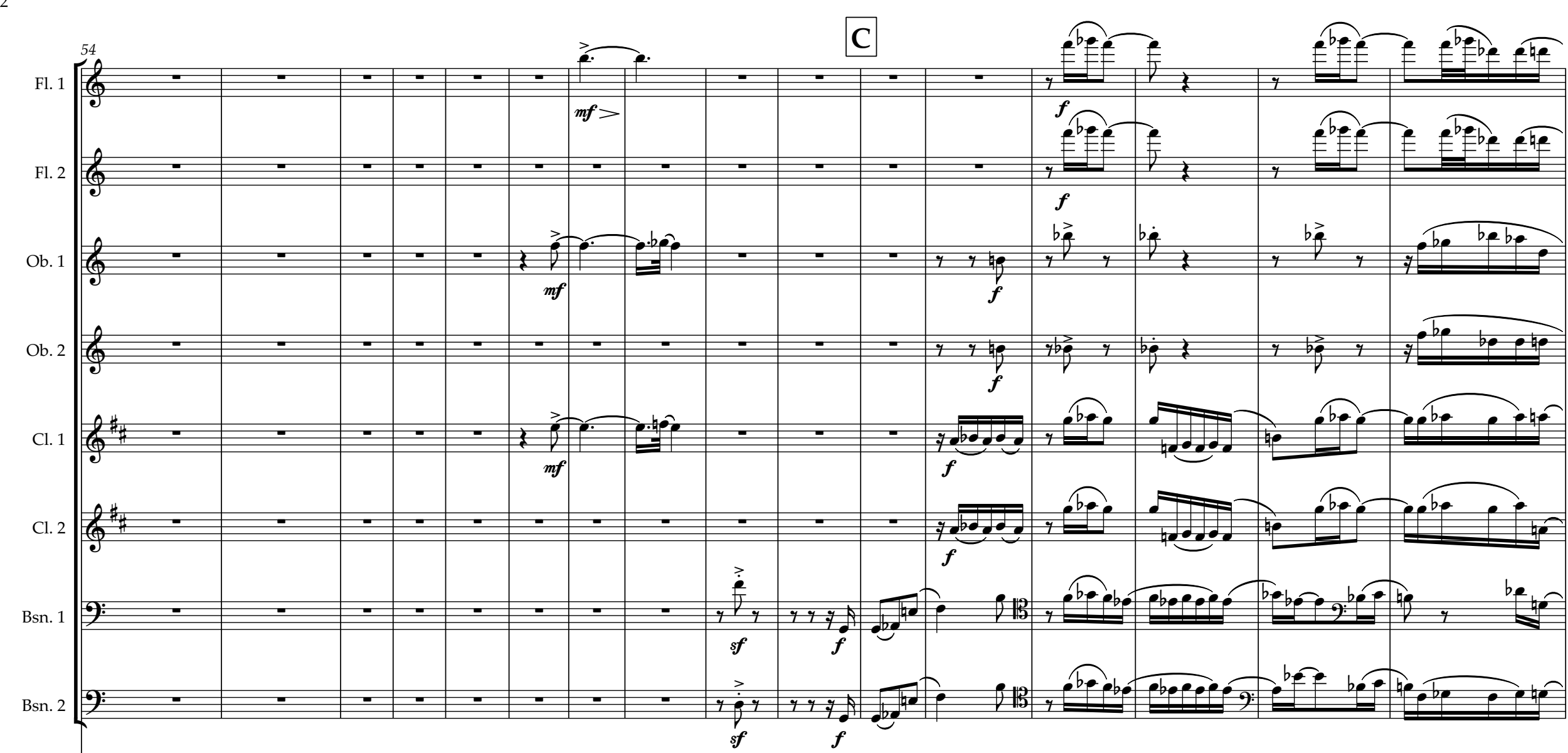

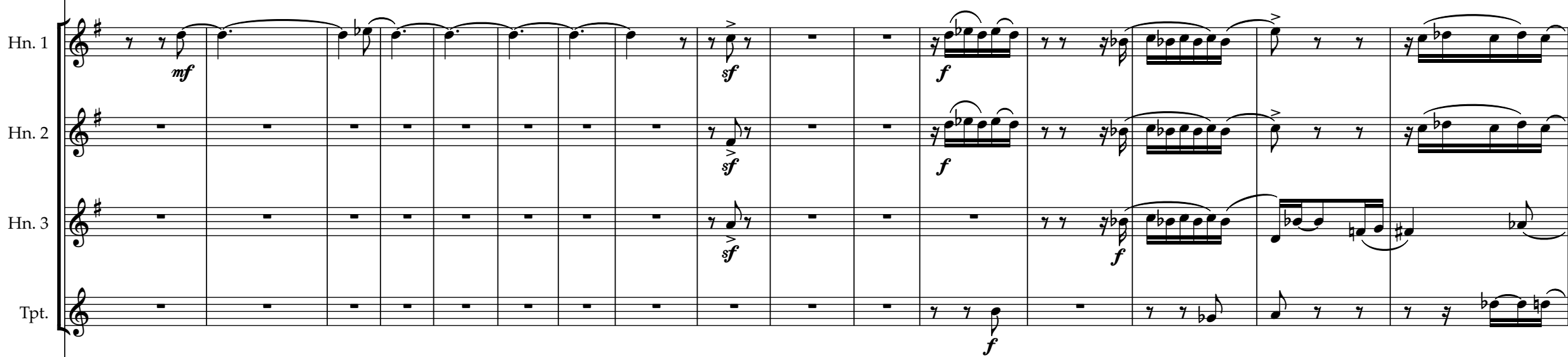

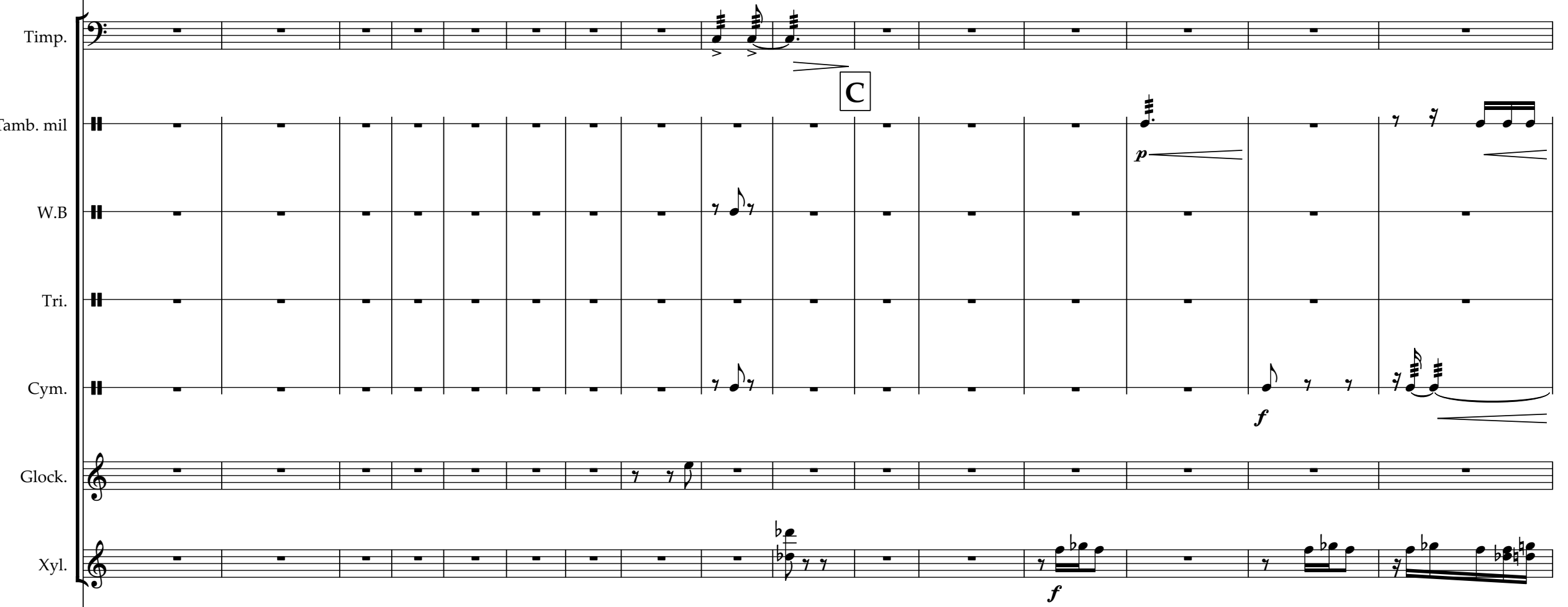

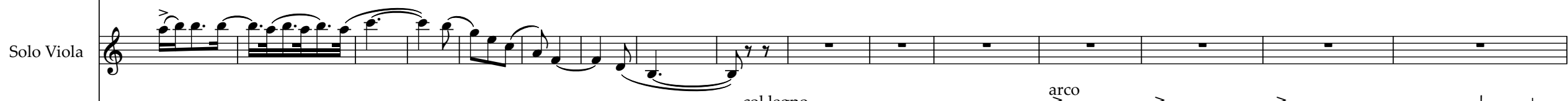

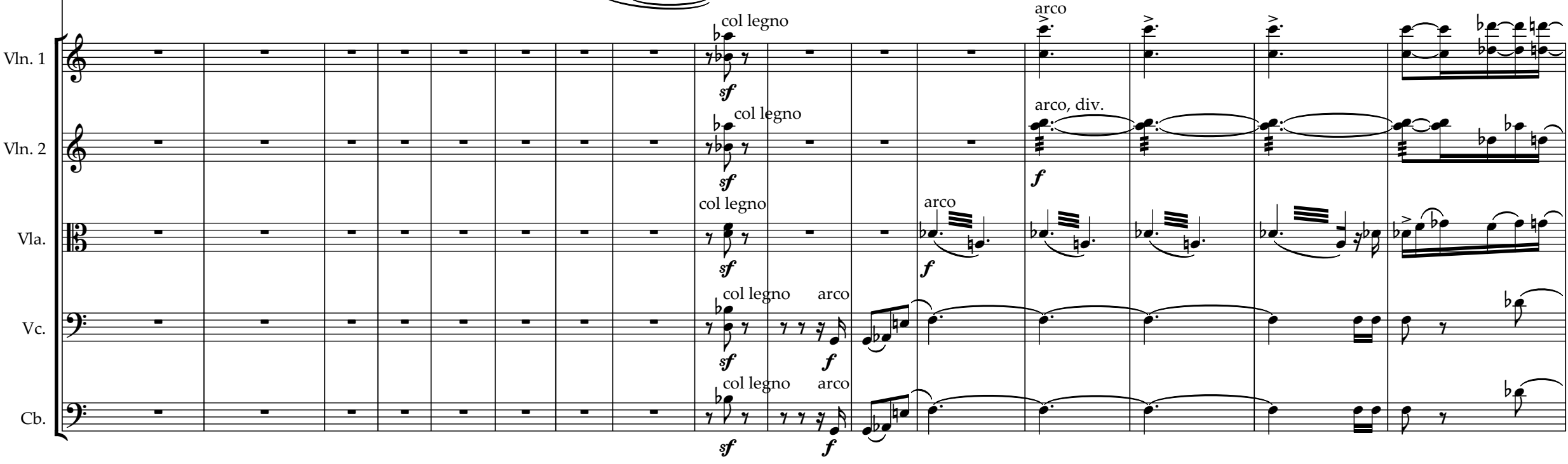



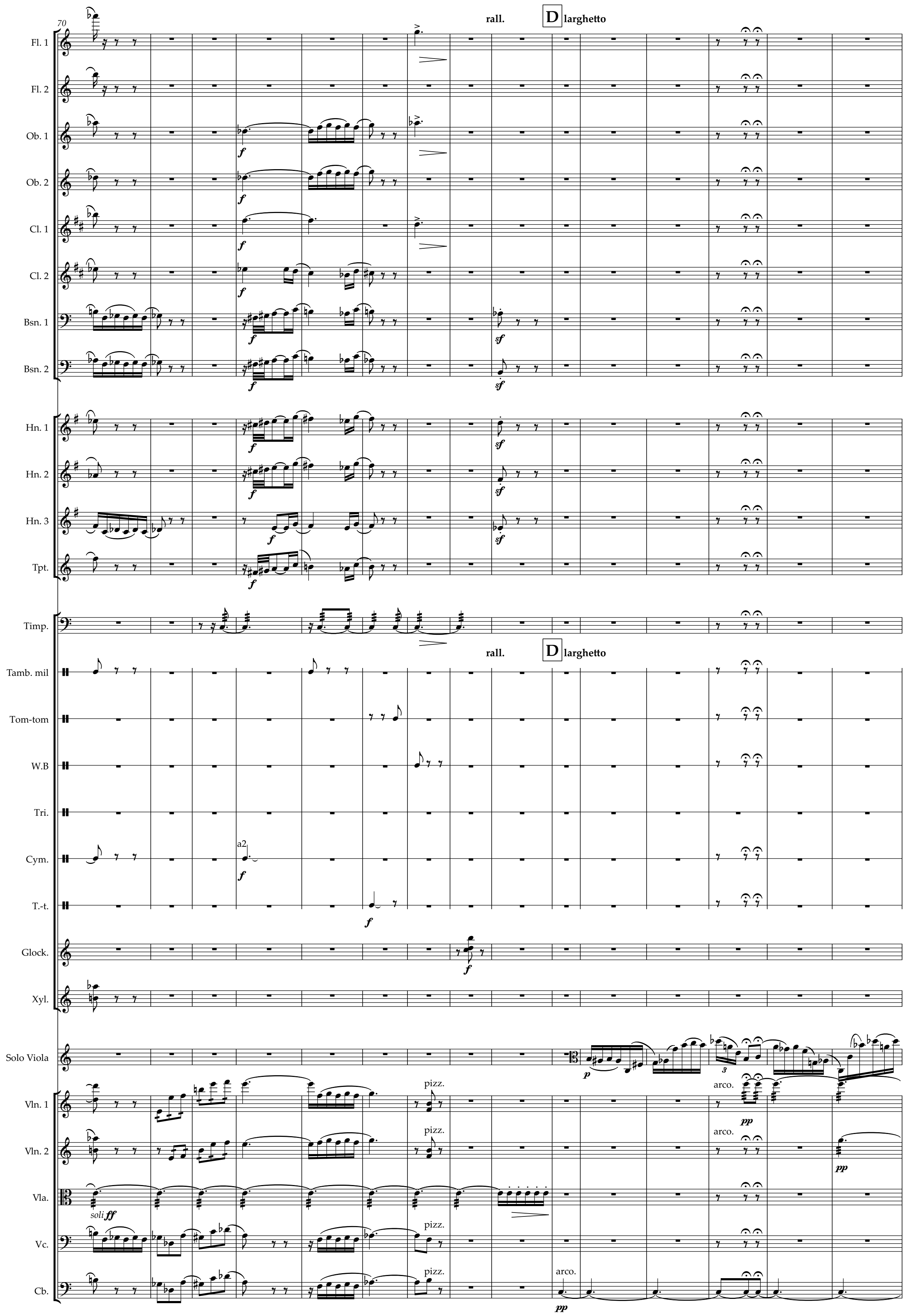

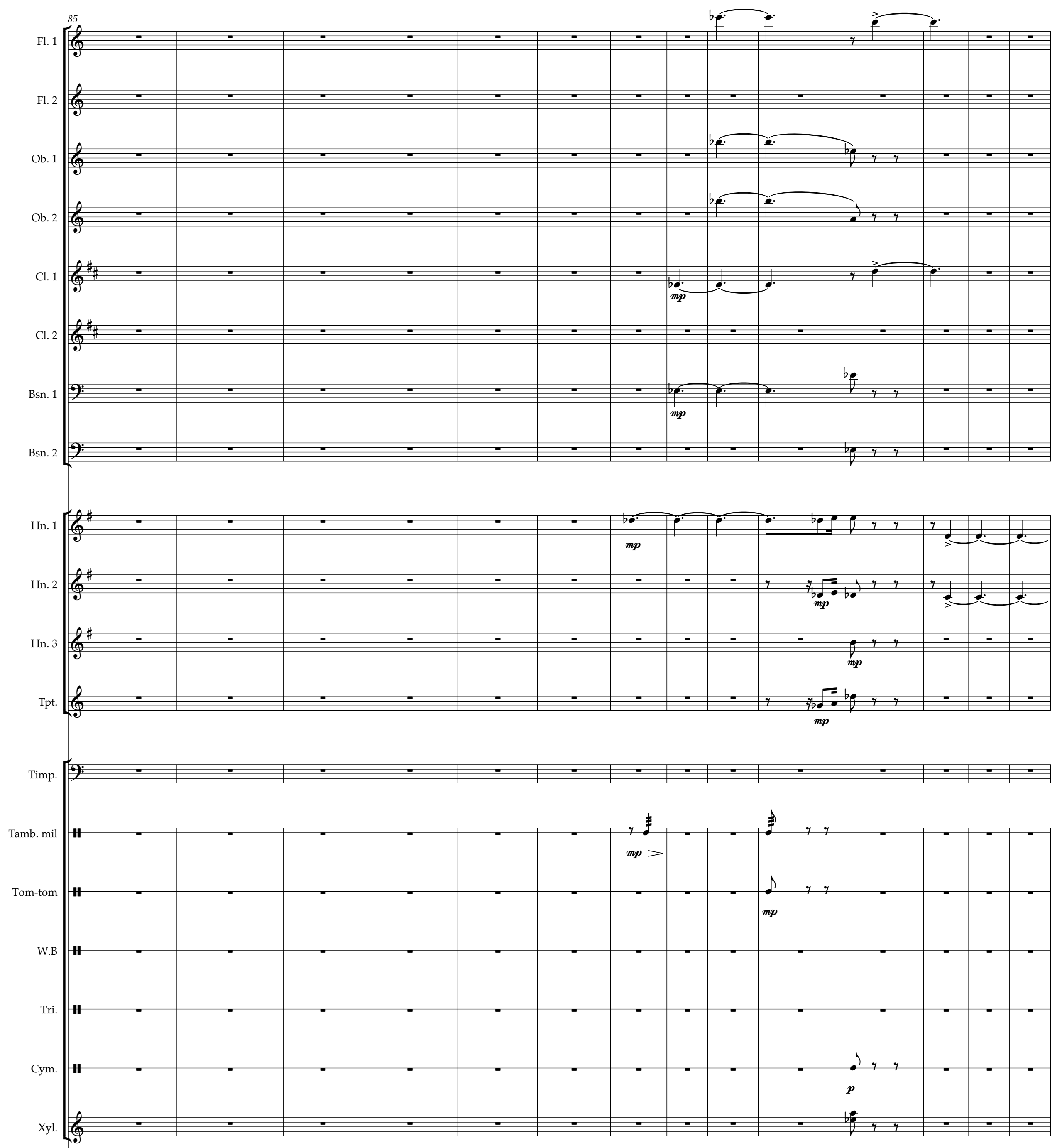

Solo Viola 19 (3)

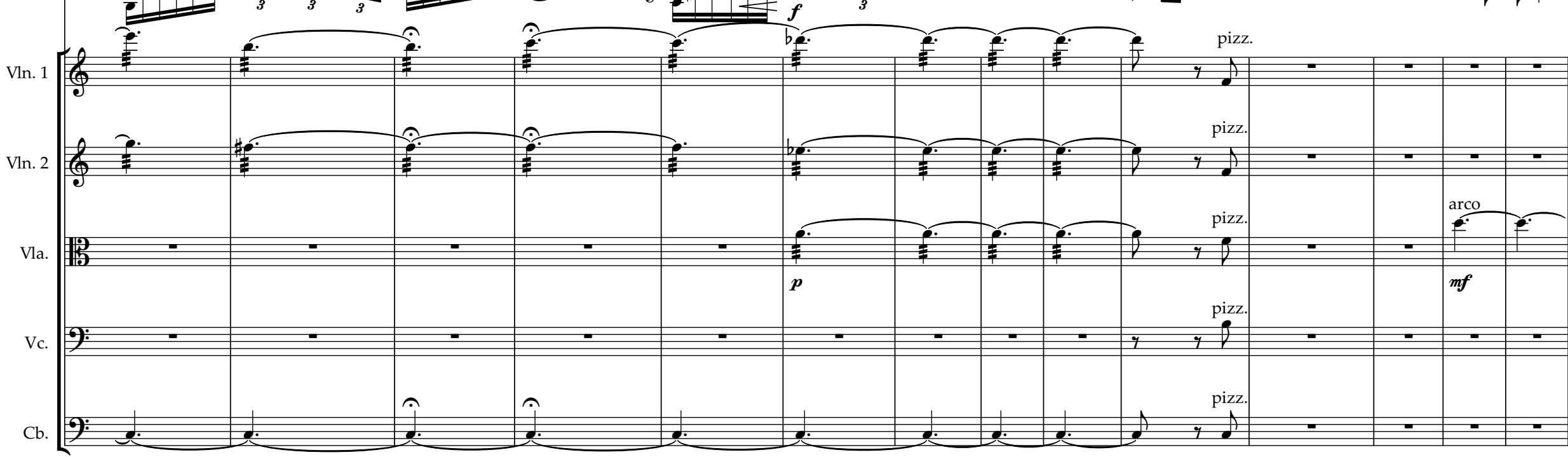



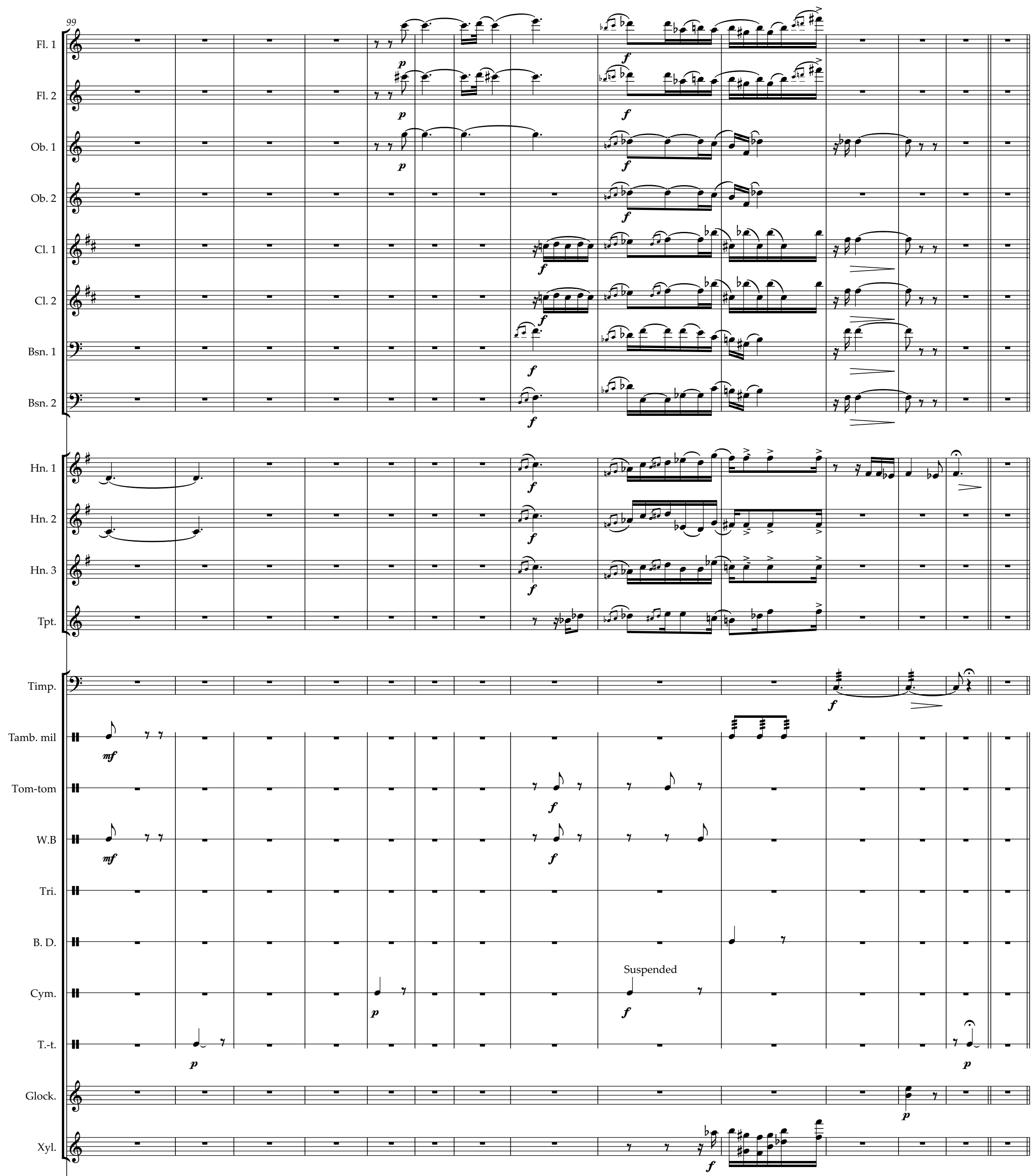

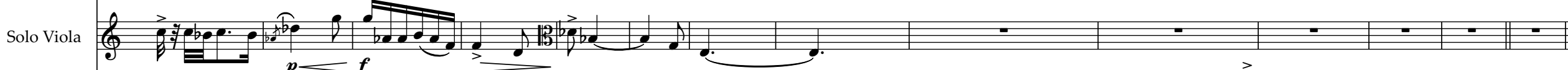

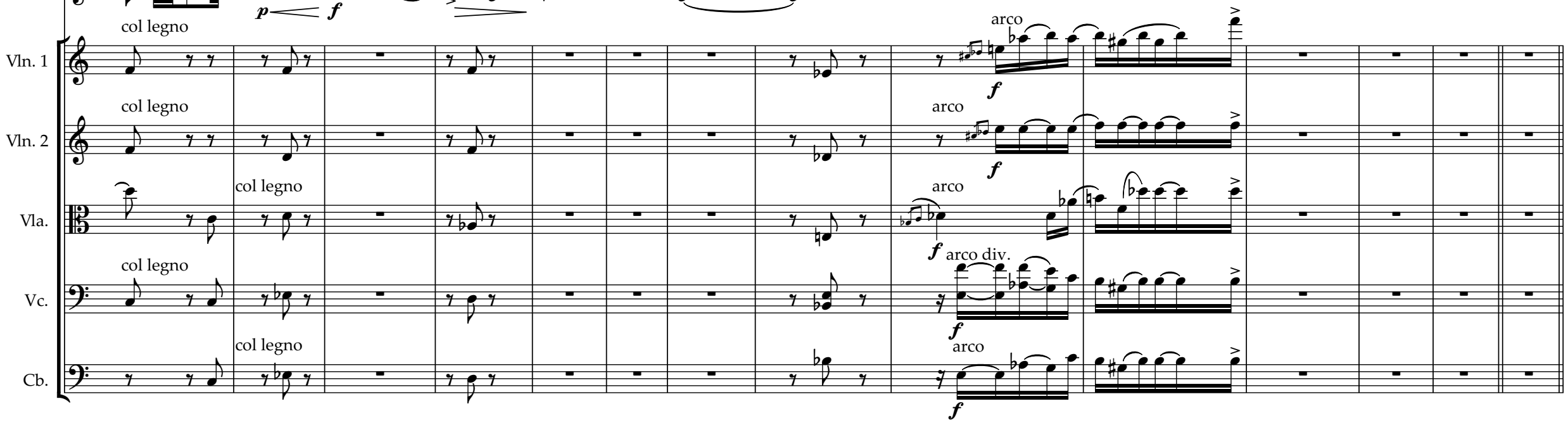




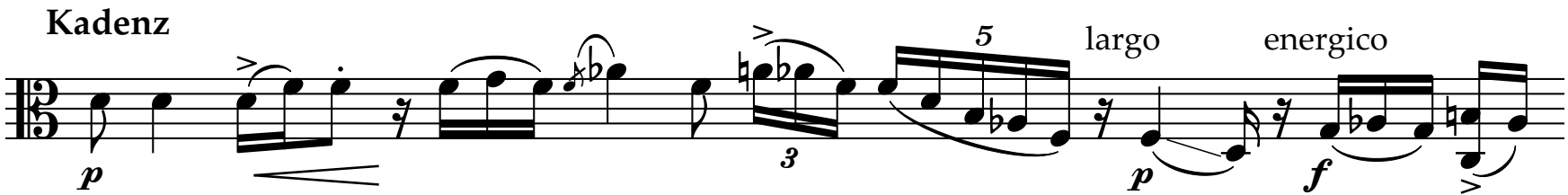

驾y 留y y E 节

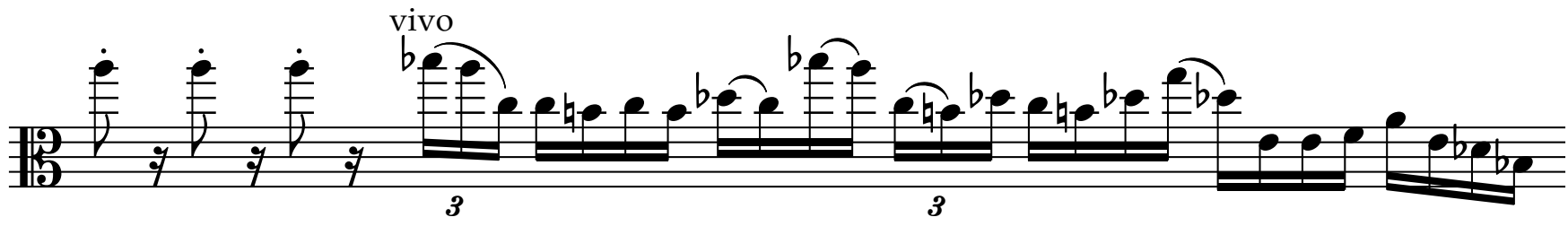

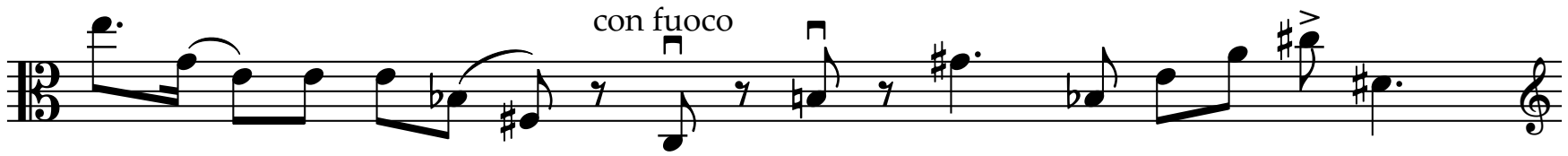
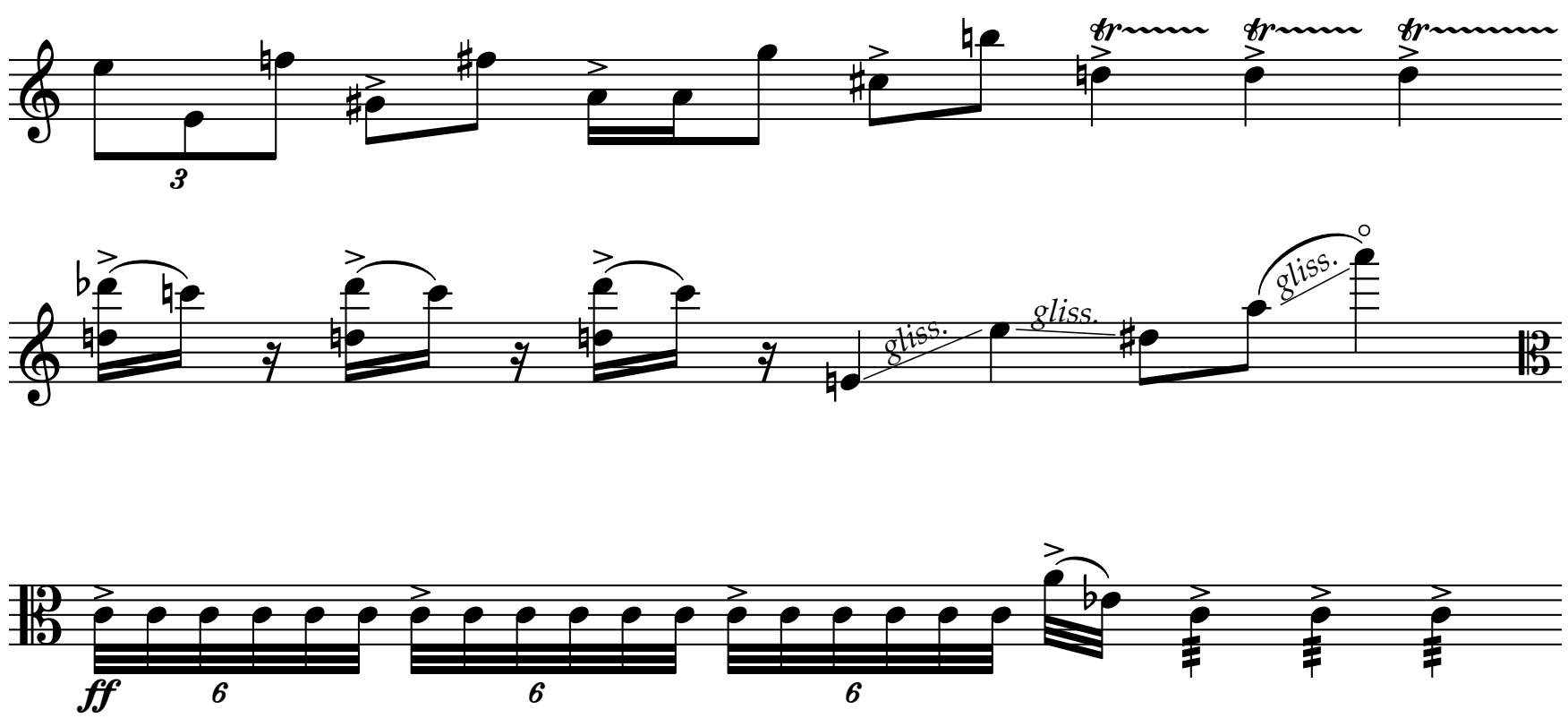

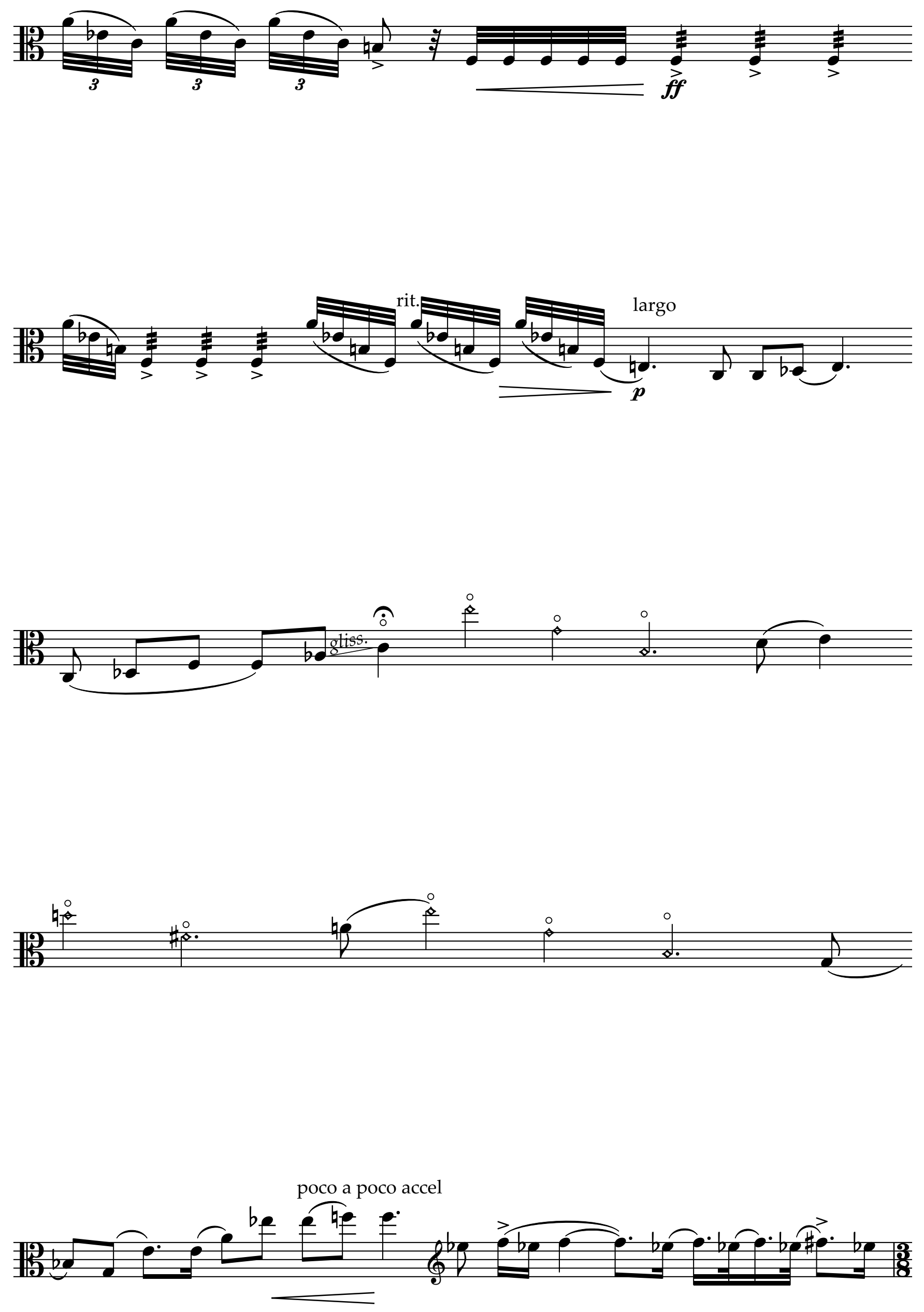

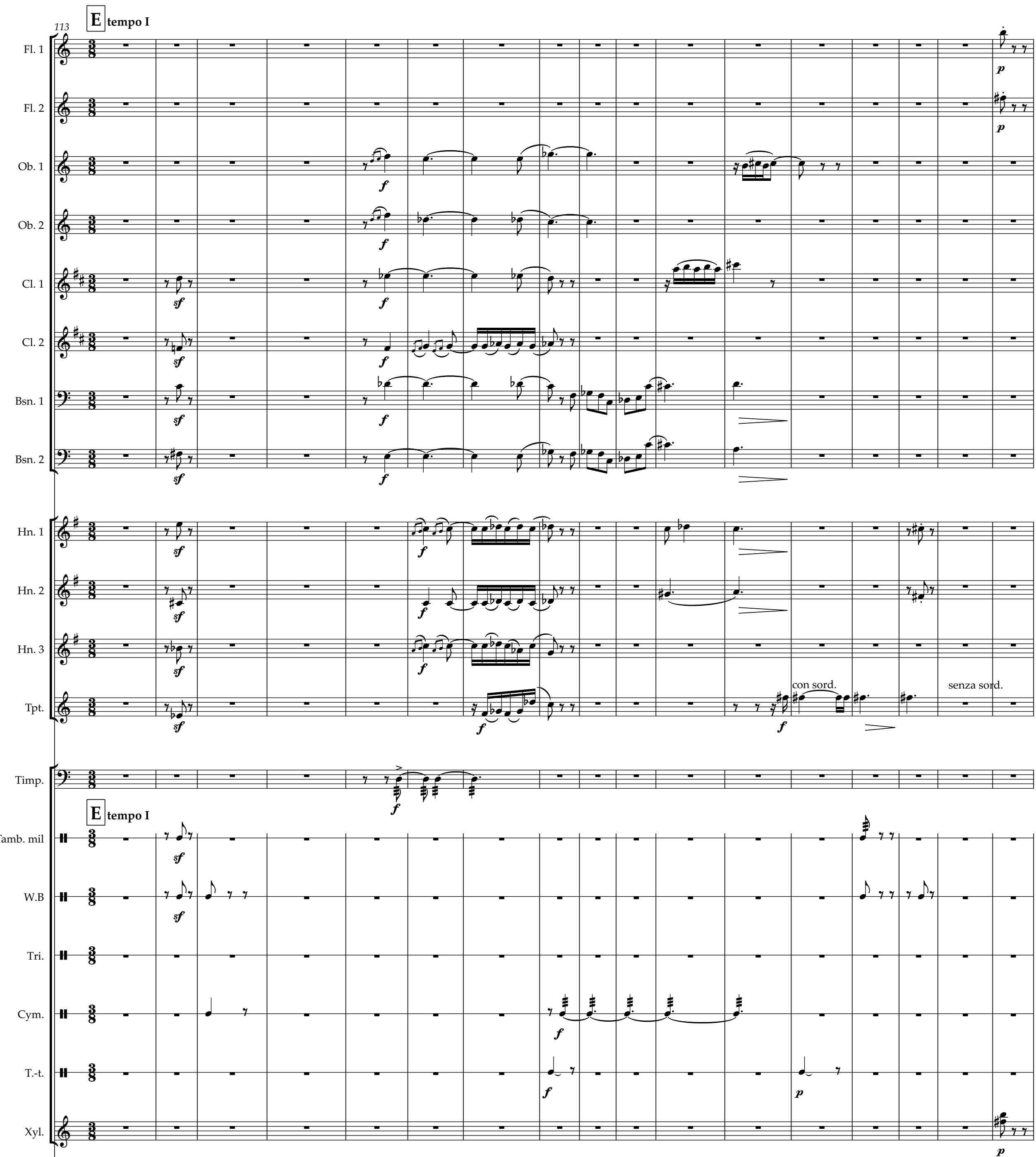

Solo Viola

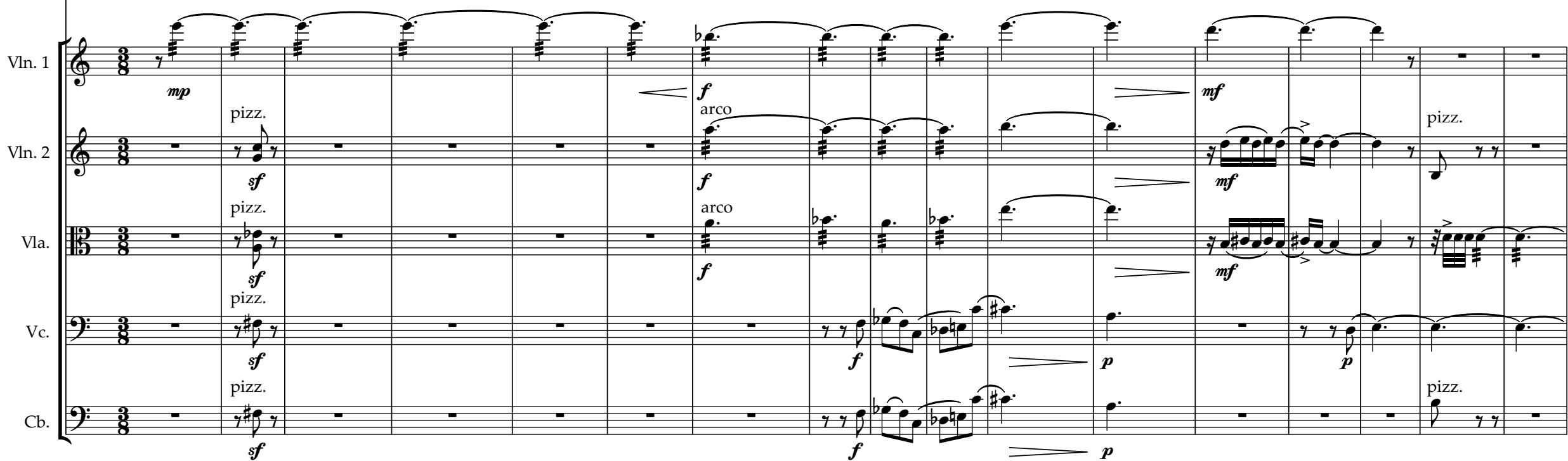



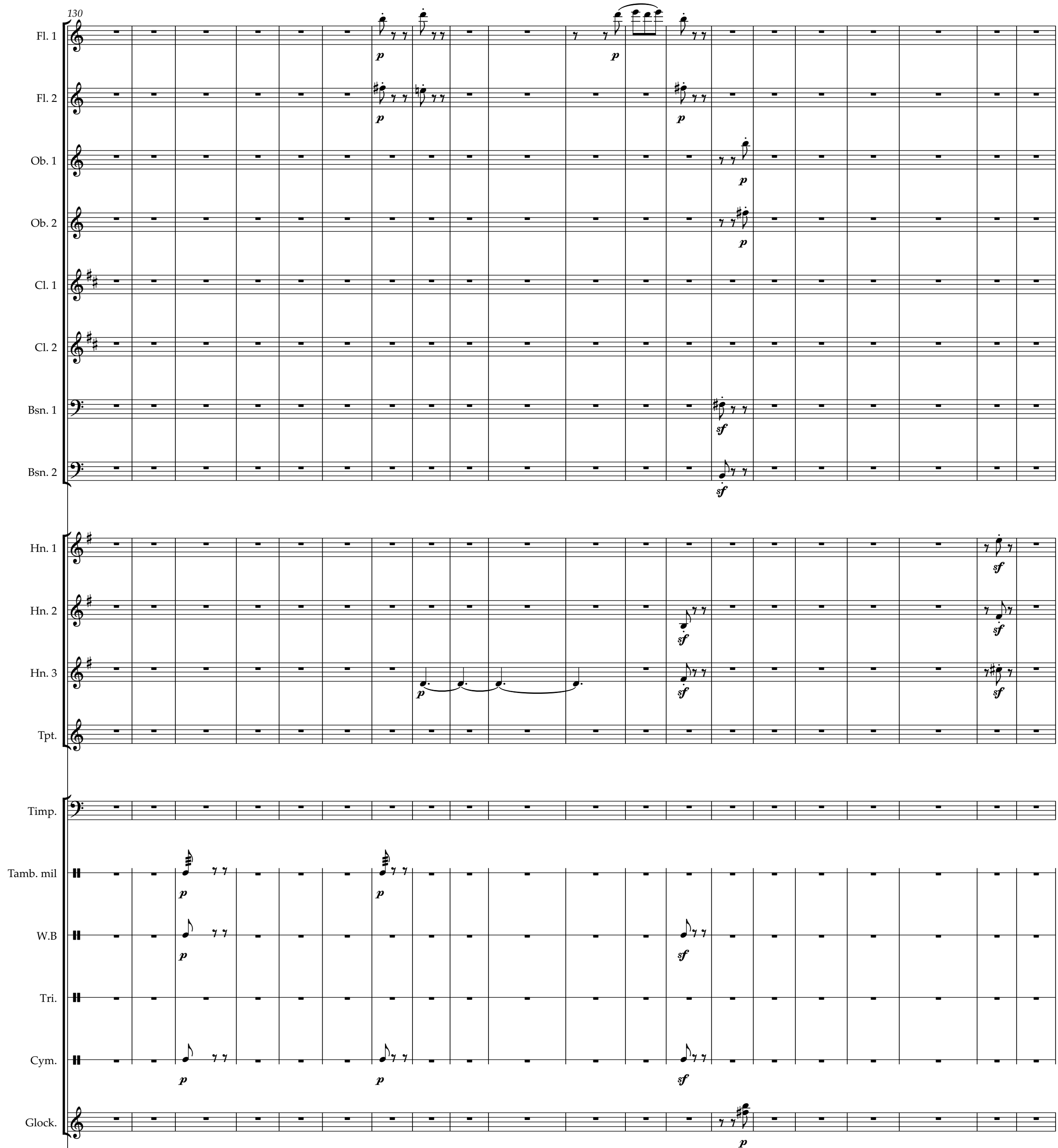

Solo Viola

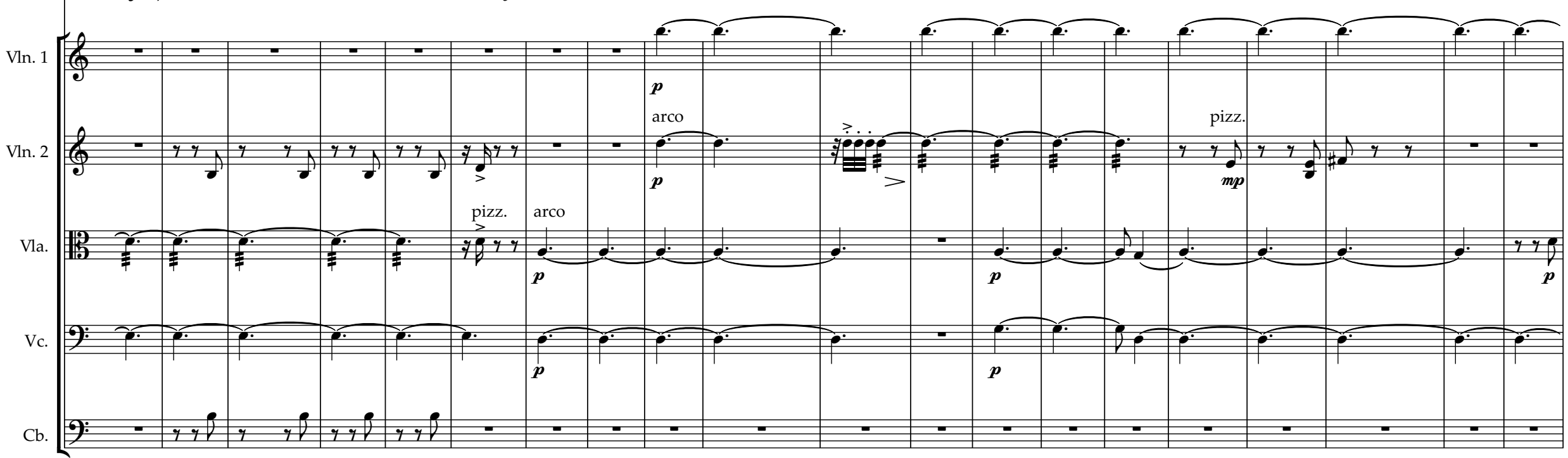


III.

30
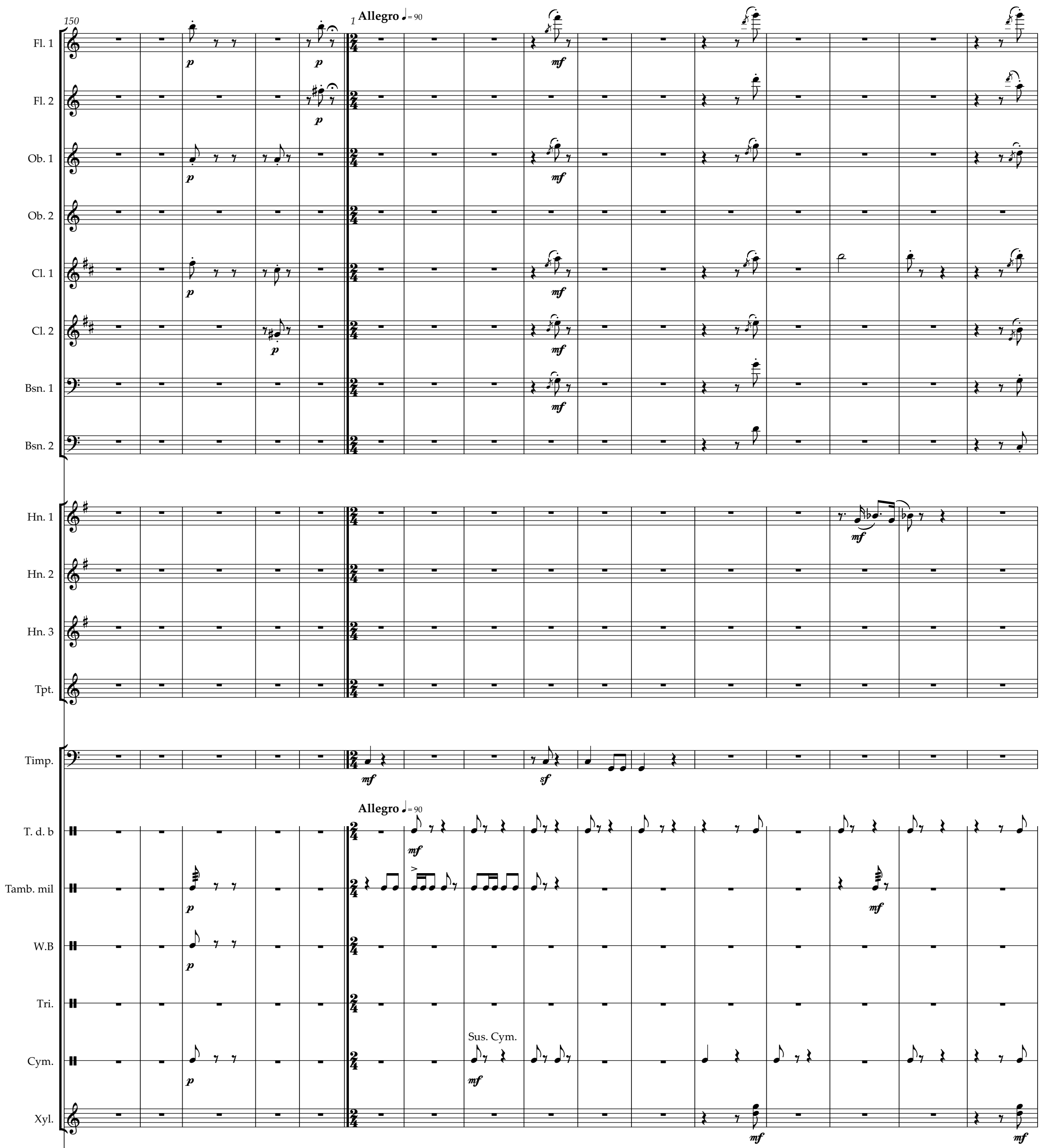

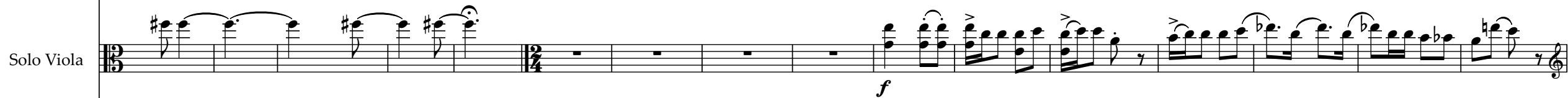

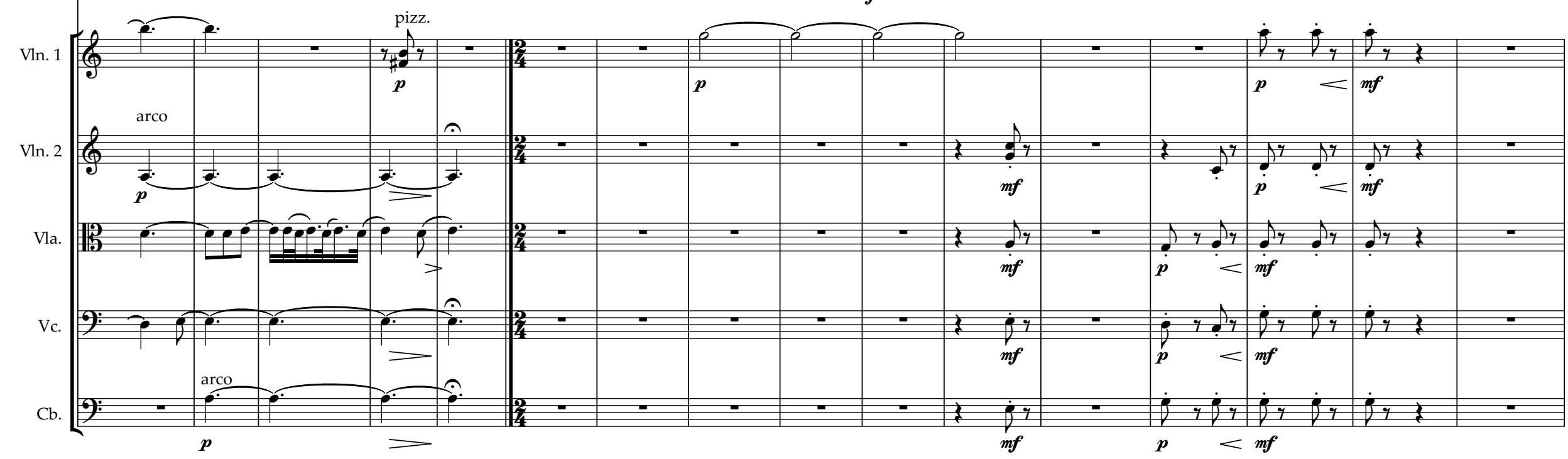



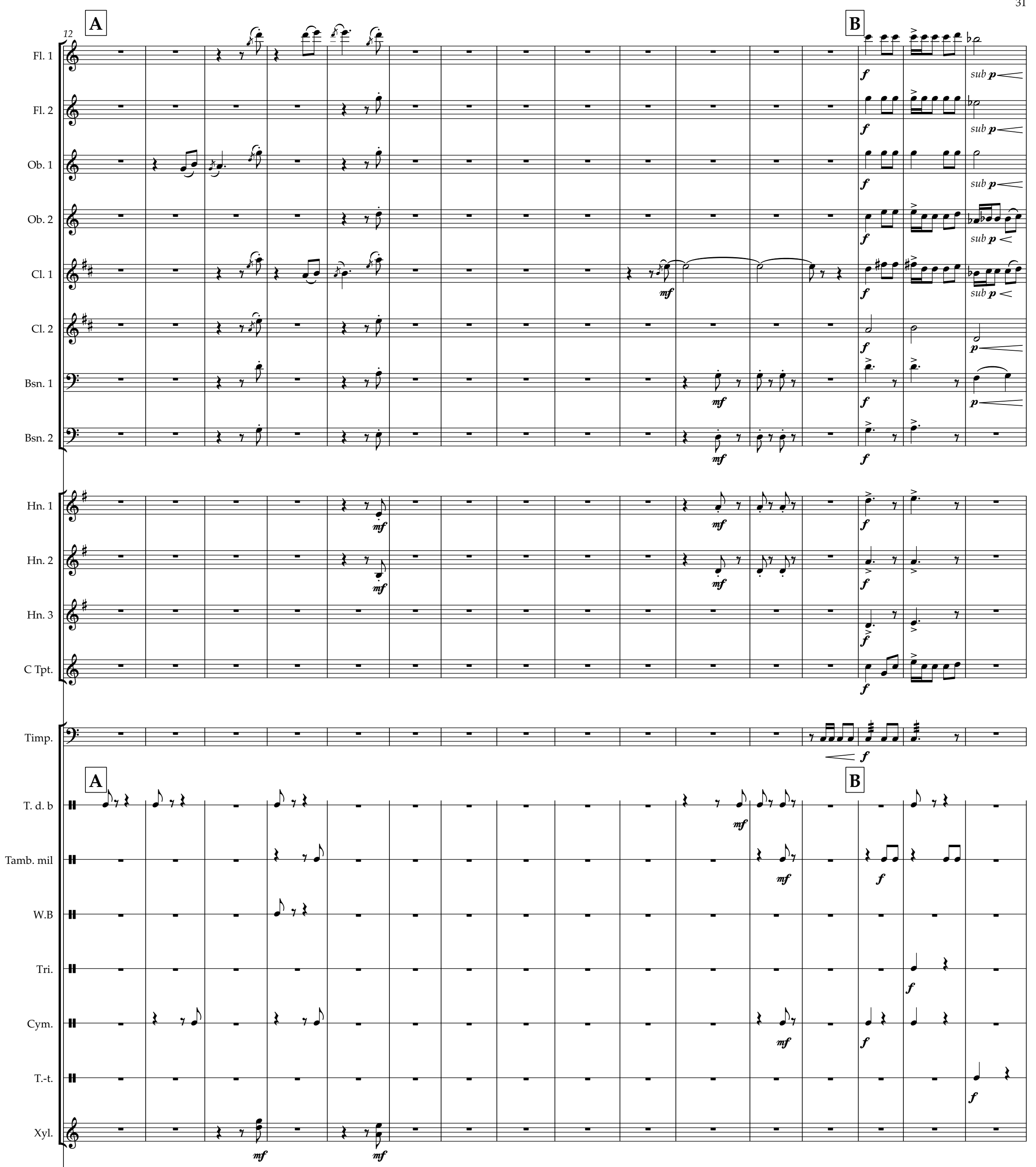

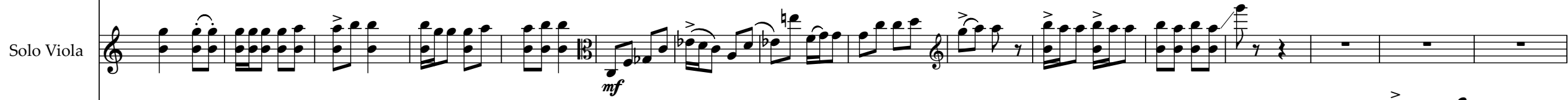

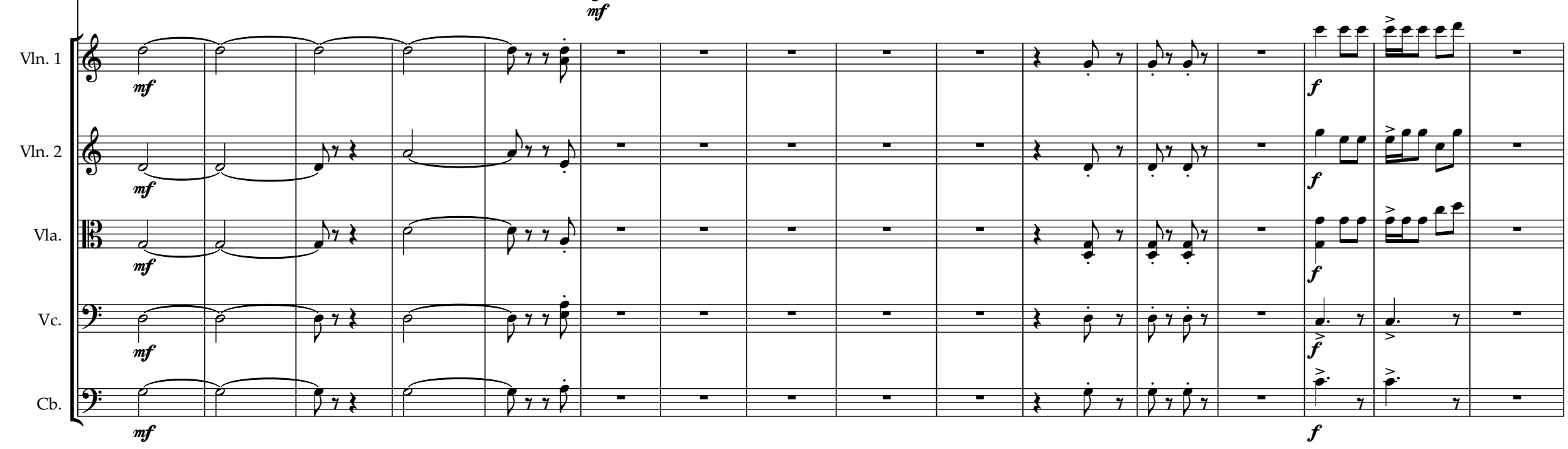


32
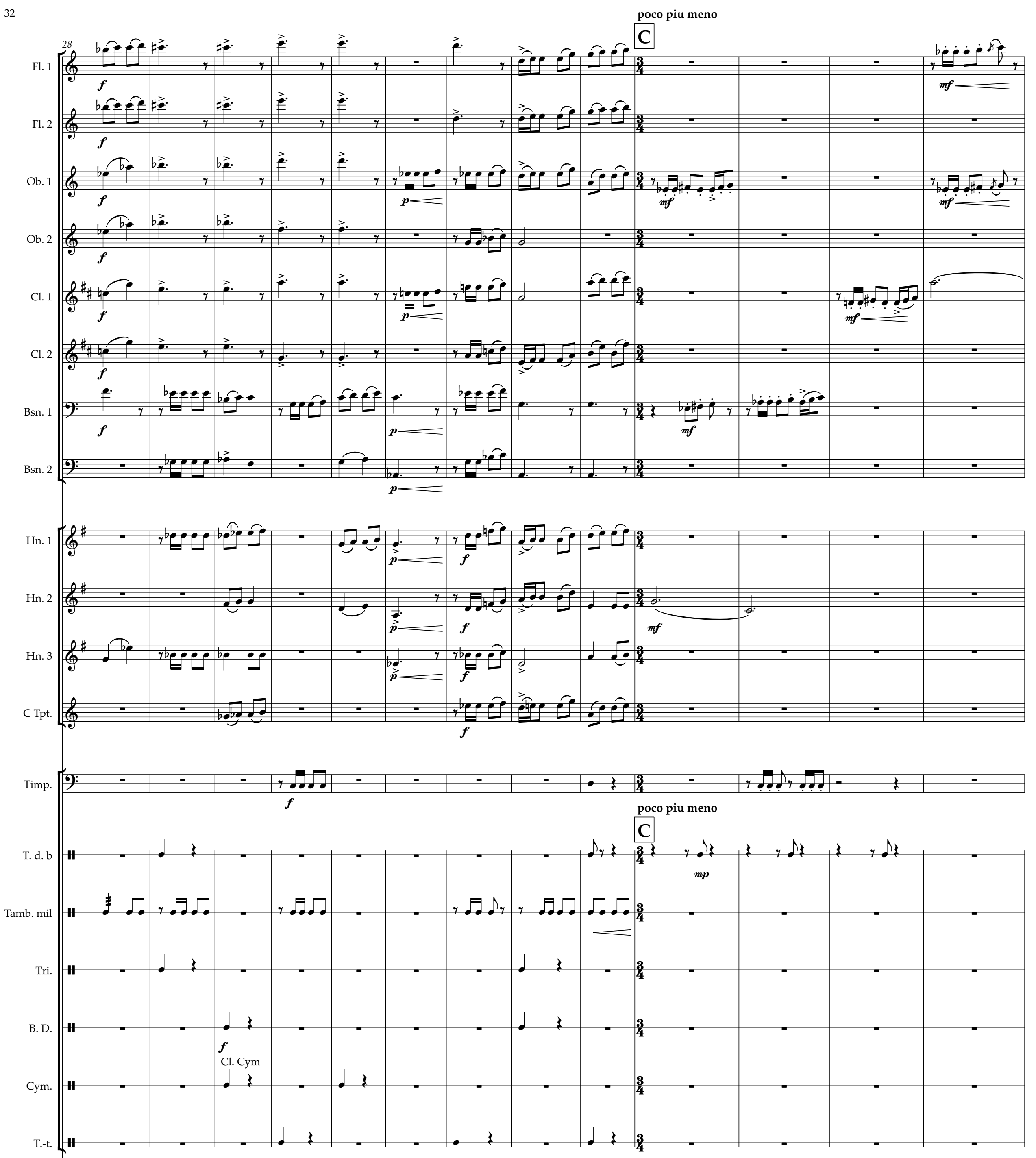

Solo Viola $\oint_{9}$

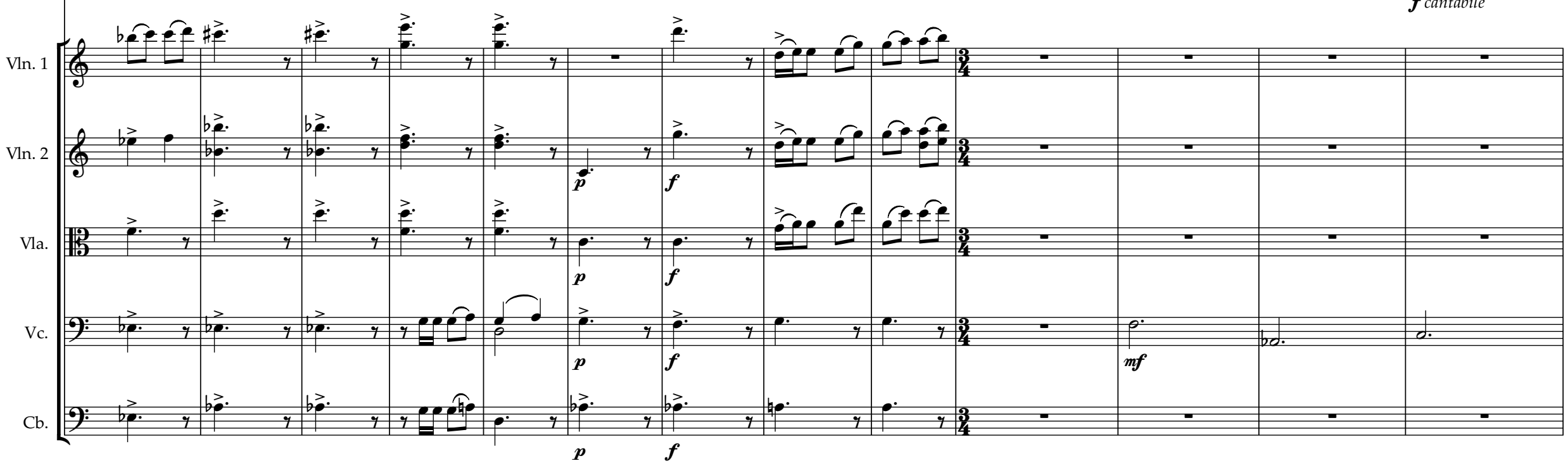



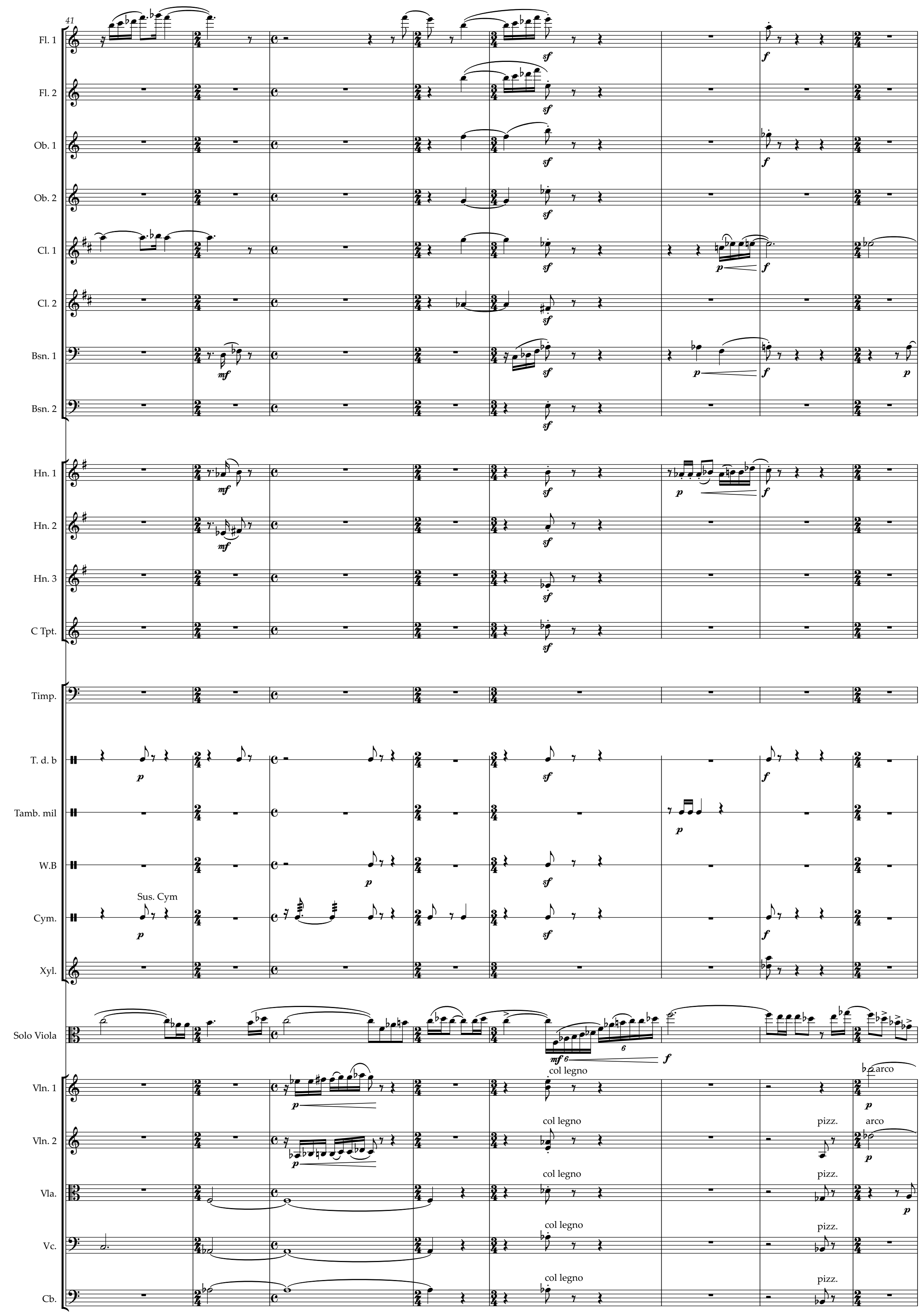
34
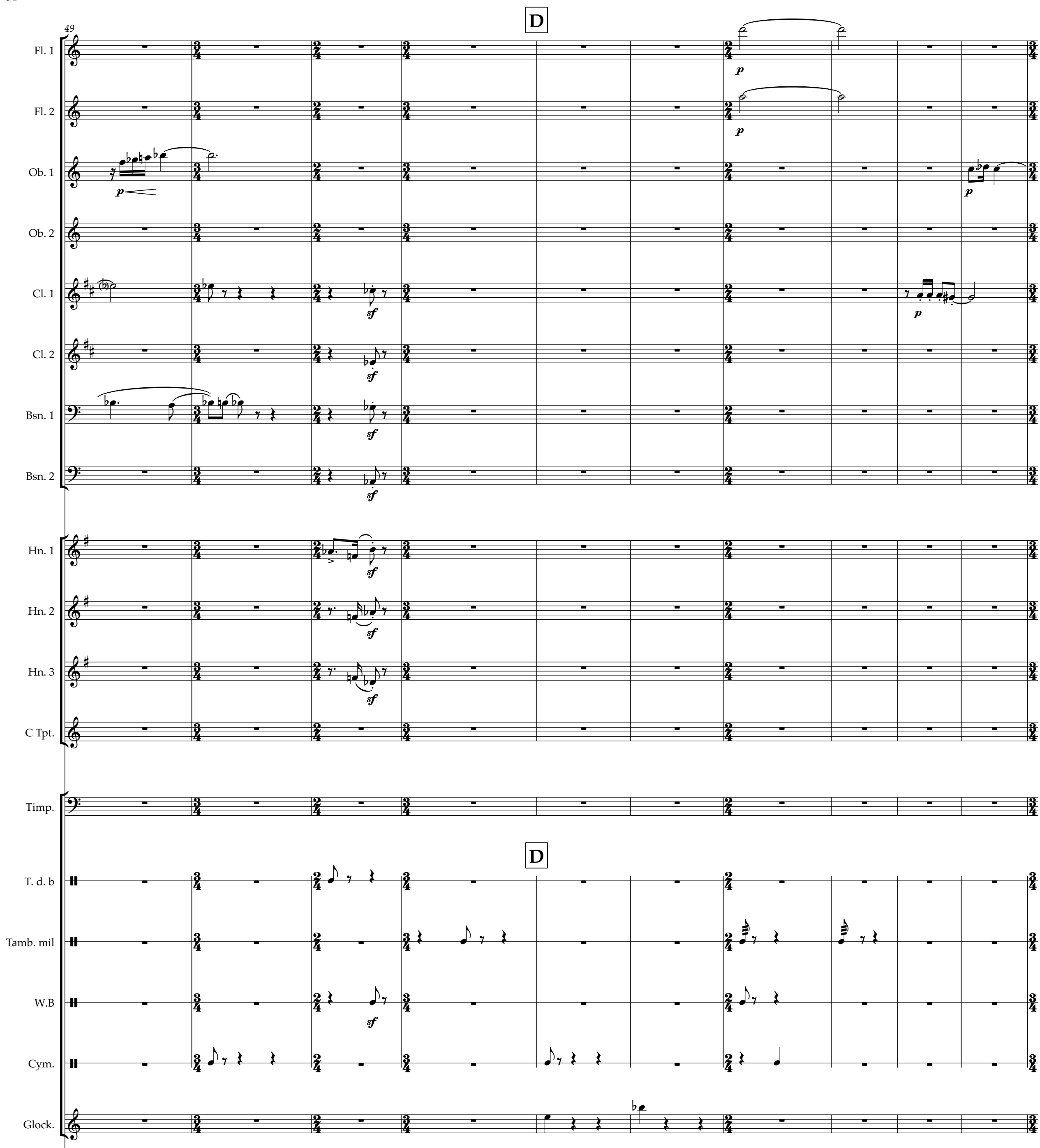

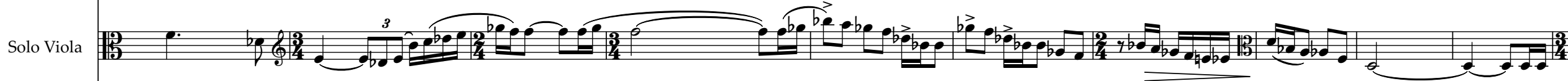

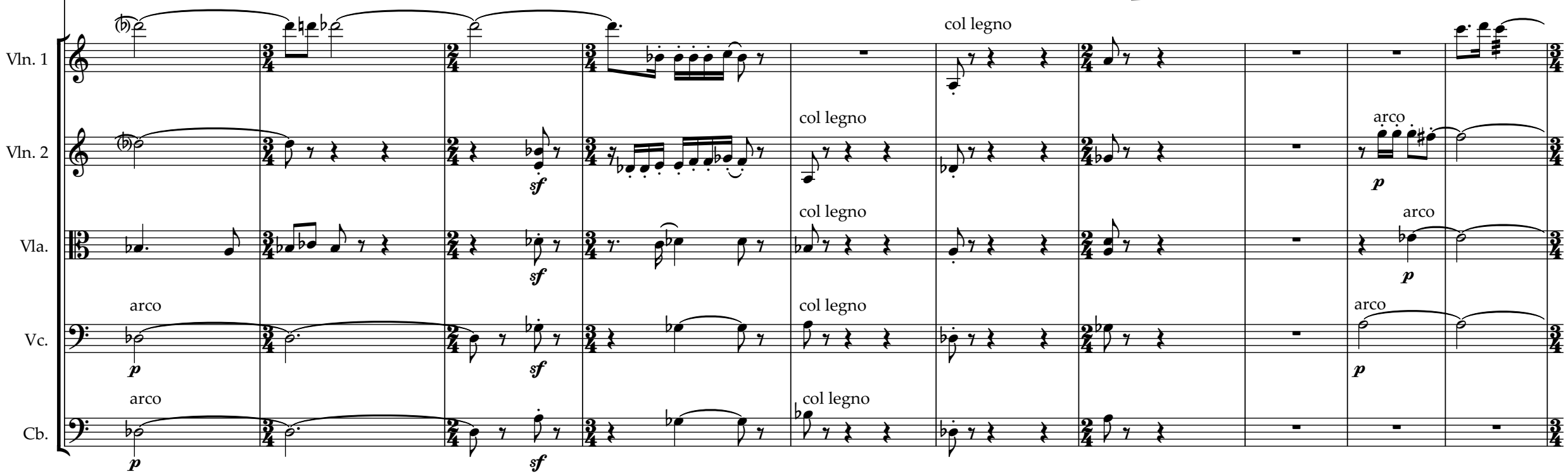



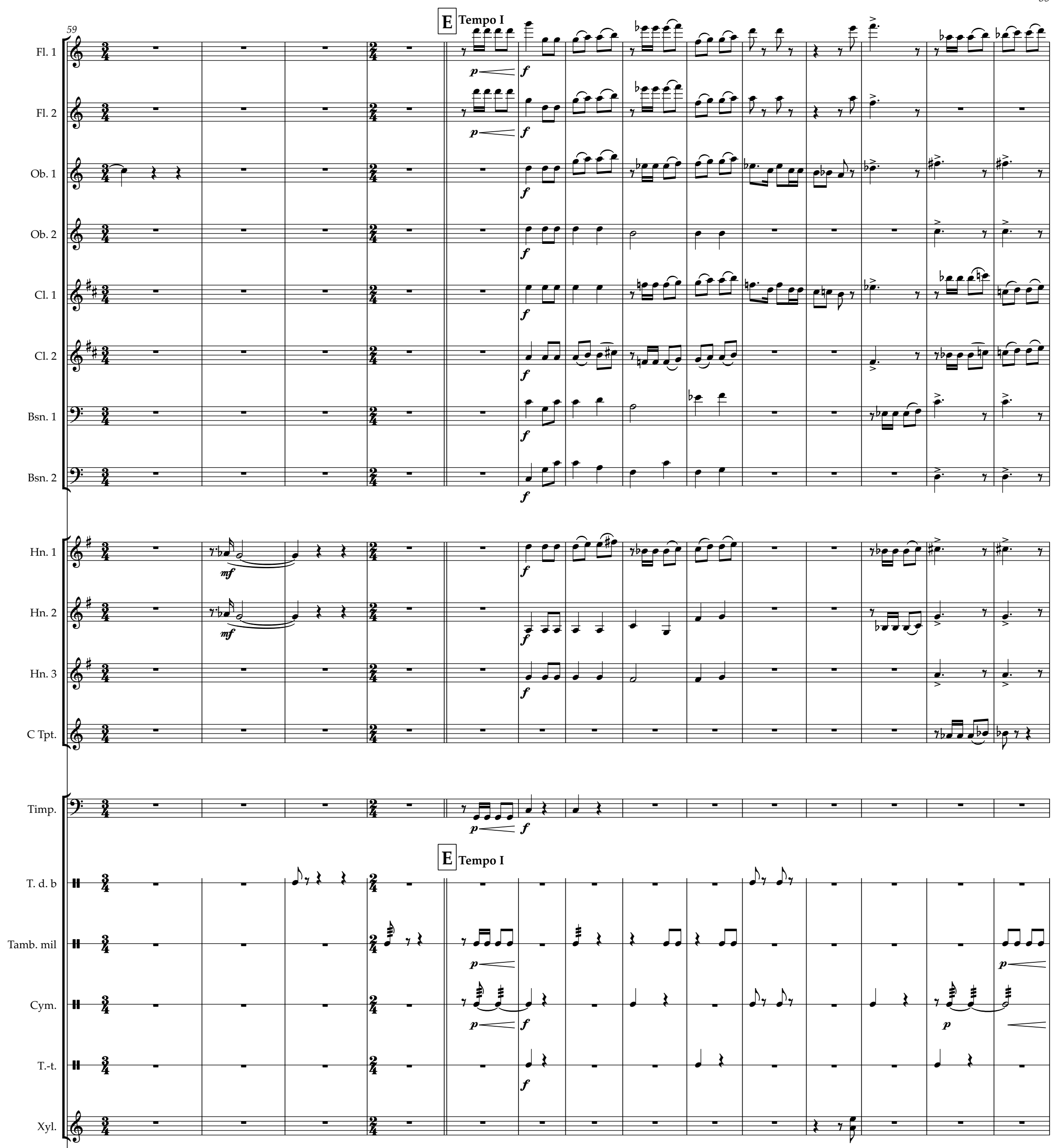

Solo Viola

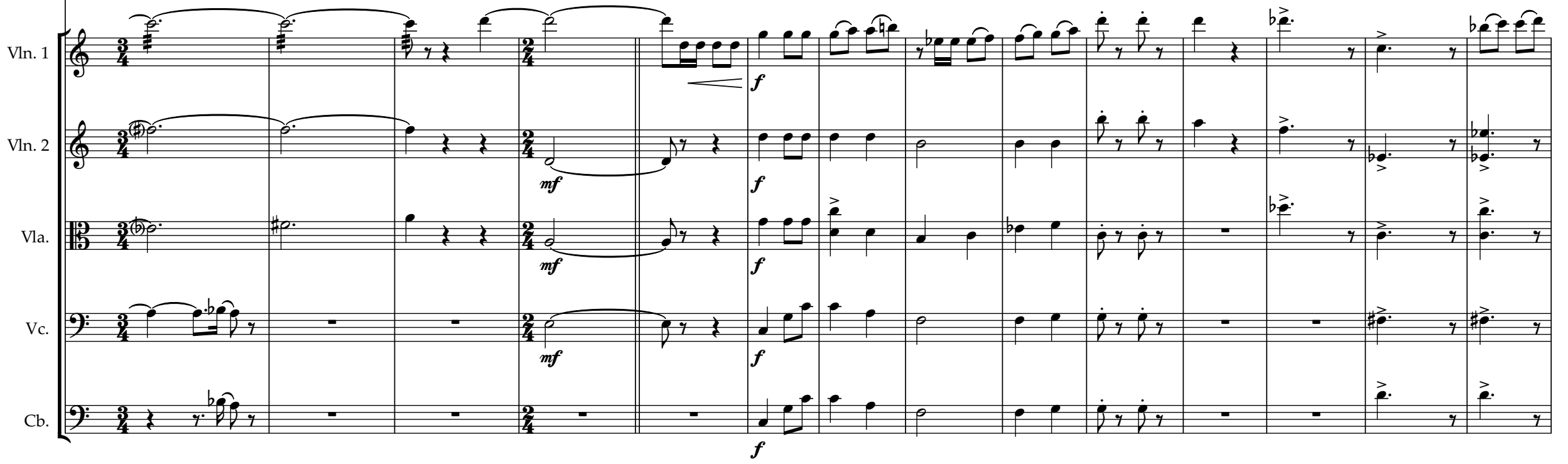



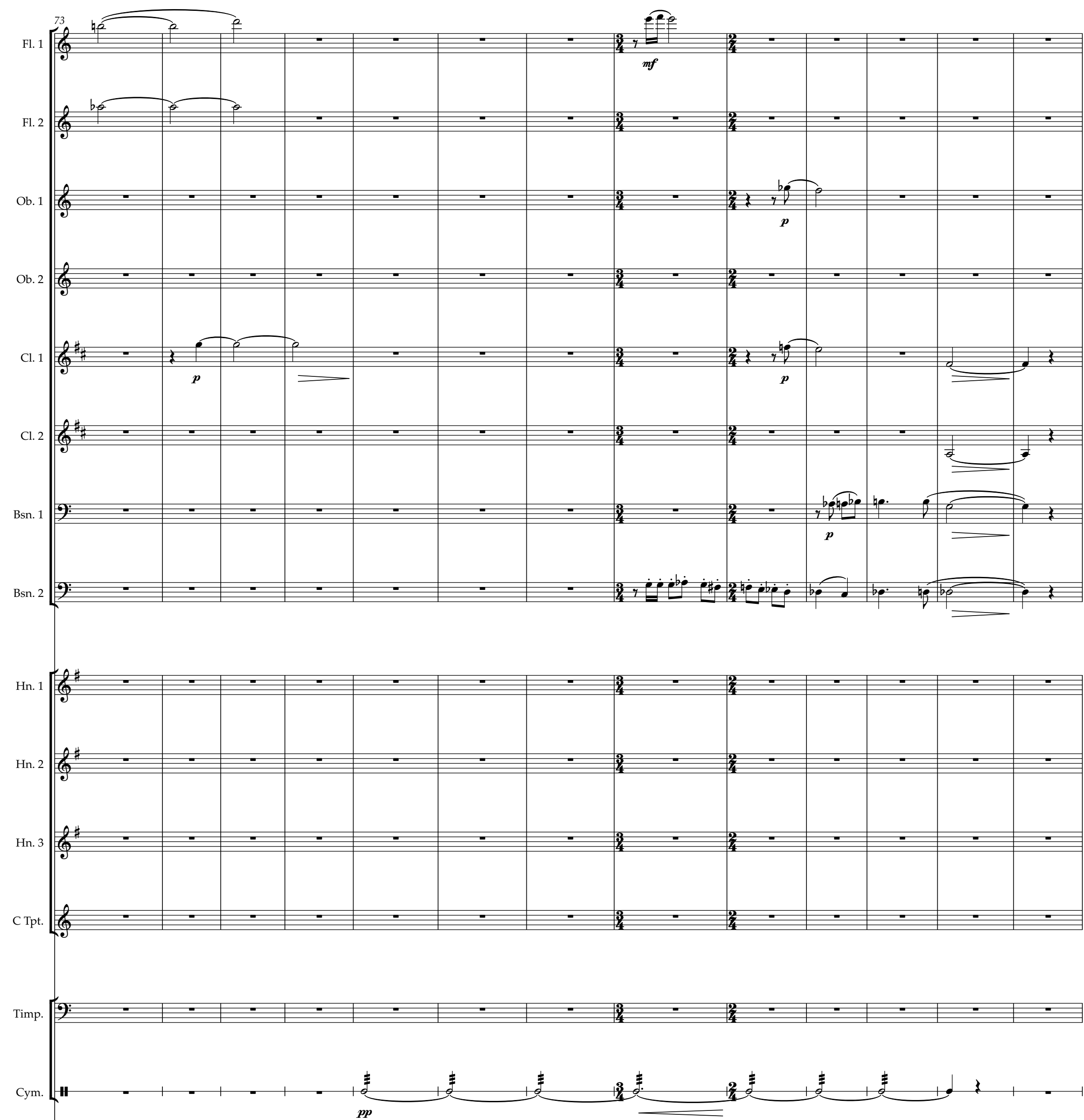

Solo Viola

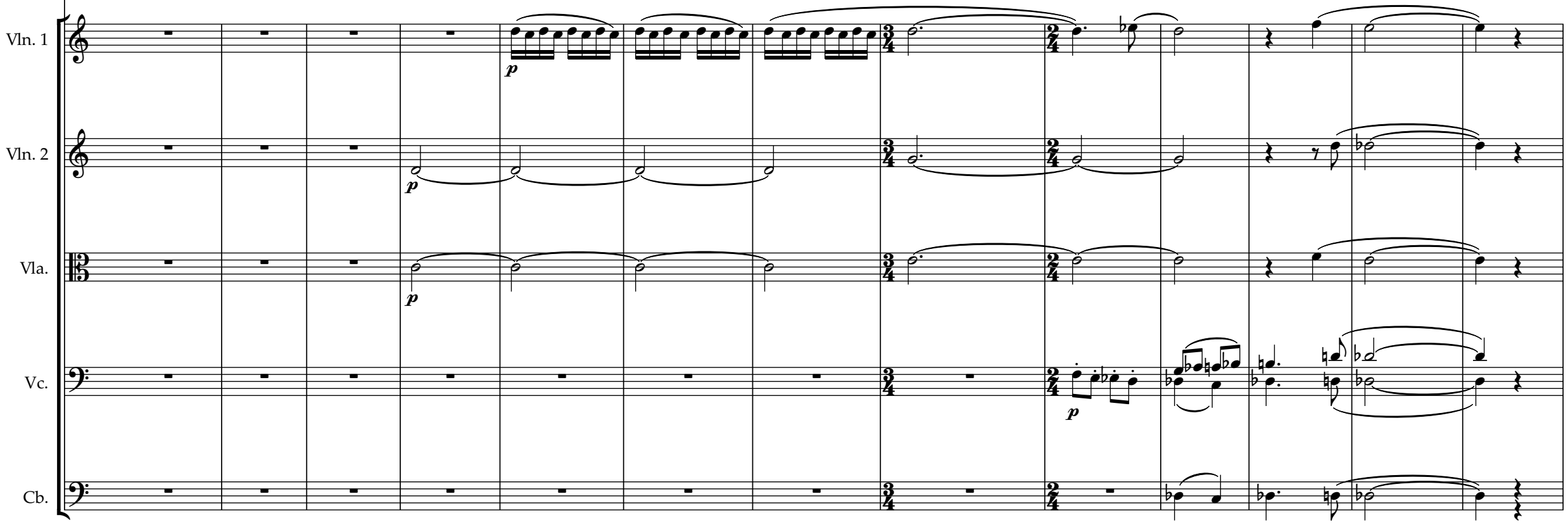



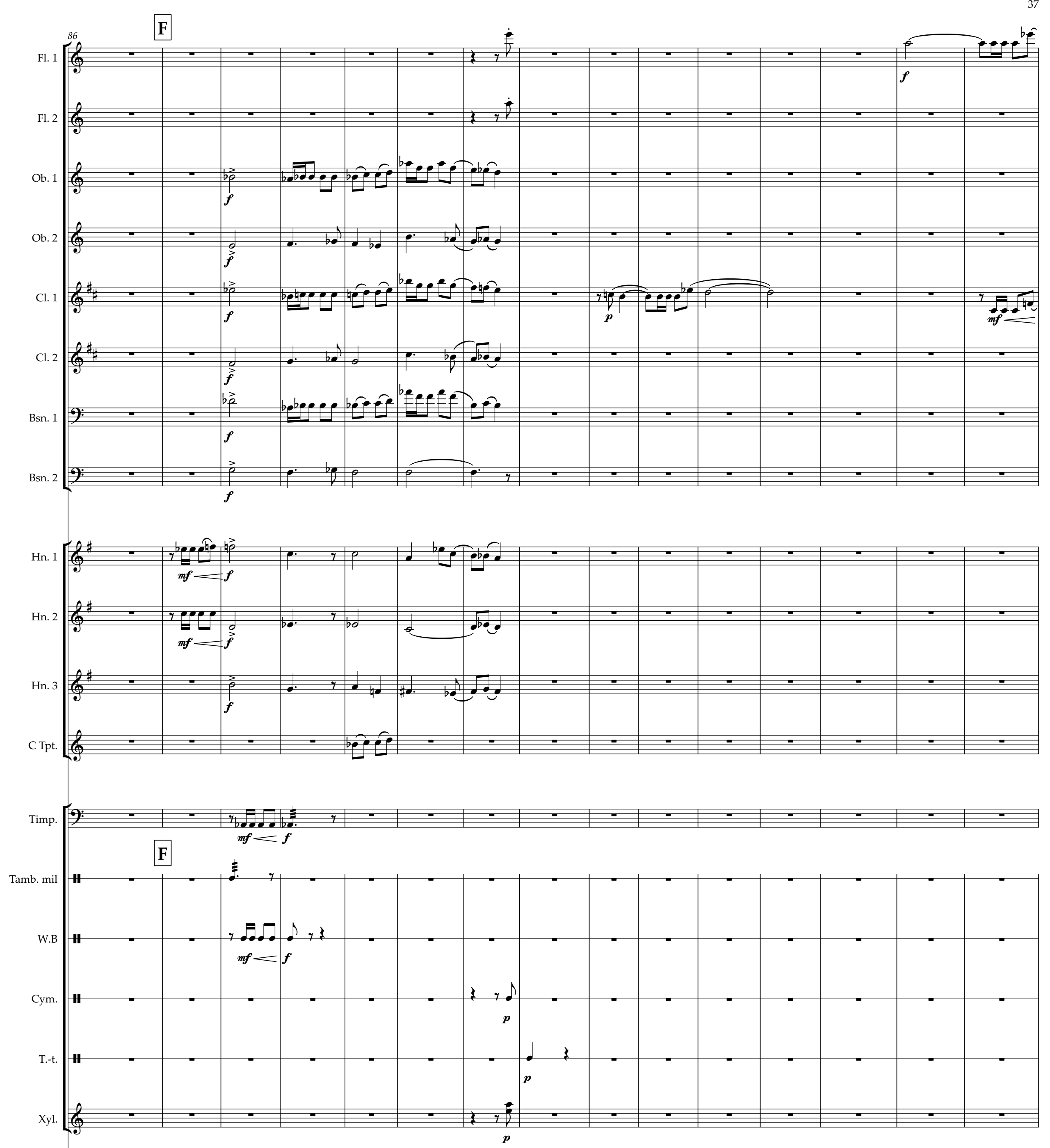

Solo Viola

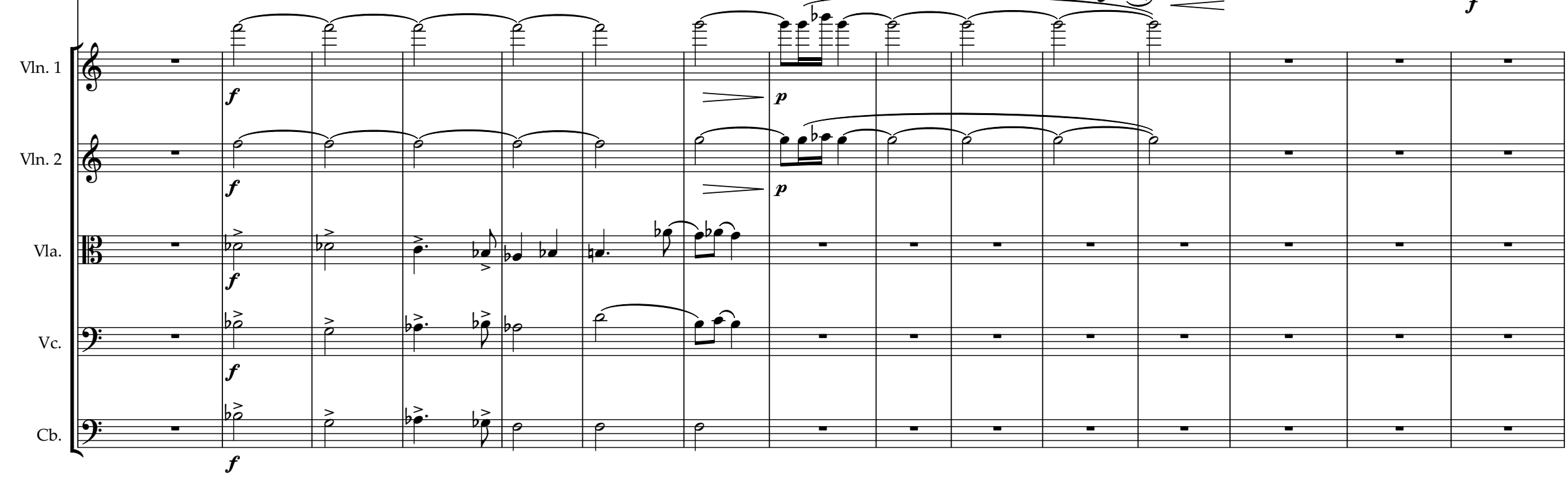



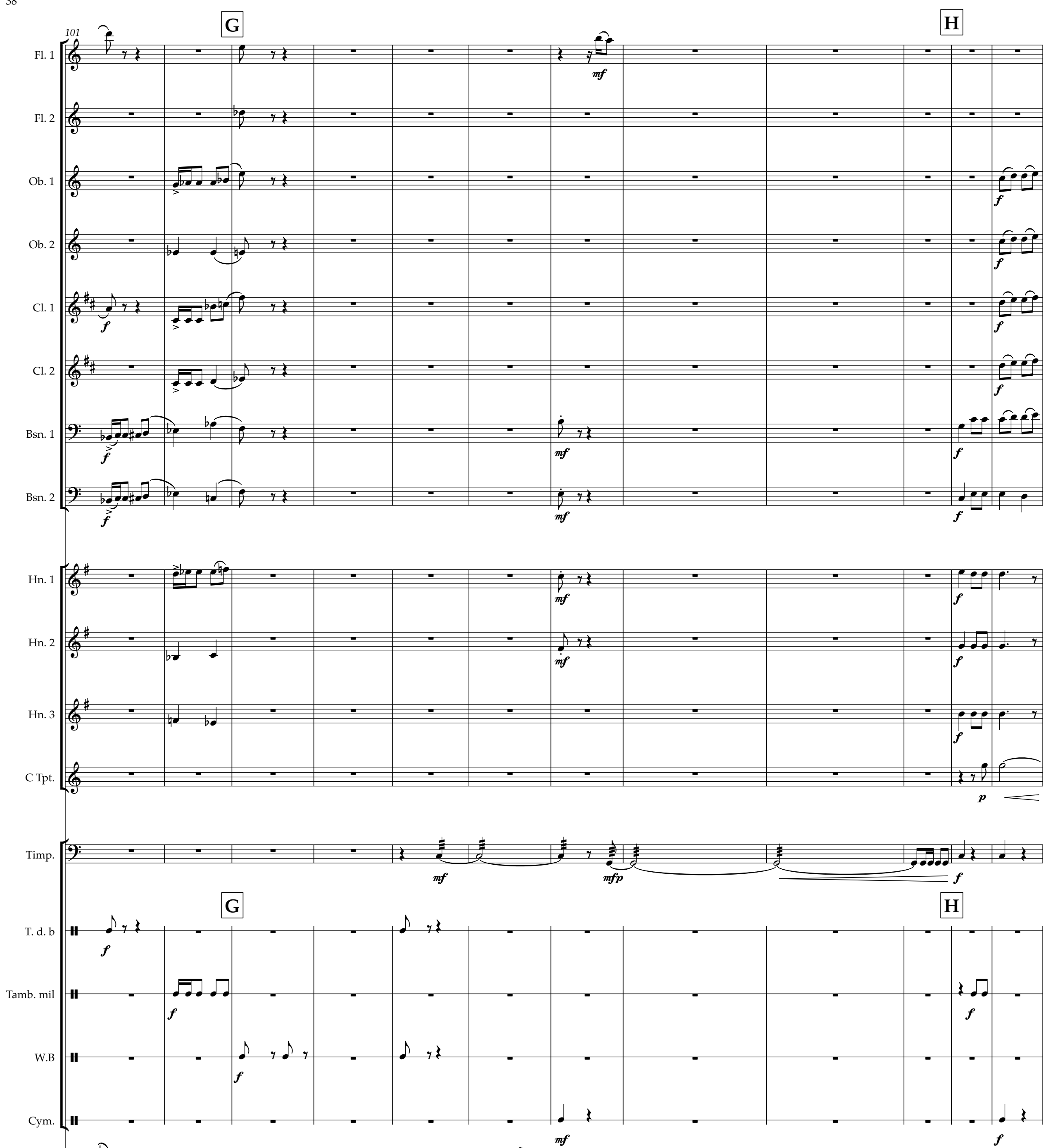

Solo Viola

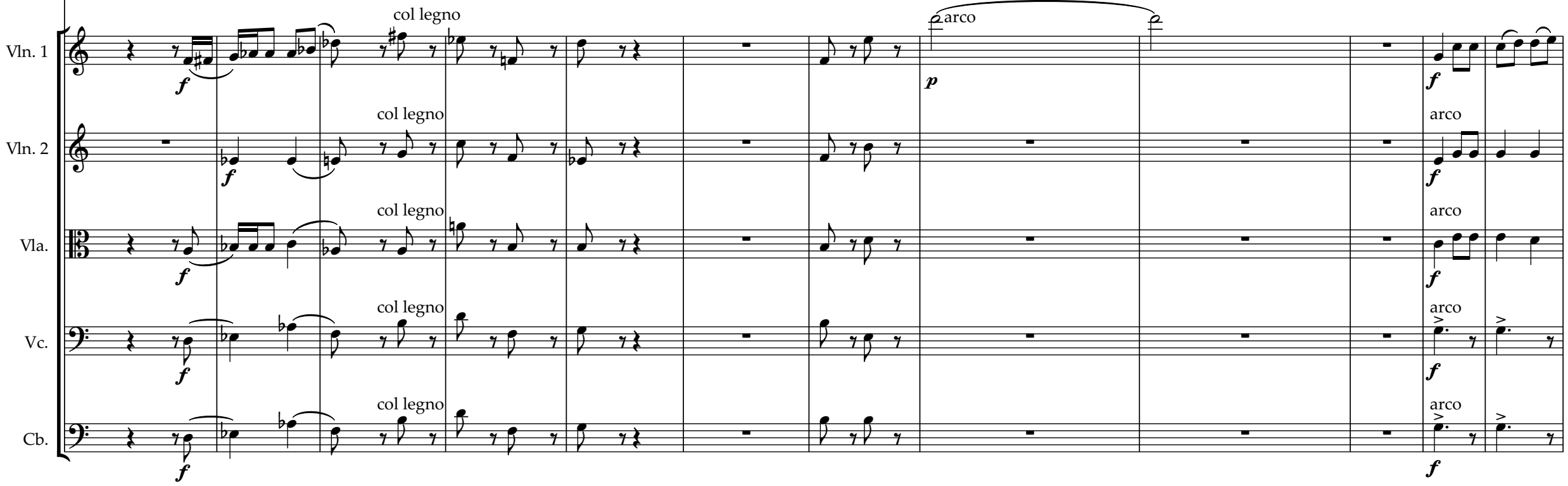



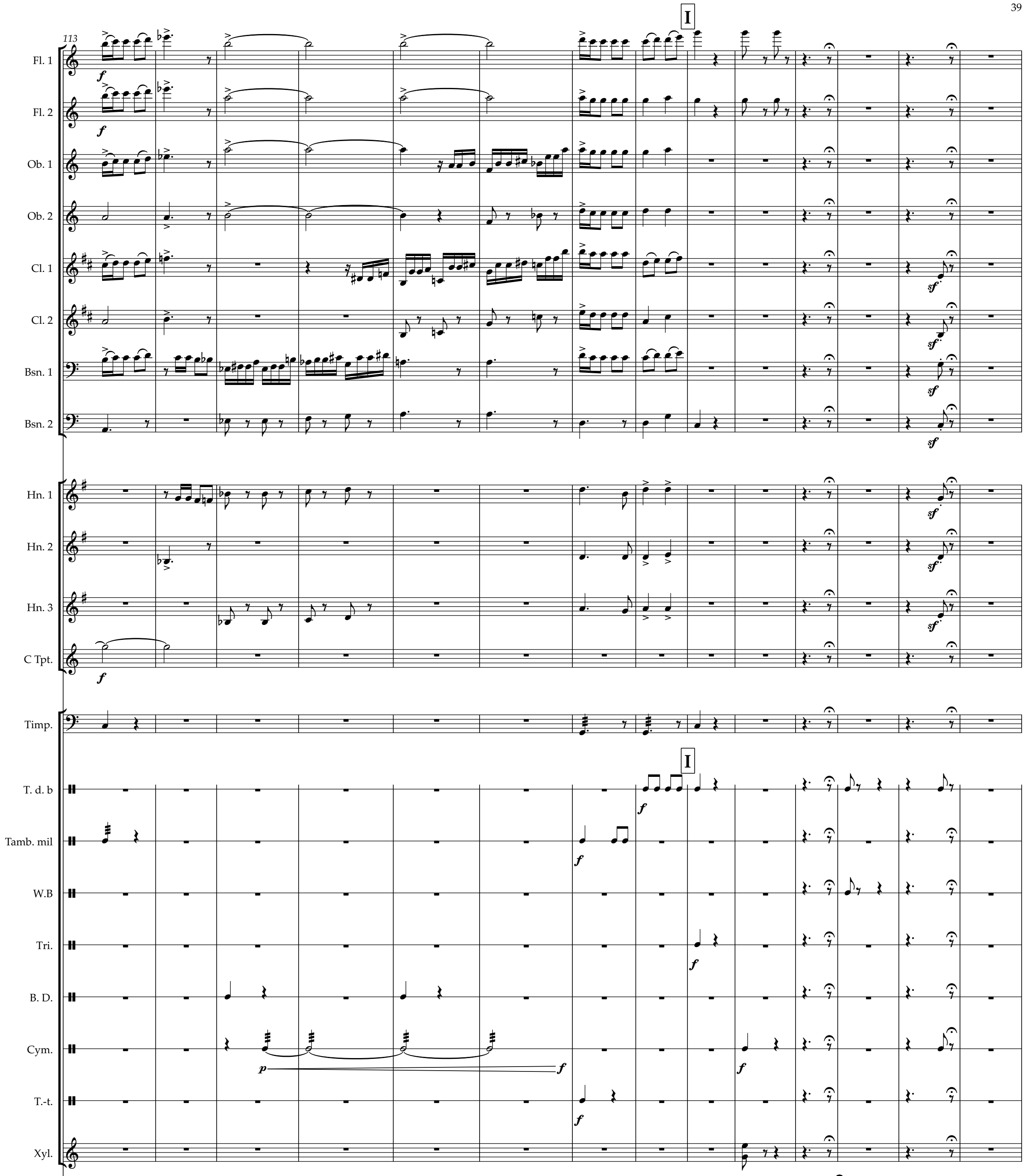

Solo Viola $b_{0}$

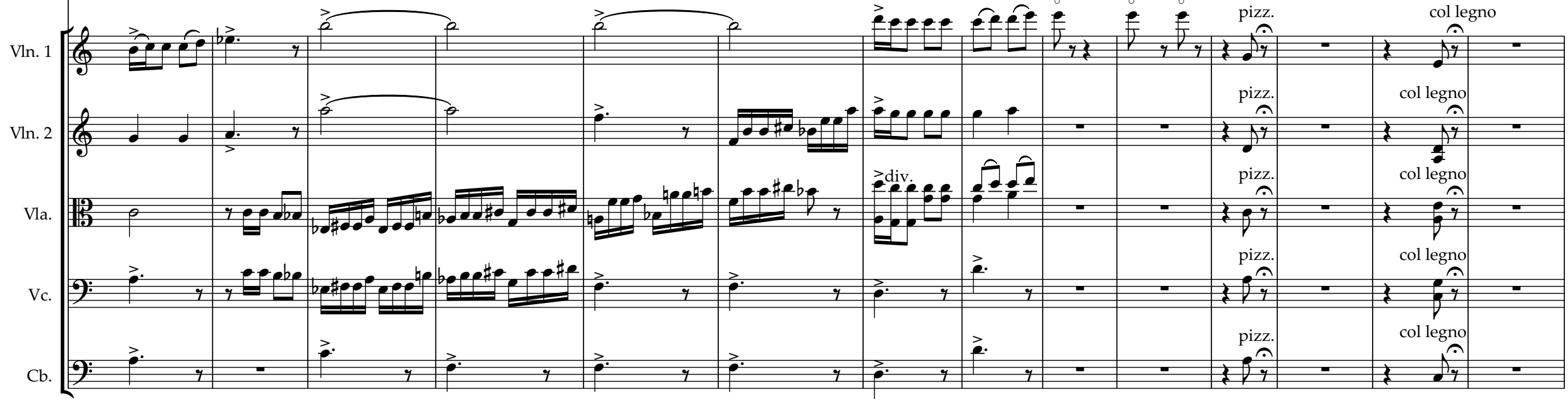



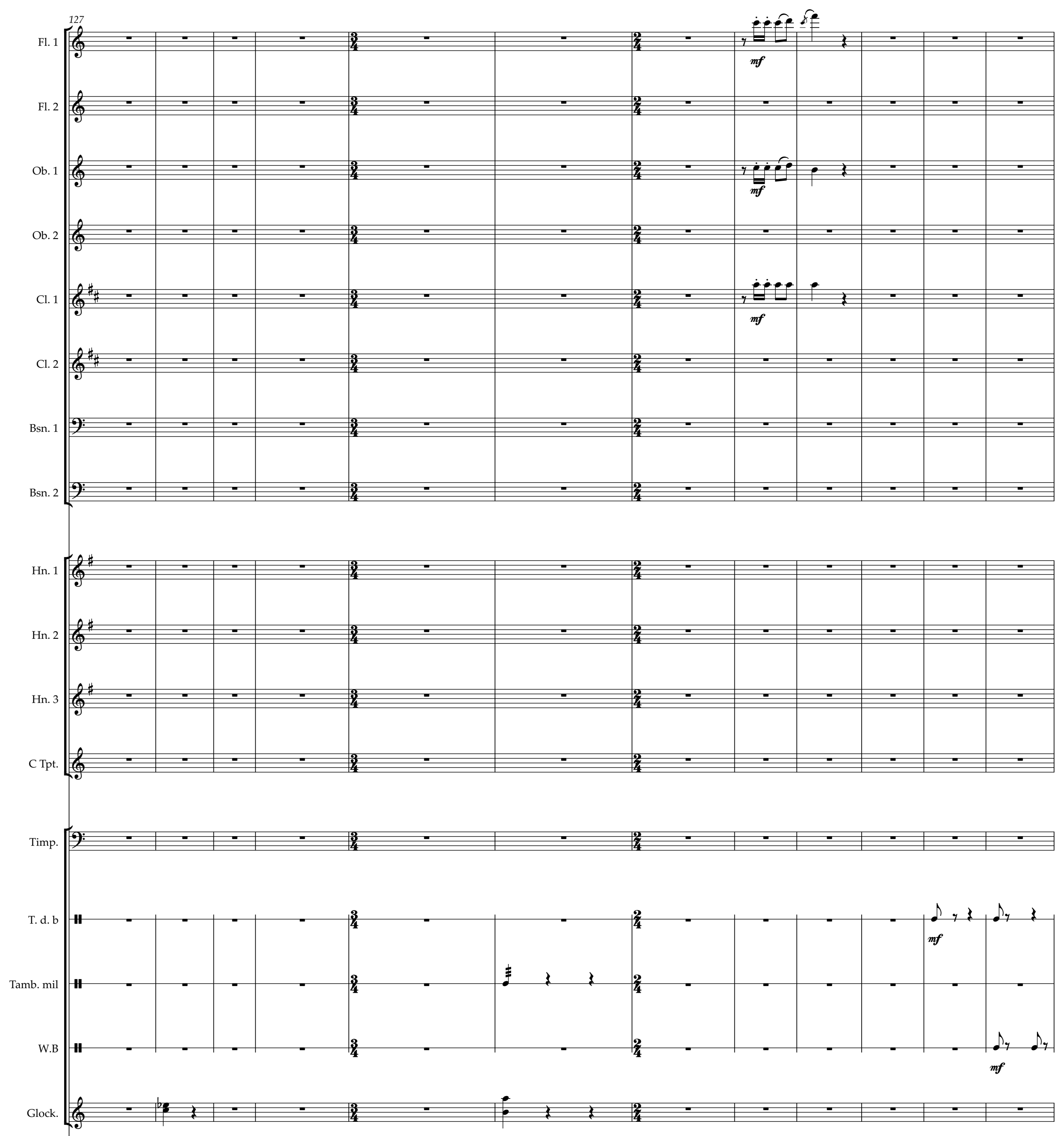

Solo Viola

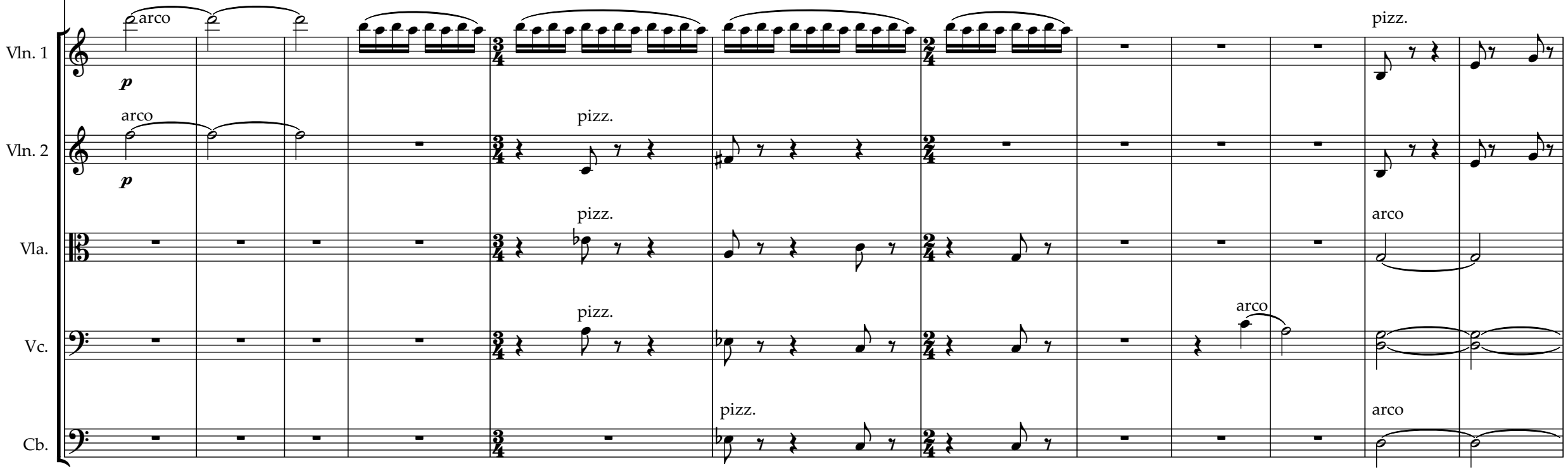



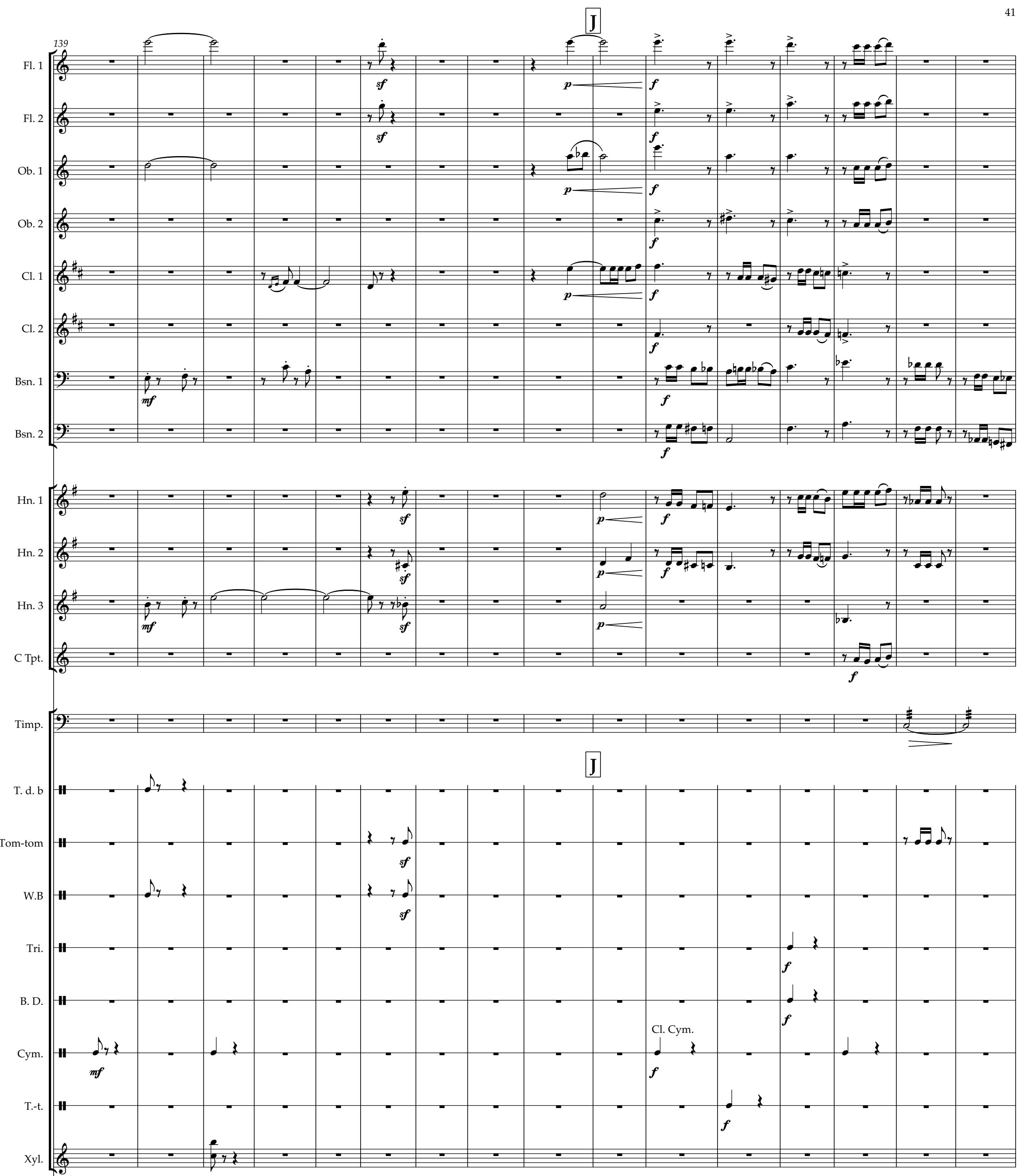

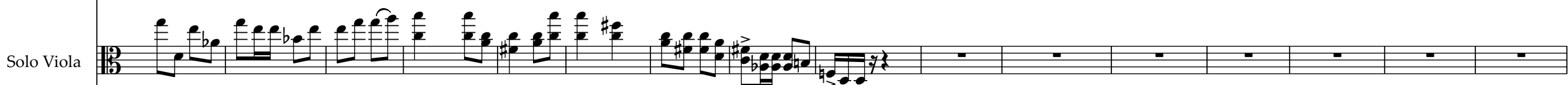

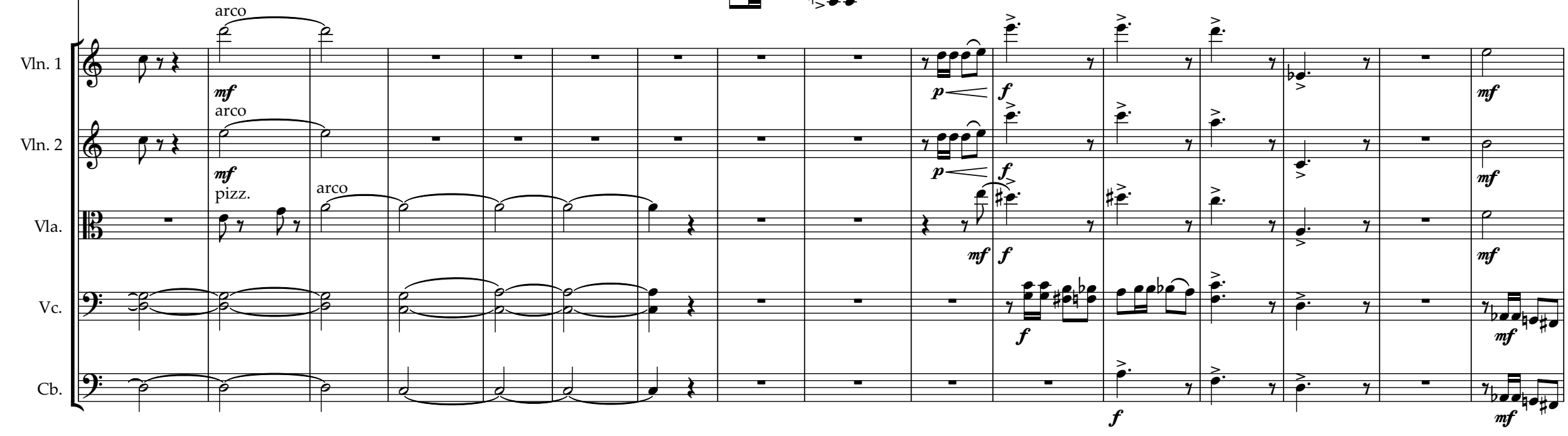


42
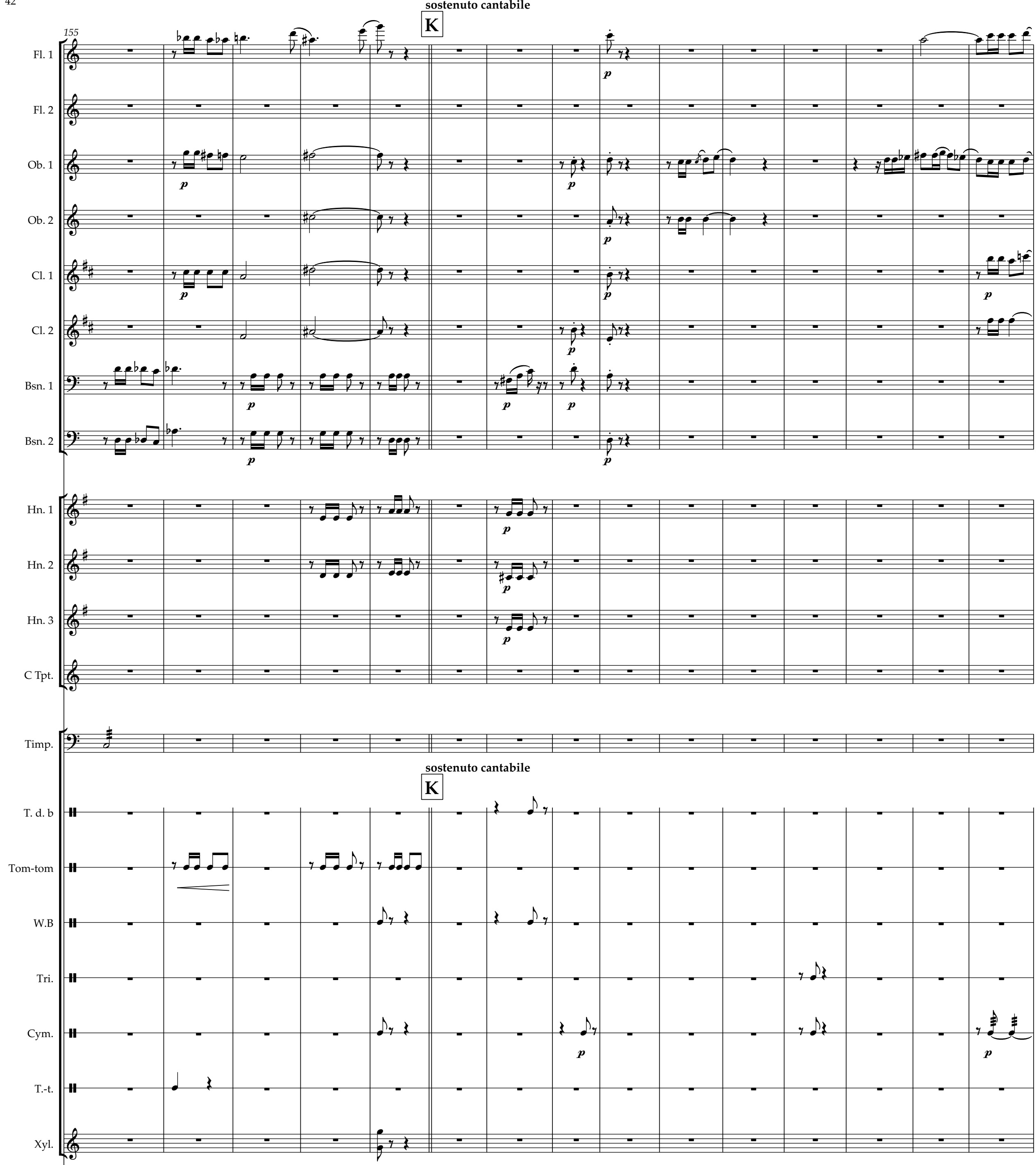

Solo Viola VIn. 

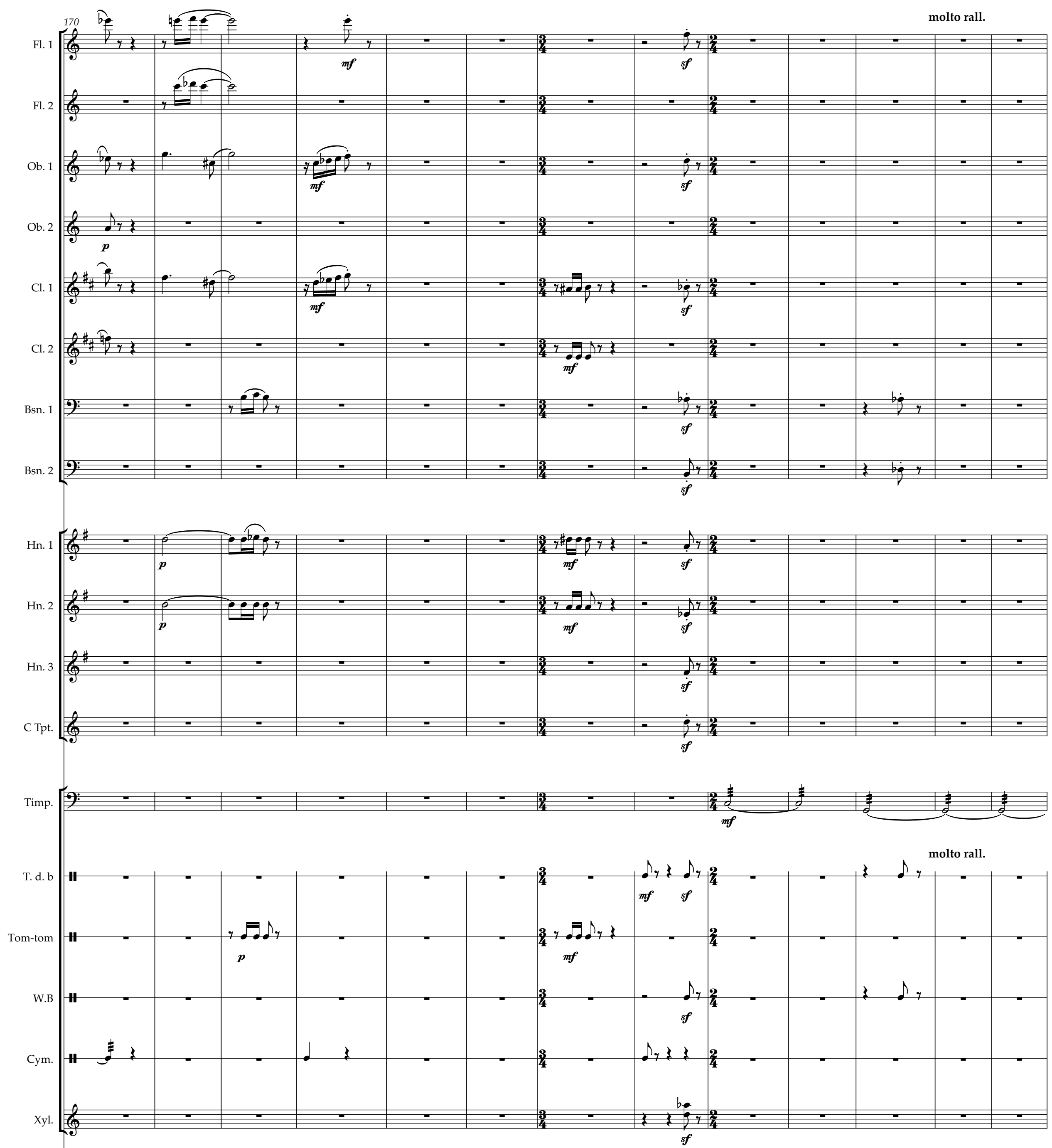

Solo Viola

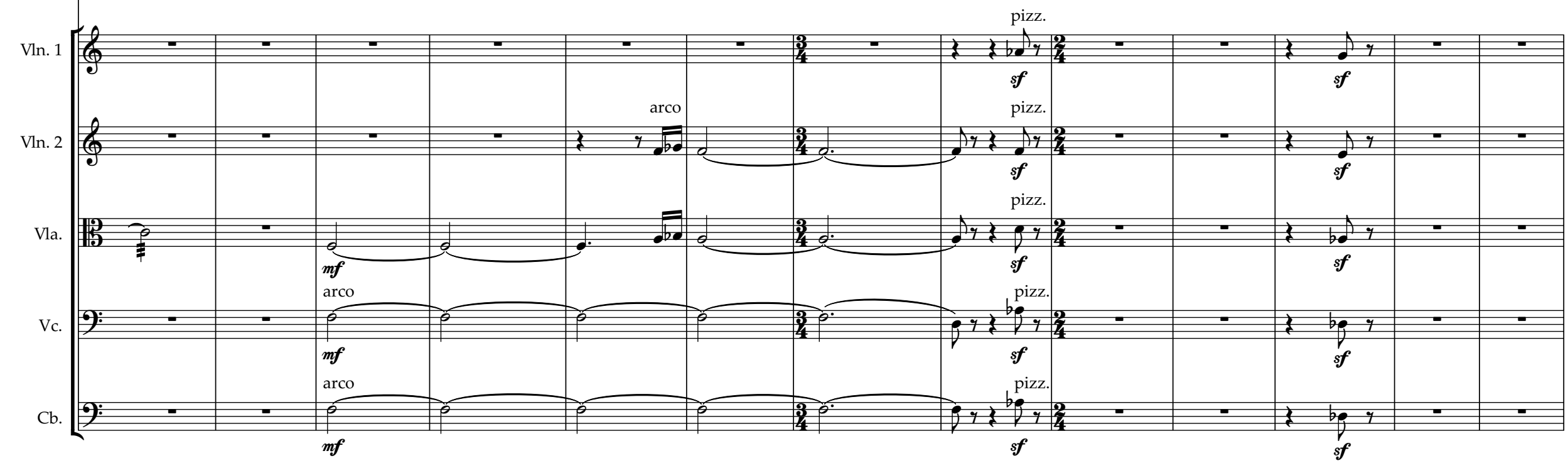


44
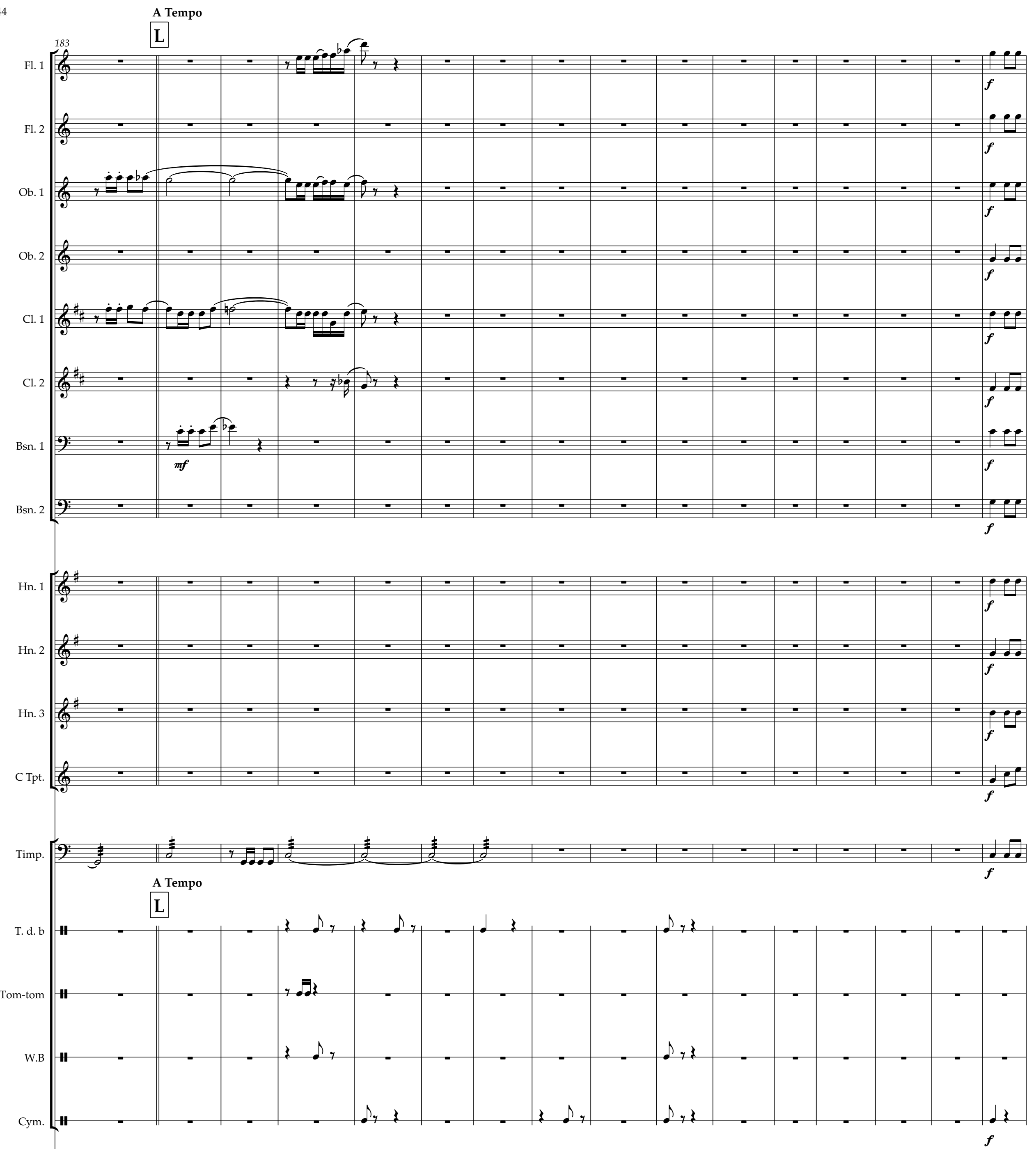

Solo Viola 1 (1)

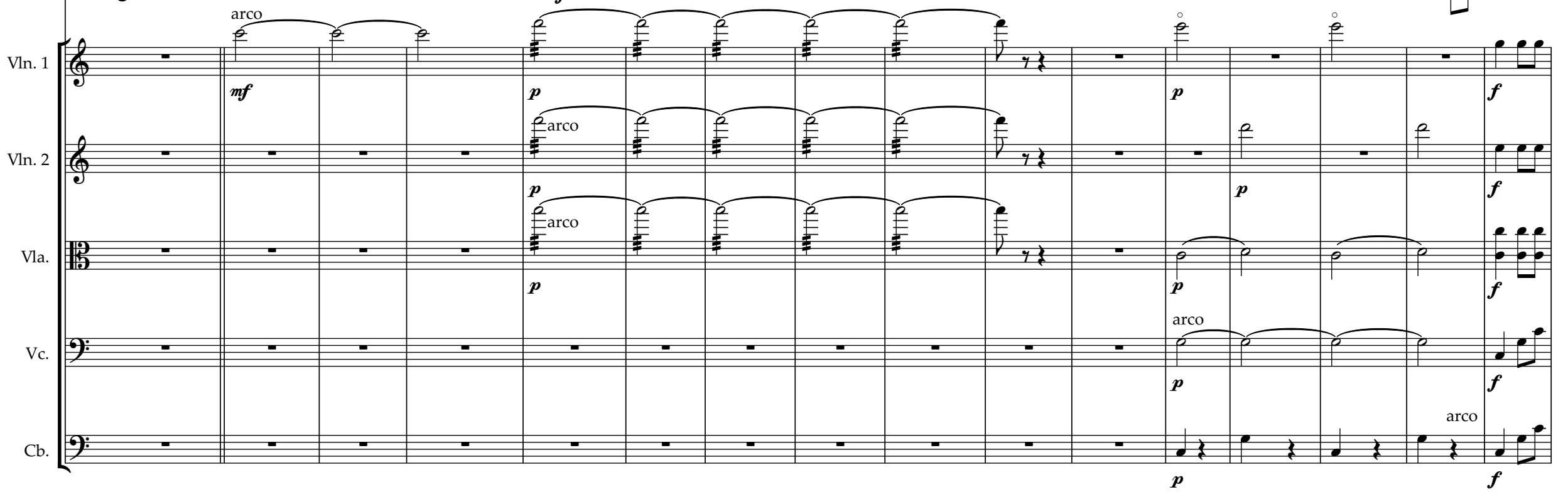



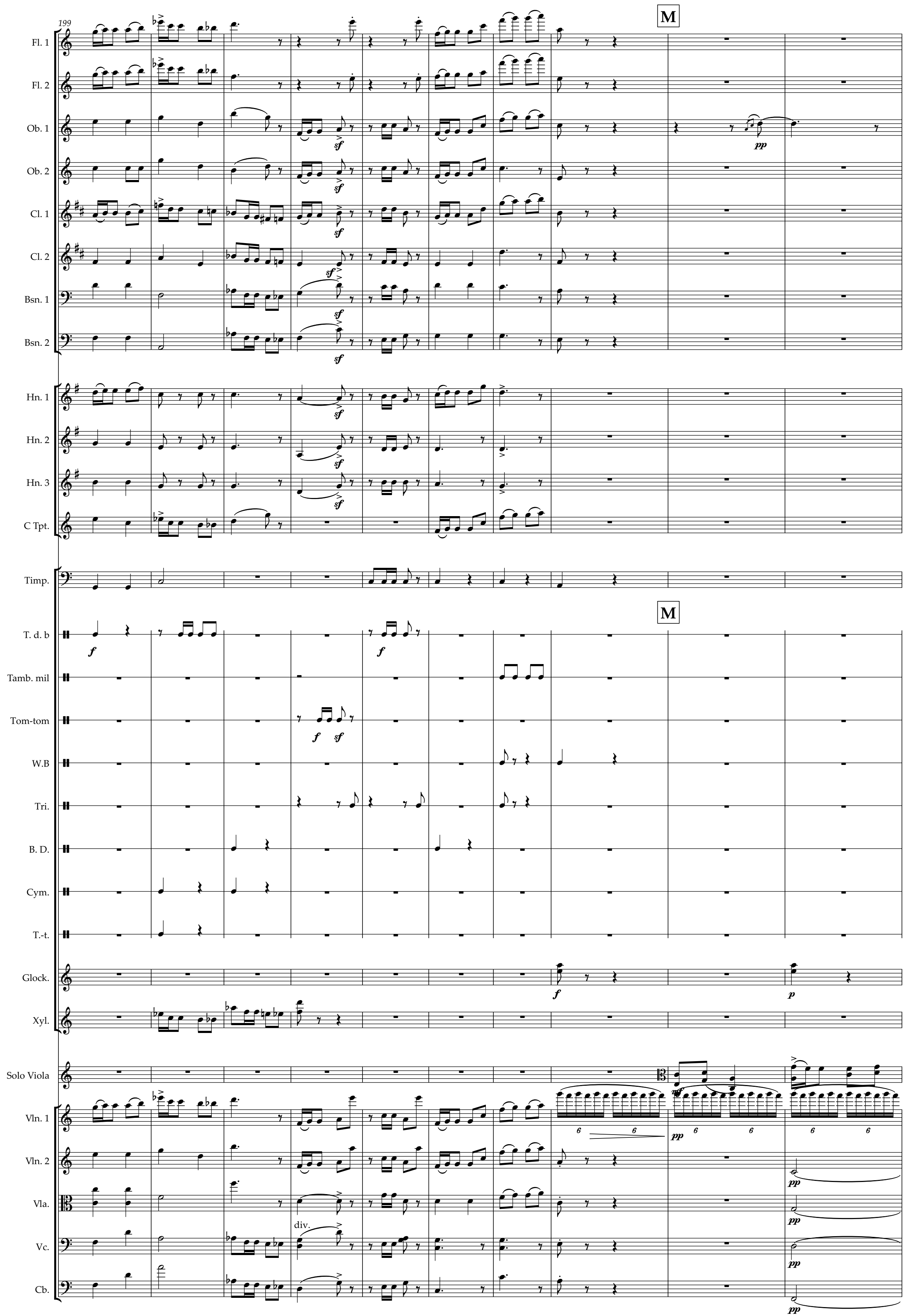

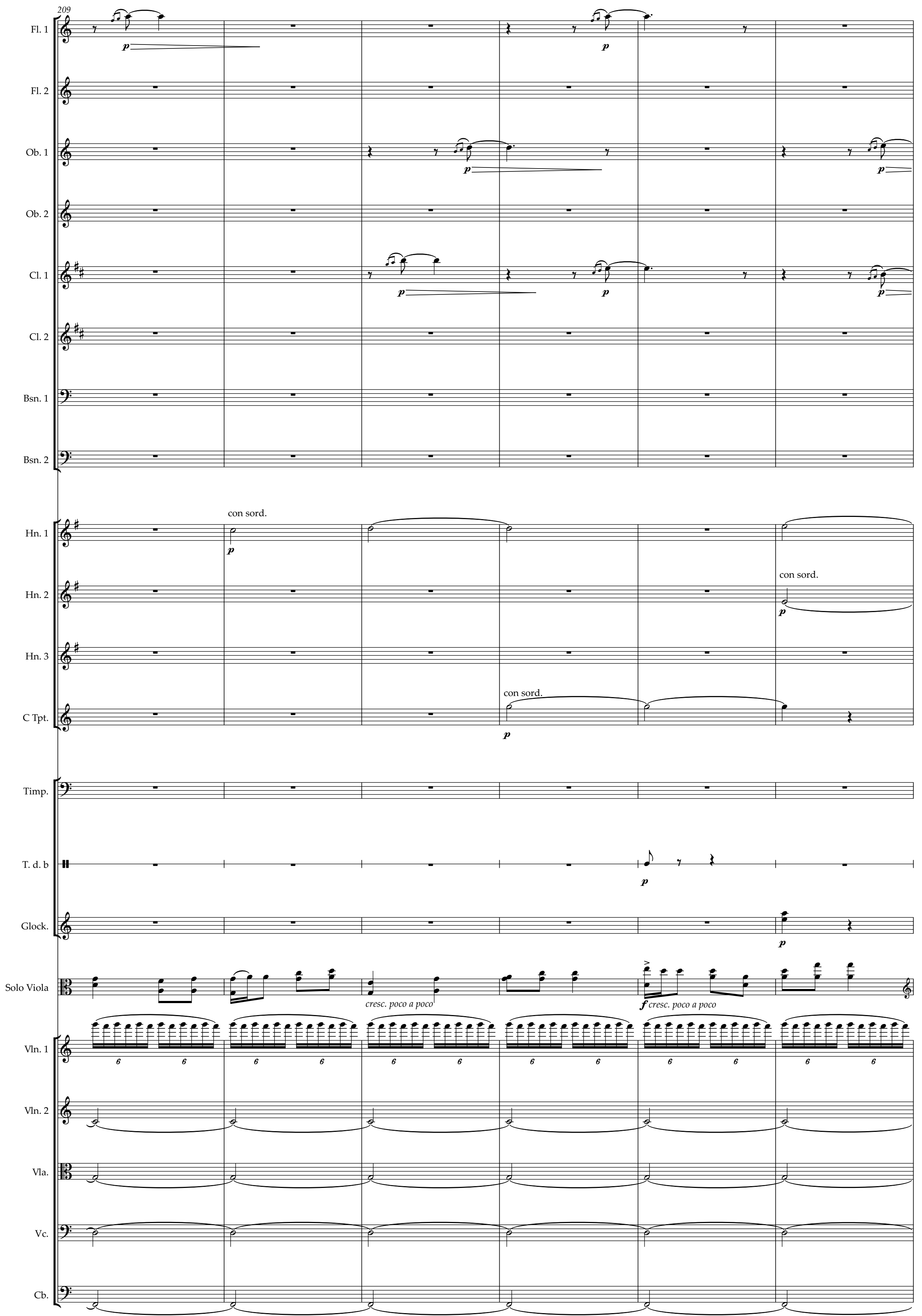

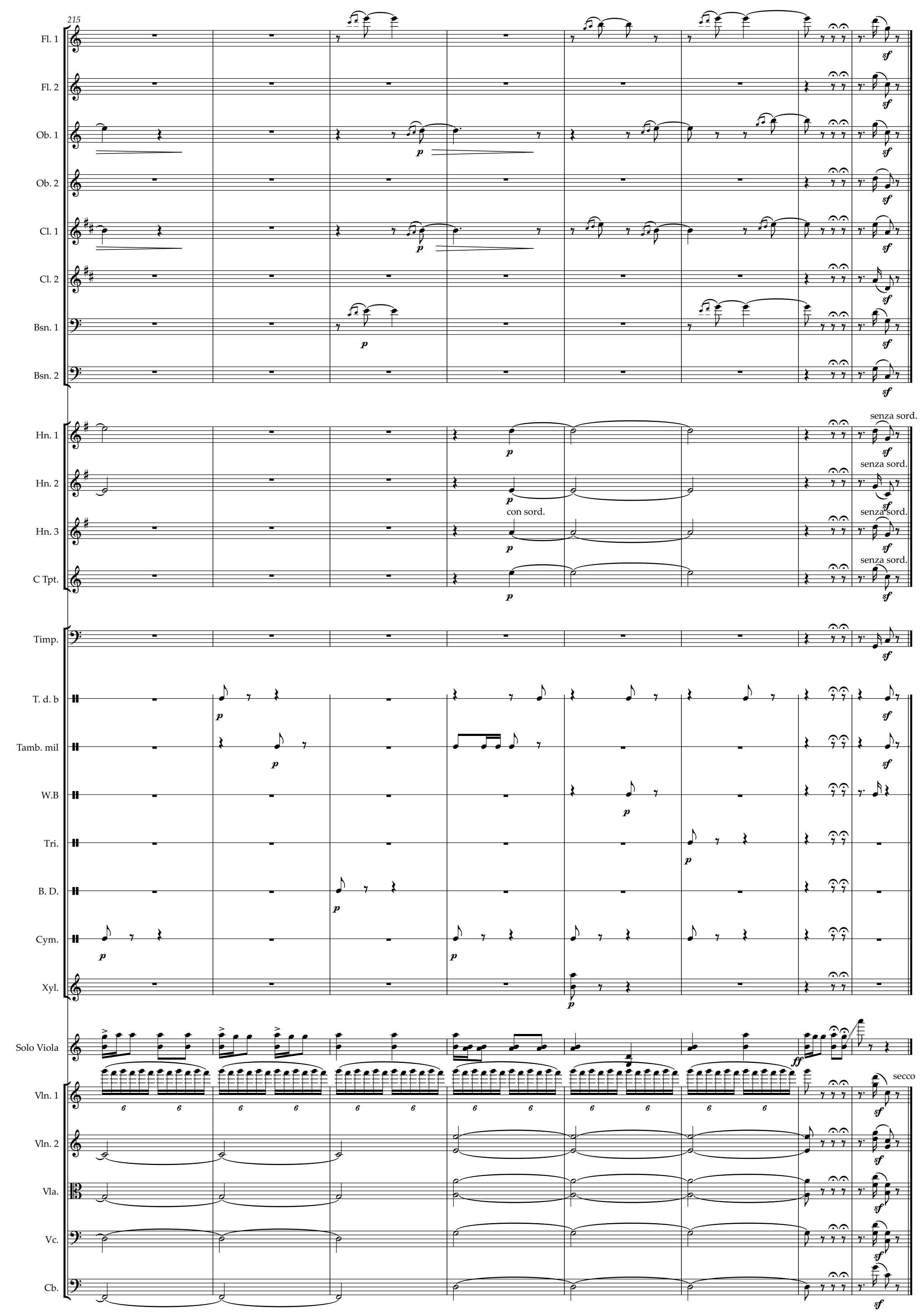
Flute 1 Concerto for Viol

la and Orchestra

Dmitris Dragatakis

Moderato $d=70$

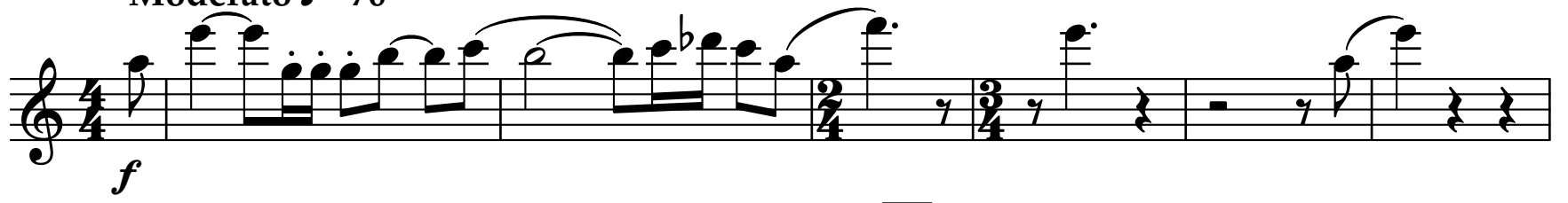
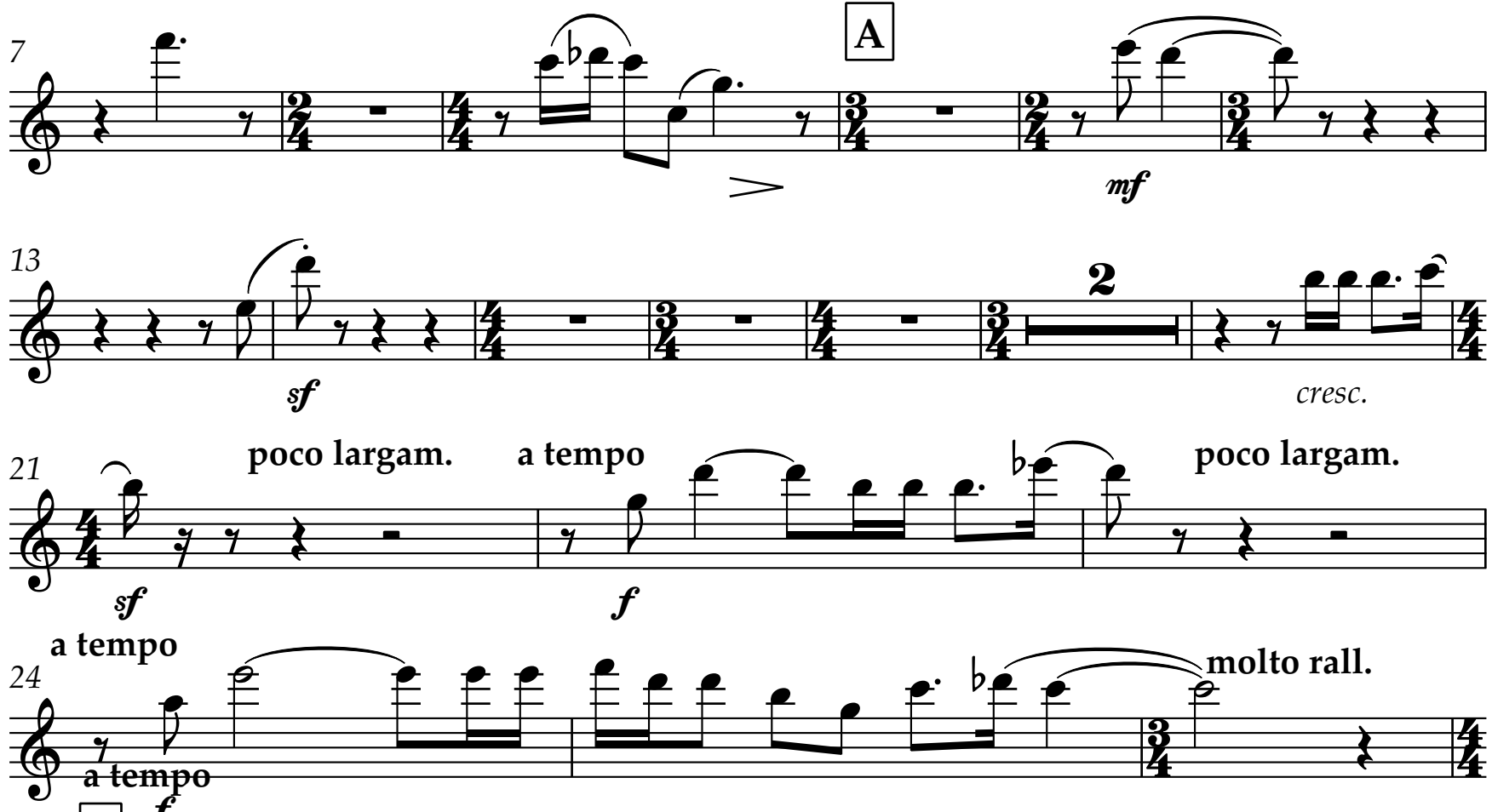

B $f$

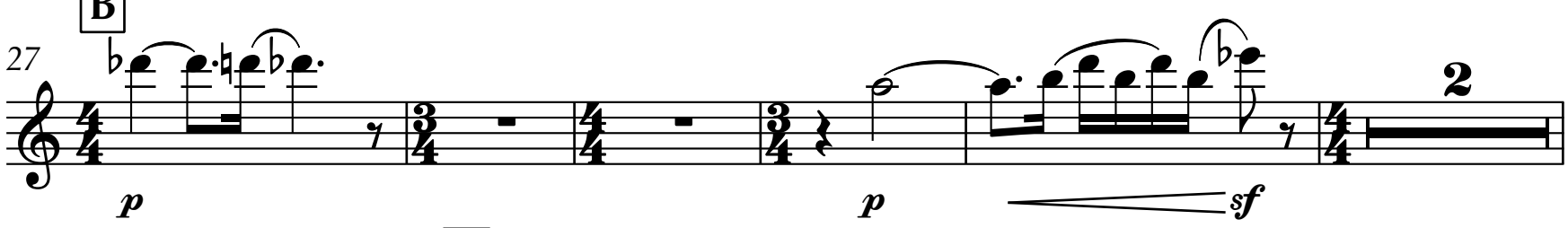

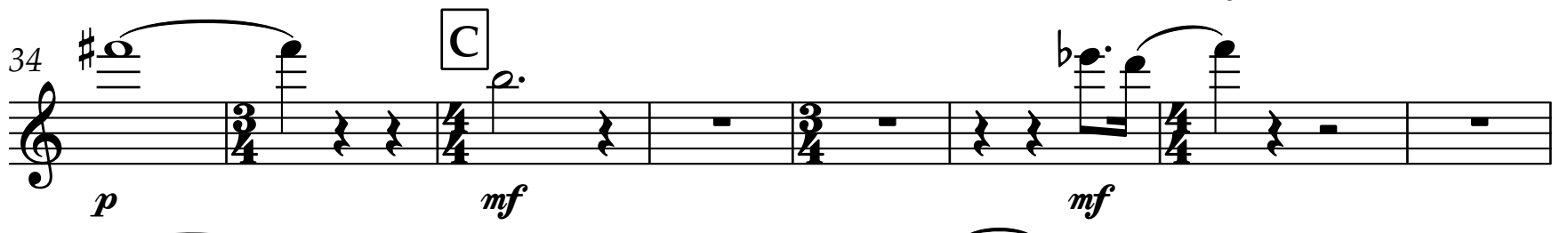

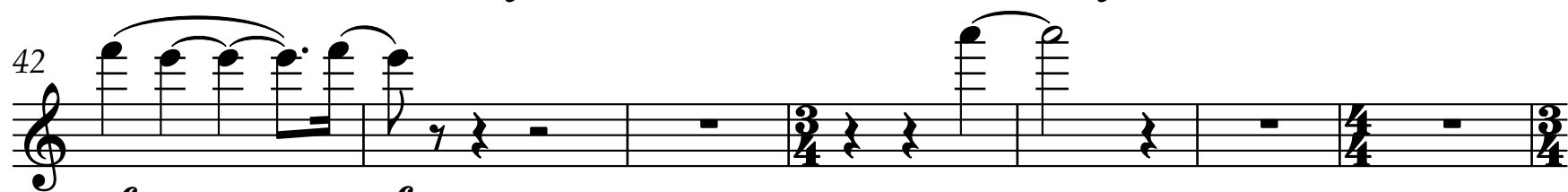
$m f-s f$

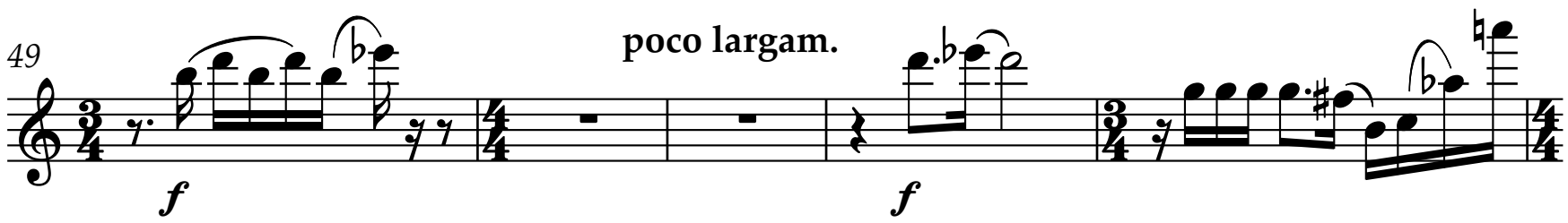

$54 \mathrm{D}$ poco sostenuto

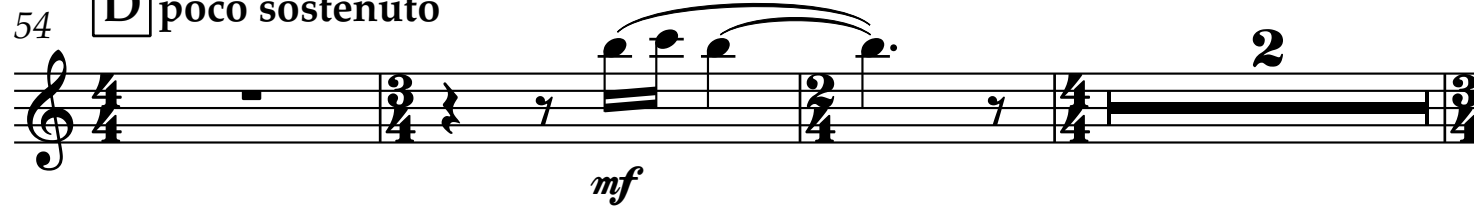


molto rall

a tempo

80

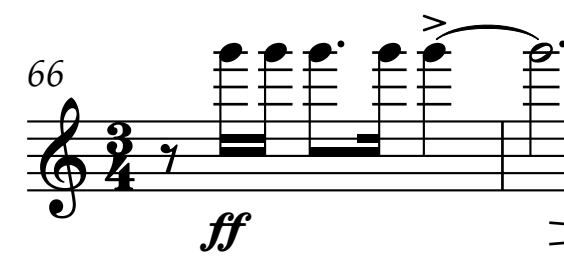

E Flute 1

31

F poco largam. a tempo

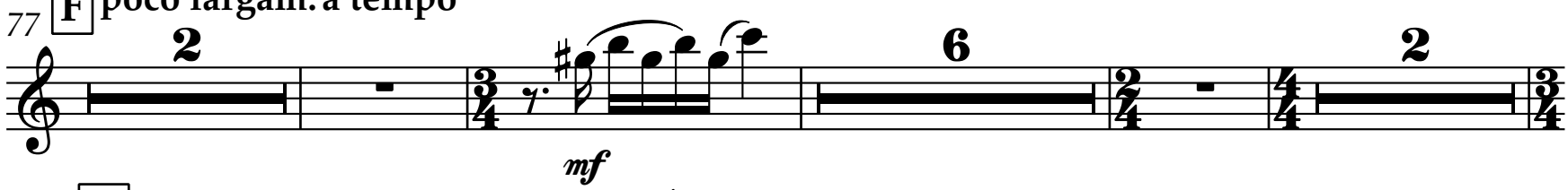

$90 \mathbf{G}$

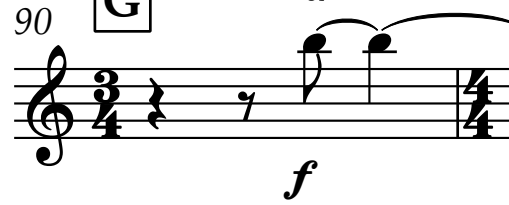

2 f

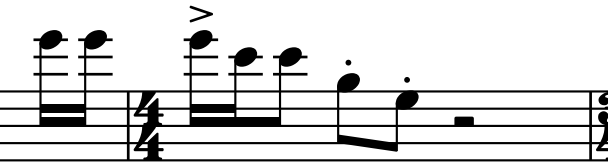

$3-2+4$
$4-25$

$\boldsymbol{m f}$ cresc. $\boldsymbol{f}$

Più larg.
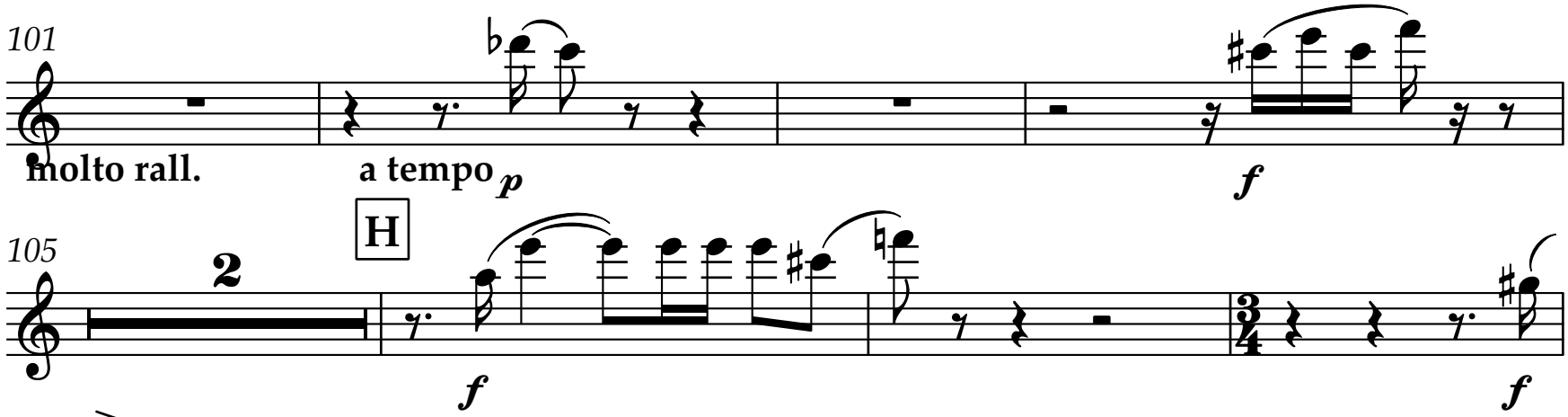

3

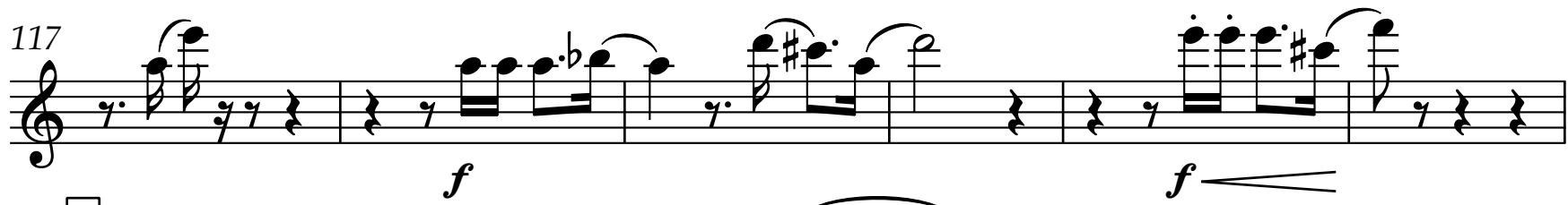

${ }_{123} \mathbf{I}$

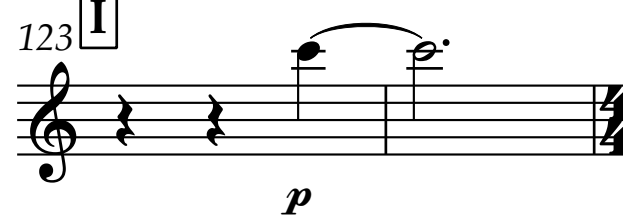

p

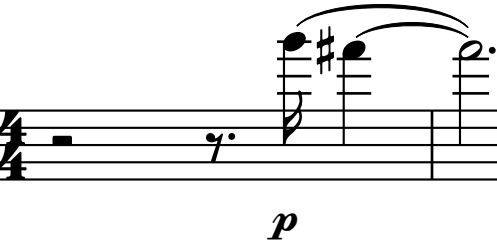

분 
Flute 1

Flute 1

3

(128)

II.

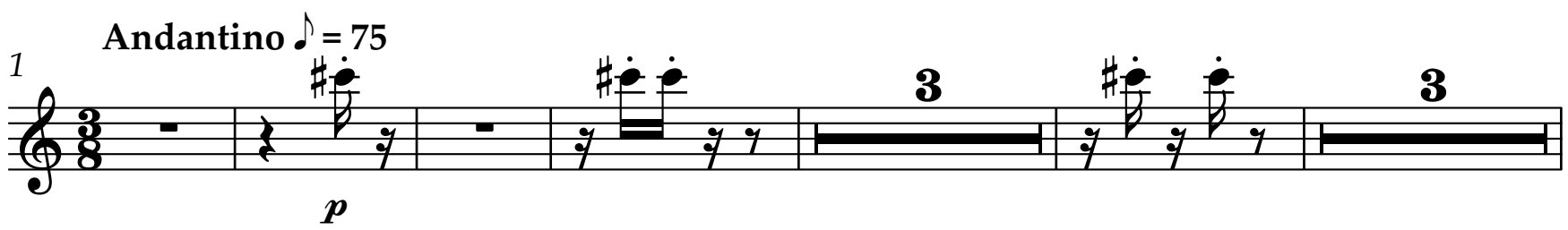

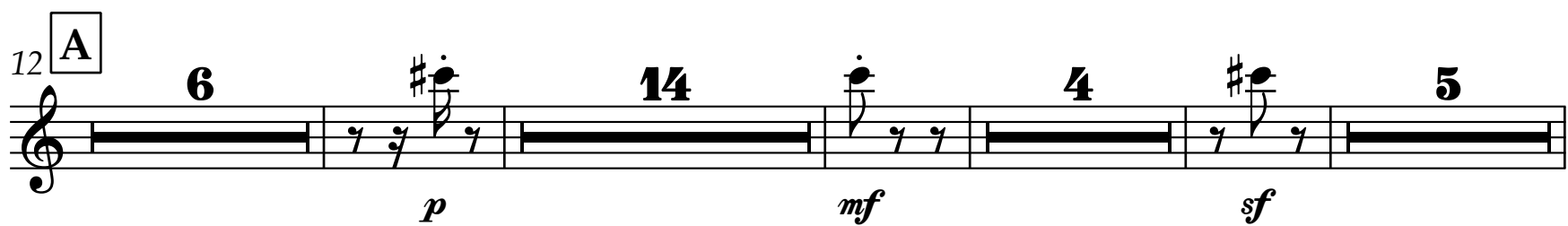
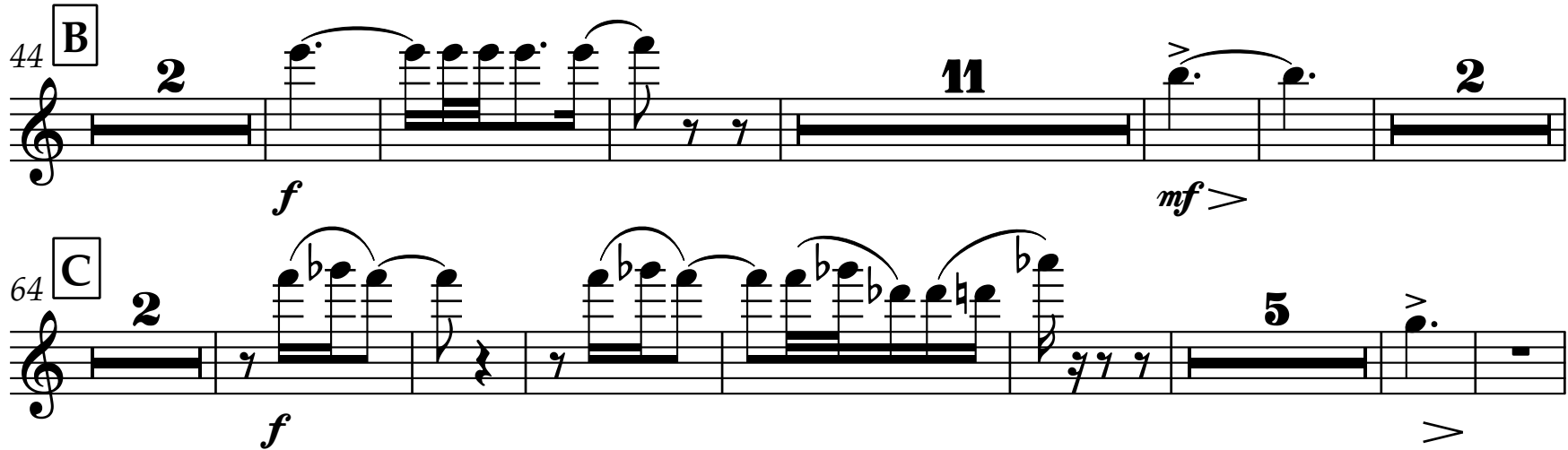

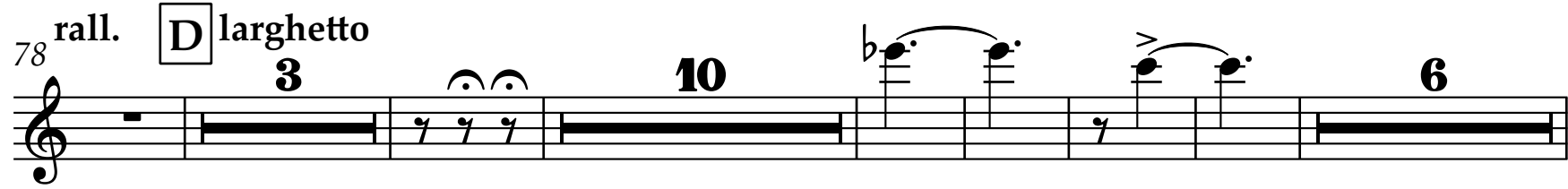

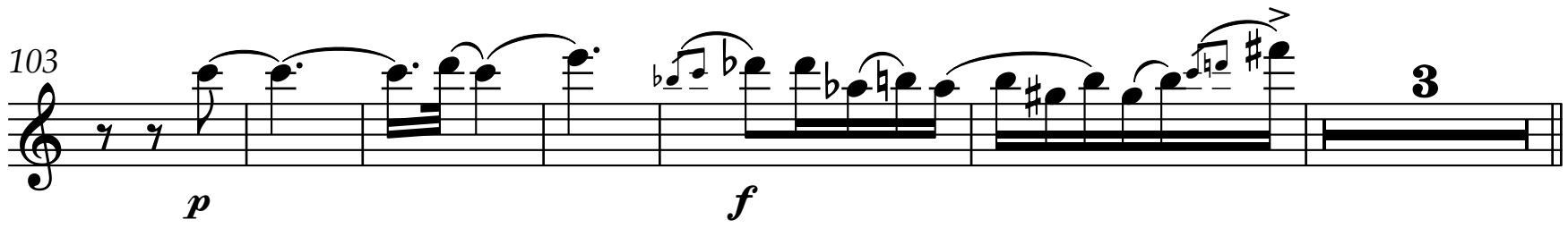

E Kadenz

9 


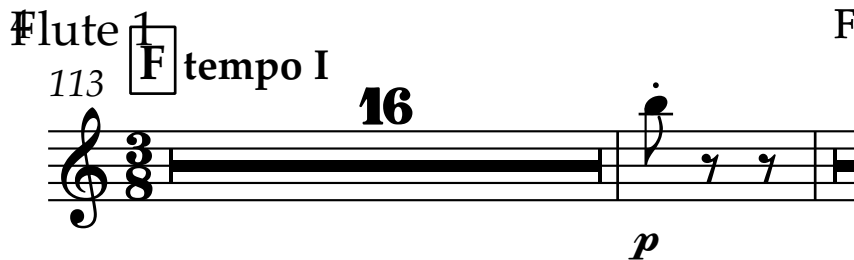

Flute 1

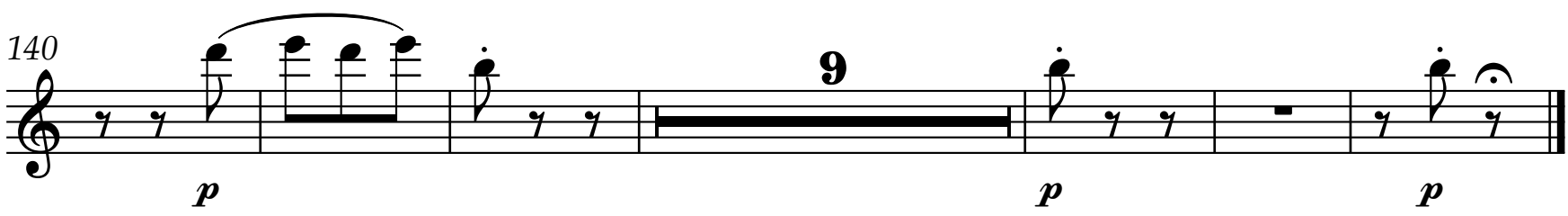

III.

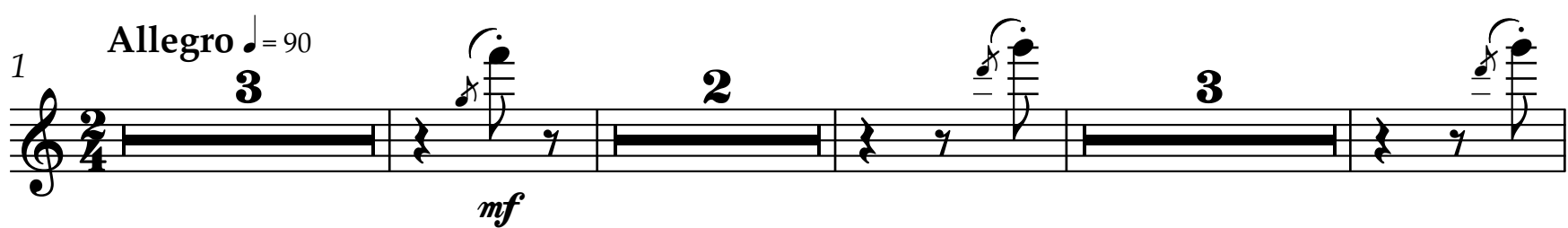

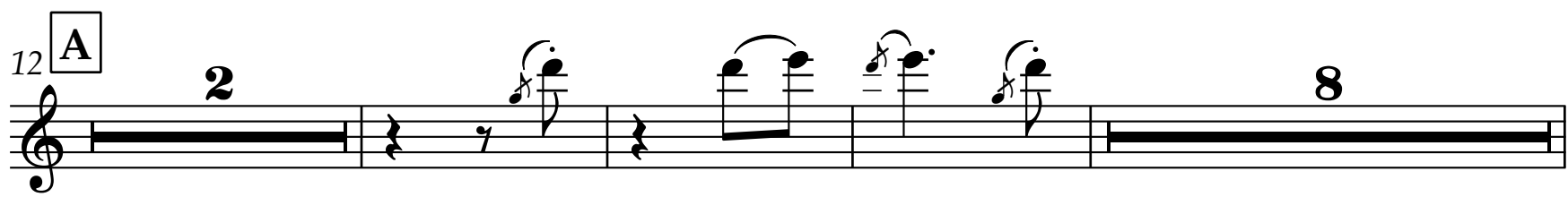

$B$

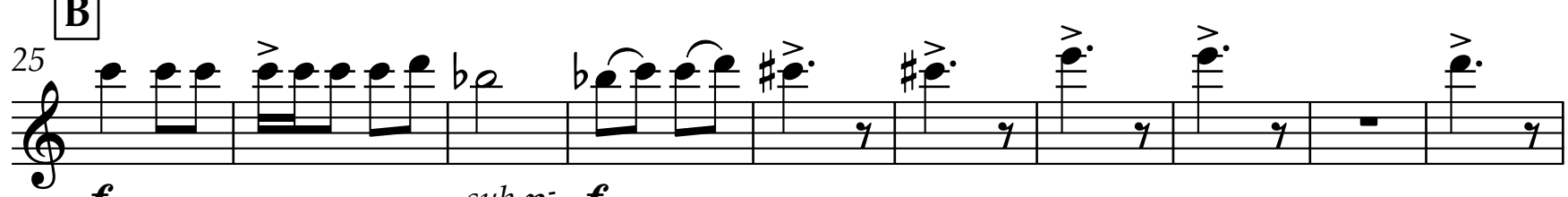

$\boldsymbol{f}$ sub $\boldsymbol{p}: \boldsymbol{f}$

(6)

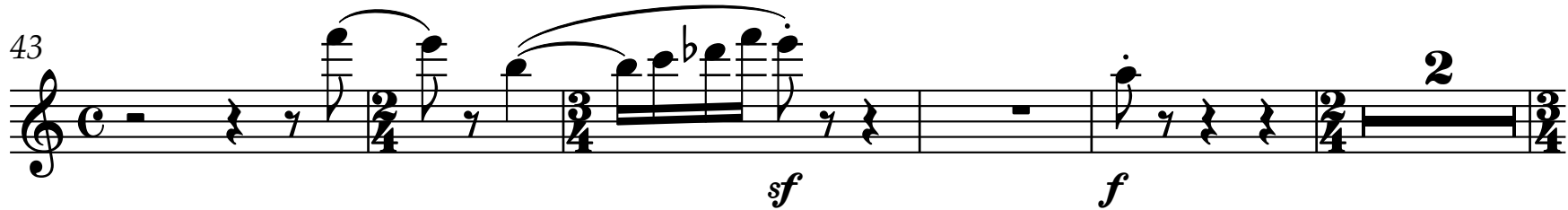

50

D

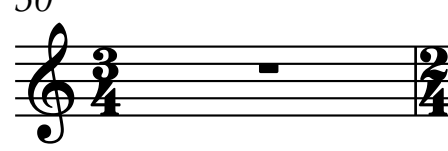

2

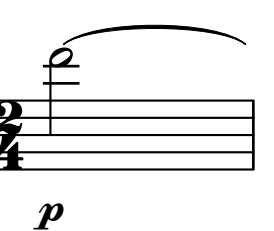


$\frac{52}{9}$

2

3

$4=$ 
Tempo I

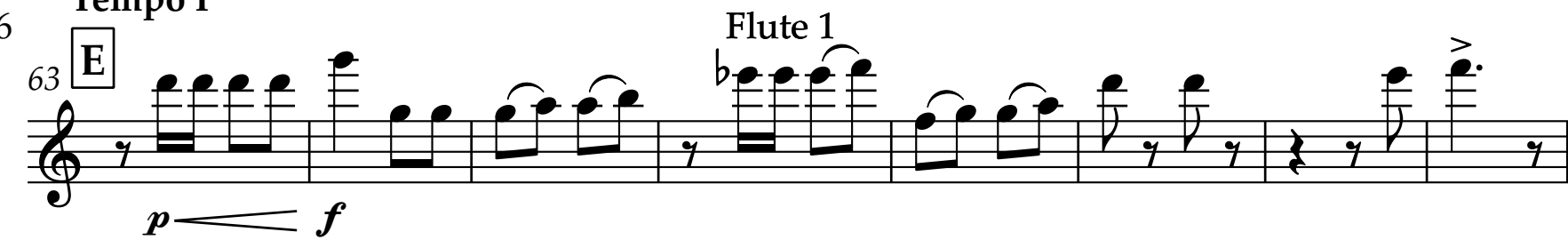

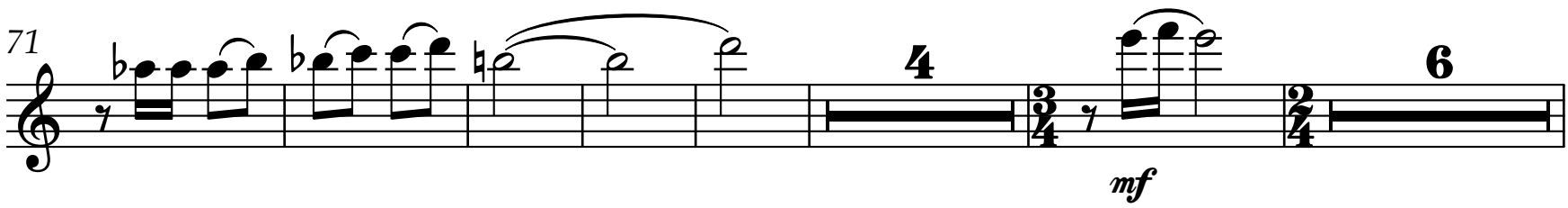

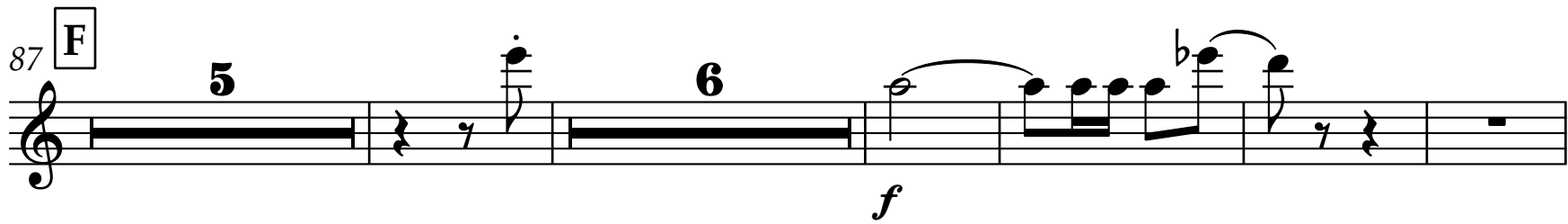

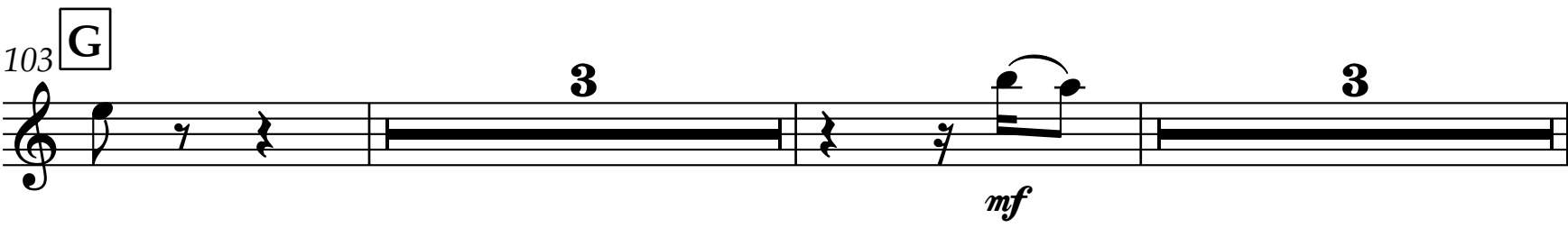

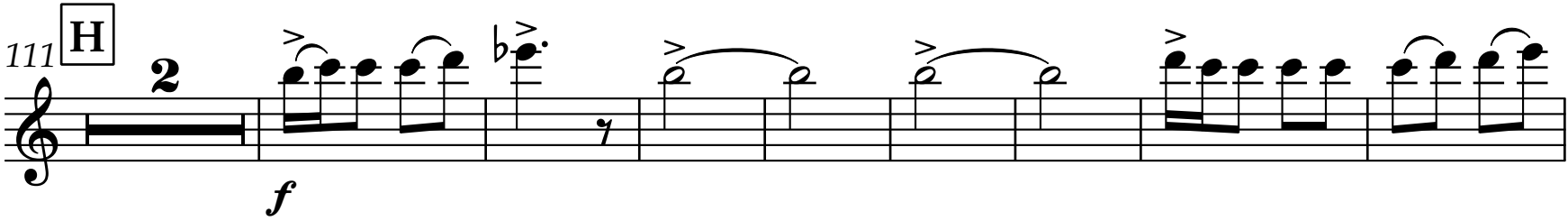

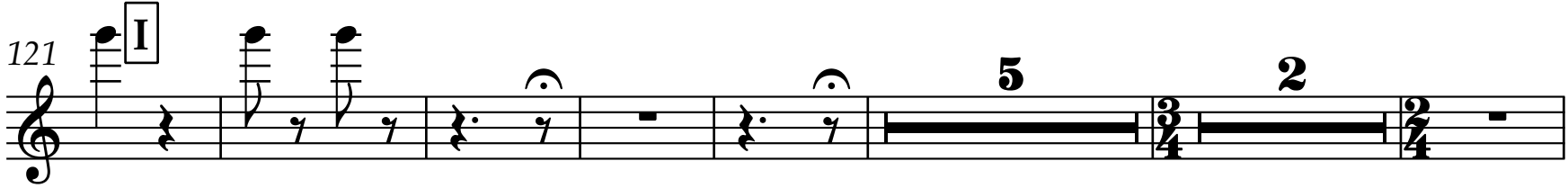
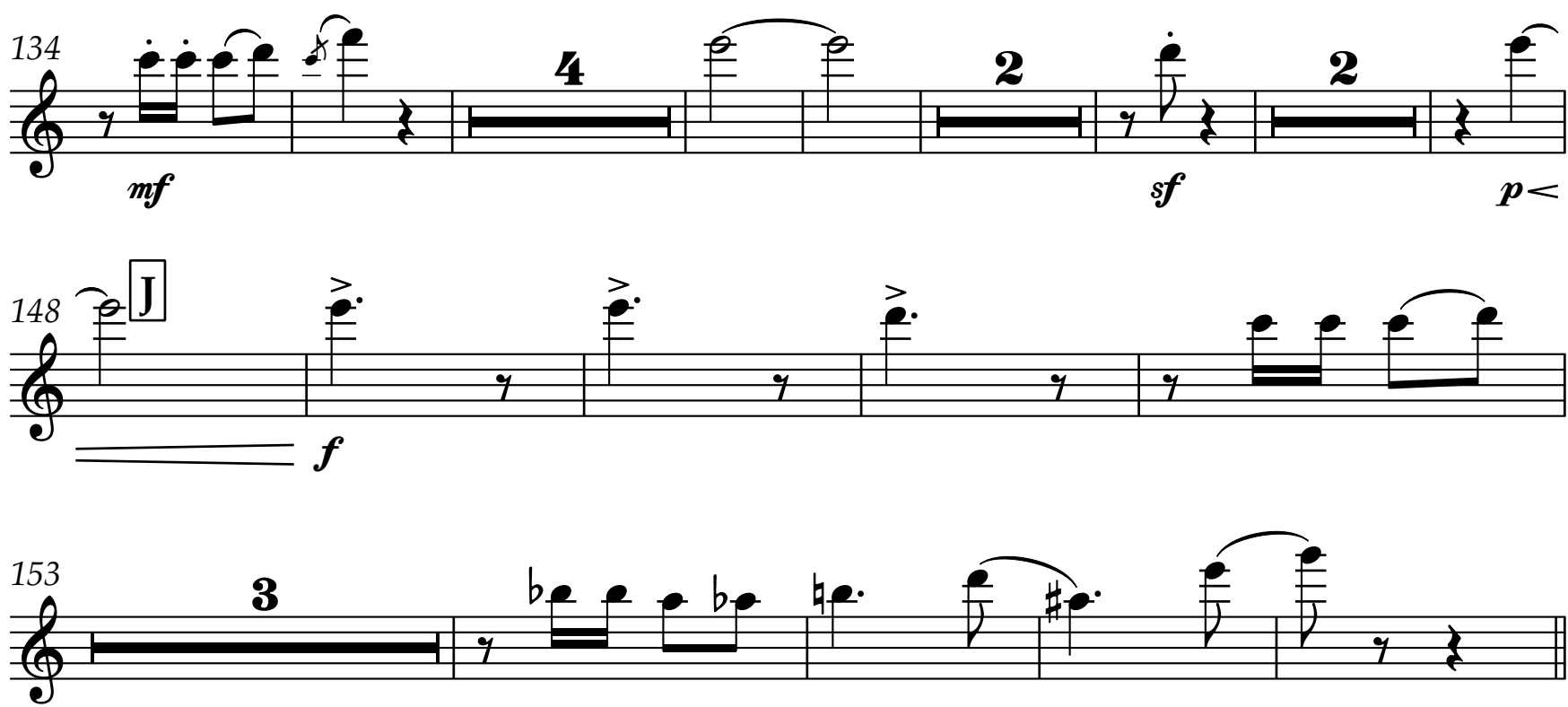

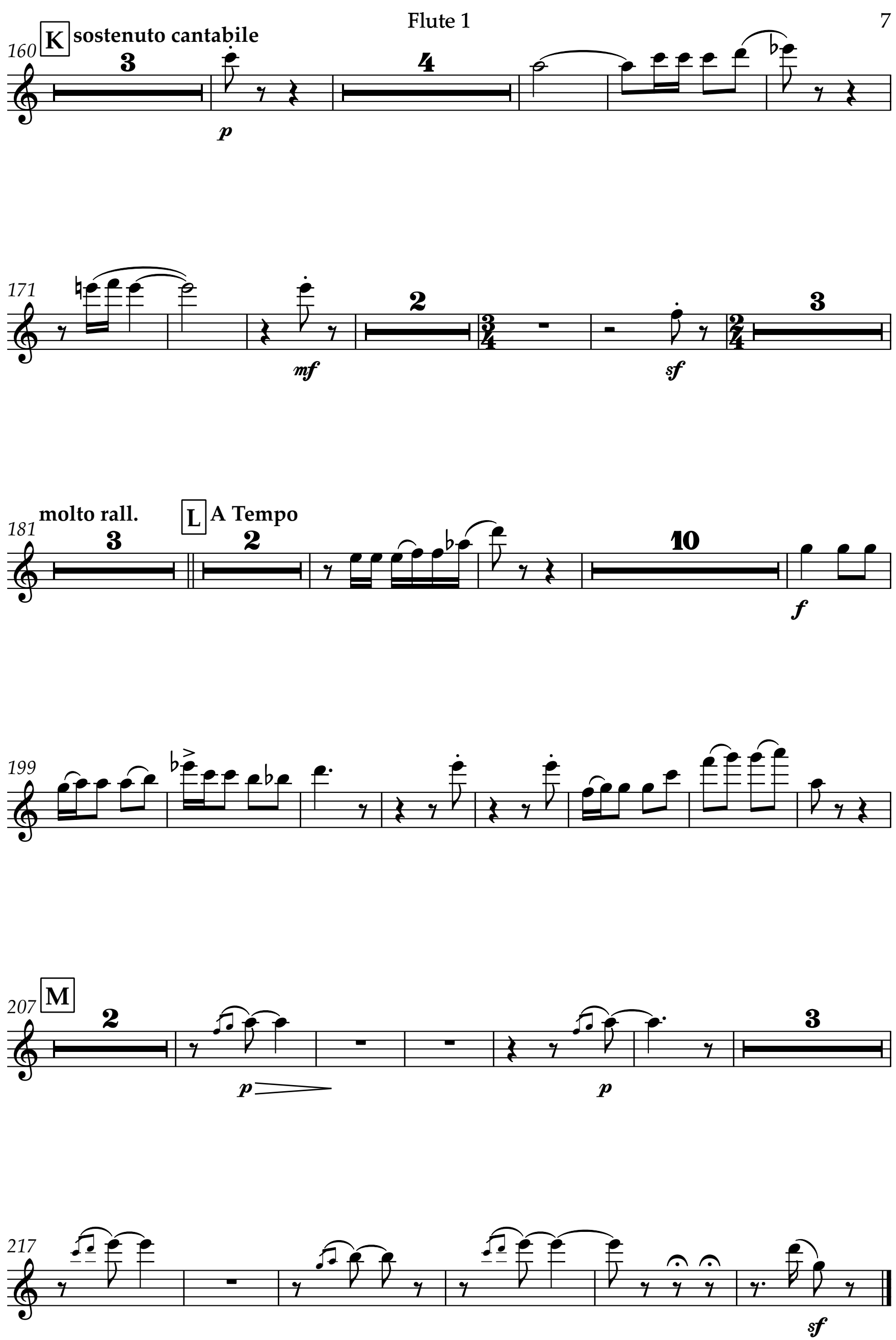
Flute 2 Concerto for Viola and Orchestra

Dmitris Dragatakis

\section{Moderato $d=70$}
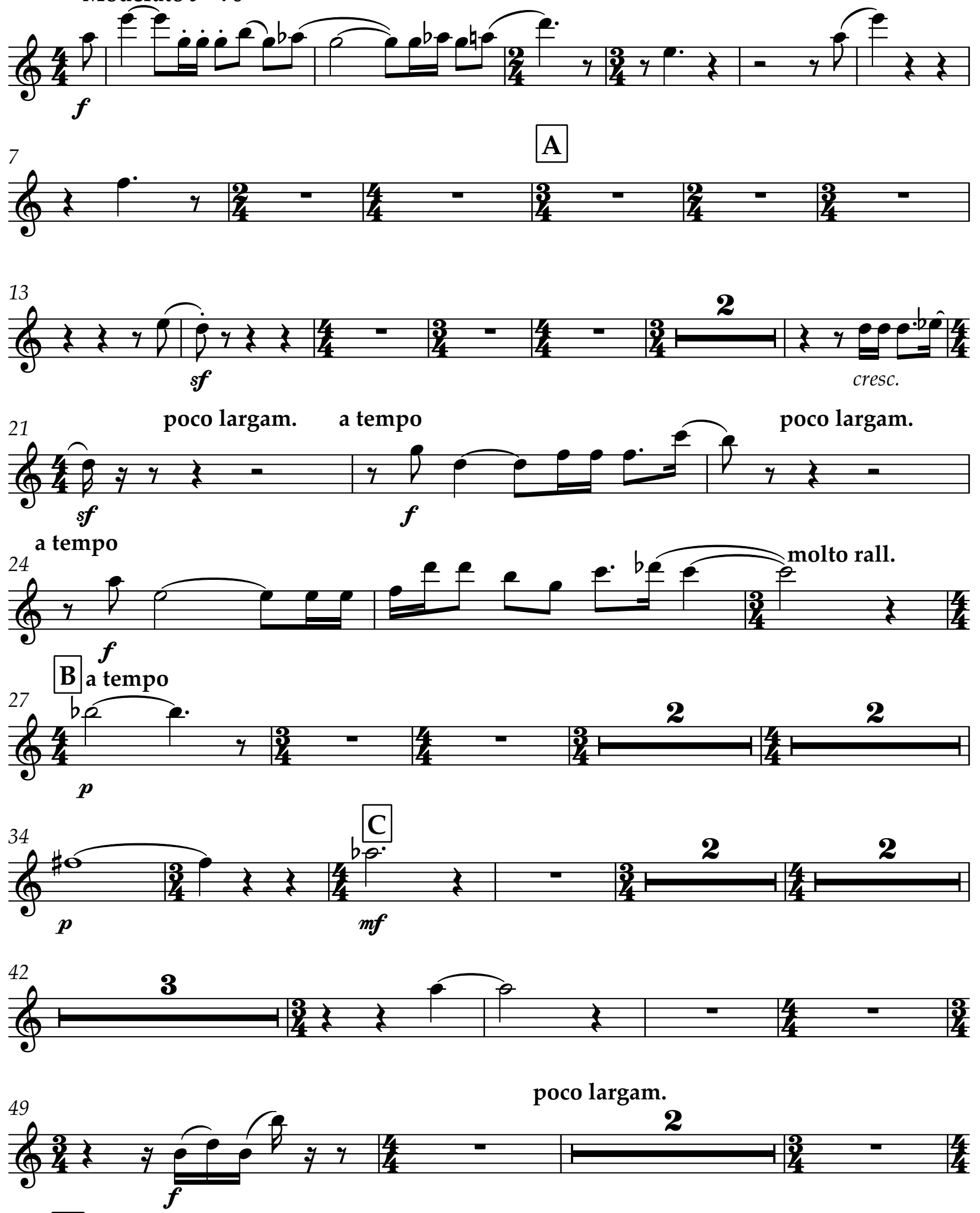

$54 \mathrm{D}$ poco sostenuto

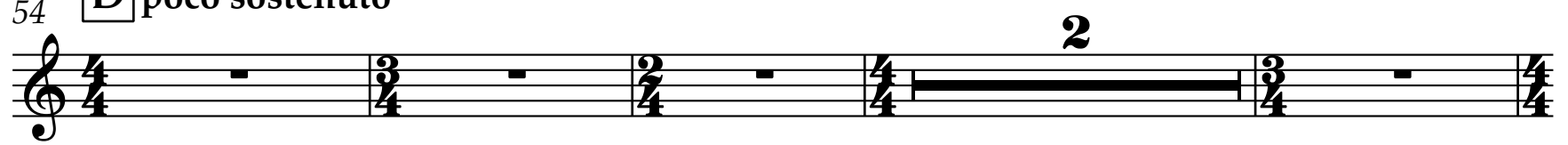


2 molto rall
a tempo

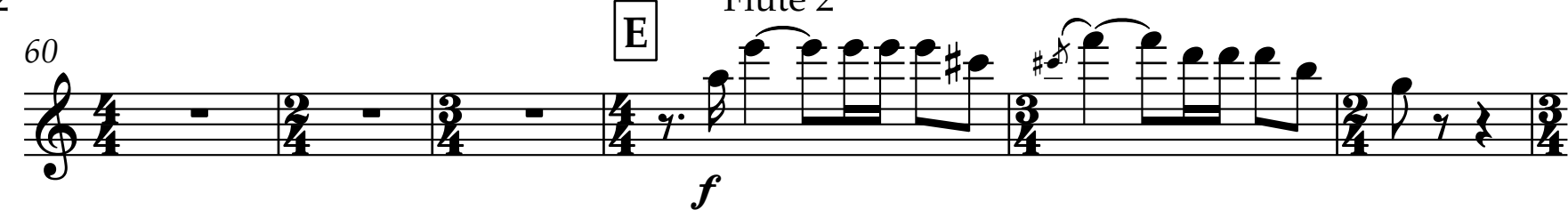
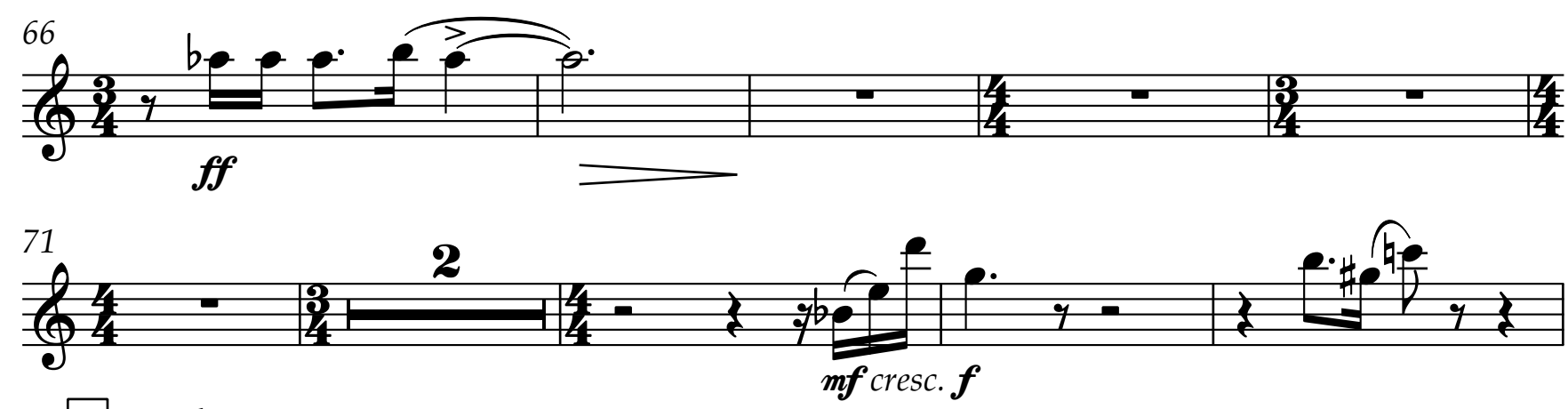

77 F poco largam. a tempo
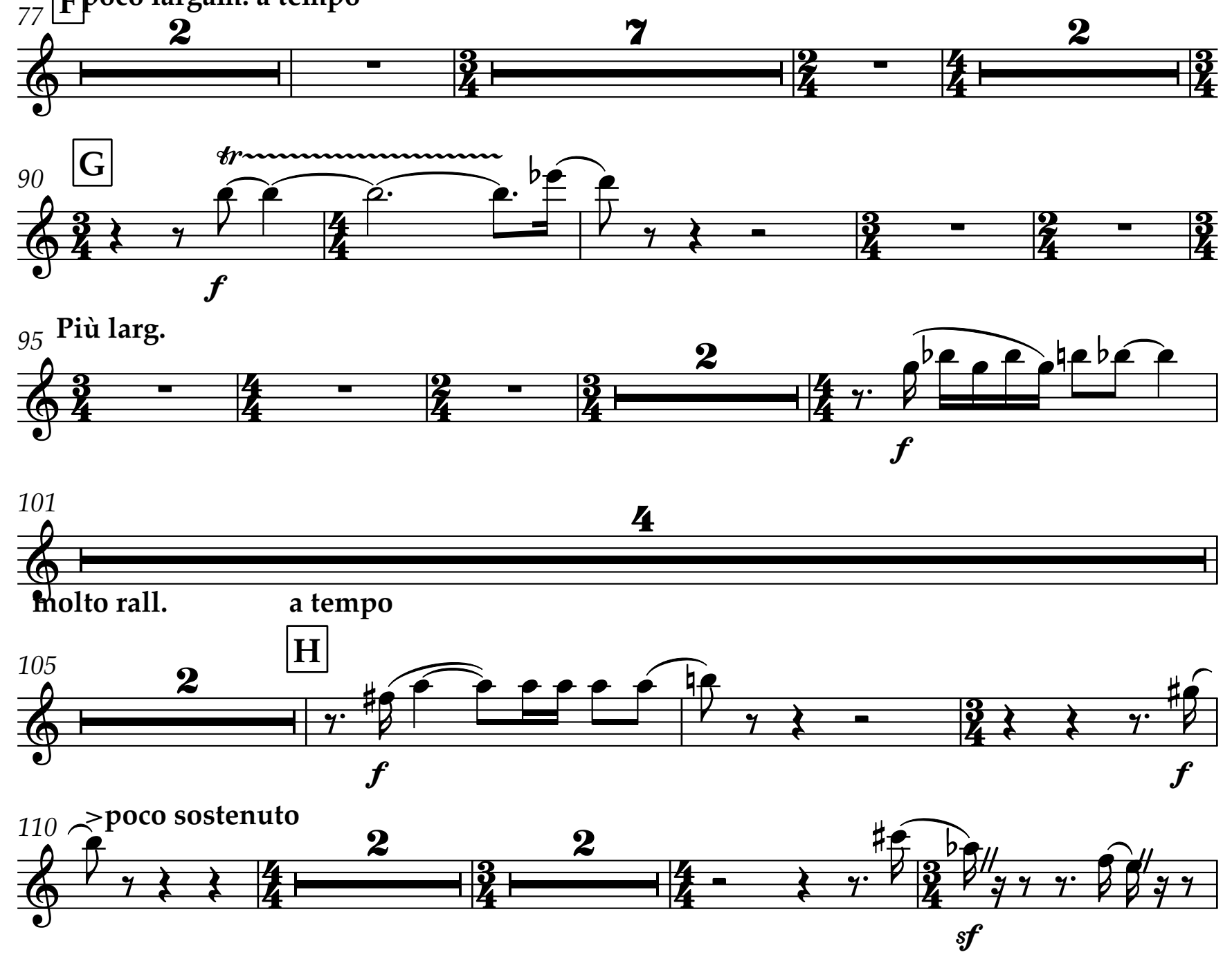

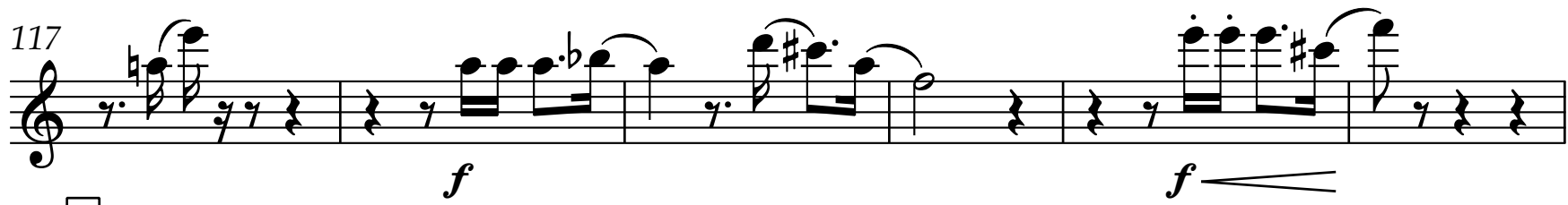

${ }_{123}$ I

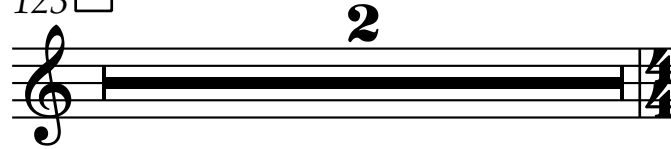

2 
Flute 2

128

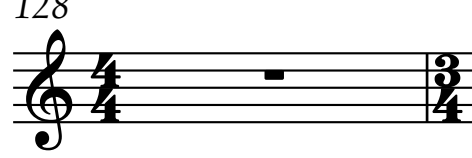

2
Flute 2

Largamente

II.
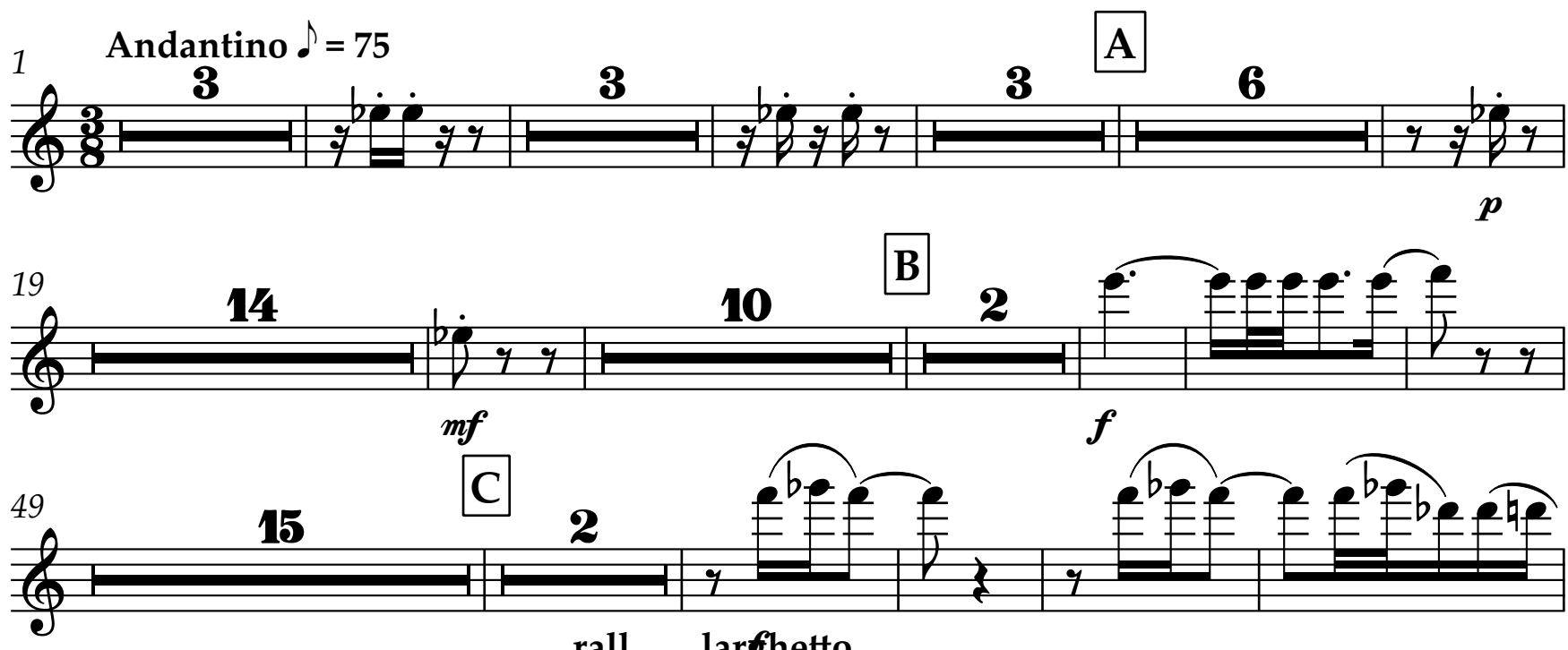
rall. larghetto
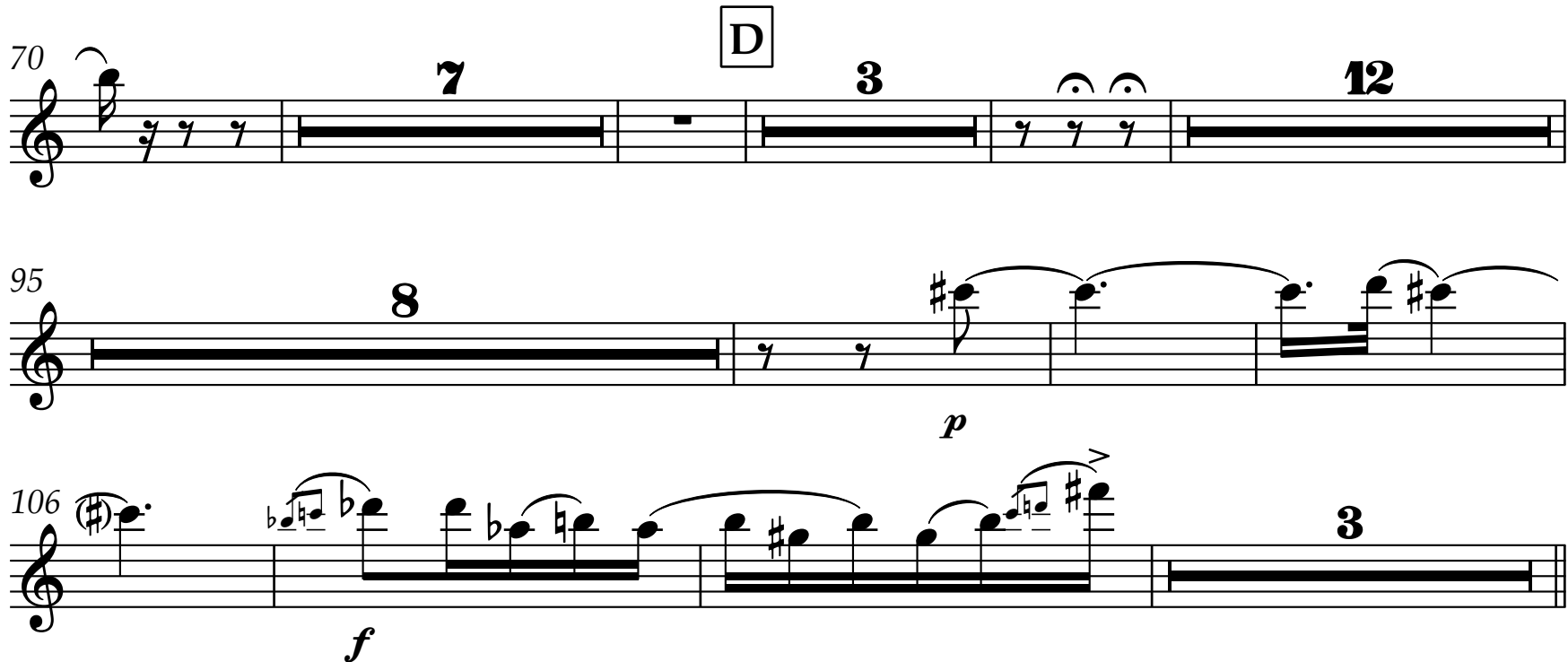
112
E Kadenz

8

$113 \mathbf{F}$ tempo I

8
68 
Flute 2

Flute 2

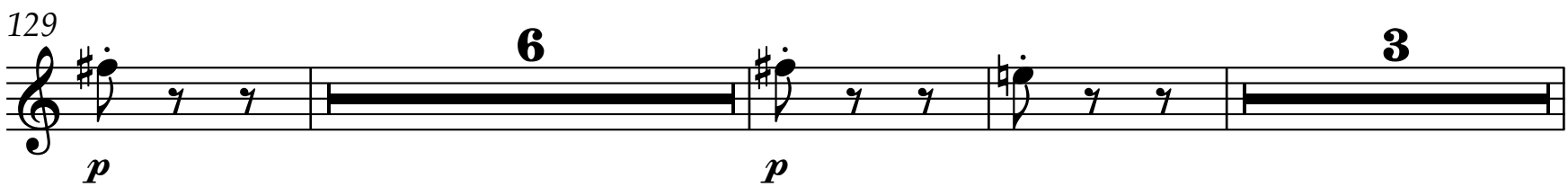

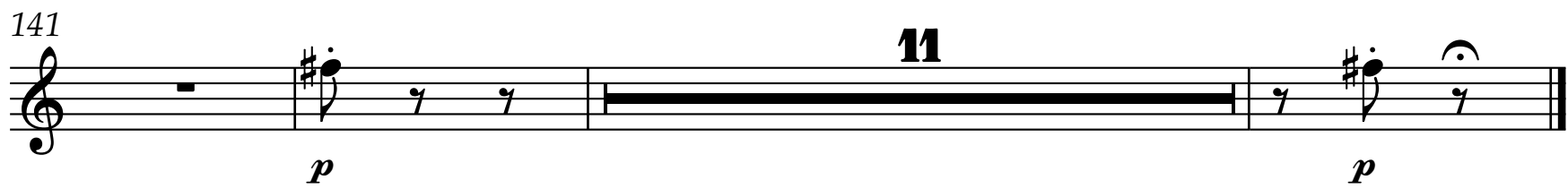

\section{III.}
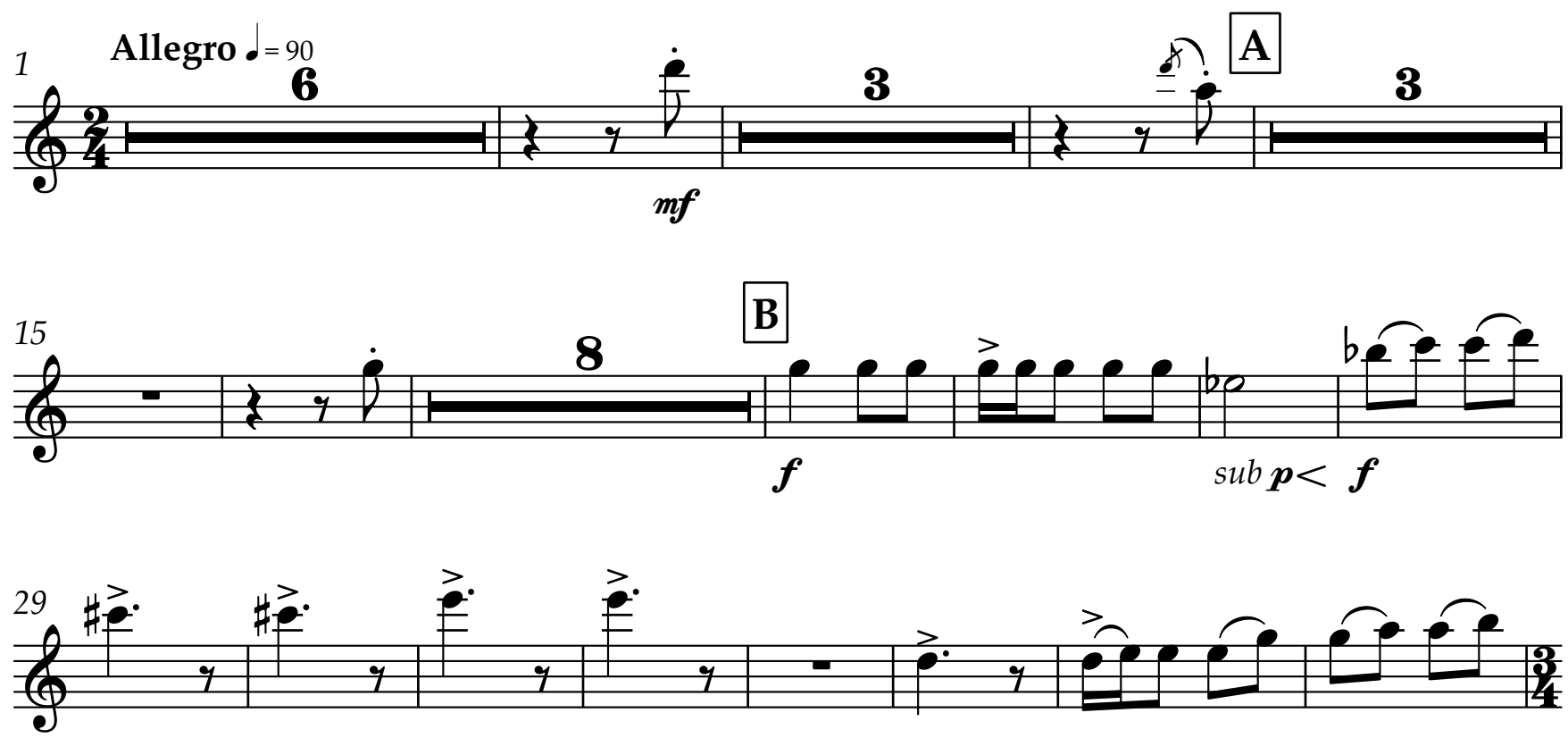

37 C poco piu meno
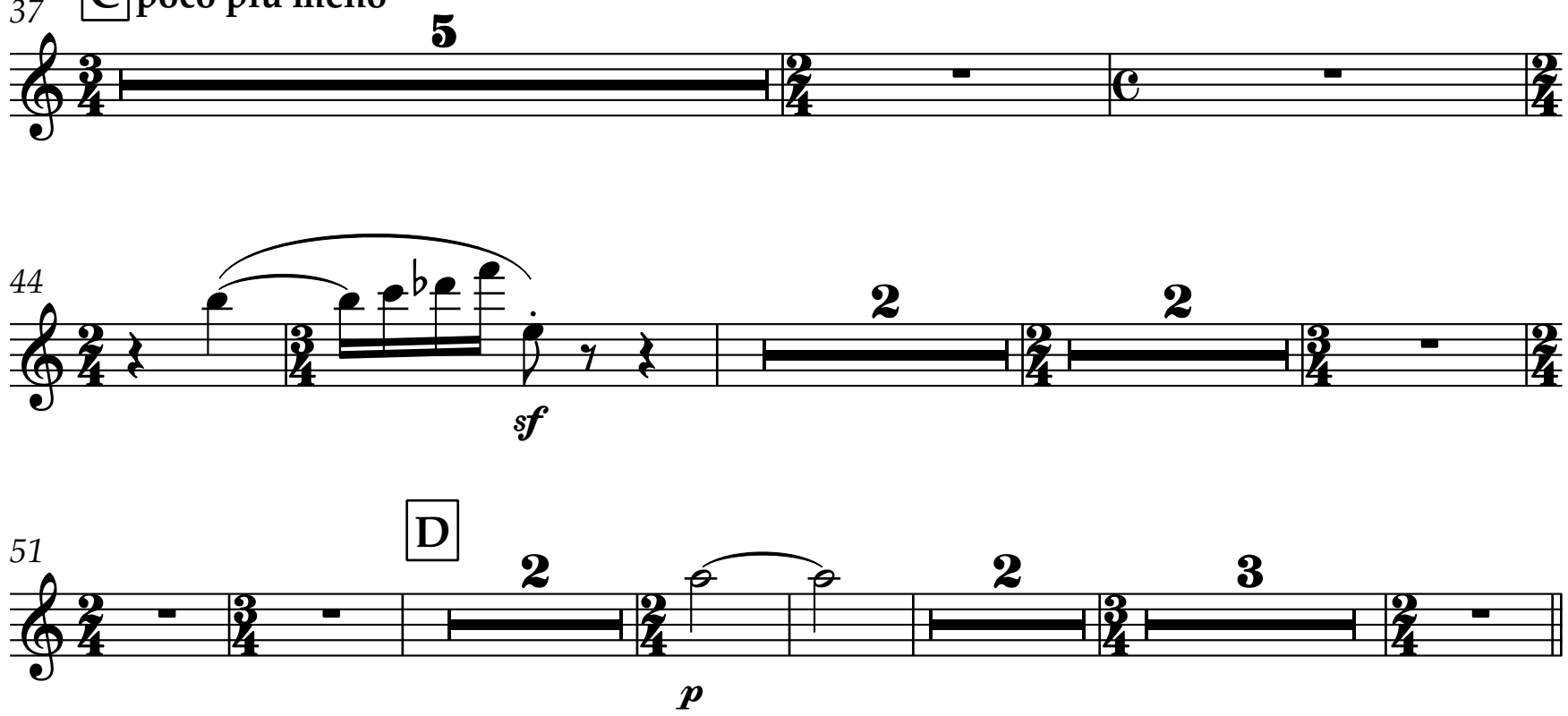
Tempo I

$\frac{6}{b=1}$
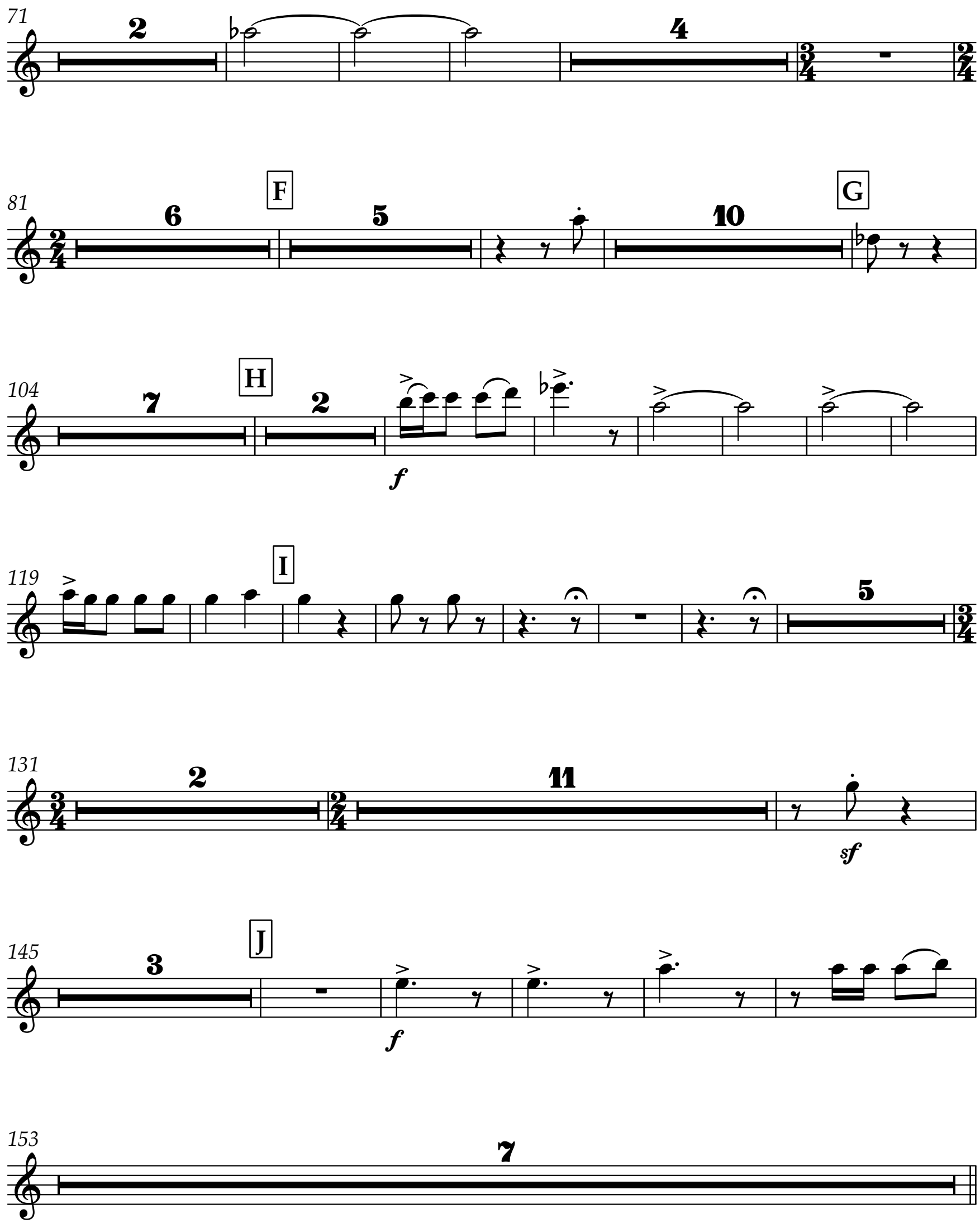
6

${ }_{160} \mathbf{K}$ sostenuto cantabile

8

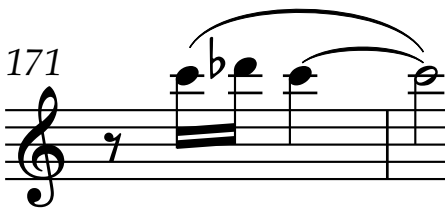

3
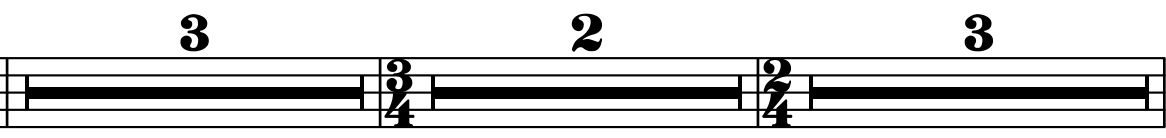
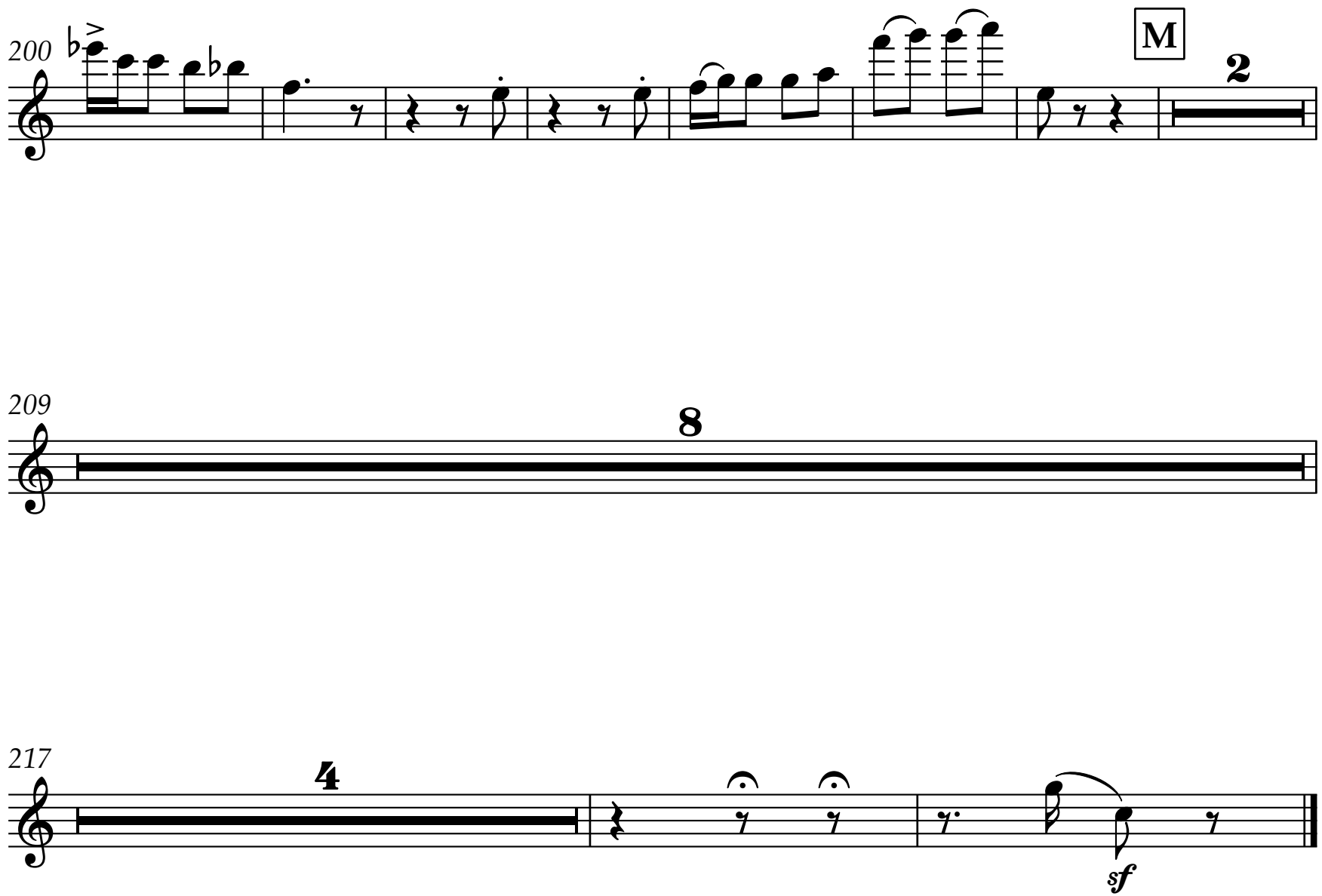


\section{Oboe 1 Concerto for Viola and Orchestra I.}

Dmitris Dragatakis
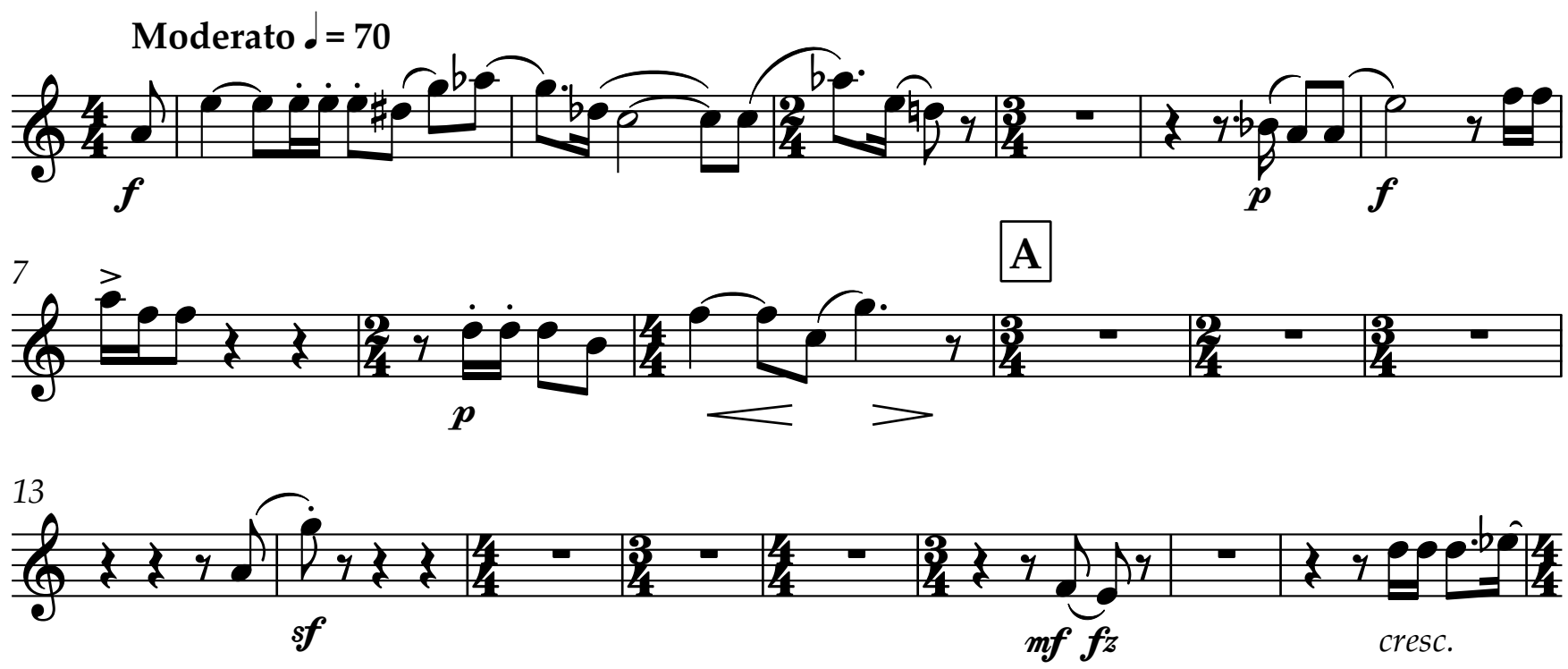

21 poco largam. a tempo pocolargam.
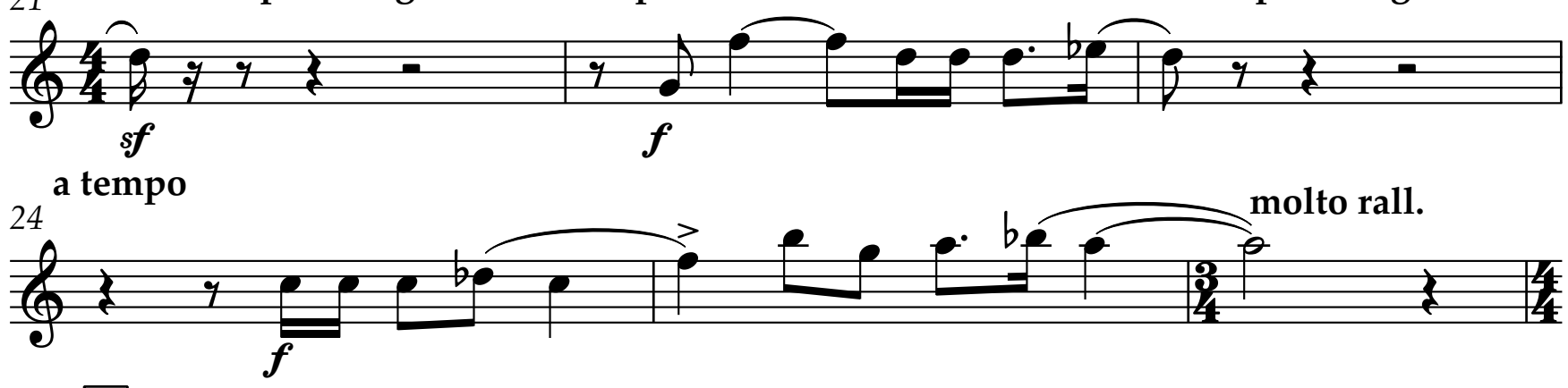

27 B a tempo
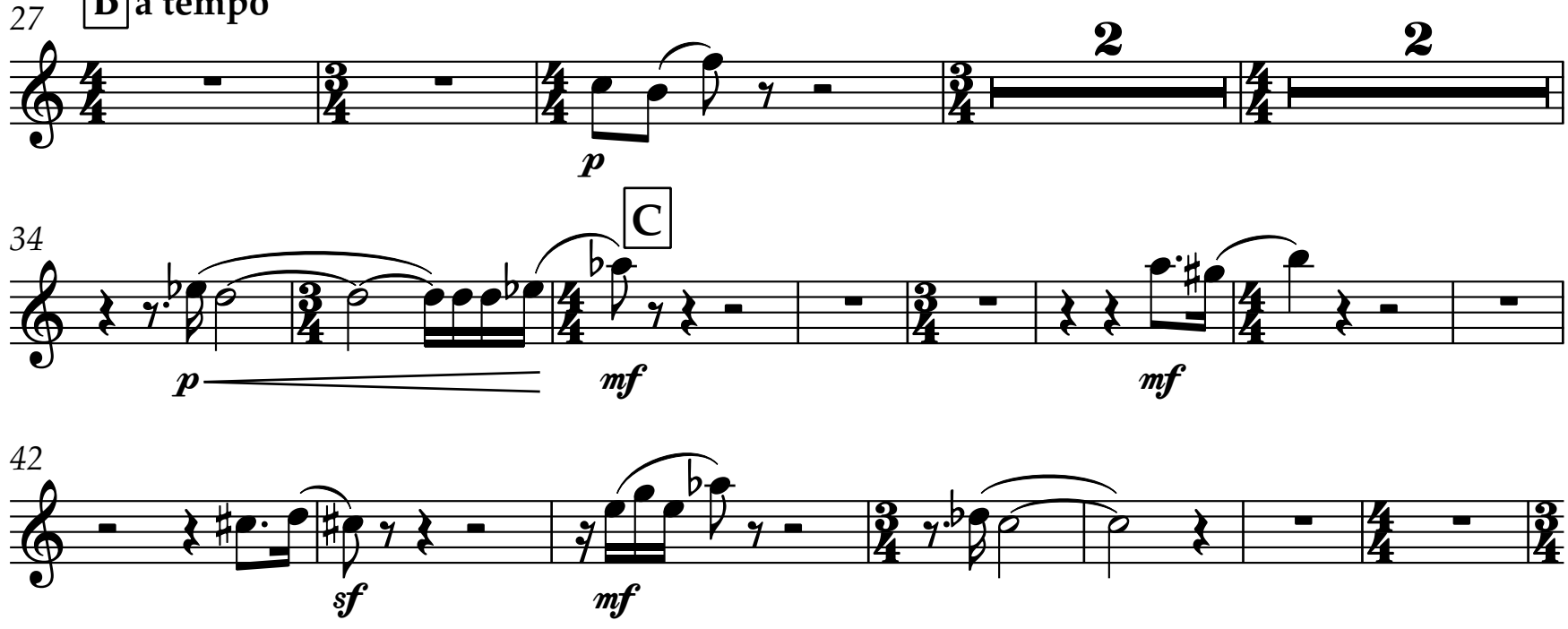

$$
49 \text { poco largam. }
$$

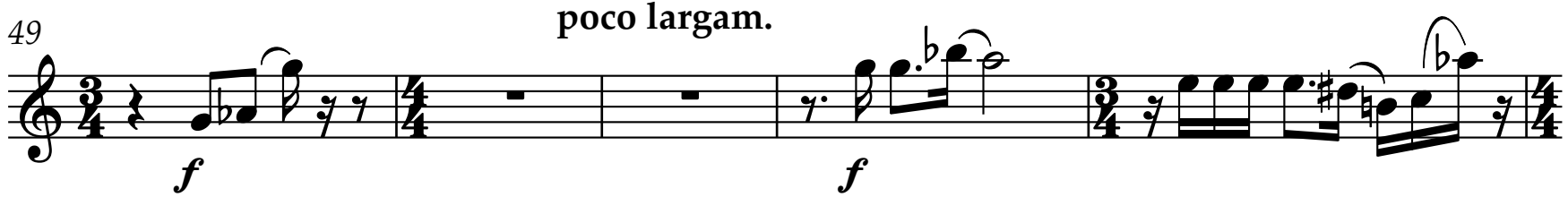
$54 \mathrm{D}$ poco sostenuto

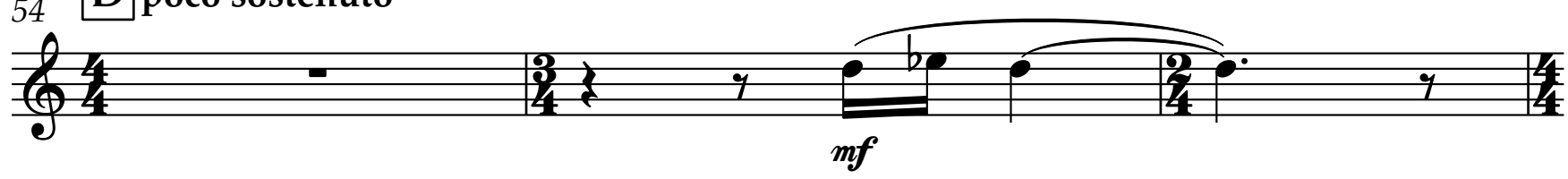



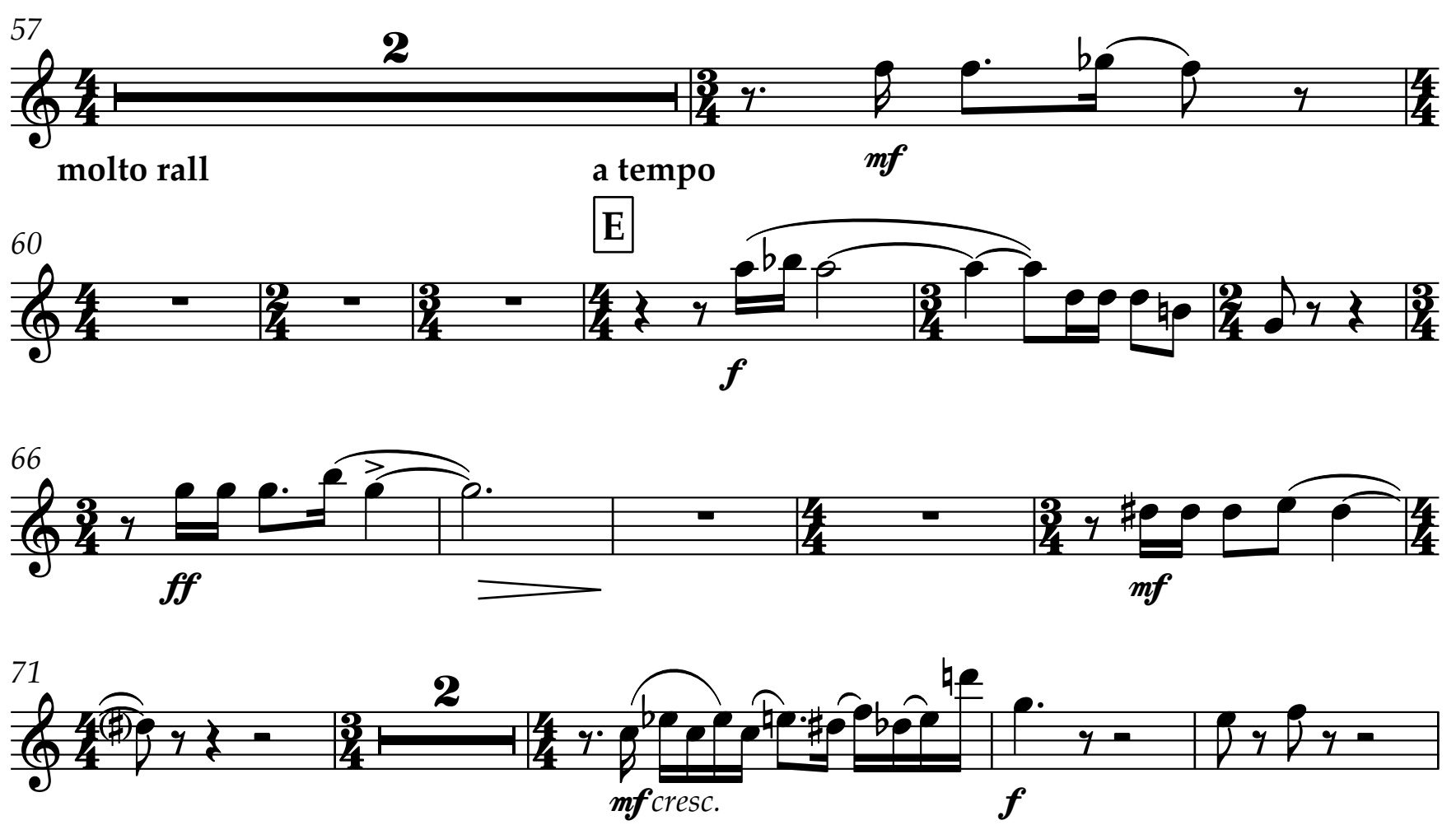
${ }_{77}$ F poco largam. a tempo
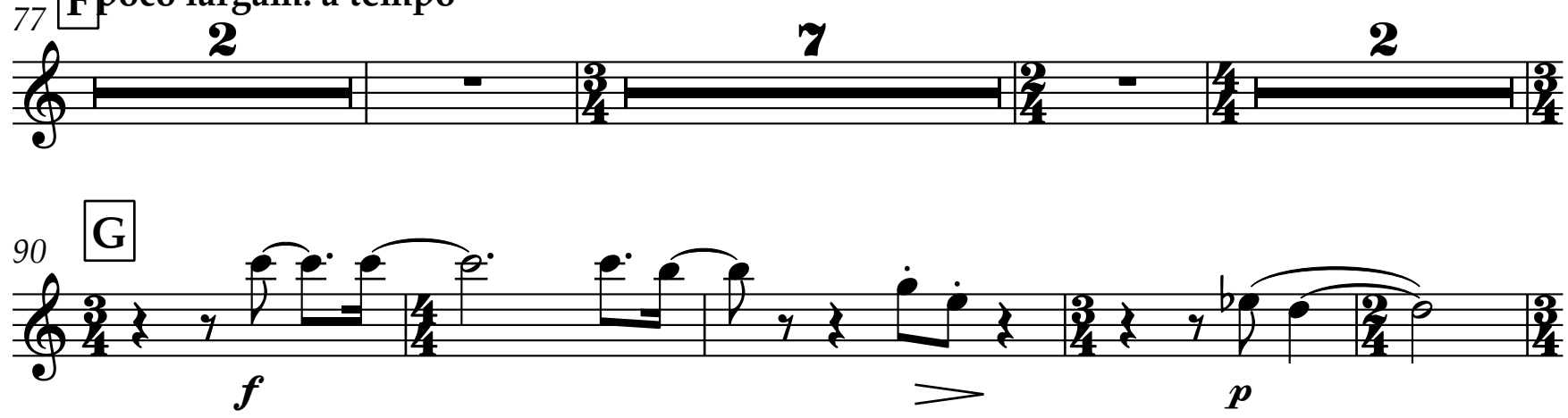
95 Più larg.
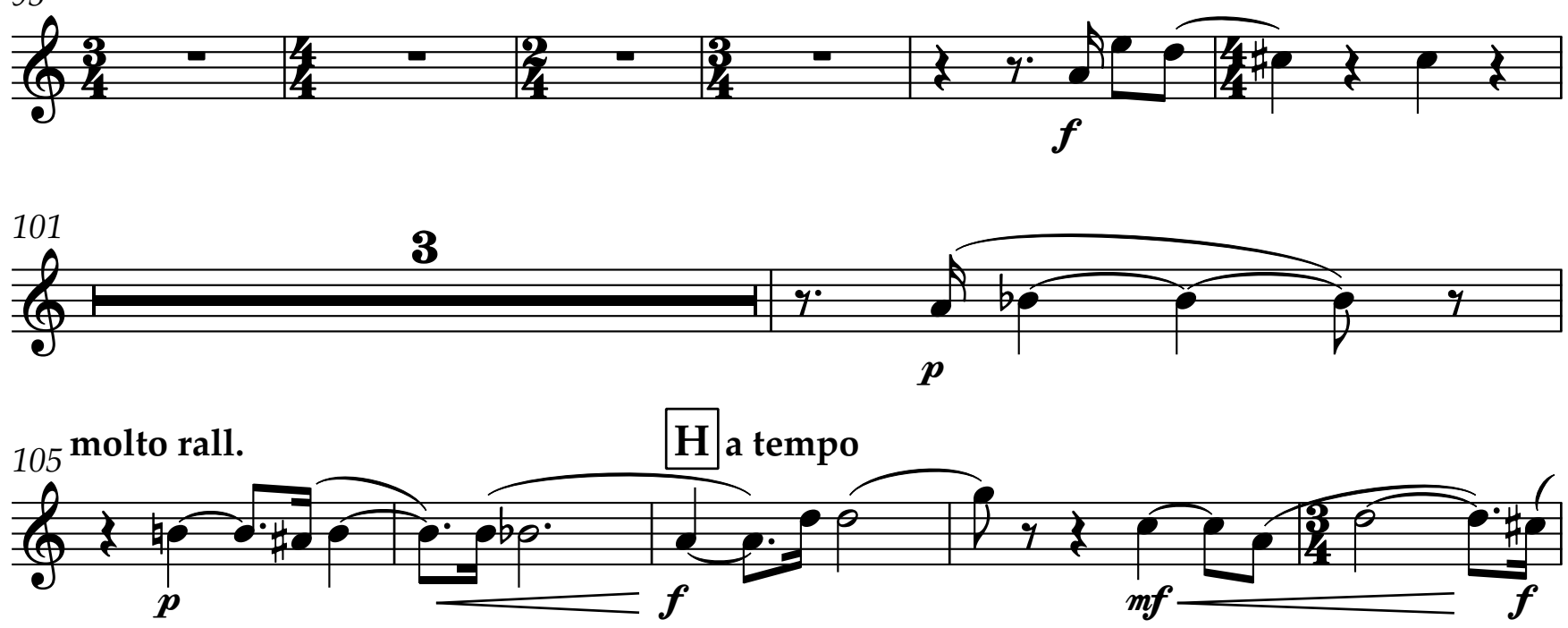

$110 \stackrel{2}{\text { poco sostenuto }}$

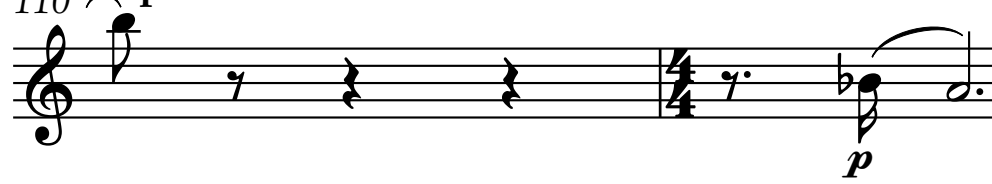


Oboe 1

Oboe 1

(3)

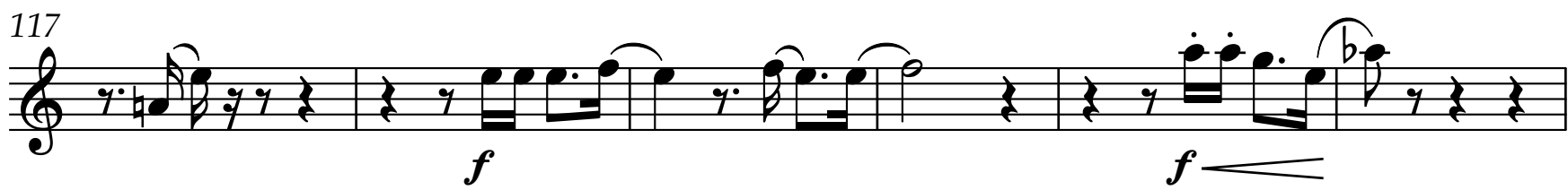

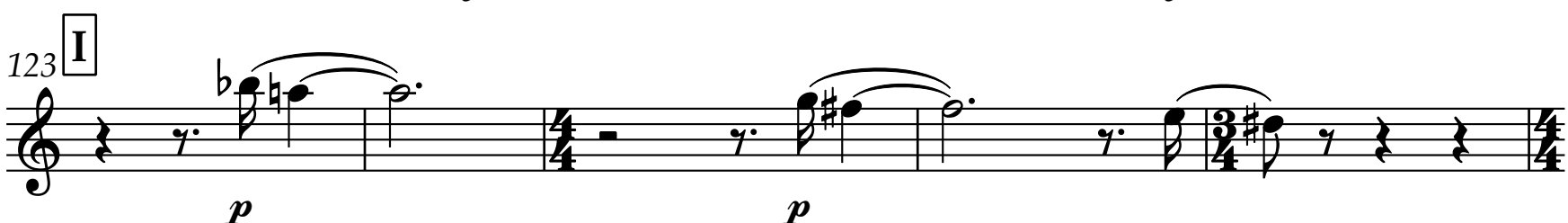
Largamente

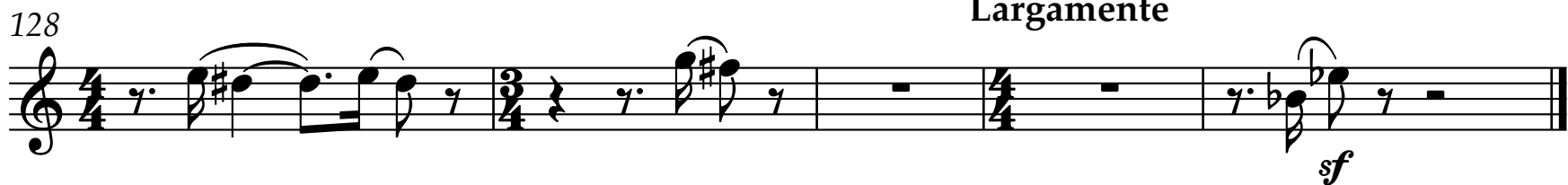

II.

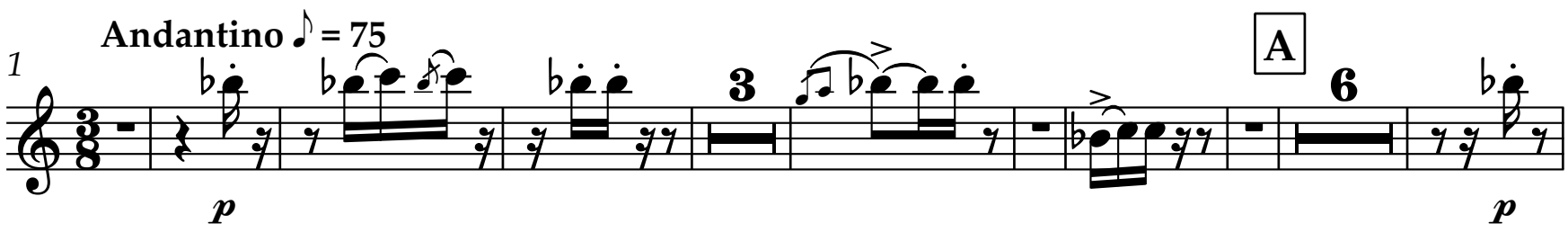
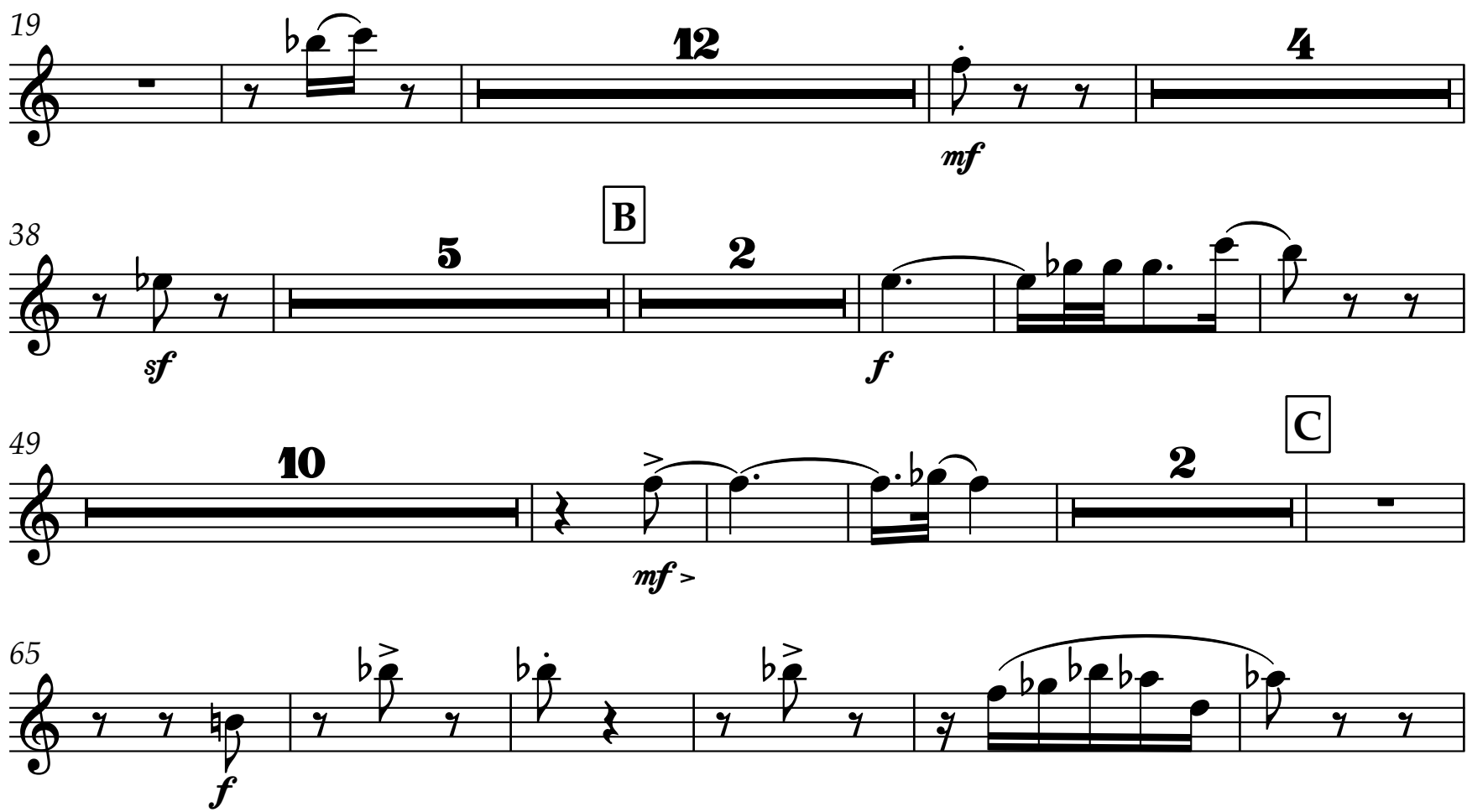
4

Oboe 1
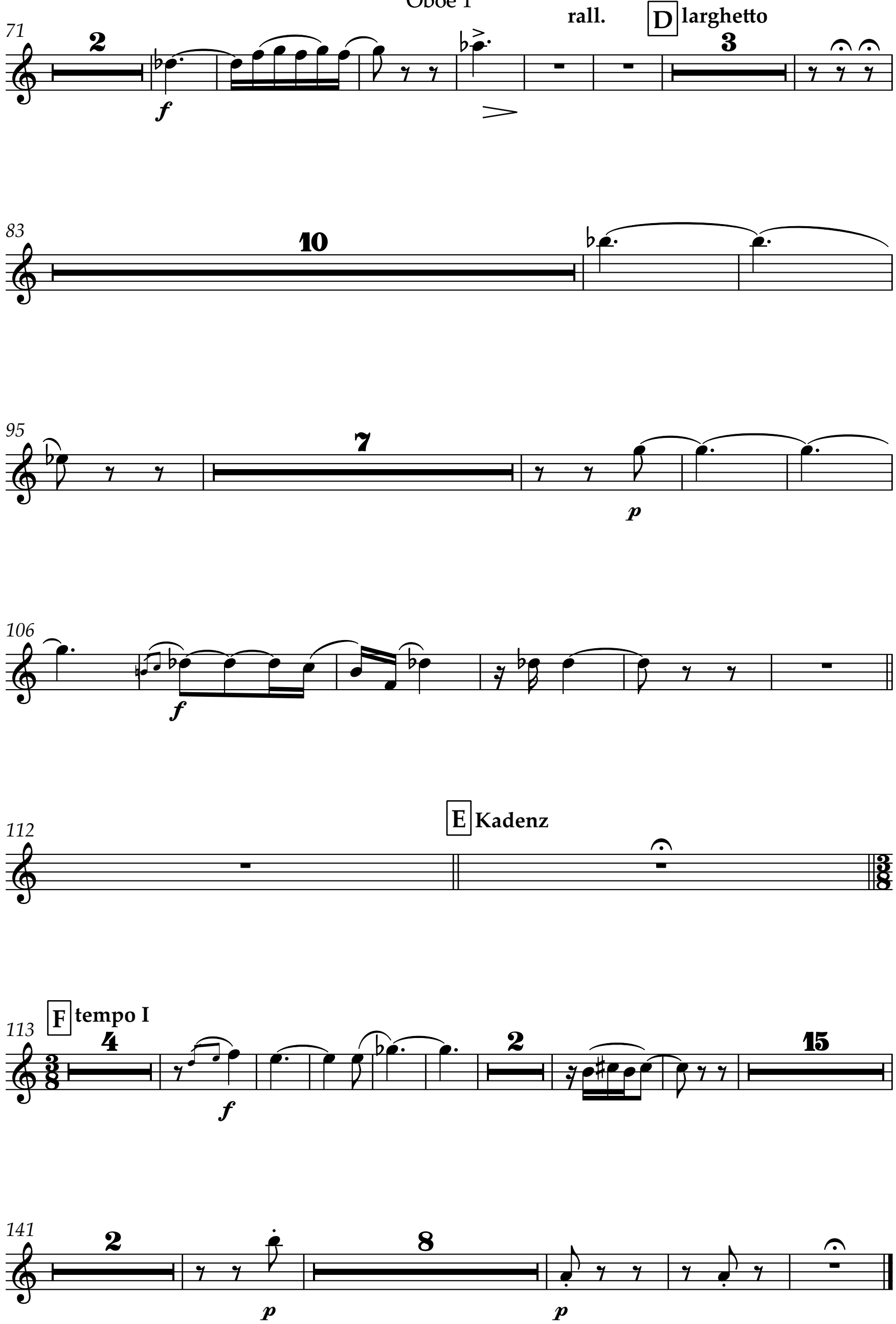
III.
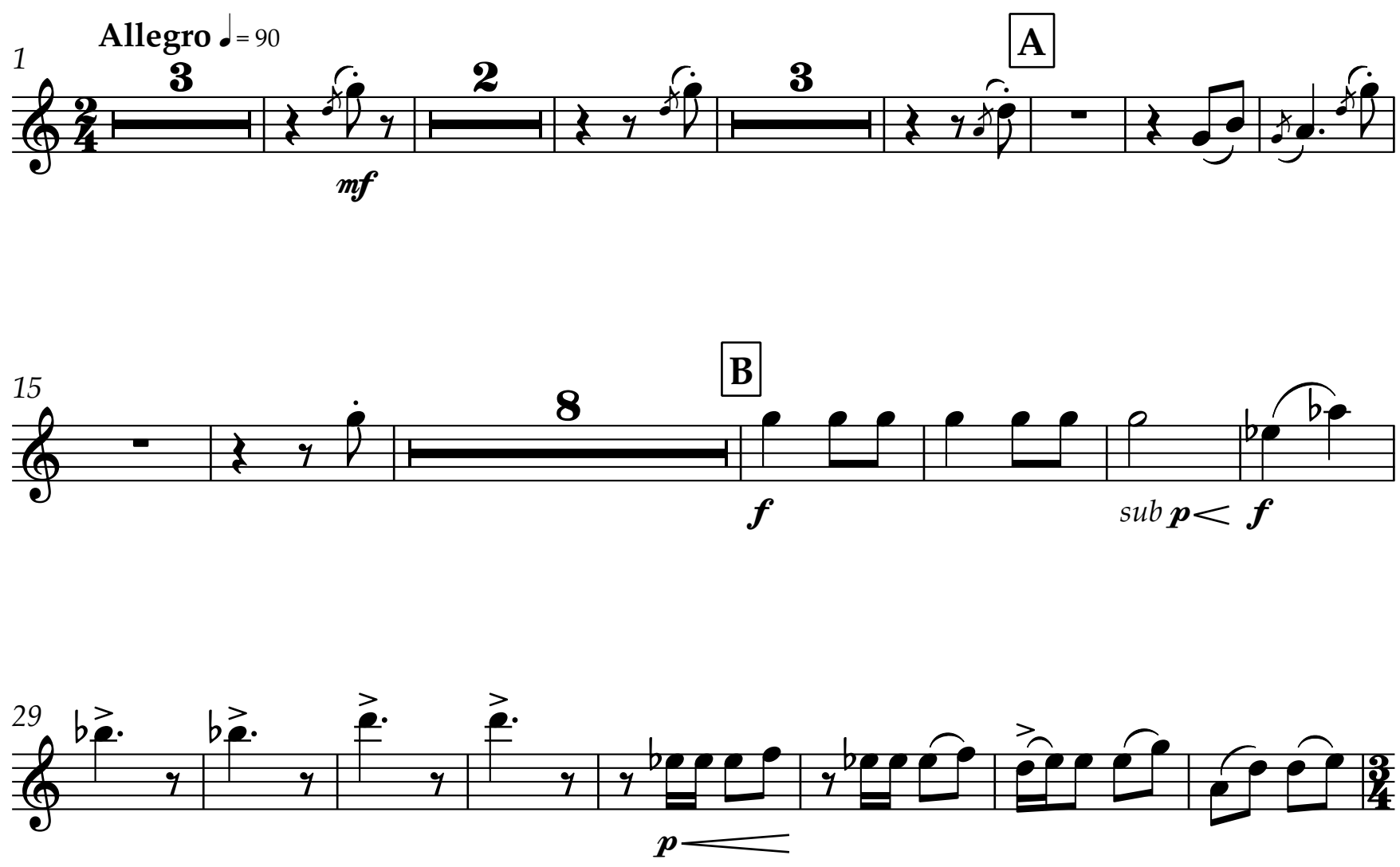

37 C poco piu meno
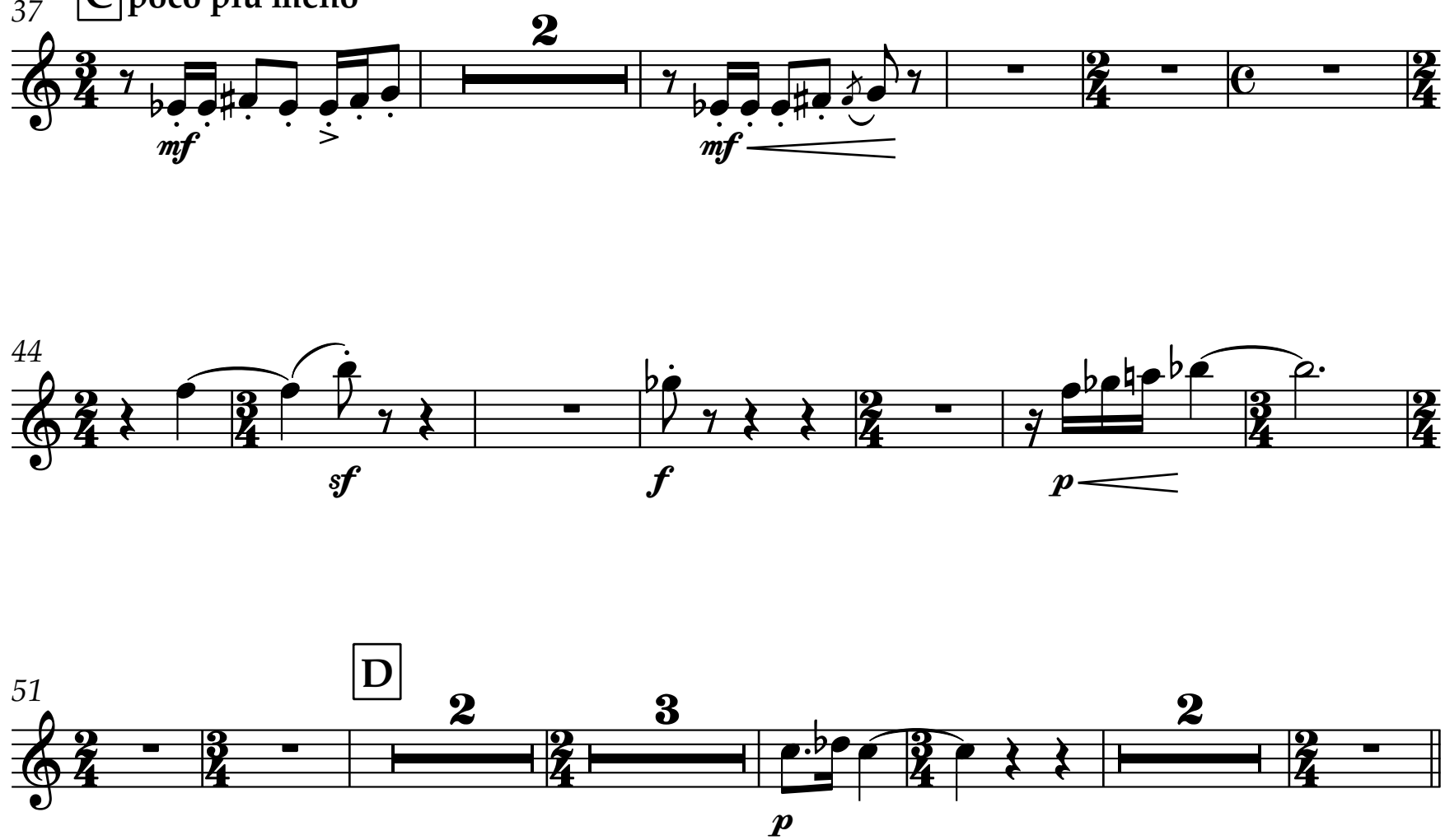
6
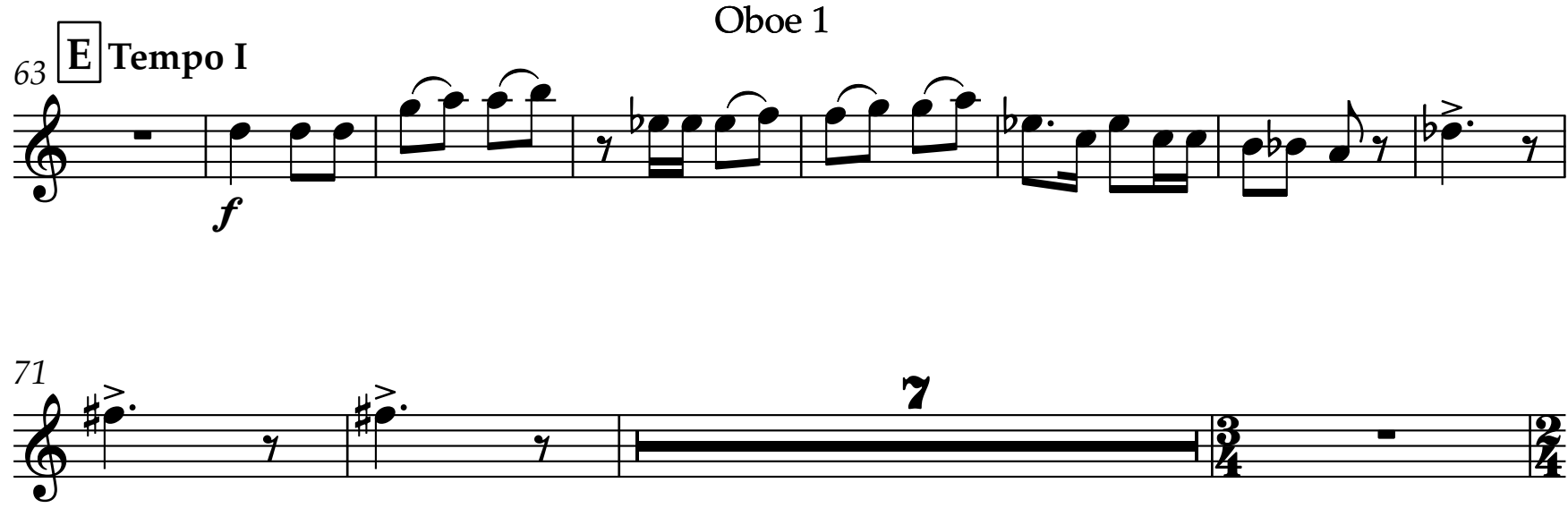

$\underbrace{81}_{f}$
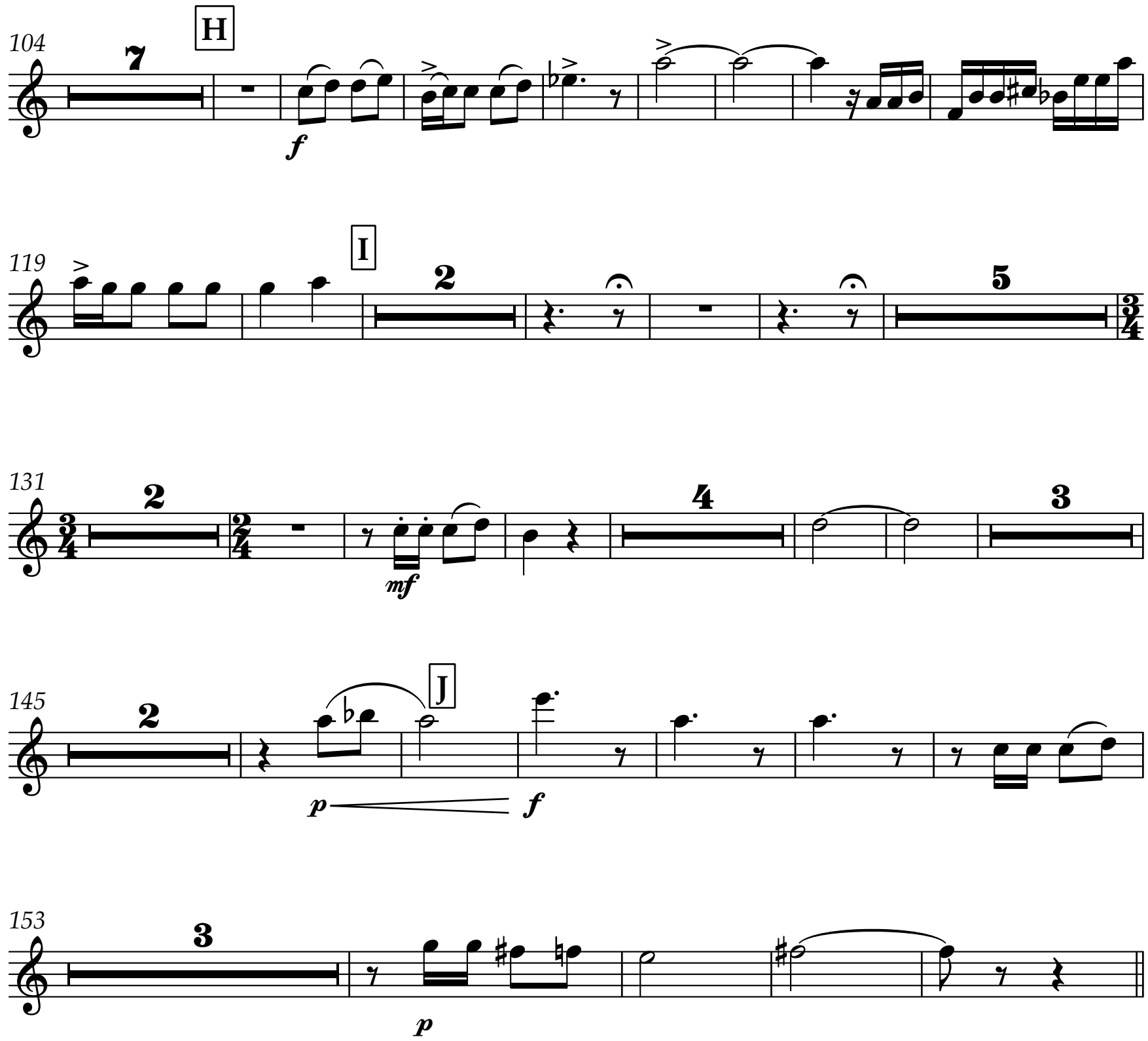
sostenuto cantabile

$\overbrace{\mathrm{g}}^{160}$

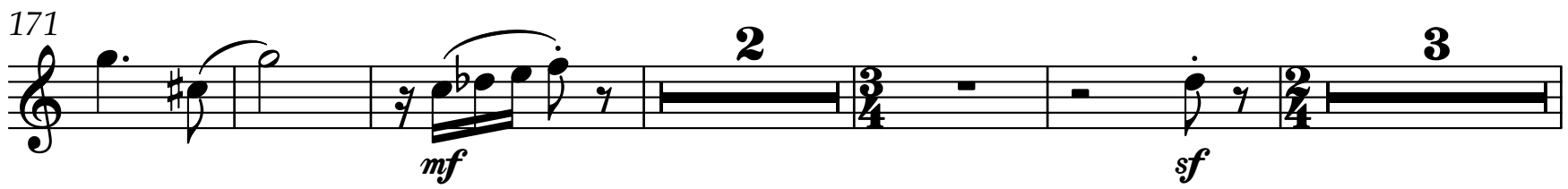

molto rall. A Tempo

L
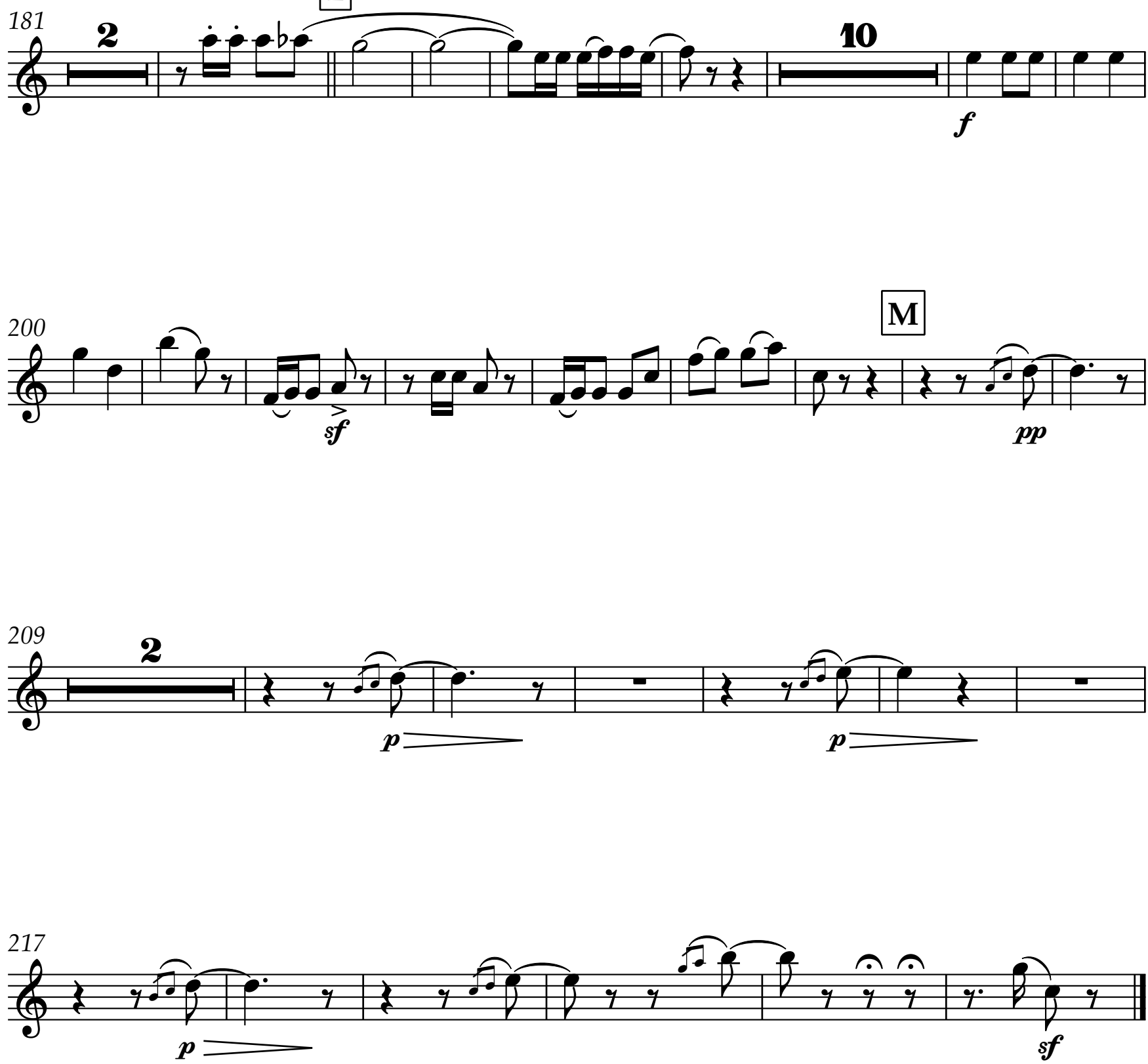


\section{Oboe 2 Concerto for Viola and Orchestra}

Dmitris Dragatakis
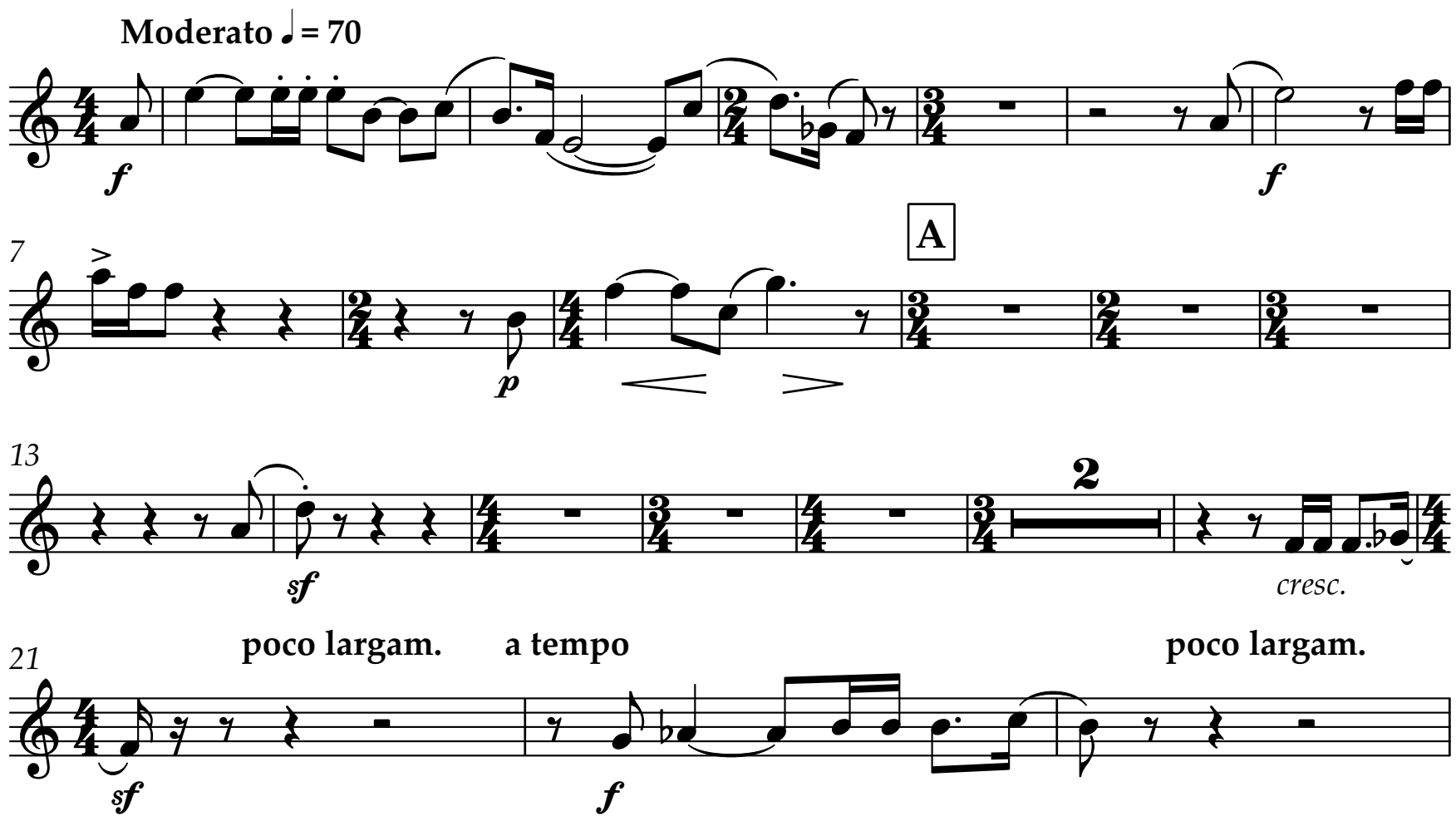
a tempo

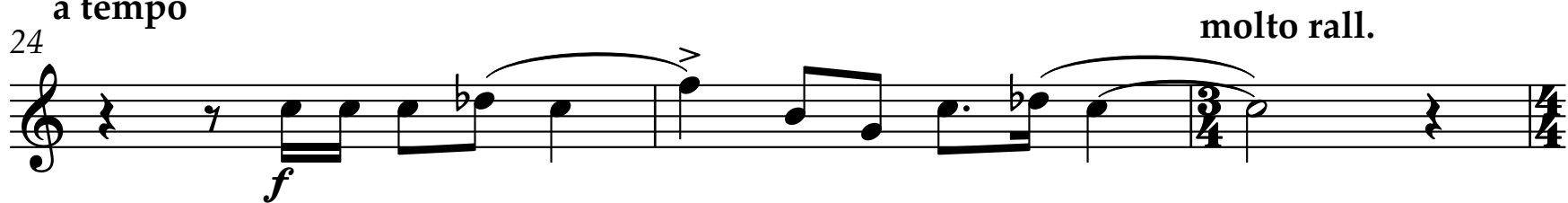

27 B a tempo
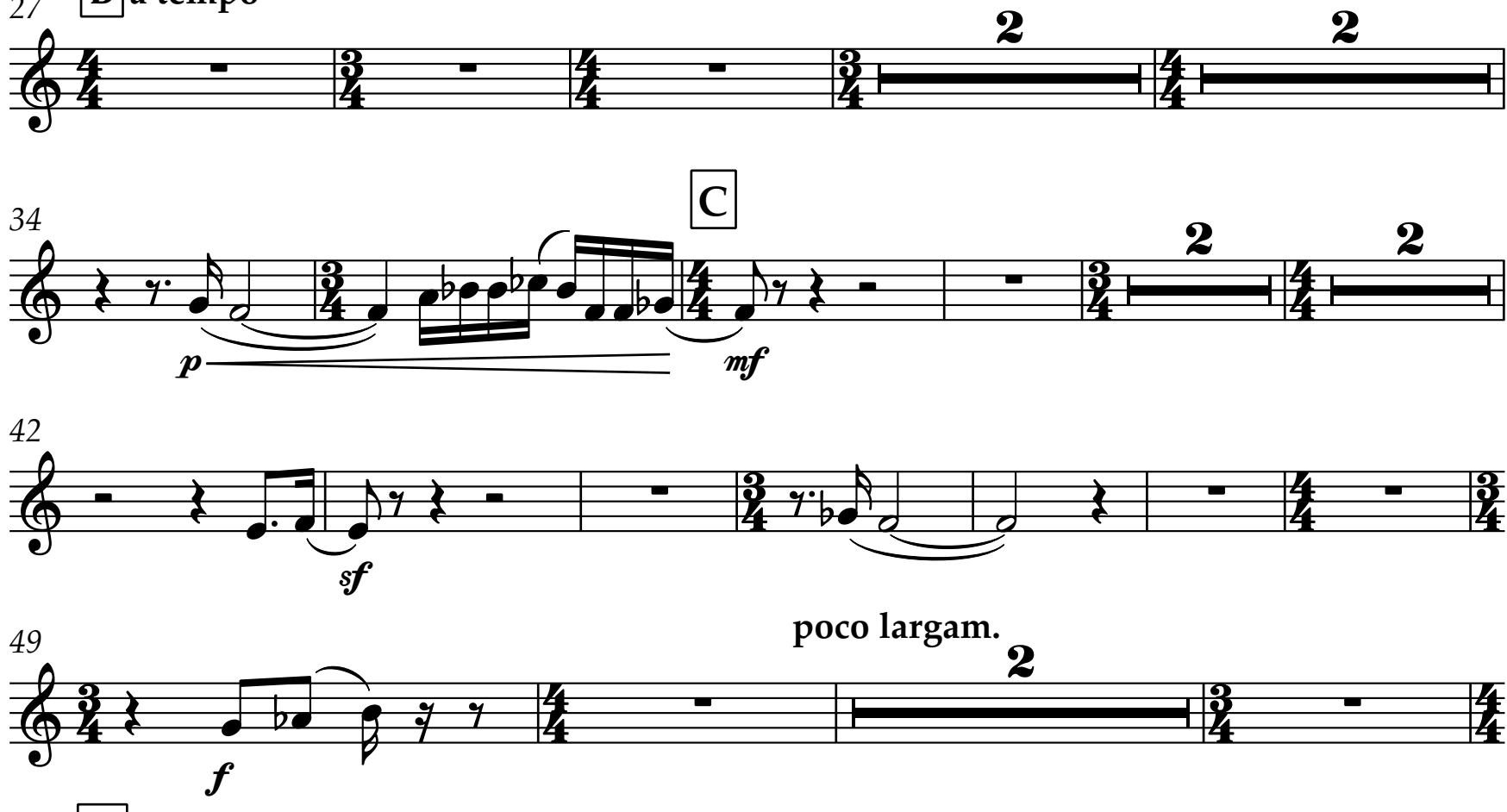
poco largam.

$54 \quad \mathbf{D}$ poco sostenuto

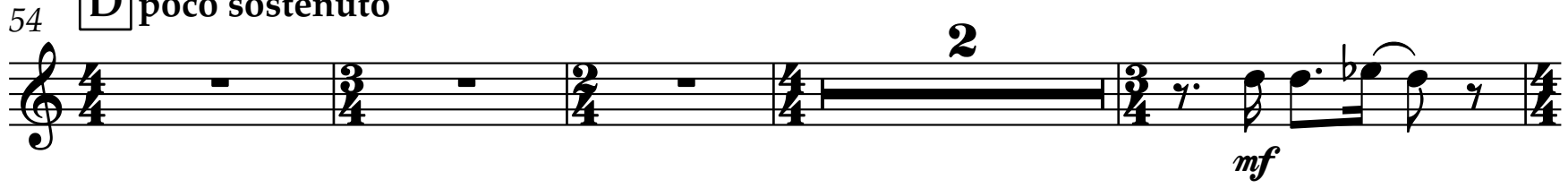


$2 \quad$ molto rall

60

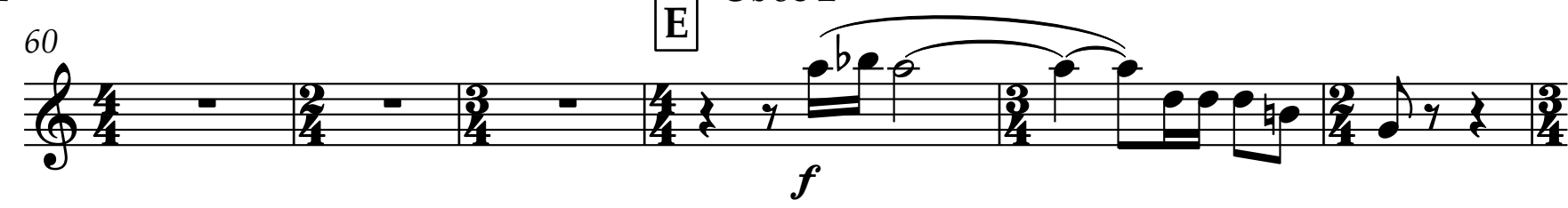

66
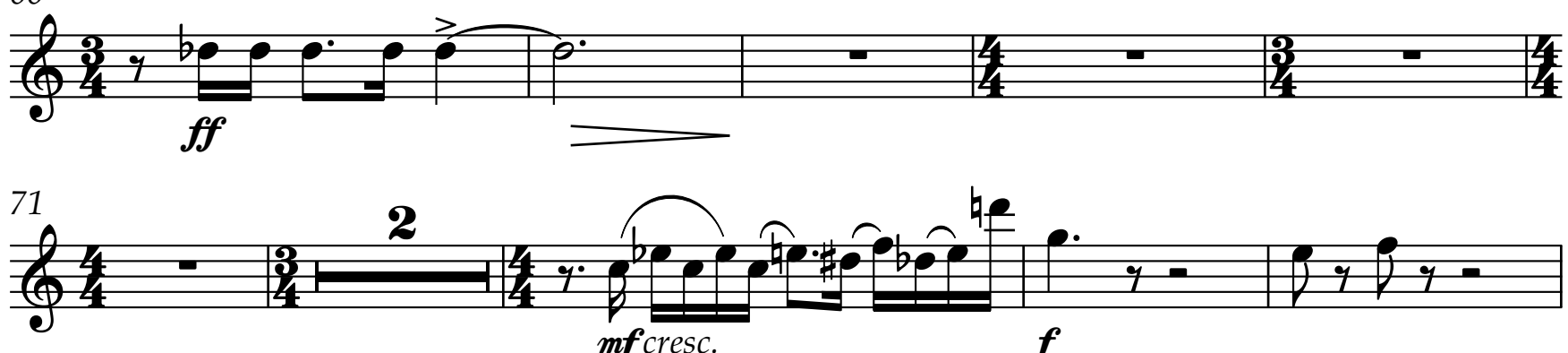

F poco largam. a tempo

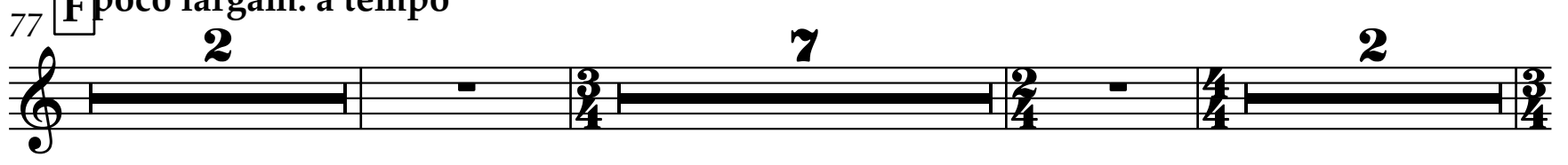

$90 \mathbf{G}$

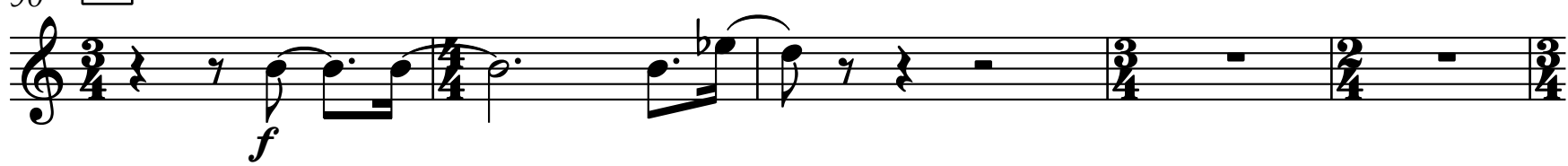
95 Più larg.
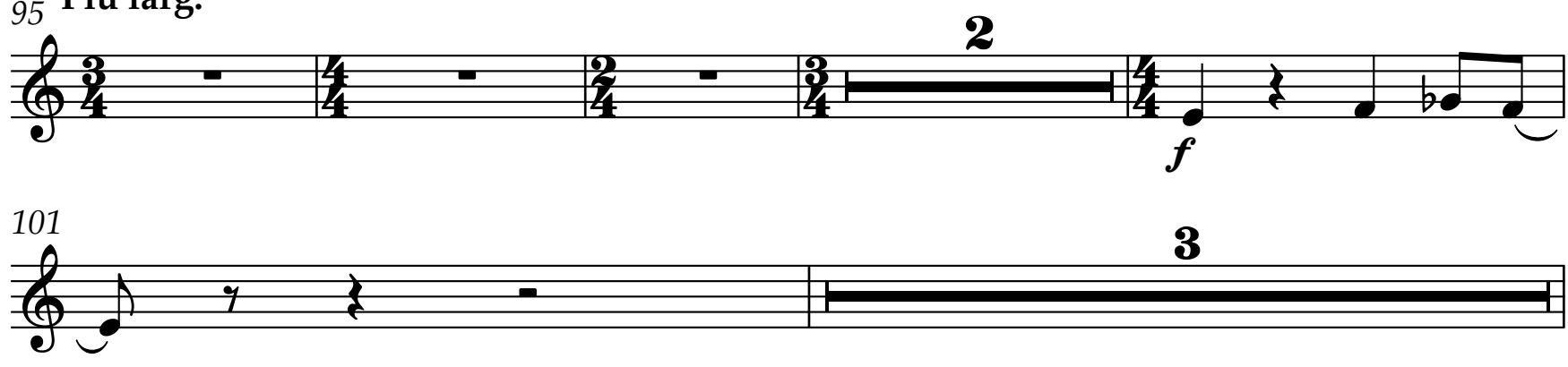

molto rall.

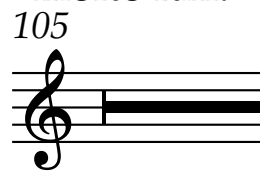

$\mathrm{H}^{\text {a tempo }}$

110 poco sostenuto

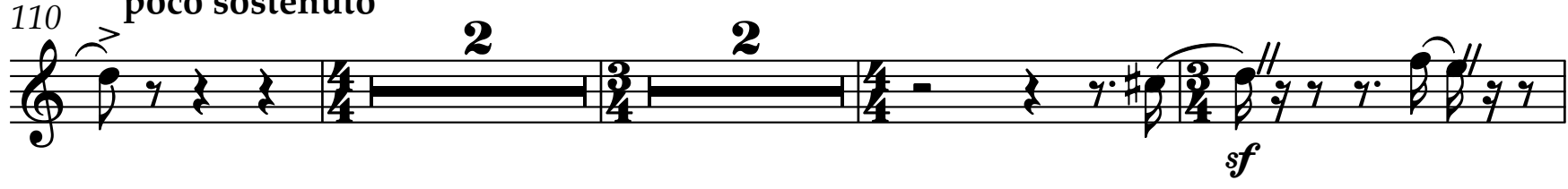

(6yं)

123 I

(2)

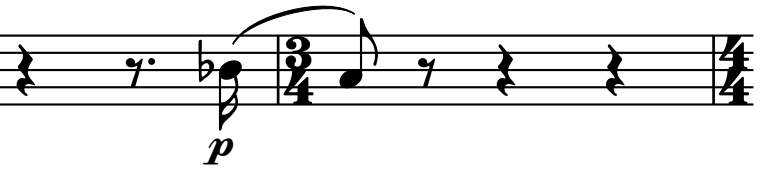


Oboe 2

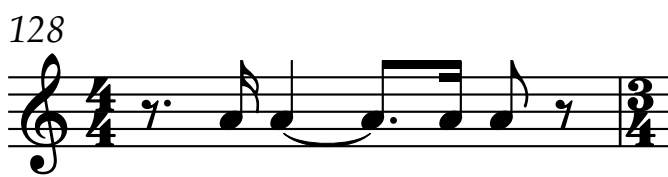

Oboe 2

2

Largamente

\section{II.}
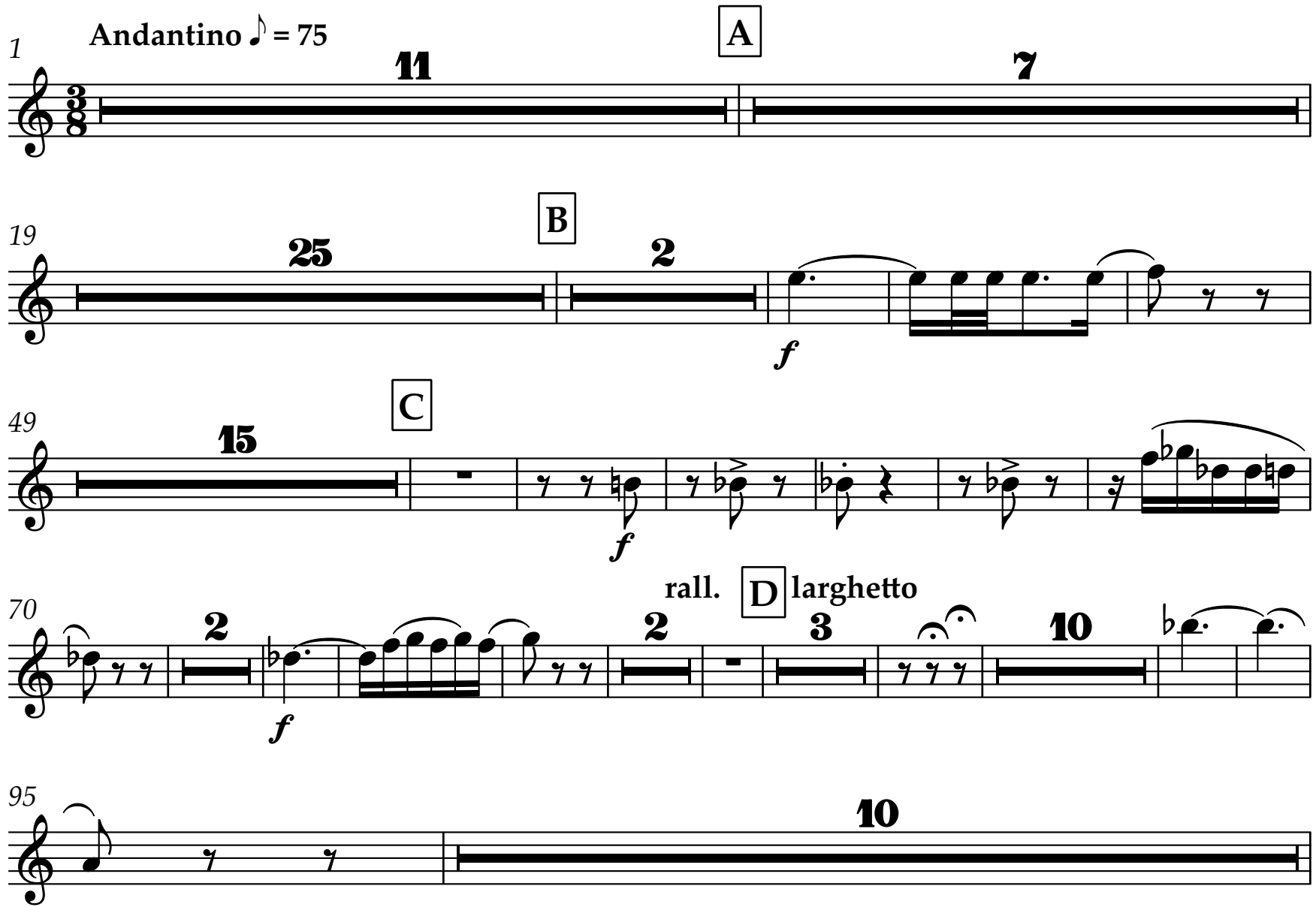

10
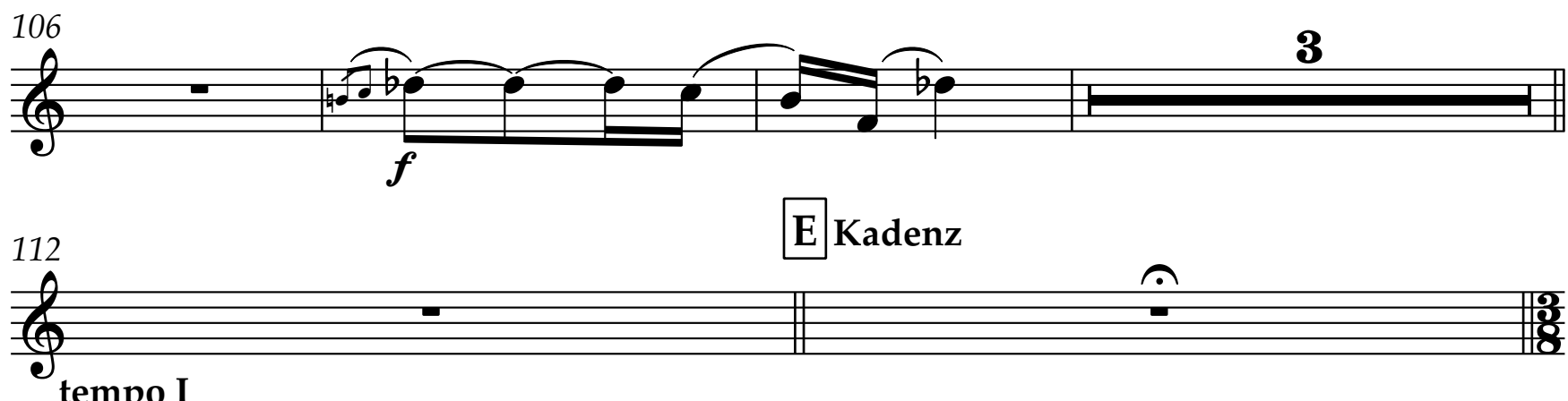

113 F

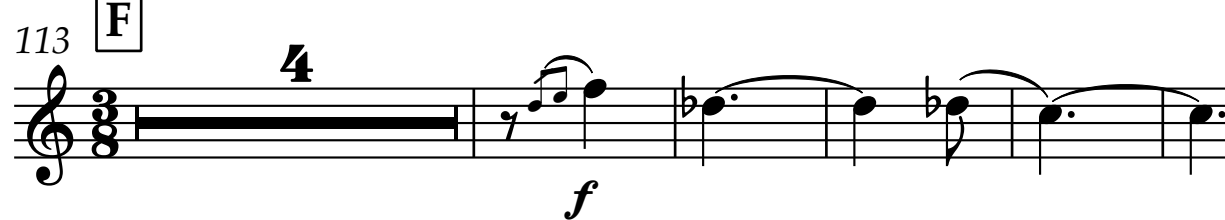

7 
Đboe 2

Oboe 2

129

12

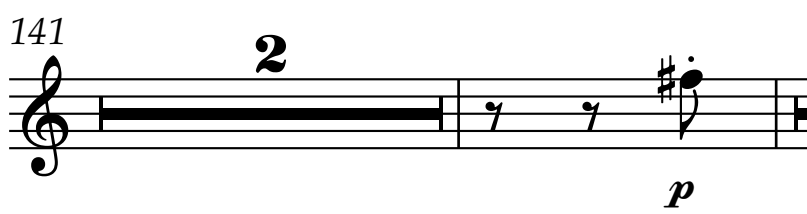

10

ค

+

III.

\begin{tabular}{lllll}
1 & Allegro $d=90$ & $\mathbf{1 1}$ & $\mathbf{A}$ & $\mathbf{3}$ \\
\hline & & & \\
\hline
\end{tabular}

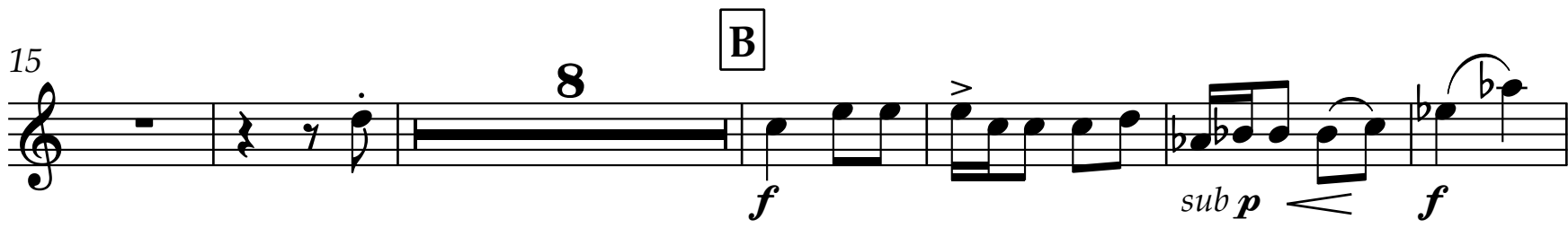

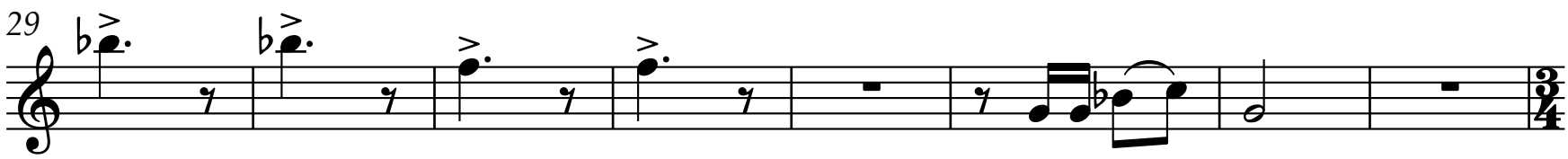

37 Coco piu meno

$6_{4}^{3}$

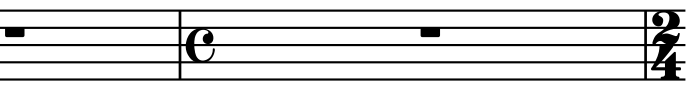
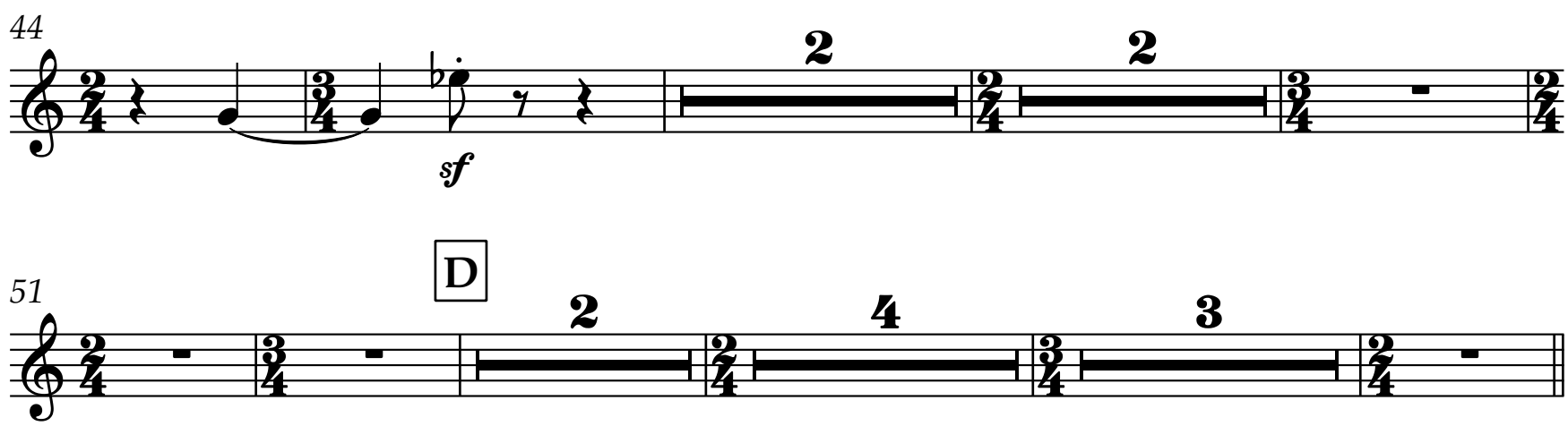
${ }_{63} \mathrm{E}$ Tempo I
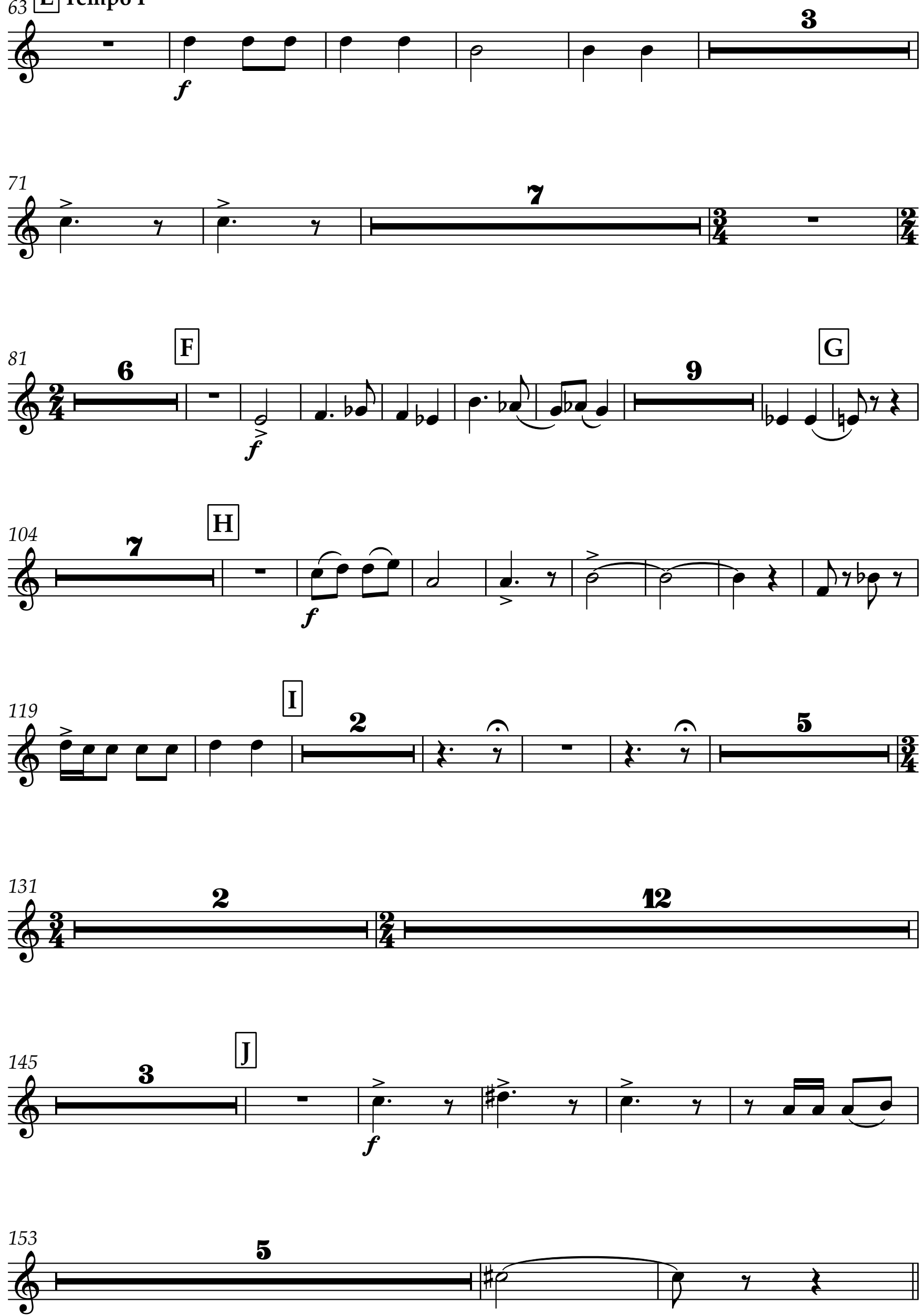
6
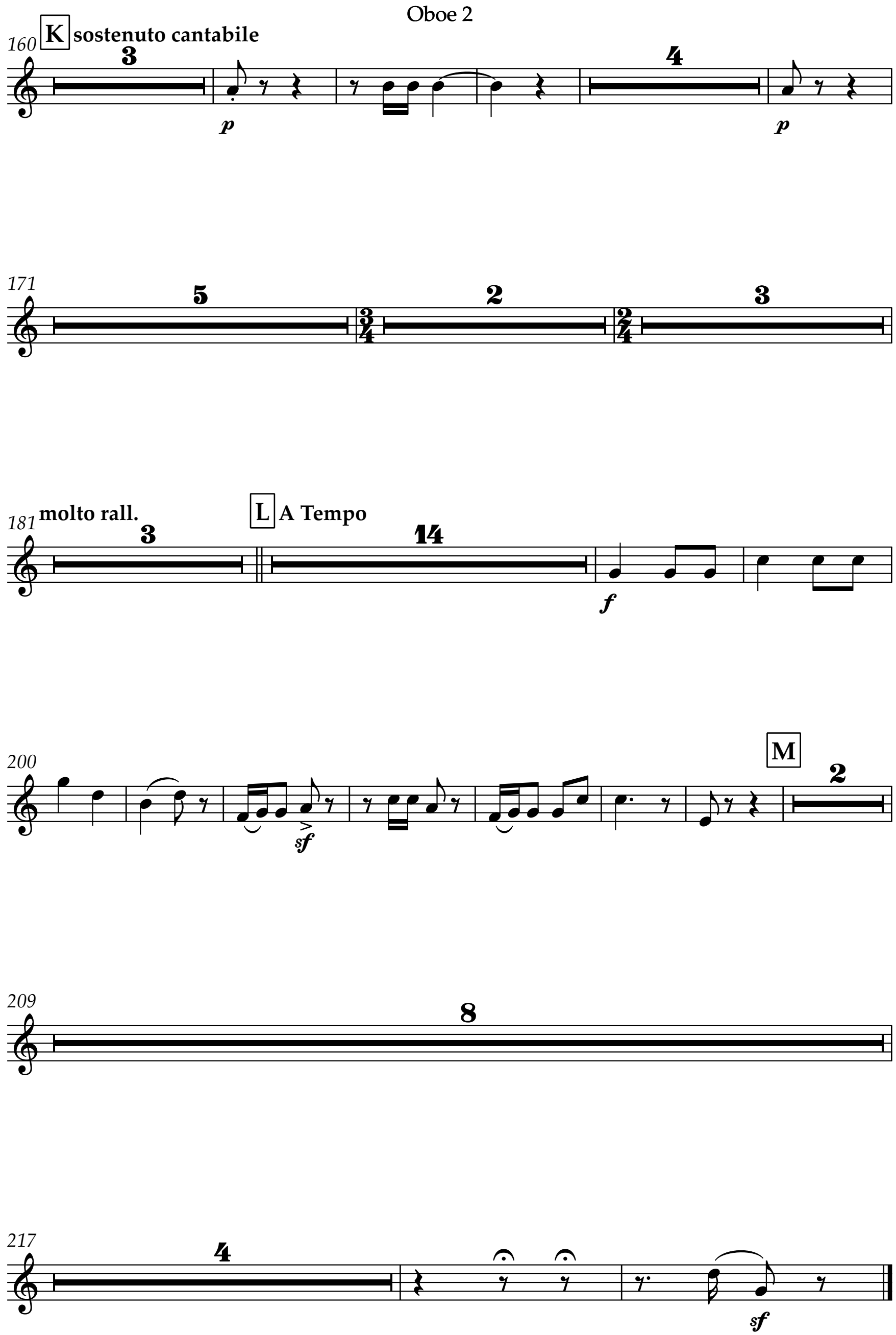


\section{Concerto for Viola and Orchestra Clarinet 1 in $\mathrm{Bb}$
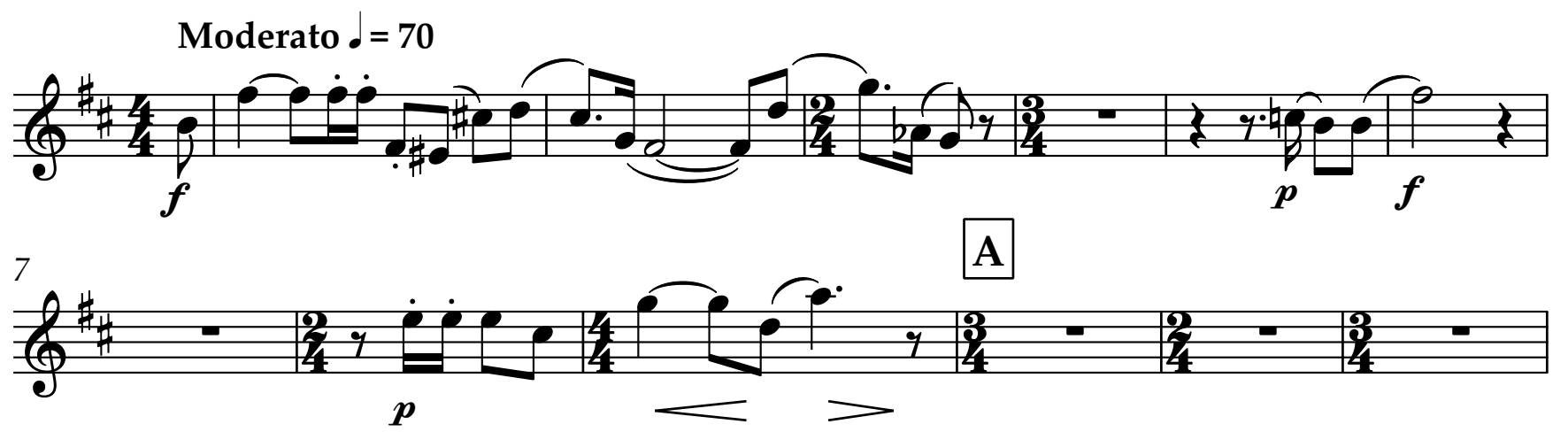

13
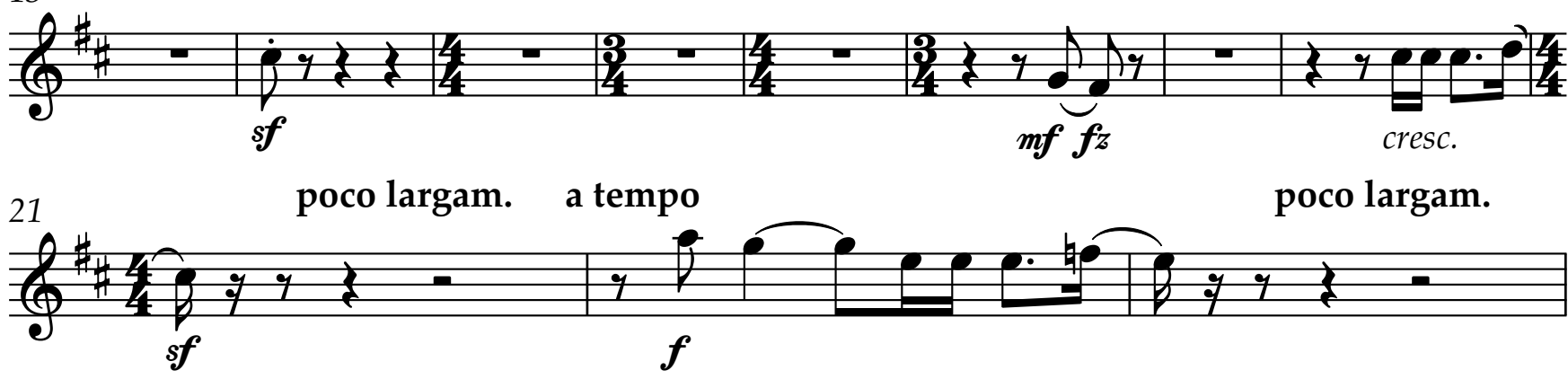

24 a tempo

molto rall.

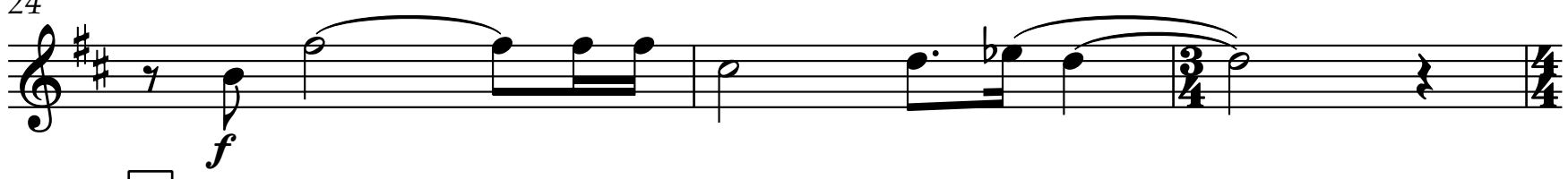

27 B a tempo

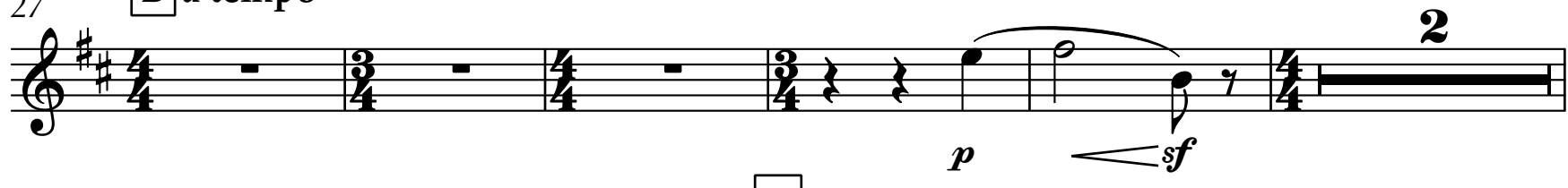

34

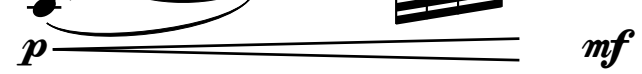

$m f$
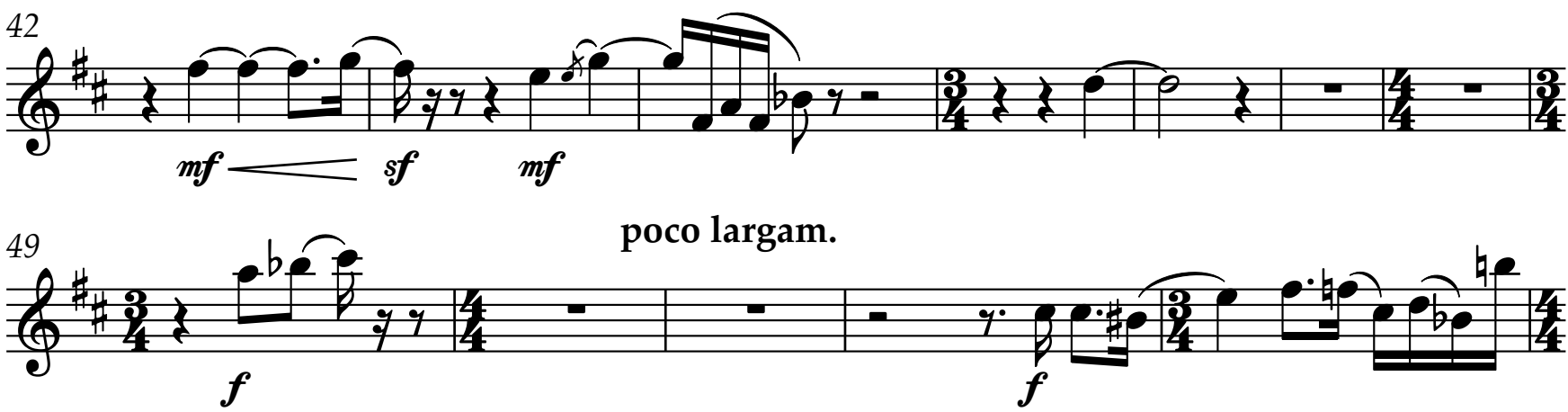
54
D poco sostenuto

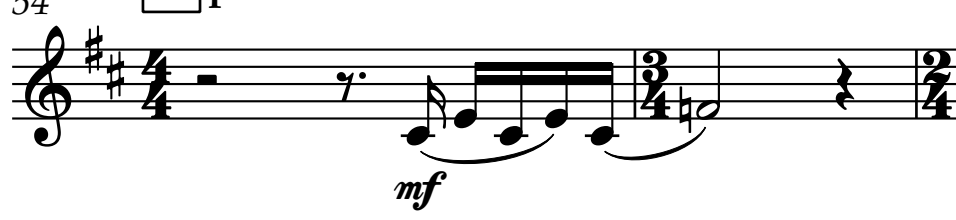

2 
2
60 molto rall
E a tempo

(9) 66 beee.e?

(4)
$77 \quad$ F poco lartigampo

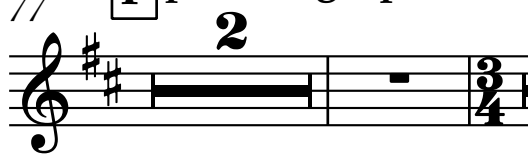

2

$\frac{G 0}{f}$

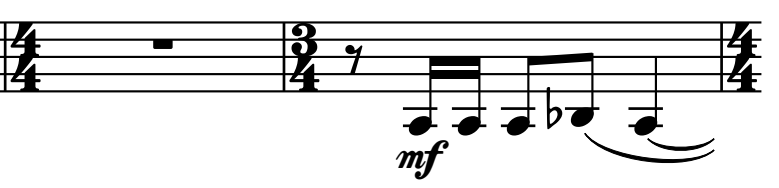

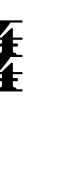


Clarinet 1 in $\mathrm{Bb}$ 128

(⿻)

Clarinet 1 in $\mathrm{Bb}$

Largamente

II.
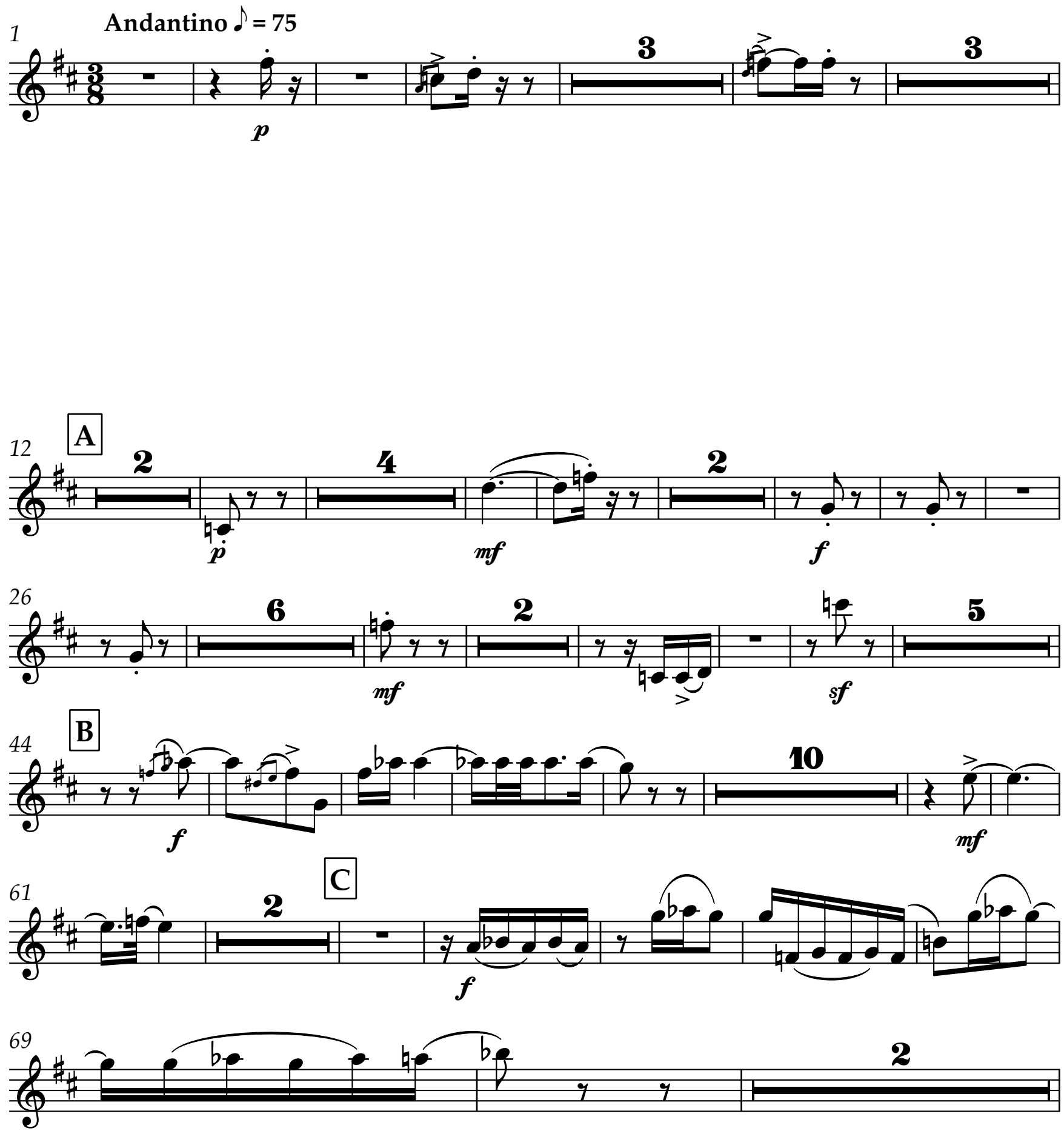

2 
Elarinet 1 in $\mathrm{Bb}$

rall. Clarinet 1 in $B b$
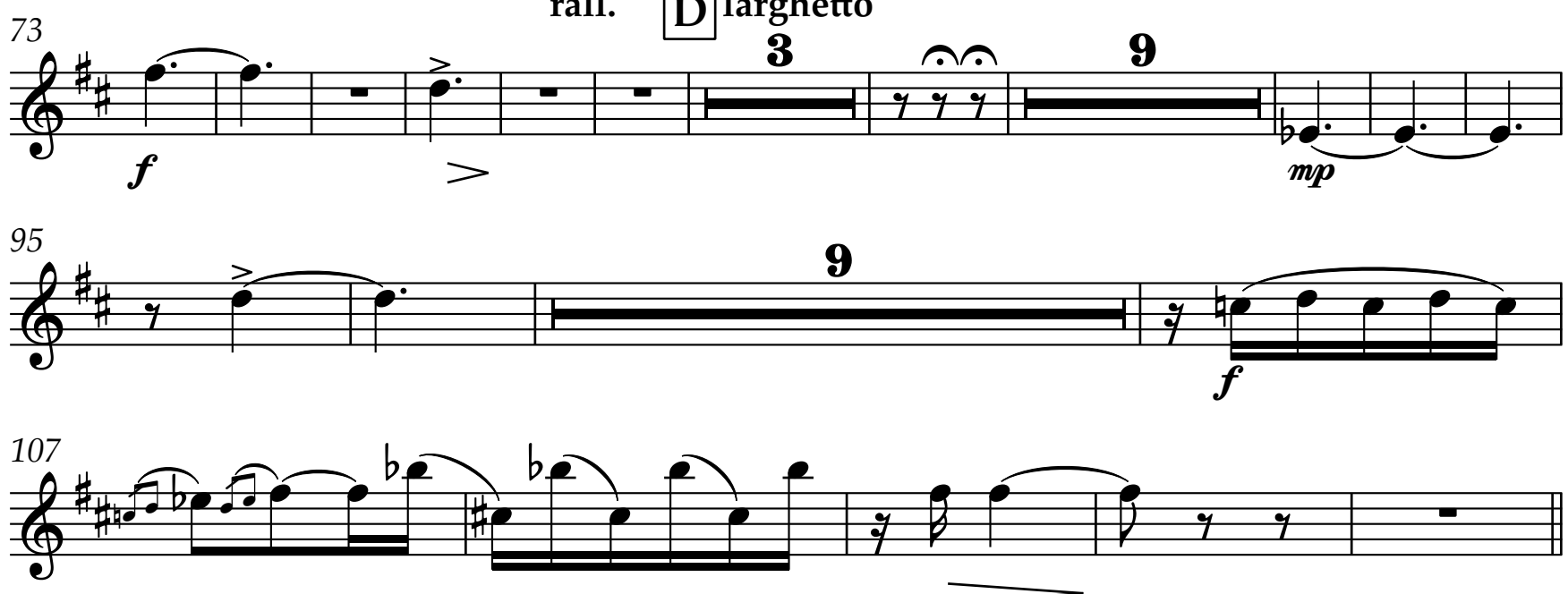

112

E Kadenz

(4)

ค

113 F tempo I

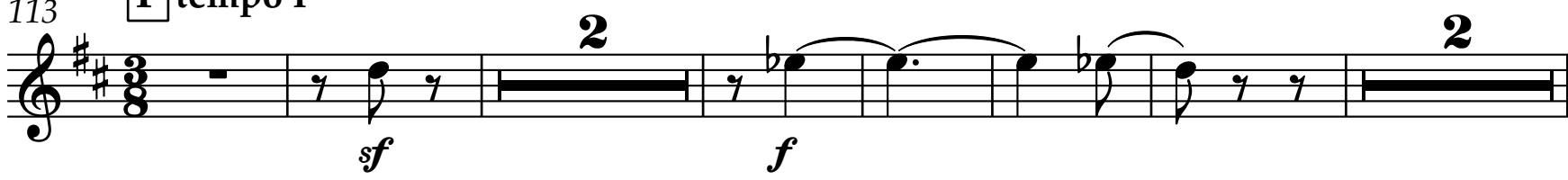

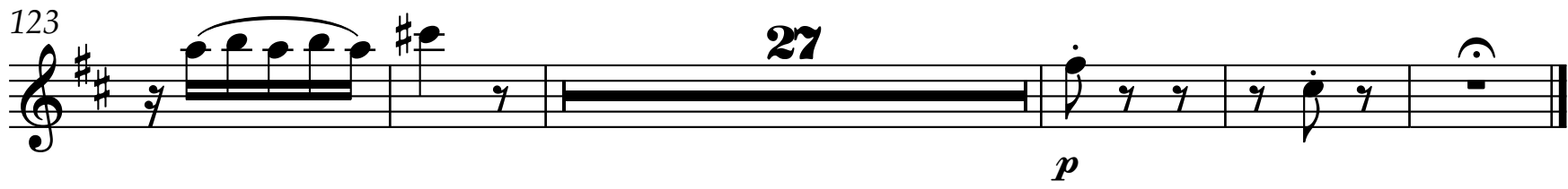

III.

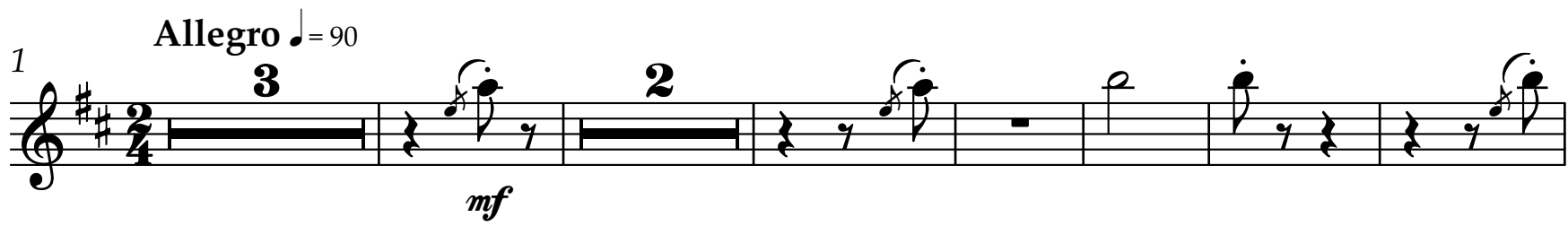

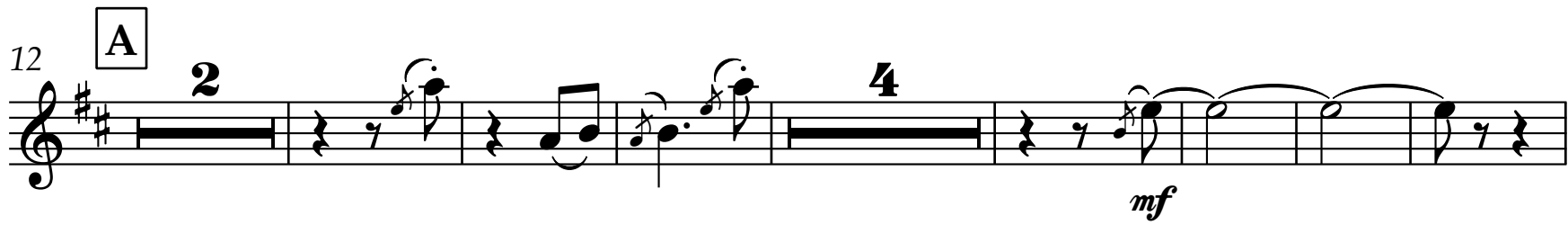



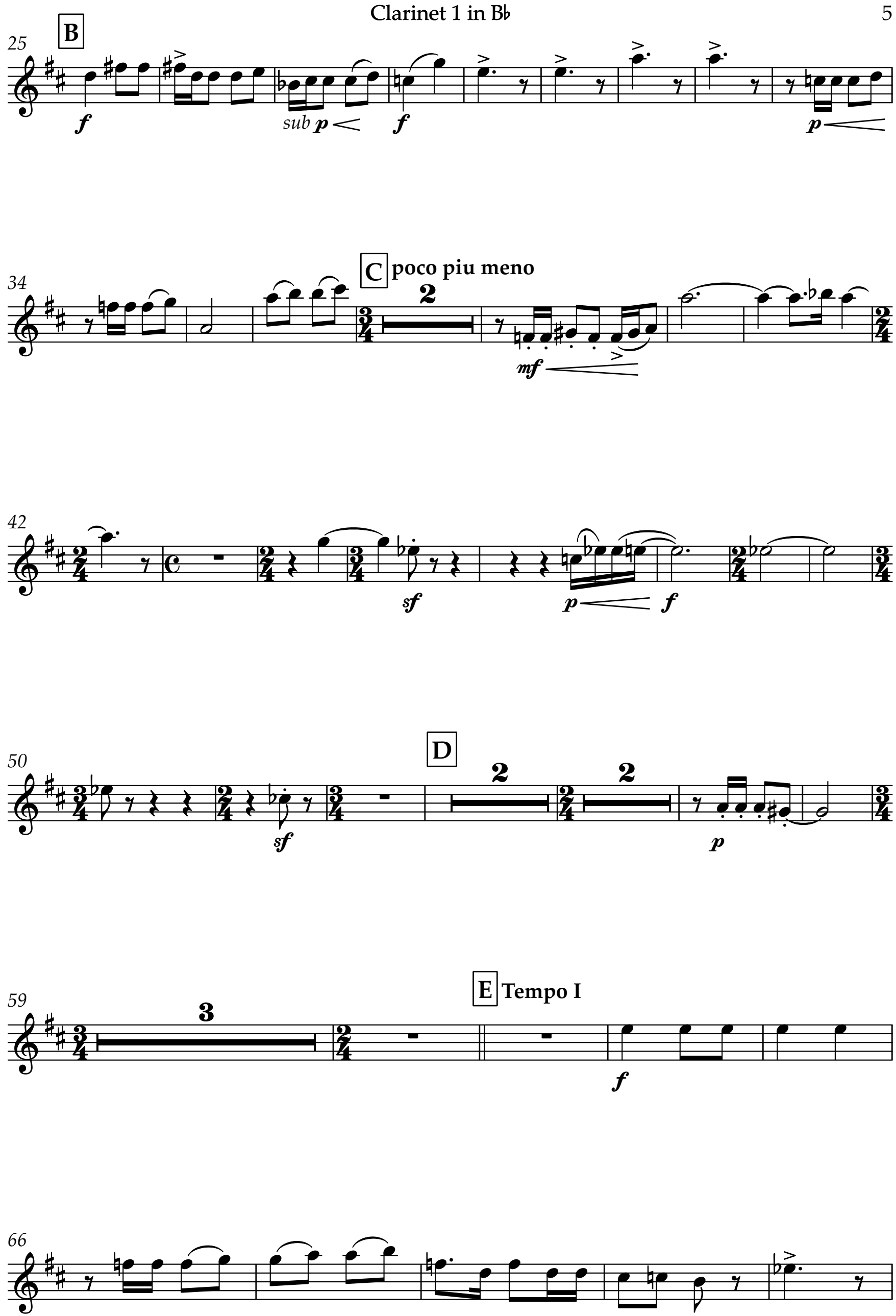
(6)

F

(5)

(g) (6) (6) 121 I

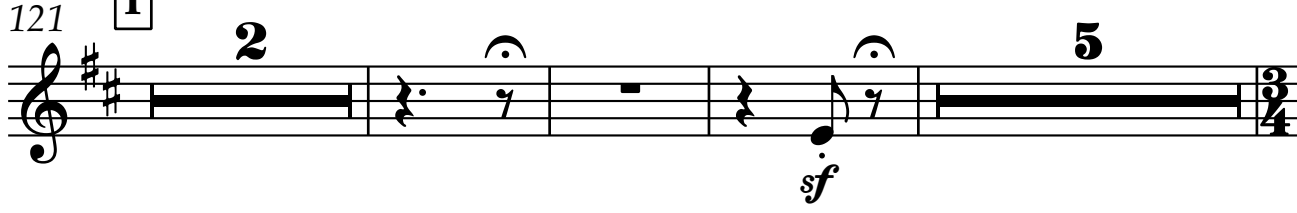
2

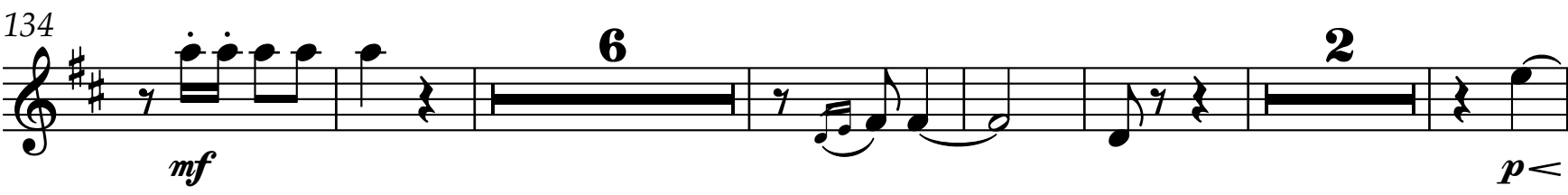
148 J

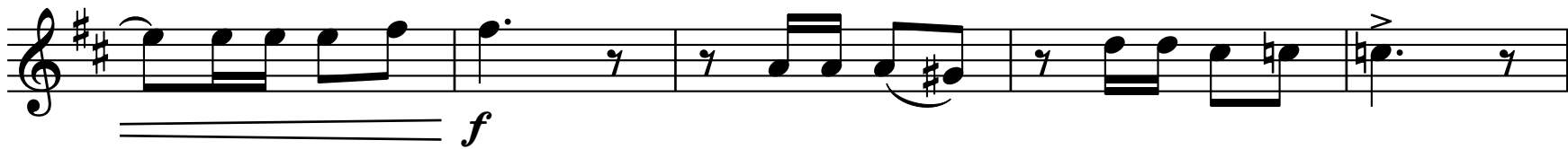

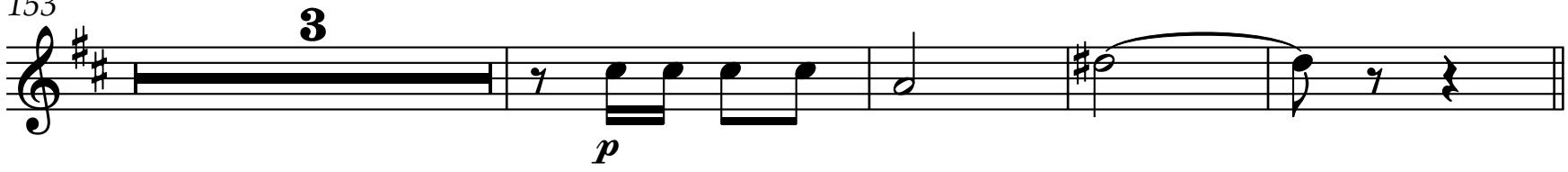



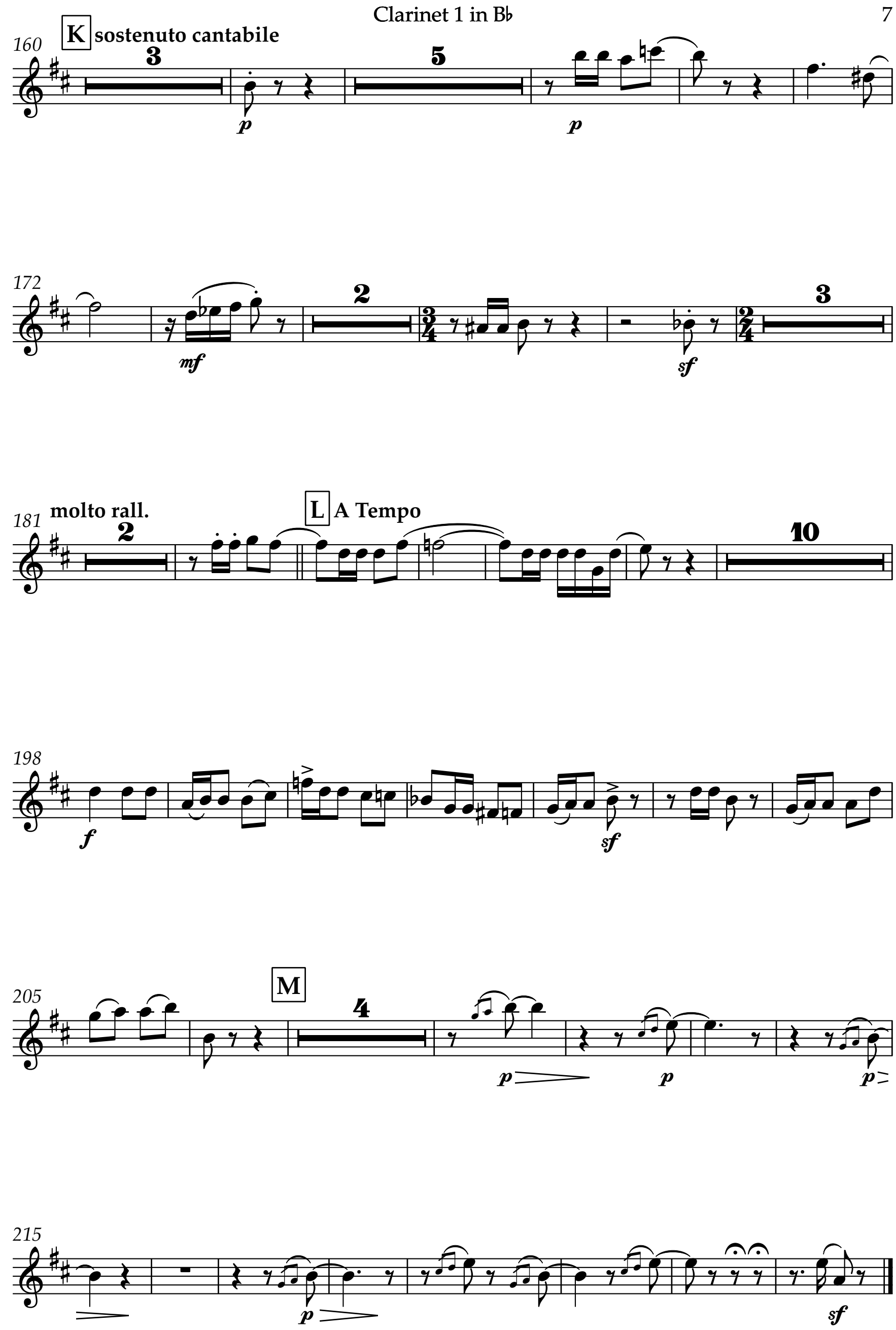


\section{Clarinet 2 in $\mathrm{Bb}$}

\section{Concerto for Viola and Orchestra I.}

Dmitris Dragatakis

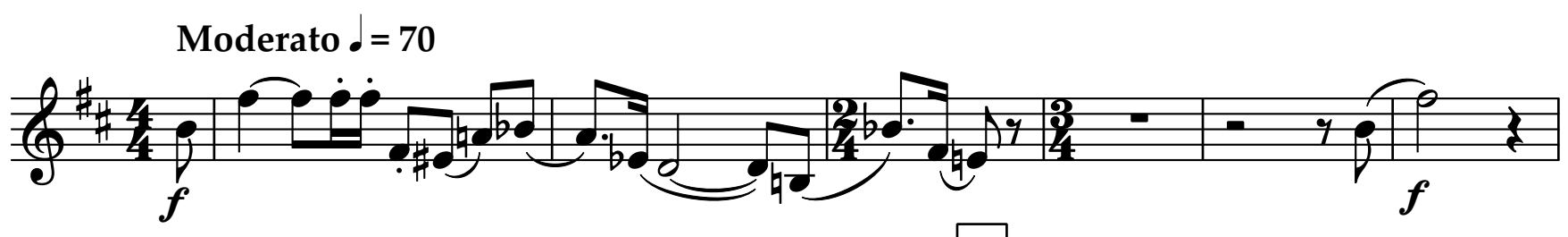

A
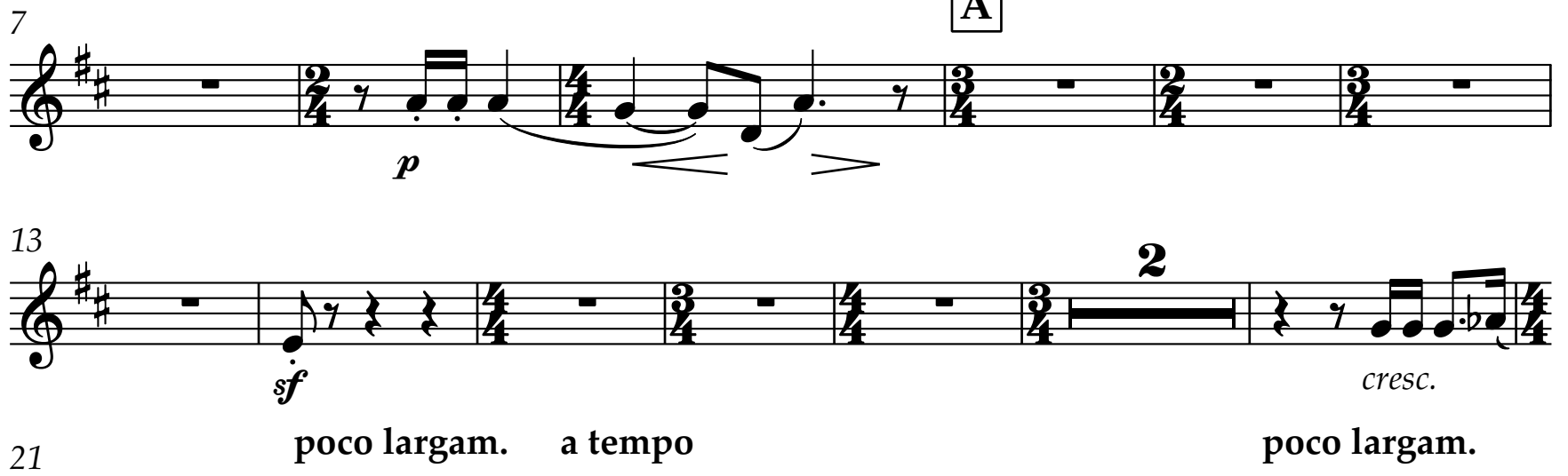

(9) a tempo

molto rall.

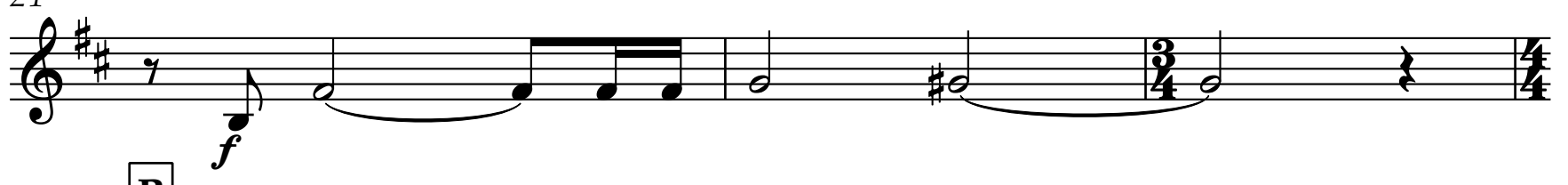

27 B a tempo

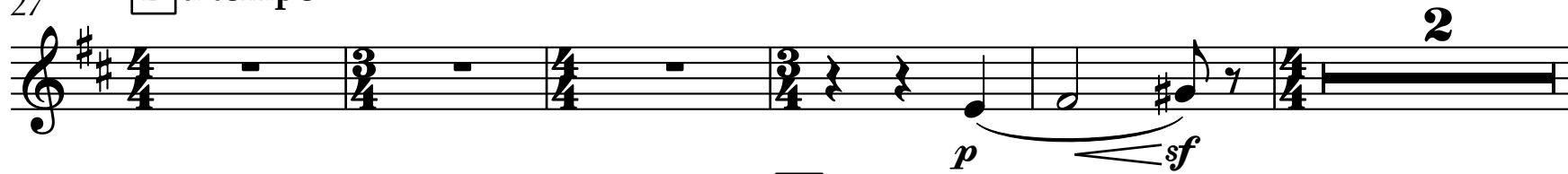

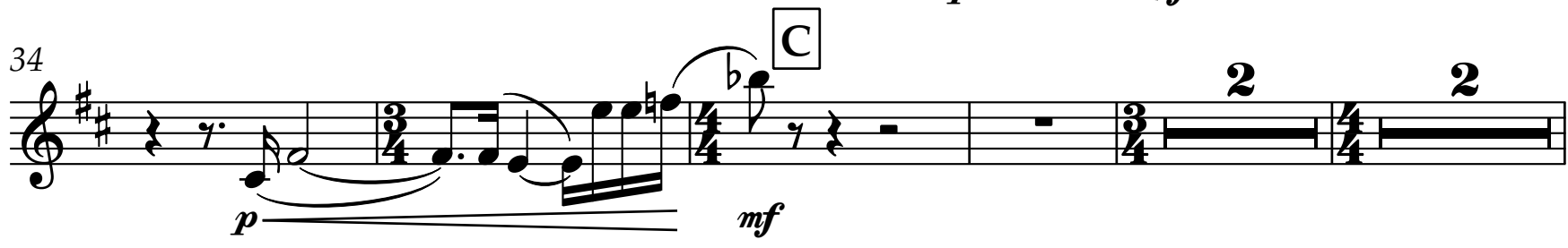

${ }_{0}^{42}$

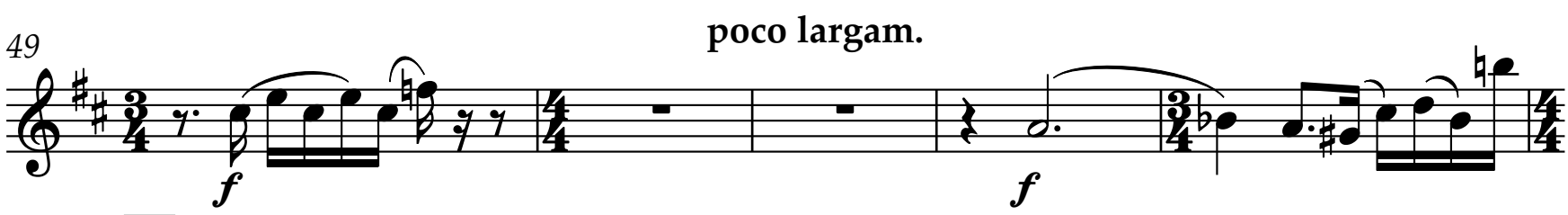

$54 \quad \mathbf{D}$ poco sostenuto

(4) 

60 molto rall
E a tempo

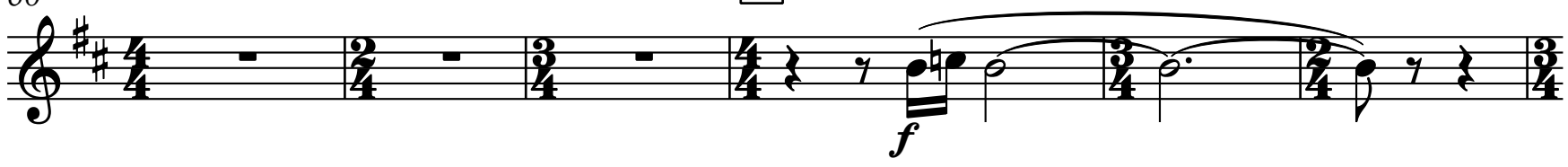

66

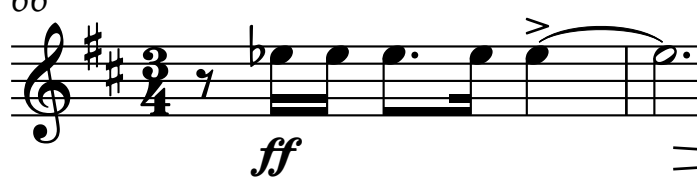
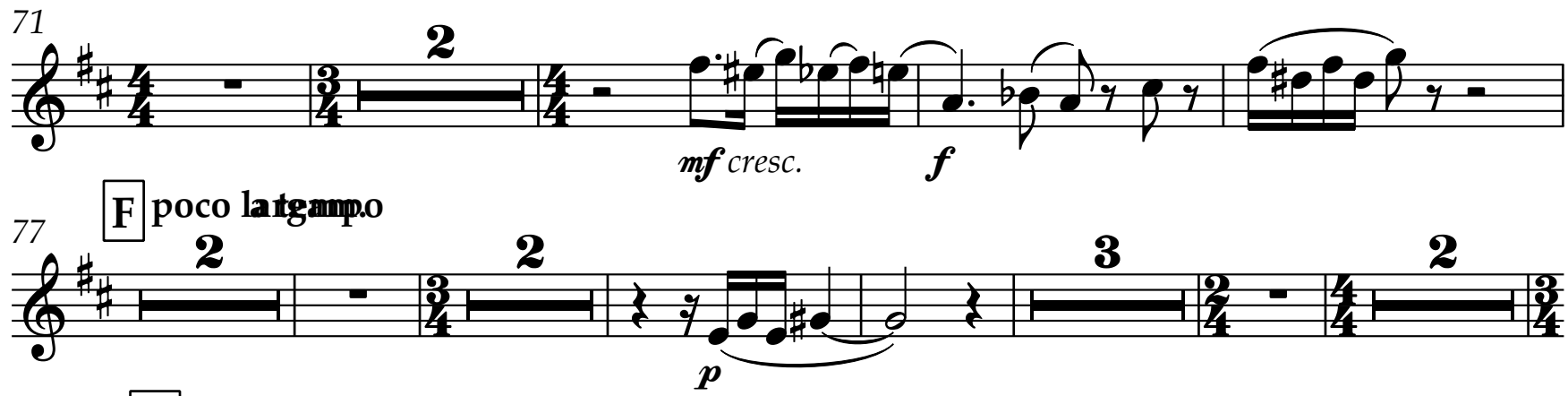

$90 \quad \mathbf{G}$

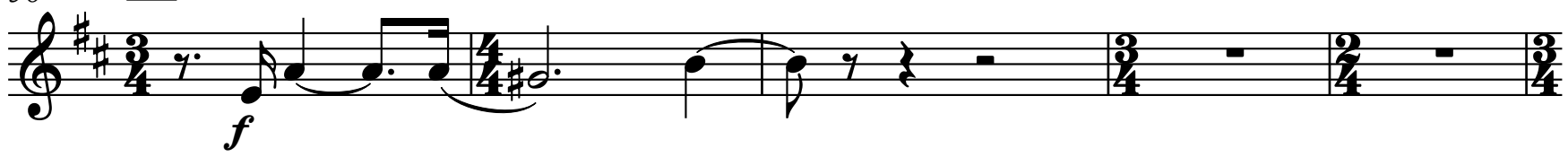

95 Più larg.

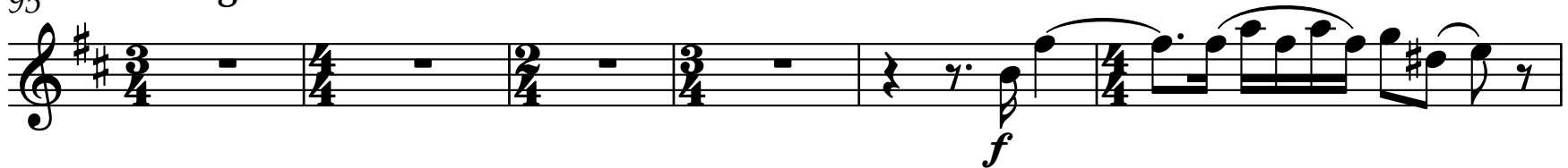

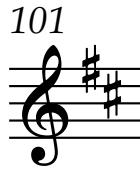

105 molto rall.

(5)

poco sostenuto 2

117

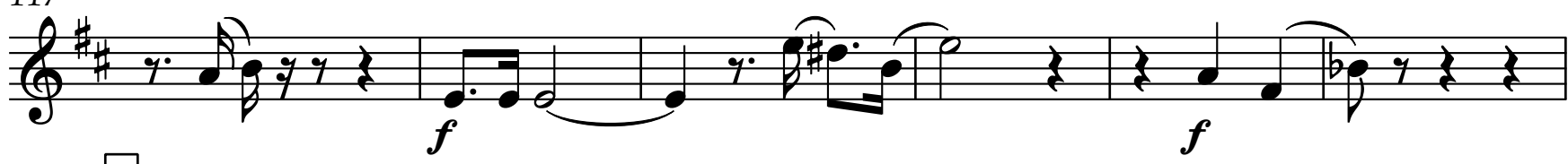

123 I

2

4

H a tempo 
Clarinet 2 in $\mathrm{Bb}$ 128

$2+4 \%$

Clarinet 2 in $\mathrm{Bb}$

2

Largamente

II.

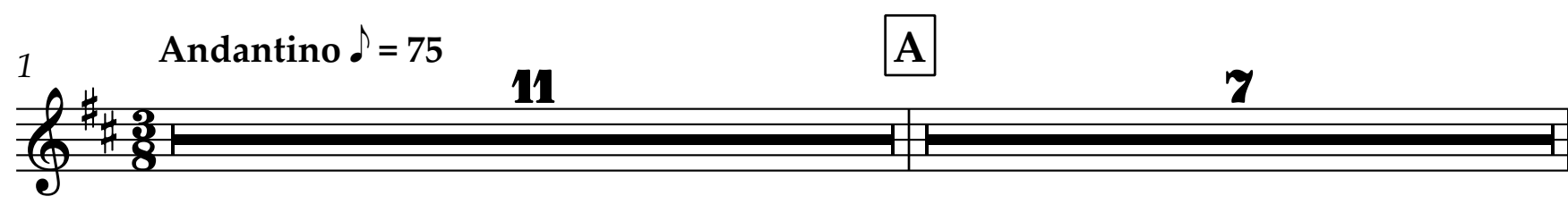

\begin{tabular}{l}
19 \\
\hline \\
\hline
\end{tabular}
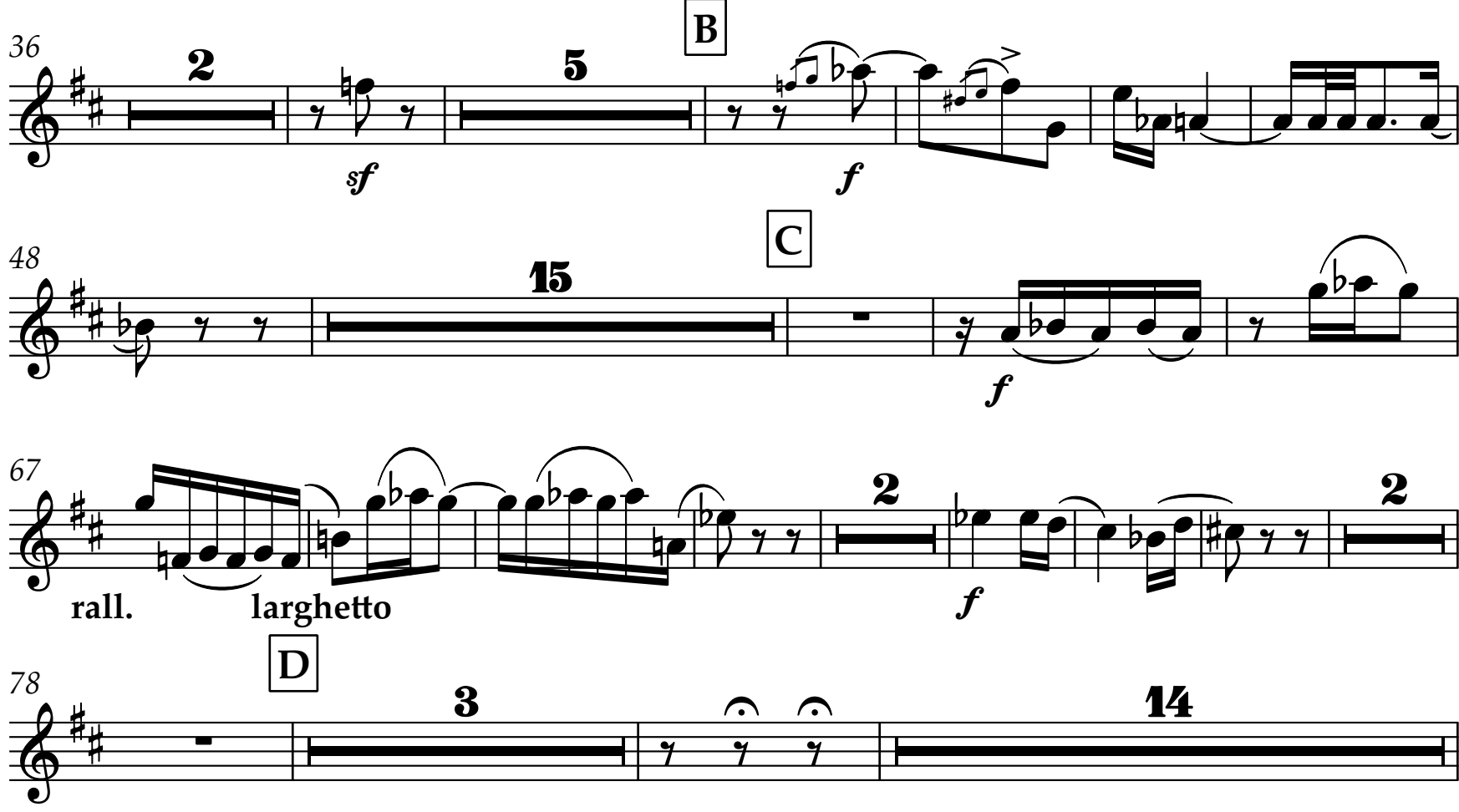

14

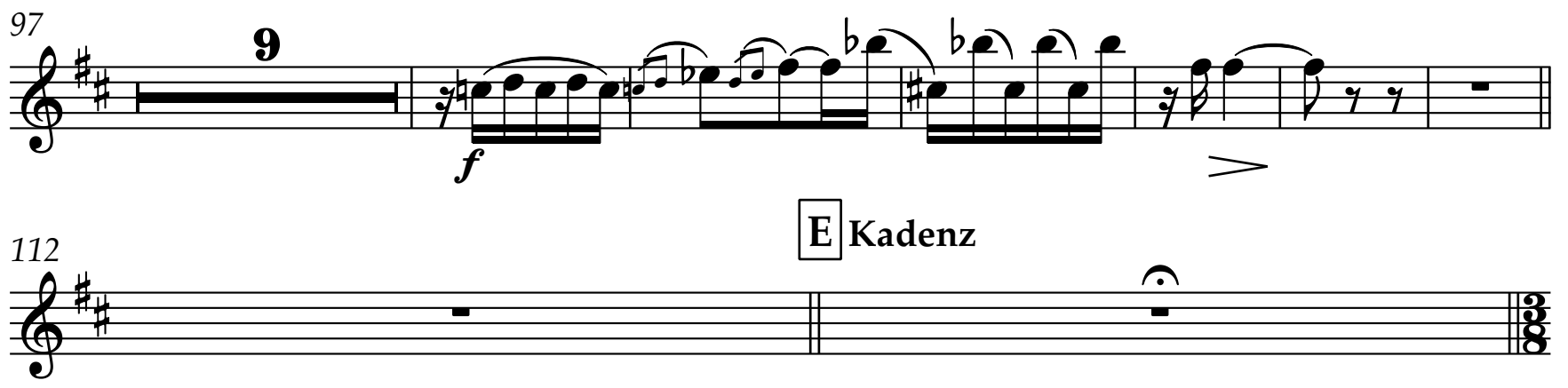


$\underset{113}{£}\left\{\begin{array}{c}\mathbf{F} \\ \text { tempo I }\end{array}\right.$

Clarinet 2 in $\mathrm{Bb}$

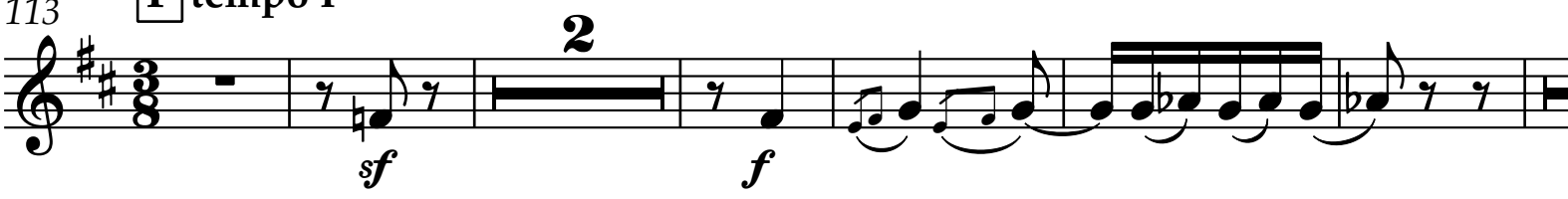

123

3

30

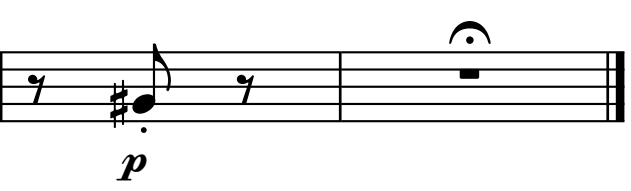

III.
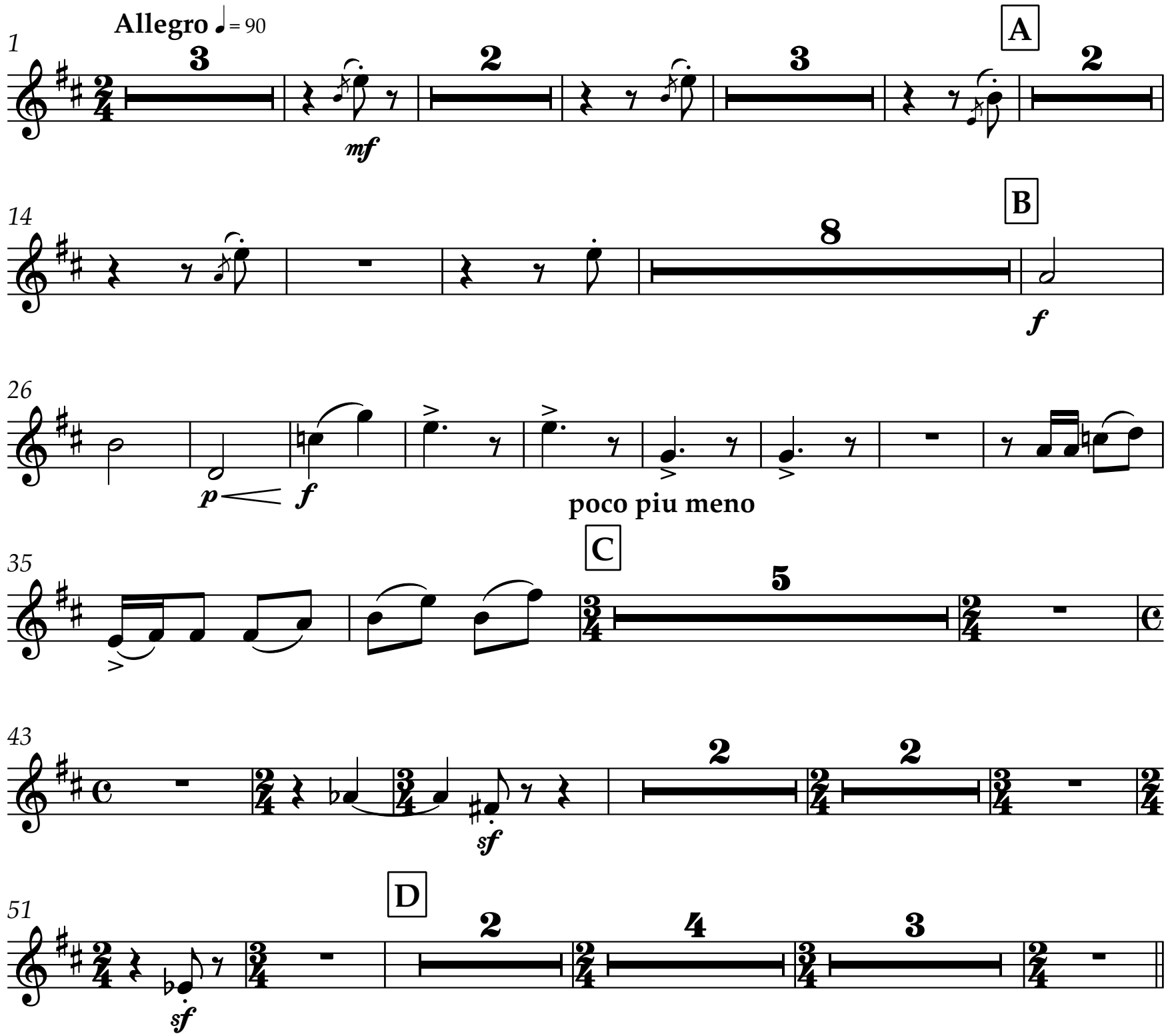

63 E Tempo I

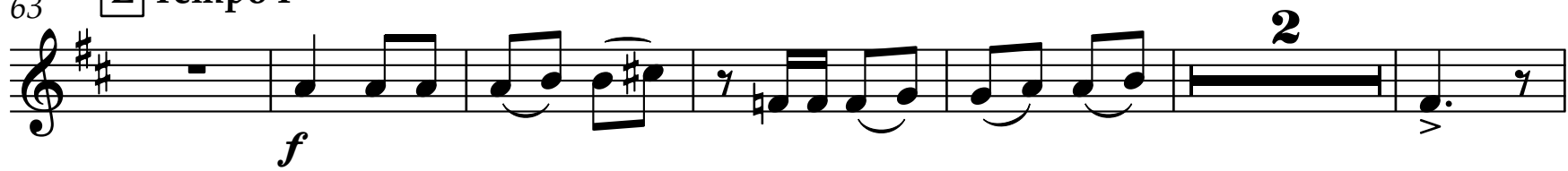



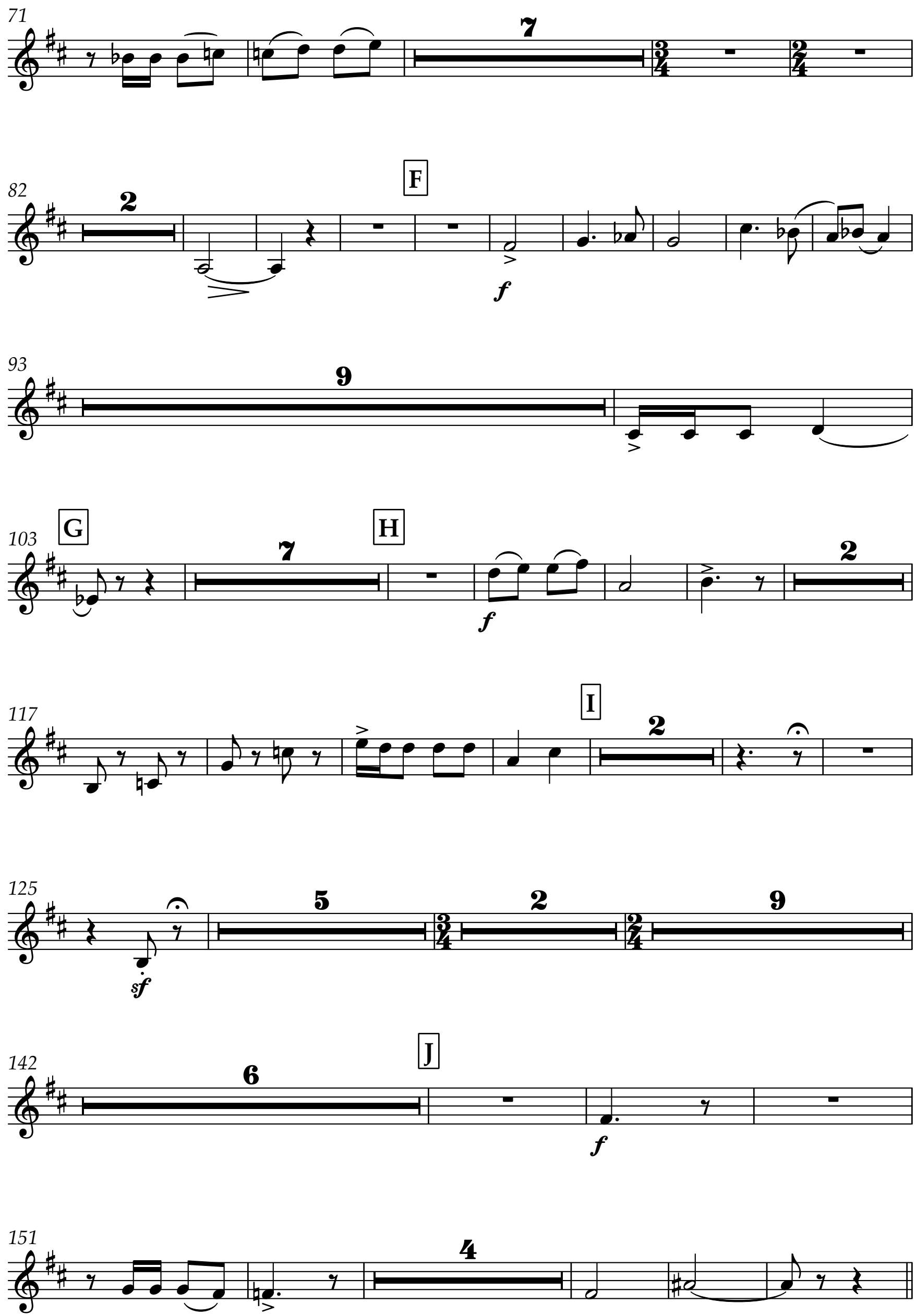
6
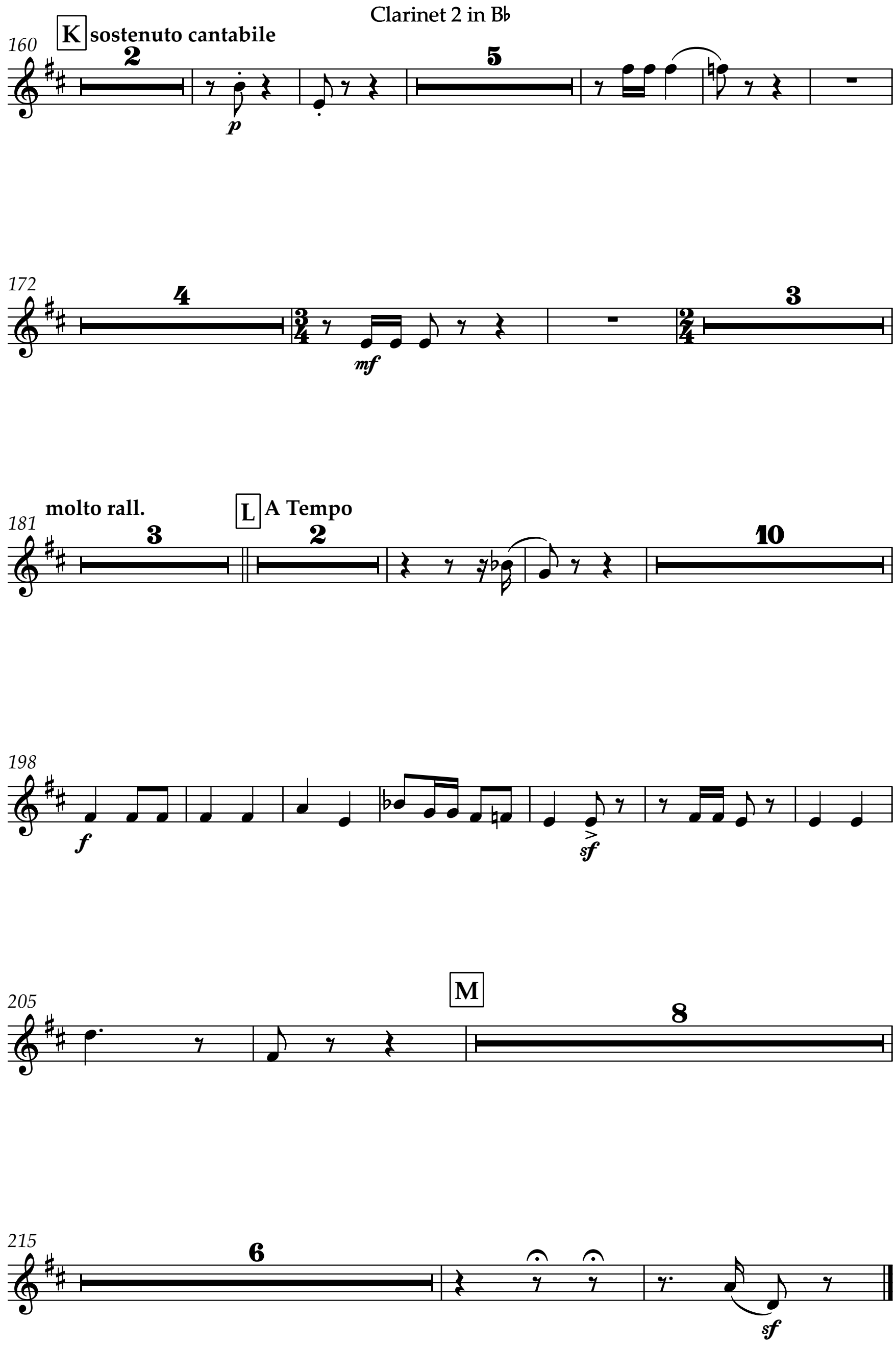
Bassoon 1

\section{Concerto for Viola and Orchestra}

Dmitris Dragatakis
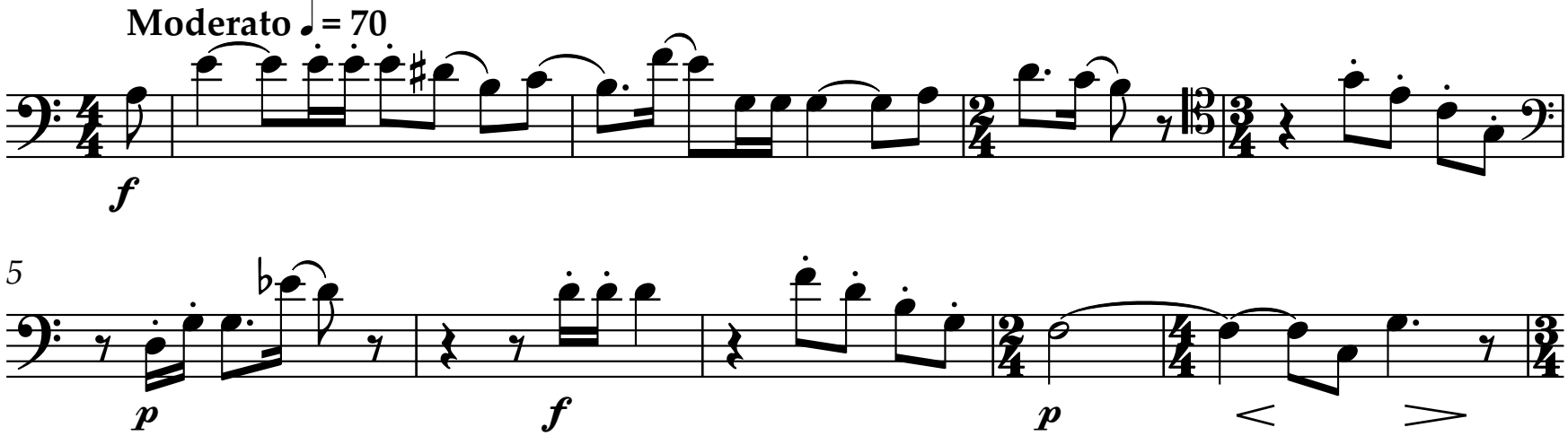

10 A

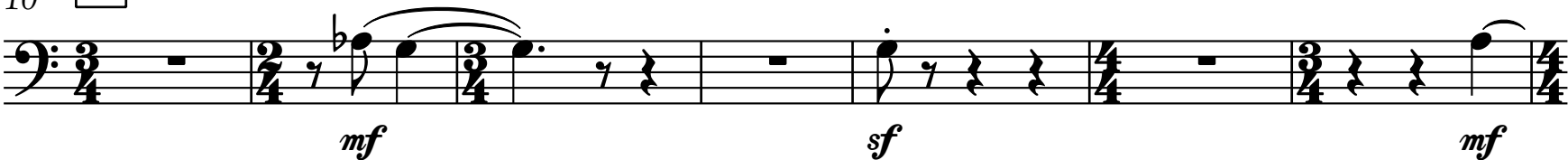

17

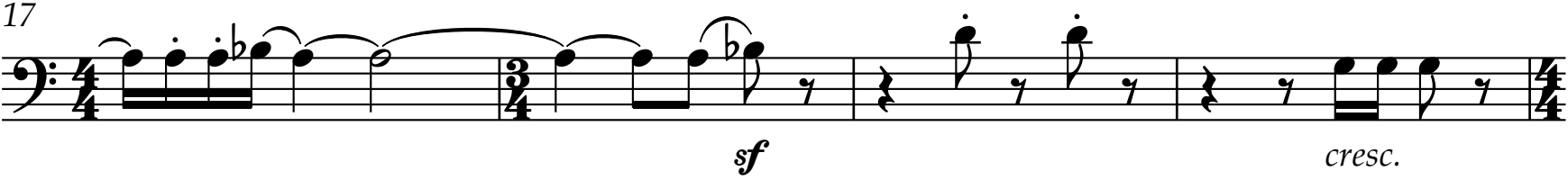
21
poco largam. a tempo
poco largam.

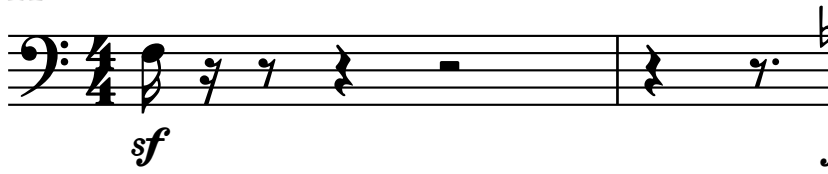

a tempo

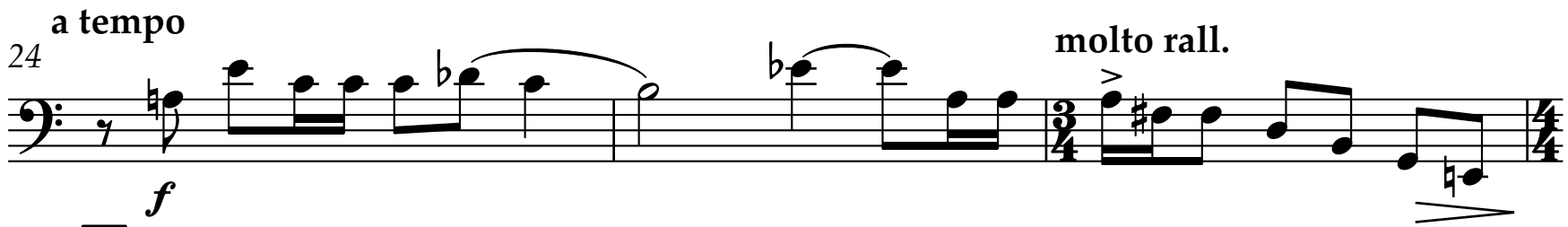

27 B a tempo

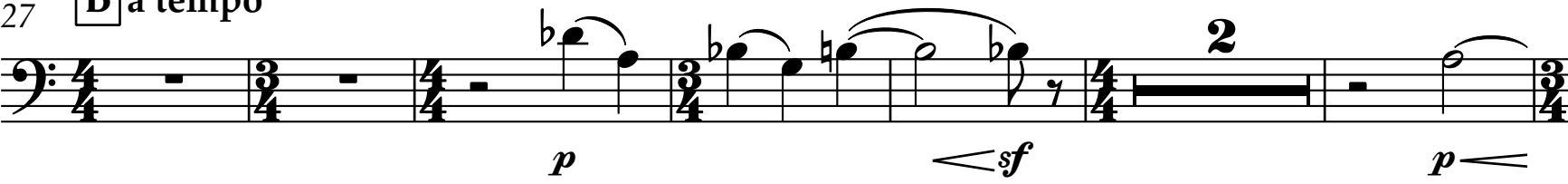

35

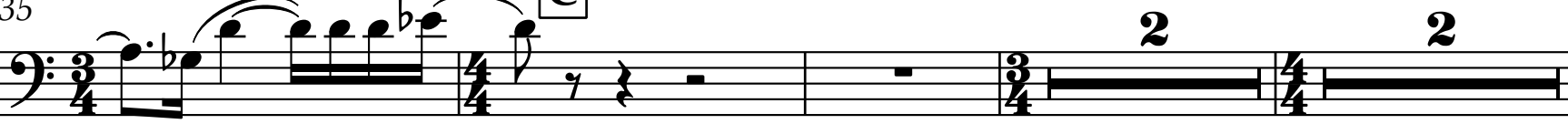
$m f$

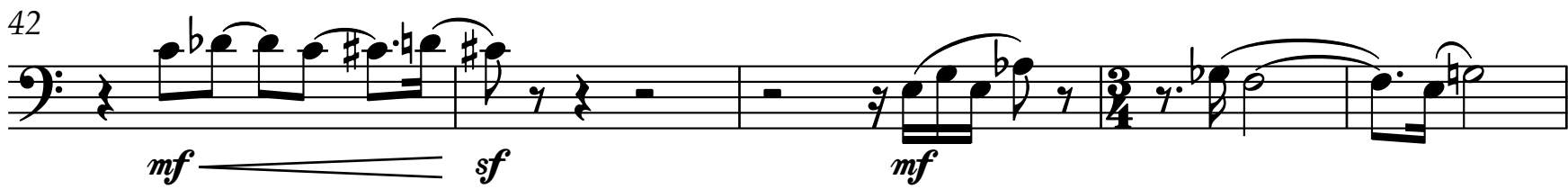

poco largam.

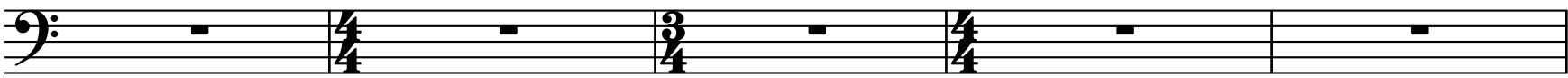




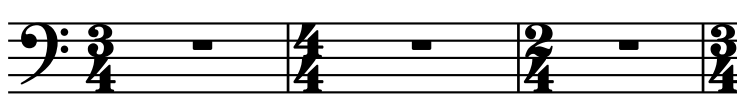
$\frac{49 q}{4}$

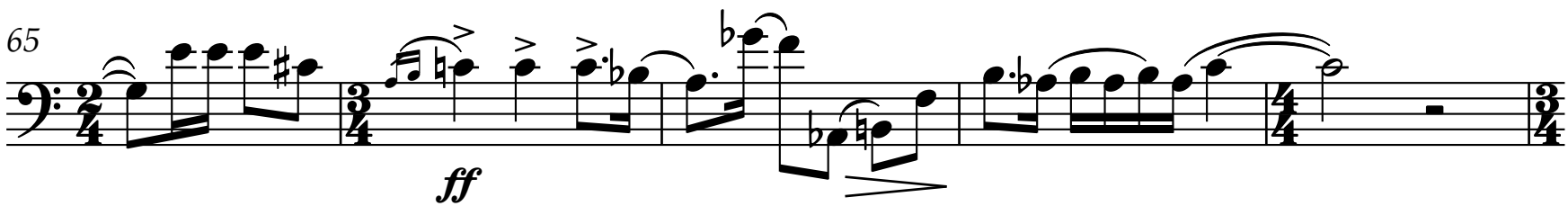
70:3\%

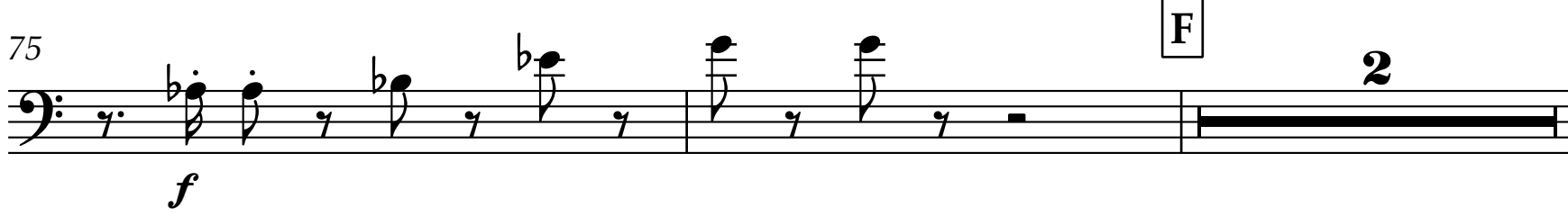
79 a tempo

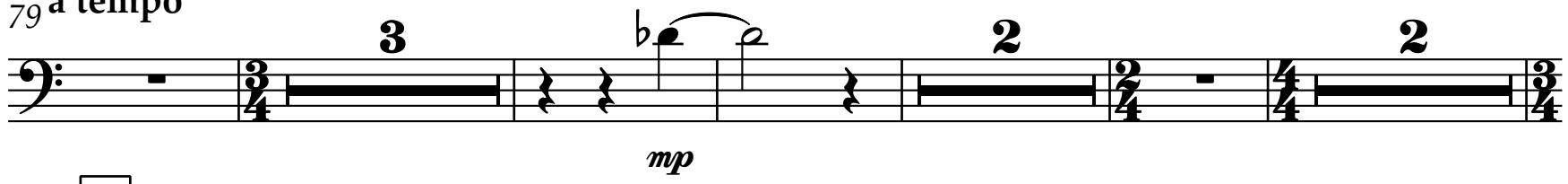

$90 \mathbf{G}$

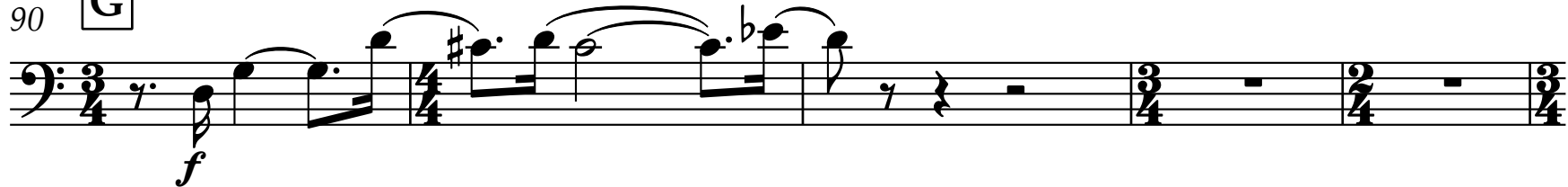
95 Più larg.
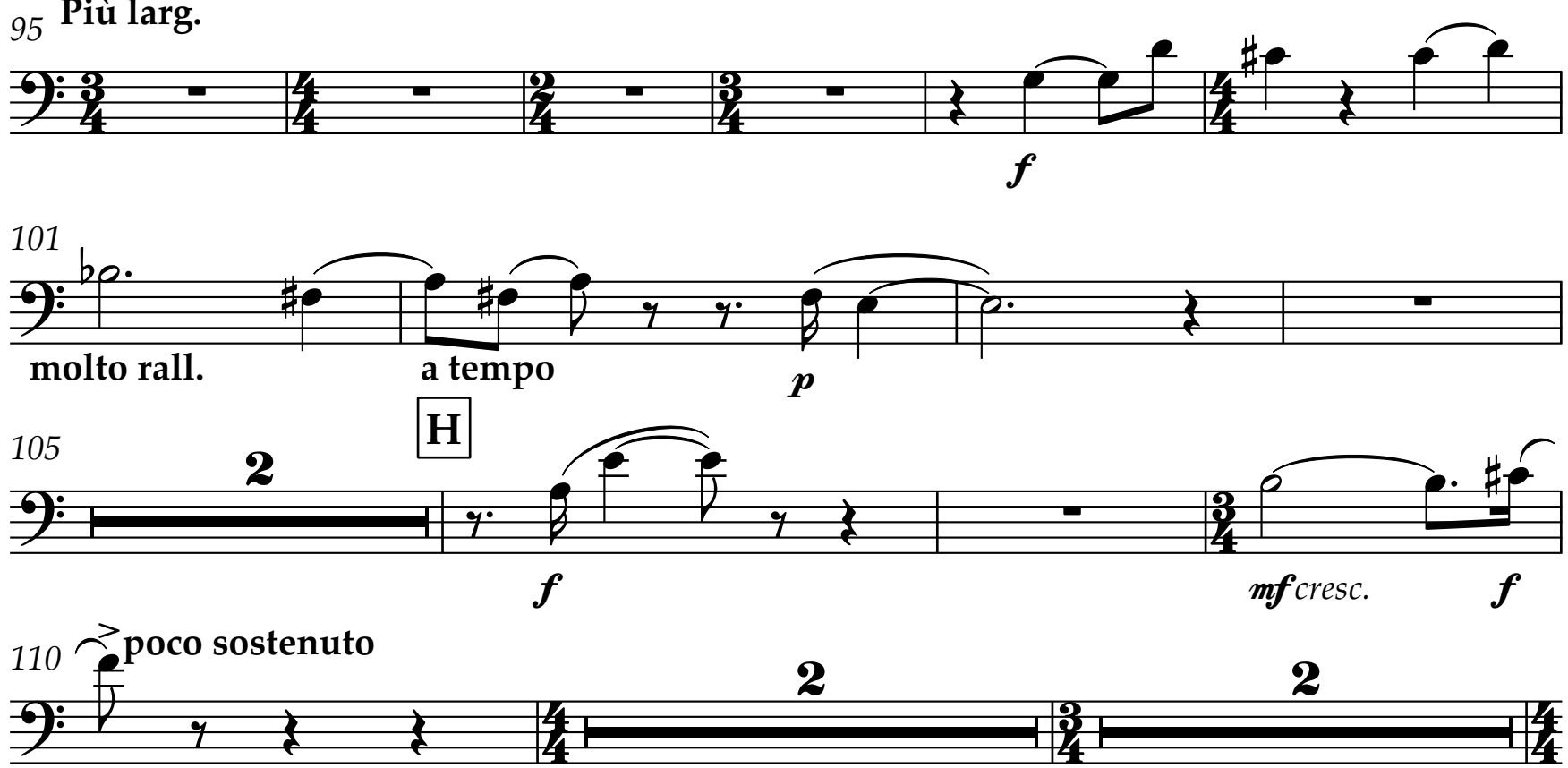

2 
Bassoon 1

Bassoon 1

F
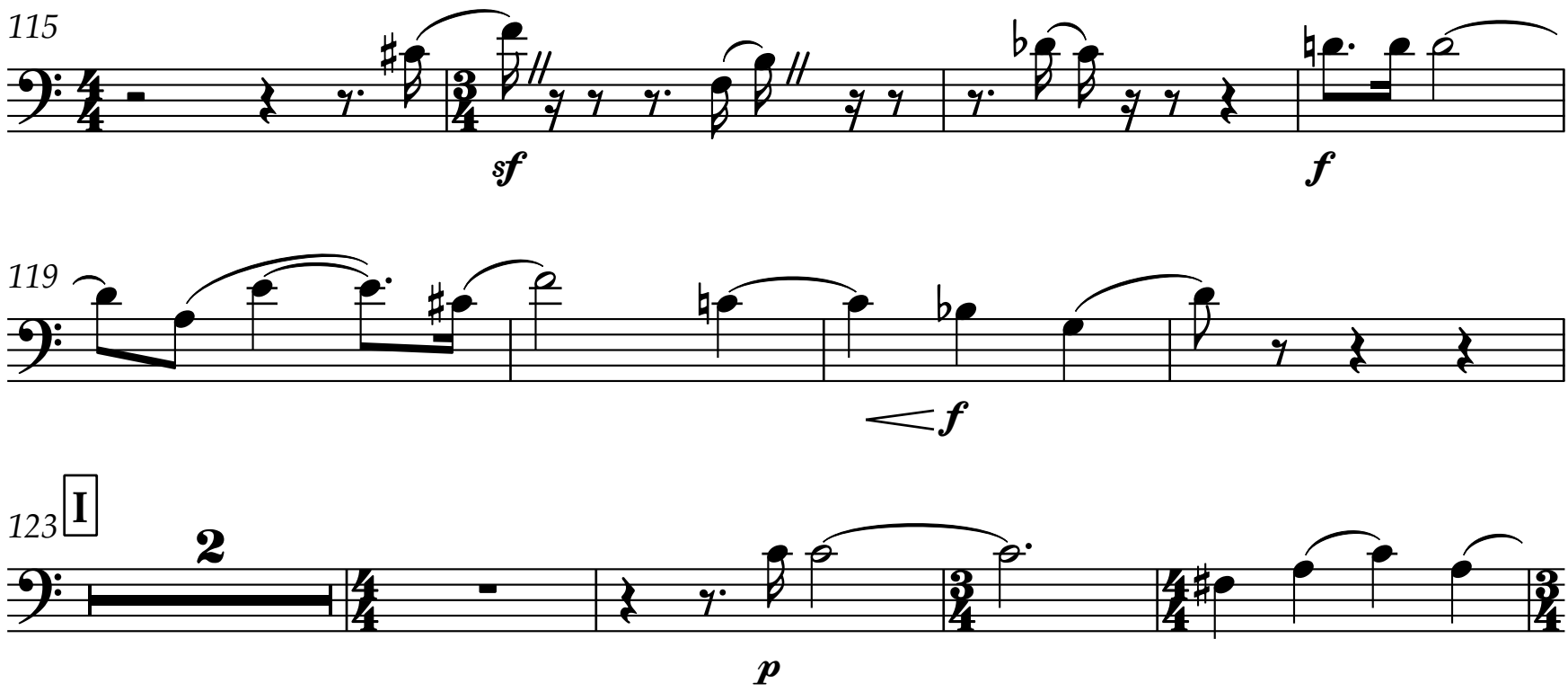

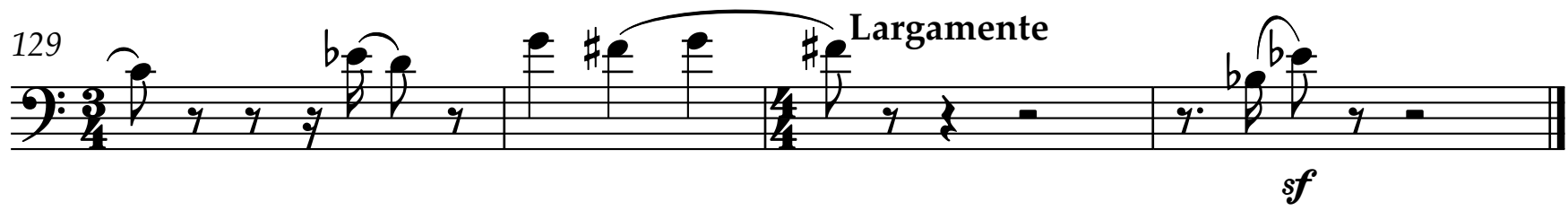

II.

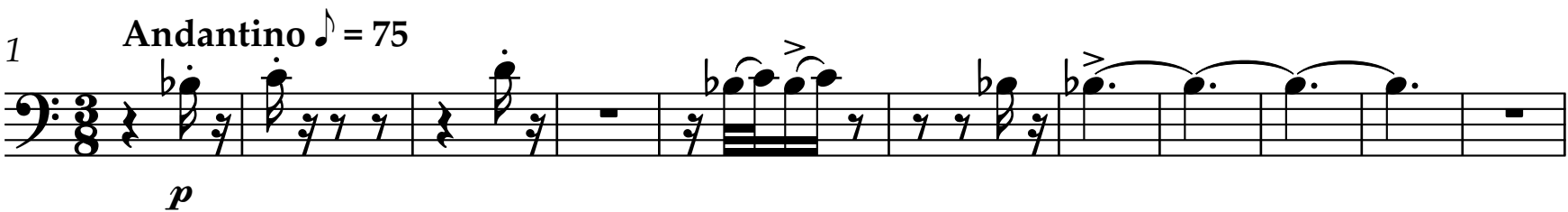
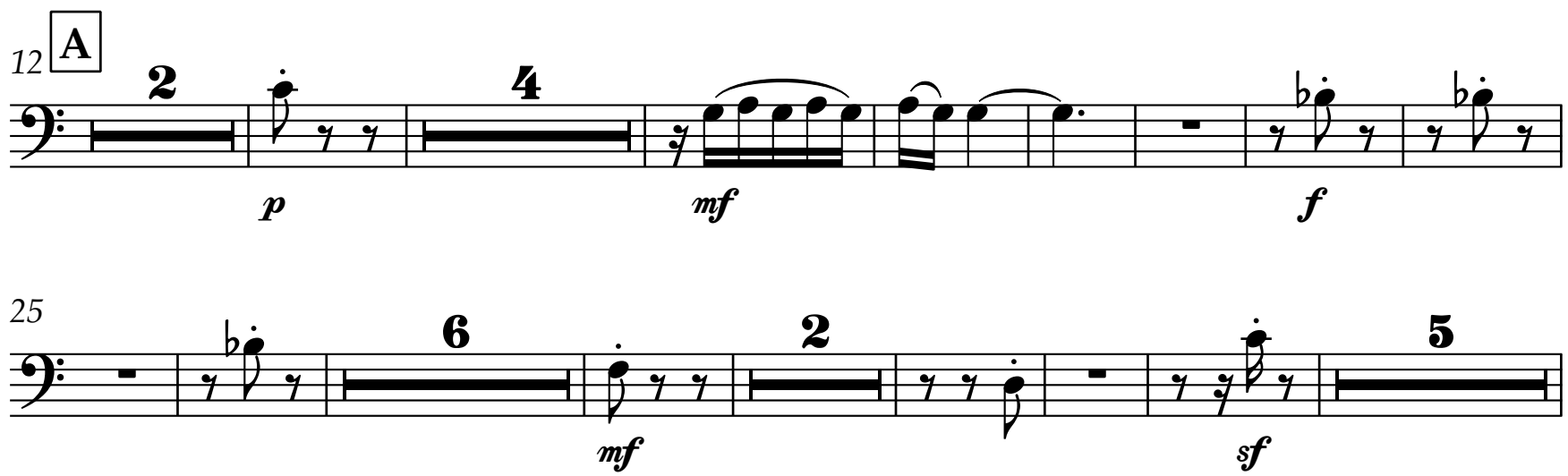

B

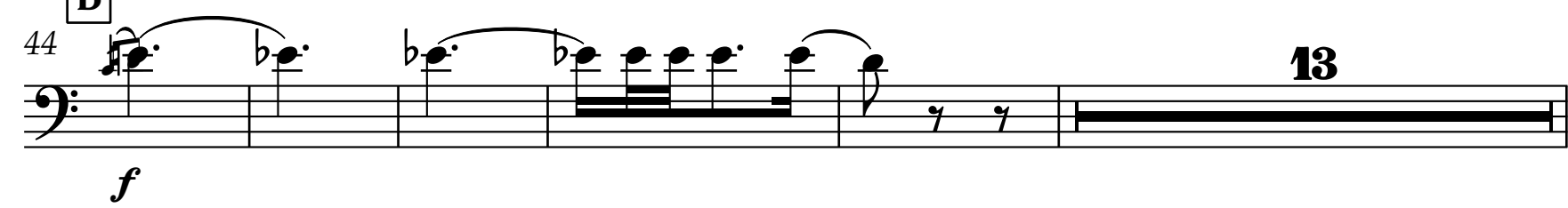


4

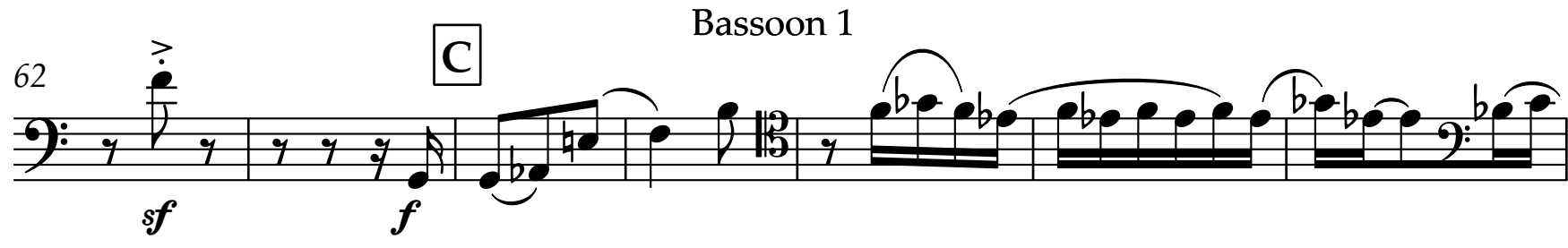

9:- If $y=0$

rall. larghetto
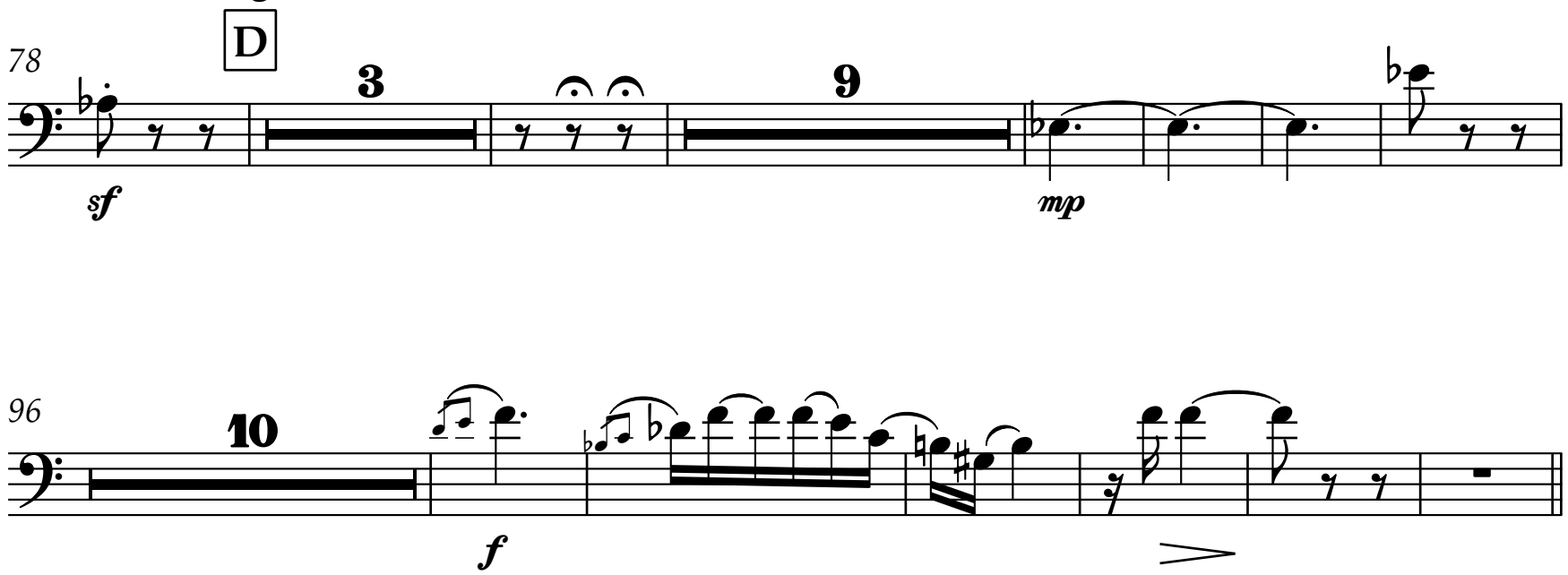
112
E Kadenz

$7 \%$

113 F tempo I

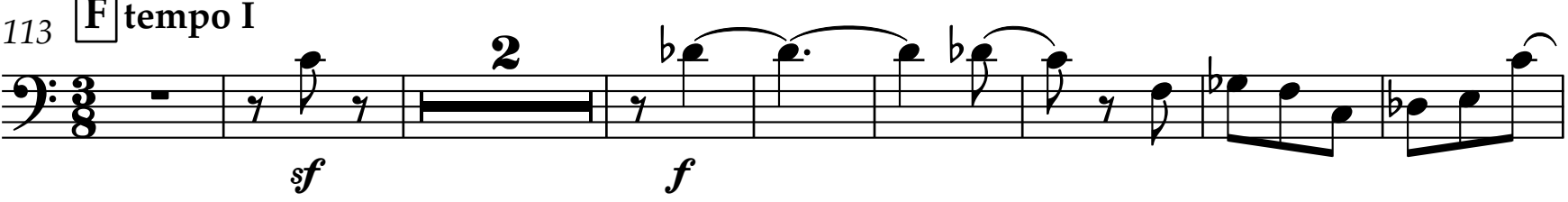

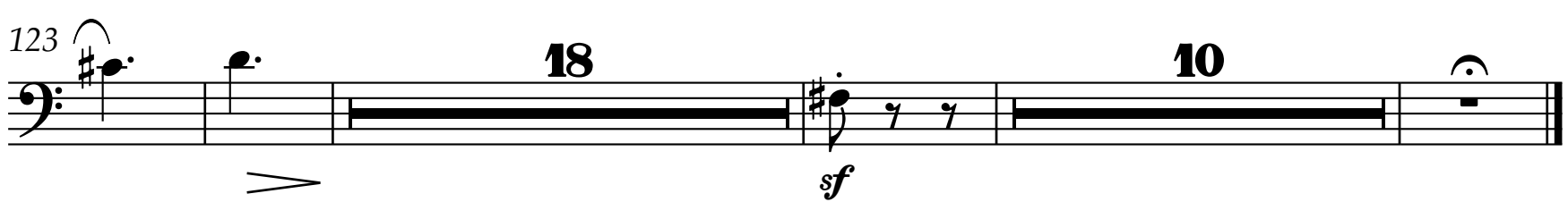




\section{III.}

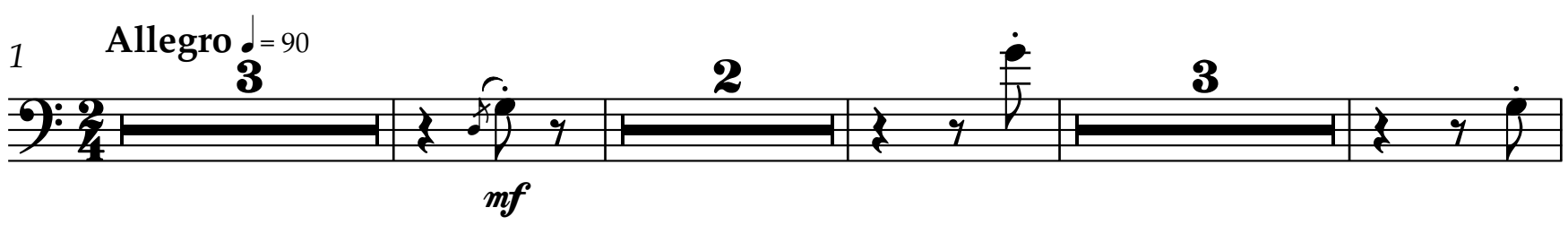

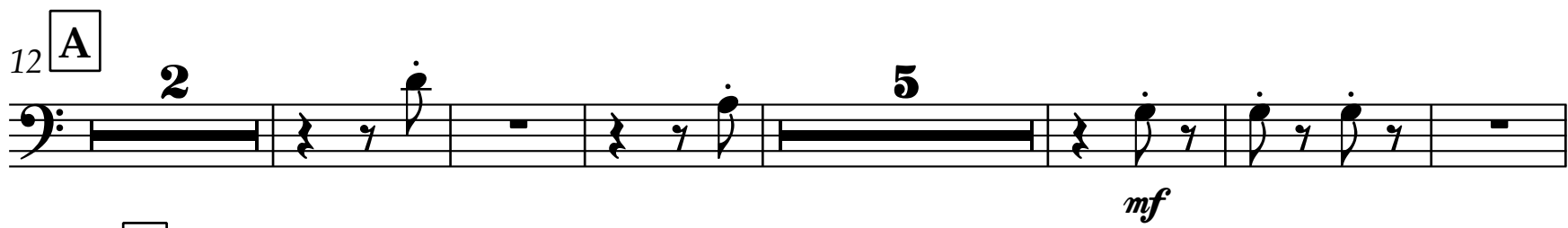

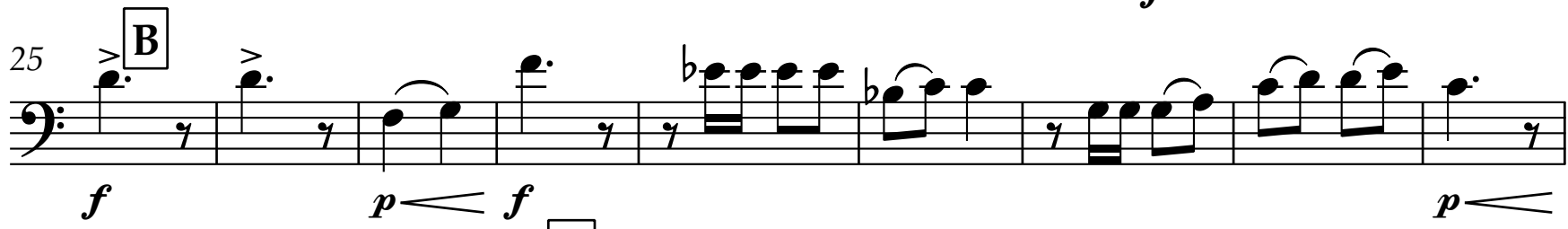

9): C poco piu meno

43

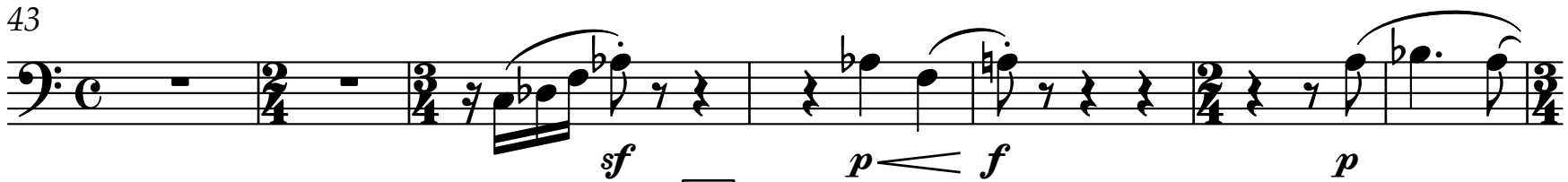
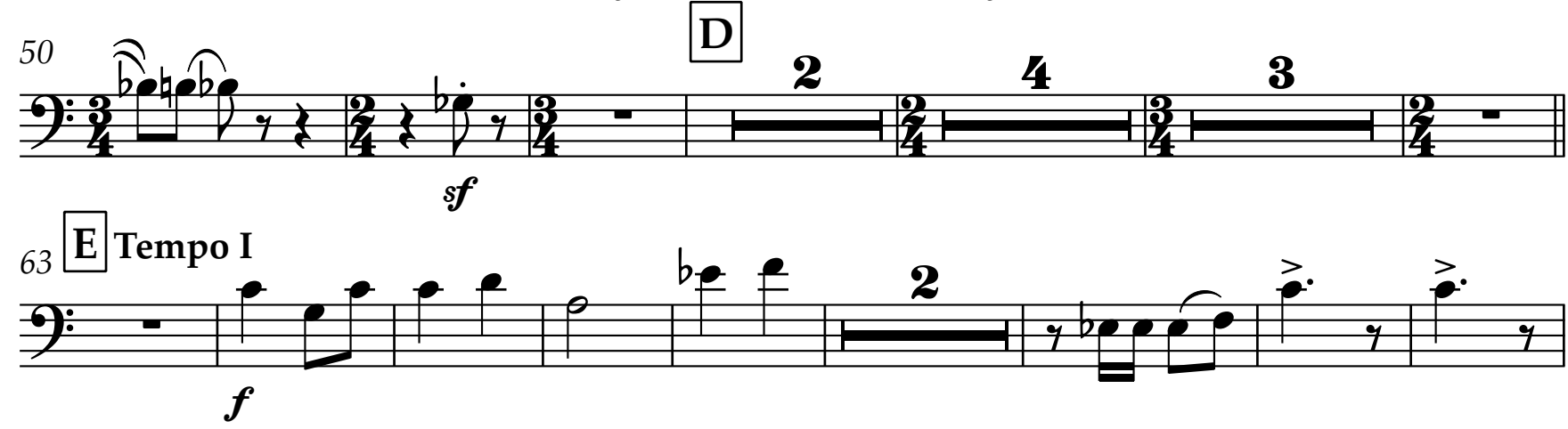

9
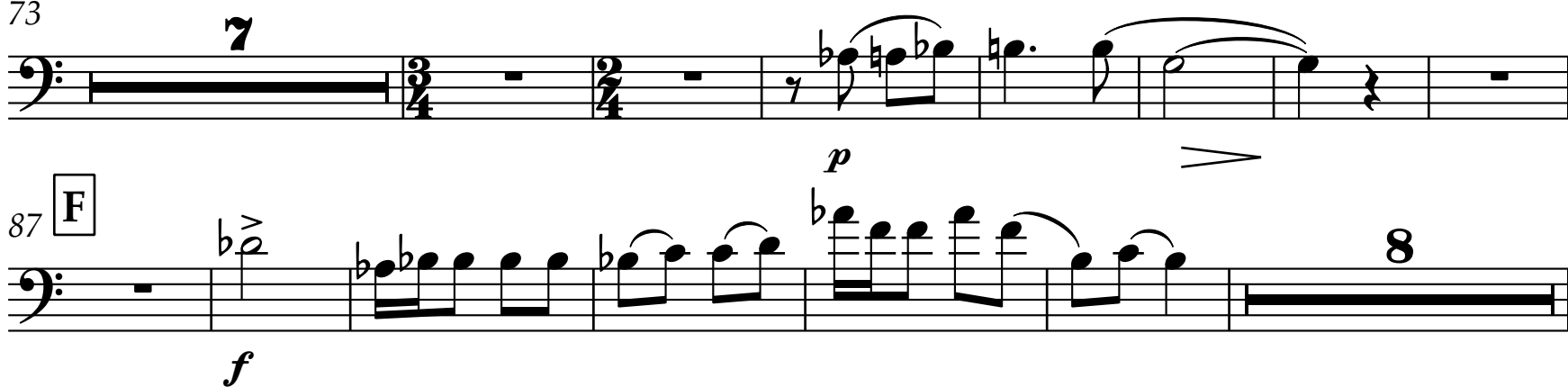

8 
6

Bassoon 1
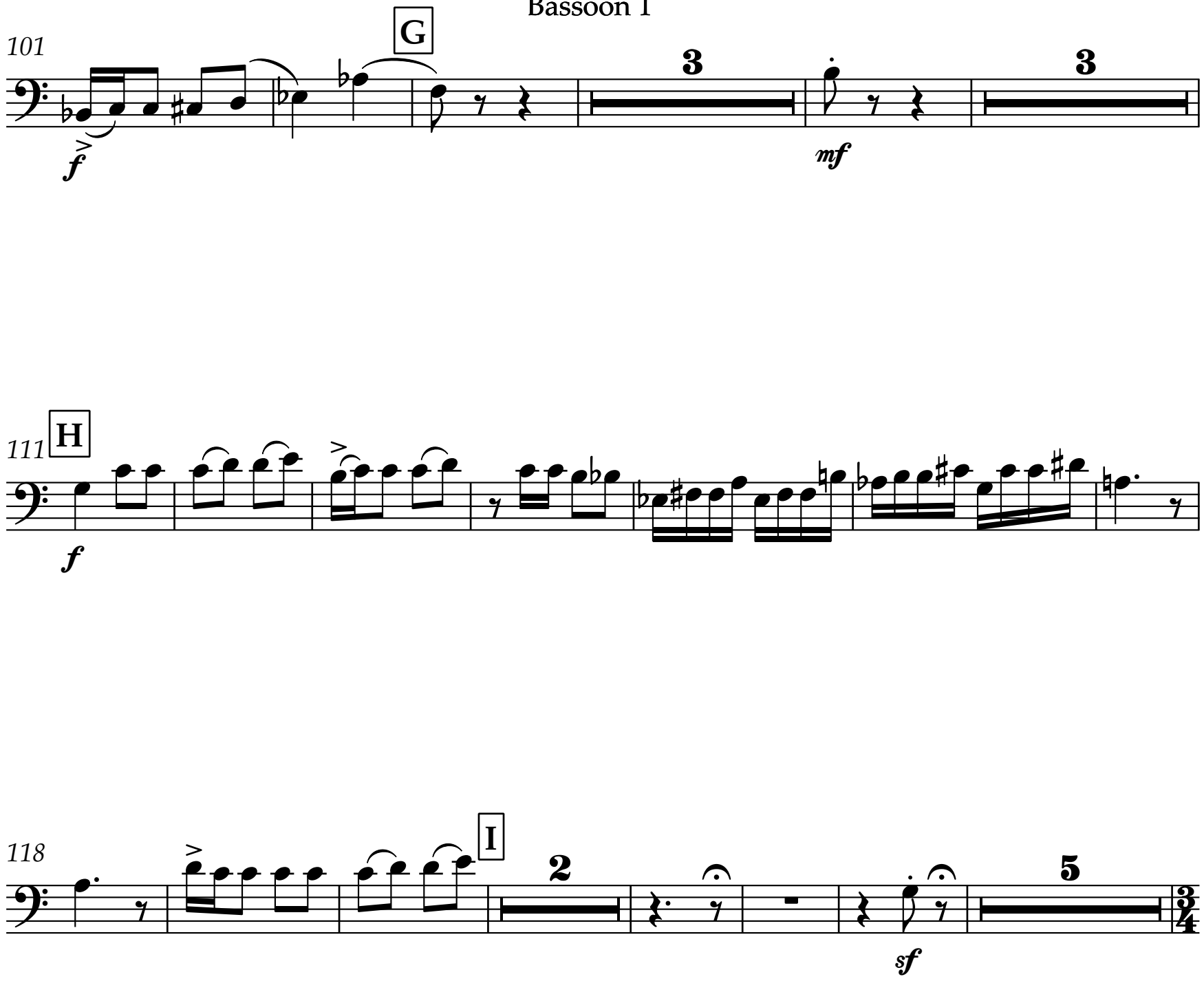

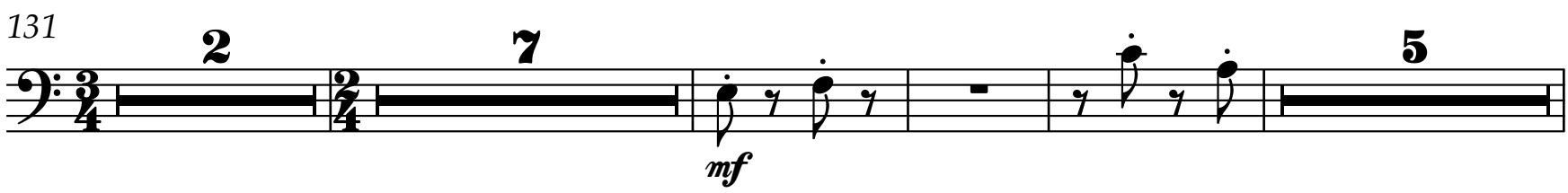

${ }_{148}^{14}$ [I

F. 


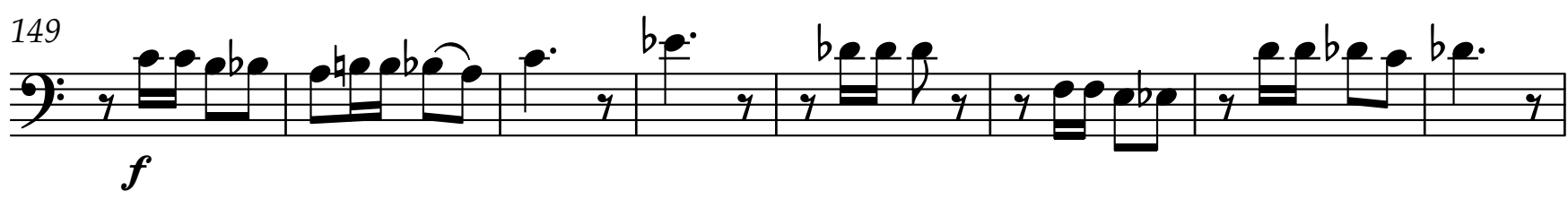
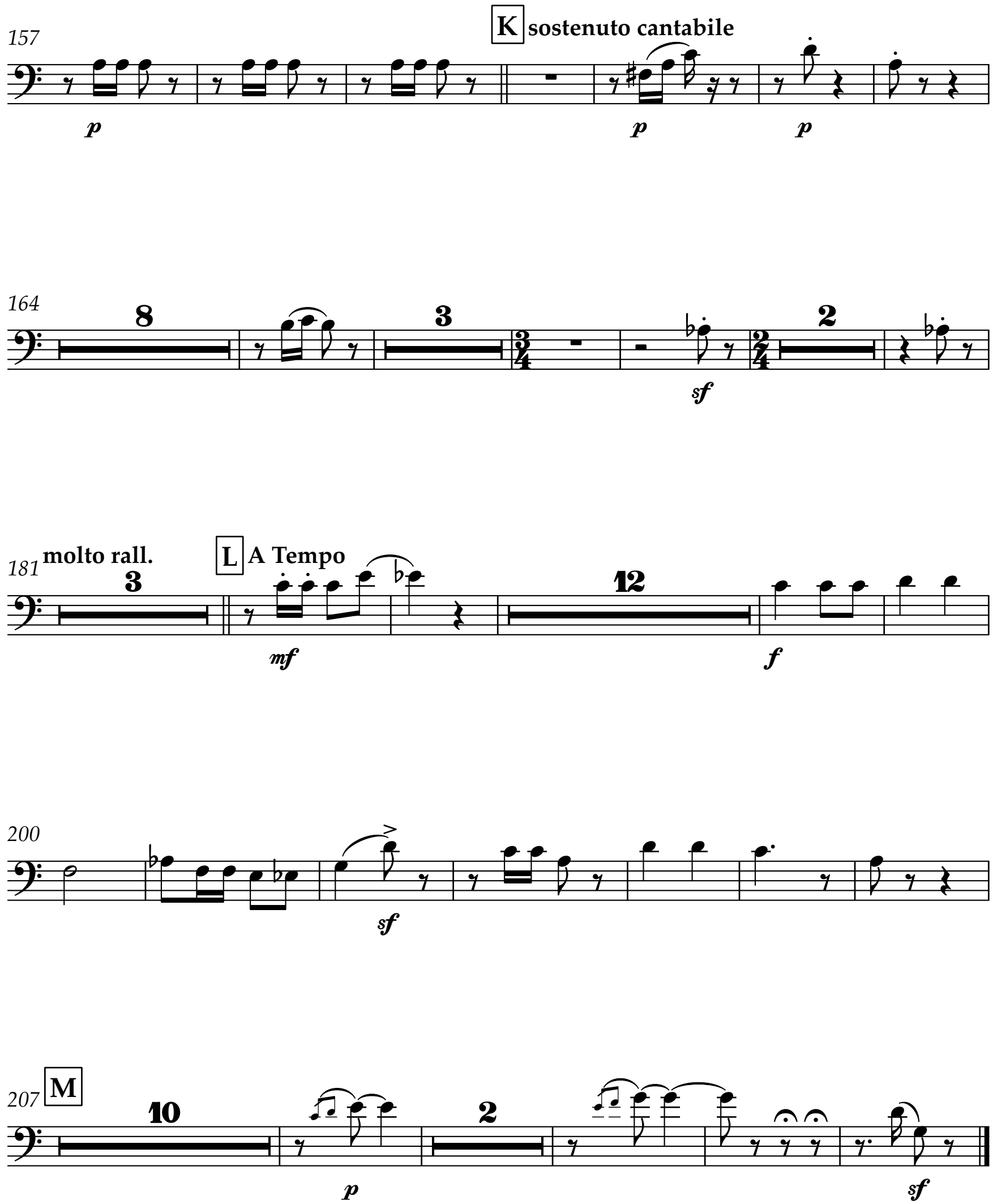
Bassoon 2

Concerto for Viola and Orchestra I.

Dmitris Dragatakis

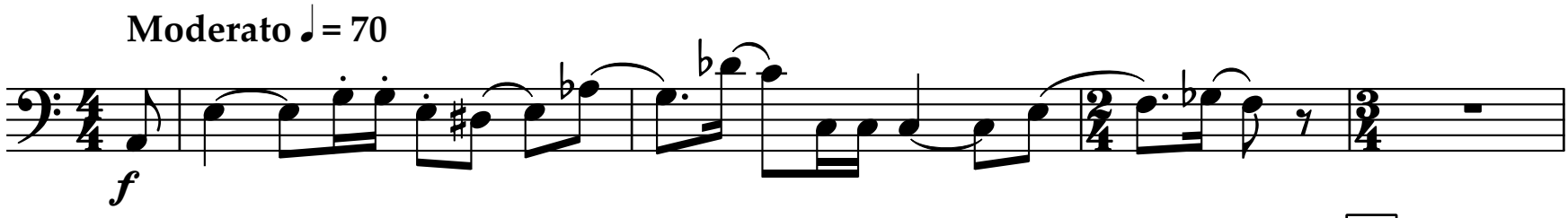

A

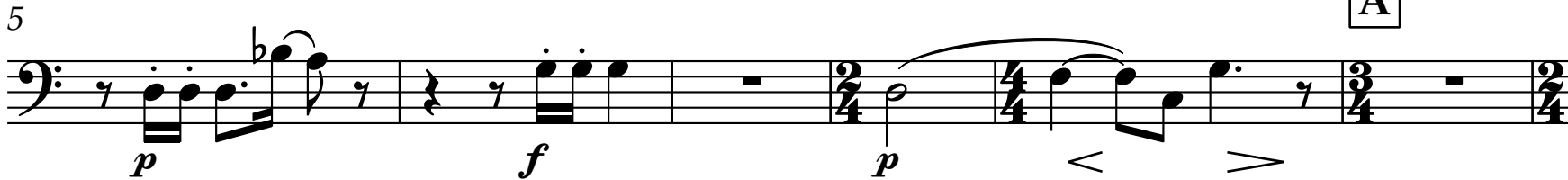

11

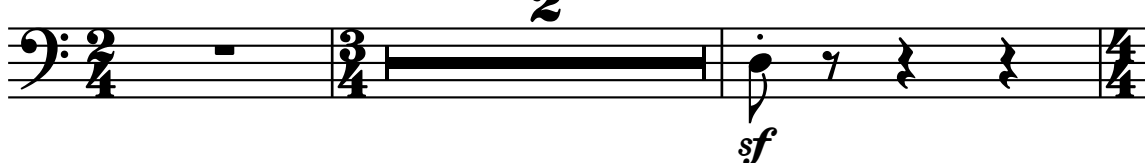

17

F"

cresc.

21 poco largam. a tempo poco largam.

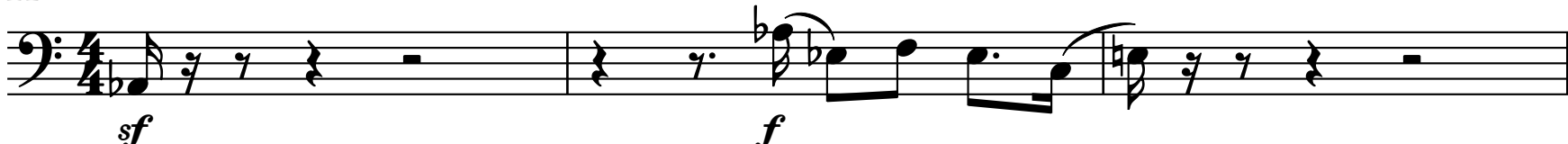
a tempo molto rall.

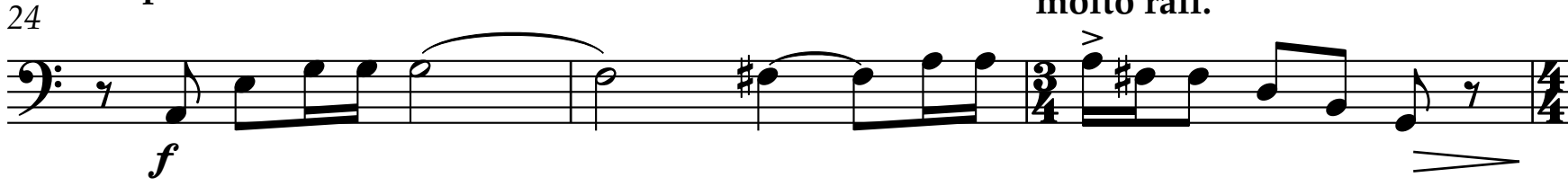

27 B a tempo

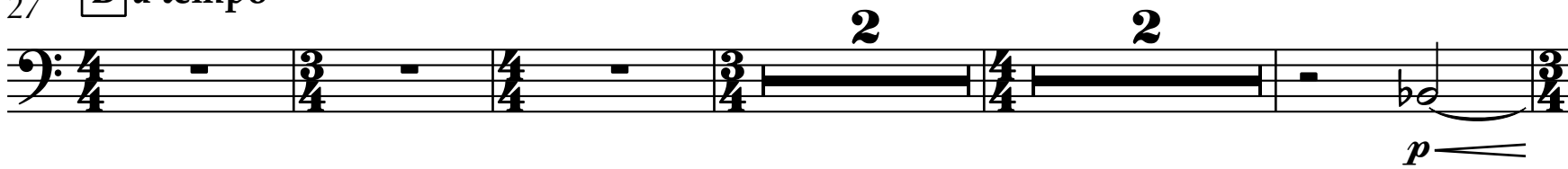

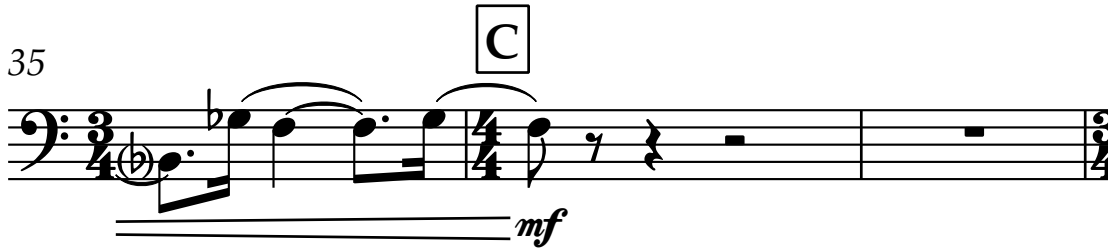

2

2

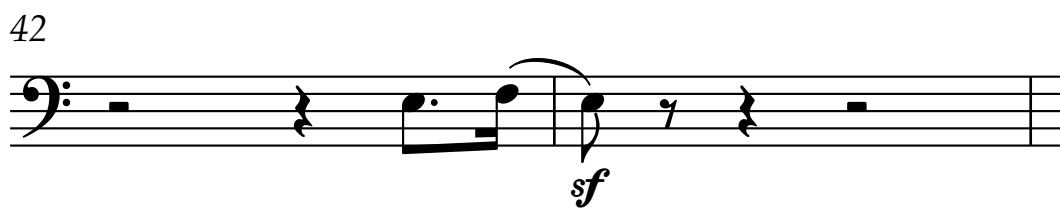

$\mathbf{2}$

poco largam.

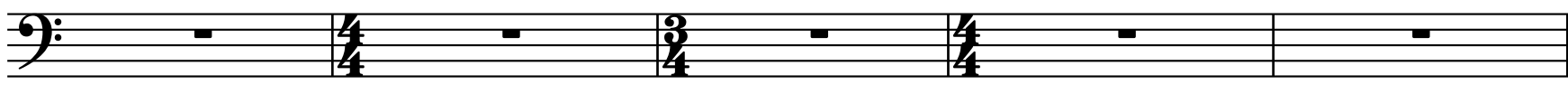


$52 \quad$ D poco sostenuto

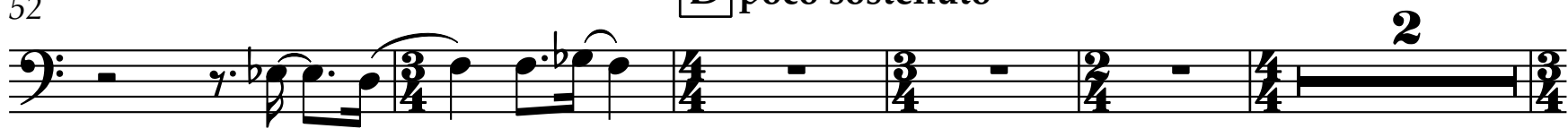

59 molto rall E a tempo

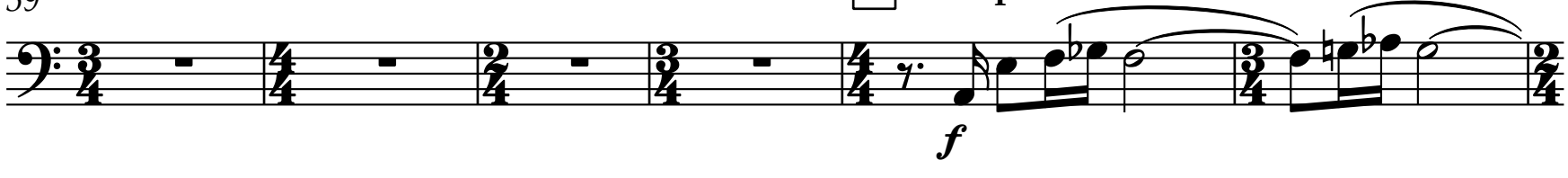

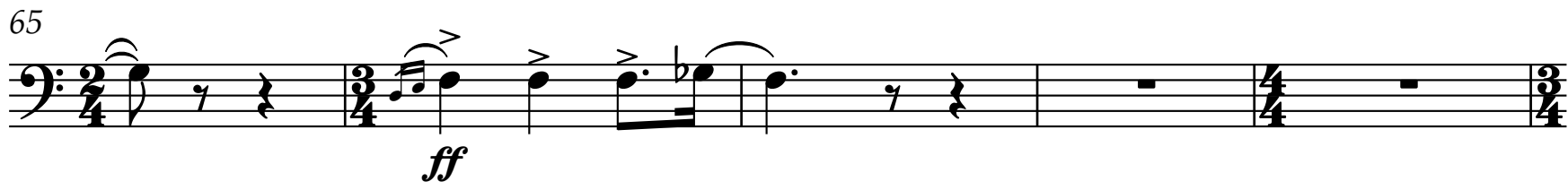

$70 \div 3$

75 F 2

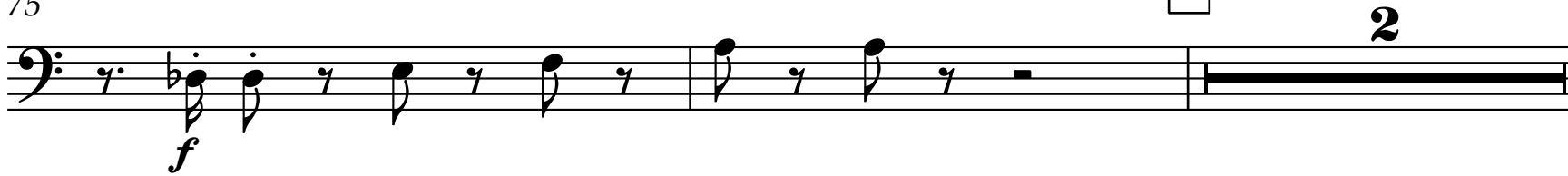

79 a tempo

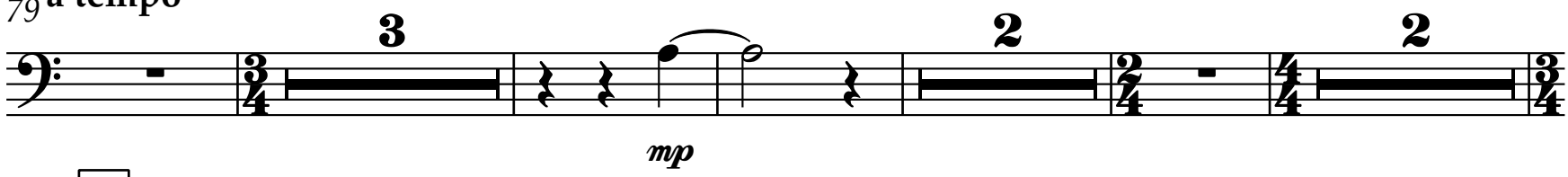

$90 \mathbf{G}$

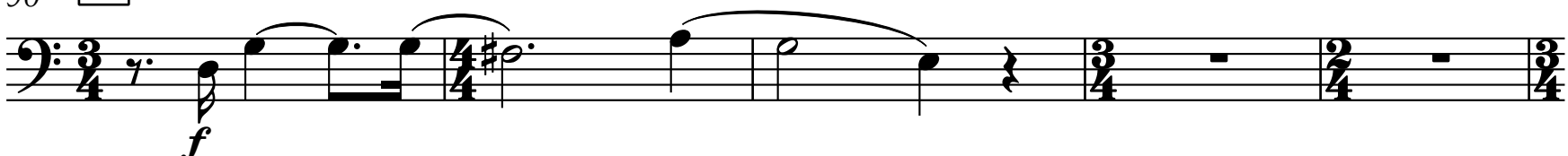

95 Più larg.

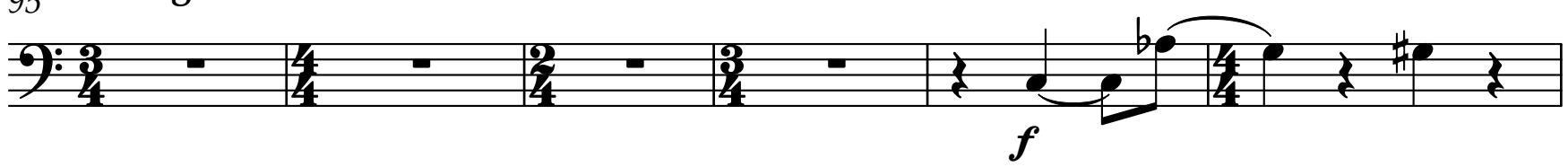

-

3

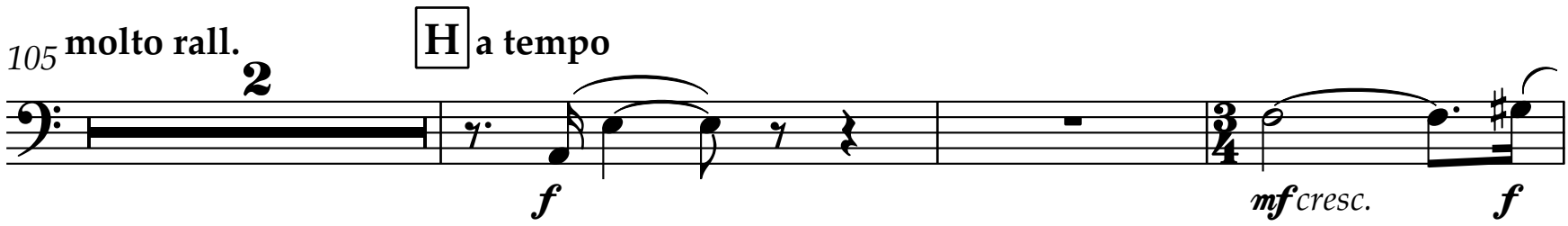
$110>$ poco sostenuto
-0)
2
$\boldsymbol{2}$ 


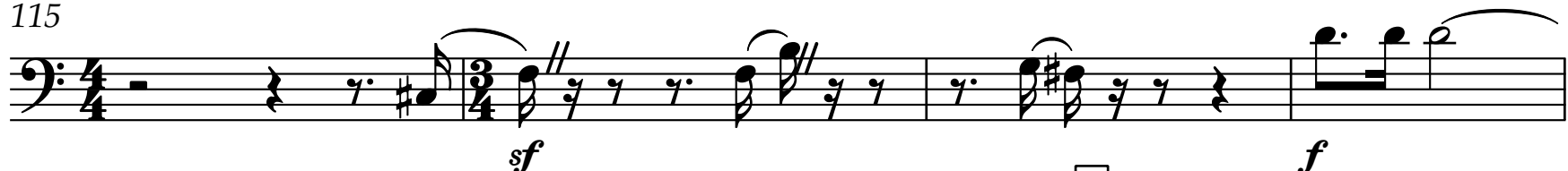

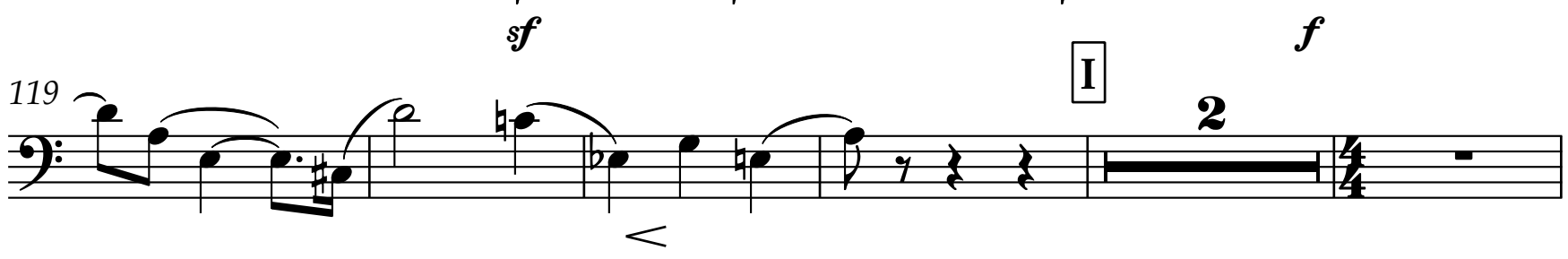

126

9

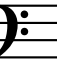

${ }_{131}$ Largamente

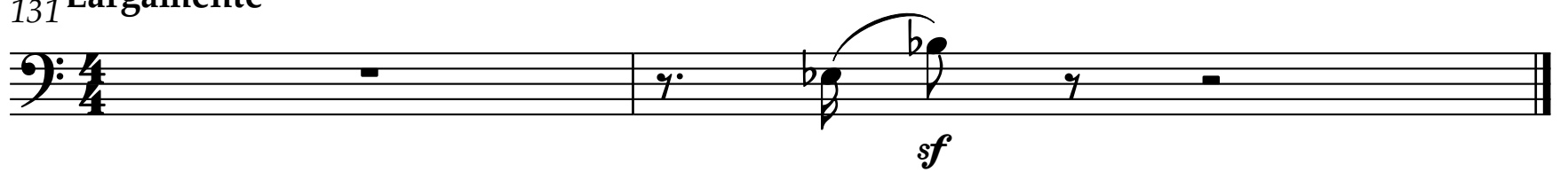

II.

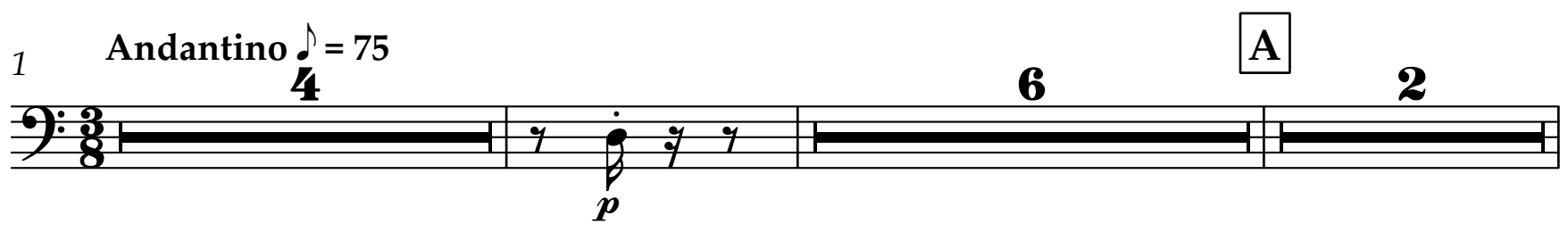

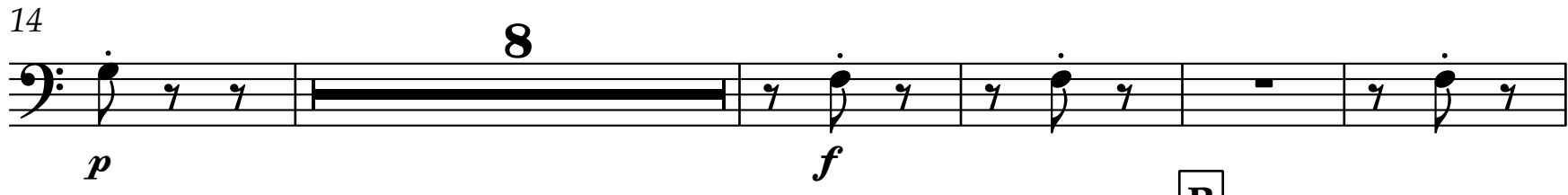
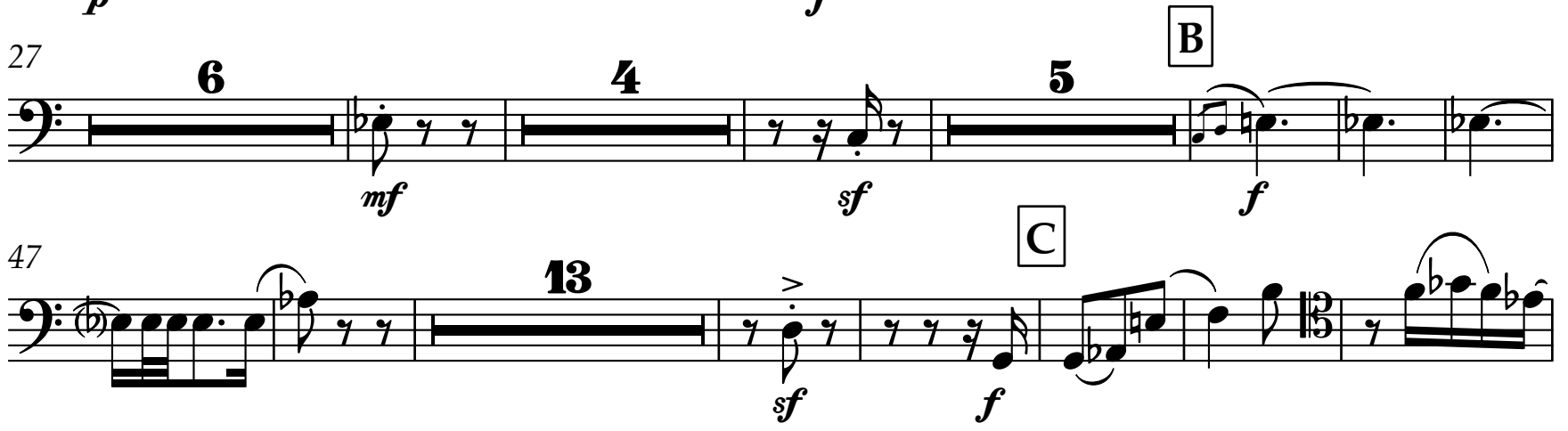

节 ebocoe

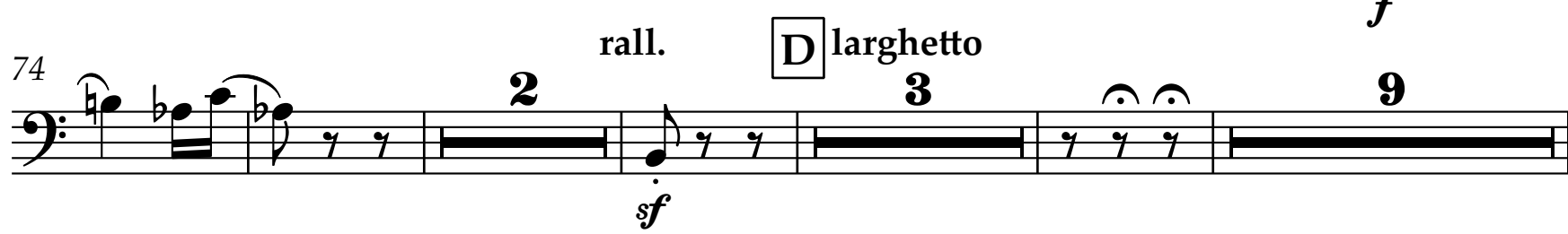


Bassoon 2

32 3
Bassoon 2

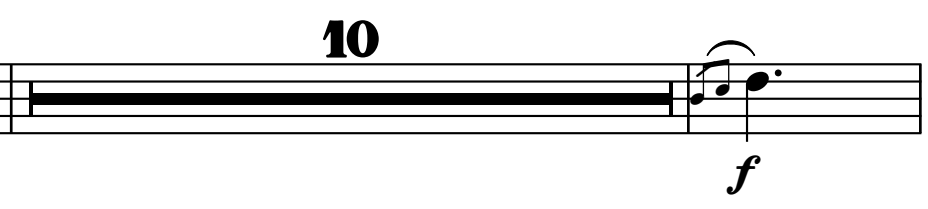

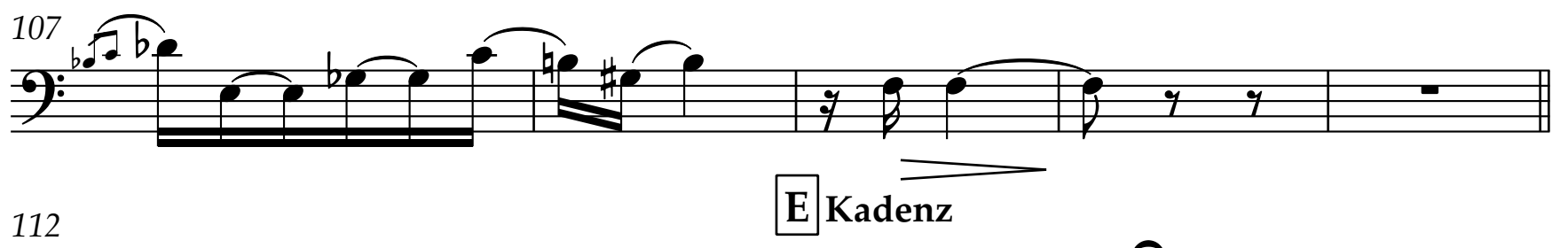

Eadenz

2:

113 F tempo I

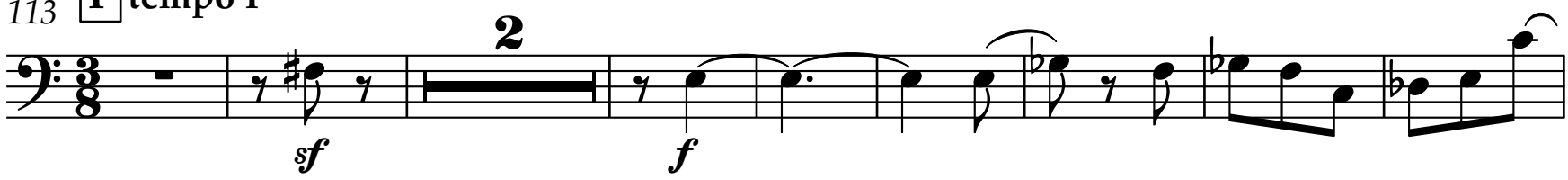

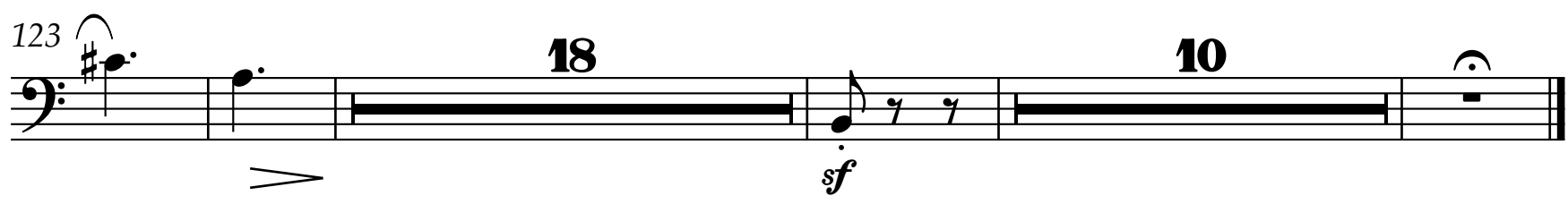

\section{III.}

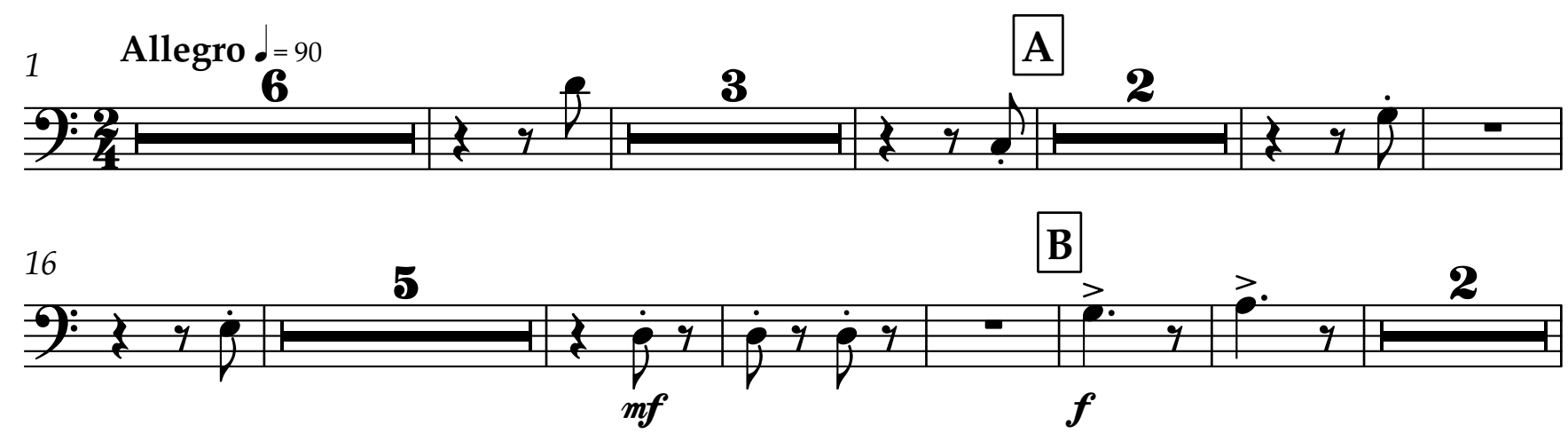

29

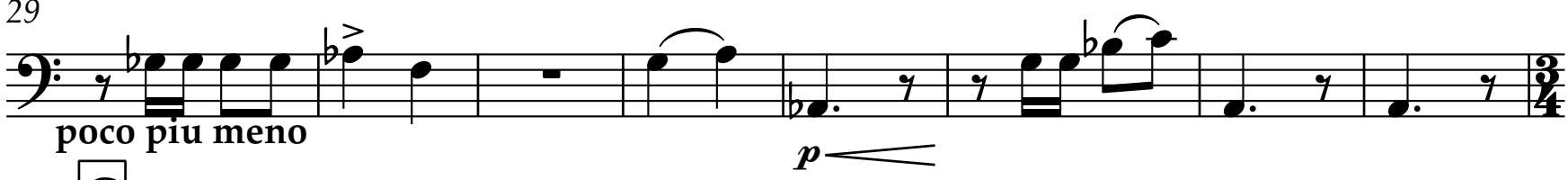

37 C

5

7):9

45

2

2

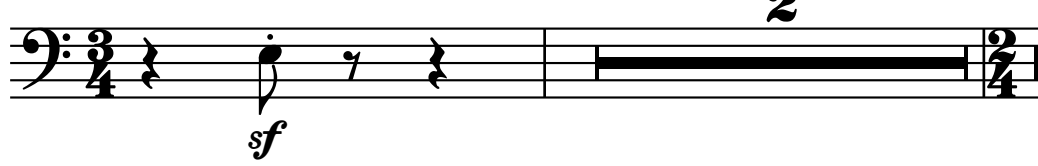




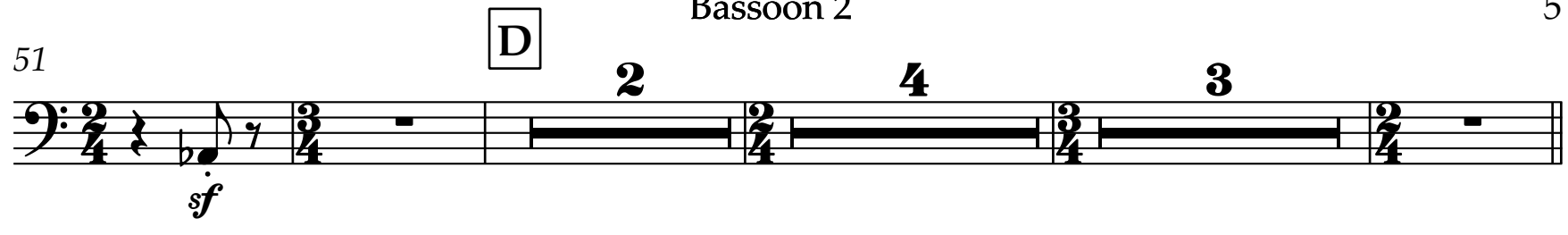

63 E Tempo I

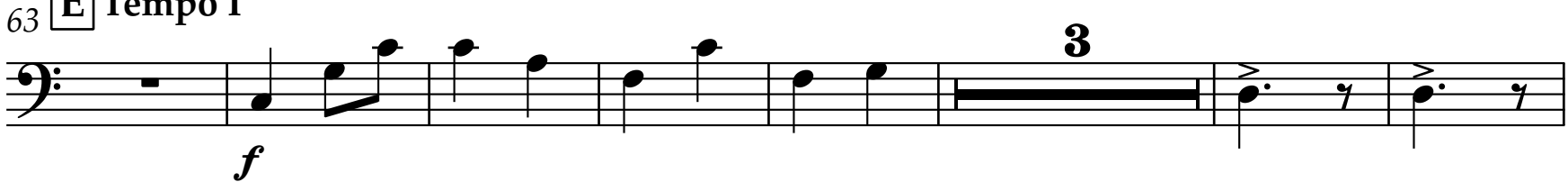

9):
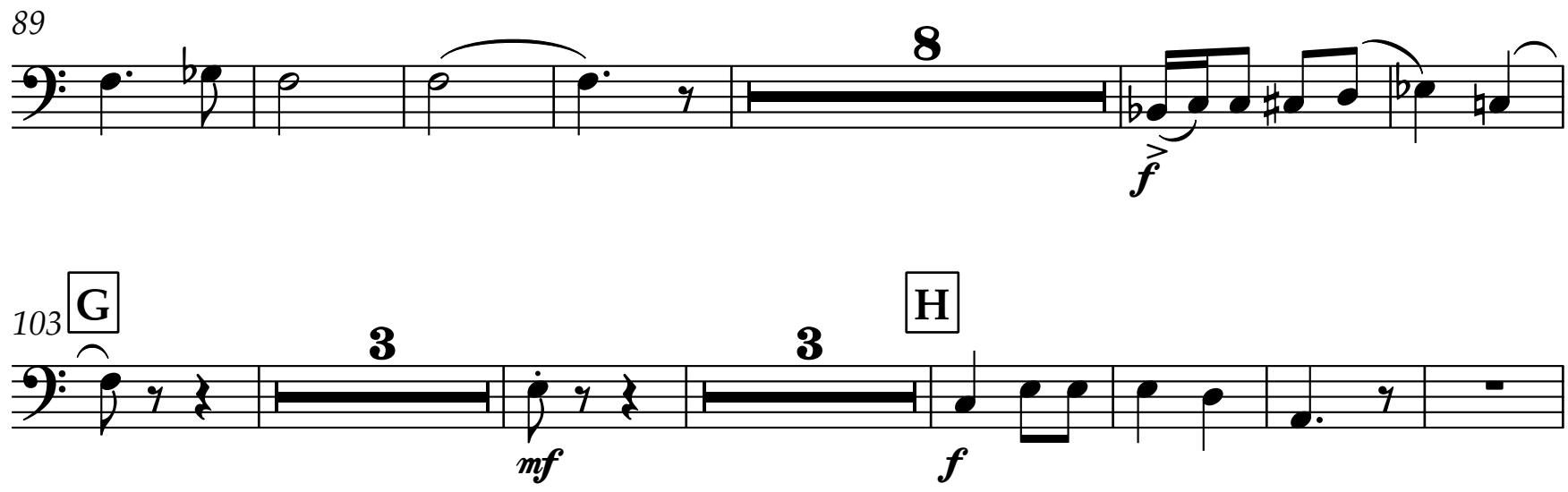

115

I

7):bg q

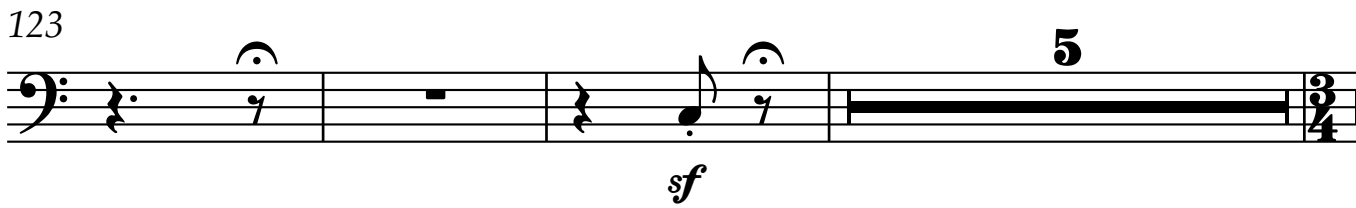

$\mathbf{2}$ 

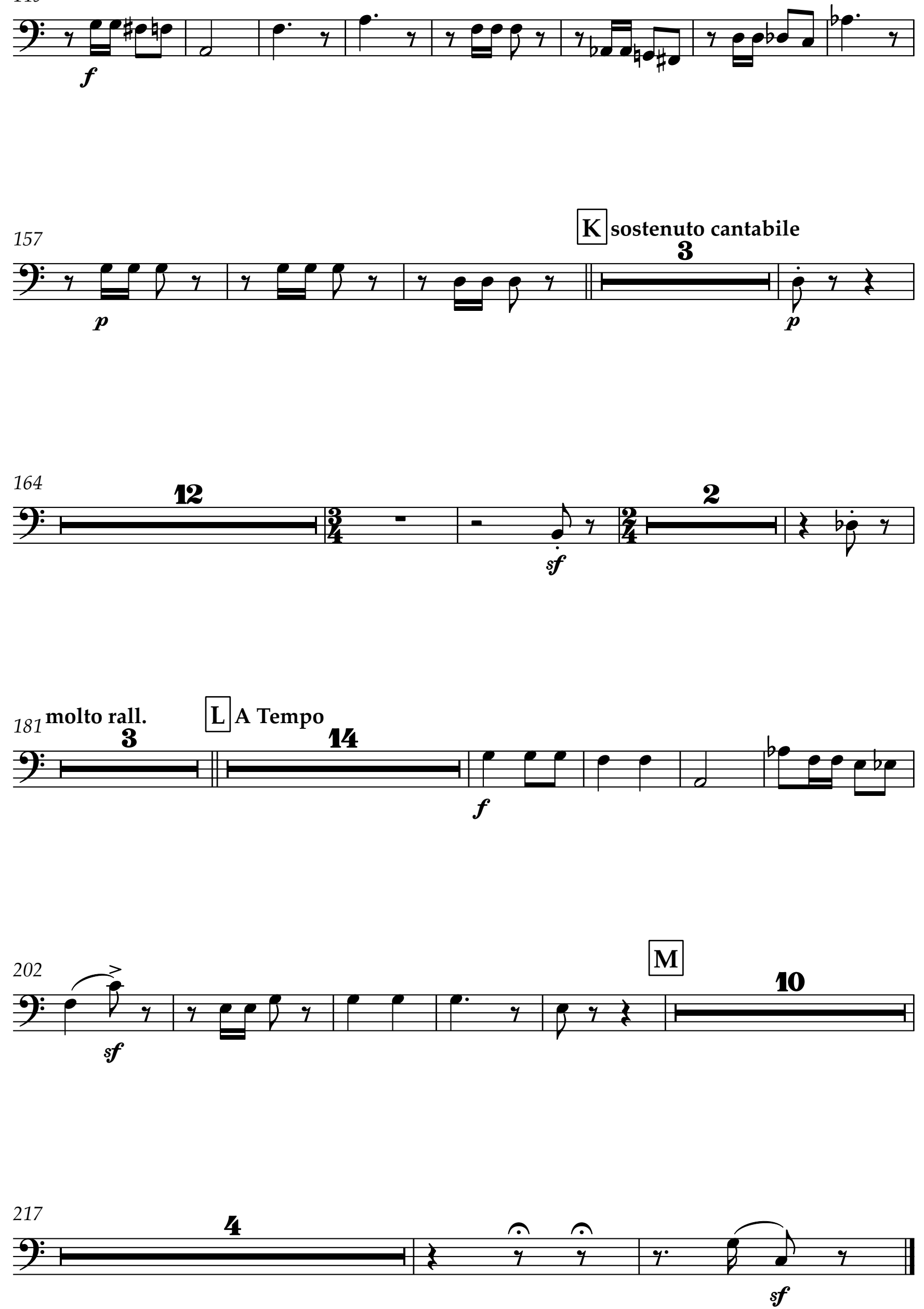
Horn 1 in $\mathrm{F}$

\section{Concerto for Viola and Orchestra}

Dmitris Dragatakis

Moderato $d=70$

(4)

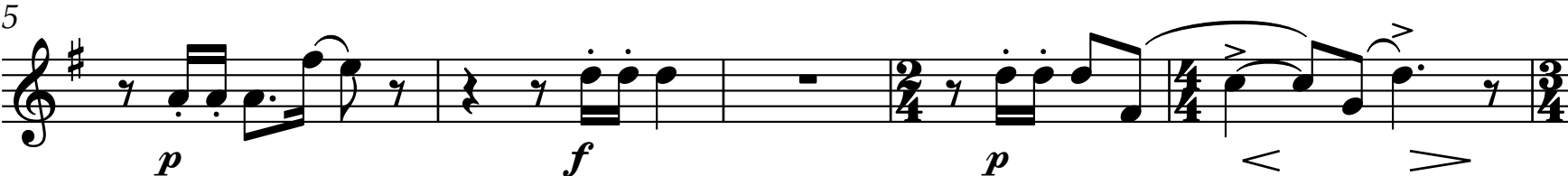
10 A

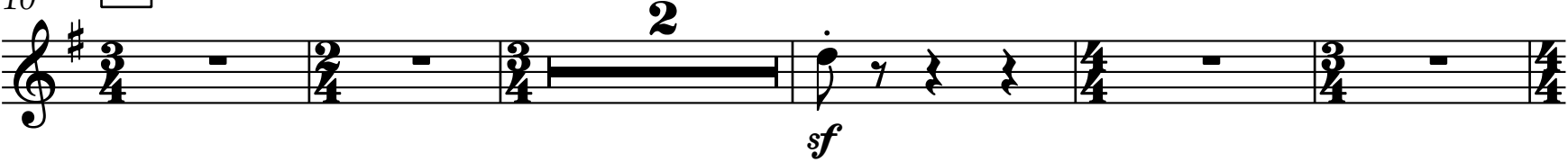

17

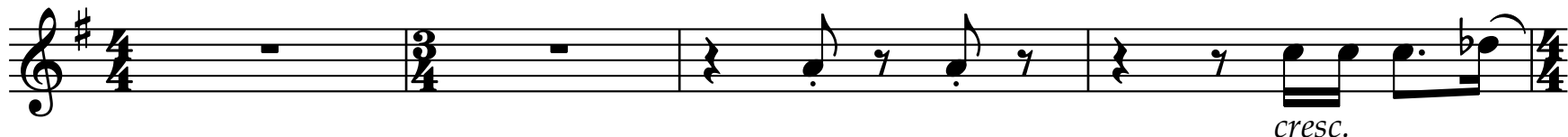

21 poco largam. a tempo poco largam. ${ }^{\text {a tempo }}$

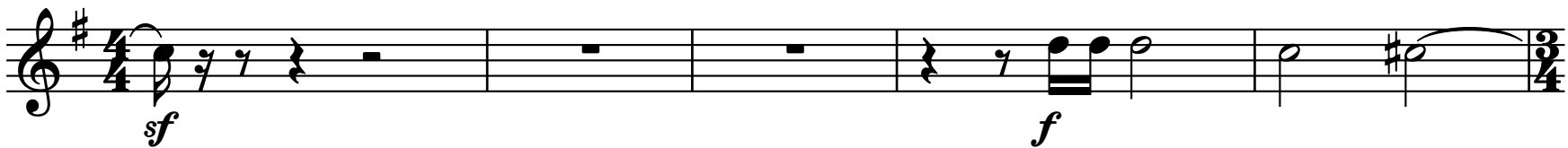

26 molto rall. B a tempo

(G)

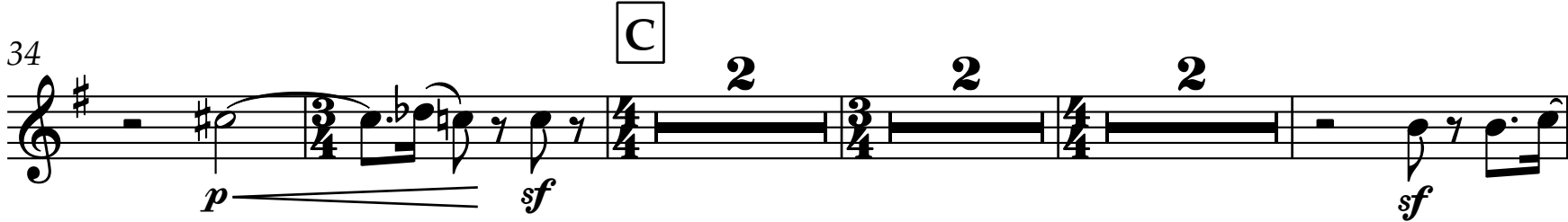

43

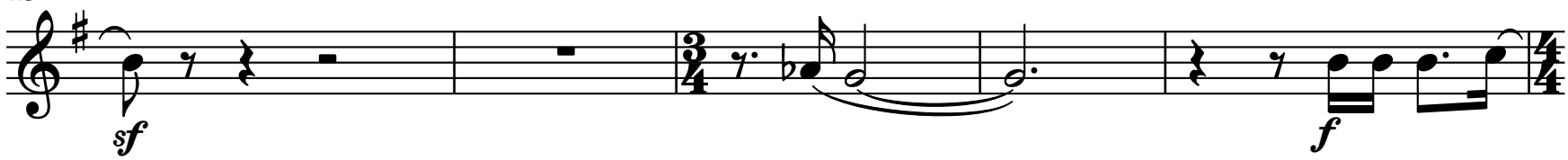

48

poco largam.

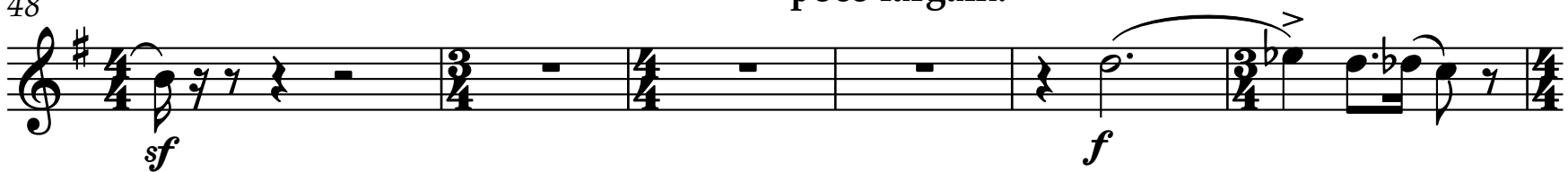

54 D poco sostenuto

3

2 
2 molto rall

(4)

a tempo

E

67

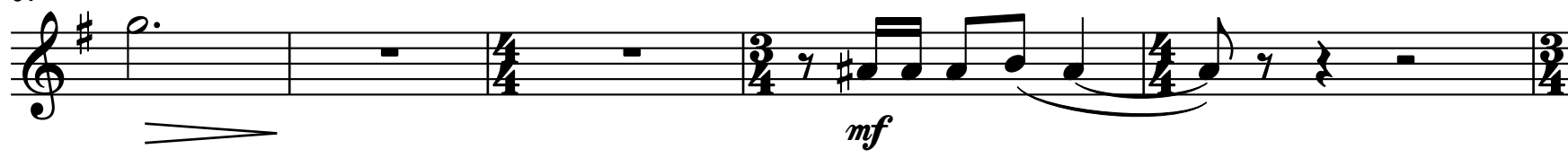

(2) $77 \quad \mathbf{F}$ poco largam. a tempo
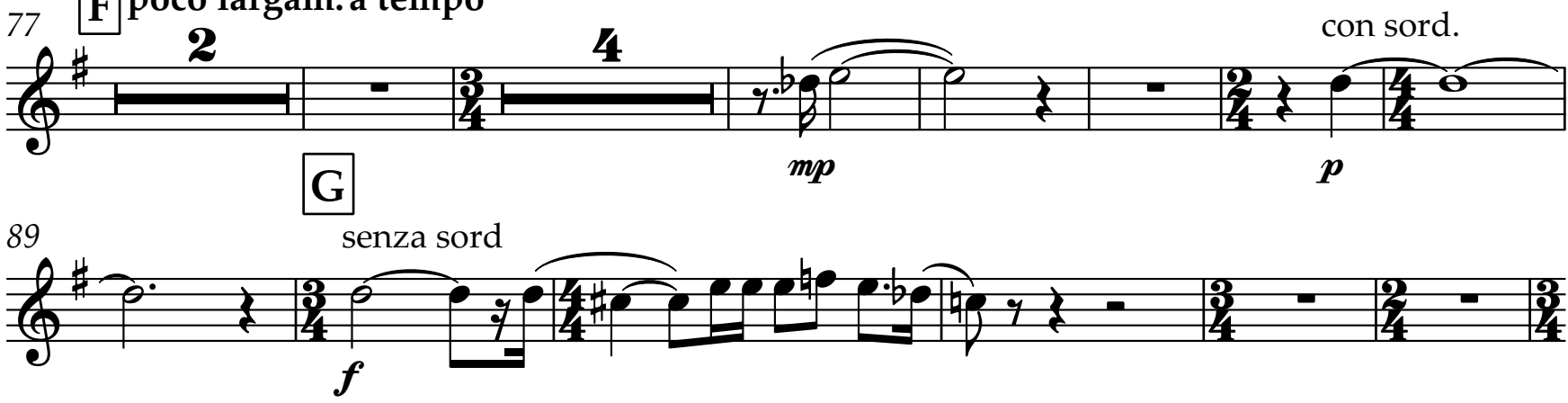

95 Più larg.

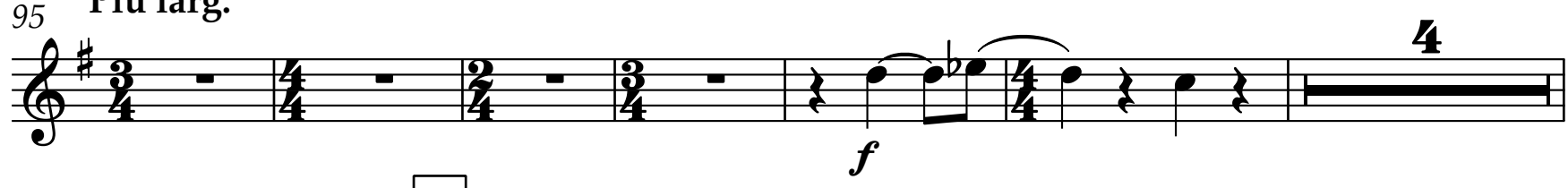

$105^{\text {molto rall. }} \quad \mathbf{H}$ a tempo

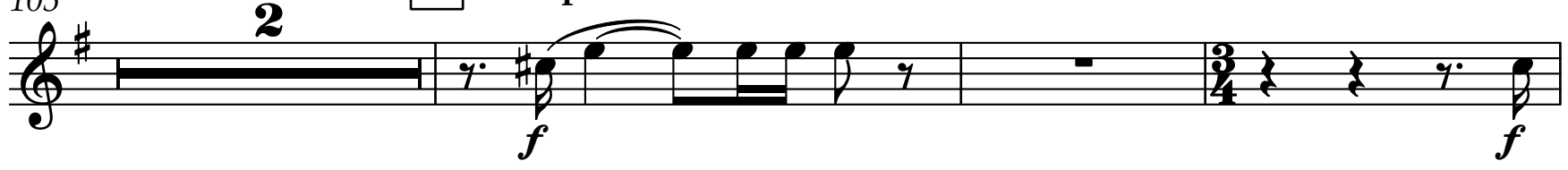

110 poco sostenuto

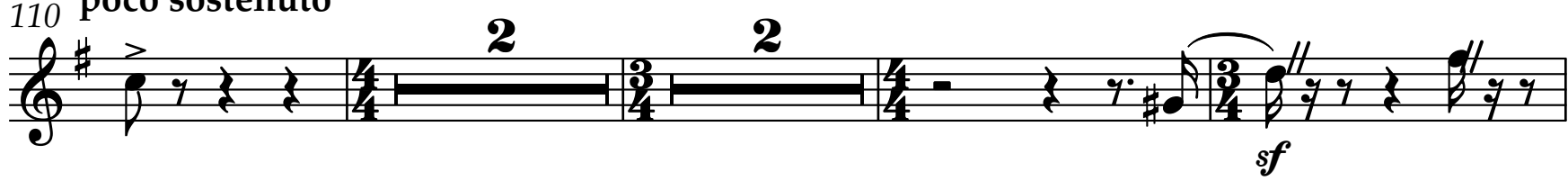

117

(g)

123 I

2

(1)

129

con sord.

b

Largamente

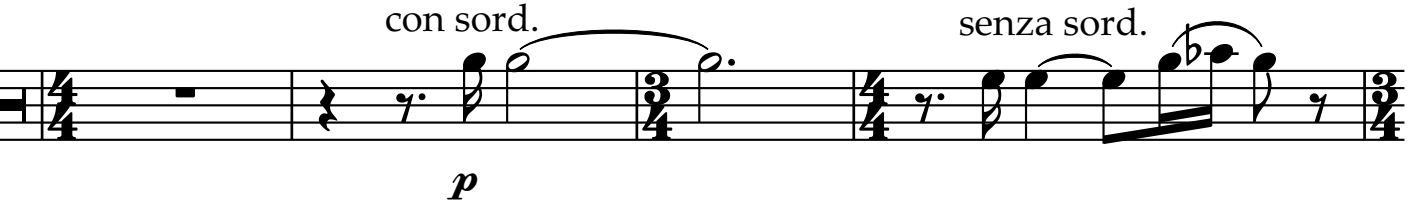

(1) 

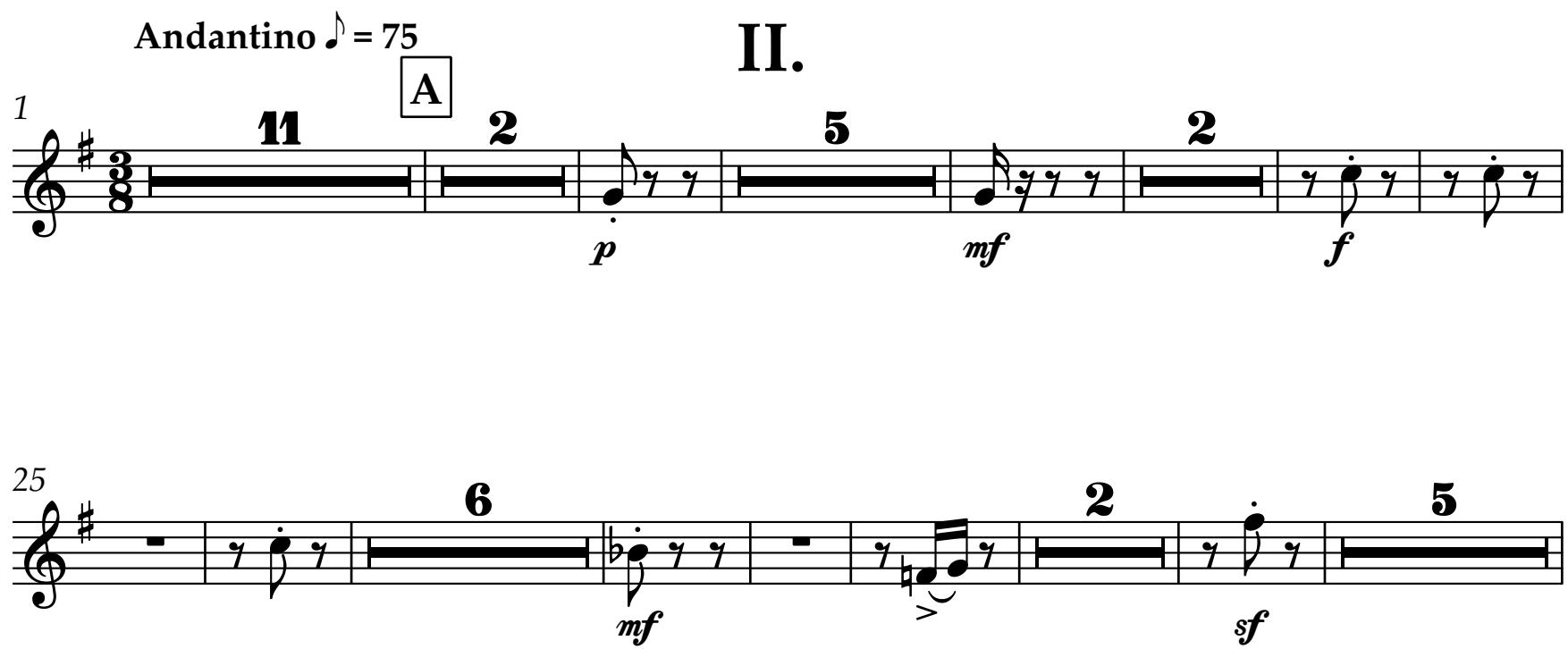

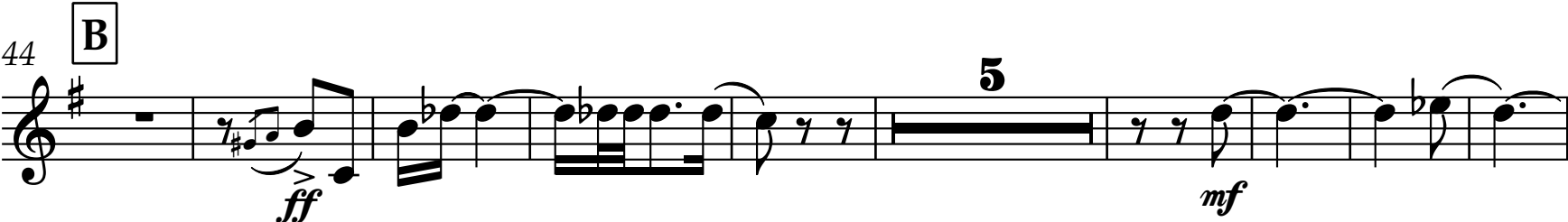

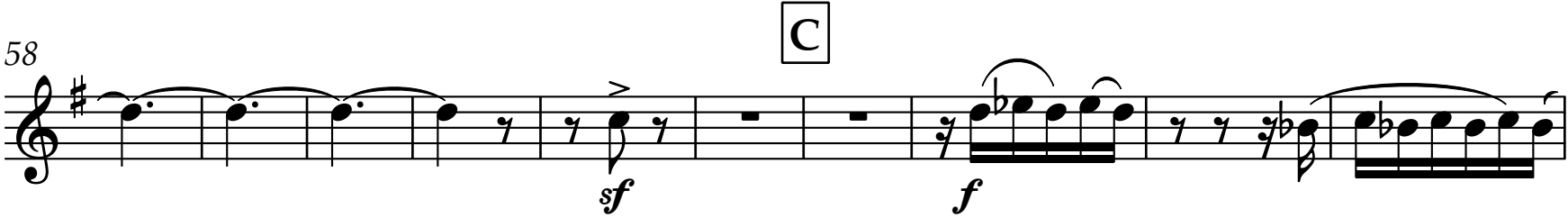
$2_{4}^{68}$

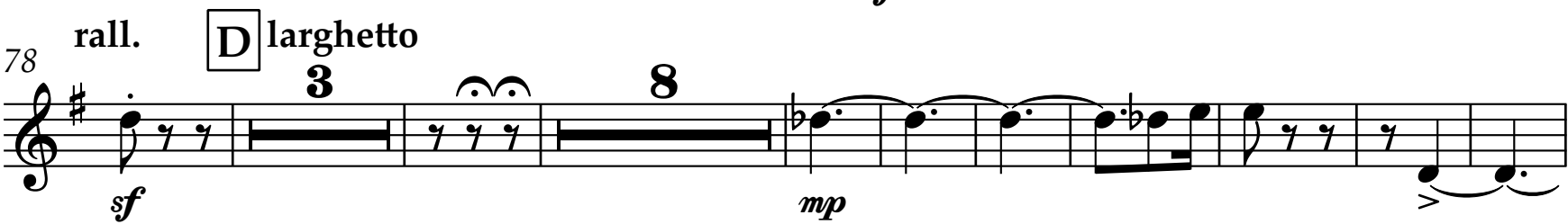
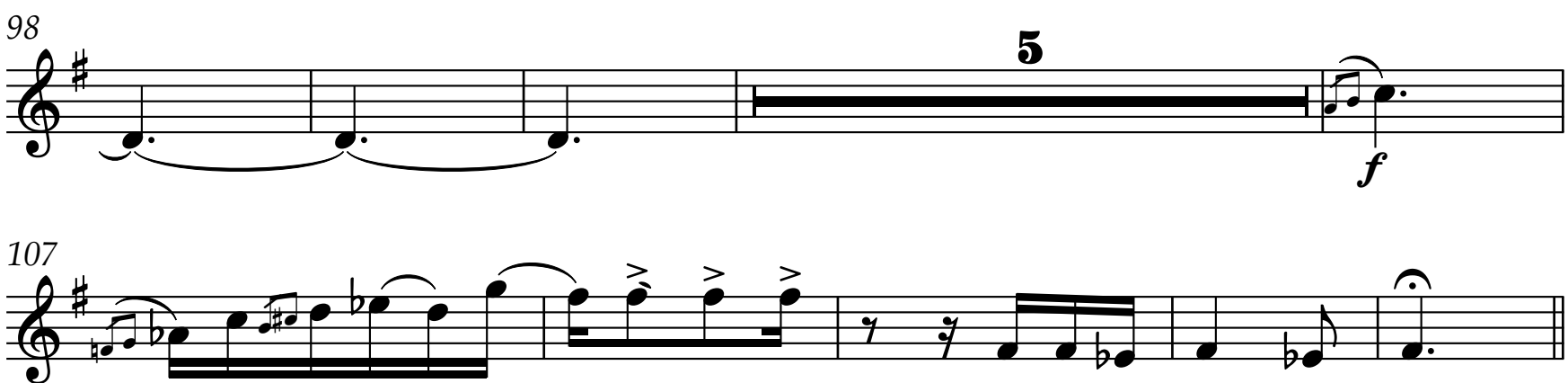

E Kadenz

6 
Horn 1, fin

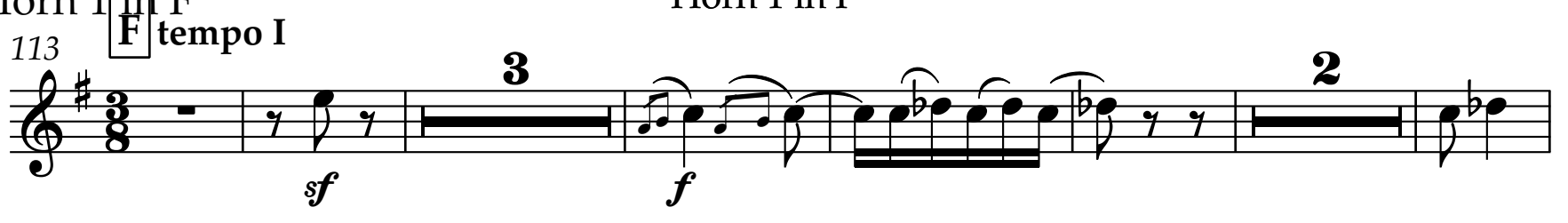

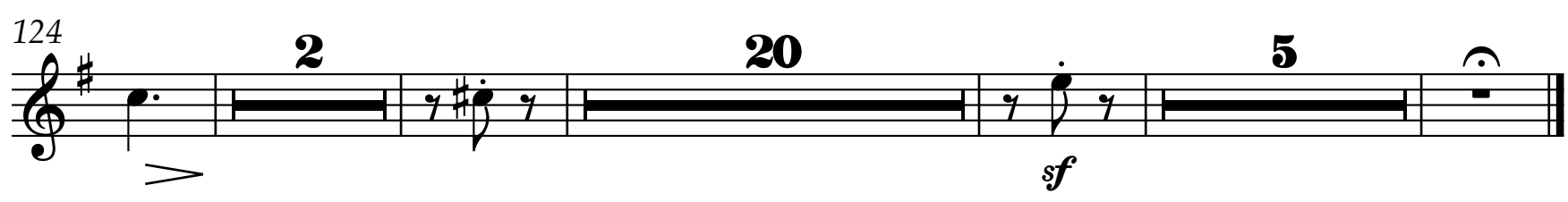

III.

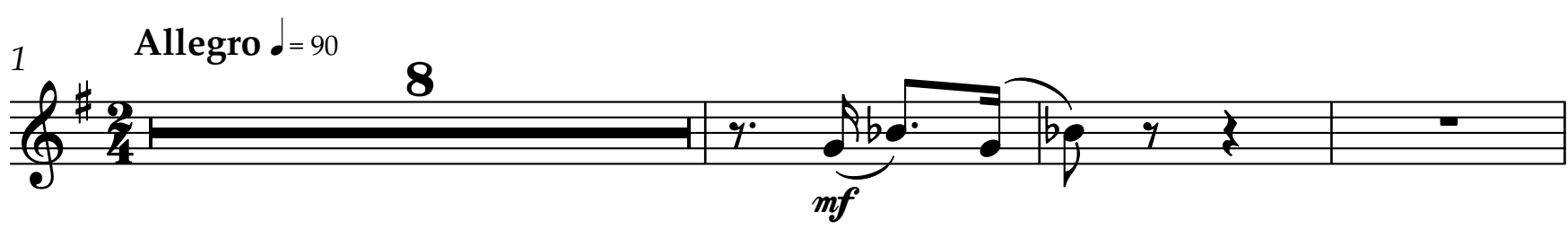

(2)

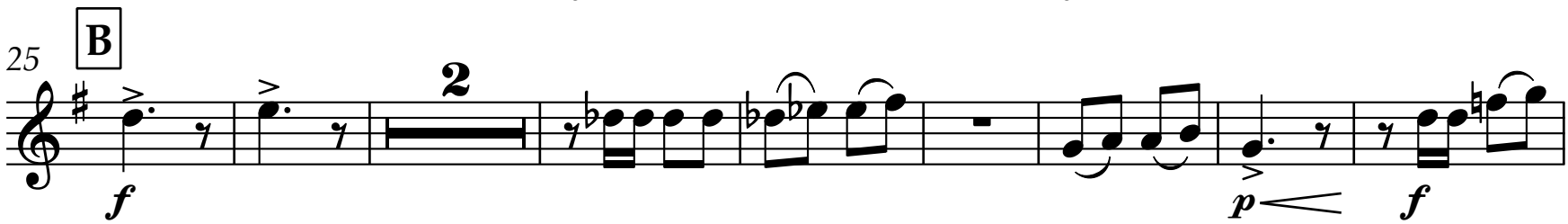
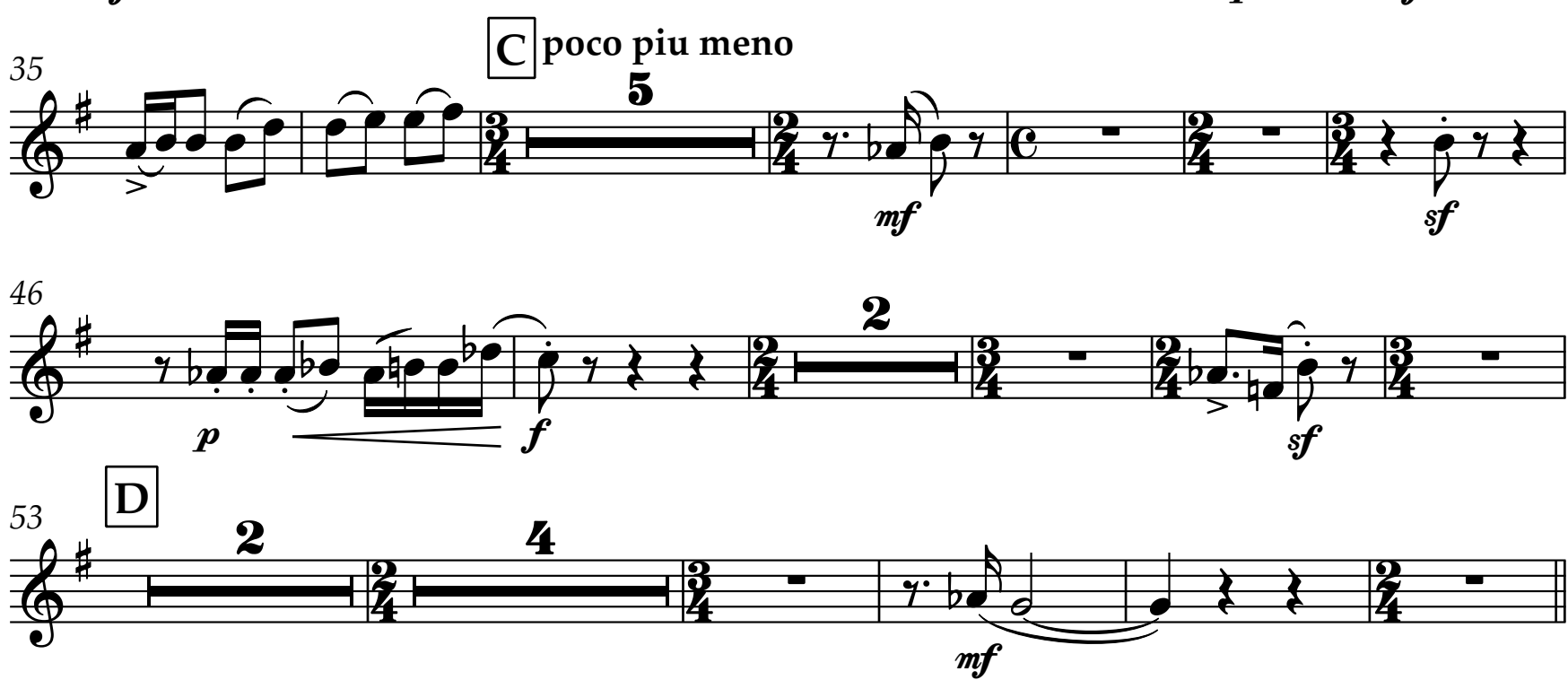
63 E Tempo I
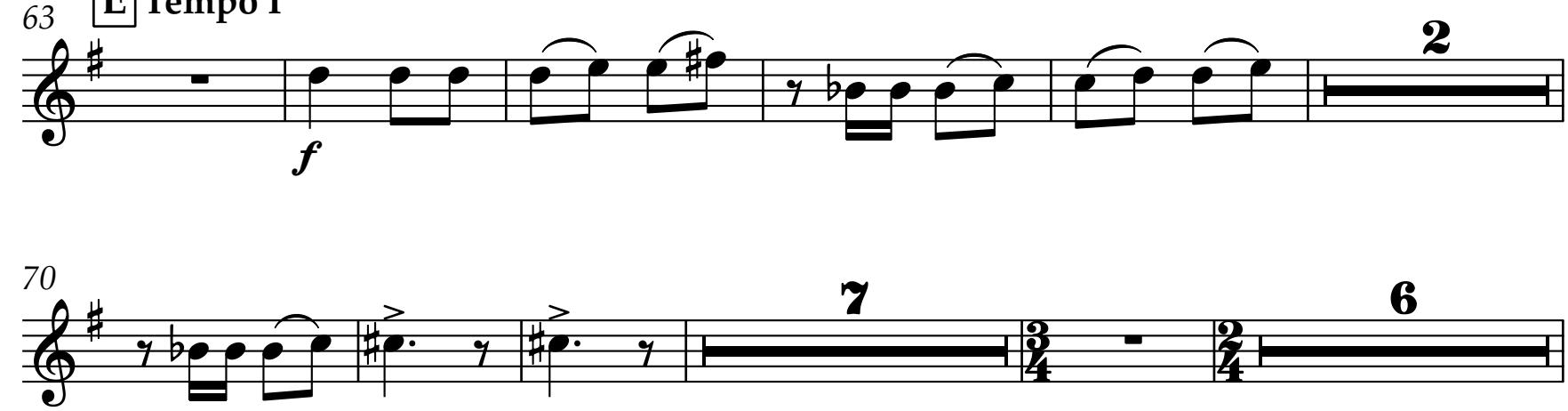

$87 \quad \mathbf{F}$

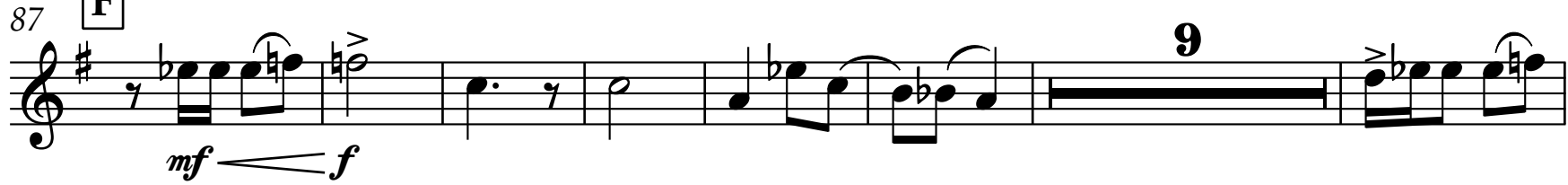
$\underbrace{}_{m f}$

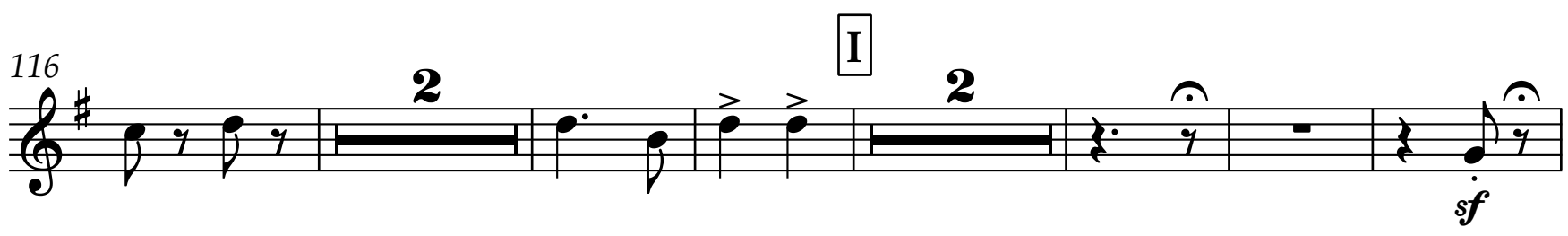

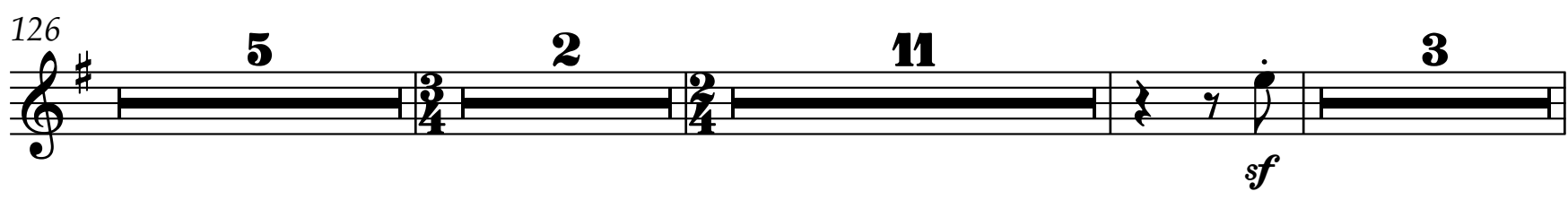
$\underbrace{148 \mathrm{~J}}_{p<x}$ (S)

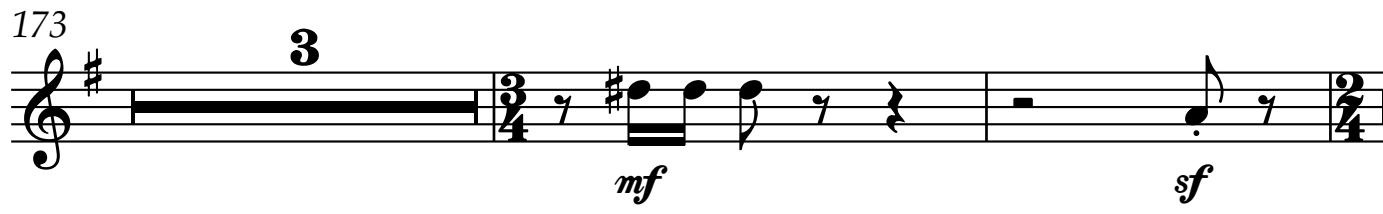

3 
6 molto rall. A Tempo
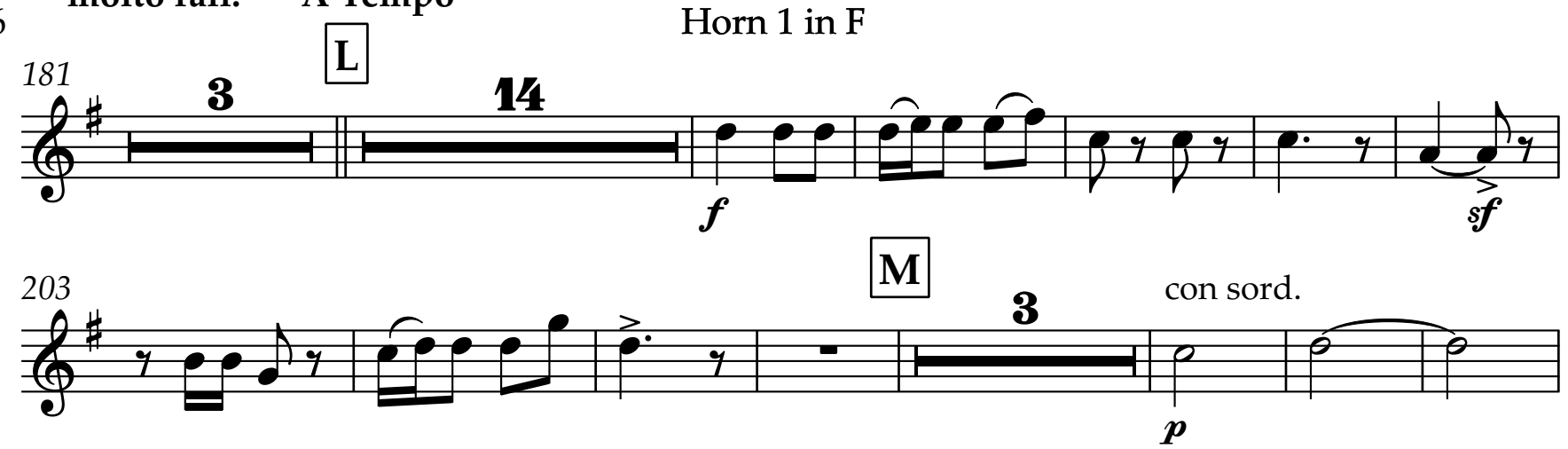
Horn 2 in $\mathrm{F}$

\section{Concerto for Viola and Orchestra}

Dmitris Dragatakis

Moderato $d=70$

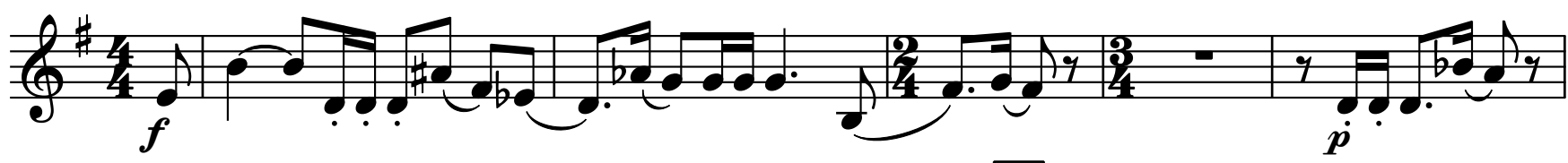

A

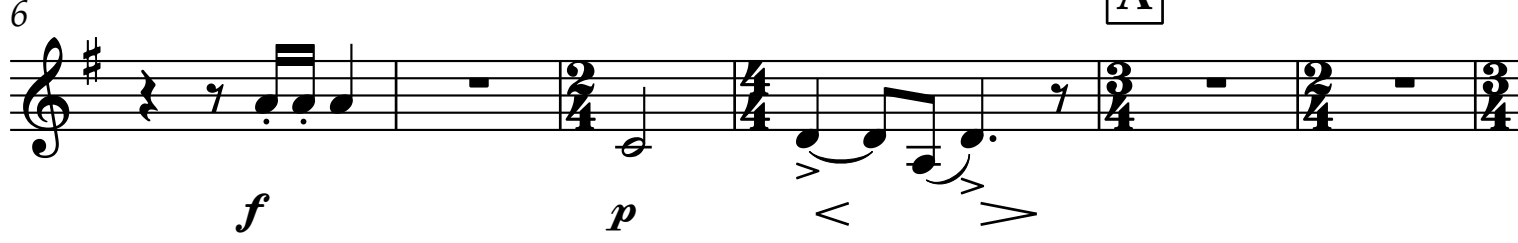

2

14

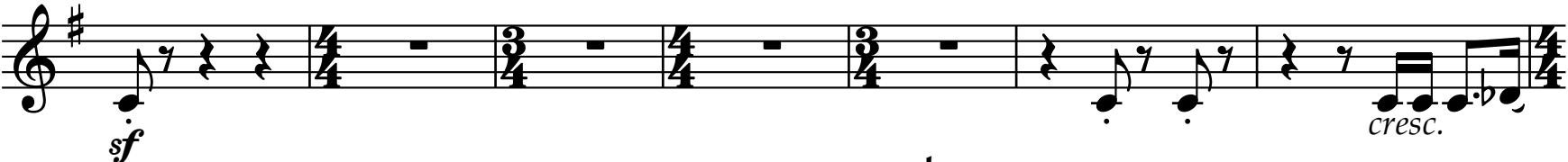

21 poco largam. a tempo poco largam. ${ }^{\text {a tempo }}$

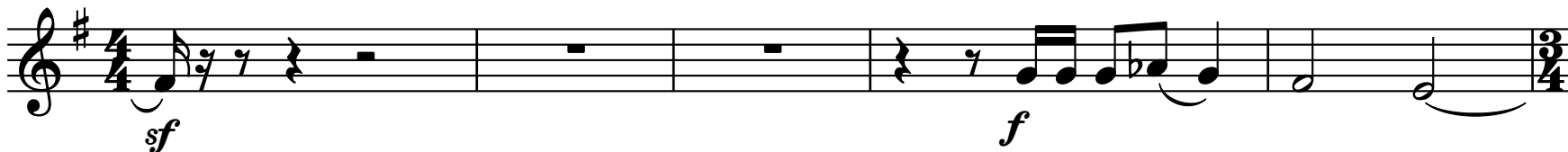

26 molto rall. B a tempo

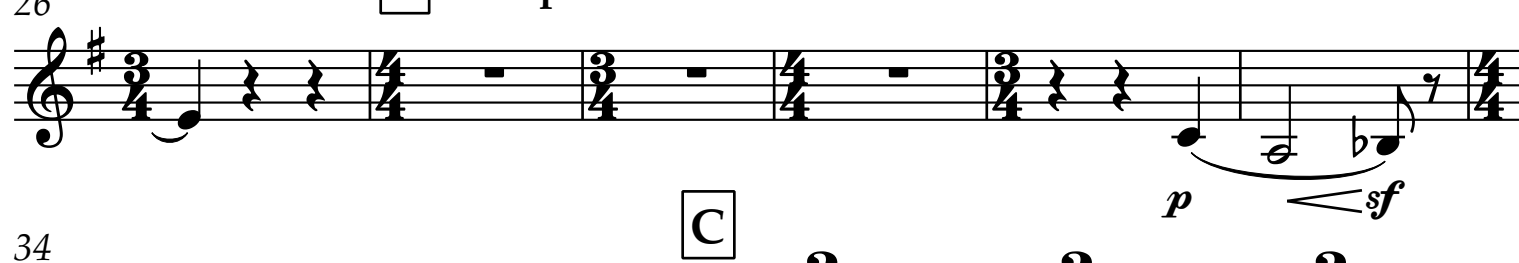

2

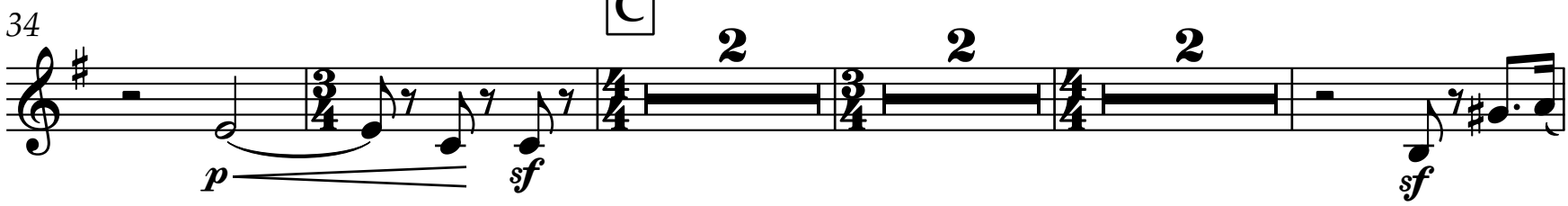

43

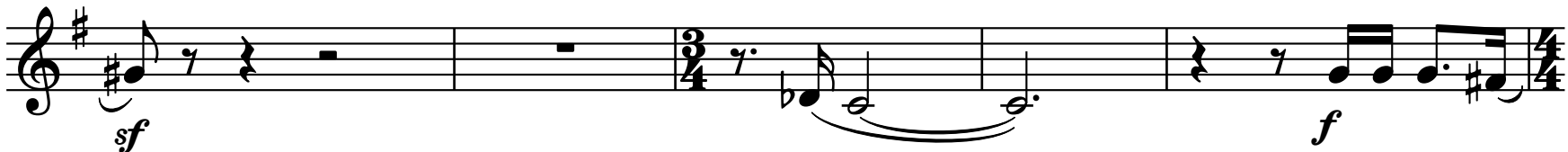

48

poco largam.

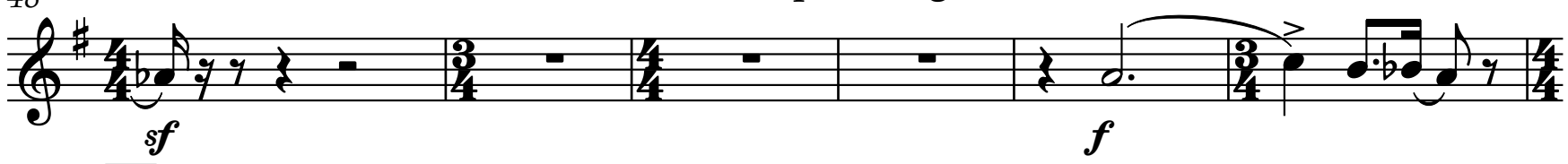

$54 \quad \mathrm{D}$ poco sostenuto

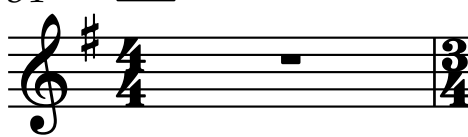

$\boldsymbol{2}$

60 molto rall

$\overbrace{4}^{4}$ 
2

63 E a tempo

Horn 2 in $\mathrm{F}$

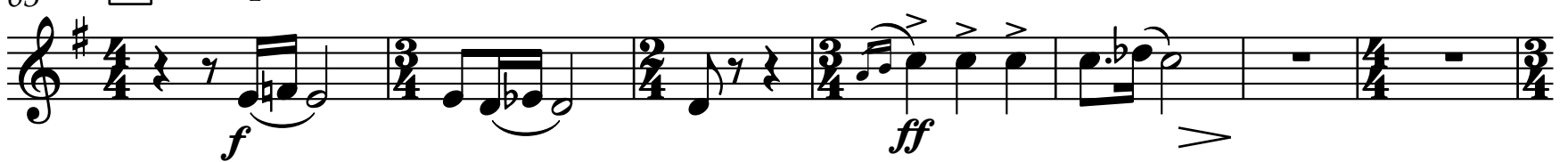

(2)
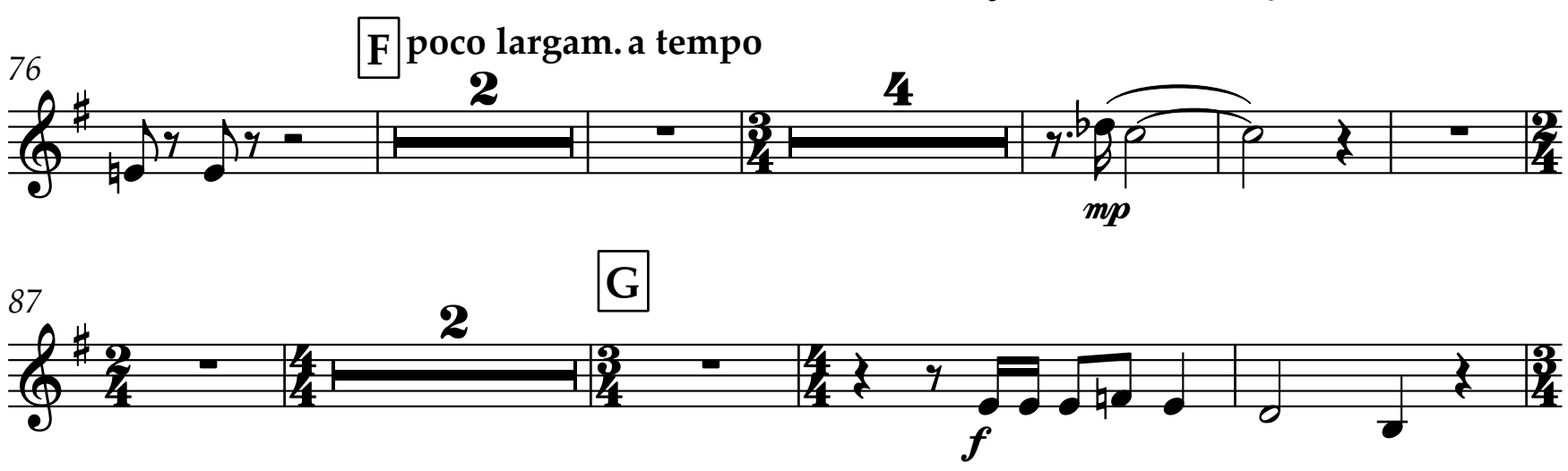

$93 \quad$ Più larg.

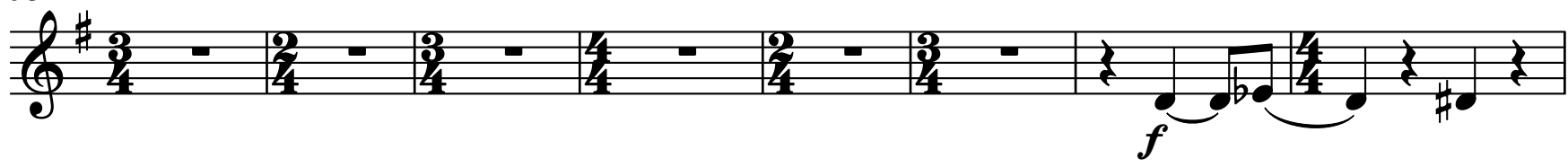

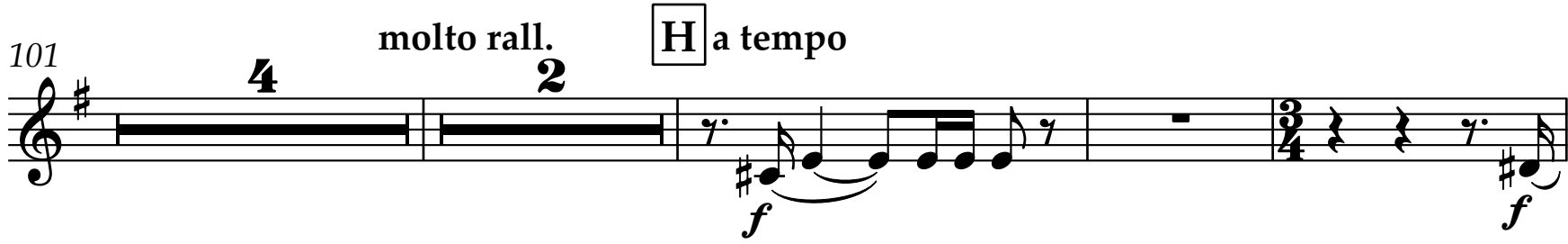

110 poco sostenuto

$\begin{array}{lll}118 & \mathbf{I} & \mathbf{2}\end{array}$

(a)

126 con sord. senza sord.

(6)

131 Largamente

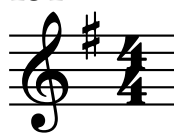



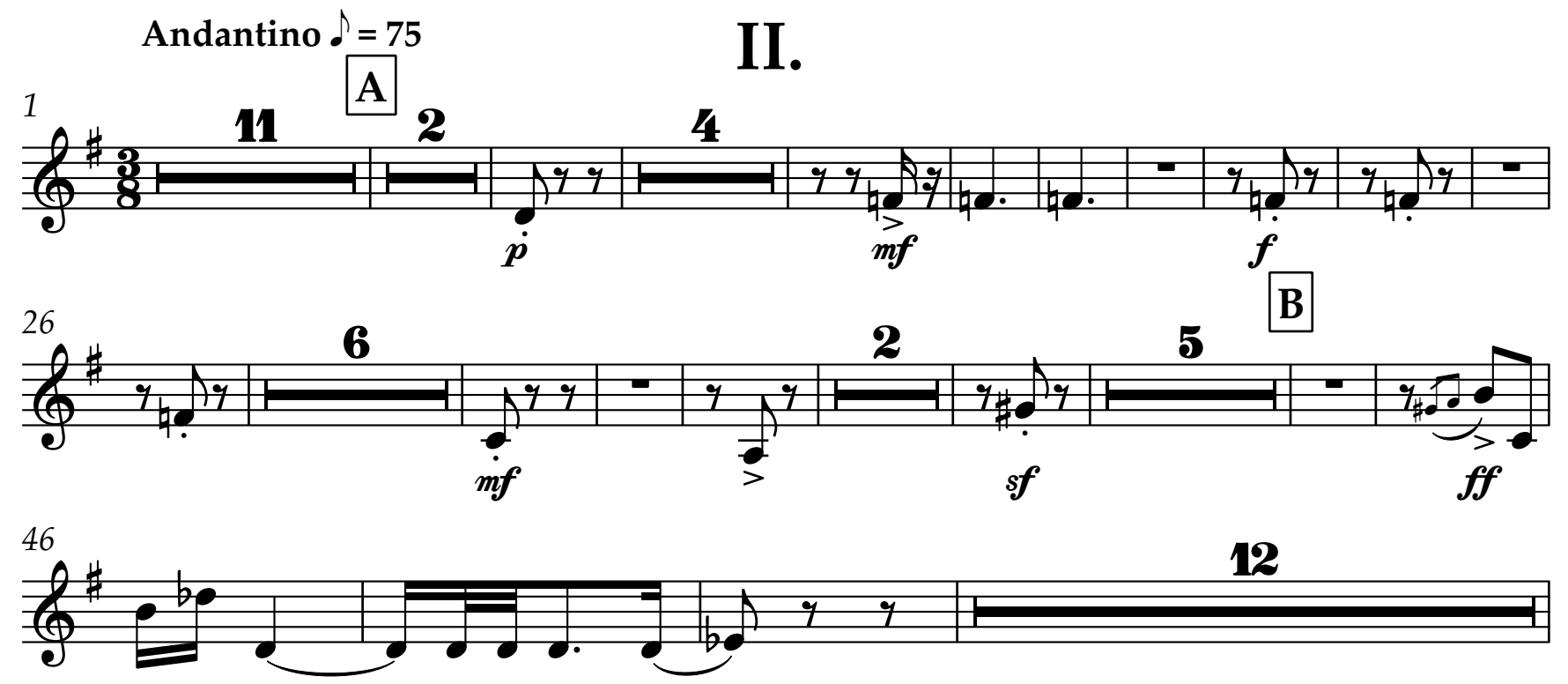

12
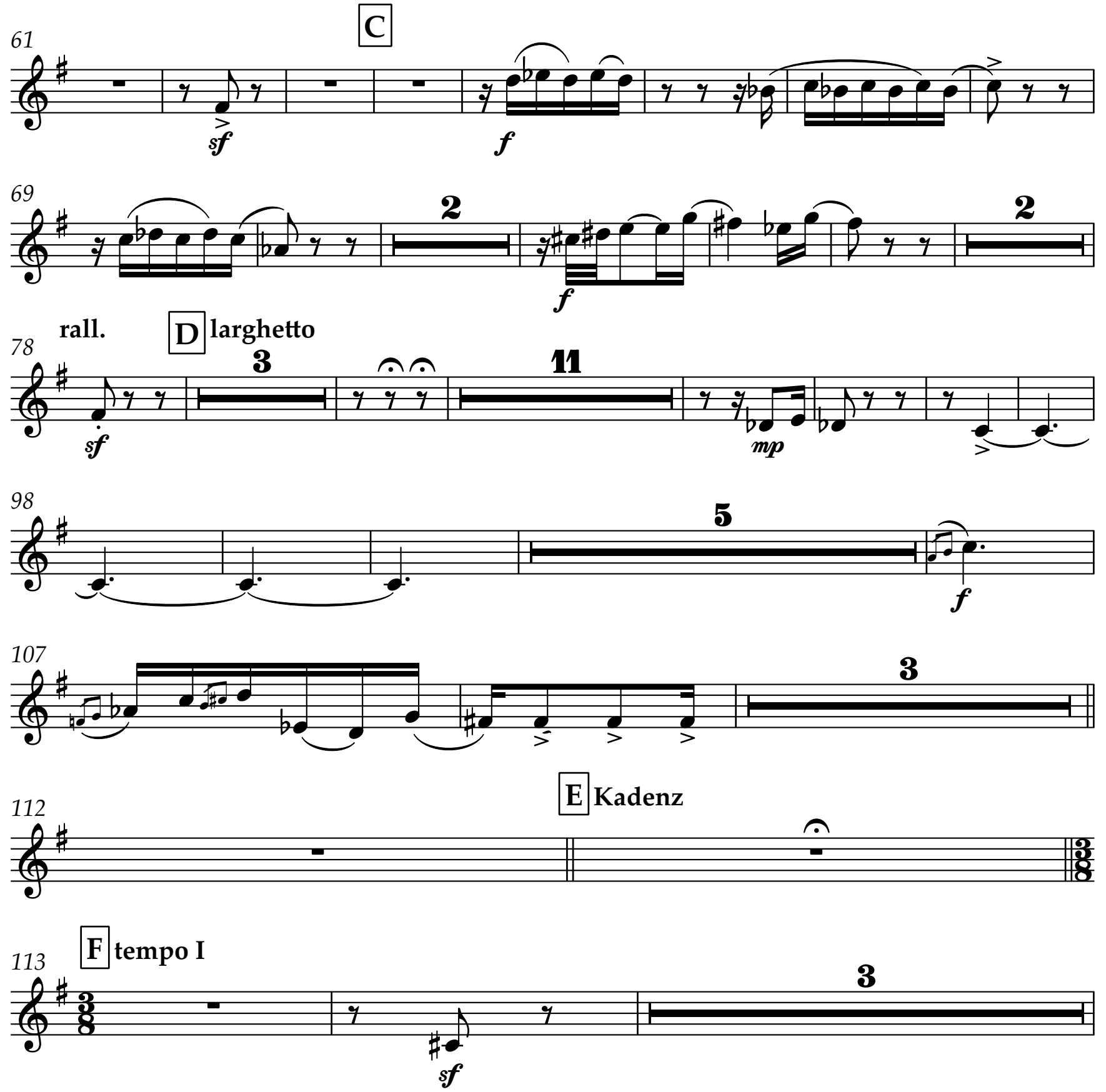
Horn 2 in $\mathrm{F}$

Horn 2 in $\mathrm{F}$

6

2

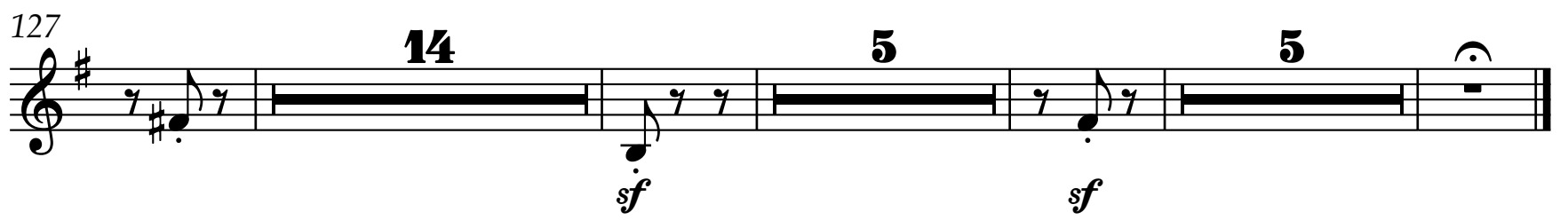

III.
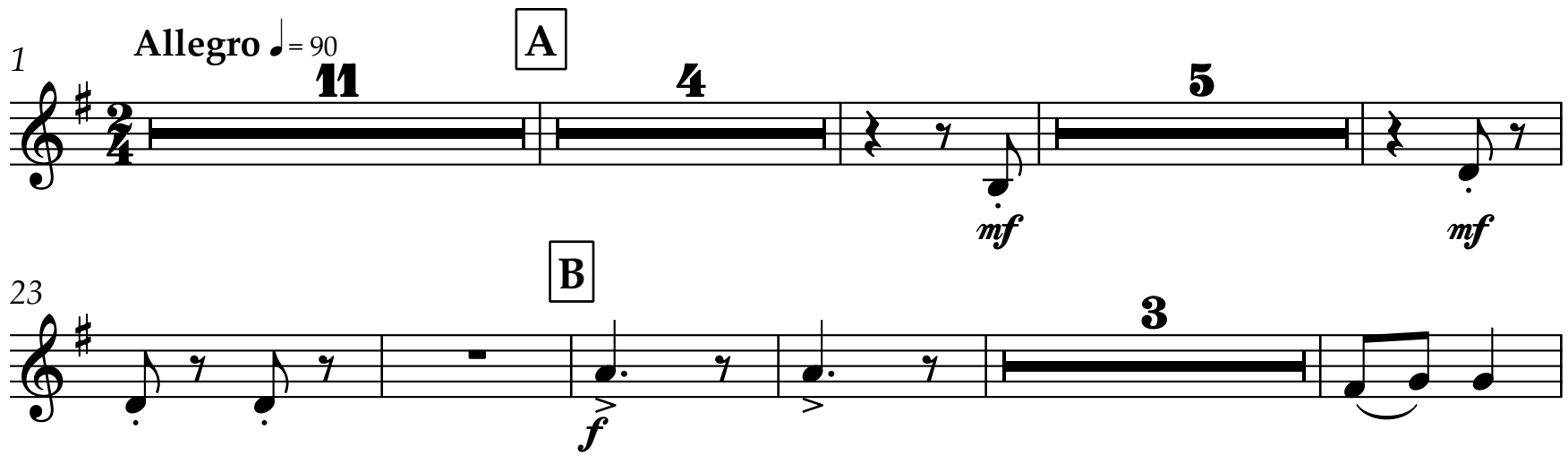

31

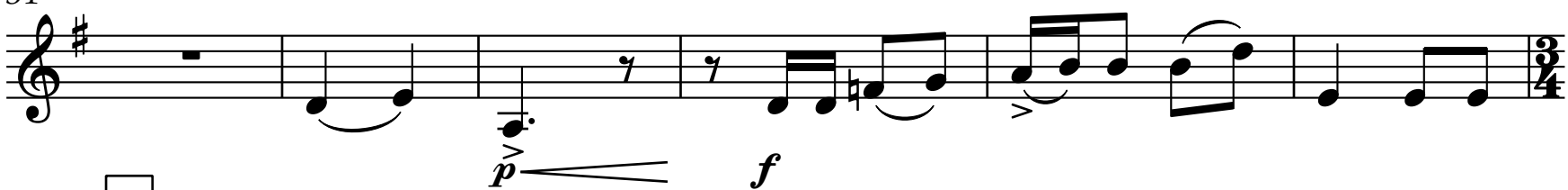

(2)
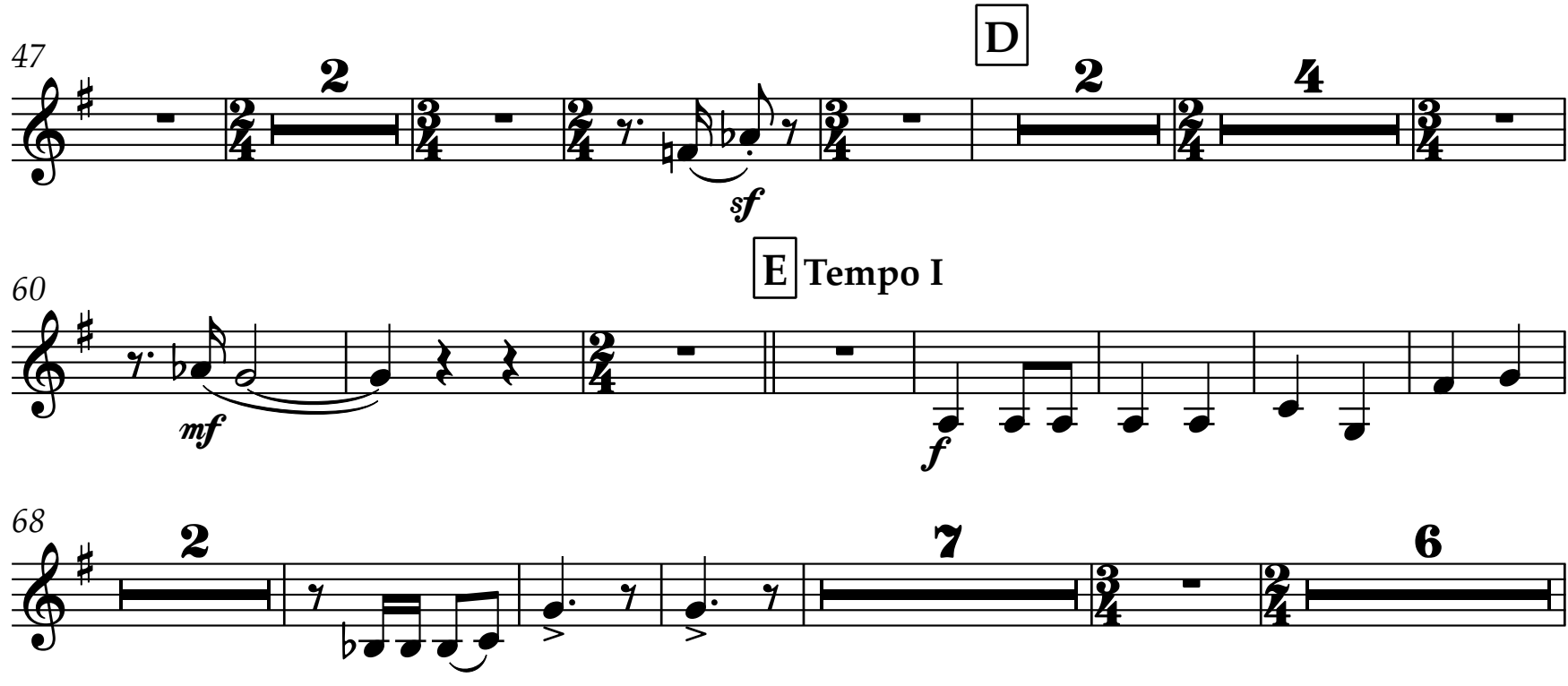
87 F

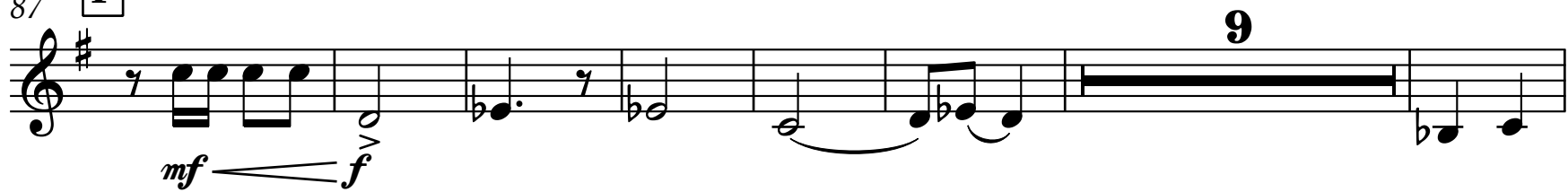
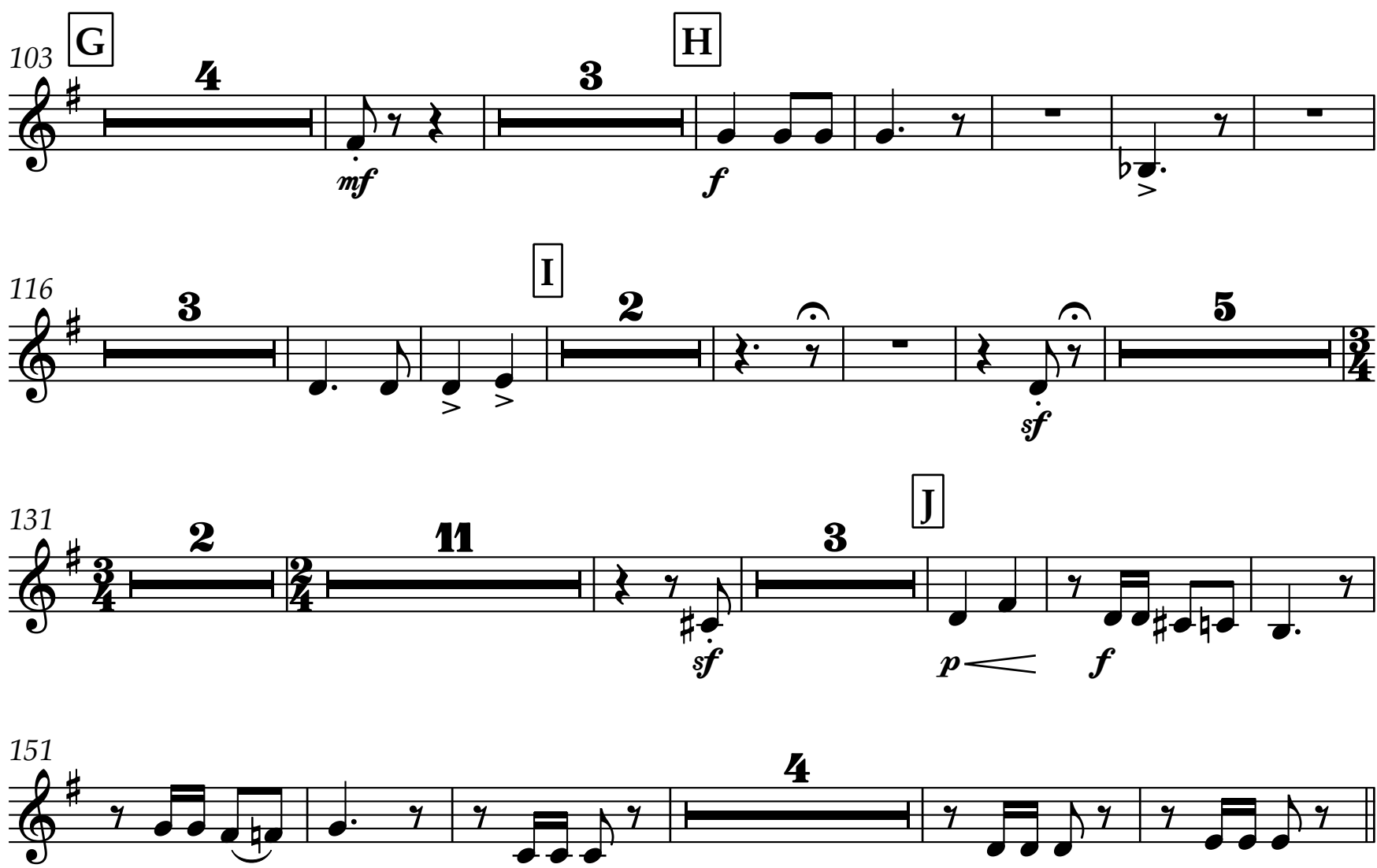

${ }_{160} \mathbf{K}$ sostenuto cantabile
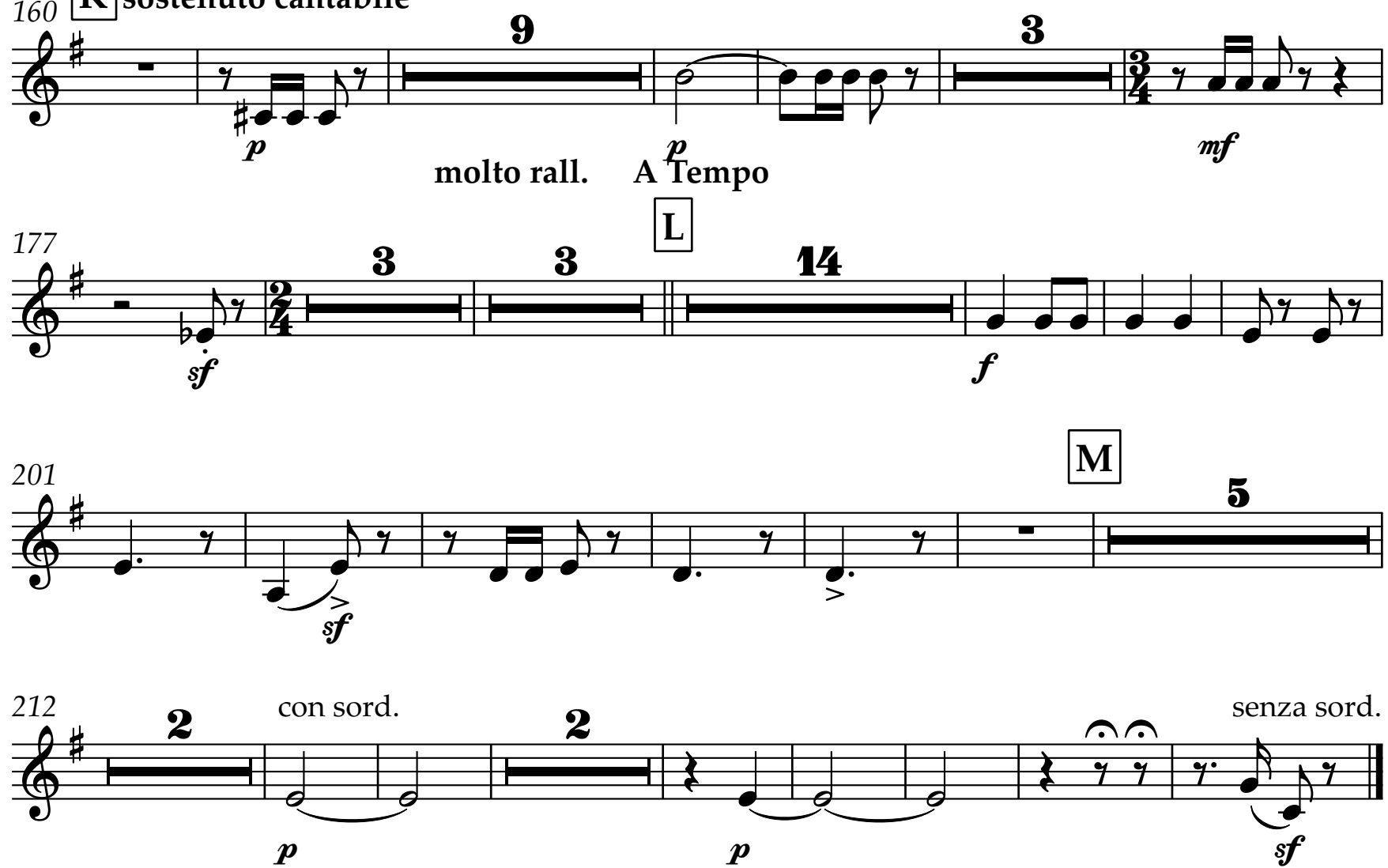
Horn 3 in $\mathrm{F}$

\section{Concerto for Viola and Orchestra}

Dmitris Dragatakis
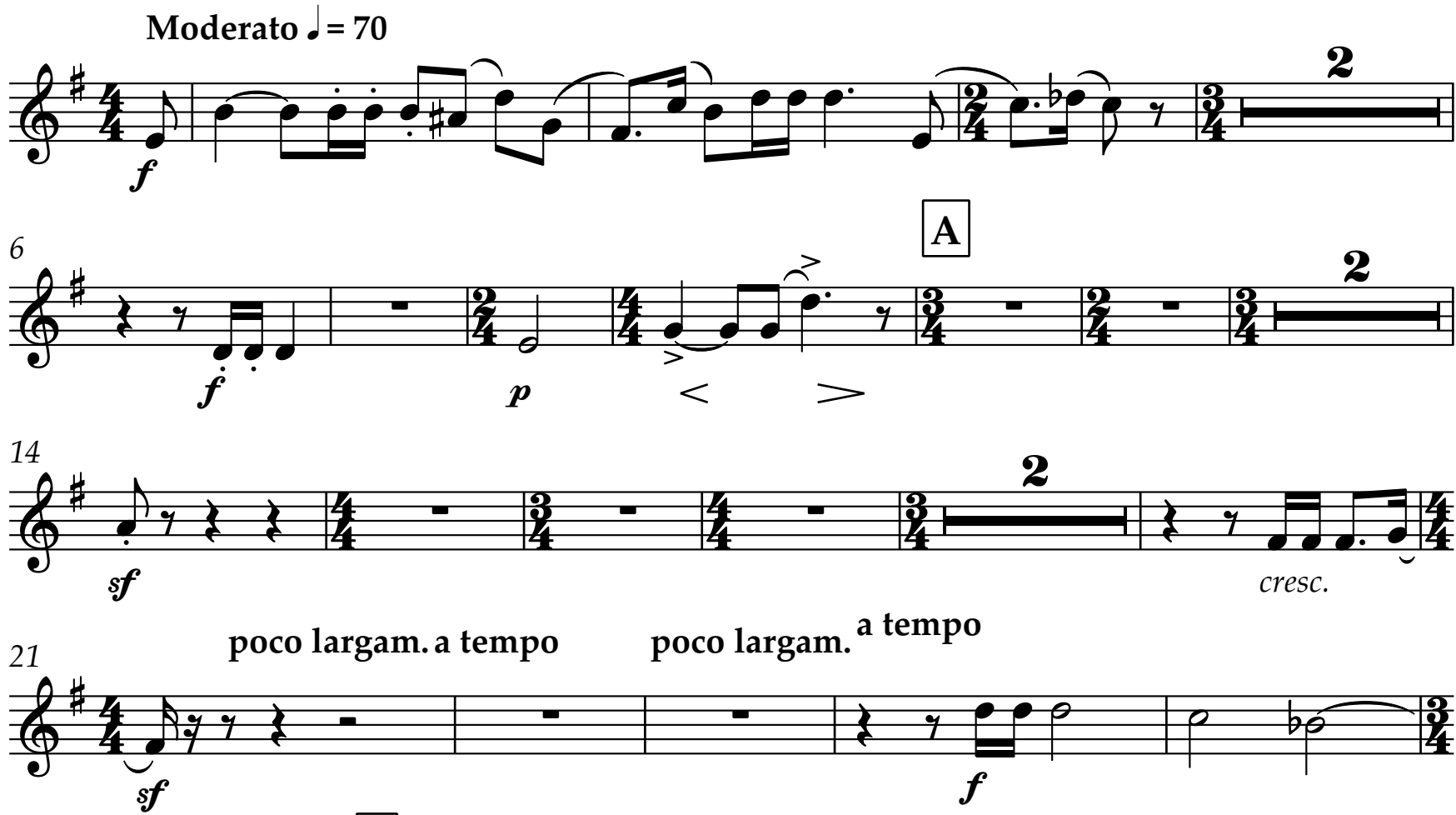

26 molto rall. B a tempo

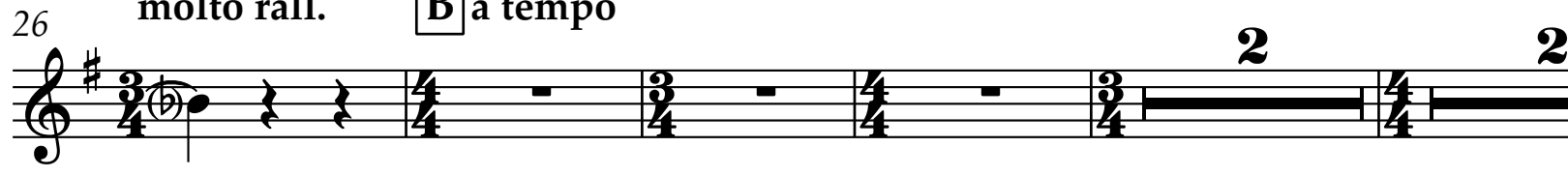

C
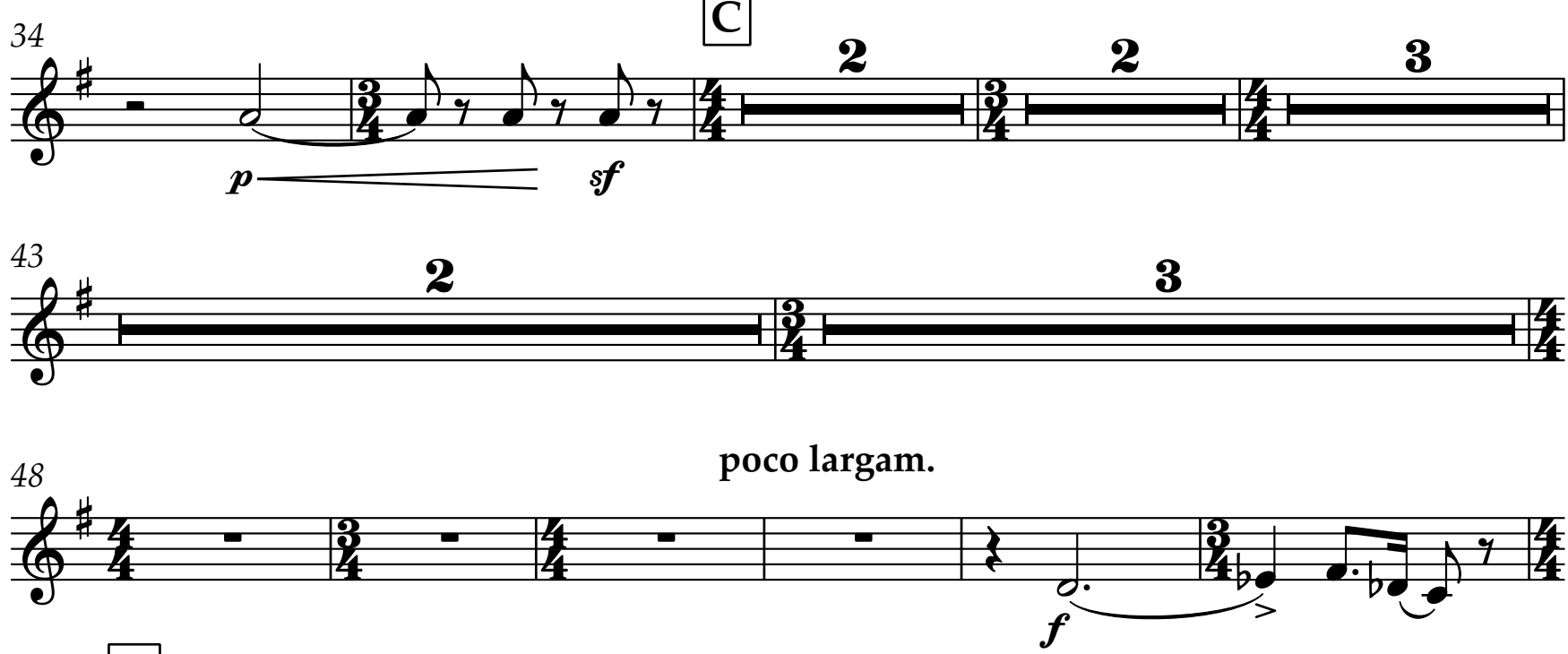

54 D poco sostenuto

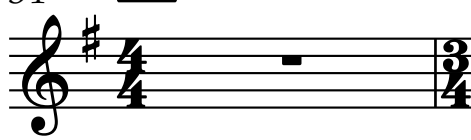

2

60 molto rall

34 
2 a tempo
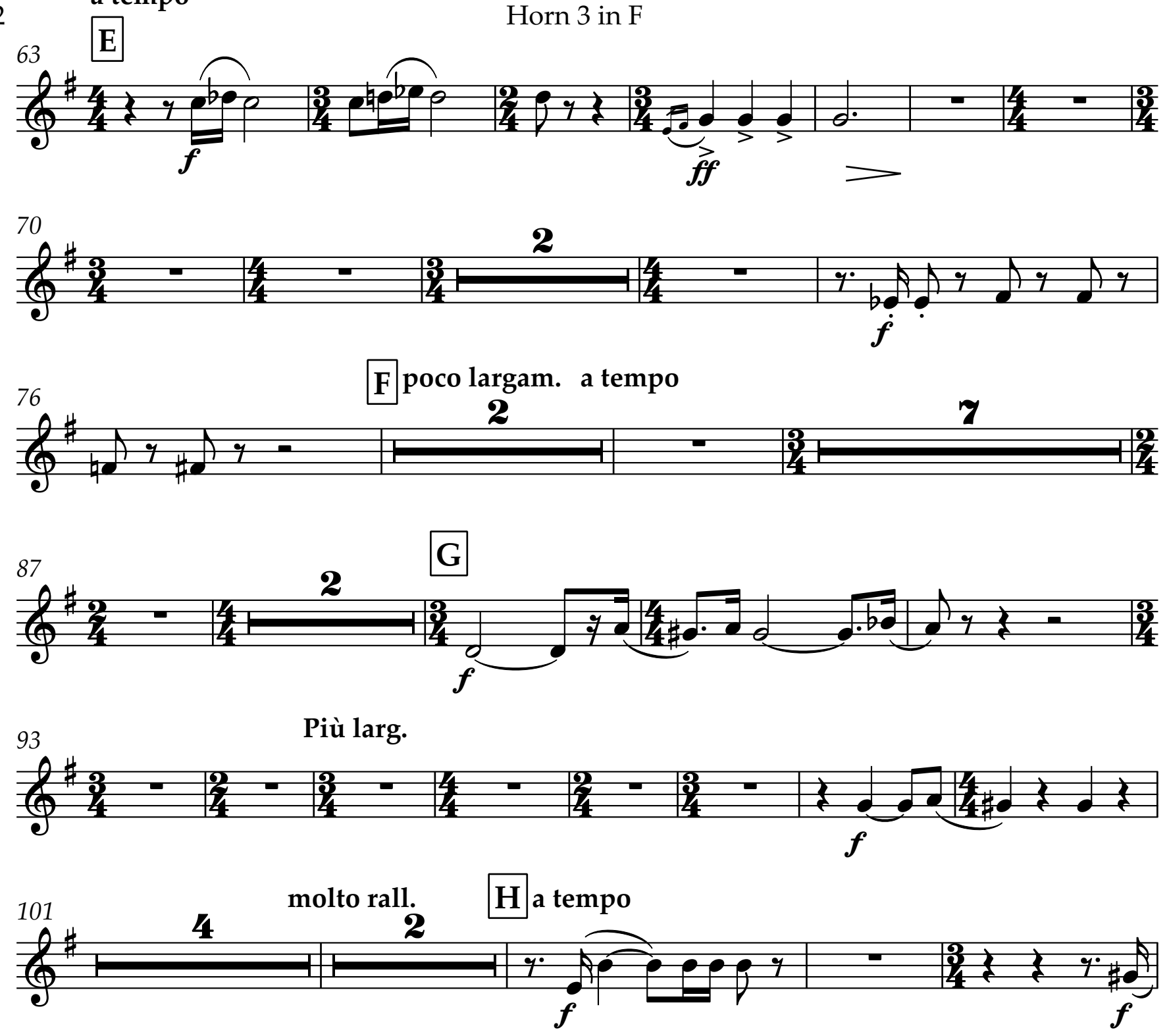

110 poco sostenuto

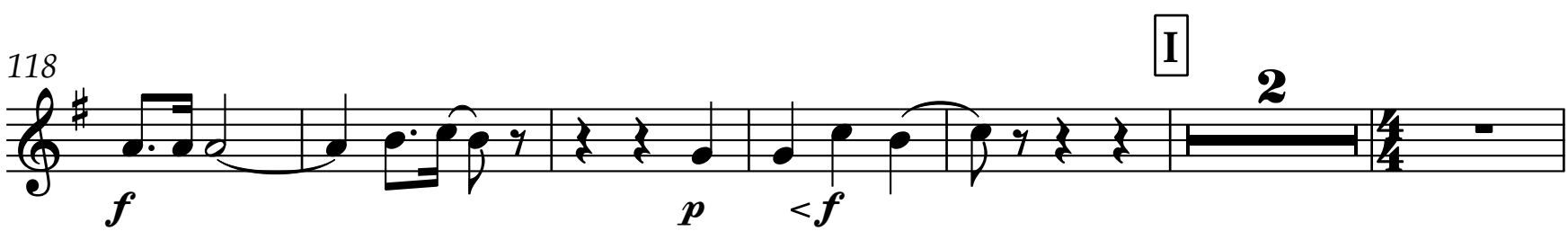

126

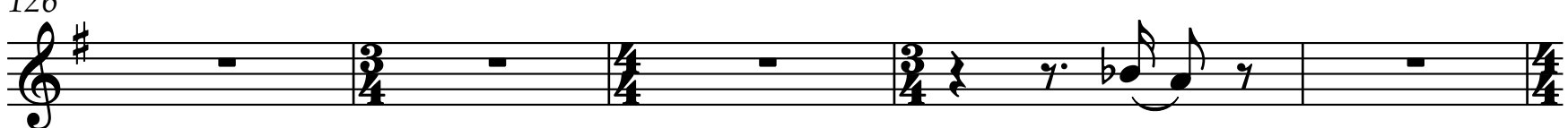

131 Largamente

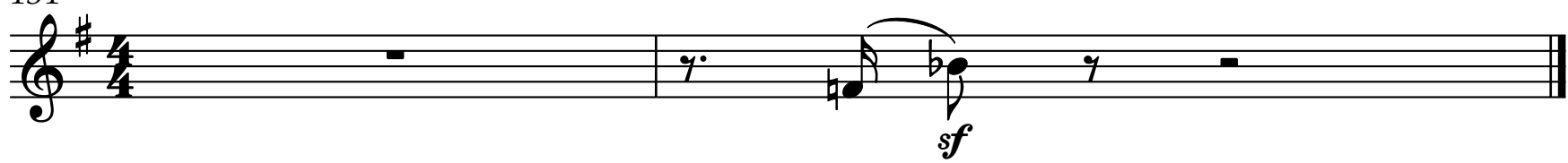




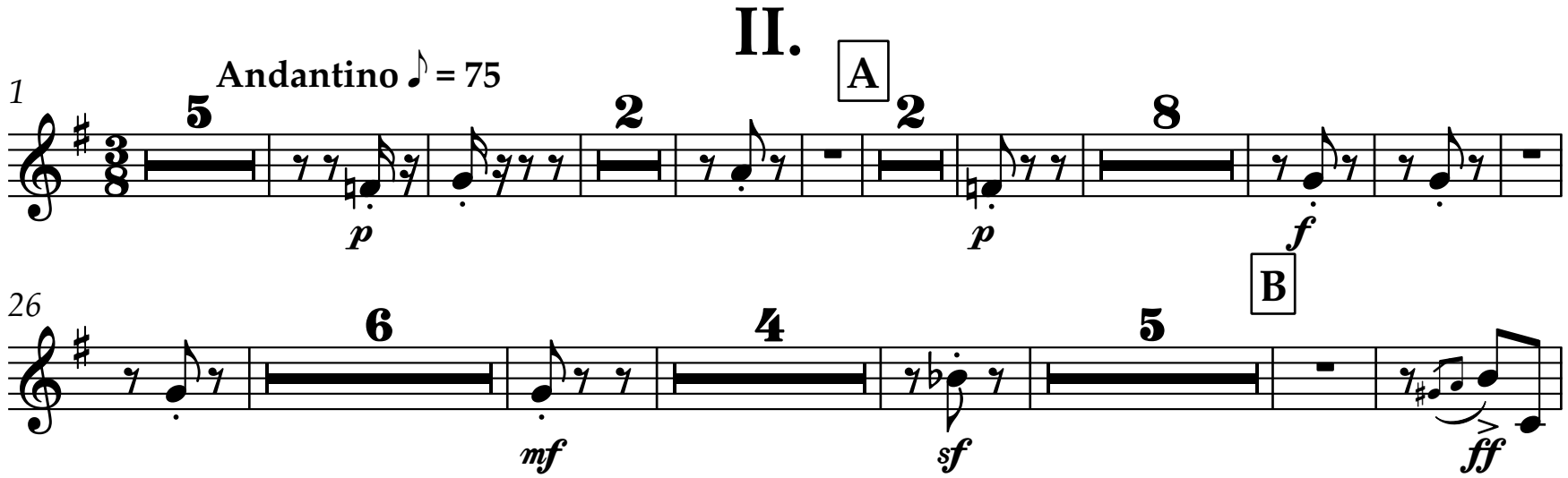

46

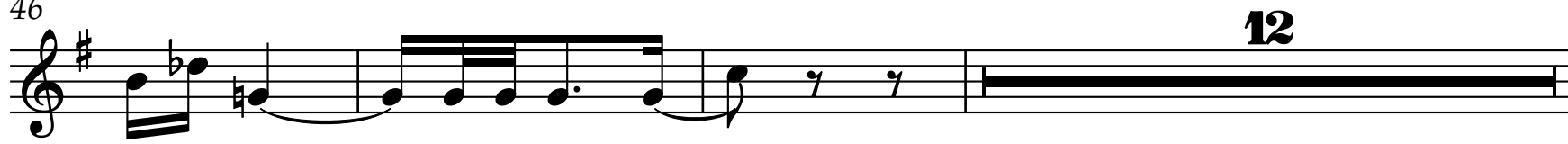

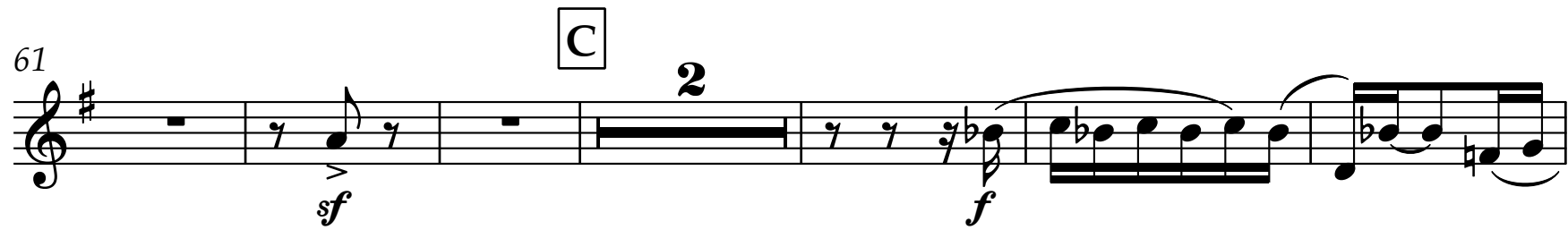

69

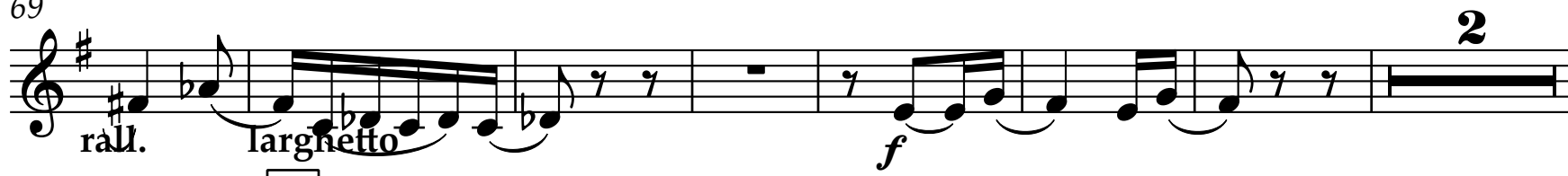

D

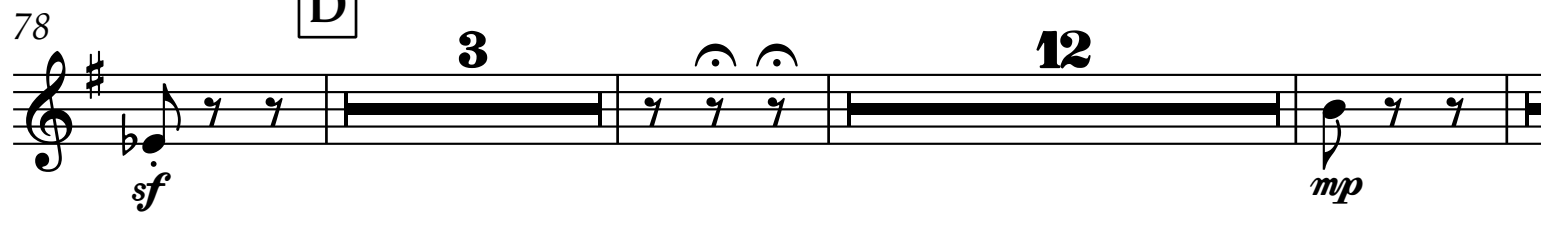

2

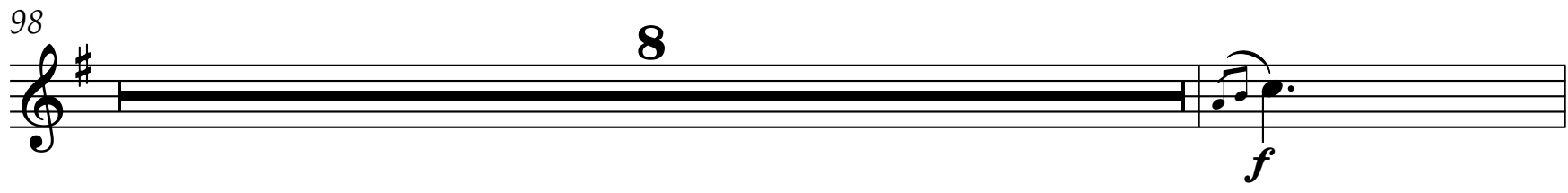

(4)
112
E Kadenz

6

113 F tempo I

\begin{tabular}{l|l|l}
\hline 8 \\
\hline
\end{tabular} 
Horn 3 in F

Horn 3 in F

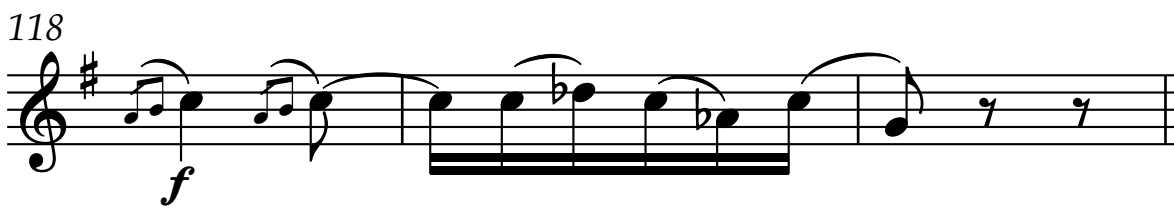

6

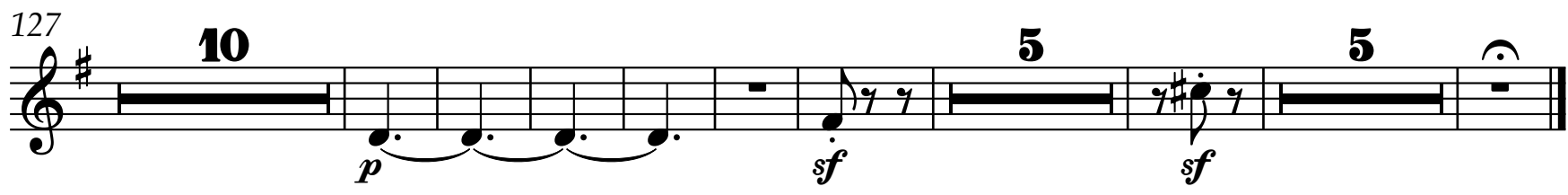

III.

\begin{tabular}{llll} 
Allegro $d=90$ & $\mathbf{A}$ & $\mathbf{A}$ & $\mathbf{1 1}$ \\
\hline
\end{tabular}
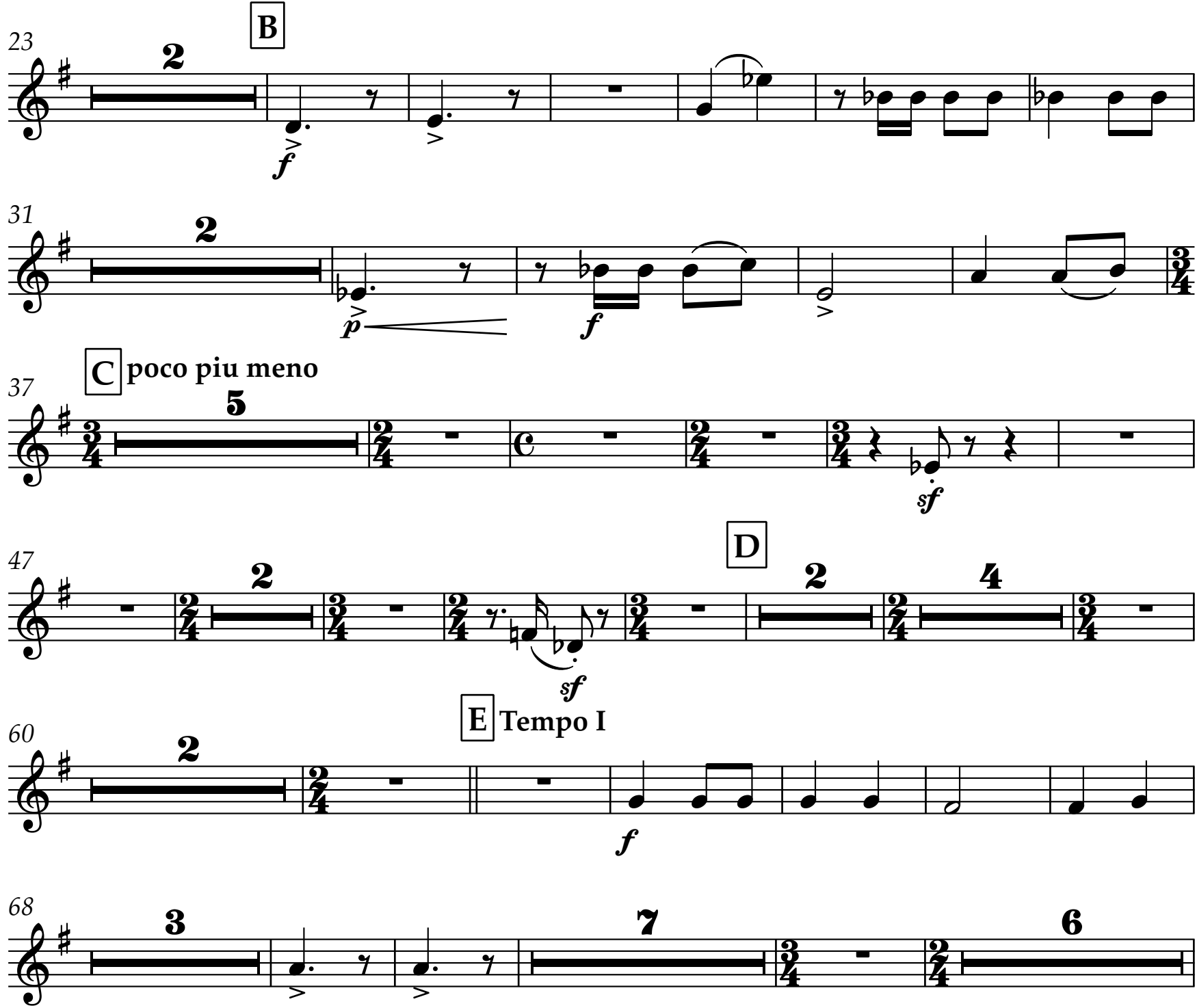

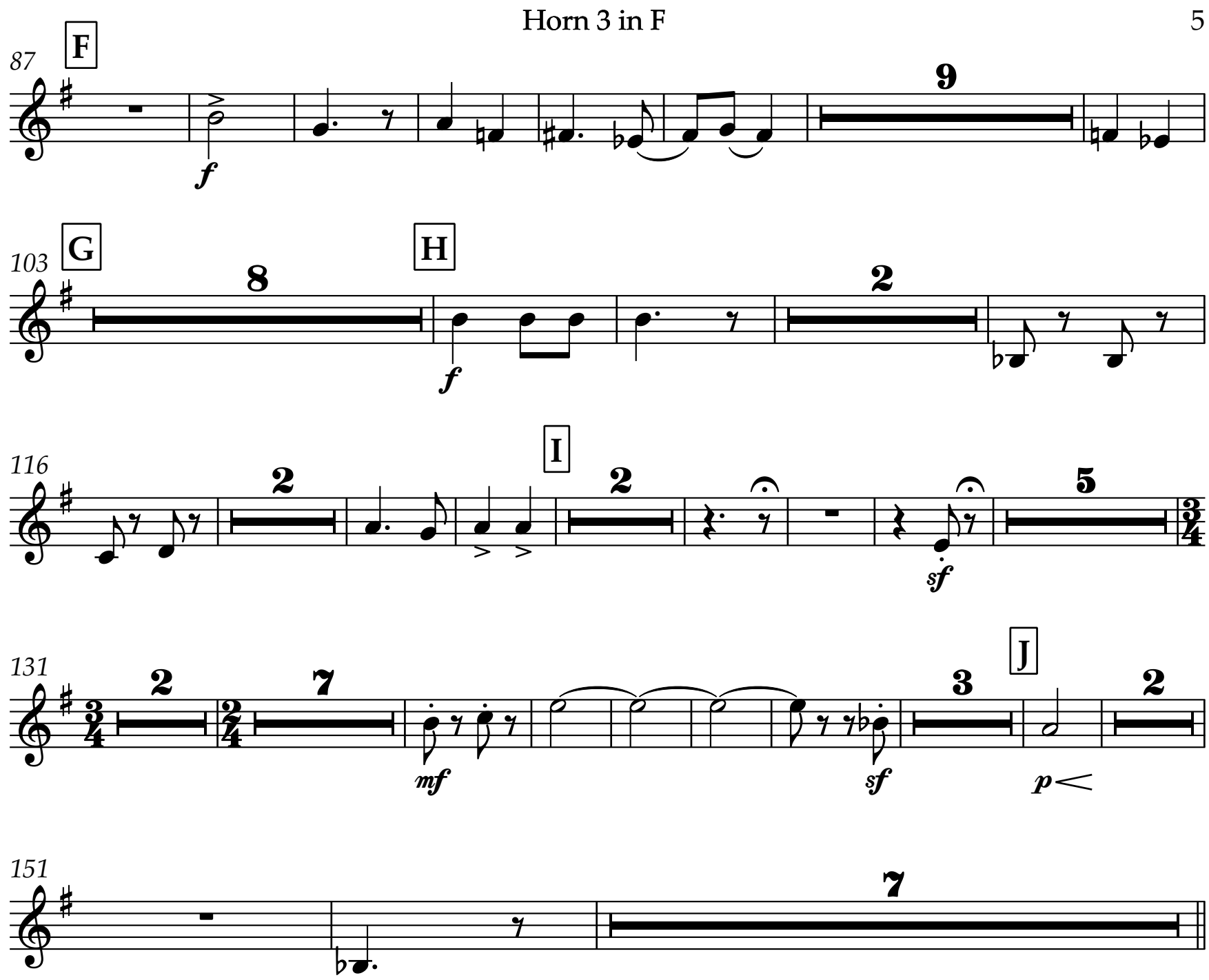

${ }_{160} \mathbf{K}$ sostenuto cantabile

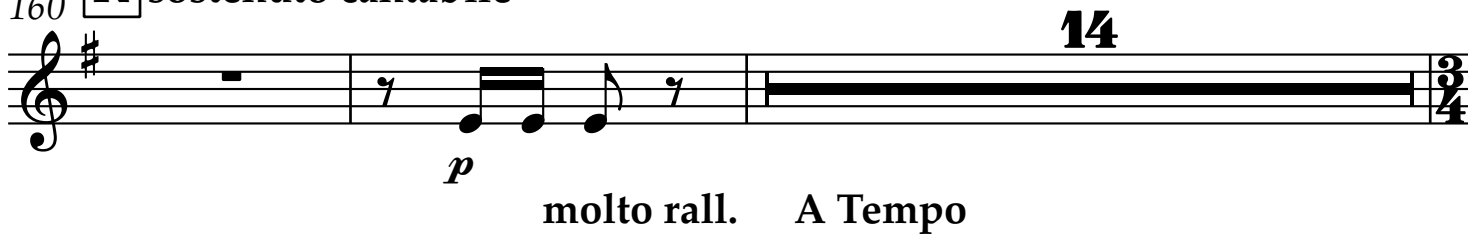

\section{4}
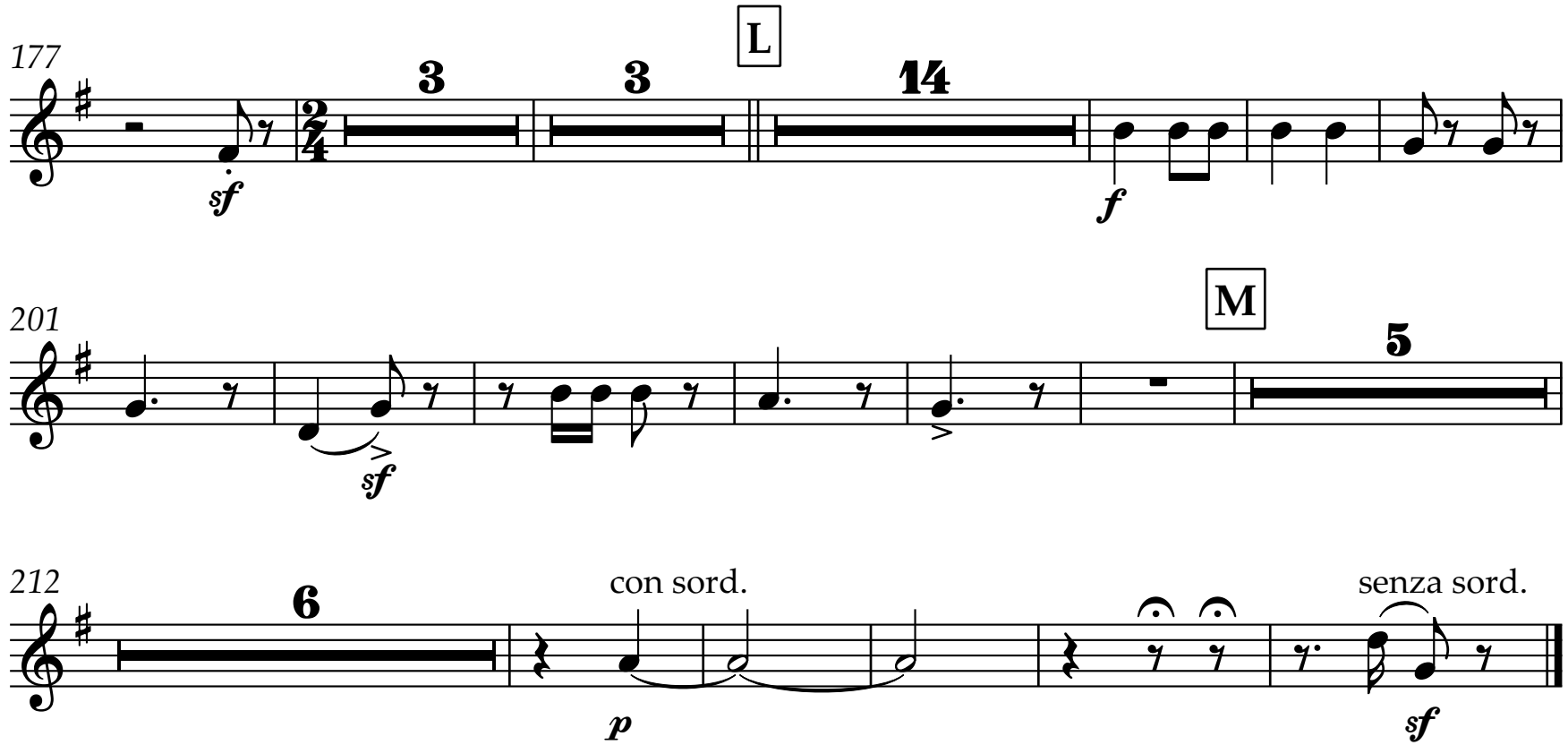
Trumpet in $\mathrm{C}$

\section{Concerto for Viola and Orchestra}

Dmitris Dragatakis
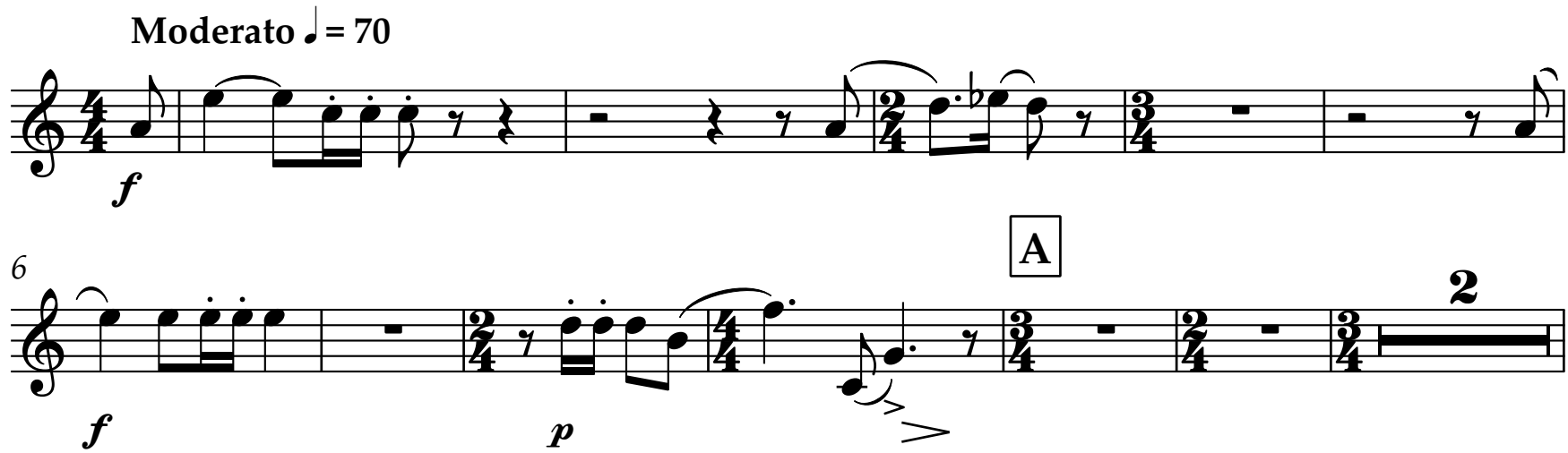

14

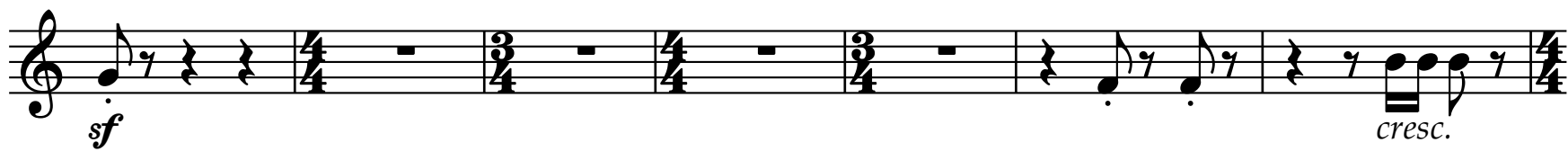

21 poco largam. a tempo poco largam. ${ }^{\text {a tempo }}$

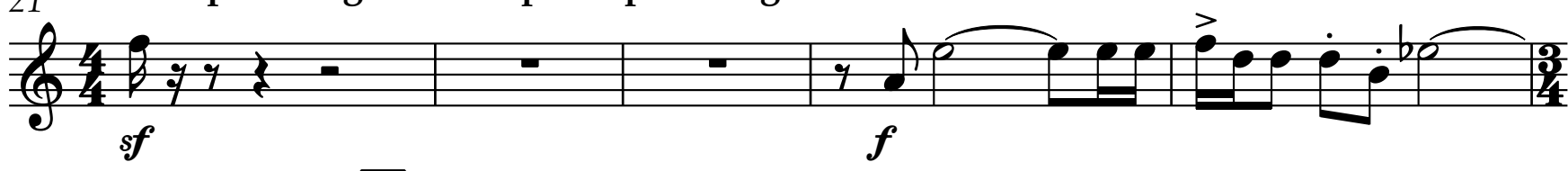

26 molto rall. B a tempo

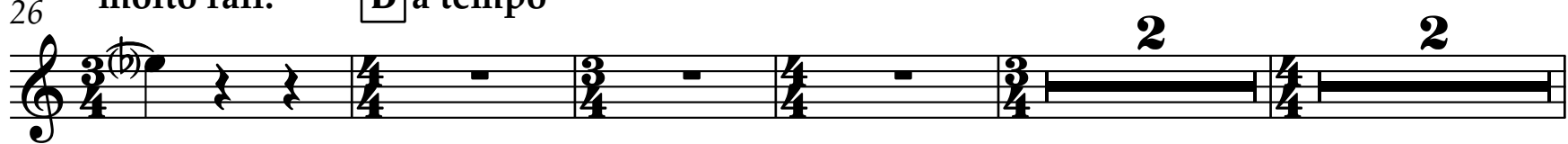

C
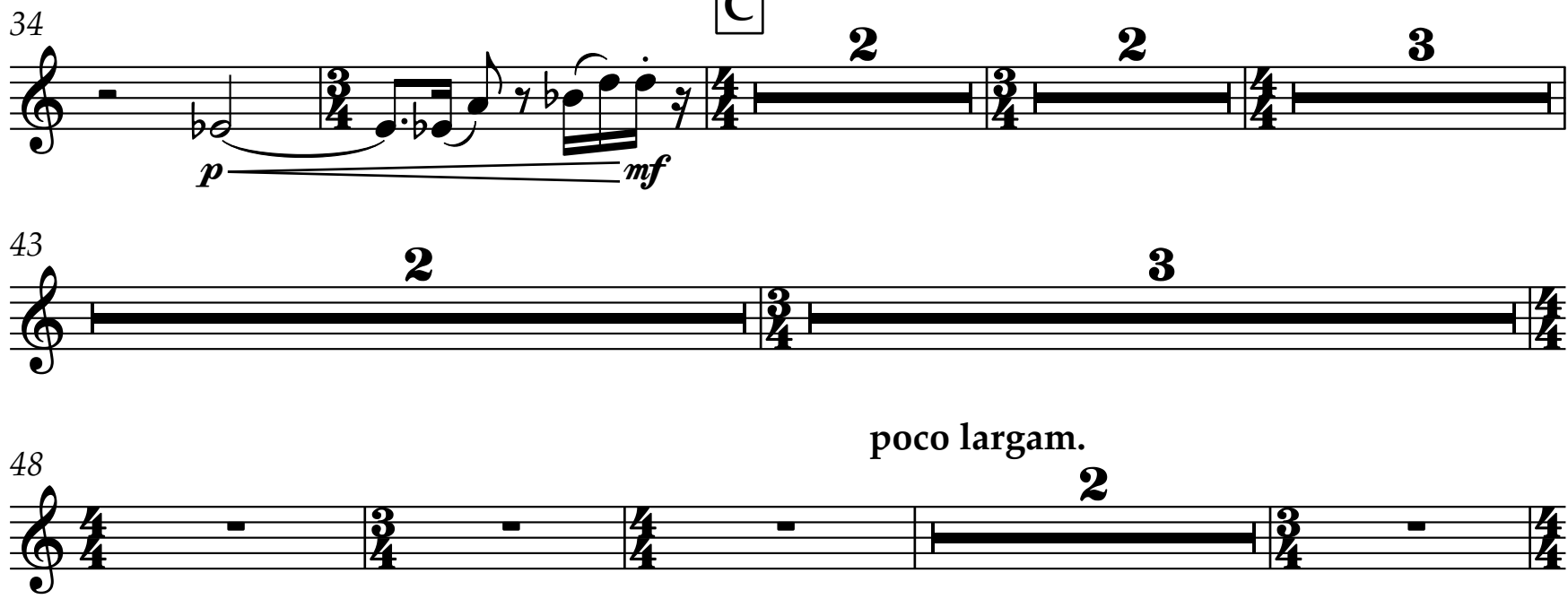

$54 \mathrm{D}$ poco sostenuto

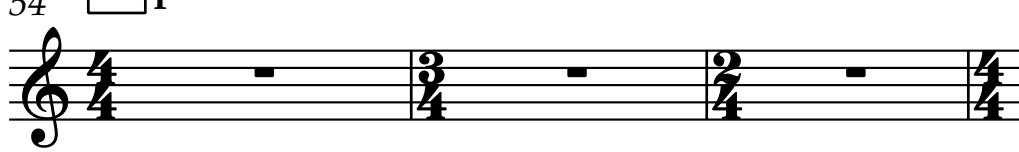

2

60 molto rall

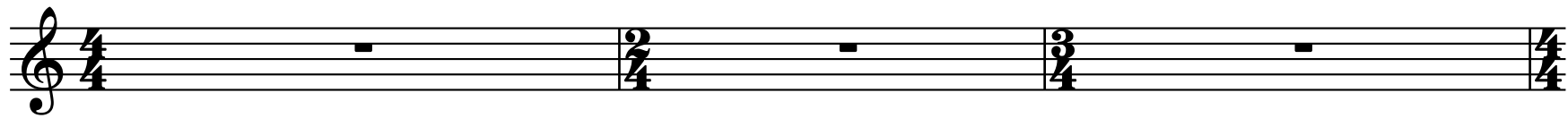


63 E a tempo

Trumpet in C

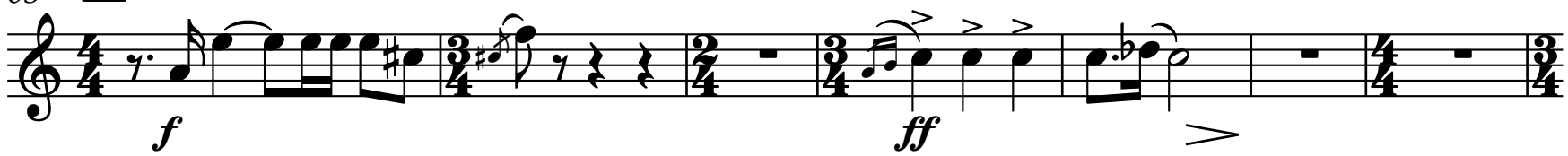
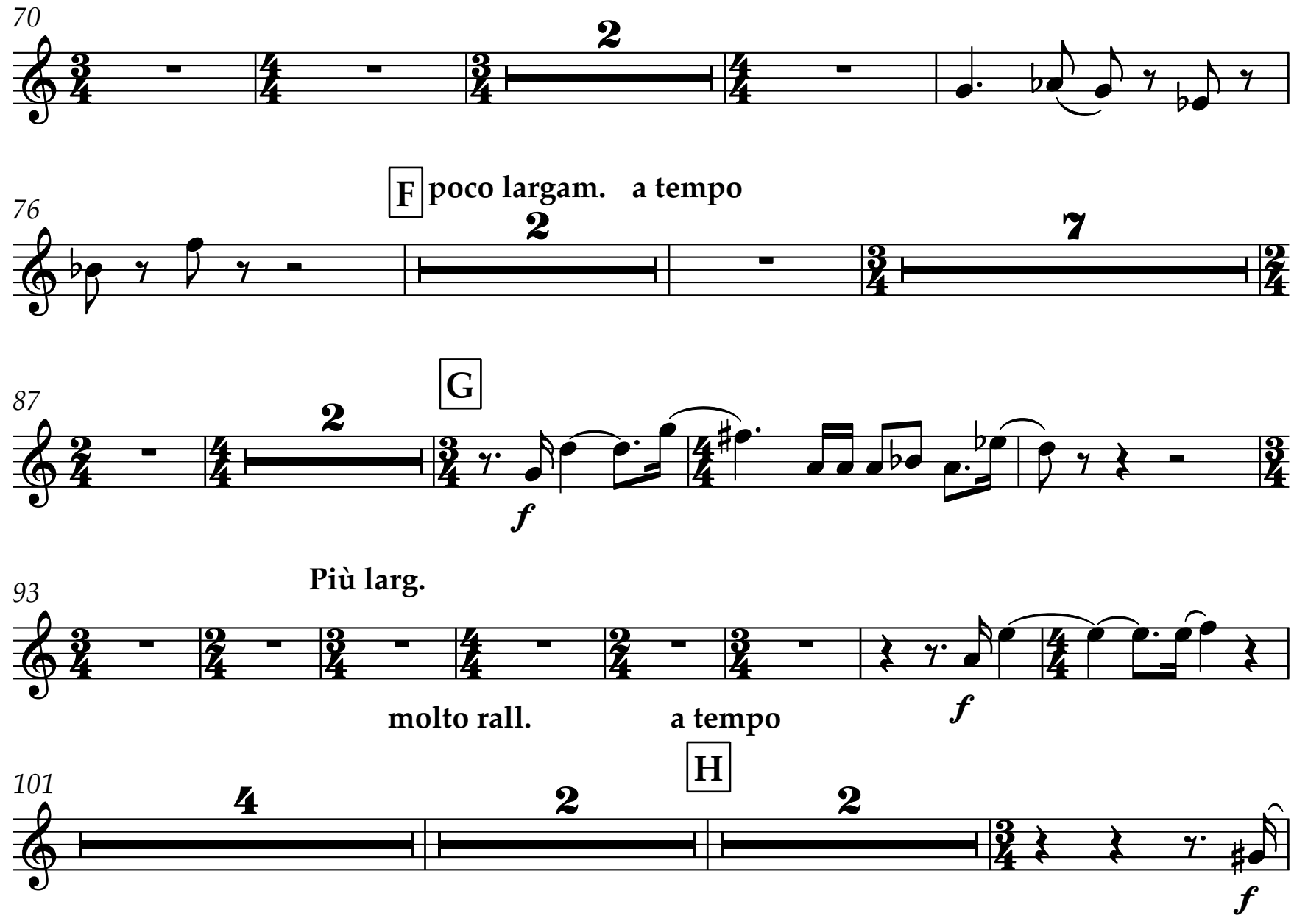

(110)

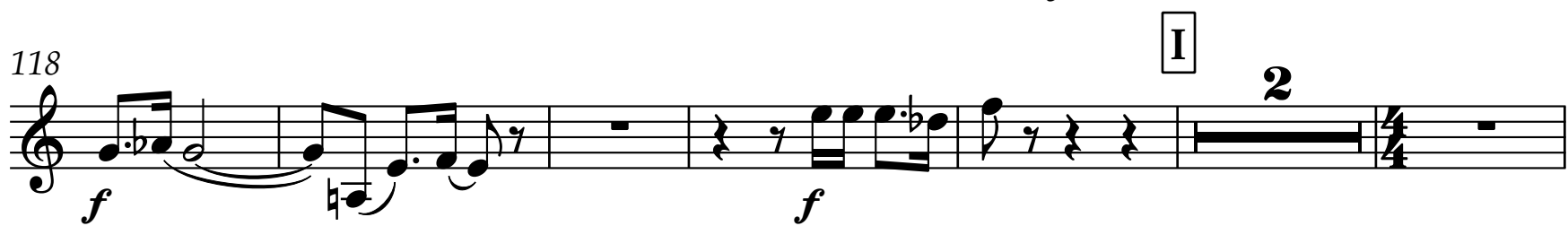

126 con sord. senza sord.

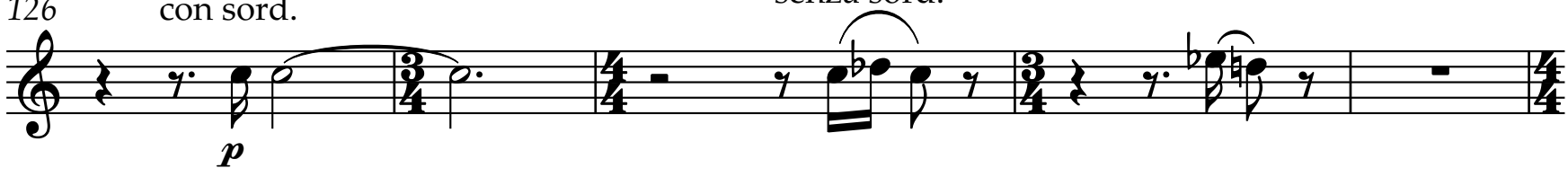

${ }_{131}$ Largamente

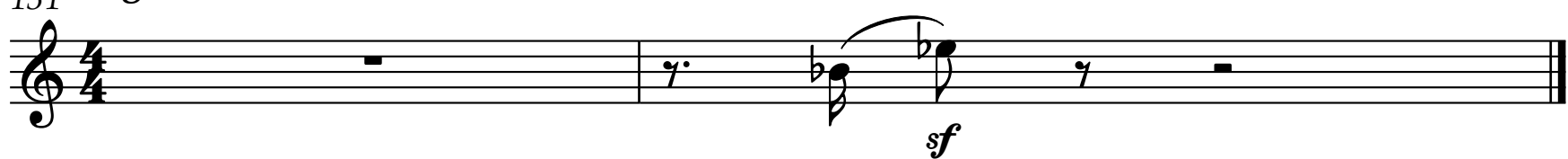



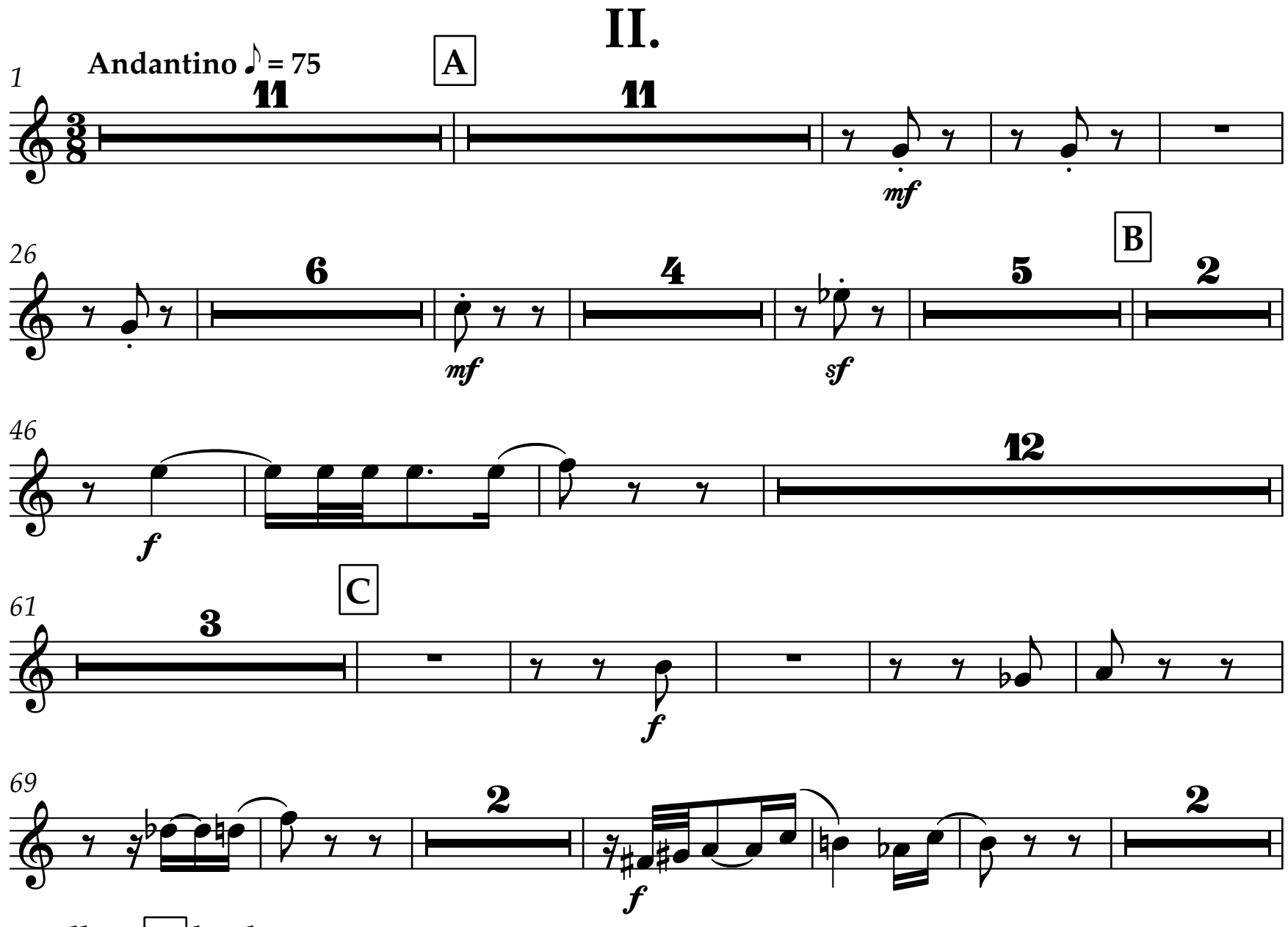

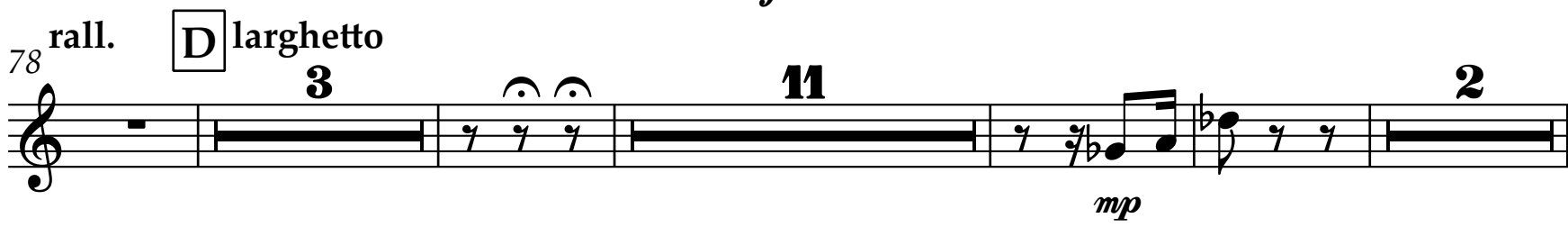
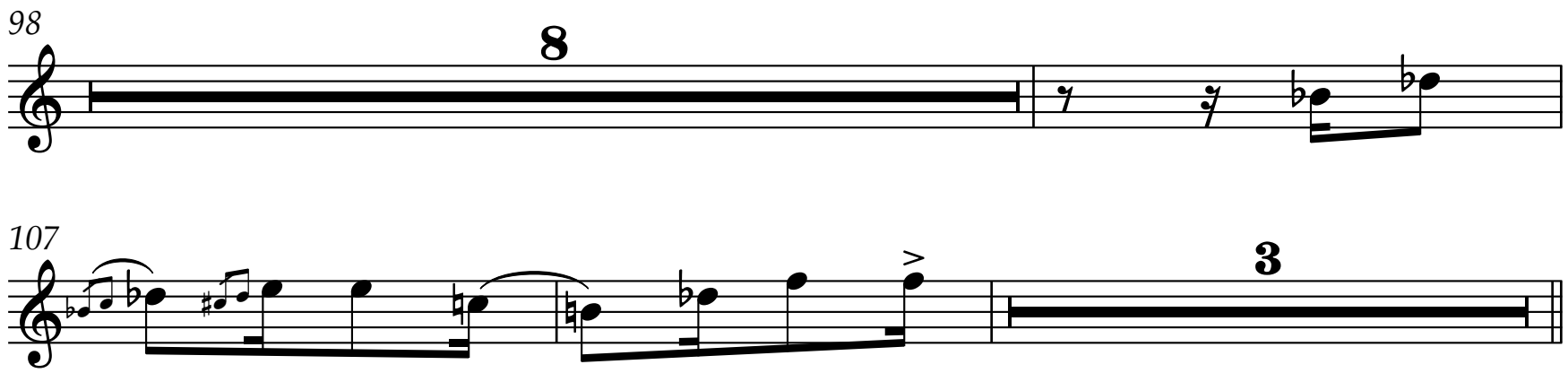

112

E Kadenz

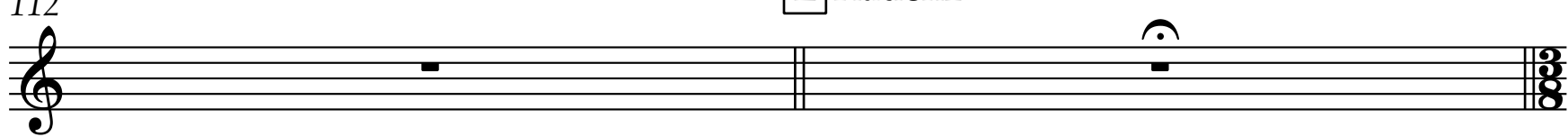

113 F tempo I

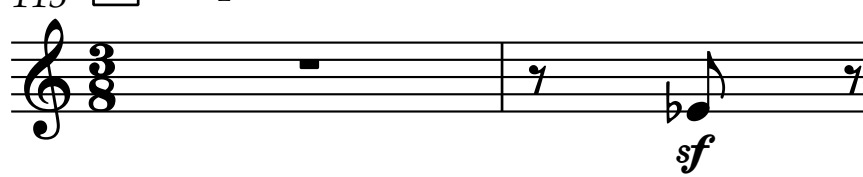


4rumpet in C

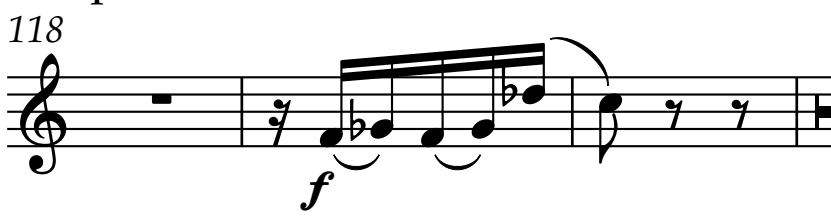

127

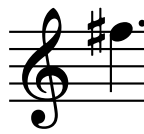

senza sord.

senza sord.

26

3

con sord.

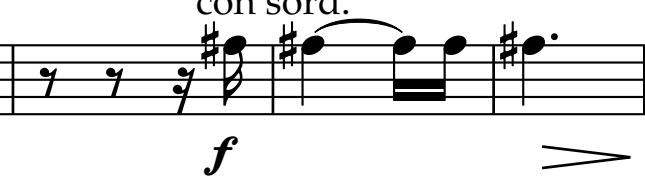

$f$

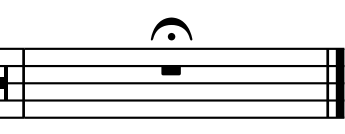

III.
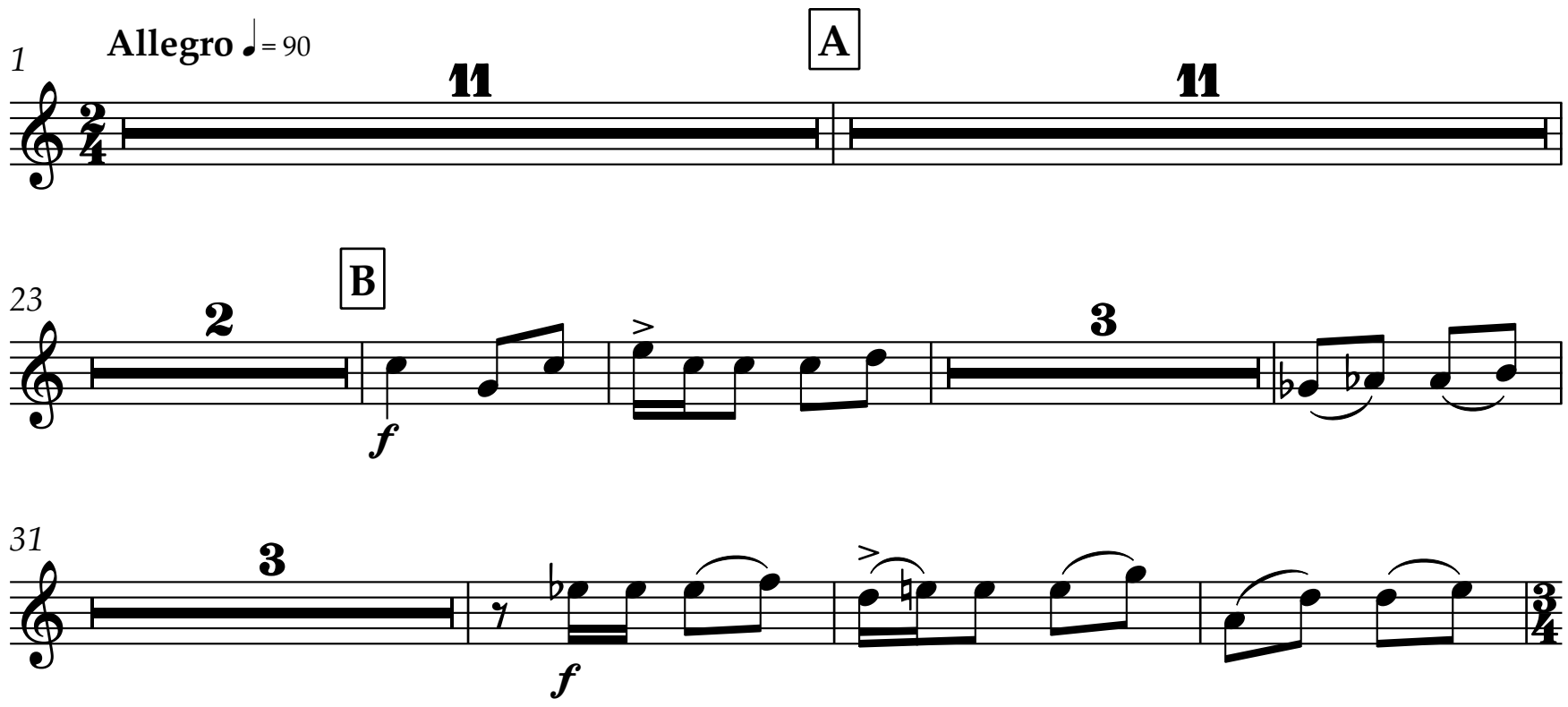

37 C poco piu meno

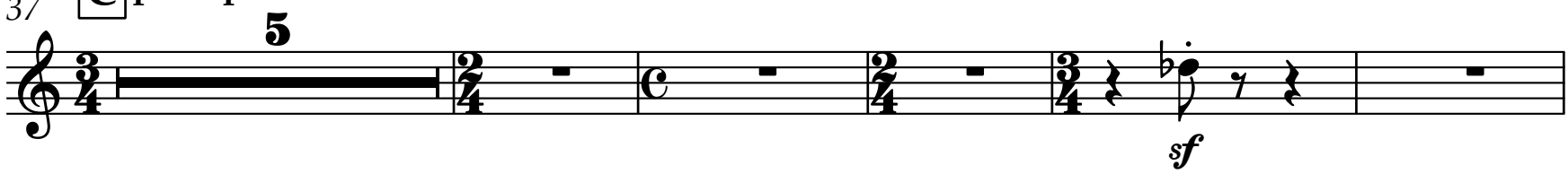
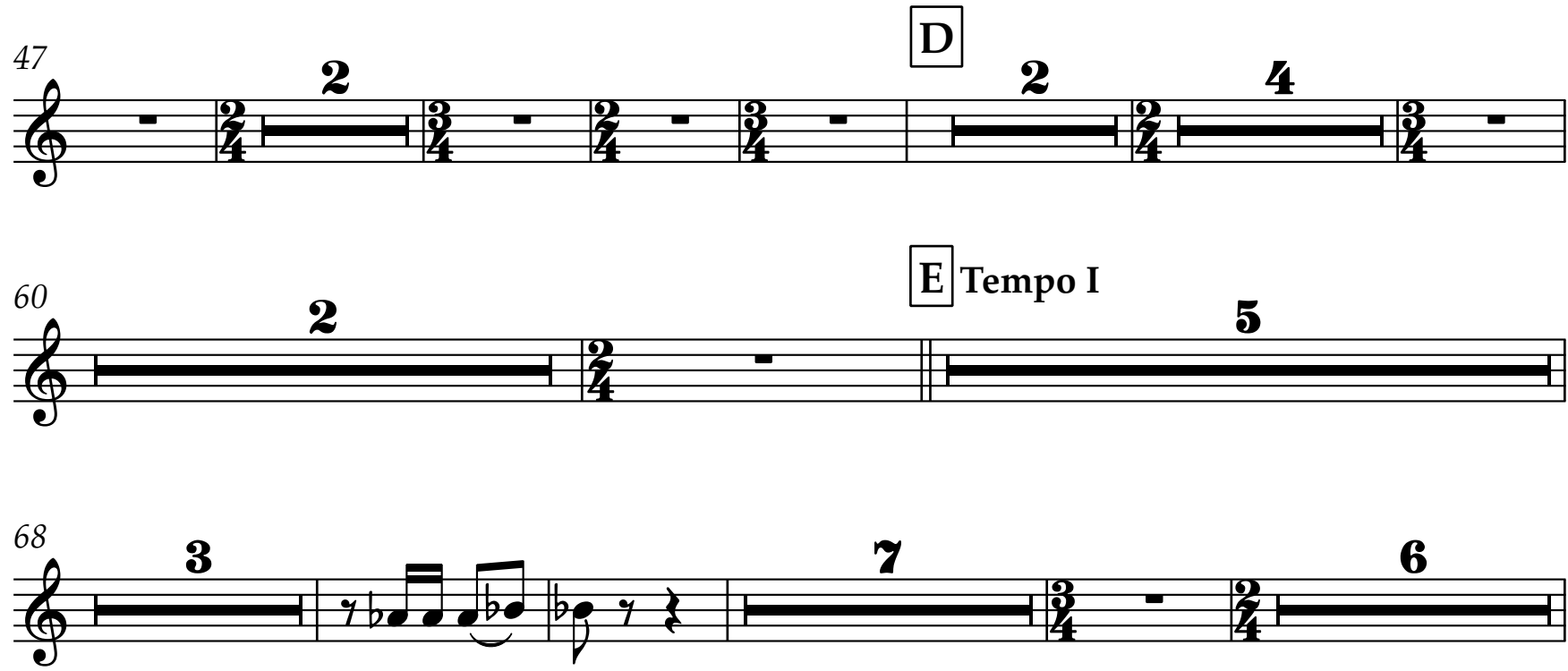
${ }_{87} \mathbf{F}$ Trumpet in C
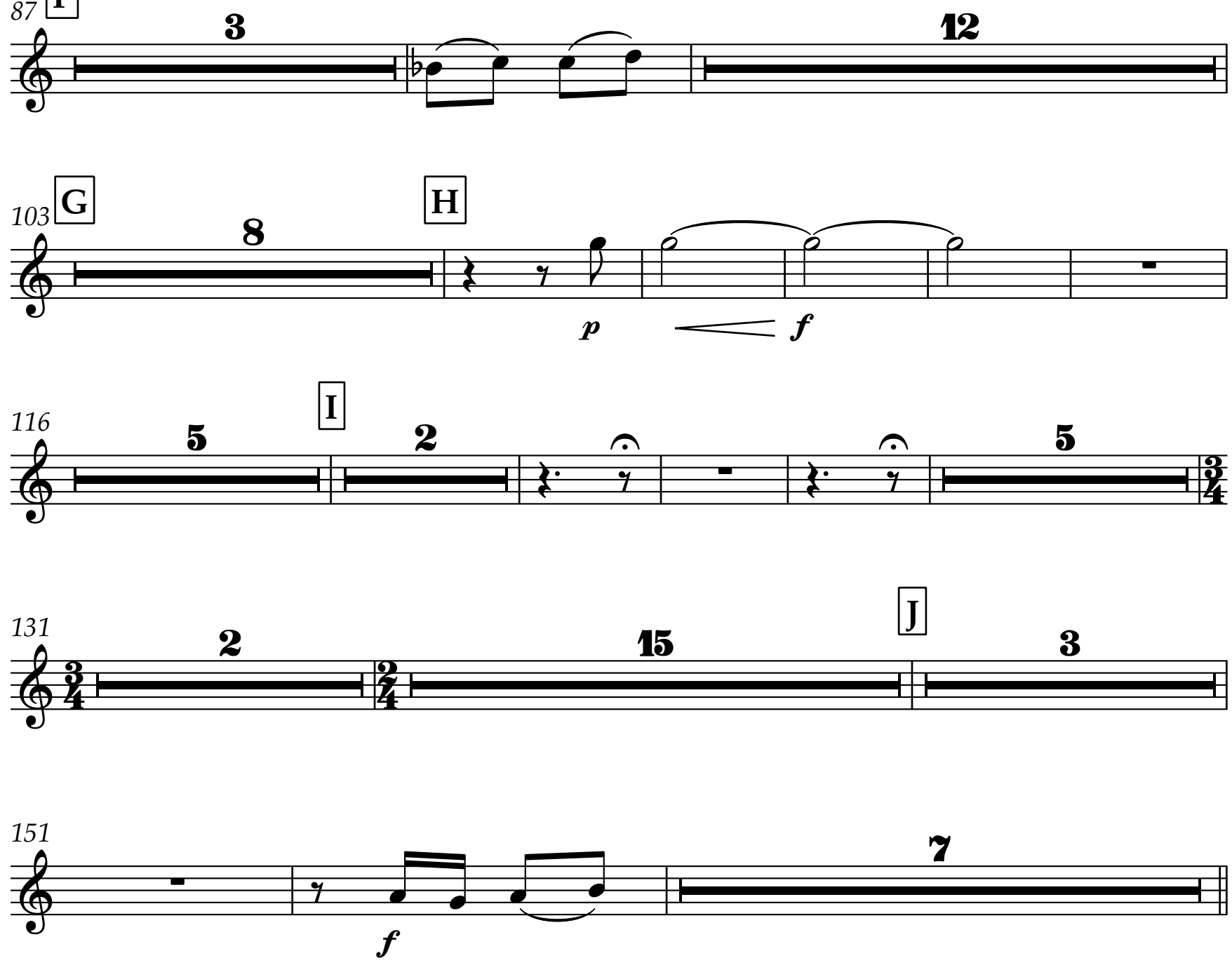

${ }_{160} \mathbf{K}$ sostenuto cantabile

16

molto rall. A Tempo
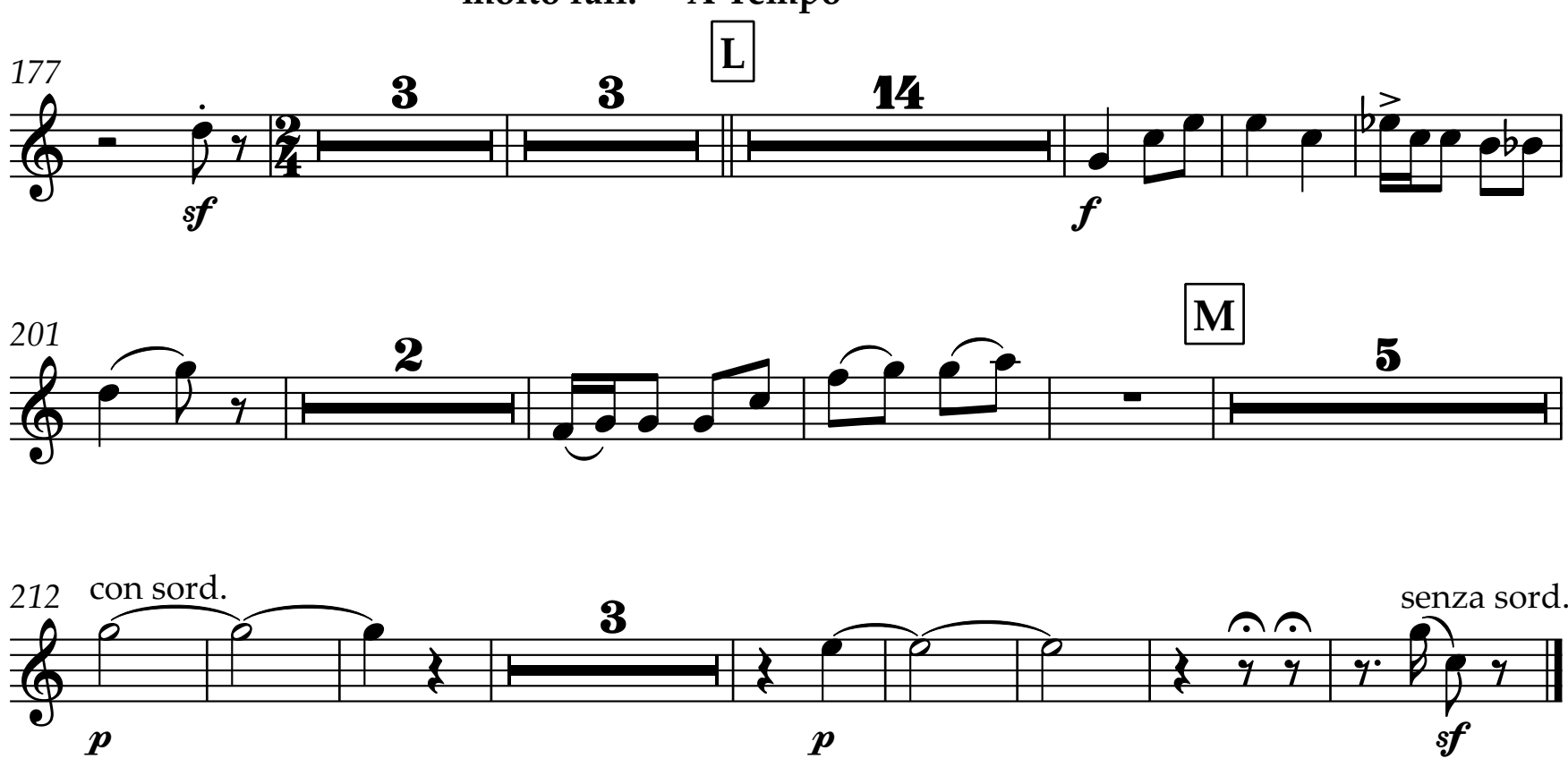


\section{Violin I Concerto for Viola and Orchestra}

Dmitris Dragatakis
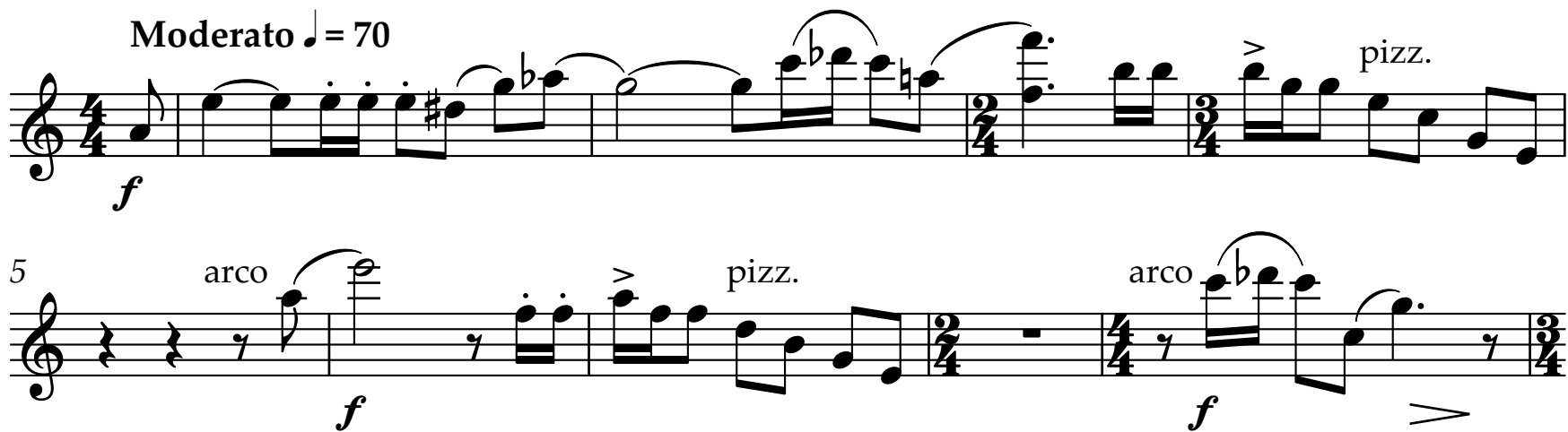
60 a

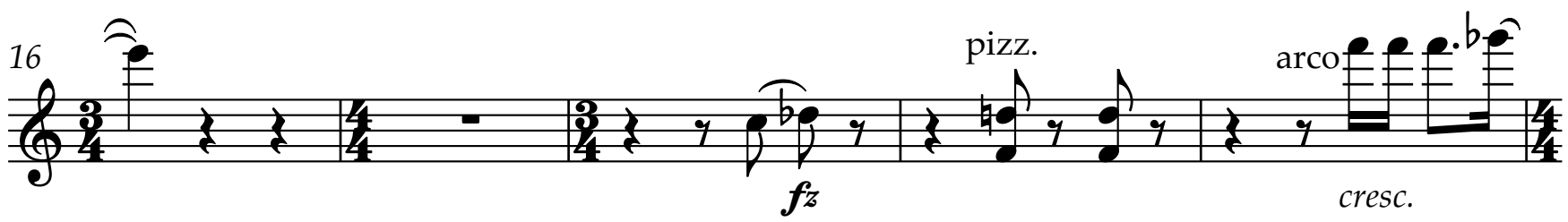

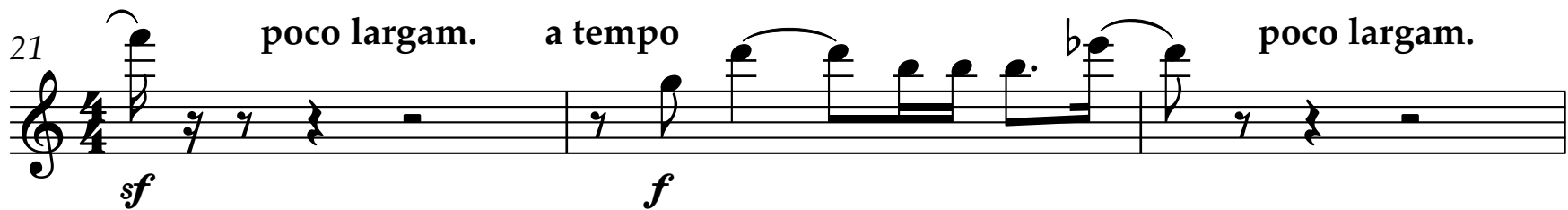

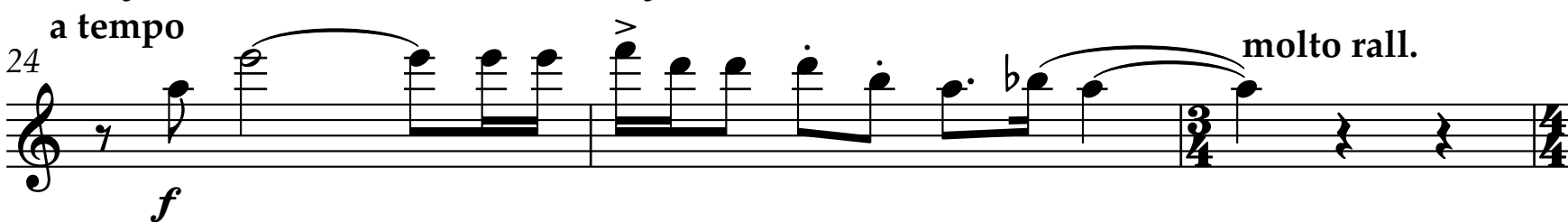
(a)

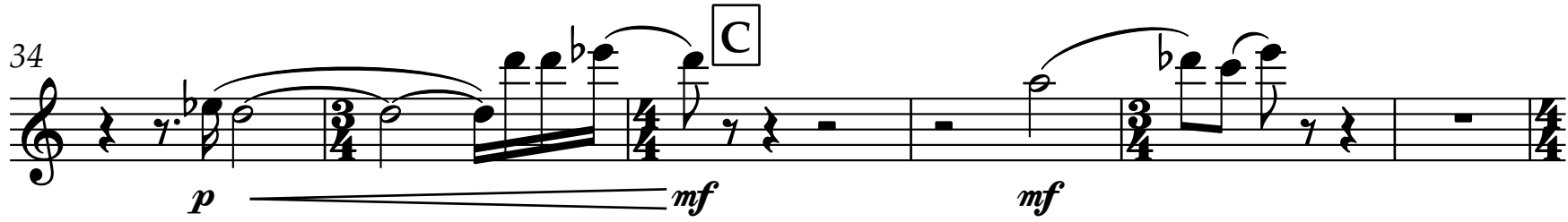

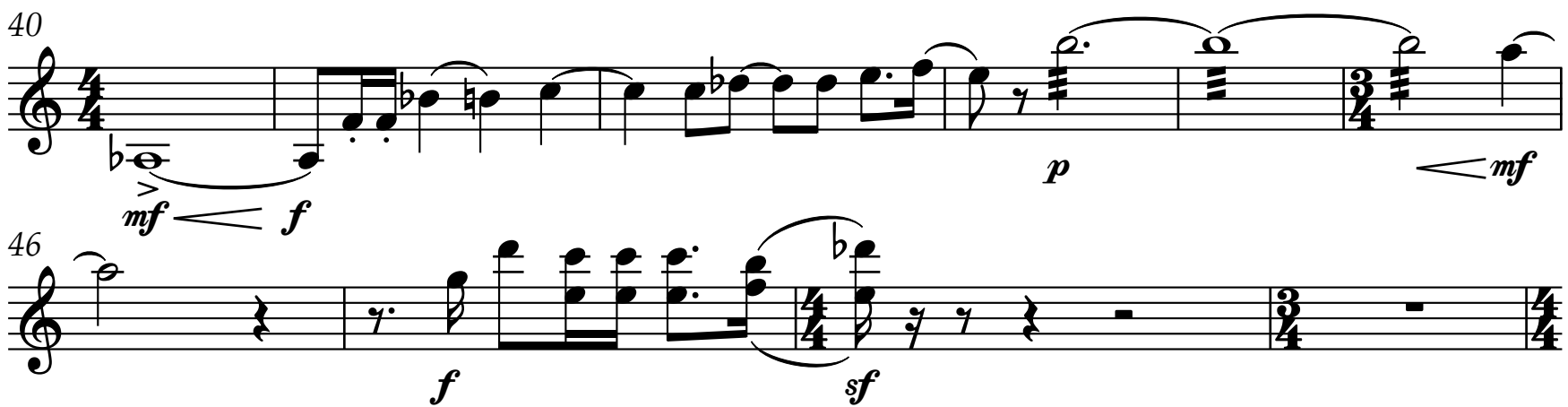


(9)

54 D poco sostenuto

col legno

arco

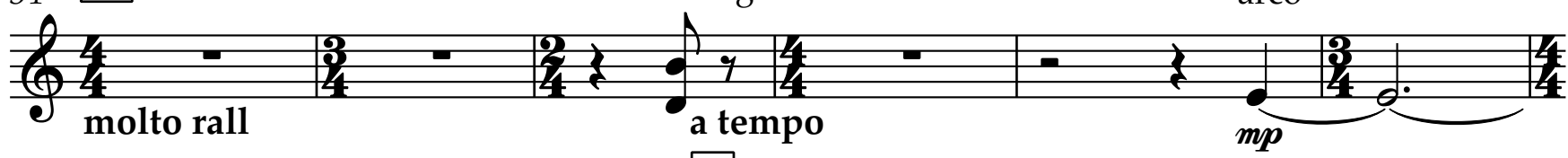

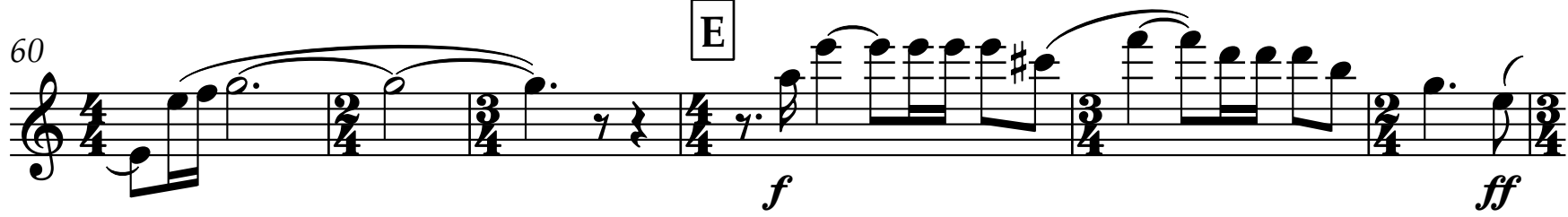

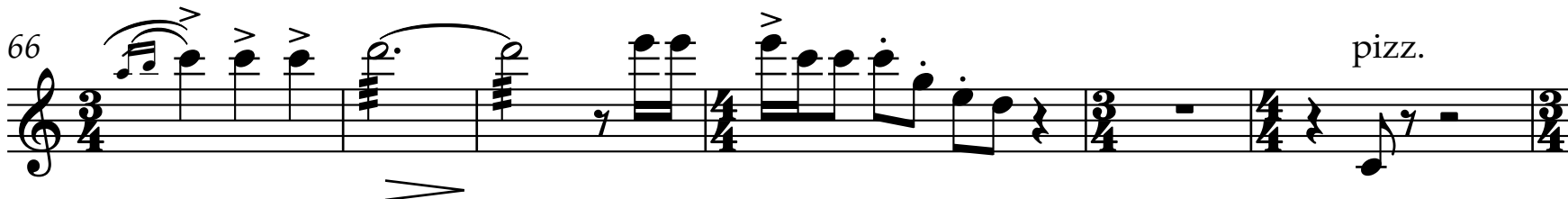
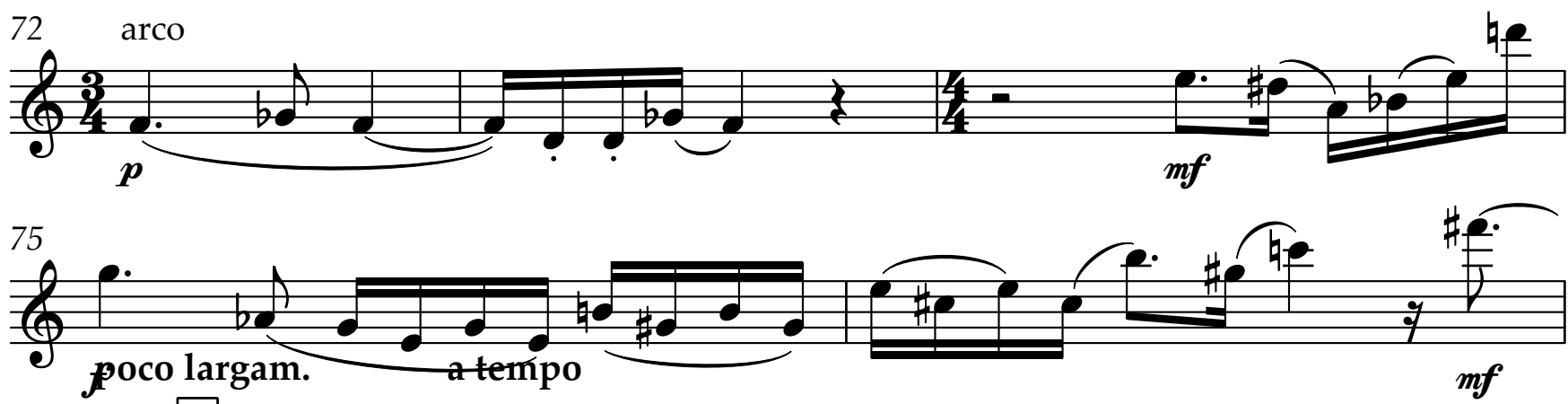

77 (\#) $\mathbf{F}$

(2)

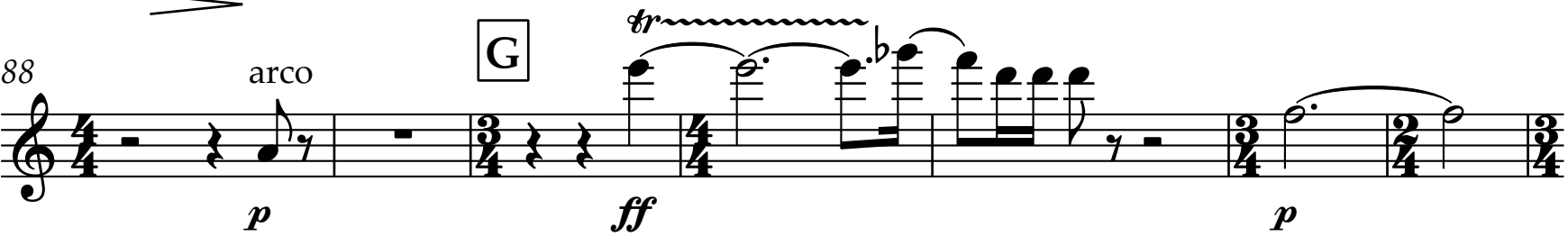

95 Più larg.

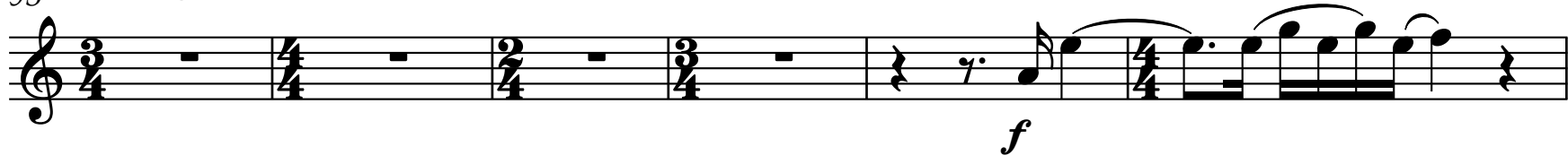
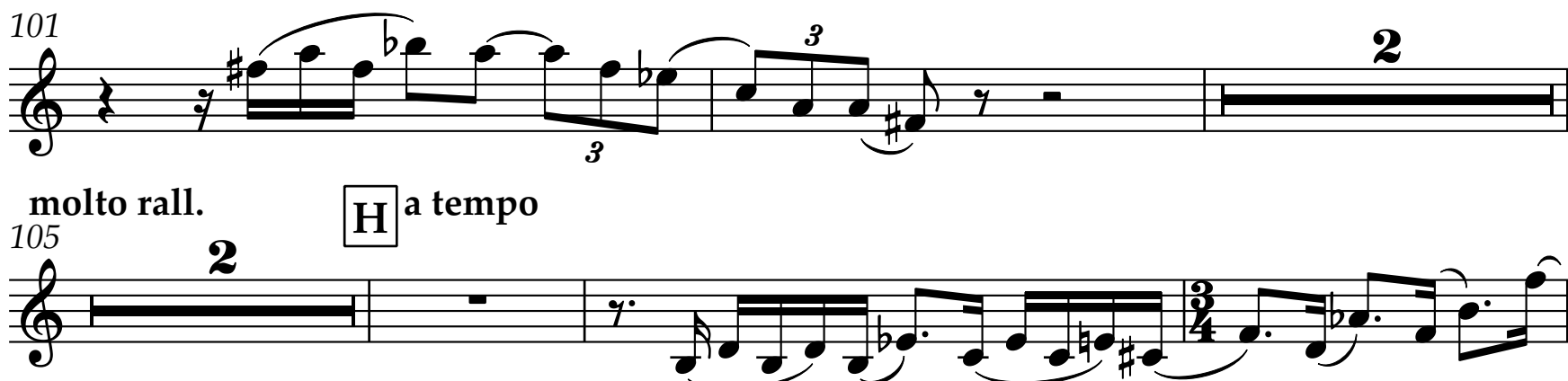

H a tempo 
Violin I

$110>$ poco sostenuto

है

Violin I

3

117

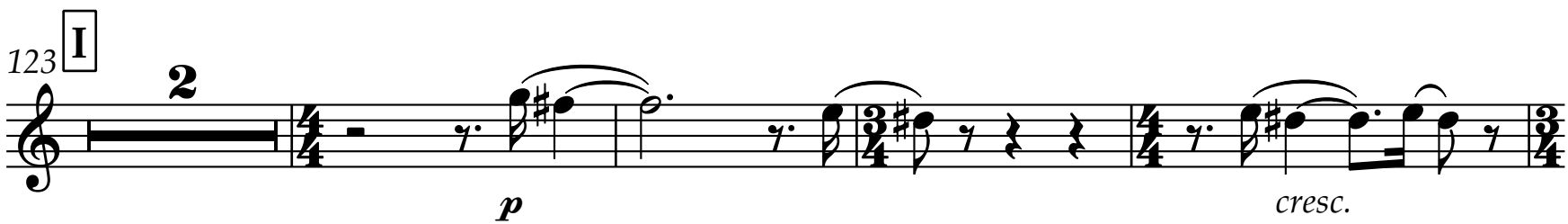

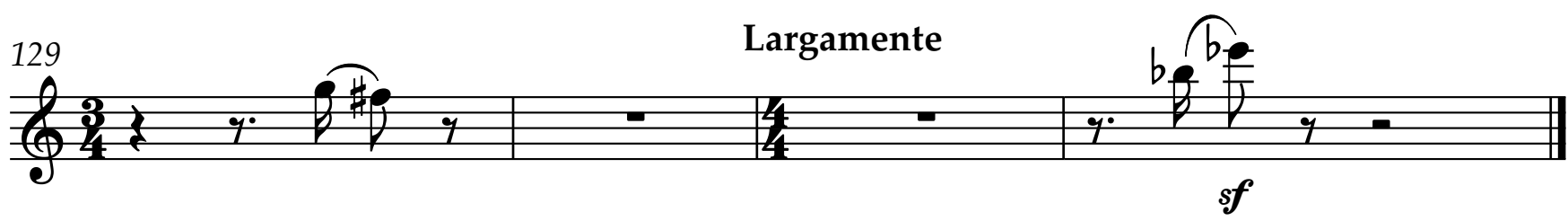

II.
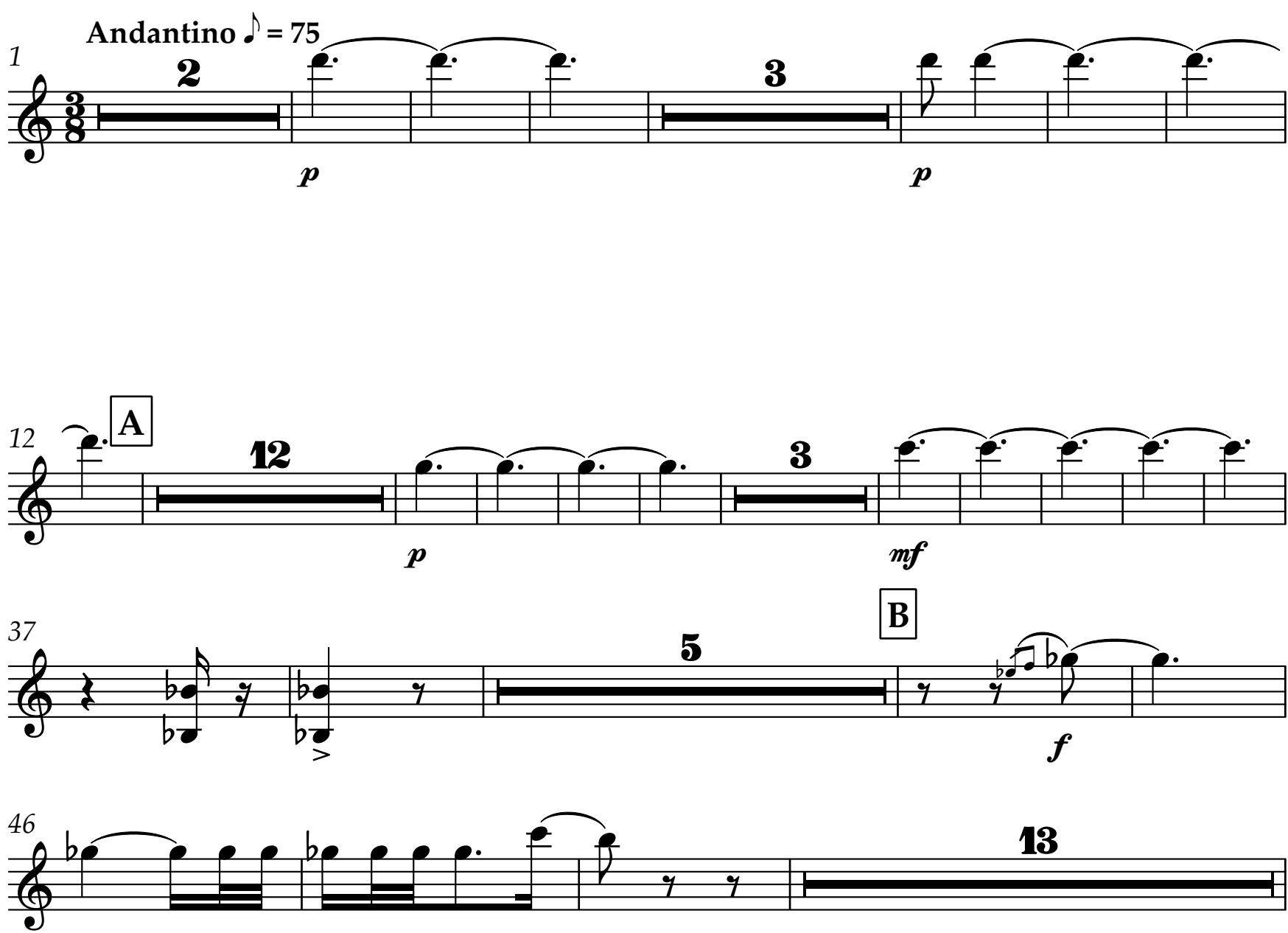
4
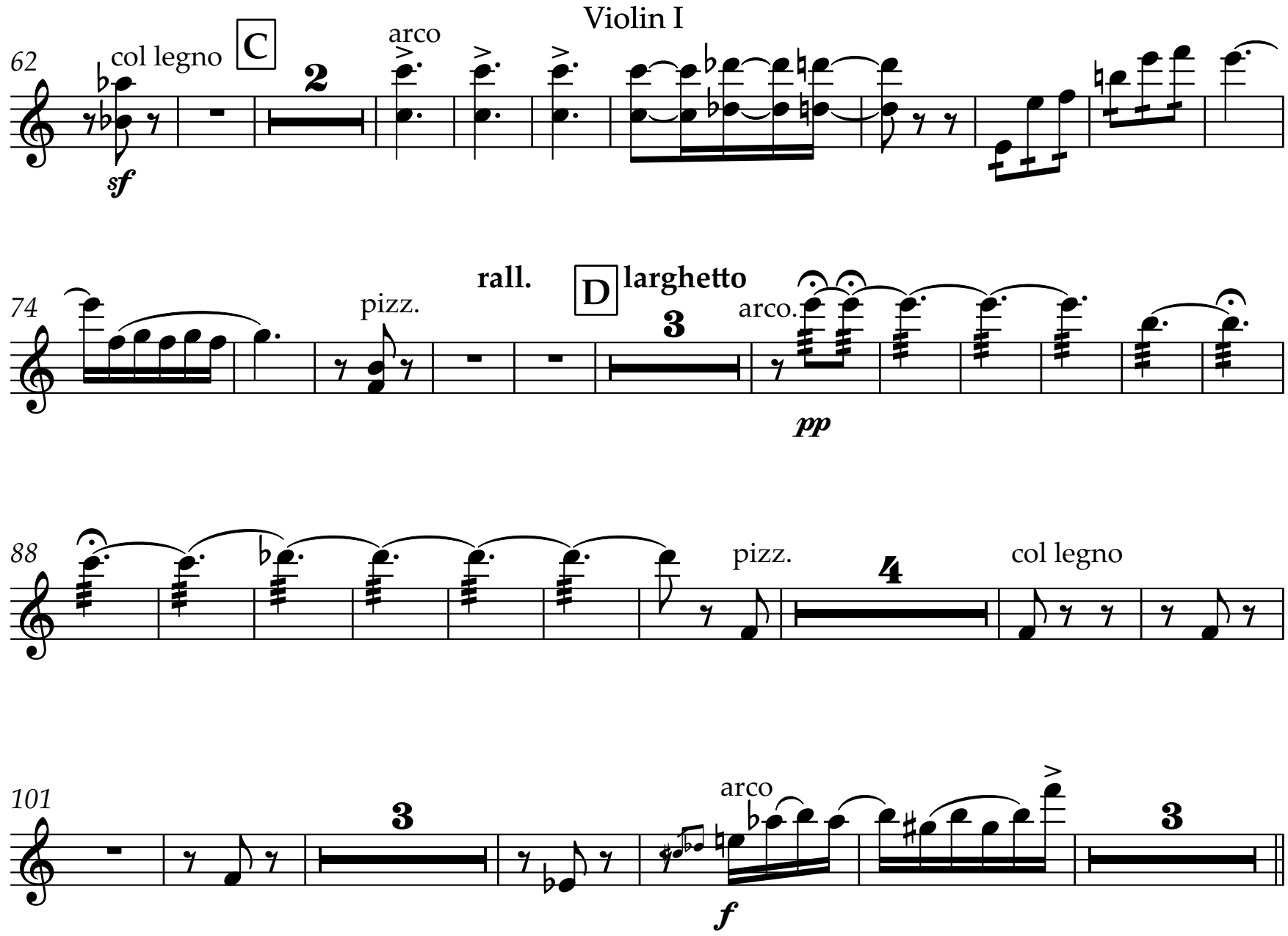

112

E Kadenz
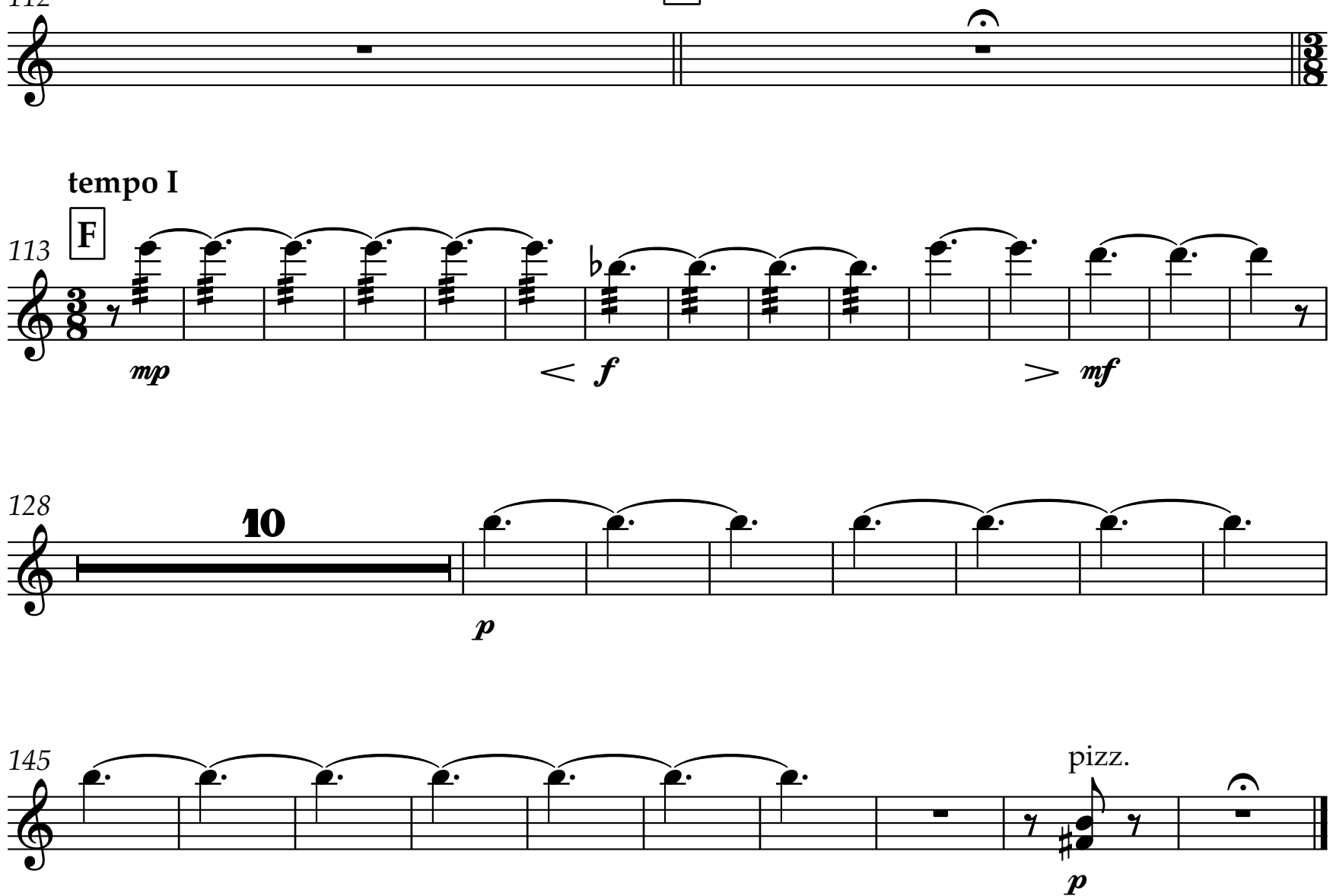


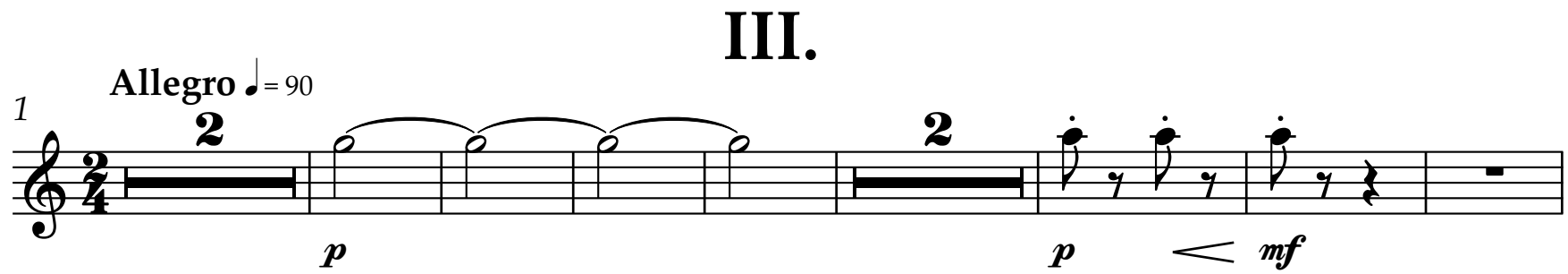

$\int_{m f}^{12}$ לf

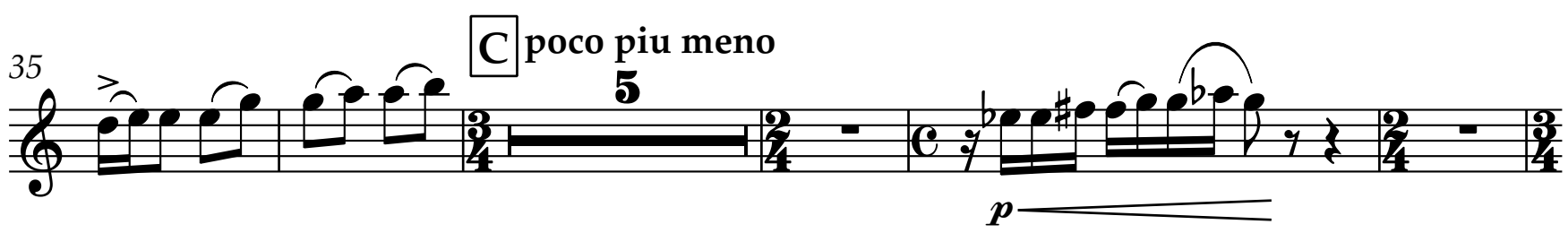
: Tempo I 每 费, לे 


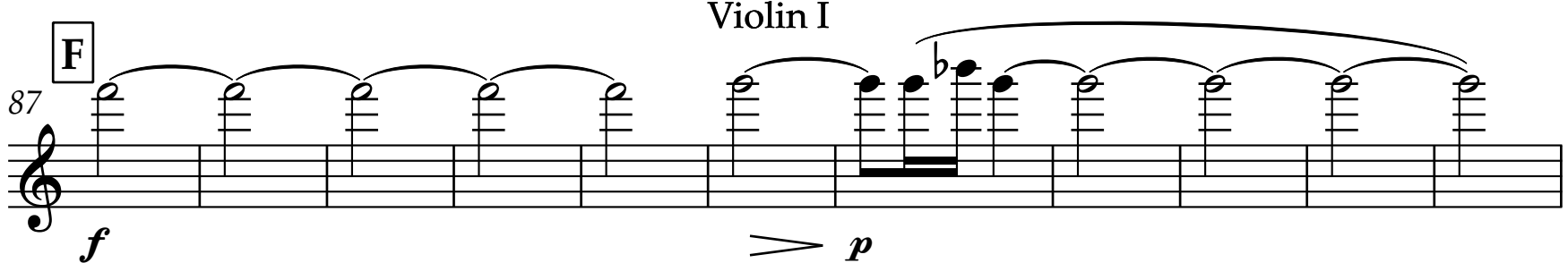

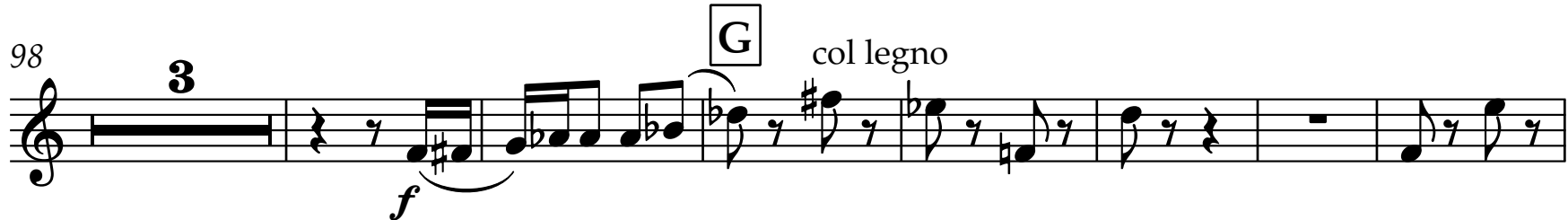
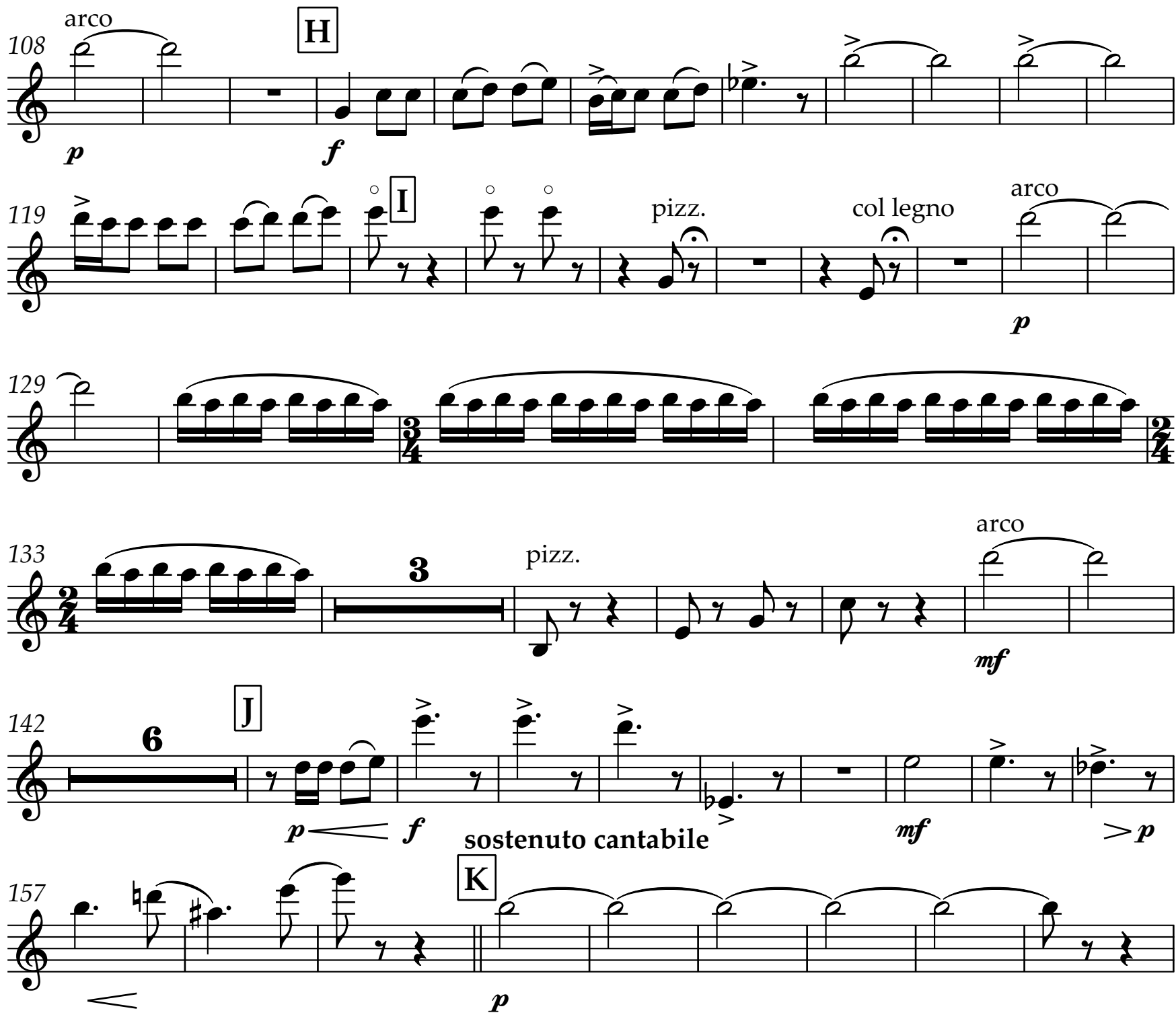

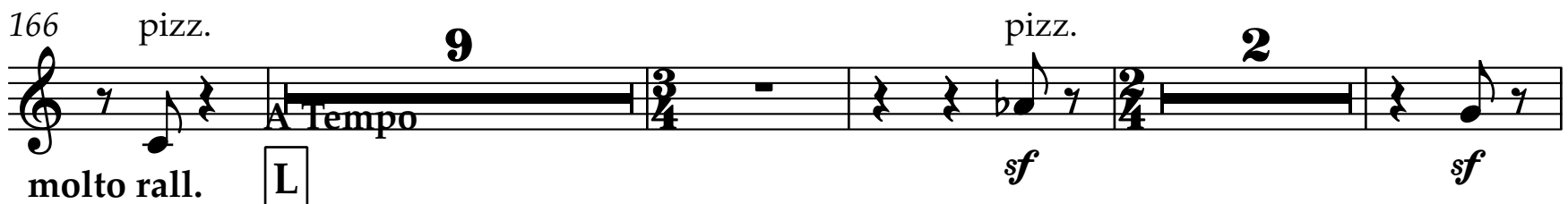

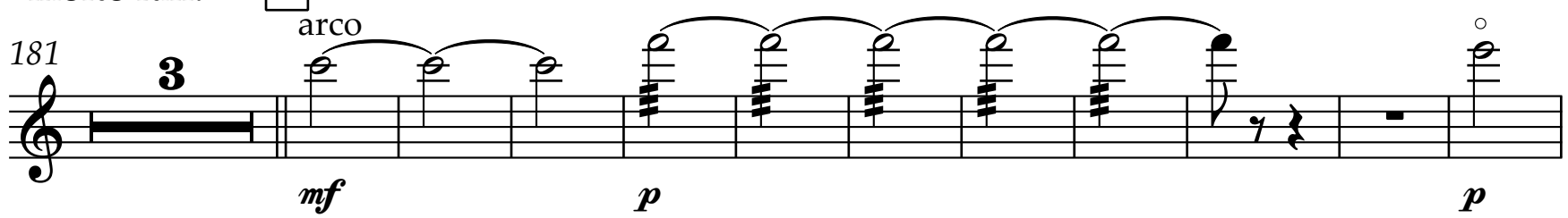



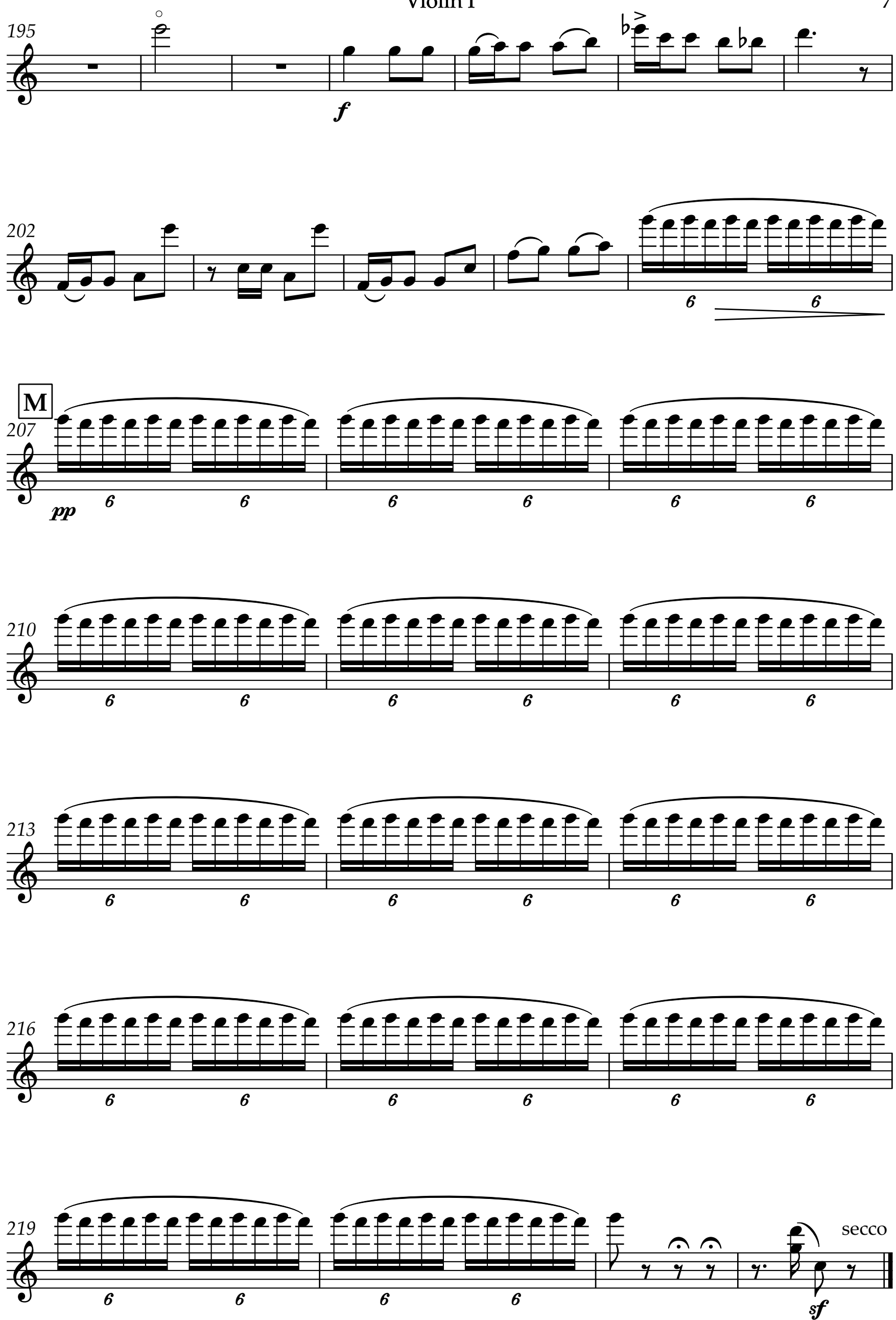
Violin II Concerto for Viola and Orchestra

Dmitris Dragatakis
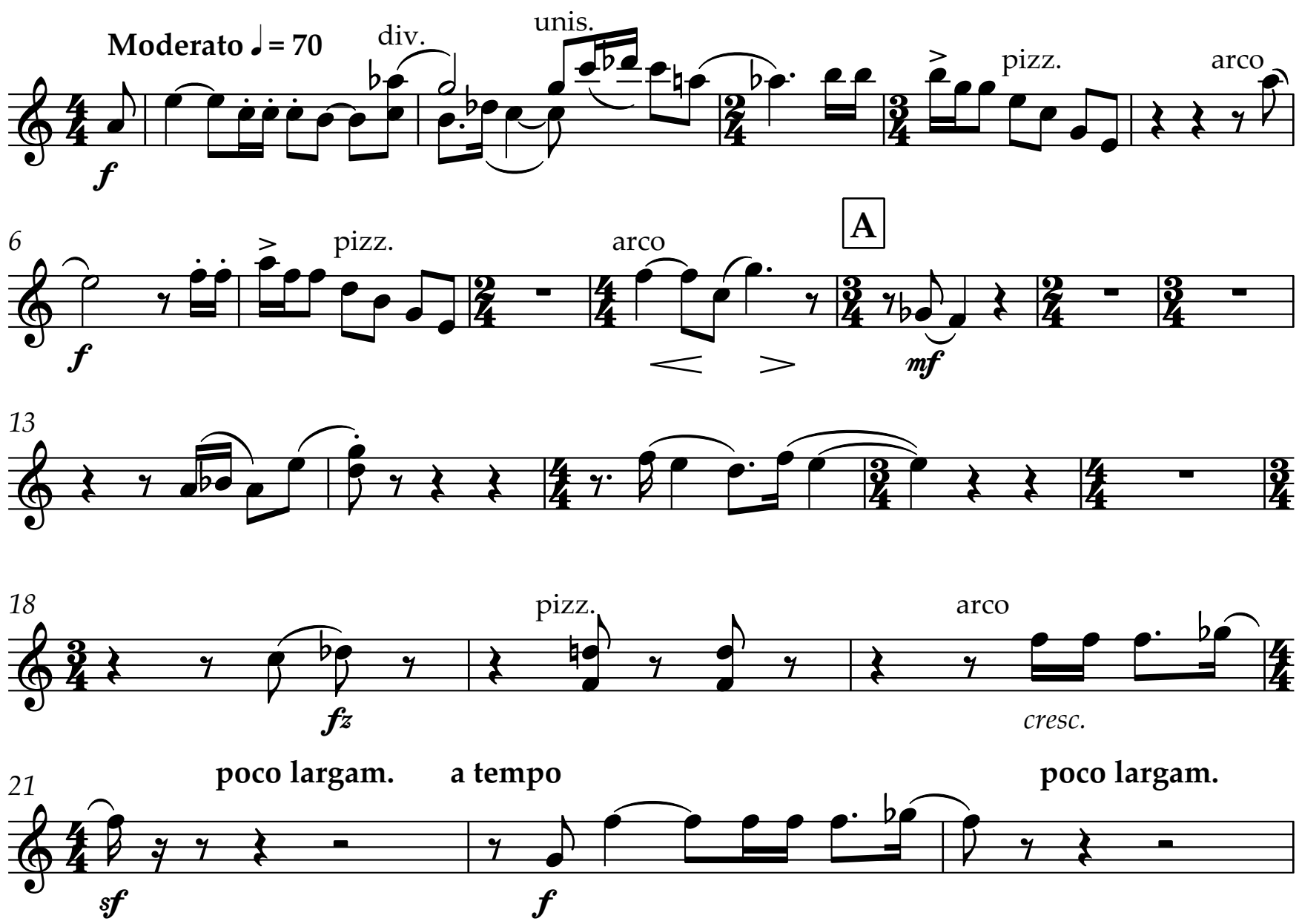
a tempo
molto rall.

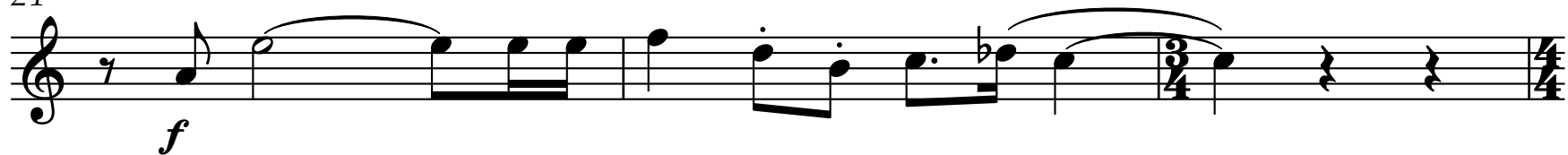

(a)
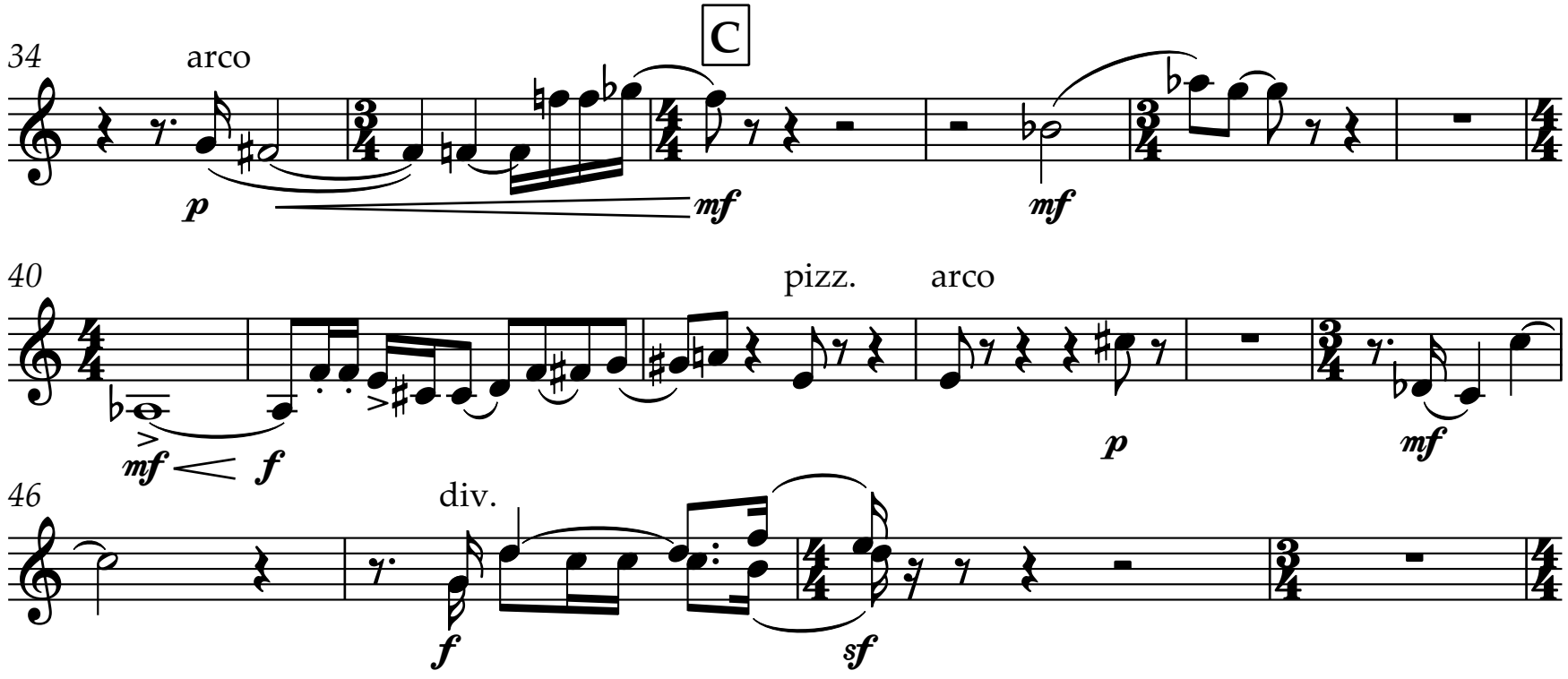

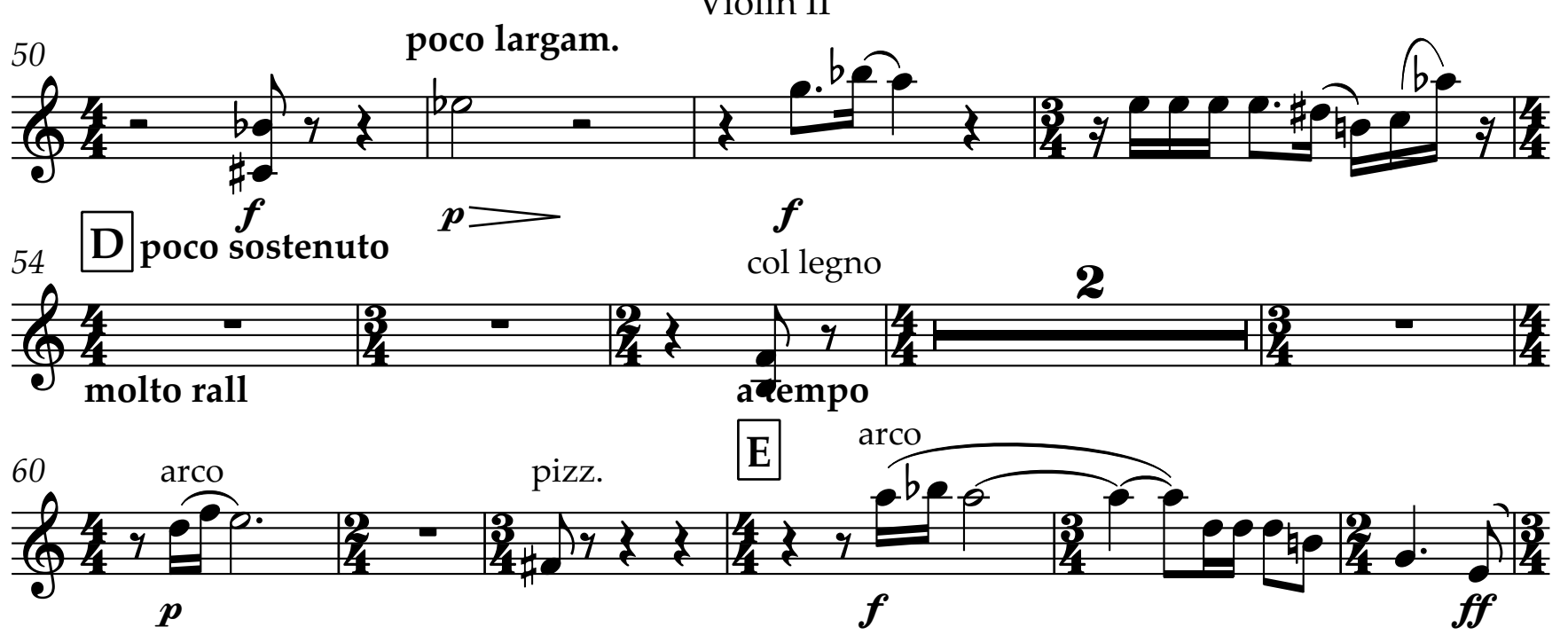

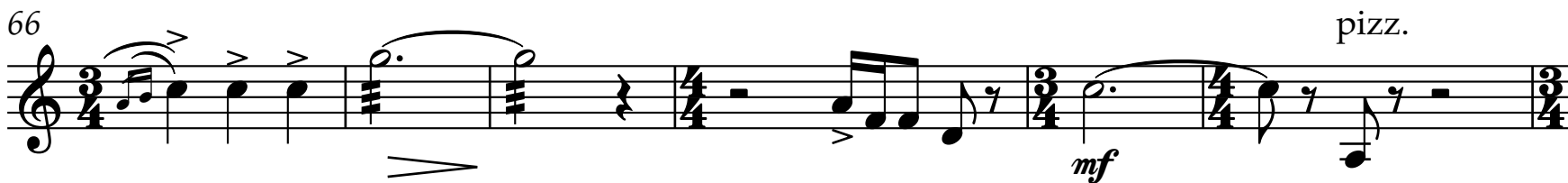
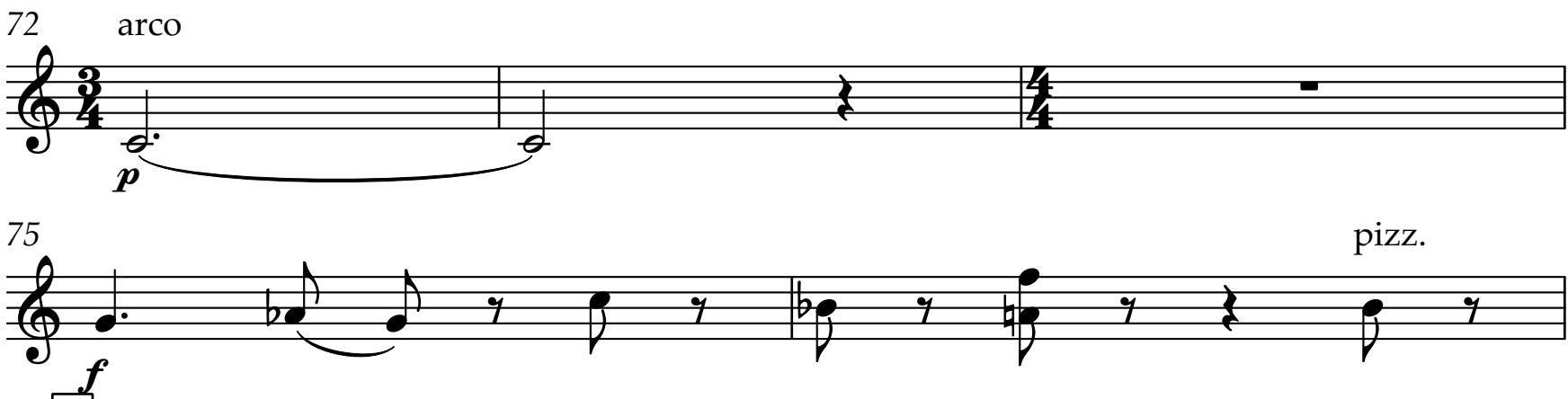
77 poco largam. a tempo
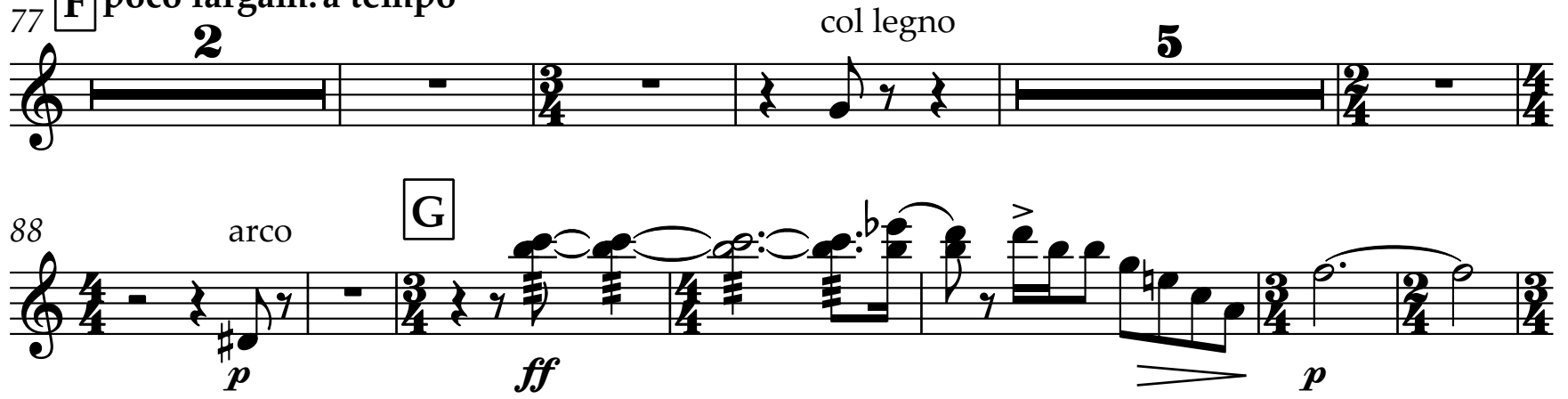
95 Più larg.

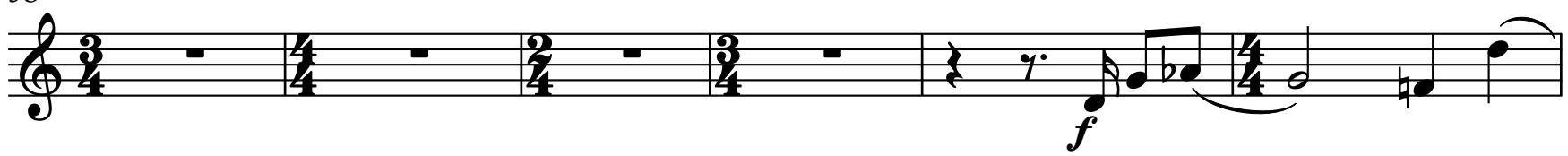
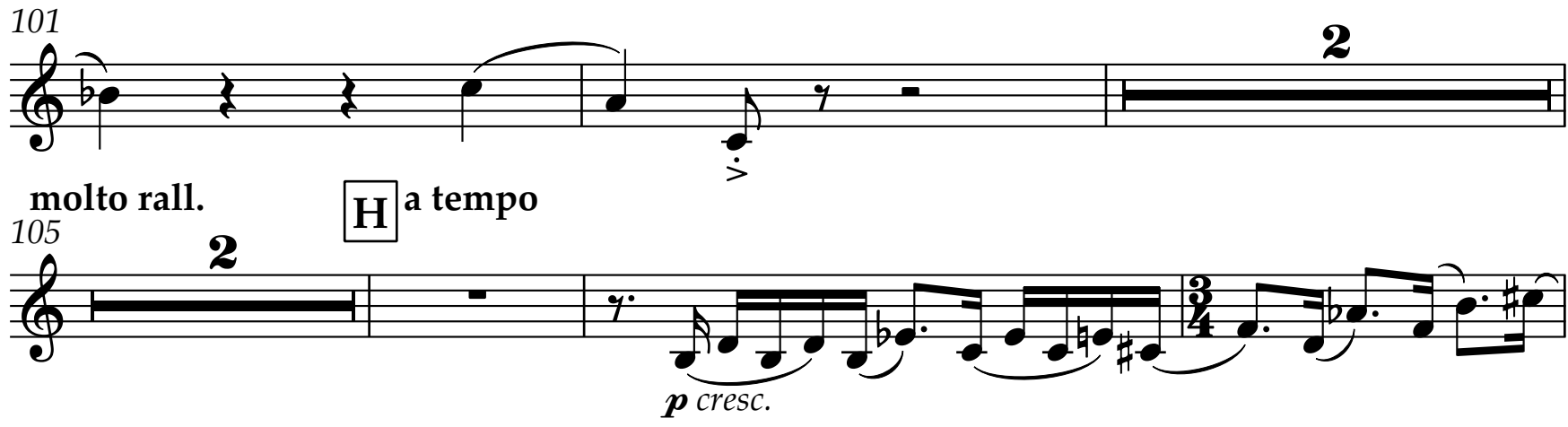
Violin II

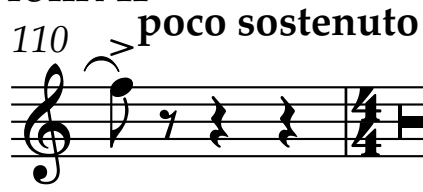

110

2
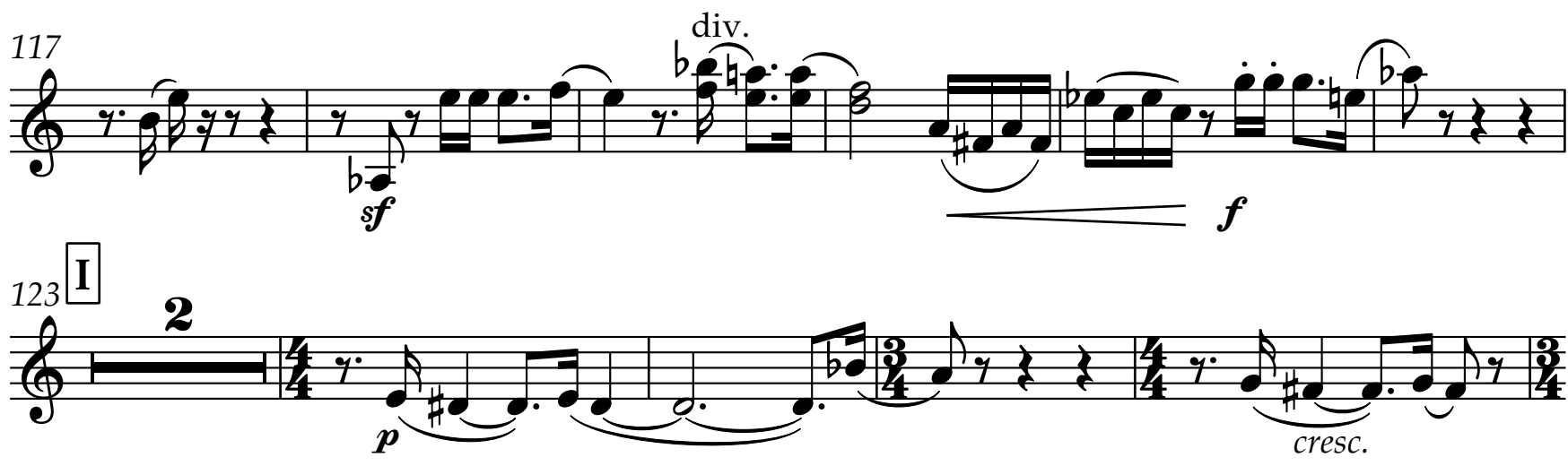

$129 \quad$ Largamente

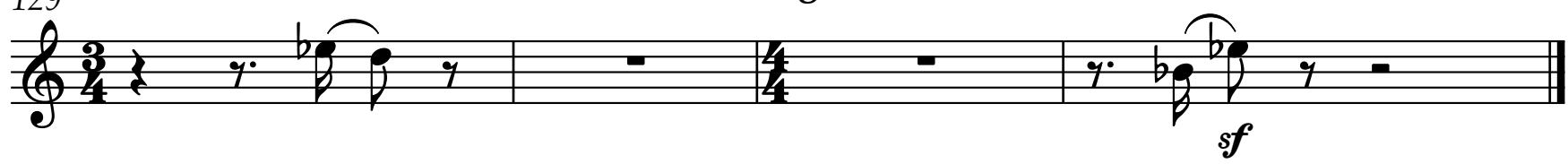

II.
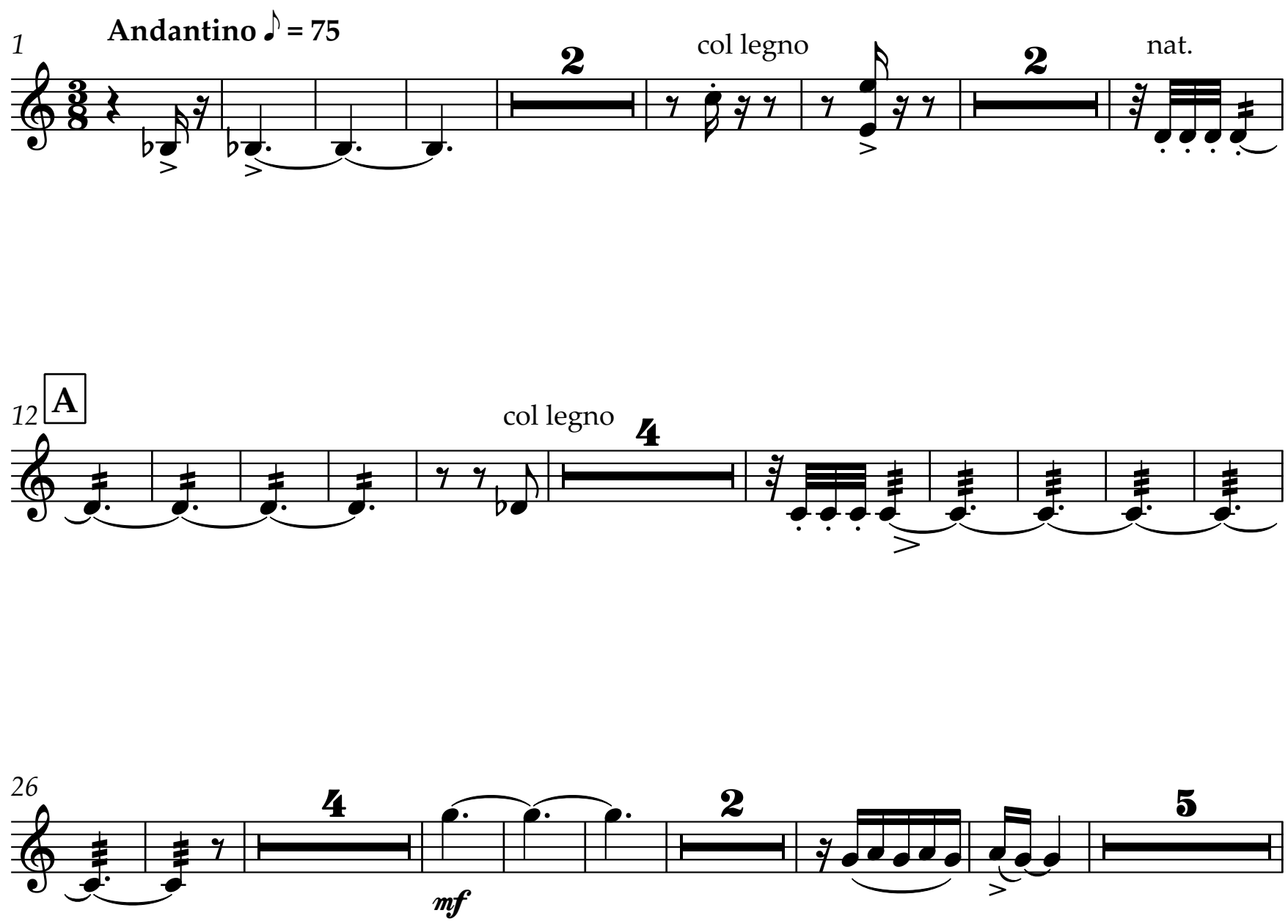
${ }_{44}$ B

8 


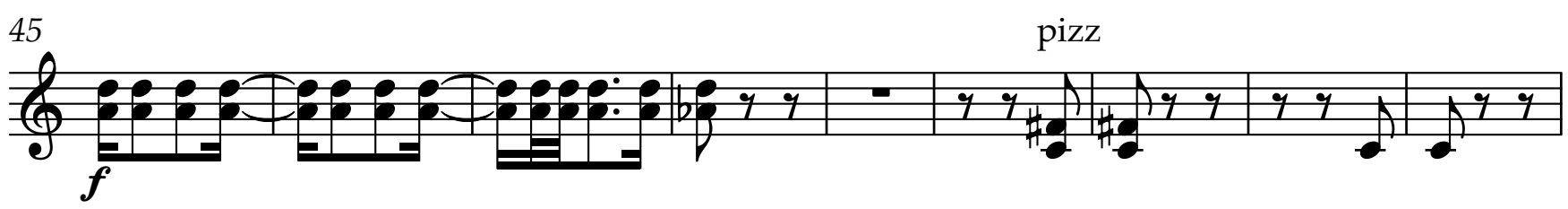
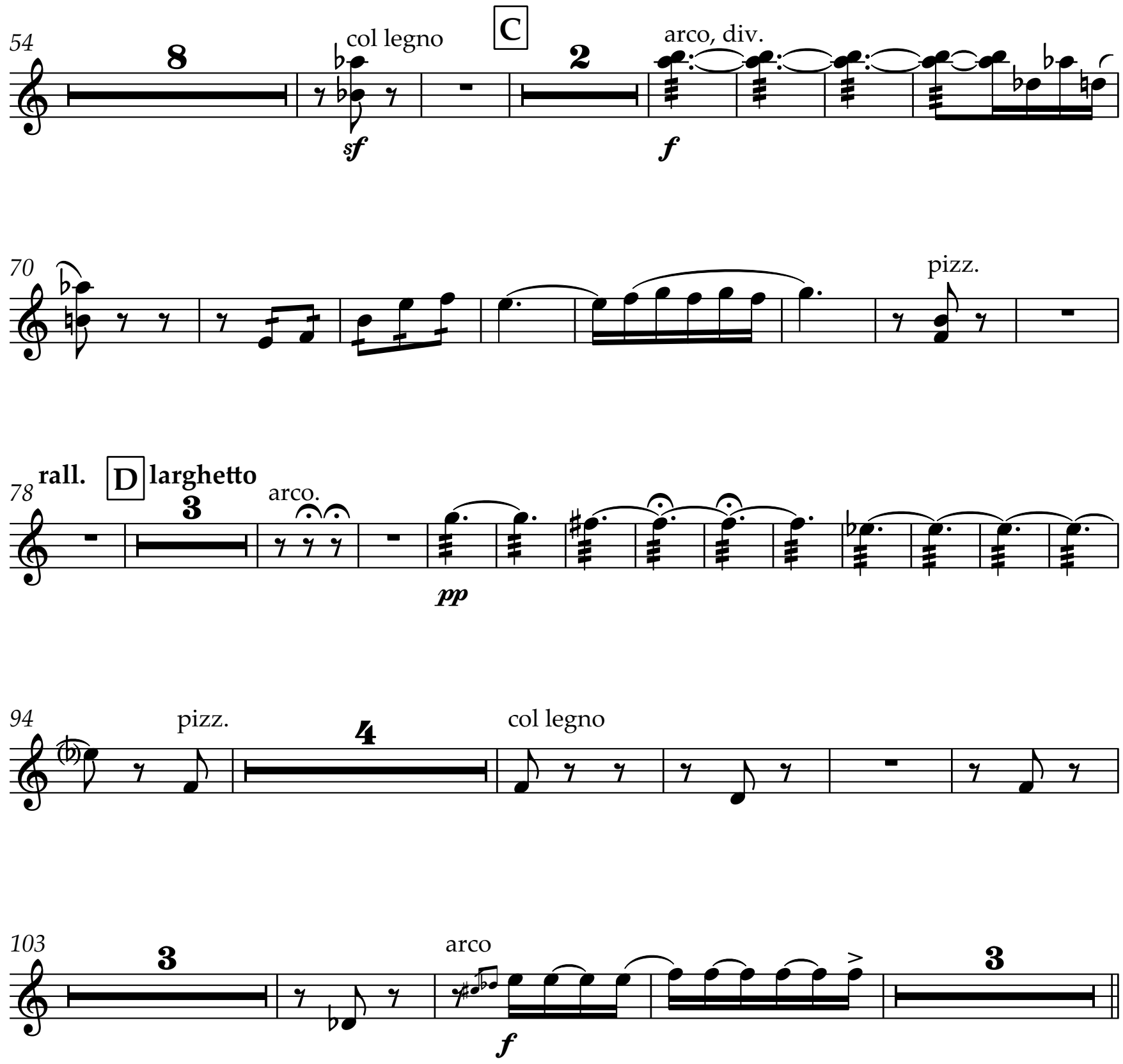
E Kadenz 


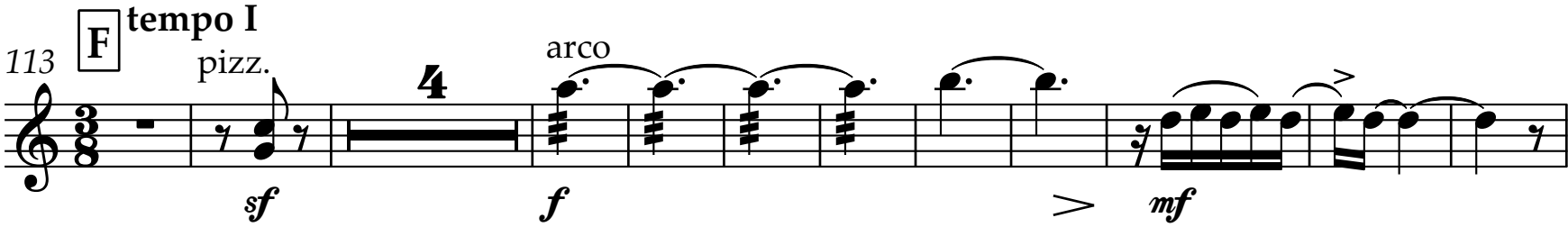

$\int_{2}^{128}$ pizz. 2

140

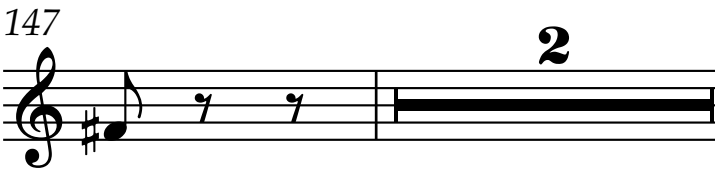

arco

$1 \quad$ Allegro $\cdot=90$

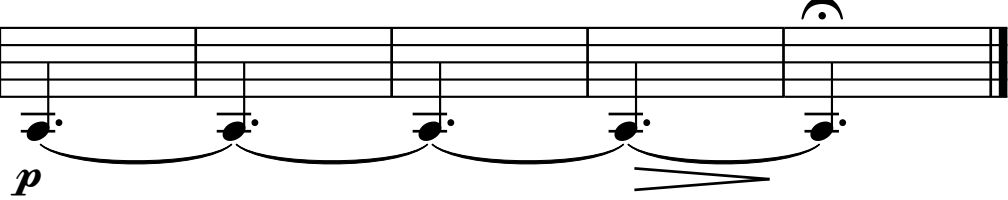

III.

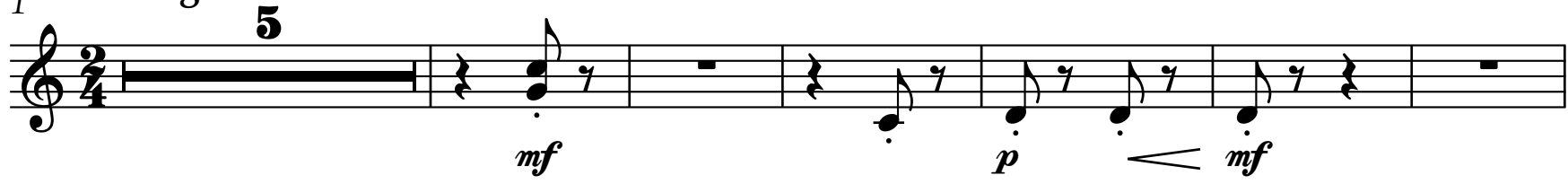

${ }_{12} \mathbf{A}$

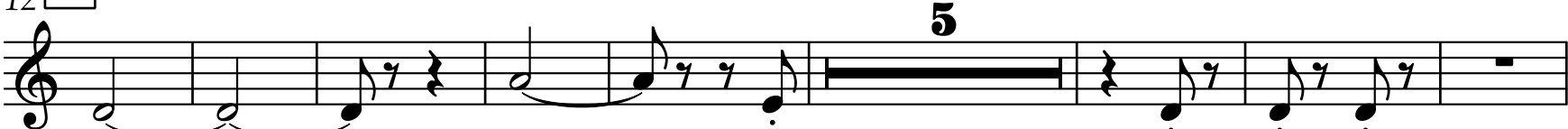

${ }^{m f^{\prime}}$
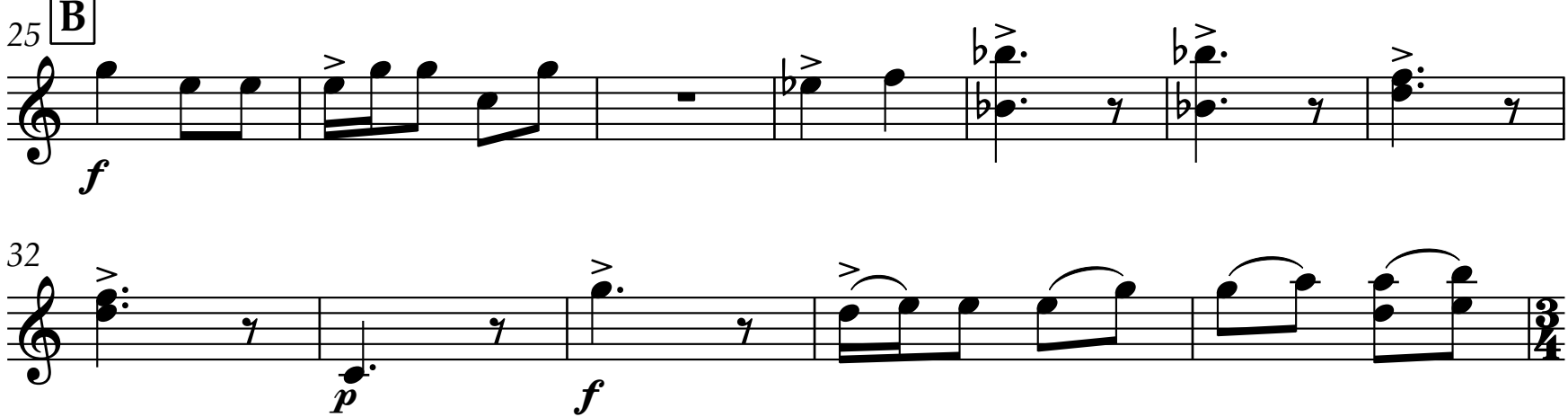

37 Coco piu meno

5

(2) 
42

col legno

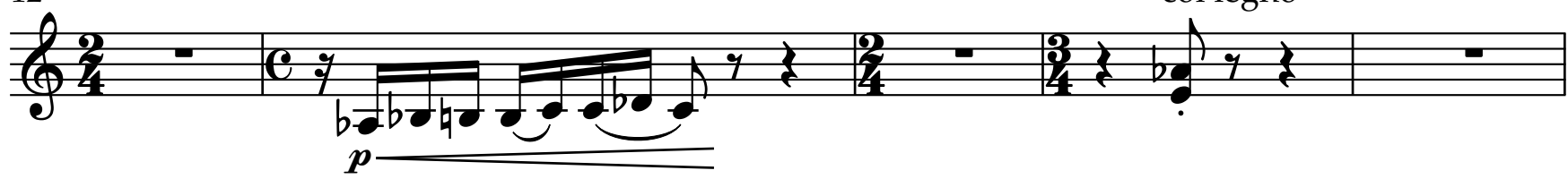

47 pizz. arco

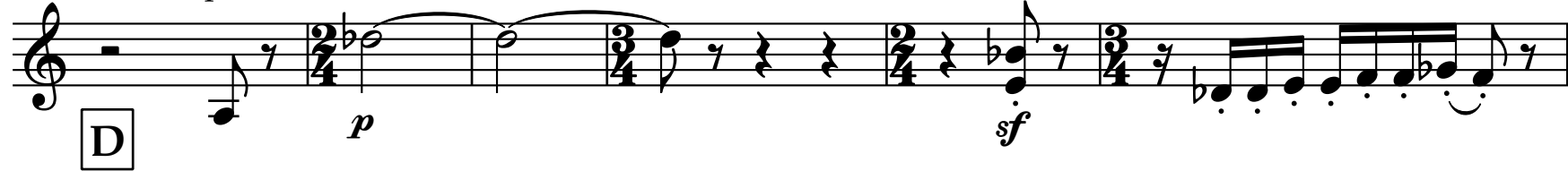

(2)

(E)

$\underbrace{}_{b}$

$\mathbf{F}$

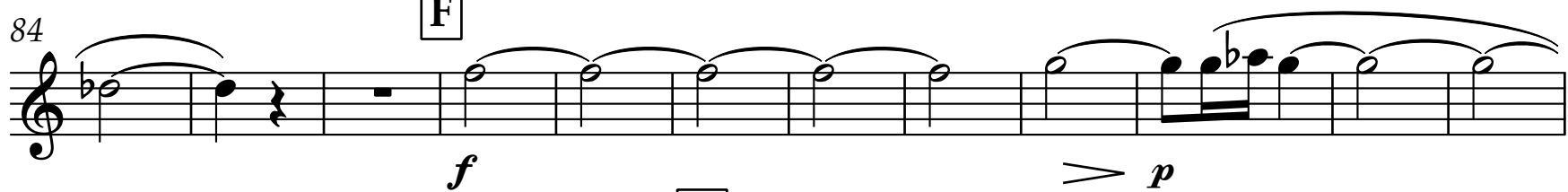

G col legno

$\mathrm{g}_{\mathrm{O}}^{\mathrm{O}}$

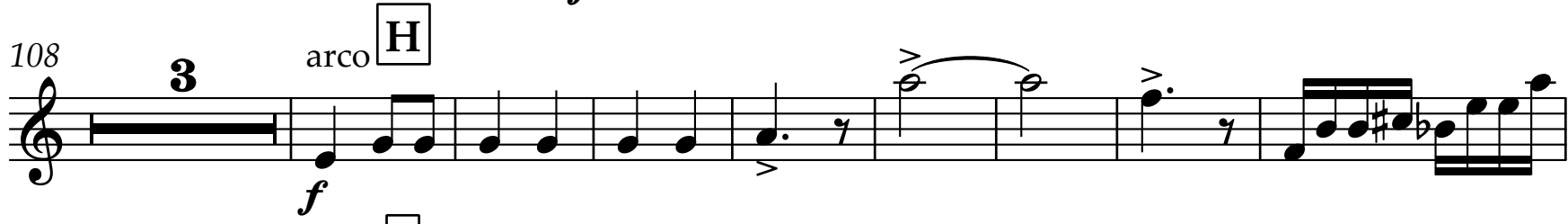

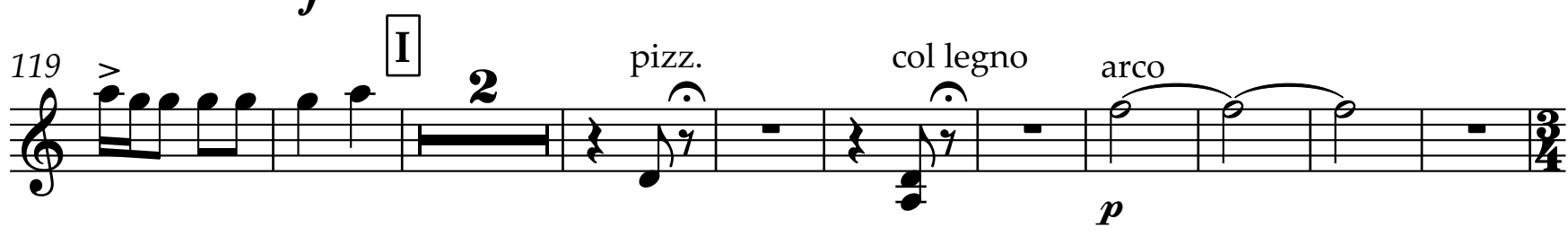

(4)

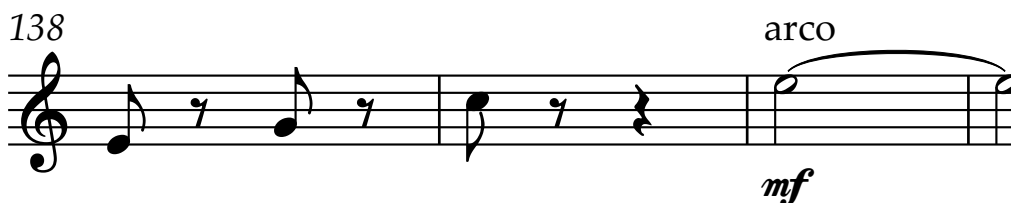

6 
8

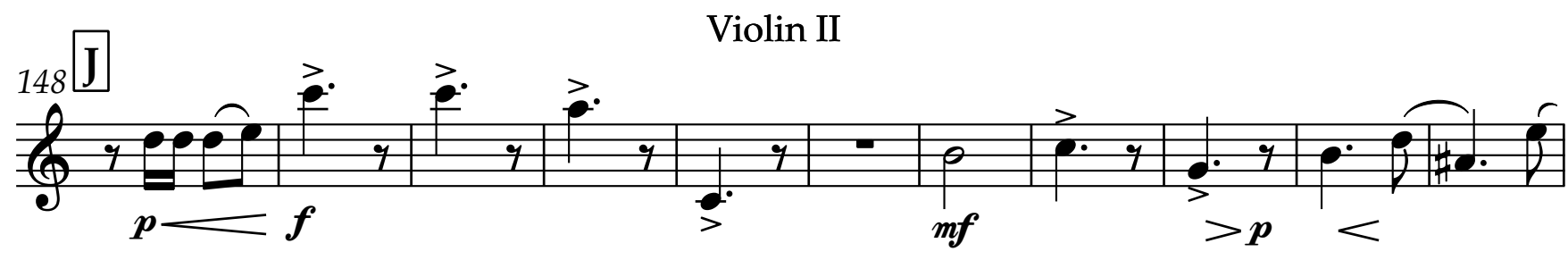

$159 \quad$ K sostenuto cantabile

(a)

(9)
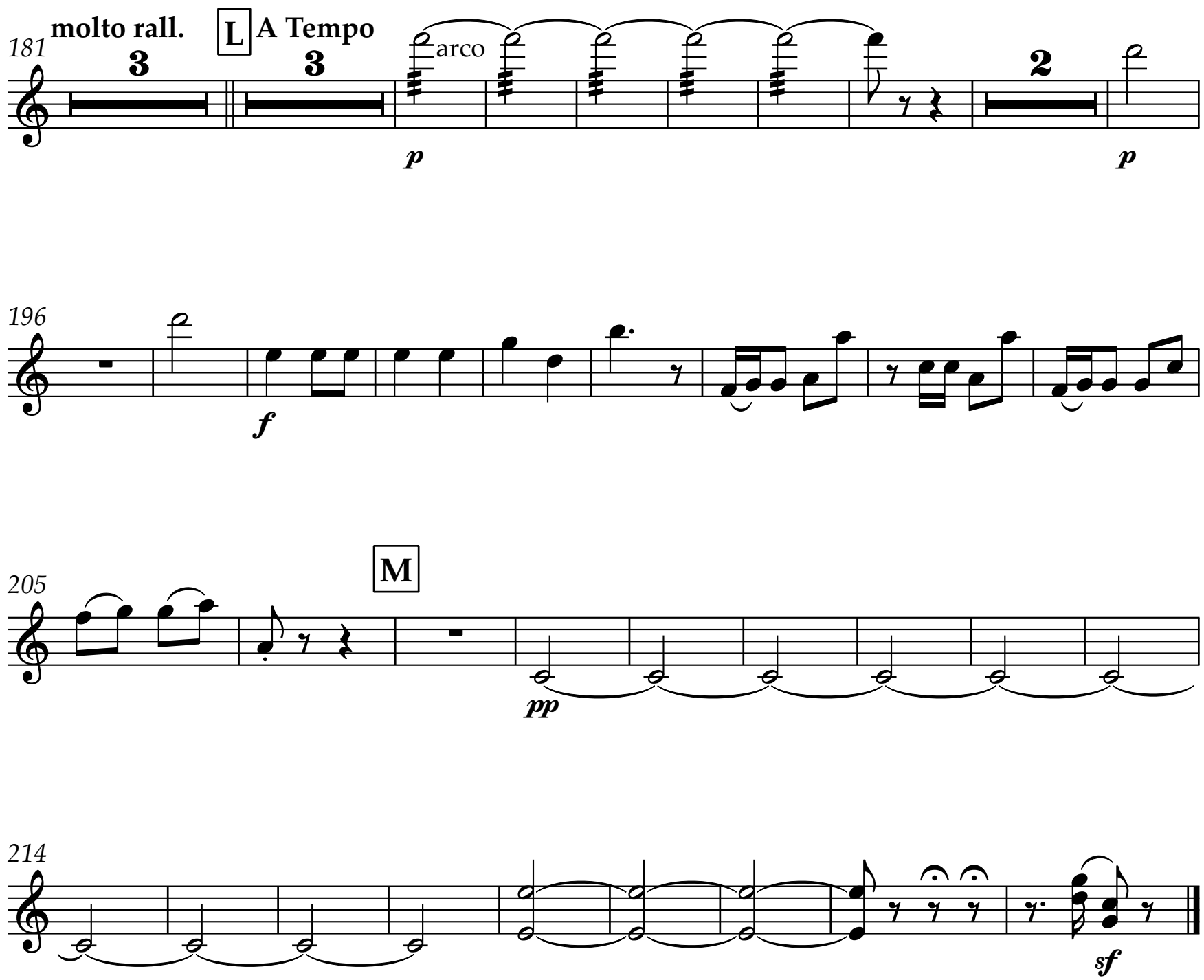


\section{Concerto for Viola and Orchestra I.}

Dmitris Dragatakis
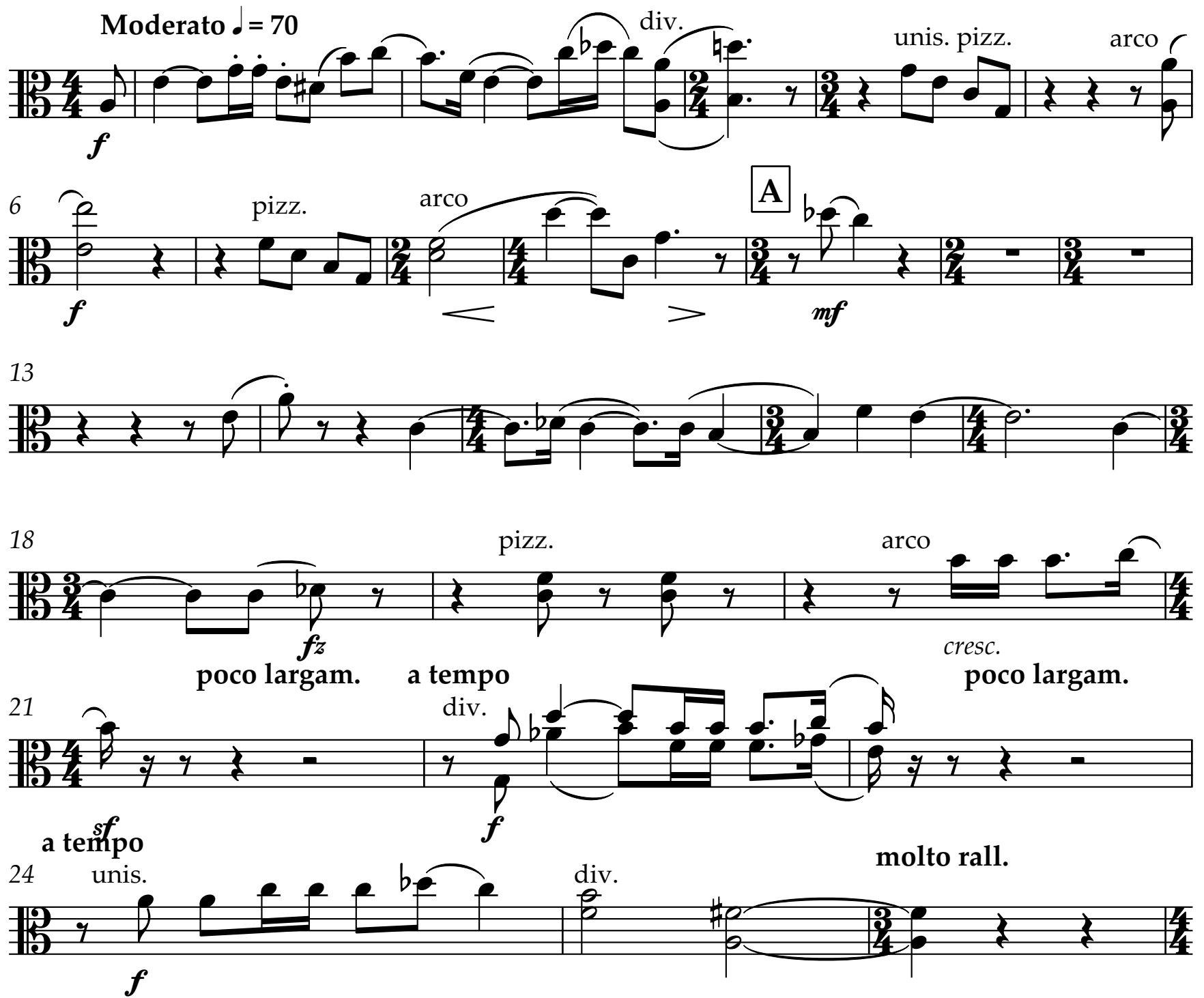

$27 \quad \mathbf{B} \begin{aligned} & \text { a tempo } \\ & \text { pizz. }\end{aligned}$

col legno

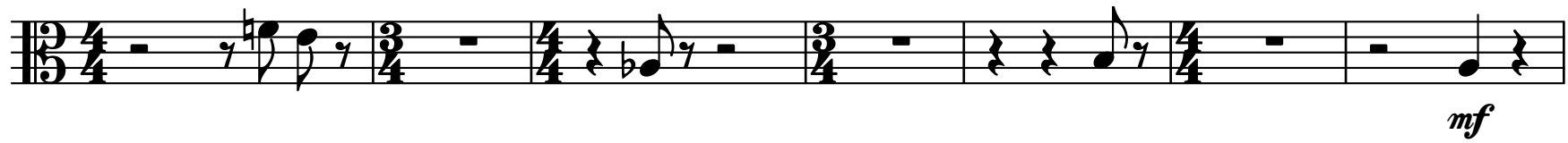

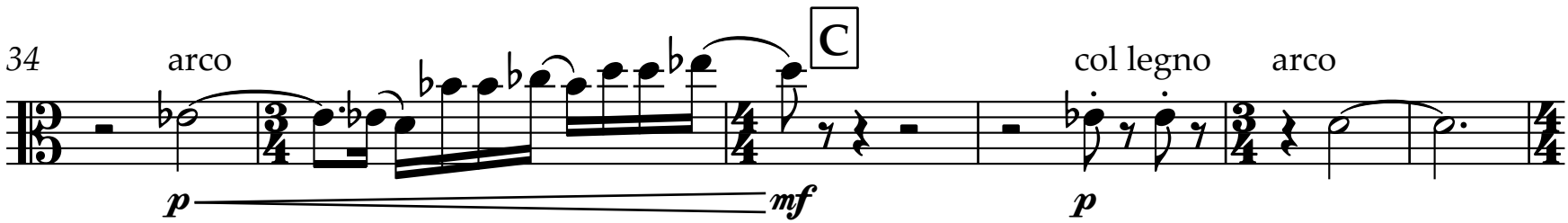

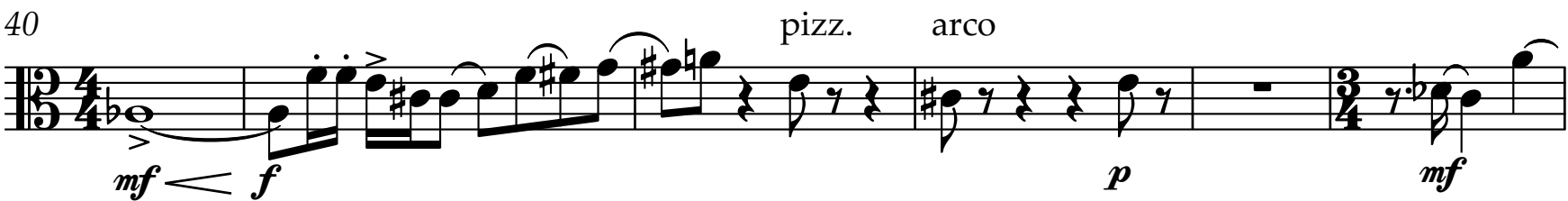

46

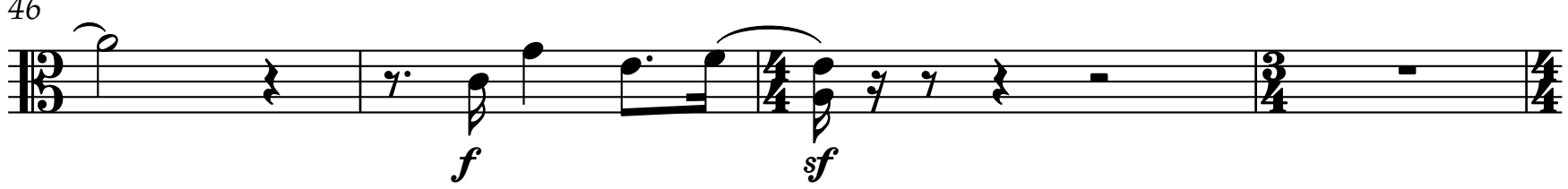




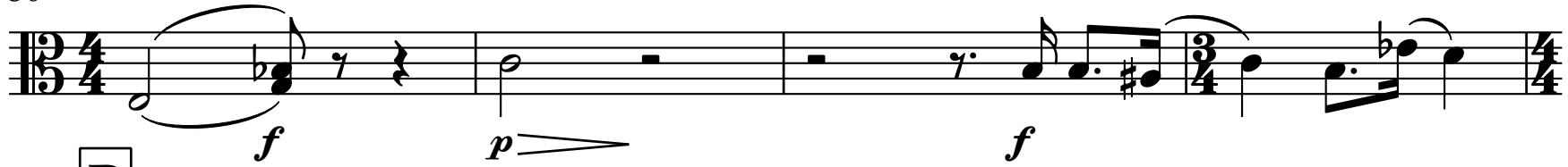

54 D poco sostenuto

col legno

2

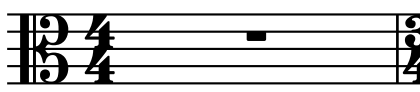

:

molto rall
col legno $\quad$ pizz. $\quad$ E

腈-4

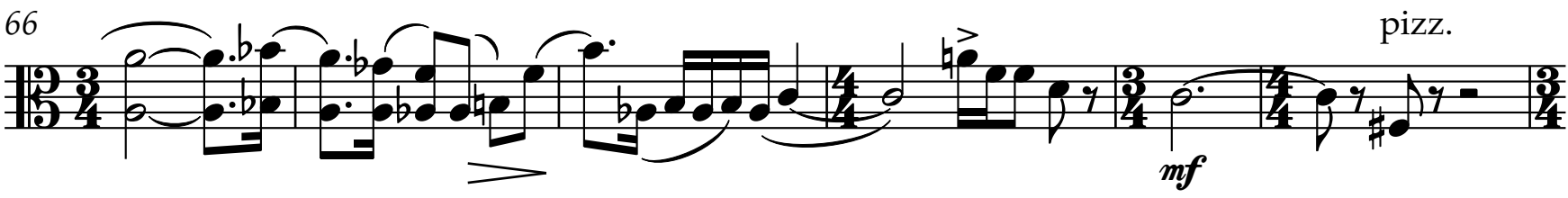

72 arco

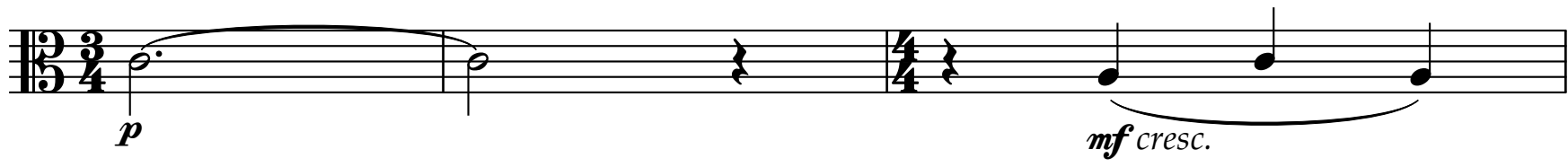

75

腈 $f$

${ }_{77} \mathbf{F}$ poco largam. a tempo

2

col legno

5

arco

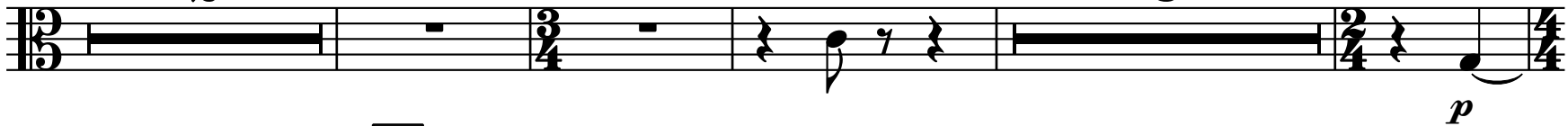

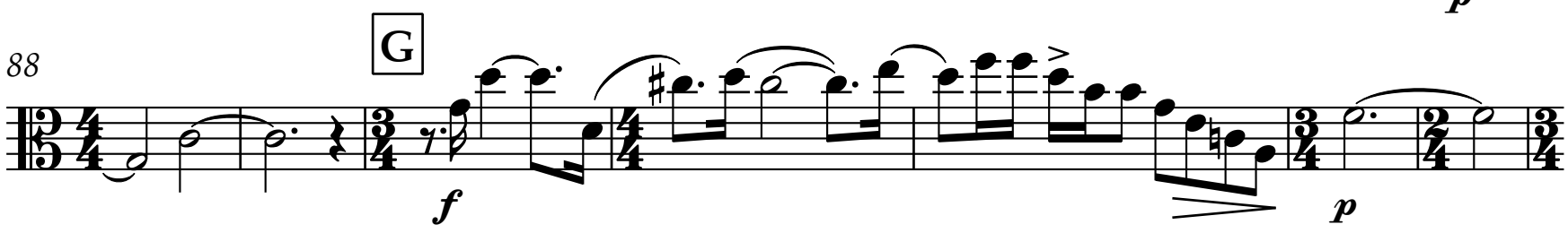
95 Più larg.

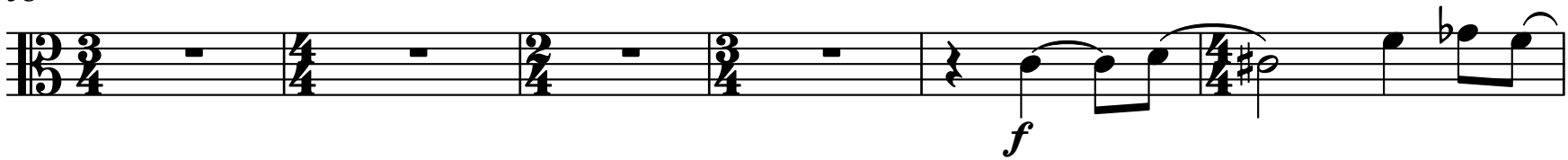

101

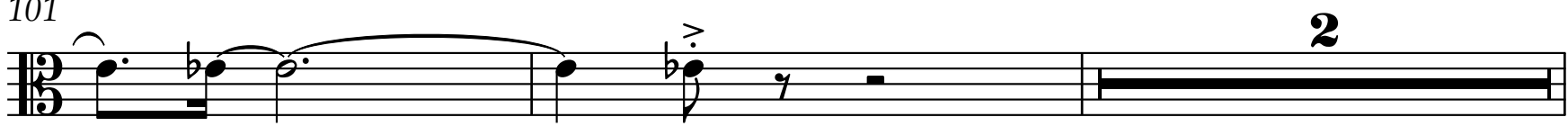

$105^{\text {molto rall. }} \boldsymbol{2} \quad \mathbf{H}$ a tempo

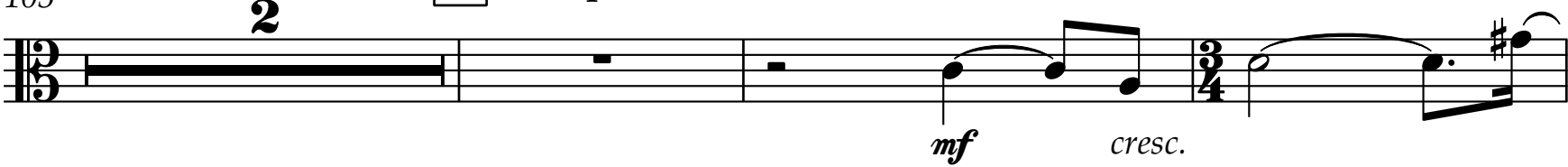


Viola

Viola

(110)

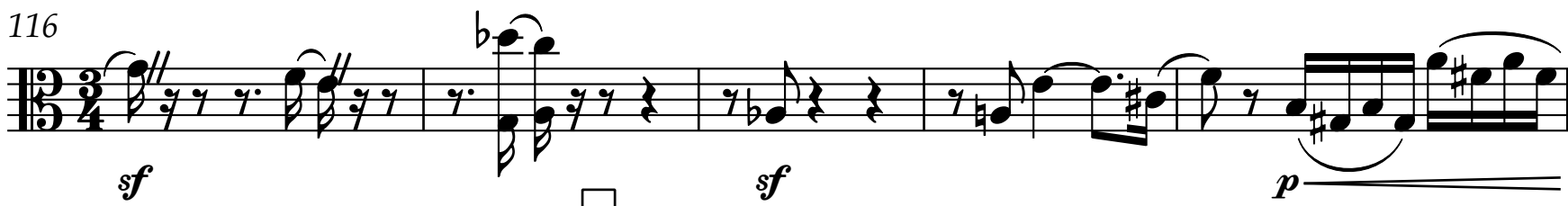

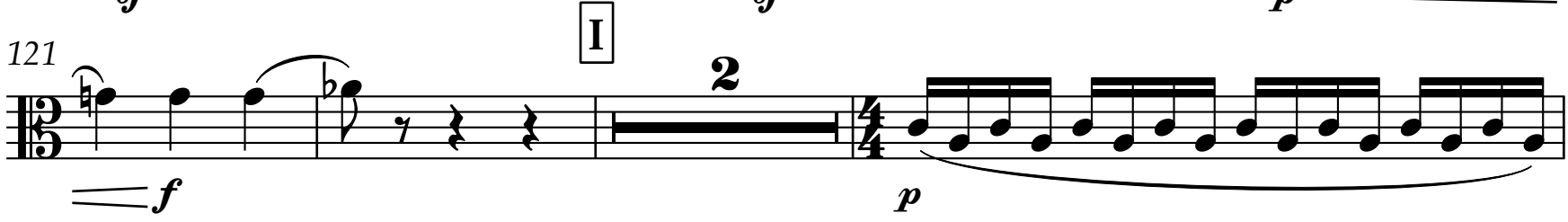

$\underbrace{126}$

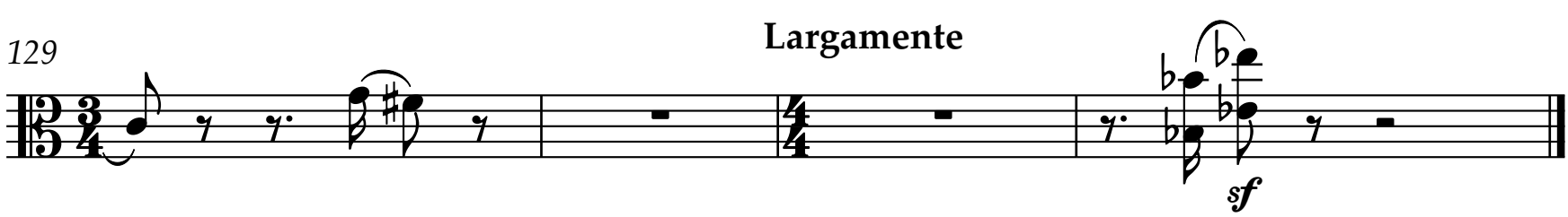

II.

1 Andantino ${ }^{\curvearrowright}=75$

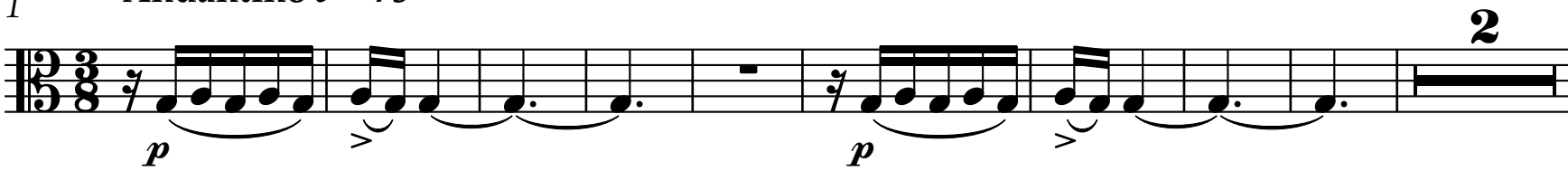

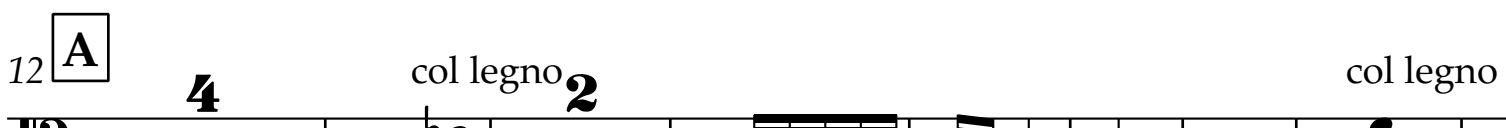
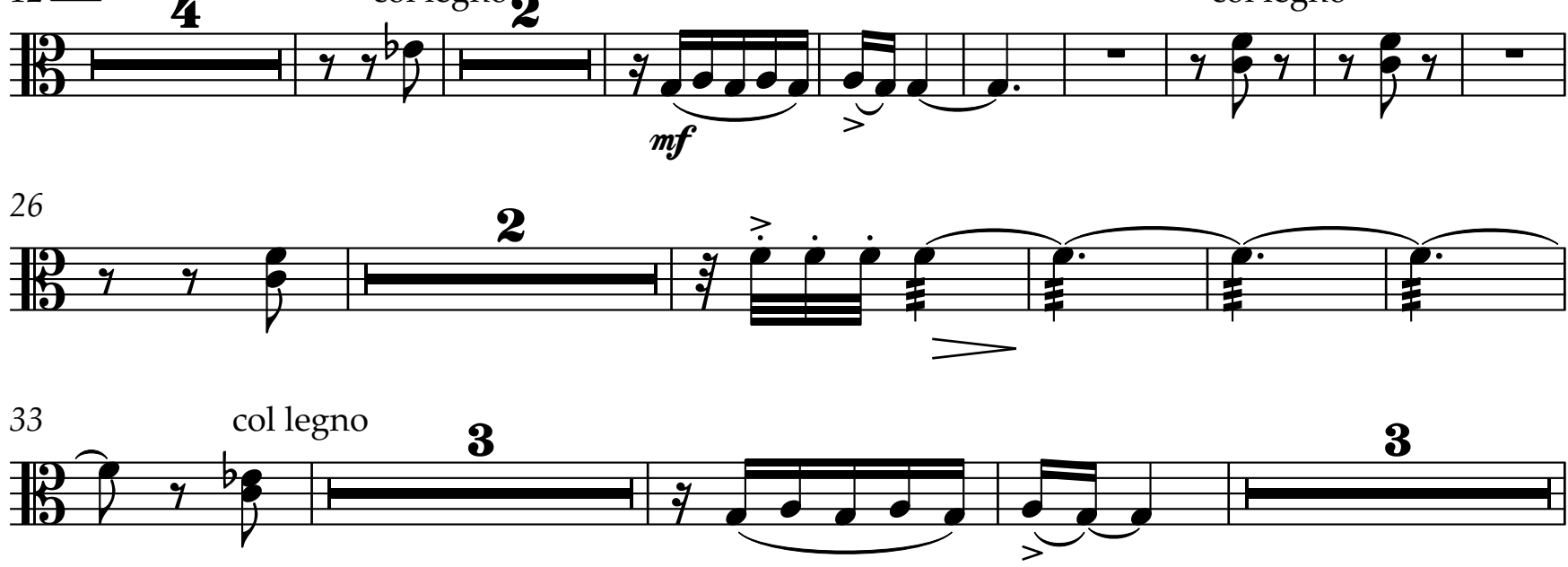
4

B Viola

42 pizz B arco be pizz

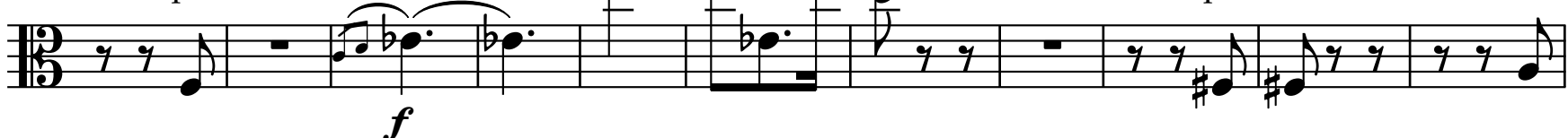

$53 \quad 8$ collegno ara

\begin{tabular}{l|l|l|l|l|l|l|l|l|}
8 & 8 & & \\
\hline
\end{tabular}

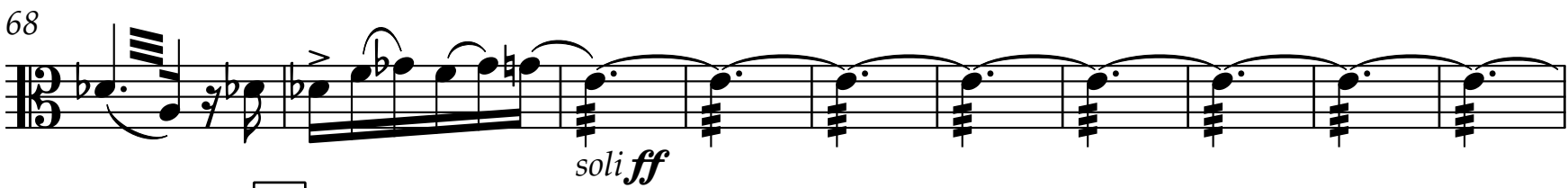

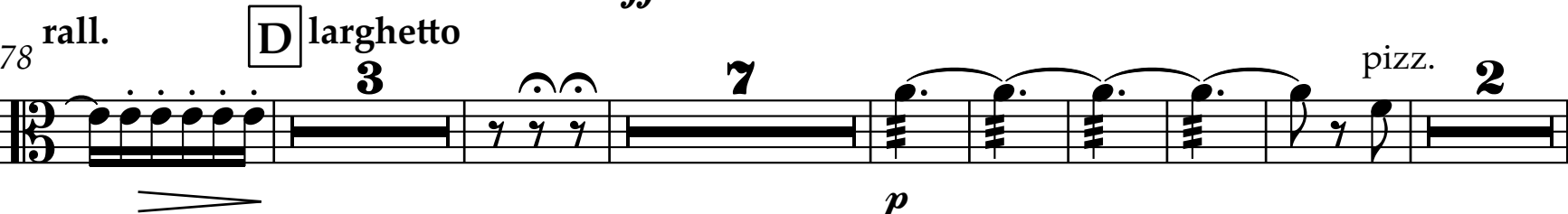

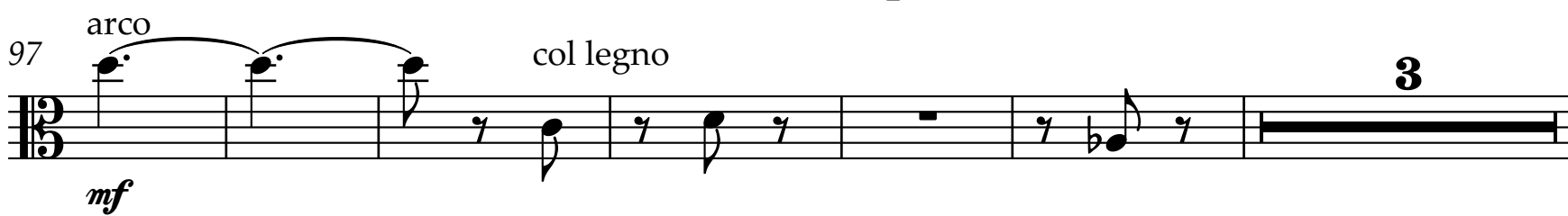

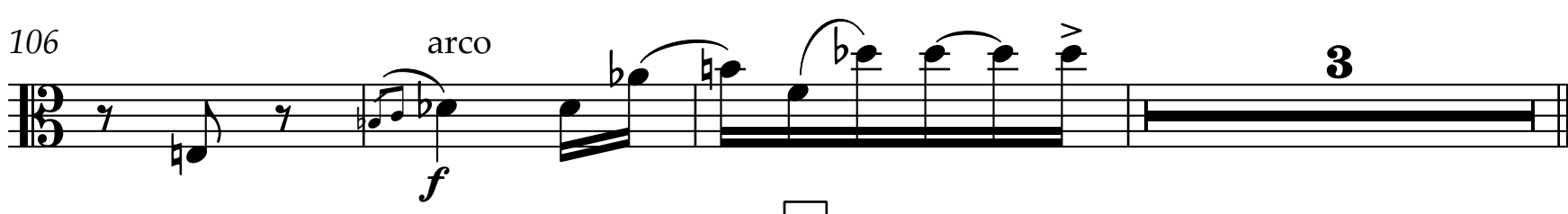

E Kadenz

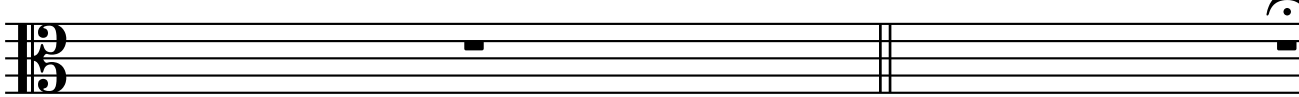

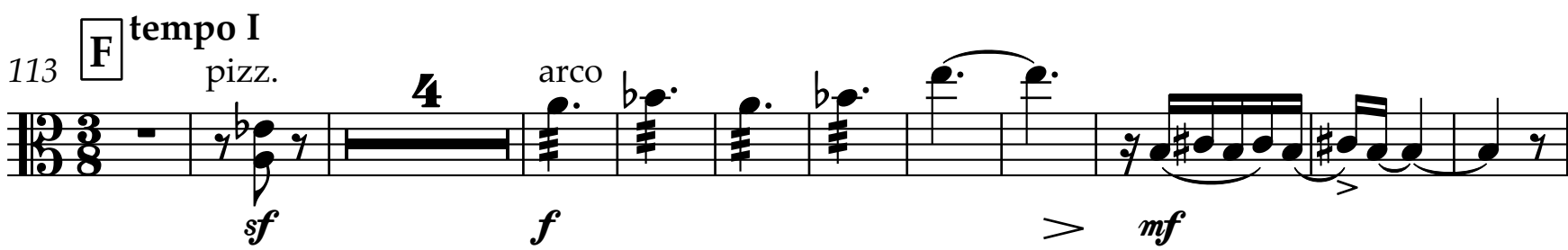
128 pizz. arco

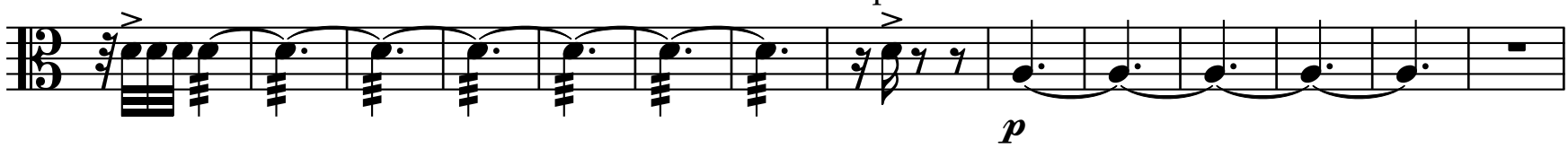
142

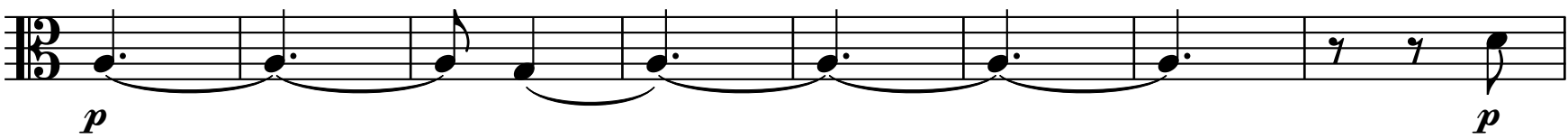

150

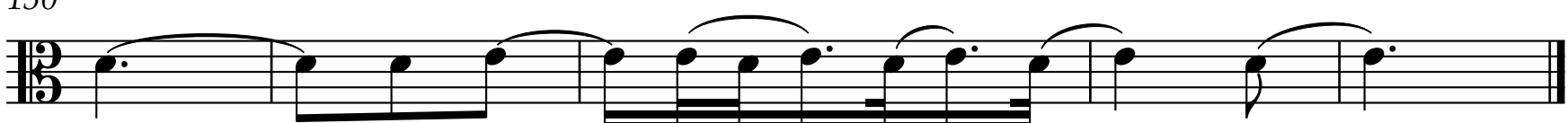




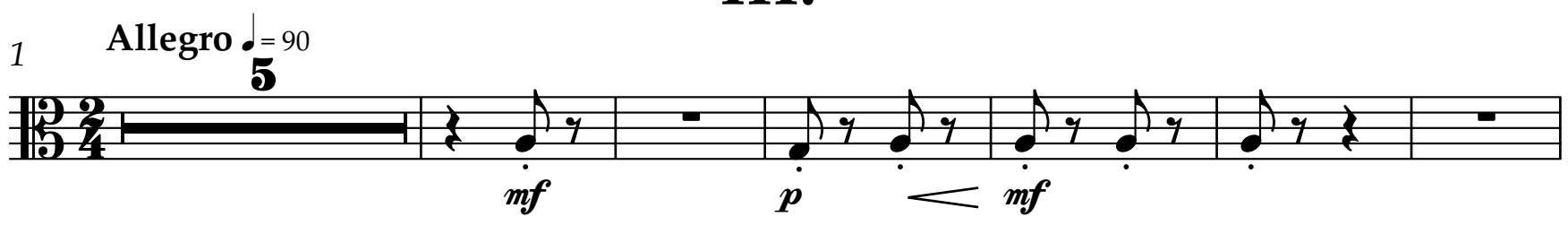

\section{III.}

${ }_{12} \mathbf{A}$

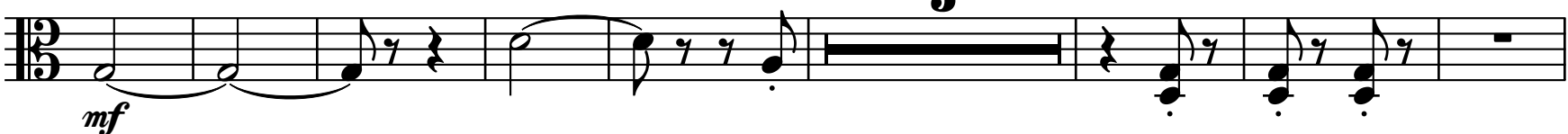

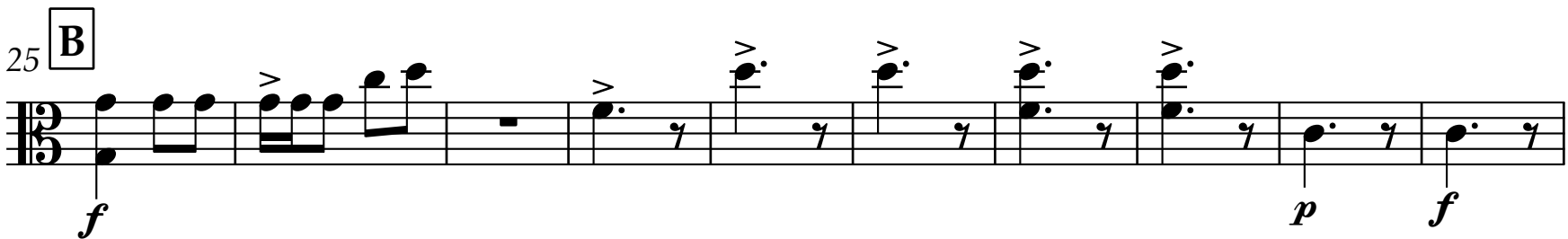

35 (1)

$46 \quad$ pizz.

腈-

D

哲

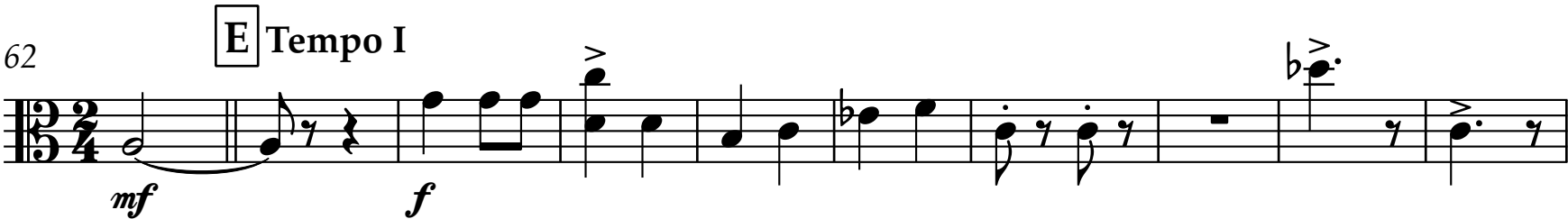

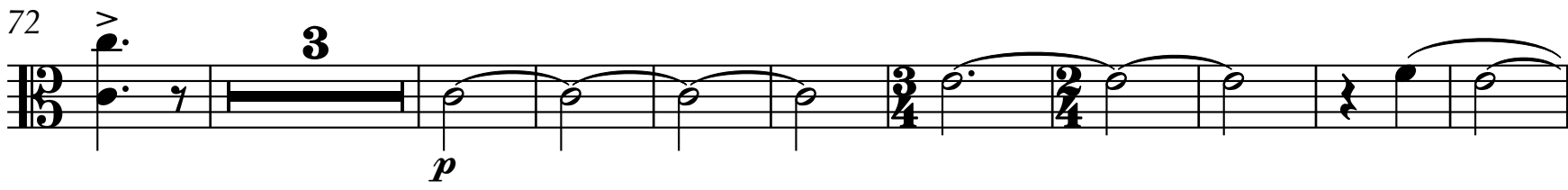

$85 \quad \mathbf{F}$

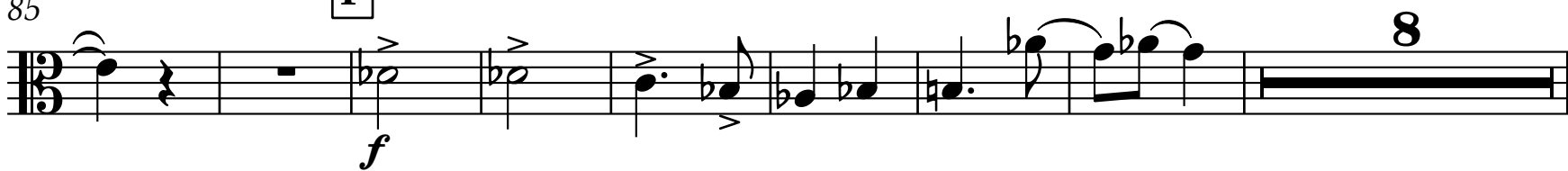


$101 \quad$ G col legno

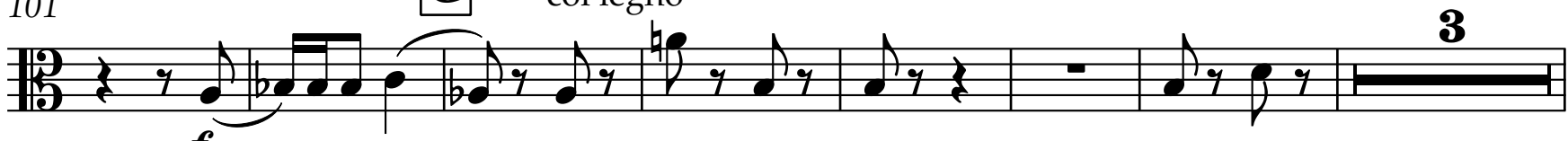
111 arco $\mathbf{f}$

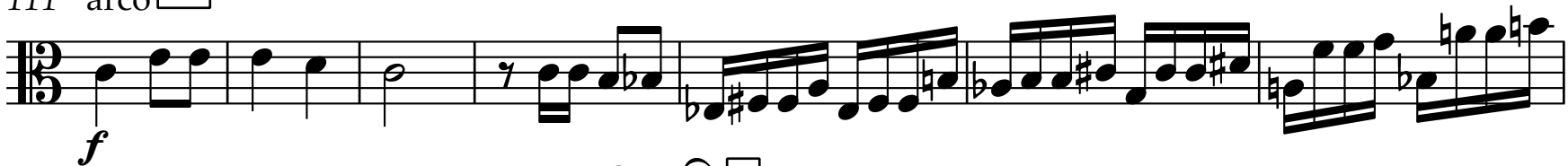

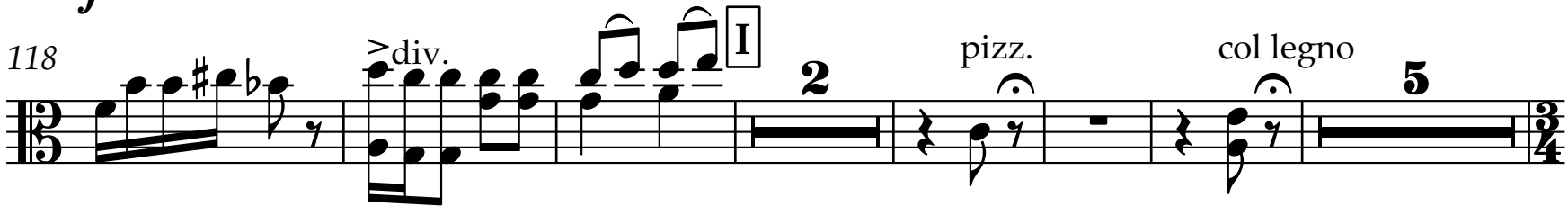
131
pizz.
3
arco

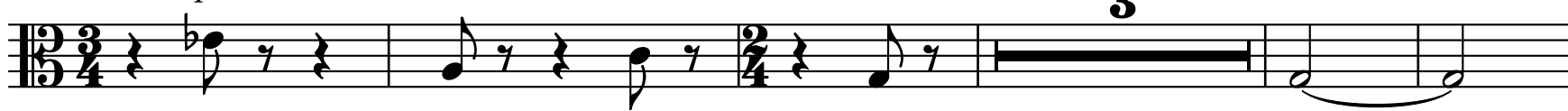

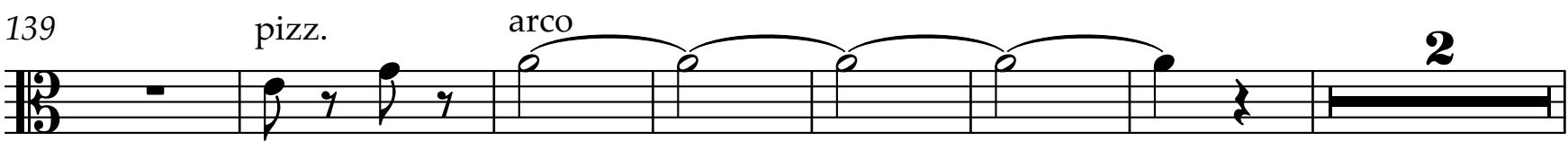

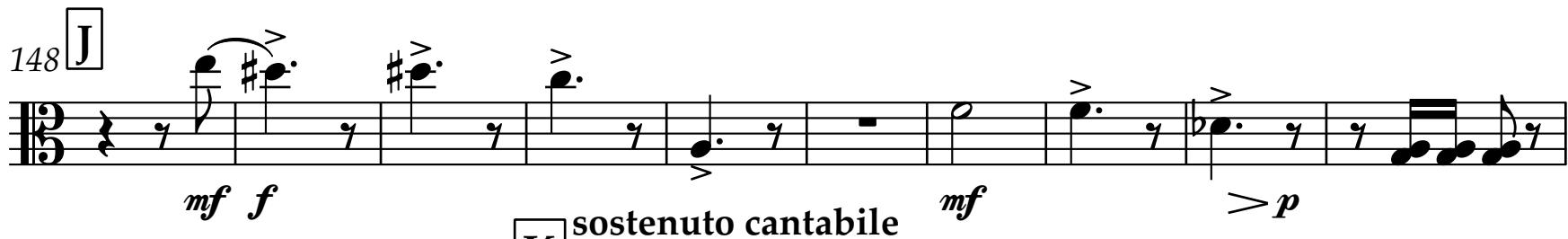

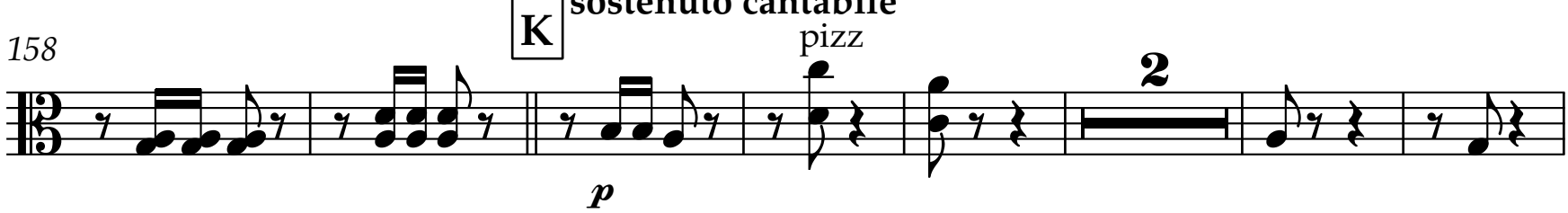

167 arco

pizz.

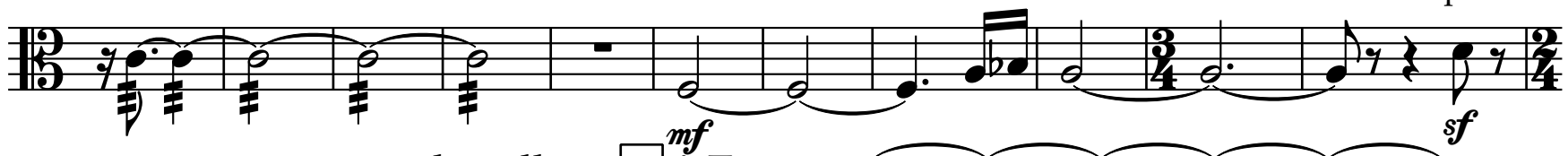

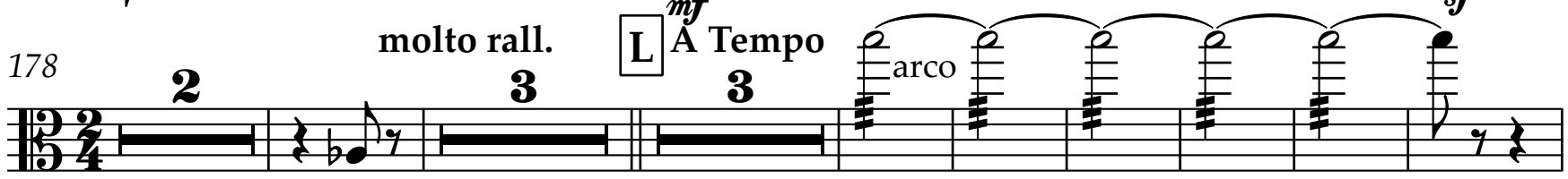

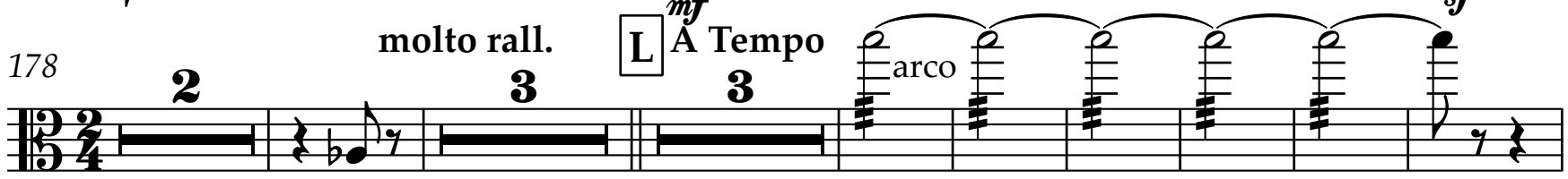
$\boldsymbol{s f}$

$\boldsymbol{p}$

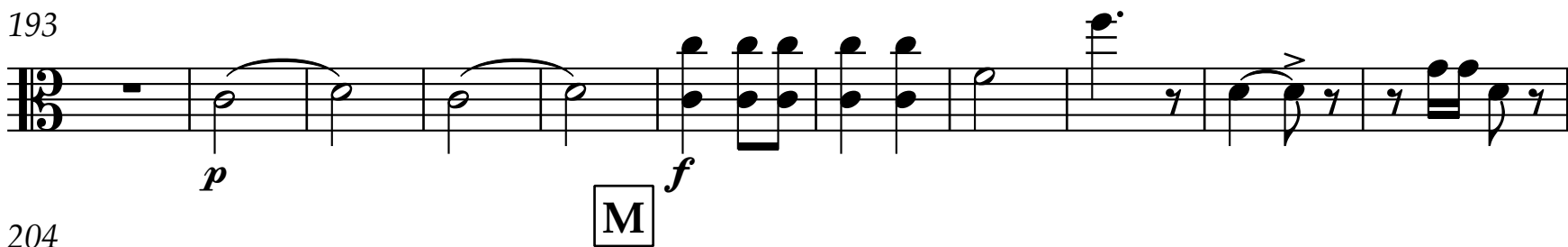

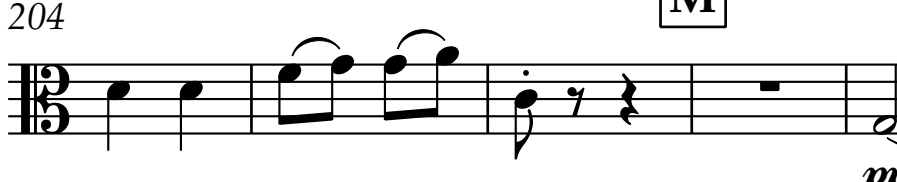




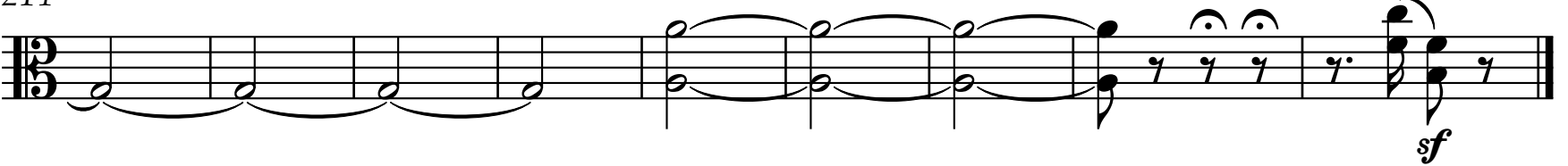


Violoncello

\section{Concerto for Viola and Orchestra}

Dmitris Dragatakis

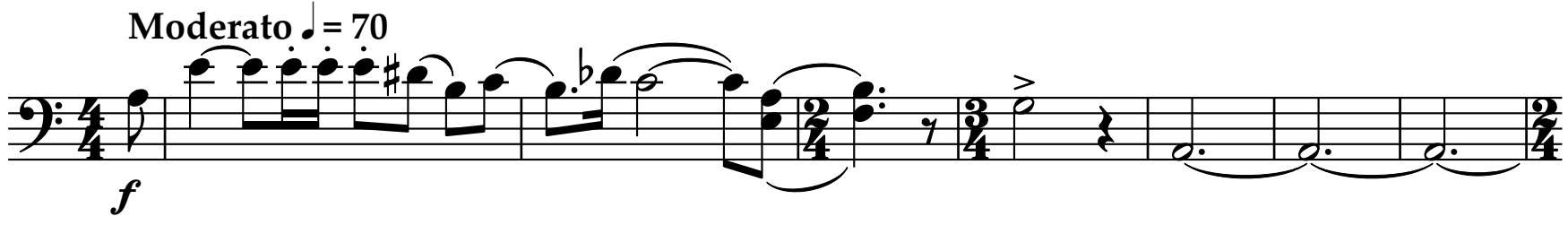

A

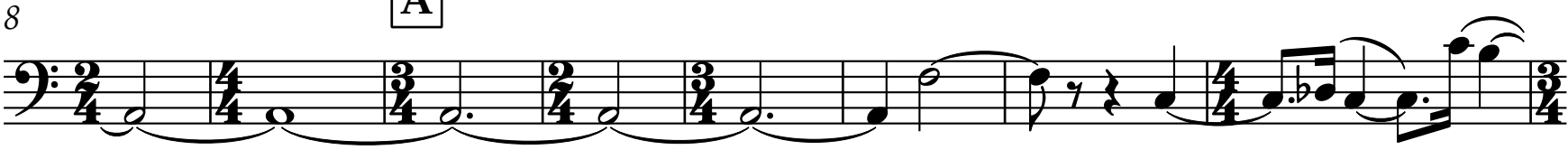

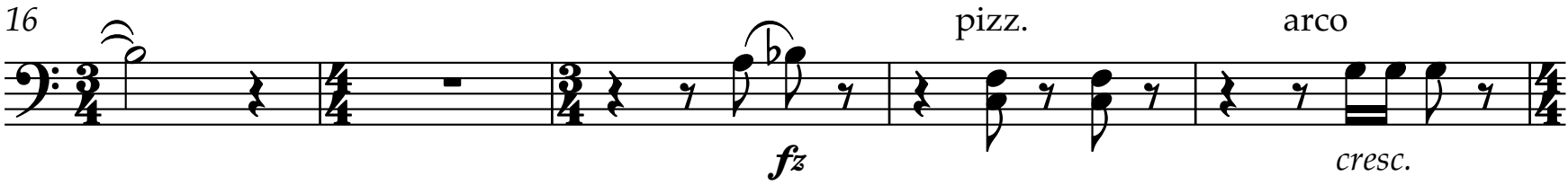
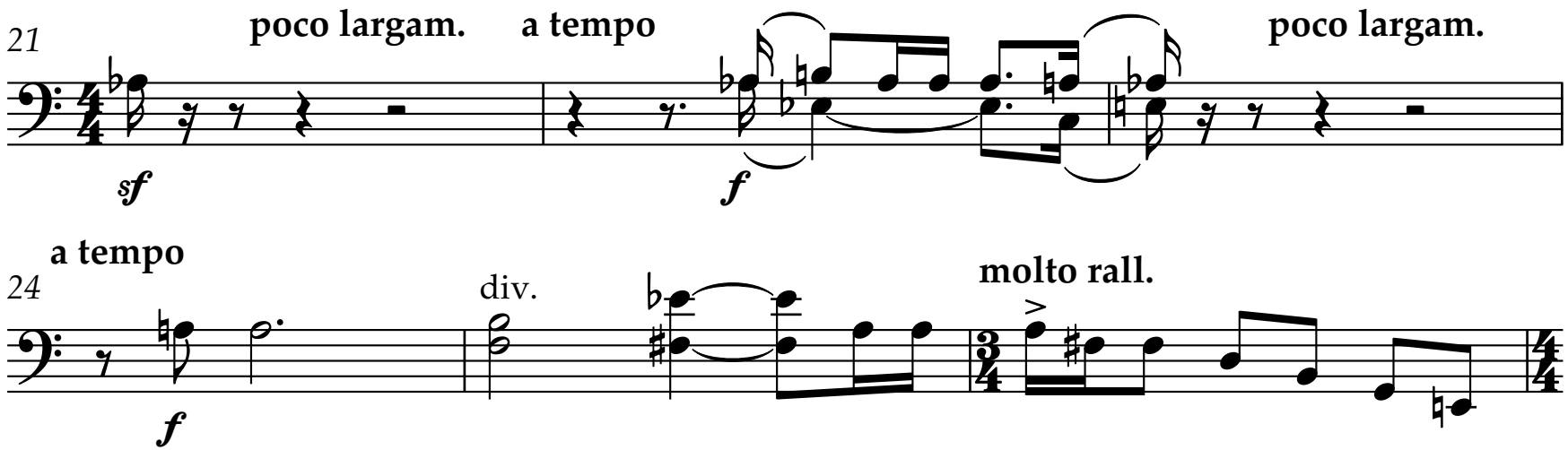

27 B a tempo pizz. col legno

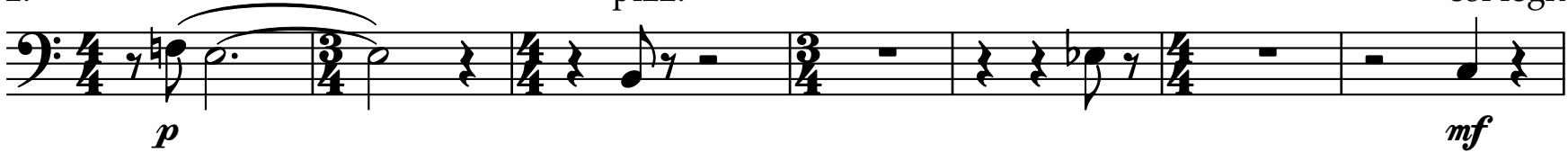

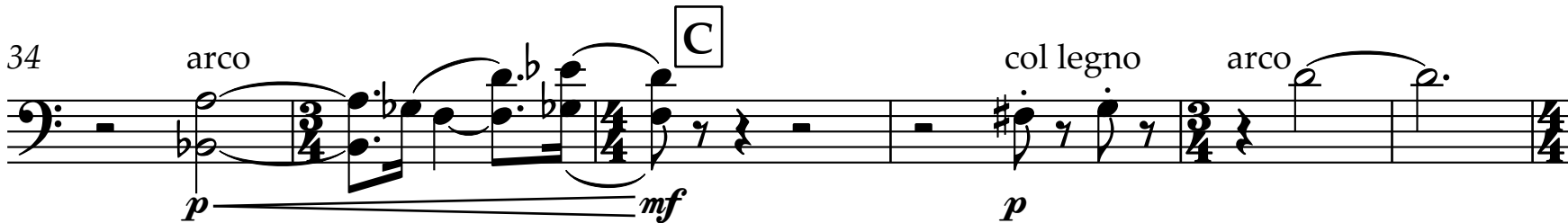

40
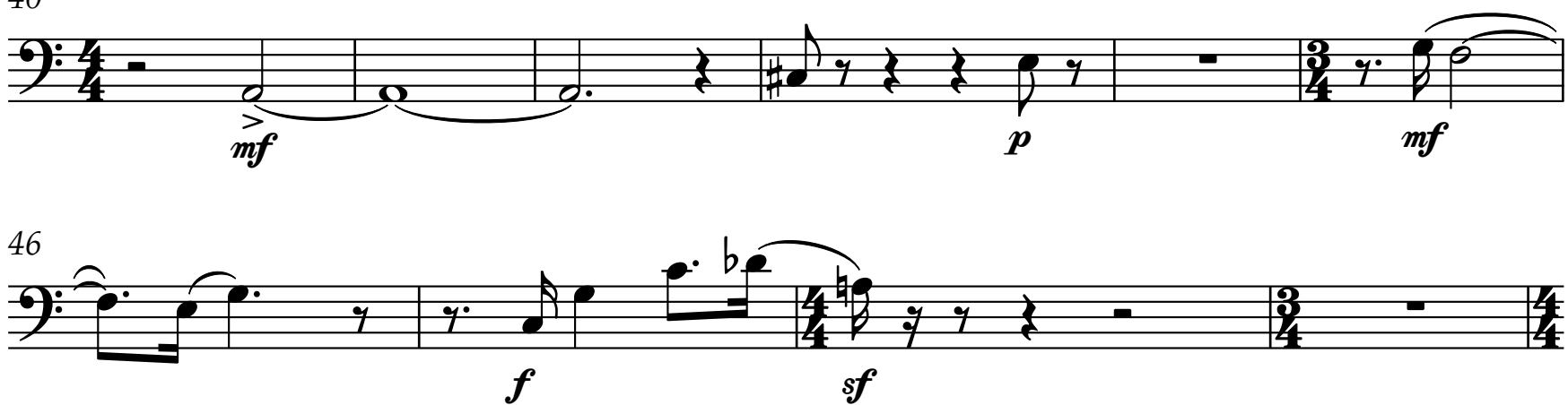

poco largam.

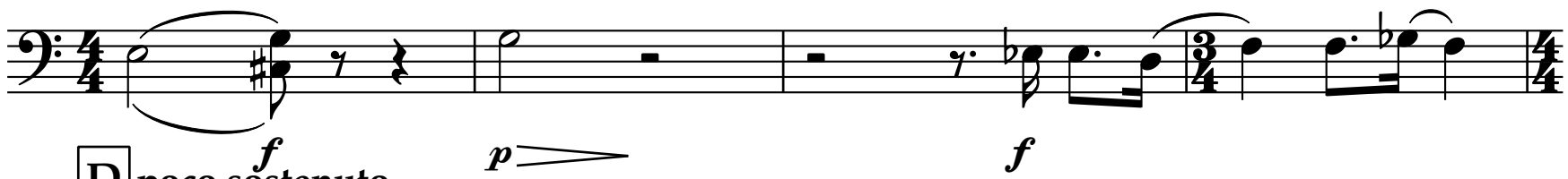

$54 \mathrm{D}$ poco sostenuto

col legno

$\frac{9}{4: 4}$

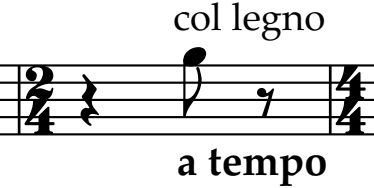

2
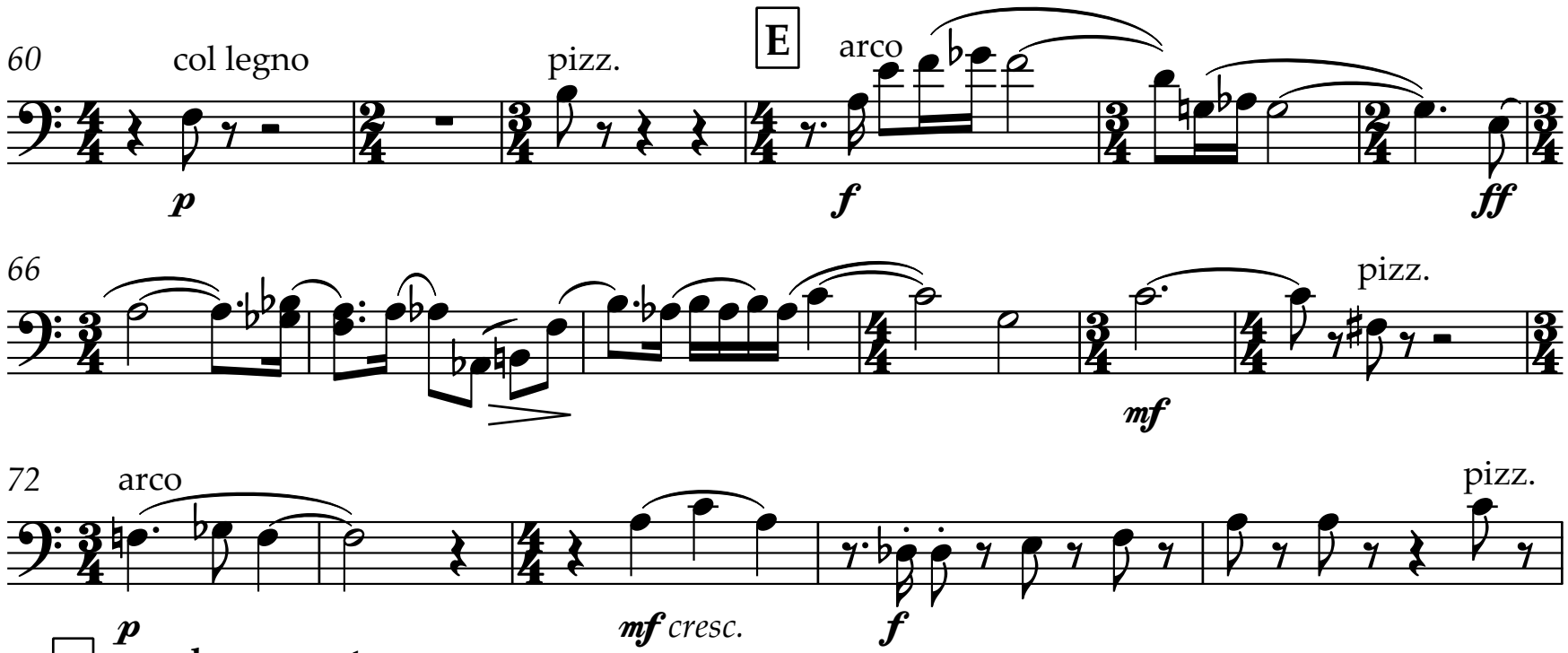
${ }_{77} \stackrel{p}{\text { poco largam. a tempo }}$
2
col legno
4
$\operatorname{arco}$

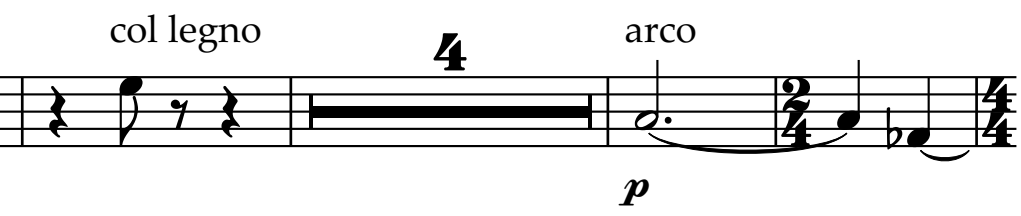

88

G

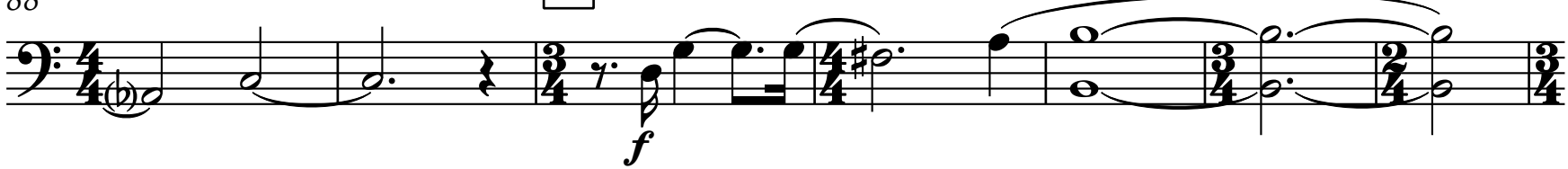

95 Più larg.

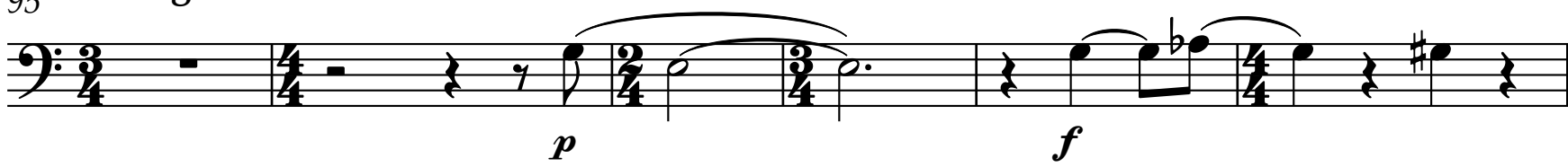

${ }^{101}$

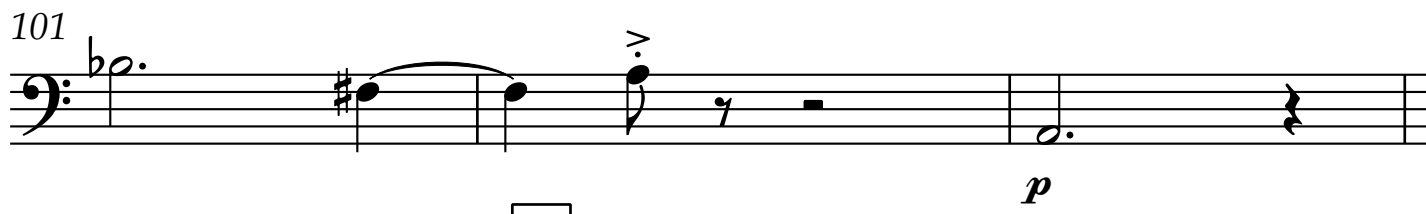

${ }_{105}$ molto rall. $2 \quad H$ a tempo

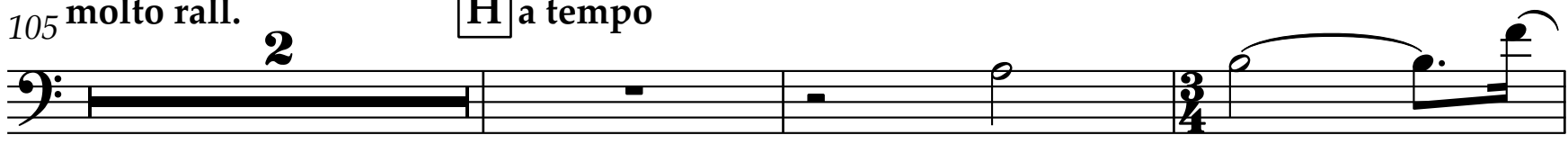

$\boldsymbol{m f}$ cresc.

(110) 

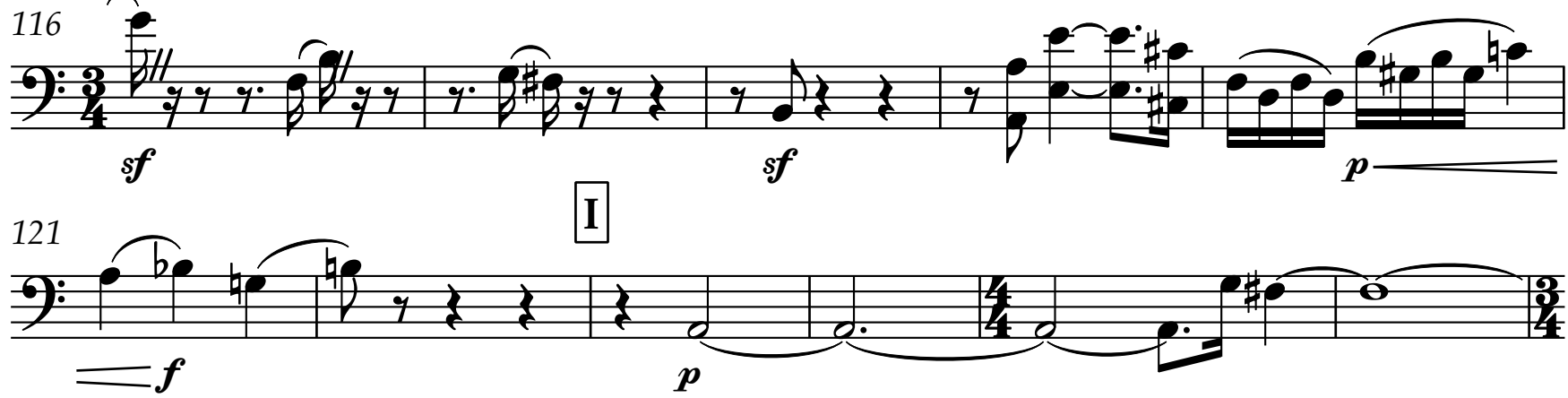

127

9:3

${ }_{131}$ Largamente

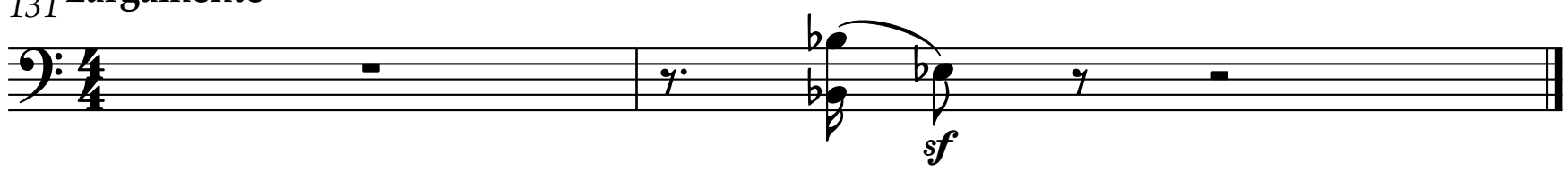

II.
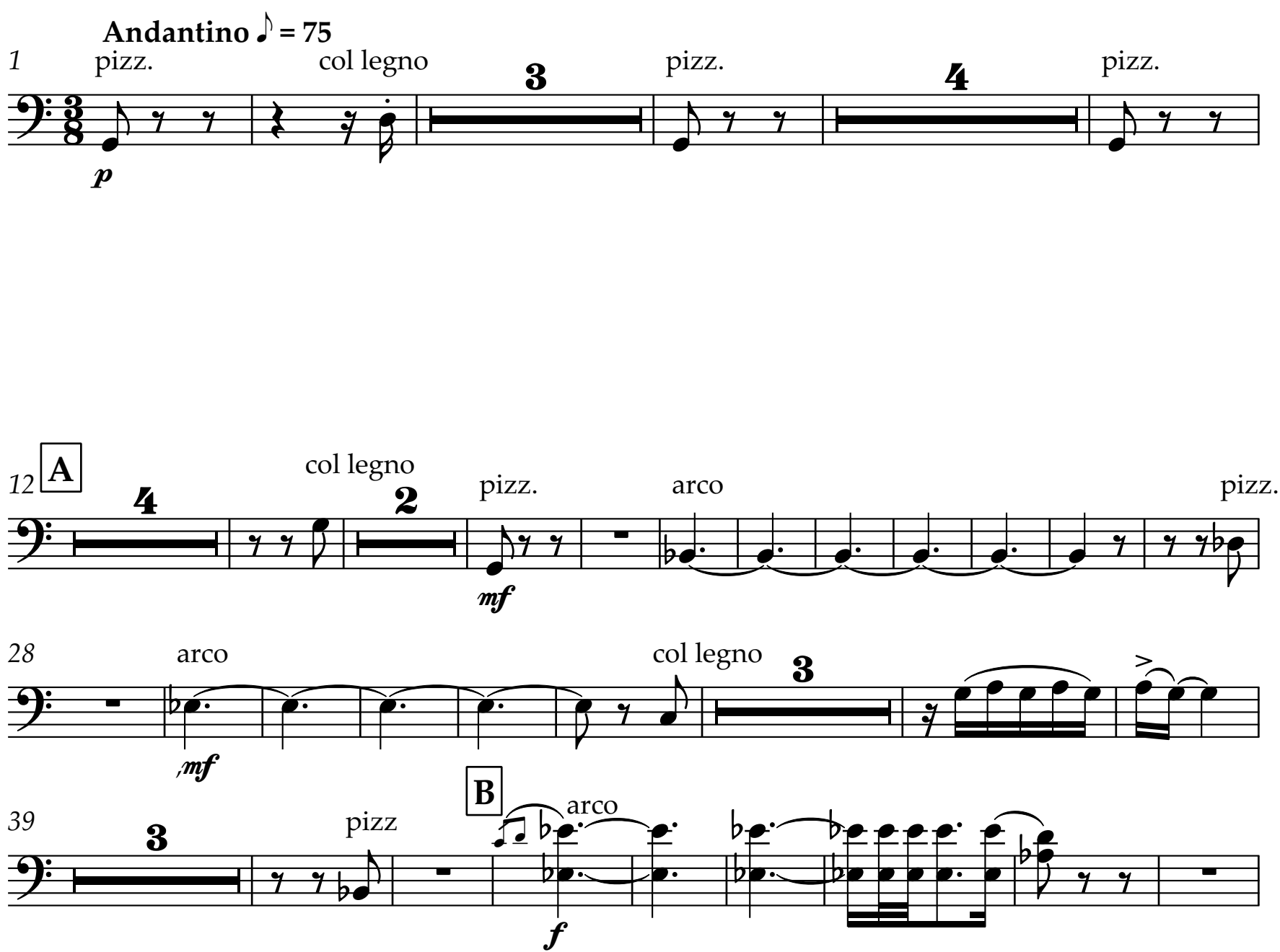


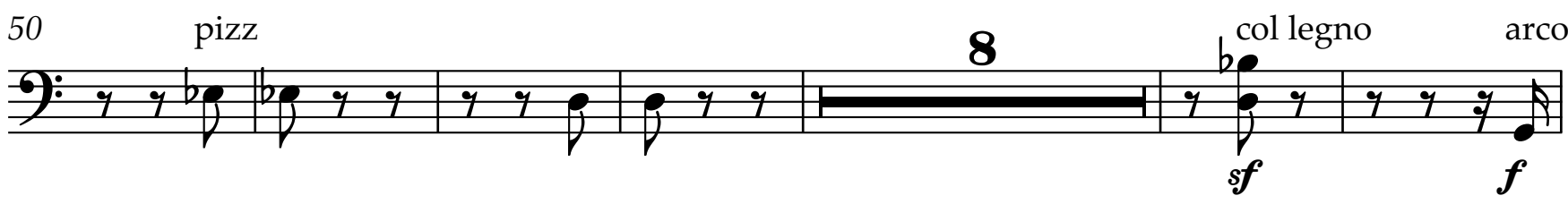
${ }_{64} \mathrm{C}$ 7):

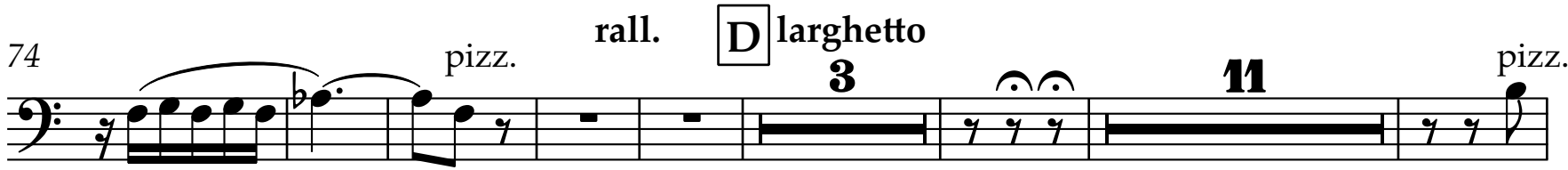

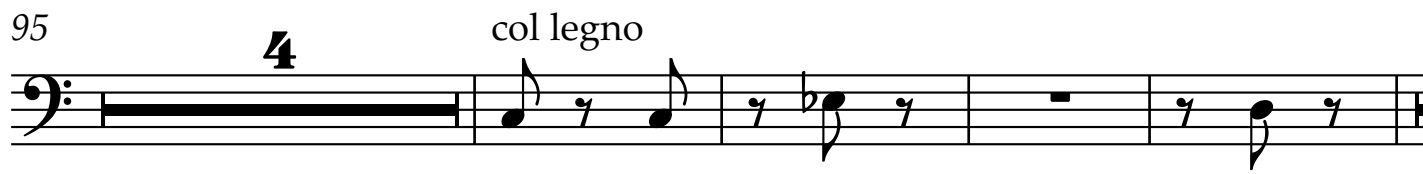

3

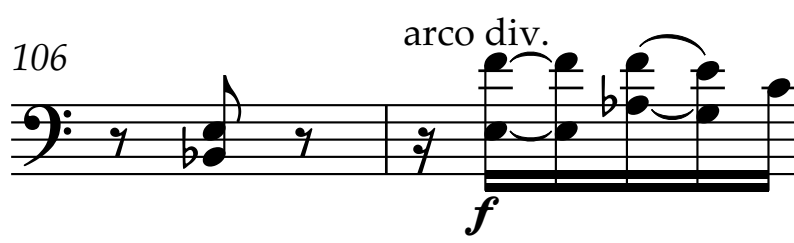

3

112

E Kadenz

$113 \mathbf{F} \begin{gathered}\text { tempo I } \\ \text { pizz }\end{gathered}$

7):8-

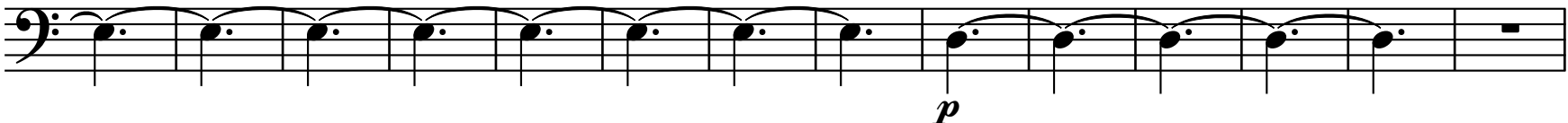

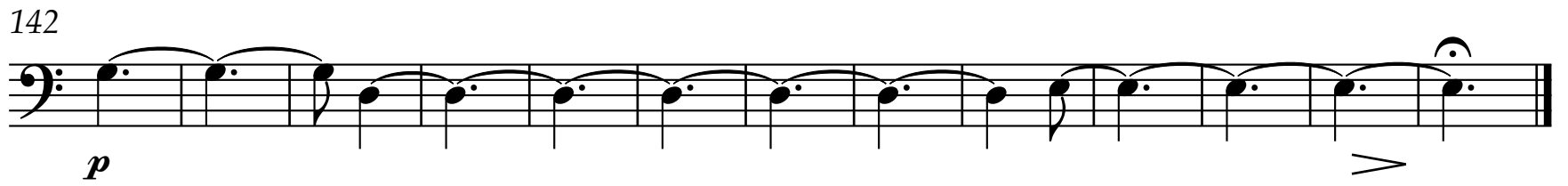




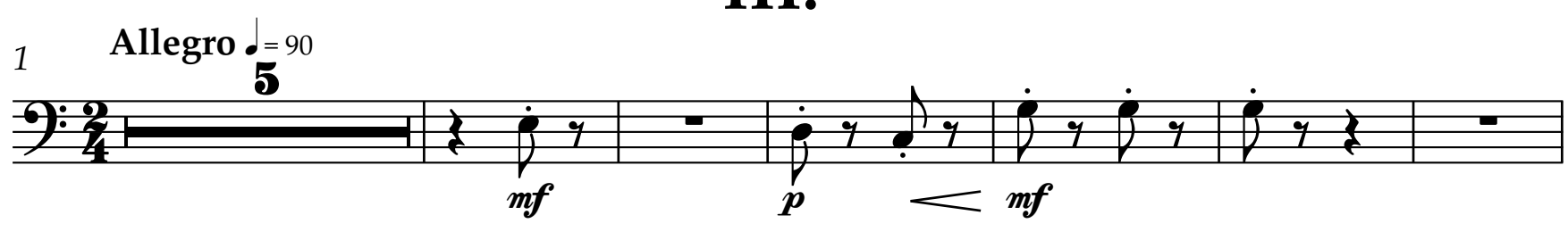

\section{III.}

${ }_{12} \mathrm{~A}$

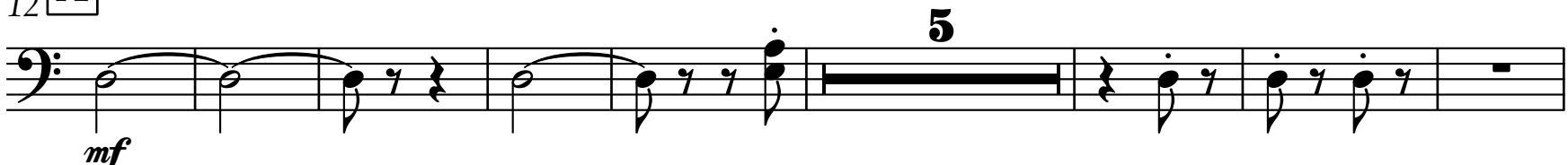

${ }_{25}$ B

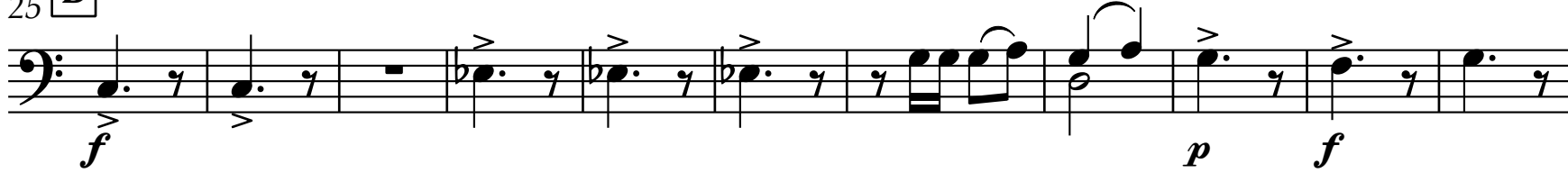

36 C poco piu meno

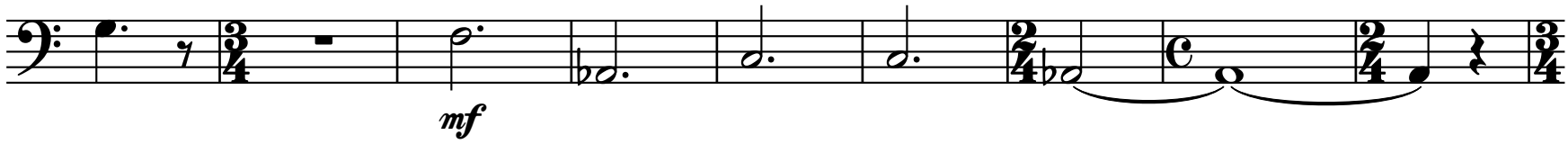

45 col legno pizz. arco

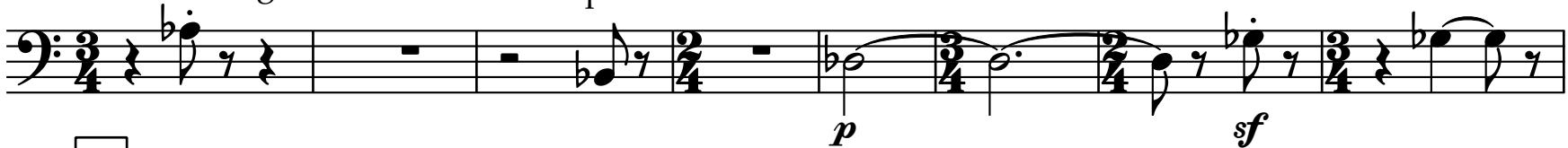

D

9.
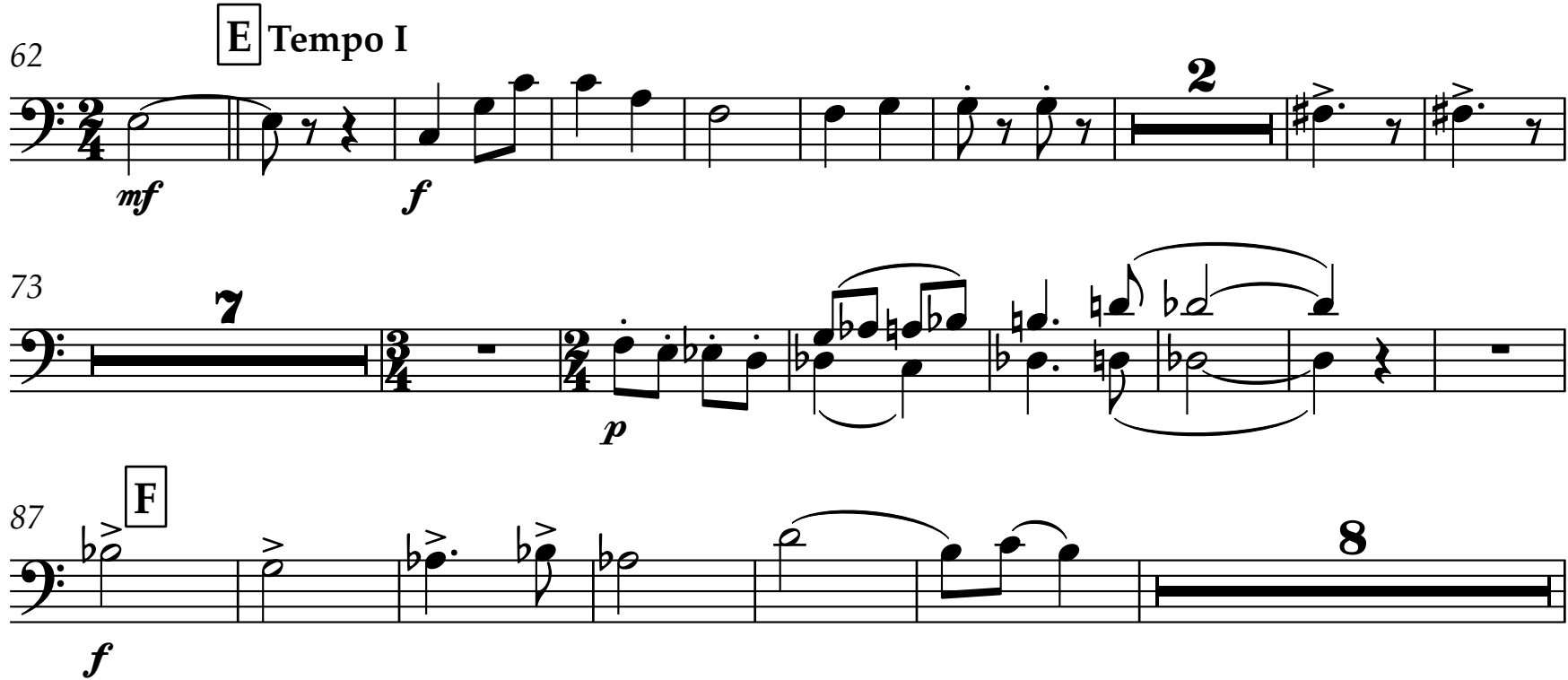

8 
6

Violoncello

101 G collegno 3

92:

111 arco $\begin{array}{r}\boldsymbol{f} \\ H\end{array}$

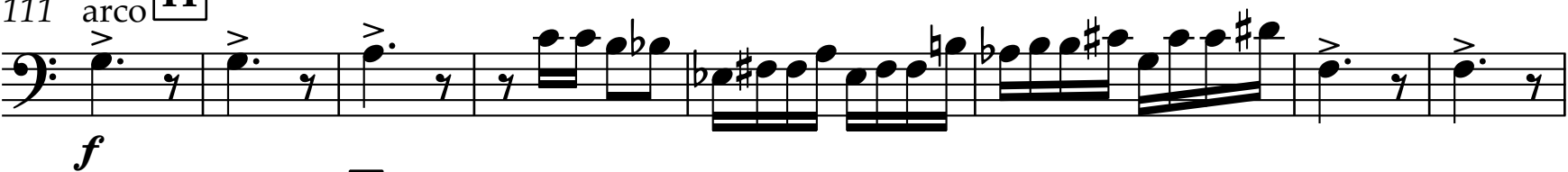

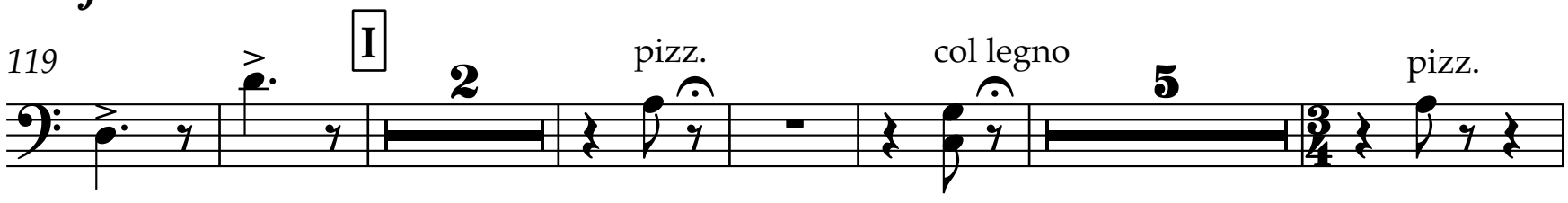

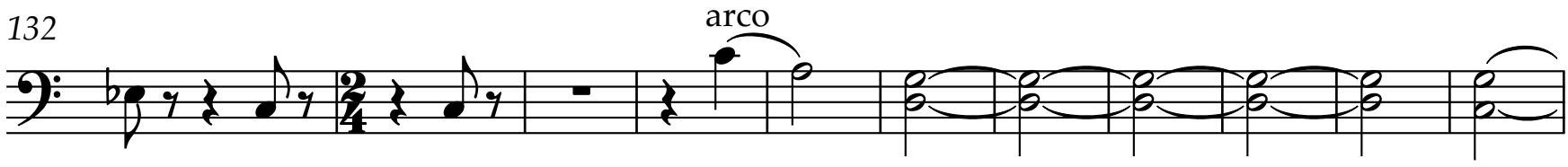

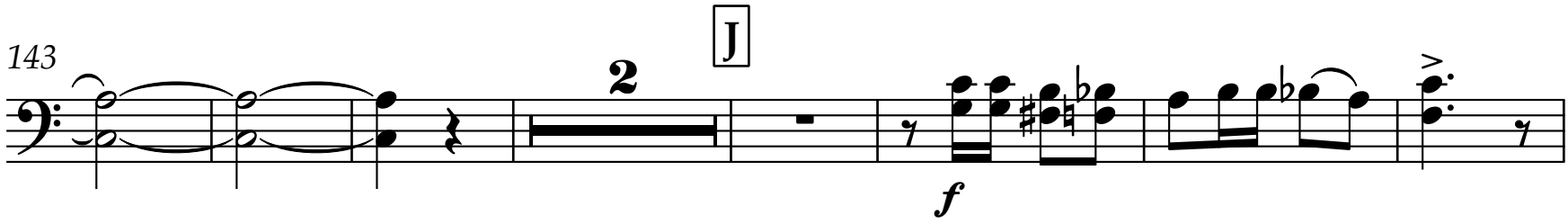

152

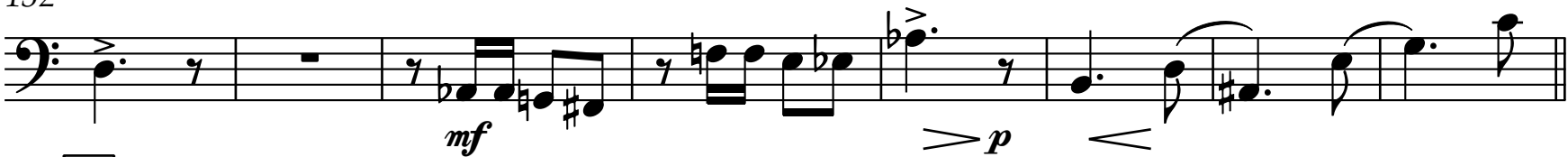
160 K $\begin{array}{r}\text { sostenuto cantabile } \\ \text { pizz. }\end{array}$

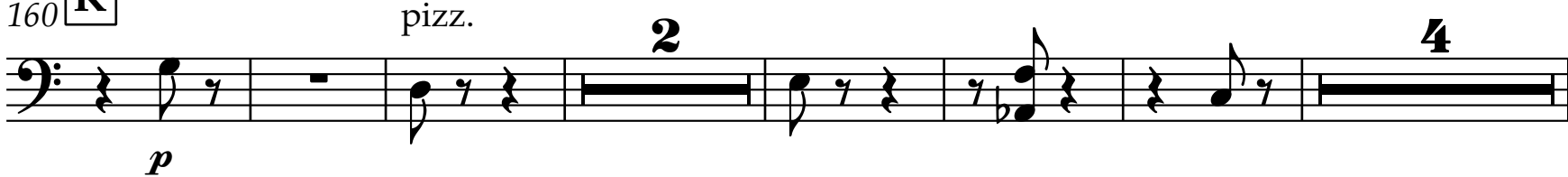

172 arco
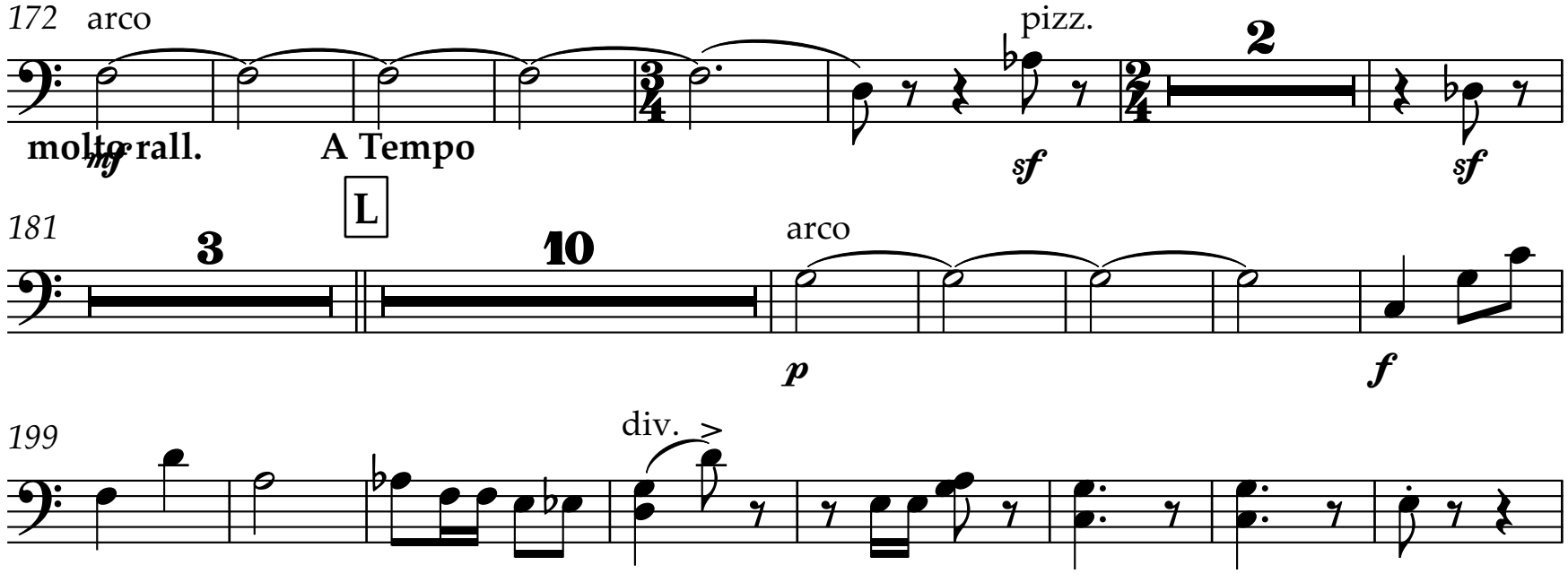

$207 \mathbf{M}$

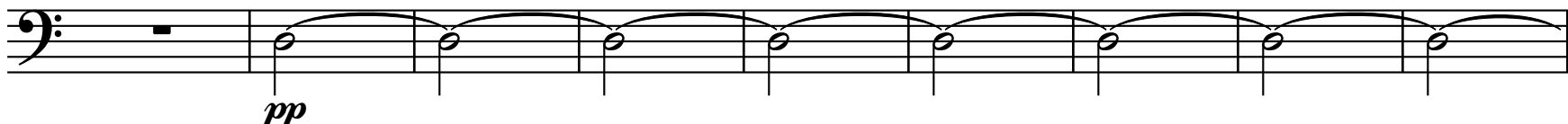


Violoncello

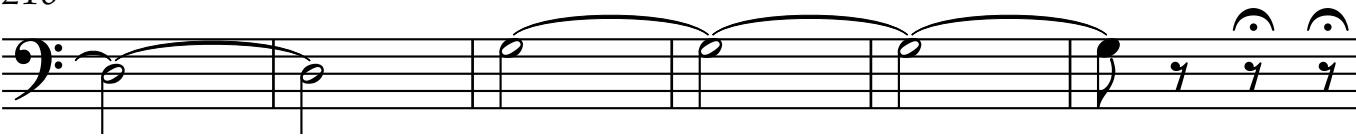
9<smiles>[C]1C[C@H]2C[C@H]12</smiles>
$\int_{s f}^{2} 9$ 
Contrabass

\section{Concerto for Viola and Orchestra}

Dmitris Dragatakis
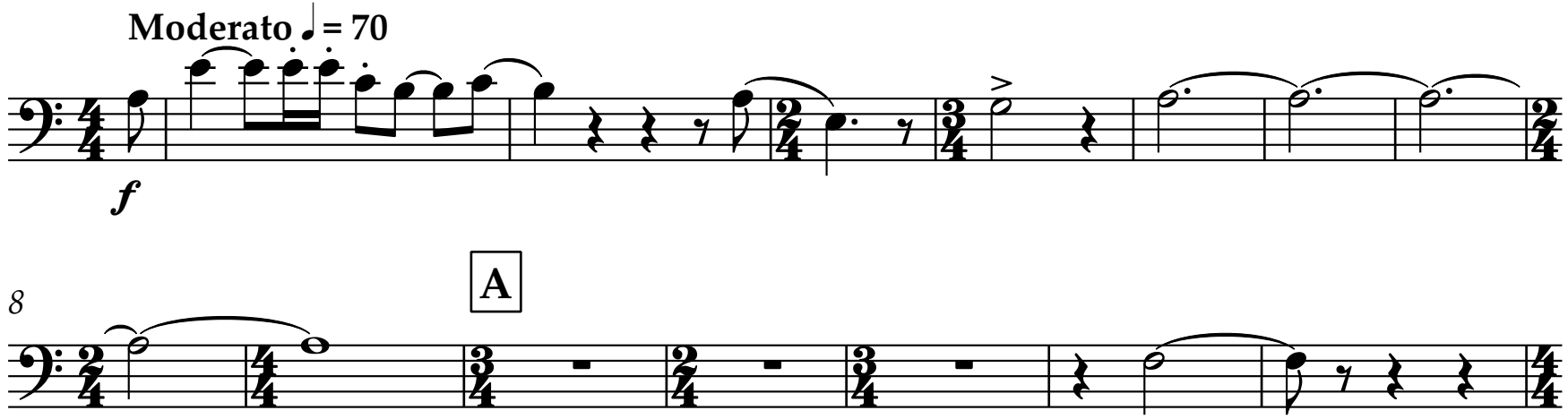

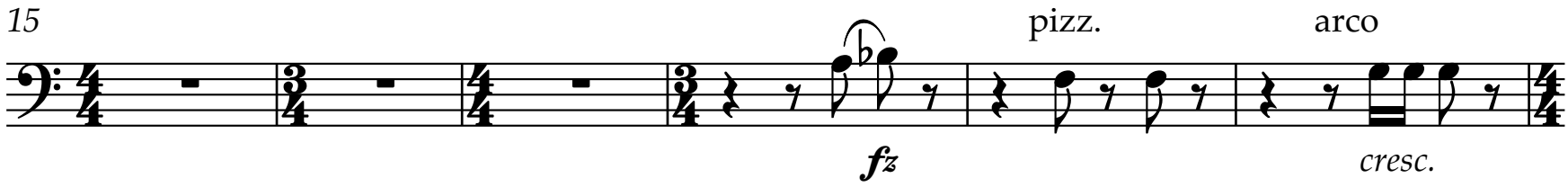

21 poco largam. a tempo poco largam.
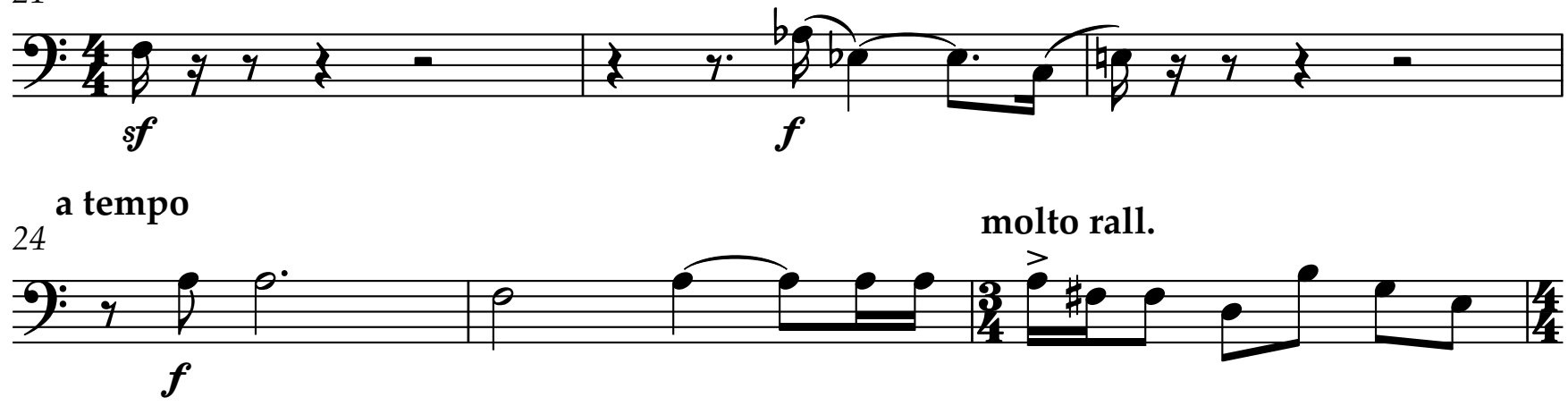

27 B a tempo

pizz.

col legno

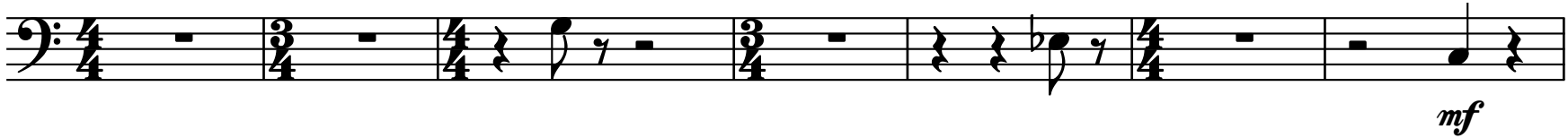
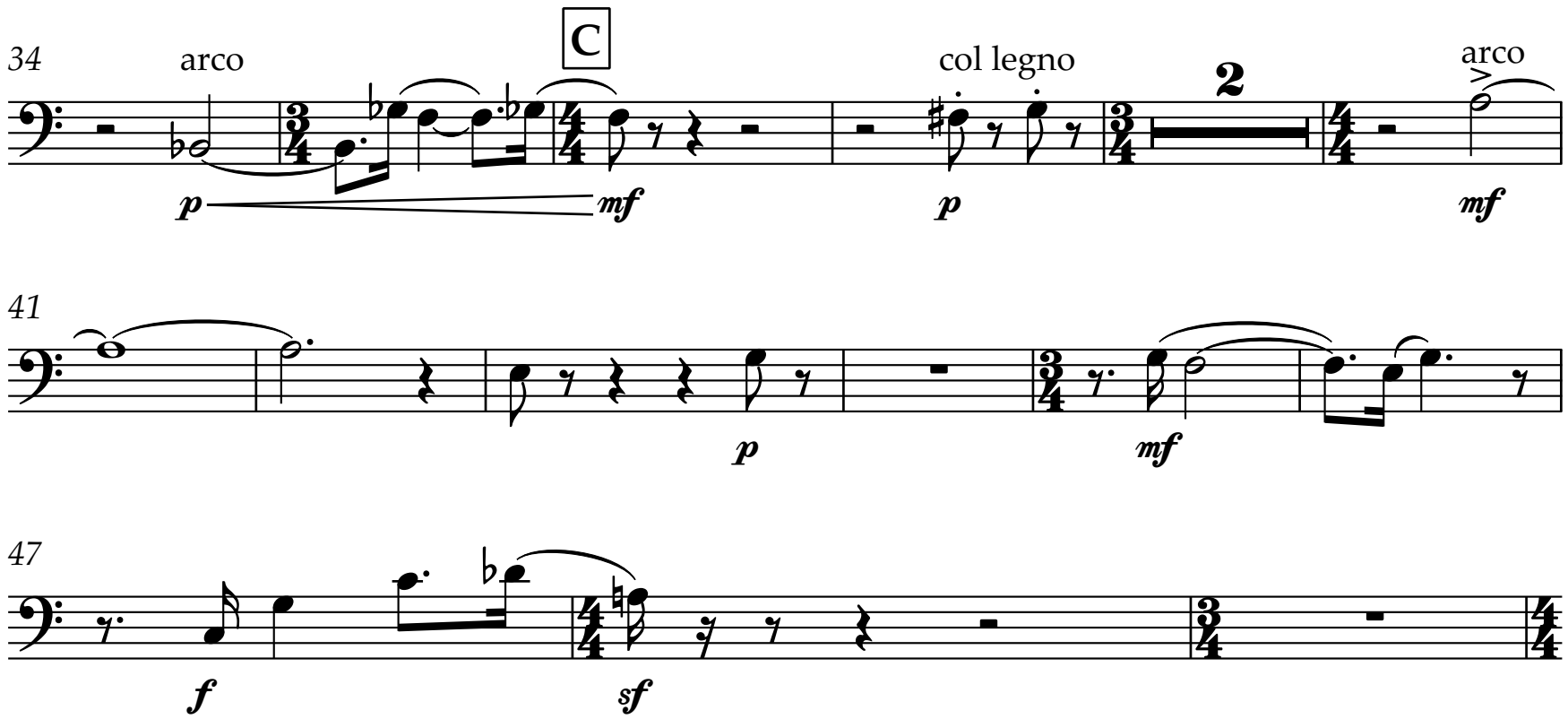

poco largam.
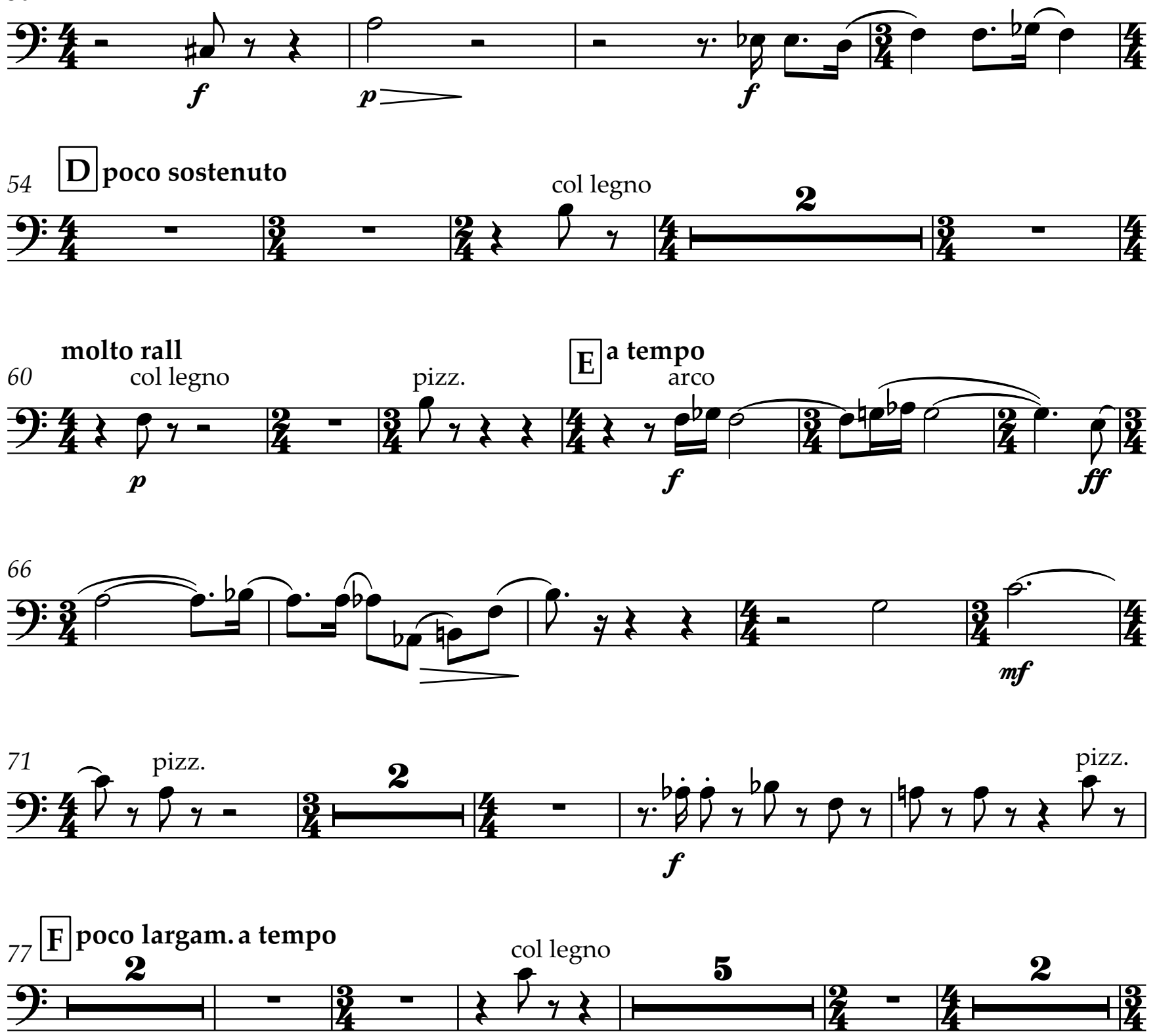

$90 \quad \mathbf{G}$ arco

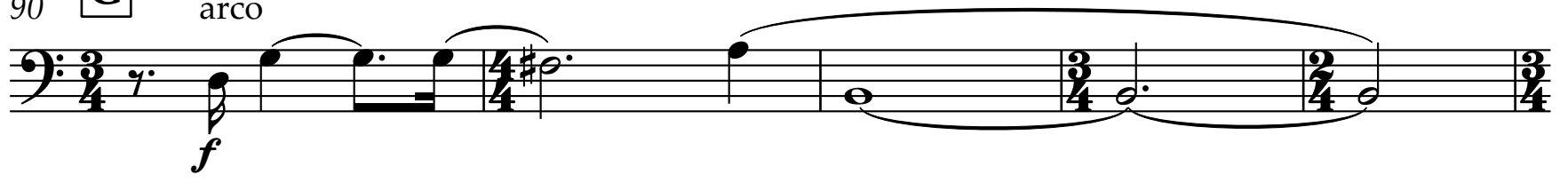

95 Più larg.
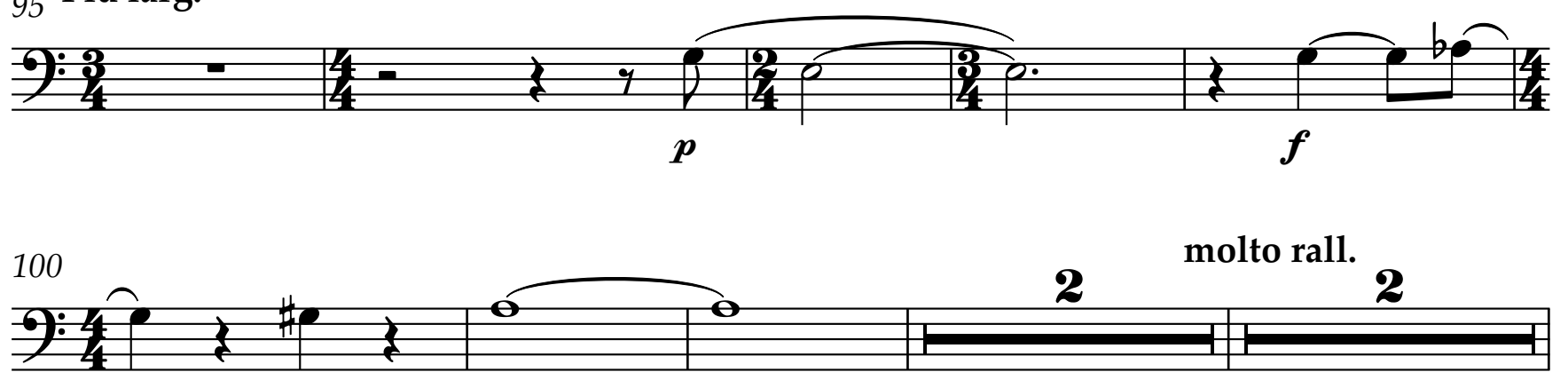

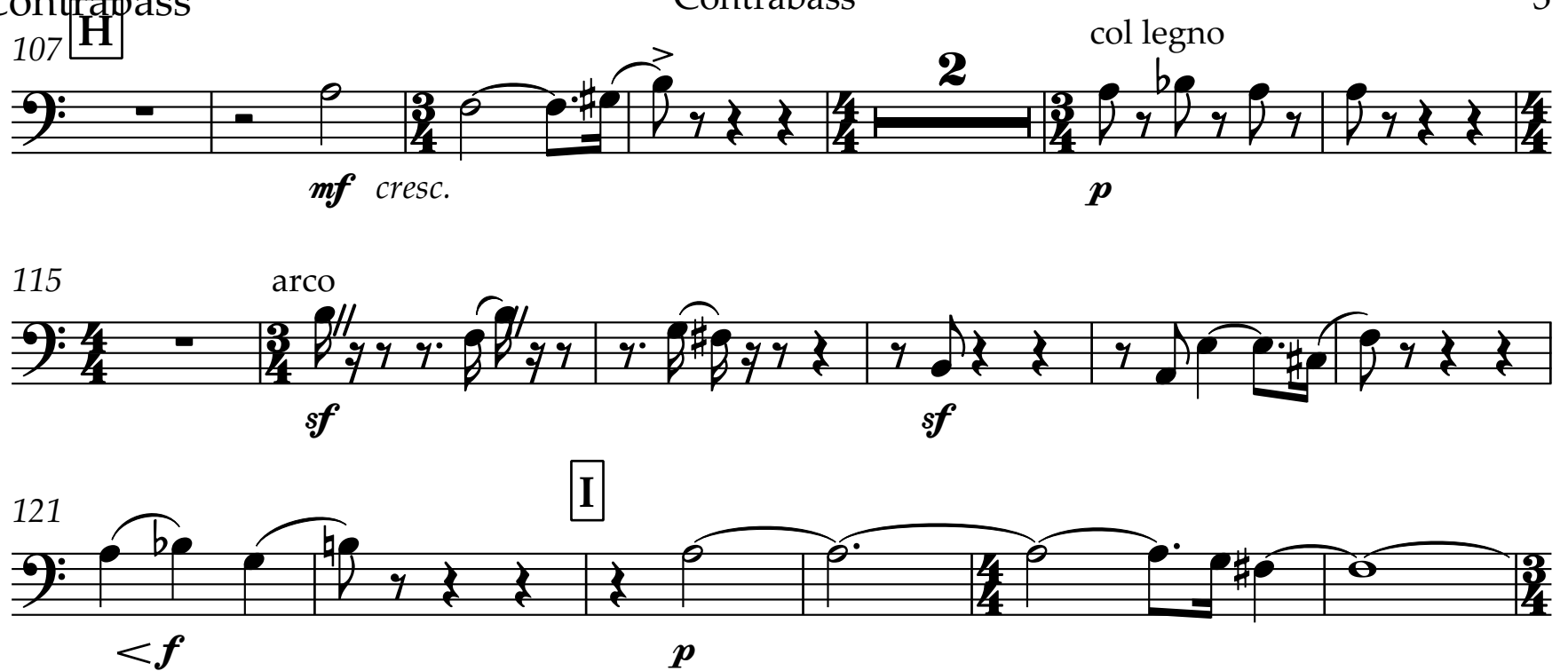

127

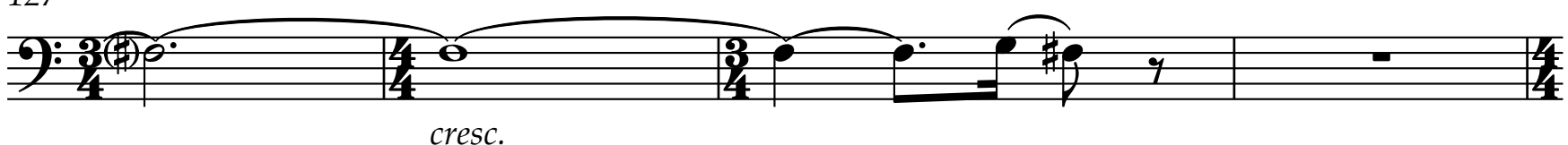

${ }_{131}$ Largamente

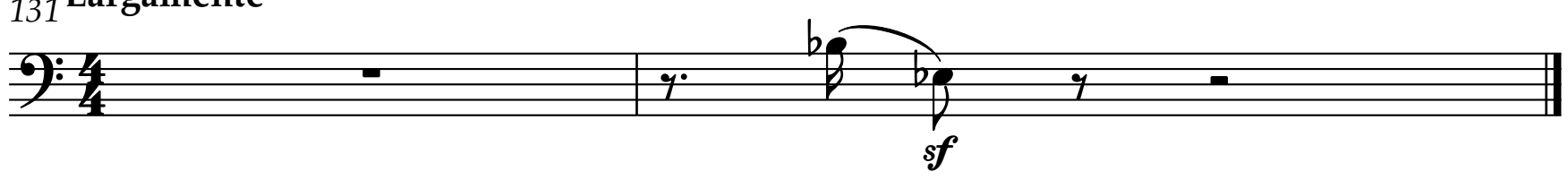

II.
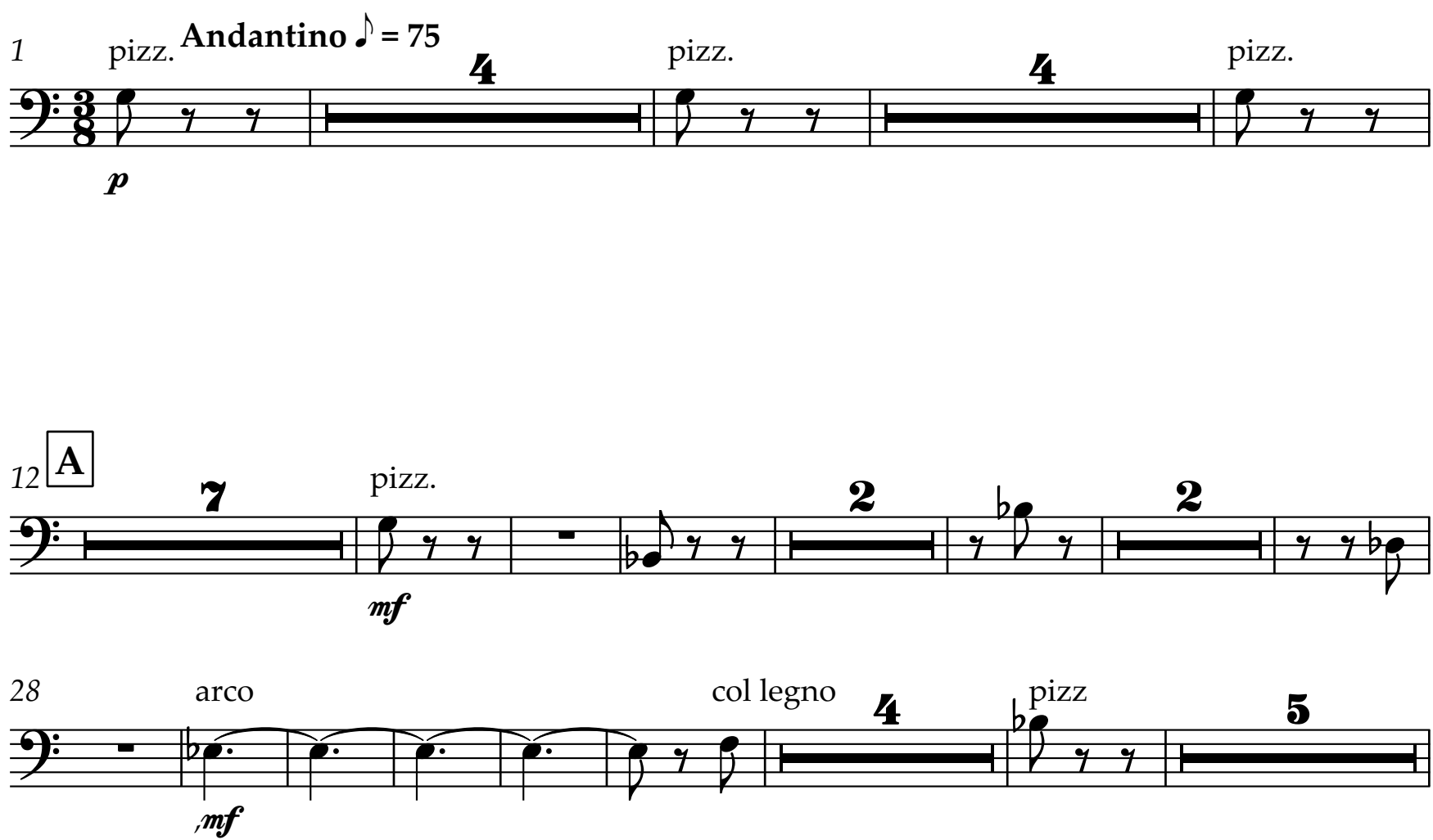
4

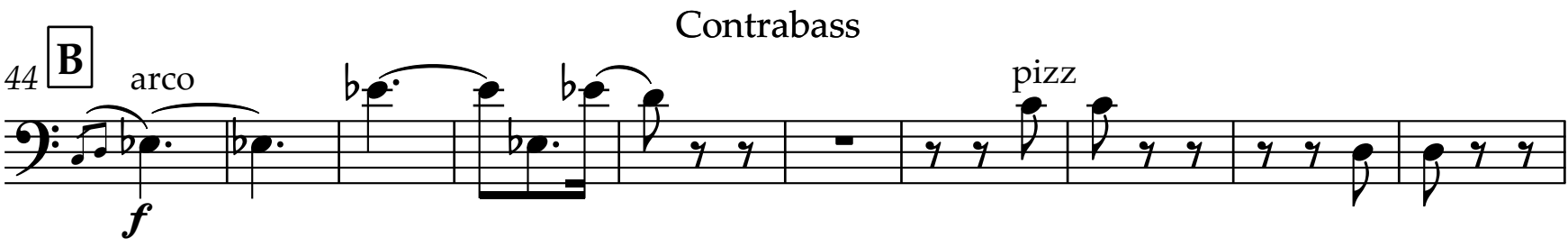

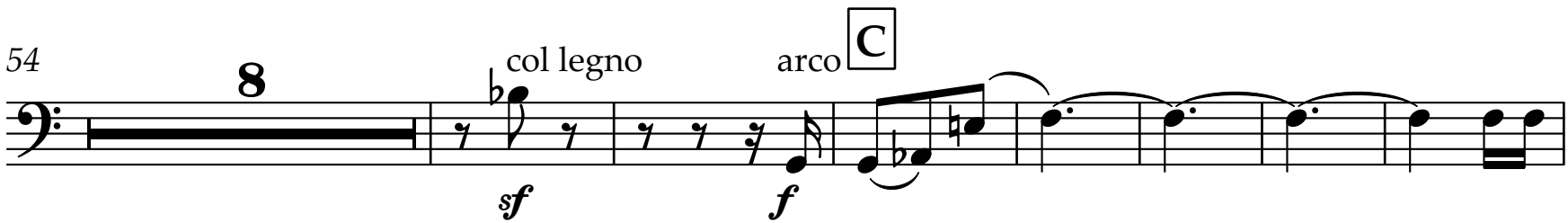

7):-jy

rall. larghetto

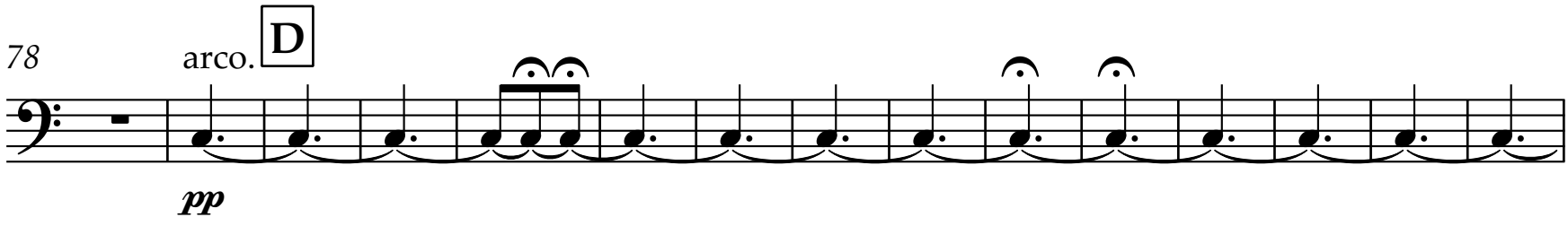

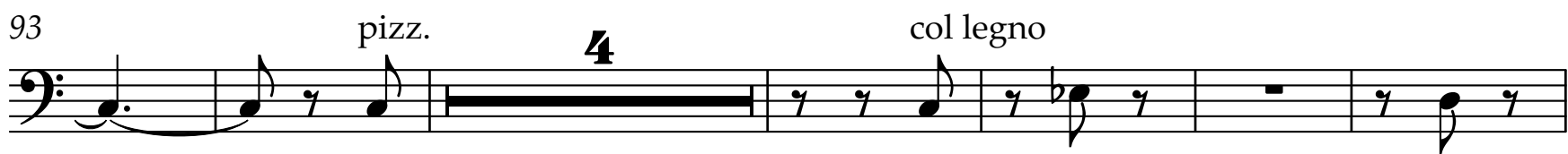

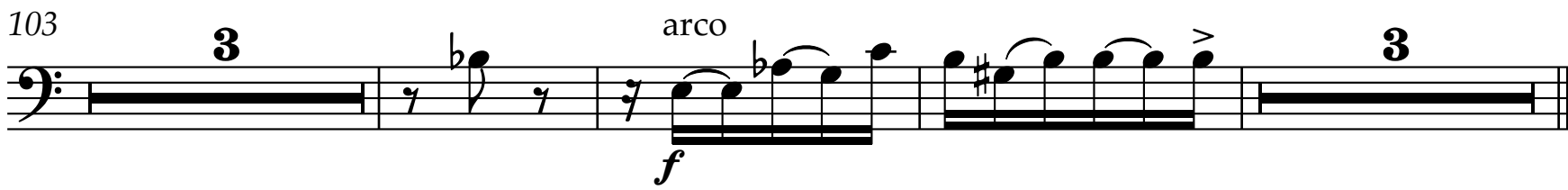
112
E Kadenz

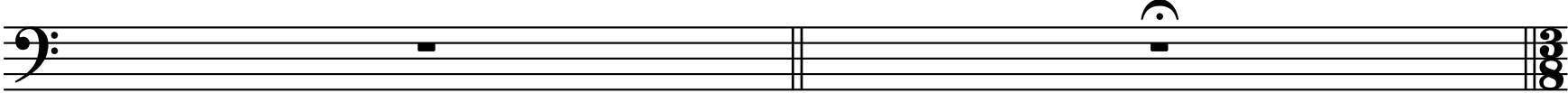
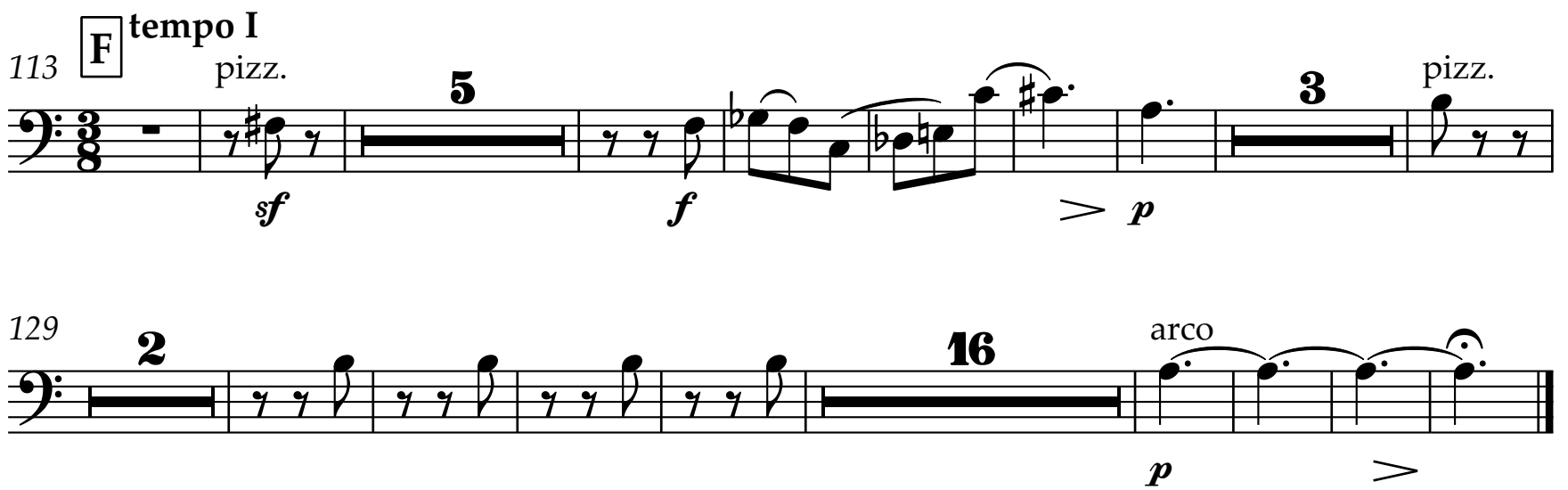


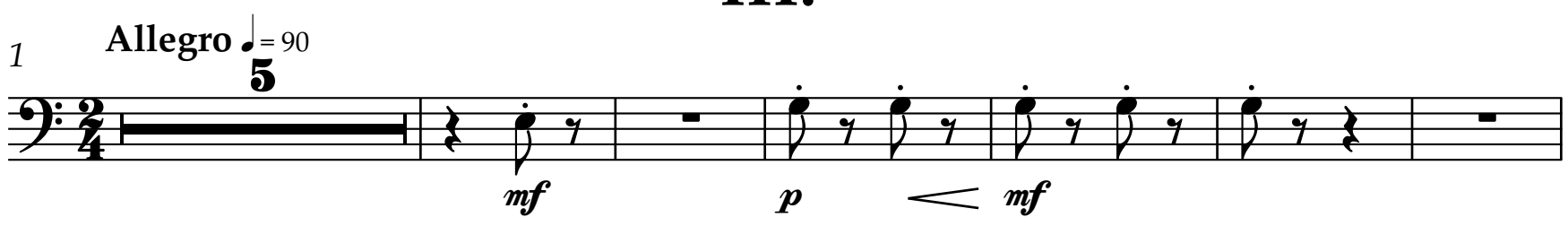

\section{III.}

${ }_{12} \mathrm{~A}$

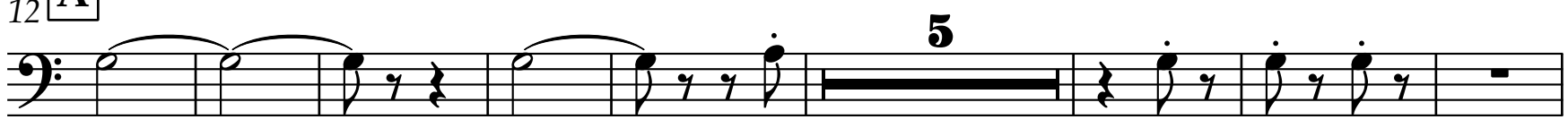
$m f$

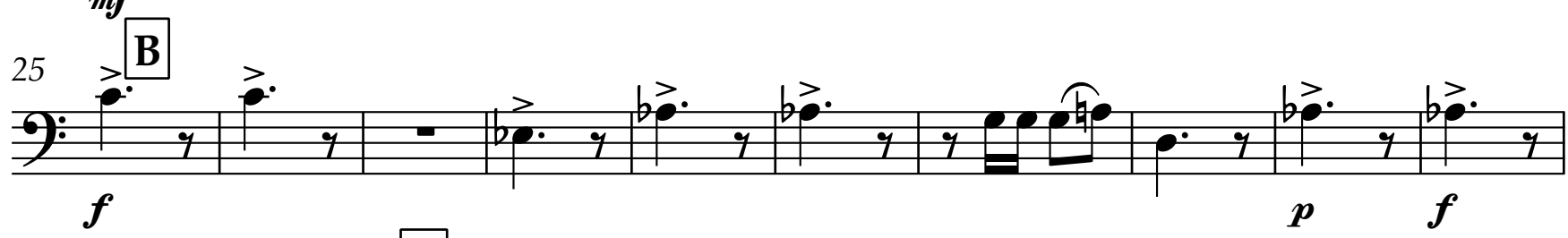

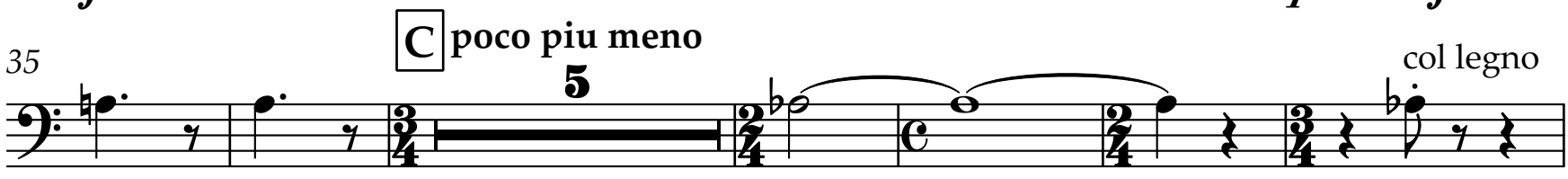

46 pizz. arco

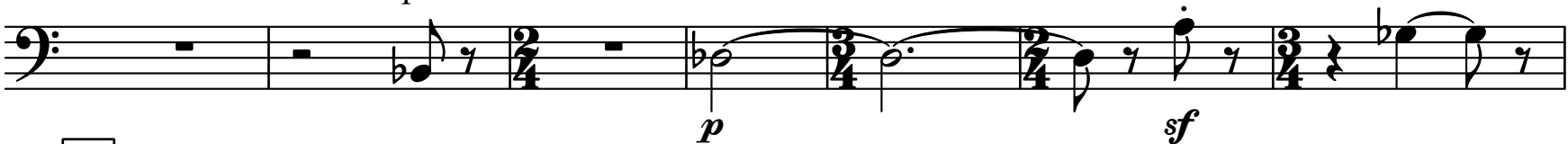

${ }_{53} \mathbf{D}_{\text {col legno }}$

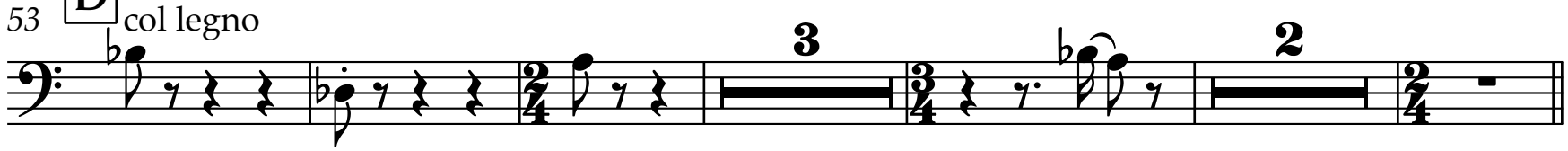

${ }_{63}$ E Tempo I

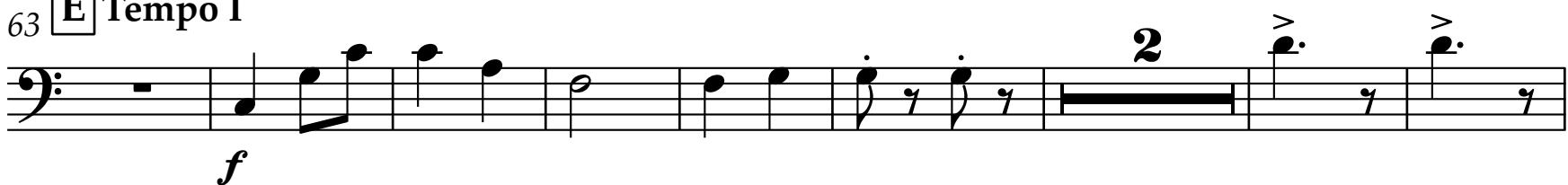

$9)^{73}$

$87, \mathbf{F}$

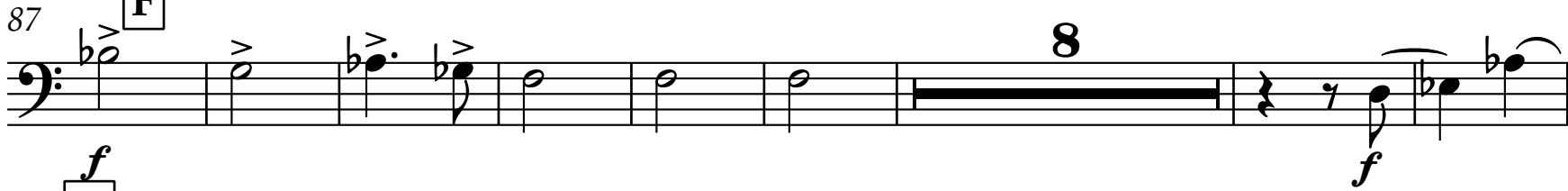

$\underset{103}{\boldsymbol{G}} \quad$ col legno

7):

3 
6

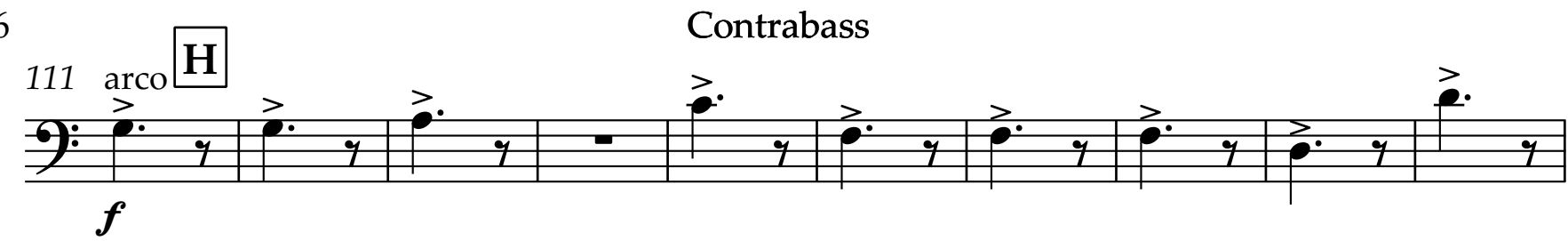

2

\begin{tabular}{l}
134 \\
\hline 0
\end{tabular}

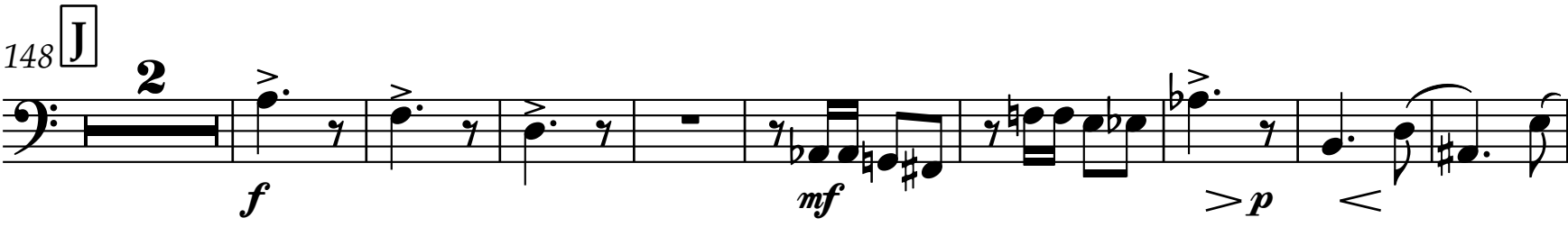
K)

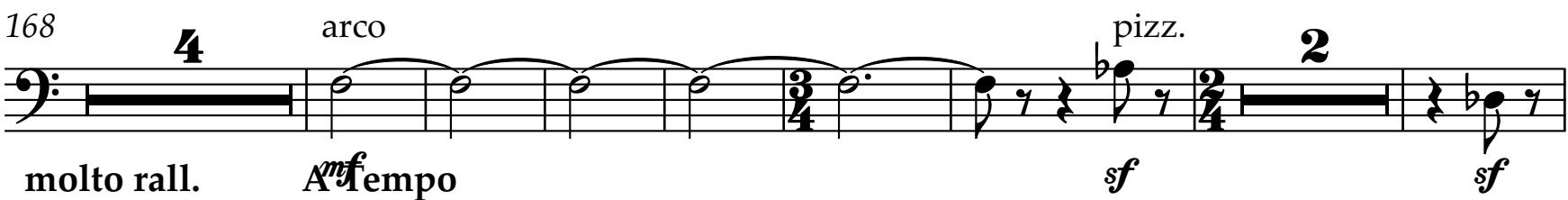
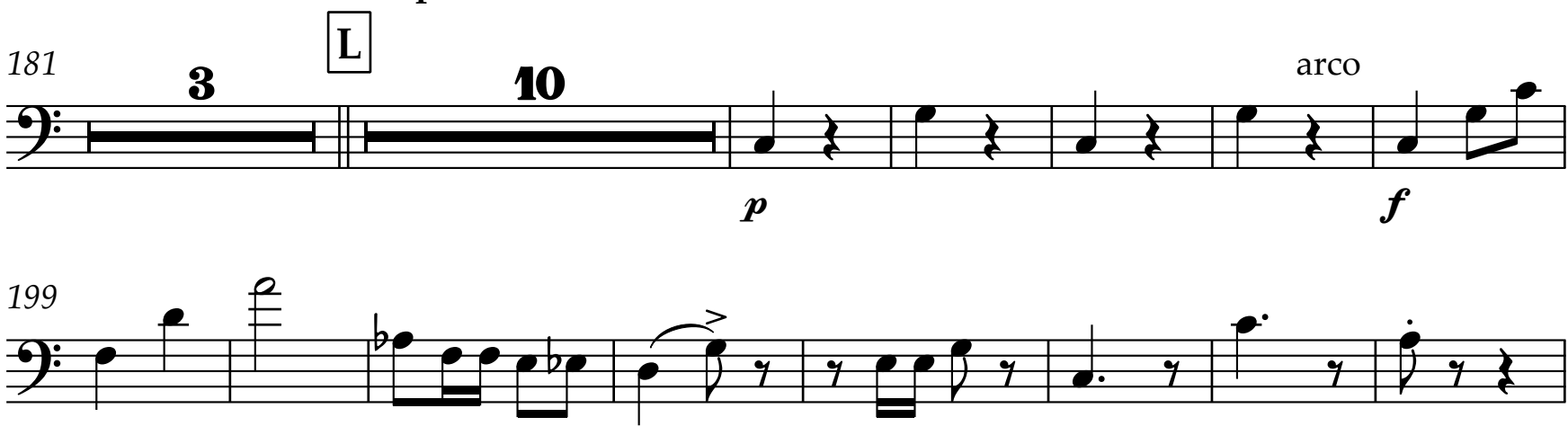
207 M
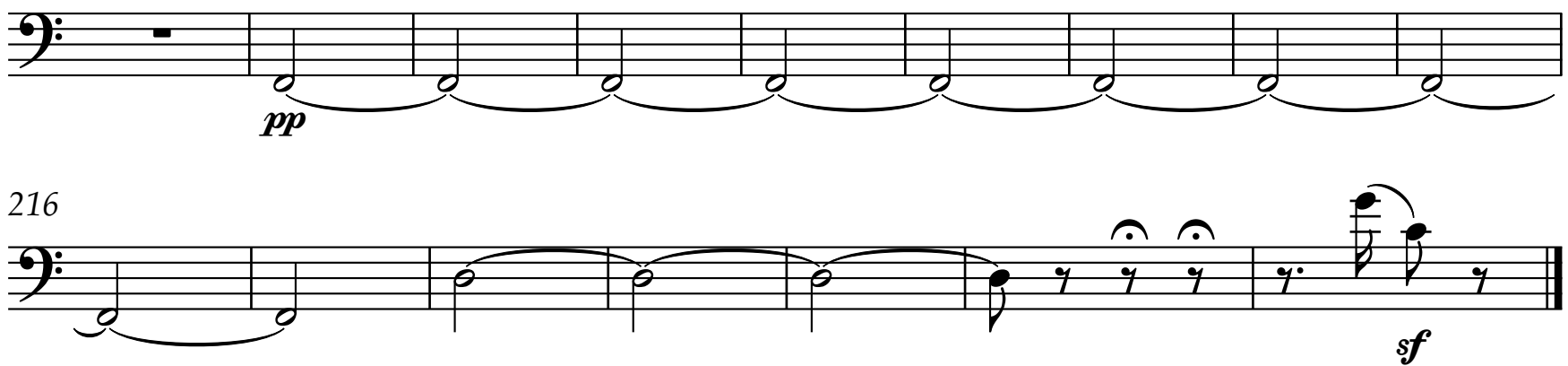


\section{Bibliography}

Bohlman, Philip V. Focus: Music, Nationalism, and the Making of New Europe. New York: Routledge, 2011.

Dalabakis, Elyse. 2019. “Dimitris Dragatakis Archive." Last modified June 2020. https://www.dimitrisdragatakis.com/.

Dalabakis, Elyse. 2019. “Dimitris Dragatakis - Composer YouTube.” Last modified June 2020. https://www.youtube.com/channel/UCkQmGQkud3iSzKse3StF ug?view as= subscriber.

Dalabakis, Elyse. 2019. "Dimitris Dragatakis." Last modified June 2020. https://open.spotify.com/artist/7mx3q8GQBomkCxdO0zVoE4.

Dalabakis, Elyse. 2019. "Friends of Dragatakis Society.” Dimitris Dragatakis Archive Database and Website. Accessed June 2020. https://www.dimitrisdragatakis.com/the-society.

Dalabakis, Elyse. 2019. "Past Events." Dimitris Dragatakis Archive Database and Website. Accessed June 2020. https://www.dimitrisdragatakis.com/pastevents.

Dalabakis, Elyse. 2019. "Photo Gallery." Dimitris Dragatakis Archive Database and Website. Accessed June 2020. https://www.dimitrisdragatakis.com/photogallery. 
Dalabakis, Elyse. 2020. “Dimitris Dragatakis Interviews” Playlist. YouTube.

Accessed June 2020.

https://www.youtube.com/playlist?list=PLEsL50b4ObArVmfV1JL2QbYuV75k $\mathrm{pKf73.}$

de Leeuw, Ton. Music of the Twentieth Century: A Study of its Elements and Structure. Amsterdam: Amsterdam University Press, 2005.

Draisey-Callishaw, Rebecca. 2012. “'Fusions and Confusions': Reflections on Intercultural Collaboration, Musical Hybridity, and the Intersubjective Nature of Reality." Journal of Canadian Society for Traditional Music, 39, no. 2 (Dec 2012): 61-82.

Dougherty, Carol, and Leslie Kurke. The Cultures within Ancient Greek Culture: Contact, Conflict, Collaboration. Cambridge: Cambridge University Press, 2003.

Dragatakis, Dimitris. Collection of Typeset Works. Dragatakis Archives (Athens, Greece).

Dragatakis, Dimitris. Collection of Manuscripts. Dragatakis Archives (Athens, Greece).

Dragatakis, Dimitris. "Concerto for Viola." Orchestra score manuscript. 1992. Dragatakis Archives (Athens, Greece).

Dragatakis, Dimitris. “Concerto for Viola.” 1993 premiere performance solo part. 1993. Artur Paciorkiewicz (Poland). 
Dragatakis, Dimitris. "Concerto for Viola." 1993 premiere performance orchestra score. 1993. Artur Paciorkiewicz (Poland).

Dragatakis, Dimitris. "Concerto for Viola." Piano reduction. 1992. Dragatakis Archives (Athens, Greece).

Dragatakis, Dimitris. Ed. Elyse Dalabakis, Brendan Agnew, Gabriela Glapska. “Concerto for Viola." Viola and piano version. 2020. New Zealand.

Dragatakis, Dimitris. Ed. Elyse Dalabakis, Brendan Agnew, Hannah Neman. “Concerto for Viola." Optional percussion part. 2020. New Zealand.

Dragatakis, Dimitris. Dragatakis Edition Collection. Dragatakis Archives (Athens, Greece).

Dragatakis, Dimitris. Dragatakis Manuscript Collection. Dragatakis Archives (Athens, Greece).

Dragatakis, Dimitris. Collection of Works by Dragatakis. Athens, Greece: Philippos Nakas Music House. Accessed June 2020. https://www.nakas.gr/ser?st=dragatakis

Dragatakis, Kelly. Interview with the author. 26 October 2019. Dimitris Dragatakis Interview Collection. Athens, Greece.

Dragatakis, Leonidas. Interview with the author. 26 October 2019. Dimitris Dragatakis Interview Collection. Athens, Greece. 
Fitzgerald, Mark, and John O'Flynn. Music and Identity in Ireland and Beyond. Farnham: Taylor and Francis, 2014.

Glapska, Gabriela. "The life and music of André Tchaikowsky: A series of performances, an analytical survey of his compositional style, and a critical/performance edition of the Sonata for Piano." PhD thesis, Victoria University of Wellington, 2019.

Grier, James. The Critical Editing of Music: History, Method, and Practice. Cambridge: Cambridge University Press, 1996.

Holst-Warhaft, Gail. "Politics and Popular Music in Modern Greece." Journal of Political and Military Sociology, 30, no. 2 (Winter 2002): 297-323.

Hutnyk, John. Critique of Exotica: Music, Politics and the Culture Industry. London: Pluto Press, 2000.

Institute for Research on Music and Acoustics (IEMA) [Institoúto Érevnas Mousikís $\mathcal{E}$ Akoustikís - Kéntro Mousikís Tekmiríosis]. “Dimitris Dragatakis.” Biography. Accessed June 2020.

http://composers.musicportal.gr/?lang=el\&c=dragatakis\&a=1.

Institute for Research on Music and Acoustics (IEMA) [Institoúto Érevnas Mousikís $\mathcal{E}$ Akoustikís - Kéntro Mousikís Tekmiríosis]. “Home Page.” Accessed June 2020. https://www.iema.gr/home/?lang=en. 
Institute for Research on Music and Acoustics (IEMA) [Institoúto Érevnas Mousikís $\mathcal{E}$ Akoustikís - Kéntro Mousikís Tekmiríosis]. 1993. "Viola and Krakow Orchestra." Physical item listing, Dragatakis collection. Accessed June 2020. http://digitize.iema.gr/is pi en.php?phys item id=305.

Institute for Research on Music and Acoustics (IEMA) [Institoúto Érevnas Mousikís E Akoustikís - Kéntro Mousikís Tekmiríosis]. 1993. “Concerto for Viola and Orchestra." Recording listing and 30-second sample, Dragatakis collection. Accessed June 2020.

http://digitize.iema.gr/is ent en.php?phys item id=305\&entity id=315.

Institute for Research on Music and Acoustics (IEMA) [Institoúto Érevnas Mousikís $\mathcal{E}$ Akoustikís - Kéntro Mousikís Tekmiríosis]. 1993. “Concerto for Viola and Orchestra." Recording listing and 30-second sample, Dragatakis collection. Accessed June 2020. http://digitize.iema.gr/is ent en.php?phys item id=354\&entity id=377.

“International Viola Society." International Viola Society website. Accessed June 2020. http://www.internationalviolasociety.org/.

Kalopana, Magdalini. Interview with the author. 11 October 2019. Dimitris Dragatakis Interview Collection. Athens, Greece.

Kalopana, Magdalini. "Dragatakis, Dimitris." Grove Music Online. 3 September 2014; Accessed 28 June 2020.

https://doi.org/10.1093/gmo/9781561592630.article.08120. 
Kalopana, Magdalini. “The Influence of Musical Avant-garde in the Works of Dimitris Dragatakis of the late '50s and the '60s." Paper presented at International Conference Beyond the Centres: Musical Avant-Gardes Since 1950, Thessaloniki, Greece, 1-3 July 2010. http://btc.web.auth.gr/.

Kalopana, Magdalini. “Dimitris Dragatakis: Katalogos ergon [Dimitris Dragatakis: catalogue of works]." PhD Dissertation, National and Kapodistrian University of Athens, 2009.

Kalopana, Magdalini. Dimitris Dragatakis: Systematic and Bio-bibliographical Works Catalogue [Systēmatikos kai Bio-bibliographikos Katalogos Ergōn]. Athens, Greece: Philippos Nakas Publishing House, 2019.

Koronidi, Iro. Interview with the author. 24 October 2019. Dimitris Dragatakis Interview Collection. Athens, Greece.

Koronidi, Ismini. Interview with the author. 24 October 2019. Dimitris Dragatakis Interview Collection. Athens, Greece.

Koronidis, Thanos. Interview with the author. 11 October 2019. Dimitris Dragatakis Interview Collection. Athens, Greece.

Koronidi, Valia. Interview with the author. 11 October 2019. Dimitris Dragatakis Interview Collection. Athens, Greece.

Little, Bliss Sheryl. "Folk Song and the Construction of Greek National Music: Writings and Compositions of Georgios Lambelet, Manolis Kalomiris, and Yannis Constantinidis." PhD thesis, University of Maryland, College Park. 2001. 
Mantzos, Constantinos, and Vassilis Nitsiakos. "Negotiating Culture: Political Uses of Polyphonic Folk Songs in Greece and Albania." In Greece and the Balkans: Identities, Perceptions and Cultural Encounters since the Enlightenment, edited by Tziovas, Dimitris, 179-191. England: Ashgate, 2003.

Paciorkiewicz, Artur. "Concerto for Viola" by Dimitris Dragatakis. Premiere recording, 1993. Dragatakis Archives. Recorded by the Athens Concert Hall: Megaron (Athens, Greece).

Pennanen, Risto Pekka. “The Nationalization of Ottoman Popular Music in Greece.” Ethnomusicology: Journal of the Society for Ethnomusicology, 48, no. 1 (Winter 2004): 1-25.

Polish Viola Society website. “46th International Viola Congress.” Accessed June 2020. http://ptal.art.pl/index.php/en/46th-viola-congress.

Ramnarine, Tina K. Musical Performance in the Diaspora. London: Taylor and Francis, 2008.

Romanou, Katy, and Maria Barbaki. “Music Education in Nineteenth-Century Greece: Its Institutions and their Contribution to Urban Musical Life." NineteenthCentury Music Review, 8, no. 1 (June 2011): 57-84.

Ramou, Lorenda. Dimitris Dragatakis - Complete solo piano works, Critical Edition. Athens: Nakas Publishing House, 2008.

Ramou, Lorenda. Dimitris Dragatakis Complete Solo Piano Music (1914-2001). Naxos $8.570789,2008$, compact disc. 
Schreibman, Susan, Raymond George Siemens, and John Unsworth. A Companion to Digital Humanities. Malden: Blackwell Pub., 2004.

Schreibman, Susan, Raymond George Siemens, and John Unsworth. A New Companion to Digital Humanities. Chichester: John Wiley \& Sons, Ltd, 2016.

Silverman, Carol. Romani Routes: Cultural Politics and Balkan Music in Diaspora. Cary: Oxford University Press, 2015.

Stanković, Peter. “Appropriating 'Balkan': Rock and Nationalism in Slovenia.” Critical Sociology, 27, no. 3 (2001): 98-115.

Tamvakos, Thomas. “Dimitris Dragatakis Discography.” Dimitris Dragatakis Archive Database and Website, accessed June 2020. https://www.dimitrisdragatakis.com/discography.

Taylor, Timothy Dean. Beyond Exoticism: Western Music and the World. Durham: Duke University Press, 2007. 